\title{
Staatsangehorigkeitsrecht im Wandel : eine rechtsvergleichende Studie uber Erwerbs- und Verlustgrunde der Staatsangehorigkeit
}

Citation for published version (APA):

de Groot, G. R. (1988). Staatsangehorigkeitsrecht im Wandel : eine rechtsvergleichende Studie uber Erwerbs- und Verlustgrunde der Staatsangehorigkeit. [Doctoral Thesis, Maastricht University]. T.M.C. Asser Instituut. https://doi.org/10.26481/dis.19881027gg

Document status and date:

Published: 01/01/1988

DOI:

10.26481/dis.19881027gg

Document Version:

Publisher's PDF, also known as Version of record

Please check the document version of this publication:

- A submitted manuscript is the version of the article upon submission and before peer-review. There can be important differences between the submitted version and the official published version of record.

People interested in the research are advised to contact the author for the final version of the publication, or visit the DOI to the publisher's website.

- The final author version and the galley proof are versions of the publication after peer review.

- The final published version features the final layout of the paper including the volume, issue and page numbers.

Link to publication

\footnotetext{
General rights rights.

- You may freely distribute the URL identifying the publication in the public portal. please follow below link for the End User Agreement:

www.umlib.nl/taverne-license

Take down policy

If you believe that this document breaches copyright please contact us at:

repository@maastrichtuniversity.nl

providing details and we will investigate your claim.
}

Copyright and moral rights for the publications made accessible in the public portal are retained by the authors and/or other copyright owners and it is a condition of accessing publications that users recognise and abide by the legal requirements associated with these

- Users may download and print one copy of any publication from the public portal for the purpose of private study or research.

- You may not further distribute the material or use it for any profit-making activity or commercial gain

If the publication is distributed under the terms of Article $25 \mathrm{fa}$ of the Dutch Copyright Act, indicated by the "Taverne" license above, 
STAATSANGEHÖRIGKEITSRECHT IM WANDEL 
Hildegard Schneider gewidmet 


\section{STAATSANGEHÖRIGKEITSRECHT IM WANDEL}

Eine rechtsvergleichende Studie über Erwerbs- und Verlustgründe der Staatsangehörigkeit

\section{PROEFSCHRIFT}

ter verkrijging van de graad van doctor aan de Rijksuniversiteit Limburg te Maastricht, op gezag van de Rector Magnificus, Prof. Dr. F.I.M. Bonke, volgens het besluit van het College van Dekanen, in het openbaar te verdedigen op donderdag 27 oktober 1988 om 16.00 uur

door

\section{Gerard-René de Groot}

geboren te Stadskanaal in 1951 
Promotor: Prof.dr. C. Flinterman LL.M.

Beoordelingscommissie: Prof. dr. J.L.M. Elders

Prof. dr.dr. A. Bleckmann

Prof. dr.dr.h.c. Th.C. van Boven M.C.L.

Prof. dr. H.U. Jessurun d'Oliveira 
Ein Vorzug bleibt uns ewig unverloren, Man nennt ihn heut die Nationalität; Sie sagt: daß irgendwo der Mensch geboren, Was freilich sich von selbst versteht.

Franz Grillparzer (1791-1872)

(in: Sämtliche Werke, herausgegeben von August Sauer, Stuttgart, o.J., Band 3 (Gedichte), 85) 
Eine Handelsedition dieser Arbeit erscheint bei Carl Heymanns Verlag KG

(C) 1988 T.M.C. Asser Instituut, 's-Gravenhage

T.M.C. Asser Instituut - Institut für Internationales und Europiaisches Recht

Alexanderstraat 20-22. Postfach 30461, 2500 GL "s-Gravenhage, Telefon (0)70-630900, Telex 34273 asser nl, Tele fax (0)70-638171

Direktor: Dr. C.C.A. Voskuil

Stab: Dr. M. Sumampouw (Internationales Privatrecht), Dr. Ko Swan Sik (Völkerrecht), Mr. A.E. Kellermann (Recht der Europäischen Gemeinschaften), J.A. Freedberg-Swartzburg (Internationale Handelsschiedsgerichtsbarkeit), G.J. de Roode (Institutswerwalter), J.A. Wade LI.B, L1.M. (juristische Übersetzungen), M.H. Bastiaans (Publikationsabteilung), Mr. J.S. de Jongh (Bibliothek und Datenverarbeitung)

Das T.M.C. Asser Instituut wurde im Jahre 1965 von den niederländischen Universitäten, an denen internationales Recht gelehrt wird, gegründet. Die Aufgabe des Instituts besteht in der Förderung des Unterrichts und der Forschung in den Bereichen, die von den Abteilungen des Instituts umfasst werden: Internationales Privatrecht, Völkerrecht einschliesslich das Recht der Internationalen Or ganisationen, das Recht der Europäischen Gemeinschaften und Internationale Handelsschiedsgerichtsbarkeit. Das Institut erfiullt diese Aufgabe durch die Einrichtung von Dokumentationssystemen und Forschungsprogrammen, in einigen Fällen in Zusanmenarbeit mit ausländischen oder internationalen Institutionen, durch die Verbreitung des dadurch gewonnenen Materials und durch die Veröffentlichung won Monographien und Schriften. Daruberhinaus verleiht das Institut Mitwirkung an der Ausgabe des Yearbook Commercial Arbitration und sorgt u.a. für die Veröffentlichung der Netherlands International Law Review und des Netherlands Yearbook of International Law:

Alte Rechte, insbesondere das Recht der Vervielfältigung und Verbreitung sowie der Übersetzung, worbehaiten. Kein Teil des Werkes darf in irgendeiner Form (durch Fotokopie, Mikrofilm ader ein anderes Verfahren) ohne vorherige Genehmigung des T.M.C. Asser Institunt reproduzient, wervielfaltigt oder verbreitet werden. 


\section{VORWORT}

Vor fünf Jahren hatte ich mich dazu überreden lassen, ein deutschsprachiges Buch zum Staatsangehörigkeitsrecht zu schreiben. Häufig habe ich diesen Beschluß bedauert. Die Realisierung dieser Aufgabe war -vor allem auch wegen sprachlicher Probleme- weitaus schwieriger, als ich vorher geahnt hatte. Diese Arbeit wäre nicht entstanden, wenn nicht viele Kollegen mich dabei andauernd ermuntert hätten. Auch wäre sie nun noch nicht abgeschlossen, wenn sich nicht mehrere deutschsprachige Freunde bereit gefunden hätten, meine Konzepte auf Sprachfehler zu korrigieren. Zu danken habe ich namentlich Frau Dr. Katherina Boele-Woelki, Frau Dr. Ilsanne Breemhaar-Schwefer, Herrn Dr. Christoph Eiden, Herm Thomas Gluns, Frau Veronika Hageloch, Frau Sabine Heidemann, Frau Edith Kessel-Crvelin, Frau Dorit Königs, Frau Dagmar Nöther, Herrn Dr. Hermann Schneider, Frau Dr. Ingeborg Schneider-Eble, Frau Susanne Schreiber und Herm Mr. Jürgen Wöretshofer, die alle einen Teil dieser Arbeit korrigiert haben. Ganz besonders muß ich mich aber bei Herrn Wolfgang Kramer bedanken, der mehrere Hunderte von Seiten meines Manuskripts mit ungeheuerer Akribie verbessert und teilweise umformuliert hat.

Sicher hätte ich weniger Literatur verarbeiten können, wenn nicht Herr Privatdozent Dr. Hellmuth Hecker mir viele von ihm gesammelte Materialien zur Verfügung gestellt und mich auf viele Fundstellen hingewiesen hä̈te. Für diese Unterstützung und für seine Gastfreundschaft, die ich während zweier Besuche im Hamburger Institut für internationale Angelegenheiten erfahren durfte, bin ich dankbar.

Prof. Dr. Cees Flinterman, Ordinarius für öffentliches Recht und Völkerrecht der Rijksuniversiteit Limburg, der bei sovielen Sitzungen in der hiesigen Fakultät betont hat, dünne Bücher zu lieben, war dennoch bereit mein Manuskript -teilweise mehrmals- zu lesen, während er selbst gerade an einem dicken Buch arbeitete; ich bin ihm dafür zu Dank verpflichtet. Froh bin ich weiter, daß die Professoren Dr. Dr. Albert Bleckmann (Ördinarius für öffentliches Recht und Völkerrecht, Westfälische Wilhelmsuniversität, Münster i.W., Bundesrepublik Deutschland), Dr. Jacques Elders (Ordinarius für Zivilrecht, Rijksuniversiteit Limburg), Dr. Dr.h.c. Theo van Boven (Ordinarius für Völkerrecht, Rijksuniversiteit Limburg) und Dr. Hans-Ulrich Jessurun d'Oliveira (Europäisches Institut, Florenz, Italien) ebenfalls bereit waren, mein Buch noch vor der Veröffentlichung zu lesen.

Wenn ein Wissenschaftler eine Arbeit übernimmt, leiden Sekretärinnen mit. Dies gilt in ganz besonderem Maße, wenn jemand auf die Idee kommt, ein Buch in einer Fremdsprache zu verfassen. Das Schreiben in einer Fremdsprache geht ja mühseliger und wesentlich langsamer als das Schreiben der eigenen Sprache. Dabei ist zu berücksichtigen, daß viele in den Niederlanden ublichen Textverarbeiter lediglich auf komplizierte Art und Weise Zeichen wie ä, ö, ỉ, ñ,

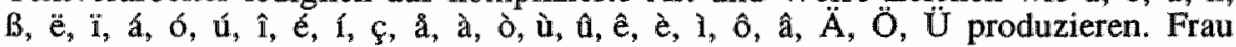
Laura Winkelman, die den größten Teil dieser Arbeit geschrieben hat, erzählte mir, daß sie des häufigeren Nachts in Alpträumen diese "besonderen" Zeichen sah. Den anderen Sekretärinnen der Fachgruppe Zivilrecht der Universität 
Limburg (Ine Corstjens, Peggy Lieben und Pia Meewis) wird es kaum anders gegangen sein. Ich verspreche den Damen, kein deutschsprachiges Buch mehr zu schreiben, bis unsere Computer besser für deren Verarbeitung geeignet sind.

Froh bin ich darüber, daß Herr Marco Braeken, Herr Mr. José Maria Blanco Fernândez und Herr Mr. Herman Zaaiman bereit waren, die Zusammenfassung zu übersetzen. Frau Mr. Annette Relou und Herr Mr. Ben Moolhuysen haben mir beim Austypen, Kontrollieren und Ergänzen der Literaturliste geholfen. Wegen der Vielsprachigkeit der verarbeiteten Literatur war dies keine geringe Aufgabe.

Wenn Frau Marjolijn Bastiaans und Herr Tjerk Halbertsma (Mitarbeiter der Publikationsabteilung des T.M.C. Asser-Instituts, 's Gravenhage) und Peter Verberne (Maastricht) mir nicht mit technischen Ratschlägen bezüglich des Layouts dieser Veröffentlichung geholfen hä̈tten, hätte ich bestimmt ein Nervenzusammenbruch erlitten. Ich bin froh und dankbar, daß sie alle und viele nicht genannten, die mich in anderer Weise unterstützt haben, mich davor behiitet haben.

Am meisten habe ich aber meiner Frau und Kollegin, Hildegard Schneider, zu danken. Sie hat die ganze Arbeit wiederholt gelesen und korrigiert, die vertretenen Ansichten kritisiert und mit mir diskutiert. Ohne ihre Hilfe wäre diese Arbeit vielleicht nie zustandegekommen, sicher hätte sie aber anders ausgesehen. Ihr widme ich deshalb dieses Buch.

Maastricht, 3. Juli 1988. 


\section{INHALTSÜBERSICHT}

Vorwort

Inhaltsverzeichnis

Abkuirzungsverzeichnis

Literaturverzeichnis

1.

1.1

1.2

Allgemeiner Teil

Einführung

Verantwortung der zu besprechenden Rechtssysteme und der inhaltlichen Abgrenzung der Länderberichte

1.3 Begriff und Funktion der Staatsangehörigkeit

1.4 Schranken der nationalen Staatsangehörigkeitsgesetzgebung

2. Erwerbs- und Verlustgründe der Staatsangehörigkeit:

Länderberichte

Belgien

Frankreich

Italien

4. Vorschläge zur Änderung des niederländischen Staatsangehörigkeitsgesetzes

5. Fremdsprachige Zusammenfassungen 



\section{INHALTSVERZEICHNIS}

Vorwort

Inhaltsverzeichnis

Abkürzungsverzeichnis

Literaturverzeichnis

1.

Allgemeiner "Teil und der inhaltlichen Abgrenzung der Länderberichte

Die Vergleichbarkeit der Staatsangehörigkeits-

Verantwortung der zu besprechenden Rechtssysteme

Schranken der nationalen Staatsangehörigkeits-

2.

Erwerbs- und Verlustgründe der Staatsangehörigkeit: Länderberichte

Rüickblick

Heutige Regelung

Verlustgründe

Rückblick 
Rückblick

Frankreichs

Erwerb der Staatsangehörigkeit durch Geburt

Erwerb der Staatsangehörigkeit nach der Geburt

Verlustgründe

Großbritannien

Allgemeine Bemerkungen

Erwerb der Staatsangehörigkeit durch Geburt

104

2.4 .2 .1

Riickblick

104

2.4 .2 .2

Heutige Regelung

104

2.4 .3

Erwerb der Staatsangehörigkeit nach der Geburt

106

2.4.3.1

Rückblick

106

2.4.3.2

2.4 .4

2.4.4.1

Heutige Regelung

108

Verlustgründe

111

Rückblick

Heutige Regelung

Italien

Allgemeine Bemerkungen

Erwerb der Staatsangehörigkeit durch Geburt

Rüickblick

Heutige Regelung

Erwerb der Staatsangehörigkeit nach der Geburt

Rückblick

120

Heutige Regelung

121

2.5 .4

Verlustgründe

123

2.5.4.1

Rückblick

123

Heutige Regelung

123

2.6

Niederlande

Erwerb der Staatsangehörigkeit durch Geburt

Heutige Regelung

Erwerb der Staatsangehörigkeit nach der Geburt

Rückblick 
Erwerb der Staatsangehörigkeit durch Geburt

Erwerb der Staatsangehörigkeit nach der Geburt

Rückblick

Heutige Regelung

Verlustgründe

Rückblick

Heutige Regelung

Schweiz

\section{Erwerb der Staatsangehörigkeit durch Geburt}

Rückblick

Heutige Regellung.

Erwerb der Staatsangehörigkeit nach der Geburt

Heutige Regelung

Verlustgriunde

Rückblick

Heutige Regelung

Rückblick

Heutige Regelung

Erwerb der Staatsangehörigkeit nach der Geburt

Rückblick 
Fälle automatischen Staatsangehörigkeitserwerbs Optionsrechte

a) Im Inland geborene Ausländer

b) Im Inland geborene Staatenlose 221

c) Personen unter elterlicher Gewalt oder Vormundschaft eines Staatsangehörigen

d) Ehemalige Staatsangehörige

e) Personen, die als Staatsangehörige behandelt wurden

a) Im Inland geborene Ausländer

b) Kinder eines (ehemaligen) Staatsangehörigen

c) Personen, die als Kind im Inland gelebt haben

d) Ausländische Ehegatten eines Staatsangehörigen

e) Ehemalige Staatsangehörige

f) Adoptions- oder Pflegekinder eines Staatsangehörigen

g) Personen, die als Staatsangehörige behandelt wurden

Anhang: Einbürgerungsansprüche

a) Staatenlose Soldaten

b) Im Inland geborene Staatenlose

c) Nichteheliche Kinder eines Staatsangehörigen

d) Ausländische Ehegatten eines Staatsangehörigen

e) Ehemalige Staatsangehörige

f) Langjährige Einwohner

g) Andere Personen

Allgemeine Bemerkungen über die

Einbürgerungsvoraussetzungen

$\begin{array}{ll}\text { Volljährigkeit } & 237\end{array}$

Wohnsitz 239

3.3 .4 .3

3.3.4.4

Fremdenrechtlicher Status

Gesellschaftliche Eingliederung 250

3.3.4.5

3.3 .4 .6

3.3.4.7

3.3.4.8

3.3 .4 .9

3.3.4.10

Kenntnis der Landessprache

Keine Gefährdung der öffentlichen Ordnung 256

Verlust der bisherigen Staatsangehörigkeit $\quad 260$

Wirtschaftliche Voraussetzungen 263

Abwesenheit von entwicklungspolitischen

Hindernissen

Abwesenheit von intensiven Beziehungen zu 
Widerruf der Einbürgerung

Änderungen im Staatsangehörigkeitsrecht: einige Tendenzen im Staatsangehörigkeitsrecht

4.

Vorschläge zur Änderung des niederländischen

Staatsangehörigkeitsgesetzes 


\section{ABKÜRZUNGSVERZEICHNIS}

A

a.A.

AA

AAe

$\mathrm{ABGB}$

ABI. EG

ABI. AHK

AB1. KR

Abs.

A.D.I.

ADI

a.F.

AJCL

Amm.it.

Anm.

Art.

AS

Aufl

\section{B}

B

Bay. VBl.

Bay.VGH

BBI.

Bd.

BGB

BGB1.

BGH

BGHZ

\section{BIMJ}

BL

BMA

BNA

BO

BR

B'T

BüG

BVerf

BVerfG

BVerfGE

BVerwG

BVerwGE

BVG

Bst.

BW

BYIL

$B Z$

bzw, anderer Ansicht

Auswärtiges Aunt (Deutschland)

Ars Aequil (Niederiande)

Allgemeines Bürgerliches Gesetzbuch (Österreich)

Amtsblatt der Europäischen Gemeinschaft

Amtsblatt der Alliierten Hohen Kommission (Deutschland)

Amtsblatt Kontrollrat (Deutschland)

Absatz

Académie de Droit International

Anuario de Derecho Internacional (Spanien)

alte Fassung

American Journal of Comparative Law

Amministrazione italiane

Anmerkung

Artikel

Amtliche Sammlung (Schweiz)

Auflage

\section{Belgien}

Bayerisches Verwaltungsblatt (Deutschland)

Bayerisches Verwaltungsgerichtshof (Deutschland)

Bundesblatt (Schweiz)

Band

Bürgerliches Gesetzbuch

Bundesgesetzblatt (Deutschland/Österreich)

Bundesgerichtshof

Entscheidungen des Bundesgerichtshofes in Zivilsachen

(Dtutschland)

Boletin de Información de Ministerio de Justicia (Spanien)

Bulletin de Lois (Frankreich)

Bundesminister fuir Arbeit und Sozialordnung

British Nationality Act

Boletin Oficiall del Estado (Spanien)

Bundesrat (Deutschland)

Bundestag (Deutschland)

Bundesgesetz uber Erwerb und Verlust des

Sclyweizerbïrgerrechts (Schweiz)

Bundesverfassung (Schweiz)

Bundesverfassungsgericht (Deutschland)

Entscheidungen des Bundesverfassungsgerichtes

(Deutschland)

Bundesverwaltungsgericht (Deutschland)

Entscheidungen des Bundesverwaltungsgerichtes

(Deutschland)

Bundesverfassungsgesetz (Österreich)

Buchstabe

Burgerlijk Wetboek (Niederlande)

The British Yearbook of International Law

Burgerzaken (Maandblad van de vereniging yoor bevolkingsboekhouding en militaire zaken) (Niederlande) beziehungsweise 
C

ch.

$\mathrm{Cc}$

C.c.esp.

C.c.it.

CIEC

CMLR

Cmnd

CNB

CNF

col.

coords.

Co.Rep.

c.s.

D

$D$

DAAD

DDR

d.G.

DGRN

d.h.

Diss.

DKP

DM

doc.

Dov

DVB1.

$\mathbb{E}$

ed.

Edw.

EEC

$\mathrm{EG}$

EGBGB

Eliz.

EPIL

ESVGH

etc.

ETS

EUGHE

EUGRZ

EWG

$\mathbf{F}$

F

FamRZ

f.

FJR

$F \mathbf{l}$.

ff. chapter (Großbritannien)

Code Civil (Belgien/Frankreich)

Codigo civil espantol

Codice civile italiano

Commission Internationale de l'Etat Civil

Coramon Market Law Review

Command Paper

Code de Nationalité belge

Code de Nationalité française

column

Corordinatores

Coke's Reports: (Großbritannien)

cum suis

\section{Deutschland}

Deutscher Akademischer Austauschdienst

Deutsche Demokratische Republik

de Groot

Dirección General de los registros y del notariado (Spanien)

das heißt

Dissertation

Deutsche Kommunistische Partei

Deutsche Mark

document

Die öffentliche Verwaltung

Deutsches Verwaltungsblatt

editor

Edward (Großbritannien)

European Economic Community

Europäische Gemeinsschaft

Einführungsgesetz zum Bürgerlichen Gesetzbuch

(Deutschland)

Elizabeth (Grobbritannien)

Encyclopedia of Public International Law

Entscheidungssammilung des Verwaltungsgerichtshofes.

(Deutschland)

et cetera

European Treaties Series

Entscheidung des Europäischen Gerichtshofes:

Europäische Grundrechte Zeitschrift

Europäische Wirtschaftsgemeinschaft

Frankreich

Familienrechtszeitschrift (Deutschland)

folgende Seilte

Tijdschrift woor Fanilie- en Jeugdrecht

Niederländische Gulden

fortfolgende Seiten 


\section{XVIII}

Foro it.

Foro pad.

Fr.

G

GB

GBL.DDR

GBIÓ

Geo

Giur. it.

Giur. costinuz.

GG

ggf.

G.U.

II

Hand.I

Hand II

HKD

Hrsg.

\section{I}

I

IA

ICJ

ICLQ

i.d.F.

IPR

IPRax

i. Rh.

i. V.m.

\section{I}

JA

IBI

JGS

JO

$\sqrt{2}$

K

$\mathrm{KB}$

L

Lc

Leggi ciw. conment LNTS

\section{Abkürzungsverzeichnis}

II Foro italiano

II Foro padono (Italien)

Francs

Grobbritannien

Gesetzblatt der Deutschen Demokratischen Republik

Gesetzblatt Osterreich

George (Großbritannien)

Giurisprudenza italiana

Giurisprudenza costituzionale

Grundgesetz (Deutschland)

gegebenenfalls

Gesetzgebungsperiode (Österreich)

Gazetta Ufficiale (Italien)

Handelingen van de Eerste Kamer der Staten Generaal (Niederlande)

Handelingen van de Tweede Kamer der Staten Generaal (Niederlande)

Hofkanzleidekret (Österreich)

Herausgeber

Italien

Informationsbrief (des) Ausländerrechts (Deutschland)

International Court of Justice

International and Comparative Law Quarterly

(Grolbritannien)

in der Fassung

Internationales Privatrecht (Deutschland)

Praxis des internationalen Privatrechts (Deutschland)

Innerrhoden (Schweiz)

in Verbindung mit

Juristische Arbeitsblätter

Juristische Blătter (Österreich)

Josephische Gesetzsammilung Osterreicly)

Journal Officiel (Frankreich)

Juristenzeitung

Koninklijk Besluit (Niederlande)

Legge sulla cittadinanza (Italien)

Le nuove leggi civili commentate (Italien)

League of Nations Treaty Serie 
M

MDR

$\mathrm{m} . \mathrm{E}$.

MvA I

MVA II

MvT

m.w.N.

$\mathbb{N}$

$\mathbb{N}$

NA

n.a.y.

NILR

NJI

NJB

NJCM

NJW

Nr.

NRC

NSDAP

NVwZ

NWG

O

$\ddot{0}$

o.c.

OJ

o.J.

OJZ

OStA

OVG

o.V.

ÖZÖR

$\mathbb{P}$

Par.

PCIJ

PGS

PS

$\mathbf{R}$

R.

Rabels Z

$\mathrm{RC}$

RCDIP

RDI

RDC

RDIPP

Rdnr.
Monatschrift fuir Deutsches Recht

meines Erachtens

Memorie van Antwoord Eerste Kamer (Niederlande)

Mentorie van Antwoord Tweede Kamer (Niederlande)

Memorie van Toelichting (Niederiande)

mit weiteren Nachweisen

Niederlande

Nationality Act (Großbritannien)

naar aanleiding van (Niederlande)

Netherlands International Law Review

Nederlandse Jurisprudentie

Nederlands Juristenblad

Nederlands Juristen Commite voor de Mensenrecliten

(Niederlande)

Neue Juristische Wochenschrift (Deutschland)

Nummer

Nieuwe Rotterdamse Courant/Handelsblad Niederlande)

National-sozialistische Deutsche Arbeiterpartei

Neue Zeitschrift fuir Verwaltungsrecht Deutschland)

Nationaliteitswetgeving (Adriaansen/van der Weg

Rilverentant) (Niederlande)

Österreich

opere citato

Official Journal

ohne Jahr

Österreichische Juristenzeitung

Österreichisches Standesamt

Oberverwaltungsgericht (Deutschland)

ohne Verfasser

Österreichische Zeitschrift für öffentliches Recht

Paragraph

Permanent Court of International Justice

Politische Gesetzessammlung (Österreich)

Personeel Statuut (Niederlande)

Rijkswet (Niederlande)

Rabels Zeitschrift

Recueil de Cours

Rewue critique de droit international privé (Frankreich)

Rivista di diritto internazionale (Italien)

Revue de droit comparé

Rivista di diritto internazionale privato e processuale (Italien)

Randnummer 
Rev, Jur. Polit.

Indep. Coop.

REDI.

Res.

Rev.

RGB1.

RHDI

RLR

RM Themis

R.O.

RS

RuStAG

RuStA.̈ndG

RWNed.

S

$\mathrm{S}$.

SC

S.c.

Schw,

s.E.

Sect.

SF

SGS

SI

Sp

SR

St.

Stat.

Stato civ.

StAGebV

StARegG

StAUrkVwV

StAZ

StBG

StBG.DDR

Stbl.

Stcrt

SiGBl.

Suppl.

$\mathrm{T}$

ThGS

Trb.

T.v.O.

TVR
Revue Juridique et Politique,

Indépendance et Coopération

Revista Española de Derecho internacional (Spanien)

Resolucionn

Review

Reichsgesetzblatt (Deutschland/Österreich)

Revue Hellénique de Droit international

Ritsumeikan Law Review

Rechtsgeleerd Magazijn Themis (Niederlande)

Recueil Official (Schweiz)

Rechtsache

Reichs- und Staatsangehờrigkeitsgesetz (Deutschland)

Gesetz zur Anderung des Reichs- und

Staatsangehörigkeitsgesetzes (Deutschland)

Rijkswet op het Nederlanderschap (Niederlande)

Seite

Senatskonsult (Frankreich)

Stato civile

Schweiz

seines Erachtens

Section

Schweizerische Franken

Sammlung geltender Staatsangehörigkeitsgesetze

Statutory Instrument

Spanien

Systematische Sammlung des Bundesrechts (Schweiz)

Sint (Niederlande)

Statute (Großbritannien)

Lo Stato civile italiano

Staatsangehörigkeits- Gebührenverordnung (Deutschland)

Gesetz zur Regelung von Fragen der Staatsangehörigkeit (Deutschland)

Allgemeine Verwaltungsvorschrift über Urkunden in

Staatsangehörigkeitsangelegenheiten (Deutschland)

Zeitschrift fitr das Standesamtswesen /Das Standesamt

(Deutschland)

Staatsbürgerschaftsgesetz (Österreich)

Staatsbirgerschaftsgesetz der deutschen demokratischen

Republik

Staatsblad (Niedlerlande)

Staatscourant (Niederlande)

Staatsgesetzblatt (Österreich)

Supplement (Großbritannien)

Theresianische Gesetzessammilung (Österreich)

Tractatenblad (Niederlande)

Tijdschrift voor Overheidsadministratie

(Niederlande)

Tijdschrift voor vreemdelingenrecht (Belgien) 
u.a.

UCV

UdSSR

UN

UNTS

U.S.W.

แ.U.

$\mathrm{V}$

w.

VFGH

VG

VGH

VGHE

vgl.

Vict.

VO

wol.

VwGH

VwVfG

VWVG

W

WNed

WPNR

Y

YBILC

Jewish YBIL

Z

ZaöRV

ZAR

Z.B.

ZNVB

ZGB

Ziff.

ZRP

ZZW unter anderen

Uitgebreide Commissie Vergadering (Niederlande)

Union der Sozialistischen Sowjet Republiken

United Nations

United Nations Treaty Series

und so weiter

unter Umständen

versus

Verfassungsgerichtshof (Österreich)

Verwaltungsgericht (Deutschland)

Verwaltungsgerichtshof

Entscheidungen des Verwaltungsgerichtshofes (Deutschland)

vergleiche

Victoria (Großbritannien)

Verordnung

volume

Verwaltungsgerichtshof (Österreich)

Verwaltungsverfahrengesetz (Deutschland)

Verwaltungswerfahrengesetz (Schweiz)

Wet op het Nederlanderschap en het ingezetenschap Weekblad voor Privaatrecht, Notariaat en Registratie (Niederlande)

Yearbook of the International Law Commission

Jewish Yearbook of International Law

Zeitschrift für ausländisches öffentliches Recht und

Völkerrecht (Deutschland)

Zeitschrift für Ausländerrecht

zum Beispiel

Zeitschrift für Verwaltung (Österreich)

Zivilgesetzbuch (Schweiz)

Ziffer

Zeitschrift für Rechtspolitik

Zeitschrift für Zivilstandswesen (Schweiz) 


\section{XXII}

\section{LITERATUR WERZEICHNIS}

Abarca: Junco

Abarca Junco/Pérez Vera

Achterberg

Adam

Adami

Adamopoulou

Adhin

Adriaansen/van der Weg

Aguilar Navarro

Aguillo Pifia, RJELL

Aguilo Piña, RDP

Ahmad Ali

Akehurst

Akguner

Aksoy

Alvarez Rodriguez, REDI 1984

Alvarez Rodriguez, REDI 1986

Amacher

Amoros Guardiola/

Bercovitz Rodiŕguez-Cano

Annoussamy
P. Abarca Junco, Nacionalidad y extranjera en la nueva constitución, in: Lecturas sobre la Constitución españolla 2. Madrid 1978, 349-364.

P. Abarca Junco/A.L. Calvo Caravaca/I.D. Gonzalez Campos/E. Pérez Vera/M. Virgós Soriano, Derecho internacional privado, Band I, Universidad nacional de educación a distancia, Madrid 1987

C.E. Achterberg, Nederlanders, Vreemdelingen en Ingezetenen (De wet van 12 december 1892), Groningen 1895

Uwe Dietrich Adam, Zur Entstehung und Auswirkung des Reichsbuirgergeselzes, in: Aus Politik und Zeitgeschichte (Beilage zur Wochenzeitung Das Parlament) B 48/85 (30. Nowember 1985), 14-27

Vincenzo Adami, Le nuove disposizioni in materia di cittadinanza, Stato civile 1983, 262-265

P. Adamopoulou, Notes sur la légitimation relative a la nationalité hellénique et le principe de l'égalité des sexes, RHDI $1982 / 3,131-146$

K.S. Adhin, De toescheidingsovereenkomst inzake nationaliteiten tussen Suriname en Nederland. Een bespreking van artikel 5, Surinaams Juristenblad 1982, 714-734

J.C. Adriaansen/S. van der Weg, Nationaliteitswetgeving, thans onder redactie van C.J. Brinkman met medewerking van F.Th. Zilverentant en R.M. Pruimers, "s Gravenhage (Loseblattausgabe)

M. Aguilar Navarro, Comunidad hispánica y nacionalidad, Revista de Estudios Americanos, Sevilla 1955, 385

J.F. Aguiló Piña, La nacionalidad española de origen, Revista Jurfídica Española La Ley Mr. 773 vom 27.9.1983, 1-4

J.F. Aguiló Piña, Adquisición de la nacionalidad española por residencia, Revista de derecho privado $1984,531-541$

H.A. Ahmad Ali, Overeenkomst tussen het Koninkrijk der Nederlanden en de republiek Suriname inzake het verblijf en de vestiging wan wederzijdse onderdanen. Een analyse uit de praktijk, Utrecht 1979

Michael Akehurst, A modern introduction to international law, 6. Auflage, Londen 1987

T. Akguner, Turkish Citizenship Act, Annales de la Faculté de Droit d'Istanbul $1979,443-458$

Murat Ugur Aksoy, Der Erwerb der deutschen Staatsangehörigkeit durch ausländische. Arbeitnehmer aus der Sicht der Turkei, IA 1982, 183-186

Aurelia Alvarez Rodríguez, Anmerkung in: REDI 1984, 588593

Aurelia Alvarez Rodriguez, Anmerkung in: REDI 1986, 185. 186

M. Amacher, Die leidige Einbürgerung nach dem neuen Kinderrecht, ZZW $1979,47,48$

M. Amorós Guardiola/R. Bercovitz Rodriguez-Cano (coords.) c.s., Comentarios a las reformas de nacionalidad y tutela, Madrid 1986

David Annoussamy, Mariage et nationalité, Rev. Jur. Polit. Indêp. Coop. 1984, 87-93 
Ansay

Arena, S.c. 1983, 195

Arena, S.c. 1983, 259

Arena, S.c. 1983, 623

Arena, S.c. 1986, 307

Arena, S.c. 1986, 555

Arndt, StAZ 1969

Arndt, NJW 1975

Aubert

Audinet

Audit

Aznar Sanchez

Bachmann

Bahrfeldt

Baker

Bakker, NJB 1948

Bakker . PS 1956

Bakker, PS 1963

Ballarino

Barbero Garcfa

Barel

Barel

Barentsen

Bariatti, Jurisclasseur
Tukrul Ansay, Doppelte Staatsangehörigkeit für Türken, IA $1981,84,85$

Salvatore Arena, Ouali sono le muove disposizioni che devono essere gia applicate in materia di cittadinanza; La recente sentenza n. 30 della Corte Costitnzionale, Stato civile 1983, 195-197

Salvatore Arena, Una prima disamina della legge 21 aprile $1983, \mathrm{n} .123$ con la quale sono entrate in vigore le nuove disposizioni in materia di cittadinanza, Stato civile 1983,259 , $323,387,439$

Salvatore Arena, Secondo comma dell'art. 5 della legge 21 aprile 1983, Stato civile $1983,623-625$

Salvatore Arena, La legge 15 maggio $1986, \mathbb{n}, 180$ a modificazione dell'art. 5 della legge 21 aprile $1983, n$. 123 recante dispozioni in materia di cittadinanza, Stato civile 1986, 307

Salvatore Arena, La cittadinanza dei minori, Stato civile 1986 , 555

Claus Amdt, Gleichberechtigung der Geschlechter im Staatsangehörigkeitsrecht, StAZ 1969, 348, 349

Claus Arndt, Staatsangehörigkeit und Gleichberechtigung, NJW $1975,140-143$

Jean-François Aubert, Traité de droit constitutionnell suisse, Tome 1, Paris/Neuchatel 1967

Eugène Audinet, Observations sur le projet de loi relatif a la nationalite française, Journal du droit international privé 1889. $197-206$

B. Audlit, Bulletin de jurisprudence française, Nationalité, Journal du droit international 1981 , 346-354

Juan Aznar Sanchez, La doble macionalidad (doctrina, legislación, jurispradencia), Madrid 1977

Franz Bachmann, Änderung des niederländischen Staatsangehörigkeitsgesetzes vom 29-12-1950, StAZ 1952, 92

Max Bahrfeldt, Der Verlust der Staatsangehörigkeit durch Naturalisation und durch Aufenthalt im Auslande, Breslau 1903

Philip Baker, A note on the British Nationality Act 1981, Current Law Bulletin 1982, 780-794

B.J.R. Bakker, Verlies van Nederlanderschap, NJB 1948 , 474 476

P. Bakker, Wijziging van de artikelen 8 en 9 van de wet op het Nederlanderschap en het Ingezetenschap en inwoeging van een nieuw artikel 8a, PS 1956, 111

P. Bakker, Intrekking van de wet op het Nederlands onderdaanschap, PS 1963, 9-11

T. Ballarino, Commentario alle legge 21 aprile 1983 n. 123; Disposizioni in materia di cittadinanza, Leggi civ. comment. 1984, 969

Adriano Barbera García, Los convenios hispano-americanos de doble nacionalidad y el registro civil, Boletin de Información 1971, Nr. 896, 3-12; Nr. 897, 3-16

B. Barel, Commento all'art. 5 I. 21 aprile 1983 n. 123, Leggi civ. comment. 1984,996

B. Barel, Commento all'art. 81. 21 aprile 1983 n. 123, Leggi civ. comment. 1984,1010

W.A. Barentsen, Overzicht van de huidige interpretatie van de overeenkomst betreffende de toescheiding van staatsburgers, PS 1962, 51-52

Stefania Bariatti, Italie, in Jurisclasseur Nationalité, Loseblattausgabe Paris 


\section{XXIV}

Bariatti, Nationalite

Bartels

Bar-Yaacov

Bastid

Bates,

SLT 1979, 33

Bates,

SLT 1979, 81

Bates, PL 1982

Battifol, Evolution

Batiffol, Interprétation

Batiffol, Observations

Batiffol, RCDIP 1983

Batilffol/Lagarde

Baumann, Colette

Baumann, Fred

Baumgartner

Beauchet

Beauthier

Beets

Beyen

Bendeddouche

Bensabat Benarroch

Benz

Berber

Bercovitz RodriguezCano

\section{Literaturverzeichnis}

Stefania Bariatti, Nationalité et statut personnel dans le droit de la nationalité italienne, in: Verwilghen, Nationalité, Brussel $1984,123-142$

Hans Joachim Bartels, Methode und Gegenstand intersystemarer Rechtsvergleichung, Tübingen 1982

N. Bar-Yaacow, Dual mationality, London/Jerusalem 1961

Suzanne Bastid, L'affáire Nottebohm devant la Cour Intemationale de Justice, RCDIP 1956, 607-633

T.St.JN. Bates, The reform of the British nationality law, Scots Law Times 1979, 33-36

T.St.J.N. Bates, British nationality law, The green paper, Scots Law Times 1979, 81-86

T.St.J.N. Bates, Judicial review and nationality law, Public Law $1982,179-187$

Henri Battifol, Evolution du droit de la perte de la nationalité française, in: Aspects nouveaux de la pensee juridique. Recueil d'Etudes en hommage Marc Ancel. Band I, Paris 1975, 243-260; ebenfalls in Choix d'articles 1976, 157-170

Henri Batiffol, De l'interprétation stricte des textes sur la nationalité française, Multinudo Legum (Festschrift W. Wengler) $1973,123-138$

Henri Batiffol, Observations sur quelques questions de procédure en matière de nationalité française, Choix d"articles 1976, $171-178$

H. Batiffol, Perte de la nationalité française, RCDIP 1983, 249-257

Henri Batiffol/Paul Lagarde, Droit intemational prive, Band 1, 7. Auflage, Paris 1981

Colette Baumann, L'évolution du "ius soli" en matière de nationalité d'origine, depuis le code civil jusqu'a la loil du 10 aout 1927, Strasbourg 1931

Frederico S. Baumann, Staatsangehörigkeitsrecht der Niederlande, Frankfurt am Main/Berlin 1953

Beda Baumgartner, Einige Aspekte zum revidierten Art. 5 BüG, ZZW 1977, 281-283 (französisch: 1978, 52-54; italiënisch: 1978, 107, 108).

L. Beauchet, Das französische Gesetz vom 26. Juni 1889 tiber die Erwwerbung und den Verlust der Staatsangehörigkeit, Archiv für offentliches Recht $1891,443-465$

Gieorges Henri Beauthier, Le droit des étrangers et le code de la nationalité, Brussell 1984

$\mathrm{N}$. Beets, Het ingezetenschap en het Nederlandsch onderdaanschap der inheemsche bevolking van Nederlandsch-Indiê, Indisch Tijdschrift van het Recht 1933, 525 528

K.H. Beyen, Het Nederlanderschap in verband met het internationale recht, Diss. Utrecht 1890

Jacqueline Bendeddouche, Notion de nationalité et nationalité algériènne, Paris 1973

S. Bensabat Benarroch, Nacionalidad española de los judios sefarditas, Revista general de legislación y jurispnudencia $1979,143-148$

Urs Benz, Die ordentliche Einbiirgerung von Ausländern in der Schweiz, Diss. Zürich 1968 , auch erschienen in: Ziircher Beitrage zur Rechtswissenschaft, Neue Follge, Heft 304, Zürich 1968

Friedrich Berber, Lehrbuch des: Volkerrechts, Bd. 1, Allgemeines Friedensrecht, 2. Auflage, Mitnchen 1975

Rodrigo Bercovitz Rodrriguez-Cano, Articulos 18-20, Comen- 
Bercovitz Rodiriquez-

Cano, ADC

van den Berghe/Huber

\section{Bergmann/Ferid}

Bergmann/Korth

Bernhardt

Bernhardt, EPIL Bd.7

Bevan

Biesenbach

Bindman

Blake

Blaser

Bleckmann

Bleckmann, CMLR 1978

Bleckmann, CMLR 1980

Bleckmann, EPIL

Bleckmann, ZaöRV

Blumenwitz

Blumenwitz, JuS

Biuntschli

Böckenförde

Bockwinkel

Boelens

Boeles tario, in: M. Amorós Guardiola/R. Bencovitz Rodriguez-Cano (coords.) c.s.. Comentarios a las reformas de nacionalidad $y$ tutela, Madrid $1986,53-71$

Rodrigo Bercovitz Rodrfuez-Cano, Vecindad civil $y$ nacionalidad, Amuario de derecho civil 1983, 1149-1167

Guido van den Berghe/Christian H. Huber, European citizenship, in: Gedächtnisschrift Christoph Sasse, Das Europa der zweiten Generation, Kehl am Rhein/Strassburg, 755-774

Alexander Bergmann/Murad Ferid, Internationales Ehe- und Kindschaftsrecht, Frankfurt (Loseblattausgabe)

Wilfried Bergmann/Jürgen Korth, Deutsches Staatsangehörigkeits- und Passrecht, Köln 1985

Rudolf Bernhardt, German nationality, in: EPIL, Bd. 8, 258260

Rudolf Bernhardt, Customary international law, in: EPIL, Band 7,61-66

Vaughan Bevan, The development of British immigration law, London 1986

Ernst Wilhelm Biesenbach, Der Erwerb der Staatsangelhörigkeit a matte durch das eheliche Kind, Diss. Bonn 1969

G. Bindman, The future shape of British nationality, New Law Journal 1976,380-382

Charles Blake, Citizenship, law and the state: the British nationality law 1981, The Modern Law Review 1982, 179-197

Pierre Michel Blaser, La nationalite et la protection juridique internationale de l'individu, Lausanne 1962

Albert Bleckmann, Das französische Kolonialreich und die Gründung newer Staaten; Die Rechtsentwicklung in Syrien/Libanon, Indochina und Schwarzafrika, Koln/Berlin 1969

Albert Bleckmann, German nationality within the meaning of the EEC Treaty, CMLR 1978, 435-446

Albert Bleckmann, The personal jurisdiction of the European Community, CMLR $1980,467-485$; auch veröffentlicht in: Albert Bleckmann, Studien zum Europäischen Gemeinschaftsrecht, Köln 1986, 373-392

Albert Bleckmann, European Law, EPIL, Band 6, 176-182

Albert Bleckmann, Staatsangehörigkeitserwerb kraft Vertravenisschutzes?, ZaöRV 1974, 320-329

Dieter Blumenwitz, Die staatsangehörigkeitsrechtlichen Folgen der Teilung Deutschlands, Festschrift Firsching, München $1985,27-39$

Dieter Blumenwitz, Die deutsche Staatsangehörigkeit und der deutsche Staat, JuS 1988, 607-613

Johann Kaspar Bluntschli, Das moderne Völkerrecht der Civilisierten Staaten als Rechisbuch dargestellt, 3. Auflage, Nördlingen 1878

Ernst-Wolfgang Böckenförde, in: Hans Barion, ErnstWolfgang Böckenförde, Emst Forsthoff, Werner Weber (Hrsg.), Festgabe Carl Schmitt, 2. Teillband, Berlin 1968, 423463

A. Bockwinkel, Spaanse krijgsdienst en het gexin wan de Nederlandse combattant, NJB 1938, 193-198

G.J. Boelens, Vreemde krijgsdienst, RM Themis 1950, 276299

P. Boeles, Vreemdelingenrecht en Nederlanderschap, 2. Auflage, Zwolle 1984 
Boele-Woelki,

Effektivitätsprifung

Boele-Woelka, StAZ

van Bogaert

Böhining

Bousservain

Bolleter

Bolten,

Nemesis 1984/85,101

Bolten,

Nemesis 1984/85,155

Bonichot

de Boo

Boshowers

Breukelaar

Bridell

Brinkman 1985

Brinkman, Leerboek

Brinkman, PS 1967

Brinkman, PS 1973

Brinkman, PS 1975, 41

Brinkman, PS 1975, 81

Brinkman, PS 1978

Brinkaman, PS 1979

Brinkman, PS 1983

Brinkman, PS 1984

Brinkman, PS 1985, 14

Brinkman, PS 1985, 35

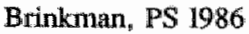

Brownlie

Brownlie, BYIL
Katharina Boele-Woelki, Die Effektivitätsprüfung der Staatsangehörigkeit im niederländischen internationalen Familienrecht ${ }_{p}$ 's Gravenhage 1983

Katharina Boele-Woelki, Niederlande: Neuregelung des Staatsangehörigkeitgrechts, StAZ 1985, 228-231

E.R.C. van Bogaert, Volkentecht, Antwerpen 1982

W. Böhning, The migration of workers in the United Kingdom and the European Community, London 1972

J.H.G. Boissevain, Staatsregt van Nederland, Wet tot witvaering van artikel 7 der Grondwet, Arnhem 1850

Walter Bolleter, Der Erwerb des aargauischen Bürgerrechtes, Aurau 1970

José \}. Bolten, Requiem voor een anachronisme, Nemesis $1984 / 5,101-104$

Josê J. Bolten, Beklag bij de Hoge Raad, Nemesis 1984/5, $155-1.56$

Jean-Claude Bonichot, La renonciation à la nationalite française en cas de double nationalité, Revue française de droit administratif $1987,120-129$

R.B. de Boo, Nederlanders uit Suriname niet als zodanigg (h)erkend, PS 1986, 67-73

Fernand Boshowers, Nationaliteit, Commentaar op de samengeordende wetten en wetgeving in bepaalde landen, Brugge 1.951

W. Breukelaar, De Rijkswet op het Nederlanderschap, AAe $1985,464-472$

Marcel Bridel, Précis de droit constitutionnel et public suisse, Tome I, Lausanne 1965

C.J. Brinkman, Het Nedlerlandse Nationaliteitsrecht in de praktijk, Alphen aan den Rijn/'s Gravenhage 1985

C.J. Brinkman, Beknopt leerboek voor het nationaliteitsrecht, Alphen a/d Rijn/"s Gravenhage 1976

C.J. Brinkman, De Oostenrijkse nationaliteitswet in de praktijk, PS 1967, 25,26

C.J. Brinkman, De Franse nationaliteit, PS 1973, 33-36

C.J. Brinkman, Duitse nationaliteitswet ingrijpend gewijzigd, PS $1975,41,42$

C.J. Brinkman, Wijziging van de Spaanse nationaliteitswetgewing, PS $1975,81,82$

C.J. Brinkman, Wijziging wan de Zwitserse nationaliteitswet, PS 1978,41

C.J. Brinkman, De moeder in het Britse nationaliteitsrecht, PS 1979,54

C.J. Brinkman, Het ontwerp van de Rijkswet op het Nederlanderschap, PS 1983, 93-94

C.J. Brinkman, De niewwe Nederlandse nationaliteitswet, PS $1984,34-40 ; 51-57$

C.J. Brinkman, De Griekse nationaliteitswet gewijzigd, PS $1985,14,32$

C.J. Brinkman, De nieuwe Belgische nationaliteitswet, PS $1985,35-37$

C.J. Brinkman, Het nieuwe nationaliteitsrecht; de Rijkswet en enkele verdragen nader bezien, PS 1986, 21-25

Ian Brownlie, Principles of public international law, 3. Auflage, Oxford 1979

Ian Brownlie. The relations of nationality in public international law, British Yearbook of International Law 1963, 284 364 
Browwer

Brunner

Buchiolz

Buczkowski/Rochowanski

Burger

de Burlet

Cahn

Calbairac

Cansacchi di Amelia

Carraro

Cases Méndez

Castro y Bravo

Cauwes

Chalenton

Chiaverini

Chiese

Churchill

Cian/Trabucchi

Clerici, RDI

Clerici, RDIPP

Closset, Jurisclasseur

Closset, Nationalité

Closset, Traite

Cockburn

Cogordan

Colomb

Constantinesco,

Rechtsvergleichung
Januina Brouwer, De nationaliteit war de gelnuwde vrouw in België en in Nederland, Disss. Amsterdam 1955

Georg Brumer, Eunfuhrung in das Recht der DDR, Schriftenreihe der juristischen Schulung, Heft 29, Munchen 1975

K. Buchholz, Sammel- und Nachsohlagewerk der Rechtsprechwng des BVerw $\mathrm{G}, 1957 \mathrm{ff}$.

Herbert Buczkowski/Erich Rochowanski Das bisterreichische Stantsbürgerschaftsrecht, 2. Auflage, Loseblatkommentar, Wien 1967

Franz-Xaver Burger, Die erleichterte Einbirgenng nach dem Bundesgesetz uber Erwerb und Verlust des Schweizerbirgerrechts vom 29. September 1952, Diss. Bern 1971

Jacques de Burlet, Nationalité des personnes pliysiques et décolonisation, Bruxelles 1975

Wilhelm Cahn, Reichs- und Statsangehorigkeitsgesetx, 4. Auflage, Berlin 1914

G. Calbairac. Traite de la nationalité de la femme mariée. Paris 1929

Giorgio Cansacchi di Amelia, La cittadinanza comunitaria, in Estudios de derecho intemacional, Homenaje al Profesor Miaja de la Muela, Bd. 2, Madrid 1979, 727-731

M. Carraro, Commento agli arti. 3 e 41.21 aprile $1983 \mathbf{n}_{\text {. }}$ 123, Leggi civ. comment. 1984, 988

José Ignacio Cases Méndez (coord.), Emigración y constitución, Guadalajara 1983

F. de Castro y Bravo, La Nationalite, la double nationalite et la supranationalité (Nacionalidad, doble nacionalidad $y$ supranacionalidad), Recueil de Cours de la A.D.I., $1961-1,521$ 632

A. Cauwes, Des rapports du mariage avec la nationalite, Paris 1900

P. Chalentom, La nationalite neerlandaise, 's Gravenhage 1928

René Chiawerini, L'évolution du droit public allemand depuis

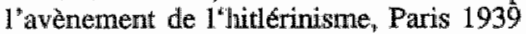

Massimo Chiese. Il valore delle muowe disposizioni in materia di cittadinanza, Legge 21 aprile $1983, n, 123$, G.U, n. 112 dell 26 aprile 1983 , Stato civile $1983,326-328$

R.R. Churchill, Nationality, Luxemburg, ICLQ 1976, 245-246 Giorgio Cian/Alberto Trabucchi, Commentario breve al codice civile, 2. Auflage, Padova 1984

Roberta Clerici, Nuove norme in tema di cittadinanza: ancora una minireforma, Rivista di Diritto Internazionale 1986, 347349

Roberta Clerici, A proposito del riacquísto della cittadinanza italiana, RDIPP 1986,575

Charles-Louis Closset, Belgique, in; Jurisclasseur, Nationalite., Paris (Editeurs Techniquew), Loseblatkonmentar

Charles-Louis Closset, Nationalité et statut personnel dans le droit positif de la mationalité belge, in: Verwilghem, Nationalite, Brussel $1984,327-350$

Charles-Louis Closset, Traite pratique de la nationalité belge, Bruxelles 1970

Alexander Cockburn, Nationality, London 1869

George Cogordan, La nationalité au point de vue des rapports intemationanx, 2. Auflage, Paris 1890

P.Colomb, L'acquisition de la nationalie française a des fins sportives, Mizza 1977

Leontin-Jean Constantinesco, Finfihrung in die Rechtsvergleichung, Band II (Die rechtsvergleichende Methode), Koln u.s.w. 1972 


\section{XXVIII}

Constantineseco, RDC

Cordova, YBLC 1953

Cordova, YBILC 1954

\section{Coscia}

Czaplinski

Czapski, Rabels $Z$

Czapski, StAZ

Dahm

Debat preadvies

Dekker, BZ 1984

Dekker, BZ 1985

Diephuis 1856

Diephuis 1886

Dfez dell Corral Rivas

Diez del Corral Rivas, Comentario

Dfez del Corral Rivas, Principios

Díez del Corrall Rivas, RDP

\section{Dirkzwager}

Dischler

Dischler, StAZ 1957

Dixon

Doerner/Hecker

\section{Literaturverzeichnis}

Leontin-Jean Constantinesco, La comparabilité des ordres juridiquesi ayant une idéologie et une structure politicoéconomique différente et la théorie des elléments déterminants, $\mathrm{RDC} 1973,5-16$

Roberto Cordova, Nationality, including statelessness, Document A/CN.4/64, Report on multiple nationality, Yearbook of the International Law Commission 1954, Band II, 166-199

Roberto Cordova, Nationalify, including statelessness, Document A/CN.4/81, Third report on the elimination or reduction of statelessness, Yearbook of the Internationall Law Commission 1954, Band II, 26-110

Antonio Coscia, La svolta legislativa in tema di cittadinanza italliana nelle nome di recente produzione "Amm. it. 1983, 1282

Wladyslaw Czaplinski, La citoyenneté de la République dérnocratique allemande et la nationalité allemande, RCDIP $1984,439-448$

Georg Czapski, Niederlande, Änderung des Staatsangehörigkeitsrechts, RabelsZ 1951/52, 483-485

Georg Czapski, $\mathrm{Zu}$ einigen Streitfragen im niederländischen Statatsangehờrigkeitsrecht, StAZ 1968,56-58

Georg Dahm, Völkerrecht, Bd. 1, Stuttgart 1958

Debat over het preadvies van Mr. G.R. de Groot, "Gelijkheid van man en vrouw in het nationaliteitsrecht", nr. 26 van de uitgaven van de Nederlandse Vereniging voor Rechtsvergelijking, Deventer 1978

J. Dekker, Rijkswet op het Nederlanderschap, BZ 1984, 8388;99-101

J. Dekker, Advisering omtrent naturalisatieverzoeken, BZ 1985, 281-285; 295-298

G. Diephuis, Het Nederlandsch Burgerlijk Recht naar de volgorde van het Burgerlijk Wetboek, 2. Auflage, Band I, Groningen 1856, 2-42

G. Diephuis, Het Nederlandsch Burgerlijk Recht, 2. Auflage, Band I, Groningen 1886, 218-246

Jesús Díz del Corral Rivas, Sintesis sobre nacionalidad y registro civil, Madrid 1978

Jesús Díez del Corral Rivas, Articulos 23-26 y disposición transitoria, Comentario, in: M. Amorós Guardiola/R. Bercovitz Rodriguez-Cano (coords.) c.s., nacionalidad y tutela, Madrid $1986,132-166$

Jesuis Diez del Corral Rivas, Principios de la reforma en materia de nacionalidad, Revista de derecho privado 1983, $791-819$

Jesús Diez del Corral Rivas, Principio de la reforma en materia de nacionalidad, Revista de derecho privado 1983 , $791-819$

A. Dirkzwager, Art. 7 sub 4 van de Wet op het Nederlanderschap en de R.K. Bisschoppen, NJB 1956, 547-552

Ludwig Dischler, Das Staatsangehörigkeitsrecht von Belgien und Luxemburg, Frankfurt am Main 1950

Ludwig Dischler, Neues französisches Staatsangehörigkeitsrecht, StAZ 1957, 19-22

Dawid Dixon, Thatcher's People: The British Nationality Act 1981. Journal of Law and Society 1983, 161-180

Heinz Doerner/Hellmuth Hecker, Das Staatsangehörigkeitsrecht Italiens, Frankfurt am Main/Berlin 1967 
Donner

Dubbink

Dubois

Dummett

Dummett/Martin

Durand

Duranton

Dutoit

Dutoit, Jurisclasseur

Dutoit, Nationalité

Edtstadler, ÖStA 1983

Edtstadler, ÖStA 1985

Edtstadler, ÖStA 1987

Ehrlich

Elias

Emmerich/Rothschildt

Erauw/de Foer

van Es

\section{Espin Cánovas}

Espín Cánovas,

Festschrift

de Esteban

Etter

Evans, AJCL

Evans, MLR

Evans, Scots Law Times

Evans, YEL

Evans, J.M.
Ruth Donner, The regulation of nationality in international law, Helsinki 1983

C.W. Dubbink, Nationaliteitsverwikkelingen bij huwelijken van Nederlanders met Engelsen, NIB 1949, 158-160

Bernard Dubois, Die Frage völkerrechtlichen Schranken landesrechtlicher Regelung der Staatsangehörigkeit, Bern 1955

Ann Dummett, The new British Nationality, British Journal of Law and Society 1981, 233-241

Ann Dummett/lan Martin, British nationality, The AGIN Guide to the law, 2. Auflage, London 1984

Andrew Durand, European Citizenship, European Law Review $1979,3-14$

M. Duranton, Cours de droit civil suivant le cote français, Bruxelles 1841

Bernard Dutoit, La nationalite de la femme mariée, Band I: Europa (Genf 1973); Band II: Afrique (Genf 1976); Band III: Amérique, Asie, Océanie (Genf 1980)

Bernard Dutoit, Theorie générale (Sources formelles du droit de la nationalité), in Jurisclasseur Nationalité (Loseblattausgabe), Paris

Bemard Dutoit, Nationalité et mariage: leur interaction dans le droit comparé de la nationalité, in: Verwilghen, Nationalité, Brussel 1984, 443-474

Karl W. Edtstadler, Staatsbürgerschaft, System und Wirklichkeit, OSSA 1983, 11-14

Karl W. Edtstadler, Grundlagen für die Entwicklung in Staatsbïrgerschaftsangelegenheiten, Materialsammlung aus Salzburger Sicht, ÖStA $1985,81-85,92,93$

Karl. W. Edtstadler, Vom Fremden zum Salzburger, Einbiirgerungspraxis im Bundesland Salzburg, ÖStA 1987, 105-112

Kurt Ehrlich, Uber Staatsangehörigkeit; Zugleich ein Beitrag zur Theorie des offentlich-rechtlichen Vertrages und der subjelktiv-öffentlichen Rechte, Aarau 1930

T.O Elias, New horizons in international law, Alphen aan den Rijn 1990

H. Emmerich/John Rothschildt, Die Rechtslage deutscher Staatsangehörigen im Ausland, Haarlem 1937

Johan Erauw/R. de Foer, Internationaal privaatrecht, De bromnen, Antwerpen/Amsterdam 1982

Marie Florence Van Es, De nieuwe nationaliteitswetten van Nederland en Italiè,, unveröffentlichtes Manuskript, Leiden 1985

Diego Espín Cấnovas, Manuel de derecho civil espanfol, Bd. 1, Parte gene, al, 3. Auflage, Madrid 1968

Diego Espín Canovas, La evolución de la equiparación entre marido y mujer en Espania en 1975, Festschrift Bosch, Bielefeld 1976, 145-252

Jorge de Esteban, Las constifuciones de España, Madrid 1981

Oskar Eitter, Der Verlust des Schweizerbuirgerrechtes, Diss. Bern 1945

A.C. Evans, European Citizenship: A novel concept in EEC Law, AJCL 1984, 679-715

A.C. Evans, European citizenship, Modern Law Review 1982, $497-515$

A.C. Evans, The new British nationality bill and European Community Law, Scots Law Tumes 1981, 133-137

A.C. Evans, Nationality law and the free movement of persons in the EEC, with special reference to the British Nationality Act 1981, Yearbook of European Law 1982, 174-189

J.M. Evans, Immigration Law, 2. Auflage, London 1983 


\section{$\mathrm{XXX}$}

Feer

Fernândez Femández

Fernández Marcana

Fernandex Mendes

Fernaindez Rozas

Fernández Rozas,

Vitoria Gasteis

Fernando Pantaleón

Filippi

Firsching

Fitzmaurice

Floyd

Forner Delaygua

Forsthoff

Fortunato/Giardina

Fourre

Foyer

Franck

Fransman

Fransman, NLJ

Freeman

Freund

Frey

Fritsche

Frowein

Füsslein

\section{Literaturverzeichnis}

Robert E. Feer, Die mehrfache Staatsangehörigkeit natürlicher Personen, Zürich 1955

Mercedes Fernândez Ferriández, El principio de igualdad y su incidencia en el nuevo derecho español de la nacionalidad, REDI 1983, 431-446

Luis Fernández Marcana, Contribución al estudio de la doble nacionalidad de los hijos de españoles nacidos en America, Havana 1924

Huge Fernaindez Mendes, De juridische positie van de Surinamers, AAve 1981, 636-643

José Carlos Femández Rozas, Derecho español de la nacionalidad, Madrid 1987

José Carlos Fernández Rozas, La reforma del derecho español de la nacionalidad, in: Cursos de derecho internacional de Vitoria-Gasteiz 1983, Uniwersidad del País Vasco 1984, 135233

A. Fernando Pantaleón, Articulos 21,22, Comentario, in: $M$. Amorós Guardiola/R. Bercovitz Rodriguez-Cano (coords.) c.s.. Comentarios a las reformas de nacionalidad y tutela, Madrid $1986,72-131$

C. Fulippi, L'opzione per una cittadinanza; un'assurda interpretazione, Stato civile 1984,520

Karl Firsching, Einfuihrung in das internationale Privatrecht, Schriftenreihe der juristischen Schulung, Heft 18, 3. Auflage, München 1987

Gerald G. Fitzmaurice, General principles of international law, Recueil de Cours 1957 II

Robert Floyd, French nationality, New Law Journal 1977, 1006-1007

Joaquín-Juan Forner Delaygua, Anmerkung, in: REDI 1987, $154-158$

Ernst Forsthoff, Deutsche Verfassungsgeschichte der Neuzeit, 2. Auflage, Stuttgart 1961

M.A. Fortunato/F. Giardina, Le nuove disposizione in materia di cittadinanza, Giur. it. 1983 IV, 324

Jean Fourré, Nationalité, religion et conception de l'homme dans les principes de la mationalité française, Revue Jur. Pol. Indêp. Coop. 1984, 561-574

Jacques: Foyer, Acquisition de la nationalité française, Art. 37-

1 du Code de la nationalite, RCDIP $1982,669-677$

Marcel Franck, Das neue luxemburgische Staltsangehörigkeitsrecht, StAZ 1975, 285-295

Lautie Fransman, British nationality law and the 1981 Act, London 1982

Laurie Fransman, Patriality: its redeployment as British citizenship under the British Nationality Act 1981, New Law Joumal 1983, 691, 692, 727-731, 739-741, 787-789

M.D.A. Freeman, British Nationality Act 1981, London 1982

D. Freund, Die Erleichterung der Einbiirgenung als Maßnahme gegen die Uberfremdung; Zeitschrift für Schweizerisches Recht $1974,61-92$

Elisabeth Frey, Über das Biirgerrecht der Ehefrau in der Schweiz und ilhren Nachbarstaaten, Diss. Zürich 1942

Robert Fritsche, Funktion und Bestand der deutschen Staatsangehörigkeit nach dem Grundvertragsurteil, Frankfurt am Main/Bern 1981

Jochen Abr. Frowein, Zur Rechtsstellung von Kindern auslärndischer Arbeitsnehmer in Europa, EuGRZ 1980, 147-155

R.W. Füsslein, Frankreich, Staatsangehörigkeitsgesetz vom 19. 10. 1945, Frankfurt a.M. 1949 
Garcia Petit

Garth

Gatteschi

Geiger

Geiger, Deutschland

van Gelderen

Gerbenzon/Algra

Gervasoni, ZZW 1969

Gervasoni, ZZW 1983

Gervasoni, ZZW 1984

\section{Geuxinge}

Giacometti/Fleiner

Giese

Giese,

Völkerrechtliche

Vereinbarungen.

Ginsburgs

Godechot

Goldemund, ÖStA 1956

Goldemund, ÖStA 1965

Goldemund, StAZ 1966

Goldemund/Ringhofer/ Theuer
Jorge García Petit, Extranjerfa, matrimonio y nacionalidad, Revista Jurldica de Cataluña 1966, 100-103

Bryant G. Garth, Migrant workers and rights of mobility in the European Community and the United States: A study of law, community and citizenship in the welfare state, in: Maurio Cappelletti, Monica Seccombe, Joseph Weller, Integration through law, Volume 1, Methods, tools and institutions, Book 3, Forces and potentials for a European identity, Berlin/New York 1986, 85-163

Silvano Gatteschi, Conmmentario delle leggi sulla cittadinanza, Bolzano 1958

Rudolf Geiger, Grundgesetz und Volkerrecht, Die Bezìge des Staatsrecht zum Volkerrecht und Europarecht, München 1985

Rudolf Geiger, Deutsche Staatsangehörigkeit und Rechtsstatus Deutschlands- Einige grundsätzliche Überlegungen zum Beschluss des BVerwG wom 30.12.1982: in: Deutschland als Ganzes (Hrsg. Zieger. Meissner, Blumenwitz), Köln 1985, $125-132$

J.W. van Gelderen, Das Staatsangehörigkeitsrecht der Niederlanden und seiner Kolonien, in: Georg Crusen/Georg Maas/Adolf Siedler, Rechtsverfolgung im internationalen Verkehr, Band VII, Das Recht der Staatsangehörigkeit der europäischen und der außereuropäischen Staaten, Erster Teil, Die europäischen Staaten, Berlin 1940

P. Gerbenzon/N.E. Algra, Voortgangh des Rechtes, Alphen a.d. Rijn 1979

Mario Gervasoni, Il diritto di cittadinanza dell'adottato, ZZW $1969,364-366$ (deutsch: 1970, 98-100)

Mario Gervasoni, Baldige Aufhebung von Art. 54 Abs. IV der Bundesverfassung?, $\mathbb{Z W} 1983,284,285$ (französisch: 296,297; italiënisch: 302,303 )

Mario Gervasoni, Zur Revision des Bürgerrechts nach der Volksabstimmung vom 4 . Dezember $1983, \mathrm{ZZW} 1984,9,10$ (italienisch: $25-27$; französisch:46-48)

J.E. Geuzinge, De Rijkswet op het Nederlanderschap, WPNR $5769(1986), 62-67 ; 295-298$

Zaccaria Giacometti/Fritz Fleiner, Schweizerisches Bundesstaatsrecht, Zürich 1949

Hannes Giese, Das Staatsangehörigkeitsrecht von Großbritannien, Sammlung geltender Staatsangehörigkeitsgesetze, Band 6, 2. neubearbeitete Auflage, Frankfurt am Main 1978

Hannes Giese, Staatsangehörigkeitsrechtliche Bestimumungen in völkerrechtlichen Veteinbarungen Großbritanniens, Veroffentlichungen aus dem Institut fuir Internationale Angelegenheiten der Universität Hamburg, Band 4, Frankfurt am Main 1976

Georg Ginsburgs, The citizenship law of the USSR, The Hageue 1983

Jacques Godechot, Les constitutions de

la France depuis 1789, Paris 1970

Ingobert Goldemund, Die Beibehaltung der östereichisschen Staatsbürgerschaft, OStA 1956, 20-22

Ingobert Goldemund, Neugestaltung des österreichischen Staatsbuirgerschaftrechtes, ÖStA $1965,4-6 ; 16-19 ; 26,27$

Ingobert Goldemund, Die Neuregelung des österreichischen Staatsbiügerschaftsrechts, StAZ 1966, 33-40

Ingobert Goldemund/Kurt Ringhofer/Karl Theuer, Das österreichische Staatsbïngerschaftsrecht, Wien 1969 
XXXII

Gonset

Gonzálbez Giner

González Campos, Comentario

Gonzallez Campos, Emigración

Gonzâlez Campos, Lecciones

Göpfert/Heinzmann

Gótz, ZZW 1970

Götz, ZZW 1979

Grabitz

Grawert

Grawert, Handbuch

Grawert, Der Staat

Green

Grendelmeier

Griffiths-Le Poole

Groeneveld, PS 1956

Groeneveld, PS 1963

de Groot,

Loseblattkommentar

de Groot, Preadvies

de Groot/Tratnik

de Groot, NJB 1975

de Groot, PS 1980

\section{Literaturverzeichnis}

Yves Gonset, La nationalite de l'enfant naturel en droit comparé, étude des lëgislations européennnes, Genf 1977

María Antonia Gonzalbez Giner, La nacionalidad de la mujer casada en ell Derecho español (A propósito de la reforma proyectrda), Amuario de Derecho internacional, I, 1974, 291307

Julio D. González Campos, Articulo 17, Comentario, in:M. Amorós Guardiola/R. Bercovitz Rodriguez-Cano (coords.) c.s... Comentarios a las reformas de nacionalidad y tutela, Madrid $1986,17-52$

Julio Gronzalez Campos, Reflexiones sobre la doble nacionalidad, Consecuencias en la emigración española, in: Cases Méndez, Emigración y constitución, Guadalajara 1983, 91-102

Julio D. González Campos, Lecciones de derecho internacional privado (derecho de la nacionalidad, derecho de extranjeria), Oviedo 1979

Robert Gôppfert/Hildebert Heinzmann, Einbürgenungsgesetzgebung und -praxis in den Kantonen und Gemeinden, Resultat der Umfrage des Schweizerischen Verbandes der Bürgergemeinden und Korporationen, Luzern/ Bern 1982

Ernst Götz, Wiedereinbürgerung, ZZW 1970, $133-136$ (italiënisch: 1971, 123-126)

Ernst Götz Schweizer Bürgerrecht. Auslegung von Art. 44 Abs. III BV, ZZW 1979, 204 (italiënisch: 1980, 27-29)

Eberhard Grabitz, Europäisches Bürgerrecht zwischen Marktbürgerschaft und Staatsbürgerschaft, Köln 1970

Rolf Grawert, Staat und Staatsangehörigkeit,

Verfassingsgeschichtliche Untersuchung zur Entstehung der Staatsangehörigkeit, Berlin 1973

Rolf Grawert, Staatsvolk und Staatsangehörigkeit, in: Josef Isensee/Paul Kirchhof (HIsg.), Handbuch des Staatsrechts, Bd. I, Heidellberg 1987

Rolf Grawert, Staatsangehörigkeit und Staatsbürgerschaft, Der Staat $1984,189-204$

N.A. Maryan Green, International Law, 3. Auflage, London 1987

Hans Rudolf Grendelmeier, Erleicherte Einbürgerung, Diss. Zürich 1969

Fre Griffiths-Le Poole, De ongelijkheid van man en vrouw met betrekking tot de verkrijging wan elkanders nationaliteit en de nationaliteit van hun kinderen, NJB 1970, 1319-1324

A.L. Groeneveld, Problemen om art. 7 sub 4 van de Wet op het Nederlanderschap, PS 1956, 114-118

A.L. Groeneveld, De intrekking van de Wet op het Nederlands

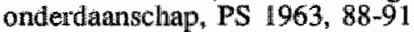

Gerard-René de Groot, Personen- en familierecht, Nationaliteitswetgeving, Deventer (lossblätterig)

Gerard-René de Groot, Gelijkheid van man en vrouw in het nationaliteitsrecht; Preadvies voor de Nederlandse Vereniging voor Rechtsvergellijking, Deventer 1977

Gerard-René de Groot/Matjaz Tratnik, Nationaliteitsrecht, Zwolle 1986

Gerard-René de Groot, Nationaliteitsrecht en emancipatie van de vrouw in de Bondsrepubliek, NJB 1975, 782-787

Gerard-René de Groot, Kanttekeningen over de famillenaam, PS 1980, 78-80, 86-92 
de Groot, BZ 1981

de Groot, NJB 1981

de Groot, BZ 1982

de Groot, JZSt 1983

de Groot, PS 1984

de Groot, JZSt 1985

de Groot, IPRax 1985

de Groot, PS 1985

de Groot, RLR 1985

de Groot, NJ 1988

de Groot, L.J.A., PS 1952

de Groot, L.J.A. Hartmans Tijdschrift

Groth

Grunsky

Guardiola/Bercovitz Rodríguez Cano

\section{Guerrero}

Guiho

\section{Gusseck}

Hall

\section{Halsbury}

Halter

Handleiding

Hamann/Lenz
Gerard-René de Groot, Gelijkheid van man en vrouw in het nationaliteitsrecht, $\mathrm{BZ} 1981,67,68,81-83,95-97$

Gerard-René de Groot, Er komt een nieuwe wet op het Nederlanderschap, NJB 1981, 1117-1126

Gerard-René de Groot, Naschrift bij de reactie van F.Th. Zilverentant, $B Z, 1982,2-4$

Gerard-Rene de Groot, Anmerkungen uber die Bekămpfung der mehrfachen Staatsangehörigkeit (auf japanisch), Japanische Zeitschrift für das Standesamtswesen 1983, Nr. 308, 13-25

Gerard-René de Groot, Wijziging van het Oostenrijkse nationaliteitsrecht, PS 1984, 18-27

Gerard-René de Groot, Tendenzen in westeuropäischen Staatsangehörigkeitsrecht (auf japanisch), Japanische Zeitschrift für das Standesamtswesen 1985, Nr. 328, 2-8; Nr. 329, 2-11; Nr. 330, 2-10; Nr.331, 36-48

Gerard-René de Groot, Das aeue Staatsangehörigkeitsgesetz. der Niederlande, IPRax 1985, 175-178

Gexard-René cle Groot, Wijziging van het Italiaanse nationaliteitsrecht, PS 1985, 51-55

Gerard-René de Groot, Das neue Staatsangehörigkeitsrecht der Niederlande (auf japanisch), Ritsumeikan Law Review 1985, Nr. 5/6, 123-167

Gerard-René de Groot, "Wien Neerlands bloed door d"aadren vloeit...", Nationaliteitsrechtelijke aantekeningen bij Hof Amsterdam 24 januari 1913, in: Nederlandse Jurisprudentie 1913-1988, Annotatoren kijken terug, Beschouwingen van de huidige annotatoren naar aanleiding van 75 jaar Nederlandse Jurisprudentie, Zwolle 1988, 50-60.

L.J.A. de Groot, De nationaliteit van gehuwde vrouwen, PS $1952,89-92$

L.J.A. de Groot, De nationaliteitswetgving wan Oostenrijk, Hartmans Tijdschrift 1948, 41

Klaus-Martin Groth, Einbiirgerungsratgeber, Frankfiurt am Main 1984

Wolfgang Grunsky, Italienisches Familienrecht, Eine Darstellung für die deutsche Praxis, 2. Auflage 1978

M. Anorós Guardiola/R. Biercovitz Rodríguez-Cano (coords.) $c_{w} s_{2}$. Comentarios a las teformas de nacionalidad y tutela, Madrid 1986

Jose Gustavo Guerrero, La codification du droit international: la première conférence (1930), Paris 1930

Pierre Guiho, Lincidence de la convention du Conseil de l'Europe du 6 mai 1963 à l'égard de la nationalité française, in: Melanges dédies à Robert Pellowx, Lyon 1980, $151-167$

Lutz Gusseck, Neues zu Deutschland und zur deutschen Staatsangelabrigkeit, NJW 1988, 1302-1306

William Edward Hall, A treatise on international law 8 . Auflage, Oxford 1924

Halsbury's Statutes of England, 3. Auflage, London 1968

Hans Halter, Bürgerrecht der Frau nach EheschlieBung , ZZW $1981,374,375$ (französisch: 1982, 114, 115)

Handleiding betreffende de Toescheidingsowereenkomst inzake nationaliteiten, gesloten tussen het Koninkrijk der Nederlanden en de Republiek Suriname, "s Gravenhage 1975

Andreas Hamann/Helmut Lenz, Das Grundgesetz fuir die Bundesrepublik Deutschland worn 23. Mai 1949, 3. Auflage, Berlin 1970 
XXXIV

Hammar

Hampe

Hampe/von Waldheim

Hannappel

Hartley

Hartung

Hartwig

Hatschek

Hausenbichler

Hecker, Bibliographie

Hecker, Code Napolén

Hecker, Deutschland

Hecker, Europa

Hecker, Materialien

Hecker, Mehrseitige

Verträtige

Hecker, IA 1981

Heoker, StAZ 1985

Hecker, StAZ 1987

Hecker, StAZ 1988

Hecker, Recht in Ost und West 1987

Hecker/Tomson

Hegi

Hegnauer, Zentrallblatt

Hegnatuer, ZZW 1980

\section{Literaturverzeichnis}

Tomas Harnmar, Citizenship and political participation of immigrants, Stockholm 1985 (nicht veröffentlicht)

Karl Alexander Hampe, Das Staatsangehörig-keitsrecht won Spanien, Pornugall und Irland, Frankfurt am Main/Berlin 1960

Karl-Alexander Hampe/Gottfried von Waltheim, Das Staatsangehbirigkeitsrecht von Spanien, Portugal und Irland, Frankfurt am Main/Berlin 1954

W. Hannappel, Staatsangehörigkeitsrecht und Völkerrecht, Frankfurt am Main 1986

Trewor C. Hartley , La loi de 1981 sur la nationalité britannique, RCDIP 1983, 573-580

Fritz Hartung, Deutsche Verfassungsgeschichte vom 15. Jahrhundert bis zur Gegenwart, 8. Auflage, Stuttgart 1950

A. Harrwig, Wirkung des Bürgerrechtsverlustes der Mutter gemäb Art. 9 Abs. I B îG auf das Kind, das ihrem Stand folgt, ZZW 1982, 8, 9 (französisch: 84-86; italienisch: 125, 126)

J. Hatschek, Vökerrecht als System rechtlich bedeutsamer Staatsakte, Leipzig/Erlangen 1923

Franz Hausenbichler, Das Staatsbürgerschaftsrecht der österreichischen Republik in systematischer Darstellung, Graz 1947

Hellmuth Hecker, Bibliographie zum Staatsangehörigkeitsrecht in Deutschland in Vergangenheit und Gegenwart (Deutsche Länder, Deutsches Reich, Bundesrepublik Deutschlland, Deutsche Demokratische Republik), Frankfurt am Main 1976

Hellmuth Hecker, Staatsangehörigkeit im Code Napoleon als europäisches Recht, Hamburg 1980

Hellmuth Hecker, Die Staatsangehörigkeitsregelungen in Deutschland (Werkhefte des Instituts für internationale Angelegenheiten der Universität Hamburg, Band 30), Hamburg 1976

Hellmuth Hecker, Die Staatsangehörigkeitsregelungen in Europa, Werkhefte des Instituts für Internationale Angelegentheiten der Universitait Hamburg, Heft 25, Hamburg 1974

Hellnuth Hecker, Materialien zum Staatsangehörigkeitsrecht in Deutschland 1970-1985, Baden-Baden 1985 (Werkheft 39)

Hellmuth Hecker, Mehrseitige völkerrechtliche Verträge zum Staatsangehörigkeitsrecht, Frankfurt am Main/Berlin 1970

Hellmuth Hecker, Beibehaltung der bisherigen Staatsangehörigkeit bei deutscher Einbürgerung von Angehörigen der sechs wichtigsten Gastarbeiterländer, IA 1981, 193-196

Hellmuth Hecker. EinfluB der Adoption auf die Staatsangehörigkeit, StAZ 1985, 153-163

Hellmuth Hecker, Italien, Materialien zum Staatsangehörigkeitsrecht, StAZ 1987, 146-151

Hellmuth Hecker, Die Adoption Volljähriger nach Par. 1772 BGB und der Staatsangehơrigkeitserwerb nach Par. 6 RuStAG, StAZ 1988, 98-100

Hellmuth Hecker, Deutsch-deutsche Doppelstaatigkeit?, Recht in Ost und West 1987, 294-300

Hellmuth Hecker/Edgar Tomson, Das Staatsangehörigkeitsrecht Frankreichs, Frankfurt a $a_{n}$ M./Berlin 1968

René Hegi, La nationalité de la femme mariée, Lausanne 1954 Cyrill Hegnaner, Wann ist eine Mutter "von Abstammung Schweizer Bürgerin"?, Schweizerisches Zentralblatt fuir Staatsund Gemeindeverwaltung 1978, 385-390

Cyril Hegnauer, Enwirbt das von einer Schweizerin und ihrem ausländischen Ehemann adoptierte Kind das Schweizer Bürgerrecht ?, ZZW 1980, 39-41 (französisch: 139-141) 
Hegnawer, ZZW 1985

Heinl

Heinsius

Heinsius, PS 1950

Hellbling

Hengeler

Henrich, FamRZ

Hepp

Hepple

Hepting

Herbert

Hermann-Ruitschi

Herrero Rubio

Hertz

Heyvaert

Hingorani

Hintermilller, ÖStA 1969

Hintermiiller, ÖStA 1975

Hirt

Hobin

Hoffmann, Archiv

Hoffmann

van Hogendorp

Holleaux/Foyer/

de la Pradelle
Cyril Hegnawer, La revision partielle de la loi sur la nationalité et l'enfant adopte, $Z Z W$ 1985, 112-114 und (auf italienisch) 242-244

Alfred Heinl, Das osterreichische Staatsbüirgerschaftsrecht, 2. Auflage, Wien 1946

A.J.H. Heinsius, Zijn zij, die behoren tot de inheemsche bevolking van Nederlandsch-Indië, ingezetenen van Nederlandsch-Indiè en Nederlandsche onderdanen?, Indisch Tijdschrift van het Recht $1933,9-14$

A.J.H. Heinsius, Hoe bewijzen "Indische Nederlanders" hun Nederlanderschap, PS 1950, 31-32

Ernst Hellbling, Das östereichische Staatsbïrgerschaftsrecht nach dem Stande von 1949, JB1 1950, 3-7; 27-29

Hengeler, Die buitrgerrechtlichen Bestimmungen des neuen Kinderrechts, ZZW 1977, 280, 281

Dieter Henrich, Gleichberechtigung in internationalen Priwatrecht und in Staatsangehörigkeitsrecht, FamRZ 1974, 105-111

Michael Hepp (ed.), Die Ausbiirgerung deutscher Staatsangehöriger 1933-1945 nach den im Reichsanzeiger veröffentlichten Listen, 3 Bände, 1985

B.A. Hepple, Commonwealth Immigrants Act 1968, Modern Law Review 1968, 424-428

Reinhard Hepting, Anerkennung und Substitution schwacher Auslandsadoptionen, StAZ 1986, 305-315

Sydney Herbert, Nationality and its problems, London 1920

Elisabeth Hermann-Rütschi, Die Staatsangehörigkeit der Kinder aus national-gemischten Ehen, Diss. Zürich 1949

Alejandro Herrero Rubio, Nuevo régimen de la nacionalidad en el Codigo civil espafiol, in: Communicazioni e studi, Band 6, Milan 1954, 3-18

M.T. Hertz, Evolution of the French code of nationality, Tulane Law Review 1973, 105-124

A. Heyvaert, De Belgische nationaliteit, Korte commentaar op het Wetboek van de Belgische nationaliteit, Antwerpen 1986

R.C. Hingorani, Modern international law, Dobbs Ferry, New York 1979

Johann Hintermiller, Der Verlust der österreichischen Staatsbiirgerschaft, ÖStA 1969, 75-76

Johann Hintermuiller, Möglichkeiten des Erwerbes oder Wiedererwerbes der österreichischen Staatsbiligerschaft bei Wohnsitz oder ohne Wohnsitz des Fremden in Osterreich. Eine tabellarische Übersicht, ÖStA 1975, 73,74

J. Hirt, Erleichterte Einbürgerung des ausländischen Ehemannes einer Schweizerin, ZZW 1976, 108, 109

Veerle Hobin, Wetboek inzake de Belgische nationaliteit, TVR $1984,146-153$

Gerhard Hoffmann, Zur Frage der Stratsangehörigkeit in Deutschland, Archiv für Völkerrecht 1981, 257-286

Gerhard Hoffmann, Die "kleine Einbürgerung". Eine staatsrechtliche Möglichkeit zur Integration ausländischer Mitbewohner in der Bundesrepublik Deutschland, Gedachtnisschrift Wolfgang Martens (Hrsg. Peter Selmer und Ingo von Münch), Berlin 1987, 84-109

W.A. van Hogendorp, Observationes ad titulum introductiones: generalis et ad titulos tres priores libri primi novi codicis belgici, Diss. Leiden 1827

Dominique Holleaux/Jacques Foyer/ Geraud de Geouffre de la Pradelle, Droit international privé, Paris 1987 


\section{XXXVI}

Hosakawa

Hoyer

Huber

Hudson

Inmer

Inglin

Isay

Isay, Jw

Isensee/Kirchhof

Itzinger

Jalles

Jayme, IPRax 1983

Jayme, IPRax 1987

Jellinek

Jellinek, $G_{\text {. }}$

Jellinek, $G$. System

Jellinek, Hansjörg

Jellinek, ZAR

Jessup

Jessurun d'Oliveira, Internationale adoptie

Jessurun d"Oliveira, NJB 1977

Jessurun d'Oliveira, NJB 1977

Jessurun d'Oliveira, NJB 1979

\section{Literaturverzeichnis}

Kiyoshi Hosakawa, Amendment of the nationality law, Japanese annual of international law 1985, 11-28

Hans Hoyer, Der immer noch unbekannte Par. 19 Abs. 3 StBG 1965, Zeitschrift fïr Rechtsvergleichung 1973, 83-85

Ernst Rudolf Huber, Deutsche Verfassungsgeschichte seit 1789, Band III (Bismarck und das Reich), Stuttgart 1963

Manley $O$. Hudson, Nationality, including statelessness, Document $\mathrm{A} / \mathrm{CN} .4 / 50$. Yearbook of the international law commission. Band II, 3-24

Pierre Inmer, La perte de la nationalité suisse par l"écoulement du temps, Lausanne 1964

Ady Inglin, Bürgerrecht des Kindes eines ausländischen Vaters und einer Schweizer Mutter (Art. 5 und 57 Abs. VI BüG), ZZW $1979,253-255$

Ernst Isay, Das Staatsangehörigkeitsrecht der juristischen Personen, in: Abhandlungen aus dem Staats-y Verwaltungsund Volkerrecht (herausgegeben von Philip Zorn und Fritz Sier-Somlo), 3. Band, Tubingen 1907

Eirnst Isay, Die mehrfache Staatsangehörigkeit, Juristische Wochenscihrift 1924, 1481

Josef Isensee/Paul Kirchhof (Hrsg.) "Handbuch des Staatsrechts, Bd. I, Heidelberg 1987

Herbert Itzinger, Die Eheschließung einer Österreicherin mit einem Ausländer, ÖStA 1962, 54-56, 61-64

Isabel Jalles, Nationalité et statut personnel dans le droit de la nationalité portugaise, in: Verwilghen, Nationalité, Brussel. $1984,169-193$

Erik Jayme, Neues italienisches Staatsangehörigkeitsgesetz (zu ital. Gesetz von 24.4.1983, n.123, Gazz. uff. 26.4 .1983 n.112, S.3149), IPRax 1983, 5, 253-254

Erik Jayme, Novelle zum italienischen Staatsangehörigkeitsgesetz, IPRax $1987,191,192$

Hansjörg Jellinek, Entwicklungstendenzen und Probleme des deutschen Staatsangehörigkeitsrechts, Regensburg 1986

Georg Jellinek, Allgemeine Staatslehre, 3. Auflage, Berlin 1914 Georg Jellinek, System der subjektiven offentlichen Rechte, 2.Auflage, Tübingen 1905

Hansjörg Jellinek, Der automatische Erwerb und Verlust der Staatsangehörigkeit durch völkerrechtliche Vorgänge: zugleich eirn Beitrag zur Lehre won der Staatensukzession, Berlin 1951

Hansjörg Jellineik, Eimbürgerungsanspruch füir die Angehörigen der "zweiten Ausländergeneration"?, Zeitschrift für Ausländerrecht, $1982,2,91-92$

Philip C. Jessup, Non-tniversal international law, Colombia Joumal of Transnational Law 1973, 415-429

Hans Ulrich Jessurun d'Oliveira, Internationale adoptie nationaliteit en vreemdelingenrecht, in: Feestbundel ter gelegenheid van het 25-jarig bestaan van de studiekring Prof. Mr. J. Offerhaus, Deventer 1987, 105-121

Hans Ulrich Jessurun d'Oliveira, Nederlanders, wie zijn dat? NJB 1977, 589-598

Hans Ulrich Jessunn d"Oliveira, Stnatloosheid voor Z.A. sympathisanten, NJB 1977, 1081-1082

Hans Ulrich Jessurun d'Oliveira, Het gehannes met het K.B. van 22 juli 1959. Stb1.262, NJB 1979, 655 
Jessurun d'Oliveira, NJJ 1982

Jessurun d'Oliveira, NJB 1982

Jessurun d'Oliveira, NJB 1983

Jessurun d'Oliveira, NJB 1984

Jessurun d'Oliveira, Bulletin 1984

Jessurun d'Oliveira, NJCM-Bulletin 1984

Jessurun d'Oliveira, NJB 1985

Jessurun d'Oliveira, AAe 1986

Jessurun d'Oliveira, Migrantenrecht 1986

Jessurun d'Oliveira/ Brunetti

Jezler

Jones

Jones 1947

Joseph, Cuthbert

Joseph, Bernard

Julien-Laferrière

Kachler

Kalan

Kammann

Kapralik

Kegel

Keller

Kewenig
Hans Ulrich Jessurun d'Oliweira, De Herziening wan ons nationaliteitsrecht, NJB $1982,245-256$

Hans Ulrich Jessurun d"Oliveira, Bipatride en naturalisatie, NJB 1982,839

Hans Ulrich Jessurun d'Oliweira, Burgers en buitenlui, NJB $1983,1301-1310$

Hans Ulrich Jessurun d'Oliveira, Moet Nederland drie nationaliteitsrechtelijke verdragen ratificeren?, NJB 1984, 417421

Hans. Ulrich Jessurun d"Oliveira, Nationaliteit en adoptie, Bulletin Werkgroep Rechtsbijstand Vreemdelingenzaken 1984, $126-128$

Hans Ulrich Jessurun d'Oliveira, Onderscheid naar nationaliteit: discriminatie?. NJCM-Bulletin 1984, 327-338

Hans Ulrich Jessurun d'Oliveira, Moet het verdrag van 20 februari 1957 betreffende de nationaliteit van de gehuwde vrouw nu wel of niet worden opgezegd?, NJB 1985, 50-54

Hans Ulrich Jessurun d'Oliveira, De nationaliteit van Richardson, AAe 1986, 224-229

Hans Ulrich Jessurun d'Oliveira, Naturalisatie en zigeuners, Migrantenrecht 1986, 59-64

Hans Ulrich Jessurun d"Oliveira/ M.L. Brunetti, Nationaliteitsproblemen in Nederlands-Italiaanse verhoudingen, PS 1987 , 73-80

Robert Jezller, Der schweizerisch-französische Optionsvertrag, Diss. Bern 1940

J. Mervyn Jones, British nationality law, revised edition, Oxford 1956

J. Mervyn Jones, British mationality law, Oxford 1947

Cuthbert Joseph, Diplomatic protection and nationality: The Commonwealth of Nations, Gateshead 1968

Bemard Joseph, Nationality; its nature and problems, London 1929

F. Julien-Laferrière, Nationalite, Journal de droit international $1984,577-583$

Gertrude Kachler, Bemerkungen und Anregungen zum newen Staatsbürgerschaftsgesetz, OStA 1965, 89, 90

A.N. Kahn, British Nationality Act 1981, Solicitors Journal $1982,403,404,421-423,438-440,459-461$

Karin Kammann, Probleme mehrfacher Staatsangehörigkeit, Diss. Hamburg, Frankfurt am Main 1984

Edgar Kapralik, La nationalité de la femme mariée, Genève 1925

Gerhard Kegel, Internationales Privatrecht, 6. Auflage, Müinchen 1987

Anton Keller, Nationalite de l'enfant de mere suisse et convention franco-suisse d'option de 1879 (zum Urteil des BG vom 11.7.1979), ZZW 1980, 19, 20

Wilhelm A.Kewenig, Die deutsche Staatsangehörigkeit, Klammer der Nation?, Europa-Archiv 1987, 517-522 
XXXVIII

Kienberger

Killerby

Killerby, Nationalite

Kimminich "Völkerrecht

Kimminich

Kissch

Klein, NJW 1983

Klein, JuS 1987

Kluyver

Knapp

Ko Swan Sik, Diss.

Ko Swan Siky

International Law

Ko Swan Sik, NILR 1982

Ko Swan Sik, Preadvies

Ko Swan Sik,

Van Rijn van Alkemadle

Koens

Koessler

Kojanec

Kokkini-latridou

Kollewijn

Kollewijn, NJB 1952

Kollewijn, NJB 1962

Kowal-Wolk

Kramer

Krawtschuk

\section{Literaturverzeichnis}

Heinrich Kienberger, Erwerb der Statatsbürgerschaft durch den Dienstantritt als außerordentlicher Universitätsprofessor an einer inländischen Universität?, in: Festschrift Klecatsky, Wien $1980,379-398$

Margaret Killerby, Nationalite et statut personnel dans les instruments internationaux du Conseil de l'Europe, in: Verwilghen, Nationalite, Brussel 1984, 73-92

Margaret Killerby, Nationalité et statut personnel dans le droit de la nationalité britannique, in: Verwilghen, Nationalité, Brussel 1984, 239-260

Otto Kimminich, Einfiuhrung in das Voblkerrecht, 2. Auflage, München u.8. ww. 1984

Otto Kimminich, Deutsche Verfassungsgeschichte, Frankfurt a.M. 1970

Isaac Kisch, Vreemde krijgsidienst, NJB 1937, 719-730

Eckart Klein, DDR-Staatsbürgerschafterwerb und deutsche Staatsangehörigkeit, NJW 1983, 2289-2292

Eckart Klein, Die Bedeutung des Staatsbiirgerschaftsrecht der DDR für die (gesamt)deutsche Staatsangehörigkeit, JuS 1987 , 279-283

Albert Kluyver, Woordenboek der Nederlandise taal, "s Gravenhage 1882

Blaise Knapp, Die Bürgerrechtsehe, ZZW 1984, 277-285 (italienisch: 90-98; französisch 1983, 331-338)

Ko Swan Sik, De meervoudige nationaliteit, Leiden 1957

Ko Swan Sik, The Netherlands and the Law concerning Nationality, Intermational Law in the Netherlands, Volume 3, Alphen a/d Rijn 1980, 1-79

Ko Swan Sik, Nationality and (public) international law, NILR $1982,100-107$

Ko Swan Sik, Nationaliteit in het wolkenrecht, Preadyies voor de Nederlandse Vereniging voor Internationaal Recht, Deventer 1981

Ko Swan Sik/ J. Van Rijn van Alkemade, Pays Bas, in: Jurisclasseur, Nationalite, Paris (Editions Techniques) 1984

M.J.C. Koens, Verkrijging van het Nederlanderschap door buitenlandse jongeren, NJB 1980, 881-8.87

Maximilian Koessler, "Subject", "Citizen", "National" and "Permanent allegiance", Yale Law Joumal 1946/1947, 58-76.

Giowanni Kojanec, La cittadinanza nel mondo, Bd. 2 (Legislazione dell' Europa), Padova 1979

D. Kokkini-Iatridou, Etapes vers l'égalité des statuts des epoux en droit internationall prive, Deventer 1968

Roeland Duco Kollewijn, Tien jaren Nederlandse Rechtspraak Internationaal Privaatrecht (1954-1963), Leiden 1966

Roeland Duco Kollewijn, Het wetsontwerp tot nadere vaststelling van art. 2 der Wet op het Nederlanderschap en de Toescheidingsovereenkomst met Indonesië, NJB 1952, 378379

Roeland Duco Kollewijn, De nationaliteit van de gehuwde vrouw, NJB 1962,954-961

Tatjana Kowal-Wolk, Die Sowjetische Staatsbuirgerschaft, insbesondere ihr Erwerb und Verlust, Frankfurt am Main/Bern 1982

Alfred Kramer, Die Staatsangehörigkeit der Altösterreicher und Ungarn nach dem Friedesverträgen, Wien 1926

S.S. Krawtschuk, Staatsrecht der UdSSR, Lehrbuch, Berlin 1982 
Krombach

Krïger, Herbert

Kühn

Laband

Lagarde

Lagarde, Nationalité

Lagarde, RCDIP 1971

Lagarde, RCDIP 1973

Lagarde, RCDIP 1977

Lagarde, RCDIP 1984

Lagarde, RCDIP 1984

Lagarde, RCDIP 1987

Land/Star Busman

Lange

de Lange

Langhoff

de Lapradelle

Lasante

Lasok

Laurent

Lauterpacht

Lauterpacht, Jewish YBIL

Lehmann

Leibholz

Leita
Diethard Krombach, Erstabgrenzungen im Staatsangehorigkeitsrecht in 19. Jahrhundert und am Anfang des 20. Jahrhunderts, Diss. Bonn 1967

Herbert Krüger, Das Staatsangehörigkeitsrecht in Deutschland (Bundesrepublik und DDR), Frankfurt a.M. 1975

Heinz Kühn, Stand und Weiterentwicklung der Intergration der ausländischen Arbeitnehmer und ihrer Familien in der Bundesrepublik Deutschland, Memorandum des Beauftragten der Bundesregierung, Bonn 1979

Paul Laband, Das Staatsrecht des Deutschen Reiches, Band I, 5. Auflage, Tübingen 1911

Paul Lagarde, La nationalite française, 1. Auflage Paris 1975

Pausl Lagarde, Nationalité et filiation: leur interaction dans le droit compare de la nationalite, in: Verwilghen, Nationalite, Brussel 1984,475-508

Paul Lagarde, Nationalité française, Etrangère épousant un Français, RCDIP $1971,141-145$

Paul Lagardle, La rénovation du code de la nationalité par la loi du 9-1-1973, RCDIP 1973, 431-469

Paul Lagarde, Nationalite, adoption plenière, effet, RCDIP 1977, 182-184 (Art. 14 Gesetz vom 22.12.1976)

Paul Lagarde, Nationalite, Loi du 7 mai 1984, RCDIP 1984, $541-546$

Paul Lagarde, Déclarations de nationalité, RCDIP 1984, 617623

Paul Lagarde, Perte de la nationalite française, RCDIP 1987, $549-553$

N.K.F. Land/C.W. Star Busman, Verklaring van het Burgerlijk Wetboek, erster Teil, 2. Auflage, Haarlem 1914, 10-30

Werner Lange, Die Aberkennung der Staatsangehø̋rigkeit, Diss. Hamburg 1936

Roel de Lange, De nieuwe Rijkswet op het Nederlanderschap, Tijdschrift voor Bestuurswetenschappen en Publiekrecht $1985,196-202$

Lucas: Langhoff, Staatsbïrgerschaft und Heimatsrecht in Österreich, Wien 1920

Albert de Lapradelle, Les décrets du 8 novembre 1921 sur la nationalite d'origine en Tunisie et au Maroc (zone française) devant la Cour Permanante de Justice Intermationale, RCDIP $1922 / 23,1$

Carios Lasante, Notas sobre la nacionalidad dell menor de edad extranjero adoptado por espanoles (Comentario del art. 20,3 del Código civil), Revista de derecho privado 1975, $511-531$

D. Lasok, The law of the economy in the European Communities, London 1980

François Laurent, Principes de droit civil français, Band I, 4. Auflage, Bruxelles 1887

Hersch Lauterpacht, The function of law in international community, reprint 1973 der Ausgabe Oxford 1933

Hersch Lauterpacht, The nationality of denationalized persons, Jewish Yearbook of International Law 1948, 164-185

Hans Georg Lehmann, In Acht und Bann (Pollitische Emigration, NS-Ausbuirgerung und Wiedergutmachung am Beispiel Willy Brandts), Minchen 1976

Gerhard Leibholz, Das Verbot der Willkuir und des Ermessensmißbrauchs im völkerrechtlichen Verkehr der Staaten, ZaöRV $1929,77-125$

F. Leita, Commento all'art. 1 1. 211 aprile 1983 n. 123, Leggi civ. comment. 1984,973 
$\mathrm{XI}$

Leita

Lenoble

Lessing

Lichter, StAZ

Lichter/Floffmanin

Liehr

Liénard-Ligny, Ann.Fac,Dr.Liège

Liénard-Ligny, BTIR

Lipovano

Locre

Loef Schuphoven

Logemann, Indisch Tijdschrift

Logemann, NJB 1958

van Loon

Louis-Lucas

Loussouarn/Bourel

Luces Gil

Luchterhandt

Luther

Lütkenhaus

Macdonald/Blake

Mackaay, NJB 1982

Mackaay, NJIB 1983

Mc Nair

\section{Literaturverzeichnis}

F. Leita, Commento all'art. 71.21 aprile 1983 n. 123, Leggi ciw. conument. 1984,1009

H. Lenoble, La nationalité de la femme mariée, Paris 1921

Hans Lessing, Aberkennung der Staatsangehörigkeit zu Strafund Sicherungszwecken, Bibliotheca Visseriana XXIX, Leiden 1937

Matthias Lichter, Die Beschlisse der Haager Kodifikationskonferrenz von 1930 und ihre Beriicksichngung in den nationalen Gesetzgebungen, StAZ 1956, 281-285

Matthias Lichter/Werner Hoffmann, Staatsangehörigkeitsrecht, 3. Auflage, Köln/Berlin/München 1966

Willibald Liehr, Verlust der österreichischen Staatsbürgerschaft und Verehelichung. ÖStA 1949, 52-56, 73-76

M. Liênard-Ligny, Nationalité belge et statut personnel depuis la loi du 28 juin 1984, Ann. Fac. Dr. Liège 1985, 195-236

M. Lienard-Ligny, A propos du Code de la nationalité belge, Belgisch Tijdschnift voor International Recht 1984/85, 649. 671

I.G. Lipovano, L'apatridie, Paris 1935

J.G. Locré, Esprit du Code Napoléon, Bd. 1, Paris 1805

R.H. Loef Schuphoven, De wet op het Nederlanderschap en het ingezetenschap, Zutphen 1893

J.H.A. Logemann, Nederlandsch onderdaanschap en het Hooggerechtshof (in Nederlandsch-Indiè), Indisch Tijdschrift van het Recht 1932, 506.

J.H.A. Logemann, De nationaliteitsregeling woor de inwoners van Nederlands Nieuw Guinea, NJB 1958, 127-130

Hans van Loon, Loi du Royaume (Rijkswet) da 19 décembre 1984 (Staatsblad, 628), portant établissement de nouvelles dispositions générales relatives à la nationalité néerlandaise en remplacement de la loi du 12 decembre 1892 (Staatsblad, 268) sur la qualité de Néerlandais et de résident, RCDIP 1986, 182192

Pierre Louis-Lucas, La nationalite française; Droit positif et conflits de lois, Paris 1929

Ywon Loussouarn/ Pierre Bourel, Droit international privé, 2. Auflage, Paris 1980

F. Luces Gil, Análisis de las modificaciones introducido en el régimen de la nacionalidad española por la ley de 2-5-1975, Revista General de Legislacion y Jurisprudencia 1975, 101-134 Otto Luchterhandt, Das Institut der Staatsbiirgerschaft in der Perspektive des soxialistischen Rechts, Osteuropa-Recht 1984, $130-144$

Markus Luther, Die Staatsangehörigkeit der einen Ausländer heiratenden Schweizerin, Diss. Zürich, Winterthur 1956

Karl Luttkenhaus, Nochmals: Die Staatsangehörigkeit der Ehefrau nach dem neuen niederländischen Recht, StAZ 1965, 112

Ian A. Macdonald/Nicholas Blake "The new nationality law, London 1982

E. Mackaay, Bipatridie: een kijkje uit den vreemde, NJB 1982,993

E. Mackaay, Verlies van het Nederlanderschap voor emigranten, NJB 1983, 1319-1322

Arnold Duncan Mc Nair, International law opinions, Bd. II, Cambridge 1956 
Magiera

Magiera, DöV 1987

Makarov, Allgemeine

Lehren

Makarov, Wörterbuch

Makarow, ZaöRV

Makarow/von Mangoldt

Mampel

Mampel, Recht in

Ost und West

de Man

Mancinelli,

S.c. 1983,200

Mancinelli.

S.c. 1983,499

Mancinelli

S.c. 1983,682

Mancinelli,

S.c. 1985

won Mangoldt, Anerkennung

von Mangoldt,

Deutschland als Ganzes

von Mangoldt,

Königsteiner Kreis

von Mangoldtr,

Politik und Kultur 1981
Siegfried Magiera, Politische Rechte im Europa der Bürger, in: Manfred Zuleeg (Hrsg.), Ausländerrecht und Ausländerpolitik in Europa, Baden-Baden 1987, 123-1411

Siegfried Magiera, Die Europäische Gemeinschaft auf dem Wege zu einem Europa der Bürger, DöV 1987, 221-231

Alexander N. Makarov, Allgemeine Lehren des Staatsangehörigkeitsrechts, 2. Auflage, Berlin 1962

Alexander N. Makarow, Staatsangehörigkeit in: Karl Strupp/ Hans Jürgen Schlochauer, Wörterbuch des Völlkerrechts, Bierlin 1962 , Band 3, 323-329

Alexander N. Makarov, Staatsangehörigkeit im Europarecht, Zä̈RV 1973, 108-124

Alexander N. Makarov/Hans won Mangoldt, Deutsches Staatsangehörigkeitsrecht, Kommentar, 3. Auflage, Frankfurt a. Main Loseblattsammlung

Siegfried Mampel, Die sozialistische Verfassung der Deutschen Demokratischen Republik, Text und Konmentar, Frankfurt a.M. 1972

Siegfried Mampel, Das Staatsangehörigkeitstecht der DDR und die deutsche Staatsangehörigkeit. Weiteres zum Urteil des BVerwG vom 30.11.1982, Recht in Ost und West, 1983, 6, 233-244

Rober de Man, De nieuwe commentaar op de burgerlijke stand in Belgie, Uga 1973

Carlo Mancinelli, Attribuzione della cittadinanza italiana dopo la setenza n. 30 della Corte Costituzionale, Stato civile 1983 , 200

Carlo Mancinelli, Modifiche apportate dalla L. $21 / 4 / 83$ n. 123 alle norme sulla cittadinanza, Stato civile 1983,499

Carlo Mancinelli, Considerazioni sull" art. 5 della legge 21 aprile 1983 n. 123 e sulla sentenza n. $30 / 1983$ della Corte Costituzionale, Stato civile 1983,682

Carlo Mancinelli, Ulteriori considerazioni sull'articolo 5 della legge 21 aprile 1983, n. 123, Stato civille 1985,259

Hans von Mangoldt, Ajuerkenunung der Staatsangehörigkeit und effektive Staatsangehörigkeit natïrlicher Personen im Völkerrecht und im Internationalen Privatrecht, in:Berichte der Deutschen Gesellschaft für Völkerrecht, Heft 29, Heidelberg $1988,37-93$

Hans von Mangoldt, Deutschland als Ganzes im Lichte der fortbestehender (gesamt) deutschen Staatsangehörigkeit, in: Oswald Hauser (Hrsg), Das geteilte Deutschland in seinen internationalen Verpflichtungen, Göttingen 1987, 234- 253

Hans von Mangoldt, Erwerb der deutschen Staatsbiurgerschaft durch Einbürgerung im anderen deutschen Staat, Königsteiner Kreis Mitteilungsblatt 1985, 4-11

Hans von Mangoldt, Deutsche Staatsangehörigkeit und Abgrenzungspolitik; die Entwicklung des deutschen Staatsangehörigkeitsrechts seit den 60er Jahren, Politik und Kultur $1981,27-46$ 
XLII

von Mangoldt, $\sqrt{ } Z \mathbf{Z} 1982$

von Mangoldit, StAZ 1983

von Mangoldt, RCDIP 1986

von Mangoldt,

RR.JDP 1987

Mänhardt

Manhardt, StAZ 1976

Mannoury

Mannoury,

Bestuurswetenschappen

Manresa y Navarro

Maraun

Marcade

Marescaux

Marescaux/Taverne

Marín López

Marin Lopez, ADI 1975

Marín López, REDI 1976

Marín López, ADI 1982

Martínez Ruiz

de Martino

Massfelder

\section{Liferaturverzeichnis}

Hans von Mangoldt. Einbürgerungsanspruch für zeitweise in Deutschland aufgewachsene Ausländerkinder?, JZ 1982, 174178

Hans von Mangoldt, Großbritannien: Neuregelung des Staatsangehörigkeitsrechts des Vereinten Königreiches (British Nationality Act 1981), StAZ 1983, 220-230

Hans von Mangoldt, La nationalite allemande, la citoyennete de la République démocratique allemande et le statut juridique de territoires au-delà de la ligne Oder-Neisse, RCDIP 1986, $33-57$

Hans von Mangoldt, Problèmes actuels de la nationalité en Allemagne, Revue de la Recherche Juridique Droit perspectif $1987,875-889$

Franz Mänhardt, Die Auslegung des Par. 19 Abs. 3 Staatsbiirgerschaftsgesetz 1965 in Theorie und Praxis, Österreichische Richterzeitung 1973, 205-210

Franz Mắnhardt, Kollisionsprobleme bei der Zustimmung zum österreichischen Staatsangehörigkeitserwerb, Standesamt 1976, 293-303

J. Mannoury, Het Nederlandse nationaliteitsrecht, 2. Auflage, Alphen aan den Rijn 1954

J. Mannoury, De herziening van onze nationaliteitswetgeving en de status van Indlonesische staatsburgers in Nederland, Bestuurs wetenschappen 1953, 125-141

José Maria Manresa y Navano, Comentarios al Código civil español, Bd. 1, 6. Auflage, Madrid 1943

Georg Maraun, Die Gleichberechtigung von Mann und Frau im Staatsangehörigkeitsrecht, Diss. Marburg 1952

V. Marcadé, Explication théorique et pratique du Code civil, Band I, 7. Auflage, Paris 1873

Marie-Hélène Marescaux, Nationalité et statut personnel dans les instzuments des Nations Unies, in: Verwilghen,

Nationalité, Brussel 1984, 13-72

Marie-Helène Marescaux/Michel Taverne, Le droit des étrangers, Moteur du code de la nationalité?, Commentaire de la loi du 28 juin 1984, relative à certains aspects de la condition des étrangers et instituant le code de la nationalite belge, Journal des Tribunaux 1984, 625-636

Antonio Marin López, Derecho internacional privado español, Parte especial I: nacionalidad y extranjerfa, 2. Auflage 1982 (inklusiv Addendum 1983)

Antonio Marrín López, Pérdida y recuperación de la nacionalidad española en la reglementación actual del Código civil, Anuario de Derecho Internacional 1975 II, 327-345

Antonio Marín Lopez, La nacionalidad de la mujer casada en Derecho espafiol, REDI 1976, 397-417

Antonio Marín Lopez, La doble nacionalidad en los tratados suscritos por España con las repúblicas americanos, Anuario de derecho internacional $1982,219-232$

Antonio Martínez Ruiz, El Código civil interpretado por el tribunal supremo, Bd.1, 2. Auflage, Madrid 1923

Vittorio de Martino, Legge d'Italia, Testo vigente, ordinate sistematicamente e perennemente aggiomato, 5 . Auflage, Loseblattausgabe, Novarra

Franz Massfelder, Deutsches Staatsangehörigkeitsrecht von 1870 bis zur Gegenwart, Frankfurt a.M. 1955 
Maury

Mayer

Maythofer/Pace

Medborgarskap

Medina Ortega

Meessen

Meijers

Menalda, NJB 1951

Menalda, NJB 1952

Menger

Menzel//psen

Merlin

Merlin, Jean

Merrills

Meyer, Jean

Meyer, Wemer

Miaja de la Muela

Miaja de la Muela, REDI 1966

Milllet

Mock

de Moffarts

Moreno Quintana

Morientes Rodriguez, REDI 1984

Morientes Rodriguez, REDI 1986

Mortati

Mosler
Jacques Maury, L'arrêt Nottebohm et la condition de la nationalite effective, Zeitschrift für ausländisches und internationales Privatrecht 1958, 515-534

Pierre Mayer, Droit international prive, 3. Auflage Paris 1987

E, Mayrhofer/Graf A. Pace, Handbuch für den polizeilichen Verwalnungsdienst, Band II, Wien 1896

Medborgarskap för barn och jämlikhet wid naturalisation, Nordisk utredningsserie 1976, Nr. 9, Stockholm 1976

Manuel Medina Ontega, La comunidad ibero-americana y los procesos de integracion, Miaja de Muela, Band 2, 743-757

Karl M. Meessen, Option of Nationality, in: EPIL, Band 8, Amsterdam/New York/Oxford 1985

Edluard Maurits Meijers, Art. 2, c van de Wet op het Nederlanderschap, WPNR 4239 (1952), 185, 186

H.H. Menalda, Het wetsontwerp houdende voorziening ter wegneming van staatloosheid, NJB 1951, 594-598

H.H. Menalda $a_{\text {, Het }}$ wetsontwerp houdende voorziening ter wegneming van staatloosheid, NJB 1952, 677-682

Christian-Friedrich Menger, Deutsche Verfassungsgeschichte der Neuzeit, Eine Einführung in die Grundlagen, Karlsruhe 1975

Eberhard Menzel/Knut Ipsen, Vblkerrecht, 2. Auflage, München 1979

Comte Merlin, Répertoire universel et raisonnê de jurisprudence, 4. Auflage, Band 5 (Paris 1812) und Band 8 (Paris 1813)

Jean Merlin, France, in: Jurisclasseur Nationalité (Loseblattausgabe), Paris

J.G. Merrills, One nationality or two? The strange case of Oppenheimer v. Cattermole, ICLQ 1974, 143-159

Jean Meyer, La perte de la nationalité suisse par mariage, Diss. Fribourg 1942

Werner Meyer, Die deutsche Staatsangehörigkeit in der Rechtsprechung des BVerwG, NVwZ 1987, 15-26

Adolfo Miaja de la Muela, Derecho internacional privado, Band 2, Parte especial, 3. Auflage, Madrid 1963

Adolfo Miaja de la Muela, Los convenios de doble nacionalidad entre España y algunas Repúblicas americanas, REDI $1966,381-410$

Timothy Millet, A comparison of British and French legislative drafting (with particular reference to their respective nationality laws), Statute Law Rewiew 1986, 130-160

H.G.F. Mock, Regeling van het Stmatsburgerschap, Diss. Leiden 1890

Gaetan de Moffarts, De betekenis van de "integratiewil" in het wetboek van de Belgische nationaliteit. TVR 1987, 27-31

Lucio Moreno Quintana, Supranacionalidad o nacionalidad común, Actas del primer congreso H.L.A. de derecho internacional, 572-575

Maria Dolores Morientes Rodrfguez, Anmerkung, in: REDI $1984,586-588$

Maria Dolores Morientes Rodriguez, Anmerkung, in: REDI 1986, 179-181

Costantino Mortati, Istituzioni dil diritto pubblico, Band 1, 8. Auflage, Padova 1969

Hermann Mosler, The international society as a legal community, Alphen aan den Rijn 1980 


\section{XLIV}

Mosler/Bernhardt/Hilf

Moya Escudero

Mulder

Müller

Mullerat Balmaffa

Muller-Sprenger

Muinch,

Festschrift Udina

Muinch,

Festschrift Kloss

Münch,

Festschrift Pallieri

von Münch

Mutharika

Nabholz

Nacarry

Nahuijs

Nascimbene

Nationaliteitsrecht

Nenarokov/Proskoerin

Nerson

Neuhaus

van Nijnatten

Novak, ôrz

Novak, ÓZOR

o. V.

Odgers

\section{Literatwrverzeichnis}

Hermann Mosler/Rudolf Bernhardt/ Meinhard Hilf, Europäsche Menschenrechts-Konvention und Europäische Gemeinschaften: intermationales Kolloquium veranstaltet vom Max Planck-Institut füir ausialindisches öffentliches Recht und Volkerrecht, Heidelberg 1977

Mercedes Moya Escudero, Anmerkung, in: REDI 1984, 583586

H.J.A. Mulder, Wet wan 12 december 1892 Staatsblad nr. 268 op het Nederlanderschap en het ingezetenschap, 2. Auflage, bearbeitet von J.J. Belinfante, "s Gravenhage 1902, supplement 1907

Kaspar Müller, Dass Problem der mehrfachen Staatsangehörigkeit, Koln 1927

Ramon Maria Mullerat Balmaina, La influencia del matrimonio en la nacionalidad de la mujer. La ley de 2.5.1975, Revista Juridica de Cataluña 1975, 787-801

Ludwig Müller-Sprenger, Die Staatsangehörigkeit der verheirateten Frau, Diss. Halle-Wittenberg 1930

Fritz Milinch, Développements récents du droit de la nationalité, in: Studi in onore di Manlio Udina, Band II, Milano 1975, 1111-1141

Fritz Münch, Beispiele integrationfeindlichen Staatsangehörigkeitsrechts" Festschrift Heinz Kloss, Hamburg 1976, Teil II, 319-336

Fritz Münch, Le jus sanguinis a matre en Allemagne, in: Studi in onore di Giorgio Balladore Pallieri, Milano 1978, 449-460

Ingo won Münch, Gundgesetz-Kommentar, Band $I_{\text {, }}$ Präambel bis Art. 20, Miunchen 1975

Peter A. Mutharika, The regulation of statelessness under international and national law, New York 1980

Andreas Nabholz, Die neuen Bestimmungen über Erwerb und Verlusit des Schweizer Bürgerrechts, ZZW 1978, 184-188 (französisch: 242-245)

Carmen Nacarry, La nationalite de la femme mariée dans les principaux pays, Paris 1925

P.C. Nahuijs, De differentiis codicis civilis francici et novi codicis belgici in acquirenda civitate, Diss. Utrecht 1827

B. Nascimbene, Nuowe norme e recenti pronunce in tema di cittadinanza, Foro it. 1983 I, 1537

Nationaliteitsrecht en minderhedenbeleid (Werkgroep knelpunten in het Nederlands recht voor etnische minderheden), Nederlands Centrum Buitenlanders, Utrecht 1983

Albert Nenarrokov/Aleksandr Proskoerin, De oplossing van het mationaliteitenvraagstuk in de USSR, Moskau 1983

Roger Nerson, Le droit français de la famille en 1976, Festschrift Bosch (Bielefeld 1976), 709-730

P.H. Neuhaus, Neufassung des Par.4 RuStAG, NJW 1971, 832, 833

G.C.M. van Mijnatten, Verlies van de Nederlandse nationaliteit, NJB 1947, 181-190

Richard Novak, Die Staatsbüirgerschaftsgesetz-Novelle 1973, OJZ $1974,589-593$

Richard Nowak, Grundsătze des österreichischen Staatsbürgerschartsrechts, ÖZOR 1969,145-186

Revision des liechtensteinischen Landesbürgerrechts, ZZW 1985,6

Walter Blake Odgers, Nationality and naturalization, London 1916 
Oliver

Oppenheim

Opzoomer

Ortiz-Arce

Otto

van Oven

Pacteau

Pagano

Pagano, Rass.civ.

Page

Palermo Fabris

Panetta

wan Panhuys

Parry

Parry, BYBIL

Parry, ZaöRV

Patoul/O'Connor/'

Fisch

Paz Agüeras

Pelletier

Penna Marinho

Pereira

Pérez Vera, Emigración

Pérez Vera, RIE

Perez Vera/Espinar

$y$ Vicente

Perlingieri

Permanente Commissie
Peter Oliver, Non-community nationals and the Treaty of Rome, in: Yearbook of European Law 1985, 57.92

L.V. Oppenheim, International Jaw, Bd. Is 8. Auflage, bearbeitet von Hersch Lauterpacht, London 1955

C.W. Opzoomer, Het Burgerlijk Wetboek verklaard, Eerste Deel, 2. Auflage, Amsterdarn 1874

Antonio Ortiz-Arce, La segunda generacion de la emigración española en Europa Oeste, REDI 1984, 527-546

H. Otto, De la nationalité et de l'indigenat en Belgique, Commentaire de la loi du 8 juin 1909 précédé d'une étude des principes généraux en la matière, $d$ "un precis de droit intemational et d'une introduction historique, Bnussel/Paris 1911 J.C. van Oven, De nationaliteit der gehuwde vrouw, NJB $1930,129-134$

Bernard Pacteau, Perte de la nationalité française, Sernaine juridique 1987, 20777

E. Pagano, L. 13 giugno 1912, n. 555 sulla cittadinanza italiana, in Perlingieri, La legisliazione civile annotata, 3-42

E. Pagano, Cittadinarza e adozione: una svista o un ripensamento, Rass. civ. 1986, 344

William Page, Letters of denization and acts of naturalization for alliens in England 1509-1603, Lymington 1893

E. Palermo Fabris, Commento all'art. 2 1. 21 aprile 1983 n. 123, Leggi civ. comment. 1984, 981

Libero Panetta, Commento alla nuova legge sulla cittadinanza, Rimini 1985

H.F. van Panhuys, The rule of nationality in international law, Leiden 1959

Clive Parry, Nationality and citizenship laws of the commonwealth and the Republic of Ireland, London 1957

Clive Parry, Plural nationality and citizenship with special reference to the Commonwealth, British YBIL 1953, 244-292

Clive Parry, The duty to recognize foreign nationality laws, ZaÖR V $1958 / 59,337-368$

Philippe de Patoul/Tony $O^{\prime}$ Connor/John G. Fish, Irlande, in: Jurisclasseur Nationalité (Loseblattausgabe), Paris

José Manuel Paz Agüeras, Comentarios a la nueva ley de nacionalidad, Madrid 1984

François Pelletier, La nationalité de la femme mariée "Paris 1925

Ilnar Penna Marinho, Tratado sobre a nacionalidade, Bd. 2 (Do direito comparado da nacionalidade). Rio de Janeiro 1957 António Garcia Pereira, Lei da nacionalidade, Lisboa 1984

Elisa Pérez Vera, El sistena español de doble nacionalidad, in: Cases Méndez, Emigración y constitución, Guadalajara $1983,71-90$

Elisa Pérez Vera, El sistema español de doble nacionalidad ante la futura adhesión de España a la Comunidades Europeas, Revista de instituciones Europeas 1981, 685-703

Elisa Pérez Vera/ José-Maria Espinar y Vicente, Espagne, in: Jurisclasseur Nationalité (Loseblattausgabe), Paris

Pietro Perlingieri, La legislazione civile annotata con la dottrina e la giurisprudenza, Bd. 1, Persone fisiche e formazioni sociali, Napoli 1985

Permanente Commissie voor advies voor de zaken van de burgerlijke stand en voor nationaliteitsaangelegenheden, Interpretatie art. 7 lid 1 onder $3 e$ en $4 e$ Wet Nederlanderschap, PS 1979, 23-27 


\section{XLVI}

Pernthaler/Weber

Perret

Pescatore

Pestalozza

Petz

Pfersmann, ÖJZ 1972

Pfersmann, OJZ 1985

Philippart/Stroobants

Pichl

Picot

Pintens

Pirrung

Pitlo/Koens/

Rood-de Boer

Plender

Plender, EPIL

Plender,

European citizenship

Plender, ICLQ

van der Poel

Polizel Hamburg

Prieto-Castro Roumier

Prieto-Castro Roumier, CHA

Prins, PS 1952

Prins $_{\text { }}$ PS 1953

Prins, PS 1962

\section{Literaturverzeichnis}

Peter Pernthaler/Karl Weber, Landesbürgerschaft und Bundesstaat, Wien 1983

M. Perret, Convention franco-suisse d"option du 23.7 .1879 , ZZW 1979, 148, 149

Pierre Pescatore, Referat, in: Mosler/Bernhardt/Hilf, 64-75

Christian Pestaloxza, Deutscher auf Zeit, NJW 1976, 507-509

Alfons Petz, Bemerkungen zum Entwurf einer Statsbürgerschaft:snovelle 1982, OStA 1981, 90-91

Hans Pfersmann, Der noch immer unbekannte Par. 19 Abs. 3 Staatsbürgerschaftsgesetz 1965 , ÖZ 1972, 542,543

Hans Pfersmann $n_{*}$ Reforme und Probleme im Staatsbürgerschaftsrecht, OJZ 1985, 72-80

E.Philippart/M.Stroobants (met medewerking van D.Spaens), Burgerlijke stand, Nationaliteit, Vreemdelingen, 2. Auflage, Brugge/Brussel (Loseblattausgabe)

Hubert Pichll, Der Staatsbürgerschaftserwerb ehelicher Kinder gemäßB Par. 7 Abs. 2 StBG 1965, ÖStA 1972, 86-89

André Picot, La réforme de la loi française sur la nationalité, Paris 1928

Walter Pintens, Bielgien: Neues Staatsangehörigkeitsrecht, StAZ 1985, 224-227

Jörg Pirrung, Internationales Privatrecht und Verfahrensrecht nach dem in Kraftreten der Neuregelung des IPR, München/Muinster 1987

A.Pitlo/Gr. van der Burght/ M.Rood-de Boer, Het personenen familierecht ${ }_{n}$ 7. Auflage, Arnhem 1985, 1-21 (Nationaliteit en Nederlanderschap), bearbeitet von M.J.C. Koens /M. Roodde Boer

Richard Plender, International migration law, Leiden 1972

Richard Plender, British commonwealth, subjects and nationality rules, in: Encyclopedia of public international law, Band 8, 53-59

Richard Plender, An incipient form of European citizenship, in: Jacobs (ed.), European law and the indiwidual, Amsterdam/New York/Oxford 1976, 39-53

Richard Plender, The new french nationality law, ICLQ 1974, 709-747

Alb. van der Poel, Nationaliteit en Staat, Diss. Nijmegen, Maastricht 1928

Die in den Europaischen Staaten geitenden Gesetze uber die Erwerbung und den Verlust der Staatsangehörigkeit unter AusschluB des Deutschen Reichsgesetzes vam 1. Juni 1870 , Nebst einem Anhang enthaltend die vor dem 1. Januar 1871 in den Deutschen Bundesstaaten in Kraft gewesenen Staatsangehörigkeitsgesetze, im Auftrage der Polizeibehörde der Freien und Hansestadt Hamburg herausgegeben und erlläutert, Berlin 1898.

F. Prieto-Castro Roumier, La nacionalidad multiple, Madrid 1962

F. Prieto-Castro Roumier, La supranacionalidad hispánica, in Cuadernos Hispano-Americanos, Nr. 152/153, 1972, 242-257

W.F. Prins, De gevolgen van de souvereiniteitsoverdracht ten aanzien wan de Nederlandse onderdanen, PS 1952, 49-74

W.F. Prins, Jurisprudentie inzake de Wet op het Nederlanderschap en de toescheidingsovereenkomst, PS 1953, 34-38 W.F. Prins, Een verwaarloosde zuster vraagt aandacht (over de nationaliteit in Nieuw Guinea), PS 1962, 25-28 
Quadri

Quiñones Escámez

Raedt van Oldebarnevelt

\section{Ramos}

Randelzhofer

Rapport CN

Ras

Rasch

Rau, StAZ 1982

Rau, IA 1985

Rau, StAZ 1986

Ravet-Gobbe

Ress

\section{Rezek}

Rheinstein

Riddler

Rieck

Riege

Riege/Kulke

Rieser

Rigaux, Conclusions

Rigaux, DIP

Rigaux,

Festschrift Abenroth

Rigaux, Personnes

Rijn van Alkemade

Ringhofer
Rolando Quadri, Cittadinanza, in. Nowissimo digesto italiano, Band 3, Torino 1959

Ana Quiñones Escámez, Anmerkung, in: REDI 1987, 148-152

H.J.A. Raedt vam Oldebarneveldt, De wet tot uitvoering van artikel 7 der Grondwet, in hare betrekking tot het burgerlijk regt en het statatsregt, Diss. Leiden 1851

Rui Manuel Gens de Monra Ramos, Do direito português da nacionalidade, Coimbra 1984

Albrecht Randelzhofer, Nationality, in: EPIL, Band 8, Amsterdam/New York/Oxford 1985

Etre français aujourd'hui et demain, Rapport de Commission de la nationalité, présenté par M. Marceau Long, président, au Premier ministre, 2 Vol., Paris 1988

Gozewin Hendrik Gerard Ras, Eenige opmerkingen omtrent den rechtstoestand van vrouw en kinderen volgens de wet van 28 juli 1850 , Diss. Leiden 1885

Harold Rasch, Wie lange noch "gesamtdeutsche" Staatsangehörigkeit ?, Bläiter für deutsche und internationale Politik $1985,262-264$

Hans Rau, Staatsangehörigkeitsrecht (Spanien), StAZ 1982, 289-291

Hans Rau, Neue Wege zur rechtlichen Integration von Ausländern, Das Beispiel Spaniens, LA 1985, 293-296

Hans Rau, Andorra: Staatsangehörigkeitsrecht, StAZ 1986, 228-232

Anne-Françoise Ravet-Gobbe, Portugal: in Jurisclasseur Nationalité, Loseblattausgabe Paris

Georg Ress, Freier Personen-, Dienstleistungs- und Kapitalverkehr, in: Dreißig Jahre Gemeinschaftsrecht, Kommission. der Europäischen Gemeinschaften, Luxemburg 1981, 311-350

José Francisco Rezek, Le droit international de la nationalité, Recueil de Cours 1986 III, 333-400

Max Rheinstein, Einfuihrung in die Rechtsvergleichung, München 1971

Helmut Ridder, Bemerkungen zum juristischen Inhalt und zur politisch-ideologischen Funktion der Doktrin von der deutschen Staatsangehorigkeit, Festschrift Abenroth. Frankfurt $1982,549-577$

J. Rieck, Neues französisches Staatsangehörigkeitsrecht, StAZ 1973, 243-251

Gerhard Riege, Die Staatsbürgerschaft der DDR, 2. Auflage, Berlin 1986

Gerhard Riege/Hans-Jïrgen Kulke, Nationalitatit: deutsch; Staatsbiurgerschaft: DDR, 2. Auflage, Berlin (Ost) 1980

Walther Rieser, Das Schweizerbirgerrecht, Bern 1892

François Rigaux, Conclusions, in: Verwilghen, Nationalité, Brussell 1984, 509-516

François Rigaux, Droit international prive, Bruxelles 1968

François Rigaux, La conformite au droit international de 1'article 116, Par. ler, de la Loil fondamentale de Bonn, in: Rafael Gutierrez Girardot, Helmut Ridder, Manohar Lal Sarin, Theo Schiller (ed.). New directions in international law (Essays in honour of Wolfgang Abendroth), Frankfurt/New York 1982, 576-589

François Rigaux, Les Personnes, Tome I, Les relations faniliales, Bruxelles 1971

J. wan Rijn van Alkemade, Verlies van Nederlanderschap door vervallenverklaring, PS 1975, 79-81

Kurt Ringhofer, Staatsbïrgerschaftsgesetz i. d. F. der Novelle 1983, Wien 1984 
XLVIII

Rodirlguez Mateos,

REDI 1984

Rodiriguez Mateos,

REDI 1985

Roman

Roper

Róper, DoV

Ros:s

Roussera:

RCDIP 1977

Rourssean,

$\mathbb{R C D I P} 1983$

Rousserat.

RCDIP 1984

Ruby

Rundstein

Sdens

Sala Torregasa

Salvo

Samtleben

Samuels

Sande Bakhuyzen

Sannes

Santos Armai/Vilä Costa

van Sasse van Ysselt, PS 1953

van Sasse van IJ Isselt, NJW 1958

van Sasse van IJsselt, PS $1960^{\circ}$

van Sasse van IJsselt van Praag

\section{Literaturverzeichnis}

Pilar Rodriguez Mateos, Anmerkung, in: REDI 1984, 579-581

Pillar Rodriguez Mateos, Anmerkung, in: REDI 1985, 174-179 Louis Roman, La perte de la nationalité française a titre de décheance, Marseille 1941

Erich Röper, Deutsche und andere Deutsche. Zur Frage der Staatsbiurgerschaft, Der Staat 1987, 31-56

Erich Röper, Die Bundesrepublik kann die deutsche Staatsangehörigkeit nicht definieren. Das Bundeswerfassungsgericht verbietet die Verfiguung liber Deutschland als Ganzes, DöV $1988,488-500$

J.M. Ross, English nationality law: soli or sanguinis, Grotian Society Papers $1972,1-22$

Charles Rousseau, Publication de 27 avril 1977 d'un livre vert sur la réforme du droit de la nationalité, RCDIP 1977, "1.1661168

Charles Rousseau, Entrée en vigeur le premier janvier 1983 du BNA de 1981, RCDIP 1983, 677

Charles Rousseau, Votation populaire en suisse sur la nationalite, RCDIP 1984, 739

Maurice Ruby, L'évolution de la nationalité allemande d'après les textes 1842-1953, Baden-Baden 1954

Rundstein, Die allgemeine Rechtsgrundsätze des Völkerrechts und die Fragen der Staatsangehörigkeit, Zeitschrift für Volkerrecht 1932, 14-71

Elisabeth Saens, Hervormde optie en naturalisatie als oplossing voor het migrantenprobleem, Jura Falconis 1982/83, $521-555$

Luis Sala Torregasa, Anmerkung, in REDI 1987, 152-154

F. Salvo, Sulle norme in materia dil cittadinanza di cui alla legge $2 !$ aprille 1983, n. 123, Rass. civ. 1985, 105

Jiirgen Samtleben. Die Statsangehörigkeit des ehelichen Kindes und der Grundsatz der Gleichberechtiging, FamRZ $1973,1-4$

Alec Samuels, British nationality law: the proposed legislation, New Law Journal 1980, 996-998

A. van de Sande Bakhuyzen, Nederlandsch onderdaanschap, Diss. Leiden 1900

T.A. Sannes, Het staatsverband. Een vergelijkende rechtsstudie, Diss. Leiden 1875

Lidia Santos Arnau/Blanca Vila Costa, Comentario a la ley $51 / 1982$ de 13 de julio de modificación de los articulos 17 a 26 del Código civil en materia de nacionalidad, Revista Juridica de Catalunya 1983, 847-895

Th. van Sasse van Ysselt, De Nederlandse nationaliteitswetgeving critisch bezien, PS 1953, 45-48

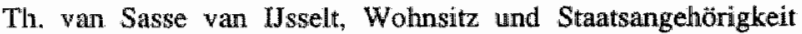
mach hollhindischem: Erbstatut, NJW 1958, 1668

Th. van Sasse van IJsselt, De nieuwe Oostenrijkse nationaliteitswet, PS 1966, 57,58

Th. van Sasse van Dsselt/A. van Praag, Nationalité, Pays-Bas, in: Commission internationale de l'Etat civile, Ficher de Documentation, Ficher II, 1952 
Sassen

\section{Sauser-Hall}

Sauveplanne

Scaevola

Sceille

Schärer, ZZW 1985, 53

Schärer, ZZW 1985, 203

Schätzel

Schätzel, Festgabe

Schätzel, Grundrechte

Scheffler, Grundrechte

Scheffler, Juristentag

Schïckedans

Schiffner

Schindler

Schlieser

Schmitz.

Schneider

Schockweiler, Jurisclasseur

Schockweiler, Nationalité

Schrameck
J.H. Sassen, Proeve van een beredeneerd overzigt van het Burgerlijk Wetboek voor het Koninkrijk der Nederlanden, Eerste Boek, titell 1-5, 's Hertogenbosch 1827

Georges Jean Sauser-Hall, La nationalité de la fenme marié, Zürich 1933

Jean Georges Sauveplanne, De methode wan de privaatrechtelijke rechtsvergelijking, Deventer 1975

Q. Mucius Scaevola, Código civil, Bd. 1, 5. Auflage, Madrid 1912

Georges Scelle, A propos de la loi allemande du 14 juillet 1933 sur la déchéance de la nationalité, Revue critique de droit international $1934,63-76$

Roland Schärer, La revisione della legge sulla cittadinanza, ZZW 1985, 53-59 (französisch: 1984, 332-338)

Roland Schärer, Das Bürgerrecht der Kinder eines schweizerischen Elternteils, ZZW 1985, 203-207 (italienisch: 238-242; französisch: 292-295)

Walter Schärzel, Geschichte der Staatsangehörigkeit ${ }_{n}$ in: Schätzel, Internationales Recht, Gesammelte Schriften und Vorlesungen, Bd. III, Internationales Staatsangehörigkeitsrecht, Bonn 1962, 15-26

Walter Schätzel, Das ius sanguinis der ehelichen Mutter, in: Festgabe für Herrfahrdt, Marburg 1961, 167-176, ebenfalls in: Schätzel, Internationales Recht, Gesammelte Schriften und Vorlesungen, Bd. III, Internationales Staatsangehörigkeitsrecht, Born 1962, 255-264

Walter Schätzel, Staatsangehörigkeit ${ }_{\text {" }}$ in: Die Grundrechte. Handbuch der Theorie und Praxis der Grundrechte, herausgegeben von Franz L. Neumann, Hans Carl Nipperdey und Ulrich Scheumer, Band II, Berlin 1954,

Erna Scheffler, in: Die Grundrechte. Handbuch der Theorie und Praxis der Grundrechte, herausgegeben won Franz $L$. Neumann, Hans Carl Nipperdey und Ulrich Scheuner, Band IV, Berlin 1954, 301

Erna Siheffler, Die Gleichberechtigung der Frau (Verhandlungen des 38. Deutschen Juristentag 1950, Teil B), Tuibingen 1951

E. Schickedans, Art. 3 Abs. Il GG und Par. 4 RuStAG, StAZ $1970,330-334$

Albert Schiffner, Allgemeines deutsches Sach-Wörterbuch aller menschlichen Kenntnisse und Fertigkeiten, 6. Band, Meissen 1827

Dietrich Schindler, Regional international law, EPIL, Band 7 , 404-409

W.Fr. Schleser, Die deutsche Staatsangehörigkeit, Frankfurt aur Main 1980

Michael Schmitz, Staatsangehörigkeitsakte der DDR und deutsche Staatsangehörigkeit, NV wZ 1987, 31-33.

J.W. Schneider, Intervention, in: Mededelingen van de Nederlandse Wereniging woor Internationaal Recht 1981, 20, ebenfalls veröffentlicht in NILR 1982, 123

Fernand Schockweiler, Luxembourg, in: Jurisclasseur Nationalité (Loseblattausgabe), Paris

Fernand Schockweiler, Nationalité et statut personnel dans le droit de la nationalite luxembourgeoise, in: Verwilghen, Nationalité, Brussel 1984, 143-167

Olivier Schrameck, La réntégration dans lia nationalité française: l'appréciation de la recevabilité des demandes, Revue française de droit administratif 1987, 616-623 
L.

Schreudler 1880

Schreuder 1893

Schröder 1949

Schroder 1954

Schröder-Hilgendorff

Schuller

Schwarz

Schwarze/Bieber

Schwimann, ÖJZ 1955

Schwimann, StAZ 1986

Scott

Seckler-Hudson

Seeler

Seidl-Hohenveldern

Seidl-Hohenveldern, ÖZÖR

\section{Seiffert}

Senaeve

Serrano Garcia

Sevig, Nationalite

Sevig, Jurisclasseur

Shevtsov

Siekmann, NJB 1979, 490

Siekmann, NJB 1979,655

\section{Literaturverzeichnis}

L.F.G.P. Schreuder, Wetten van 28 juli 1850 Staatsblad nr. 44, 21 december 1850 Staatsblad $n$ r. 75 en 3 mei 1851 Staatsblad nr. 46 , betreffende het Nederlandlerschap en het ingezetenschap en de Naruralisatie, Schiedam 1880

L.F.P.G. Schreuder, Wet van 12 december 1892 Staatsblad nr. 268 op het Nederlanderschap en het ingezetenschap, 2. Auflage, Zutphen 1893

Hans Schuröder, Das schweizerische Staatsangehörigkeitsrecht, Sammlung geltender Staatsangehớrigkeitsgesetze, Band 2, Frankfurt am Main 1949

Hans Schröder, Das schweizerische Staatsangehörigkeitsrecht, Sammlung geltender Staatsangehörigkeitsgesetze, Band 2a, Frankfurt am Main/Berlin, 1954

Wolfgang Schröder-Hilgendorff, Die Gleichberechtigung der Geschlechter im Staatsangehörigkeitsrecht, Diss. Frankfurt 1970

R. Schüier, Inhalt und Entwicklungstendenzen der sozialistischen Staatsbürgerschaft, Staat und Recht 1984, 248-250

Elisabeth Schwarz, Die Anpassung des deutschen Staatsangehörigkeitsrecht an den Grundsatz der Gleichberechtigung von Mann und Frau, Diss. Hamburg 1955

Jürgen Schwarze/ Roland Bieber (Hrsg.), Eine Verfassung für Europa, Von der Europäischen Gemeinschaft zur Europäischen Union, Baden-Baden 1984

Michael Schwimann, Über die Verlusttatbestände des österreichischen Staatsbürgerschaftsrechtes, OJZ 1955, 381-391

Michael Schwimann, Osterreich: Erneute Änderung des Staatsbiügerschaftsrechts, StAZ 1986, 110-116

James Brown Scott, Observations on nationality, New York 1930

Catheryn Seckler-Hudson, Statelessness, with special reference to the United States, Washington D.C. 1934 (reprint New York 1971)

Hans Joachim Seeler, Das Staatsangehörigkeitsrecht Österreichs, 2. Auflage, Frankfurt am Main 1966

Ignaz Seidl-Hohenveldem, Völkerrecht, 6. Auflage, Köln u.s.w. 1987

Ignaz Seidl-Hohenveldern, Die österreichische Staatsbürgerschaft von 1938 bis heute, ÖZÖR 1955, 21-39

Wolfgang Seiffert, Wechsellseitige Respektierung der Staatsangehörigkeitsregelung der beiden deutschen Staaten, Politik und Kultur 1982, 60-68

Patrick Senaeve, Recente hervormingen in het Belgische familierecht, FIR 1987, 179-188

Ignacio Serrano García, Notas sobre la nacionalidad de los conyuges segun la reforma del Código civil de 2-5-1975, Documentación Juridica 1978, 665-690

Vedat Rasit Sevig, Nationalité et statut personel dans le droit de la nationalitê turque, in Verwilghen (1984), 195-213

Vedat Rasit Sevig, Turquie, in: Jurisclasseur Nationalité, Loseblattausgabe Paris

V. Shevtsov, Citizenship of the USSR (a legal study), Moskow 1979

R.C.R. Siekmann, Art. 7 jo sub 4 Wet Nederlanderschap en het anti-apartheidsbeleid van de Nederlandse regering, NJB $1979,490-492$

R.C.R. Siekmann, Nogmaals: het treden in Zuidafrikaanse burgerlijke staatsdienst en het anti-apartheidsbeleid van de Nederlandse regering, NJB 1979, 655-656 
di Siena

Sillagi, StAZ 1988

Silagi, Recht in Ost und West 1988

Silving

Simmonds

Sinagra

Smet

Söhngen

Sonnenberger

Sorensen

Spinedii

Staatscommissie BR

Staatscommissie IPR

Stanbrook

Stanbrook,

Jurisclasseur

Standaert

Steffensen

Steffensen,

Jurisclasseur

Stern

Stichlberger

Stoffels

Stoll

de Stoppelaar

Strupp
G. Di Siena, Le nuove norme sulla cittadinanza, Gazetta valut. 1983,1019

Michael Silagi, Staatsangehörigkeit im geteilten Deutschland. Zum BeschluB des Bundesverwaltungsgerichts vom 21. 10. 1987, StAZ 1988, 64-71

Michael Silagi, Ein Sezessionsmißverständnis und das Bundesverfassungsgericht, Recht in Ost und West 1988, 151157

Helen Silving, Nationality in comparative law, AJCL 1956, 410-442

Kenneth $\mathbb{R}$. Simmonds, The British Nationality Act 1981 and the definition of the term "national" for Community purposes, CMLR 1984, 675-686

A. Sinagra, La sentenza n. 30 del 1983 della Corte costiruzionale e la Legge 21/4/83 recante disposizioni in materia di cittadinanza, Giur. costituz. 1983 I, 578-591

A. Smet, Wetboek van de Belgische nationaliteit, unveröffentlichtes Maruuskript 1984

F.A. Söhngen, De nationaliteit wan de gehuwde vrouw, Amsterdam 1930

Hans Jirgen Sonnenberger, Anerkennung der Staatsangehörigkeit und effektive Staatsangehörigkeit natürlicher Personen im Völkerrecht und im Internationalen Privatrecht, in: Berichte der Deutschen Gesellschaft für Volkerrecht, Heft 29, Heidelberg 1988, 9-36

Max Sorensen, Statsforfatningsret, 2. Auflage, Kopenhagen 1973

Marina Spinedi, Proposte di modifica alla legislazione italiana in materia di cittadinanza, RDI 1967, 126

Advies Staatscommissie voor de burgerlijke wetgeving over voorontwerp Nederlanderschap, PS 1978, 23-28

Advies Staatscommissie voor het internationaal privaatrecht ower voorontwerp wet Nederlanderschap, PS 1977, 73-82

Ivor Str.nbrook, British nationality: The new law, London 1982

Ivor Stanbrook, Royaume-Uni de Grande Bretagne et d'Irlande du Nord, in : Jurisclasseur Nationalite (Loseblattausgabe), Paris

$R$, Standaert, La nationalité belge. Lois coordinées sur la nationalite. Statut de la Calamine etl des cantons d'Eupen, Malmédy et St. Vith. Convention franco-belge sur la nationalité de la femme mariee, Luttre 1934

Torben Steffensen, Juridisk Formularbog, 12. Auflage, Kopenhagen 1983

Torben Steffensen, Danemark, in: Jurisclasseur Nationalite (Loseblattausgabe), Paris

Klaus Stern, Die deutsche Staatsangehörigkeit. Position und Begriffe, DVBI. 1982, 165-173

Günther Stichlberger. Entzug der österreichischen Statatsbuirgerschaft nach Par. 34 Abs. 1 Ziffer 4 StBG 1965. Österreichisches Verwaltungs Atchiv 1979, 9-13

H. Stoffels, Nederlanders in Spaanschen dienst, NJB 1937, $921-926$

Hiermann Stoll. Der Verlust des Schweizerbirgerrechtes, Diss. Zürich 1.888

J.W. de Stoppelaar, Nederianderschap en Nederlandsch onderdaanschap, Koloniaal Tijdschrift 1937, 268-272

Karl Strupp, Elérnents do droit international public, Bd. I, 2. Auflage, Paris 1930 
Stuber

Sturm, Jurisclasseur

Sturm, Nationalité

Sturm, StAZ 1973

Sturm, FamRZ 1974

Sturm, FamRZ 1975

Sturm/Sturm

Stuttenheim

Tanaka

Terré

Thomas

Thränhardt

Thränhardt,

Politik und Zeitgesch.

van Tijen

Tomson

Toneatti

Torley Duwel

Torrente/Schlesinger

Torres Ugena

Tratnik

Trevisan

Triepel

Triepel, ZaóRV 1929

Trost
Werner Stuber, Nationalite suisse selon lirticle 5 , all 1 , lit. a LN, ZZW 1984, 83, 84 (deutsch: 1983, 249)

Fritz Sturm, Allemagne, RFA, in: Jurisclasseur Paris

Fritz Sturm, Nationalitế et statut personnel dans le droit de la nationalité allemande, autrichienne et suisse, in: Verwilghen, Nationalité, Brusssel 1984, 93-122

Fritz Sturm, Das Bundeswerfassungsgericht in der $Z$ wickmithle, StAZ 1973, 292-295

Fritz Sturm, Deutsch wie Vater oder Mutter, FamRZ 1974 , 617-631

Fritz Sturm, Zur Staatsangehörigkeitsnovelle 1974, FamRZ $1975,198-202$

Fritz Sturm/ Gudrun Sturm, Erwerb des Schweizer Bürgerrechts durch Kinder einer Schweizer Mutter, StAZ 1986, 2934: $57-64$

C.V. Stuttenheirn, Terugwerken van optie/ verwerpingsverklaringen krachtens de overeenkomst nopens de toescheiding van staatsburgers, PS 1957, 31-33

Yasuhisa Tanaka, Parentage and Nationality problems to be considered in revision of the nationality law in: Law in Japan, Tokio 1983, 115-128

François Terte, Réfexions sur la nationalite, RCDIP 1975, 197214

H.W.B. Thomas, De wet op het Nederlanderschap en het ingezetenschap van 12 december 1892 Staatsblad mr. 268, Diss. Leiden/'s Gravenhage 1893

Dietrich Thränhardt, Die europäische Dimension der allgemeinen Ausländerpolitik in den Mitgliedstaaten der $\mathrm{EG}_{r}$ in: Manfred Zuleeg (Hrsg.), Ausländerrecht und Ausländerpolitik in Europa, Baden-Baden 1987,13-36

Dietrich Thrinhardt, Die Bundesrepublik Deutschland: ein unerklärtes Einwanderungsland, Aus Politik und Zeitgeschichte, Beilage zur Wochenzeitung das Parlament, B 24/88, 3-13

D. van Tijen, Verlies van Nederlanderschap door minderjarigen die in vreemden krijgsdienst treden, NJB 1946, 237

Edgar Tomson, Das Staatsangehörigkeitsrecht Frankreichs nach dem Gesetz vom 9. Januar 1973, Frankfurt am Main 1974

E. Toneatti, Ancora sulla legge 21 aprile 1983, n. 123 "disposizioni in materia di cittadinanza" ${ }_{4}$ "Osservazioni, Stato civile $1983,687-691 ; 1984,13$

C.L. Torley Duwel, Aanteekeningen naar aanleiding van het ontwerp van wet houdende voorzieningen ter wegneming van staatloosheid, WPNR 4196 (1951) . 287-288

Andrea Torrente/Piero Schlesinger, Manuale di diritto privato, 11. Auflage, Milano 1985

Nila Torres Ugena, La nueva ley de nacionalidad británica de 1981, Revista Juridica de Catalunya 1983, 917-932

Matjaz Tratnik, Enkele problemen en een lacune in verband met de overgangsregeling van de nieuwe Rijkswet op het Nederlanderschap, NIB 1985, 1402-1403

Annemarie Trevisan, Wie kann eine nicht gebürtige Schweizerin den neuen Art. 5 BiiG umgehen- oder ist das Konkubinat ein Ausweg? ZZW 1977, 359 (französisch: 51, 51; italiènisch: 1978, 109)

Heinrich Triepel, Virtuelle Staatsangehörigkeit, Berlin 1921

Heinrich Triepel, Internationale Regelung der Statsangehörigkeit, Zä̈RV 1929, 185-199

Rachel Trost, British nationality - the 1981 Act, New Law Journal 1983, 3-5 
Turpin

Uhlitz,

Recht und Politik 1986

Uhlitz, ZRP 1987

Uluocak

Valéry

de Valkeneer

Valkhoff

Vanderveeren

Vanel, Diss.

Vanel, RCDIP 1946

Vanel, RCDIP 1951

Vendrell Ferrer

Vercelli, S.c. 1984

Vercelli, S.c. 1986

Verdross, Ius Gentium

Verdross, Völkerrecht

Verfassung der DDR

Verwilghen

Verwillghen, Nationalité

Verzijl

Vialte

Vieira de Andrade

Vierdag
C.C. Turpin, British nationality and the right to abode 1.9481983, in: The Cambridge-Tiburg Law Lectures, Fifth Series 1982, Dewenter 1986, 183-269

Otto Uhlitz, Deutsches Volk oder "Multikulturelle Gesellschaft", Recht und Politik 1986, 143-152

Otto Uhlitz, Das Wiedervereinigungsgebot als verfassungsrechuliche Schranke der Einwanderungs- und Einbiirgerungspolitik, ZRP 1987, 141-192

N. Uluocak, Exposé sur la législation turque relative a la nationalite des enfants et les cas d'apatridie, Annales de la Faculté de Droit d'Istanbul 1980, 203-207

Jules Valéry La nationalité française, Commentaire de la loi du 10 aout 1927 , Paris 1927

$R$. de Valkeneer. Condition des étrangers et code de la mationalité belge, Revue du notariat belge 1984, 389-419

J. Valkhoff, Gevolgen van de toepassing van art. 7 sub 4 van de wet op het Nederlanderschap en Ingezetenschap van 12 december 1892, Stb.268 op Nederlanders in Sovjet-staatsdienst, RM Themis 1933, 1-27

Christine Vanderveeren, De Belgische nationaliteitswetgeving, Jura falconis 1982/83, 557-592

Marguerite Vanel, Evolution historique de la notion de Français d'origine du XVIe siècle au Code civil, Diss. Paris 1944

Marguerite Vanel, Histoire de la nationalité française d'orgine, RCDIP 1946, 224

Marguerite Vanel, La notion de nationalité. Evalution historique en droit interne et en droit colonial comparé (droit français et droit britannique), RCDIP $1951,3-39$

Eudald Vendrell Ferrer, La nacionalidad y el "ius soli", Revista Jurfdica de Cataluña 1981, 163-193

Otello Vercelli, Gli effetti della mancata opzione ex art. 5 legge n. 123/1983, Stato civile 1984,521

Otello "ercelli, L'art. 12 della legge n. $555 / 1912$ e 1"art. 5 della legge n. 123/1983: due norme ancora compatibili fra loro?, Stato civile 1986, 494

Alfred Verdross-Drossberg, Die völkerrechtliche Abgrenzung der Statsangehörigkeit, in: Jus Gentum, Band I, 1949, 137146

Alfred Verdross, unter Mitarbeit won Stephan Verosta und Karl Zemanek, Volkerrecht, 5. Auflage, Wien 1964

Verfassung der DDR, Dokumente, Kommentar Band 2 (Herausgegeben von Klaus Sorgenicht, Wolfgang Weichelt, Tord Riemann und Hans-Joachim Semler), Berlin (Ost) 1969

Michel Verwilghen, Le code de la nationalite belge, Bruxelles 1985

Michel Verwilghen, Nationalité et statut personnel, Bnussel 1984

J.H.W. Verzijl, Intemational law in historical perspective, Part $V$. Nationality and other matters relating to individuals, Leiden 1972

Jean Viatte, Modificationes aux règles d'attribution de la nationalite française, Journal des notaires $1973,553.560$

José Carlos Vieira de Andrade, Der Erwerb der deutschen Staatsangehörigkeit durch ausländische Arbeitnehmer im Himblick auf das neue portugiesische Staatsangehörigkeitsrecht, IA $1982,4,186-189$

E.W. Vierdag, Nationaliteit en vreemdelingenrecht, in: Volkenrechtelijke aspecten van de Antilliaanse onafhankelijkheid (red. H. Meijers), Alphen aan den Rijn 1980, 417-446 
LIV

Vila Costa

Viñas if Farre

Vifias if Farre, Jurisclaspeur

Vifas i Farre. RUC

Vinas i Fairte, RDIPP

de Visscher

Volkerrecht DDR wan Vollenhoven

Voorduin

Voss

Vucusa, S.c. 1983, 201

Vucusa, S.C. 1983,562

Weber, Alice

Weber, Wolfgang

van der Weg,

PS 1955, 63

van der Weg, PS 1956

van der Weg.

PS 1957, 95

van der Weg,

PS 1957, 129

van der Weg,

PS 1964,18

van der Weg,

PS 1966, 72

Weidelener/Hemberger

Weil

Weis, Paul

Weis, ICLQ

Weiss, Hugo

\section{Literaturverzeichnis}

Blanca Vilá Costu, Anmerkung, in: REDI 1986, 177, 178

Ramón Vinas i Farre, La nacionalitat andorrana, Barcelona 1980

Ramón Viñas i Farré, Andorne, in: Jurisclasseur Nationalité (Loseblattausgabe), Paris

Ramón Viñas i Farré, La normativa andorrana sobre nacionalidad, Revista Jurídica de Cataluña 1980, 725-756

Ramón Viñas i Farré, Notas para una reforma del código de la riacionalidad andorrana, RDIPP 1983, 87-93

Paul de Visscher, La constitution belge et le droit international, Revue belge de droit international $1986,5-58$

Völkerrecht, Lehrbuch, Bd.1, Berlin 1981

A.J. van Vollenhoven, Eenige opmerkingen over naturalisatie, Diss. Utrecht $\mathbb{1 8 8 0}$

J.C. Voorduin, Geschiedenis en beginselen der Nederlandse wetboeken, Band II, Utrecht 1837

Karl Ulrich Voss, Belgien: Kindschaft praeter und contra legem, IPRax 1986, 120-124

Riccardo Vucusa, Una recente sentenza della Corte Costituzionale: ill figlio è italiano se italiana è la madre ed i figli funalmente uguali, Stato civile 1983, 201

Riccardo Vucusa, Principi innovatori introdotti in tema di cittadinanza dalla legge 21 aprile 1983, n.123, Stato civile 1983,83 und 562,563

Alice Weber, Die Staatsangehörigkeit der Ehefrau nach dem französischen Gesetz vom 10. August 1927, Diss. Zürich, Lachen 1930

Wolfgang Weber, Kapitel Niederlande, in: Bergmann/Ferid (88. Lieferung, Stand 30. November 1986)

S. van der Weg, De artikelen 8 en 9 van de overeenkomst betreffende toescheiding van staatsburgers, PS 1955, 63-66

S. van der Weg, Nieuw Duits nationaliteitsrecht, PS 1956, 21 27

S. van der Weg, Zweites Gesetz zur Regelung won Fragen der Staatsangehorigkeit van 17 mei 1956 (liquidatie van nationaliteitsproblemen voortvloeiende wit de Anschluss), PS 1957, $95-$ 100

S. van der Weg, "Drittes Gesetz zur Regelung von Fragen der Staatsangehorigkeit", PS 1957, 129-134

S. Van der Weg, Een belangrijke wijziging van de Duitse nationaliteitswet, PS $1964,18-20$

S. van der Weg, Nogmaals de nationaliteit van de gehuwde vrouw, PS 1966, 72-74; 87-90

Helmut Weidelener/Fritz Hemberger, Deutsches Staatsangehörigkeitsrecht, 2. Auflage, München 1986

Alfred Weil, La double nationalite en droit allemand avant et apres la loi du 22 juillet 1913 . Revue de droit internationa! privé $1915 / 16,142-158$

Paul Weis, Nationality en Statelessness in internationall law, 2

Auflage, Alphen ad. Rijn 1979

Paul Weis, The United Nations convention on the reduction $c$ statelessness 1961, ICLQ 1962, 1073-1096

Hugo Weiss, Das Heimatrecht, Wien 1906 
Weiss, André

Wengller

Wengler

White, Gillian

White, ICLQ 1974

White, JLSS 1983

White/Evans/Hampson. New Law Joumal 1981

White/Hampson, ICLQ 1981.

White/Evans/Hampson, Scots Law Times 1982

White/Hampson,

Public Law 1982

White/Hampson,

ICLQ 1982

Wiederkehr

Wille

Williams

Winkler

de Winter, WPNR 1949

Wooldridge

Wyduckel

Wyduckel, DVBI.

Yamauchi

Yamauchi, IPRax 1985

Yiepes

de Zaaijer

Zabalo Escudero
Andre Weiss, Traite theorique et pratique de droit international prive, Band I (La nationalité), 2. Auflage, Paris 1907

Wilhelm Wengler, Betrachtungen zum Begriff der Staatsangehörigkeit, in: Festschnift Schätzel, Düsseldorf 1960, 545-558

Willhelm Wengler, Anerkennung und Umdeutung der DDRStaatsbuirgerschaft in die deutsche Sttatsangehorigkeit des Rechtes der Bundesrepublik als grundgesetzlich gebotene Folgerung aus dem Wiedervereinigungsgebot? Bemerkungen zu BVerfG 2 BvR 373/83, Beschl. vorn 21.10.1987, Recht in Ost und West 1988, 145-151

Gillian White, Current legal problems 1977, 141-158

Rabin White, When is a British Protected Person not a British Protected Person?, ICLQ 1974, 866-873

Robin $M$. White, Nationality law and the british nationality act 1981. Journal of the Law Society of Scotland 1983, 267$270 ; 302-306$

Robin M. White/Andrew C. Evans/Françoise Hampson, Unsanguine observations on the British nationality bill, New Law Journal 1981, 328, 329

Robin M. White/Françoise J. Hampson, British nationality law, Proposed changes, ICLQ 1981, 247-259

Robin M. White/Andrew C.Evans/Françoise Hampson, British Nationality Act: Exclusion of citizenship, The Scots Law Times 1982, 17-21; 49-51

Robin M. White/Françoise J. Hampson, The british nationality act 1981 - Civitas in tres partes divisa, Public Law 1982, 6-20

Robin M. White/Françoise J. Hampson, "What is my nation? Who talks about my nation?", ICLQ $1982,849-855$

Ewelyn Beatrice Wiederkehr, Erwerb und Verlust des Schweizer Bïrgerrechts von Gesetzes wegen, Zürich 1983

Herbert Wille, Das neue liechtensteinische Ehe-, Zivilstandsund Bürgerrecht, ZZW 1975, 11-13, 35-38

Glanville L. Williams, The correlation of allegiance and protection, Cambridge Law Journal 1948, 54-76

Pierre Winkler, Essai sur la nationalitế dans les protectorats de Tunesie et du Maroc, Paris 1926

L.I. de Winter, Nederlandse nationaliteit, zelfstandige nationaliteit der gehuwde vrouw en vreemde krijgsdienst, WPNR 4080 (1949), 166-167

F. Wooldridge, The British Nationality Bill of 1981, Trent Law Journal 1981, 23-47

Dieter Wyduckel, Erwerb der deutschen Staatsangehörigkeit durch Einbiirgerung in der DDR?, Recht und Staat im sozialen Wandel, $1983,663-686$

Dieter Wyduckel, Anmerkung, DVBI. 1988, 284-287

Koresuke Yanauchi, Der Zwischenentwurf zur Andenung des japanischen Staatsangehörigkeitsgesetzes, Hikakuho Zasshi (Japanese) Comparative Law Review 1983, 31-47

Koresuke Yamauchi, Zur Anderung des japanischen Staatsangehörigkeits- und Personenstandsgesetzes, IPRax $1985,59,60$

J.M. Yiepes, Doble nacionalidad o supranacionalidad, Mundo Hispánico, Nr. 142, Januar 1960, 4

H.R. de Zaaijer, Nederlanderschap en gewezen politieke delinquenten, NJB 1952, 355-358

María Elena Zabalo Escudero, Anmerkung, in: REDI 1985, 179,180 
Zachariae von

Lingenthal/Dreyer

Zatzepine:

Zeballos

Zedrwitz

won Zeiller

Zenthiofer

Zepf

Zeyringer/Mussger 1985

Zeyringer/Mussger 1986

Ziccardi

Zieger, 1969

Zieger, 1971

Zueger,

Gesamtdeutsche Staatsangehörigkeit

\section{Zieger, NJW 1984}

Zilverentant, BZ

Zilverentant, PS

Zitelimann

Zuleeg, Auslinderrecht

Zuleeg, NJW

Zuleeg, ZRP
Karl Salomon Zachariae von Lingenthal/Heinrich Dreyer, Handbuch des französischen Civilrechts, Band I, 7. Auflage, Heidelberg 1886

Alexandre Zatzépine, Quelques réflexions sur la nationalite des personnes dans les républiques francophomes d'Afrique et de Madagascar vingt après l'indépendance, Recueil Pénant $1986,482-496$

Estanislao S. Zeballos, La nationalité an point de vue de la législation comparée et du droit privé humain, 5 Bände, Paris $1914-1919$

Hans Georg Zedrwitz, Staatsbïrgerschaftsgesetz 1965, Kurzkommentar, Teil I und $\mathbb{I I}_{v}$ Wien 1966 und Nachtrag 1968 Franz Edller von Zeiller, Commentar uilber das ABGB, Band $I_{*}$ Wien 1811

Erich Zenthöfer, Zur Geschichte des Begriffs der Staatsangehörigkeit, Königs berg 1937

Karl Zepf, Die Staatsangehörigkeit der werheirateten Frau, Diss. Tübingen 1929

Walter Zeyringer/Herbert Mussger, Öster-reichisches Staatsburgerschaftsrecht, Wien 1985

Walter Zeyringer/Herbert Mussger, Staatsbïrgerschaftsgesetz 1985. Staatsbürgerschaftsverordnung 1986, Wien 1986

Piero Ziccardi, Osservazione sul disegno di legge contenente nuove norme sulla cittadinanza, in: Studi in onere di Antonio Amorth, Bd. 2, Milano 1982, 642-648

Gottfied Zieger, Das Staatsbürgerschaftsgesetz der DDR, Frankfurt am Main/Berlin 1969

Gottfried Zieger, Die Staatsangehörigkeit im geteilten Deutschland, Schriftenreithe der Niedersäichsischen Landeszentrale für Politische Bildung, Gesamtdeutsche Probleme, Band 6 , Hannover 1971

Gottfried Zieger, Die gesamtdeutsche Stalatsangehörigkeit als rechtliches Band des deutschen Staatsvolks unter besonderer Beriicksiclitigung der Ostdeutschen, Die Auslegung der Ostverträge, $1980,85-145$

Gottfried Zieger, Das Verhaltnis der Staatsangehorigkeitsregelungen in den beiden deutschen Staaten, NJW 1984, 699-704

F.Th. Zilverentant, Polemiek over de gelijkheid yan man en vrouw in het nationaliteitsrecht, BZ 1982, 1-2

F.Th. Zilverentant, Behoud/verlies van de Italiaanse nationaliteit door bipatriden, PS 1987, 16

Ernst Zitelmann, Internationales Privatrecht, Bd. I, Leipzig 1897

Manfred Zuleeg (Hrsg.), Ausländerrecht und Ausländerpolitik in Europa, Baden-Baden 1987

Manfred Zuleeg, Einbürgerung von ausländischen Ehegatten Deutscher, NJW 1981, 1878-1879

Manfred Zuleeg, Der unwollkommene Nationalstaat als Einwanderungsland, ZRP 1987,188-191 
1. ALLGEMENNER TEIL

\subsection{Einführung}

Ziel dieser Arbeit ist eine rechtsvergleichende Studie über die Erwerbs- und Verlustgründe der Staatsangehörigkeit. AnlaB zu dieser Untersuchung bildet das, am 1. Januar 1985 in den Niederlanden in Kraft getretene, neue Staatsangehörigkeitsgesetz (1). Zusammen mit diesem Gesetz wurde ein weiteres verabschiedet, worin die Ratifizierung dreier, sich auf das Staatsangehörigkeitsrecht beziehende, multinationale Abkommen genehmigt wurde (2):

a) Das Abkommen von New York vom 30. August 1961 zur Verminderung der Staatenlosigkeit (3) im folgenden abgekuirzt als "New Yorker Abkommen $1961^{\prime \prime}$.

b) Das Abkommen von Straßburg vom 6. Mai 1963 zur Verminderumg von Fällen mehrfacher Staatsangehörigkeit und betreffend Wehrpflicht bei mehrfacher Staatsangehörigkeit (4), abgekürzt "Straßburger Abkommen 1963" und

c) Das Abkommen von Bern vom 13. September 1973 zur Verringerung der Falle von Staatenlosigkeit (5), abgekiirzt "Berner Abkommen 1973".

Es ist deshalb nicht erstaunlich, daß die Bekämpfung der Staatenlosigkeit und der Wunsch mehrfache Staatsangehörigkeiten möglichst zu vermeiden, deutliche Ausgangspunkte des neuen niederländischen Staatsangehörigkeitsgesetzes sind. Weiter ist die neue Regelung dergestalt, daß Mann und Frau, anders als im bisherigen niederländischen Staatsangehörigkeitsrecht, gleich behandelt werden (6).

Die drei erwähnten Ausgangspunkte des neuen miederländischen Gesetzes - die Bekämpfung der Staatenlosigkeit, die Vermeidung der mehrfachen Staatsangehörigkeit und die Verwirklichung der Gleichberechtigung von Mann und Frau im Staatsangehörigkeitsrecht - findet man auch in vielen neueren Staatsangehörigkeitsgesetzen anderer Staaten (7). Dabei kann man feststellen, daB der Wunsch, Staatenlosigkeit möglichst vorzubeugen, heute fast allgemein akzeptiert ist. Unterschiede gibt es in der Art und Weise, worauf die Staatenllosigkeit bekämpft wird (8).

Vor rund drei Jahrzehnten wurde noch häufig behauptet, daß die Gleichberechtigung von Mann und Frau keine Änderungen der Staatsangehörigkeitsgesetze, die etwa bei der Regelung des Erwerbs der Staatsangehörigkeit durch Geburt grundsätzlich auf die Staatsangehörigkeit des Vaters abstellten, notwendig mache (9). Seitdem hat sich diese Auffassung gewandelt (10). In der Bundesrepublik Deutschland und in Italien haben sogar das Bundesverfassungsgericht und der Corte costitutionale ausdrïcklich festgestellt, daß die Anerkenuming des Grundsatzes der Gleichberechtigung auch für das Staatsangehörigkeitsrecht Folgen haben muß (11). Viele Staaten haben deshalb inzwischen ihre Staatsangehörigkeitsregelungen geändert. Ein Vergleich dieser relativ neuen Änderungen ist deshalb interessant, da die meisten Staaten - wie nun auch das neue niederländische Gesetz - versuchten ihre Staatsangehörigkeitsregelungen zugleicherzeit so zu gestalten, daß möglichst wenige Fälle mit Mehrfachstaatsangehörigkeiten auftreten (12). Diese beiden Tendenzen, Verwirklichung der Gleichberechtigung im Staatsangehörigkeitsrecht und Bekämpfung der mehrfachen Staatsangehörigkeit, widersprechen sich teilweise (13). Denn gerade die Rea- 
lisierung der Gleichberechtigung bewirkt - insbesondere bei der Regelung des Erwerbs der Staatsangehörigkeit iure sanguinis in der Gestalt, daß die Staatsangehörigkeit durch Abstammung grundsätzlich vom Vater und von der Mutter abgeleitet werden kann - eine weit größere Zahl von Mehrstaatlem als vorher. Jeder Gesetzgeber muß deshalb die Frage beantworten, wo er die Grenze zwischen den beiden erwähnten Tendenzen gezogen haben will (14). In dieser Arbeit werden in den Paragraphen 2.1 bis 2.9 die Staatsangehörigkeitsregelungen mehrerer europäischer Staaten aus dieser Perspektive beschrieben. In Paragraph 1.2 wird die Wahl der Staaten, deren Staatsangehörigkeitsrecht untersucht wird, näher erläutert und verantwortet.

Vor den unterschiedlichen Länderberichten sei aber zuerst noch ein kurzer allgemeiner Diskurs über Begriff und Funktion der Staatsangehörigkeit sowie über die Schranken der nationalen Staatsangehörigkeitsgesetzgebung gegeben. Diesen Bemerkungen sind die Paragraphen 1.3 und 1.4 gewidmet.

Nach den Länderberichten wird in Kapitel 3 versucht, Unterschiede und Übereinkiunfte der verschiedenen Staatsangehörigkeitsregelungen zu analysieren. Schließlich möchte ich in Kapitel 4 Vorschläge zur Änderung des neuen niederländischen Staatsangehörigkeitsrechts unterbreiten. Es versteht sich, daß ich entsprechende Änderungen der Staatsangehörigkeitsregelungen auch in anderen Staaten für wünschenswert halte. Als niederländischer Jurist fühle ich mich jedoch nicht dazu berufen, anderen Staaten Vorschläge zu unterbreiten, welchem Personenkreis diese ihre Staatsangehörigkeit verleihen sollten (15).

Am Schluß dieser Einführung soll - gerade wegen des vorigen Satzes - noch kurz verantwortet werden, weshalb diese Veröffentlichung auf deutsch und nicht auf niederländisch verfaßt ist. Eine in niederländischer Sprache geschriebene Arbeit über Staatsangehörigkeit würde mit Sicherheit nur von einer ganz kleinen Zahl belgischer und niederländischer Juristen gelesen und möglicherweise auch noch von einigen wenigen Ausländern, die niederländisch beherrschen. Wegen des rechtsvergleichenden Charakters der vorliegenden Arbeit ist sie vielleicht aber auch für einen etwas größeren Personenkreis, der sich im Ausland mit Fragen des Staatsangehörigkeitsrechts beschäftigt, interessant. Dies gilt insbesonders für die Ausführungen über das neue niederländische Staatsangehörigkeitsgesetz, da sowohl über das alte (16) als über das neue (17) niederländische Staatsangehörigkeitsrecht nur wenige fremdsprachige Veröffentlichungen existieren. Das gleiche gilt für das neue belgische Staatsangehörigkeitsgesetz (18). Aus diesem Grunde habe ich mich entschlossen diese Arbeit nicht auf niederländisch zu verfassen. Deutsch wurde gewählt, da ich diese Sprache weitaus besser als andere Fremdsprachen beherrsche. Außerdem können diejenigen, die sich in den Niederlanden für Staatsangehörigkeitsrecht interessieren deutschsprachige Veröffentlichungen ohne Schwierigkeiten lesen. 
1.2 Verantwortung der zu besprechenden Rechtssystemen und der inhaltlichen Abgrenzung der Länderberichte

Wenn jemand ein juristisches Problem rechtsvergleichend erörtern möchte, stellt sich zunächst als erste wichtige Frage, welche Rechtssysteme zum Vergleich herangezogen werden sollen (19). Die Auswahl der zu vergleichenden Rechtssysteme wird durch viele Umstände bedingt. Dabei steht an erster Stelle die Vergleichbarkeit der durch die unterschiedlichen Rechtsordnungen angebotenen Lösungen. Zweitens ist die Schwierigkeit oder gerade Leichtigkeit, womit Materialien über die verschiedenen Rechtsordnungen gesammelt werden können ein beachtlicher Faktor. Hierbei muB berücksichtigt werden, daB - wenigstens unmittelbar - nur Materialien verarbeitet werden können, die in einer Sprache verfaßt sind, die der betreffende Rechtsvergleicher - wenigstens einigermaßen beherrscht (20). Drittens spielt bei der Festsetzung der Anzahl heranzuziehender Rechtssysteme die für eine Studie zu Verfügung stehende Zeit selbstverständlich eine wichtige Rolle. Und - last but not least - ist das Ziel der Rechtsvergleichung außerordentlich wichtig. Dabei muß berïcksichtigt werden, daß die erwähnten Faktoren nicht streng von einander unterschieden oder getrennt werden können. Die unterschiedlichen Begründungen beeinflussen einander.

\subsubsection{Die Vergleichbarkeit der Staatsangehörigkeitsregelungen}

Die Vergleichbarkeit von Rechtssystemen ist themengebunden (21). Soweit es die Staatsangehörigkeit betrifft ist $\mathrm{m}$.E. grundsätzlich eine weltweite Vergleichbarkeit vorhanden (22). Jeder Staat hat eine Staatsangebörigkeitsregelung, deren Ziel es ist zu bestimmen, welche Menschen zum Personensubstrat dieses Staates gehören. Es ist deshalb wissenschaftlich immer interessant, die unterschiedlichen Kriterien, die Staaten benützen, um ihre Personensubstrate von denen anderer Staaten abzugrenzen, zu vergleichen. Dabei können Übereinstimmungen oder Unterschiede aufgezeigt, sowie deren mögliche Ursachen erklärt werden. Die verschiedenen Haltungen dem Begriff der Staatsangehörigkeit gegenüber sind nicht dermaßen unterschiedlich, daß ein Vergleich der Staatsangehörigkeitsregelungen bestimmter Staaten unsinnig wäre. Diese grundsätzliche Vergleichbarkeit aller Staatsangehörigkeitsregelungen wird unter anderem dadurch bestätigt, daß die Vereinten Nationen mehrmals versucht haben, die Staatsangehörigkeitsregelungen aller Mitgliedstaaten durch Resolutionen, bzw. Konventionen zu beeinflussen (23). Bezüglich einer Materie, die eine weltweite prinzipielle Vergleichbarkeit vermissen läBt, sind UN-Konventionen oder Resolutionen zwecklos.

Falls - wie im vorliegenden Falle - Ziel der rechtsvergleichenden Betrachtungen der Wunsch ist, Vorschliage zur Verbesserung, beziehungsweise Änderung der Staatsangehörigkeitsregelung des eigenen Staates zu unterbreiten, ist es aber zweckmäßig gerade die Regelungen jener Staaten zum Vergleich heranzuziehen, deren Auffassungen hinsichtlich der Funktion der Staatsangehörigkeit so weit möglich mit denen des eigenen Staates übereinstimmen. Aufgrund dieses ZweckmäBigkeitsgedankens empfahl es sich im vorliegenden Falle, jedenfalls die Staatsangehörigkeitsregelungen kommunistischer Staaten grundsätzlich außer Betracht $\mathrm{zu}$ lassen, da diese Staaten die Staatsangehörigkeit, anders als heutzutage die Staaten Westeuropas, als Auszeichnung eines Bürgers betrachten (24). Diese Auffassung hat auf Einzelpunkte derartige Folgen, daß eine Verglei- 
chung westeuropäischer Staatsangehörigkeitsregelungen mit den osteuropäischen weniger nützlich ist. Dies gilt um so mehr, wenn das Forschungsworhaben Verbesserungsvorschläge der eigenen Staatsangehörigkeitsregelung bezweckt. Es sei mir gestattet, dies im folgenden näher zu erläutern.

In der sozialistischen juristischen Literatur selbst wird betont, daß die sozialistische "Staatsbürgerschaft" grundsätzlich verschieden von der bürgerlichen Staatsangehörigkeit ist. So erklärt Riege, in seinem Buch "Die Staatsbürgersehaft der DDR" (25):

"Insofern ist das vom analogen bürgerlichen Rechtsinstitut erfaßte Rechtswerhältnis ein wesenmäßig anderes, selbst dann, wenn es gleich bezeichnet sein sollte".

Riege definiert die Staatsbürgerschaft der DDR als (26)

"die stabile, dauerhafte, vom Aufenthaltsort unabhängige politisch-rechtliche Beziehung zwischen einer Person und der DDR, die sich auf die sozialistischen Produktionsverhältnisse und die politische Macht der Arbeiterklasse gründet, in der der Bürger als Mitträger der Volkssouveränität die Gesamtheit der Grundrechte, -freiheiten und -pflichten besitzt".

Er betont weiter, daB (27)

"der Inhalt der sozialistischen Staatsbürgerschaft zwar weitgehend, jedoch nicht vollständig mit den juristisch fixierten Rechten und Pflichten der Bürger umrissen wird. Um diesen Inhalt zu erfassen, muß der Ansatz nicht bei den einzelnen Rechten und Pflichten, sondern bei der ihnen zugrunde liegenden, sie umfassenden und über sie hinausgehenden Stellung des einzelnen als Mitträger der Volkssouveränität gesucht werden".

Die Staatsangehörigkeit bürgerlicher Prägung sieht er als (28)

"die für moderne Gegebenheiten umfunktionierte Untertanenschaft".

Die abweichende Auffassung der sozialistischen Staaten bezüglich der Staatsangehörigkeit läßt sich an dem Rechtsinstitut der Aberkennung der Staatsangehörigkeit werdeutlichen. Gemäß $\S 13$ Staatsbürgerschaftsgesetz DDR (StBGDDR) kann Bürgern, die ihren Wohnsitz oder Aufenthalt auBerhalb der Deutschen Demokratischen Republik haben, "wegen grober Verletzung der staatbürgerlichen Pflichten" die Staatsbürgerschaft aberkannt werden (29). Die Aberkennung geschieht durch Entscheidung des Ministerrats der Deutschen Demokratischen Republik ( $\$ 16$ StBG-DDR). Man vergleiche in diesem Zusammenhang auch den Widerruf der Verleihung der Staatsbürgerschaft wegen "grober Mißachtung der mit ihrer Verleihung übernommenen Verpflichtungen", gemäß $\S 12$ Abs. 1 Buchstabe b StBG-DDR. Riege (30) weist darauf hin, daß der sozialistische Staat mit der Aberkennung der Staatsbürgerschaft auf ein individuelles Verhalten reagiert, 
"das staatsbürgerliche Pflichten schwerwiegend verletzt, sich in zugespitzter Weise gegen die DDR, ihre Staats- und Rechtsordnung, die Grundsätze des sozialistischen Zusammenlebens der. Bürger und gegen deren Interessen richtet. Die Aberkennung zerschneidet das Band, das zwischen der sozialistischen Staats- und Gesellschaftsordmung und der betreffenden Person gegeben war. Sie schließt diese aus den Reihen der Gesellschaftsmitglieder aus. Damit ist die Aberkennung die weitestgehende juristischpolitische Reaktion der Gesellschaft gegenüber einem Bürger, der in außergewöhnlicher Weise den Verpflichtungen aus seiner Staatsbürgerschaft zuwidergehandelt hat".

\subsubsection{Verantwortung der zu besprechenden Rechtssysteme}

Die unterschiedliche Auffassungen iiber das Wesen der Staatsangehörigkeit in "kapitalistischen" und "sozialistischen" Staaten macht - wie oben schon betont wurde - Rechtsvergleichung der staatsangehörigkeitsrechtlichen Regelungen sicher nicht prinzipiell unmöglich. Dies beweist auch das zitierte Buch von Riege, worin gerade das sozialistische und "bürgerliche" Staatsangehörigkeitsrecht verglichen wird (31). Es kann durchaus interessant und fruchtbar sein $\mathrm{zu}$ untersuchen, welche Detailunterschiede Folgen der unterschiedlichen Funktionsauffassungen sind. Eine Vergleichbarkeit ist - wie bereits gesagt - grundsätzlich vorhanden. $\mathrm{Da}$ nun die vorliegende Studie zum Ziel hat, Vorschläge zur Verbesserung des eigenen Rechts zu unterbreiten, erscheint es aber weniger zweckmäßig auch die sozialistische Rechtsordnungen zum Vergleich heranzuziehen. Dies gilt um so mehr, da die sozialistische Auffassung sehr erheblich abweicht von meiner - in Paragraph 1.3 zu erörtenden - Betrachtungsweise der Staatsangehörigkeit als juristisch-technischer Koppelungsbegriff ohne wesentlichen Inhalt.

Aufgrund der Schwierigkeit, ausreichende Materialien innerhalb nicht allzulanger Zeit zusammenzutragen, habe ich mich bei der vorliegenden Veröffentlichung dazu entschlossen, außereuropäische Rechtssysteme ebenfalls außer Betracht zu lassen (32). Die ursprüngliche Wahl der heranzuziehenden Rechtssysteme beschränkte sich damit allmählich auf - grosso modo - die Mitgliedstaaten des Europarates. Da die europäischen Staaten sich gerade im Rahmen des Europarates in der Vergangenheit des häufigeren gemeinsam mit Staatsangehörigkeitsfragen beschäftigt haben (33), wird diese Beschränkung hierdurch noch zusätzlich legitimiert.

Es hätte also auf der Hand gelegen, in der vorliegenden Studie Staatsangehörigkeitsregelungen sämtlicher Europaratsmitglieder heranzuziehen. Aus mehreren Gründen ist die Anzahl der zu besprechenden Staaten aber weiter eingeschränkt. Der erste Grund war der Wunsch, die vorliegende Arbeit nicht zu unübersichtlich zu machen. Weiterhin schien es sinnvoll, ausschließlich das Recht jener Staaten zu behandeln, die in jüngster Vergangenheit ihre Staatsangehörigkeitsregelungen entweder wegen des Wunsches, darin die Gleichberechtigung von Mann und Frau zu verwirklichen, oder infolge Ratifizierung des Straßburger Abkommens über die Verringerung der mehrfachen Staatsangehörigkeit geändert haben. Die Wahl fiel dadurch letzlich auf die Länder Belgien, Bundesrepublik Deutschland, Frankreich, Großbritannien, Italien, Niedlerlande, Österreich, Schweiz und Spanien. 
Aus dem Ziel dieser Arbeit ergab sich zwangsläufig, daß jedenfalls das Staatsangehörigkeitsrecht der Niederlande beschrieben werden mußte. Die Darstellung des niederländischen Staatsangehörigkeitsrechts ist relativ knapp gehalten und ist vielleicht kürzer als man es von einem niederlảndischen Juristen erwarten würde. Eine ausführlichere Beschreibung des niederländischen Staatsangehörigkeitsrechts hätte jedoch zu einer Überbetonung geführt und das Gleichgewicht der unterschiedlichen Länderberichte ganz erheblich gestört. Für eingehendere Betrachtungen des niederländischen Staatsangehörigkeitsrechts sei deshalb auf andere Veröffentlichungen verwiesen (34).

Ferner lag es auf der Hand wenigstens das Recht der Nachbarländer der Niederlande wegen der Zugänglichkeit der Materialien in diese Studie einzubeziehen. Aus diesem Grund wurde das Recht Belgiens, der Bundesrepublik Deutschland und Großbritanniens ausgewählt. Diese Wahl war auch deshalb vertretbar, weil diese Staaten bereits versucht haben, die Gleichberechtigung von Mann und Frau im Staatsangehörigkeitsrecht zu verwirklichen. Belgien und Deutschland haben dabei zugleich danach gestrebt, mehrfache Staatsangehörigkeiten möglichst zu vermeiden, Großbritannien hat sich dieses letzte Ziel dagegen nicht ausdrücklich gestellt. Interessant war weiter, daß die Bundesrepublik Deutschland im Staatsangehörigkeitsrecht von einem strengen ius sanguinis ausgeht und grundsätzlich keine Ausnahmen zugunsten des ius soli kennt, während das Staatsangehörigkeitsrecht Belgiens und Großbritanniens auf einer Mischung von ius soli und ius sanguinis beruht. Die grundlegende Änderungen des Staatsangehörigkeitsrechts Belgiens und Großbritanniens in der Perspektive der Gleichberechtigung der Geschlechter sind dabei noch sehr jung, sie traten am 1. Januar 1985 (35), beziehungsweise am 1. Januar 1983 (36) in Kraft. Die für die Gleichberechtigung wichtigste Änderung des deutschen Staatsangehörigkeitsrechts ist schon älteren Datums (1. Januar 1975 (37)). Sie war durch eine Entscheidung des Bundesverfassungsgerichtes (38) notwendig geworden, in der betont wurde, daß die Gleichberechtigung der Geschlechter grundsätzlich auch für die Staatsangehörigkeitsregelung Konsequenzen haben muß. Jene Änderung war auch international bedeutsam, da sie wohl den entgültigen Anstoß zur Diskussion über Gleichberechtigung im Staatsangehörigkeitsrecht in anderen westeuropäischen Staaten gegeben hat (39).

Da diese Veröffentlichung in deutscher Sprache erscheint, durfte nicht unterlassen werden, das Staatsangehörigkeitsrecht von zwei anderen westeuropäischen (teilweise) deutschsprachigen Staaten, der Schweiz und Österreich, einzubeziehen. Auch das Recht dieser Staaten ist in jüngster Zeit unter Berücksichtigung der Gleichberechtigung eingehend geändert. Diese Änderung trat in der Schweiz am 1. Juli 1985 (40) in Kraft und in Österreich am 1. September 1983 (41). Beide Staaten gehen wie die Bundesrepublik Deutschland von einem strengen ius sanguinis aus.

Außer dem Staatsangehörigkeitsrecht der bereits erwähnten Staaten wird das Recht Frankreichs, Italiens und Spaniens behandelt. Das Staatsangehörigkeitsrecht Frankreichs ist bedeutsam, da das modeme europäische Staatsangehörigkeitsrecht seine historischen Wurzel im französischen Code civil hat (42). Außerdem war Frankreich der erste westeuropäische Staat, der bereits 1927.allerdings aus bevölkerungspolitischen Gründen - ein ius sanguinis a patre et a matre anerkannt (43) und dadurch (teilweise) Gleichberechtigung der Geschlechter im Staatsangehörigkeitsrecht realisiert hat. Die konsequente Gleichberech- 
tigung von Mann und Frau im Staatsangehörigkeitsrecht wurde 1973 verwirklicht (44), also - im Vergleich zu anderen westeuropäischen Staaten - recht früh. Italien und Spanien haben ihre Staatsangehörigkeitsregelungen seit dem 27. April 1983 (45), beziehungsweise dem 20. August 1982 (46) in Übereinstimmung mit dem Gleichberechtigungsgrundsatz gebracht. Die neue italienische Regelung der Staatsangehörigkeit verdient namentlich Interesse wegen der neu eingeführten Wahlpflicht für Doppelstaatler (47), während die spanische Regelung bemerkenswert ist, weil Spanien - u.a. gegenüber Bürgern lateinamerikanischer Staaten - eine abweichende Auffassung hinsichtlich mehrfacher Staatsangehörigkeit vertritt (48).

Das Staatsangehörigkeitsrecht der übrigen europäischen Staaten wird in dieser Monographie nicht erörtert. Hierfür sprach vor allem die Erwägung, daß diese Studie ansonsten zu ausgedehnt geworden wäre und damit zu viel Zeit beansprucht hätte. Außerdem hätte die Beschreibung des Staatsangehörigkeitsrechts Griechenlands und der Türkei wegen fehlender Sprachkenntnisse der neugriechischen und türkischen Sprache sich ausschlieBlich auf Sekundärquellen stützen müssen. Allerdings sei darauf hingewiesen, daß das Staatsangehörigkeitsrecht Griechenlands durch eine am 8. Mai 1984 in Kraft getretene Gesetzesänderung in Übereinstimmung mit der Gleichberechtigung von Mann und Frau gebracht und insoweitem beachtenswert ist (49). Im türkischen Staatsangehörigkeitsrecht ist ebenfalls die Gleichberechtigung der Geschlechter realisiert und zwar durch Änderungsgesetz vom 13. Februar 1981 (50). Mangelnde Sprachkenntnisse hätten eventuelle Beschreibungen der Staatsangehörigkeitsgesetzgebungen der skandinavischen Staaten und Portugals unter Verwendung der Originalmaterialien zwar nicht absolut unmöglich, jedoch mühselig gemacht. Dies hat letzlich dazu gefuihrt diese Regelungen ebenfalls außer Betracht zu lassen. Hinweisen möchte ich jedoch darauf, daß in den meisten skandinavischen Staaten das Staatsangehörigkeitsrecht bereits im Hinblick auf die Gleichberechtigung reformiert ist. Entsprechende Gesetzesänderungen traten in Dänemark am 1 . Januar 1979 (51), in Norwegen am 1. Juli 1979 (52), in Schweden ebenfalls am 1. Juli 1979 (53) und in Finnland am 1. September 1984 (54) in Kraft. Allein im Staatsangehörigkeitsgesetz Islands ist bis jetzt die Gleichberechtigung von Mann und Frau noch nicht realisiert (55). Portugal reformierte seine Staatsangehörigkeitsregelung 1981 durch Einführung eines neuen Staatsangehörigkeitsgesetzes unter Berïcksichtigung des Gleichberechtigungsgrundsatzes (56).

Eine eigenartige Position nahm bis vor kurzem Irland ein. Bereits seit 1956 galt in Irland neben ius soli ein ius sanguinis a patre et a matre (57). Die Gleichberechtigung war im irischen Staatsangehörigkeitsrecht aber nicht konsequent realisiert; alleine die ausländische Ehegattin eines gebürtigen Iren hatte ein Optionsrecht auf die irische Staatsangehörigkeit, der ausländische Mann einer irischen Frau konnte die Staatsangehörigkeit hingegen nicht durch Optionserklärung erwerben. Seit dem 1. Juli 1986 ist dieses Optionsrecht aufgehoben; das heutige irische Staatsangehörigkeitsrecht sieht sowohl für die ausländische Frau eines Iren als für den ausländischen Mann einer irischen Frau eine erleichterte Einbürgerung vor.

Der Gleichberechtigungsgrundsatz ist im Staatsangehörigkeitsrecht der meisten kleinen europäischen Staaten nicht realisiert. Zwar ist das Staatsangehörigkeitsgesetz Liechtensteins noch in den letzten Jahren reformiert worden (58), die 
Gleichberechtigung der Geschlechter hat sich in diesem neugefassten Gesetz aber noch nicht durchsetzen können. Als 'altmodisch' können weiter die Staatsangehöríigkeitsregelungen Monacos und San Marinos bezeichnet werden. In Monaco können eheliche Kinder ihre Staatsangehörigkeit nur vom Vater herleiten; bemerkenswert ist weiter, $\mathrm{daB}$ eine ausländische Frau noch immer durch Eheschließung mit einem Monegassen die monegassische Staatsangehörigkeit erwirbt (59). In San Marino gab es bis 1984 kein besonderes Gesetz, das den Erwerb und Verlust der Staatsangehörigkeit regelte; das Staatsangehörigkeitsrecht San Marinos bestimmte sich nach römischem Gewohnheitsrecht. Demnach wurde das Bürgerrecht iure sanguinis a patre erworben (60). Am 5. April 1984 traten aber ein Staatsangehörigkeitsgesetz und ein Gesetz betreffend außerordentliche Vorschriften über die Einbürgerung in Kraft (61). Grundsätzllich muB auch nun die Staatsangehörigkeit von einem sanmarinischen Vater abgeleitet werden. Nur Kinder eines unbekannten oder staatenlosen Vaters können die Staatsangehörigkeit von der Mutter herleiten. Das Kind unbekannter Eltern erwirbt die Staatsangehörigkeit iure soli. Seit 1984 verlieren sanmarinische Frauen durch Eheschließung mit einem Ausländer nicht mehr ihre bisherige Staatsangehörigkeit. Die ausländische Ehefrau eines sanmarinischen Bürgers kann jedoch durch Verzicht auf ihre bisherige Staatsangehörigkeit die ihres Mannes erwerben.

In Andorra wurde am 1. April 1977 ein neues Staatsangehörigkeitsgesetz eingeführt (62). Danach wird die Staatsangehörigkeit durch Abstammung a patre et a matre erworben. Bei Geburt im Ausland erhält man die Staatsangehörigkeit allerdings nur, wenn wenigstens ein Elternteil selbst in Andorra geboren ist. Die andorianische Staatsangehörigkeit wird auch yon einem in Andorra geborenen Kind eines selbst in Andorra geborenen Ausländers oder einer in Andorra geborenen Ausländerin erworben. Diese Ausgangspunkte des Staatsangehörigkeitsrechts Andorras entsprechen deshalb denen des französischen Rechts. Das Staatsangehörigkeitsrecht Luxemburgs wurde 1986 eingehend geändert (63). Ab dem 1. Januar $1987 \mathrm{kann}$ die luxemburgische Staatsangehörigkeit iure sanguinis sowohl vom Vater als von der Mutter hergeleitet werden. Es ist dabei unbeachtlich, ob das Kind im Inland oder im Ausland geboren wurde. Das Staatsangehörigkeitsrecht der kleinen europäischen Staaten ist - wie aus dem vorherigen gefolgert werden kann - im allgemeinen etwas veraltet, wobei Andorra und Luxemburg Ausnahmen bilden. Für alle diese Staaten gilt aber, daß in den jeweiligen Gesetzgebungen keine überraschenden Lösungen zu finden sind. Diese Tatsachen, sowie die, international gesehen, wegen der kleinen Bevölkerungszahl relativ geringe statistische Bedeutung jener Staatsangehörigkeitsregelungen, unterstützte den Beschluß, sie außer Betracht zu lassen.

\subsubsection{Aufbau der Länderberichte}

Zweck der Länderberichte ist Materialien zu präsentieren, worauf sich die im dritten Kapitel dieser Arbeit gegebenen rechtsvergleichenden Betrachtungen über die Erwerbs- und Verlustgründe der Staatsangehörigkeit stützen können. An sich wäre es dazu nützlich das ganze materielle Staatsangehörigkeitsrecht der ausgewählten Staaten (also alle Regelungen der Erwerbs- und Verlustgründe der Staatsangehörigkeit) eingehend zu behandeln. Ein solches Vorhaben wäre aber im Rahmen einer Monographie kaum zu bewältigen. Außer Betracht bleiben deshalb grundsätzlich alle Erwerbs- und Verlustgründe einer Staatsangehörigkeit, 
die in (billateralen) völkerrechtlichen Verträgen vorgesehen oder aus speziellem Anlaß in befristeten Sonderregelungen formuliert sind. Das gleiche gilt für sämtliche Übergangsregelungen (64). Die Länderberichte konzentrieren sich daher auf die allgemeinen Erwerbs- und Verlustgründe der Staatsangehörigkeit. Zuerst wird die allgemeine historische Entwicklung des Staatsangehörigkeitsrechts des jeweiligen Staates beschrieben. Die Beschreibung der historischen Entwicklung des Staatsangehörigkeitsrechts ist in erster Linie bedeutsam, da viele der heutzutage geltenden Regelungen nur in historischer Perspektive verstanden werden können. Man kann den Worten von Bevan (65) nur zustimmen:

"Most legal books include an historical introduction to set the scene and for some it is a necessarily pedestrian and questionably relevant burden. For this work, it is essential because in studying the current law and practice ... it is remarkable how many of the issues have been encountered before and dealt with in the same way as today".

Weiter soll aber im Auge behalten werden, daß gerade im Staatsangehörigkeitsrecht bereits außer Kraft getretene Regelungen auch aktuellen Wert behalten, weil für die Beantwortung der Frage, ob jemand eine bestimmte Staatsangehörigkeit hat, häufig auf ältere Regelungen der betreffenden Staatsangehörigkeit zurüickgegriffen werden muB. Die historischen Betrachtungen sind insoweit auch relevant für diejenigen, die diese Arbeit für die Lösung konkreter, staatsangehörigkeitsrechtlichen Fragen benützen möchten. Von diesem Leserkreis darf dann aber das Studium der Sonder- und Übergangsvorschriften nicht unterlassen werden. Die Konsultierung dieses Werkes darf für sie lediglich eine erste Orientierung sein.

Nach den allgemeinen historischen Bemerkungen werden die einzelnen Erwerbsund Verlustgründe in drei unterschiedlichen Paragraphen beschrieben. Zuerst wird die Regelung des Erwerbs der Staatsangehörigkeit durch Geburt besprochen. In diesem Paragraphen wird gegebenenfalls auch der Erwerb der Staatsangehörigkeit von nichtehelichen Kindern durch Feststellung der Abstammung, Anerkennung und Legitimierung erörtert, auch wenn es sich hierbei stricto sensu nicht um einen Erwerb im Moment der Geburt handelt. Das gleiche gilt fïr den Erwerb aufgrund einer Adoption. Die Beschreibung der positivrechtlichen Regelung der Staatsangehörigkeit durch Geburt wird jeweils eingeleitet mit einem UTberblick dieser Erwerbsgründe in früheren Staatsangehörigkeitsregelungen des betreffenden Staates. Zwar kann dadurch häufig eine gewisse Wiederholung der bereits in der allgemeinen historischen Einfuihrung schon enthaltenen Daten nicht vermieden werden, dieses Vorgehen vereinfacht aber dem Leser die Wertung der geltenden Lösungen in historischer Perspektive erheblich.

Ein weiterer Abschnitt der Länderberichte ist dem Erwerb der Staatsangehörigkeit nach der Geburt durch automatische Vorgänge, Optionserklärung oder Einbuirgerung gewidmet. Auch dieser Paragraph wird wieder mit einem Uberblick dieser Erwerbsgründe in früheren Regelungen eingeleitet. In diesem Paragraphen wird der staatsangehörigkeitsrechtlichen Position des ausländischen Ehegattens eines Bürgers besondere Aufmerksamkeit gewidmet. Die Erörterungen konzentrieren sich auf den selbständigen Erwerb einer Staatsangehörigkeit. 
Die Regelung der Erstreckung eines Staatsangehörigkeitserwerbs auf Familienmitglieder wird nur in den Hauptzïgen erwähnt.

Im letzten Paragraphen der Länderberichte werden - wieder nach einem historischen Überblick - die positivrechtlichen Verlustgründe der jeweiligen Staatsangehörigkeit erörtert. Die Beschreibung konzentriert sich grundsätzlich auf den selbstândigen Verlust einer Staatsangehörigkeit. Die Erstreckung des Verlustes auf Familienmitglieder wird nur gestreift.

\subsection{Begriff und Funktion der Staatsangehörigkeit}

Im Rahmen dieses Buches dürfen einige allgemeine Betrachtungen über Begriff und Funktion der Staatsangehörigkeit nicht fehlen, da die Auffassungen, die jemand explizit oder implizit über die Staatsangehörigkeit hat, eventuelle Änderungsvorschläge direkt oder indirekt beeinflussen können. Zweck dieses Kapitels soll nicht die Entwicklung einer ausfuhrlichen Theorie über die Staatsangehörigkeit sein. Ziel dieser Betrachtungen ist vielmehr ausschließlich, meine theoretischen Ausgangspunkte zu verdeutlichen (66).

\subsubsection{Der Begriff der Staatsangehörigkeit}

Der Begriff der Staatsangehörigkeit ist nicht eindeutig. Dies wird deutlich von Makarov hervorgehoben, der in seinem Buch "Allgemeine Lehren des Staatsangehörigkeitsrechts"' an erster Stelle die Staatsangehörigkeit im allgemeinen und funktionellen Sinne unterscheidet (67). Von einer funktionellen Staatsangehörigkeit ist die Rede, wenn ein Gesetz oder ein Staatsvertrag für die Abgrenzung der personalen Wirkung gewisser Regelungen bestimmt, daß als Bürger im Sinne dieses Gesetzes oder Vertrages "derjenige, der ...." betrachtet werden muß (68). Es wäre aber sehr ineffizient, wenn jedes Gesètz bei der Beschränkung seiner personalen Wirkung solche Bestimmungen beinhalten miißte (69). Im allgemeinen wird deshalb derjenige als Bürger eines Staates betrachtet, der nach den Bestimmungen des Staatsangehörigkeitsrechtes dieses Staates dessen Statatsangehörigkeit besitzt. Die nach den Regelln einer solchen Staatsangehörigkeitsgesetzgebung erworbene Staatsangehörigkeit wird von Makarov die allgemeine Staatsangehörigkeit genannt (70). Wo in diesem Buch über Staatsangehörigkeit gesprochen wird, ist immer diese allgemeine Staatsangehörigkeit gemeint. Als eine Art von Zwischenform zwischen der allgemeinen und funktionellen Staatsangehörigkeit erwähnt Makarov die "sachlich beschränkte" Staatsangehörigkeit (71). Als Beispiel hierzu kann die niederländische Staatsangehörigkeitsregelung im 19. Jahrhundert genannt werden (72). Die Art. 5 - 12 des Burgerlijk Wetboek (in der Fassung von 1838) regelten ab 1850 ausschlieBlich die niederländische Staatsangehörigkeit für zivilrechtliche Angelegenheiten, während für öffentlichrechtliche Fragen ein Gesetz vom 28. Juli 1850 (Stbl. 44) maßgebend war (73).

Neben den Begriffen der allgemeinen, funktionellen und sachlich-beschränkten Staatsangehörigkeit begegnet man in der Literatur dem Begriff der "soziologischen" Staatsangehörigkeit (74). Dieser. Begriff wird verwandt, wenn jemand abstrahiert von juristischen Regehn, soziologisch betrachtet, zum Personensub- 
strat eines Staates gerechnet werden soll (75). In der niederländischen Literatur wird in einem Falle auch der Begriff der "moralischen" Staatsangehörigkeit benutzt (76). Von moralischer Staatsangehörigkeit ist die Rede, wenn eine Person sich selbst als zum Volk eines bestimmten Staates rechnet, beziehungsweise sich selber als Bürger eines bestimmten Staates benimmt. Was das Verhältnis zwischen der allgemeinen (juristischen), soziologischen und moralischen Staatsangehörigkeit betrifft, könnte man vertreten, daß die Regeln der Staatsangehörigkeitgesetzgebung eines Staates idealiter dergestalt sein sollten, daß derjenige der soziologisch und moralisch zu diesem Staate gehört auch die allgemeine, juristische Staatsangehörigkeit dieses Staates besitzt (77). Aus dieser These kann man aber selbstverständlich keine konkreten Richtlinien für die Zuteilungskriterien einer Staatsangehörigkeit folgern, da die Begriffe der soziologischen und moralischen Staatsangehörigkeit vage und deren Grenzen undeutlich sind (78). Die soziologischen und moralischen Staatsangehörigkeitsbegriffe beeinflussen aber in Einzelpunkten die allgemeine, juristische Staatsangehörigkeit (79). Dies ist z.B. häufig bei Regelungen der Einbürgerung der Fall. Als Voraussetzung für eine Einbürgerung wird in den Staatsangehörigkeitsregelungen vieler Staaten die m.E. soziologische Forderung gestellt, daß derjenige, der die Einbürgerung beantragt, in die Gemeinschaft des betreffenden Volkes aufgenommen (integriert) sein $\mathrm{muB}$ (80). Eine Beeinflussung der allgemeinen Staatsangehörigkeit durch den soziologischen Begriff kann man auch in Diskussionen über eventuelle Änderungen von Staatsangehörigkeitsregelungen erkennen, wenn betont wird, daß bestimmten Gruppen die Staatsangehörigkeit zugeteilt werden soll, weil sie eine reelle Beziehung zu dem betreffenden Staat hätten, dagegen einer bestimmten anderen Gruppe die Staatsangehörigkeit nicht gegeben werden soll, weil solche Beziehungen gerade fehlen würden. Eine "moralische" Forderung im Rahmen der Einbürgerungsvoraussetzungen ist ebenfalls zu finden, z.B. wo für die Einbürgerung ein "volonté d'intégration" gefordert wird (81).

In der Literatur begegnet man noch mehr spezifischen Staatsangehörigkeitsbegriffen. Zul erwähnen ist der Begriff der effektiven Staatsangehörigkeit, der angibt mit welchem Heimatstaat ein Mehrstaatler die engste Beziehung hat (82). Anläßlich der nach dem Ersten Weltkrieg benutzten juristischen Konstruktion, wonach französische Einwohner des von Deutschland 1871 annektierten Elsaß-Lothringen immer französische Staatsangehörige geblieben waren, wurde der Begriff der virtuellen Staatsangehörigkeit introduziert (83).

Im Gegensatz zum deutschen Begriff der Staatsangehörigkeit, der immer auf die Zugehörigkeit zu einem Staat hindeutet, wird der, ursprïnglich aus dem französischen und englischen stammende, Begriff "Nationalität" als solcher in einer Doppelbedeutung benutzt (84). Zum einen wird Nationalität als Synonym von Staatsangehörigkeit benutzt. Nationalität bezeichnet dann wie die Staatsangehörigkeit die allgemeine Zugehörigkeit zu einem Staat, einen Status, dessen Erwerb und Verlust durch Rechtsnormen dieses Staates bestimmt werden (85). Nationallität wird aber häufig auch im ethnischen Sinne verstanden. Unter der Nationalität ist dann die Zugehörigkeit zu einem Volk im ethnischen Sinne zu verstehen (86). Häufig deutet Nationalität in dieser Bedeutung die Zugehörigkeit zu einem Volk an, das als Minderheit in einem oder in mehreren Staaten lebt (87). Manchmal wird dieser Begriff aber auch benutzt, um die ethnische Verbundenheit der Staatsangehörigen mehrerer Staaten zu betonen (88). Eng 
verwandt mit dem Begriff der ethnischen Nationalität ist der in Art. 116 Abs. 1 des deutschen Grundgesetzes benutzte Terminus Volkszugehörigkeit. Deutscher Volkszugehöriger ist in diesem Sinne an sich derjenige, der soziologisch betrachtet zum deutschen Volk im ethnischen Sinne gehört (89). Der Begriff des deutschen Volkszugehörigen hat sich aber allmählich zu einem Rechtsbegriff entwickelt, nachdem er in $\$ 6$ des Bundesvertriebenengesetzes in der Fassung vom 14. August 1957 (90) definiert wurde (91) und diese Definition später auch bei der Anwendung des Art. 116 Abs. I GG angewandt wurde (92).

In der Literatur wird ausführlich darüber diskutiert, ob die Staatsangehörigkeit ein Rechtsverhältnis zwischen Staat und Individuum oder einen Status darstellt, den eine Person besitzt und worauf sie ein Recht hat. In der älteren staatsangehörigkeitsrechtlichen französischsprachigen Literatur wird vor allem betont, daß die Staatsangehörigkeit ein Rechtsverhältnis (lien juridique) ist (93) (94), während in der deutschsprachigen und französischsprachigen zivilrechtlichen Literatur der Nachdruck auf die Statusfunktion der Staatsangehörigkeit gelegt wird (95). Durchgesetzt hat sich wohl die vermittelnde Theorie Makarovs (96), die die Staatsangehörigkeit beschreibt als

"ein Rechtsverhältnis zwischen dem Staat und seinen Angehörigen...., bei dessen Regelung die Eigenschaft der Person als Subjekt dieses Rechtsverhältnisses einen rechtlichen Status dieser Person bildet" (97).

Makarov begründet diese Definition wie folgt (98):

"Wenn man unter Rechtsverhältnis ein rechtlich erfaßtes Lebensverhältnis versteht, so wird man zugeben müssen, $\mathrm{daB}$ die Zugehörigkeit zu einer Gebietskörperschaft ein rechtlich geregeltes Lebensverhältnis darstellt. Bezeichnenderweise nehmen auch die Vertreter der Statustheorie in ihre Definition Hinweise auf das mit dem Status im allgemeinen oder speziell mit der Staatsangehörigkeit verknüpfte Verhältnis auf. Anderseits darf nicht bezweifelt werden, daß das Hauptgewicht der rechtlichen Erfassung der Staatsmitgliedschaft als eines Rechtsverhältnisses doch in der Festsetzung der rechtlichen Voraussetzungen des Erwerbes oder des Verlustes der Eigenschaft eines dem Staate gegenüberstehenden Subjektes dieses Rechtsverhältnisses liegt und daß diese Eigenschaft einen rechtlichen Status darstellt, der einen ganzen Komplex von Rechtsfolgen nach sich zieht. Das positive Staatsangehörigkeitsrecht regelt, wie oben bereits dargelegt, eben diese Voraussetzungen. Es ist wiederum kein Zufall, wenn Emst Isay, also ein Vertreter der Rechtsverhältnistheorie, den engen Zusammenhang der Begriffsbestimmung der Staatsangehörigkeit mit den Definitionen eines rechtlichen Status hervorhebt. Es scheint mir daher angebracht zu sein, bei der Definition der juristischen Natur der Staatsangehörigkeit diese beiden Elemente zu berücksichtigen und sie beide in diese Definition miteinzuschließen".

Ich teile mit vielen anderen (99) diese Auffassung Makarovs und betrachte die Staatsangehörigkeit primär als Status, aber dieser Status indiziert zu gleicher Zeit eine rechtliche Beziehung zwischen Staat und Person. Eine gewisse Parallele besteht hinsichtlich dem Familiennamen: Der Familienname einer Person zeigt, daß jemand zu einer bestimmten Familie gehört, aber zu gleicher 
Zeit hat der Betreffende ein höchst persönliches Recht auf diesen Namen, der einen Teil seines Personalstatutes bildet (100).

\subsubsection{Die Funktion der Staatsangehörigkeit}

Was ist nun die Funktion der Staatsangehörigkeit? Diese Frage ist nicht dadurch erschöpfend beantwortet, daß man darauf hinweist, daß durch die Staatsangehörigkeit das zu einem Staate gehörende Staatsvolk bestimmt wird (101). Zwar ist die Existenz eines Staatsvolkes wesentlich für die Existenz eines Staates (102), aber ein solches Staatsvolk braucht nicht unbedingt anhand eines Staatsangehörigkeitsbegriffes im modemen Sinne (103) definiert zu werden (104).

Die Frage nach der Funktion soll prinzipiell beantwortet werden anhand der juristisch-technischen Bedeutung der Staatsangehörigkeit, $d . h$. in der Perspektive der Rechtsfolgen der Staatsangehörigkeit. Juristisch-technisch betrachtet ist die Staatsangehörigkeit ein Koppelungsbegriff, durch den Rechte und Pflichten an Personen gekoppelt werden. Die Staatsangehörigkeit ist damit ein Bereitschaftsstatus (105), an den Rechtsordnungen Rechtsfolgen knüpfen können. Diese Meinung wird auch von Makarov (106) vertreten:

"Wellche Rechte und welche Pflichten den Staatsangehörigkeitsstatus zur Voraussetzung haben, ist für den Begriff der Staatsangehörigkeit irrelevant. Auf Grund rechtsvergleichender Betrachtungen kann festgestellt werden, daß gewisse Rechte und gewisse Pflichten in den einzelnen Rechtsordnungen die inländische Staatsangehörigkeit voraussetzen, wie z.B. das Wahlrecht und die Wehrpflicht. Es wäre aber verfehlt, eines dieser Rechte oder eine dieser Pflichten als zum Wesen der Staatsangehörigkeit gehörend zu betrachten und sie in den Begriff der Staatsangehörigkeit miteinzuschließen. Jedes neue Gesetz, das in einem Staate erscheint, kann eine Änderung des Inhalts der an die Staatsangehörigkeit angeknüpften Rechte und Pflichten mitsichbringen".

Die gleiche Ansicht vertritt Ko Swan Sik, wenn er schreibt:

"Es gibt kein Recht und keine Pflicht, die für das Individuum begriffsmäßig Folge der Staatsangehörigkeit sind; Rechte und Pflichten bestehen nicht wegen der Staatsangehörigkeit, sondern entstehen aus einer anderen Rechtsquelle, die die Staatsangehörigkeit als Anknüpfungspunkt benutzt für die Bestimmung des personalen Geltungsbereiches jener Rechte und Pflichten. Diese Bestimmung des personalen Geltungsbereiches kann sowohl nationalrechtliche als völkerrechtliche Regeln betreffen" (107).

Die Staatsangehörigkeit ist eine an und für sich leere Hülle, die dadurch aufgefuillt wird, daß der Staat, überstaatliche Institutionen oder sogar die Völkerrechtsgemeinschaft die Staatsangehörigkeit als Anknüpfungspunkt für die Zuteilung von Rechten und Pflichten brauchen. Viele andere Autoren teilen diese Ansicht (108). So schreibt z.B. Wiederkehr (109), daß an die Staatsangehörigkeit nicht unmittelbar Rechte angeknüpft werden: 
"Der Staat ist weder zu einem Leisten noch zu einem Dulden verpflichtet. Die Staatsangehörigkeit als Status ist erst Voraussetzung und Ursache gegenseitiger Rechte und Pflichten zwischen Bürger und Staat. Grundsätzlich ist jeder Staat frei, darüber zu bestimmen, welchen Inhalt seine Staatsangehörigkeit hat. Erst durch diese Regelung entstehen für den betreffenden Bürger Rechte und Pflichten".

Wiederkehr folgert aus dieser Tatsache allerdings, daß die Staatsangehörigkeit einen Status darstellt und kein Rechtsverhältnis manifestiert. Soweit möchte ich nicht gehen, da der Status der Staatsangehörigkeit eindeutig als Beziehung zwischen Staat und Individuum formuliert wird. Aber mit Wiederkehr möchte ich betonen, daß aus der Tatsache, daß die Staatsangehörigkeit u.a. als Rechtsverhälnis typiert wird, nicht gefolgert werden darf, daß die Staatsangehörigkeit an sich schon Rechtsfolgen hat.

Manche Autoren unterscheiden in diesem Zusammenhang aber die Staatsangehörigkeit im innerstaatlichen Recht von der Staatsangehörigkeit im internationalen Recht (110). Daß die Staatsangehörigkeit im innerstaatlichen Recht ein leerer Koppelungsbegriff, ein Bereitschaftsstatus darstelit, wird außer in der älteren (111) oder osteuropäischen (112) Literatur, die die psychologische Dimension der Staatsangehörigkeit stark betonen, meistens anerkannt. Dieser Bereitsschaftsstatus wird durch die jeweiligen nationalen Rechtsordnungen autonom ausgefuillt (113). Die Autonomie beim Ausfüllen dieses Status hat sogar dazu geführt, daß behauptet wurde, es gäbe keinen einheitlichen innerstaatlichen Staatsangehörigkeitsbegriff, sondern jede innerstaatliche Rechtsordnung habe ihren eigenen Staatsangehörigkeitsbegriff; einen einheitlichen Staatsangehörigkeitbegriff gebe es nur im Völkerrecht (114).

Von der innerstaatlichen Staatsangehörigkeit haben einige Autoren den intemationalen Begriff der Staatsangehörigkeit so stark unterschieden, daß die Ansicht vertreten wurde, es handele sich um zwei unterschiedliche Staatsangehörigkeiten (115). Bestimmte völkerrechtliche Folgen (wie das Recht diplomatischen Schutz. zu verleihen) wären begriffsmäßig mit diesem internationalen Staatsangehörigkeitsbegriff verbunden (116). Die Dualität der innerstaatlichen und völkerrechtlichen Staatsangehörigkeit muß jedoch verneint werden (117). Wie das innerstaatliche Recht knüpft auch das Völkerrecht Rechtsfolgen an die Staatsangehörigkeit an. Dabei benützt das Völkerrecht eindeutig die von dem Nationalstaat autonom verliehene, innerstaatliche Staatsangehörigkeit als Anknüpfungspunkt. Die Tatsache, daß das Völkerrecht für die Anknüpfung der völkerrechtlichen Folgen fordert, daB diese vom innerstaatlichen Recht verliehene Staatsangehörigkeit einen "genuine link" representiert (118), fuihrt nicht zu einer selbständigen völkerrechtlichen Staatsangehörigkeit. Aus dieser Tatsache kann lediglich gefolgert werden, daß das Völkerrecht die innerstaatliche Staatsangehörigkeit nur unter Vorbehalt als Anknüpfungspunkt akzeptiert (119).

Eine andere Frage ist jedoch, ob die Staatsangehörigkeit im Völkerrecht auch wie im innerstaatlichen Recht - einen Bereitschaftsstatus darstellt, oder ob in Völkerrecht begriffsmäßig Rechtsfolgen an die Staatsangehörigkeit verbunden sind (120). Auch die völkerrechtliche Rechtsfolgen der Staatsangehörigkeit sind aber nicht begriffsmäßig mit dem Staatsangehörigkeitsbegriff im modernen Sinne verbunden (121). Zwar sind diese Folgen nach positivem Völkerrecht 
Konsequenzen der Staatsangehörigkeit, dies ist aber nur der Fall, weil das Völkerrecht diese an die innerstaatliche Staatsangehörigkeit koppelt; das Völkerrecht hätte auch einen anderen Zugehörigkeitsbegriff - zu denken wäre etwa an den Wohnsitz oder Geburtsort einer Person - entwickeln können oder könnte dies theoretisch in der Zukunft tun, um diesen für die betreffenden Rechtsfolgen als Anknüpfungspunkt $\mathrm{zu}$ benutzen (122). Allerdings kann nicht verneint werden, daß durch die Formulierung der Staatsangehörigkeit im Völkerrecht als Menschenrecht, die Verbundenheit der Staatsangehörigkeit mit den Folgen, die das positive Völkerrecht an die Staatsangehörigkeit koppelt eine sehr enge geworden ist (123). Von einer logisch zwingenden Beziehung der Staatsangehörigkeit und den nach positivem Völkerrecht bestehenden Folgen kann aber dennoch keine Rede sein.

Unter dem Gesichtspunkt der vorherigen Ausführungen ist es unlogisch daB die Staatsangehörigkeit in der Allgemeinen Erklärung der Menschenrechte vom 10. Dezember 1948 im Menschentechtskatalog aufgenommen ist (124). Das "Recht" auf eine Staatsangehörigkeit liegt anf einer völlig anderen Ebene als die übrigen Menschenrechte, die in der Allgemeinen Erklärung formuliert werden (125). Die übrigen Menschenrechte beriihren direkt die persönliche Existenz eines Individuums. Sie geben existentielle Garantien (das Recht auf das Leben selbst, auf Freiheit) oder untersagen Handlungen, die die Integrität oder freie Entfaltung von Personen verletzen würden (Sklaverei, Folter, willkürliche Festnahme). Das Recht auf eine Staatsangehörigkeit ist jedoch weniger essentiell. Eigentlich garantiert dieses Recht nichts, da mit der Staatsangehörigkeit weder im nationalen noch im internationalen Recht begrifflich Rechte oder Pflichten verknüpft sind. Wenn wir nun feststellen können, daß die Allgemeine Erklärung der Menschenrechte den Besitz einer Staatsangehörigkeit garantiert, müssen wir deshalb folgern, daß dies die Garantie eines Überraschungspakets ist! Art. 15 der Allgemeinen Erklärung garantiert die Rechtsfolgen, die nationale und internationale Rechtssysteme an eine (bestimmte) Staatsangehörigkeit koppeln. Der Inhalt des Überraschungspaketes kann von diesen Rechtssystemen im Prinzip selbständig bestimmt und geändert werden. Diese Tatsache bewirkt, daß das Recht auf eine Staatsangehörigkeit ein dubioses Menschenrecht bleibt. Eigentlich sollte Art. 15 der Allgemeinen Erklärung wohl garantieren, daß jede Person überall von einem gewissen Staat diplomatisch geschützt werden muß und wenigstens in irgendeinem Staat leben kann, ohne daß Ausweisung theoretisch möglich ist. Diese Rechte hätten aber auch selbständig - ohne Benutzung der Staatsangehörigkeit als Anknüpfungspunkt - garantiert werden kỏnnen. So hätte z.B. der diplomatische Schutz dem Wohnsitz-oder Geburtsstaat überlassen werden können und hätte das Recht garantiert werden können, daß jederman zumindest zu jeder Zeit in seinen Geburtsstaat zurüickkehren und sich dort niederlassen darf. Hiergegen könnte möglicherweise der Einwand erhoben werden, daß die betrefferiden Staaten vielleicht keinen diplomatischen Schutz gewähren werden oder den betroffenen Personen möglicherweise die Einreise und Niederlassung untersagen werden. Diese Einwände sind jedoch nicht überzeugend, da wir leider auch regelmäßig feststellen können, daß Staaten unterlassen bestimmten Staatsangehörigen diplomatischen Schutz zu geben oder die Niederlassung verweigem. Noch häufiger kann beobachtet werden, daß Staatsangehörige aus Sicherheitsgründen "ihren" Heimatstaat nicht um diplomatischen Schutz bitten und sich aus diesen Grinden gerade nicht in diesem Staat (mehr) aufhalten möchten. Die Tatsache, daß die Staatsangehörigkeit hier als 
leerer Koppelungsbegriff oder als Bereitschaftstatus beschrieben wurde, nimmt aber die "psychologische Dimension" (125) der Staatsangehörigkeit nicht weg. Auf diese Dimension wird auch von Ko Swan Sik hingewiesen, wenn er den chinesischen Delegierten auf der Kodifikationskonferenz von 1930 zitiert:

"Nationality is not merely a matter of law, it is not a matter of accident, it is not a matter of technicality, it is a matter of the heart" (126).

Diese psychologische Dimension hat zwei unterschiedliche Aspekte: eine psychologische Dimension aus der Perspektive des Staates sowie aus der des Bürgers. Vor allem in der älteren europäischen Literatur wird betont, daß die Staatsangehörigkeit ein besonderes Treueverhältnis darstellt. In diesem Zusammenhang lassen sich als Beispiel die Worte von André Weiss (127) zitieren, der schreibt:

"La nationalité ..... réclame du citoyen tout son activité, tout son dévouement; elle absorbe sa personalité tout entière".

Weiss åußert dies in Zusammenhang mit der mehrfachen Staatsangehörigkeit und unterstreicht seine Ansicht mit dem Ausspruch:

"On ne peut avoir deux patries, comme on ne peut avoir deux mères". Die psychologische, fast mystische Dimension der Staatsangehörigkeit manifestiert sich auch, wenn ein Staat betont, es sei fiir ein Individuum eine Ehre, die Staatsangehörigkeit des betreffenden Staates zu besitzen (128). Der Staatsangehörigkeit wird auf diese Art und Weise eine Aureole gegeben. Die Einbürgerung wird durch solche Äußerungen fast zu einer Art von Sakrament, während auf schlechtes Benehmen als Strafe die Exkommunikation in Gestalt der Zwangsausbürgerung droht. In der modernen westeuropäischen Literatur wird diese extreme Auffassung grundsätzlich abgelehnt; dies entspricht auch der Ansicht, daß die Staatsangehörigkeit ein grundsätzlich leerer Koppelungsbegriff ist. In der osteuropäischen Literatur findet man dagegen wohl Ansätze, die diese von dem Staat betonte psychologische Dimension der Staatsangehörigkeit manifestieren (129). Diese psychologische Dimension der Staatsangehörigkeit wird ebenfalls unterstrichen, wenn außereuropäische Staaten ihre Staatsangehörigkeit als Symbol der bewahrten oder neuerworbenen Unabhängigkeit bezeichnen (130).

Es kann aber andererseits nicht verneint werden, daß Staatsangehörige manchmal eine besondere Verbundenheit empfinden mit dem Staate dessen Staatsangehörigkeit sie besitzen, auch wenn sie - manchmal sogar gerade wenn sie - im Ausland leben (131). Es wäre irrealistisch diese Dimension der Staatsangehörigkeit gänzlich zu verneinen. Zwar mag man diese Dimension für die eigene Person ablehnen, für sehr viele Personen ist sie jedoch schlicht und einfach eine Realităt, der Staatsangehörigkeitsregelungen Rechnung tragen sollten. Zum Ausdruck kommt diese psychologische Dimension u.a. wenn Ausländer keinen Einbürgungsantrag im Wohnsitzsstaat stellen, da eine Einbürgerung Verlust der bisherigen Staatsangehörigkeit zur Folge haben würde (132). 
Resumierend soll deshalb folgendes festgehalten werden. Die Begriffe "Staatsangehörigkeit" oder "Nationalität" werden in vielfacher Bedeutung benutzt. In dieser Arbeit werden diese Begriffe aber immer im Sinne der "allgemeinen Staatsangehörigkeit" gebraucht. Die Staatsangehörigkeit wird primär als Status betrachtet. Dieser Status indiziert aber zur gleichen Zeit eine rechtliche Beziehung zwischen dem betreffenden Staat und dem Individuum. Die Staatsangehörigkeit ist sowohl im intemen Recht als im internationalen Recht grundsätzlich ein leerer Koppelungsbegriff: sie hat weder im nationalen noch im internationalen Recht begriffsmäßige Folgen. Unterschiedliche nationale und internationale Staatsangehörigkeitsbegriffe gibt es nicht, vielmehr ist der Begriff der Staatsangehörigkeit einheitlich. Die Staatsangehörigkeit hat eine psychologische Dimension. Diese Dimension sollte $m . E$. von Staaten nicht überbetont werden (132a), es wäre jedoch irrealistisch und der einzelnen Person gegenüber ungerecht, diese Dimension ganz zu negieren.

\subsection{Schranken der nationalen Staatsangehörigkeitsgesetzgebung}

\subsubsection{Allgemeine Bemerkungen}

Jeder Staat kann grundsätzlich selbständig bestimmen, welchen Personen er seine Staatsangehörigkeit verleiht (133). Dieser Satz, Ausfluß der territorialen Souveränität jedes Staates, wird vor allem in der älteren Literatur betont (134). Anlaß für diese Äußerungen in der Lehre war eine Entscheidung aus dem Jahr 1923 des Ständigen Internationalen Gerichtshofs in Den Haag (135). Im Streit standen zwei französische Dekrete vom 8. November 1921, die die französische Staatsangehörigkeit in Marokko, beziehungsweise Tunesien betrafen. Behauptet wurde, daß diese Dekrete, kraft denen britischen Staatsangehörigen die französische, beziehungsweise marokkanische oder tunesische Staatsangehörigkeit verliehen wurde, völkerrechtswidrig wären (136). In seiner Entscheidung über die Völkerrechtsmäßigkeit dieser Dekrete wurde vom Ståndigen Internationalen Gerichtshof die primzipielle Autonomie von Staaten bei der Regelung der Staatsangehörigkeit ausdrücklich anerkannt. Der Gerichtshof stellte allerdings fest:

"La question de savoir si une certaine matière rentre ou ne rentre pas dans le domaine exclusif d'un Etat est une question essentiellement relative: elle dépend du developpement des rapports internationaux. C'est ainsi que, dans l'état actuel du droit international, les questions de nationalité sont, en pruncipe, de l'avis de la Cour, comprises dans ce domaine réservé".

Diese Entscheidung fand ihren Niederschlag in Art. 1 Satz 1 der Haager "Konvention über gewisse Fragen beim Konflikt von Staatsangehörigkeitsgesetzen" vom 12. April $1930(137)$, worin die grundsätzliche Autonomie ebenfalls anerkannt wurde:

"Dem einzelnen Staate steht es zu, durch seine Gesetzgebung zu bestimmen, wer seine Staatsangehörigkeit besitzt" (138).

Obwohl dieses Haager Abkommen nur für ganz wenige Staaten in Kraft getreten ist, wird allgemein anerkannt, daß der eben zitierte Satz als Regel des 
Völkergewohnheitsrecht gilt (139). Dennoch muß die Frage aufgeworfen werden, ob diese grundsätzliche Autonomie durch das Völkerrecht eingeschränkt werden kann.

Eindeutig zu bejahen ist diese Frage, soweit eine Beschränkang der nationalen Autonomie aufgrund völkervertragsrechtlicher Verpflichtungen vorliegt. Gerade wegen seiner Souveränität ist jeder Staat dazu berechtigt völkervertragsrechtliche Verpflichtungen einzugehen, wodurch seine Autonomie beschränkt werden kann (140). Völlig unbeachtlich ist, ob es sich dabei um die Staatsangehörigkeit oder ein anderes, normalerweise ausschließlich der nationalen Gesetzgebungskompetenz unterliegendes, Rechtsgebiet handelt. Diese gerade zu banale Feststellung relativiert bereits das Argument der Omnipotenz der Staaten auf dem Gebiet des Staatsangehörigkeitsrechts. Wenn wir den heutigen Stand des Staatsangehörigkeitsrechts betrachten, können wir feststellen, daß die nationale Autonomie der Staaten vielfach auch tatsächlich durch internationale Abkommen eingeschränkt wird (141). Bei diesen internationalen Verträgen können wir zwei Hauptkategorien unterscheiden (142):

a) Abkommen bezüglich der Staatsangehörigkeit anläßlich Änderungen des Territoriums eines Staates (143) und

b) allgemeine Abkommen bezüglich der Staatsangehörigkeit.

Die letztgenannten allgemeinen internationalen Verträge auf dem Gebiet des Staatsangehörigkeitsrechts und die darin niedergelegten vertraglichen Einschränkungen sollen im folgenden unter Paragraph 1.4.3 näher beleuchtet werden.

Bei den Abkommen bezüglich Staatsgebietsänderungen kann man wiederum mindestens drei Untergruppen aufzeigen:

Zum einen gibt es bilaterale, manchmal aber auch multilaterale Abkommen, anläßlich tatsächlicher Staatsgebietsverschiebungen, worin ein Teil des Territoriums des einen Staates einem anderen Staat zugeteilt wurde (144). Beispiele formen die von Deutschland mit mehreren Staaten geschlossenen Optionsabkommen beziiglich der Gebiete, die nach dem Ersten Weltkrieg im Versailler Vertrag abgetreten wurden (z.B. die deutsch-belgische Optionsabkommen vom 31. August und 11. September 1922 bezüglich der Einwohner von Eupen und Malmedy, Preußisch- und Neutral Moresnet) (145). Eine zweite Untergruppe formen die Abkommen anläßlich Unabhängigkeitserklärungen eines Teiles des Staatsgebietes. Als Beispiele können die Abkommen bezüglich der Zuteilung von Staatsangehörigen, die vom Königreich der Niederlande 1949 mit der neuen Republik Indonesien (146) und 1975 mit der neuen Republik Surinam geschlossen wurden (147), genannt werden. Als eine (Unter-)Gruppe sind die staatsangehörigkeitsrechtlichen Folgen der Okkupation eines ganzen Staates durch einen anderen Staat anzusehen, beziehungsweise - aus anderer Perspektive beschrieben, aber grundsätzlich identisch - die Folgen der Vereinigung eines ganzen Staates mit einem anderen Staat. Die Regelung der deutschen Staatsangehörigkeit in Österreich aus dem Jahre 1938 kann hier als Beispiel dienen (148).

Neben diesen vertraglichen Beschränkungen könnte die Autonomie der Staaten bezüglich des Staatsangehörigkeitsrechts auch durch Völkergewohnheitsrecht oder durch allgemeine Rechtsgrundsätze beschränkt sein. Diese Möglichkeit wird bereits durch Art. 1 Satz 2 der Haager Konvention von 1930 indiziert:

"Die anderen Staaten müssen diese Gesetzgebung anerkennen, so weit sie mit den internationalen Verträgen, der internationalen Übung und den auf 
dem Gebiet der Staatsangehörigkeit allgemein erkannten Rechtsgrundsätzen im Einklang stehen".

In der Lehre scheiden sich jedoch an dieser Frage die Geister (149). Einige Autoren vemeinen überhaupt die Möglichkeit der Autonomiebeschränkung durch Völkergewohnheitsrecht. Andere Autoren dagegen versuchen inhaltlich bestimmte Völkergewohnheitsrechtssätze aufzustellen, durch die der nationale Gesetzgeber beschränkt sein soll (150). Dabei gehen die Meinungen über den Inhallt wiederum weit auseinander. Bei Beantwortung der Frage nach völkergewohnheitsrechtlichen Schranken werden die Autoren offensichtlich durch ihre Haltung zum Völkerrecht im allgemeinen beeinfluBt (151). Hier soll einer vermittelnden Meinung das Wort geredet werden. Zwar muß festgestellt werden, daß die Staatsangehörigkeitsregelungen der verschỉedenen Staaten en détail zu unterschiedlich sind, so daß sich schwerlich eine allgemeine Rechtsuiberzeugung und Staatenpraxis nachweisen lassen, die es zulassen würden, einen völkerrechtlichen Normenkatalog zum Staatsangehörigkeitsrecht aufzustellen. Hingegen darf der Einfluß allgemeiner Prinzipien, vor allem seien erwähnt Rechtsmißbrauch (152), Willkür- und Interventionsverbot, auf das Staatsangehörigkeitsrecht nicht unterschätzt werden. Auch lassen sich Tendenzen feststellen, die zumindest regional von einer derartigen Rechtsüberzeugung und Staatenpraxis getragen sind, daß sie als (regionales) Völkergewohnheitsrecht angesehen werden können (153).

Als ein Beispiel des Interventionsverbotes kann genannt werden, daß es Staaten absolut untersagt ist, die Staatsangehörigkeit anderer Staaten zu regeln. Jede Regelung einer fremden Staatsangehörigkeit ist ein Übergriff in den Souveränitätsbereich eines fremden Staates und somit wegen der Einmischung in die inneren Angelegenheiten dieses anderen Staates völkerrechtswidrig (154). Makarov (155) weist darauf hin. daß sich das Verbot der Regelung einer fremden Staatsangehörigkeit nur auf die allgemeine Staatsangehörigkeit bezieht, das heißt auf den Status, an den verschiedene Rechte und Pflichten geknüpft werden können. Er betont, daß die Regelung einer fremden, funktionellen Staatsangehörigkeit im Sinne eines bestimmten Gesetzes nicht gegen das Völkerrecht verstößt. Als Beispiel erwähnt er die Immigrationsgesetze der Vereinigten Staaten von 1921 und 1924, die zur Feststellung der Einwanderungsquote die Staatsangehörigkeit einer Person ganz einheitlich nach deren Geburtsland bestimmten. Der Auffassung Makarov's ist, soweit es das gegebene Beispiel betrifft, sicher zuzustimmen.

Problematisch ist jedoch, ob aus dem Interventionsverbot abgeleitet werden kann, daß es einem Staat untersagt ist, seine Staatsangehörigkeit allen Bürgern eines anderen Staates zu verleihen. Zwar wird dieses Beispiel in der Literatur als völkerrechtswidrige Einmischung in die imneren Angelegenheiten eines anderen Staates genannt (156), jedoch kann meiner Ansicht nach dieser Schiuß nicht generell gezogen werden. Eine solche Verleihung kann völkerrechtswidrig sein, aber hierauf sind unter ganz besonderen Umständen Ausnahmen möglich. Die These, daß das Verleihen einer Staatsangehörigkeit an alle Bürger eines anderen Staates nicht unbedingt als völkerrechtswidrig betrachtet werden muß, wird durch die staatsangehörigkeitsrechtliche Problematik im deutsch-deutschen Verhältnis unterstrichen (157). In der Bundesrepublik Deutschland werden mehrere Theorien bezüglich des Fortbestehens der deutschen Staatsangehörigkeit 
nach Zusammenbruch des deutschen Reiches in Mai 1945 vertreten. Allen diesen Theorien ist aber gemeinsam, daß an sie staatsangehörigkeitsrechtliche Konsequenzen für die Bürger der DDR verbunden sind (158). Als. Folge dieser Theorien besitzen die Bürger der DDR grundsätzlich die noch weiterexistierende, einheitliche deutsche Staatsangehörigkeit. So vertritt auch das Bundesverfassungsgericht in seinem BeschluB vom 21. Oktober 1987 die Ansicht (159):
"Auls dem Gebot der Wahrung der Einheit der deutschen Staatsangehörig- keit (Art. 116 Abs. 1, 16 Abs. 1 GG), das eine normative Konikretisie- rung des $\mathrm{im}$ Grundgesetz enthaltenen Wiedervereinigungsgebots ist, folgt, daß dem Erwerb der Staatsbuirgerschaft der Deutschen Demokratischen Republik für die Rechtsordnung der Bundesrepublik Deutschland in den Grenzen des ordre public die Rechtswirkung des Erwerbs der deutschen Staatsangehörigkeit beizumessen ist" (160).

Diese Auffassung des Bundesverfassungsgerichts und der Mehrheit in der bundesdeutschen Lehre kann meiner Ansicht nach zumindest zum heutigen Zeitpunkt noch nicht alls völkerrechtswidrig bezeichnet werden. Die Bundesrepublik Deutschland benutzt als Staatsangehörigkeitsrechtsregelung eine abgeảnderte Fassung des Staatsangehörigkeitsgesetzes des deutschen Kaiserreiches (161). Wegen der grundsätzlichen Autonomie in Staatsangehörigkeitsfragen ist die Bundesrepublik dazu berechtigt. Die Regelung bewirkt jedoch, daß die Bundesrepublik grundsätzlich auch die Bürger der DDR alls ihre eigene Bürger betrachtet. Dies könnte völkerrechtswidrig sein. Die gemeinsame Vergangenheit beider deutschen Staaten und die Verbundenheit der beiden Staaten, die viele Deutsche auch nach der Gründung zweier Republiken auf deutschem Bodem noch empfinden, bewirken jedoch, daß zum heutigen Zeitpunkt aus historischen Gründen keine Völkerrechtswidrigkeit vorliegt (162). Die Bürger der Deutschen Demokratischen Republik haben aus dieser Perspektive eine Doppelstaatsangehörigkeit. Neben der Staatsbürgerschaft der DDR besitzen sie die bundesrepublikanischen Staatsangehörigkeit (163), die auf Grund der "Terminologie des RuStAG normalerweise als "deutsche Staatsangehörigkeit" bezeichnet wird. Völkerrechtswidrigkeit wiirde nur eintreten, wenn die Bundesrepublik an diese Tatsache Rechtsfolgen verbinden würde, die als unzulässige Einmischung in die Angelegenheiten der DDR betrachtet werden müBten (164). Dies wăre Z.B. der Fall, wenn die Bundesrepublik einen Bürger der DDR, der sich als Tourist in der Bundesrepublik aufhält, unter Berufung auf dessen bundesrepublikanische Staatsangehörigkeit, zum Militärdienst verpflichten wiirde.

Eben wurde betont, daß die Verleihung der bundesrepublikanischen Staatsangehörigkeit an alle DDR-Bürger wegen der gemeinsamen historischen Vergangenheit nicht völkerrechtswidrig ist. Diese Relevanz der historischen Dimension gilt nur beim heutigen Stand und sicher nicht in perpetuum (165). Falls das Königreich der Niederlande im Jahre 1988 plötzlich allen Belgiern die niederländische Staatsangehörigkeit verleihen, oder der ganzen belgischen Bevölkerung ein Optionsrecht auf die niederländische Staatsangehörigkeit einrüumen wïrde, müBte dies als völkerrechtswidrig bezeichnet werden. Die geneinsame Vergangenheit, die im Jahre 1839 mit dem Londoner Abkommen (166) abgebrochen wurde, wäre keine ausreichende Basis mehr für einen 
solchen Staatsakt. Dahingegen waren im vorigen Jahrhundert die belgische Optionsrechte für alle Einwohner der niederländischen Provinz Limburg und für alle Einwohner Luxemburgs sicher nicht völkerrechtswidrig, auch nicht nach heutigem Stand des Völkerrechts (167).

Neben der Völkerrechtswidrigkeit wegen Einmischung in die inneren Angelegenheiten eines anderen Staates, könnte eine Staatsangehörigkeitsverleihung oder -entziehung gegen das Willkärverbot sowie gegen bestimmte Menschenrechte verstoßen (168). Eine solche Menschenrechtswidrigkeit könnte vorliegen, wenn eine Staatsangehörigkeit aus rassischen Gesichtspunkten verliehen oder entzogen wird. Ein Entzug der Staatsangehörigkeit aus rassischen Grïnden muß wohl grundsätzlich als menschenrechtswidrig betrachtet werden. Die Folgerung, daß die Verleihung einer Staatsangehörigkeit aus rassischen Gründen einen menschenrechtswidrigen Akt darstellt, kann dagegen nicht ohne weiteres gezogen werden. Die Regelung von Art. 116 Abs. 1 des Grundgesetzes der deutschen Bundesrepublik bezüglich deutscher Volkszugehörigen kommt einer solchen Verleihung nahe, jedoch darf diese gerade wegen der deutschen Geschichte keineswegs als menschenrechtswidrig betrachtet werden. Es ist aber u.U. denkbar, daß eine Staatsangehörigkeitsverleihung, die unter Benutzung rassischer Kriterien geschieht, wegen Verletzung der Menschenwürde als menschenrechtswidrig betrachtet werden muB. Wenn Deutschland 1949 allen noch lebenden ehemaligen deutschen Juden, die ausgebürgert worden waren, die deutsche Staatsangehörigkeit automatisch zurïckgegeben hätte, wäre wohl zu vertreten gewesen, daß ein solcher Akt die Menschenwürde dieser Personen verletzt. Gerade um die Gefühle dieses Personenkreises nicht zu verletzen, ist deshalb von einer solchen Regelung abgesehen und in Art. 116 Abs. 2 GG lediglich ein Einbürgerungsanspruch geschaffen worden (169).

Eine Einschränkung der nationalen Autonomie zur Regelung der Staatsangehörigkeit wurde auch aus der berühmten Nottebohmentscheidung des Internationalen Gerichtshofes gefolgert. Der Gerichtshof stellte fest:

"The diversity of demographic conditions has thus far made it impossible for any general agreement to be reached on the rules relating to nationality, although the latter by its very nature affects international relations. It has been considered that the best way of making such rules accord with the varying demographic conditions in different countries is to leave the fixing of such rules to the competence of each State. On the other hand, a State cannot claim that the rules it has thus laid down are entitled to recognition by another State unless it has acted in conformity with this general aim of making the legal bond of nationality accord with the individual's genuine connection with the State which assumes the defence of its citizens by means of protection as against other States" (170).

Aus dieser Entscheidung haben manche Autoren gefolgert, daß gemäß dem Völkerrecht das Staatsangehörigkeitsrecht eines Staates immer zu berüicksichtigen habe, ob die Personen, denen die betreffende Staatsangehörigkeit verliehen wird, auch tatsächlich eine "genuine connection" mit dem betreffenden Staat haben (171). Diese Ansicht muß jedoch abgellehnt werden. Einerseits sei darauf hingewiesen, daß das Kriterium der "genuine connection" zal vage ist, um als deutliche Einschränkung der nationalen Autonomie zu gelten. Anderseits muß 
die Nottebohmentscheidung so interpretiert werden, daß eine Verleihung der Staatsangehörigkeit an eine Person, die keine "genuine connection" mit dem betreffenden Staat hat, zwar guiltig ist, aber einem Staat kein Recht verschafft, den betreffenden Bürger diplomatisch zu vertreten (172).

Desweiteren ist es fraglich, ob der Internationale Gerichtshof, angesichts der zunchrrenden Mobilität von Personen und der damit verbundenen Konsequenz, daß solche Migranten häufig mit mehreren Staaten faktisch und emotional enge Beziehungen haben, heute die Relevanz eines "genuine link" noch in solchem Umfang wie bei der Nottebohmentscheidung betonen wïrde.

Nach dem oben gesagten muß aber die Relativität der völkerrechtlichen Schranken bezüglich Staatsangehörigkeitsverleihung oder -entziehung ausdrücklich hervorgehoben werden. Die Tatsache, daß eine Staatsangehörigkeitsverleihung oder -entziehung als völkerrechtswidrig betrachtet werden muß, führt nämlich keineswegs dazu; daß ein solcher Akt nicht effektiv wäre (173). Ein Staat darf zwar bei seiner Staatsangehörigkeitsregelung nicht völkerrechtswidrig handeln, faktisch kann er es aber sehr wohl. Der völkerrechtswidrige Akt ist damit nicht nonexistent. Andere Staaten werden den Akt - auch bei konstatierter Völkerrechtswidrigkeit - häufig als gültig anerkennen müssen (174). So wäre es etwa im Falle einer völkerrechtswidrigen Staatsangehörigkeitsentziehung unangemessen, in einigen Fällen vielleicht sogar wiederum völkerrechtswidrig (175), wenn andere Staaten diese Entziehung negieren würden (176). Die Staatenlosigkeit bekämpfenden Bestimmungen der Staatsangehörigkeitsgesetzgebungen anderer Staaten wïrden anderenfalls nicht aktiviert. Gerade dies hätte zur Folge, daß das durch Menschenrechtspakte garantierte Recht auf eine Staatsangehörigkeit erneut angetastet wïrde. Will man dies vermeiden, so bleibt nur die Anerkennung des völkerrechtswidrigen Staatsangehörigkeitsentzugs. Wie oben bereits kurz angedeutet, lassen sich Tendenzen feststellen, die die Annahme von regionalem Völkergewohnheitsrecht, beziehungsweise auf den regionalen Raum beschränkte, allgemeine Rechtsgrundsätze rechtfertigen. Dies gilt hinsichtlich einiger Punkte für die Länder des Europarates, aber ganz im besonderen für die Mitgliedstaaten der Europäischen Gemeinschaften. So hat auch der Europäische Gerichtshof in Luxemburg des häufigeren in seinen Urteilen auf allgemeine, allen Mitgliedstaaten gemeinsame Rechtsgrundsätze verwiesen, wobei vor allem angenommen wurde, daß fundamentale Menschenrechte diesen allgemeinen Rechtsgrundsätzen zugerechnet werden müssen (177). Auch verweist Art. 215 Absatz 2 EWG-Vertrag auf allgemeine Rechtsgrundsätze der Mitgliedstaaten.

Unter Berüicksichtigung des oben gesagten könnte man auch für den Bereich des Stratsangehörigkeitsrecht, die Entwicklung von völkerrechtlichen Schranken, basierend auf regionalem Völkergewohnheitsrecht, beziehungsweise auf den regionalen Raum beschränkten, allgemeinen Rechtsgrundsätzen, bejahen. Dies gilt besonders nun, da die westeuropäischen Staaten im Rahmen des Europarates, sich schon des häufigeren gemeinschaftlich mit Staatsangehörigkeitsfragen beschäftigt haben (178). Zwar mußte grundsätzlich festgestellt werden, daß die Staatsangehörigkeitregelungen der verschiedenen Staaten en détail zu unterschiedlich sind (179), um eine allgemeine Rechtsüberzeugung und Staatenprax is bezïglich eines umfassenden und spezifizierten völkerrechtlichen Normenkatalogs zum Staatsangehörigkeitsrecht nachzuweisen, dieser Schluß braucht jedoch für den regionalen, westeuropäischen Raum nicht unbedingt gezogen werden. In den westeuropäischen Staatsangehörigkeitsgesetzen lassen sich vielmehr gemein- 
same Rechtsüberzeugungen konstatieren, die zumindest als Grundstein für die Entwicklung eines regionalen Völkergewohnheitsrecht auf dem Gebiete des Staatsangehörigkeitsrechts bezeichnet werden körnen. $\mathrm{Zu}$ dieser gemeinsamen Rechtsüberzeugung rechne ich etwa die Verwirklichung des Grundsatzes der Gleichberechtigung von Mann und Frau im Staatsangehörigkeitsrecht. Es läßt sich feststellen, daß in fast allen westeuropäischen Ländem dieses Prinzip inzwischen seinen Niederschlag in den gesetzlichen Regelungen gefunden und damit eine kongruente Staatenpraxis bewiesen hat. Würde nun eines dieser Länder seine Staatsangehörigkeitsgesetzgebung erneut ändern, wobei das Prinzip der Gleichberechtigung abgeschafft würde, so müßte man meiner Ansicht nach eine solche Regelung als im Streit mit regionalem Völkergewohnheitsrecht bezeichnen (180).

\subsubsection{Entwicklung einer europäischen Staatsangehörigkeit}

In diesem Kapitel über die Schranken der nationalen Autonomie im Staatsangehörigkeitsrecht soll nicht unterlassen werden, den Einfluß zu erwähnen, der die Zusammenarbeit mehrerer Staaten in den Europäischen Gemeinschaften auf das Staatsangehörigkeitsrecht haben kann. An dieser Stelle soll zuerst kurz auf die denkbare Entwicklung einer Staatsangehörigkeit der Europäischen Gemeinschaften eingegangen werden (181), die auf Dauer die Staatsangehörigkeiten der Mitgliedstaaten ersetzen könnte. Selbstverständlich ist eine solche Entwicklung möglich, aber von einem Ersetzen der einzelnen Staatsangehörigkeiten der Mitgliedstaaten durch eine europäische Staatsangehörigkeit sind wir noch weit entfernt. Sicher ist es auch nicht notwendig, daß bereits bei Schaffung einer Staatsangehörigkeit der Europäischen Gemeinschaften zugleïch die Staatsangehörigkeiten der Mitgliedlstaaten wegzufallen hätten. Beide könnten zunächst nebeneinander bestehen. Dabei ist zu berücksichtigen, daß die Bedeutung der europäischen Staatsangehörigkeit im Laufe der Jahre zunehmen könnte. Es sei daran erinnert, daß die Staatsangehörigkeit m.E. ein Koppelungsbegriff ist. Nur dadurch, daß Rechtssysteme die Staatsangehörigkeit als Anknüpfungsbegriff für die Zuteilung von Rechten und Pflichten benutzen, bekommt die Staatsangehörigkeit Bedeutung und Inhalt (182). Auch eine europäische Staatsangehörigkeit bekäme nur Bedeutung und Inhalt, wenn, und in soweit, Rechtssysteme an diesen Begriff Rechtsfolgen anknüpfen würden. Dabei muß man im Auge behalten, daß eine solche europäische Staatsangehörigkeit sicher im Beginn kein völlig selbständiger, von den Staatsangehörigkeiten der Mitgliedstaaten getrennter, Begriff zu sein braucht. Man könnte hier eine Parallele zur Entstehungsgeschichte der Staatsangehörigkeit des deutschen Kaiserreiches ziehen. Bis zur Gründung des Kaiserreiches im Jahre 1870 gab es lediglich die Staatsangehörigkeiten der unterschiedlichen deutschen (Bundes)Staaten. Durch $\$ 1$ des Gesetzes über die Erwerbung und Verlust der Reichs- und Staatsangehörigkeit vom 1 . Juni 1870 (183) wurde die Reichsangehörigkeit als Folge der Staatsangehörigkeit eines Bundesstaates geregelt:

"Die Reichsangehörigkeit wird durch die Staatsangehörigkeit in einem Bundesstaat erworben und erlischt mit deren Verlust."

Die Reichsangehörigkeit konnte also lediglich durch die Staatsangehörigkeit eines Bundesstaates vermittelt werden. Dieses zwingende Band zwischen Reichs- und Staatsangehörigkeit wurde ursprünglich noch besonders bestätigt 
durch den, mit Gesetz vom 22. April 1871 (184) aufgehobenen, zweiten Absatz dieses Paragraphen, kraft dessen die Angehörigen des Großherzogtums Hessen nur dann die Bundesangehörigkeit besaßen, wenn sie in den zum Bunde gehörigen Teilen des Großherzogstums heimatberechtigt waren.

Analog dieser von den Staatsangehörigkeiten der Bundesstaaten vermittelten Reichsangehörigkeit könnte sich auch eine, durch die Staatsangehörigkeiten der Mitgliedstaaten vermittelte, europäische Staatsangehörigkeit als Anknüpfungsbegriff bilden. Es ist interessant die Entwicklung der Reichsangehörigkeit Deutschlands an dieser Stelle noch kurz weiter zu verfolgen. Das Reichs- und Staatsangehörigkeitsgesetz von $1913 \mathrm{sah}$ die Staatsangehörigkeit noch grundsătzlich als eine von der Staatsangehörigkeit eines Bundesstaates vermittelten Status, gleichzeitig bestand aber bereits die Möglichkeit einer unmittelbaren Reichsangehörigkeit gemäß den $\$ \S 33$ bis 35 (185). Ferner muß berücksichtigt werden, daß sowohl in 1870 als in 1913 der Erwerb und Verlust der Staatsangehörigkeiten der Bundesstaaten durch Reichsgesetz, also Bundesgesetz geregelt wurden. Die Entwicklung der Reichsangehörigkeit wurde - leider unter traurigen Sternen - 1934 abgerundet, als durch den einzigen Paragraphen der Verordnung vom 5 . Februar 1934 bestimmt wurde:

"Die Staatsangehörigkeit in den deutschen Ländern fält fort. Es gibt nur noch eine deutsche Staatsangehörigkeit (Reichsangehörigkeit)" (186).

Man könnte allerdings die These vertreten, daß es bereits heute praktisch eine europäische "Bürgerschaft" gibt (187). Zwar besteht kein solcher Rechtsstatus, der schon als europäische Staatsangehörigkeit bezeichnet wird oder bezeichnet werden dürfte. Wenn man momentan über eine europäische Staatsbüirgerschaft sprechen würde, hieße dies ja, die Europärsche Gemeinschaften als (Bundes)Staat aufzufassen und dies ginge bei der heutigen Rechtslage sogar unter Anwendung eines ausgedehnten Staatsbegriffes zu weit (188). Dennoch läßt sich so etwas wie eine tatsächliche europäische Bürgerschaft bereits feststellen. Nicht nur das Rechtssystem der Europäischen Gemeinschaften selbst, sondern auch die Rechtssysteme der Mitgliedstaaten knüpfen bereits manche Rechtsfolgen an den Status "Angehöriger eines Mitgliedstaates der Europäischen Gemeinschaften" (189). Es ist nur ein Schritt, um diesen weitläufigen Anknüpfungsbegriff durch den Terminus "europäischer Bürger" zu ersetzen, eine Eigenschaft, die grundsätzlich durch die nationalen Staatsangehörigkeitsregelungen der Mitgliedstaaten vermittelt wird (190). Zwar muß zugegeben werden, daß eine solche Etikettenänderung prinzipiell unbedeutend sein mag, aufgrund des psychologischen Werts, den man gefühlsmäßig einer Bürgerschaft noch immer entgegen bringt, aber zumindest große politische Bedeutung haben diirfte (191).

Die wichtigste Folge der heute schon vorhandenen "europäischen Bürgerschaft" (Eigenschaft eines Bürgers eines Mitgliedstaates der Europäischen Gemeinschaft) ist zweifelsohne die von Art. 48 E.W.G.-Vertrag garantierte Freizügigkeit für Arbeitnehmer (192). Es ist bemerkenswert, daß diese Freizügigkeit den individuellen Personen in Prinzip durch die, von den Mitgliedstaaten ganz autonom aufgestellten, Staatsangehörigkeitsregelungen vermittelt wird (193). Ohne zu sehr auf den rechtsvergleichenden Teil dieses Buches vorgreifen zu wollen, fällt auf, daß die Unterschiede zwischen den nationalen Erwerbs- und Verlustgründen der Staatsangehörigkeit erheblich sind und doch vermitteln all diese Regelungen ganz gleichwertig die Freizügigkeit im Rahmen des E.W.G.-- 
Vertrages. In diesem Zusammenhang ist die Frage berechtigt, ob die Tatsache der Freizügigkeitsgarantie des E.W.G.-Vertrages im Moment schon die nationale Autonomie der Mitgliedstaaten bei der Regelung ihrer Staatsangehörigkeit wenigstens marginell beeinfluBt.

Auf Fragen der Staatsangehörigkeit bestimmter Mitgliedstaaten und ihr Verhältnis zum E.W.G.-Vertrag wurde in der Literatur schon einige Male eingegangen (194). Zwar genießen prinzipiell die Staatsangehörigen der Mitgliedstaaten den Schutz des E.W.G-Vertrages, in Bezug auf einige Mitgliedstaaten ist dies aber klausuliert. Hinsichtlich Deutschlands wurde die Auslegung des Begriffs "deutsche Staatsangehörige" für den Bereich des E.W.G-Vertrages ausdrüicklich bestimmt (195). In Bezug auf Großbritannien wurde ebenfalls festgestellt, wie der Begriff "national" von Großbritannien und Nord-Irland interpretiert werden muß (196). Evans (197) hat aus diesen Klausulierungen zurecht gefolgert, daß die Position einer Person, die den Schutz des E.W.G-Vertrages genießt (also den Status sines europäischen Bürgers) zwar sehr eng mit den Staatsangehörigkeiten der Mitgliedstaaten verknüpft ist, aber eine solche Staatsangehörigkeit einerseits nicht unbedingt die Position eines europäischen Bürgers vermittelt und andererseits es Personen gibt, die den Schutz des E.W.G.-Vertrages genießen, die nicht Bürger einss Mitgliedstaates sind.

Aan könnte daraus ableiten, daß sich im EG-Recht allmählich ein selbständiges, europäisches Staatsangehörigkeitsrecht entwickelt. Dies kann vor allem dann beachtlich werden, wenn Mitgliedstaaten die Konzeption ihrer Staatsangehörigkeit grundsätzlich revidieren, wie dies z.B. 1981 in Großbritannien geschah (198). Im Falle einer solchen Gesetzesänderung kann man vertreten, daß für den Schutz des E.W.G.-Vertrages die alte Konzeption der Staatsangehörigkeit (selbstverständlich unter Beachtung eventueller Klausulierungen) weiterhin maßgebend bleibt. Nach dieser Ansicht ist die Autonomie der Mitgliedstaaten hinsichtlich der Regelung ihrer Staatsangehörigkeit vom EG-Recht nicht eingeschränkt. Änderungen der staatsangehörigkeitsrechtlichen Konzeption haben aber im Bereich des Gemeinschaftsrechts keine Konsequenzen. Infolge dessen könnten die personale Schutzwirkung des E.W.G.-Vertrages und die Staatsangehörigkeiten der Mitgliedstaaten sich im Laufe der Jahre erheblich von einander entfernen.

Ein anderer Ausgangspunkt wäre, daß ein Mitgliedstaat seine Konzeption der Staatsangehörigkeit nicht mehr olhne Rücksprache (199) oder sogar (stillschweigender) Einwilligung der Europäischen Gemeinschaft ändern kann. Nach dieser Auffassung bleiben der personale Schutz des E.W.G.-Abkommens und die Staatsangehörigkeiten der Mitgliedstaaten eng miteinander verknüpft. Die Autonomie der Mitgliedstaaten im Staatsangehörigkeitsrecht wird dann aber vom Gemeinschaftsrecht eingeschränkt. Beim heutigen Stand des EG-Rechts läßt sich noch nicht sagen, ob die eine oder die andere Ansicht sich durchsetzen wird (200).

Evans hat seine Erörterungen auf Fragen konzentriert, die sich aus der Tatsache ergaben, daß ein Mitgliedstaat (Großbritannien) die ganze Konzeption seiner Staatsangehörigkeit änderte. Mutatis mutandis werden wir aber mit den gleichen Fragen konfrontiert, wenn ein Mitgliedstaat die Erwerbs- oder Verlustgründe seiner Staatsangehörigkeit auf erheblichen Punkten neu regeln würde. Bis jetzt hat die Europäische Gemeinschaft nicht versucht, durch Richtlinien, gestützt etwa auf Art. 235 E.W.G.-Vertrag, diesen Regelungsbereich an sich zu ziehen. 
Es war auch wohl sicher nicht die ursprüngliche Absicht der "Väter" des E.W.G.-Vertrages dieses klassisch zum "domaine reservé" eines Nationalstaates gehörende Gebiet mit einzubeziehen. Die Tatsache, daf die Erwerbs- und Verlustgründe der Staatsangehörigkeit in den verschiedenen Mitgliedstaaten manchmal erhebliche Unterschiede aufweisen, führt aber dazu, daß die Hürde, die genommen werden muB, um den Schutz des E.W.G.-Abkommens (also gewissermaßen die Eigenschaft eines EG-Bürgers) vermittelt zu bekommen, unterschiedlich ist, je nachdem über welche Staatsangehörigkeit eines Mitgliedstaates man diesen Status erwerben möchte. So kann einem Bürger eines lateinamerikanischen Staates nur geraten werden zu versuchen, diese Eigenschaft mittells der spanischen Staatsangehörigkeit $z \mathrm{u}$ bekommen und nicht den Versuch eines Erwerbs z.B. der deutschen Staatsangehörigkeit unternehmen zu wollen (201). Bietet vielleicht nicht gerade diese Feststellung möglicherweise Grund und Anlaß fuir die Europäische Gemeinschaften, um danach zu streben, die Erwerbs- und Verlustgründe zu beeinflussen und soweit möglich einigermaßen zu vereinheitlichen? (202) Wir können feststellen, daß die Europäische Gemeinschaft im Moment noch die Autonomie der Mitgliedstaaten auf diesem Gebiete respektiert (203). Die unterschiedlichen Erwerbs- und Verlustgruinde, die schon vor der Gründung der Europäischen Gemeinschaften, beziehungsweise vor Beitritt der betreffenden Staaten zu den Europäischen Gemeinschaften, historisch gewachsen sind, werden akzeptiert. Aber sind die Mitgliedstaaten wirklich noch völlig autonom in der Regelung der Staatsangehörigkeit? Könnte die niederländische Regierung im Hinblick auf den E.W.G.-Vertrag wirklich noch - falls sie dies wollte - allen Bürgern Indonesiens das Recht geben, für die niederländische Staatsangehörigkeit zu optieren? Es ist zweifelsohne vertretbar, diese Frage zu verneinen (204). Es stünde zu erwarten, daß eine solche Regelung in Indonesien Verärgerung und Protest auslösen würde - und nicht zu unrecht, weil hierin wohl ein Eingriff in die innere Angelegenheiten Indonesiens gesehen werden könnte -, man könnte jedoch auch erwarten, daß eine solche Maßnahme Unruhe in den europäischen Nachbarländern bewirken würde aufgrund der zu erwartenden Immigrantenwelle.

Daß die Europäische Gemeinschaft sich dazu entschließen könnte, die Regelung der Staatsangehörigkeiten ihrer Mitgliedstaaten zu beeinflussen oder gar an sich zu ziehen, geht bereits aus der Entschließung des Europäischen Parlements vom 20. Januar 1984 bezüglich Diskriminierung hinsichtlich der Übertragung der Staatsangehörigkeit hervor (205):

"Das Europäische Parlament

- in der Erwägung, daß bei der derzeitigen Rechtslage in einigen Mitgliedstaaten das Prinzip der rechtlichen Gleichbehandlung von Mann und Frau hinsichtlich der Übertragung der Staatsangehörigkeit und bei Eheschliessungen zwischen Eheleuten verschiedener Staatsangehörigkeit nicht beachtet wird,

- in Erwägung der Wichtigkeit der Gesetze, die den Erwerb und die Übertragung der Staatsangehörigkeit in den einzelnen Mitgliedstaaten regeln, da diese auch den Erwerb und die Übertragung des Rechtsstatus des Gemeinschaftsrechtssubjekts bestimmen, für die Gemeinschaft,

- in der Erwägung, daB die besagten Diskriminierungen eine Behinderung der Freizügigkeit des einzelnen in der Gemeinschaft darstellt, 
- in der Erwägung, daB Artikel 3 des EWG-Vertrags genau festlegt, daß die Tätigkeit der Gemeinschaft u.a. zur Beseitigung der Behinderung der Freizügigkeit des einzelnen führt,

- in der Erwägung, daß eine Harmonisierung der Rechtsvorschriften der Mitgliedstaaten, zumindest hinsichtlich der Eheschließungen zwischen Staatsangehörigen der Gemeinschaftsländer und hinsichtlich ihrer Kinder, aus den oben genannten Gründen angebracht wäre,

- in Kenntnis des Berichts des Rechtsausschusses (Dok. 1-1166/83),

1. fordert die Kommission gemäß Artikel 235 des EWG-Vertrags auf, eine Empfehlung an die Mitgliedstaaten auszuarbeiten, die gleiche Rechte für Väter und Mutter hinsichtlich der Übertragung der Staatsangehörigkeit auf die ehelich geborenen und auf die nichtehelichen Kinder sowie gleiche Rechte für Mann und Frau hinsichtlich der Übertragung der Staatsangehörigkeit bei der Eheschließung zwischen Eheleuten verschiedener Staatsangehörigkeit vorsieht, jedoch unter Beibehaltung des Grundsatzes, den Erwerb mehrerer Staatsangehörigkeiten zu vermeiden;

2. fordert seinen Präsidenten auf, diese Entschließung dem Rat und der Kommission sowie dem Europarat und den Mitgliedstaaten zu übermitteln ${ }^{\text {t" }}$.

Zurecht sieht das Europäische Parlament einen Zusammenhang zwischen der vom E.W.G.-Vertrag garantierten Freizügigkeit und der Regelung der Staatsangehörigkeiten der Mitgliedstaaten und folgert daraus schlïssig, daß damit eine Regelungtkompetenz der Europäischen Gemeinschaft kraft Art. 235 E.W.G.-Vertrages gegeben ist.

Sehr bemerkenswert ist schließlich Art. 1 Abs. 2 des Entwurfes zur Ausarbeitung einer Europäischen Verfassung (Mitglieder der Europäischen Volkspartei im Europäischen Parlament) vom 26 September 1983:

"Unionsbürger sind alle Staatsbürger der Unionsstaaten nach Maßgabe eines Unionsgesetzes. Das Unionsrecht bestimmt, inwieweit Staatsangehörige anderer Staaten oder Staatenlose Rechten und Pflichten unterliegen." (206).

Eine solche Bestimmung würde die Regelungskompetenz auf dem Gebiete der Staatsangehörigkeit von den Mitgliedstaaten entgültïg wegnehmen. Zwar würde es noch weiterhin Belgier, Britten, Dänen, Deutsche, Griechen, Italiener, Luxemburger, Niederländer, Portugiesen und Spanier geben, aber durch in Brüssel - bis dahin vielleicht in Straßburg - festgestellten Regeln würde bestimmt werden, welche Personen diese Eigenschaften erwerben oder verlieren. Vielleicht wird die Zeit dann reif sein, um in Brüssel oder Straßburg - hoffentlich unter guten Sternen - ein ganz kurzes Gesetz zu verabschieden, mit etwa folgendem Text:

"Die Staatsangehörigkeit in den Mitgliedstaaten der Europäischen Union fällt fort. Es gibt nur noch eine europäische Staatsangehörigkeit". 
1.4.3 Allgemeine völkerrechtliche Verträge, Deklarationen und Empfehlungen auf dem Gebiete des Staatsangehörigkeitsrechts (207).

Vereinzelte Bestimmungen über Staatsangehörigkeit in völkerrechtlichen Verträgen und Deklarationen.

Art. 15 Abs. 1 dler Allgemeinen Erklärung der Menschenrechte vom 10. Dezember 1948 (208) lautet:

"Jeder Mensch hat Anspruch auf Staatsangehörigkeit".

Und Abs. 2 des gleichen Artikels fügt daran hinzu:

"Niemandem darf seine Staatsangehörigkeit willkürlich entzogen, noch ihm das Recht versagt werden, seine Staatsangehörigkeit zu wechseln".

Entsprechend bestimmt Art. 3 der Erklärung der Rechte des Kindes (209):

"Das Kind hat ab seiner Geburt Recht auf einen Namen und eine Staatsangehörigkeit".

Für die Vertragsparteien wirđł der Inhalt dieser Bestimmung völkerrechtlich verbindlich durch die Konkretisierung in Art. 24 Abs. 3 des Internationalen Paktes über bürgerliche und politische Rechte vom 19. Dezember 1966 (210):

"Jedes Kind hat das Recht, eine Staatsangehörigkeit zu erwerben".

Welche Staatsangehörigkeit erworben werden soll und auf welcher Art und Weise dieser Erwerb geschehen soll, wird aber nicht ausgearbeitet. Von den Staaten deren Staatsangehörigkeitsrecht in diesem Buch beschrieben werden, ist der Internationale Pakt über bürgerliche und politische Rechte für Belgien ( 21 . Juli 1983), die Bundesrepublik Deutschland (23. März 1976), Frankreich (4. Februar 1981), Italien (15. Dezember 1978), die Niederlande (11. März 1979), Österreich (10. Dezember 1978), Spanien (27. Juli 1977) und das Vereinigte Königreich (20. August 1976) in Kraft getreten. Lediglich die Schweiz ist keine Partei.

Etwas konkreter ist Art. 5 des Internationalen Übereinkommens zur Beseitigung jeder Form von Rassendiskriminierung vom 7. März 1966 (211). Aus diesem Artikel geht hervor, daß die Vertragsstaaten die Rassendiskriminierung in jeder Form verbieten und beseitigen, und das Recht jedes einzelnen, ohne Unterschied der Rasse, der Hautfarbe, des nationalen Ursprungs oder des Volkstums, auf Gleichheit vor dem Gesetz gewährleisten (212). Dies gilt insbesondere auch für das Recht auf die Staatsangehörigkeit (Buchstabe d, Ziffer iii). Bei diesem Vertrag sind u.a. Belgien (6. September 1975), die Bundesrepublik Deutschland (15. Juni 1969), Frankreich (27. August 1971), Italien (4. Februar 1976), die Niederllande (9. Januar 1972), Österreich (8. Juni 1972), Spanien (4. Januar 1969) und das Vereinigte Königreich (6. April 1969) Partei (213). Deutliche Aussagen über die Staatsangehörigkeit beinhaltet auch Art. 9 des Übereinkommens zur Beseitigung jeder Form von Diskriminierung der Frau vom 19. Dezember 1979 (214): 
"(1) Die Vertragsstaaten gewähren Frauen die gleichen Rechte wie Männern hinsichtlich des Erwerbs, des Wechsels oder der Beibehaltung der Staatsangehörigkeit. Insbesondere stellen die Vertragsstaaten sicher, daß weder durch Eheschließung mit einem Ausländer noch durch Wechsel der Staatsangehörigkeit des Ehemannes im Laufe der Ehe ohne weiteres sich die Staatsangehörigkeit der Frau andert, diese staatenlos wird oder ihr die Staatsangehörigkeit ihres Mannes aufgezwungen wird.

(2) Die Vertragsstaaten gewähren Frauen die gleichen Rechte wie Männem im Hinblick auf die Staatsangehörigkeit ihrer Kinder".

Diesem Abkommen sind u.a. Belgien (9. August 1985), die Bundesrepublik Deutschland (9. August 1985), Frankreich (13. Januar 1984), Italien (10. Juli 1985), Österreich (30. April 1982) und Spanien (4. Februar 1984) beigetreten.

Das Recht auf eine Staatsangehörigkeit wird auch in praktischer Weise betont durch Art. 34 des Abkommens über die Rechtsstellung der Flüchtlinge vom 28 . Juli 1951 (215):

"Die vertragschliessenden Staaten werden soweit wie möglich die Eingliederung und Einbürgerung der Flüchtlinge erleichtern. Sie werden insbesondere bestrebt sein, Einbürgerungsverfahren zu beschleunigen und die Kosten dieses Verfahrens soweit wie möglich herabzusetzen".

Dieses Abkommen ist für folgende in diesem Buch besprochene Staaten in Kraft getreten: Belgien (22. April 1954), Frankreich (21. September 1954), die Bundesrepublik Deutschland (22. April 1954), Italien (13. Februar 1955), die Niederlande (1. August 1956), Österreich (30. Januar 1955), Schweiz (21. April 1955) und das Vereinigte Königreich (9. Juni 1954).

Diese Bestimmung des Art. 34 des Abkommens aus 1951 wird fast buchstäblich wiederholt im Art. 32 des Übereinkommens über die Rechtsstellung der Staatenlosen vom 28. September 1954 (216):

"Die Vertragsstaaten erleichtern soweit wie möglich die Eingliederung und Einbürgerung Staatenloser. Sie werden insbesondere bestrebt sein, das Einbürgerungsverfahren zu beschleunigen und dessen Kosten soweit wie möglich herabzusetzen".

Dieser Vertrag ist u.a. für Belgien (25. August 1960), die Bundesrepublik Deutschland (24. Januar 1977), Frankreich (6. Juni 1960), Großbritannien (6. Juni 1960), Italien (3. März 1963), die Niederlande (11. Juli 1962) und die Schweiz (1. Oktober 1972), in Kraft getreten.

Neben diesen vereinzelten Bestimmungen bezüglich des Staatsangehörigkeitsrechts in völkerrechtlichen Verträgen und Deklarationen gibt es eine Reihe von Abkommen, die sich grundsärzlich mit Fragen der Staatsangehörigkeit beschäftigen. 
Die Haager Konvention von 1930 und Zusatzprotokolle.

Das erste dieser Abkommen ist die Haager "Konvention über gewisse Fragen beim Konflikt von Staatsangehörigkeitsfragen vom 12. April 1930" (217). Diese Konvention war das Ergebnis von Beratungen mit dem Ziel, das internationale Recht auf dem Gebiete des Staatsangehörigkeitsrechts einigermaßen zu kodifizieren. Dies geht deutlich aus der Präambel dieses Abkommens hervor:

\begin{abstract}
"In der Erwägung, daß es zweckmäßig erscheint, durch internationale Vereinbarung die aus mangelnder Übereinstimmung der Staatsangehörigkeitsgesetze ergebenden Fragen $\mathrm{zu}$ regelln, und in der Überzeugung, daß es im allgemeinen Interesse der internationalen Gemeinschaft liegt, wenn alle ihre Mitglieder sich die Auffassung zu eigen machen, wonach jeder Mensch eine Staatsangehörigkeit, und zwar nur eine einzige besitzen sollte, in der Erkenntnis also, daß das Ziel, dem die Menschheit auf diesem Gebiete zustreben sollte, die gänzliche Beseitigung der Staatenlosigkeit und der Doppelstaatigkeit ist, in der Meinung andererseits, daß es bei der gegenwärtigen wirtschaftlichen und sozialen Lage der einzelnen Länder nicht möglich ist, schon jetzt eine einheitliche Regelung aller vorgenannten Probleme herbeizuführen, gleichwohll von dem Wunsche geleitet, dieses große Werk dadurch mit einem ersten Versuch fortschreitender Kodifikation zu beginnen, $\mathrm{da} \beta$ diejenigen der aus mangelnder Übereinstimmung der Staatsangehörigkeitsgesetze sich ergebenden Fragen geregelt werden, über die eine internationale Verständigung gegenwärtig möglich ist ...."'.
\end{abstract}

Die Konvention anerkannte in Art. 1 die grundsätzliche Autonomie der Nationalstaaten in Staatsangehörigkeitsangelegenheiten. Nach Art. 2 muß die Frage, ob jemand einem bestimmten Staat angehört, stets nach den Gesetzen dieses Staates entschieden werden. Mehrstaatler durften in jedem der Heimatstaaten als Staatsangehörige angesehen werden, für Drittstaaten galt bezüglich Mehrstaatler das Prinzip des gewöhnlichen oder tatsächlichen Aufenthaltes oder gegebenfalls das Prinzip der engsten Verbundenheit (Art. 3-5). Die Konvention eröffnete für Mehrstaatler grundsätzlich die Möglichkeit, auf eine seiner Staatsangehörigkeiten zu verzichten (Art. 6). Eine Entlassung aus der Staatsangehörigkeit sollte unwirksam sein, wenn davon Staatenlosigkeit die Folge wäre (Art. 7). In den Art. 8-11 gab die Konvention einige Bestimmungen bezüglich der Staatsangehörigkeit der verheirateten Frau: Sie sollte ihre Staatsangehörigkeit nicht durch Ehe verlieren, wenn Staatenlosigkeit davon die Folge wäre; sie sollte ihre Staatsangehörigkeit ebenfalls nicht dadurch verlieren, daß ihr Ehemann während der Ehe seine Staatsangehörigkeit wechselte und davon für die Frau Staatenlosigkeit die Folge wäre; Einbürgerung des Ehemannes sollte für seine Ehefrau nur Erwerb einer fremden Staatsangehörigkeit zu Folge haben, wenn die Frau zugestimmt hat; nach der Ehe sollte eine Ehefrau ihre frühere Staatsangehörigkeit nur auf Antrag zurückerwerben. Bezüglich der Staatsangehörigkeit der Kinder kodifizierte die Konvention folgende Regel (Art. 12-16): ein eventuelles ius-soli galt nicht für Diplomatenkinder; mehrstaatliche Kinder von Berufskonsuln oder von anderen Beamten ausländischer Staaten, die von ihren Regierungen mit einer amtlichen Aufgabe betreut waren, konnten eine eventuelle Staatsangehörigkeit des Geburtstaates aufgeben; eine Einbürgerung der Eltern erstreckte sich in Prinzip auf minderjährige Kinder; das Kind unbekannter 
Eltern erwarb die Staatsangehörigkeit des Geburtstaates; ein staatenloses Kind konnte die Staatsangehörigkeit seines Geburtstaates erwerben; Verlust der Staatsangehörigkeit durch Anerkennung, Legitimation oder Adoption trat nur ein, wenn dadurch zugleicherzeit eine fremde Staatsangehörigkeit erworben wurde. Von den in diesem Buch beschriebenen Staaten ist die Konvention für Belgien (3. Juli 1939), Großbritannien (1. Juli 1937) und die Niederlande (1. Juli 1937, mit Vorbehalt bezïglich der Art. 8-10) in Kraft getreten.

Zu der Haager Konvention gehören drei Protokolle. Das erste Protokol (ebenfalls vom 12. April 1930) (218) betrifft keine staatsangehörigkeitsrechtlichen Fragen, sondern Probleme des Militärdienstes in gewissen Fällen doppelter Staatsangehörigkeit. Das zweite Protokoll (auch vom 12. April 1930) (219) betrifft einen wichtigen Fall von Staatenlosigkeit. Art. 1 dieses Protokolls bestimmt:

"Ein Kind dessen Vater staatenlos oder unbekannter Staatsangebörigkeit ist, besitzt die Staatsangehörigkeit des Geburtsstaates, sofern die Mutter sie besitzt, auch dann wenn die Staatsangehörigkeit dieses Staates nicht schon durch die bloße Tatsache der Geburt auf dessen Gebiet erworben ist".

Von den beschriebenen Staaten trat dieses Protokoll für Großbritannien (14. Januar 1932) und die Niederlande (2. April 1934) in Kraft. Ein drittes Protokoll betreffend Staatenlosigkeit (auch vom 12. April 1934) trat mangels ausreichender Ratifikationen nie in Kraft (220).

Erwähnenswert sind in Zusammenhang mit der Haager Konvention aus 1930 noch einige der Empfehlungen der Schlußakte der Haager Konferenz zur Kodifikation des internationalen Rechts (221). Betont wurde, daß Staatenlosigkeit und Mehrstaatigkeit bekämpft werden müssen. Bemerkenswert ist aber vor allem, daß damals schon in Empfehlung VI betont wurde, daß Staaten überprüfen sollten, ob es möglich sei:

"1. innerstaatlich den Grundsatz der Gleichberechtigung der Geschlechter auf dem Gebiete der Staatsangehörigkeit zur Geltung zu bringen, wobei die Interessen der Kinder besonders zu berücksichtigen wären, und

2. besonders zu bestimmen, daß die Staatsangehörigkeit der Frau in Zukunft grundsätzlich nicht ohne ihre Zustimmung lediglich durch die Tatsache berührt wird, daß der Ehemann seine Staatsangehörigkeit wechselt".

Die Grundprinzipien der Haager Konvention wurden später in mehreren internationalen Abkommen näher präzisiert. Sie sind auch wieder zurückzuerkennen in den vereinzelten staatsangehörigkeitsrechtlichen Bestimmungen der bereits erwähnten Deklarationen und Verträge. Art. 15 Abs. 1 der Allgemeinen Erklärung der Menschenrechte, Art. 3 der Erklärung der Rechte des Kindes, Art. 24 Abs. 3 des Internationalen Paktes über bürgerliche und politische Rechte und Art. 5 des Internationalen Übereinkommen zur Beseitigung jeder Form von Rassendiskriminnierung manifestieren alle den Wunsch Staatenlosigkeit zu bekämpfen. Sie liegen also auf der gleichen Linie als die Haager Konvention von 1930 (und 
zwar namentlich deren Art. 12 ff) und des zweiten Protokolls bei der Haager Konvention von 1930. Auch Art. 9 des Übereinkommens zur Beseitigung jeder Form vorn Diskriminierung der Frau baut weiter auf eine Tendenz, die in der Konvention won 1930 sich erstmal manifestierte: der Wunsch der Frau im Staatsangehörigkeitsrecht eine selbständige(re) Stellung zu geben. Der zweite Absatz von Art. 9 könnte man als Folge der VI. Empfehlung der Schlußakte der Haager Konferenz von 1930 betrachten.

\section{Die New Yorker Konvention von 1957.}

Eine ungeheuer wichtige Position in der Entwicklungsgeschichte der Staatsangehörigkeitsregelungen nimmt die am 22. Februar 1957 in New York im Rahmen der Vereinten Nationen zustandgekommene Konvention betreffend die Staatsangehörigkeit der Ehefrau ein (222). Die Konvention hat als Ziel, die selbständige Position der Ehefrau im Staatsangehörigkeitsrecht zu bewirken. In der Präambel wurde dieses Ziel als Folge des Art. 15 der Allgemeinen Erklärung der Menschenrechte präsentiert, da gemäß dieser Bestimmung "jeder Mensch Anspruch auf eine Staatsangehörigkeit hat" und $\mathrm{da} ß$ "niemandem willkürlich seine Staatsangehörigkeit entzogen werden darf, noch das Recht versagt werden darf, die Staatsangehörigkeit zu wechseln". Die Konvention von New York kann dazu auch als logischer weiterer Schritt nach den Art. 8-10 der Haager Konvention aus 1930 und Empfehlung VI der Schlußakte der Haager Konferenz aus 1930 betrachtet werden.

In den Art. 1 und 2 der New Yorker Konvention wurde vorgeschrieben, daB die Ehefrau eine von ihrem Manne völlig selbständige Position haben würde, Eheschließung, Ehescheidung oder Wechsel der Staatsangehörigkeit des Ehemannes würden keine staatsangehörigkeitsrechtlichen Folgen für die Ehefrau haben. Interessanterweise wurde in Art. 3 der Konvention aber bestimmt, daß die ausländische Ehefrau auf ihren Antrag die Staatsangehörigkeit ibres Ehemannes durch ein besonders privilegierte Einbürgerungsverfahren erwerben kann. Der Erwerb der Staatsangehörigkeit kann aber von Bedingungen abhängig gemacht werden, die möglicherweise im Interesse der nationalen Sicherheit oder der öffentlichen Ordnung notwendig sind. Nach Art. 3 Abs. 2 durfte der ausländischen Ehefrau statt ein privilegiertes Einbürgerungsverfahren auch ein Optionsrecht eingeräumt werden. Von den in diesem Buch behandelten Staaten ist die New Yorker Konvention aus 1957 für die Bundesrepublik Deutschland (8. Mai 1974), die Niederlande (6. November 1966), Österreich (18. April 1968) in Kraft getreten. Für Großbritannien trat das Abkommen am 11. August 1958 in Kraft, wurde aber am 24. Dezember 1982 in Zusammenhang mit dem bevorstehenden Inkrafttreten des BNA 1981 gekündigt.

\section{Das New Yorker Abkommen von 1961.}

Im Rahrnen der Vereinten Nationen wurde seit Mitte 1950 an einer Konvention über die Verminderung der Staatenlosigkeit gearbeitet, die am 30. August 1961 in New York geschlossen wurde (223). In dieser Konvention wurde zum ersten Mal versucht, Staatenlosigkeit systematisch zu bekämpfen. Gerade durch diese Systematik geht die Konvention von 1961 wesentlich weiter als die die Staatenlosigkeit bekämpfende Bestimmungen der Haager Konvention aus 1930. Die 
New Yorker Konvention war selbstverståndlich eine logische Folge des Art. 15 der Allgemeinen Erklärung der Menschenrechte.

Art. 1 Abs. 1 der Konvention schreibt vor, daß ein auf dem Grundgebiet eines Staates geborenes potentiell staatenloses Kind entweder automatisch die Staatsangehörigkeit dieses Staates erwerben sollte oder auf Antrag diese Staatsangehörigkeit erwerben kann. Im letzteren Falle darf der Staatsangehörigkeitserwerb nur wegen in Abs. 2 limitativ erwähnten Gründen verweigert werden. Art. 1 Abs. 3 bestimmte - wie im zweiten Protokoll zum Haager Abkommen aus 1930 - daß ein in einem Vertragsstaat geborenes eheliches Kind, dessen Mutter die Staatsangehörigkeit dieses Staates besitzt, diese Staatsangehörigkeit erwerben soll, falls es sonst staatenlos sein würde. Art. 1 Abs. 4 schreibt vor, daB ein staatenloses Kind eines Staatsangehörigen unter bestimmten Bedingungen sogar bei Geburt im Ausland einen Einbürgerungsanspruch im Staate eines Elternteils haben sollte. Beziiglich Findlinge wurde in Art. 2 bestimmt, daß diese ohne Nachweis des Gegenteils gelten, als seien sie innerbalb des Staates, wo sie gefunden wurden, aus Eltern geboren, die die Staatsangehörigkeit jenes Staates besassen. Art. 3 stellt klar, daß Geburt auf einem Schiff oder Flugzeug, als Geburt in dem Staate gilt, dessen Flagge das Schiff führt oder in dem das Flugzeug registriert ist. Unter bestimmten Voraussetzungen soll ein Staat weiter seine Staatsangehörigkeit einem nicht in einem Vertragsstaat geborenen staatenlosen Kind verleihen, wenn einer der Elternteile zur Zeit dessen Geburt die Staatsangehörigkeit dieses Staates hat (Art. 4). Nach Art. 5 Abs. 1 darf eine Staatsangehörigkeit wegen Änderung des Personalstatus nur erfolgen, wenn davon nicht Staatenlosigkeit die Folge ist. Bemerkenswert ist weiter die Bestimmung des Art. 5 Abs. 2, kraft deren ein uneheliches Kind, das eine Staatsangehörigkeit durch Vaterschaftsanerkenntnis verloren hat, die Gelegenheit gegeben werden soll die verlorene Staatsangehörigkeit durch schriftlichen Antrag wieder zurück zu erwerben. Der Wiedererwerb darf nur aus limitativ beschriebenen Gründen verweigert werden. Auch die Erstreckung eines Staatsangehörigkeitsverlustes auf die Ehefrau und die Kinder, darf nach Art. 6 für diese Personen nie Staatenlosigkeit zur Folge haben. Die Art. 7-10 beschäftigen sich ebenfalls mit dem Verlust der Staatsangehörigkeit. Nur in wenigen Ausnahmefällen wird für zulässig erklärt, daß ein Staatsangehörigkeitsverlust Staatenlosigkeit zur Folge hat. Die New Yorker Konvention aus 1961 ist von vierzehn Staaten ratifiziert worden; von den im nächsten Kapitel beschriebenen Staaten sind die Bundesrepublik Deutschland (29. November 1977), die Niederlande (11. August 1985), Österreich (13. Dezember 1975) und Großbritannien (13. Dezember 1975) Partei.

\section{Protokolle zu den Wiener Diplomaten- und Konsularabkommen.}

Im Haager Abkommen von 1930 betraf Art. 12 die Diplomatenkinder. Im Fakultativ-Protokoll über Staatsangehörigkeitserwerb zum im Rahmen der Vereinten Nationen geschlossenen Wiener Übereinkommens über diplomatische Beziehungen vom 18. April 1961 (224), wurde die staatsangehörigkeitsrechtliche Position von Diplomaten noch klarer formuliert. Nachdem Art. I den Begriff "Mitglieder der Mission" definiert als "der Missionschef und die Mitglieder des Personals der Mission" stellt Art. II fest, daß Mitglieder der Mission; die nicht Angehörige des Empfangsstaates sind, sowie die zu ihrem Haushalt gehörenden Familienmitglieder nicht lediglich kraft der Rechtsvorschriften des Empfangs- 
staates dessen Staatsangehörigkeit erwerben. Dieses Fakultativ-Protokoll trat u.a. für Belgien (1. Juni 1968), die Bundesrepublik Deutschland (11. Dezember 1964), Großbritannien (1. Oktober 1964), Italien (25. Juli 1969), die Niederlande (7. Oktober 1984), und Österreich (28. Mai 1966) in Kraft. Frankreich, die Schweiz und Spanien sind zwar dem Wiener Abkommen zugetreten, haben aber das Facultiv-Protokoll nicht ratifiziert.

Eine entsprechende Bestimmung für die Mitglieder einer konsularischen Vertretung (Konsularbeamten, die Bediensteten des Verwaltungs- oder technischen Personals und die Mitglieder des dienstlichen Hauspersonals) findet sich im Fakultativ-Protokoll über Staatsangehörigkeitserwerb zum Wiener Übereinkommen uiber Konsularbeziehungen vom 24. April 1963 (225). Dieses Protokoll trat u.a. in Kraft für Belgien (9. Oktober 1970), die Bundesrepublik Deutschland (7. Oktober 1971), Italien (25. Juli 1969) und die Niederlande (16. Januar 1986). Frankreich, Österreich, die Schweiz, Spanien und das Vereinigte Königreich sind zwar auch diesem Wiener Übereinkommen zugetreten, haben aber nicht das Fakultativ-Protokoll über den Staatsangehörigkeitserwerb ratifiziert.

\section{Das Berner CIEC-Abkommen von 1973.}

Auf europäischer Ebene sind ebenfalls Abkommen bezüglich des Staatsangehörigkeitsrechts zustandegekommen. Zu erwähnen ist das im Rahmen der Internationalen Zivilstandskommission (CIEC) realisierte Abkommen von Bern zur Verringerung der Fälle von Staatenlosigkeit von 13. September 1973 (226). In diesem Abkommen wurde in Art. 1 bestimmt, daß das Kind einer Staatsangehörigen die Staatsangehörigkeit seiner Mutter erwirbt, wenn es ansonsten staatenlos sein würde. Art. 2 des Abkommens stellt fest, daß für die Anwendung des Art. 1 das Kind eines Vaters, der Flüchtling ist, so behandelt wird, als besässe es nicht die Staatsangehörigkeit des Vaters. Das Berner Abkommen ist u.a. für die Bundesrepublik Deutschland (24. September 1977) und die Niederlande (19. Mai 1985) in Kraft getreten. Die Niederlande haben einen Vorbehalt bezüglich Art. 2 gemacht.

\section{Das Pariser CIEC-Abkomen von 1964.}

Im Rahmen der CIEC kam am 10. September 1964 in Paris auch die Konvention betreffend Austausch von Informationen auf dem Gebiete des Erwerbes einer Staatsangehörigkeit (227) zustande. Diese Konvention beinhaltet aber keine materiellrechtlichen Vorschriften. Die Bedeutung der Konvention ist jedoch insofern beachtlich, als gerade Informationen uiber den Erwerb einer fremden Staatsangehörigkeit wesentlich sind um festzustellen, daß die bisherige Staatsangehörigkeit verloren wurde. U.a. sind Belgien (8. März 1975), Italien (6. August 1972), die Niederlande (17. Juni 1967; ohne Niederländische Antillen) und Österreich (30. September 1965) Partei bei diesem Abkommen.

\section{Das Straßburger Europaratsabkommen von 1963.}

Es war aber vor allem der Europarat, der sich im Laufe der Jahre intensiv in Resolutionen, aber auch durch internationale Verträge mit Staatsangehörigkeitsfragen beschäftigt hat (228). Das wichtigste Ergebnis der Bemühungen des Europarates ist zweifelsohne die Konvention zur Verminderung von Fäller 
mehrfacher Staatsangehörigkeit und betreffend Wehrpflicht bei mehrfacher Staatsangehörigkeit, die am 6. Mai 1963 in Straßburg geschlossen wurde (229) (230).

Art. 1 des Abkommens bestimmt an erster Stelle, daß volljährige Staatsangehörige, die infolge einer ausdruicklichen Willenserklärung die Staatsangehörigkeit einer anderen Vertragspartei erwerben dadurch automatisch ihre bisherige Staatsangehörigkeit verlieren, und es nicht gestattet ist, die bisherige Staatsangehörigkeit beizubehalten. Für minderjährige Staatsangehörige gilt dasgleiche, unter der Voraussetzung daß sie ordnungsgemäß ermächtigt oder vertreten gewesen sind. Wenn Minderjährige eine fremde Staatsangehörigkeit automatisch infolge der Einbürgerung, Option oder Wiedereinbürgerung ihrer Eltern erwerben, verlieren sie im Prinzip ebenfalls ihre bisherige Staatsangehörigkeit. Eine Ausnahme gilt unter den in Abs. 3 erwähnten Voraussetzungen, wenn nur ein Elternteil die fremde Staatsangehörigkeit erwirbt.

Art. 2 regelt die Möglichkeit für Doppelstaatler, auf eine ihrer Staatsangehörigkeiten zu verzichten. Bestimmt wird, daß die Genehmigung einer Verzichtserklärung Volljährigen nicht verweigert werden darf, wenn der Doppelstaatler schon mehr als zehn Jahren außerhalb des Staates, auf dessen Staatsangehörigkeit er verzichten möchte und im Hoheitsgebiet einer Vertragspartei, deren Staatsangehörigkeit er auch besitzt lebt. Minderjährigen, die diese Voraussetzungen erfuillen, darf eine Verzichtsgenehmigung auch nicht versagt werden, falls sie gemäß ihrem Heimatrecht durch einfache Erklärung die Staatsangehörigkeit aufgeben können und sie weiter ordnungsgemäß ermächtigt oder vertreten sind. Für den Verzicht dürfen keine Gebühren erhoben werden.

Das Abkommen trat bis jetzt u.a. für die Bundesrepublik Deutschland (am 18. Dezember 1969; die Bundesrepublik Deutschland hat bei der Unterzeichnung erklärt, daß für die Anwendung dieses Übereinkommens jede Person, die Deutscher im Sinne des Artikels 116 des Grundgesetzes ist, als Staatsangehöriger der Bundesrepublik Deutschland gilt), Frankreich (am 28. März 1968, Frankreich hat bei der Unterzeichnung den Vorbehalt gemacht, daß eine Erklärung, die eine Frau zu dem Zweck abgibt, durch Eheschließung und im Zeitpunkt derselben, die Staatsangehörigkeit des Ehemannes zu erwerben, nicht als Option im Sinne des Artikel 1 anzusehen), Italien (28. Mărz 1968), die Niederlande (am 10. Juni 1985) in Kraft. Großbritannien (8. August 1971) und Spanien (17. August 1987) haben lediglich die Vertragsbestimmungen betreffend Wehrpflicht ratifiziert (231).

Das Abkommen von Straßburg wurde durch ein Straßburger Protokoll vom 24. November 1977 geändert (232). Art. 2 des Abkommens wurde dahingehend abgeändert, daß einem Doppelstaatler die Genehmigung zu einer Verzichtserklärung durch eine Vertragspartei nicht verweigert werden darf, dessen Staatsangehörigkeit ein Volljähriger von rechtswegen besitzt, falls dieser seinen gewöhnlichen Aufenthalt außerhalb des Territoriums dieser Partei hat. Dieses Anderungsprotokoll ist in Kraft getreten für Großbritanmien (8. September 1978) und die Niederlande (10. Juni 1985). Am 24. November 1977 wurde auch noch ein Zusatzprotokoll zum Straßburger Abkommen verabschiedet, worin Staaten sich verpflichten anderen Mitgliedstaaten Auskünfte über den Erwerb der Staats- 
angehörigkeit durch Staatsangehörigen dieser anderen Mitgliedstaaten zu geben (233).

Art. 11 der Europaratskonvention über die Adoption.

Ebenfalls im Rahmen des Europarates ist am 24. April 1967 eine Konvention uiber die Adoption von Kindern zustande gekommen (234). Art. 11 dieser Konvention betrifft die staatsangehörigkeitsrechtlichen Folgen einer Adoption. Abs. 1 dieses Artikels bestimmt, daß ein Staat zumindest eine erleichterte Einbürgerung eines von ihren Bürgern adoptierten Kindes vorsehen sollen. Nach Abs. 2 darf die Adoption jedenfalls nicht zufolge haben, daß das Adoptivkind seine Staatsangehörigkeit verliert, wenn es nicht bereits eine andere Staatsangehörigkeit besitzt oder diese erwirbt. Die Adoptionkonvention trat bisher u.a. für die Bundesrepublik Deutschland (11. Februar 1981), Großbritannien (26. April 1968), Italien (26. August 1976), Österreich (29. August 1980) und die Schweiz (1. April 1973) in Kraft.

\section{Europaratsresolutionen.}

Auch mittels Entschließungen und Empfehlungen hat der Europarat versucht die Staatsangehörigkeitsgesetzgebungen seiner Mitgliedstaaten zu beeinflussen (235). Viele dieser Entschließungen und Empfehlungen betreffen die Bekämpfung tatsächlicher oder "de facto" Staatenlosigkeit. Zu erwähnen ist Empfehlung 194 (1959) der Parlamentarischen Versammlung betreffend die Staatsangehörigkeit der Kinder von Staatenlosen (236). Empfohlen wurde, Staatsangehörigkeitsregelungen so zu gestalten, daß das eheliche Kind eines staatenlosen Vaters die Staatsangehörigkeit der Mutter erwirbt, wenn es in ihrem Heimatstaat geboren wurde.

Durch Empfehlung 564 (1969) (237) der Parlamentarischen Versammlung wurden die Mitgliedstaaten des Europarates eingeladen, um die Einbürgerung von Flüchtlingen $\mathrm{zu}$ vereinfachen:

"a) by a liberal interpretation of the legal requirements in respect of assimilation of refugees, taking particularly into account their total period of residence in the host country and the fact that most of them have adopted the way of life of the community which has welcomed them;

b) by making every effort to remove, or at least reduce legal obstacles to naturalisation, such as the minimum period of residence when it exceeds five years, the cost of naturalisation fees when it exceeds the financial possibilities of the majority of refugees, the length of time elapsing between the receipt of applications for naturalisation and their consideration, and the requirement that refugees should prove loss of their former nationality".

Weiter wurde empfohlen, das New Yorker Abkommen von 1961 zu ratifizieren. Auch sollten im Inland geborene Kinder von Staatlosen entweder iure soli die Staatsangehörigkeit ihres Geburtsstaates erwerben oder diese vor Erreichung der Volljährigkeit durch Optionserklärung erwerben können. 
Durch Empfehlung 519 (1968) (238) der Parlamentarischen Versammlung wurde den Mitgliedstaaten empfohlen, die New Yorker Konvention über die Staatsangehörigkeit der verheirateten Frau zu ratifizieren oder jedenfalls ihre Gesetzgebung dermaßen zu revidieren, daß eine ausländische Frau, die einen Staatsangehörigen heiratetc, selbst entscheiden kann, ob sie die Staatsangehörigkeit ihres Mannes erwerben möchte.

Durch EntschlieBung des Ministerkomitees (77) 12 vom 27. Mai 1977 wurde empfohlen Männer und Frauen auf gleicher Weise die Möglichkeit zu geben, die Staatsangehörigkeit des Ehepartners zu erwerben und, für die Einbürgerung eines ausländischen Ehepartners keinen längeren Inlandsaufenthalt als fünf Jahre zu fordern, wovon höchstens drei Jahre nach Eheschließung. Weiter sollten die Einbürgerungsvoraussetzungen, die von ausländischen Ehepartnern erfüllt sein müssen, leichter sein als die anderer Ausländer (239).

Ebenfalls am 27. Mai 1977 wurde von Ministerkomitee eine Resolution (77) 13 angenommen, die Empfehlungen bezüglich der Staatsangehörigkeit von Kindern aus gemischten Ehen enthielt. Beide Eltern sollten entweder ihre jeweilige Staatsangehörigkeit ihren Kindern weitergeben können, oder den Kindern muß bis zum Erfüllung des 22. Lebensjahres die Möglichkeit gegeben werden, diese Staatsangehörigkeiten zu erwerben (240). Es wurde aber weiter empfohlen auch Maßnahmen zu treffen, die als Ziel haben weitere Anhäufung von Staatsangehörigkeiten zu vermeiden. Dazu wurde empfohlen

1. um alle Staatsangehörigen, die auch eine andere Staatsangehörigkeit besitzen, zu erlauben auf ihre Staatsangehörigkeit zu verzichten;

2. um ihren Staatsangehörigen, die auch eine andere Staatsangehörigkeit besitzen zu erlauben eine Erklärung zugunsten einer ihren Staatsangehörigkeiten abzugeben und zu bestimmen, daß die eigene Staatsangehörigkeit verloren wird, falls sie eine Erklärung zugunsten einer anderen Staatsangehörigkeit abgeben. Im Rahmen dieser letzten Möglichkeit könnte ein Staat auch eine Verpflichtung einfiihren auf der Art und Weise, daß ein Staat einem Bürger der Mehrstaatler ist und mindestens das 22. Lebensjahr erreicht hat, mitteilt daß er innerhalb von sechs Monaten eine Erklärung zugunsten einer seiner Staatsangehörigkeiten abzugeben hat und der Betreffende mangels Erklärung danach die Staatsangehörigkeit des betreffenden Staates verliert.

Die Resolution empfahl schließlich daß die Mitgliedstaaten sich gegenseitig informieren über Erwerb, Beibehaltung oder Verlust der Staatsangehörigkeit.

Neuere Bemuihungen des Europarates betreffen die staatsangehörigkeitliche Position der Gastarbeiter und Gastarbeiterkinder. Dies manifestierte sich in Empfehlung 841 (1978) betreffend Migranten der zweiten Generation der Parlamentarischen Versammlung des Europarates. Die Parlamentarische Versammlung empfahl dem Komitee der Minister die Regierungen der Mitgliedstaaten einzuladen

"to make it easier for young migrants who wish to acquire the nationality of the immigration country, when they have either been born or completed most of their schooling in it."'(241). 
Auch die Konferenz europäischer Minister verantwortlich für Migrationsfragen beschäftigt sich mit diesem Problem. Nach ihre Sitzung im Jahre 1980 meinten die Minister:

"l'acquisition par les migrants de la nationalité du pays d'accueil ne
devrait pas être entravée par des mesures trop restrictives; cela est d'au-
tant plus vrai pour les jeunes de la deuxième génération éduqués et
formés dans le pays d'accueil, pour lesquels il conviendrait de tenir
compte de la valeur qu'elle peut avoir dans le contexte de leur intégration
" (242).

In der Perspektive dieser Folgerung verabschiedete das Ministerkomitees des Europarates die Entschließung (84) 9 betreffend Gastarbeiter der zweiten Generation, in der den Mitgliedstaten u.a. empfohlen wurde

"a. provide all the information needed by parents and second-generation migrants on the conditions in which nationality may be acquired and lost, and also on the consequences thereof, as well as reinstatement of nationality of origin and the procedures to be followed;

b. do everything that is necessary and possible to ensure that procedures for acquisition of nationality or reinstatement of nationality of origin are simple and speedy as possible, and charges are as limited as possible, and do not exceed administrative costs;

c. ensure, within the framework of international agreements, that young migrants holding the nationalities of two or more member states are subject to national service or military service obligations in only one state." (243).

Man kann deshalb erwarten, daß im Rahmen des Europarates weitere Verträge über staatsangehörigkeitsrechtlichen Fragen vorbereitet werden. Es ist weiter nicht undenkbar, daß gerade die Beratungen über die staatsangehörigkeitsrechtliche Lage der Migranten dazu führt, daß eine Änderung des Straßburger Abkommens vom 6. Mai 1963 zur Verminderung von Fällen mehrfacher Staatsangehörigkeit und betreffend Wehrpflicht bei mehrfacher Staatsangehörigkeit initiiert wird (244).

Im Rahmen der Europäischen Gemeinschaft wurde bis jetzt nicht an einer Harmonisierung der Staatsangehörigkeitsgesetzgebungen der Mitgliedstaaten gearbeitet (245). 


\section{LÄNDERBERICHTE}

\subsection{BELGIEN}

\subsubsection{Allgemeine Bemerkungen}

Das geltende belgische Staatsangehörigkeitsrecht ist im "Code.de la nationalité belge" (Wetboek van de Belgische nationaliteit) vom 28. Juni 1984 (1) (2) geregelt. Dieses Gesetzbuch trat am 1. Januar 1985 in Kraft (3). Die vorherigen Staatsangehörigkeitsbestimmungen aus dem Jahre 1932 verloren hierdurch ihre Gültigkeit.

Die Geschichte des heutigen Belgiens und der belgischen Staatsangehörigkeii beginnt im Anfang des vorigen Jahrhunderts. Auf dem Wiener Kongreß (4) wurde am 16. März 1815 das Territorium der früheren Österreichischen Niederlande (Belgien) mit dem Grundgebiet der niederländischen Republik zum Königreich der Niederlande vereint (5). In Personalunion mit diesem Königreich der Niederlande stand das vom Wiener Kongreß zum Großherzogtum erhobene Herzogtum Luxemburg: Der Sohn des letzten Statthalters der Republik der Vereinten Niederlande, der König des neuen Königreiches der Niederlande, bekam zu gleicher Zeit den Titel eines Großherzogs von Luxemburg.

Im Königreich der Niederlande waren in jener Zeit die staatsangehörigkeitsrechtlichen Bestimmungen auf zwei Gesetze, dem Code civil und dem Grundgesetz, verteilt (6). Der französische Code civil blieb mit seinen staatsangehörigkeitsrechtlichen Bestimmungen im neven Königreich weiter in Kraft. Das spätere Belgien war Teil Frankreichs, als der Code Napoléon erlassen wurde (7). In den Niederlanden trat der Code civil ebenfalls in Kraft, als dieses Gebiet 1811 als Teil Frankreichs einverleibt wurde (8). Nach der Neugründung der Niederlande hat man zwar gleich angefangen, ein eigenes Zivingesetzbuch vorzubereiten. Die für 1830 geplante Einführung eines neuen niederländischen Zivilgesetzbuches ist aber durch die Trennung Belgiens verhindert worden (9).

Neben diesen Code civil-Bestimmungen, die grundsätzlich vom ius sanguinis ausgingen, standen die staatsangehörigkeitsrechtlichen Bestimmungen des ersten Grundgesetzes der Niederlande vom 24. August 1815 (10). Die Art. 8-10 des Grundgesetzes gingen deutlich vom Erwerb der Staatsangehörigkeit iure soli aus. Jeder, der im Königreich oder seinen Kolonien von dort lebenden Eltern geboren wurde, erwarb die niederländische Staatsangehörigkeit (Art. 8 Grundgesetz 1815) (11).

Am 25. August $1830 \mathrm{kam}$ Belgien in Aufstand gegen den niederländischen König. Am 9. Februar 1831 wurde die belgische Konstitution verkündet. Die Art. 4, 5 und 133 dieser Konstitution bezogen sich auf das Staatsangehörigkeitsrecht (12). Nach Art. 4 waren der Erwerb, die Erhaltung und der Verlust der belgischen Staatsangehörigkeit durch Gesetz zu regeln. Art. 5 bestimmte u.a., daß nur die große Naturalisation einen Ausländer hinsichtlich der Ausübung der politischen Rechte einem Belgier gleichstellt. Auf diese Bestimmung geht die in Belgien noch immer existierende Unterscheidung zwischen großer und normaler (kleiner) Einbürgerung zurück. Art. 133 gab schließlich den in 
Belgien seit dem 1. Januar 1814 ansässigen Ausländern ein Optionsrecht auf die belgische Staatsangehörigkeit (13). Wie vor der Unabhängigkeit blieben die Erwerbs- und Verlustgründe der Staatsangehörigkeit durch die Bestimmungen des Code civil geregelt.

In den ersten Jahrzehnten nach der belgischen Unabhängigkeit beschäftigten sich mehrere Gesetze mit der "Abgrenzung" der Bevölkerung des neuen Königreiches (14). Im Rahmen dieser Arbeit braucht darauf nicht näher eingegangen zu werden. Vor allem versuchte Belgien, durch Optionsrechte und erleichterte Einbürgerungsmöglichkeiten Bewohner der niederländischen Provinz Limburg und des Großherzogtums Luxemburg in Belgien einzugliedern (15). Der Grund dafür war, dafi die Provinz Limburg und das Großherzogtum Luxemburg 1830 während des Aufstandes fast ganz die Seite Belgiens gewählt hatten. Nur etwa die Hälfte Limburgs und die Hälfte Luxemburgs wurden aber tatsächlich belgisches Hoheitsgebiet (die heutigen belgischen Provinzen Limburg und Luxemburg). Die Optionsrechte richteten sich nun an die Bevölkerung des niederländischen Teils Limburgs und des Großherzogtums.

Nach den in Belgien geltenden Code civil-Bestimmungen wurde die belgische Staatsangehörigkeit grundsätzlich iure sanguinis a patre erworben, wo auch immer die Geburt stattfand (Art. $10 \mathrm{Cc}$ ) (16). Ein in Belgien geborenes Kind eines Ausländers hatte innerhalb eines Jahres nach Volljährigkeit ein Optionsrecht auf die belgische Staatsangehörigkeit (Art. 9 Cc). Im Jahre 1889 wurde Art. 9 dahingehend geändert, daß die Ausübung des Optionsrechts unter bestimmten Bedingungen bereits mit achtzehn Jahren möglich war (17). Ein nichteheliches, vom Vater nicht anerkanntes, Kind bekam die Staatsangehörigheit der Mutter, wenn diese das Kind anerkannt hatte (18). Das Gesetz regelte nicht die Staatsangehörigkeit von in Belgien geborenen Kinder unbekannter Eltern (zu denen auch die von keinem Elternteil anerkannten Kinder zu rechnen sind). Ein Gesetz vom 15. August 1881 bestimmte aber, daß solche Kinder aufgrund von Art. $10 \mathrm{Cc}$ als in Bellgien geborene Kinder von Belgiem zu betrachten wären (19).

Die Naturalisation wurde im Gesetz des 27. September 1835 (20) geregelt. Infolge der Konstitution unterschied das Gesetz zwischen der großen und der normalen Einbürgerung. Die große Naturalisation wurde nur im Falle von großen Verdiensten gegenüber dem belgischen Staat verliehen (21). Auch in Belgien lebenden Personen, die in Belgien geboren waren, jedoch das Optionsrecht von Art. 9 nicht benutzt hatten, konnte die große Einbürgerung gewährt werden. Die normale Einbürgerung konnte jedem verliehen werden, der mindestens 21 Jahre alt war und seit wenigstens 5 Jahre in Belgien lebte (22). Die ausländische Frau, die einen belgischen Mann heiratete, erwarb dadurch automatisch die belgische Staatsangehörigkeit (Art. $12 \mathrm{Cc}$ ).

Die Gründe für den Verlust der Staatsangehörigkeit fanden sich in den Art. 17, 19 und $21 \mathrm{Cc}$. Bei Einbürgerung im Ausland wurde die belgische Staatsangehörigkeit verloren (Art. 17 Ziffer $1 \mathrm{Cc}$ ). Das gleiche galt im Falle der Annahme eines von einer fremden Regierung verliehenen Amtes oder den Eintritt in ausländischen Militärdienst (Art. 17 Ziffer 2 und Art. $21 \mathrm{Cc}$ ), es sei denn, der Betreffende hatte dazu eine Ermächtigung der belgischen Regierung. Die belgische Staatsangehörigkeit wurde ebenfalls von denjenigen verloren, die sich im Ausland niederliessen, ohne die Absicht, nach Belgien zurückzukehren (Art. 17 Ziffer $3 \mathrm{Cc}$ ). Schließlich verlor eine belgische Frau ihre Staatsangehörigkeit 
durch die Ehe mit einem Ausländer (Art. $19 \mathrm{Cc}$ ). Ein Verzicht auf die belgische Staatsangehörigkeit war nicht vorgesehen. Die Code civil-Bestimmungen sahen für diejenigen, die die Staatsangehörigkeit verloren hatten, erleichterte Wiedererwerbsmöglichkeiten vor (Art. 18, 19 Abs. 2, 20, 21 Abs. 2).

Mit Gesetz vom 21. Juni 1865 (23) wurden zwei Verlustgründe aufgehoben, und zwar die der Art. 17 Ziffer 2 und Art. $21 \mathrm{Cc}$ : fremder Staats- oder Militärdienst. Denjenigen, die bis zu diesem Zeitpunkt die Staatsangehörigkeit aus diesen Gründen verloren hatten, wurde die belgische Staatsangehörigkeit ex nunc wieder zurückgegeben.

Die Einbürgerungsvoraussetzungen wurden in dem Gesetz betreffend die Naturalisation vom 6. August 1881 (24) neu formuliert. Die Art. 1-13 des Gesetzes vom 27 . September 1835 wurden damit aufgehoben. Die Erfordernisse für die normale Einbürgerung blieben die gleichen (21 Jahre und fünfjähriger Wohnsitz in Belgien) (25). Die Voraussetzungen für die große Einbürgerung wurden mehr spezifiziert als im Jahre 1835 (26).

Am 8. Juni 1909 wurde ein Gesetz über die belgische Staatsangehörigkeit erlassen, das die Bestimmungen des Code civil aufhob (27). Das Gesetz über die Naturalisation vom 6. August 1881 blieb aber in Kraft (28). Das neue Gesetz. hielt am Grundsatz des ius sanguinis a patre fest, führte aber auch für mehrere Fälle ein Erwerb iure soli ein. Iure sanguinis erwarb das eheliche Kind eines belgischen Vaters die Staatsangehörigkeit Belgiens. Falls der Vater keine Staatsangehörigkeit besaß, konnte ein eheliches Kind die belgische Staatsangehörigkeit von seiner Mutter herleiten (Art. 1, Ziffer 1). Ein uneheliches Kind erwarb die belgische Staatsangehörigkeit, wenn der Elternteil, von dem es zuerst anerkannt wurde, belgischer Staatsangehöriger war (Art. 2). Iure soli erwarben die Kinder unbekannter oder staatenloser Eltern die belgische Staatsangehörigkeit (Art. 4). Das Gesetz von 1909 gab den in Belgien geborenen ausländischen Kindern kein bloßes Optionsrecht auf die Staatsangehörigkeit, sondern bestimmte nunmehr, daB diese Kinder unter bestimmten Voraussetzungen nach Vollendung des 22. Lebensjahres automatisch die belgische Staatsangehörigkeit erwarben, sofern sie in dem, dem 22. Geburtstag vorausgegangenen, Jahr ihren Wohnsitz in Belgien hatten, und nicht erklärt hatten, ihre ausländische Staatsangehörigkeit beibehalten zu wollen (Art. 7), Diese Regel galt auch für das Kind ausländischer Eltern, von dem ein Elternteil selbst in Belgien geboren war oder dort seit zehn Jahren ohne Unterbrechung ansässig war, und für das Kind ausländischer Eltern, das selbst seit sechs Jahren ohne Unterbrechung in Belgien lebte. Die in Belgien geborenen Ausländerkinder, die nicht kraft. Art. 7 automatisch die Staatsangehörigkeit erwarben, hatten aufgrund des Art. 9 ein in ihrem 22. Lebensjahr auszuübendes Optionsrecht, vorausgesetzt, daß sie in Belgien lebten oder erklärten, in Belgien Wohnsitz nehmen zu wollen, und diesen auch innerhalb eines Jahres nach Abgabe der Erklärung tatsăchlich begrüindeten.

Das Gesetz sah noch einige Optionsrechte auf die Staatsangehörigkeit zugunsten von Personen vor, die die belgische Staatsangehörigkeit verloren hatten und zugunsten deren Kinder (Art. 8 und 13). Ferner erwarb kraft Art. 5 die ausländische Ehegattin eines Belgiers die belgische Staatsangehörigkeit von Rechts wegen. Auch das Gesetz von 1909 ging also vom "système unitaire" aus. 
Die Gründe für den Verlust der Staatsangehörigkeit wurden in den Art. 11 und 12 formuliert. An erster Stelle wurde die Staatsangehörigkeit durch freiwilligen Erwerb einer fremden Staatsangehörigkeit verloren (Art. 11 Ziffer 1). Eine Belgierin verlor ihre Staatsangehörigkeit durch Ehe mit einem Ausländer, falls sie dadurch dessen Staatsangehörigkeit erwarb; das gleiche galt für eine Frau und minderjährige Kinder, wenn der Ehemann, beziehungsweise Vater, freiwilling eine andere Staatsangehörigkeit erwarb (Art. 11 Ziffer 2 und 3). Art. 12 eröffnete die Möglichkeit des Verzichts auf die Staatsangehörigkeit für das im Ausland geborene Kind eines Belgiers, der selbst auch schon im Ausland geboren war, unter der Voraussetzung, daß das betreffende Kind eine fremde Staatsangehörigkeit kraft Gesetzes erworben hatte. Im Gesetz von 1909 wurden die Niederlassung im Ausland und fremder Staats- oder Wehrdienst nicht als Verlustgründe erwähnt.

Im Ersten Weltkrieg wurde das neutrale Belgien größtenteils von der deutschen Armee besetzt. Als Wiedergutmachung erhielt Belgien durch den Versailler Vertrag vom 28. Juni 1919 einige deutsche Gebiete (29). Im Zusammenhang mit diesem Gebietsübergang wurden auch staatsangehörigkeitsrechtliche Regelungen geschaffen (30).

Das allgemeine belgische Staatsangehörigkeitsrecht wurde emeut reformiert durch Gesetz vom 15. Mai 1922 (31), das sowohl das Einbürgerungsgesetz vom 6. August 1881 als das Gesetz vom 8. Juni 1909 aufhob. Das neue Gesetz regelte Erwerbs- und Verlustgründe der Staatsangehörigkeit einschlließlich der Materie der Einbürgerung. Es führte eine fundamentale Revidierung des Staatsangehörigkeitsrechts durch. Das Gesetz von 1922 bildete bis zum 1. Januar 1985 die Basis des belgischen Staatsangehörigkeitsrechts. Unter dem Einfluß der traumatischen Erfahrungen des Ersten Weltkriegs ist es wesentlich weniger großzügig als das Gesetz von 1909 (32). Das Gesetz von 1922 wurde durch drei Gesetze präzisiert und angefüllt (33). Dies trug nicht zur Übersichtlichkeit der Regelung bei. Aufgrund des Art. 12 des Gesetzes vom 15. Oktober 1932 wurden die erwähnten Gesetze durch Königlichen Beschluß vom 14. Dezember 1932 zu einem Gesetz zusammengefasst (34).

Bezüglich des Erwerbs der Staatsangehörigkeit iure sanguinis galt aufgrund des Art. 1 des Gesetzes von 1932 (35) grundsätzlich das gleiche wie vorher: Erwerb iure sanguinis a patre, bei nichtehelichen Kinder war maßgebend, welcher Elternteil das Kind als erster anerkannt hatte (Art. 2). Bei während der Minderjährigkeit legitimierten Kindern war die Staatsangehörigkeit des Vaters maßgebend. Iure soli wurde die Staatsangehörigkeit ausschließlich von Kindern unbekannter Eltern erworben (36). Es galt kein ius soli mehr zugunsten von Kindern staatenloser Eltern. Ebensowenig konnte ein Kind eines staatenlosen Vaters die Staatsangehörigkeit won der belgischen Mutter herleiten. Ein automatischer Erwerb der Staatsangehörigkeit durch 22-Jährige in Belgien geborene Ausländer war nicht mehr vorgesehen. Solche Personen hatten nun wieder ausschließlich ein Optionsrecht auf die Staatsangehörigkeit. Zur Ausübung der Option mußten einige Bedingungen erfiullt sein:

a) Im Jahre vor der Optionserklärung mußte der Betreffende in Belgien gelebt haben und sich dazu noch entweder zwischen dem 14. und 18. Lebensjahr oder während wenigstens neun Jahren dort aufgehalten haben; Personen, von denen ein Elternteil die belgische Staatsangehörigkeit besessen hatte, brauch- 
ten nur nachzuweisen, daß sie im vorangegangenen Jahr in Belgien gelebt hatten.

b) Die Optionserklärung mußte vor Vollendung des 22 . Lebensjahres abgegeben werden.

c) Es durfte nach dem Gesetz des Heimatstaates des Betroffenen nicht möglich sein, sich bei Erwerb einer neuen Staatsangehörigkeit die Ermächtigung zur Beibehaltung seiner alten Staatsangehörigkeit erteilen zu Iassen. Diese Bedingung richtete sich vor allem gegen die Regelung des $\S 25$ Abs. 2 RuStAG.

Eine Optionsmöglichkeit hatten auch die im Ausland geborenen Kinder von Eltern, von denen der eine Teil die belgische Staatsangehörigkeit besaß oder besessen hatte (37).

Ausführlich wurde im Gesetz von 1932 die Einbürgerung geregelt. Für die normale Einbürgerung wurden die Vollendung des 22. Lebensjahres und ein zehnjähriger gewöhnlicher Aufenthalt in Belgien gefordert. Diese Frist belief sich auf fünf Jahre für den Ehegatten einer gebürtigen Belgierin (38) (Art. 13). Die Voraussetzangen für die große Einbürgerung wurden erheblich erschwert.

Auch gemäß dem Gesetz von 1932 erwarb eine Ausländerin durch die Ehe mit einem Belgier die belgische Staatsangehörigkeit. Seit 1926 konnte sie aber innerhalb von sechs Monaten nach Erwerb der belgischen Staatsangehörigkeit wieder auf diese verzichten (Art. 4 Gesetz 1932 (39).

Als Verlustgründe (40) kannte das Gesetz von 1932 den freiwilligen Erwerb einer ausländlischen Staatsangehörigkeit und den Verzicht. Eine Verzichtserklärung konnten diejenigen abgeben, die kraft Gesetzes auch eine fremde Staatsangehörigkeit besaßen (41). Eine Frau verlor die Staatsangehörigkeit weiter durch Ehe mit einem Ausländer unter der Voraussetzung, daß sie die Staatsangehörigkeit ihres Mannes erwarb. Das gleiche galt für die Ehefrau und die Kinder bei einem Staatsangehörigkeitswechsel des Mannes. Die Ehefrau konnte aber den durch Ehe oder Staatsangehörigkeitswechsel ihres Mannes verursachten Verlust der belgischen Staatsangehörigkeit rückgängig machen durch eine innerhalb von sechs Monaten nach Verlust abzugebende Erklärung, weiterhin Belgierin bleiben zu wollen.

Durch Gesetz vorn 30. Juli 1934 (42) wurde noch ein Verlustgrund hinzugefügt. GemäB Art. 18bis konnte den Belgiern, die ihre Staatsangehörigkeit nicht von einem Erzeuger herleiteten, der am Tage ihrer Geburt die belgische Staatsangehörigkeit besaß, die Staatsangehörigkeit auf Antrag der Staatsanwaltschaft wegen grober Verletzung ihrer Pflichten als belgischer Staatsangehöriger aberkannt werden (43). Im Jahre 1944 wurde durch Einfügung des Art. 18ter zudem bestimmt, daß derjenige die belgische Staatsangehörigkeit verlor, der im Abwesenheitsverfahren zu einer Strafe wegen bestimmter im Krieg begangener strafbarer Handlungen verurteilt worden war (44).

Gleich nach dem Zweiten Weltkrieg wurden einige Sonderregelungen erlassen, die die kriegsbedingte staatsangehörigkeitsrechtliche Probleme regelten und einigen Gruppen Optionsrechte gaben (45). Seitdem wurde das Gesetz von 1932 einige Male, aber nicht sehr einschneidend geändert. 
Die meisten nach dem Zweiten Weltkrieg verabschiedeten Änderungen betrafen verfahrensrechtliche Bestimmungen (46). Durch Gesetz vom 11. Februar 1953 (47) wurde eine Bestimmung aufgenommen, kraft derer ein von einem Belgier oder einer Belgierin adoptiertes Kind ein Optionsrecht auf die belgische Staats/angehörigkeit erwarb. Nach einer kleinen Änderung im Jahre 1962 (48) wurden die Voraussetzungen für die normale Einbürgerung durch Gesetz vom 17. März 1964 (49), durch Gesetz vom 8. April 1965 (50) einige Artikel in Zusiammenhang mit der Novellierung des elterlichen Sorgerechts im Zivilgesetzbuch geändert. Seit Inkrafttreten des Gesetzes wom 21. März 1969 (51) erwarb das Adoptivkind eines belgischen Mannes automatisch dessen Staatsangehörigkeit.

Seit Anfang der siebziger Jahre versuchte man in Belgien, das Staatsangehörigkeitsrecht zu erneuern. Am 3. März 1971 wurde ein Entwurf eines neuen Staatsangehörigkeitsgesetzes vom damaligen Justizminister Vranckx beim Parlament eingereicht (52). Der Entwurf hatte eine übersichtliche Struktur und schlug mehrere wünschenswerte Detailänderungen des belgischen Staatsangehörigkeitsrechts vor. Sehr grundsätzliche inhaltliche Änderungen wurden jedoch nicht vorgeschlagen. Zwar berïcksichtigte der Entwurf das Abkommen von New York vom 29. Januar 1957 über die Staatsangehörigkeit der verheirateten Frau (gemäß dem Entwurf hatte die Ehe also keine automatische Auswirkungen mehr auf die Staatsangehörigkeit der Frau), auch entsprach der Entwurf weitgehend den Zielen des Straßburger Abkommens vom 6. Mai 1963 bezüglich der mehrfachen Staatsangehôrígkeit und des New Yorker Abkommens vom 30. August 1961 betreffend Fälle der Staatenlosigkeit. Im Entwurf wurde die Gleichberechtigung von Mann und Frau aber noch nicht im Staatsangehörigkeitsrecht realisiert. Den ausländischen Männem belgischer Frauen wurde nicht die gleiche Möglichkeit gegeben, die belgische Staatsangehörigkeit zu erwerben, wie sie die ausländischen Gattinnen belgischer Männer hatten. Die belgische Staatsangehörigkeit wurde iure sanguinis grundsätzlich noch vom belgischen Vater hergeleitet. Durch Beendigung der Legislaturperiode wurde über den Entwurf Vranckx nicht weiter beraten.

Von größerer Bedeutung für die Entwicklung des belgischen Staatsangehörigkeitsrechts war der Gesetzesentwurf Nr. 305 beziglich Abstammung und Adoption vom 15. Februar 1978 (53). Dieser Entwurf schlug auch mehrere Ânderungen im Staatsangehörigkeitsgesetz vor. Aber auch über diesen Entwurf wurde wegen des Ablaufs der Legislaturperiode nicht weiter beraten (54). Abgesehen von diesen Regierungsentwïrfen wurden auch im Parlament einige Vorschläge zur Änderung des Staatsangehörigkeitsrecht gemacht, die jedoch alle keinen Erfolg hatten (55).

Erst Ende 1983 wurde ein Gesetzesentwurf eingereicht, der zu einer fundamentalen Änderung des belgischen Staatsangehörigkeitsrechts fuihrte (56). Der Entwurf enthielt Regeln über einige Aspekte der Position von Ausländern und weiter ein Staatsangehörigkeitsgesetzbuch. Nach relativ kurzen Beratungen wurde dieser Entwurf verabschiedet. Das Staatsangehörigkeitsgesetzbuch (Nationaliteitswetboek, Code de la nationalite) (CNB) trat am 1. Januar 1985 in Kraft, wodurch das belgische Staatsangehörigkeitsrecht seine heutige Fassung bekam. Als Ziele dieses neuen Gesetzes wurden in den Motiven neun Punkte formuliert (57):

1. Gleichberechtigung von Mann und Frau

2. Integrierung der Ausländerkinder der zweiten und dritten Generation 
3. Bekämpfung des "legal kidnapping" (58)

4. Gewisse Folgen der Ehe für die Staatsangehörigkeit

5. Irrelevanz der Ehelichkeit oder Nichtehelichkeit der Abstammung

6. Vereinfachung, Beschleunigung und Verbesserung der Verfahren

7. Verminderung der Fälle der Doppelstaatlichkeit

8. Verminderung der Fälle der Staatenlosigkeit

9. Gleichstellung von einigen Fällen des Auslandsaufenthalts und des Aufenthalts in Belgien.

\subsubsection{Enwerb der Staatsangehörigkeit durch Geburt}

\subsubsection{Rückblick}

Die heutige Regelung des Erwerbs der belgischen Staatsangehörigkeit durch Geburt weicht erheblich von den bisherigen Regelungen $a b$. Die belgische Staatsangehörigkeit wird nun aufgrund einer gewissen Kumulierung von ius sanguinis a parentibus und ius soli erworben. Bisher war ius sanguinis a patre jedoch die Grundlage des belgischen Staatsangehörigkeitsrechts. Dies war bereits im Anfang des vorigen Jahrhundents der Fall durch die Bestimmung von Art. $10 \mathrm{Cc}$, kraft dessen eheliche Kinder die Staatsangehörigkeit des belgischen Vaters erwarben (59). Entsprechendes galt für die vom Vater anerkannten nichtehelichen Kinder. Nur für die vom Vater nichtanerkannten nichtehelichen Kinder galt ius sanguinis a matre $(60)$. Neben dieser ius sanguinis-Regelung galt von 1815-1830 die ius soli-Bestimmung der niederländischen Verfassung (61).

Das Gesetz über die belgische Staatsangehörigkeit vom 8. Juni 1909 sah eine etwas andere Regelung vor. Grundsätzlich wurde am ius sanguinis a patre festgehalten, aber in zwei Ausnahmefällen konnte ein eheliches Kind auch die belgische Staatsangehörigkeit von der Mutter herlleiten. Dies war erstens der Fall, wenn der Vater staatenllos war (Art. 1 Gesetz 1909) Außerdem erwarb das eheliche Kind eines Ausländers die belgische Staatsangehörigkeit seiner Mutter, wenn es nach Auflösung der Ehe geboren wurde (Art. 1, Ziffer 2) (62). Die Regelung der Staatsangehörigkeit nichtehelicher Kinder wich auch von den Regelungen des $\mathrm{Cc}$ ab: das nichteheliche Kind wurde Belgier, wenn der Elternteil, der das Kind als erster anerkannt hatte, diese Staatsangehörigkeit besaB. Bemerkenswert war weiter Art. 3, in dem das Adagium "puer conceptus pro iam nato habetur" für die Staatsangehörigkeit konkretisiert wurde. Falls der maßgebende Elternteil zur Zeit der Geburt des Kindes kein belgischer Staatsangehöriger war, aber diese Staatsangehörigkeit zur Zeit der Zeugung wohl besaß, war letzteres entscheidend (63).

Die Bestimmungen über den Erwerb der belgischen Staatsangehörigkeit iure sanguinis in den späteren Regelungen bis 1985 entsprachen grundsätzlich der Regelung von 1909. Bemerkenswert war aber, daß seit 1922 das Kind eines staatenlosen Vater die Staatsangehörigkeit nicht mehr von der Mutter herlleiten konnte (64). Auch die interessante Regelung des ius sanguinis a matre für nach Auflösung der Ehe geborene, eheliche Kinder wurde wieder aufgehoben.

Die Geburt in Belgien war auch im vorigen Jahrhundert bereits fuir die staatsangehörigkeitsrechtliche Position einer Person relevant (65). Bereits Art. $9 \mathrm{Cc}$ gab dem in Belgien geborenen Kind eines Ausländers nach Volljährigkeit' ein Optionsrecht auf die belgische Staatsangehörigkeit. Ab 1889 war die Ausübung 
dieses Optionsrecht u.U. sogar mit achtzehn Jahren möglich. Seit 1881 stand fest, $\mathrm{daB}$ die in Belgien geborenen Kinder unbekannter Eltern die belgische Staatsangehörigkeit iure soli erwarben (66).

1909 wurden weitere Fälle des Erwerbs iure soli eingeführt (67). Neben den Kindern unbekannter Eltern erwarben nun auch die Kinder staatenloser Eltern die belgische Staatsangehörigkeit kraft Geburt im Inland. Der Erwerb der belgischen Staatsangehörigkeit von den übrigen in Belgien geborenen ausländischen Kindern wurde nun auch anders geregelt. Diese erhielten kein Optionsrecht mehr, sondern erhielten unter bestimmten Voraussetzungen die belgische Staatsangehörigkeit nach Vollendung des 22 . Lebensjahres automatisch, es sei denn, sie erklärten, ihre ausländische Staatsangehörigkeit behalten zu wollen (Art. 7). Diejenigen in Belgien geborenen Kinder, die die belgische Staatsangehörigkeit nicht derart erwarben, hatten unter bestimmten Bedingungen ein Optionsrecht.

Ab 1922 galt ausschließlich noch ein ius soli zugunsten von Kindern unbekannter Eltern und nicht mehr für Kinder staatenloser Eltern (68). Auch der automatische Erwerb der belgischen Staatsangehörigkeit von in Belgien geborenen Zweiundzwanzigjährigen wurde wieder abgeschafft. In Belgien geborene Ausländerkinder hatten nunmehr ausschließlich ein bedingtes Optionsrecht auf die Staatsangehörigkeit ihres Geburtsstaates. Ein entsprechendes Optionsrecht finden wir nun auch wieder in Art. 13 des neuen Gesetzes von 1985.

\subsubsection{Heutige Regelung}

Der Erwerb der belgischen Staatsangehörigkeit durch Geburt geschieht durch eine Mischung von ius sanguinis a patre et a matre und ius soli (69).

Das in Belgien geborene Kind eines belgischen Elternteils ist belgischer Staatsangehöriger (Art. $8 \& 1$, Ziffer $1 \mathrm{CNB}$ ). Es ist dabei unbeachtlich, ob Vater oder Mutter belgischer Staatsangehöriger sind. Diese Regel gilt gleichermaßen fuir eheliche und nichteheliche Kinder. Art. 8 bestimmt jedoch nicht, wer als Vater oder Mutter eines nichtehelichen Kindes gilt. Bis 1987 kamen gemäß den Vorschriften des Zivilgesetzbuches erst durch Anerkennung familienrechtliche Beziehungen zwischen einem nichtehelichen Kind und der Mutter, beziehungsweise dem Vater, zustande. Obwohl Belgien bereits 1979 vom Europäischen Gerichtshof für die Menschenrechte wegen dieser Regelung verurteilt worden war (70), wurde das belgische Recht erst durch Gesetz vom 31. März 1987 (71) geändert (72). Seitdem gilt, daß ein Kind die Person als Mutter hat, die als solche in seiner Geburtsurkunde eingetragen ist (Art. 312 C.c.belge) (73). Die so festgestellte mütterliche Abstammung kann aber aufgrund von z.B. Kindesunterschiebung oder Kindeswerwechslung angefochten werden. Falls der Name der Mutter aus irgendeinem Grund (z.B. weil die Geburt in einem Staat stattfand, wo der Prinzip "mater semper certa est" nicht gilt) nicht in der Geburtsurkunde eingetragen ist, oder wenn sogar eine Geburtsurkunde fehlt, dann kann die Mutter ihr Kind anerkennen (Art. 313 C.c.belge); die mútterliche Abstammung kann auch gerichtlich festgestellt werden (Art. 314 C.c.belge). Zwischen einem Mann und einem nichtehelichen Kind entstehen familienrechtliche Beziehungen durch Anerkennung (Art. 319-321 C.c.belge) oder durch die gerichtliche Feststellung der Vaterschaft (Art. 322-330 C.c.belge). Durch ein Urteil, in dem ein Mann, der der Mutter eines Kindes während der gesetzlichen Empfängniszeit 
beigewohnt hat, verurteilt wird dem Kind eine Rente für Unterhalt, Erziehung und angemessene Ausbildung zu bezahlen, entstehen keine familienrechtlichen Beziehungen zwischen Mann und Kind und wird deshalb die belgische Staatsangehörigkeit nicht erworben.

Das im Ausland geborene Kind belgischer Eltern oder eines belgischen Elternteils erwirbt die belgische Staatsangehörigkeit nur unter gewissen Voraussetzungen automatisch (A.rt. $8 \& \mathbb{1}$, Ziffer $2 \mathrm{CNB}$ ): entweder muB ein Elternteil selber in Belgien oder in unter belgischer Verwaltung stehenden Ländern geboren sein, oder das Kind muß sonst staatenlos sein oder vor seinem achtzehnten Lebensjahr werden (74). Falls diese Voraussetzungen nicht vorliegen, wird die belgische Staatsangehörigkeit erworben, wenn der belgische Elternteil dies innerhalb von fünf Jahren nach der Geburt des Kindes beantragt (75) (76). Eine entsprechende Regelung gilt für Adoptionskinder (Art. $9 \mathrm{CNB}$ ). Dabei ist bemerkenswert, daß nicht nur in Belgien ausgesprochene Adoptionen, sondern auch ausländische Adoptionen in Belgien staatsangehörigkeitsrechtliche Folgen haben können (77).

Aus dem Vorherigen geht schon hervor, daß im ius sanguinis schon ius soliElemente zu erkennen sind. In einigen Fällen wird aufgrund eines ius soli die belgische Staatsangehörigkeit erworben (Art. $10 \mathrm{CNB}$ ). Das in Belgien geborene staatenlose Kind oder das Kind, das vor seinem achtzehnten Lebensjahr staatenlos werden würde, erwirbt ebenfalls iure soli die belgische Staatsangehörigkeit (78). Auch in Belgien aufgefundene Kinder erhalten iure soli die Staatsangehörigkeit. Falls vor dem achtzehnten Lebensjahr nachgewiesen wird, daB diese Kinder eine andere - dauerhafte - Staatsangehörigkeit besitzen, fällt die belgische wieder weg (79).

Die Regelungen des Art. $10 \mathrm{CNB}$ sind aufgenommen, damit Apatridie vermieden wird. Grundsätzlich ist aber die ius soli-Regelung des Art. 11 CNB viel bedeutender (80): das in Belgien geborene Kind eines Elternteils, der selbst ebenfalls in Belgien geboren ist, erwirbt iure soli die belgische Staatsangehörigkeit, wenn der betreffende Eltemteil vor der Vollendung des zwölften Lebensjahres des Kindes eine diesbezügliche Erklärung abgibt, während er und das Kind in Belgien ihren Wohnsitz haben. Entsprechendes gilt wieder für Adoptionskinder. Ziel dieser Regelung ist eine Integrierung der Abkömmlinge von Gastarbeitern.

Ein in Belgien geborenes Kind, dessen ausländische Eltern beide außerhalb Belgiens geboren sind, erwirbt die belgische Staatsangehörigkeit nicht iure soli. Es hat aber ein zwischen dem achtzehnten und zweiundzwanzigsten Geburtstag auszuuibendes kontrolliertes Optionsrecht auf die belgische Staatsangehörigkeit (Art. 13 Ziffer $1 \mathrm{CNB}$ ). Unten wird dieses Recht ausführlicher besprochen.

\subsubsection{Enwerb der Staatsangehörigkeit nach der Geburt}

\subsubsection{Rückblick}

In Belgien gibt es seit der belgischen Konstitution vom 1831 einen bemerkenswerten Unterschied zwischen der großen und der normalen Einbürgerung.

Im Gesetz vom 22 . September 1835 wurden für die große Naturalisation hervorragende Dienste für Belgien gefordert (vgl. Art. 20 Ziffer 3 des Gesetzes 1985). 
Auch in Belgien geborenen Personen, die das Optionsrecht von Art. $9 \mathrm{Cc}$ nicht benutzt hatten, konnte die große Einbürgerung verliehen werden. Für die normalle Naturalisation wurde - wie heute noch - fünfjähriger Aufenthalt in Belgien gefordert und zusätzlich Erfüllung des 21. Lebensjahres (heutzutage des 18. Lebensjahres) (81).

Im Gesetz betreffend die Naturalisation vom 6. August 1881 wurden für die normale Einbürgerung dieselben Voraussetzungen wie zuvor formuliert. Die Voraussetzungen für die große Einbürgerung wurden näher präzisiert und entsprachen teilweise bereits den heutigen des Art. 20 des Gesetzes 1985. Gefordert wurde die Vollendung des 25. Lebensjahres (vgl. Art. 20 Ziffer 1 Gesetz 1985) und ein mindestens 10-jähriger Aufenthalt (82). Heute fordert Art. 20 Ziffer 3 grundsätzlich einen fünfjährigen Aufenthalt nach Erwerb der belgischen Staatsangehörigkeit durch gewöhnliche Einbürgerung, was insgesamt auch eine Aufenthaltsdauer von mindestens zehn Jahren bewirkt. 1881 wurde weiter grundsätzlich gefordert, daß der Betreffende verheiratet war oder zumindest Kinder aus einer Ehe hatte. Diejenigen, die mit einer Belgierin verheiratet waren oder aus einer Ehe mit einer Belgierin Kinder hatten, konnten nach fünfjährigem Aufenthalt die große Einbürgerung erwerben. In Belgien geborene und wohnhafte Ausländer brauchten diese Bedingungen nicht zu erfüllen. Im Falle von hervorragenden, dem Staate geleisteten Dienste konnte die große Einbürgerung ebenfalls ohne die erwähnten Voraussetzungen geschehen. Bemerkenswert ist, daß unverheirateten oder verwitweten, kinderlosen Ausländern die große Naturalisation erst verliehen werden konnte, nachdem sie das Alter von fünfzig Jahren erreicht hatten und bereits 15 Jahre in Belgien gewohnt hatten (83).

Die Einbürgerungsvoraussetzungen wurden im Gesetz von 1932 erschwert (84). Für die normale Einbürgerung wurde nunmehr Vollendung des 22 . Lebensjahres und 10-jähriger Aufenthalt, für die große Einbürgerung Vollendung des 30 . Lebensjahres und 15-jähriger Aufenthalt gefordert. Für bestimmte Gruppen von Personen waren die Voraussetzungen erleichtert. Falls das Heimatrecht des Naturalisandus die Möglichkeit einer Beibehaltsgenehmigung der bisherigen Staatsangehörigkeit kannte, wurde in Belgien nicht eingebürgert (85). Das Einbürgerungsverfahren wurde weiter noch durch Gesetz des 17. März 1964 geändert.

Anders als in der heutigen Regelung wurde früher im Rahmen des Einbürgerungsverfahrens nicht der Integrationswille überprüft, sondern die "idoneité (die Eignung) (86) des einzubürgernden oder optierenden Ausländers untersucht. Dabei wurde namentlich auf die "adaptation" und "assimilation" (87) geachtet. Das Staatsangehörigkeitsgesetz von 1985 hat dies nunmehr abgelehnt (88) und spricht statt dessen von einer "volonté d'intégration". Die staatsangehörigkeitsrechtliche Position der ausländischen Frau eines Belgiers war bis 1985 einfach: Sie erwarb automatisch die Staatsangehörigkeit ihres Mannes (Art. $12 \mathrm{Cc}$; Art. 5 vom Gesetz des 8. Juni 1909; Art. 4 vom Gesetz des 15. Mai 1922). Seit 1926 konnte sie aber innerhalb von sechs Monaten nach Eheschließung wieder auf die bellgische Staatsangehörigkeit verzichten (Art. 4 Gesetz 1932) (89). Der ausländische Mann einer Belgierin erwarb die belgische Staatsangehörigkeit nicht, hatte aber ab 1922 Eine Sonderposition bei den Einbürgenungsvoraussetzungen (90). 
Auch vor 1985 kannte das belgische Staatsangehörigkeitsrecht Optionsrechte. Bereits Art. $9 \mathrm{Cc}$ kannte ein Optionsrecht für in Belgien geborene Ausländer; 1909 wurde dies teilweise zu einem automatischen Erwerb mit Verzichtsmöglichkeit umgestaltet; 1932 wurde erneut ein bedingtes Optionsrecht eingefuihrt (91).

\subsubsection{Heutige Regelung}

Das belgische Staatsangehörigkeitsrecht kennt, dazu von der Konstitution gezwungen (92), zwei unterschiedliche Arten der Einbirgerung: Die große Einbürgerung, aufgrund derer eine einem gebürtigen Belgier gleiche Position erworben wird, und die ordentliche Einbürgerung, aufgrund derer man grundsätzlich alle Rechte eines Belgiers bekommt außer den politischen Rechten, für die das Grundgesetz oder besondere Gesetze die große Naturalisation fordern (93). Neben diesen beiden Naturalisationen gibt es noch die Möglichkeit, die Staatsangehörigkeit durch Optionserklärung zu erwerben (Art. 13 und $16 \mathrm{CNB}$ ). Da es sich bei diesen Optionsrechten um eine sogenannte kontrollierte Option handelt, die von den Behörden zurückgewiesen werden kann aufgrund wichtiger, den Optierenden betreffenden gewichtigen Tatsachen (94) oder aufgrund unzureichenden Integrationswillens des Betreffenden (95), handelt es sich hierbei aber tatsächlich um ein erleichtertes Einbürgerungsverfahren. Ein solches "Optionsrecht" auf die belgische Staatsangehörigkeit haben nach Art. 13 CNB:

a) das in Belgien geborene Kind (Art. 13 Ziffer 1);

b) das im Ausland geborene (Adoptions)kind einer Person, die zur Zeit der Optionserklärung die belgische Staatsangehörigkeit besitzt (Art. 13 Ziffer 2);

c) das im Ausland geborene (Adoptions-)Kind einer Person, die zur Zeit der Geburt Belgier war oder gewesen war (Art. 13 Ziffer 3);

d) das Kind, das vor seinem siebten Lebensjahr während mindestens eines Jahres zusammen mit seinem gesetzlichen Vertreter in Belgien lebte (Art. 13 Ziffer 4).

Die Optionserklärung kann aber in den Fällen von Art. 13 nur abgegeben werden, falls folgende Voraussetzungen vorliegen (Art. $14 \mathrm{CNB}$ ).

a) Der Optierende muß mindestens 18 Jahre sein, aber darf noch nicht das Alter von 22 Jahren erreicht haben. Zweck dieser Einschränkung ist vor allem vorzubeugen, daß eine Erklärung nicht solange herausgeschoben wird, bis man nicht mehr zur Wehrpflicht eingezogen werden kann (96).

b) Der Betreffende muß während der zwölf der Erklärung vorausgegangenen Monate in Belgien gelebt haben (97).

c) Er muß von seinem vierzehnten bis achtzehnten Geburtstag oder insgesamt neun Jahre in Belgien gelebt haben (98). Diese letzte Bedingung braucht nicht erfïllt zu sein, falls ein (Adoptions-)Elternteil zur Zeit der Geburt des Betreffenden die belgische Staatsangehörigkeit hatte oder gehabt hatte (99). Bemerkenswert ist weiter, daß der letzte Absatz von Art. 14 CNB den Aufenthalt im Ausland dem Aufenthalt in Belgien gleichstellt, falls der Betreffende nachweist, tatsächlich Bande mit Belgien behaiten zu haben (100).

Die Art und Weise, in der die Erklärung abgegeben werden muß, ist in Art. 15 CNB geregelt. Oben wurdle schon darauf hingewiesen; daß die Option zurückgewiesen werden kann. Die belgische Staatsangehörigkeit wird durch die Erklärung erworben, nachdem sie vom Landgericht (tribunal de première instance) 
genehmigt worden und anschließend in die Standesamtregister eingetragen ist. Ein Optionsrecht - sei es auch unter abweichenden Bedingungen - haben auch die ausländischen Ehegatten von belgischen Staatsangehörigen (Art. $16 \mathrm{CNB}$ ). Dieses Recht hat der ausländische Ehepartner, nachdem er mindestens sechs Monate in Belgien mit seinem belgischen Partner zusammengelebt hat (101). Die Erklärung kann nur abgegeben werden, solange das Zusammenleben fortdauert (102). Zusammenleben im Ausland wird dem Zusammenleben in Belgien gleichgestellt, falls der Betreffende wieder nachweist, daß zwischen ihm und Belgien tatsăchliche Bande entstanden sind. Auch diese Option kann aber wieder zurückgewiesen werden wegen wichtiger, den Optierenden betreffenden Grüinden oder unzureichendem Integrationswillen. AuBerdem kann das Optionsverfahren bis zu zwei Jahre ausgesetzt werden, falls das Gericht, das die Option genehmigen $\mathrm{muB}$, der Ansicht ist, daß die Dauer des Zusammenlebens nicht ausreichend ist, um den Integrationswillen zu beurteilen (103).

Im Zusammenhang mit den Optionsrechten muß schließlich noch die bemerkenswerte Regelung des Art. $17 \mathrm{CNB}$ erwähnt werden. Falls jemand während zehn Jahren ununterbrochen als Belgier behandelt worden ist, und sich nachträglich herausstellt, daf3 dies zu Unrecht geschah, kann diese Person während eines Jahres, nachdem sich dies herausgestellt hat, durch Optionserklärung die belgische Staatsangehörigkeit erwerben (104).

Jene Optionerklärung kann ausschließlich zurückgewiesen werden, falls der Nachweis, daß er während zehn Jahren als Belgier behandelt worden ist, nicht ausreichend ist (105).

Die ordentliche Einbürgerung kann von Personen, die älter als achtzehn Jahren sind und seit mindestens fünf Jahren in Belgien leben, beantragt werden. Für Flïchtlinge und Staatenlose genügt eine Aufenthaltsdauer von drei Jahren. Auch hier wird wieder Aufenthalt im Ausland dem Aufenthalt in Belgien gleichgestellt, wenn nachgewiesen wird, daß der Betreffende während der geforderten Zeit reelle Beziehungen zu Belgien hatte. Die Einbürgerungsurkunde muß von den beiden Kammern des Parlaments genehmigt und vom König bestätigt werden. Die Einbürgerung wird im Gesetzblatt veröffentlicht. Im Rahmen des Einbürgerungsverfahrens wird wieder überprüft, ob wichtige Tatsachen vorliegen, die gegen den Kandidaten sprechen, und ob er Integrationswillen hat (106). Das Parlament kann auch fordern, daß noch andere Tatsachen untersucht werden (Art. 21, \&1, Abs. 2 CNB) (107). Es wird nicht ausdruicklich gefordert, daß der Einbürgerungsbewerber dazu bereit sein muß, seine bisherige Staatsangehörigkeit aufzugeben (108).

Die große Eimbürgerung kann Personen verliehen werden, die bereits 25 Jahre alt sind, alle Voraussetzungen für die normale Einbürgerung erfüllen und entweder für Belgien besondere Dienste geleistet haben, leisten können oder die belgische Staatsangehörigkeit seit mindestens fünf Jahren erworben haben durch die normale Einbürgerung oder durch Optionserklärung gemäß Art. 16 (109). Auch die große Einbürgerungsurkunde muß wieder vom Parlament genehmigt und vom König bestätigt werden.

Sowoll für die kontrollierte Option als auch für die Einbürgerung ist also nun ein Integrationswillen (volonté d'intégration) erforderlich (110). Diese Integration braucht ausdrücklich keine Assimilation zu sein (111). Was nun aber die 
genauen Kriterien für die Annahme eines Integrationswillen sind geht weder aus dem Gesetz noch aus den Motiven hervor. Verwilghen (112) zitiert in diesem Zusammenhang Frau Hermann-Michielsens, die wăhrend der Beratungen im Senat sagte: "Je ne crois pas qu"il soit possible de fixer des critères objectifs permettant de déterminer la volonté d'intégration" (113). Der Einbürgerungsbewerber muß sich aber jedenfalls in einer der nationalen Sprachen ausdruicken können und gewisse soziale Beziehungen zu Belgiern haben (114).

Die für eine Einbürgerung zu zahlenden Kosten betragen seit 1964 im Prinzip 16.000 Belgische Franken, sowohl für die normale als auch für die große Einbürgerung (115). Falls der Antragsteller jedoch noch keine 22 Jahre alt ist, brauchen lediglich 2000 Belgische Franken gezahlt zu werden; das gleiche gilt für diejenigen, die um die große Einbürgerung nachsuchen und schon die Kosten für eine normale Einbürgerung gezahlt hatten. Personen mit niedrigen Einkünften können Ermäßigung der zu zahlenden Kosten beanspruchen. Bergwerkarbeiter und deren Witwen können unter gewissen Voraussetzungen kostenlose Einbürgerung beantragen.

Art. 24 BNW sieht für diejenigen, die ihre belgische Staatsangehörigkeit verloren haben, die Möglichkeit vor, durch ein kontrolliertes Optionsverfahren gemäß Art. $15 \mathrm{BNW}$ ihre alte Staatsangehörigkeit zurïckzuerwerben. Voraussetzungen sind grundsätzlich, daß man durch Geburt Belgier war, mindestens 18 Jahre ist und während der letzten zwölf Monate in Belgien lebte (116). Wenn die Staatsangehörigkeit durch Verzicht verloren wurde, kann von der letzten Bedingung abgesehen werden.

Wenn ein Ausländer durch Option oder Einbürgerung die belgische Staatsangehörigkeit erwirbt, erstreckt sich dieser Erwerb auf seine noch nicht 18 Jahre alten (Adoptiv)Kinder, falls er über diese die elterliche Gewalt ausübt (117).

\subsubsection{Verlustgründe}

\subsubsection{Rückblick}

Bis 1985 wurde die belgische Staatsangehörigkeit von der Belgierin verloren, die einen Ausländer heiratete. Seit 1926 konnte die gebürtige Belgierin aber innerhalb von sechs Monaten nach dem Verlust erklären, weiterhin Belgierin bleiben zu wollen (118). Diese Möglichkeit hatte aber nur die gebürtige Belgierin. Die kraft Eheschließung gewordene Belgierin konnte im Falle einer Zweitehe mit einem Ausländer von dieser Möglichkeit nicht Gebrauch machen.

Einbürgerung im Ausland war bereits in den Cc-Bestimmungen ein Verlustgrund der belgischen Staatsangehörigkeit. Auch die Gesetze von 1909 und 1932 erwähnten "freiwilligen Erwerb" einer anderen Staatsangehörigkeit als Verlustgrund (119).

Nach Art. 17 unter 2 und Art. $21 \mathrm{Cc}$ waren die Annahme eines von einer fremden Regierung verliehenen Amtes oder der Eintritt in ausländischen Militärdienst Verlustgründe der Staatsangehörigkeit, es sei denn, die belgische Regierung hatte dazu eine Ermächtigung gegeben. Diese Verlustgründe wurden 1865 aufgehoben. Im Gesetz von 1909 wurden sie ebenfalls nicht erwähnt, ebenso wenig im Gesetz von 1932. Im Jahre 1934, beziehungsweise 1944 wurden aber "ähnliche" Verlustgründe eingeführt durch Hinzufügung der Art. 18bis, beziehungsweise 18ter: Aberkennung der Staatsangehörigkeit wegen grober Verlet- 
zung der Plichten als belgischer Staatsbürger und Verlust der Staatsangehörigkeit wegen bestimmter im Krieg begangener strafbarer Handlungen (120).

In Art. 17 unter $3 \mathrm{Cc}$ war der Auslandsaufenthalt als Verlustgrund vorgesehen. Das Gesetz von 1909 kannte diesen Verlustgrund jedoch nicht, ebenso wenig das Gesetz von 1932 (121).

Die früheren Regelung sahen für die verheiratete Frau und für minderjährige Kinder u.U. einen vom Staatsangehörigkeitsverlust des Ehemannes, beziehungsweise Vaters verursachten Verlust der belgischen Staatsangehörigkeit vor (122).

Durch Gesetz vom 4. August 1926 (Art. 16) bestimmte der Gesetzgeber, daß der Verlust der belgischen Staatsangehörigkeit durch Verzicht der Zustimmung der belgischen Behörden bedürfe (123).

\subsubsection{Heutige Regelung}

Die Verlustgründe der belgischen Staatsangehörigkeit sind in den Art. 22 und $23 \mathrm{CNB}$ enthalten.

An erster Stelle wird die belgische Staatsangehörigkeit durch freiwilligen Erwerb einer anderen Staatsangehörigkeit verloren (Art. $22 \& 1$, Ziffer 1 CNB) (124). Weiter kann eine Person, die mindestens achtzehn Jahre alt ist und nachweist, daß sie auch eine andere Staatsangehörigkeit besitzt, auf die belgische Staatsangehörigkeit verzichten. Verzicht ist auch möglich, wenn als Folge der Verzichtserklärung eine andere Staatsangehörigkeit zurückerworben wird (Art. 22, § 1, Ziffer 2 CNB). Wehrpflichtige können die belgische Staatsangehörigkeit grundsätzlich nur durch Verzicht oder freiwilligen Erwerb einer fremden Staatsangehörigkeit verlieren, nachdem sie dazu vom König ermächtigt sind. Diese Ermächtigung ist nicht erforderlich, wenn der Betreffende die belgische Staatsangehörigkeit infolge freiwilligen Erwerbs dieser Staatsangehörigkeit durch einen (Adoptiv-)Elternteil erworben hat (125).

Die belgische Staatsangehörigkeit kann auch durch ununterbrochenen Auslandsaufenthalt verlorengehen. Voraussetzungen sind, da $B$ der Betreffende zwischen seinem 18. und 28. Geburtstag ununterbrochen im Ausland lebte und dort nicht im Auftrag von oder durch Vermittlung der belgischen Regierung arbeitete, oder im Dienste einer Gesellschaft oder eines Vereins nach belgischem Recht stand. Der Verlust tritt nicht ein, wenn er dadurch staatenlos werden wïrde. Außerdem kann dem Verlust vorgebeugt werden durch das Abgeben einer Erklärung, weiterhin Belgier bleiben zu wollen. In letzterem Falle beginnt eine neue Frist von zehn Jahren (126). Verwilghen (127) betrachtet diesen Verlustgrund als stillschweigenden Verzicht (abdication tacite).

Minderjährige verlieren die belgische Staatsangehörigkeit grundsätzlich, wenn die (Adoptiv-)Eltern beide die belgische Staatsangehörigkeit verlieren (Art. 22 $\$ 1$, Ziffer 3 und $6 \mathrm{CNB}$ ) (128) und, wenn sie von Ausländern adoptient werden (129). Die Staatsangehörligkeit kann aber aus diesem Grunde nicht verloren werden, wenn dadurch Staatenlosigkeit die Folge wäre.

Einen alten Verlustgrund finden wir in Art. $23 \mathrm{CNB}$ : dem Belgier, der seine Staatsangehörigkeit nicht von einem Elternteil ableitet, wellcher Belgier zur Zeit 
seiner Geburt war, kann die Staatsangehörigkeit auf Antrag der Staatsanwaltschaft vom Gerichtshof aberkannt werden (130). Eine solche Aberkennung kann u.U. sogar Staatenlosigkeit zu Folge haben.

Die belgische Staatsangehörigkeit kann schließlich verloren werden wegen Wegfall der familienrechtlichen Beziehungen, aufgrund derer die Staatsangehörigkeit erworben wurde (131). 


\subsection{BUNDESREPUBLIK DEUTSCHLAND}

\subsubsection{Allgemeine Bemerkungen}

Die Hauptquelle des Staatsangehörigkeitsrechts in der Bundesrepublik Deutschland bildet das Reichs- und Staatsangehörigkeitsgesetz (RuStAG) vom 22. Juli 1913 (1). Dieses Gesetz hat viele Narben. Seit seinem Inkrafttreten am 1. Januar 1914 ist es häufig geändert worden (2). Im Augenblick des Zustandekommens des Gesetzes war Wilhelm II noch Kaiser des Deutschen Reiches, innerhalb dessen die Bundesstaaten eine gewisse Autonomie innehatten (3). Nach dem Sturz des Kaiserreiches und der Gründung der Weimarer Republik (4) im Jahre 1918 galt das RuStAG weiter. Sogar während des darauffolgenden Tausendjährigen Reiches von Hitler wurde es nicht eingezogen. Wohl aber sind in dieser Periode beachtliche Änderungen vorgenommen worden, um den Text des RuStAG an die Situation anzupassen, die entstanden war, nachdem 1934 ein zentralistischer Staat (5) geschaffen wurde und, um die Bestimmungen des Gesetzes auch weiter den "Idealen" der Nationalsozialisten entsprechen zu lassen. Nach dem Untergang des Dritten Reiches galt das Gesetz in ganz Deutschland (also in allen Besatzungszonen) weiter (6). Seit der Gründung der Bundesrepublik Deutschland im Jahre 1949 ist das RuStAG Teil der Gesetzgebung dieses Staates. Das gleiche war der Fall in der ebenfalls 1949 gegriundeten Deutschen Demokratischen Republik, wo es jedoch 1967 durch das Staatsbürgerschaftsgesetz (7) abgelöst wurde.

Vor Inkrafttreten des RuStAG galt das Gesetz über die Erwerbung und den Verlust der Bundes- und Staatsangehörigkeit vom 1. Juni 1870 (8). Dies war die erste für das ganze Deutsche Reich geltende Staatsangehörigkeitsregelung. Vorher gab es lediglich Gesetze der einzelnen deutschen Staaten, in denen Gründe für den Erwerb und Verlust der Staatsangehörigkeit oder doch eines ihr sehr ähnlichen Rechtsstatus aufgestellt wurden (9). Das Gesetz vom 1. Juni 1870 war ursprüinglich ein Gesetz des Nord-Deutschen Bundes. Es wurde aber nach der Reichsgründung (10) im Jahre 1871 als Reichsgesetz übernommen und wurde seitdem als Reichs- und Staatsangehörigkeitsgesetz bezeichnet (11) (im folgenden zu zitieren als RuStAG 1870).

Das 1871 gegründete Deutsche Kaiserreich war kein Einheitsstaat, sondern hatte eine föderalistische Struktur (12). Dies äußerte sich auch im Staatsangehörigkeitsrecht. In \& 1 RuStAG 1870 wurde bestimmt:

"Die Reichsangehörigkeit wird durch die Staatsangehörigkeit in einem Bundesstaat erworben und erlischt mit deren Verlust".

Grundsätzlich war man primär Bürger eines Bundesstaates und hatte dadurch auch die Reichsangehörigkeit.

Das RuStAG 1870 ging für eheliche und vom Vater anerkannte, nichteheliche Kinder vom ius sanguinis a patre aus.

Gemäß \& 5 RuStAG 1870 bewirkte die Verheiratung mit einem Deutschen, daß eine ausländische Ehefrau đie deutsche Staatsangehörigkeit erwarb. Die Einbürgerung war in den $\$ \$ 8$ ff. RuStAG 1870 geregelt. Ausländer, die mittelbar oder unmittelbar im Dienst von Staat, Gemeinde, Schule oder einer anerkannten 
Religionsgemeinschaft standen, erwarben durch die Bestallungsurkunde die deutsche Staatsangehörigkeit ( $\$ 9$ RuStAG 1870).

Die Staatsangehörigkeit wurde aus einigen in $\$ 13$ RuStAG 1870 erwähnten Gründen verloren. Erster Grund war die Entlassung auf Antrag. Die Staatsangehörigkeit konnte weiter entzogen werden, und zwar denjenigen, die sich im Ausland befanden und bei Krieg oder Kriegsgefahr eine Rückkehrsaufforderung nicht befolgten ( $\$ 20$ RuStAG 1870). Auch war Entzug der Staatsangehörigkeit möglich, wenn jemand ohne Erlaubnis in fremden Staatsdienst trat und einer Austrittsaufforderung nicht folgte $(\$ 22$ RuStAG 1870). Nichteheliche Kinder verloren die deutsche Staatsangehörigkeit bei Legitimation, wenn der Vater Ausländer war. Die Anerkennung durch einen Ausländer hatte nicht diese Folge. Eine deutsche Frau verlor ihre Staatsangehörigkeit durch Verheiratung mit einem Ausländer, auch wenn sie dadurch staatenlos wurde. Schliesslich sah $\S$ 21 RuStAG vor, daß die Staatsangehörigkeit durch zehnjährigen ununterbrochenen Auslandsaufenthalt verloren wurde, der allerdings durch Konsulatseintragung unterbrochen werden konnte.

Während der Geltungsdauer des RuStAG 1870 sind nur einige kleinere Änderungen vorgenommen worden (13). Vor allem die Bestimmung über den stillschweigenden Verlust der deutschen Staatsangehörigkeit durch fortdauernden Aufenthalt im Ausland fand man unbefriedigend (14). Man wollte dies ändern und benutzte diesen Anlaß, um das ganze Staatsangehörigkeitsrecht zu revidieren. Dies führte zu der Verkündigung des Reichs- und Staatsangehörigkeitsgesetzes 1913. Die vorgenommenen Änderungen waren aber nicht einschneidend. Man kann das RuStAG 1913 deshalb als eine abgeänderte und verbesserte Fassung des RuStAG 1870 betrachten.

$\mathrm{Zu}$ den wesentlichsten Änderungen gehörte, daß $\$ 4$ RuStAG für Findelkinder den Erwerb der deutschen Staatsangehörigkeit vorsah. Weiter machte $\S 10$ den Wiedererwerb der Staatsangehörigkeit möglich für die von Geburt deutsche Witwe oder geschiedene Ehefrau eines Ausländers; auch gewissen anderen Gruppen von ehemaligen Deutschen (Entlassenen und Staatenlosen) wurde die Möglichkeit des Wiedererwerbs geboten. \& 12 RuStAG gab einem Ausländer, der mindestens ein Jahr in der deutschen Armee gedient hat, einen Einbürgerungsanspruch. Die Bestimmung, daß die deutsche Staatsangehörigkeit durch fortdauernden Auslandsaufenthalt verloren wurde, war im RuStAG grundsätzlich gestrichen. Eine ähnliche Bestimmung enthielt jedoch dennoch \& $26 \mathrm{RuStAG}$. für im Ausland lebende wehrpflichtige Deutsche.

Auch das RuStAG stand ursprünglich ganz in Übereinstimmung mit der föderalistischen Struktur des Kaiserreiches. 1 RuStAG lautete ursprünglich:

"Deutscher ist, wer die Staatsangehörigkeit in einem Bundesstaat oder die unmittelbare Reichsangehörigkeit besitzt".

Derjenige, der die Staatsangehörigkeit eines Bundesstaates besaß, hatte zu gleicher Zeit die Reichsangehörigkeit. Umgekehrt gab es aber einige Fälle unmittelbarer Reichsangehörigkeit ( $\$ 33$ und 34 RuStAG).

Am 10. November 1918 floh der deutsche Kaiser Wilhelm II in die Niederlande, nachdem ein Tag zuvor in Berlin die Republik ausgerufen worden war, 
die als Weimarer Repubilik bekannt werden würde. Auch die Verfassung dieser Republik ging von einer föderalistischen Struktur aus (15). In Art. 110 Abs. I dieser "Weimarer" Verfassung wurde in Bezug auf die Staatsangehörigkeit bestimmt"

"Die Staatsangehörigkeit im Reiche und in den Ländern wird nach den Bestimmungen eines Reichsgesetzes erworben und verloren. Jeder Angehörige eines Landes ist zugleich Reichsangehöriger".

Während der Weimarer Repablik wurden keine wichtigen Änderungen des RuStAG vorgenommen (16). Von den staatsangehörigkeitsrechtlichen Bestimmungen aus anderen Gesetzen sind die $\S \S 23-25$ des Gesetzes gegen die Steuerflucht erwähnenswert, die u.U. als Sanktion Verlust der deutschen Staatsangehörigkeit kannten (17).

Am 30. Januar 1933 kamen die Nationalsozialisten an die Macht (18). 1934 wurde das Gesetz über den Neuaufbau verkündet, das die föderalistische Struktur des Deutschen Reiches beendete (19). Alle Gesetze mußten mit diesem Neuaufbau in Übereinstimmung gebracht werden. Deshalb wurde auch das RuStAG durch die Verordnung über die deutsche Staatsangehörigkeit vom 5. Februar 1934 geändert (20). \& 1 dieser Verordnung lautete:

"Die Staatsangehörigkeit in den deutschen Ländern fällt fort. Es gibt nur noch eine deutsche Staatsangehörigkeit (Reichsangehörigkeit)" (21).

1935 wurden wichtige Änderungen im RuStAG angebracht. Im Gesetz von 1913 standen relativ viele Fälle von Einbürgerungsansprüchen für bestimmte Personenkreise (22). Diese Einbürgerungsansprüche wurden durch $\S 2$ des Gesetzes vom 15. Mai 1935 (23) aufgehoben.

Während des Dritten Reiches wurde die staatsangehörigkeitsrechtliche Position deutscher Bürger von mehreren besonderen Gesetzen und Verordnungen beeinflußt (24). Am wichtigsten waren aber zweifelsohne das bereits kurz nach der Machtübernahme verkündete Gesetz über den Widerruf von Einbürgerungen und die Aberkennung der deutschen Staatsangehörigkeit vom 14. Juli 1933 (25) und die Elfte Verordnung zum Reichsbürgergesetz vom 25. November 1941 (26).

Das ersterwähnte Gesetz offnete u.a. die Möglichkeit, jenen Personen, die im Ausland lebten und deutschen Interessen zuwider handelten (27), die deutsche Staatsangehörigkeit zu entziehen. Vor allem bei jüdischen Bürgem wurde diese Möglichkeit benutzt. Die Verordnung aus dem Jahre 1942 ging noch einen Schritt weiter und entzog sämtlichen Juden, die außerhalb Deutschlands waren, die deutsche Staatsangehörigkeit (28). \& 1 des Gesetzes vom 14. Juli 1933 ermöglichte weiter, Einbürgerungen, die in der Zeit zwischen dem 9 . November 1918 und dem 30. Januar 1933 vorgenommen waren, zu widerrufen, falls die Einbürgerung nicht als erwünscht anzusehen war.

Durch eine während des Dritten Reiches verkündete Verordnung (20. Januar 1942, RGBI. I, 40) wurde $\$ 26$ RuStAG (kraft dessen wehrpflichtige Auslandsdeutsche die deutsche Staatsangehörigkeit verlieren konnten) eingezogen. Dieselbe Verordnung eröffnete die Möglichkeit einer Einbürgerung bei Auslandswohnsitz. 
Die meisten besonderen staatsangehörigkeitsrechtlichen Gesetze und Verordnungen, die von den Nationalsozialisten eingeführt waren, sind gleich nach dem Zweiten Weltkrieg widernufen worden (29). Dies gilt namentlich für die Ausbürgerungsgesetze. Das RuStAG blieb aber mit den während des Dritten Reiches vorgenommenen Änderungen weiterbestehen.

Seit der Gründung der Bundesrepublik Deutschland im Jahre 1949 hat das Staatsangehörigkeitsrecht starken Einfluß des Grundgesetzes (30) dieses neuen Staates unterfunden. Im Grundgesetz wird die Staatsangehörigkeit in vier Artikeln erwähnt. An erster Stelle bestimmt Art. 16 Abs. 1 GG:

"Die deutsche Staatsangehörigkeit darf nicht entzogen werden. Der Verlust der Staatsangehörigkeit darf nur auf Grund eines Gesetzes und gegen den Willen des Betroffenen nur dann eintreten, wenn der Betroffene dadurch nicht staatenlos wird".

Diese Bestimmung ist eine eindeutige Reaktion auf die Ausbürgerungspraxis Hitlers (31). Als Konsequenz des Art. 16 Abs. 1 GG wurde die Wirkung einiger Verlustbestimmungen des RuStAG ab in Krafttreten des GG am 23. Mai 1949 dermaßen eingeschränkt, daß kein Verlust der deutschen Staatsangehörigkeit mehr auftrat, wenn Staatenlosigkeit die Folge wäre. Dies war namentlich von Bedeutung für den vorgesehenen Verlust der deutschen Staatsangehörigkeit im Falle einer Eheschließung einer deutschen Frau mit einem Ausländer oder im Falle einer Legitimation eimes deutschen Kindes durch einen Ausländer.

Weiter begegnen wir dem Begriff der Staatsangehörigkeit in den Art. 73 Ziffer 2. und 74 Ziffer 8 GG, worin die Gesetzgebungskompetenz des Bundes geregelt ist (32). Von großer Bedeutung ist weiter Art. 116 Abs. $1 \mathrm{GG}$ :
"Deutscher im Sinne dieses Grundgesetzes ist vorbehaltlich anderweitiger gesetzlicher Regelung, wer die deutsche Staatsangehörigkeit besitzt oder als Flüchtling oder Vertriebener deutscher Volkszugehörigkeit oder als dessen Ehegatte oder Abkömmling in dem Gebiete des Deutschen Rei- ches nach dem Stande vom 31. Dezember 1937 Aufnahme gefunden hat."

Auch diese Bestimmung ist im Lichte der deutschen Geschichte verständlich. Nach dem Zweiten Weltkrieg kamen Massen von Flüchtlingen nach Deutschland, die wegen ihrer deutschen Abstammung (oder wenigstens wegen der Benutzung der deutschen Sprache) aus ihrer Heimat vertrieben worden waren. Viele dieser Flüchtlinge hatten nicht die deutsche Staatsangehörigkeit. Diese Personen mußten aufgefangen werden. Man wollte sie nicht als Ausländer behandeln (33). Durch die Bestimmung des Art. 116 Abs. 1 GG haben sie weitgehend die gleiche Rechtsposition wie diejenigen, die deutsche Staatsangehörige sind.

Schließlich ist auch Art. 116 Abs. 2 GG eine Reaktion auf die Geschehnisse in nationalsozialistischer Zeit. Im Jahre 1949 hat man daruber nachgedacht, die Massenausbürgerungen, die von Hitler vorgenommen worden waren, - vielleicht mit rückwirkender Kraft - zu widerrufen. Man hat dies jedoch unterlassen, weil man es als weniger wünschenswert empfand, Personen, die aus Deulschland flüchten mußten und ausgebürgert waren, plötzlich wieder die deutsche Staats- 
angehörigkeit aufzudrängen. Viele dieser Personen hatten sich ja aus verständlichen Gründen geschworen, nie wieder einen FuB auf deutschen Boden zu setzen. Deshalb bestimmt Art. 116 Abs. 2 GG, daß Personen, die zwischen dem 30. Januar 1933 und 8. Mai 1945 ausgebuirgert worden waren, auf ihren Antrag einzubürgern sind. Für ihre Abkömmlinge gilt das gleiche. Soweit die betreffenden Personen sich nach dem Untergang des Dritten Reiches wieder in Deutschland niedergelassen haben, sind sie automatisch wieder deutsche Staatsangehörige geworden, es sei denn, sie haben eine gegenteilige Erklärung abgegeben (34).

Die Grundgesetzbestimmung, die das Staatsangehörigkeitsrecht Deutschlands aber weitaus am meisten beeinflußt hat, ist die des Art. 3 Abs. 2 GG: "Männer und Frauen sind gleichberechtigt".

Diese Bestimmung bewirkte nicht, daß sämtliche Regelungen, die mit dem Prinzip der Gleichheit der Geschlechter streitig waren, im Augenblick der Verkuindung des Grundgesetzes im Jahr 1949 außer Kraft traten, da Art. 117 Abs. 1 GG eine Übergangsregelung vorsah (35). Das Recht, das Art. 3 widersprach, blieb in Kraft, bis es geändert wurde, aber höchstens bis einschließlich 31. März 1953 (36). Selbstwerständlich wurde die Frage gestellt, inwieweit das Staatsangehörigkeitsrecht auf Grund des Art. 3 GG geändert werden müßte. Es würde erheblich zu weit führen, die damals geführte Diskussion hier detailliert zu besprechen. Einige Stimmen in der Literatur vertraten die Ansicht, daB Art. 3 GG für das Staatsangehörigkeitsrecht überhaupt keine Konsequenzen zu haben brauchte (37). Die Mehrheit der Autoren dachte hierüber jedoch anders, die Meinungen waren jedoch sehr geteilt über die Beantwortung der Frage, wieweit man bei der Realisierung der Gleichberechtigung auf diesem Gebiet gehen mußte (38). Die Bundesregierung legte nicht rechtzeitig einen Gesetzesentwurf vor (39). Die Folge davon war, daß am 31. März 1953 noch nichts im RuStAG geändert war. Das Bundesverfassungsgericht entschied an 18. Dezember 1953, daß nach Ablauf der Frist des Art. 117 GG Art. 3 GG direkte Gesetzeskraft hatte, wodurch sämtliche mit Art. 3 streitigen Bestimmungen außer Kraft getreten waren (40). Schwierig war es aber, festzustellen, welche Teile des RuStAG hierdurch nicht mehr galten. Hinsichtlich einiger Bestimmungen war man sich wohll einig. Dies war z.B. der Fall bei der Regelung des \& 17 Ziffer 6 RuStAG, kraft dessen eine deutsche Frau, die einen Ausländer heiratete, ihre deutsche Staatsangehörigkeit verlor. Umstritten war aber z.B., ob eine ausländische Frau, die einen Deutschen heiratete, weiterhin aufgrund des $\$ 6$ RuStAG die Staatsangehörigkeit ihres Gatten erwarb (41).

Dieser Unsicherheit wurde durch das Dritte Gesetz zur Regelung von Fragen der Staatsangehörigkeit vom 19. August 1957 (42) ein Ende gemacht, das die Gleichberechtigung von Mann und Frau im Staatsangehörigkeitsrecht verwirklichen sollte. Nach heutiger Auffassung ging man dabei nicht weit genug. Fortan wurde die deutsche Staatsangehörigkeit von der deutschen Frau, die einen Ausländer heiratete, nicht mehr verloren. Dem gegenüber stand, daß auch die ausländische Gattin eines Deutschen nicht mehr automatisch Deutsche wurde. Sie konnte aber bei der Eheschließung erklären, die deutsche Staatsangehörigkeit erwerben zu wollen (43). 1957 versuchte man aber noch nicht, auch den ausländischen Mann einer Deutschen in dieselbe staatsangehörigkeitsrechtliche Lage zu versetzen. Insoweit kann man eine deutliche Ungleichbehandlung kon- 
statieren. Ebensowenig änderte man die Regel hinsichtlich der Staatsangehörigkeit der Kinder aus gemischt-nationalen Ehen.

Die Diskussion über das Verhältnis des Staatsangehörigkeitsrechts zum Prinzip der Gleichberechtigung verstuminte aber keineswegs. Im Jahre 1960 bat der Bundestag (44) die Bundesregierung, die Regel über die Statsangehörigkeit ehelicher Kinder im Lichte des Art. 3 GG dermaßen zu ändern, daß die ehelichen Kinder einer deutschen Frau und eines Ausländers die deutsche Staatsangehörigkeit erwerben würden, falls sie sonst staatenlos sein würden (45). Auch die Gerichte ließen von sich hören. Das Bundesverwaltungsgericht entschied 1962 (46), daß es verfassungswidrig sei, daß das eheliche Kind einer deutschen Mutter und eines staatenlosen Vaters, nicht die Staatsangehörigkeit der Mutter durch Geburt erwarb. Daraufhin wurde \& 4 RuStAG entsprechend geändert (47).

Im Jahre 1969 wurde das RuStAG erneut geändert, un die Gleichberechtigung besser zu realiseren (48). Diesmal änderte man die Bestimmungen des RuStAG dermaßen, daß die Position eines ausländischen Partners einer Deutschen dieselbe sein würde wie die der ausländischen Partnerin eines Deutschen. Das Optionsrecht, das die ausländische Frau seit 1957 hatte, wurde abgeschafft (49). Sowohl der ausländische Mann als die ausländische Frau hatten nach der Eheschließung mit einem Deutschen oder einer Deutschen ausschließlich die Möglichkeit einer erleichterten Einbürgerung.

L'histoire se repète! Eben wurde schon gezeigt, daß die Rechtsprechung häufiger entschieden hatte, daß das Staatsangehörigkeitsrecht nicht verfassungsgemäß war, und der Gesetzgeber danach das RuStAG änderte. Dies geschah auch wieder in den siebziger Jahren, als eine lebendige Diskussion über die Frage entstand, ob es wohl mit dem Gleichheitsgrundsatz zu vereinbaren war, daß die ehelichen Kinder einer deutschen Mutter nur in Ausnahmefällen die Staatsangehörigkeit ihrer Mutter erwarben (50). Die Diskussion wurde 1974 durch ein Urteil des Bundesverfassungsgerichtes abgeschlossen (51). Das Verfassungsgericht betonte, daß es nicht verfassungsgemäß sei, daß das eheliche Kind eines deutschen Vaters und einer ausländischen Mutter immer die deutsche Staatsangehörigkeit erwirbt, wohingegen das eheliche Kind einer deutschen Mutter und eines ausländischen Vaters ausschließlich dann, wenn es sonst staatenlos wäre. Das Bundesverfassungsgericht forderte deshalb den Gesetzgeber auf, das RuStAG zu ändern. Dies geschah daraufhin durch Gesetz vom 20. Dezember 1974 (52). Seit dem 1. Januar 1975 erwerben deshalb alle Kinder einer deutschen Mutter die deutsche Staatsangehörigkeit. Durch das Gesetz von 1974 sind auch noch mehrere andere Vorschriften des RuStAG diesem Ausgangspunkt angepasst (53). Seitdem kann die Verwirklichung der Gleichberechtigung im deutschen Staatsangehörigkeitsrecht als beendet betrachtet werden.

Seit 1974 ist das RuStAG noch fünfmal geändert. Das Gesetz zur Erleichterung der Verwaltungsreform in den Ländern vom 10. März 1975 hat einige kleine Änderungen bewirkt (54). Im Jahre 1976 wurde das deutsche Adoptionsrecht eingehend geändert. Dies bewirkte auch Änderungen der sich auf die Adoption beziehenden staatsangehörigkeitsrechtlichen Bestimmungen (55). Fortan konnte die deutsche Staatsangehörigkeit durch Annahme an Kindes statt erworben werden. Eine weitere Änderung des RuStAG erfolgte durch das Gesetz zur Verminderung der Staatenlosigkeit vom 29. Juni 1977 (56). Eine kleine Ände- 
rung wurde auch durch das Gesetz zur Regelung des Rechts der elterlichen Sorge vom 18. Juli 1979 (57) herbeigeführt, daß an allen Stellen, wo das RuSt.AG den Begriff der "elterlichen Gewalt" benutzte, diesen Begriff durch "elterliche Sorge" ersetzte. Eine letzte - kleine - Änderung des RuStAG wurde durch das am 1. September 1986 in Kraft getretene neue IPR-Neuregelungsgesetz realisiert (58).

Seit ungefahlhr 1980 wird darüber diskutiert, ob in Deutschland wohnhafte Ausländer nicht u.U. einen Einbürgerungsanspruch haben sollten. Eine entsprechende Regelung war in einem 1982 beim Bundestag eingereichten Regierungsentwurf eines 4 . Staatsangehörigkeitsregelungsgesetzes enthalten (59). Die Behandlung dieses Entwurfes erledigte sich jedoch durch Auflösung des Bundestages.

Im Rahmen dieser allgemeinen Bemerkungen zum deutschen Staatsangehörigkeitsrecht darf ein typisch deutsches Problem nicht unerwähnt bleiben. Wir sahen bereits, daß das RuStAG viele Änderungen der Staatsform überstanden hat. Das Gesetz ist 1913 für das Grundgebiet des ganzen damaligen deutschen Reiches verkündet worden. Auf diesem Grundgebiet gibt es seit 1949 zwei deutsche Staaten. Oben wurde schon darauf hingewiesen, daß das RuStAG nach dem Kriege sowohl in der BRD als in der DDR weitergalt. Beide deutschen Staaten hielten nach 1949 zuerst auch am Prinzip fest, daß nach dem Zweiten Weltkrieg nur eine deutsche Staatsangehörigkeit existierte (60). Dies bedeutete, daß3 die DDR Deutsche aus der Bundesrepublik Deutschland nicht als Ausländer betrachtete und umgekehrt (61). Erst in der zweiten Hälfte der fünfziger Jahren hat die DDR diesen Ausgangspunkt verlassen (62) Seitdem gehen die Äußerungen der DDR-Behörden von einer selbständigen DDR-Staatsangehörigkeit aus. Die Auffassungsänderung äußerte sich vor allem in der Verabschiedung des 1967 in Kraft getretenen Staatsbürgerschaftsgesetzes (63). Das alte RuStAG wurde aufgehoben. Die Tatsache, daß das neue DDR-Gesetz von Staatsbürgerschaft statt von Staatsangehörigkeit spricht ist ein Versuch sich von der alten Reichsangehörigkeit zu distanzieren (64). In der Bundesrepublik Deutschland hält man dagegen noch immer an der Konzeption einer gesamtdeutschen Staatsangehörigkeit fest (65). Dies hat namentlich Folgen für die Anwendung bundesdeutschen Rechts auf DDR-Bürger, die sich im Bundesgebiet niederlassen (66).

In der Bundesrepublik Deutschland ist die Diskussion über das Wesen der gesamtdeutschen Staatsangehörigkeit in letzter Zeit vor allem im Zusammenhang mit Problemen der Divergierung der Verlust- und Erwerbsgründe der Staatsangehörigkeit in den beiden deutschen Staaten geführt worden, namentlich im Zusammenhang mit der Frage, ob in der $\mathbb{D D R}$ vorgenommene Einbürgerungen auch den Erwerb der (gesamt) deutschen Staatsangehörigkeit bewirken.

\subsubsection{Erwerb der Staatsangehörigkeit durch Geburt}

\subsubsection{Rüickblick (67)}

Im RuStAG 1870 und im RuStAG 1913 erwarben eheliche Kinder ausschließlïch die deutsche Staatsangehörigkeit, wenn der Vater diese Staatsangehörigkeit besaB ( $\$ 3$ RuStAG 1870). Erst durch das RuStAGÄndG vom 19. Dezember 1963 wurde die Regelung dermaßen geändert, daß das eheliche Kind einer deutschen Frau die Staatsangehörigkeit der Mutter erwarb, falls es sonst staaten- 
los sein würde (68). Es war im Rahmen dieser Regelungen jeweils gleichgültig. wo das Kind geboren wurde. 1974 wurde die Gleichberechtigung von Mann und Frau in $\$ 4$ RuStAG realisiert, und dieser Paragraph bekam die heutige Fassung.

Aufgrund eines ius soli wurde nach dem RuStAG 1870 die deutsche Stalsangehörigkeit nie erworben. Sogar eine Bestimmung über Findelkinder gab es im Gesetz von 1870 nicht. Die betreffende Regelung wurde erst 1913 ins Gesetz eingeführt (69).

Auch bereits im RuStAG 1870 erwarb das nichteheliche Kind eines deutschen Mannes und einer ausländischen Frau erst durch Legitimation die deutsche Staatsangehörigkeit ( $\$ 4$ RuStAG 1870). Die Anerkennung eines Kindes durch einen deutschen Mann bewirkte nicht, daß dieses die deutsche Staatsangehörigkeit erwarb. Weder das Gesetz von 1870 noch die Fassung des heutigen Gesetzes im Jahre 1913 gaben dem nicht-legitimierten nichtehelichen Kinde einen Einbürgerungsanspruch. Dieser Anspruch wurde erst 1974 (70) eingeführt (71). Es erscheint zunächst erstaunlich, daß nicht sämtliche nichteheliche Kinder eines deutschen Vaters die deutsche Staatsangehörigkeit erwerben oder wenigstens ein unklausuliertes Optionsrecht haben. Die deutsche Lösung scheint streitig mit der Gleichberechtigung von Mann und Frau und streitig mit der Gleichberechtigung von ehelichen und nichtehelichen Kindern. Es ist deshalb interessant, die Motive zu zitieren, die dazu geführt haben, diese Lösung zu wählen (72):

"In zahlreichen Staaten ist die Anerkennung der Vaterschaft Erwerbsgrund für die Staatsangehörigkeit des Vaters durch das nichteheliche Kind, und zwar überwiegend in den Nachbarstaaten der Bundesrepublik Deutschland und in allen Ostblockstaaten. Eine verfassungsrechtliche Notwendigkeit zur Gleichstellung des nichtehelichen Kindes einer deutschen Mutter mit dem eines deutschen Vaters besteht nach Auffassung des Innenausschusses nicht. Bei nichtehelichen Kindern bestehen in aller Regel soziale Bindungen ausschließlich zwischen Mutter und Kind. Die Ungleichgewichtigkeit der Beziehungen von Vätern und Müttern zu ihren nichtehelichen Kindern spricht daher dafür, nur dem nichtehelichen Kind einer deutschen Mutter durch Geburt die deutsche Staatsangehörigkeit vermitteln zu lassen. Ein Erwerb der deutschen Staatsangehörigkeit kraft Gesetzes auch für nichteheliche Kinder eines deutschen Vaters und einer ausländischen Mutter wurde dagegen nicht für erforderlich erachtet.

Der Ausschuß vermag jedoch auch eine Regelung nicht zu empfehlen, nach der das nichteheliche Kind eines Deutschen allein durch die Erklarung, Deutscher werden zu wollen, die Staatsangehörigkeit erwirbt, wenn eine nach den deutschen Gesetzen wirksame Feststellung der Vaterschaft erfolgt ist. Bei einer solchen Ausgestaltung könnten auch solche nichtehelichen Kinder die deutsche Staatsangehörigkeit für sich in Anspruch nehmen, die keinerlei Beziehungen zu Deutschland haben. Der Ausschuß hat es daher vorgezogen, nichtehelichen minderjährigen Kindern eines Deutschen unter bestimmten Voraussetzungen einen Einbürgerungsanspruch zu geben. Die Möglichkeit der mißbräuchlichen Geltendmachung des Anspruchs auf die deutsche Staatsangehörigkeit soll dadurch eingeschränkt werden, daß eine nach deutschen Gesetzen wirksame Feststel- 
lung der Vaterschaft verlangt wird und das Kind seit fünf Jahren seinen dauernden Aufenthalt im Inland hat".

Durch Adoption wurde die deutsche Staatsangehörigkeit bis 1977 nicht erworben; es gab für von Deutschen adoptierte Kinder bis dahin sogar keine Einbürgerungserleichterungen.

\subsubsection{Heutige Regelung}

Seit dem 1. Januar 1975 erwirbt das eheliche Kind eines deutschen Vaters oder einer deutschen Mutter die deutsche Staatsangehörigkeit durch Geburt ( $\$ 4$ Abs. 1 Ziffer 1 RuStAG) (73). Diese Regelung wurde eingeführt, nachdem das BVerfG die frühere Regelung der Staatsangehörigkeit ehelicher Kinder als verfassungswidrig erklärt hatte.

Das nichteheliche Kind hat die deutsche Staatsangehörigkeit, wenn die Mutter diese besitzt. Die Mutter braucht ihr Kind nicht anzuerkennen, kraft Geburt bestehen juristische Beziehungen zwischen ihr und ihrem Kind. Diese Regelung gilt seit 1870. Ein nichteheliches Kind einer Ausländerin, das von einem deutschen Manne anerkannt ist oder dessen Abstammung gerichtlich festgestellt ist, erwirbt die deutsche Staatsangehörigkeit des Vaters nicht. Ein solches Kind hat aber seit 1975 einen Einbürgerungsanspruch gemäß \& 10 RuStAG (74), falls es seit drei (75) Jahren rechtmäßig seinen dauernden Aufenthalt im Inland hat und der Antrag vor der Vollendung des 23. Lebensjahres gestellt wird. Falls das Kind jünger als 16 Jahre ist, muß der gesetzliche Vertreter den Antrag stellen. Ist das Kind bereits sechzehn, dann muß es den Antrag selbst, aber mit Zustimmung des gesetzlichen Vertreters, stellen.

Infolge Legitimation durch einen deutschen Mann wird die deutsche Staatsangehörigkeit jedoch von dem legitimierten ausländischen Kind erworben, sogar wenn es schon volljährig ist (76). Auch Adoption durch einen Deutschen bewirkt seit 1977, daß das adoptierte Kind die deutsche Staatsangehörigkeit erwirbt, falls es im Zeitpunkt des Annahmeantrages das achtzehnte Lebensjahr noch nicht vollendet hat. Der Erwerb erstreckt sich auf eventuelle Abkömmlinge des Kindes (77) ( $\$ 6$ RuStAG).

Bemerkenswert ist das streng durchgeführte ius sanguinis-Prinzip im deutschen Staatsangehörigkeitsrecht (78). Lure soli wird die Staatsangehörigkeit im Prinzip nie erworben. Zwar erwerben nach $\S 4$ Abs. 2 RuStAG in Deutschland aufgefundene Kinder die deutsche Staatsangehörigkeit, aber sogar diese Bestimmung ist nicht als ius soli formuliert. Diese Kinder gelten bis zum Beweis des Gegenteils als Kind eines oder einer Deutschen (79). In Deutschland geborene Kinder haben grundsätzlich auch keinen Einbürgerungsanspruch. Diese Regel gestattet ausschließlich Ausnahmen für einige Gruppen von Staatenlosen (80).

\subsubsection{Erwerb nach der Geburt}

\subsubsection{Rückblick}

Im RuStAG 1870 standen die Minimalerfordernisse für die Einbürgerung in $\$ 8$. Gefordert wurden - wie heute - Geschäftsfähigkeit (oder Antrag des gesetzlichen Vertreters), unbescholtener Lebenswandel, eigene Wohnung oder Unterkommen und die Fähigkeit, sich selbst zu emähren. Inlandswohnsitz wurde nicht gefor- 
dert. Die Praxis entwickelte sich aber schon wnter Geltung des Gesetzes von 1870 demaßen, daß in der Regel Inlandswohnsitz Voraussetzung für die Einbürgerung war. Im Jahre 1913 wurde dies in neuen RuStAG ausdricklich gefordert. Sowohl $\$ 8$ des RuStAG 1870 als auch $\$ 8$ des RuStAG 1913 waren "kann"-Vorschriften; die Behörden konnten nach freiem Ermessen über Einbürgerungsanträge entscheiden. Anläßlich des RuStAG in der Fassung von 1913 wurde geschrieben:

"Es bleibt den Einzelstaaten anheimgegeben, Ausländem die Einbürgerung zu verweigern, auch wenn sie den Voraussetzungen des \$ genulgen, oder die Einbürgerung von noch weiteren, in 8 nicht aufgeführten Bedingungen abhängig zu machen"' (81).

Im RuStAG 1913 waren aber einige Fälle formuliert, in denen Personen Einbürgerungsansprüche hatten (82). Diese wurden jedoch 1935 von der nationalsozialistischen Regierung ersatzlos gestrichen (83). Betont wurde (84):

"Uber die Verleihung der deutschan Staatsangehörigkeit entscheiden die Einbürgerungsbehörden nach pflichtmäBigem Ermessen. Ein Anspruch auf Einbürgerung besteht nicht".

Nach dem Zweiten Weltkrieg wurden die gestrichenen Einbürgerungsansprüche nicht neu aufgenommen (85), aber in Sonderregelungen und auch im RuStAG (z.B. \& 10 RuStAG) wurden wieder neue Einbürgerungsansprüche geschaffen (86). AuBer in den Fällen, in denen ein Einbürgerungsanspruch besteht, wird auch nach dem Zweiten Weltkrieg die Einbürgerung als eine Ermessensangelegenheit beurteilt. Im Laufe der Jahre sind aber Einbürgerungsrichtlinien entwickelt worden, die nach und nach verfeinert wurden. Das freie Ermessen der Behörden wird durch diese Richtlinien eingeschränkt (87),

GemäB \& 5 RuStAG 1870 und \$ 6 RuStAG 1913 erwarb die ausländische Frau eines Deutschen durch ihre Verheiratung die deutsche Staatsangehörigkeit.. Dies galt bis zum 31. März 1953. Diese Regelung wurde als streitig mit dem Gleichberechtigungsgrundsatz von Art. $3 \mathrm{GG}$ beurteilt. GemäB Art. $117 \mathrm{GG}$ entfaltete Art. 3 GG erst am 1. April 1953 seine volle Wirkung. Seit dem 1. April 1953 erwarb die ausländische Frau eines Deutschen die deutsche Staatsangehörigkeit nicht mehr automatisch (88). Sie konnte aber bis zum 31. Dezember 1969 bei der Eheschließung erklären, die deutsche Staatsangehörigkeit erwerben zu wollen. Seit dem 1. Januar 1970 ist dieses Optionsrecht aufgehoben (89).

GemäB \& 9 RuStAG 1870 und $\$ 14$ Abs. 1 RuStAG 1913 erwarb ein Ausländer, der in Deutschland als Beamter emannt wurde durch diese Ernennung die deutsche Staatsangehörigkeit. Seit 1937 war die deutsche Staatsangehörigkeit jedoch grundsätzlich eine Voraussetzung für die Emennung als Beamter. \& 14 RuStAG wurde dadurch praktisch bedeutungslos, er wurde jedoch erst im Jahre 1953 aufgehoben (90).

Nach \& 16 Abs. 2 RuStAG 1913 erstreckte eine Einbilirgerung eines Mannes sich auf dessen Ehefrau und auf diejenigen Kinder, deren gesetzliche Vertretung dem Eingebürgerten kraft elterlicher Gewalt zusteht. Eine entsprechende Regelung kannte \& 11 RuStAG 1870 (91). Die Erstreckung von Einbürgerungen auf Ehefrauen ist seit dem 1. April 1953 verfassungswidrig. 


\subsubsection{Heutige Regelung}

$\$ 8$ RuStAG ôffnet die Möglichkeit, daß ein in Deutschland niedergelassener Ausländer auf seinen Antrag hin eingebürgert wird. Die Einbürgerung kann erfolgen, wenn die folgenden Bedingungen erfüllt sind:

a) der Betreffende muß geschäftsfähig sein, oder der Antrag muß von seinem gesetzlichen Vertreter gestellt sein;

b) er muß einen unbescholtenen Lebenswandel haben;

c) er muß eine eigene Wohnung oder ein eigenes Unterkommen haben;

d) er muß sich und seine Angehörigen emähren können;

e) er muß einen Wohnsitz im Inland haben.

Die in 8 RuStAG erwähnten Bedingungen für die Einbürgerung sind die minimalen Voraussetzungen für eine Einbürgerung. Falls die Bedingungen erfüllt sind, kann eingebürgert werden. $\mathrm{Ob}$ dies auch geschieht, liegt im Ermessen der Behörden. Neben den zwingenden Mindestvoraussetzungen des \& 8 RuStAG darf die Einbürgerung deshalb im Rahmen des Ermessens von weiteren sachgerechten Voraussetzungen abhängig gemacht werden (92). Wichtig sind deshalb die Einbürgerungsrichtlinien (93). In diesen Richtlinien werden die Forderungen von $\& 8$ RuStAG in sehr detaillierter Art näher erläutert und ausgearbeitet. Zuerst beinhaltet die Richtlinien Ausführungen über die allgemeinen Grundsätze für die Einbürgerung. Betont wird, daß das Vorliegen der im RuStAG formulierten Voraussetzungen die Einbürgerung noch nicht rechtfertigt (Richtlinie 2.2):

"Die Verleihung der deutschen Staatsangehörigkeit kann nur in Betracht kommen, wenn ein öffentliches Interesse an der Einbürgerung besteht. Öffentliches Interesse ist hier ein staatliches Interesse oder ein gesellschaftliches Interesse von gleichem Rang; die persönlichen Wünsche und wirtschaftlichen Interessen des Einbürgerungsbewerbers können nicht ausschlaggebend sein, zumal auch die hier ansäßigen Ausländer nach der deutschen Rechtsordnung weitgehende Rechte und Freiheiten genießen. $\mathrm{Ob}$ ein öffentliches Interesse besteht, beurteillt sich nach den in den Nummern $3 \mathrm{ff}$. aufgeführten Gesichtspunkten. Das schlieBt nicht aus, daB in Ausnahmefallen aus anderen als den darin erwähnten Gesichtspunkten das öffentliche Interesse an einer Einbürgerung bejaht oder verneint wird. Die Bundesrepublik Deutschland ist kein Einwanderungsland; sie strebt nicht an, die Anzahl der deutschen Staatsangehörigen gezielt durch Einbürgerung zu vermehren".

Auch in der Rechtssprechung wird betont, daß für die Einbürgerung ein öffentliches Interesse vorliegen muB (94). Wohl unter diesem Gesichtspunkt betont Richtlinie 3.1.1, daß eine Einbürgerung nicht in Betracht kommen kann, wenn sie lediglich zur Erlangung wirtschaftlicher Vorteile erstrebt wird, ohne daß eine Hinwendung zu Deutschland erkennbar ist.

Es wïrde za viel Platz fordern, an dieser Stelle die sehr nuanzierten Kriterien der Einbürgerungsrichtlinien eingehend zu erläutem. Hier seien deshalb nur die wichtigsten Kriterien der Richtlinien erwähnt: Die Richtlinien fordern eine freiwillige und dauernde Hinwendung zu Deutschland, Grundkenntnisse der 
deutschen staatlichen Ordnung und ein Bekenntnis zur freiheitlichen demokratischen Grundordnung (95) (Richtlinie 3.1). Der Einbürgerungsbewerber muB grundsätzlich die deutsche Sprache in Wort und Schrift in dem MaBe beherrschen, wie dies von Personen seines Lebenskreises zu erwarten ist (96).

Weitere Voraussetzung der Einbürgerung ist die Einordnung in die deutschen Lebensverhältnisse. In diesem Zusammenhang wird grundsätzlich ein Inlandsaufenthalt won mindestens zehn Jahren verlangt (97). Für viele Kategorien von Personen reicht aber einen kürzerer Aufenthalt aus (98), namentlich (Richtlinie 3.2.2 und 6) bei ehemaligen Deutschen; deutschen Volkszugehörigen, die keinen Einbürgerungsanspruch haben; Einbürgerungsbewerbern, die aus dem deutschsprachigen Raum stammen oder sich dort längere Zeit aufgehalten haben; Einbürgenungsbewerbern, die sich zwar erst fünf Jahre im Inland aufhalten, aber zusammen mit ihrem Ehegatten eingebürgert werden sollen, der bereits die Einbürgerungsvoraussetzungen erfüllt; Personen, für die ein herausragendes öffentliches Interesse zur Einbürgerung besteht; Personen mit einer schweren Kriegsbeschädigung in deutschen Diensten; Angehörigen von beil der deutschen Wehrmacht gefallenen oder vermissten Personen; Ehegatten von deutschen Staatsbürgern; Staatenlosen (99); Flüchtlingen (100), u.s.w.

Eine Einbürgerung ist nicht möglich, wenn ein Bewerber sich nicht rechtmäßig im Inland aufhält (Richtlinie 3.2.4). Aber es ist nicht notwendig, daß der Antragsteller sich während der ganzen geforderten Zeit rechtmäßig niedergelassen hatte (101). Bemerkenswert ist, $\mathrm{daB}$ ein Inlandsaufenthalt überwiegend unter Ausländern, z.B. in Ausländerwohnstätten, in der Regel nicht auf die geforderte Aufenthaltsdauer angerechnet wird (Richtlinie 3.2.1)

Das von \& 8 RuStAG bereits erwähnte Kriterium der Unbescholtenheit wird (von Richtlinie 3.3) dermaßien ausgearbeitet, daß eine Einbürgerung im Prinzip nicht vorgenommen werden kann, wenn der Betreffende bestraft worden ist. Die Forderung der Unbescholtenheit darf nicht ausschließlich nach strafrechtlichen Gesichtspunkten beurteilt werden (102). Einerseits kann über eine Bestrafung hinweggesehen werden, wenn es sich um geringfügige oder längere Zeit zurïckliegende Strafen handelt und eine emeute Straffälligkeit nach dem Gesamtverhalten des Einbürgerungsbewerbers nicht zu erwarten ist (103). Andererseits können auch wiederholte Ordnungswidrigkeiten eine Einbürgerung ausschließen, wenn aus der Art und der Häufigkeit der Rechtsverstöße zu schließen ist, daß der Einbürgerungsbewerber nachhaltig die Rechtsordnung mißachtet (104). Auch Rauschmittel- oder Alkoholsucht, fortdauernde Verletzung der Unterhaltspflicht, Arbeitsunwilligkeit schlieBen die Einbuirgerung aus (105). Was die wirtschaftlichen Voraussetzungen betrifft, muB der Einbürgerungsbewerber im Inland eine Wohnung oder ein Unterkommen haben. Weiter ist grundsätzlich vorauszusetzen, daß er sich und seine Angehörigen aus eigenen Kräften und Mitteln ernähren kann (106). Von dieser Regel gibt es aber Ausnahmen (Richtlinie 3.4).

Grundsätzlich ist nach einer einheitlichen Staatsangehörigkeit in der Familie zu streben. Möglichst sollen deshalb alle Familienmitglieder, soweit diese in Hausgemeinschaft leben, zusammen eingebürgert werden (107) (Richtlinie 4).

Nach den Richtlinien sind bei der Einbürgerung auch die Interessen fremder Staaten zu berüicksichtigen, da bei der Einbürgerung auch deutsche außenpolitische Belange im Auge behalten werden müssen. In diesem Zusammenhang werden Angehörige von Entwicklungsländern, die in Deutschland eine Ausoder Weiterbildung erfahren haben, grundsätzlich nicht eingebürgert (108) 
(Richtlinie 5.2.1). Das Bereitstellen von Schul-, Studien- und Forschungsplätzen sowie von Lehr- und Praktikantenstellen in Deutschland wird als personelle Entwicklungshilfe gesehen. Dies gilt auch, wenn dem Aus- oder Weiterzubildenden keine finanziellen Ausbildungshilfen (wie Stipendien, Zuschüße, Darlehen) gewährt wurden (109) (110). Die Richtlinie betont:

\begin{abstract}
"Der damit angestrebte Erfolg wird nur erreicht, wenn diese Personen nach Beendigung der Aus- oder Weiterbildung in ihre Heimat zurückkehren und dort am Aufbau mitwirken. Die Einbürgerung von Angehörigen der Entwicklungländer, die im Bundesgebiet oder in anderen Industriestaaten im Rahmen der personellen Entwicklungshilfe eine Ausoder Weiterbildung erfahren haben, soll deshalb unterbleiben. Die personelle Entwicklungshilfe dient nicht dazu, den aus- oder weitergebildeten Ausländern persönlich zu einem von ihnen angestrebten gesellschaftlichen und finanziellen Standard zu verhelfen. Deshalb müssen persönliche Wünsche der Betroffenen, im Bundesgebiet zu verbleiben und zu arbeiten, zurïickstehen".
\end{abstract}

Von diesem Prinzip werden aber einige Ausnahmen gemacht. Namentlich ist dies der Fall, wenn der betreffende Ausländer mit einem oder einer Deutschen verheiratet ist (111). Aber sogar dann ist erst eine Einbürgerung möglich, wenn der Einbürgerungsbewerber sich bereits acht Jahre im Inland rechtmäßig aufhält und sein Abschlußexamen oder eine andere Aus- oder Weiterbildung mindestens seit zwei Jahren beendet hat (Richtlinie 5.2.3). Von den anderen Ausnahmen ist jedenfalls erwähnenswert, daß ein Staatsangehöriger aus einem Entwicklungsland auch eingebürgert werden kann, wenn er sich länger als fünfzehn Jahre nicht mehr im Heimatstaat und davon zwölf Jahre im Bundesgebiet rechtmäßig aufgehalten hat, über fünfunddreißig Jahre alt ist und sein Abschlußexamen oder eine andere Aus- oder Weiterbildung seit mindestens drei Jahren beendet hat (Richtlinie 5.2.5.3). Aber sogar in diesen Ausnahmefällen wird ausschließlich eingebürgert, wenn der Antragsteller die von deutschen Stellen gewährten finanziellen Ausbildungshilfen zurüickzahlt (Richtlinie 5.2.6) (112) (113). Weiter soll eine Einbürgerung im Prinzip nur geschehen, wenn nachgewiesen ist, daß der Einbuirgerungsbewerber spätestens mit der Einbürgerung aus seiner bisherigen Staatsangehörigkeit ausscheidet. Falls dies nicht automatisch geschieht, kann gefordert werden, daß er sich aus seiner alten Staatsangehörigkeit entlassen läßt (114). Von dieser Regel gibt es wieder mehrere Ausnahmen. Generell können Ausnahmen in Betracht kommen,

"wenn vorrangige Gesichtspunkte es erfordern, daß das rechtspolitische Ordnungsprinzip, Mehrstaatigkeit zu vermeiden, zurücktritt, und wenn die Versagung der Einbürgerung eine unzumutbare Härte darstellen würde" (Richtlinie 5.3.3).

Die Richtlinien betonen aber:

"Das (d.h. das Vorhandensein einer solchen unzumutbaren Härte; d.G.) ist nicht der Fall, wenn der Einbürgerungsbewerber eintretende Schwierigkeiten in zurechenbarer Weise selbst verursacht hat, so wenn er beispielsweise seine - finanziellen oder dienstrechtlichen - Verpflichtungen gegenüber dem Heimatstaat verletzt hat. Es ist dem Einbürgerungsbewerber 
zuzumuten, daß er den allgemein geltenden und den besonders übermommenen Pflichten nachkommt. Zumutbar ist auch, daß er längere, unter Umständen mehrjährige Wartefristen bei Entlassungsanträgen hinnimmt, wenn nach den gewonnenen Erfahrungen Beharrlichkeit zum Ziele führt. Zumutbar sind ferner wirtschaftliche Nachteile im Heimatstaat (z.B. Erbrechtsbeschränkungen oder die Auflage, Grundbesitz zu veräuBern). Der Einbürgerungsbewerber muß bereit sein, solche Folgen eines Staatsangehörigkeitswechsels zu tragen, zumall der Erwerb der deutschen Staatsangehörigkeit häufig auch wirtschaftlich vorteilhaft sein wird" (115).

Bei den obenstehenden Ausführungen muß berücksichtigt werden, daß mehrere Kreise von Personen unter erleichterten Bedingungen eingebürgert werden können oder sogar einen Einbürgerungsanspruch haben. Das deutsche Einbürgerungsrecht wird dadurch sehr verwickelt; einerseits sind die Kriterien des $\$ 8$ RuStAG und der Einbürgerungsrichtlinien sehr streng, andererseits gibt es zahlreiche Ausnahmen. Viele Möglichkeiten der erleichterten (Wieder-)Einbürgerungen und Einbürgerungsansprüche finden sich in Sondergesetzen.

Im RuStAG (in der heutigen Fassung) sind geregelt: die erleichterte Einbürgerung der Ehegatten von Deutschen ( $\$ 9$ ), der Einbürgerungsanspruch von nichtehelichen Kindern deutscher Väter $(\S 10)$ und die erleichterte Einbürgerung von ehemaligen Deutschen ( $\$ 13$ ). Außerhalb des RuStAG gibt es zwei Vorschriften, die für Staatenlose unter gewissen Voraussetzungen Einbürgerungsansprüche formulieren: Art. 2 Abs. 2 des Wehrpflichtgesetzes und das Ausfiihrungsgesetz zu dem Übereinkommen zur Vermeidung der Staatenlosigkeit vom 29. Juni 1977.

Die staatsangehörigkeitsrechtliche Position des ausländischen Ehegatten eines oder einer Deutschen bedarf näherer Erläuterung. $\S 9$ RuStAG bestimmt (116):

"Ehegatten Deutscher sollen unter den Voraussetzungen des $\$ 8$ eingebürgert werden, wenn

1. sie ihre bisherige Staatsangehörigkeit verlieren oder aufgeben und

2. gewährleistet ist, daß sie sich in die deutschen Lebensverhältmisse einordnen, es sei denn, daß der Einbürgerung erhebliche Bellange der Bundesrepublik Deutschland, insbesondere solche der äußeren und inneren Sicherheit sowie der zwischenstaatlichen Beziehungen entgegenstehen".

Gemäß \& Abs. 2 gilt die dem ausländischen Partner von Abs. 1 erteilte Einbürgerungserleichterung bis zum Ablauf eines Jahres nach dem Tode des deutschen Ehegatten oder nach Rechtskraft des die Ehe auflösenden Urteills, falls dem Antragsteller die Sorge für die Person eines Kindes aus der Ehe zusteht, das bereits die deutsche Staatsangehörigkeit besitzt. Durch \& 9 RuStAG wird die Einbürgerung eines ausländischen Ehepartners eines oder einer Deutschen erheblich erleichtert; die Richtlinien (Nr. 6.1) sagen darüber:

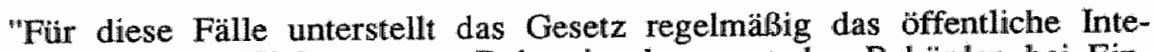
resse an einer Einbürgerung. Daher ist das sonst den Behörden bei Einbürgerungen eingeräumte Ermessen durch die ermessensbindende Sollvorschrift des § 9 RuStAG erheblich eingeschränkt". (117). 
Über die Einordnung in die deutschen Lebensverhältnisse sagen die Richtlinien (Nr. 6.1.3):

"Es genügt, daß die Einordnung in die deutschen Lebensverhältnisse nach dem Umständen des Falles mit Sicherheit zu erwarten ist. Diese Erwartung gründet sich auf den Inlandsaufenthalt und auf den Bestand der Ehe mit dem deutschen Ehegatten. Deshalb ist eine gewisse Dauer des Inlandsaufenthaltes und der Ehe erforderlich. In der Regel soll ein Inlandsaufenthalt von fünf Jahren als ausreichend angesehen werden; für Eïnbürgerungsbewerber aus dem deutschsprachigen Raum genügt in der Regel ein Inlandsaufenthalt von zwei Jahren. In beiden Fällen soll die Ehe bereits zwei Jahre bestehen. Wenn nach den tatsächlichen Feststellungen in einem Einzelfall die Einordnung nicht zu erwarten ist, kommt eine Einbürgerung nicht in Betracht".

Der ausländische Ehegatte muß grundsätzlich seine vorherige Staatsangehörigkeit aufgeben; dies wird anders als im Falle des \& 8 sogar ausdücklich im \& 9 RuStAG als Voraussetzung formuliert. Die Rechtsprechung meint aber, daß wenn der ausländische Ehegatte nicht auf seine bisherige Staatsangehörigkeit verzichten möchte - eine Einbürgerung nach $\$ 8$ RuStAG möglich ist (118). \& 9 RuStAG betont weiter, daß die Einbürgerung ausgeschlossen ist, wenn ihr erhebliche Belange der Bundesrepublik Deutschland, insbesondere solche der äußeren oder inneren Sicherheit sowie der zwischenstaatlichen Beziehungen entgegenstehen. Interessant ist in diesem Zusammenhang die Richtlinie bezüglich der Einbürgerung von Einbürgerungsbewerbern aus Entwicklungsländern. Richtlinie 5.2.3 lautet:

"Bei mit deutschen Ehegatten verheirateten Einbürgerungsbewerbern, die Angehörige eines Entwicklungslandes sind und im Rahmen der personellen Entwicklungshilfe eine Aus- oder Weiterbildung erfahren haben, kommt Artikel 6 des Grundgesetzes, der Ehe und Familie unter den besonderen Schutz der staatlichen Rechtsordnung stellt, gegenüber Belangen der Entwicklungspolitik erhebliche Bedeutung $\mathrm{zu}$. Entwicklungspolitische Bedenken gegen eine Einbürgerung können daher zurückgestellt werden, wenn sich der Einbürgerungsbewerber mindestens acht Jahre im Inland rechtmäBig aufhält und sein Abschlußexamen oder eine andere Aus- oder Weiterbildung mindestens seit zwei Jahren beendet hat".

Aus den Richtlinien geht deshalb hervor, daß die Ehegatten deutscher Bürger unter einfacheren Bedingungen eingebürgert werden als andere Ausländer. Ihre Position ist aber sehr weit von einem Einbürgerungsanspruch entfernt.

Normalerweise wird nur eingebürgert, wenn der Antragsteller einen Wohnsitz in Deutschland hat. Aufgrund des noch immer geltenden $\S 1$ der Verordnung zur Regelung von Staatsangehörigkeitsfragen vom 20. Januar 1942 kann aber in besonderen Fällen auch eine im Ausland lebende Person eingebürgert werden (119). Gemäß Art. 16 Abs. 2 RuStAG erstreckt eine Einbuirgerung sich auf diejenigen Kinder, deren gesetzliche Vertretung dem (oder der) Eingebürgerten kraft elterlicher Sorge zusteht, es sei denn, in der Einbürgerungsurkunde ist ein Vorbehalt gemacht. 
Bermerkenswert ist nunmehr, daß die Einbürgerungsbehörden seit dem 1. Januar 1977 verpflichtet sind, Einbürgerungsurkundenformulare zu benützen, wo der Satz "Die Einbürgerung hat sich nicht auf Kinder des/ der Eingebürgerten erstreckt" schon vorgedruckt ist (120). Praktisch kommt eine Erstreckung der Einbürgerung auf Kinder des Eingebürgerten deshalb nicht mehr vor (121).

Die Einbürgerungsgebühren liegen zwischen 100 und 5000 DM. Die Regelgebühr soll $75 \%$ eines Monatseinkommens nicht übersteigen (122).

In der Literatur wurde darauf hingewiesen, daß die deutsche Staatsangehörigkeit ausnahmsweise kraft Vertrauensschutzes erworben werden kann. Dies ist der Fall, wenn

"eine für Staatsangehörigkeitsfragen zuständige, mit Einbürgerungskompetenz versehene und dem GG bzw. den rechtsstaatlichen Vertrauensschutzgrundsätzen unterworfene deutsche Behörde durch nicht befristeten Verwaltungsakt zur Entscheidung einer staatsangehörigkeitsrechtlichen Frage die deutsche Staatsangehörigkeit einer Person bejaht, die sie zum Zeitpunkt der Feststellung nicht besa $\beta^{\text {t" }}$ (123).

Oben haben wir feststellen können, daß die Einbürgerungsvorschriften in der Bundesrepublik Deutschland streng sind. In Deutschland wird in den letzten Jahren darïber diskutiert, die Einbürgerungsvoraussetzungen in bestimmten Fällen zu erleichtern. Am 19. März 1980 billigte das Bundeskabinett "Orientierungslinien für die Weiterentwicklung der Ausländerpolitik" (124). In dieser Zusammenhang beschloß das Bundeskabinett (125):

"Der Bundesminister des Innern wird beauftragt die rechtlichen Voraussetzungen für eine erleichterte Einbürgerung zu schaffen. Für die zweite und dritte Ausländergeneration soll unter bestimmten Voraussetzungen ein Anspruch auf Einbürgerung ab dem 18. Lebensjahr eingeräumt werden; hierzu soll vor allem der Antrag des Landes Nordihein-Westfalen zur Schaffung eines gesetzlichen Einbürgerungsanspruchs für in der Bundesrepublik aufgewachsene ausländische Jugendliche (Entwurf eines Vierten Gesetzes zu Regelung von Fragen der Staatsangehörigkeit) unterstützt werden".

Dieser Beschluß wurde wie folgt begründet:

"Für Ausländer, die beabsichtigen, im Bundesgebiet auf Dauer zu bleiben und die volle rechtliche Gleichstellung mit den Inländern anstreben, kann die Einbürgerung den Abschluß der Integration fördern. An der Einbürgerung von Personen, die im Bundesgebiet aufgewachsen sind und hier den überwiegenden Teil ihrer Schulausbildung erhalten haben, besteht ein besonderes offentliches Interesse. Ihre Einbürgerung soll daher wie folgt erleichtert werden:

- Mehrstaatigkeit soll dann hingenommen werden, sofern der Heimatstaat. die Entlassung durchweg verwehrt oder die Entlassung auf unverhältnismäßige Schwierigkeiten stößt.

- Geringfügige typische Jugendverfehlungen sollen der Einbürgerung nicht entgegenstehen. 
- Der Grundsatz der einheitlichen Staatsangehörigkeit in der Familie soll zurücktreten (Einbürgerung auch ohne die Eltern).

Entwicklungspolitische Belange stehen der Einbürgerung nicht entgegen. Bei Vorliegen dieser Voraussetzungen soll den hier aufgewachsenen Kindern ausländischer Arbeitnehmer daher ein Einbürgerungsanspruch eingerälumt werden. Die gesetzliche Festlegung hätte eine wesentliche Vereinfachung und Beschleunigung des Einbürgerungsverfahrens zur Folge. Darüber hinaus ginge von ihr eine positive Signalwirkung für den angesprochenen Personenkreis aus. Die Bundesregierung unterstuitzt daher die Gesetzesinitiative des Landes Nordrhein-Westfalen, einen gesetzlichen Einbürgerungsanspruch zu schaffen.....(Zitat unterbrochen)

In Zusammenhang mit den Überlegungen, den hier aufgewachsenen Jugendlichen einen Einbürgerungsanspruch unter erleichterten Voraussetzungen gegenüber der bisherigen Praxis zu gewähren, stellt sich die Fra$\mathrm{ge}$, ob auch der ersten Ausländergeneration (Arbeitnehmer, die ins Bundesgebiet im Wege der Anwerbung gekommen sind) der Erwerb der deutschen Staatsangehörigkeit in der Weise erleichtert werden soll, daß nur eine Mindestaufenthaltsdauer von 6 Jahren verlangt wird. Hierbei geht es darum, die Folgerungen zu ziehen, die sich aus der Anwerbung einer großen Zahl von ausländischen Arbeitnehmern, der Zulassung des Familiennachzugs und dem Verzicht auf eine Rückkehrforderung ergeben haben. Es ist zu überlegen, ob diesem Personenkreis, dessen Aufenthalt nach den bisherigen Enfahrungen auf Dauer angelegt ist, eine Integrationshilfe dergestalt angeboten werden soll, daß die Anforderungen für eine Einbürgerung niedriger angesetzt werden".

Der vom Land Nordrhein-Westfalen eingebrachte Entwurf eines Vierten Gesetzes zu Regelung von Fragen der Staatsangehörigkeit (126) enthielt die folgende Bestimmung:

"(1) Ein Ausländer, der das 18. Lebensjahr vollendet hat, ist auf seinen Antrag einzubürgern, wenn er

1. seit Vollendung des 12. Lebensjahres rechtmäßig seinen dauernden Aufenthalt im Inland hat und sich darïber hinaus vorher insgesamt mindestens zwei Jahre hier aufgehalten hat;

2. seine bisherige Staatsangehörigkeit aufgibt oder verliert, sofern nicht der Heimatstaat die Entlassung durchweg verwehrt oder die Entlassung auf unverhältnismäßige Schwierigkeiten stößt und

3. den Antrag vor Vollendung des 21. Lebensjahres stellt, es sei denn, $\mathrm{da} \beta$ er rechtskräftig zu Freiheits- oder Jugendstrafe von insgesamt einem Jahr oder mehr werurteilt worden ist.

(2) Kann die Einbürgerung wegen der erforderlichen Entlassung aus der bisherigen Staatsangehörigkeit (Abs. 1, Nr. 2) zunächst nicht vollzogen werden, erhält der Ausländer eine Einbürgerungszusicherung; er kann nicht ausgewiesen werden".

Die Bundesregierung kam 1982 aber mit einem eigenen Entwurf eines Vierten Gesetzes zur Regelung von Fragen der Staatsangehörigkeit (127), in dem vorgeschlagen wurde, einem Ausländer einen Einbürgerungsanspruch zu geben, 
wenn er seit mindestens acht Jahren rechtmäßig seinen dauemden Aufenthait in Deutschland hat. $\$ 1$ dieses Entwurfes lautete:

"(1)Ein Ausländer, der das 18. Lebensjahr vollendet hat, hat einen Anspruch auf Einbürgerung, wenn er:

1. seit acht Jahren rechtmäßig seinen dauerenden Aufenthalt im Geltungsbereich des Gesetzes hat;

2. aus seiner bisherigen Staatsangehörigkeit ausscheidet, sofern nicht der Heimatstaat die Entlassung durchweg verwehrt oder die Entlassung auf unverhältnismäßige Schwierigkeiten stößt und

3. das 21 . Lebensjahr noch nicht vollendet hat.

(2) Der Anspruch besteht nicht, wenn der Ausländer rechtskräftig wegen einer vorsätzlichen Tat zu Freiheitsstrafe oder zu Jugendstrafe von mindestens einem Jahr verurteilt worden ist. Der Anspruch ruht, solange gegen den Ausländer ein Strafverfahren wegen einer vorsätzlichen Tat anhängig ist"t.

Der Bundesrat betonte, daB die Einbürgerung der zweiten Ausländergeneration erleichtert werden soll, meinte aber, daß für eine gesetzliche Regelung kein Bedürfnis besteht. Es würde genügen, die Einbürgerungsrichtlinien zu erleichtem (128). Die Bundesregierung sagte daraufhin a.a. aber, daß aus Rechtssicherheitsgründen eine gesetzliche Regelung notwendig wäre und zudem die vorgeschlagene Regelung in einigen Punkten von \& 8 RuStAG abweicht (129). Eine Änderung der Richtlinien genüge deshalb nicht.

Wegen des Endes der 9. Wahlperiode des Bundestages wurde die Behandlung des Entwurfes abgebrochen. Er wurde während der 10. Wahlperiode nicht neu eingereicht. In der 10. Wahlperiode des Bundestages ist in diesem Zusammenhang vor allem der am 25. April 1984 von der Partei "Die Grünen" eingereichte Entwurf eines Gesetzes über die Niederlassung von Ausländem (130) interessant. Ziel jenes Gesetzesentwurfes war es, einem Großteil der in Deutschland lebenden Ausländern und Ausländerinnen bessere aufenthaltsrechtliche Garantien zukommen zu lassen. Dies sollte dadurch geschehen, daß manche Auslånder den Rechtsstatus eines Niederlassungsberechtigten bekommen würden. Diese Niederlassungsberechtigten würden nicht mehr der Kontrolle und Überwachung der Ausländerbehörden unterliegen. $\S 1$ Abs. 2 des Entwurfs definierte, welche Personen zur Niederlassung zugel.assen werden:

"1. Ausländer nach einem rechtmäßigen Aufenthalt von acht Jahren $(\$ 2)$.

2. Sonstige Ausländer (politisch Verfolgte, Kontingentflüchtlinge, heimatlose Ausländer, Aufenthaltsberechtigte, Ausländer nach fünfjähriger rechtmäßiger unselbständiger Erwerbstätigkeit) ( $(3)$.

3. Familienangehörige Niederlassungsberechtiger $(\$ 4) . "$

$\S 16$ des Entwurfes konstituierte danach einen Einbürgerungsanspruch:

"(1) Auf Antrag wird Niederlassungsberechtigten die deutsche Staatsangehörigkeit verliehen, wenn sie aus ihrer bisherigen Staatsbürgerschaft entlassen werden. 
(2) Wird die Entlassung verweigert und von unzumutbaren Bedingungen abhängig gemacht, steht der schriftliche Verzicht auf die bisherige Staatsangehörigkeit der Entlassung gleich.

(3) Kinder niederlassungsberechtigter Ausländer, die im Geltungsbereich des Gesetzes geboren wurden und leben, erhalten bis zur Vollendung des 25.Lebensjahrs auf Antrag auch ohne Entlassung aus der bisherigen Staatsangehörigkeit nach Absatz 1 und 2 die deutsche Staatsangehörigkeit. Dieser Rechtsausspruch erlischt nicht durch Ruickkehr oder Auswanderung der Eltem".

Interessant ist dabei die Begründung:

"Die in Absatz 1 bis 3 geregelten Erleichterungen der Einbürgerung von Niederlassungsberechtigten sind deshalb notwendig, weil das gegenwärtige Einbürgerungsrecht in bezug auf langjährig in Deutschland aufhältliche Ausländer sehr unbefriedigend ist. In einem demokratischen Rechtsstaat wäre zu erwarten, daß die "Staatsbürgerschaft" erreicht werden kann, wenn vom Gesetzgeber nüchtem festgestellte Voraussetzungen erfüllt sind, die jeder Einwanderer, der sich seit einem Jahrzehnt oder länger im Lande aufgehalten hat oder gar dort geboren ist, ohne weiteres zu erfüllen vermag. So ist es aber gegenwärtig nicht. Die "deutsche" Staatsbürgerschaft ist etwas ganz besonderes, das nur im "Einzelfall" nach "freiem Ermessen" der Exekutive verliehen wird. Vorab muB der Einwanderer dem Idealbild des "Deutschen" entsprechen, d.h. er muß "einen unbescholteten Lebenswandel" geführt haben und "sich und seine Angehörigen zu ernähren imstande" sein. Ob der Einwanderer diese Voraussetzungen zu schaffen vermag, liegt aber zum guten Teil nicht in seinem Vermögen, sondern wird durch die Praxis der deutschen Institutionen bestimmt. Zusätzlich verlangt die Exekutive in ihren Einnbürgerungsrichtlinien noch "eine freiwillige und dauerende Hinwendung zur Bundesrepublik Deutschland", die Gewähr der Verfassungstreue sowie - fast ausnahmslos - das Ausscheiden aus der alten Staatsangehörigkeit.

Wer als Auswanderer alle diese Voraussetzungen erfüllen will, gerät in nichtunerhebliche Schwierigkeiten. Da wird zum einem von ihm verlangt, daß er "Deutscher" sein soll, als es Millionen Menschen sind, die bereits die Staatsangehörigkeit dieses Landes besitzen - von den weiteren Millionen deutschen Vorbestraften und angeblichen "Verfassungsfeinden" ganz zu schweigen...."

\section{2 .4 Veriustgründe}

\subsubsection{Rückblick}

Im Gesetz von 1870 wurden die Verlustgründe in $\$ 13$ erwähnt. Erster Grund war die Entlassung auf Antrag ( $\$ \S 14$ ff. RuStAG 1870); diese blieb nur wirksam, wenn der Entlassene innerhalb von sechs Monaten nach Aushändigung der Entlassungsurkunde seinen Wohnsitz außerhalb des Reiches verlegte; zweitens der Ausspruch der Behörde im Falle der Verweigenung der Rückkehr nach Deutschland in Falle eines Krieges oder bei Kriegsgefahr ( $\$ 20$ RuStAG 1870) (131); oder der Ausspruch der Behörde, falls ein Deutscher ohne Erlaubnis seiner Regierung in fremden Staatsdienst trat ( $\$ 22$ RuStAG 1870) (132); drit- 
tens durch zehnjährigen Aufenthalt in Ausland ( $\$ 21$ RuStAG 1870) (133); viertens bei Legitimation nichtehelicher Kinder einer deutschen Mutter und eines ausländischen Vaters (134); und schließlich beil Ehe einer Deutschen mit einem Ausländer (135). Der Verlust der deutschen Staatsangehörigkeit wegen Erwerbs einer fremden Staatsangehörigkeit war im RuStAG 1870 nicht vorgesehen.

Der Verlust wegen zehnjärigen Aufenthalts im Ausland wurde bereits 1913 aus dem Staatsangehörigkeitsrecht gestrichen (136). Statt dessen führte das RuStAG 1913 den Verlust der deutschen Staatsangehörigkeit wegen freiwilligen Erwerbs einer fremden Staatsangehörigkeit ein ( $\$ 25$ RuStAG), \& 26 RuStAG sah noch im Falle eines ausländischen Wohnsitzes den Verlust der Staatsangehörigkeit wegen Nichterfiullung der Wehrpflicht vor (137). Im letzten Jahr des Ersten Weltkriegs wurde der Verlust der Staatsangehörigkeit wegen Steuerflucht ermöglicht (138).

Bereits sechs Monate nach der Machtübemahme ermöglichte die nationalsozialistische Regierung durch Gesetz die Möglichkeit der Widerrufung von "unerwünschten" Einbürgerungen zwischen dem 9. November 1918 und dem 30. Januar 1933, sowie die Aberkennung der Staatsangehörigkeit von im Ausland lebenden Deutschen,

"sofern sie durch ein Verhalten, das gegen die Pflicht zur Treue gegen Reich und Volk verstösst, die deutschen Belange geschädigt haben" (139).

Das Vermögen dieser Personen konnte konfisziert werden (140). Noch ein Schritt weiter gingen die Nationalsozialisten im Jahre 1941 (141): allen deutschen Juden, die sich im Ausland befanden, wurde die deutsche Staatsangehörigkeit entzogen; es ist makaber, feststellen zu müssen, daß den Juden, die im Inland bleiben mußten, nicht die Staatsangehörigkeit entzogen wurde: Sie wurden als Deutsche ermordet!!

Der Verlust durch Ausspruch der Behörden (noch vorgesehen in den $\$ \$ 27$ und 28 RuStAG) ist seit der Gründung der Bundesrepublik Deutschland wegen des Widerspruchs zu Art. 16 Abs. $1 \mathrm{GG}$ unmöglich (142). Die $\$ \S 27,28$ RuStAG sind deshalb am 23. Mai 1949 (Inkrafttreten des Grundgesetzes) wirkungslos geworden. Durch die Wirkung von Art. 16 GG wurde seit 1949 die Staatsangehörigkeit nie verloren, wenn Staatenlosigkeit die Folge wäre. Die Verlustgründe "Eheschließung mit Ausländer" und "Legitimation durch einen Ausländer" wurden dementsprechend eingeschränkt. Der Verlust wegen Legimation durch einen Ausländer ist im Rahmen der Verwirklichung der Gleichberechtigung im RuStAG 1974 aufgehoben worden (143).

Die deutsche Frau, die einen Ausländer ehelichte, verlor dadurch ihre deutsche Staatsangehörigkeit, auch wenn sie dadurch staatenlos wurde $(\$ 13$ Gesetz 1870 , \& 17 RuStAG 1913). Diese Regel trat mit dem Wirksamwerden des Gleichberechtigungsgrundsatzes des Art. 3 Abs. 2 GG am 1. April 1953 außer kraft. Seitdem behält die Frau ihre Staatsangehörigkeit im Fall einer Ehe mit einem Ausländer. Durch die Wirkung von Art. $16 \mathrm{GG}$ Abs. 1 trat seit dem 23. Mai 
1949 schon kein Verlust der deutschen Staatsangehörigkeit mehr ein, wenn davon Staatenlosigkeit die Folge gewesen wäre (144) (145).

\subsubsection{Heutige Regelung}

Die deutsche Staatsangehörigkeit wird nach $\$ 17$ RuStAG verloren durch Entlassung, durch Erwerb einer ausländischen Staatsangehörigkeit, durch Verzicht und durch Annahme als Kind durch einen Ausländer. Aufgrund des $\$ 18$ RuStAG kann ein Staatsangehöriger aus der deutschen Staatsangehörigkeit entlassen werden, während er aufgrund des \& 26 RuStAG auf die deutsche Staatsangehörigkeit verzichten kann, falls er Doppelstaatler ist. Der wichtigste Unterschied zwischen Entlassung und Verzicht ist der Zweck der beiden Rechtsinstitutionen. Der Verzicht zielt nur auf den Verlust der deutschen Staatsangehörigkeit, während die Entlassung bezweckt, dem Betroffenen den Erwerb der von ihm erstrebten fremden Staatsangehörigkeit zu ermöglichen (146).

Der Verlust der deutschen Staatsangehörigkeit wegen Erwerbs einer fremden Staatsangehörigkeit tritt nur ein, wenn der Betreffende weder seinen Wohnsitz noch seinen dauernden Aufenthalt in Deutschland hat (147). Nach $\$ 25$ Abs. 2 tritt kein Verlust der Staatsangehörigkeit ein, wenn der Betreffende auf seinen Antrag vor dem Erwerb der ausländischen Staatsangehörigkeit die schriftliche Genehmigung der zuständigen deutschen Behördlen erhalten hat. Diese Beibehaltungsgenehmigung wird nur in Ausnahmefällen erteilt,

"wenn schwerwiegende persönliche Gründe des Antragstellers für die Beibehaltung der deutschen Staatsangehörigkeit sprechen, z.B. wenn er die fremde Staatsangehörigkeit aus einer Zwangslage heraus erwirbt und für ihn dabei eine seine Lebensgrundlage berührende Existenzfrage auf dem Spiel steht; weniger gewichtige Nachteile muß er hingegen grundsätzlich in Kauf nehmen" (148).

Die Bundesrepublik kennt den Verlust der Staatsangehörigkeit wegen längeren Auslandsaufenthaltes nicht. Wichtig ist die Vorschrift des Art. 16 Abs. 1 Grundgesetz, aufgrund dessen die Staatsangehörigkeit nicht entzogen werden darf. Der Verlust der Staatsangehörigkeit darf - nach Satz 2 von Art. 16 Abs. 1 GG - nur aufgrund eines Gesetzes geschehen und gegen den Willen des Betroffenen nur dann eintreten, wenn der Betroffene dadurch nicht staatenlos wird.

Das deutsche Recht kennt weder im Falle einer Entlassung noch im Falle eines Verzichts eine Erstreckung des Verlustes auf minderjährige Kinder. Für minderjährige Deutsche kann aber gemäß $\S 19$ RuSt.AG selbständig Entlassung oder Genehmigung einer Verzichtserklärung beantragt werden. Eine Zustimmung des Vormundschaftsgerichts ist dann grundsätzlich notwendig (149). Wenn ein Minderjähriger auf Antrag seines gesetzlichen Vertreters eine fremde Staatsangehörigkeit erwirbt und eine Zustimmung des deutschen Vormundschaftsgerichts vorliegt, wird ebenfalls die deutsche Staatsangehörigkeit verloren (150).

Ein Minderjähriger verliert die deutsche Staatsangehörigkeit, wenn er durch eine nach den deutschen Gesetzen wirksame Adoption durch einen Ausländer dessen Staatsangehörigkeit erwirbt. Der Verlust tritt nicht ein, wenn er mit einem deutschen Elternteil verwandt bleibt ( $\$ 27$ RuStAG) (151). 
Das RuStAG sieht nicht die Möglichkeit vor, eine Einbürgenung zu widerrufen, weil die Einbürgerung durch falsche Angaben oder betrügerische Handlungen erschlichen worden ist. Dennoch wird von vielen Autoren angenommen, daß eine solche Widerrufung aufgrund allgemeiner Rücknahmeregeln des Verwaltungsverfahrensrechtes möglich ist (152). 


\subsection{FRANKREICH}

\subsubsection{Allgemeine Bemerkungen}

Das heutige französische Staatsangehörigkeitsrecht ist im "Code de la nationalité française" von 1945 geregelt, der 1973 eingehend revidiert wurde und seitdem wiederum häufiger, aber nicht eingreifend geändert worden ist (im folgenden abgekiirzt: CNF) (1). Das Staatsangehörigkeitsrecht Frankreichs hat eine lange Geschichte, die mindestens (2) bis auf die große Französische Revolution zurückgeht. Bereits in den französischen Verfassungen von 1791, 1793, 1795 und 1799 fanden sich erste Regelungen der Staatsangehörigkeit (3). In der Verfassung vom 3. September 1791 betrafen die Artikel 2-6 die Erwerbs- und Verlustgründe der Staatsangehörigkeit, in der Verfassung vom 24. Juni 1793 (Jahr $D$ ) bezogen sich die Artikel 4-6 auf die Staatsangehörigkeit, in der Verfassung vom 22. August 1795 (5. Fructidor Jahr III) waren es die Artikel 8-10, in der vom 13. Dezember 1799 (22. Frimaire Jahr VIII) die Artikel 2-4. Es würde zu weit führen, diese unterschiedlichen konstitutionellen Regelungen, die alle nur ganz kurz gegolten haben, zu beschreiben. Es sei aber darauf hingewiesen, daß der französische konstitutionelle Gesetzgeber beim Erwerb durch Geburt grundsätzlich vom ius soli-Prinzip ausging (4) (5).

Dauerhaften Einfluß auf die Regelung der französischen Staatsangehörigkeit hatten die Bestimmungen über die Staatsangehörigkeit des Code Civil (abgekürzt: Cc) vom 21. März 1804 (6). Sein Inhalt ist schon in den Allgemeinen Bemerkungen zum belgischen Staatsangehörigkeitsrecht beschrieben worden (7). An dieser Stelle sei daran erinnert, daß Art. $10 \mathrm{Cc}$ vom ius sanguinis (a patre) ausging, während Art. $9 \mathrm{Cc}$ jedem in Frankreich geborenen Kind ein innerhalb eines Jahres nach Volljährigkeit auszuübendes Optionsrecht auf die französische Staatsangehörigkeit gab (8). Die bemerkenswerte Tatsache, daß der Code civil anders als frühere Verfassungen das ius sanguinis wählte, kann aus verschiedenen Gründen erklärt werden. Loussouarn/Bourel (9) schreiben darüber:

"Le Code civil a été rédigé dans une période de guerres où s"exacerbe le
sentiment national et où l'on désirait en conséquence obtenir une forte cohé-
sion nationale. Or il est incontestable que la nationalité de filiation assure
cette cohésion plus sûrement que la nationalité de territoires" (10).

Auch entsprach der Erwerb iure sanguinis den demographischen Bedürfnissen. Frankreich war damals keineswegs ein Immigrationsland, das sich vielleicht aus Gründen der Integration der Zuwanderer einiges vom ius soli versprochen hätte. Im Gegenteil Frankreich war zu jener Zeit das bevölkerungsreichste Land Westeuropas (11), das kein ius soli-Prinzip brauchte, um die Bevölkerung zunehmen zu lassen.

Hinsichtlich der staatsangehörigkeitsrechtlichen Position der Frau ging der Code civil vom Einheitsprinzip aus. Verlustgründe der Staatsangehörigkeit waren: Einbürgerung im Ausland, die Ausübung ausländischer öffentlicher Ämter ohne Genehmigung des Kaisers, Niederlassung im Ausland ohne Absicht der Rückkehr nach Frankreich und der Eintritt in einen ausländischen Militärdienst ohne Erlaubnis des Kaisers (Art. 17, 21 Cc) (12) (13). Eine Französin verlor ihre 
Staatsangehörigkeit weiter noch durch Eheschließung mit einem Ausländer (Art. $12 \mathrm{Cc}$ ). Auch der bürgerliche Tod (mort civile: Art. $25 \mathrm{Cc}$ ) bewirkte Verlust der Staatsangehörigkeit (14).

Der Code Civil von 1804 enthielt keine Bestimmungen über die Einbürgerung. Dafür blieb Art. 3 der Verfassung des Jahres VIII (1799) maBgebend, gemäB welchem ein Ausländer ein Optionsrecht auf die französische Staatsangehörigkeit hatte, sofern er erklärte, in Frankreich bleiben zu wollen ("declaré l'intention de se fixer en France) und bereits zehn aufeinander folgende Jahre in Frankreich gelebt hatte. Am 4. September 1802 (26. Vendémiaire Jahr XI) wurde durch organisches Senatskonsult die Möglichkeit eröffnet, daß Ausländer, die

"rendront ou qui auraient rendu des services importants à la République, ou qui apporteront dans son sein des talents, des inventions ou des industries utiles, ou qui formeront de grands établissements"

nach einjährigem Domizil in Frankreich eingebürgert werden konnten (15). Durch kaiserliches Dekret vom 17. März 1809 wurde das Optionsrecht gemäß Art. 3 der Konstitution zur Einbürgerungsvorschrift umgedeutet (16). Am 26. August 1811 wurde schließlich durch kaiserliches Dekret die Position von im Ausland eingebürgerten Franzosen näher bestimmt. Diejenigen, die ohne Einwillung des Kaisers im Ausland eingebürgert wurden, verloren gemäß Art. 6 dieses Dekrets alle Güter in Frankreich und ebenfalls das Recht, in Frankreich zu erben. Denjenigen, die ohne Einwilligung in fremdlem Staats- oder Wehrdienst waren, traf die gleiche Sanktion (Art. 25) (17).

Nach 1814/1815 galten die staatsangehörigkeitsrechtlichen Bestimmungen des Code Civil 1804 und die des Dekrets aus dem Jahre 1809 weiter. Spätere französische Konstitutionen enthielten keine inhaltliche Bestimmungen bezüglich der Staatsangehörigkeit mehr. Im März 1848 wurde durch Dekret ein Einbürgerungsanspruch nach fünfjährigem Wohnsitz eingeführt; diese Regelung wurde aber am 26. Juni desselben Jahres suspendiert (18). Im Jahre 1849 wurde ein neues Gesetz ïber die Einbürgerung und Aufenthalt von Ausländern in Frankreich erlassen (19), worin für die Einbürgerung wieder - wie 1799 - ein zehnjähriger Aufenthalt gefordert wurde.

Das in Art. $9 \mathrm{Cc}$ formulierte Optionsrecht eines in Frankreich geborenen ausländischen Kindes wurde 1849 (20) dahingehend geändert, daß der Optant zusätzlich noch seine Wehrpflicht erfüllen muBte. Durch Gesetz vom 7. Februar 1851 wurde das ius soli-Element in der französischen Gesetzgebung mehr betont: jenes Gesetz verlieh die französische Staatsangehörigkeit den in Frankreich geborenen Kindern, deren Vater selbst auch in Frankreich geboren war (21). Diese Regelung wurde 1874 und 1882 leicht revidiert (22).

Im Jahre 1867 wurden durch ein Gesetz vom 29. Juni die Einbürgerungsvoraussetzungen erheblich erleichtert (23): die geforderte Aufenhaltsfrist wurde auf drei Jahre festgesetzt. Das Gesetz fügte die Bestimmungen bezüglich der Einbuirgerung in den Code Civil ein.

Durch Gesetz vom 26. Juni 1889 wurde das Staatsangehörigkeitsrecht fast insgesamt neu kodifiziert (24). Der Text des neuen Staatsangehörigkeitsrechts 
wurde aber wieder in den Code Civil eingefügt alls Art. 8 bis 21.

Nach Art. 8 Ziffer $1 \mathrm{Cc}$ (1889) erwarb das eheliche Kind eines Franzosen immer die französische Staatsangehörigkeit, auch bei Geburt im Ausland. Ein uneheliches Kind war Franzose, wenn der Elternteil, der das Kind als erster anerkannte, diese Staatsangehörigkeit besaß. Iure soli erwarben alle in Frankreich geborenen Kinder die französische Staatsangehörigkeit, von denen ein Eltemteil auch selber in Frankreich geboren war (Art. 8 Ziffer $3 \mathrm{Cc} 1889$ ) (25). Auch jedes in Frankreich geborene Kind unbekannter Eltern oder von Eltern, deren Staatsangehörigkeit unbekannt war, erwarb automatisch die französische Statsbürgerschaft (Art. 8 Ziffer $2 \mathrm{Cc}$ 1889) (26). Die ius soli-Bestimmung des Art. 8 Ziffer $3 \mathrm{Cc}$ in der Fassung von 1889 bewirkte, daß in Frankreich geborene Kinder von einer in Frankreich geborenen Mutter die französische Staatsangehörigkeit erwarben, auch wenn sie von ihrem ausländischen Vater iure sanguinis eine ausländische Staatsangehörigkeit herleiteten. Hinsichtlich dieser Regelung legten mehrere ausländische Regierungen Protestschreiben ein (27). Unter Druck des Auslandes wurde deshalb die Regelung dahingehend geändert, daB ein Kind, dessen Mutter in Frankreich geboren war, auf die iure soli erworbene Staatsangehörigkeit während eines Jahres nach Erreichung der Volljährigkeit verzichten konnte (Art. 8 Ziffer $3 \mathrm{Cc}$ in der Fassung vom 22. Juli 1893) (28). Alle übrigen in Frankreich geborenen Ausländerkinder erwarben ipso iure die französische Staatsangehörigkeit, wenn sie bei Volljährigkeit noch ihren Wohnsitz in Frankreich hatten (Art. 8 Ziffer $4 \mathrm{Cc} 1889$ ). Innerhalb eines Jahres nach Erreichung der Volljährigkeit konnte die so erworbene Staatsangehörigkeit unter bestimmten Voraussetzungen wieder ausgeschlagen werden. Falls ein in Frankreich geborenes Ausländerkind zur Zeit seiner Volljährigkeit nicht in Frankreich lebte, konnte es sich bis zum vollendeten 22 . Lebensjahr verpflichten, sich in Frankreich niederzulassen und dann innerhalb eines Jahres für die französische Staatsangehörigkeit optieren (Art. $9 \mathrm{Cc}$ 1889). Die Optionserklärung konnte aber seit 1893 wegen Unwürdigkeit ("indignité") verweigert werden (29). Daraus kann gefolgert werden, daß es sich von dieser Zeit an nicht mehr um ein reines Optionsrecht handelte. Aufgrund des letzten Absatzes von Art. $9 \mathrm{Cc} 1889$ wurde der in Frankreich geborene Ausländer, auch wenn er Domizil im Ausland hatte, automatisch Franzose, sofern er sich der französischen Musterung für den Militärdienst unterwarf. Für andere Ausländer waren die Einbürgerungsvoraussetzungen in Art. 8 Ziffer $5 \mathrm{Cc} 1889$ geregelt (30).

Die Verlustgründe der französischen Staatsangehörigkeit entsprachen in großen Limien denen des $\mathrm{Cc}$ 1804. Eine Französin verlor grundsätzlich ihre Staatsangehörigkeit durch Ehe mit einem Ausländer, es sei denn, sie erwarb nicht die Staatsangehörigkeit ihres Mannes (Art. $19 \mathrm{Cc} 1889$ ). Weiter ging der Status eines Franzosen verloren durch den freiwilligen Erwerb einer fremden Staatsangehörigkeit (für Wehrpflichtige allerdings nur im Fall einer Einwilligung der französischen Regierung) (Art. 17 Abs. $1 \mathrm{Cc} 1889$ ), in bestimmter Fällen durch Verzicht (Art. 17 Abs. 2, 8 Ziffer 4, und $12 \mathrm{Cc} 1889$ ) und im Falle fremden Staats- und Militärdienstes ohne Einwilligung der französischen Behörden (Art. 17 Abs. 3, 4, 21 Cc 1889). Einen Verlust wegen Auslandsaufenthalts gab es im Cc 1889 nicht mehr (31). 
Die Entwicklungen des französischen Staatsangehörigkeitsrecht im vergangenen Jahrhundert wurden geprägt durch das Verlangen, möglichst vielen Personen die französische Staatsangehörigkeit zu geben (32). Die Bevölkerung Frankreichs wuchs viel langsamer als die Einwohnerzahl anderer europäischen Staaten (33). Von 1789 bis 1913 wuchs Rußland von 25 auf 175 Millionen Einwohner, Großbritannien von 12 auf 48 Millionen, Deutschland von 19 auf 67 Millionen, Italien von 11 auf 36 Millionen und Frankreich lediglich von 26 nach 39 Millionen. Die Geburtrate (34) ging im Laufe der Jahre dermaßen zuruick, daß in der Mitte des zwanzigsten Jahrhunderts die Zahl der natïrlichen Todesfälle, die der Geburten übertraf. Auch die Anzahl der Einwanderer nahm rapide zu (35). Im Jahre 1872 betrug die Anzahl der Ausländer 2,03\%, $18863 \%$ und 1931 sogar 7,42 \% (2.890.923 Einwohner). In der Anwesenheit beachtlicher Gruppen von Ausländern sah man eine Gefahr für die nationale Einheit. Durch die Ánderung der Staatsangehörigkeitsgesetzgebung versuchte man nunmehr, diese Ausländer in die Gemeinschaft der Franzosen zu integrieren. Daneben entwickelten sich auch die Ideen über die Staatsangehörigkeit (36). Unter diesen Gesichtspunkten muß die 1851 bewirkte Einführung des ius soli-Prinzips für die zweite in Frankreich geborene Generation gesehen werden. Der Erwerb der Staatsangehörigkeit iure soli wurde 1889 - wie wir bereits sahen - noch verstärkt und lediglich wegen äußerer Proteste 1893 wieder etwas abgeschwächt. Den Gipfel erreichte das Streben, möglichst viele Ausländer in Frankreich einzugliedem, in dem Staatsangehörigkeitsgesetz von 1927 (37).

Die 1889 in den $\mathrm{Cc}$ aufgenommenen staatsangehörigkeitsrechtlichen Vorschriften wurden zweimal leicht durch die Gesetze vom 22. Juli 1893 (38) und vom 5. April 1909 (39) geändert. Die Regelung von 1889 führte zu einer umfangreichen Rechtsprechung. Schon am Vorabend des Ersten Weltkriegs wurde deshalb über die Möglichkeit diskutiert, die Staatsangehörigkeit Frankreichs wieder neu zu kodifizieren. Dabei war klar, daß der Regelungsumfang wahrscheinlich dermaßen sein würde, daß die Vorschriften nicht mehr in den $\mathrm{Cc}$ passen würden, sondern als Einzelgesetz erlassen werden müßten. Der erste Entwurf eines neuen Staatsangehörigkeitgesetzes wurde am 11. November 1913 (40) im Parlament eingebracht. Der Anfang des Krieges verzögerte das Zustandekommen eines neuen Gesetzes. Während des Krieges wurden nur einige kriegsbedingte Staatsangehörigkeitsvorschriften erlassen (41). Nach dem Ersten Weltkrieg wurde nach ausführlichen Diskussionen über mehrere Gesetzesentwürfe am 10. August 1927 ein aus 15 Artikeln bestehendes Staatsangehörigkeitsgesetz verabschiedet (42).

Durch Geburt erwarb jedes eheliche Kind eines Franzosen die Staatsangehörigkeit Frankreichs, ungeachtet seines Geburtsortes. Das in Frankreich geborene eheliche Kind eines ausländischen Vaters erwarb ebenfalls die französische Staatsangehörigkeit, falls auch der Vater in Frankreich geboren war. Falls dies nicht der Fall war, wurde das eheliche in Frankreich geborene Kind dennoch Franzose, wenn es von einer französischen Mutter geboren wurde (Art. 1, Ziffer 1-3 CNF 1927). Für uneheliche Kinder galt - soweit möglich - eine entsprechende Regelung. 
Das in Frankreich geborene Kind von unbekannten Eltern oder von Eltern, deren Staatsangehörigkeit unbekannt war, wurde ebenfalls iure soli französisch (Art. 1, Ziffer 7 CNF 1927).

Gemäß Art. 2 CNF 1927 erwarb das in Frankreich geborene eheliche Kind einer auch selbst in Frankreich geborenen ausländischen Mutter die französische Staatsangehörigkeit bei Erreichung der Volljährigkeit, konnte diese Staatsangehörigkeit aber innerhalb Jahresfrist unter bestimmten Voraussetzungen wieder ausschlagen. Eine entsprechende Regelung galt für uneheliche Kinder. Alle anderen in Frankreich geborene Kinder konnten bis zu ihrem 21. Geburtstag fiur die französische Staatsangehörigkeit optieren, falls sie ihren Wohnsitz in Frankreich hatten. Die Option konnte aber wegen Unwiirdigkeit zurückgewiesen werden. Im Alter von 21 Jahren erwarben diese Personen die französische Staatsangehörigkeit von Rechts wegen, wobei sie aber die Möglichkeit hatten, unter bestimmten Voraussetzungen die Staatsangehörigkeit innerhalb eines Jahres wieder auszuschlagen.

Die Einbürgerungsvorschriften waren im Gesetz von 1927 zwar großzïgig formuliert, manifestierten aber ein Mißtrauen Ausländern gegenüber. Die Folge war eine starke Kontrolle der Behörden im Rahmen der Einbürgerung. Bemerkenswert war, daß die eingebürgerten Franzosen erst nach zehn Jahren bestimmte Ämter bekleiden konnten (Art. 6 Abs V-VIII CNF 1927). Art. 9 Ziffer 5 CNF 1927 sah weiter die Möglichkeit vor, den eingebürgerten Franzosen innerhalb von zehn Jahren die französische Staatsangehörigkeit wegen Handlungen gegen die innere oder äußere Sicherheit des Staates wieder abzuerkennen. Gleiches galt, wenn er sich zum Vorteil eines fremden Landes in Handlungen eingelassen hatte, die mit der Eigenschaft als französischer Bürger unvereinbar waren und gegen die Interessen Frankreichs gerichtet waren sowie dann, wenn er sich französischen Militärverpflichtungen entzog.

Eine der wichtigsten Änderungen des Gesetzes von 1927 war, daß im Bezug auf die Staatsangehörigkeit der Frau das Gesetz das "système unitaire" verließ. Die Französin, die einen Ausländer heiratete, verlor fortan nicht mehr ihre Staatsangehörigkeit, es sei denn, sie verzichtete auf diese (Art. 8 Abs. II). Die Ausländerin, die einen Franzosen heiratete, erwarb aber auch nicht mehr automatisch die Staatsangehörigkeit ihres Mannes; sie erwarb aber ein Optionsrecht auf die französische Staatsangehörigkeit (Art. 8 Abs. I) (43).

Nach Art. 9 CNF 1927 wurde die französische Staatsangehörigkeit durch Einbürgerung im Ausland, Verzicht, ausländischen Staats- oder Wehrdienst gegen das ausdrückliche Verbot der französischen Regierung verloren. Noch unter Einfluß der Erfahrungen des Ersten Weltkrieges bestand die Möglichkeit, neu Eingebürgerten u.U. die französische Staatsangehörigkeit wieder abzuerkennen (44).

Nach 1927 wurde das Mißtrauen Ausländern gegenüber noch grösser (45). So wurden durch Gesetz vom 19. Juli 1934 (46) die Rechte der Eingebürgerten noch weiter beschränkt durch Einführung eines Abs. 6 in Art. 6 CNF: fortan konnte ein Eingebürgerter erst nach zehn Jahren ein besoldetes Staatsamt bekleiden, als Rechtsanwalt zugelassen oder Beamter werden. Dies wurde jedoch 
wieder etwas abgeschwächt durch Gesetze von 1936 (47) und 1937 (48), die Ausnahmen von der Regel des Art. 6 Abs. 6 formulierten (49).

Im Jahre 1938 (50) wurde das Gesetz von 1927 eingreifend geändert. Dabei wurde versucht, die Fälle des Erwerbs der französischen Staatsangehörigkeit ohne Kontrolle der Regierung auszuschließen. Die Gründe für den Verlust der Staatsangehörigkeit, insbesondere die der Aberkennung, wurden erweitert und das Aberkennungsverfahren beschleunigt.

Seit September 1939 wurden die Aberkennungsmöglichkeiten noch erheblich erweitert. Auch wurden kriegsbedingte Staatsangehörigkeitsworschriften erlassen (51).

Die zahlreichen Änderungen des CNF 1927, vor allem bezüglich der Einbürgerung und der Verlustgründe, hatten den Gesetzestext weniger übersichtlich und schwer leserlich gemacht. Kurz vor Ende des Krieges entstand deshalb das Bedürfnis, das Staatsangehörigkeitsrecht neu zu formulieren (52) und in einem neuen Text zusammenzufassen. Zu dieser Zeit wollte man zu dem Stand von 1927 zurückkehren. In der Perspektive dieser Zielsetzungen entstand der aus 151 Artikeln bestehende Code de la nationalité française, der am 19. Oktober 1945 verkiindet wurde (53).

Der CNF 1945 bildet auch heutzutage noch die Grundlage des französischen Staatsangehörigkeitsrechts. An dieser Stelle sollen deshalb lediglich auf einige bemerkenswerte Unterschiede zu dem bisherigen Recht hingewiesen werden. Fortan erwarben auch die im Ausland geborenen ehelichen Kinder einer französischen Mutter und eines ausländischen Vaters die französische Staatsangehörigkeit (Vgl. Art. 1 Ziffer 3 CNF 1927 mit Art. 19 Ziffer 1 CNF 1945). Wie vor 1927 erwarb die Ausländerin, die einen Franzosen heiratete, wieder automatisch die französische Staatsangehörigkeit (Art. 37 CNF 1945); das "système dualiste" wurde also micht mehr so streng durchgefuihrt wie 1927. Die so erworbene Staatsangehörigkeit konnte aber ausgeschlagen werden (Art. 38 CNF 1945). Die Französin, die einen Ausländer heiratete, verlor aber weiterhin ausschließlich ihre bisherige Staatsangehörigkeit, wenn sie ausdrücklich auf diese verzichtete (Art. 94 CNF 1945). Auch wurden die Fälle, in denen die französische Staatsangehörigkeit aberkannt werden konnte, wieder reduziert (Art. 98, 99 CNF 1945).

Einer der Ziele der Neukodifizierung von 1945 war, das Staatsangehörigkeitsrecht Frankreichs dermaßen zu gestalten, daß zu häufige Reformen überflüssig wïrden (54). Gerade deshalb versuchte der Gesetzgeber, möglichst viele Details ausdrücklich zu regeln. Aber gerade diese vielen Einzelheiten haben in den folgenden Jahren häufige Gesetzänderungen notwendig gemacht. Lagarde (55) schreibt darüber:

"Pourtant, en entrant dans les plus infimes détails, il s'est attiré le reproche de compliquer la tâche de l'interprête, astreint à l'application littérale du texte, et de rendre difficile l'élaboration des principes généraux de la matière qui auraient pu guider la jurisprudence dans la solution des inévitables ob- 
scurités ou lacunes du texte. C'est probablement ce qui explique les fréquentes interventions du législateur qui, depuis 1945, n'a pas cessé de modifier, souvant sur des points de détail, le Code de la nationalité, pour régler des situations particulières qui n"avaient pas été envisagées par les auteurs du code".

Es würde zu weit ins Detail führen, alle vorgenommenen Änderungen zu besprechen (56). Eine sehr grundlegende Revision der CNF wurde realisiert durch das Gesetz vom 9. Januar 1973 (57): 51 Artikel wurden aufgehoben, 88 Artikel geändert und 14 neu eingefügt. Hauptziel dieser Reform war, das Staatsangehörigkeitsrecht Frankreichs in Übereinstimmung mit neuesten Entwicklungen des Familienrechts zu bringen, die Gleichberechtigung von Mann und Frau zu verwirklichen und eheliche und nichteheliche Kinder möglichst gleich zu behandeln (58). Die Verlustgründe der Staatsangehörigkeit wurden reformiert zugunsten von im Ausland lebenden Franzosen. Bestimmungen über Staatsangehörigkeitsausweise, über Beweis der Staatsangehörigkeit und Gerichtsverfahren in Staatsangehörigkeitsangelegenheiten wurden aus dem CNF entfernt und in Durchfuihrungsverordnungen untergebracht (59). Nach 1973 wurde der CNF noch wieder in vielen Details abgeändert. Durch Gesetz vom 5. Juli 1974 (60) wurde das Volljährigkeitsalter auf 18 Jahre heruntergesetzt. Demzufolge wurden einige Artikel der CNF angepasst (61).

Die nächste Änderung wurde vorgenommen durch Gesetz vom 22. Dezember 1976 (62), das das Adoptionsrecht änderte. In diesem Zusammenhang wurde an Art. 26 CNF ein Absatz zugefügt, während Art. 35 aufgehoben wurde.

In Juli 1978 wurden zwei Gesetze verabschiedet, die Änderungen des CNF verursachten. Das Gesetz vom 12. Juli fügte einige Verwaltungsvorschriften in den CNF ein (63). Durch Gesetz des 17. Juli wurde die Position eines Eingebürgerten verbessert (64). Die Art. 81 und $82 \mathrm{CNF}$ wurden geändert. Das einzige Recht, das eine Person, die in Frankreich eingebürgert wurde, fortan während der sechs Jahre unmittelbar nach der Einbiirgerung noch nicht hatte, war die Möglichkeit, eine Funktion zu bekleiden oder ein politisches Mandat auszuïben, für die die französische Staatsangehörigkeit notwendig ist.

Durch Gesetz vom 8. Dezember 1983 (65) wurden die Unterschiede zwischen Personen, die durch Geburt die französische Staatsangehörigkeit besaßen und die diese Position durch Einbürgerung erwarben, endgültig durch Änderung von Art. $80 \mathrm{CNF}$ und Aufhebung der Art. 81-83 CNF ersatzlos gestrichen (66).

Die wichtigste Änderung seit 1973 wurde aber durch das Gesetz vom 7. Mai 1984 vorgenommen (67). Bis dann hatte der ausländische Ehegatte eines Franzosen durch die Eheschließung ein kontrolliertes Optionsrecht auf die französische Staatsangehörigkeit. Nunmehr wurde Art. 31-1 CNF dermaßen geändert, daß erst sechs Monate nach Eheschließung eine Optionserklärung abgegeben werden kann (68).

Auch nach allen diesen Änderungen wird im französischen Staatsangehörigkeitsrecht wohl kaum eine gesetzgeberische Ruhe eintreten. Am 12. November 1986 
hat die Regierung Chirac einen Gesetzesentwurf zur Änderung des CNF eingereicht (69). Zwar wurde dieser Entwurf nach den Pariser Studentenunruhen vom Dezember 1986 als "umstritten" wieder zurückgenommen, aber der Inhalt dieses Entwurfes ist dennoch erwähnenswert, da daraus deutlich wird, welche Regelungen des CNF momentan zur Diskussion stehen. So wird in dem Entwurf vorgeschlagen, Art. $44 \mathrm{CNF}$, der vorsieht, daß in Frankreich geborene Personen unter bestimmten Voraussetzungen mit Erreichung der Volljährigkeit automatisch die französische Staatsangehörigkeit erwerben (eine Regelung, die Frankreich mit gewissen kleineren Anderungen seit 1889 kennt) durch ein Optionsrecht zu ersetzen:

"Toute personne née en France de parents étrangers peut, à partir de l'âge de seize ans et tant qu'elle n'a pas atteint l'âge de vingt-trois ans, réclamer la nationalité française par déclaration si, au jour de la demande, elle a sa résidence en France et si elle y réside d'une manière habituelle depuis au moins cinq ans".

Eine solche Option kann nach dem Entwurf von der Verwaltung zuruickgewiesen werden aufgrund der in Art. 79 (neu) genannten Gründe. Erstens darf der Optant nicht von einem französischen Gericht zu einer Gefängnisstrafe von mehr als sechs Monaten verurteilt worden sein oder zu einer kürzeren Gefängnisstrafe wegen bestimmter Delikte (70). Weiter muß die Option zurückgewiesen werden:

"-S'il est sous le coup d"une messure de faillite personelle ou d'interdiction de diriger, gérer, administrer ou contrôler une entreprise commerciale, lorsque la faillite personelle ou l'interdiction a été prononcée par une jurisdiction française ou déclarée exếcutoire en France.

-S'il a été prononcé contre lui un arrêté d'expulsion ou d'assignation à résidence non expressement rapporté dans les formes où il est intervenu.

-S'il n'est pas assimilé à la communauté française, notamment par une connaissance suffisante, selon sa condition, de la langue française".

Zwar hat die französische Regierung auch nach geltendem Recht die Möglichkeit, den automatischen Staatsangehörigkeitserwerb bei Unwürdigkeit oder mangelnder Assimilierung zu verhindern, aber es ist offensichtlich, daß die vorgeschlagene Kontrolle des Optionsrechts einerseits wahrscheinlich strenger und andererseits sicher "effektiver" sein wird. Interessant ist es, die in den Motiven erwähnten Vorteile der vorgeschlagenen Regelung zu zitieren. Außer der besseren Kontrollmöglichkeit ist die neue Regelung dermaßen, daß vermieden wird

"d'intégrer des personnes qui ne le souhaitent pas réellement ou qui n'ont pas conscience d'être devenues françaises".

Weiter wird darauf hingewiesen, daß

"La déclaration de nationalité, titre non équivoque et ayant date certaine, dispensera le jeune étranger devenu français à ce titre de conservẹr une 
preuve, souvent malaisée à constituer, de sa résidence en France à l'époque de sa majorité, comme le système actuel l'a contraint".

Dennoch dürften für die meisten Personen die Vorteile des neuen Systems wohl kaum gegen die vorgeschlagenen strengeren Kontrollen aufwiegen.

Anscheinend hatte die Regierung Chirac sogar darüber nachgedacht, den seit 1851 in Frankreich existierenden automatischen Staatsangehörigkeitserwerb durch die zweite in Frankreich geborene Generation abzuschaffen, da in den Motiven ausführlich betont wird, weshalb jener automatische Erwerbsgrund gehandhabt werden soll (71). Einerseits wird darauf hingewiesen, daB in dem Falle eine Integration in die französische Gesellschaft wohl angenommen werden darf. Andererseits wïrde Abschaffung dieser Regelung den Beweis der französischen Staatsangehörigkeit erschweren, da man nun regelmäßig diese Staatsangehörigkeit beweist durch den Nachweis, daß man die zweite in Frankreich geborene Generation ist.

Ein weiterer wichtiger Vorschlag des Entwurfes ist, das Optionsrecht des ausländischen Ehegatten durch eine erleichterte Einbürgerung zu ersetzen (72). Nachdem in Jahre 1984 das Optionsrecht erst sechs Monate nach EheschlieBung ausgeübt werden konnte, wird nun vorgeschlagen, die Hürde, die der ausländische Ehegatte überwinden muß, um Franzose zu werden, nochmal erheblich zu erhöhen. Nicht verlangt wird eine bestimmte Dauer der Ehe oder des Aufenthaltes in Frankreich. In den Motiven wird indessen darauf hingewiesen, daß das Einbürgerungsverfahren bis zu anderthalb Jahren dauern könnte. Eine Einbürgerung konnte wieder aufgrund der bereits erwähnten Gründe von Art. 79 zuriickgewiesen werden. Bemerkenswert ist noch, was die Motive über die erleichterte Einbürgerung des ausländischen Ehepartners sagen:

"Elle concordera, en outre, avec l'évolution des moeurs et du droit de la famille qui reconnaissent l'autonomie juridique des époux".

Anscheinend wurde vergessen, daß auch das heutige Optionsrecht schon diese Autonomie berücksichtigt.

Der von der Regierung Chirac eingereichte Entwurf schlug noch weitere - kleinere - Änderungen vor. Bis zum Abschließen dieses Manuskripts wurde kein neuer Entwurf wieder eingereicht (73). Am 22. Juni 1987 installierte Ministerpräsident Chirac eine "Commission de la Nationalité" unter der Führung von Marceau Long, die damit beauftragt wurde, die in Frankreich vorhandenen Ansichten über wünschenswerte Änderungen der CNF zu inventarisieren und Vorschläge zu Änderungen zu machen. Diese Kommission hat im Februar 1988 Bericht erstattet (74). Mit dem Ausgang der Wahl in Frankreich im Mai 1988 und dem Ende der Regierung Chirac dürfte der Entwurf sein -zumindest vorläufiges- Ende gefunden haben. 


\subsubsection{Erwerb der Staatsangehörigkeit durch Geburt}

\subsubsection{Rückblick}

Iure sanguinis erwarb ursprïnglich ein eheliches Kind sowohl bei Geburt im Inland als auch bei Geburt im Ausland die französische Staatsangehörigkeit, wenn sein Vater diese besaß (Art, $10 \mathrm{Cc} 1804$; Art. 8 Ziffer $1 \mathrm{Cc}$ i.d.F. 1889) (75). Auch in dem CNF 1927 galt dieser Grundsatz (Art. 1 Ziffer 1 CNF 1927), aber bei Geburt in Frankreich erwarb das eheliche Kind einer französischen Mutter und eines ausländischen Vaters ebenfalls die französische Staatsangehörigkeit (76). Seit 1945 erwarb auch ein im Ausland geborenes eheliches Kind einer französischen Mutter und ihres ausländischen Ehemannes die Statatsangehörigkeit seiner Mutter (Art. 19 Abs. 1 CNF i.d.F. 1945); ein solches Kind konnte diese Staatsangehörigkeit aber innerhalb der Frist von sechs Monaten, die seiner Volljährigkeit vorausgeht, wieder ausschlagen. Seit 1973 gilt die heutige Regelung.

1804 erwarb das nichteheliche Kind einer Französin die französische Staatsangehörigkeit; das nichteheliche Kind eines Franzosen erwarb die Staatsangehörigkeit seines Vaters, wenn dieser es anerkannte (77).Beziiglich nichtehelicher Kinder galt sowohl im Cc i.d.F. 1889 als im CNF 1927, daß ein nichteheliches Kind, dessen Abstammung während der Minderjährigkeit durch Anerkennung oder Urteil festgestellt wurde, französisch wurde, wenn derjenige Elternteil, für den zuerst der Beweis gefïhrt worden ist, die Staatsangehörigkeit besaß. Bei gleichzeitiger Feststellung der väterlichen und mütterlichen Abstammung wurde die französische Staatsangehörigkeit erworben, wenn der Vater diese innehatte (Art. 8 Ziffer 1 Cc i.d.F. 1889; Art. 1 Ziffer 4 CNF 1927) (78), In dem CNF 1945 konnte ein nichteheliches Kind die französische Staatsangehörigkeit von beiden Eltern ableiten (Art. 17 Ziffer 2; Art 18 Ziffer 2 CNF i.d.F. 1945). Sowohl in dem CNF 1927 als in dem CNF 1945 konnte die so erworbene Staatsangehörigkeit u.U. ausgeschlagen werden. Seit 1973 gilt die heutige Regelung.

In dem Cc 1804 sah Art. 9 Cc lediglich ein Optionsrecht für in Frankreich geborene Ausländer vor. Seit 1851 galt, daß ein in Frankreich geborenes Kind eines selbst auch in Frankreich geborenen Vaters am 22. Geburtstag die französische Staatsangehörigkeit erwarb, wenn es diese nicht ausschlug. Ein richtiger Erwerb iure soli wurde vom Cc 1889 eingeführt: Wenn ein Elternteil in Frankreich geboren war, erwarb das ebenfalls in Frankreich geborene Kind die französische Staatsangehörigkeit (Art. 8 Ziffer 3 Cc i.d.F. 1889; Art, 1, 2 CNF 1927; Art. 23 CNF 1945) (79). Seit 1893 konnte die so erworbene Staatsangehörigkeit u.U. ausgeschlagen werden. Seit 1973 gilt die heutige Regelung.

Seit 1889 steht weiter fest, daß das in Frankreich geborene Kind unbekannter Eltern die französische Staatsangehörigkeit erwirbt (Art. 8 Ziffer 2 Cc i.d.F. 1889; Art. 1 Ziffer 7 CNF 1927; Art. 21 CNF 1945). Von 1889 bis 1938 galt dasselbe für Kinder von Eltern unbekannter Staatsangehörigkeit. Seit 1973 gilt nun wieder eine entsprechende Regelung (Art. 21-1 CNF 1973).

Ein während seiner Minderjährigkeit legitimiertes ausländisches Kind erwirbt die französische Staatsangehörigkeit des Vaters (Art. 1 Ziffer 4 CNF 1927; Art. 
34 CNF 1945). Seit 1973 enthält die CNF keine entsprechende ausdrückliche Bestimmung mehr. Die Staatsangehörigkeit wird aber aufgrund von Art. 17 CNF erworben.

Durch volle Adoption wird erst seit 1945 die französische Staatsangehörigkeit erworben, wenn der Adoptivvater Franzose war (Art. 35 CNF). Art. 35 wurde 1966 und 1973 neugefasst und 1976 aufgehoben. Seitdem sind für die Adoption Art. $26 \mathrm{Abs} .2,36$ und $55 \mathrm{CNF}$ maßgebend.

\subsubsection{Heutige Regelung}

Das französische Recht geht hinsichtlich des Erwerbs der Staatsangehörigkeit durch Geburt vom ius sanguinis-Prinzip aus, obwohl wir im Code de nationalité auch sehr starke ius soli-Elemente sehen können (80). Der Erwerb der französische Staatsangehörigkeit iure sanguinis ist in Art. $17 \mathrm{CNF}$ geregelt: Franzose ist das eheliche oder nichteheliche Kind, bei dem mindestens ein Elternteil französisch ist (81). Der Erwerb geschieht also sowohl "iure sanguinis a patre" als "a matre" (82). Wenn aber nur ein Elternteil französisch ist, kann das außerhalb Frankreichs geborene Kind (83), innerhalb der Frist won sechs Monaten, die seiner Volljährigkeit (84) vorausgeht, auf die französische Staatsangehörigkeit verzichten. (Art. 19 Abs. 1 CNF) (85). Ein solcher Verzicht ist jedoch nicht möglich, wenn der ausländische Elternteil vorher die französische Staatsangehörigkeit erworben hat (Art. 19 Abs. 2 CNF). Der Verzicht darf nicht zur Folge haben, daß der Betreffende staatenlos wird. (vgl. Art. 31 CNF).

Aufgrund des Art. 17 CNF ist die staatsangehörigkeitsrechtliche Position nichtehelicher Kinder grundsätzlich die gleiche wie die ehelicher Kinder (86). Auch sie erwerben durch Abstammung die französische Staatsangehörigkeit, wenn Mutter oder Vater französisch ist (87). Dabei müssen aber folgende Anmerkungen gemacht werden (88). Nach französischem Recht existieren nicht automatisch familienrechtliche Beziehungen zwischen einer Mutter und dem von ihr geborenen Kind. Die Regel "mater semper certa est" gilt also nicht. Mußte früher die Mutter ihr nichteheliches Kind immer ausdrücklich anerkennen, damit juristische Beziehungen zwischen ilhr und dem Kind entstanden, heutzutage kann die mütterliche Abstammung auch gerichtlich festgestellt werden (89).

Ein Kind gilt als nichteheliches Kind eines Mannes, wenn dieser das Kind anerkannt hat oder die Vaterschaft gerichtlich festgestellt ist (90). Sowohl hinsichtlich der Feststellung der mütterlichen als der väterlichen Abstammung ist die Bestimmung von Art. 29 CNF von Bedeutung: Die Feststellung der Abstammung eines Kindes beeinflußt dessen Staatsangehörigkeit nur dann, wenn sie während seiner Minderjährigkeit festgestellt wird. Wenn sowohl familienrechtliche Beziehungen zwischen Vater und Kind als zwischen Mutter und Kind fehlen, wird das Kind Franzose aufgrund Art. 21 CNF (91). Es ist dann ein Kind von juristisch unbekannten Eltern. In der gleichen Position befindet sich ein in Frankreich gefundenes Kind. Ein in Frankreich aufgefundenes neugeborenes Kind gilt nämlich aufgrund von Art. $22 \mathrm{CNF}$ i.V.m. Art. $58 \mathrm{Cc}$ als in Frankreich geboren. Wird jedoch während der Minderjährigkeit solcher Kinder 
eine ausschließlich ausländische Abstammung festgestellt, dann wird die französische Staatsangehörigkeit wieder verloren (Art. 21 Abs. 2 CNF).

Das ius soli-Element äußert sich im französischen Staatsangehörigkeitsrecht vor allem in den Art. 21-1 und 23 CNF (92).Aufgrund des erstgenannten Artikels ist das in Frankreich geborene Kind, das von seinen Eltern keine fremde Staatsangehörigkeit herleitet, Franzose (93). Es ist dabei irrelevant, ob die Eltern selber staatenlos sind oder zwar selber eine Staatsangehörigkeit besitzen, die sie aber nicht auf ihr Kind übertragen können. Von großer Bedeutung ist Art. 23 CNF, der bestimmt, daß ein in Frankreich (94) geborenes Kind französisch ist, wenn einer der Eltern auch in Frankreich geboren wurde. Die zweite auf franzö.sischem Bodem geborene Generation ist also automatisch französisch, auch wenn sie neben dieser Staatsangehörigkeit noch eine andere besitzt (95). Innerhalb der Frist von sechs Monaten, bevor ein Kind, das aufgrund des Art. 23 CNF Franzose ist, volljährig wird, kann es auf diese Staatsangehörigkeit verzichten, falls nur ein Elternteil in Frankreich geboren wurde (Art. 24 Abs.1 CNF) (96). Sind beide Eltem in Frankreich geboren, dann ist ein Verzicht unmöglich. Dies gilt auch, wenn der im Ausland geborene Elternteil inzwischen die französische Staatsangehörigkeit erworben hat (Art. 24 Abs. 2 CNF).

Das ius soli manifestiert sich auch stark in den Art. $44 \mathrm{ff}$. und $52 \mathrm{ff}$. CNF (97). Aufgrund des Art. 44 erwirbt jeder, der in Frankreich geboren ist, mit der Volljährigkeit die französische Staatsangehörigkeit, wenn er zu diesem Zeitpunkt in Frankreich lebt und dort auch während der letzten fünf Jahre seinen Wohnsitz hatte. Sowohl die betreffende Person als auch die französische Regierung können aber diesen automatischen Erwerb verhindern. Während des seiner Volljährigkeit vorangehenden Jahres kann derjenige, auf den Art. 44 CNF anzuwenden ist, erklären, die französische Staatsangehörigkeit nicht erwerben zu wollen (Art. $45 \mathrm{CNF}$ ). In dem gleichen Jahr kann auch die französische Regierung sich dem Erwerb widersetzen wegen Unwürdigkeit oder wegen mangelnder Assimilierung ("pour indignité ou pour défaut d'assimilation") (Art. 46 CNF).

Das Gesetz verbindet den automatischen Erwerb der Staatsangehörigkeit von Art. 44 noch mit einigen zusätzlichen Bedingungen: Derjenige, gegen den ein Ausweisungsbefehl (98) erlassen worden ist, oder ein Befehl, sich an einem bestimmten Ort aufzuhalten (99), kann die französische Staatsangehörigkeit nicht aufgrund Art. 44 CNF erwerben; das gleiche gilt für diejenigen, die zu einer Gefängnisstrafe von mindestens 6 Monaten verurteilt worden sind (Art. 79 CNF). Auch die Kinder von Diplomaten erwerben die französische Staatsangehörigkeit nicht auf diese Art. (Art. 45 CNF). Ein Minderjähriger darf nicht auf den Erwerb der französischen Staatsangehörigkeit gemäB Art. 44 CNF verzichten, wenn Staatenlosigkeit die Folge wäre (Art. 47 in Verbindung mit Art. 31 CNF). Verzicht ist ebenfalls nicht mehr möglich, wenn der betreffende junge Ausländer sich in die französische Armee verpflichtet oder freiwillig an den Erfassungsoperationen teilnimmt, um den nationalen Militärdienst abzuleisten, ohne seine Ausländereigenschaft vorzubehalten (Art. 47 CNF). In dem Moment, da er tatsächlich in den Dienst eintritt, erwirbt er ipso iure die französische Staatsangehörigkeit (Art. 48 CNF).

Wir haben eben gesehen, daß ein in Frankreich von ausländischen Eltern geborenes Kind grundsätzlich Franzose wird, wenn es am Tage seines achtzehnten 
Geburtstages in Frankreich lebt und dort schon seit seinem 13. Lebensjahr seinen Wohnsitz hatte. Sind diese Bedingungen nicht erfuillt, ist der Betreffende aber in Frankreich geboren, dann sind die Art. 52 ff. CNF anzuwenden. Wenn eine solche Person seit mindestens fünf Jahren in Frankreich lebt, kann für die französische Staatsangehörigkeit optiert werden (100) (Art. 52 CNF).Auch hier gilt wieder, daß die französische Regierung sich dem Erwerb der Staatsangehörigkeit widersetzen kann (101). Dies muß innerhalb eines Jahres nach der Optionserklärung geschehen (Art. 57 CNF). Unter bestimmten Bedingungen kann die Option auf die französische Staatsangehörigkeit auch bereits vor dem 18. Geburtstag ausgeübt werden. Wenn der betreffende Minderjährige bereits 16 Jahre ist, kann er selber mit Einwilligung der Personen, die über ihn die elterliche Gewalt ausüben, für die französische Staatsangehörigkeit optieren. Wenn der Minderjährige noch keine 16 Jahre ist, kann der gesetzliche Vertreter für ihn optieren, unter der Bedingung, daß dieser - wenn er selber Ausländer ist schon mindestens fünf Jahre in Frankreich lebt (Art. 54 CNF).

Durch Volladoption (102) erwirbt ein minderjähriges Kind die gleiche staatsangehörigkeitsrechtliche Position wie ein eheliches Kind (Art. 26 Abs. 2 i.V.m. Art. 29 CNF). Es kann deshalb unter den Voraussetzungen der Art. 17, 19, 21-1, 23 und 24 CNF die französische Staatsangehörigkeit erwerben. Dies ist also nicht nur der Fall, wenn ein Elternteil diese Staatsangehörigkeit besitzt, sondern auch, wenn es selber und ein Elternteil in Frankreich geboren wurde.

\subsubsection{Erwerb der Staatsangehörigkeit nach der Geburt}

\subsubsection{Rückblick}

Eine ausländische Frau erwarb gemäß den Cc-Bestimmungen von 1804 und 1889 (Art. 12) durch ihre Ehe mit einem Franzosen automatisch die französische Staatsangehörigkeit (103). Gemäß Art. 8 CNF 1927 war dies nur noch der Fall, wenn sie ihre bisherige Staatsangehörigkeit automatisch verlor. Für die übrigen Fälle sah Art. $8 \mathrm{CNF}$ ein Optionsrecht vor. Seit 1938 konnte die mit einem Franzosen verheiratete Ausländerin ausschließlich durch Option Französin werden; die Optionsmöglichkeit war übrigens stark eingeschränkt. Gemäß Art. $37 \mathrm{ff}$. CNF 1945 erwarb die Ausländerin durch die Eheschließung mit einem Franzosen grundsätzlich wieder automatisch die französische Staatsangehörigkeit, in der Periode 1951-1961 allerdings nur, wenn sie Wohnsitz in Frankreich hatte. Sowohl die ausländische Frau als die französische Regierung konnten jedoch den Staatsangehörigkeitserwerb ablehnen (104). Im Jahre 1973 wurde die Gleichberechtigung im französischen Staatsangehörigkeitsrecht völlig realisiert. Seitdem konnten sowohl eine ausländische Frau als ein ausländischer Mann nach Eheschließung mit einem französischen Staatsangehörigen optieren (105), seit 1984 allerdlings erst sechs Monate nach Eheschließung.

Seit 1889 kennt das französische Recht die Regel, daß ein in Frankreich Geborener unter bestimmten Voraussetzungen im Alter von 21 bzw. 18 Jahren automatisch Franzose wurde, wenn die französische Staatsangehörigkeit nicht ausgeschlagen wurde (Art. 8, 9 Cc i.d.F. 1889; Art. 4 CNF 1927) (106). Die heuti- 
ge Regelung gilt seit 1945, mit gewissen - kleineren - Änderungen von 1973 und 1974.

Seit 1804 sah der $\mathrm{Cc}$ ein Optionsrecht auf die französische Staatsangehörigkeit für in Frankreich geborene Ausländer vor (Art. $9 \mathrm{Cc}$ i.d.F. 1804). Entsprechende Regelungen kannten auch der Cc i.d.F. 1889 (Art. 9), der CNF 1927 (Art. 3) und der CNF 1945 (107). Dabei ist bemerkenswert, daß seit 1927 keine Option möglich war bei einem Ausweisungsbefehl und seit 1938 auch nicht bei einem Zwangaufenthaltsbefehl. Seit 1945 konnte die Verwaltung eine Optionserklärung wegen Unwürdigkeit oder mangelnder Assimilierung ablehnen.

Weitere Optionsrechte kannte das französische Recht u.a. in Art. $19 \mathrm{Cc}$ i.d.F. 1889 (Kinder einer verwitweteten ehemaligen Französin), Art. 10 Cc i.d.F. 1889 (Kinder ehemaliger Franzosen) und Art. 55 CNF 1945 (Adoptiv- und Pflegekinder).

Sowohl Art. 3 der Verfassung von 1799 als das Gesetz von 1849 forderten für die Einbürgerung grandsätzlich den zehnjährigen Wohnsitz in Frankreich (108). Aber schon das Senatskonsult von 1802 ermöglichte die Einbuirgerung bereits nach einjährigem Wohnsitz im Falle besonderer Verdienste. 1848 wurde ein Einbürgerungsanspruch nach fünfjährigem Wohnsitz eingeführt, schon nach drei Monaten aber wieder suspendiert. Seit 1867 wurde für den Einbürgerungsantrag ein dreijähriger Wohnsitz gefordert. Im Cc i.d.F. 1889 wurde wieder ein zehnjähriger Wohnsitz gefordert oder ein dreijähriger Wohnsitz nach Niederlassungsgenehmigung (Art. 8 Ziffer 5 Buchstaben a und b Cc i.d.F. 1889) (109). Art. 6 Abs. III Ziffer 1 CNF 1927 forderte lediglich einen dreijährigen Wohnsitz. Der Cc i.d.F. $1889 \mathrm{sah}$ vor, daß bei bestimmten besonderen Verdiensten oder bei der Ehe mit einer Französin die Einbürgerung schon nach einjährigem Wohnsitz möglich war. Unter bestimmten Umständen war auch die Einbürgerung von im Ausland lebenden Personen möglich (Art. 8 Ziffer 5 Buchstaben b und c Cc 1889). Entsprechendes sah auch der CNF 1927 vor, wo anch der Dienst in der französischen oder einer verbündeten Armee, das Diplom einer französischen Universität oder die Geburt in Frankreich und der Wohnsitz nach Volljährigkeit eine so rasche Einbürgerung möglich machten. Gemäß dem CNF 1927 konnte in einigen Fällen auch ohne Wartezeit eingebürgert werden. Die heutige Regelung datiert weitgehend von 1945.

Ehemalige Franzosen konnten gemäß den Cc i.d.F. 1804 nach ihrer Rückkehr nach Frankreich wiedereingebürgert werden (Art. 10, 18, 19, $21 \mathrm{Cc} 1804$ ). Entsprechende allgemeine Bestimmungen enthielten die Art. 18 und 19 des $\mathrm{Cc}$ i.d.F. 1889 und der CNF 1927 (110). Im CNF 1945 wurde die Wiedereinbürgerungsmöglichkeit eingeschränkt (Art. 75-77 CNF 1945).

\subsubsection{Heutige Regelung}

Art. $59 \mathrm{CNF}$ öffnet den Abschnitt über die Einbürgerung: Die Einbürgerung geschieht auf Antrag eines Ausländers durch Dekret. Sehr ausführlich werden die Einbürgerungsvoraussetzungen formuliert.

Art. $61 \mathrm{CNF}$ bestimmt, daß niemand eingebürgert werden kann, der nicht zur Zeit der Unterzeichnung des Einbürgerungsdekrets seinen Aufenthalt in Frank- 
reich hat. Sogar zufällige Abwesenheit oder Abwesenheit aus höherer Gewalt machen das Einbürgerungsdekret unguiltig (111). Grundsätzlich werden nur Personen eingebürgert, die schon mindestens fünf Jahre in Frankreich leben (Art. $62 \mathrm{CNF}$ ) (112). Der Aufenthalt in einigen eng mit Frankreich verbunden Staaten wird dem Aufenthalt in Frankreich gleichgestellt (Art. 62 und 78 Abs.1. Ziffer 2) CNF). Auch der Aufenthalt im Ausland wegen einer öffentlichen oder privaten Tätigkeit für den französischen Staat oder für eine Einrichtung, deren Tätigkeit für die französische Wirtschaft oder Kultur von wesentlichem Interesse ist, gilt als Aufenthalt in Frankreich (Art. 78 Abs.1 Ziffer 1) (113). Gleiches gilt zugunsten des Ehegatten einer Person, die eine solche Tätigkeit ausübt, unter der Voraussetzung, daß die Ehegatten tatsächlich zusammenleben (Art. 78 Abs.2 CNF). Dem Aufenthalt in Frankreich ist ebenfalls der Aufenthalt außerhalb Frankreichs in einem regulären Verband der französischen Armee oder in Ausübung des Wehrdienstes gleichgestellt (Art. 78 Abs. 1 Ziffer 3 CNF) (114). Dies gilt ebenfalls für tatsächlich zusammenlebende Ehepartner.

Ein mindestens fünfjähriger Aufenthalt wird nicht immer gefordert. Art. 64 und 64-1 (115) geben eine seltsame Aufschlüsselung von Personen, die ohne fuinfjährigen Aufenthalt eingebürgert werden können. Auch diese Personen müssen jedoch im Moment der Unterzeichnung des Einbürgerungsdekrets in Frankreich sein. Außerdem müssten auch die übrigen Einbürgerungsvoraussetzungen erfüllt sein. Aufgrund ihres Verwandschaftsverhältnisses können der Ehegatte und volljährige Kinder eines Ausländers, der die französische Staatsangehörigkeit erworben hat, ohne Frist eingebürgert werden. Von der Aufenthaltsfrist sind auch diejenigen befreit, die tatsächlich in einer Einheit der französischen Armee gedient haben oder die sich in Kriegszeiten freiwillig zum Dienst in der französischen oder einer verbündeten Armee verpflichtet haben (Art. 64 Ziffer 4 CNF). Auch Ausländer, die für Frankreich außergewöhnliche Dienste geleistet haben oder deren Einbürgerung für Frankreich von außerordentlichem Interesse ist, können ohne Berücksichtigung einer Aufenthaltsfrist eingebürgert werden, unter der Voraussetzung, daß der Conseil d'Etat seine Einwilligung gibt (Art. 64 Ziffer 6 CNF) (116). In einem besonderen Falle eines besonderen Verdienstes ist eine Einwilligung des Staatsrates nicht notwendig: Der Vater oder die Mutter von drei minderjährigen Kinder kann ohne Fristworaussetzung die Einbürgerung erlangen! (Art. 64 Ziffer $3 \mathrm{CNF}$ ).

Eine Befreiung von der Voraussetzung eines fünfjährigen Aufenthalts gilt weiter für die (ehernaligen) Angehörigen von Gebieten oder Staaten, über die Frankreich die Souveränität, ein Protektorat, ein Mandat oder eine Treuhänderschaft ausgeübt hat (Art. 64 Ziffer 5 CNF). Gleiches gilt für Personen, die der kulturellen und sprachlichen französischen Völkergruppe angehörten, sofern sie Angehörige eines Gebietes oder Staates sind, deren Amtssprache Französisch ist oder wenn Französisch eine der Amtssprachen ist. Außerdem muß nachgewiesen werden, daß Französisch die Muttersprache der Betreffenden ist (Art. 64-1 CNF) (117).

Für zwei Gruppen von Personen wird die Aufenthaltsfrist zwar nicht auf null reduziert, aber dennoch auf zwei Jahre herabgesetzt. Dies ist der Fall für Ausländer, die mit Erfolg zwei Jahre lang höhere Studien durchgeführt haben, um 
ein Universitätsdiplom oder das Diplom einer französischen Anstalt des höheren Schulwesens zu erwerben, und für Ausländer, die aufgrund ihrer Leistungsfähigkeit oder ihrer Fähigkeiten Frankreich wichtige Dienste geleistet haben oder leisten können (118).

Art. 68 Abs. 1 CNF fordert, daß der einzubürgemde Ausländer "bonne vie et moeurs" hat (119). Damit zusammen hängt die Bestimmung des Art. $79 \mathrm{CNF}$, daß niemand eingebürgert werden kann, der zu einer Freiheitsstrafe von mehr als sechs Monaten verurteilt worden ist oder zu einer Freiheitsstrafe von beliebiger Dauer wegen bestimmten in dem betreffenden Artikel erwähnten Taten (120).

Eine weitere Voraussetzung ist die Assimilierung in die französische Gemeinschaft, die sich insbesondere durch ausreichende Kenntnisse der französischen Sprache äussern muß (Art. 69, 71 CNF) (121). Art. 31 der Durchfiihrungsverordnung zum CNF enthält nähere Vorschriften über die Kontrolle dieser Assimilierung (122). Außer der Beherrschung der französischen Sprache wird überprüft, inwieweit eine Assimilierung an die französischen Sitten und Gebräuche stattgefunden hat.

Art. 71 CNF fordert einen guten Gesundheitszustand der einzubürgenden Person. Die Überprïfung dieses Gesundheitszustandes wird näher geregelt von Art. 32 der Durchführungsverordnung zum CNF (123).

Schließlich wird grundsätzlich bestimmt, daß das Mindestalter für die Einbürgerung 18 Jahre ist (Art. 66). Ausgenommen sind aber diejenige, die aufgrund von Art. 64 CNF ohne Aufenthaltsfrist eingebürgert werden können.

Wenn alle Voraussetzungen für eine Einbürgerung erfüllt sind, besteht noch kein Einbürgerungsanspruch. In diesem Zusammenhang ist Art. 110 CNF bemerkenswert. In dieser Bestimmung wird betont, daß eine Entscheidung, die einen Antrag auf Einbürgerung oder auf Wiedereinbürgerung durch Dekret für unzulässig erklärt, mit Gründen versehen werden muß. Eine Entscheidung, die einen Antrag verwirft, braucht aber keine Grüinde zu enthalten (124).

In einigen Fällen kann die französische Staatsangehörigkeit durch Optionserklärung erworben werden (125). Es handelt sich hierbei aber nicht um reine Optionsrechte: Die Optionserklärung kann von der Verwaltung aufgrund einiger ziemlich vagen Klauseln abgelehnt werden.Der ausländische Ehegatte eines Franzosen hat ein Optionsrecht auf die französische Staatsangehörigkeit (Art. 37-1 CNF i.d.F. 1984). Seit 1984 kann dieses Optionsrecht aber erst sechs Monate nach Eheschließung ausgeübt werden; die eheliche Gemeinschaft muß im Moment der Option noch bestehen (126). Eine abgegebene Optionserklärung kann von der Regierung wegen Unwürdigkeit oder mangelnder Anpassung abgelehnt werden. Der ausländische Ehegatte kann nicht optieren, wenn ein Ausweisungsbefehl oder ein Zwangsaufenthaltsbefehl gegen ihn ergangen ist (Art. 40 CNF) (127).

Weitere Optionsrechte haben in Frankreich von ausländischen Eltern geborene minderjährige Kinder, nachdem sie fünf Jahre in Frankreich gelebt haben (Art. 
52 CNF 1945), die von Franzosen durch einfache Adoption angenommenen Kinder (Art. 55 Abs. 1 CNF 1945), bestimmte von französischen Staatsangehörigen aufgezogene Pflegekinder (Art. 55 Abs. 2 CNF 1945) und Personen, die während zehn Jahren dauerhaft den Stand eines Franzosen besessen haben (Art. 57-1 CNF i.d.F. 1973). Die Optionserklärungen können nicht abgegeben werden von Personen, gegen die eine Auswelisung oder ein Zwangsaufenthalt angeordnet ist (Art. $58 \mathrm{CNF}$ ). Eine Optionserklärung kann von der Regierung wieder wegen Unwürdigkeit oder mangelnder Anpassung zurückgewiesen werden.

Oben wurde schon darauf hingewiesen, daß in Frankreich geborene Ausländer die französische Staatsangehörigkeit unter gewissen Voraussetzungen mit Erreichung der Volljährigkeit automatisch erwerben, es sei denn, die Regierung benutzt ihr Widerspruchsrecht. Seit 1973 kann die französische Staatsangehörigkeit von diesen in Frankreich geborenen Ausländern auch erworben werden bei "l'incorporation dans l'armée française". Da eine Person jedoch fast nie vor dem 18. Geburtstag in die Armee aufgenommen wird, kommt dieser Erwerbsgrund kaum vor (128).

Gemäß Art. 84 CNF erstreckt sich der Erwerb der französischen Staatsangehörigkeit auf alle unverheirateten, noch minderjährigen ehelichen, nichtehelichen und (voll)adoptierten Kinder des Neubürgers (129). Dabei ist unbeachtlich, ob Vater oder Mutter die französische Staatsangehörigkeit erwirbt. Ebensowenig ist relevant, ob die Staatsangehörigkeit aufgrund einer Einbürgerung, Optionserklärung oder von Rechts wegen erworben wird.

Ehemalige Franzosen können durch Dekret eingebürgert werden, ohne daß gefordert wird, daß sie bereits eine gewisse Zeit (wieder) in Frankreich wohnhaft sind (Art. 97-3 CNF). Diejenigen, die die französiche Staatsangehörigkeit durch Eheschließung oder durch Einzelerwerb einer fremden Staatsangehörigkeit verloren haben, können diese Staatsangehörigkeit sogar durch Optionserklärung wiedererwerben, falls sie nachweisen, mit Frankreich erkennbare Bande, insbesondere kultureller, beruflicher, wirtschaftlicher oder familiärer Art bewahrt oder aufgenommen zu haben (Art. 97-4 CNF). Die Regierung hat aber ein innerhalb von sechs Monaten auszuübenes Widerspruchsrecht (130).

\subsubsection{Verlust der Staatsangehörigkeit}

\subsubsection{Rückblick}

Gemäß dem Cc i.d.F. 1804 verlor eine Französin ihre bisherige Staatsangehörigkeit durch Eheschließung mit einem Ausländer (Art. $19 \mathrm{Cc}$ ). Eine entsprechende Regelung war auch in Art. $19 \mathrm{Cc}$ i.d.F. 1889 vorgesehen (131). Gemäß Art. 8 Abs. III CNF 1927 wurde die Staatsangehörigkeit ausschließlich durch Eheschließung verloren, wenn die Ehegatten ihren Wohnsitz außerhalb Frankreichs nahmen und die Frau durch die Ehe automatisch die Staatsangehörigkeit ihres Ehemannes erwarb (132). Seit 1938 wurde die Staatsangehörigkeit nicht mehr durch Eheschließung verloren; Verzichtsmöglichkeiten waren aber vorgesehen. 
Der Verlust der Staatsangehörigkeit wegen Einbïrgerung im Ausland war in dem $\mathrm{Cc}$ von 1804 (Art. 17 Abs. 1), dem $\mathrm{Cc}$ von 1889 (Art. 17 Abs. 1), dem CNF von 1927 (Art. 9 Ziffer 1) und dem CNF von 1945 (Art. 87) vorgesehen. Der CNF 1927 und der CNF 1945 kannten auch den Verlust bei sonstigem freiwilligen Erwerb der Staatsangehörigkeit (133). Seit 1889 galt, daß Wehrpflichtige auf diese Art die Staatsangehörigkeit nur nach Genehmigung der französischen Behörden verlieren konnten (134). Seit 1973 wird die französische Staatsangehörigkeit durch Erwerb einer fremden Staatsangehörigkeit nicht mehr automatisch verloren. Der Eintritt in einen fremden öffentlichen Dienst oder Militärdienst ohne Genehmigung des Kaisers war schon 1804 ein Verlustgrund der französischen Staatsangehörigkeit (Art. 17 Ziffer 2; Art. 21 Abs. 1 Cc 1804). Seit 1889 wurde im Falle ausländischen Zivildienstes die Staatsangehörigkeit lediglich verloren, wenn eine Aufforderung der französischen Behörden, jenes Amt niederzulegen, nicht befolgt wurde (135) (Art. 17 Ziffer 3 und 4 Cc i.d.F. 1889). Seit 1927 galt dies auch für den Militärdienst (Art. 9 CNF 1927) (136). Im CNF 1945 gab Art. 97 eine ähnliche Regelung (137). Die heutige Regelung datiert von 1961.

Im Cc von 1804 sah Art. 17 Ziffer 3 vor, daß die französische Staatsangehörigkeit durch Niederlassung im Ausland obne Rückkehrabsicht verloren wurde. Entsprechende Bestimmungen kannten spätere Regelungen nicht mehr (138). Gewisse Ähnlichkeiten damit hat die heutige Bestimmung des Art. 95 CNF 1945 (Ausbürgerung eines Auslandsfranzosen), aber heutzutage erfolgt dieser Verlust durch Urteil.

Von 1945 bis 1973 wurde die französische Staatsangebörigkeit u.U. verloren, wenn ein uneheliches Kind durch einen Ausländer legitimiert wurde und dadurch die Staatsangehörigkeit des Vaters erwarb (Art. 93 CNF 1945) (139).

Weder im heutigen noch im früheren französischen Recht gibt es eine generelle Möglichkeit, auf die französische Staatsangehörigkeit zu verzichten. Es gibt und gab aber viele Einzelfälle, in denen Doppelstaatler auf die französische Staatsangehörigkeit verzichten können (vgl. Art. 8 und $12 \mathrm{Cc}$ i.d.F. 1889; Art. 2 CNF 1927; Art. 19 und 24 CNF 1945) (140).

Die Möglichkeit der Aberkennung der französischen Staatsangehörigkeit war im Cc von 1804 unbekannt. Seit 1848 wurde aber diese Möglichkeit eröffnet, um Sklavenhändlern die französische Staatsangehörigkeit entziehen zu können (141). Während des Ersten Weltkrieges wurde die Wiederausbürgerung ehemaliger Feindesangehöriger ermöglicht. Seit Einführung des CNF 1927 konnte ein eingebürgerter Franzose imnerhalb von zehn Jahren nach Erwerb der Staatsangehörigkeit wieder aus im Gesetz erwähnten Gründen ausgebürgert werden (142). Diese Gründe wurden 1938 noch näher präsiziert. Zwischen 1940 und 1945 war auch nach Ablaufen der Zehnjahresfrist noch Ausbürgerung möglich (143). Die heutige Regelung datiert von 1945 (Art. 98, 99 CNF 1945). Der CNF führte auch die Ausbürgerung wegen dauernden Aufenthaltes im Ausland ein (Art. 95 CNF 1945). 


\subsubsection{Heutige Regelung}

Die französische Staatsangehörigkeit wird nie automatisch verloren. Namentlich wird die französische Staatsangebörigkeit nicht durch freiwilligen Erwerb einer fremden Staatsangehörigkeit verloren (144). Unter bestimmten Voraussetzungen kann aber auf sie verzichtet werden, während in mehreren Fällen auch die Aberkenunung der Staatsangehörigkeit möglich ist. Der Verlust der Staatsangehörigkeit erstreckt sich seit 1984 nie mehr auf Ehefrau und Kinder (Aufhebung von Art. 96 Abs. 2 CNF) (145). Bei oberflächlicher Betrachtung der Verlustbestimmungen des vierten Titels des CNF könnte man meinen, daß neben Verzicht und Aberkennung noch weitere Verlustgründe vorhanden sind, wie z.B. der Erwerb einer fremden Staatsangehörigkeit, die Eheschließung oder ein Auslandsaufenthalt. Es sei aber betont, daß in allen diesen Fällen entweder eine Verzichtserklärung oder ein Ausbürgerungsdekret notwendig ist.

Es gibt für Doppelstaatler im französischen Recht keine generelle Möglichkeit, um auf die französische Staatsangehörigkeit zu verzichten (146). Verzichtsmöglichkeiten werden aber erwähnt in den Art. 19 (für das nicht in Frankreich geborene Kind mit lediglich einem französischen Elternteil), 24 (für das in Frankreich geborene Kind mit lediglich einem Elternteil, der selber in Frankreich geboren wurde), 45 (fürr das in Frankreich geborene Kind eines selbst ebenfalls in Frankreich geborenen Elternteils), 87 (in Zusammenhang mit dem Erwerb einer ausländischen Staatsangehörigkeit), 97 (in Zusammenhang mit einer Eheschließung). Art. 91 CNF sieht die Möglichkeit der Ausbürgerung eines Doppelstaatlers auf dessen Antrag vor (147). Ausbürgerungen werden in den Art. 95, 96, 97, 98 und 99 CNF vorgesehen (148). GemäB Art. 95 CNF kann durch Gerichtsurteil festgestellt werden, daß ein im Ausland geborener Franzose, der nie in Frankreich gelebt hat, nie den Status eines Franzosen gehabt hat und dessen Vorfahren ebenfalls seit mehr als fünfzig Jahren nicht mehr in Frankreich lebten und auch nicht (mehr) den Status eines Franzosen besassen, die französische Staatsangehörigkeit (gegebenfalls mit rückwirkender Kraft) verloren hat (149). Durch Dekret kann gemäß Art. 96 CNF einem Franzosen, der sich tatsächlich als ausländischer Staatsangehöriger benimmt, die französiche Staatsangehörigkeit entzogen werden, wenn der Betreffende die Staatsangehörigkeit des Landes, als dessen Bürger er sich verhält, tatsächlich besitzt (150). Die Verlustgruinde des Art. 95 und 96 wurden 1945 ins französische Staatsangehörigkeitsrecht eingefüht. Durch Dekret verliert ebenfalls jener Franzose seine bisherige Staatsangehörigkeit, der, obwohl die Regierung ihn dazu aufgefordert hat, seine Tätigkeit in einer fremden Armee, einem fremden öffentlichen Dienst oder einer internationalen Organisation, deren Mitglied Frankreich nicht ist, nicht aufgibt. Diese Entzugsmöglichkeit existiert nicht nur im Falle einer offiziellen Emennung, jedoch auch bei tatsächlichter Mitarbeit (Art. $97 \mathrm{CNF}$ ) (151).

Während einer Periode von zehn Jahren, nachdem die französische Staatsangehörigkeit erworben wurde, kann einer Person in einigen in Art. 98 erwähnten Fällen die französische Staatsangehörigkeit wieder aberkannt werden (152). Zu beachten ist schlieBlich Art. $112 \mathrm{CNF}$, aufgrund dessen eine Einbürgerung nach vorheriger Zustimmung des Conseil d'Etat innerhalb einer Frist von einem Jahr 
seit ihrer Veröffentlichung im Journal Officiel zurückgenommen werden kann, wenn der Betreffende nicht die gesetzlichen Bedingungen erfüllt. Bei Betrug oder Täuschung kann eine Einbürgerung innerhalb einer Frist von zwei Jahren seit der Aufdeckung dieser Täuschung zurückgenommen werden. 


\subsection{GROSSBRITANNIEN}

\subsubsection{Allgemeine Bemerkungen}

Erst seit dem 1. Januar 1983 gibt es eine den Staatsangehörigkeiten der westeuropäischen Staaten vergleichbare britische Staatsangehörigkeit (1). An diesem Tag trat der British Nationality Act 1981 (BNA 1981) (2) in Kraft. Zwar war der BNA 1981 nicht das erste Staatsangehörigkeitsgesetz Großbritanniens, doch hatten die vorhergehenden Regelungen Sonderformen, die dem britischen Empire wie dem Commonwealth entsprachen. Bis 1983 galt der British Nationality Act 1948 (BNA 1948) (3) und davor der British Nationality Act 1914 (BNA 1914) (4).

Die Grundprinzipien des Gesetzes von 1981 unterscheiden sich erheblich von denen der vorherigen Regelungen. Das Gesetz von 1981 geht vom Begriff des "British Citizen" aus. Darunter versteht man den Bürger Großbritanniens (d.h. Englands, Schottlands, Wales, Nordirlands, der Kanalinseln und der Isle of Man (5)) Die vorherigen Regelungen gebrauchten dagegen den Begriff des "British Subjects", der Büirger des Commonwealth war (6). Eine gewisse Unklarheit erwächst aus dem BNA 1981, weil er neben dem Begriff des "British Citizen" auch die Begriffe "British Dependant Territories Citizen" (7) und "British Overseas Citizens" (8), und weiterhin die Begriffe "British Subject without Citizenship" (9) und "British Protected Persons" (10) verwendet. Personen die zu diesen vier letzteren Kategorien gehören, sind aber keine britische Staatsangehörige stricto sensu (11). Sie können deshalb zum Beispiel nicht ohne weiteres in das Vereinigte Königreich einreisen. Im Rahmen des internationalen Rechts müssen sie aber als britische Staatsangehörige betrachtet werden (12) und genießen sie insofern diplomatischen Schutz. Vorrangiges Ziel des British Nationality Act 1981 war es, die uneingeschränkte Einwanderung von Inhabern britischer Pässe in das Vereinigte Königreich zu begrenzen (13). Daneben sollten die britischen Regelungen über die Staatsangehörigkeit in Einklang mit dem New Yorker Abkommen von 1961 gebracht werden. Die Neuregelung sollte gleichzeitig dazu dienen, die Realiserung der Gleichberechtigung im britischen Staatsangehörigkeitsrecht (14) voranzutreiben.

Die unterschiedlichen Kategorien innerhalb der britischen Staatsangehörigkeit lato sensu können nur unter historischer Gesichtspunkten verstanden werden. An dieser Stelle soll deshalb zuerst die historische Entwicklung der britischen Staatsangehörigkeit dargestellt werden (15).

Ein wichtiger Begriff in der Geschichte der britischen Staatsangehörigkeit ist die "allegiance to the Crown" (perpetual allegiance) (16). Alle Personen, die diese "allegiance" schuldeten, wurden als "British Subject" bezeichnet. "British Subjects" hatten ein absolutes Recht auf Einreise und Niederlassung in dem Vereinigten Königreich.

Im Common Law bildeten sich allmählich Erwerbsgründe für den Status eines "British Subject" (17). Bereits vor der normannischen Eroberung im Jahre 1066 galt das ius soli (18). Britischer Staatsangehöriger war, wer "within His Majesty"s dominions" geboren war. Eine Ausnahme von dieser Regelung bestand seit 1351 dann, wenn der britische Thronfolger im Ausland geboren war. Auch er 
besaß die britische Staatsbürgerschaft (19). Von großer Bedeutung für die weitere Entwicklung des Staatsangehörigkeitsrechts in Großbritannien war der sogenannte Calvin's Case von 1608 (20). Darin wurde betont, daß die Staatsangehörigkeit grundsätzlich durch Geburt im Machtbereich der Krone erworben wurde, davon ausgenommen waren lediglich die Kinder feindlicher Ausländer. Personen, die außerhalb des Machtsbereiches der Krone geboren waren, waren nur dann British Subject, wenn es sich um Kinder des Königs, Abkömmlinge englischer Botschafter und der Angehörigen englischer Streitkräfte handelte. Eine weitere Ausnahme galt dann, wenn die Geburt auf englischen Schiffen oder in Gebieten erfolgte, wo die Krone "extraterritorial jurisdiction" ausïbte. Insoweit wurde also die Möglichkeit eines Erwerbs der Staatsangehörigkeit iure sanguinis anerkannt.

Die Möglichkeit eines Erwerbs der "Staatsangehörigkeit" iure sanguinis wurde durch die Naturalisation of Foreign Protestants Act der Queen Ann aus dem Jahre 1708 bestätigt (21). Danach waren die im Ausland geborenen Kinder britischer Untertanen den auf der Insell geborenen gleichzustellen (22). Diese Regelung verursachte jedoch erhebliche Interpretationsschwierigkeiten (23). Unklar war, ob beide Eltem "British Subject" sein mußten oder ob es ausreichte, wenn dies nur der Vater war (24). Zudem war nicht deutlich, ob das betreffende Kind seinen Status an die nächste im Ausland geborene Generation weitergeben konnte (25).

Nach den Bestimmungen des Common Law konnte der Status des "British Subject" außer durch Geburt auch durch Einbürgerung erworben werden. Es gab zwei Formen der Einbürgerung (26): die Naturalisation (27), die einer Person grundsätzlich die gleiche Position wie die eines "natural born British Subjects" gab und die Denisation (28), die einem Ausländer nur bestimmte beschränkte Rechte eines British Subjects einräumte. Auch die Naturalisation übertrug jedoch die britische Staatsangehörigkeit nicht frei von gewissen Beschränkungen. So konnte z.B. ein Eingebürgerter weder Parlamentsmitglied noch Eigentümer eines britischen Schiffes werden (29). Erst durch den Aliens Act von 1844 (30) wurden die meisten für Eingebürgerte geltenden Rechtsbeschränkungen aufgehoben. Dieser Aliens Act 1844 klärte außerdem die bis dahin umstrittene Frage, ob eine ausländische Frau durch Eheschließung mit einem "British Subject" dessen Status erwerben konnte (31).

Einige grundlegende Änderungen erfolgten durch den Naturalization Act vom 12. Mai 1870 (32). Erstens wurde der bis dann geltende Grundsatz der "perpetual allegiance" verlassen (33). Bis 1870 ging man davon aus, daß die "allegiance" nur durch den Tod erlöschen konnte (34). Dies führte vor allem im Verhältnis zu den Vereinigten Staaten von Nordamerika zu großen Schwierigkeiten; diese wurden darch den Bancroft-Vertrag vom 13. Mai 1870 gelöst, in dem England das Prinzip der "perpetuality" aufgab (35). Entsprechend sah der Naturalization Act von 1870 vor, daß volljährige und unbeschränkt geschäftsfähige Untertanen, die zugleich iure sanguinis eine andere Staatsangehörigkeit besaßen, sowie im Ausland geborene Untertanen auf die britische Staatsangehörigkeit verzichten konnten. Der Verlust der Staatsangehörigkeit trat fortan auch im Falle einer Einbürgerung im Ausland ein, wenn keine Erklärung abgegeben wurde, daneben weiterhin die britische Staatsangehörigkeit beibehalten zu wollen. Auch eine Frau, die einen Ausländer heiratete, verlor fortan die britische 
Staatsangehörigkeit, selbst wenn sie auf diese Weise staatenlos wurde (36). Der Naturalization Act formulierte auch zum erstenmal die Voraussetzungen für eine Einbürgerung (37).

Die Section 16 des Naturalisation Act 1870 erlaubte örtlich beschränkte Einbürgerungen (38). Diese Regelung empfanden die älteren "dominions" als Nachteil des Naturalization Act von 1870. Insbesondere Australien, Canada und Südafrika erhoben Widerspruch, da sie den Einwanderem in ihre Territorien durch Einbürgerung zwar den Status eines "British Subject" geben konnten, dieser Status seine Wirkung jedoch nur auf dem Staatsgebiet des eigenen "dominion", nicht aber im britischen Mutterland oder anderen Gebieten der britische Krone entwickelte (39). Im Jahre 1901 empfahl deshalb ein Ausschuß des "Home Office" den Kolonien und iuberseeische Besitzungen zu erlauben, Immigranten den Status eines "Britisch Subjects" zu geben, der dann im ganzen Empire als "common status" anerkannt wuirde (40). Dieses System erforderte nach Meinung des Ausschußes einen "common code", der die Voraussetzungen für Erwerb und Verlust dieses Status regeln sollte. Nicht zuletzt aus diesem Grund wurde ein Nationality Act entworfen (41). Weiter wollte man durch diesen neuen Act verschiedene andere Unklarheiten im britischen Staatsangehörigkeitsrecht beseitigen (42). Dieser Nationality Act wurde 1914 verabschiedet (43) und trat am 1. Januar 1915 in Kraft. Kraft Section 1 (1) dieses Nationality Acts wurde die Staatsangehörigkeit grundsätzlich iure soli erworben. Bei Geburt im Ausland erhielt man den Status eines "British Subject", wenn der Vater (44) im Inland geboren oder selbst eingebürgert war.

Die Einbürgerungsvoraussetzungen waren grundsätzlich die gleichen wie 1870 , zusätzlich wurden jedoch auch ein guter Leumund und hinreichende Kenntnisse der englischen Sprache gefordert (45). Dominions mit Selbstverwaltung konnten num auch durch Einbürgerung den allgemeinen Status eines British Subjects verleihen. Neu waren weiter die Möglichkeiten einer Aberkennung der Staatsangehörigkeit auf Antrag sowie der Widerruf einer Einbürgerung (46), wenn diese erschlichen worden war. Der Nationality Act 1914 galt bis zum in Krafttreten des Nationality Act 1948 am 1. Januar 1949. Im Verlauf dieser Jahre wurde er jedoch viermal geändert.

Die erste Novellierung des Nationality Acts 1914 wurde bereits im Jahre 1918 mit dem British Nationality and Status of Alien Act 1918 vorgenommen (47). Der Erwerb der britischen Staatsangehörigkeit iure sanguinis wurde erweitert. Die Novellierung von 1918 erweiterte ferner die Möglichkeit zum Widerruf einer Einbürgerung. Vier Jahre später wurden die Erwerbsgründe iure sanguinis erneut erweitert (48).

Durch Novellierung von 1933 (49) wurde die Position einer britischen Frau, die einen Ausländer heiratete, verbessert. Den Grundsätzen des Haager Abkommen von 1930 entsprechend führte eine solche Ehe fortan nicht mehr zum Verlust der Staatsangehörigkeit, falls dann Staatenlosigkeit die Folge gewesen wäre. Aber sogar wenn die Frau die Staatsangehörigkeit ihres Ehegatten erwarb, konnte sie innerhalb von 12 Monaten nach Eheschließung wieder fuir die britische Staatsangehörigkeit optieren. Entsprechendes galt bei Staatsangehörigkeitswechsel des Ehemannes. 
Mit der Novellienung von 1943 (50) wurde die 1918 und 1922 bereits erweiterte Möglichkeit des Staatsangehörigkeitserwerbs durch Abstammung bei Geburt im Ausland nochmals ausgedehnt.

Nach dem Zweitem Weltkrieg wurde es notwendig, die Erwerbs- und Verhstvoraussetzungen für die britische Staatsangehörigkeit umfassend neu zu regeln. Der Inhalt des Begriffes des "British Subject" verlor allmählich seine Konturen. Das wachsende NationalbewuBtsein in den verschiedenen Gebieten des Commonwealth lie $B$ es erforderlich werden, den bisher undifferenziert verwendeten Begriff des "British Subject" zu modifizieren (51). Die Notwendigkeit einer Neuregelung wuchs als z.B. Canada 1946 neben dem Status des "British Subject" eine eigene Staatsangehörigkeit einführte (52). Eine Konferenz der Commonwealth-Staaten beschäftigte sich deshalb 1947 mit diesem Problem (53). Aufgrund der dort erzielten Einigung über den Inhalt des Begriffes des "British Subject" wurde 1948 der "British Nationality Act" (54) verabschiedet, der an 1. Januar 1949 in Kraft trat. Vorrangiges Ziel dieses Gesetzes war es, den Begriff des 'British Subject' so zu definieren, daß dieser neben der britischen auch die Staatsangehörigkeit der Einzelstaaten des Commonwealth erfasste.

Der BNA 1948 definierte den Begriff des "British Subject" als Oberbegriff. Section 1 , subsection 1 bestimmte:

"Every person who under this Act is a citizen of the United Kingdom and Colonies or who under any enactment for the time being in force in any country mentioned in subsection 3 of this section is a citizen of that country shall by virtue of that citizenship have the status of a british subject".

In Subsection 3 wurden sämtliche Staaten des Commonwealth erwähnt. Der Status des "British Subject" wurde also in zwei Hauptkategorien gespalten: einerseits gab es die "Citizens of the United Kingdom and Colonies", andererseits die "Citizens of independent Commonwealth countries". Die Angehörigen beider Kategorien blieben aber "British subjects", also Bürger des Commonwealth. Besonders deutlich wurde dies von Section 1, Subsection 2 des BNA 1948 formuliert:

"Any person having the status aforesaid may be known either as a British subject or as a Commonwealth citizen; and accordingly in this Act and in any instrument whatever, whether made before or after the commencement of this Act, the expression "British subject" and the expression "Commonwealth citizen" shall have the same meaning".

Neben den Kategorien "Citizens of the United Kingdom and Colonies" und "Citizens of Commonwealth Countries" kannte der BNA 1948 noch die "British Subjects without Citizenship" and die "British Protected Persons". SchlieBlich wurde den Bürgem Irlands eine Sonderstellung eingeräumt.

Im Zeitpunkt des Inkrafttretens des BNA 1948 hatten mehrere unabhängige Commonwealth-Staaten ihre Staatsangehörigkeit noch nicht geregelt (55). "British subjects" die potentiell in Zukunft Bürger eines dieser Staaten werden würden, erwarben deshalb im Zeitpunkt des Inkrafttretens des neuen Gesetzes we- 
der die "Citizenship of the United Kingdom and Colonies" noch die "Citizenship of a commonweallh country". Da grundsätzlich nur diese "citizenships" den Status des "British Subjects" vermittelten, wurde in Section 13 BNA 1948 für diese Personen der Status des "British subject without citizenship" geschaffen. Obwohl dieser Status nur als Utbergangregelung gedacht war, gibt es auch heute noch Personen, die diesen Status besitzen (56).

"British Protected Persons" sind in Prinzip keine "British Subjects" (57). In vielfacher Hinsicht wirden und werden sie als Ausländer behandelt (58). Sie haben aber ein Recht auf britischen diplomatischen Schutz (59). Section 32 BNA 1948 definiert sie als "...persons (from) any protectorate, protected state, mandated territory or trust territory..." $(60)$.

"British Subjects without Citizenship" hatten ein (bedingtes) (61) Optionsrecht auf die "Citizenship of the United Kingdom and Colonies". Durch "registration" konnten sie diese "citizenship" erwerben. Für "British Protected Persons" war dies nicht möglich. Wenn diese Personen die "Citizenship of the United Kingdom and Colonies" erwerben wollten, war eine konkrete Einbürgerung notwendig (Section 10 BNA 1948).

Wie bereits erwähnt, wurde den Bürgern von Irland einen Sonderstatus eingeräumt. Die irische Republik wollte kein Teil des Commonwealth sein. Section 2 BNA 1948 betonte aber, daß unter bestimmten Bedingungen irische Bürger, die vor Inkrafttreten des BNA 1948 "British Subjects" waren, diesen Status nicht verlieren sollten (62). AuBerdem bekamen inische Bürger das Recht, nach einem Aufenthalt von zwölf Monaten im Vereinigten Königreich die "Citizenship of the United Kingdom and Colonies" durch "registration" zu erwerben (BNA 1948, Section 6) (63).

Die Voraussetzungen für den Erwerb und Verlust der Staatsbïrgerschaft war nur hinsichtlich der "Citizenship of the United Kingdom and Colonies" durch das Mutterland konkret geregelt. Die Erwerbs- und Verlustgründe der "Citizenships of the independent Commonwealthcountries" wurden von den jeweiligen Staaten bestimmt (64). Für den Erwerb des Status eines "British subject without citizenship" gab es keine allgemeine Regeln: dieser Status war nur als Übergangsregelung eingeführt. Ebenso wenig gab es Bestimmungen über Erwerb des Status einer "British Protected Person" (65).

Die "Citizenship of the United Kingdom and Colonies" konnte durch Geburt, Abstammung, "registration", Einbürgerung und Annexion erworben werden. Diesen letzten in Section 11 BNA 1948 erwähnten Erwerbsgrund wollen wir hier auBer Betracht lassen (66).

Bemerkenswert ist die Unterscheidung zwischen "Erwerb durch Geburt" (acquisition by birth) und "Erwerb durch Abstammung" (acquisition by descent). Die Regelung des Erwerbs der Staatsangehörigkeit durch Geburt (67) manifestierte das ius soli als Grundlage des englischen Statsangehörigkeitsrechts. Jeder, der innerhalb des Vereinigten Königreichs oder Kolonien geboren wurde, erwarb die "Citizenship of the United Kingdom and Colonies" (Section 4 BNA 1948). Die Regelung des Erwerbs der Staatsangehörigkeit durch Abstammung (68) war neben der eben erwähnten Regelung nur bei Geburt außerhallb des Vereinigten 
Königreiches oder in den Kolonien von Bedeutung. Ein im Ausland geborenes eheliches Kind erwarb die Staatsangehörigkeit "by descent", falls der Vater diese zur Zeit der Geburt des Kindes hatte (Section 5 BNA 1948). Auch dies galt jedoch nicht, wenn der Vater seine britische Staatsangehörigkeit selbst nur "by descent" erworben hatte. Section 5 BNA 1948 formuliert von dieser Regel einige Ausnahmen (69). Die wichtigste war die Möglichkeit das Kind innerhalb eines Jahres nach seiner Geburt in einem Konsulat des Vereinigten Königreiches registrieren zu lassen (Section $5(1,6)$ BNA 1948). Das nichteheliche Kind wurde ebenso behandelt, wenn es durch nachfolgende Ehe seiner Eltem legitimiert wurde (Section 23, subsection 1 BNA 1948). Das nichteheliche Kind einer britischen Frau dagegen erwarb bei Geburt im Ausland nicht die englische Staatsangehörigkeit (70).

Außer der zweiten im Ausland geborenen Generation konnten auch weitere Personen die "Citizenship of the United Kingdom and Colonies" durch "registration" erwerben:

a. "Citizens of Commonwealth Countries" konnten sich nach einjährigem Aufenthalt im Vereinigten Königreich in einer britischen Kolonie registrieren lassen (Section 6 and 8 BNA 1948); die gleiche Möglichkeit bestand nach einjährigem britischen Staatsdienst.

b. Den Ehefrauen von "Citizen of the United Kingdom and Colonies" stand ebenfalls das Recht zur "registration" $z u$.

Minderjährigen konnten - ebenso wie ehemalige "Citizen of the United Kingdom and Colonies" und "British Subjects without Citizenship" - die "Citizenship of the United Kingdom and Colonies" "by registration" erwerben. Diese Gruppen hatten aber kein generelles Recht auf "registration". Die "registration" war lediglich "at the discretion of the Secretary of State", also in das Ermessen des "Secretary of State" gestellt. Diese "registrations" können deshalb nicht als Optionsrecht oder auch nur bedingtes Optionsrecht betrachtet werden. Sie sind wohl eher als vereinfachtes Einbürgerungsverfahren einzustufen (71). Die Voraussetzungen für eine normale Einbuirgerung wurden in einer bei Section 10 BNA 1948 gehörenden "Second Schedule" geregelt.

Der Verlust der "citizenship of the United Kingdom and Colonies" konnte gemäB Sections 19 und 20-22 BNA 1948 eintreten. Aufgrund Section 19 konnte jeder volljährige Doppel- oder Mehrstaatler auf die britische Staatsbiurgerschaft verzichten. Die Staatsangehörigkeit von eingebürgerten oder bestimmten registrierten Personen konnte aus gewissen Gründen wieder entzogen werden. Die britische Frau, die einen Ausländer heiratete, verlor seit 1949 nicht mehr automatisch ihre Staatsangehörigkeit (72). Die Ausländerin, die einen Briten heiratete, erwarb aber auch nicht mehr automatisch dessen Staatsangehörigkeit. Sie konnte diese aber durch "registration" erwerben. Auch der freiwillige Erwerb einen fremden Staatsangehörigkeit war fortan kein Verlustgrund mehr.

Es muß nochmals betont werden, daß jedes "British Subject" ohne weiteres in das Vereinigte Königreich einreisen und sich dort niederlassen konnte. Die Einführung des BNA 1948, worin zwischen "British Subjects" mit Beziehungen zu dem Vereinigten Königreich und Kolonien und "British Subjects" mit Beziehungen zu unabhängigen Commonwealth Countries unterschieden wurde, war 
notwendig, um selbständige Staatsangehörigkeitsregelungen in den neuen nunmehr souverăn werdenden Commonwealth-Staaten zu ermöglichen. Der BNA 1948 legte einer Einwanderung von British Subjects in das Vereinigte Königreich keine Schwierigkeiten in den Weg.

Der BNA 1948 wurde durch vier "Nationality Acts" abgeändert und erweitert (73). Diese haben aber die Entwicklung des britischen Staatsangehörigkeitsrecht weitaus weniger beeinflußt als die drei "Immigration Acts" aus den Jahren 1962,1968 und 1971 (74).

Während der fünfziger Jahre waren sehr viele "British Subjects" in das Nereinigte Königreich eingewandert (75). Diese Einwanderungswelle wurde 1962 durch den "Commonwealth Immigrants Act 1962" eingedämmt (76). Nur "British Subjects", die selbst im Vereinigten Königreich geboren oder im Besitz eines "U.K. passport" (in Gegensatz zu von "Colonial Authorities" ausgegeben Pässen) waren, hatten fortan das unbedingte Recht, in das Vereinigte Königreich einzureisen und sich dort niederzulassen (77). Alle übrigen "British Subjects" wurden der Kontrolle der Immigrationsbehörden unterworfen. Außerdem wurde bestimmt, daß Bürger des Commonwealth und "British protected persons" erst dann durch "registration" oder Einbürgerung "Citizen of the United Kingdom and Colonies" werden konnten, wenn sie für fünf Jahre ihren Wohnsitz im Königreich gehabt hatten (78). Die Unterscheidung zwischen "im Vereinten Königreich geboren" und "Besitzer eines U.K. Passes" war vor allem für die in Uganda, Kenia und Tanganyka wohnhaften Asiaten bedeutsam. Diese hatten bei der Unabhängigkeit dieser Staaten ihre "Citizenships of the U.K. and Colonies" nicht verloren und waren folglich im Besitz eines "U.K.-passports". Da diese Asiaten in den ersten Jahren der Unabhängigkeit der neuen Staaten stark diskriminiert wurden, wanderten sie in großer Zahl nach Großbritannien aus (79). Um eine weitere Massenimmigration zu verhindern, wurde der Commonwealth Immigrants Act 1968 (80) verabschiedet, kraft dessen nur jene "British Subjects" ohne Immigrationkontrolle einwandern durften, die selbst oder von denen ein Eltern- oder Großelternteil im Vereinigten Königreich geboren, adoptiert, registriert oder eingebürgert waren. Auf diese Weise wurde die weitere Einwanderung von britischen Asiaten erschwert.

Die Commonwealth Immigrants Acts von 1962 und 1968 wurden durch den "Immigration Act 1971" (IA 1971) widerrufen (81), der am 1. Januar 1973 in Kraft trat. Dieser änderte auch mehrere Bestimmungen bezïglich der "registration" aus dem BNA 1948. Der Immigration Act 1971 führte die Begriffe des "patrial" und "non-patrial" ein (82). Ein "patrial" ist eine Person, die das "right to abode" im Vereinigten Königreich hat (Section 2, Subsection 6 IA 1971). Die Folge der "right of abode" wird beschrieben als
"...free to live in, and to come and go into and from, the U.K. without let or hindrance, except such as may be required under and in accordance with this Act to enable their right to be established..." (Section 1, Subsec- tion $1 \mathbb{I A}$ 1971).

Weitere Komplikationen verursachte der Beitritt Großbritanniens zu den Europäischen Gemeinschaften. Artikel 227, Abs. 4 E.W.G.-Abkommen bestimmt: 
"Dieser Vertrag findet auf die europäischen Hoheitsgebiete Anwendung, deren auswärtige Beziehungen ein Mitgliedstaat wahrnimmt".

Deshalb sind die Freizügigkeitbestimmungen des E.W.G.-Vertrages namentlich auch auf Gibraltar anwendbar (83). Personen, die zwar kein "patrial" sind, aber in Gibraltar geboren oder dort durch "registration" oder Einbürgerung "citizen of the U.K. and Colonies" geworden sind, haben darum eine Rechtsstellung die fast derjenigen der "patrials" entspricht. Sie haben im Rahmen der Immigrationskontrolle einen Sonderstatus:

"Thus, non-patrial Gibraltarians are only minimally removed from the scope of patriality, but acquire this advantage from Brussells, and not from Westminister" (84).

Ein "non-patrial" kann in das Vereinigte Königreich nur einreisen und "...live, work and settle in the U.K. by permission and subject to such regulation and control....as imposed by this Act..." (Section 1, Subsection 2 IA 1971). Section 2 LA 1971 beschreibt, welche Personen das "right to abode" haben (85). Durch IA 1971 wurde zu dem das Recht eines "British Subject", um durch "registration" die "citizenship of the United Kingdom and Colonies" zu erwerben, erheblich erschwert (86).

Der Begriff der "patriality" ist ein Versuch aus der Masse der "British Subjects" "reine" "Bürger des Vereinigten Königreichs zu "destillieren". Dadurch ebnete dieser Begriff den Weg fǘr das Konzept einer neuen restriktiven britischen Staatsangehörigkeitspolitik. Dieser restriktive Begriff der britischen Staatsangehörigkeit wurde, nachdem 1977 ein "Grünbuch" (87) mit Reformvorschlägen veröffentlicht und 1980 ein "Weißbuch" (88) über diese Problematik vorgelegt wurde, im Jahre 1981 durch Verabschiedung eines neuen British Nationality Act geschaffen. Dieser schuf den Begriff eines "British Citizen". Der British Nationality Act 1981 kann als eine Art "Erstabgrenzung" der Staatsbürger des Vereinigten Königreiches angesehen werden (89).

Der British Nationality Act 1981 hob den Status eines "Citizen of the United Kingdom and Colonies" auf (90). An dessen Stelle setzte er drei unterschiedliche Staatsangehörigkeiten: die "British citizenship", als Status für eine Person, die eine besonders enge Beziehung zum Vereinigten Königreich hat (91); die "British Dependent Territories citizenship", welche der Status einer Person mit besonders engen Beziehungen zu den von Großbritannien abhängigen Gebieten ist (92); die "British Overseas Citizenship", die einer Person zukommt, die zwar 1982 "Citizen of the United Kingdom and Colonies" war, aber bei Inkrafttreten des neuen "Nationality Act" nicht "British Citizen" oder "British Dependent Territories Citizen" wurde (93).

Bei Einführung des British Nationality Act 1981 erlosch der Begriff "British Subject" als Synonym von "Commonwealth citizen" (94). Nach dem 1. Januar 1983 werden lediglich noch die früheren "British Subjects without citizenship" weiterhin als "British Subjects" bezeichnet. Schätzungsweise haben rund 50.000 Personen diesen Status (95). Diese "British Subjects" sind "Commonwealth citizen". Daneben gibt es noch etwa 140.000 "British Protected Persons", die aber nicht den Status eines "Commonwealth Citizen"t haben (96). 


\subsubsection{Erwerb der Staatsangehörigkeit durch Geburt}

\subsubsection{Rüuckblick}

Die heutige Regelung des Erwerbs der britischen Staatsangehörigkeit durch Geburt weicht erheblich von früheren Regelungen ab. Ausgangspunkt der früheren Regelungen war stets ein Erwerb der Staatsangehörigkeit iure soli. Diese ius soli-Regel wurde im Laufe der Jahrhunderte lediglich für in Großbritannien geborene Kinder ausländischer Diplomaten und für Kinder feindlicher Ausländer eingeschränkt, die in vom Feind besetzten Teilen des Königreiches geboren würden (so noch Sec. 4 BNA 1948) (97). Entsprechendes galt für Geburt an Bord eines britischen Schiffes oder Flugzeuges (Section 32 (5) BNA 1948).

Für einige besonders gelagerte Einzelfälle wurde die Möglichkeit des Erwerbs der britischen Staatsangehörigkeit iure sanguinis bereits 1351 zum ersten Mal anerkannt. Im Laufe des 18. Jahrhunderts fand der Erwerb der britischen Staatsangehörigkeit iure sanguinis dann allgemeine Anerkennung.

Die Staatsangehörigkeitsregelung von 1914 erlaubte lediglich der ersten im Ausland geborenen Generation den Erwerb der britischen Staatsangehörigkeit iure sanguinis (98). Seit 1918 erwarb auch ein im Ausland geborenes Kind die britische Staatsangehörigkeit, wenn sein Vater im Wege der Annexion seiner Heimat "British Subject" geworden war. Weiter konnte ein im Ausland geborenes Kind eines selbst im Ausland geborenen Vaters die britische Staatsangehörigkeit erwerben, wenn der Vater im Zeitpunkt der Geburt im Dienst der Krone stand. Im Jahre 1922 wurde dann für weitere im Ausland geborene Generationen die Möglichkeit des Erwerbs durch "registration" eingeführt. War der Vater eines im Ausland geborenen Kindes britischer Staatsangehöriger, und hatte das Kind die britische Staatsangehörigkeit nicht aufgrund der übrigen Bestimmungen des Staatsangehörigkeitsgesetzes erworben, so konnte es den Status eines "British Subjects" fortan durch "registration" erwerben. Diese Möglichkeit des Staatsangehörigkeitserwerbs blieb in leicht geänderter Form auch in den Neuregelungen der BNA von 1943 und 1948 erhalten. Ein Erwerb der britischen Staatsangehörigkeit iure sanguinis war bis 1983 nur "a patre" möglich. Das im Ausland geborene nichteheliche Kind einer britischen Frau erwarb nicht die Staatsangehörigkeit der Mutter (99).

Die Anerkennung durch einen britischen Mann konnte den Erwerb der Staatsangehörigkeit nicht hervorrufen: bis 1949 erfolgte dies nicht einmal durch nachträgliche Legitimierung (100). Erst durch Section 23 Abs. 2 BNA 1948 erhielt die Legitimierung Enwerbsfunktion; und erst seit 1950 stellt auch eine Adoption einen Erwerbsgrund dar (101).

\subsubsection{Heutige Regelung}

Seit dem 1. Januar 1983 erfolgt der Erwerb der britischen Staatsangehörigkeit grundsätzlich iure sanguinis (102). Dieser Erwerb iure sanguinis kann a patre und a matre eintreten. Der neue Nationality Act beseitigte also die Diskriminierung der Geschlechter. Dennoch bestehen zu dieser grundsätzlichen Regelung einige Ausnahmen, die dem ius soli weiterhin Geltung belassen, und andererseit gilt der Erwerb iure sanguinis bei einer Geburt im Ausland nicht unbeschränkt. 
Wird ein Kind in Großbritannien geboren, so erwirbt es die britische Staatsangehörigkeit, wenn der Vater oder die Mutter britische Staatsbürger sind (Section 1 (1) unter a BNA 1981). Für nach dem Tode eines Elternteils geborene Kinder ist die Staatsangehörigkeit des betreffenden Elternteils zur Zeit seines Todes maßgebend (Section 48 BNA 1981). Nichteheliche Kinder können die Staatsangehörigkeit stets von ihrer Mutter herleiten. Vom natürlichen Vater dagegen können nichteheliche Kinder die britische Staatsangehörigkeit nicht erwerben (Section 50 (9) unter b BNA 1981) (103). Nur durch Legitimierung bei nachfolgender Eheschließung der Eltern erhält ein solches Kind die britische Staatsangehörigkeit des Vaters (Section 47 BNA) (104).

Bei einer Geburt außerhalb des Vereinigten Königreiches wird die britische Staatsangehörigkeit nur unter bestimmten Voraussetzungen iure sanguinis erworben (Section 2 BNA 1981) (105). So darf der britische Elternteil nicht selbst bei seiner Geburt die britische Staatsangehörigkeit nur iure sanguinis erworben haben. Die Kinder von Briten, die selbst im Ausland geboren sind und auch die Staatsangehörigkeit iure sanguinis erworben haben, erwerben bei ihrer Auslandsgeburt lediglich dann automatisch die britische Staatsangehörigkeit, wenn der britische Elternteil bestimmte dienstliche Beziehungen zum Vereinigten Königreich hat. Dies gilt insbesondere für diejenigen, die im Dienste der britischen Krone im Ausland tätig sind; allerdings nur unter der weiteren Voraussetzung, $\mathrm{daß}$ die Einstellung in dieses Dienstverhältnis im Vereinigten Königreich stattgefunden hat. Die gleiche Berechtigung besteht bei Personen, die ein Dienstverhältnis bei einer Einrichtung der Europäischen Gemeinschaften haben; die Einstellung in dieses Dienstverhältnis muß in dem Fall in einem Mitgliedstaat der Europäischen Gemeinschaften erfolgt sein (106). Daneben kann der Secretary of State durch Verordnung Dienstverhältnisse bestimmen, die seines Erachtens in Zusammenhang mit außerhalb des Vereinigten Königreiches verrichteten Tätigkeiten im Dienst der Regierung ihrer Majestät stehen (107). Auch in diesem Falle muß jedoch die Einstellung in das betreffende Dienstverhältnis wieder im Vereinigten Königreich stattgefunden haben.

Unter bestimmten Voraussetzungen hat das im Ausland geborene Kind eines britischen Elternteils einen Anspruch darauf, durch Registrierung (also durch Optionserklärung) die britische Staatsangehörigkeit zu erwerben (Section 3 Abs. 1-4 BNA 1981) (108). Der britische Eiternteil muB selbst einen britischen Elternteil haben, der diese Staatsangehörigkeit nicht bei Geburt im Ausland iure sanguinis erworben hat. Weiter muB der britische Elternteil irgendwann in seinem Leben drei Jahre unumterbrochen (109) in Großbritannien gelebt haben. Die Optionserklärung muB grundsätzlich innerhalb der ersten 12 Monate nach der Geburt abgegeben werden (110). Von den im Ausland geborenen nicht-britischen Kindern eines britischen Elternteils kann die britische Staatsangehörigkeit auch durch Option erworben werden, wenn sie während ihrer Minderjährigkeit ununterbrochen drei Jahre zusammen mit ihren Eltern im Vereinigten Königreich gelebt haben; die Optionserklärung muß vor Erreichung der Volljährigkeit abgegeben werden (Section 3 (5) BNA 1981) (111). Nur Kinder, die im Vereinigten Königreich geboren sind (112) und deren Vater oder Mutter dort niedergelassen waren, können die britische Staatsangehörigkeit iure soli erwerben (Section 1 (1) under b BNA 1981). Eine Person gilt als "niedergelassen" (113), wenn sie im Vereinigten Königreich ihren gewöhnlichen Aufenthalt hat, ohne nach den Einwanderungsgesetzen Beschränkungen hinsichtlich der Aufenthalts 
dauer zu unterliegen (Section 50 (2) BNA 1981). In einigen Fällen reicht die unbeschränkte Aufenthaltserlaubnis eines Elternteils nicht aus, um die britische Staatsangehörigkeit seiner im Vereinigten Königreich geborenen Kinder zu begründen. Dies ist der Fall, wenn der betreffende Elternteil ein in Großbritannien stationierter ausländischer Armeeangehöriger ist (114). Das gleiche gilt für Inhaber einer Sonderbefreiung nach Section 8 (2) Immigration Act, es sei denn, diese Befreiung bestimmt selbst etwas anderes (115). Auch in Großbritannien lebende Diplomaten und ihre Angehörige, gelten in Prinzip nicht als niedergelassen (116), aber von dieser Regel formuliert Section $50 \mathrm{Sec}$. (4) wieder eine Ausnahme. Die im Vereinigten Königreich geborenen Kinder, die nicht durch Geburt Briten werden, haben ein bedingtes Optionsrecht auf die britische Staatsangehörigkeit. Wenn ein solches Kind sich während den ersten zehn Jahre seines Lebens in keinem Jahr außerhalb des Vereinigten Königreiches mehr als 90 Tage lang aufgehalten hat, kann es nach seinem zehnten Geburtstag auf Antrag als Brite registriert werden (117). Ein solcher Erwerb der Staatsangehörigkeit durch Registrierung ist auch möglich, wenn der Vater oder die Mutter eines im Vereinigten Königreich geborenen nicht-britischen Kindes die britische Staatsangehörigkeit erwirbt oder sich nach dessen Geburt, aber noch während dessen Minderjährigkeit im Vereinigten Königreich niederläßt, d.h. eine unbeschränkte Aufenthaltserlaubnis erwirbt (Section 1 (3) und (4) BNA 1981) (118).

In Großbritannien aufgefundene neugeborene (119) Kinder erwerben die britische Staatsangehörigkeit aufgrund der Section 1 (2) BNA 1981. Es wird unterstellt, daß diese Kinder im Vereinigten Königreich als Kind eines britischen Elternteils oder eines im Vereinigten Königreich niedergelassenen Elternteils geboren sind. Diese Vermutung kann aber widerlegt werden (120).

Durch Geburt im Vereinigten Königreich erwerben potentiell staatenlose Kinder nicht die britische Staatsangehörigkeit. Der Anhang 2 des britischen Staatsangehörigkeitsgesetzes widmet aber einige Vorschriften der Bekämpfung der Staatenlosigkeit. Erwähnenswert ist vor allem Section 3 dieses Anhangs. Jene Section gibt einem im Vereinigten Königreich geborenen, staatenlosen Kind ein bedingtes Optionsrecht auf die britische Staatsangehörigkeit. Voraussetzung ist, $\mathrm{dla}$ es während der fünf, der Optionserklärung vorausgehenden Jahre im Vereinigten Königreich gelebt und nicht mehr als 450 Tage im Ausland verbracht hat (121). Das Optionsrecht muß zwischen dem 10. und 22. Lebensjahr des Betroffenen ausgeübt werden.

Das britische Recht kennt keinen Staatsangehörigkeitserwerb durch Anerkennung (122). Durch Adoption wird die Staatsangehörigkeit nur erworben, wenn diese Adoption durch Gerichtsbeschluß im Vereinigten Königreich vollzogen wird (123) (Section 1 (5) BNA 1981).

\subsubsection{Erwerb der Staatsangehörigkeit nach der Geburt}

\subsubsection{Rüickblick}

Schon im Mittelalter gab es die Möglichkeit, die britische Staatsangehörigkeit durch Einbürgerung zu erwerben. Eingebürgerte Personen hatten aber nicht den gleichen Status wie Personen, die durch Geburt "British Subject" waren. Dies änderte sich erst allmählich im 19. und Anfang des 20. Jahrhunderts. 
Die Einbürgerungsvoraussetzungen wurden zum ersten Mal in dem Naturalization Act von 1870 systematisch formuliert. Neben fünfjährigem Aufenthalt im Vereinigten Königreich oder fünfjährigem britischen Staatsdienst, wurde zur Voraussetzung gemacht, daß der Neubürger die Absicht habe, auch weiterhin im Vereingten Königreich oder im britischen Staatsdienst zu bleiben. Daneben muBte er einen "oath of allegiance" leisten. Im British Nationality Act von 1915 wurden neben diesen Voraussetzungen noch "a good character" und ausreichende Sprachkenntnisse gefordert. Erleichternd wurde dabei der Wohnsitz in einer Kolonie dem in Großbritannien gleichgestellt (124).

Im BNA 1948 wurden diese Voraussetzungen grundsätzlich beibehalten (125). Gefordert wurde aber nunmehr ein fünfjähriger Wohnsitz im Vereinigten Königreich während der acht letzten dem Einbürgerungsantrag vorausgehenden Jahre oder ein entsprechend langer Staatsdienst. Das letzte dieser Jahre hatte dem Einbürgerungsantrag unmittelbar vorauszugehen. Von vielen dieser Voraussetzungen konnte jedoch der "Secretary of State" im Einzelfall Ausnahmen machen. Nachdem dann einem Neubürger ein "certificate of naturalisation" uiberreicht worden war, mußte dieser einen "oath of allegiance" leisten.

Im Naturalization Act 1870 war nicht die Möglichkeit vorgesehen, eine Einbürgerung zu widerrufen. Erst seit 1914 war die Entziehung der Staatsangehörigkeit im Falle der Erschleichung der Einbürgerung möglich (126). Nach einer Erweiterung der Entziehungsmöglichkeit im Jahre 1918 entwickelt sich der BNA 1948 diesbezüglich als Vorläufer für das heute geltende Recht (127). Section 20 Abs. 4 BNA 1948 sah zudem vor, daß einem Eingebürgerten die Staatsangehörigkeit bei mindestens siebenjährigem Auslandsaufenthalt wieder entzogen werden konnte (128); dieser Entziehungsgrund wurde 1964 aufgehoben (129).

Die Einbürgerung eines Mannes bewirkte 1870 ebenfalls die Einbürgerung seiner Gattin (Section 10 Ziffer 1 BNA 1870) (130). Der Staatsangehörigkeitserwerb erstreckte sich auch auf die minderjährige Kinder, die mit dem Vater in Großbritannien lebten; seit 1895 galt das gleiche für Kinder, die mit ihrem Vater, der im Dienste der Krone stand, außerhalb des Vereinigten Königreiches lebten (131). Wenn eine verwitwete Frau eingebürgert wurdle, erstreckte sich diese Einbürgerung ebenfalls auf ihre minderjährigen Kinder, die mit ihr im Vereinigten Königreich lebten. Gemäß Section 5 (1) BNA 1914 erstreckte sich die Einbürgerung eines Ausländers nicht mehr automatisch auf dessen minderjährige Kinder; diese aber konnten gesondert in die Einbürgerungsurkunde aufgenommen werden. Kinder, die auf diese Art die britische Staatsangehörigkeit erwarben, konnten diese Staatsangehörigkeit innerhalb eines Jahres nach Erreichung der Volljährigkeit durch Erklärung wieder ablegen (132). Ursprünglich erstreckte sich die Einbürgerung eines Mannes infolge des BNA 1914 jedenfalls auf seine Ehefrau (Section 10 (1) BNA 1914). Ab 1933 (133) war dies nicht mehr der Fall; die Ehefrau hatte aber ein Optionsrecht auf die britische Staatsangehörigkeit, das sie grundsätzlich innerhalb eines Jahres nach der Einbïrgerung ihres Mannes ausüben mußte. Der BNA 1948 enthielt keine Vorschriften mehr über die Erstreckung der Einbürgerung. Section 7 BNA 1948 eröffnete aber die generelle Möglichkeit für einen minderjährigen Ausländer als britischer Bürger registriert zu werden. Eine Sonderregelung der Erstreckung der Einbürgerung eriibrigte sich damit (134). Eine verheiratete Frau konnte ab 1949 auch ohne ihren Ehemann eingebürgert werden. Die Einbürgerung ihres Mannes hatte 
für sie nicht die Konsequenz, daß auch sie die britische Staatsangehörigkeit erwarb.

Es wurde bereits darauf hingewiesen, dal3 das britische Recht ursprïnglich neben der Einbürgerung die sogenannte "denisation" kannte. Die Möglichkeit einer "denisation" blieb auch in den Neuregelungen von 1870 und 1914 bestehen (135). Erst durch Einführung der BNA 1948 verschwand dieses Rechtsinstitut aus dem britischen Staatsangehörigkeitsrecht.

Eine ausländische Frau, die einen Briten heiratete, erwarb vermutlich schon nach den Regeln des "Common Law" durch Eheschließung die britische Staatsangehörigkeit. Ausdrücklich wurde dies jedoch von Section 16 Nationality Act 1844, Section 10 (1) Naturalization Act 1870 und. Section 10 (1) BNA 1914 bestimmt. Der BNA 1948 kannte diesen automatischen Erwerb der britischen Staatsangehörigkeit nicht mehr, sah jedoch in Section 6 (2) einen Erwerb durch Registrierung vor. Die früheren britischen Staatsangehörigkeitsregelungen sahen - vor allem seit 1948 - auch noch verschiedene andere Fälle vor, in denen Personen durch "registration" die britische Staatsangehörigkeit erwerben konnten.

\subsubsection{Heutige Regelung}

Gemäß Sec. 6 BNA 1981 können volljährige, vollgeschäftsfähige Personen eingebürgert werden, wenn sie die Voraussetzungen für eine Einbürgerung erfïlllen (136). Diese Voraussetzungen, die in Anhang 1 des Staatsangehörigkeitsgesetzes stehen, sind folgende:

a) Der Betreffende muB die fünf dem Einbürgenungsantrag vorausgehende Jahre im Vereinigten Königreich gelebt und in der Zeit nicht mehr als 450 Tage im Ausland verbracht haben.

b) Er darf sich während der letzten zwölf Monate vor Antragstellung nicht mehr als 90 Tage im Ausland aufgehalten haben.

c) Er muß sich während des ganzen Zeitraums von fünf Jahren legall, das heißt ohne Verletzung der Einwanderungsgesetze, im Vereinigten Königreich aufgehalten haben; dabei muß er während der letzten zwölf Monate eine unbefristete Aufenthaltserlaubnis gehabt haben.

d) Weiter muß der Antragsteller "of good character" sein, über ausreichende Kenntnisse der englischen, walisischen oder schottischen Sprache verfügen und schließlich die Absicht haben, seinen (Haupt)wohnsitz in das Vereinigte Königreich zu verlegen. An die Stelle eines Wohnsitzes im Vereinten Königreich kann auch der Eintritt in den öffentlichen Dienst des Königreiches, ein Dienstverhältnis bei einer internationalen Organisation, deren Mitglied das Vereinigte Königreich ist, oder in ein Dienstverhältnis bei einem im Vereinigten Königreich niedergelassenen Unternehmen oder Verein treten.

Ohne nachgewiesenen Aufenthalt in Großbritannien können diejenigen eingebürgert werden, die auBerhalb des Vereinigten Königreiches im Dienste der Krone sind und auch vorhaben, dies zu bleiben. Sie müssen ebenfalls aber "of good character" sein und über ausreichende Sprachkenntnisse verfügen. Die Einbürgerungsvoraussetzungen sind relativ klar. Es ist jedoch von Bedeutung zu wissen, wie die Forderung des "good charakter" konkretisiert wird (137): 
${ }^{\text {"f }}$ A person with a serious criminal record cannot be regarded as a person of good character. Equally, it is normal to refuse applicants with few or no convictions who are strongly suspected of being engaged in crime or are known associates of serious criminals. Sexual morality, however, is not normally taken into account, nor are, for instance, homosexual activities within the law. Scandalous sexual misbehaviour migth, however, when combined with other personal characteristics, be a factor in a very few cases. Applicants are expected to meet their financial responsibilities. Financial irresponsibility, serious insolvency or bankruptcy invariably leads to refusal. But mere financial incompetence is not necessarily a bar, and neither is unemployment or receipt of social security benefits. Where a person is in debt but is making efforts to repay what he owes, it is usual to postpone a decision on his application for a year or two to give him time to put matters right. Commercial malpractices are taken seriously. They are usually calculated and sustained acts which reflect adversely on the applicant's general character. Defects of temperament on their own are not normally held to bar an applicant on grounds of character. Heavy drinking, gambling or a disinclination to work are not in thernselves sufficient to warrant refusal. There comes a point in a very few cases, however, where failings of this type becomes so pronounced, or notorious in the locality, that it would be unwise to grant naturalisation."

Anläßlich dieses Zitates wurde von Bevan (138) betont:

"The description highlights both the flexibility of the requirement and the dangers inherent in that flexibility" (139).

Im Parlament wurde darauf hingewiesen, daß "spent offences under the Rehabilition of Offenders Act 1974" beim Einbürgerungsantrag nicht erwähnt werden missen. Falls dies versehentlich doch geschieht, müssen sie negiert werden (140). Personen, die die öffentliche Sicherheit gefährden, werden im allgemeinen die Einbürgerungsvoraussetzungen nicht erfüllen. Dabei wird aber nicht zwingend eine Beziehung zwischen bestimmten politischen Ansichten und Gefährdung der öffentlichen Sicherheit hergestellt. So kann auch ein Mitglied der kommunistischen Partei eingebürgert werden. Falls aber der Neubürger Ansichten vertritt, die Gewaltaktionen oder einen Staatsstreich (destroying the State) auslösen können, wird sein Einbürgerungsantrag zurückgewiesen (141).

Sprachkenntnisse werden nicht gefordert, wenn der Secretary of State

"considers that because of the applicant's age or physical or mental condition it would be unreasonable to expect him to fulfil it" (Schedule 1, Par. 2 (e)).

Über das Niveau der Sprachkenntnisse bemerken Macdonald/Blake (142):

"The language tests will usually take the form of a conversation with a policeman. An ability to comprehend the language orally will suffice, it is not necessary to be able to pass a written test. The standard indicated by the govemment in Committee was an ability to communicate with fellow citizens". 
Interessant ist es festzustellen, daß = anders als in manchen anderen europäischen Staaten - für die Einbürgerung nicht gefordert wird, daß die bisherige Staatsangehörigkeit aufgegeben wurde. Ebenso bewirkt ein freiwilliger Erwerb einer fremden Staatsangehörigkeit keinen Verlust der britischen Staatsangehörigkeit. Beil der Vorbereitung des Nationality Act 1981 wurde zwar über die Möglichkeit einer Bekämpfung der mehrfachen Staatsangehörigkeit diskutiert, aber:

\begin{abstract}
"The abolition of dual nationality was ultimately resisted "because it is true that to some extent people can have dual obligations in their heart ... and also because, as a matter of practice, it seems a workable concept". This approach can be welcomed for recognising the pluralistic nature of modern society and the inevitable insecurity which would be felt within ethnic communities if dual nationality were to be abolished" (143).
\end{abstract}

Der ausländische Ehegatte eines britischen Bürgers kann unter erleichterten Bedingungen eingebürgert werden. Für ihn genügt ein Aufenthalt von drei Jahren im Vereinigten Königreich. Während dieser drei Jahre darf er höchstens 270 Tage im Ausland verbracht haben, davon während des letzten dem Antrag vorausgehenden Jahres nur 90 Tage. Er darf in diesen drei Jahren nicht unter Verletzung der Einwanderungsgesetze in GroBbritannien gewesen sein (144). Im Zeitpunkt des Einbürgerungsantrages muß er im Besitz einer unbeschränkten Aufenthaltsgenehmigung für das Vereinigten Königreich sein (145). Schließlich muß auch er "of good character" sein. Sprachkenntnisse dagegen werden nicht gefordert! (146).

Weder gewöhnliche Antragsteller noch ausländische Ehegatten britischer Bürger haben, wenn sie die im Anhang 1 formulierten Einbürgerungsvoraussetzungen erfüllen, einen Einbürgerungsanspruch. Der Secretary of State verfügt gemäß Section 6 BNA 1981 über ein ausdrücklich freies Ermessen; "he may, if he thinks fit, grant ..... a certificate of naturalization ..." (147).

Das britische Staatsangehörigkeitsrecht kennt zudem viele Optionsrechte. Mehrere dieser Optionsrechte wurden an anderer Stelle bereits erwähnt. Nicht-britische Kinder eines britischen Bürgers können unter bestimmten Voraussetzungen für die britische Staatsangehörigkeit optieren (148), das gleiche gilt für bestimmte auf britischen Staatsgebiet geborene Personen (Staatenlose, Kinder neu eingebürgerter Briten oder neu niedergelassener Ausländer) (149). Das Staatsangehörigkeitsgesetz kennt daneben Optionsrechte für bestimmte "British Dependent Territories Citizens", "British Overseas Citizens", "British Subjects" und "British Protected Persons" (Section 4 BNA 1981) (150). Section 5 BNA 1981 gibt allen British Dependent Territories Citizens die im Sinne der EG-Verträge als Staatsangehörige des Vereinigten Königreiches gelten ein Optionsrecht. Diese Bestimmung ist für die Einwohner Gibraltars von Bedeutung (151).

Aufgrund der Bestimmungen der Section 7 bis 9 BNA 1981 gibt es noch mehrere Optionsrechte im Rahmen der Übergangsregelung nach Inkrafttreten dieses neuen britischen Staatsangehörigkeitsgesetzes. Diejenigen, die die britische Staatsangehörigkeit (durch Verzicht) verloren haben, besitzen gemäß Section 13 Abs. 1 BNA 1981 ein bedingtes Optionsrecht auf die britische Statsangehörigkeit (152). Voraussetzung für dieses Optionsrecht ist die volle Geschäftsfähigkeit des Antragstellers; zudem muß der Verzicht auf die britische Staatsbürgerschaft erforderlich gewesen sein, um eine andlere Staatsangehörigkeit behalten oder erwerben zu können. Für den Fall, daß dieses Optionsrecht be- 
nutzt wurde, und die britische Staatsangehörigkeit später emeut durch Verzicht verloren wird, entsteht kein erneutes Optionsrecht (Section 13 Abs. 2 BNA 1981). Falls die Verzichtserklärung nicht für den Erwerb oder die Beibehaltung eines fremden Staatsangehörigkeit erforderlich war, kann der Secretary of State mach seinem Ermessen die Registrierung als britischer Staatsbürger veranlassen. Man kann deshalb in diesem Falle eher von einem kontrollierten Optionsrecht zum Wiedererwerb der britischen Staatsangehörigkeit sprechen oder von einer erleichterten Einbürgerung.

Die an einer Einbürgerung verbundenen Kosten sind 160,- Pounds. Ehegatten eines britischen Bürgers brauchen lediglich 55,- Pounds zu zahlen. Die Kosten einer "registration" sind ebenfalls 55,- Pounds (153).

\subsubsection{Verlust der Staatsangehörigkeit}

\subsubsection{Rückblick}

Vor 1870 galt der Grundsatz der "perpetual allegiance": ein Verlust der britischen Staatsangehörigkeit war nicht möglich (154).

Seit 1870 konnten volljährige, unbeschränkt geschäftsfähige Personen, die iure soli britisch waren und iure sanguinis noch eine andere Staatsangehörigkeit besaßen, auf die britische Staatsangehörigkeit verzichten. Auf die britische Staatsangehörigkeit konnte auch der im Ausland geborene Brite verzichten (Section 4 Naturalization Act 1870). Festgestellt wurde 1870 weiter, daß eine britische Frau durch Eheschließung mit einem Ausländer die bisherige Staatsangehörigkeit verlor (Section 10 Ziffer 1). Bei Einbürgerung im Ausland trat ebenfalls der Verlust der britischen Staatsangehörigkeit ein, wemn der Betroffene keine Erklärung abgegeben hatte, daß er die britische Staatsangehörigkeit beibehalten wolle (Section 6).

Die Möglichkeit des Verzichts auf die britische Staatsangehörigkeit wurde 1914 leicht erweitert und umformuliert (Sections 5, 7, 14 BNA 1914). GemäB Section 10 Abs. 1 verlor die mit einem Ausländer verheiratete Frau ihre britische Staatsangehörigkeit. Seit 1934 allerdings nur dann, wenn sie die Staatsangehörigkeit ihres Mannes erwarb. Durch Einbürgerung im Ausland trat grundsätzlich Verlust der Staatsangehörigkeit ein, jedoch war eine Beibehaltserklärung möglich (Section 10 (3) und (4)). Neu eingeführt war die Möglichkeit, eine Einbürgerung zu widernufen, wenn diese erschlichen worden war. Die Möglichkeit um Einbürgerungen zu widerrufen wurde 1918 erweitert (155). Nicht nur im Falle der Erschleichung der Einbürgerung konnte diese fortan widerrufen werden, sondern ebenfalls, wenn der Betreffende während eines Krieges durch Geschäfte mit dem Feind diesen wissentlich unterstützt hatte. Auch bei Verurteilung zu einer Haft- oder Geldstrafe in bestimmter Höhe und bei tatsächlichem Fehlen eines guten Leumunds. Gleiches galt, wenn der Betreffende nach der Einbürgerung seiner neuen Heimat mehr als ein Jahr ferngeblieben war, oder falls er Bürger eines Staates geblieben war, der sich mit Großbritannien im Kriegzustand befand (Section 7). In 1914 wurde weiter bestimmt, daß Personen, die als Minderjährige durch "registration" die britische Staatsangehörigkeit erworben hatten, diese wieder verloren, wenn sie nicht innerhalb eines Jahres nach Erreichen der Volljährigkeit erklärten, weiterhin britische Staatsbürger bleiben zu wollen. Auch gemäß den Regelungen des BNA 1948 konnte die britische 
Staatsangehörigkeit einem Eingebürgerten wieder entzogen werden. Dies war u.a. möglich wenn eine solche Person "has shown himself by act or speech to be disloyal or disaffected towards His Majesty (156).

Seit 1964 war ein Verzicht auf die Staatsangehörigkeit nur möglich, wenn keine Staatenlosigkeit die Folge war. Eine Verzichtserklärung war auch möglich, um eine fremde Staatsangehörigkeit erwerben zu können. Wenn aber dieser Erwerb dann nicht innerhalb von sechs Monaten erfolgte, war der Verzicht nichtig. Eine Elheschließung hatte fortan keinen Verlust der Staatsangehörigkeit mehr zur Folge. Der Widerruf einer Einbürgerung blieb möglich, und wurde auch auf Widerruf bei Staatsangehörigkeitserwerb durch Registration erweitert. Weitere Verlustgrïnde kannte der BNA 1948 nicht, namentlich auch keinen Verlust der britischen Staatsangehörigkeit wegen Erwerbs einer fremden Staatsangehörigkeit.

\subsubsection{Heutige Regelung}

Der Verlust der britischen Staatsangehörigkeit tritt in der Regel nur durch Verzicht ein (Section 12 BNA 1981) (157). Durch die reine Verzichtserklärung hört der Erklärende jedoch noch nicht auf, britischer Staatsbürger zu sein. Dies ist erst der Fall, wenn die Erklärung von den zuständigen britischen Behörden registriert ist. Die Erklärung wird ausschließlich registriert, wenn nachgewiesen ist, daß der Betreffende noch eine andere Staatsangehörigkeit hat oder erwerben wird. Hat der Erklärende zur Zeit der Registrierung noch keine fremde Staatsangehörigkeit und erwirbt er diese auch nicht innerhalb von sechs Monaten, dann gilt der Verlust der britischen Staatsangehörigkeit als nicht eingetreten. Aufgrund der Section 12 Abs. 4 BNA 1981 kann die Registrierung einer Verzichtserklärung im Kriegsfalle verweigert werden. Allgemeine Voraussetzungen für die Abgabe einer Verzichtserklärung sind Volljährigkeit und volle Geschäftsfähigkeit.

Bemerkenswert ist, daß der Verzicht auf die britische Staatsangehörigkeit eine relativ "schwache" Wirkung hat, da ein Ex-Brite in der Regel ein Optionsrecht auf die britische Staatsangehörigkeit behält (Section 13 BNA 1984) (158).

Denjenigen, die die britische Staatsangehörigkeit durch Einbürgerung oder Registrierung erworben haben, kann außerdem die Staatsangehörigkeit entzogen werden (Section 40 BNA). Als Gründe dafür kommen in Betracht: Erschleichung der Einbürgerung, Illoyalität, während eines Krieges Beziehungen zum Feind, oder innerhalb von fünf Jahren nach Erwerb der britischen Staatsangehörigkeit Verurteilung zu einer Freiheitsstrafe won mehr als 12 Monaten. Die Staatsangehörigkeit wird nur entzogen, falls es dem öffentlichen Wohl nicht zuträglich ist, wenn der Betreffende weiterhin britischer Staatsbürger bleibt. Eine Entziehung der Staatsangehörigkeit wegen einer Freiheitsstrafe erfolgt nicht, wenn Staatenlosigkeit die Folge wäre (159).

Durch freiwilligen Erwerb einer fremden Staatsangehörigkeit tritt kein Verlust der britische Staatsangehörigkeit ein (160); das gilt auch bei Änderungen im familienrechtlichen Status einer Person, wie EheschlieBung, Ehescheidung oder Adoption. 


\subsection{ITALIEN}

\subsubsection{Allgemeine Bemerkungen}

Der italienische Staat entstand im vorigen Jahrhundert durch Zusammenfügung der vielen kleinen Staaten der italienischen Peninsula. Die ersten staatsangehörigkeitsrechtlichen Bestimmungen des Königreiches Italien wurden nach französischem Vorbild in das Bürgerliche Gesetzbuch aufgenommen (1). Dieser itallienische Codice civile vom 25. Juni 1865 (im folgenden zitiert als C.c.it.) trat am 1. Januar 1866 in Kraft (2). Die Art. 4 bis 15 betrafen das Staatsangehörigkeitsrecht. Vorher gab es in Italien vereinzelt staatsangehörigkeitsrechtliche Bestimmungen in den Gesetzgebungen der unterschiedlichen italienischen Staaten (3).

Ausgangspunkt des in dem Codice civile enthaltenen Staatsangehörigkeitsrechts war das ius sanguinis a patre (Art. 4 C.c.it.). Daneben manifestierte sich in mehreren Bestimmungen des Codice civile 1865 das ius soli. So bestimmte Art. 5 Abs. 1 C.c.it., daß das Kind eines Mannes, der vor dessen Geburt die italienische Staatsangehörigkeit verloren hatte, dennoch die italienische Staatsangehörigkeit erwarb, falls es in Italien geboren wurde und dort wohnhaft war (4). Wichtig war in diesem Zusammenhang weiter Art. 8 Abs. 1 C.c.it. kraft dessen das in Italien geborene Kind eines Ausländers mit der Geburt die italienische Staatsangehörigkeit erwarb, falls der Vater schon mindestens zehn Jahre ununterbrochenen Wohnsitz in Italien hatte. Nach Art. 5 Abs. 2 und 8 Abs. 2 C.c.it. konnten die Kinder, die so iure soli die italienische Staatsangehörigkeit erworben hatten, die Staatsangehörigkeit innerhalb eines Jahres nach Erreichung des 21. Lebensjahres wieder ausschlagen. Das in Italien geborene Kind unbekannter Eltern erwarb nach Art. 7 Abs. 3 C.c.it. 1865 ebenfalls die italienische Staatsangehörigkeit iure soli. Den Regelungen anderer europäischen Staaten entsprechend bestimmte Art. 9 C.c.it., daB die ausländische Ehegattin eines Italieners automatisch die Staatsangehörigkeit ihres Mannes erwarb.

Art. 10 C.c.it. sah zwei Arten von Einbürgerung vor: Die große Einbürgerung (grande oder legislativa naturalita), durch die auch politische Rechte erworben wurden und die kleine Einbürgerung ((piccola oder esecutiva naturalitả), die zwar den vollen Genuß der privaten Rechte verschaffte, nicht dagegen den aller politischen (5). Die große Einbürgerung geschah durch Gesetz, die kleine durch Königliches Dekret. Art. 36 des Auswanderungsgesetzes vom 31. Januar 1901 (6), eröffnete die Möglichkeit für einige Personengruppen mittels Ministerialdekret die große Einbürgerung zu gewähren. Gemäß dem Gesetz vom 17. Mai 1906 (7), konnte die große Einbürgerung allen Ausländern, die bestimmte Voraussetzungen erfüllten, durch Königliches Dekret zugesprochen werden. Weiter sahen Art. 13 und 14 C.c.it. für einige Personengruppen einen erleichterten Wiedererwerb der italienischen Staatsangehörigkeit vor (8).

Die Verlustgrände wurden in Art. 11 C.c.it. geregelt. Die Staatsangehörigkeit wurde werloren

a. durch Abstandserklärung und Verlegung des Aufenhalts ins Auslland (9),

b. durch freiwilligen Erwerb einer fremder Staatsangehörigkeit und

c. durch fremden Kriegs- oder Staatsdienst ohne Erlaubnis der italienischen Regierung.

Art. 13 C.c.it. bestimmte, daß die italienische Staatsangehörigkeit zurückerworben wurde, 
a. wenn der Betreffende mit besonderer Erlaubnis der italienischen Regierung wieder nach Italien zurückkehrte;

b. wenn der Betreffende auf die fremde Staatsangehörigkeit bzw. auf das fremde Dienstverhältnis verzichtete oder

c. wenn er vor dem Zivilstandsbeamten erklärte, sich wieder in Italien niederlassen zu wollen und diesen Entschluß auch innerhalb eines Jahres ausführte. Eine Italienerin verlor ihre Staatsangehörigkeit neben den genannten Verlustgründen noch durch Ehe mit einem Ausländer. Dieser Verlust trat aber nicht elin, wenn sie durch die Eheschließung nicht die Staatsangehörigkeit ihres Mannes erwarb (Art. 14 C.c.it.)

In Ergänzung zu den staatsangehörigkeitsrechtlichen Bestimmungen des C.c.it. kamen später staatsangehörigkeitsrechtliche Regelungen in einigen anderen Gesetzen hinzu (10). Hierdurch wurde das italienische Staatsangehörigkeitsrecht unübersichtlich. Deshalb drang der Senat darauf an, das ganze Staatsangehörigkeitsrecht in einem Gesetz zu kodifizieren (11). Dies fuihrte schließlich zu der nun noch heute geltenden Staatsangehörigkeitsregelung (Legge sulla cittadinan$\mathrm{za}$, im folgenden gekürzt als L.c.) vom 13. Juni 1912 (12).

Der Erwerb iure sanguinis entsprach im Staatsangehörigkeitsgesetz von 1912 weitgehend der Regelung des $\mathrm{Cc}$ 1865: Falls aber ein eheliches oder vom Vater anerkanntes Kind von diesem aus irgendeinem Grund keine Staatsangehörigkeit herleiten konnte, erwarb es fortan die italienische Staatsangehörigkeit der Mutter (13).

Der Erwerb der italienischen Staatsangehörigkeit kraft Geburt in Italien wurde etwas eingeschränkt. Iure soli erwarben nunmehr die italienische Staatsangehörigkeit in Italien aufgefundene Findelkinder (Art. 1 Abs. 2 L.c.), in Italien geborene nichteheliche Kinder deren Abstammung juristisch unbekannt war und in Italien geborene Kinder staatenloser Eltern oder Kinder, die die Staatsangehörigkeit ihrer Eltern nicht erwarben (Art. 1 Abs. 2 Ziffer 3 L.c.) (14).

GemäB Art. 10 L.c., ging auch das Staatsangehörigkeitsrecht von 1912 von dem Prinzip der Familieneinheit aus (15). Die Ausländerin, die einen Italiener heiratete, erwarb dadurch automatisch die italienische Staatsangehörigkeit. Die Italienerin, die einen Ausländer heiratete, verlor grundsătzlich ihre italienische Staatsangehörigkeit, es sei denn, sie erwarb nicht die Staatsangehörigkeit ihres Ehegatten. Art. $3 \mathrm{~L}$.c. regelte den Erwerb der italienischen Staatsangehörigkeit aufgrund einer besonderen Bindung mit Italien (16). Ausländer, die in Italien geboren waren oder deren Eltern zur Zeit ihrer Geburt wenigstens zehn Jahre ihren Wohnsitz in Italien hatten oder deren Vater, Mutter oder Großvater väterlicherseits italienische Staatsangehörige waren, konnten die italienische Staatsangehörigkeit erwerben, falls sie eine der folgenden Bedingungen erfüllten:

a. Wehrdienst in Italien oder Übernahme eines öffentlichen Amtes in Italien.

b. Wohnsitz nach Vollendung des 21. Lebensjahres in Italien und Option für die italienische Staatsangehörigkeit innerhallb eines Jahres.

c. Wohnsitz seit wenigstens zehn Jahren in Italien und keine Erklärung innerhalb des 22 . Lebensjahres, daß sie die ausländische Staatsangehörigkeit beibehalten möchten. 
Art. 3 L.c. galt ebenfalls für ehemalige Italiener, die durch Erstreckung des Staatsangehörigkeitsverlusts eines Elternteils die italienische Staatsangehörigkeit verloren hatten (Art. 12 Abs. 2 L.c.).

Im Gesetz von 1912 wurde die normale Einbürgerung in Art. 4 geregelt. Die Voraussetzungen für die Einbürgerung entsprachen in großen Linien denen des Gesetzes von 1906, wobei die erforderlichen Fristen unterschiedlich waren (17).

Die Verlustgründe der italienischen Staatsangehörigkeit finden sich in den Art. $7,8,11$ und 12 L.c. (18). Im Unterschied zu den Bestimmungen des C.c.it. 1865 wurde es jedoch schwieriger, auf die italienische Staatsangehörigkeit zu verzichten.

Der Text des L.c. 1912 wurde im Laufe der Zeit nur selten ausdrücklich geändert, jedoch häufig modifiziert. Zu erwähnen ist das Dekretgesetz vom 1 . Dezember 1934 (19), das die Einbürgerungsvoraussetzungen von Art. 4 L.c. erleichterte. Art. 6 L.c., worin die Möglichkeit der Einbürgerung wegen außergewöhnlicher Dienste für Italien vorgesehen war, wurde durch das gleiche $\Gamma$.kretgesetz aufgehoben (20). Der Inhalt des Staatsangehörigkeitsgesetzes au, 1912 wurde weiterhin häufig durch Sondervorschriften ergänzt bzw. durch spätere $\operatorname{Re}^{-}$ gelungen implizit aufgehoben. Ein Beispiel einer solcher impliziten Aufhebung bildet Art. 8 des Gesetzes vom 21. April 1983 (21), der bestimmte "Sono abrogate tutte le disposizioni incompatibili con la presente legge" (Alle diesem Gesetz entgegenstehenden Bestimmungen sind aufgehoben) (22). Mittels dieser Konstruktion wurden einige Vorschriften des L.c. 1912 mit Sicherheit aufgehoben. Es ist jedoch unklar, ob manche dieser Vorschriften noch weiterhin gelten.

Weiter gab es in Italien außerordentlich viele Gesetze und Dekrete auf dem Gebiete des Staatsangehörigkeitsrechts als Folge der Grundgebietsänderungen (23). Zuerst betrafen diese Regelungen Territorien, die durch Italien okkupiert waren (Tirol, Somalia, Eritrea, Fiume (Rijeka), Dodekanes, Cyrenaika, Tripolis). Später mußten die staatsangehörigkeitsrechtlichen Folgen des Verlustes der meisten dieser Gebiete wieder geregelt werden. Teilweise erfolgte dies aufgrund völkerrechtlicher Abkommen, teilweise aber auch durch innerstaatliches Recht. Alle diese territorialbedingten Regelungen sollen hier aber außer Betracht gelassen werden.

Von den das L.c. 1912 ergänzenden oder modifizierenden Regelungen bis zum Ende des Zweiten Weltkriegs seien folgende erwähnt. Die Bestimmungen des Art. 3 Ziffer 2 und 3 L.c. wurden für die Dauer des 1 . Weltkrieges durch Dekret vom 25. Juli 1915 (24) aufgehoben. Potentiell staatenlose Kinder konnten deshalb in dieser Zeit keine Staatsangehörigkeit von der italienischen Mutter herleiten und in Italien geborene Personen konnten ihr Optionsrecht auf die italienische Staatsangehörigkeit nicht ausüben (25). Ein Dekret vom 18. Januar 1918 (26) ermöglichte die Aufhebung der ab 1908 vorgenommen Einbürgerungen von ehemaligen Staatsangehörigen feindlicher Staaten. Im Jahre 1922 wurde Mussolini Ministerpräsident Italiens. Das Dekretgesetz vom 10. September 1922 (27) schuf die Möglichkeit bestimmten außerhalb Italiens lebenden, Personen die italienische Staatsangehörigkeit zu verleihen, ohne die Voraussetzungen von Art. 4 L.c. zu beachten. Es betraf 
a. Familien italienischen Ursprungs, die die ursprüngliche Staatsangehörigkeit verloren hatten oder

b. italienischen Schutz genossen oder früher genossen hatten und zur Zeit von keinern anderen Staat Schutz erhielten, oder

c. unzweifelhafte Beweise italienischer Gesinnung gegeben hatten und in mehrfacher Hinsicht die Gewähr boten, zur Aufrechterhaltung des guten Namens und des Ansehens Italiens beizutragen. Es handelte sich hierbei um eine sogenannte "kleine" Einbürgerung.

Ab dem 10. Januar 1926 eröffnete ein Dekretgesetz (28) die Möglichkeit, die gemäß den nach dem ersten Weltkrieg geschlossenen Friedensverträgen durch Option erworbene italienische Staatsangehörigkeit wieder abzuerkennen, falls der Betroffene sich ihrer durch seine politische Haltung unwürdig erwiesen hatte. Aberkennung der Stalatsangehörigkeit wurde durch Gesetz vom 31. Januar 1926 auch in folgenden Fällen möglich (29): einem Italiener konnte die Staatsangehörigkeit entzogen werden, wenn er im Ausland eine Tat beging oder daran teilnahm, die darauf abzielte, die öffentliche Ordnung in Italien zu stören, oder die den italienischen Interessen Schaden zufügen oder den guten Namen und das Ansehen Italiens beeinträgtigen konnte. Unter Umständen konnte das Vermögen einer solchen Person konfisziert werden. Im Jahre 1938 wurde allen Juden, die nach dem 1. Januar 1919 eingebürgert waren, die italienische Staatsangehörigkeit aberkannt (30). Diese Ausbürgerung der Juden wurde nach dem Sturz Mussolinis wieder rückgängig gemacht (31). Das Dekretgesetz aus dem Jahre 1926 trat mittels Wirkung von Art. 22 der italienischen Verfassung von 1947 faktisch außer Kraft (32). Hierin wurde der Entzug der Staatsangehörigkeit aus politischen Gründen untersagt ("Nessuno può essere privato, per motivi politici, della capacità giuridica, della cittadinanza, del nome"') (33).

In den ersten Nachkriegsdezennien erfolgte keine Änderung der allgemeinen Erwerbs- und Verlustgründe der italienischen Staatsangehörigkeit. Wohl aber wurde über eine grundsätzliche Neukodifizierung des Staatsangehörigkeitsrechts diskutiert. Gesetzesentwiirfe wurden 1960 (34) und 1961 (35) (36) veröffentlicht. Diese griffen auf einen Entwurf, der bereits aus dem Jahre 1930 stammte, zurüick (37). Die aufgestellten Entwürfe erreichten aber nie die Gazzetta Ufficiale.

Die erste inhaltliche Änderung der allgemeinen Erwerbs- und Verlustgründe in der Nachkriegszeit geschah durch das Adoptionsgesetz vom 5. Juli 1967 (38). Aufgrund Art. 5 dieses Gesetzes erwarb das von Italienem adoptierte minderjährige ausländische Kind durch die Adoption von Rechts wegen die italienische Staatsangehörigkeit.

Erst 1975 wurde eine weitere wichtige Änderung des Staatsangehörig- keitsrechts durchgefiihrt. Der italienische Corte costituzionale erklärte am 16. April 1975 (39) Art. 10 Abs. 3 L.c. für verfassungswidrig. Bis zu diesem Zeitpunkt verlor kraft dieser Bestimmung eine Italienerin, die einen Ausländer heiratete ihre Staatsangehörigkeit, falls sie durch die Eheschließung die Staatsangehörigkeit ihres Mannes erwarb. Daraufhin wurde durch Gesetz vom 19. Mai 1975 $(40)$, in den Codice civile ein Artikel 143ter eingefïgt, worin betont wurde, daß eine italienische Frau ihre Staatsangehörigkeit im Falle einer Ehe mit einem Ausländer behielt, auch wenn sie durch die Eheschlließung eine andere Staatsangehörigkeit erwirbt. Infolge des Gesetzes vom 19. Mai 1975 wurden alle Vor- 
schriften, die mit diesem Gesetz unvereinbar waren, aufgehoben. Dies traf selbstverständlich Art. 10 Abs. 3 L.c.. Im Jahre 1975 wurde weiter die Volljährigkeitsgrenze in Italien von 21 Jahren auf 18 Jahre herabgesetzt, was technische Konsequenzen für Art. 3 Abs. 2 L.c. hatte (41).

Vorauszusehen war, daß auch in Italien die Frage gestellt werden würde in wieweit die Gesetzesbestimmungen der Art. 1 und 2 L.c. (über die Staatsangehörigkeit von Kindern italienischer Eltern) und die des Art. 10 Abs. 1,2 (über die Staatsangehörigkeit der ausländischen Frau eines Italieners) (42) unter dem Gesichtspunkt der Gleichberechtigung verfassungsmäßig wären. Es war deshalb auch nicht erstaunlich, da $B$ dem Corte Costituzionale mehrere Fragen bezüglich der Verfassungsmäßigkeit dieser Artikel vorgelegt wurden. Am 24. Juni 1980 legte der Pretore di Roma dem Verfassungsgerichtshof die Frage vor, ob der ausländische Ehegatte einer Italienerin ebenso wie die ausländischen Ehepartnerin eines italienischen Mannes (43) die italienische Staatsangehörigkeit automatisch erwirbt (44). Gefragt wurde, ob Art. 10 Abs. 2 L.c. verfassungswidrig sei. Laut Urteil des Corte Costituzionale war diese Frage aber nicht zuläBig (45). Bereits am 17. Februar 1977 hatte das Tribunale di Grosseto dem Verfassungsgerichtshof eine andere Frage bezüglich der Verfassungsmäßigkeit von Art. 10 Abs. 2 L.c. vorgelegt (46). Gefragt wurde, ob der automatische Erwerb der italienischen Staatsangehörigkeit durch Eheschließung einer Ausländerin mit einem Italiener mit der Gleichberechtigung von Mann und Frau zu vereinbaren sei, da nun jene Frau die neu erworbene Staatsangehörigkeit nicht ausschlagen kann. Durch Beschluß vom 31. Dezember 1982, nr. 258 erklärte der Corte Costituzionale diese Frage für zulässig (47).

Auf die Verfassungmäßigkeit der Art. 1 und 2 L.c. bezogen sich die Fragen von vier weiteren gerichtlichen Instanzen, nämlich Fragen des Tribunale per i minorenni di Firenze vom 23. Januar 1978 (48), des Tribunale per i minorenni di Milano vom 3. Oktober 1980 (49), des Tribunale di Milano vom 18. Februar 1981 (50) und der Pretura di Genova vom 28. Juni 1982 (51). Anläßlich der von den ersten drei Gerichten vorgelegten Fragen entschied der Corte Costituzionale am 9. Februar 1983, daß die Art. 1 Ziffer 1 und 2 und 2 Abs. 2 L.c. verfassungswidrig sind (52).

Bereits vor dem Urteil des Corte Costituzionale hatte der italienische Gesetzgeber den Entwurf eines Gesetzes in Angriff genommen, um die Gleichberechtigung im Staatsangehörigkeitsrecht zu realisieren (53). Mit Gesetz vom 21. April 1983, nr. 123 wurde deshalb das Staatsangehörigkeitsrecht Italiens geändert (54). Die Änderung trat am 27. April 1983 in Kraft (55). Ein Artikel des neuen Gesetzes (Art. 5) ist dem Erwerb der italienischen Staatsangehörigkeit kraft Geburt gewidmet, die übrigen Artikell betreffen die staatsangehörigkeitsrechtliche Position des ausländischen Ehepartners eines italienischen Bürgers. Dieses Gesetz vom 21. April 1983 war nicht als Änderungsgesetz zum L.c. formuliert, sondern als selbständiges Gesetz. Art. 8 des Gesetzes bestimmte, daß alle diesem Gesetz entgegenstehenden Bestimmungen aufgehoben werden. Dies traf selbstverständlich viele bis dann geltende Bestimmungen des Staatsangehörigkeitsgesetzes aus 1912. Diese Methodik der allgemeinen Aufhebung entgegenstehender Bestimmungen, ohne diese Bestimmungen einzeln zu nennen, erleichtert nicht die Übersichtlichkeit des heutigen italienischen Staatsangehörigkeitsrechts. Bei jeder Regelung des Staatsangehörigkeitsgesetzes aus $1912 \mathrm{muB}$ einzeln überprüft werden, ob sie mit dem Gesetz aus $1983 \mathrm{zu}$ vereinbaren ist. Das 
Gesetz vom 21. April 1983 hat noch nicht alle Fragen bezüglich der ungleichen Behandlung von Mann und Frau im Staatsangehörigkeitsrecht befriedigend gelöst. Art. 20 Codice civile bestimmt, daB bei ehelichen Kindern die Beziehung zwischen Eltern und Kindern vom Heimatrecht des Vaters geregelt wird. Diese Bestimmung kanu auch Konsequenzen für das Staatsangehörigkeitsrecht haben und dürfte verfassungswidrig sein. Dennoch wird sie im Moment noch angewandt (56).

Momentan wird in Italien an einem neuen Staatsangehörigkeitsgesetz gearbeitet (57). Dies geht hervor aus einem Gesetz vom 15. Mai 1986, Nr. 180 (58), worin geregelt wird, daß die Frist von Art. 5 Abs. 2 des Gesetzes vom 21. April 1983 verlängert wird bis ein neues Gesetz bezüglich der italienischen Staatsangehörigkeit in Kraft tritt (59).

\subsubsection{Erwerb der Staatsangehörigkeit durch Geburt}

\subsubsection{Rüickblick}

Bis zu der Entscheidung des Corte Costitutionale vom 28. Januar 1983 galt in Italien grundsätzlich ius sanguinis a patre mit einigen Ausnahmen zugunsten des ius sanguinis a matre und ius soli. Das ius sanguinis a patre war bereits in Art. 4 C.c.it. verkörpert. Dies galt für eheliche Kinder und für nichteheliche Kinder, falls sie vom Vater anerkannt waren oder die väterliche Abstammung gerichtlich festgestellt wurde (60). Das nichteheliche Kind einer italienischen Mutter erwarb die italienische Staatsangehörigkeit, wenn das Kind weder von einem Manne anerkannt war, noch die Vaterschaft durch gerichtliche Feststellung feststand (Art. 7 C.c.it.). Weiteres Erfordernis für den Erwerb der Staatsangehörigkeit war jedoch auch, daß entweder die Mutter ihr Kind anerkannt hatte oder die Mutterschaft gerichtlich festgestellt wurde (61). Die Staatsangehörigkeit wurde iure sanguinis auch bei Geburt im Ausland erworben. Im Staatsangehörigkeitsgesetz von 1912 wurde die mütterliche Abstammung etwas wichtiger: Eheliche Kinder erwarben zwar grundsätzlich die Staatsangehörigkeit des Vaters, wenn dieser Italiener war (Art. 1 Abs. 1 Ziffer 1 L.c.). Sic erhielten die italienische Staatsangehörigkeit der Mutter, wenn sie nicht die Staatsangehörigkeit des Vaters erwarben (Art. 1 Abs.1 Ziffer 2 L.c.). Nichteheliche Kinder erwarben auch wieder unter der Voraussetzung der Anerkennung bzw. Vaterschaftsfeststellung die italienische Staatsangehörigkeit des Vaters (Art. 1 Abs. 1 Ziffer 1 L.c.). Die italienische Staatsangehörigkeit der Mutter war erheblich, wenn ausschließlich diese das Kind anerkannt hatte, bzw. nur die Mutterschaft gerichtlich festgelegt war, oder aber das Kind von seinem Vater keine Staatsangehörigkeit herleiten konnte (Art. 1 Abs. 1 Ziffer 2 L.c.) (62). Erst 1983 wurde dies geändert. In der neuen Regelung ist vor allem die Haltung des italienischen Gesetzgebers Doppelstaatlern gegenuiber auch aus historischer Perspektive bemerkenswert. Diese Haltung ist sehr streng: Nach ihrer Volljährigkeit müssen diese wählen, zu welchem Staat sie gehören wollen. Dies ist eine erhebliche Änderung gegenüber der früheren Praxis. So schrieben Doemer/Hecker (63) noch 1967:

"Die mehrfache Staatsangehörigkeit einer Person wird vom italienischen Gesetzgeber grundsätzlich als Faktum hingenommen und nach Art. 7 StAG berüicksichtigt. Artikel 7 bestimmt nämlich, daß der im Ausland geborene Italiener, der nach jus sanguinis die italienische, nach ius soli, eine fremde Staatsangehörigkeit besitzt - der häufigste Fall doppelter 
Staatsangehörigkeit - von Italien als Italiener beansprucht wird, sofern er nicht nach Volljährigkeit darauf verzichtet. Italien läßt hier also dem Doppelstaatler die freie Entscheidung, welche Staatsangehörigkeit er endgültig besitzen will. Aber auch, wenn der Betreffende nicht auf die italienische Staatsangehörigkeit verzichtet, bleibt er Doppelstaater".

Die ius soli-Elemente waren im italienischen Staatsangehörigkeitsrecht in der Vergangenheit stärker als heute: Bereits in dem C.c.it. 1865 gab es eine ius soli-Bestimmung zugunsten von in Italien geborenen Kindem unbekannter Eltern (64). Eine ius soli-Regelung zugunsten von in Italien geborenen potentiell staatenlosen Kinder wurde 1912 eingeführt (65). Wichtig ist, darauf hinzuweisen, daB diese Bestimmung nicht nur relevant war für Findelkinder, sondern auch für jene Kinder, die weder vom Vater noch von der Mutter anerkannt wurden (66). 1865 gab es aber noch andere interessante ius solli-Bestimmungen. Das in Italien geborene und wohnhafte Kind eines ehemaligen Italieners erwarb nach Art. 5 Abs. 1 C.c.it. die italienische Staatsangehörigkeit. Dieser Erwerb ist allerdings eine gewisse Mischung zwischen ius soli und einem latenten ius sanguinis. Reines ius soli wurde aber von Art. 8 Abs.1 manifestiert, kraft dessen das in Italien geborene Kind eines dort bereits mindestens zehn Jahren wohnhaften Vaters antomatisch italienischer Staatsbürger wurde. Ein solches Kind konnte die italienische Staatsangehörigkeit aber innerhalb eines Jahres nach Erreichung der Volljärigkeit wieder ausschlagen. Die übrigen in Italien geborenen Ausländerkinder hatten ein Optionsrecht auf die Staatsangehörigkeit Italiens (Art. 8 Abs. 3 i.V.m. Art. 6 Abs. 2 und 3 C.c.it). Ein Optionsrecht auf die italienische Staatsangehörigkeit hatten ebenfalls die im Ausland geborenen Kinder ehemals italienischer Eltern (Art. 6 Abs. 1 C.c.it.). Die betreffenden Personen konnten innerhalb eines Jahres nach Vollendung der Volljährigkeit (67) von diesem Optionsrecht Gebrauch machen, wobei sie ihren Wohnsitz in Italien nehmen muBten (art. 6 Abs. 2 C.c.it.). Nach Art. 6 Abs. 3 C.c.it. wurden diese Personen auch automatisch Italiener, wenn sie in Italien ein öffentliches Amt antraten oder die Wehrpflicht erfüllten. Im letzteren Falle galt keine Frist und es wurde von dem Erfordlemis eines Wohnsitzes in Italien abgesehen.

\subsubsection{Heutige Regelung}

Nach Art. 5 Abs. 1 des Gesetzes vom 21. April 1983 ist das eheliche Kind eines italienischen Vaters oder einer italienischen Mutter italienisch. Dies gilt auch für legitimierte Kinder (68). Es gilt also ein ius sanguinis a patre et a matre. Es ist nicht relevant, ob die Geburt im Inland oder im Ausland stattgefunden hat. Falls ein Kind Doppelstaatler ist, muß es sich innerhalb eines Jahres nach seiner Volljährigkeit (69) fürr eine seiner Staatsangehörigkeiten entscheiden (Art. 5 Abs. 2) (70).

Nichteheliche Kinder erwerben aufgrund des Art. 5 Abs. 1 des Gesetzes vom 21. April 1983 jedenfalls die Staatsangehörigkeit der italienischen Mutter. Die Mutter muß das Kind aber anerkannt haben oder die Mutterschaft muß anderweitig rechtlich feststehen. Dazu reicht bereits das Einverständnis der Mutter aus, daß die Geburt beim Standesamt gemeldet wird (71). Vom nichtehelichen Vater können Kinder auch die italienische Staatsangehörigkeit herleiten. In dem Falle muß aber wohl Art. 2 des Gesetzes vom 13. Juni 1912 berücksichtigt werden, kraft dessen dafür Anerkennung oder gerichtliche Feststellung der Vater- 
schaft notwendig ist. Auch wenn die Feststeliung der Vaterschaft nicht zulässig ist, die Abstammung jedoch aufgrund einer Verurteilung zur Zahlung von Lebensunterhalt feststeht, wird die italienische Staatsangehörigkeit erworben (72). Die Anerkennung, beziehungsweise die Feststellung der Vaterschaft haben keine staatsangehörigkeitsrechtlichen Folgen, wenn das Kind in dem Moment bereits volljährig ist. Ein solches Kind hat dann aber während eines Jahres nach Anerkennung oder Feststellung der Vaterschaft ein Optionsrecht auf die italienische Staatsangehörigkeit (Art. 2 Abs. 3 L.c.) (73). Auch durch Adoption wird die italienische Staatsangehörigkeit erworben. Dies geht aus Art. 5 des Gesetzes Nr. 123 vom 21. April 1983 und auch aus Art. 39 des Gesetzes Nr. 184 vom 4. Mai 1983 hervor (74). Iure soli erwerben die italienische Staatsangehörigkeit in Italien aufgefundene Kinder (Art. 1 Abs. 3 L.c.) und in Italien geborene Kinder, die sonst staatenlos sein würden (Art. 1 Abs. 3 L.c.) (75). Andere in Italien geborene Ausländer erwerben unter bestimmten Voraussetzungen am 18. Geburtstag die italienische Staatsangehörigkeit. Entsprechendes gilt für diejenigen, deren Vater oder Mutter oder Großvater väterlicherseits durch Geburt Italiener waren (76).

\subsubsection{Erwerb der Staatsangehörigkeit nach der Geburt}

\subsubsection{Rückblick}

Der C.c.it. 1865 (Art. 10) unterschied eine kleine und eine große Einbürgerung; jene erfolgte durch Dekret, diese durch Gesetz. Ab 1901 konnte die große Einbürgerung einigen Gruppen von Personen auch durch Ministerialdekret verliehen werden. Seit 1906 konnten sämtliche Ausländer durch Königliches Dekret eingebürgert werden, falls sie bestimmte Voraussetzungen erfülllten. Sie muBten entweder
a. sechs Jahre in Italien oder seinen Kolonien gelebt haben oder
b. dem italienischen Staat vier Jahre gedient haben oder
c. lediglich drei Jahre in Italien gelebt, aber eine Italienerin geheiratet oder für Italien hervorragende Dienste geleistet haben.

Der Unterschied zwischen großer und kleiner Einbürgerung verschwand im Jahre 1912 durch Einfiihrung des Staatsangehörigkeitsgesetzes. Lediglich $1922 \mathrm{gab}$ es vorïbergehend aufgrund eines Dekretgesetzes wieder kleine Einbüirgerungen für im Ausland lebende Personen mit besonderen Bindungen zu Italien (77). Die Einbürgerungsvoraussetzungen waren im L.c. i.d.F. 1912 ähnlich, wie die im Gesetz von 1906 für die großen Einbürgerung durch Königliches Dekret gefordert wurden. Unterschiede betrafen hauptsächlich die geforderten Fristen, die etwas heruntergesetzt wurden. 1934 wurden diese Fristen ein zweites Mal heruntergesetzt. Gefordert wurden nunmehr a) fünfjähriger Wohnsitz, b) drei Jahre im italienischen Dienst oder c) dreijähriger (seit 1934: zweijähriger) Wohnsitz in Italien und Ehe mit einer Italienerin oder beachtliche Dienste für Italien. Seit 1913 genügten für Personen, die die italienische Staatsangehörigkeit durch Option bä̈tten erwerben können, aber diese Möglichkeit aus irgendwelchem Grunde nicht benutzt hatten; ein einjähriger (seit 1934 sogar: sechsmonatiger) Wohnsitz in Italien. Art. 4 Abs. 2 L.c. ermöglichte die Einbürgerung ohne Beachtung dieser Voraussetzungen (78). Bis 1934 kannte der L.c. noch eine Art von Ehreneinbürgerung durch Gesetz im Falle außergewöhnlicher Dienste. 
Bis 1983 erwarb die Ausländerin, die einen Italiener heiratete von Rechts wegen (iure communicationis) die talienische Staatsangehörigkeit (Art. 9 C.c.it; Art. $10 \mathrm{~L}$.c.).

\subsubsection{Heutige Regelung}

Die Voraussetzungen für eine Einbürgerung werden in Art. 4 L.c. 1912 (in der Fassung von 4. April 1935) formuliert. Die italienische Staatsangehörigkeit wird verliehen durch Dekret des Präsidenten, gefoigt durch einen Treueeid des Betroffenen (Art. 5 L.c.) (79). Für die Einbürgerung wird eine Giebiihr von 41.000 Liren verlangt (80). Grundsätzlich ist ein fünfjähriger Aufenthalt in Italien eine Voraussetzung für die Einbürgerung. Für Ausländer, die für Italien wichtige Dienste geleistet haben, ist ein Aufenthalt von zwei Jahren ausreichend. Eine Aufenthaltsfrist von sechs Monaten reicht aus für Ausländer, die kraft Gesetz für die italienische Staatsangehörigkeit hätten optieren können, aber dies unterlassen haben. Weiter können Ausländer, die (im Ausland) bereits drei Jahre im Dienste des italienischen Staates stehen, eingebürgert werden. Ausnahmsweise und aufgrund besonderer Umstände kann die italienische Regienung ihre Staatsangehörigkeit Personen verleihen, die die eben erwähnten Voraussetzungen nicht erfüllen (Art. 4 Abs. 2 L.c.). Verzicht auf die bisherige Staatsangehörigkeit ist keine ausdruickliche Eunbürgerungsvoraussetzung (81).

Mehrere Gruppen von Personen haben ein Optionsrecht auf die italienische Staatsangehörigkeit. Erstens sind das die in $\$ 2.5 .2 .2$ bereits erwähnten Personen, die während ihrer Volljährigkeit von einem italienischen Vater oder von einer italienischen Mutter anerkannt wurden oder deren italienische Abstammung gerichtlich festgestellt wurde (Art. 2 Abs. 3 L.c.): Innerhalb eines Jahres nach Anerkennung oder Feststellung der Abstammung ist eine Option möglich. Diejenigen, die in Italien geboren sind, oder außerhalb Italiens geboren wurden als Kind von Eltern, die zur Zeit der Geburt bereits mehr als zehn Jahre in Italien lebten, oder abstammen von einem Vater, Mutter oder Großvater väterlicherseits, der (die) durch Geburt italienisch war, können die italienische Staatsangehörigkeit durch eine innerhalb eines Jahres nach Vollendung des 18. Lebensjahres (82) abzugebene Optionserklärung erwerben, unter der Voraussetzung, daß sie in Italien ansässig sind (Art. 3 Ziffer 2 L.c.). Sind die betreffenden Personen in dem Moment schon mehr als zehn Jahre in Italien wohnhaft, dann erwerben sie die italienische Staatsangehörigkeit sogar von Rechts wegen, es sei denn, sie erklären innerhalb eimes Jahres nach Vollendung des 18. Lebensjahres ihre ausländische Staatsangehörigkeit beibehalten zu wollen (Art. 3 Ziffer 3 L.c.). Die gleichen Personen erwerben die italienische Staatsangehörigkeit automatisch, wenn sie in den italienischen Militär-oder Staatsdienst eintreten (Art. 3 Ziffer 1 L...c.).

Eine besondere Position nehmen diejenigen ein, die die italienische Staatsangehörigkeit besaßen, aber diese infolge der Bestimmungen der Art; 7 und 8 L.c. verloren haben. Im Falle von geleistetem italienischen Staats- oder Militärdienst werden diese Personen automatisch wieder italienisch (Art. 9 Ziffer 1 L.C.). Auch Niederlassung in Italien (83) kann unter bestimmten Voraussetzungen Wiedererwerb der Staatsangehörigkeit begründen (Art. 9 Ziffer 2 und 3 L.c.), die italienische Regienung kann sich in diesen Fällen aber unter Berufung auf wichtige Griinde dem Erwerb widersetzen. 
Die staatsangehörigkeitsrechtliche Lage des ausländischen Ehegatten eines Italieners ist im Gesetz vom 21. April 1983 in verwickelter Weise neu formuliert. In Art. 1 jenes Gesetzes wird festgestellt, daß der ausländische Ehegatte eines Italieners die italienische Staatsangehörigkeit erwirbt, falls er mindestens sechs Monate in Italien lebt oder - bei Auslandswohnsitz - drei Jahre nach der Eheschließung, unter der Voraussetzung daß keine Auflösung (84), Nichtigerklärung (85) oder Aufhebung der zivilen Wirkungen der Ehe (86) erfolgt ist und keine gerichtliche Trennung (87) besteht.

Der Erwerb der italienischen Staatsangehörigkeit geschieht in diesem Falle aber nicht automatisch. Erstens werden von Art. 2 des Gesetzes einige Gruppen von Personen vom Erwerb der italienischen Staatsangehörigkeit ausgeschlossen, nämlich diejenigen, die wegen bestimmter politischer Delikte (88) verurteilt sind (Abs. 1), diejenigen, die von italienischen Gerichten wegen eines unpolitischen Vergehens zu einer Freiheitsstrafe von mehr als zwei Jahren verurteilt wurden (Abs. 2); und diejenigen gegen die im Einzelfall erwiesene Grïnde vorliegen, die die Sicherheit der Republik betreffen (Abs. 3). Außerdem geht weiter aus Art. 3 Abs. 1 des Gesetzes hervor, daß die Staatsangehörigkeit nur auf Antrag erworben wird. Dieser Antrag muß beim Bürgermeister des Wohnortes oder bei der zuständigen konsularischen Behörde gestellt werden. Die Staatsangehörigkeit wird durch Dekret des Präsidenten der Republik auf Vorschlag des Innenministers erworben. Überraschend ist in diesem Zusammenhang die Bestimmung des Art. 3 Abs. 2, woraus hervorgeht, daB auch der italienische Ehepartner den Antrag stellen kann. In dem Falle wird der gestellte Antrag dem ausländischen Partner mitgeteilt (89), der dann innerhalb von dreißig Tagen erklären kann, die italienische Staatsangehörigkeit nicht erwerben zu wollen.. Eine solche Erklärung schließt den Erlaß eines präsidialen Dekrets aus. In diesem Zusammenhang muß die Frage gestellt werden, was geschieht, wenn der ausländische Ehegatte aus irgendwelchen Grunden nicht rechtzeitig reagiert. Wird er dann - u.U. gegen seinen Willen - eingebürgert? Dies muß wohl verneint werden. Art. 3 muß in Zusammenhang mit Art. 5 L.c. gelesen werden, kraft dessen das Verleihungsdekret des Präsidenten ohne Wirkung bleibt, wenn die Person, der die Staatsangehörigkeit verliehen wird, nicht einen Treueeid leistet (90). In dem Falle der Ablehnung eines von einem ausländischen Ehegatten gestellten Einbürgenungsantrages aus Gründen der Staatssicherheit, kann nach fünf Jahren ein neuer Antrag gestellt werden (Art. 4 Abs. 1). Weiter bestimmt Art. 4 Abs. 2, daß ein Antrag ein Jahr nach dessen Einreichung nicht mehr abgelehnt werden kann. Als Übergangsbestimmung verlängert Art. 6 diese Frist jedoch für die ersten drei Jahre nach Einführung des Gesetzes auf zwei Jahre. Anläßlich der Formulierung von Art. 1 des Gesetzes vom 21. April 1983 ist die Frage gestellt worden, ob der in Italien lebende Ehepartner eines Italieners erst sechs Monate nach Eheschliessung den Antrag gemäß Art. 3 stellen kann oder ob für die Berechnung der Frist von sechs Monaten auch bereits die vor der Eheschließung in Itallien verbrachten Monate mitzählen. Das italienische Innenministerium stellt sich auf den Standpunkt, daß seit der Eheschließung sechs Monate vergangen sein müssen (91). Gemäß Art. 12 L.c. erwerben minderjährige, nicht volljährig erklärte Kinder einer Person, die die italienische Staatsangehörigkeit erwirbt, diese ebenfalls, es sei denn, sie leben im Ausland und behalten ihre ausländische Staatsangehörigkeit. 


\subsubsection{Verlustgründe}

\subsubsection{Rückblick}

Die heutigen Verlustbestimmungen fanden sich größtenteils auch bereits in dem C.c.it. 1865. Nur Details waren unterschiedlich. Die Staatsangehörigkeit konnte 1865 durch Abstandserklärung und Verlegung des Aufenthalts ins Ausland verloren werden (Art. 11 Ziffer Il C.c.it.), 1912 wurde für Verzicht Doppelstaatlichkeit gefordert und grundsätzlich Auslandsaufenthalt (vgl. aber auch die Verzichtsmöglichkeiten der Art. 5 Abs. 2, 8 Abs. 2 und 10 Abs. 4 L.c.). Freiwilliger Erwerb einer anderen Staatsangehörigkeit führte ebenfalls zum Verlust der italienischen Staatsangehörigkeit (Art. 11 Ziffer 2 C.c.it.); seit 1912 wurde auch hierbei Auslandsaufenthalt gefordert. Bis zur Entscheidung des Corte Costituzionale vom 16. April 1975 wurde die italienische Staatsangehörigkeit von der Italienerin, die einen Ausländer heiratete, verloren (Art. 14 Abs. 1 C.c.it.; Art. 10 Abs. 3 L.c.). Interessanterweise war dieser Verlustgrund bereits seit 1865 dermaßen klausuliert, daß kein Verlust eintrat, wenn die Frau aus irgendwelchem Grund nicht die Staatsangehörigkeit ihres ausländischen Ehepartners erwarb.

Art. 11 Ziffer 3 C.c.it. bestimmte, daß ausländischer Staats- oder Militärdienst ohne Erlaubnis der italienischen Regierung Verlust der italienischen Staatsangehörigkeit bewirkte. In 1912 formulierte Art. 8 Ziffer 3 eine Nuance anders: Die Staatsangehörigkeit wurde verloren, wenn der Betreffende trotz Aufforderung der italienischen Regierung, die Anstellung oder den Dienst innerhalb einer bestimmten Frist aufzugeben, darin verbleibt. Gemäß der Regelung von 1865 erstreckte der Verlust der Staatsangehörigkeit sich auf Ehefrau und minderjährige Kinder, es sei denn, diese blieben in Italien (Art. 11 Abs. 2 C.c.it.). Auch im L.c. 1912 erstreckte der Verlust sich grundsätzlich auf diese Personen. Die Art. 11 und 12 Abs. 2 und 3 L.c. formulierten aber einige Ausnalhmen.

Verlust durch Legitimation oder Anerkennung eines nichtehelichen italienischen Kindes durch einen ausländischen Mann wurde im italienischen Gesetz nicht ausdrüicklich als Verlustgrund erwähnt. Dennoch muß wohl ein derartiger Verlust jedenfalls bis 1985 angenommen werden (92). Die Möglichkeit der Aberkennung der Staatsangehörigkeit gab es aufgrund der Dekrete vom 18. Januar 1918 (Aufhebung von Einbürgerungen von ehemaligen Angehörigen feindlicher Staaten), vom 10. Januar 1926 (Wiederausbürgerung unwürdiger Optanten) und vom 31. Januar 1926 (Aberkennung wegen anti-italienischer Aktivitäten im Ausland) (93). Seit Inkrafttreten der Verfassung von 1947 ist eine Aberkennung der Staatsangehörigkeit aus politischen Griinden verfassungswidrig.

\subsubsection{Heutige Regelung}

Die italienische Staatsangehörigkeit wird durch freiwilligen Erwerb einer ausländischen Staatsangehörigkeit, unter der Voraussetzung, daß3 der Betreffende im Ausland lebt oder sich dort niederläBt, verloren (Art. 8 Ziffer 1 L.c. 1912) (94). Doppelstaatler können auf die italienische Staatsangehörigkeit verzichten, unter der Voraussetzung, daß sie im Ausland leben oder sich dort niederlassen (Art. 8 Ziffer 2 L.c., vgl. ebenfalls Art. 2 Abs 3 und Art. 7 L.c.). Die italienische Regierung kann aber in beiden Fällen von der Bedingung der Verlegung des Aufenthaltes ins Ausland befreien. Durch fremden Staats- oder Wehrdienst wird 
die italienische Staatsangehörigkeit erst verloren, wenn einer Aufforderung der italienischen Regierung, jenen Dienst aufzugeben, nicht innerhalb einer bestimmten Frist gefolgt wird (art. 8 Ziffer 3 L.c.) (95).

Durch ununterbrochenen Auslandswohnsitz wird die italienische Staatsangehörigkeit nicht verloren. Art. 7 L.c. 1912 stellt dies ausdrücklich fest. Durch Gesetz vom 31. Januar 1926 wurde ein noch immer geltender zusätzlicher Verlustgrund eingeführt. Ein Staatsangehöriger, der im Ausland eine Handlung begeht oder daran teilnimmt, welche die italienischen Interessen schädigen oder den guten Namen oder das Ansehen Italiens beeinträchtigen kann, verliert die italienische Staatsangehörigkeit auch wenn diese Tat keine strafbare Handlung darstellt. Der Verlust der Staatsangehörigkeit wird in dem Falle durch Dekret ausgesprochen. Seit 1947 kann ein solcher Verlust jedoch nicht mehr aus politischen Gründen ausgesprochen werden; eine Anwendung dieses Gesetzes aus anderen Gründen wäre theoretisch denkbar.

Ein neuer Verlustgrund wurde durch Gesetz Nr. 123 vom 21. April 1983 introduziert. Art. 5 dieses Gesetzen verpflichtet italienisch/ausländische Doppelstaatler innerhalb eines Jahres nach Erlangung der Volljährigkeit für eine einzige Staatsangehörigkeit zu optieren (96). Das Gesetz bestimmt aber nicht genau, auf welche Art dies geschehen soll. Eine logische Konsequenz aber ist, daß die italienische Staatsangehörigkeit verloren wird, wenn der Betreffende seine andere Staatsangehörigkeit wählt (97). Falls er aber die italienische Staatsangehörigkeit wählt, wird dadurch die fremde Staatsangehörigkeit nicht verloren (98), denn Italien kann nicht über den Verlust einer fremden Staatsangehörigkeit entscheiden. Dazu ist ausschließlich der betreffende fremde Staat zuständig. Bemerkenswert ist weiter, daß Art. 5 Abs. 2 keine Sanktion fuir den Fall beinhaltet, daß ein Doppelstaatler es unterläßt, in der ihm gegebenen Frist zwischen seinen Staatsangehörigkeiten zu wählen. Behält er in diesem Fall seine beiden Staatsangehörigkeiten oder verliert er die italienische? Ein Rundschreiben des Innenministeriums vom 19. März 1984 (99) betont, daß das Unterlassen einer Option Verlust der italienischen Staatsangehörigkeit verursacht. Diese Sanktion stößt in der Literatur aber auf Ablehnung (100).

Die Erstreckung des Verlusts der italienischen Staatsangehörigkeit auf minderjährige Kinder wird grundsätzlich in Art. 12 Abs. 2 L.c. geregelt. Da aber Art. 8 des Gesetzes 123 vom 21. April 1983 alle ältere Gesetzesbestimmungen aufhebt, die dem Gesetz 123 widersprechen, kann Art. 12 Abs. 2 L.c. nicht ohne weiteres angewandt werden. Gemäß einem Rundschreiben des Innenministeriums vom 19. März 1984 kann die Regelung der Erstreckung des Verlustes wohl wie folgt zusammengefaßt werden (101). Wenn beide Eltern die italienische Staatsangehörigkeit verlieren, verliert auch ein minderjähriges Kind diese, falls es die neue Staatsangehörigkeit seiner Eltern erwirbt. Das gleiche gilt, wenn der Eltemteil, von dem das Kind seine italienische Staatsangehörigkeit herleitet, diese Staatsangehörigkeit verliert. Wenn lediglich ein Elternteil die italienische Staatsangehörigkeit verliert, bleibt das minderjährige Kind Italiener; falls es dadurch Doppelstaatler wird, muB es infolge Art. 5 Abs. 2 Gesetzes 123 zwischen seinen Staatsangehörigkeiten wählen. 


\subsection{NIEDERLANDE}

\subsubsection{Allgemeine Bemerkungen}

Die allgemeinen Bestimmungen des niederländischen Staatsangehörigkeitsrechts finden sich seit dem 1. Januar 1985 im "Rijkswet op het Nederlanderschap" (Reichsgesetz über die niederländische Staatsangehörigkeit vom 18. Dezember 1984, Stbl. 628, im folgenden jeweils abgekürzt als RwNed) (1). Bis dahin galt der "Wet op het Nederlanderschap en het ingezetenenschap" (Gesetz uber die niederländische Staatsangehörigkeit und die Einwohnerschaft; im folgenden jeweils abgekürzt als WNed) vom 12. Dezember 1892, Stbl. 268, in Kraft getreten am 1. Juli 1893 (2).

Vor Inkrafttreten des WNed war die staatsangehörigkeitsrechtliche Lage in den Niederlanden sehr kompliziert. Ubberhaupt kann erst seit etwa 1800 von einer niederländischen Staatsangehörigkeit gesprochen werden. Nach französischem Vorbild wurde die Staatsangehörigkeit ursprünglich im Zivilgesetzbuch geregelt (3). Die ersten Bestimmungen fanden sich in den Art. 8-18 des "Wetboek Napoléon, ingerigt voor het Koningrijk Holland" (Gesetzbuch Napoléon für das Königreich Holland) aus dem Jahre 1809 (4). Dieses Gesetzbuch galt bis zur Einverleibung des Landes durch Frankreich im Jahre 1811 (5). Ab 1811 galt der Code Civil, in dem das Staatsangehörigkeitsrecht in den Art. 9, 10, 12, 17 und 21 geregelt wurde (6). Auch nachdem die Niederlande 1815 ein unabhängiges Königreich geworden waren, galt der Code Civil weiter bis zum Jahre 1838 (7).

Gleich nach der neu erworbenen Unabhängigkeit wurde ein Ausschuß damit beauftragt, neue Gesetzbücher zu entwerfen. Als das fertige Zivilgesetzbuch am 1. Februar 1831 eingeführt werden sollte, wurde dessen Inkrafttreten jedoch wegen des belgischen Aufstandes aufgeschoben (8). Erst nach einer neuen Bearbeitung wurde das niederländische Zivilgesetzbuch (Burgerlijk Wetboek) am 1. Oktober 1838 eingeführt (9). Im Zivilgesetzbuch von 1838 bezogen sich die Art. 5-12 auf die Staatsangehörigkeit. Die Regelung des Staatsangehörigkeitsrechts im Zivilgesetzbuch galt allerdings grundsätzlich nur in zivilrechtlichen Angelegenheiten. Durch Gesetz vom 28. Juli 1850 wurde eine Staatsangehörigkeitsregelung für öffentlichrechtliche Angelegenheiten eingeführt (10). In dieser Zeit galten in den Niederlanden deshalb zwei "sachlich beschränkte" Staatsangehörigkeitsregelungen (11). Diese beiden Staatsangehörigkeitsregelungen waren in Einzelpunkten machmal unterschiedlich, beide gingen jedoch grundsätzlich von ius soli-Prinzipien aus (12). Die verheiratete Frau hatte im Staatsangehörigkeitsrecht jener Zeit keine selbständige Position: ihre niederländische Staatsangehörigkeit war davon abhängig, daß ihr Ehemann Niederländer war. Es gelt also ein streng durchgeführtes "système unitaire" (13).

Die beiden sachlich beschränkten Staatsangehörigkeitsregelungen wurden von dem bereits erwähnten Staatsangehörigkeitsgesetz von 1892 (WNed) abgelöst. Anders als die vorherigen Regelungen ging das Staatsangehörigkeitsgesetz von 1892 grundsätzlich (14) vom ius sanguinis-Prinzip aus und zwar vom ius sanguinis a patre: Ein Kind erwarb die niederländische Staatsangehörigkeit, falls sein Vater diese innehatte. Nur für nichteheliche Kinder galt ein ius sanguinis a matre. Allerdings wurden später durch Änderungsgesetze wieder stärkere ius 
soli-Elemente eingefuihrt und zwar mit Rückwirkung bis zum 1. Juli 1893 (15). Die verheiratete Frau hatte auch im Gesetz von 1892 eine von der ihres Ehegatten abhängige Staatsangehörigkeit.

Im Rahmen dieser allgemeinen Bemerkungen ist es nicht zweckmäßig, alle Gesetze, die den WNed geändert haben, zu besprechen (16). Insgesamt wurde der WNed 17 mal abgeändert. Nur zwei unbedeutende Artikel hatten letzten Endes noch die ursprüngliche Fassung von 1892 (Artikel 4 und 16). Einige wichtige Änderungen sollen hier jedoch noch ausdrücklich erwähnt werden.

Am 21. Dezember 1936 wurde die Ratifikation des Haager Abkommens vom 12. April 1930 über gewisse Fragen beim Konflikt von Staatsangehörigkeitsfragen (17), so wie des Haager Protokolls vom 12. April 1930 über Militärdienst in gewissen Fällen doppelter Staatsangehörigkeit und des Haager Protokolls vom 12. April 1930, das einen bestimmten Fall von Staatenlosigkeit betrifft, genehmigt. In Zusammenhang damit wurde der WNed durch Gesetz vom 21. Dezember 1936, Stb1. 209, am 1. Juli 1937 in Kraft getreten, geändert. Eingefügt wurde ein Artikel 2 Buchstabe c, worin bestimmt wurde, daß ein in den Niederlanden geborenes Kind einer niederländischen Mutter und eines staatenlosen Vaters die niederländische Staatsangehörigkeit kraft Geburt erwirbt (18). Im Art. 3 Absatz 4 Ziffer 2 wurde die Möglichkeit eröffnet, daB ein in den Niederlanden geborenes staatenloses Kind ohne Rücksicht darauf, wie lange es schon in den Niederlanden wohnhaft war, eingebürgert werden konnte. Bis 1936 verlor eine niederländische Frau durch Heirat mit einem nicht-niederländischen Mann immer die niederländische Staatsangehörigkeit. Durch Änderung des Art. 5 des WNed wurde 1936 bewirkt, daß die niederländische Frau ihre Staatsangehörigkeit behielt, falls sie sonst staatenlos werden würde. Die Änderungen von 1936 wirkten bis zum 1. Juli 1893 zurück.

Am 27. Dezember 1949 wurde die Hoheit über Niederländisch-Indien übertragen (Gesetz vom 21. Dezember 1949, Stbl. J 570). Dies machte eine Verteilung der Bürger zwischen dem Königreich der Niederlande und der neuen Republik Indonesien notwendig. Diese Verteilung fand durch ein am 21. Dezember 1949 geschlossenes Abkommen statt (19). Im Zusammenhang mit der Unabhängigkeit Indonesiens wurde auch der WNed geändert. Dies geschah durch Gesetz vom 21. Dezember 1951, Stbl. 593, in Kraft getreten am 29. Dezember 1951 mit Rückwirkung bis zum 27. Dezember 1949. Das Gesetz von 1892 war bis zu diesem Zeitpunkt nur für das niederländische Königreich in Europa anwendbar (20). Durch das Änderungsgesetz wurde die Wirkung des Gesetzes auf Surinam und die Niederländischen Antillen ausgedehnt.

Eine weitere wichtige Änderung des Staatsangehörigkeitsgesetzes wurde durch Gesetz vom 15. Mai 1953, Stbl. 233, in Kraft getreten am 27. Mai 1953, vorgenommen. Im Art. 2 Buchstabe a wurde bestimmt, daß das Kind eines im Zeitpunkt der Geburt des Kindes in den Niederlanden, Surinam oder den Niederländischen Antillen wohnhaften Vaters (21), der selbst eine im Königreich wohnhafte Mutter hat; automatisch die niederländische Staatsangehörigkeit erwarb, ohne Rücksicht darauf, ob es kraft Geburt auch noch eine andere Staatsangehörigkeit erwarb. Durch diese Änderung wurde also für die zweite in den Niederlanden geborene, oder, andlers formuliert, für die dritte in den Niederlanden lebende Generation, das ius soli (22) eingeführt. 
Durch Gesetz vom 14. November 1963, Stbl. 467, in Kraft getreten am 1. Mărz 1964, wurde die niederländische Staatsangehörigkeitsgesetzgebung im Hinblick auf die damals bevorstehende Ratifizierung des New Yorker Abkommens úber Staatsangehörigkeit der Ehefrau vom 29. Februar 1957 geăndert (23). War bisher die Staatsangehörigkeit der Ehefrau von der ihres Mannes abhängig, so hatte seit 1964 die niederländische Frau eine von ihrem Mann völlig unabhängige Staatsangehörigkeit (24). Dies hatte zur Folge, daß durch die Ehe mit einem Ausländer die niederländische Staatsangehörigkeit nicht mehr verloren ging. Dem stand aber gegenüber, daß die ausländische Ehegattin eines Niederländers die niederländische Staatsangehörigkeit nicht mehr automatisch erwarb. Sie hatte seit 1964 lediglich ein Optionsrecht auf diese Staatsangehörigkeit.

Mit der Unabhängigkeit von Surinam am 25. November 1975, wurde zwischen dem Königreich der Niederlande und der Republik Surinam ein Zuteilungsabkommen bezüglich der Staatsangehörigkeit ihrer Bürger geschlossen (25). Am gleichen Tag trat auch ein Gesetz zur Anderung des WNed in Kraft.

Seit Mitte der siebziger Jahre wurde in den Niederlanden darïber diskutiert, ein neues niederländisches Staatsangehörigkeitsgesetz einzuführen (26). Im Dezember 1976 veröffentlichte das Justizministerium den Referentenentwurf eines neuen Staatsangehörigkeitsgesetzes (27). Auf diesen Referentenentwurf wurde von Seiten der Lehre unterschiedlich kritisch reagiert (28). Aufgrund dieser Kritik wurde der Entwurf an einigen Stellen geändert und am 23. Juni 1981 beim niederländischen Parlament als Entwurf eines neuen niederländischen Staatsangehörigkeitsgesetzes eingereicht (Gesetzesentwurf 16947, R 1181) (29). $\mathrm{Zu}$ gleicher Zeit wurde auch ein Gesetzesentwurf 16946, R 1180 vorgelegt, worin die Ratifizierung

a) Der New Yorker Konvention vom 30. August 1961 über die Verminderung der Staatenlosigkeit (30),

b) Des Straßburger Abkommens vom 6. Mai 1963 zur Verminderung von Fällen mehrfacher Staatsangehörigkeit und betreffend Wehrpflicht bei mehrfacher Staatsangehörigkeit (31) and

c) Des Berner Abkommens vom 13. September 1973 zur Verringerung der Fälle von Staatenlosigkeit (32) vorgeschlagen wurde.

Nach ausführlichen Debatten wurde das neue niederländische Staatsangehörigkeitsgesetz am 19. Dezember 1984 verabschiedet (33). Am gleichen Tag wurde auch ein Gesetz verabschiedet, in dem die Ratifizierung der drei erwähnten Staatsangehörigkeitsabkommen genehmigt wurde (34). Es ist deshalb nicht erstaunlich, daß die Bekämpfung der Staatenlosigkeit und der Wunsch, mehrfache Staatsangehörigkeiten möglichst zu vermeiden, deutliche Schwerpunkte des neuen niederländischen Staatsangehörigkeitsrechts sind. Anders als bisher werden im neuen Gesetz Männer und Frauen gleich behandelt, d.h. die Staatsangehörigkeit einer Person kann sowohl vom Vater wie von der Mutter abgeleitet werden.

Das neue Staatsangehörigkeitsrecht trat am 1. Januar 1985 in Kraft (35). Die Ratifizierung der drei Abkommen erfolgte im Laufe des Jahres 1985 (36). Wăhrend uiber die Ratifizierung der Staatenlosigkeitsverträge Einigkeit bestand, war die Ratifizierung des Straßburger Abkommens zur Verminderung von Fällen mehrfacher Staatsangehörigkeit umstritten. Nach langem Zögern haben sïch die 
Niederlande schließlich doch zur Ratifizierung entschlossen, eine Tatsache, die zumindest in der Lehre nicht auf einhellige Begeisterung gestoßen ist (37).

Seit Inkrafttreten des neuen niederländischen Staatsangehörigkeitsgesetzes fand eine Gesetzesänderung statt. Bis zum 1. Januar 1986 bestand das Königreich der Niederlande aus zwei Ländem, dem Königreich in Europa und den aus sechs Inseln (Aruba, Bonaire, Curacao, St. Maarten, St. Eustatius und Saba) bestehenden Niederländischen Antillen. Ab 1. Januar 1986 hat nun die Insel Aruba den Status eines selbständigen Landes ("Status aparte") im Rahmen des Königreiches der Niederlande erworben. Seitdem besteht das Königreich der Niederlande aus drei Ländern, dem Königreich in Europa, den Niederländischen Antillen und Aruba. Durch Gesetz vom 12. Dezember 1985, Stb.661, wurde die Terminologie des niederländischen Staatsangehörigkeitsgesetzes dementsprechend geändert (38). Diese Änderung trat am 1. Januar 1986 in Kraft (39).

\subsubsection{Erwerb der Staatsangehörigkeit durch Geburt}

\subsubsection{Rückblick}

Im Rahmen der allgemeinen Bemerkungen wurde schon darauf hingewiesen, daß sich der Erwerb der niederländischen Staatsangehörigkeit durch Geburt im vorigen Jahrhundert (bis zum 1. Juli 1893) auf ius soli stützte. Mit Inkrafttreten des Gesetzes von 1892 vollzog sich ein grundsätzlicher Wandel zum ius sanguinis (40). Maßgebend war grundsätzlich die niederländische Staatsangehörigkeit des Vaters. Die niederländische Staatsangehörigkeit der Mutter war, gemäß Art 1 Buchstabe c WNed nur relevant im Falle eines wohl von der Mutter, aber nicht vom Vater anerkannten Kindes (41). 1936 wurde durch Art. 2 unter c dem in den Niederlanden geborenen Kind einer niederländischen Mutter und eines staatenlosen Vaters die niederländische Staatsangehörigkeit gegeben (42). Erst 1962 wurde diese Bestimmung so geändert, daß ein Kind einer niederländischen Mutter die niederländische Staatsangehörigkeit bei Geburt in den Niederlanden auch dann erwarb, wenn der Vater zwar nicht Staatenloser war, das Kind aber dennoch von ihm keine Staatsangehörigkeit herleitete (43).

Erst allmählich hat also die niederländische Staatsangehörigkeit der Mutter neben dem Falle des vom Vater nicht anerkannten, nichtehelichen Kindes- für die staatsangehörigkeitsrechtliche Position des Kindes Bedeutung bekommen. Jedoch erwarb das Kind die niederländische Staatsangehörigkeit gemäß den damaligen Ausnahmebestimmungen nicht ausschlieBlich aufgrund Abstammung von einer nicht-niederländischen Mutter. Die niederländische Staatsangehörigkeit wurde von ehelichen, legitimierten oder vom Vater anerkannten Kindern iure sanguinis a matre ausschließlich bei Geburt in den Niederlanden erworben. Nur die Kumulation von ius sanguinis a matre und ius soli konnte also unter Umständen (potentielle Staatenlosigkeit des Kindes) den Erwerb der niederländischen Staatsangehörigkeit begründen.

Die Regelung des Erwerbs der niederländischen Staatsangehörigkeit durch $\mathrm{Ge}$ burt unmittelbar vor Inkrafttreten des neuen RwNed am 1. Januar 1985 kann wie folgt zusammengefaßt werden: Ein eheliches Kind war nach Art. 1 Buchstabe a WNed Niederländer, wenn der Vater zur Zeit seiner Geburt die niederländische Staatsangehörigkeit besaß. Es war dabei unbeachtlich, ob es innerhalb 
oder außerhalb der Niederlande (44) geboren wurde. Das gleiche galt gemäß Art. 1 Buchstabe a WNed für ein während seiner Minderjährigkeit (45) legittmiertes Kind (46). Die niederländische Staatsangehörigkeit der Mutter eines ehelichen oder legitimierten Kindes war nur beachtlich im Falle von Art. 2 Buchstabe c: falls ein Kind in den Niederlanden geboren wurde, zu einer Zeit zu der die Mutter die niederländische Staatsangehörigkeit besa $B_{\text {, während es }}$ von seinem nicht-niederländischen Vater keine Staatsangehörigkeit herleitete, erwarb es die niederländische Staatsangehörigkeit der Mutter. Wenn sich allerdings während der Minderjährigkeit des Kindes herausstellte, daß es die gleiche Staatsangehörigkeit wie sein Vater besaß, verlor es die niederländische. Die niederländische Staatsangehörigkeit wurde in diesem Falle auf Grund einer Mischung (und zwar Kumulierung) von ius sanguinis und ius soli erworben (47). Das im Ausland geborene eheliche Kind einer niederländischen Mutter erwarb die niederländische Staatsangehörigkeit nicht; es konnte falls es noch keine 25 Jahre und seit seiner Geburt staatenlos war, infolge Art. 5 Buchstabe d WNed aber schneller als andere Personen eingebürgert werden (nach dreijährigem Aufenthalt in den Niederlanden, während normalerweise ein fünfjähriger Aufenthalt gefordert wurde). Das minderjährige eheliche Kind einer niederländischen Mutter konnte nach dem Tode seines Vaters oder nachdem die Ehe seiner Eltern geschieden oder nichtig erklärt war, bereits nach einjährigem Aufenthalt in den Niederlanden eingebürgert werden (Art. 5 Buchstabe e WNed) (48).

Bezüglich der iure sanguinis im Ausland erworbenen niederländischen Staatsangehörigkeit muß noch auf die Bestimmung des Art. 7 Ziffer 5 WNed hingewiesen werden. Ein solches Kind verlor die niederländische Staatsangehörigkeit, falls es nach seiner Volljährigkeit während zehn aufeinanderfolgenden Jahren im Ausland lebte, es sei denn, es lebte dort im Dienste der Niederlande. Die Staatsangehörigkeit ging nicht verloren, falls den niederländischen Behörden vor Ablauf der Frist mitgeteilt wurde, weiterhin Niederländer bleiben zu wollen; in diesem Falle fing eine neue Frist von zehn Jahren an. Falls ein eheliches Kind in den Niederlanden geboren wurde, während sein Vater dort wohnhaft war und dieser geboren wurde, während dessen Mutter in den Niederlanden ansässig war, erwarb es automatisch die niederländische Staatsangehörigkeit (Art. 2 Buchstabe a WNed), auch wenn es kraft Geburt noch eine andere Staatsangehörigkeit erwarb: eine deutliche Manifestierung eines ius domicilii. Der WNed enthielt keine Bestimmung, auf Grund der ein eheliches, potenziell staatenloses Kind durch Geburt in den Niederlanden die niederländische Staatsangehörigkeit erwarb. Ein solches Kind konnte aber schneller als andere Personen (nach dreijährigem Aufenthalt) eingebuirgert werden (Art. 5 Buchstabe a WNed). Iure soli (oder besser: praesumptione iuris sanguinis) erwarb infolge des Art. 2 Ziffer 3 WNed das in den Niederlanden aufgefundene Kind die niederländische Staatsangehörigkeit. Ein nichteheliches Kind war grundsätzlich niederländisch, wenn seine Mutter zur Zeit seiner Geburt Niederländerin war, unabhängig davon, wo das Kind geboren wurde. Bei Geburt im Ausland war Art. 7 Ziffer 5 selbstverständlich wieder von Bedeutung. Wurde das Kind während seiner Minderjährigkeit von einem Ausländer anerkannt und erwarb es dadurch eine andere Staatsangehörigkeit, dann ging dadurch die niederländische Staatsangehörigkeit verloren. Etwas anderes galt nur dann, falls das Kind in den Niederlanden geboren wurde und der betreffende Ausländer ebenfalls geboren wurde, während dessen Mutter in den Niederlanden lebte. Wurde ein nichteheliches Kind einer auslän- 
dischen Frau von einem Niederländer während seiner Minderjährigkeit (Art. 2 ter WNed) anerkannt, dann erwarb es dadurch die niederländische Staatsangehörigkeit (49).

SchlieBlich erwarb das nichtanerkannte Kind einer ausländischen Frau, die niederlǚndische Staatsangehörigkeit, wenn es in den Niederlanden geboren wurde und sonst staatenlos gewesen wäre (Art. 1 Buchstabe $\mathrm{c}$ WNed): also eine Mischung von ius soli und ius sanguinis a matre, oder vielleicht sogar eine Vermutung des Erwerbs iure sanguinis.

\subsubsection{Heutige Regelung}

Da das neue Gesetz gerade auch die Gleichberechtigung von Mann und Frau im Staatsangehörigkeitsrecht verwirklichen wollte, weicht die Regelung des Erwerbs der niederländischen Staatsangehörigkeit durch Geburt erheblich vom früheren Recht ab. Nach dem neuen Recht erwerben eheliche Kinder die niederländische Staatsangehörigkeit, wenn Vater oder Mutter zur Zeit der Geburt Niederländer sind, oder falls der Vater bereits gestorben ist, er zur Zeit seines Todes die niederländische Staatsangehörigkeit besessen hatte (Art. 3 Abs. 1 RwNed) (50). Es ist dabei grundsätzlich unbeachtlich, ob das Kind innerhalb Her außerhalb der Niederlande geboren ist. Falls das Kind jedoch im Ausland geboren ist, muB die Verlustklausel des Art. 15 Buchstabe $c$ RwNed berücksichtigt werden. Diese bewirkt, daß ein Kind, das ab seinem achtzehnten Lebensjahr während eines ununterbrochenen Zeitabschnittes von zehn Jahren außerhalb der Niederlande Wohnsitz in dem Lande hat, in dem es geboren ist und dessen Stalatsangehörigkeit es ebenfalls besitzt, die niederländische Staatsangehörigkeit verliert (51). Diese Bestimmung gilt nicht, wenn es selbst oder sein Ehegatte im Dienst der Niederlande steht. Ein Minderjähriger kann die Staatsangehörigkeit auch verlieren, wenn seine Eltern aufgrund des Art. 15 Buchstabe c RwNed die niederländische Staatsangehörigkeit verlieren (Art. 16 Abs. Bụchstabe $c$ RwNed). Ein nichteheliches Kind ist jedenfalls Niederländer, wenn die Mutter zur Zeit der Geburt die niederländische Staatsangehörigkeit besitzt (Art. 3 Abs. 1 RwNed). Das nichteheliche Kind einer ausländischen Mutter wird Niederländer, wenn es während seiner Minderjährigkeit von einem niederländischen Mann anerkannt oder legitimiert wird (Art. 4 RwNed) (52). Auch durch Adoption kann die niederländische Staatsangehörigkeit erworben werden, wenn die Adoption eines ausländischen Kindes von einem niederländischen Gericht ausgesprochen wird (Art. 5 RwNed) (53). Die Regelung, daß die zweite in den Niederlanden geborene Generation automatisch die niederländische Staatsangehörigkeit erwirbt, wollte die Regierung zunächst nicht in das neue Gesetz aufnehmen (54). Erwerb der niederländischen Staatsangehörigkeit $\mathrm{kraft}$ ius soli wurde im ursprünglichen Entwurf nur vorgesehen für in den Niederlanden aufgefundene Kinder (Art. 3 Abs. 2 RwNed) (55). Nach längeren Debatten hat das Parlament doch noch eine Regelung zugunsten der zweiten in den Niederlanden geborenen Generation in das neue Gesetzaufgenommen. Art. 3 Abs. 3 RwNed bestimmt, daß3 die niederländische Staatsangehörigkeit automatisch (iure soli) erworben wird, wenn ein Kind in den Niederlanden geboren wird als Kind eines Vaters oder einer Mutter, der, bzw. die, selbst geboren wurde während seine, bzw. ihre, Mutter in den Niederlanden lebte. Interessant ist in diesem Zusammenhang festzustellen, daß der Erwerb der Staats- angehörigkeit iure soli (oder besser: iure domicilii) durch diese Regelung erheblich ausgedehnt ist. Unter dem alten Recht war für eheliche, legitimierte oder vom Vater anerkannte Kinder der 
Wohnsitz der Großmutter väterlicherseits maßgebend und nur für vom Vater nicht anerkannte Kinder der Wohnsitz der GroBmutter mütterlicherseits, während in der neuen Regelung die Wohnsitze beider Großmütter den Erwerb der niederländischen Staatsangehörigkeit durch die Enkel begründen können. Bemerkenswert ist aber, daß die Wohnsitze der Großväter unbeachtlich sind. Man kann sich fragen ob dies mit dem Gleichberechtigungsprinzip zu vereinbaren ist (56). Es wäre nicht erstaunlich, wenn niederländische Gerichte diese Frage einmal beantworten müßten. Es sei darauf hingewiesen, daß Art. 3 Abs.3 RwNed keine reine ius soli-Regelung beinhaltet, sondern eine Bestimmung, daB nach ius domicilii (des Vaters oder der Mutter, und der Großmütter) die niederländische Staatsangehörigkeit erworben wird. Nach Art. 3 Abs.2 RwNed wird die niederländische Staatsangehörigkeit ebenfalls automatisch von einem in den Niederlanden aufgefundenen Kind erworben. Ein solches Kind verliert jedoch die nach dieser Regelung erworbene Staatsangehörigkeit, wenn innerhalb won fünf Jahren festgestellt wird, daß es durch Geburt ausschließlich (57) eine andere Staatsangehörigkeit besitzt. Auch diese Regelung manifestiert kein reines ius soli, sondern eher eine praesumptio iuris sanguinis.

Auf niederländischem Boden geborene Staatenlose erwerben die niederländische Staatsangehörigkeit hingegen nicht iure soli. Sie erwerben gemäß Art. 6 Abs. 1 Buchstabe b RwNed ausschließlich ein Optionsrecht auf die niederländische Staatsangehörigkeit, das sie nach dreijährigem Aufenthalt in den Niederlanden ausüben können. Dieser Optionsanspruch erlischt nach Vollendung des 25. Lebensjahres. Ebenfalls ein Optionsrecht auf die niederländische Staatsangehörigkeit besitzen volljährige Ausländer, die in den Niederlanden geboren sind und dort seit ihrer Geburt leben: Auch dieses Optionsrecht muß vor Erfüllung des 25. Lebensjahres ausgeübt werden (58).

\subsubsection{Erwerb der Staatsangehörigkeit nach der Geburt}

\subsubsection{Rückblick}

Im Gesetz von 1850 war die Einbürgerung von Volljährigen grundsätzlich nach sechsjährigem Aufenthalt in den Niederlanden möglich (Art. 5) (59). Optionsrechte auf die niederländische Staatsangehörigkeit gab es nicht. In den staatsangehörigkeitsrechtlichen Bestimmungen des Zivilgesetzbuches von 1838 wurde die Einbürgerung in Art. 5 Ziffer 5 zwar vorgesehen, die Voraussetzungen wurden jedoch nicht geregelt (60). Im Gesetz von 1892 wurde für die Einbürgerung der Nachweis eines fünfjährigen Aufenthaltes in den Niederlanden gefordert oder der Nachweis, daß man die niederländische Staatsangehörigkeit früher besessen hatte (61). Im WNed in der Fassung von 1892 bezogen sich ausschlließlich die Art. 3 und 4 auf Einbuirgerung. 1936 wurde der Texı des Art. 3 WNed dergestalt geändert, daß fortan auch die in den Niederlanden geborenen Kinder staatenloser Eltern ohne Rücksicht auf die Fünfjahresfrist eingebürgert werden konnten. 1958 wurde ein Art. 8a in den WNed eingeführt, der die Einbürgerung eines Kindes einer (ursprünglich) niederländischen Mutter und eines ausländischen Vater nach dem Tode des Vater auf Antrag der Mutter regelte (62). Die Vorschriften über die Einbürgerung wurden 1976 eingehend reformiert: eingeführt wurden die neuen Art. 5, 5a und 5b WNed (63). 1977 wurden zudem Einbürgerungsrichtlinien veröffentlicht (64).

Bis 1964 wurde die niederländische Staatsangehörigkeit automatisch von der ausländischen Frau erworben, die einen Niederländer heiratete (65). 
Die Regelung des Erwerbs der niederländischen Staatsangehörigkeit durch Option oder Einbürgerung kann bis zum Inkrafttreten des neuen Reichsgesetzes in 1985 wie folgt zusammengefaßt werden. Die ausländische Frau, deren Ehegatte zur Zeit der Eheschließung die niederländische Staatsangehörigkeit besaß, konnte den niederländischen Behörden gegenüber eine Erklärung abgeben, da $B$ sie Niederländerin werden möchte. Durch diese Erklärung erwarb sie unmittelbar die Staatsangehörigkeit. Die niederländischen Behörden hatten kein Einrederecht. Die Erklärung konnte während der Ehe zu jeder Zeit abgegeben werden, sollange der Mann noch Niederländer war (Art. 8 WNed). Nach Auflösung der Ehe konnte die Frau, die auf diese Art Niederländerin geworden war, die Staatsangehörigkeit durch einfache Erklärung den niederländischen Behörden gegenuber wieder verlieren, falls sie neben der niederländischen Staatsangehörigkeit noch eine andere Staatsangehörigkeit besaß (Art. 8c WNed). Eine niederländische Frau, die einen Ausländer heiratete, behielt ihre niederländischen Staatsangehörigkeit bei. Falls sie auch die gleiche Staatsangehörigkeit wie ihr Ehemann besass, konnte sie durch einfache Erklärung ihre niederländische Staatsangehörigkeit aufgeben (Art. 8a WNed). Wenn sie eine Aufgabeerklärung nach Art. 8a abgegeben hatte, konnte sie nach Auflösung der Ehe die niederländische Staatsangehörigkeit durch einfache Optionserklärung wieder zurückerwerben. Der ausländische Gatte einer niederländischen Frau hatte kein Optionsrecht auf die niederländische Staatsangehörigkeit. Falls er Niederländer werden wollte, war eine Einbürgerung notwendig. Dem niederländischen Ehemann einer ausländischen Frau, der seine Staatsangehörigkeit aufgegeben hatte zugunsten der SDtaatsangehörigkeit seiner Ehefrau, stand das Recht des Wiedererwerbs der niederländischen Staatsangehörigkeit gemäß Artikel 8a WNed nicht zu.

Außer Art. 8 sah der WNed in Art. 10 ferner ein Optionsrecht für solche Personen vor, die während ihrer Minderjährigkeit wegen Einbürgerung ihrer Eltern in einem anderen Staat die niederländische Staatsangehörigkeit verloren hatten.

Die Einbürgerung war im WNed geregelt in den Artikeln 3, 3bis, 4, 5, 5a und 5b. Voraussetzung für die Einbürgerung war grundsätzlich ein fünfjähriger Aufenthalt in den Niederlanden. Laut Art. 3 Abs. 3 konnte ohne Nachweis eines fünfjährigen Aufenthaltes eingebürgert werden, wer nachwies, daß er die niederländische Staatsangehörigkeit besessen aber verloren hatte, oder daß er in den Niederlanden als Staatenloser geboren war. Weitere Ausnahmen von der fünfjâhrigen Frist fanden sich in A.rt. 5 WNed. Die Einbiirgerung erfolgte grundsătzlich durch Gesetz. Die Einbürgerungen nach Art. 5 WNed konnten aber auch aufgrund Gesetzes durch ministerielle Verordnung geschehen. In Art. 5 wNed wurde nur in einem Falle von der in Art. 3 gegebenen Frist abgewichen, und zwar für Kinder einer niederländischen Mutter und eines ausländischen Vaters nach dem Tode des Vaters oder nach Auflösung oder Nichtigerklärung der Ehe der Eltern. In diesem Falle konnte das Kind bereits nach einjährigem Aufenthalt in den Niederlanden eingebuirgert werden.

Hinzuweisen ist ferner auf Art. 5 Buchstabe $f$ WNed, wo für den ausländischen Ehegatten einer Person, die nach Eheschließung die niederländische Staatsangehörigkeit erworben hatte, die Möglichkeit eröffnet wurde durch ministerielle Verordnung die niederländische Staatsangehörigkeit zu erwerben (66). Die normale fünfjährige Frist des Art. 3 WNed mußte allerdings erfüllt sein. Bemerkenswert ist, daß der ausländische Ehemann einer Frau, die bereits bei der 
Eheschließung Niederländerin war, nicht durch ministerielle Verordnung eingebürgert werden konnte; für ihn war nur Einbürgerung durch Gesetz möglich. Schließlich ist in diesem Zusammenhang auf Art. 4. WNed hinzuweisen, der bestimmte, daß im Interesse des Staates die Einbürgerung in Abweichung von allen Voraussetzungen des Art. 3 verliehen werden konnte. Diese Bestimmung hat namentlich hinsichtlich drei ausländischen Ehemännem niederländischer Frauen Anwendung gefunden, und zwar für Heinrich Herzog von Mecklenburg-Schwerin, Bernard Prinz von Lippe-Biesterfeld und Claus von Amsberg, den Gatten von Königin Wilhelmina, Königin Juliana und Königin Beatrix (67). In der Nederlandse Staatscourant von 27. April 1977 (Nr. 81) wurde eine Richtlinie des Justizministers veröffentlicht, die die Voraussetzungen für die Einbürgerung nach Art. 5 WNed näher ausarbeitete. In dieser Richtlinie wurde betont, $\mathrm{daB}$ nur solche Personen eingebürgert werden konnten, gegen deren Aufenthalt für unbestimmte Zeit in den Niederlanden, beziehungsweise den Niederländischen Antillen, keine Bedenken bestanden. Weiter wurde verlangt, dal3 der Betroffene von der niederländischen Gesellschaft aufgenommen ("ingeburgerd") worden ist (68).

Ein Einbürgerungsantrag mußte abgewiesen werden, wenn ernsthafte Verdachtsgründe bestanden, daß der Antragesteller die öffentliche Ordnung, die guten Sitten, die Volksgesundheit oder die Sicherheit des Königreiches gefährden könnte (69). Von großer Bedeutung war schließlich Art. 5a WNed, wonach bei einer Einbürgerung gefordert werden konnte, daB der Antragsteller nachweist, daß er seine frühere Staatsangehörigkeit verloren hat oder verlieren wird an dem Tage, an dem er die niederländische Staatsangehörigkeit erworben hat, oder das Mögliche tun wird, um seine alte Staatsangehörigkeit zu verlieren. In der Richtlinie von 10. März 1977 wurde betont, daß ein solcher Nachweis nicht zu fordern war, wenn dies billigerweise nicht verlangt werden konnte.

\subsubsection{Heutige Regelung}

Das bis 1985 geltende niederländische Staatsangehörigkeitsrecht war zweifelsohne mit dem Gleichberechtigungsgrundsatz unvereinbar. Die ausländische Ehegattin eines Niederländers konnte durch einfache Erklärung den zuständigen niederländischen Behörden gegenüber die niederländische Staatsangehörigkeit erwerben; der ausländische Mann, der eine Niederländerin geheiratet hatte, mußte hingegen eingebürgert werden. Es wäre denkbar gewesen das Optionsrecht auf die niederländische Staatsangehörigkeit auch ausländischen Männern niederländischer Frauen zu geben. Die Erfahrungen mit dem Optionsrecht waren aber nicht in jeder Hinsicht positiv (70). Im neuen Recht wurde die Gleichberechtigung deshalb dergestalt realisiert, daß fortan weder der ausländische Ehemann noch die ausländische Ehefrau eines niederländischen Staatsangehörigen ein Optionsrecht besitzt: es fand also eine Nivellierung nach unten statt.

Im neuen Staatsangehörigkeitsgesetz wird die Einbürgerung in den Artikeln 7 bis einschließlich 13 RwNed geregelt. Artikel 7 RwNed bestimmt, daß Ausländer in den Niederlanden durch königlichen Beschluß eingebürgert werden können; ein Einbürgerungsgesetz wie bisher ist nicht mehr notwendig. In den Art. 8 und 9 RwNed werden nähere Voraussetzungen für die Einbürgerung geregelt (71). Der Antragsteller muß volljährig sein (Arr. 8 Abs. 1 Buchstabe a RwNed) (fïr Minderjährige gilt Art. 11 RwNed), gegen seinen Aufenthalt für unbestimmte Zeit in den Niederlanden, beziehungsweise den Niederländischen Antil- 
len oder Aruba, dïrfen keine Bedenken bestehen (Art. 8 Abs. 1 Buchstabe b RwNed) (so auch bereits die Richtlinie von 1977) (72), er muß die fünf unmittelbar dem Antrag vorhergehenden Jahre in den Niederlanden gelebt haben (73) (Art. 8 Abs. 1 Buchstabe c RwNed) (allerdings mit der Ausnahme, daß diese Frist auf zwei Jahre reduziert wird für diejenigen, die insgesamt mindestens zehn Jahre in den Niederlanden, bzw. den Niederländischen Antillen gelebt haben) (Art. 8 Abs. 3 RwNed), und der Betreffende muB als in der niederländischen Gesellschaft aufgenommen ("ingeburgerd") (74) betrachtet werden können, auf Grund der Tatsache daß er über Kenntnisse der niederländische Sprache verfügt (75) und er sich auch im übrigen in die niederländische Gesellschaft hat aufnehmen lassen (Art. 8 Abs. 1 unter d RwNed). Es sei darauf hingewiesen, dabs es die Fünfjahresfrist von Art. 8 Abs. 1 unter c RwNed auch bereits im bis 1985 geltenden Recht gab (76). Auch die Forderung, daß derjenige, der einen Einbürgerungsantrag stellt, in der niederländischen Gesellschaft aufgenommen ("ingeburgerd") sein muß, galt bereits seit den anläßlich des Art. 5 des alten Gesetzes. WNed veröffentlichten Richtlinien (77).

Es wurde schon darauf hingewiesen, daß die Fünfjahresfrist auf zwei Jahre gekürzt ist für diejenigen, die insgesamt bereits zehn Jahre in den Niederlanden gelebt haben (Art. 8 Abs. 3 RwNed). Aufgrund der Bestimmung von Art. 8 Abs. 2 gilt weiter überhaupt keine Frist für diejenigen, die die niederländische Staatsangehörigkeit oder den Status eines niederländischen Untertanen-Nicht-Niederländers (78) früher besessen haben (dies entspricht der Regelung des früheren Art. 3 WNed), als Volljährige durch Anerkennung, durch Legitimation oder Adoption Kind eines Niederländers geworden sind, oder seit mindestens drei Jahren mit einer Person niederländischer Staatsangehörigkeit verheiratet sind. Diese letzte Ausnahme ist neu. Im folgenden wird hierauf noch näher eingegangen. Sehr bemerkenswert ist weiter die Bestimmung des Art. 8 Abs. 4 RwNed kraft derer die Fünfjahresfrist auf drei Jahre gekürzt wird für Unverheiratete, die seit mindestens drei Jahren mit einem unverheirateten Niederländer in einem eheähnlichen Verhältnis in den Niederlanden zusammenleben (79). Ein Einbürgerungsantrag, der die Voraussetzungen des Art. $8 \mathrm{RwNed}$ erfüllt, wird dennoch zurückgewiesen, wenn aufgrund des Benehmens des Antragstellers emsthafte Verdachtsgrïnde bestehen, daß er die öffentliche Ordnung, die guten Sitten, die Volksgesundheit oder die Sicherheit des Königreiches gefährdet (80) (dies entspricht auch wieder der Richtlinie von 1979) (Art. 9 Abs. 1 Buchstabe a RwNed), oder der Antragsteller, der eine andere Staatsangehörigkeit besitzt, nicht das Mögliche getan hat, um jene Staatsangehörigkeit zu verlieren, es sei denn, daß dies billigerweise nicht von ihm verlangt werden kann (Art. 9 Abs. 1 unter b RwNed) (81). Diese letzte Forderung entspricht Art. 5a WNed (82) in Kombination mit der Richtlinie von 1977. Neu ist aber die Regelung des Art. 15 Buchstabe d, kraft derer eine Einbürgerung widerrufen werden kann, falls der Betreffende es nach dem Zustandekommen einer Einbürgerung unterlassen hat, das Mögliche zu tun um seine ursprüngliche Staatsangehörigkeit zu verlieren. Diese Regelung ist eine deutliche Manifestierung des Wunsches, Doppelstaatlichkeit vorzubeugen (83). Es wurde bereits dargelegt, daß bestimmte Gruppen von Personen eingebürgert werden können, ohne daß ein Aufenthalt von gewisser Dauer in den Niederlanden gefordert wird (Art. 8 Abs. 2 RwNed). Art. 9 Abs. 1 Buchstabe $c$ RwNed schreibt für diese Fälle aber vor, daB solche Antragsteller nicht eingebürgert werden können, wenn sie in einem Land, dessen Staatsangehörigkeit sie besitzen, wohnhaft sind (84). Aufgrund des Art. 13 
RwNed wird in der Regel die Zahlung von Einbürgerungsgebühren gefordert. Diese Summe beträgt gemäß der Durchführungsverordnung von 27. Januar 1986, Stb. 1986, 18 (geändert durch Verordnung vom 2. Mai 1988, Stb. 1988, 247) grundsätzlich 400 Gulden. Die Zahlung dieses Betrages kann ganz oder teilweise erlassen werden. Im Falle der Einbürgerung von Ehe- oder Konkubinatspartnern braucht die Gebühr nur einmal entrichtet werden. Die Gebühr ist im voraus zu bezahlen. Bis Inkrafttreten der Änderungsverordnung von 1988 wurde das Geld zurückerstattet, falls der Einbürgerungsantrag zuriickgewiesen wurde. In der niederländischen juristischen Literatur wird die Tatsache, daB man u.U. für eine Einbürgerung zahlen muß, stark kritisiert.

Über die Position des ausländischen Ehegatten eines Niederländers sollen an dieser Stelle noch einige weitere Bemerkungen gemacht werden. Die neue Regelung ist für den ausländischen Ehemann einer niederländischen Frau im Vergleich zu der bisherigen Regelung günstiger. Er kann schneller als nach den bisherigen Vorschriften eingebürgert werden. Für die ausländische Ehefrau eines niederländischen Mannes ist die neue Regelung aber schlechter. Sie hat kein Optionsrecht mehr. Zwar wird von ihr nicht gefordert, daß sie bereits fünf Jahre in den Niederlanden wohnhaft ist, aber die weiteren Voraussetzungen für eine Einbürgerung gelten auch für sie. Das heißt, daß auch ihr Antrag zurückgewiesen werden kann, wenn ernsthafte Verdachtsgründe bestehen, daß sie die niederländische Gesellschaft gefährdet, oder wenn sie das Mögliche nicht tut, um ihre bisherige Staatsangehörigkeit zu verlieren. Femer dürfen gegen ihren Aufenthalt für unbestimmte Zeit in den Niederlanden, beziehungsweise in den Niederländischen Antillen oder Aruba, keine Bedenken bestehen (85). Schließlich kann sie nicht eingebürgert werden, wenn sie noch in ihren Heimatstaat lebt. Über die Formulierung "keine Bedenken dürfen bestehen gegen einen Aufenthalt für unbestimmte Zeit in den Niederlanden" muß noch eine Bemerkung gemacht werden. Diese Formulierung entspricht der der Niederlassungsgenehmigung aus der niederländischen Ausländergesetzgebung. Nach den Bestimmungen des niederländischen Ausländergesetzes (Vreemdelingenwet) wird diese Genehmigung dem ausländischen Ehegatten eines Niederländers in der Regel erst nach dreijährigem Aufenthalt in den Niederlanden gegeben (86). Die für den ausländischen Ehegatten günstige Ausnahmebestimmung des Art. 8 Abs. 2 hinsichtlich der geforderten Aufenthaltsfrist wird dadurch teilweise wieder zurückgenommen. Von Bedeutung ist weiter, daß die Einbürgerung dles ausländischen Ehegattens auch verweigert werden darf, falls dieser noch nicht in der niederländischen Gesellschaft aufgenommen ("ingeburgerd") ist. In diesem Zusammenhang darf nicht unerwähnt bleiben, daß der Referentenentwurf (1976) eine für den ausländischen Ehegatten eines Niederländers günstigere Regelung vorschlug. Art. 16 des Referentenentwurfes gab ihm ein Optionsrecht auf die niederländische Staatsangehörigkeit, allerdings unter der Bedingung daß er sich bemühen müisse, seine bisherige Staatsangehörigkeit zu verlieren (Art. 8 Abs. 2 Referentenentwurf). Durch die Optionserklärung wurde die niederländische Staatsangehörigkeit nicht automatisch erworben; die Erklärung bedurfte vielmehr der Bestätigung der niederländischen Behörden. Diese mußten die Behörden innerhalb Jahresfrist erteilen oder verweigeren. (Art. 16 Abs. 2 Referentenentwurf). Die Bestätigung durfte versagt werden, falls der ernsthafte Verdacht bestand, daß der Betreffende die niederländische Gemeinschaft gefährdet, oder sich nicht bemühen würde, seine bisherige Staatsangehörigkeit zu verlieren. Schließlich durfte die Bestätigung auch verweigent werden, wenn die Ehe inzwischen ge- 
schieden, für nichtig erklärt oder die Trennung von Tisch und Bett ausgesprochen war. Auch während eines Ehescheidungs-, eines Nichtigerklärungsprozesses oder eines Prozesses zur Trennung von Tisch und Bett durfte die Bestätigung verweigert werden. (87). Erst mit der Bestätigung wurde nach dem Referentenentwurf die niederländische Staatsangehörigkeit erworben. Außerordentlich wichtig war weiter Art. 18 Abs. 3 des Referentenentwurfes, der bestimmte, daB die infolge Art. 16 Referentenentwurf durch Option erworbene Staatsangehörigkeit wieder automatisch verloren wurde, falls die Ehe innerhalb von drei Jahren nach Eheschließung aufgelöst, für nichtig erklärt oder die Trennung von Tïsch und Bett ausgesprochen wurde. Ziel dieser Bestimmung war es möglichst staatsangehörigkeitsrechtlichen Scheinehen vorzubeugen. Die im Referentenentwurf vorgeschlagene Regelung wurde in der juristischen Literatur scharf kritisiert (8.8). Die Regelung wurde einerseits als zu kompliziert, anderseits aber auch als ineffektiv beurteilt. Da nach Art. 17 Abs. 2 Referentenentwurf (dem Art. 14 Abs. 2 des neuen Gesetzes entsprechend) die niederländische Staatsangehörigkeit verlorengehen sollte, wenn Staatenlosigkeit davon die Folge wäre, würde die Regelung des Art. 18 Abs. 3 des Referentenentwurfes nur für diejenigen (ausländischen) Ehegatten wirken, die außer der niederländischen Staatsangehörigkeit auch noch ihre bisherige Staatsangehörigkeit beibehalten hatten. Gemäß Art. 16 Abs. 1 und 8 Abs. 2 des Referentenentwurfes wäre dies jedoch nur möglich, wenn vom Betreffenden billigerweise nicht verlangt werden konnte, daß er sich bemühte, die bisherige Staatsangehörigkeit zu verlieren (89). Gerade in dem Falle war es aber fraglich, ob es zweckmäßig wäre, daß er nach Auflösung der Ehe die niederländische Staatsangehörigkeit wieder verlieren würde (90). Es ist deshallb nicht erstaunlich, daß in das neue Gesetz eine vom Referentenentwurf abweichende Regelung aufgenommen wurde. Kritik an dem Entwurf hat vor allem Jessurun d'Oliveira ausgeiibt. Er kritisierte zum einen die Forderung, daß jemand in der niederländischen Gesellschaft integriert ("ingeburgerd") sein muß, bevor er eingebürgert werden kann. In welche niederländische Gesellschaft muß der Betreffender integriert sein, fragt Jessurun d'Oliviera (91). Die Niederlande haben sich in den letzten Jahrzehnten zu einer multi-ethnischen und multi-kulturellen Gesellschaft entwickelt. Im Entwurf eines Berichtes über Minderheiten in den Niederlanden hat die niederländische Regierung diese Tatsache auch ausdrücklich anerkannt und bestätigt. In diesem Zusammenhang ist die Forderung der Integration inadäquat. Genügt es etwa, wenn der Betreffende in einer der in den Niederlanden lebenden Minderheiten integriert ist? Schwere Kritik übte Jessurun d'Oliviera auch an dem Verlangen, daß der Betreffende das Mögliche tun müsse, um seine bisherige Staatsangehörigkeit zu verlieren. Er meinte, daß die Bekämpfung der mehrfachen Staatsangehörigkeit kein Ziel des neuen Staatsangehörigkeitsrechts sein solle, da gerade für in den Niederlanden lebende ethnische Minderheiten eine eventuelle mehrfache Staatsangehörigkeit von Bedeutung sei. Dies gilt s.E. namentlich für die Generation der Gastarbeiterkinder. Er betonte, daß Doppelstaatsangehörigkeit für die zweite Ausländergeneration eine hervorragende Übergangsform bilde, die diesen Personen helfen könne, ihre Erwartungen auf eine Zukunft in den Niederlanden zu manifestieren ohne ihre Beziehungen zu ihren Eltern und ihrem Ursprungsland in sozialer Hinsicht abbrechen zu müssen (92). Jessurun d'Oliviera wies in diesem Zusammenhang weiter darauf hin, daß ihm das Bestreben der Staaten mehrfache Staatsangehörigkeiten (Polypatridie) zu verhindern, auch deshalb unverständlich sei, weil Polypatriden die Grenzen, also Gegensätze, zwischen Staaten abschwächen. Polypatriden bewirken eine Osmose zwischen Staaten und 
dadurch einen Identitätsverlust der Staaten, was dem Frieden förderlich sei (93). Die niederländische Regierung hat die Forderung, daß die bisherige Staatsangehörigkeit grundsätzlich aufgegeben werden muß, dennoch beibehalten (94) und dies namentlich damit begründet, daß dies zwar nicht vom Straßburger Abkommen zur Verminderung von Fällen mehrfacher Staatsangehörigkeit gefordert wiirde, dies jedoch wohl im Sinne dieses Abkommens wäre (95). Sogar die Tatsache, daB im Rahmen des Europarats gerade darüber diskutiert wurde, ob die Ermöglichung mehrfacher Staatsangehörigkeiten nicht für die Integrierung von Gastarbeitern wünschenswert wäre (96), hat die Regierung nicht dazu bewegen können, diesen Standpunkt aufzugeben (97). Bemerkenswert ist ferner, daß die niederländische Regierung in den Motiven zum neuen Staatsangehörigkeitsgesetz wiederholt betont hat, die neue Regelung der Einbürgerung wäre nun derart gestaltet, daß die Einbürgerung nicht mehr wie bisher als Gunst betrachtet werden müsse, sondern als Recht (98). Diese Auffassung ist interessant und auch politisch zu begrïßen. Sie findet leider aber keinen Niederschlag in der positivrechtlichen Regelung (99).

\subsubsection{Verlustgründe}

\subsubsection{Rückblick}

Die Verlustgründe nach dem Staatsangehörigkeitsrecht des vergangenen Jahrhunderts entsprachen nur teilweise den heutigen Verlustgründen der niederländischen Staatsangehörigkeit. Nach Art. 10 des Gesetzes vom 28. Juli 1850 ging die Staatsangehörigkeit verloren durch Einbürgerung in einen anderen Staat, durch ausländischen Wehr- oder Staatsdienst ohne Einwilligung der niederländischen Behörden oder nach fünfjährigem Aufenthalt im Ausland mit der deutlichen Absicht nicht in die Niederlande zuruickzukehren. Der Verlust der Staatsangehörigkeit wegen Erwerbs einer anderen Staatsangehörigkeit durch Option war nicht vorgesehen, ebenfalls fehlte die Möglichkeit einer Verfalls- oder Abstandserklärung. Die Bestimmungen des Zivilgesetzbuches waren ähnlich. Wichtiger Verlustgrund der Staatsangehörigkeit war für eine Frau weiter die Heirat mit einem nicht-niederländischen Manne (100).

Im Gesetz von 1892 wurden die Verlustgründe nicht entscheidend geändert (101). Außer dem Verlust der niederländischen Staatsangehörigkeit wegen Einbürgerung im Ausland, wurde nun aber auch anderer freiwilliger Erwerb einer fremden Staatsangehörigkeit als Verlustgrund erwähnt (Art. 7 Ziffer 3 WNed). Die Regelung des Verlustes der Staatsangehörigkeit wegen Auslandsaufenthalt wurde anders formuliert. Art. 7 Ziffer 5 WNed in der Fassung von 1892 bestimmte, daß Niederländer, die zehn Jahre, ununterbrochen im Ausland lebten, die Staatsangehörigkeit verloren, es sei denn, sie teilten niederländischen Behörden mit, die niederländische Staatsangehörigkeit beibehalten zu wollen. Diese Verlustklausel galt für alle Niederländer, also nicht nur für diejenigen, die im Ausland geboren wurden. Letztere Beschränkung wurde jedoch 1910 eingefuigt (102). Die Verlustbestimmungen wurden 1936 teilweise revidiert (103). Wie oben schon erörtert, verlor seitdem die mit einem Ausländer verheiratete, niederländische Frau, ihre Staatsangehörigkeit nur dann, wenn sie dadurch nicht staatenlos wurde. Weiter wurde 1936 die Möglichkeit der Verzichtserklärung eingefügt und zwar als Art. 7 Ziffer 2 neuer Fassung. Eine weitere Änderung wurde 1963 noch vorgenommen (104). 
Die Regelung des Verlusts der niederländischen Staatsangehörigkeit kann für die Zeit unmittelbar vor Inkrafttreten des neuen Reichsgesetzes im Jahre 1985 wie folgt zusammengefaßt werden: Außer wegen Wegfallens der familienrechtlichen Beziehungen (105), auf Grund deren jemand die niederländische Staatsangehörigkeit besaß, ging die niederländische Staatsangehörigkeit verloren, wenn ein niederländisches Kind während seiner Minderjährigkeit durch Anerkennung oder Legitimitation eine ausländische Staatsangehörigkeit erwarb (Art. 2ter WNed). Weitere Verlustgründe fanden sich in Art. 7 WNed. Nach Art. 7 Ziffer 1 WNed ging die niederländische Staatsangehörigkeit durch Einbürgerung in einen anderen Staat verloren. Dies galt allerdings nur, wenn der Betreffende nach Erreichung der Volljährigkeit eingebürgert wurde. Minderjährige gingen der niederländischen Staatsangehörigkeit verlustig, wenn derjenige, von dem sie die niederländische Staatsangehörigkeit herleiteten, im Ausland eingebürgert wurde und sie am Erwerb der ausländischen Staatsangehörigkeit teillhatten (106). Ein solches Kind hatte infolge Art. $10 \mathrm{WNed}$ jedoch nach Erreichung der Volljährigkeit ein befristetes Optionsrecht auf die niederländische Staatsangehörigkeit. Durch selbständige Einbürgerung im Ausland verlor ein Minderjähriger die niederländische Staatsangehörigkeit nicht! Nach Art. 7 Ziffer 3 WNed ging die niederländische Staatsangehörigkeit auch verloren, wenn ein volljähriger Niederländer auf andere Art als durch Einbürgerung freiwillig eine andere Staatsangehörigkeit erwarb (z.B. durch Ausübung eines ausländischen Optionsrechtes). Dieser Verlust trat übrigens auch ein, wenn der Betreffende zur Zeit der Ausübung des Optionsrechtes in den Niederlanden wohnhaft war. Gemäß Art. 7 Ziffer 2 WNed konnte die niederländische Staatsangehörigkeit weiter auf Antrag des Betreffenden für verfallen erklärt werden, falls er im Ausland lebte und außer der niederländischen Staatsangehörigkeit noch eine andere Staatsangehörigkeit besaß, während beide Staatsangehörigkeiten automatisch (also nicht durch Einbürgerung oder Option) erworben waren. In diesem Zusammenhang ist ferner Art. 8a WNed zu erwähnen. Die niederländische, mit einem Ausländer verheiratete Frau, die außer der niederländischen Staatsangehörigkeit auch die Staatsangehörigkeit ihres Ehemannes besaß, konnte durch einfache Erklärung die niederländische Staatsangehörigkeit aufgeben (107). Diese Aufgabeerklärung war auch möglich, wenn die Frau in den Niederlanden lebte. Automatischer Verlust der niederländischen Staatsangehörigkeit trat weiter ein, wenn ein Niederländer ohne Erlaubnis der niederländischen Behörden in einem ausländischen Wehr- oder Staatsdienst trat (Art. 7 Ziffer 4 WNed) (108).

Schließlich ist Art. 7 Ziffer 5 WNed zu erwähnen, wonach ein Niederländer, der im Ausland geboren war, die niederländische Staatsangehörigkeit verlor, wenn er nach seiner Volljährigkeit während zehn Jahren im Ausland lebte. Er konnte diesem Verlust aber dadurch zuvorkommen, daß er vor Ablauf der Zehnjahresfrist niederländischen Behörden mitteilte, Niederländer bleiben zu wollen. In diesem Falle begann eine neue Zehnjahresfrist. Aufgrund des Art. 7 Ziffer 5 WNed ging die niederländische Staatsangehörigkeit auch verloren, wenn der Betreffende dadurch staatenlos wurde.

Bei den Verlustgründen der niederländischen Staatsangehörigkeitsregelung konnte man deshalb fünf Gruppen unterscheiden:

a) Verlust infolge Änderung der familienrechtlichen Beziehungen, aufgrund deren die Staatsangehörigkeit erworben worden war (Art. 2 ter WNed),

b) Verlust wegen freiwilligen Erwerbs einer fremden Staatsangehörigkeit (Einbürgerung oder Erwerb durch Optionserklärung), da davon ausgegangen 
wurde, daß der Betreffende sich dadurch aus dem niederländischen Staatsverband lösen möchte. Doppelstantlichkeit wurde so vorgebeugt (Art. 7 unter 1 und 3 WNed),

c) Verlust durch Verfalls-, beziehungsweise Aufgabeerklärung (Art. 7 unter 2 und Art, 8a) im Falle der Doppelstaatlichkeit,

d) Verlust wegen langjährigen Aufenthalts im Ausland; es wurde davon ausgegangen, $\mathrm{daB}$ die Beziehungen $\mathrm{zu}$ den Niederlanden dann so vage geworden seien, daß die Innehabung der niederländischen Staatsangehörigkeit nicht mehr gerechtfertigt sei.

e) Verlust wegen ausländischen Wehr- oder Staatsdienstes. Man kann diesen Verlustgrund als Strafe wegen Untreue dem eigenen Staate gegenüber betrachten.

Von den fünf so unterschiedenen Gruppen von Verlustgründen blieben die gruppen a und b nach Einfuihrung des neuen Reichsgesetzes 1985 fast unverändert bestehen. Gruppe c (Mögliclakeit einer Abstandserklärung) wurde weiter gefaßt; fortan wird nach dem neuen Gesetz in allen Fällen eine Aufgabeerklärung auch bei Wohnsitz im Inland möglich sein. Gruppe d (Verlust wegen Aufenthalts im Ausland) wurde einerseits weiter (keine Verlängerungsmöglichtkeit), anderseits aber enger gefaßt (nur wenn der Betreffende auch die Staatsangehörigkeit seines Geburtslandes, wo er auch seinen Wohnsitz hat, besitzt). Gruppe e (Verlust wegen ausländischen Wehr- oder Staatsdienstes) verfiel. Statt dessen wurde aber ein neuer Tatbestand eingeführt: Verlust der Staatsangehörigkeit wegen fortgesetzter Doppelstaatlichkeit. Ein Verlustgrund, der nur dadurch seine Rechtfertigung findet, daß Doppelstaatlichkeit "coûte que coûte" verhindert werden soll. Im neuen Recht sind schließlich die Verlustgründe für Kinder so eingeschränkt, daß minderjährige Kinder möglichst nur dann die niederländische Staatsangehörigkeit verlieren, wenn kein Elternteil mehr die niederländische Staatsangehörigkeit besitzt.

\subsubsection{Heutige Regelung}

Im neuen Reichsgesetz von 1985 sind die Verlustgründe der niederländischen Staatsangehörigkeit systematisch in den Artikelen 14 bis 16 geregelt (109). Im Art. 14 Abs. 1 RwNed wird der Verlust wegen Fortfalls der familienrechtlichen Beziehung, der die Staatsangehörigkeit entliehen ist, geregelt (110). Art. 14 Abs. 2 betont, daß kein Verlust der niederländischen Staatsangehörigkeit eintritt, wenn Staatenlosigkeit die Folge wäre. Art. 15 RwNed gibt die unterschiedlichen Verlustgründe an, soweit es Volljährige betrifft (111). Dịe Staatsangehörigkeit geht erstens verloren bei freiwilligem Erwerb einer ausländischen Staatsangehörigkeit (Art. 15 Buchstabe a RwNed; Einbürgerung und Option werden also nicht einzeln erwähnt) (112). Zweitens geht die Staatsangehörigkeir durch Aufgabeerklärung verloren (Art. 15 Buchstabe b) (113). Das neue Recht unterscheidet den Verlust wegen Verfallenserklärung und Aufgabeerklärung nicht. Art. 15 Buchstabe $b$ muß im Zusammenhang mit Art. 14 Abs. 2 RwNed betrachtet werden. Die Aufgabeerklärung ist nur möglich, wenn der Betreffende dadurch nicht staatenlos wird, d.h. also daß dieser Doppelstaatler sein muß. Die Aufgabeerklärung kann auch bei Wohnsitz im Inland abgegeben werden. Drittens tritt Verlust der Staatsangehörigkeit ein, wenn der Betreffende nach seiner Volljährigkeit während eines ununterbrochenen Zeitabschnittes von zehn Jahren seinen Wohnsitz in dem Lande hat, dessen. Staatsangehörigkeit er auch kraft Geburt besitzt, es sei denn, er oder sein Ehegatte haben ein Dienstverhältnis mit 
den Niederlanden (Art. 15 Buchstabe $c$ RwNed) (114). Eine Verlängerung der niederländischen Staatsangehörigkeit, wie früher Art. 7 Ziffer 5 WNed vorsah, ist nicht möglich. Bemerkenswert ist die Bestimmung von Art. 15 Buchstabe d RwNed wonach ein Einbürgerungsbeschluß widerrufen werden kann, falls der Betreffende es nach der Einbürgerung unterlassen hat, das Mögliche zu tun, um seine bisherige Staatsangehörigkeit zu verlieren (115). Minderjährige verlieren nach Art. 16 RwNed die niederländische Staatsangehörigkeit, falls sie an der Einbürgerung des Vaters oder der Mutter im Ausland teilhaben (Art. 16 Buchstabe b RwNed), oder im Falle einer selbständigen Einbürgerung, wenn sie dieselbe Staatsangehörigkeit wie ihr Vater oder ihre Mutter erwerben. In den Fallen des Art. 15 Buchstaben $b_{v} c$ und $d$ verlieren minderjährige Kinder der Betreffenden auch die niederländische Staatsangehörigkeit. Der Verlust der niederländischen Staatsangehörigkeit tritt nicht ein, sofern ein Elternteil noch Niederländer bleibt (116). 


\section{7 ÖSTERREICH}

\subsubsection{Allgemeine Bemerkungen}

Das geltende Staatsangehörigkeïtsrecht Österreichs ist im Staatsbürgerschaftsgesetz aus dem Jahre 1965 geregelt. Das Gesetz ist seitdem sechsmal geăndert worden (1).

Im 19. Jahrhundert billdeten die staatsangehörigkeitsrechtlichen Bestimmungen des Allgemeinen Bürgerlichen Gesetzbuches Österreichs vom 1. Juni 1811 (im folgenden zu zitieren als ABGB) die Grundlage des österreichischen Staatsangehörigkeitsrechts. Dieses Gesetz, in dem sich die $\$ 28-32$ auf die Staatsangehörigkeit bezogen (2), trat am 1. Januar 1812 in Kraft (3). \& 28 Satz 2 ABGB bestimmte, daB die Kinder eines österreichischen Bürgers durch Geburt die österreichische Staatsangehörigkeit erwarben. Die staatsangehörigkeitsrechtliche Regelung des ABGB stützte sich daher formell auf das ius sanguinis. In diesem Zusammenhang muß aber auch \& 29 ABGB beriicksichtigt werden, in dem es hieß:

"Fremde erwerben die österreichische Staatsbürgerschaft ....; durch einen in diesen Staaten vollendeten zehnjährigen ununterbrochenen Wohnsitz, jedoch unter der Bedingung, daß der Frende diese Zeit hindurch sich wegen eines Verbrechens keine Strafe zugezogen hat".

In Prinzip erwarben also auch alle Kinder von Personen, die bereits mindestens zehn Jahre in Österreich gelebt hatten, durch Geburt die österreichische Staatsbürgerschaft. $\S 29 \mathrm{ABGB}$ stellte weiter fest, daß die Staatsbürgerschaft durch Eintritt in den öffentlichen Dienst oder durch Aufnahme eines Gewerbes, dessen Betreibung die ordentliche Ansässigkeit im Lande notwendig machte, erworben wurde. Weiter ermöglichte $\S 30$ ABGB den Erwerb der Staatsangehörigkeit durch Einbürgerung. Gemäß $\S 32$ ABGB wurde der Verlust der Staatsangehörigkeit durch Auswanderung oder Eheschließung einer Österreicherin mit einem Ausländer durch die Auswanderungsgesetze bestimmt (4).

Sehr wichtig für das österreichische Staatsangehörigkeitsrecht war das Staatsgrundgesetz vom 21. Dezember 1867 ubber die allgemeinen Rechte der Staatsbürger (5). Art. 1 Abs. 1 dieses Gesetzes bestimmte, daß es für alle Angehörigen der im Reichsrate vertretenen Königreiche und Länder ein allgemeines österreichisches Staatsbürgerrecht gebe. Neben dieser allgemeinen österreichischen Staatsbürgerschaft bestand aber infolge der dualistischen Staatsform der österreichisch-ungarischen Monarchie ab 1867 auch eine ungarische Staatsangehörigkeit (6).

Von großer Bedeutung für das österreichische Staatsangehörigkeitsrecht wurde das Heimatrecht (7). Die Institution des Heimatrechts ging auf Bestimmungen über die Zugehörigkeit einer Person zu einem Territorium zurück, wie sie die Bettlerschub- und Verpflegsordnung vom 16. November 1754 (8) sowie das Konscriptions - und Rekrutierungspatent vom 25 . Oktober 1804 (9) enthielten. $\$ 20$ des provisorischen Gemeindegesetzes vom 17. März 1849 (10) verpflichtete bereits Gemeinden, die Gemeindemitglieder in einer Heimatrolle zu verzeichnen und Heimatscheine auszustellen. In diese Heimatrolle konnten nur 
diejenigen eingetragen werden, die die österreichische Staatsangehörigkeit besaßen (11). Dies kam besonders im Heimatgesetz vom 3. Dezember 1863 (12) zum Ausdruck, wo \& 2 bestimmte, daB nur österreichische Staatsbürger das Heimatrecht in einer Gemeinde erwerben konnten und jeder Staatsbürger in (ausschließlich) einer Gemeinde heimatberechtigt sein sollte. \& 2 Heimatgesetz bewirkte, daß die Heimatscheine faktisch zum wichtigsten Nachweis der österreichischen Staatsangehörigkeit wurden.

Die Erwerbsgriunde der österreichischen Staatsbürgerschaft wurden im vergangenen Jahrhundert durch einige neue Vorschriften angefüllt und revidiert. Der Erwerb der österreichischen Staatsangehörigkeit durch Eintritt in den öffentlichen Dienst wurde am 29. September 1818 (13), 15. April 1828, 6. April 1833 (14) eingeschränkt und beeinflußt von Art. 3 des Staatsgrundgesetzes vom 1867 (15). Im Jahre 1860 wurde Aufnahme eines Gewerbes alls Erwerbsgrund gestrichen (16). Auch der Erwerb der Staatsangehörigkeit durch zehnjährigen Aufenthalt wurde 1833 von einem Untertaneneid und einer Beglaubigungsurkunde abhängig gemacht (17). Im Jahre 1833 wurde durch Hofkanzleidekret festgestellt, daß eine ausländische Frau durch Eheschließung mit einem Österreicher die Staatsangehörigkeit ihres Mannes erwarb (18). Für die Einbürgerung wurde seit 1850 eine Aufnahmezusicherung einer österreichischen Gemeinde gefordert (19). Daneben wurde teilweise auch ein vorläufiger Nachweis der Entlassung des Antragstellers aus einem bisherigen Staatsverband (20) und "Beibringung eines Auswanderungsconsenses", bzw. der glaubwürdige Nachweis der "erfüllten oder nachgesehenen Militärpflicht" gefordert (21).

Die Geschichte des österreichischen Staatsangehörigkeitsrechts im zwanzigsten Jahrhundert wurde vor allem von den Geschehnissen der Jahre 1918, 1938 und 1945 geprägt. Der Zerfall der österreichisch-ungarischen Monarchie im Jahre 1918 machte es notwendig, die Staatsbürger zwischen den neu entstandenen Staaten zu verteilen (22). Die Republik Osterreich versuchte den Kreis ihrer Staatsbürger durch innerstaatliche Regelungen festzulegen (Gesetze vom 22. November 1918 (23) und vom 5. Dezember 1918 (24)). Weiter erfolgte die Aufteilung durch Staatsverträge, namentlich durch das Abkommen von St.Germain-en-Laye vom 10. September 1919 (25) sowie (im Verhältnis zu der Tschechoslowakei) durch das Brünner Abkommen vom 7. Juni 1920 (26). Die Grundlage für das Aufteilungsverfahren bildete vor allem das Heimatrecht. Diejenigen Personen, die am 16. Juli 1920 das Heimatrecht in einer zum Gebiet der Republik Österreich gehörenden Gemeinde besaßen, wurden automatisch, ohne eine besondere Erklärung abgeben zu müssen, österreichische Staatsbürger (27). Daneben sahen die erwähnten Regelungen mehrere Optionsmöglichkeiten vor.

Die Republik Österreich wurde der Struktur des Kaisertums folgend als ein aus mehreren Ländern zusammengesetzter Bundesstaat konstruiert (Art. 2 des Bundesverfassunggesetzes vom 1. Oktober 1920, im folgenden zu zitieren als BVG) (28). Art. 6 Abs. 1 und 2 BVG nahm deshalb eine Teilung in Landesbürgerschaft und Bundesbürgerschaft vor. Nach $\S 14$ des Übergangsgesetzes vom 1. Oktober 1920 (29) wurde jeder Staatsbürger der Republik Landesbürger jenes Bundeslandes, zu dem seine Heimatgemeinde gehörte, und zugleich auch Bundesbürger (Vgl. Art. 6 Abs. $\mathbb{B}$ BVG). 
Am 30. Juli 1925 wurde ein Bundesgesetz über den Erwerb und Verlust der Landes- und Bundesbürgerschaft (30) erlassen, das die bisherigen staatsangehörigkeitsrechtlichen Vorschriften (vor allem die des ABGB) aufhob. Das Bürgerschaftsgesetz von 1925 griff hinsichtlich der Erwerbs- und Verlustgründe der österreichischen Staatsangehörigkeit im wesentlichen auf die bis dann geltenden Regelungen zurück. Gemäß \& 5 waren eheliche oder legitimierte Kinder österreichisch, wenn der Vater diese Staatsangehörigkeit hatte; nichteheliche Kinder, wenn die Mutter Österreicherin war. $\$ 6$ bestimmte, daß eine Ausländerin durch Ehe mit einem Österreicher automatisch die österreichische Staatsangehörigkeit erwarb. Dagegen verlor eine Österreicherin gemäß § 9 durch Ehe mit einem Ausländer die österreichische Staatsangehörigkeit. Dieser automatische Verlust trat jedoch nicht ein, wenn die betreffende Frau durch die Verehelichung nicht die Staatsbürgerschaft ihres Mannes erwarb.

Besonders ausführlich regelte $\$ 4$ des Gesetzes die Verleihung der Staatsangehörigkeit. Diese war kraft Bundesverfassungsgesetz keine Bundes-, sondern Länderangelegenheit. Die ausfïhrliche Bestimmung des $\$ 4$ sollte' garantieren, $\mathrm{da} 3$ alle Bundesländer bei der Verleihung der Staatsangehörigkeit grundsätzlich die gleichen Kriterien anwendeten. Dabei war der Antritt eines öffentlichen Amtes im allgemeinen nicht mehr als Erwerbsgrund der österreichischen Staatsangehörigkeit vorgesehen; umso bemerkenswerter ist in diesem $\mathrm{Zu}$ sammenhang die Bestimmung des $\S 3$ Ziffer 2 Buchstabe b: danach erwarben Ausländer durch Antritt eines öffentlichen Lehramtes an einer inländischen Hochschule die österreichische Staatsangehörigkeit.

Wichtigster Verlustgrund der österreichischen Staatsangehörigkeit war der freiwillige Erwerb einer fremden Staatsangehörigkeit ( $\$ 10 \mathrm{Abs}$. 1 Ziffer 1). "Aus triftigen Gründen" konnte aber Beibehaltung der österreichischen Staatsangehörigkeit genehmigt werden. Weiterhin trat der Verlust der Staatsangehörigkeit durch den freiwilligen Eintritt in den ausländischen öffentlichen Dienst oder Militärdienst ein ( $\$ 10$ Abs. 1 Ziffer 2) (31).

Das Gesetz vom 1925 wurde am 16. August 1933 (32) in bemerkenswerter Hinsicht geändert. Die neue Bestimmung schrieb den Verlust der Bürgerschaft vor,
"wenn ein Bürger im Ausland offenkundig, auf welche Weise immer österreichfeindliche Handlungen unterstützt, fördert oder an derartigen Unternehmungen teilnimmt oder wenn er sich zu diesem Zweck ins Ausland begeben hat. Das gleiche gilt, wenn er sich ohne Ausreise- bewilligung in einen Staat begibt, für den eine solche vorgeschrieben ist."

Diese Vorschrift sollte vor allem jene österreichischen Nationalsozialisten treffen, die sich nach Deutschland begeben hatten, um dort die Einverleibung Österreichs "vorzubereiten". Das erwähnte Gesetz bestimmte weiter, daß das Vermögen des aus diesen Gründen Ausgebürgerten vom Bundeskanzleramt zugunsten des Bundesschatzes für verfallen erklärt werden konnte. Dieser Verlust der Staatsangehörigkeit trat allerdings nicht automatisch ein. Die zuständigen Behörden mußten das Vorhandensein der angeführten Voraussetzungen feststellen und zutreffendenfalls den Verlust der Staatsangehörigkeit ausdrücklich aussprechen ( $\$ 16$ Abs. 2 StBG 1925, in der Fassung vom 16. August 1933). 
Durch Gesetz vom 13. März 1938 (33) wurde Österreich mit dem Deutschen Reich "wiedervereinigt". Es bekam den Status eines Landes des Deutschen Reiches. Die Verordnung über die deutsche Staatsangehörigkeit im Land Österreich vom 3. Juli 1938 (34) bestimmte, daß ab dem 13. März 1938 die bisherige österreichische Bundesbürgerschaft und die Landesbürgerschaft der ehemaligen österreichischen Bundesiänder weggefallen waren und alle bisherigen österreichischen Bundesbürger deutsche Staatsangehörige geworden waren.

Am 27. April 1945 (35) wurde proklamiert, daß der im Jahre 1938 dem österreichischen Volk aufgezwungene "AnschluB" null und michtig wäre (36). Durch Kundmachung der provisorischen Staatsregierung vom 29. Mai 1945 (37) wurden alle deutschen Rechtsvorschriften auf dem Gebiete der Staatsangehörigkeit außer Kraft gesetzt. Durch diese Aufhebung wurde aber die alte österreichische Regelung nicht wieder wirksam. Der Kreis der Personen, die ab dem 27. April 1945 automatisch österreichische Staatbürger waren, wurde durch das Staatsbürgerschaftsüberleitungsgesetz vom 10. Juli 1945 festgelegt (38). Daneben wurden wieder Optionsmöglichkeiten vorgesehen. Das Gesetz vom 10. Juli 1945 (39) (Staatsbürgerschaftsgesetz) regelte dann Erwerb und Verlust der Staatsbürgerschaft neu. Dieses Staatsbürgerschaftsgesetz 1945 entsprach in weiten Zügen dem Gesetz aus dem Jahre 1925 (40). Es wurde aber 1949 wesentlich geändert (41) und durch Kundmachung der Regierung vom 4. November 1949 als Staatsbürgerschaftsgesetz 1949 neu verkündet (42).

Folgende 1949 vorgenommene Änderungen sind an dieser Stelle erwähnenswert (43). So sollte das Kind eines staatenlosen Vaters und einer österreichischen Mutter die österreichische Staatsangehörigkeit erwerben ( $\S 3$ Abs. 1). Die Verehelichung einer Österreicherin mit einem Ausländer hatte zwar weiterhin zur Folge, daß eine solche Frau grundsätzlich die österreichische Staatsangehörigkeit verlor, falls sie die Staatsbürgerschaft ihres Ehegatten erwarb, aber die Beibehaltung der österreichischen Staatsbürgerschaft konnte ihr "aus triftigen Gründen" bewilligt werden ( 88 Abs. 1 Satz 2) (44).

Anfang der sechziger Jahre sollte das Staatsbürgerschaftsgesetz 1949 erneut geändert werden. Der unmittelbare Anlaß für die Neugestaltung des Staatsbürgerschaftsrechtes bildete die Notwendigkeit, neue beweisrechtliche Regeln bezüglich der Staatsangehörigkeit einzuführen (45) (46). Weiter wollte man das österreichische Staatsangehörigkeitsrecht in Übereinstimmung bringen mit der UN-Konvention vom 20. Februar 1957 betreffend die Staatsbürgerschaft der Ehefrau, mit dem UN-Abkommen vom 30. August 1961 betreffend die Verminderung der Staatenlosigkeit und mit der Europarat-Konvention vom 6. Mai 1963 über die Verminderung von Fällen mehrfacher Staatsangehörigkeit und betreffend Wehrpflicht bei mehrfacher Staatsangehörigkeit. Da wegen der vielen notwendigen Neuerungen kaum eine Bestimmung des Staatsbürgerschaftsgesetzes 1949 unverändert gelassen hätte werden können, wurde schließlich aus Gründen der Übersichtlichkeit ein völlig neues Gesetz beschlossen.

Das neue Staatsbürgerschaftsgesetz 1965 (47) brachte viele Änderumgen (48), die im Rahmen dieser allgemeinen Bemerkungen nicht alle erörtert werden 
können. Erwähnt sei aber, daß die Frau fortan eine völlig selbständige Position in der Staatsangehörigkeit einnahm.

Die erste Änderung des Staatsbürgerschaftsgesetzes 1965 erfolgte durch Novelle vom 11. Juli 1973 (49). Vor allem wurden Änderungen der Einbürgerungsvoraussetzungen vorgenommen (50). Bereits 1974 wurde wieder eine Staatsbürgerschaftsgesetznovelle (51) verabschiedet. Sie enthielt insbesondere Änderungen, die wegen Einführung eines neuen Strafgesetzbuches erforderlich geworden waren (52). Zudem wurde die Vertretung minderjahriger Kinder in staatsangehörigkeitsrechtlichen Angelegenheiten durch Art. XIV des Bundesgesetzes vom 30. Juni 1977 über die Neuordnung des Kindschaftsrechts (53) geändert (54).

Die bisher wesentlichste Änderung des Staatsbürgerschaftsgesetzes 1965 erfolgte durch Bundesgesetz des 3. März 1983 (in Kraft getreten am 1. September 1983) (55). Kem dieser Reform war die Gleichstellung von Mann und Frau in staatsbürgerlicher Hinsicht. Diese Gleichstellung erfasste sowohl die Vermittlung der Staatsbürgerschaft an eheliche Kinder als auch den Enwerb der österreichischen Staatsangehörigkeit durch Ehepartner österreichischer Staatsbürger. Weiter wurde die Rechtsposition nichtehelicher Kinder österreichischer Männer und die staatsangehörigkeitsrechtliche Position von Adoptivkindern verbessert. Schließlich wurde eine erleichterte Einbürgerung volljähriger Behinderter unter besonderen Umständen möglich gemacht.

Auch nach dieser Staatsbürgerschaftsnovelle von 1983 ist jedoch keine gesetzgeberische Ruhe eingetreten (56), da der österreichische Verfassungsgerichtshof mit Urteil vom 12. Juni 1984 (57) den Erwerb der Staatsangehörigkeit durch Legitimation für verfassungswidrig erklärte. \& $7 \mathrm{Abs}$. $4 \mathrm{StBG}$ ist infolgedessen mit Wirkung vom 1. Juni 1985 außer Kraft getreten. Dieser Paragraph ordnete an, daß ein unehelich geborener Ausländer, insofern er noch minderjährig und ledig ist, mit seiner Legitimation die österreichische Staatsbürgerschaft erwarb, wenn sein Vater zu diesem Zeitpunkt oder bei seinem Tode Österreicher war. Grundsätzlich sah der Verfassungsgerichtshof den Erwerb der Staatsbürgerschaft von Rechts wegen infolge Legitimation als gerechtfertigt an. Der Gerichtshof wies sogar ausdrücklich auf die Notwendigkeit einer solchen Regelung hin, da sonst der Erwerb der Staatsbïrgerschaft dem Kind eines Österreichers durch bloß kurzfristige Verzögenung der Eheschließung der Eltern endguiltig hätte verwehrt werden können. Der Gerichtshof vertrat aber die Ansicht, daß diese Zielsetzung allein es nicht rechtfertigte, "den Erwerb der österreichischen Staatsbürgerschaft ohne Rücksicht auf das Alter bis hin zur Großjährigkeit des Kindes gleicherweise zwingend vorzuschreiben".

In diesem Zusammenhang wurde darauf hingewiesen, daß das eheliche Kind ausländischer Eltern nicht automatisch die österreichische Staatsangehörigkeit erwerbe, wenn sein Vater oder seine Mutter durch Einbürgerung österreichischer Staatsbürger würde; es müsse vielmehr auch für das Kind die Staatsbürgerschaft gesondert beantragt werden ( $\$ \$ 17$ und 19 StBG). Der Verfassungsgerichtshof führte dazu aus:

"Vergleicht man nämlich die rigide Regellung der staatsbürgerschaftsrechtlichen Folgen der Legitimation mit der elastischen Gestaltung der 
Folgen des Erwerbes der österreichischen Staatsbürgerschaft durch einen Elternteil nach der Geburt eines ehelichen Kindes, so zeigt sich, daB das Gesetz Sachverhalte mit praktisch gleicher Interessenlage dermaßen unterschiedlich regelt, daß die familienrechtlichen Wirkungen diese Unterschiede nicht mehr tragen. Der Gesetzgeber verkennt offenbar, daB die nachträgliche Gleichstellung des unehelich geborenen mit dem ehelichen Kind in ihrer Wirkung auf eine Ungleichbehandlung hinausläuft, deren Berechtigung rasch abnimmt. Ist zwischen Geburt und Legitimation bereits eine längere Zeit verstrichen - das Kind etwa gar schon mündig (das heißt 14 Jahre, d.G) geworden -, so ist der Erwerb der Staatsbürgerschaft gegen den Willen aller Beteiligten jedenfalls dann nicht mehr sachgerecht, wenn die Mutter jene Staatsangehörigkeit beibehalten hat, die das Kind von ihr herleitet. Der Gesetzgeber hat folglich mit der Regelung des $\$ 7$ Abs. 4 Staatsbürgerschaft seinen rechtspolitischen Gestaltungsraum überschritten".

Der österreichische Gesetzgeber mußte nunmehr die durch die Aufhebung des $\$ 7$ Abs. 4 StBG entstandene Lücke durch eine verfassungskonforme Regelung schließen, die das legitimierte Kind mit dem ehelich geborenen Kind auch auf dem Gebiet des Staatsbürgerschaftsrechtes gleichstellte. In den Erläuterungen zu dem von der Regierung beim Nationalrat eingereichten Gesetzesentwurf wies die Regierung darauf hin, daß beim Entwerfen einer neuen Regelung nicht auf erprobte Vorbilder im Staatsangehörigkeitsrecht anderer Staaten zurückgegriffen werden konnte,

"weil die vergleichbaren Rechtsordnungen gleichartige Regelungen vorsehen wie die aufgehobene Bestimmung, sofern sie nicht sogar, wie etwa einige romanische Staaten, in welchen die Staatsangehörigkeit schon mit dem Vaterschaftsanerkenntnis erworben wird, den Erwerb der Staatsangehörigkeit kraft Gesetzes zu einem noch früheren Zeitpunkt eintreten lassen" (58).

Die Regierung hat sich deshalb von der neuen österreichischen Regelung der namensrechtlichen Wirkungen der Legitimation inspirieren lassen (59). Vorgeschlagen warde deshalb eine Regelung, kraft derer die Legitimation für den minderjährigen ledigen Fremden wie schon bisher den Erwerb der österreichischen Staatsbürgerschaft nach sich zieht. Ein bereits vierzehnjähriger Minderjähriger wird jedoch nur dann österreichischer Staatsbürger, wenn er und sein gesetzlicher Vertreter dem Erwerb der Staatsbürgerschaft zustimmen. Dieses "Mitbestimmungsrecht" soll nach dem Willen der Regierung jedoch nicht nur im Rahmen des Staatsangehörigkeitserwerbs bei Legitimation Anwendung finden. Es soll vielmehr konsequent im gesamten Staatsbürgerschaftsrecht verwirklicht werden. Der Regierungsentwurf sah deshalb vor, daß bei einem bereits vierzehnjährigen Minderjährigen jeder auf einer Willenserklärung beruhende Erwerb der österreichischen Staatsbürgerschaft an dessen Zustimmung gebunden ist, und daß auch ein Verlust der österreichischen Staatsbürgerschaft nummehr nicht mehr gegen seinen Willen sollte eintreten können. Die vorgeschlagene Staatsbürgerschaftsgesetz-Novelle 1985 wurde vom Parlement genehmigt und trat am 1. Juni 1985 in Kraft (60). Außer den bereits erwähnten Anderungen wurden durch die Novelle 1985 einige unwesentliche Detailkorrek- 
turen vorgenommen (61). Die letzte Staatsbürgerschafts-Novellierung fand 1986 statt (62), wodurch aber lediglich Art. 48 StBG revidiert wurde.

\subsubsection{Erwerb der Staatsangehörigkeit durch Geburt}

\subsubsection{Rückblick}

Schon \$ 28 ABGB (1811) fixierte den Grundsatz des ius sanguinis: Das eheliche Kind erwarb die österreichische Staatsangehörigkeit nur dann, wenn der Vater zum Zeitpunkt seiner Geburt österreichischer Staatsbürger war, das uneheliche hingegen, wenn die Mutter Österreicherin war. In diesem Zusammenhang sei aber auf $\S 29$ ABGB hingewiesen (63), kraft dessen Einwohner Österreichs nach zehnjährigem Wohnsitz im österreichischen Staat die österreichische Staatsangehörigkeit erwarben, insofern der betreffende Ausländer sich während dieser Zeit keine Strafe wegen eines Verbrechens zugezogen hatte. Alle in Österreich geborenen Kinder, deren Eltern schon mehr als 10 Jahre in Österreich lebten, erwarben also bei Geburt die Staatsangehörigkeit.

Die durch die Verehelichung eines österreichischen Mannes mit einer ausländischen Mutter legitimierten nichtehelichen Kinder erwarben als Folge der Legitimation die österreichische Staatsangehörigkeit (64). Durch Adoption hingegen konnte die österreichische Staatsangehörigkeit nicht erworben werden. Für in Österreich geborene Findelkinder trat die Vermutung ein, Österreicher zu sein $(65)$.

Mit Hof-Kanzlei-Dekret vom 1. März 1833 (66) wurde die Möglichkeit des Erwerbs der Staatsangehörigkeit durch zehnjährigen Aufenthalt in Österreich erheblich eingeschränkt: fortan wurde die österreichische Staatsangehörigkeit aus diesem Grund nicht mehr automatisch erworben. Der neue Staatsbürger mulBte vielmehr erst einen Untertaneneid leisten und darüber eine ihm ausgestellte Beglaubigungsurkunde erhalten. Diese Änderung hatte zur Folge, daB die österreichische Staatsangehörigkeit auch in wenigeren Fällen als vorher iure sanguinis erworben wurde.

Auch im Staatsbürgerschaftsgesetz 1925 wurde die österreichische Staatsangehörigkeit von ehelichen oder legitimierten Kindern ausschlieBlich iure sanguinis a patre erworben. Die österreichische Staatsangehörigkeit der Mutter war nur im Falle von nichtehelichen Kindern zu beachten ( $\$ 5$ StBG 1925). Eine entsprechende Regelung enthielt \& 3 StBG 1945. Erst durch die StBG-Änderung von 1949 konnte das eheliche oder legitimierte Kind einer österreichischen Mutter die österreichische Staatsangehörigkeit erwerben, falls der Vater staatenlos war.

Schon die Einführung des StBG 1965 bewirkte eine erneute Änderung: Seither erwarb das eheliche oder legitimierte Kind einer österreichischen Mutter und eines Ausländers, im Gegensatz zu der vorigen Regelung, in allen Fällen, in denen es sonst staatenlos sein würde, die österreichische Staatsangehörigkeit (67). Dies galt nicht nur, wenn der Vater staatenlos war, sondern auch, wenn er Angehöriger eines fremden Staates war, das Kind jedoch von ihm keine Staatsangehörigkeit herleiten konnte bzw. nicht kraft ius soli eine andere Staatsangehörigkeit erwarb ( $\$ 8$ Abs. 2 StBG 1965). Problemlos erwarben nichteheliche Kinder einer österreichischen Mutter deren Staatsangehörigkeit ( $\$ 3$ Abs. 1 StBG 1949). 
Durch Legitimation seitens eines österreichischen Vaters erwarb ein ausländisches nichteheliches Kind dessen Staatsbürgerschaft ( 83 Abs. 1 Satz 2 StBG 1949).

GemäB 12 StBG 1949 erwarben Findelkinder - bis zum Nachweis einer anderen Staatsangehörigkeit - iure soli die österreichische Staatsangehörigkeit. \$11 StBG 1949 bestimmte ausdrücklich, daß die staatsangehörigkeitsrechtliche Position eines Kindes nicht durch Adoption, Pflegeübernahme, Namensgebung oder Namensänderung beeinflußt würden.

Wesentliche Änderangen der Regelung des Erwerbs der Staatsangehörigkeit kraft Geburt erfolgten 1983, als die Gleichberechtigung von Mann und Frau im österreichischen Staatsangehörigkeitsrecht grundsätzlich realisiert wurde. Im Jahre 1985 wurde dem bereits vierzehnjährigen Minderjährigen ein Mitbestimmungsrecht in allen ihn betreffenden Fällen des Staatsangehörigkeitserwerbs oder -verlustes eingerăumt.

\subsubsection{Heutige Regelung}

Seit dem 1. September 1983 laßßt das österreichische Staatsbürgerschaftsgesetz ehelliche Kinder die österreichische Staatsbürgerschaft mit der Geburt erwerben, wenn zu diesem Zeitpunkt ein Elternteil österreichischer Staatsbürger ist oder vorher gestorben ist und zur Zeit seines Todes Österreicher war ( $\$ 7$ StBG). Es ist dabei unbeachtlich, ob das Kind im Inland oder im Ausland geboren ist.

Nichteheliche Kinder erwerben die österreichische Staatsangehörigkeit durch Geburt, wenn ihre Mutter zu dieser Zeit österreichische Staatsbürgerin ist (\$7 Abs. 3 StbG). Nichteheliche Kinder einer ausländischen Frau und eines österreichischen Vaters erwerben die österreichische Staatsangehörigkeit nicht automatisch. Dies gilt auch, wenn der Vater das Kind anerkannt hat oder die Vaterschaft durch gerichtliches Urteil festgestellt worden ist. Diese Kinder haben aber die Möglichkeit, unter erleichterten Bedingungen eingebürgert zu werden. Durch Legitimation erwirbt das nichtehelich geborene Kind einer ausländischen Mutter und eines österreichischen Vaters die österreichische Staatsbürgerschaft, wenn sein Vater zu diesem Zeitpunkt Österreicher ist oder dies bei seinem Tode war. Der Legitimierte, der zum Zeitpunkt der Legitimation jedoch bereits das 14. Lebensjahr vollendet hat, erwirbt durch die Legitimation ausschließlich die österreichische Staatsangehörigkeit, wenn er und sein gesetzliicher Vertreter diesem Erwerb innerhalb von drei Jahren nach der Legitimation zustimmen ( $\$ 7$ a StBG) (68). Sobald die letzte benötigte $\mathrm{Zu}-$ stimmungserklärung bei der Behörde vorliegt, wird der Legitimierte von Rechts wegen österreichischer Staatsangehöriger. Aus Gründen der Rechtssicherheit tritt ein rüickwirkender Erwerb der Staatsbürgerschaft nicht ein. Durch Adoption wird die österreichische Staatsangehörigkeit nicht erworben. Das Adoptivkind eines österreichischen Staatsbürgers kann jedoch unter erleichterten Voraussetzungen eingebürgert werden (69).

Das österreichische Recht kennt nicht die Möglichkeit von eindeutigem Erwerb der Staatsangehörigkeit kraft ius soli. $\& 8$ Abs. 1 StBG bestimmt jedoch, daß ein im Gebiet der Republik Österreich aufgefundenes Kind, das jünger als sechs Monate ist, bis zum Beweis des Gegenteiles als österreichischer Staatsbürger gilt. Ein Findling erwirbt die Staatsangehörigkeit also nicht iure soli; es gilt zu seinen Gunsten (nur) die praesumptio iuris, daß er durch Geburt Österreicher 
ist. Eine solche praesumptio iuris gilt auch zugunsten aller Personen, die in Österreich geboren werden, falls ihre Eltern (im Falle nichtehelicher Geburt ihre Mutter) ebenfalls in Österreich geboren wurden ( $\$ 8$ Abs. 2 StBG). Unter diesen Aspekten könnte man behaupten, daß \& 8 ius soli-Elemente beinhalte. Eine solche Wertung des $\$ 8$ wirkt jedoch mißverständlich. $\$ 8$ ist daher eher als eine widerlegbare praesumptio iuris dahingehend $\mathrm{zu}$ beschreiben, daB die österreichische Staatsangehörigkeit iure sanguinis erworben wurde (70).

Ein auf österreichischem Boden geborenes potentiell staatenloses Kind erwirbt nicht durch Geburt die österreichische Staatsangehörigkeit. \$14 StBG gibt einem solchen Kind lediglich die Möglichkeit, nach mindestens zehnjährigen Wohnsitz in Österreich unter erleichterten Bedingungen eingebürgert zu werden.

\subsubsection{Erwerb der Staatsangehörigkeit nach der Geburt}

\subsubsection{Rückblick}

\$29 ABGB (1811) eröffnete drei Möglichkeiten, die österreichische Staatsbürgerschaft anders als durch Geburt oder Legitimation zu enwerben. Dies geschah durch den Eintritt in den öfentlichen Dienst, durch zehnjährigen ununterbrochenen Wohnsitz in Österreich unter der Bedingung, daß̉ der Betreffende sich während dieser Zeit nicht wegen eines Verbrechens eine Strafe zugezogen hatte, oder durch Aufnahme eines Gewerbes, das die ordentliche Ansässigkeit im Lande notwendig machte. Ausdriicklich wurde dagegen von $\S 31$ ABGB bestimmt, daß "durch die bloße Inhabung oder zeitliche Benützung eines Landgutes, Hauses oder Grundstückes; durch die Anlegung eines Handels, einer Fabrik, oder die Theilnahme an einem von beiden, ohne persönliche Ansässigkeit in einem Lande dieser Staaten" die österreichische Staatsangehörigkeit nicht erworben wurde.

Gemäß § 30 ABGB konnte die österreichische Staatsangehörigkeit auch durch Einbürgerung erworben werden. Für die Einbürgerung wurde ausreichende Erwerbsfähigkeit vorausgesetzt oder ein Vermögen, das für die Emährung des Antragstellers ausreichte. Daneben mußte der Neubürger ein tadelloses sittliches Benehmen nachweisen (71). Später trat noch die Zusicherung des Heimatrechts durch eine österreichische Gemeinde für den Fall der Einbürgerung als Voraussetzung hinzu (72). Die Einbuirgerung erstreckte sich auf die Ehefrau und minderjährige Kinder des neuen Bürgers.

Die Erwerbstatbestände des $\$ 29$ ABGB wurden im Laufe des vergangenen Jahrhunderts erheblich eingeschränkt. Bezuiglich des Erwerbs durch Eintritt in den öffentlichen Dienst wurde bereits 1818 festgestellt, daß dies nicht für den Dienst als Offizier in der österreichischen Armee galt. 1828 wurde ausdrücklich festgestellt, $\mathrm{daB}$ es sich um einen wirklichen Staatsdienst und nicht nur um eine provisorische Dienstleistung handeln müsse. 1860 wurde die "Antretung eines Gewerbes" in Österreich als Erwerbsgrund aufgehoben (73). Der Erwerb der österreichischen Staatsangehörigkeit durch zehnjährigen Aufenthalt wurde 1855 dergestalt eingeschränkt, daß, neben dem Nachweis dieses Aufenthalts, es nun Voraussetzung wurde, auch einen Untertaneneid abzulegen. Erst durch Aushändigung einer Beglaubigungsurkunde erwarb der Neubürger dann die österreichische Staatsangehörigkeit (74). 
Die Vorschriften bezüglich der Einbürgerung waren im StBG 1925 wesentlich knapper gefasst als im StBG 1965 der heutigen Fassung. Dennoch entsprach \& 4 StBG 1925 weitgehend der heutigen Regelung. Auch 1925 wurde z.B. schon grundsätzlich gefordert, daß man die bisherige Staatsangehörigkeit im Falle der Einbürgenung aufgab ( $\$ 4$ Abs. 1 Ziffer 3 StBG 1925). Ein wichtiger Unterschied zu der heutigen Regelung war aber, daß die Einbürgenung prinzipiell schon dann erfolgen konnte, wenn ein vierjähriger Wohnsitz in Österreich nachzuweisen war (\& 4 Abs. 1 Ziffer 4 StBG 1925). Einbürgerungsansprüche kannte das Gesetz von 1925 nicht ( $\$ 4$ Abs. 5). Die ausländische Frau eines Österreichers wurde nach dem Gesetz von 1925 durch Ehe automatisch Österreicherin ( $86 \mathrm{StBG} 1925$ ).

Die Einbürgerungsworschriften, beziehungsweise die gesetzliche Stellung der ausländischen Ehegattin österreichischer Männer, erfuhren durch das StBG 1945 keine grundsätzliche Änderung (vgl. den $\$ 4$, bzw. 6 StBG 1945). Laut \& 5 Abs. 4 konnten jedoch Ausländer, die mehr als zehn Jahre ihren Wohnsitz in Österreich hatten, unter leichteren Bedingungen eingebürgert werden als andere. Das StBG 1925 kannte dagegen eine solche Bestimmung nicht (75). Neu war aber die Bestimmung des $\S 10$ StBG 1945, in der bestimmten Personen, die früher die österreichische Staatsangehörigkeit besessen hatten, ein Einbürgerungsanspruch gegeben wurde.

1947 wurden die Einbürgerungsvorschriften emeut geändert. Die erforderliche Dauer eines Wohnsitzes in Österreich wurde auf zehn Jahre festgelegt ( 85 Abs. 4 StBG). Ausländern, die bereits seit dreißig Jahren in Österreich lebten, wurde ein bedingter Einbïrgerungsanspruch gegeben ( $\$ 5$ Abs. $3 \mathrm{StBG}$ ).

Seit Einführung des neuen StBG 1965 erwarb die ausländische Frau, die einen Österreicher heiratete, nicht mehr automatisch die österreichische Staatsangehörigkeit. \& 9 des Gesetzes gab ihr aber die Möglichkeit, die Staatsbürgerschaft durch einfache Optionserklärung zu erwerben (76). Der ausländische Ehegatte einer Österreicherin dagegen hatte dieses Recht nicht. Falls er die österreichische Staatsangehörigkeit erwerben wollte, war eine gewöhnliche Einbürgerung erforderlich. Die Bedingungen für die Verleihung der Staatsbürrgerschaft wurden durch das Gesetz von 1965 im Vergleich zu dem vorigen StBG ausgebaut und verschärft. Allerdings wurde auch die Zahl der Einbürgerungsberechtigten vergrößert.

Nach 1965 wurden die Vorschriften bezüglich der Einbürgerung in mehreren Details geändert. Eine wesentliche Änderung der Rechtsstellung won ausländischen Ehegatten österreichischer Bürger erfolgte 1983. Seit 1985 erstreckt sich eine Einbürgerung nicht mehr auf bereits vierzehnjährige Kinder, wenn diese nicht ihre schriftliche Einwilligung erteilt haben.

\subsubsection{Heutige Regelung}

Außer durch Geburt und Legitimation kann die österreichische Staatsangehörigkeit durch Einbürgerung (Verleihung) erworben werden. Ein bemerkenswerter Erwerbsgrund der österreichischen Staatsangehörigkeit neben dieser Einbürgerung ist der Dienstantritt als ordentlicher Universitätsprofessor ader als ordentlicher Hochschulprofessor an einer österreichischen Universität oder Hochschule (77). Diese Regelung ergibt sich aus $\$ 25 \mathrm{Abs}$. 1 StBG, der auf Art. 6 des österreichischen Bundesverfassungsgesetzes zurückgeht. Der Ehegatte 
und die Kinder eines solchen Professors haben laut $\$ 25$ Abs. 2 und 3 StBG ein bedingtes und befristetes Optionsrecht auf die österreichische Staatsangehörigkeit. Weitere Optionsrechte gibt es im österreichischen Staatsbürgerschaftsgesetz. nicht (78). Hingewiesen sei aber noch auf $\$ 58 \mathrm{c}$ StBG: Diejenigen, die zwischen dem 5. März 1933 und 13. März 1938 aus Österreich ausgewandert sind, weil sie wegen ihres Eintretens für die demokratische Republik Österreich Verfolgungen ausgesetzt waren oder solche zu befürchten hatten, können unter bestimmten Voraussetzungen durch Wohnsitzbegründung in Österreich die österreichische Staatsbürgerschaft erwerben. Gleiches gilt für diejenigen, die nach dem 13. März 1938 aus Österreich geflohen waren, weil sie Verfolgungen durch Organe der Nationalsozialisten oder die Behörden des Dritten Reiches mit Grund zu befürchten hatten oder erlitten haben.

Die Einbürgerungsvorschriften werden im Staatsbürgerschaftsgesetz von 1965 besonders ausführlich behandelt. Der Grund dafür ist, daß die Einbürgerung der Kompetenz der einzelnen Bundesländer unterliegt. Die Vorschriften des StBG sollen daher bewirken, daß die Länder bei der Verieihung der österreichischen Staatsbürgerschaft weitgehend nach denselben Richtlinien vorgehen. Grundsätzlich muB ein Ausländer auch heute seit mindestens zehn Jahren seinen Wohnsitz in Österreich haben, bevor er eingebürgert werden kann ( $\$ 10$ Abs. 1 Ziffer 1 StBG). Minderjährige und Ausländer, die seit mindestens vier Jahren ununterbrochen ihren Wohnsitz in Österreich haben, können eingebürgert werden, wenn ein besonders zu beriicksichtigender Grund vorliegt (79). Allerdings muß das Land einen solchen Fall vor der Einbürgerung zunächst dem Bundesministerium für Inneres zur Anhörung vorlegen ( $\S 10$ Abs. 3 StBG). Außer der Forderung nach einem zehnjährigen Wohnsitz in Österreich werden in $\$ 10$ StBG noch andere Voraussetzungen genannt, deren Vorliegen für die Verleihung der österreichischen Staatsbürgerschaft erforderlich ist. So darf der Neubürger nicht wegen bestimmter strafbarer Handlungen verurteilt oder deswegen gegen ihn ein Verfahren anhängig sein ( $\$ 10$ Abs. 1 Ziffer 2, 3 und 4 StBG) (80). Ebensowenig ist eine Einbürgerung möglich, wenn dem Betreffenden der Aufenthalt in Österreich verboten ist $(\$ 10 \mathrm{Abs}$. 1 Ziffer $5 \mathrm{StBG})$. Weiter muß das bisherige Verhalten des Betreffenden Gewähr dafür bieten, daß er eine bejahende Einstellung zur Republik Österreich vertritt und keine Gefahr für die öffentliche Ruhe, Ordnung oder Sicherheit darstellt ( $(10$ Abs. 1 Ziffer 6 StBG) (81). In diesem Rahmen fordert das Staatsbürgerschaftsgesetz auch ein Treuegelöbnis ( $\$ 21$ StBG). \& 10 Abs. 1 Ziffer 7 StBG verlangt, daß der Lebensunterhalt der einzubürgernden Person hinreichend gesichert ist, es sei denn, daß sie sich ohne Verschulden in einer finanziellen Notlage befindet (82). GemäB $\$ 10$ Abs. 1 Ziffer 8 StBG darf der Neubürger nicht mit fremden Staaten in solchen Beziehungen stehen, die im Falle der Verleihung der Staatsbürgerschaft an ihn die Interessen oder das Ansehen von Österreich schädigen würden. Abs. 2 des $\S$ $10 \mathrm{StBG}$ enthălt Bestimmungen, die verhindern sollen, daß ein österreichischer Staatsbürger gleichzeitig noch Bürger anderer Staaten ist. Falls der Betreffende die für das Ausscheiden aus seinem bisherigen Statsverband erforderlichen Handlungen unterläßt, obwohl diese ihm möglich und zumutbar sind, wird er in Österreich nicht eingebürgert. In diesem Zusammenhang sei auch auf $\$ 34$ Abs. 1 Ziffer 4 StBG hingewiesen, der den Behörden die Möglichkeit eröffnet, die neue österreichische Staatsangehörigkeit wieder zu entziehen, wenn die bisherige Staatsangehörigkeit beibehalten wird. Ausnahmsweise ( $\$ 10$ Abs. 4 StBG) kann eine Einbürgerung auch ohne einen zehnjährigen Wohnsitz in Österreich 
(83) und den Nachweis der Sicherung des Lebensunterhaltes gewährt werden ( 810 Abs. 1 unter 1 und 7). Dazu bedarf es der Bestätigung der Bundesregierung, daß die Verleihung der Staatsbürgerschaft wegen der von dem betreffenden Ausländer bereits erbrachten oder von ihm noch zu erwartenden auBerordentlichen Leistungen, insbesondere auf wissenschaftlichen, wirtschaftlichen, künstlerischen oder sportlichen Gebieten, im Interesse der Republik liegt (84). Hervorzuheben ist, daß die Landesbehörden bei der Anwendung des \&10 StBG freies Ermessen haben (85). $\$ 11$ StBG betont, daß dieses freie Ermessen unter Berificksichtigung des allgemeinen Wohls, der öffentlichen Interessen und des Gesamtverhaltens der einzubürgernden Person ausgeübt werden soll.

In einigen anderen Fällen ist den Behörden dagegen die Errnessensfreiheit entzogen. Die $\$ \$ 11 \mathrm{a}$ bis $14 \mathrm{StBG}$ geben bestimmten Ausländern einen Einbürgerungsanspruch. Alle diese Einbürgerungsansprüche bestehen allerdings nur, wenn die in $\$ 10$ Abs. 1 Ziffer 2 bis 8 und Abs. 2 StBG erwähnten Voraussetzungen erfuillt sind; nur die Forderung des zehnjährigen Wohnsitzes des $\$ 10$ Abs. 1 Ziffer 1 StBG entfallt also (obwohl in den $\$ 11$ a bis $14 \mathrm{StBG}$ häufig selbst abweichende Aufenthaltsforderungen gestellt werden).

§ 11a StBG gibt dem ausländischen Gatten eines österreichischen Bürgers einen bedingten Einbürgerungsanspruch. Dazu müssen aber zunächst die Voraussetzungen des $\& 10$ Abs. 1 Ziffer 2 bis 8 und Abs. 2 StBG erfüllt sein. Daneben ist dás Vorliegen folgender Voraussetzungen erforderlich. Selbstverständlich muß nachgewiesen werden, daß der Ehegatte Österreicher ist; weiter darf die Ehe nicht von Tisch und Bett oder auf sonstige Weise ohne Auflösung des Ehebandes gerichtlich geschieden sein. Die Ehe muß zudem bereits eine gewisse Zeit bestanden haben, bevor der Einbürgerungsanspruch entsteht. Wenn der ausländische Ehegatte keinen Wohnsitz in Österreich hat, entsteht der Anspruch erst nach fünfjähriger Ehe; zusätzlich wird gefordert, daß der österreichische Gatte zum Zeitpunkt der Einbürgerung seit mindestens zehn Jahren ununterbrochen österreichischer Staatsbürger ist. Lebt jedoch der ausländische Ehegatte in Österreich, so entsteht sein Einbürgerungsanspruch bereits früher. Nach vierjälhrigem ununterbrochenen Wohnsitz in Österreich entsteht der Anspruch nach einjähriger Ehe; nach dreijährigem Wohnsitz entsteht der Anspruch nach zweijähriger Ehe ( $\S 11 \mathrm{a}$ Abs. $4 \mathrm{StBG})$. Ein Einbürgerungsanspruch aufgrund des § 11. StBG entsteht nicht, falls der ausländische Gatte fríher Österreicher gewesen ist, die Staatsangehörigkeit ihm aber wegen erheblicher Schädigung der österreichischen Interessen oder des Ansehens der Republik im Dienste eines fremden Staates entzogen worden ist.

Es würde zu weit führen, hier die Einbürgerungsansprüche der $\S 12-14$ im Detail zu beschreiben. Es sollen hier deshalb nur noch die Grundzüge dieser Bestimmungen dargelegt werden. Laut $\S 12$ Buchstabe a StBG hat ein Ausländer nach 30-jährigem ununterbrochenen Wohnsitz in Österreich einen Einbürgerungsanspruch. Eine Ausnahme von dieser Regelung besteht dann, wenn er früher die österreichische Staatsangehörigkeit besaß, diese ihm aber entzogen worden ist, oder wenn er auf sie verzichtete. $\$ 12$ Buchstabe b StBG gibt Personen, die die österreichische Staatsangehörigkeit mindestens zehn Jahre ununterbrochen besessen haben und diese anders als durch Entziehung oder Verzicht verloren haben, einen Einbürgerungsanspruch nach einjährigem Wohnsitz in Österreich. Minderjährige, die die Staatsangehörigkeit anders als durch 
Entziehung verloren haben, haben nach Volljährigkeit einen auf zwei Jahre befristeten Einbürgerungsanspruch ( $\S 12$ Buchstabe c StBG).

Österreichischen Frauen, die durch Eheschließung mit einem Ausländer oder in Zusammenhang damit die österreichische Staatsangehörigkeit verloren haben, wird durch $\S 13$ StBG unter bestimmten Voraussetzungen ein Recht auf Wiedereinbürgerung gegeben.

In Österreich geborene Staatenlose haben nach mindestens zehnjährigem Wohnsitz in Österreich ein bedingtes Einbürgerungsrecht, es sei denn, sie hä̈tten bestimmte strafbare Handlungen begangen ( $\$ 14 \mathrm{StBG}$ ). Dieses Einbürgerungsrecht besteht $\mathrm{ab}$ Vollendung des 18 . Lebensjahres und muß spätestens zwei Jahre nach Eintritt der Volljährigkeit beantragt werden.

Eine Einbürgerung gilt nicht nur für den betreffenden Neubürger, sie erstreckt sich unter Umständen auch auf andere Personen, insbesonders auf seine minderjährigen Kinder $(\$ 17 \mathrm{StBG})$. Ausgenommen davon sind grundsätzlich bereits vierzehnjährige Kinder, die diesem Erwerb nicht zugestimmt haben ( $\$ 19$ Abs. 2 und $3 \mathrm{StBG}$ ) (86). Die Staatsbürgerschaftsverleihung kann auch auf ein volljähriges Kind erstreckt werden, wenn dieses Kind erheblich behindert ist und es entweder mit dem für die Erstreckung der Verleihung maßgebenden Elternteil im gemeinsamen Haushalt lebt oder diesem Elternteil die Sorgepflicht für das Kind obliegt und er seiner Unterhaltspflicht nachkommt (87). Bemerkenswert ist in diesem Zusammenhang noch die Vorschrift des $\$ 16 \mathrm{StBG}$, aufgrund derer die Verleihung der Staatsbürgerschaft sich unter bestimmten Voraussetzungen auch auf den Ehegatten der einzubürgernden Person erstreckt. Die Kosten einer Einbürgerung sind in $\$ 14 \mathrm{TP} 2$ Gebührengesetz geregelt. Für eine Ermessenseinbürgerung müssen 4000 Schilling, für eine Einbürgerung kraft Rechtsanspruch 3000 Schilling gezahlt werden. Die Kosten einer Erstreckung einer Einbiirgerung auf eine Ehefrau oder Erwerb der österreichischen Staatsangehörigkeit kraft Erklärung betragen 1000 Schilling.

\subsubsection{Verlustgründe}

\subsubsection{Rückblick (88)}

Nach $\$ 32$ ABGB verlor eine österreichische Frau ihre bisherige Staatsangehörigkeit durch Eheschließung mit einem Ausländer, auch wenn sie dadurch staatenlos wurde. Durch Legitimation verlor das noch minderjährige Kind einer Österreicherin und eines Ausländers seine österreichische Staatsbürgerschaft (89). Die Staatsbürgerschaft konnte weiter durch Auswanderung, d.h. endgültige Niederlassung im Ausland verloren werden (90).

Auch nach dem Gesetz von 1925 verlor eine Frau ihre österreichische Staatsangehörigkeit, wenn sie einen Ausländer heiratete. Der Verlust trat jedoch nur unter der Bedingung ein, daß sie durch die Ehe die Staatsangehörigkeit ihres Mannes erwarb ( $\$ 9 \mathrm{StBG} 1925)$. Die weiteren Verlustgründe entsprachen in ihren Grundzigen der heutigen Regelung. Einen Verzicht auf die österreichische Staatsangehörigkeit sah das Gesetz von 1925 nicht vor. In den allgemeinen Bemerkungen wurde schon darauf hingewiesen, daß 1933 die Verlustgriunde durch Einfügung des $\S 10$ Abs. 2 StBG 1925 ausgedehnt wurden. Danach 
fuihrte auch die im Ausland erfolgte Unterstützung von österreichfeindlichen Handlungen zum Verlust der österreichischen Staatsangehörigkeit.

Im StBG 1945 waren die Verlustgründe der Staatsangehörigkeit entsprechend dem Gesetz von 1925 geregelt. Der Inhalt des 1933 eingefügten $\S 10$ Abs. 2 StBG 1025 wurde allerdings nicht mehr aufgenommen.

1947 wurde die Position der österreichischen mit einem Ausländer verheirateten Frau etwas verbessert: auch wenn sie durch Ehe die Staatsangehörigkeit ihres Mannes erwarb, konnte ihr "aus triftigen Gründen" die Beibehaltung der bisherigen österreichischen Staatsangehörigkeit bewilligt werden $(\S 8$ Abs. 1 Satz 2 StBG) (91). 1965 wurde bestimmt, daß die österreichische Frau fortan durch Ehe mit einem Ausländer die Staatsangehörigkeit nicht mehr verlor. Der Verlust ihrer bisherigen Staatsangehörigkeit sollte nur eintreten, wenn sie bei oder nach der Eheschließung aufgrund ihrer ausdrücklichen Willenserklärung die Staatsangehörigkeit ihres Ehegatten erwarb. Die Verlustgründe der Staatsangehörigkeit wurden 1965 ausgedehnt. Der Erwerb einer fremden Staatsangehörigkeit durch Legitimation stellte fortan einen selbständigen Verlustgrund dar (\$31 StBG 1965). Die \$37 und 38 StBG 1965 öffneten weiterhin die Möglichkeit, im Falle der Mehrstaatlichkeit auf die österreichische Staatsangehörigkeit zu verzichten. Erwähnenswert ist schließlich die Bestimmung der § 34-36 StBG 1965, kraft derer Personen, welche die österreichische Staatsbürgerschaft durch Verleihung oder Erstreckung erworben haben, diese unter Umständen wieder zu entziehen ist, wenn sie aus Gründen, die sie selber zu vertreten haben, eine fremde Staatsangehörigkeit beibehalten haben.

Seit 1965 wurden die gesetzlichen Bestimmungen bezüglich des Verlustes der Staatsangehörigkeit in einigen Einzelheiten geändert, letztlich durch das Änderungsgesetz von 1983, das den Erwerb einer ausländischen Staatsangehörigkeit durch Legitimation als Verlustgrund aufhob. Seit 1985 kann ein bereits vierzehnjähriges Kind die österreichische Staatsangehörigkeit nicht mehr gegen seinen Willen verlieren.

\subsubsection{Heutige Regelung}

Der heute wichtigste Verlustgrund der österreichischen Staatsangehörigkeit ist der des \& 27: Erwerb einer fremden Staatsangehörigkeit aufgrund eines Antrages, einer Erklärung oder einer ausdrücklichen Zustimmung. Der Verlust tritt aber nicht ein, wenn dem Betreffenden vorher die Beibehaltung der österreichischen Staatsangehörigkeit bewilligt worden ist. Die Umstände, unter denen eine solche Bewilligung erfolgen kann, werden in $\$ 28$ StBG gegeben, wobei die Bestimmung des $\$ 28$ Abs. 1 Ziffer 1 besonders bemerkenswert ist: die Beibehaltung der österreichischen Staatsangehörigkeit muß im Interesse Österreichs liegen. Auch minderjährige Österreicher verlieren die österreichische Staatsangehörigkeit, wenn sie freiwillig eine ausländische Staatsangehörigkeit erwerben, aber dies nur, wenn der gesetzliche Vertreter (und u.U. Vormundschaftsgeticht oder Pflegschaftsgericht) ihre ausdrückliche Zustimmung zu dem Erwerb der anderen Staatsangehörigkeit gegeben haben. Soweit sie selbst schon das vierzehnte Lebensjahr vollendet haben, ist weiterhin ihre eigene ausdrückliche Zustimmung nötig; ohne diese Zustimmung tritt ein Verlust der Staatsangehörigkeit nicht ein. Es besteht übrigens ein seltsamer Kontrast zwischen der in $\$ 27$ 
Abs. 1 und 28 gebotenen Möglichkeit, die österreichische Staatsangehörigkeit u.U. beizubehalten im Falle des Erwerbs einer fremden Staatsangehörigkeit, und der - vor allem durch die Drohung des nachher noch zu besprechenen $\$ 34$ strengen Forderung des $\S 10$ Abs. 2, kraft dessen bei Erwerb der österreichischen Staatsangehörigkeit alles Mögliche getan werden muB, um die bisherige Staatsangehörigkeit zu verlieren.

Der Verlust der österreichischen Staatsangehörigkeit tritt automatisch ein, wenn ein Österreicher freiwilligen Militärdienst für einen fremden Staates aufnimmt ( $\$ 32 \mathrm{StBG}$ ). Das StBG sieht nicht die Möglichkeit vor, durch Einwilligung von österreichischen Behörden diesem Verlust vorzubeugen (92). Der Eintritt in den Staatsdienst eines fremden Staates bewirkt dagegen keinen automatischen Verlust der Staatsangehörigkeit. Wenn der Betreffende aber durch sein Verhalten die Interessen oder das Ansehen Österreichs erheblich schädigt, kann ihm die Staatsangehörigkeit entzogen werden (93).

Die Staatsangehörigkeit kann weiter unter bestimmten Voraussetzungen denjenigen entzogen werden, die die österreichische Staatsbuirgerschaft durch Einbürgerung erworben und zweil Jahre nach der Einbürgerung noch immer ihre friihere Staatsangehörigkeit beibehalten haben ( $\$ 34-36$ StBG) (94). \& $37 \mathrm{StBG}$ regelt den Verlust der Staatsangehörigkeit durch Verzicht (95). Ein Verzicht auf die österreichische Staatsbürgerschaft ist nur möglich, wenn der Betreffende noch eine andere Staatsangehörigkeit besitzt. Der Verzicht darf also keine Staatenlosigkeit zur Folge haben. Unter einigen Umständen kann derjenige, der noch nicht mehr als fünf Jahre seinen ununterbrochenen Wohnsitz auBerhalb Österreichs hat, nicht auf die österreichische Staatsangehörigkeit verzichten. Dies ist z.B. der Fall, wenn gegen den Betreffenden wegen einer strafbaren Handlung, die mit mehr als sechs Monaten Freiheitsstrafe bedroht ist, ein Strafverfahren anhängig oder eine Strafvollstreckung eingeleitet ist. Männer dürfen zudem nicht auf die Staatsangehörigkeit verzichten, soweit sie im österreichischen Bundesheer Dienst tun oder - wenn sie zwischen 16 und 36 Jahre alt sind - noch Militärdienst leisten müssen (siehe dazu die genaue Aufschliüsselung in $\$ 37$ Abs. 1 Ziffer 3). Laut \& 29 StBG erstreckt sich der Verlust der Staatsbürgerschaft u.U. auch auf die Kinder desjenigen, der die Staatsangehörigkeit durch Einbürgerung in ein anderes Land verliert. Dies gilt für bereits vierzehnjährige Kinder allerdings nur, wenn diese dazu ihre Zustimmung erteilt haben. 


\subsection{SCHWEIZ}

\subsubsection{Allgemeine Bemerkungen}

Das Staatsangehörigkeitsrecht der Schweiz ist im "Bundesgesetz über Erwerb und Verlust des Schweizer Bürgerrechts" (1) vom 29. September 1952 (weiter abgekürzt BüG) geregelt; es ist am 1. Januar 1953 in Kraft getreten. Die Schweiz ist ein Bundesstaat (2), der sich in Kantone und Gemeinden gliedert. Dieser Gliederung entsprechend unterliegt auch die schweizerische Staatsangehörigkeit einem dreistufigen Aufbau. Man muß daher Gemeindebürgerrecht, Kantonsbürgerrecht und Schweizer Bürgerrecht (3) (4) voneinander unterscheiden. Diese drei Bürgerrechte bilden trotz aller Unterschiede eine Einheit. Im Prinzip können sie nicht losgelöst voneinander bestehen (5). Die enge Beziehung zwischen dem Kantonsbürgerrecht und dem Schweizer Bürgerrecht (6) geht aus Art. 43 Bundesverfassung hervor. Dort heißt es: 'Jeder Kantonsbürger ist Schweizer Bürger". Dagegen wird das Gemeindebürgerrecht in der Bundesverfassung nicht erwähnt. Der Zusammenhang zwischen Kantonsbürgerrecht und Gemeindebürgerrecht ist aber wohl deutlich aus den einzelnen Verfassungen der Kantone zu erkennen. So heißt es z.B. in Art. 64 Abs. 1 der Verfassung des Kantons Bern wom 4. Juni 1893: "Das Gemeindebürgerrecht bildet die Grundlage des Kantonsbürgerrechts". Die Verbindung zwischen den drei Bürgerrechten wird weiter durch verschiedene Bestimmungen des BüG illustriert. Hervorzuheben sind in dieser Hinsicht namentlich die Art. 4 und 11 dieses Gesetzes. Art. 4 BüG lautet: "Wer das Schweizer Bürgerrecht erwirbt, erhält das Kantonsund Gemeindebürgerrecht....", während wir in Art. 11 BüG lesen können: "Wer das Schweizer Bürgerrecht von Gesetzes wegen verliert, verliert damit das Kantons- und Gemeindebürgerrecht." Auch von den Artikeln 6, 12 Abs. 1, 24, 28 Abs. 3, 30 Abs. 2, 42 Abs. 3 und 48 BiiG werden die engen Beziehungen zwischen den drei Bürgerrechten bestätigt.

Die Dreistufigkeit der schweizerischen Staatsangehörigkeit ist das Ergebnis einer langen historischen Entwicklung (7). Auf Grund bestimmter Regelungen, die den Unterhalt und die Versorgung von Armen betrafen, entstand zunächst das Gemeindebürgerrecht. Infolge des Tagsatzungsbeschlusses vom 30. September 1551 war jede Gemeinde verpflichtet, ihre eigenen Armen und Notleidenden zu unterstützen. Deshalb wurden Regelungen entwickelt, die die Zugehörigkeit der betroffenen Personen zu einer Gemeinde und mithin deren Zuständigkeit für diese bestimmten. Auf diese Weise entwickelte sich das Gemeindebürgerrecht. Die Gemeinden trugen diese Pflichten nur ungern. Sie wollten gewöhnlich eine Person erst dann als ilhren Bürger anerkennen, nachdem auch der Kanton, in dlem die Gemeinde lag, zu dieser Einbürgerung seine Einwilligung erteilt hatte (8). So entstand allmählich das Kantonsbürgerrecht. Das Schweizer Bürgerrecht ist jüngeren Datums. Zwar wurde um das Jahr 1800 die Schweiz als zentralistischer Staat gegrïndet (9), der nur eine schweizerische Staatsangehörigkeit kannte (10), aber dieser Staat bestand nur kurze Zeit. Erst die schweizerische Bundesverfassung von 1848 kannte dann wieder ein Schweizer Bürgerrecht, das eng mit dem Kantonsbürgerrecht und dem Gemeindebürgerrecht verknüpft war (11). Diese Konstruktion wurde von der noch heute geltenden Bundesverfassung aus dem Jahre 1874 übernommen.

Die Verteilung der Zuständigkeit zwischen Bund, Kantonen und Gemeinden in Angelegenheiten der Staatsangehörigkeit ist kompliziert. Sie soll daher an dieser 
Stelle nur in groben Zügen dargelegt werden. Der Schwerpunkt der Zuständigkeit hat sich im Laufe der Zeit allmählich von den Gemeinden über die Kantone zum Bund hin verschoben (12). Die Entwicklung der Zuständigkeitsverteilung läßt sich grundsätzlich aus den verfassungstechtlichen Vorschriften bezüglich der Staatsbürgerschaft ablesen. Diese Verfassungsvorschriften stellten auch den Rahmen dar, der mit den konkreten Bundesgesetzen über die Staatsbürgerschaft ausgefuillt wurde. In der Verfassung von 1848 lag das Schwergewicht der staatsangehörigkeitsrechtlichen Kompetenzen noch bei den Kantonen. Sie waren grundsätzlich berechtigt, eigenständig Regelungen für den Erwerb und Verlust des Bürgerrechts zu treffen. Dabei waren ihnen keine verfassungsrechtlichen Schranken gesetzt. Lediglich die Entziehung der Staatsbürgerschaft war ihnen durch die Verfassung verwehrt. Diese Kompetenzzuweisung änderte sich mit der heute noch geltenden Bundesverfassung vom 29. Mai 1874. In dieser Verfassung bezogen sich in der ursprünglichen Fassung die Art. 43, 44, 54 Abs. 4, 68 en 110 auf die Staatsangehörigkeit. In der heute geltenden Fassung sind diesbeziiglich lediglich noch die Art. 43, 44, 68 und 110 relevant. Die Aussage des Art. 44 hat sich im Laufe der Zeit aber erheblich geändert.

Art. 43 Abs. 1 BVerf, der noch heute in seiner ursprünglichen Fassung gilt, formuliert die enge Verbindung des Kantonsbürgerrechts mit dem Schweizer Bürgerrecht. Die Absätze 2-5 beziehen sich auf die politischen Rechte eines Kantonsbürgers. Absatz 6 bestimmt schließlich u.a., daß die kantonalen Gesetze uiber die Niederlassung der Genehmigung des Bundesrates unterliegen. In der ursprünglichen Fassung bestimmte Art. 44 Abs. 1 BVerf, daß kein Kanton einen Kantonsbürger aus seinem Gebiet verweisen oder ihn des Bürgerrechts verlustig erklären durfte. Für die Verteilung der Zuständigkeiten in. Angelegenheiten der Staatsangehörigkeit war Abs. 2 maßgebend:

"Die Bedingungen für die Erteilung des Bürgerrechts an Ausländer, sowie diejenigen, unter welchen ein Schweizer zum Zwecke der Erwerbung eines ausländischen Bürgerrechts auf sein Bürgerrecht verzichten kann, werden durch die Bundesgesetzgebung geordnet".

Art. 54 Abs. 4 BVerf bestimmte weiter, daß eine ausländische Frau durch Eheschließung mit einem schweizerischen Mann dessen Bürgerrecht erwarb. Art. 68 BVerf stellte fest, daß

"die Ausmittlung von Bürgerrechten für Heimatlose und die Maßregeln zur Verhinderung neuer Heimatloser"

Gegenstand der Bundesgesetzgebung waren. Schließlich bestimmte Art. 110 BVerf, daß Probleme bezüglich der Heimatlosigkeit und Buirgerrechtsstreitigkeiten zwischen Gemeinden verschiedener Kantone vom Bundesgericht zu beurteilen seien. Art. 68 und 110 BVerf gelten auch heute noch in ihrer ursprünglichen Fassung. Der Bund konnte also 1870 Vorschriften über die Einbürgerung, Wiedereinbürgerung und den Verzicht auf die Staatsbürgerschaft erlassen. Die Verfassung garantierte auch den Erwerb des schweizerischen Bürgerrechts durch die ausländische Gattin eines Schweizers. Die übrigen Erwerbs- und Verlustgriunde wurden mit Ausnahme der. Entziehung von den Kantonen geregelt. Für die kantonalen Regelungen hatte weiter Art. 54 Abs. 5 
BVerf Bedeutung, kraft dessen vorehelich geborene Kinder durch die nachfolgende Ehe der Eltern legitimiert wurden. Mit Inkrafttreten des schweizerischen Zivilgesetzbuches vom 10. Dezember 1907 am 1. Januar 1912 wurden Erwerb und Verlust des Bürgerrechts durch familienrechtliche Vorgänge einheitlich geregelt (13).

Nachdem bereits im Jahre 1922 vergeblich versucht wurde, Art. 44 BVerf zu ändern (14), wurde dieser Artikel 1928 neu gefaßt (15). Der Grund für diese Verfassungsänderung war die drohende Überfremdung der Schweiz durch die Menge der niedergelassenen Ausländer. Art. 44 BVerf erhielt folgende Fassung:

" 1) Ein Schweizer Bürger darf weder aus der Schweiz noch aus seinem Heimatkanton ausgewiesen werden.

2) Die Bedingungen für die Erteilung und den Verlust des Schweizer Bürgerrechts werden durch die Bundesgesetzgebung aufgestellt.

3) Sie kann bestimmen, daß das Kind ausländischer Eltern von Geburt an Schweizer Bürger ist, wenn seine Mutter von Abstammung Schweizer Bürgerin war und die Eltern zur Zeit der Geburt in der Schweiz ihren Wohnsitz haben. Die Einbürgerung erfolgt in der früheren Heimatgemeinde der Mutter.

4) Die Bundesgesetzgebung stellt die Grundsätze für die Wiederaufnahme in das Bürgerrecht auf.

5) Die auf Grund dieser Bestimmungen eingebürgerten Personen haben die Rechte eines Gemeindebürgers, mit der Einschränkung, daß sie keinen Anteil an den Bürger- oder Korporationsgütern erhalten, soweit die kantonale Gesetzgebung es nicht anders ordnet. Der Bund übernimmt bei den Einbürgerungen, die bei der Geburt erfolgt sind, bis zum vollendeten achtzehnten Altersjahr der Eingebürgerten wenigstens die Hälfte der den Kantonen und Gemeinden erwachsenden Unterstützungskosten. Einen gleichen Anteil übernimmt er bei Wiederaufnahmen in das Bürgerrecht während der ersten zehn Jahre nach der Aufnahme.

6) Die Bundesgesetzgebung bestimmt, in welchen Fällen bei Einbürgerungen Heimatloser eine Beitragsleistung an die den Kantonen und den Gemeinden erwachsenden Kosten stattfindet" .

Hervorzuheben ist insbesondere, daß mit der Neuregelung der Grundsatz der Unentziehbarkeit der Staatsbürgerschaft aufgegeben wurde. Daneben konnte der Bund nunmehr nicht nur die Bedingungen für Einbürgerung und Verzicht aufstellen, er konnte vielmehr auch die Voraussetzungen für eine (Wieder-)Einbürgerung und für alle Verlustgründe formulieren. Sehr bemerkenswert ist schlieBlich die Bestimmung des dritten Absatzes. Es sollte allerdings noch 50 Jahre dauern bis diese verfassungsrechtliche Möglichkeit im Jahre 1.978 tatsächlich benutzt wurde (16).

Anfang der siebziger Jahre wurde aufs neue über eine Änderung der yerfassungsrechtlichen Bestimmungen bezüglich des Bürgerrechts diskutiert. Ein Vorschllag zur Änderung des Art. 44 BVerf wurde 1977 verworfen (17). Eine umfassende Änderung wurde aber 1983 durchgeführt. Wichtigstes Ziel dieser Novellierung war es, die Gleichberechtigung von Mann und Frau im Staatsangehörigkeitsrecht zu realisieren. Der Wunsch nach Gleichbehandlung im Staatsangehörigkeitsrecht war spätestens ab 1981 sehr aktuell geworden, nachdem der 
Grundsatz der Gleichberechtigung der Geschlechter in die Verfassung aufgenommen worden war (18). Eine Durchfïhrung der Gleichberechtigung im Staatsangehörigkeitsrecht stieB jedoch auf verfassungsrechtliche Schranken. Namentlich die Art. 44 Abs. 3 und Art. 54 Abs. 4 BVerf standen der Verwirklichung entgegen. Art. 44 Abs. 3 BVerf ließ einen Erwerb des Schweizer Bürgerrechts a matre ausschlieBlich dann zu, wenn die Eltem ihren Wohnsitz in der Schweiz hatten. Bei Wohnsitz im Ausland konnte die Staatsangehörigkeit allein iure sanguinis a patre stattfinden. Art. 54 Abs. 4 BVerf sah einen automatischen Erwerb der schweizerischen Staatsangehörigkeit durch die ausländische Gattin eines Schweizer Bürgers vor. Diese Bestimmung diskriminierte eindeutig die ausländischen Männer schweizerischer Frauen. Durch Bundesbeschluß über Änderungen der Bürgerrechtsregelung vom 24. Juni 1983 wurde die Novellierung der Bundesverfassung beschlossen (19) und durch Referendum vom 4. Dezember 1983 angenommen (20). Durch diese Änderung wurde Art. 44 BVerf neu gefaßt und Art. 54 Abs. 4 BVerf aufgehoben. Seitdem ist der Wortlaut von Art. 44 BVerf:

" 1) Der Bund regelt den Erwerb und den Verlust des Bürgerrechts durch Abstammung, Heirat und Adoption sowie den Verlust des Schweizer Bürgerrechts und die Wiedereinbürgerung.

2) Das Schweizer Bürgerrecht kann auch durch Einbürgerung in einem Kanton und einer Gemeinde erworben werden. Die Einbürgerung erfolgt durch die Kantone, nachdem der Bund die Einbürgerungsbewilligung erteilt hat. Der Bund erläßt Mindestvorschriften.

3) Wer eingebürgert ist, hat die Rechte und Pflichten eines Kantons- und Gemeindebürgers. Soweit das kantonale Recht dies vorsieht, hat er Anteil an den Bürger- und Korporationsgütem."

Diese Neufassung von Art. 44 BVerf gibt dem Bund die Möglichkeit, unabhängig von der Kantonen, den Erwerb der Staatsbürgerschaft durch familienrechtliche Vorgänge sowie die Gründe für einen Verlust der Staatsbürgerschaft zu regeln. Für die Einbürgerung ist klar formuliert, daB der Bund zwar Mindestvorschriften erlässt, die Einbürgerungen jedoch tatsächlich von den Kantonen vorgenommen werden, nachdem der Bund eine entsprechende Einbürgerungsbewilligung erteilt hat. Den Kantonen steht also bezuiglich der Einbürgerungen durchaus eine eigenständige Entscheidungs- und Regelungskompetenz zu.

Gemäß den Verfassungsbestimmungen von 1874 wurden vom Bund zum ersten Mal im Bundesgesetz betreffend Erteilung des Schweizer Bürgerrechtes und den Verzicht auf dasselbe vom 3. Juli 1876 (21) eine entsprechende Regelung ausgearbeitet. Art. 4 dieses Gesetzes stellte fest, daß eine Erteilung des Gemeinde- und Kantonsbürgerrechts (und damit des Schweizer Bürgerrechts) ohne die Bewilligung des Bundesrates ungültig sei. Art. 2 formulierte die Voraussetzungen, die erfüllt werden mußten, damit der Bund seine Einwilligung erteilte. Art. 6 des Gesetzes von 1876 ließ den Verzicht auf die schweizerische Staatsangehörigkeit nur unter bestimmten Voraussetzungen zu.

Das Gesetz vom 3. September 1876 wurde abgelöst durch das Gesetz vom 25. Juni 1903 (22). In groben Zügen entsprachen sich cliese Gesetze fast buchstäblich. Abweichend war allerdings der Inhalt des neuen Art. 5, kraft dessen die Kantone unter gewissen Voraussetzungen den Erwerb der Kantonsbürgerschaft 
iure soli einführen durften. Diese Möglichkeit wurde jedoch nie genutzt. Weiter wurde die Regelung der Wiedereinbürgerung novelliert. Neu war auch die Möglichkeit, eine bereits erteilte Einbürgerungsbewilligung für nichtig zu erklären. Die Voraussetzungen für eine Einbürgerung und für eine Verzichtserklärung blieben aber unberiihrt. Das Gesetz von 1903 wurde in den Jahren 1920 und 1941 zweimal geändert (23). Durch Bundesgesetz vom 26. Juni 1920 (24) wurden die Einbürgerungsworaussetzungen des Art. 2 revidiert. Nachdem durch die oben bereits erwähnte Verfassungsnowelle von 1928 der Grundsatz der Unentziehbarkeit der Staatsangehörigkeit aufgegeben wurde, ermöglichte Art. 3 des Bundesratsbeschlusses vom 11. November 1941 (25) die Ausbürgerung von Doppelstaatlem. Am 18. Mai 1943 wurde durch BundesratsbeschluB sogar die Ausbiürgerung von Schweizern gestattet, die keine Doppelstaatler waren. Auch die Voraussetzungen für eine Einbürgerungseinwilligung wurden verschärft. Der Beschlu $B$ von 1941 änderte auch die staatsangehörigkeitsrechtliche Position einer mit einem Ausländer verheirateten schweizerischen Frau. Gemäß Art. 5 Abs. 1 verlor sie fortan nicht mehr die schweizerische Staatsangehörigkeit, wenn sie durch Eheschließung nicht die Staatsangehörigkeit ithres Ehemannes erwarb und diese auch nicht erwerben konnte (26).

Das schweizerische Staatsangehörigkeitsrecht wurde vom Bundesgesetz über Erwerb und Verlust des Schweizer Bürgerrechts vom 29. September 1952 (BüG) eingehend reformiert. Das neue Gesetz, das 59 Artikel zählte, trat am 1. Januar 1953 in Kraft. Es bildet - obwohl des öfteren geändert - bis heute die Grundlage des schweizerischen Staatsangehörigkeitsrechts. Auf Bundesebene existieren weiter einige Verordnungen, die u.a. die zu erhebenden Gebühren betreffen. Daneben finden sich auch mehrere Vorschriften zum Staatsangehörigkeitsrecht im Zivilgesetzbuch (ZGB) aus dem Jahre 1907. Grundsätzlich betont Art. $22 \mathrm{ZGB}$, daß die Regelung der Staatsangehörigkeit eine Angelegenheit des öffentlichen Rechts ist. Da aber die Staatsangehörigkeit den sogenannten Personalstatus betrifft, haben doch viele Regelungen ihren Platz im ZGB gefunden. Dies sind namentlich solche Regelungen, die den Erwerb und Verlust der Staatsangehörigkeit durch familienrechtliche Fakten betreffen (Ehe, Abstammung, Legitimierung, Anerkennung). Im ZGB wird die Staatsangehörigkeit ausdrücklich in den Artikeln 22, 120 Ziffer 4, 161 Abs. 1, 271 und 422 Ziffer 2 erwähnt. Aber auch andere Artikel sind direkt oder indirekt für das Staatsangehörigkeitsrecht von Bedeutung. Beispiele dafür sind Art. 134 und 149 Abs. 1 ZGB. Neben diesen Vorschriften auf Bundesebene sind für die Einbürgerung vor allem staatsangehörigkeitsrechtliche Vorschriften auf kantonaler Ebene wichtig. Fast alle Kantone haben in ihrer Kantonsverfassung diesbeziigliche Bestimmungen. Selbstverständlich findet man auch in den Kantonen Gesetze, die den Erwerb und Verlust des Bürgerrechtes näher regeln, und die ihrerseits wiederum häufig durch Verordnungen ausgestaltet worden sind. Die Regelung des Gemeindebürgerrechts wird meistens in einem Gemeindegesetz getroffen (27).

Da mehrere Details des BüG bei der Besprechung der geltenden Erwerbs- und Verlustgründe erläutert werden, soll an dieser Stelle zum Stand der gesetzlichen Regelung im Jahre 1953 lediglich das folgende beispielhaft hervorgehoben werdlen. Ein eheliches Kind erwarb grundsätzlich die schweizerische Staatsangehörigkeit iure sanguinis a patre und ein nichteheliches Kind iure sanguinis a matre (Art. 1 BüG i.d.F. 1952). Erwarb ein eheliches Kind einer schweizeri- 
schen Mutter und eines ausländischen Vaters durch Geburt keine andere Staatsangehörigkeit, dann war es Schweizer Bürger (Art. 5 BüG i.d.F. 1952). Eine ausländische Frau, die einen Schweizer heiratete erwarb auch gemäß Art. 3 BüG i.d.F. 1952 automatisch die Staatsangehörigkeit ihres Mannes. Durch eine Änderung von Art. 120 ZGB (vorgenommen mittels Art. 56 Abs, 1 BüG) konnte aber eine Ehe fortan für nichtig erklärt werden,
"wenn die Ehefrau nicht eine Lebensgemeinschaft begruinden will, sondern die Vorschriften über die Einbürgerung umgehen will".

Einen bemerkenswerten Bruch mit dem alten Recht stellte Art. 10 BüG i.d.F. von 1952 dar: er betraf das im Ausland geborene Kind eines selbst ebenfalls im Ausland geborenen Schweizer Bürgers, das noch eine andere Staatsangehörigkeit besaB. Das Kind verlor am 22. Geburtstag die schweizerische Staatsbïrgerschaft, falls es nicht bis dahin einer schweizerischen Behörde gemeldet war oder schriftlich erklärt hatte, die schweizerische Staatsangehörigkeit beibehalten zu wollen. Daneben wurden die Voraussetzungen verschärft, unter denen die Schweizer Bürgerschaft im Wege der Einbürgerungsbewilligung erworben werden konnte.

Seit 1953 wurde das BüG viermal geändert. Eine Novellierung aus dem Jahre 1956 bot schweizerischen Frauen die Möglichkeit, ihre schweizerische Staatsangehörigkeit wiederzuerlangen, wenn sie diese durch Eheschließung wegen der im Zeitpunkt der Eheschließung geltenden rechtlichen Bestimmungen verloren hatten (28). Die anderen Änderungen des BüG hängen damit zusammen, daß man in der Schweiz - wie in vielen anderen Staaten - daran arbeitet, allmählich das Familienrecht den seit Anfang dieses Jahrhunderts grundlegend geänderten allgemeinen Lebensauffassungen anzupassen. Die erste Novellierung, die auch auf das Staatsangehörigkeitsrecht einwirkte, erfolgte auf dem Gebiet des Adoptionsrechts. Sie trat am 1. April 1973 in Kraft (29). Danach wurde mit Wirkung vom 1. Januar 1978 das Kinderrecht reformiert (30). Mit dieser Änderung des Kinderrechts sollte eine möglichst weitgehende Gleichbehandlung ehelicher und nichtehelicher Kinder erzielt werden. Dabei wurde unter anderem, die von Art. 44 Abs. 3 BVerf in der damaligen Fassung gegebene Möglichkeit der Einführung eines ius soli für in der Schweiz geborene Kinder einer schweizerischen Mutter, durch Einfügung des Art. 5 Bü zu Grunde gelegt. Eine weitere bemerkenswerte Änderung lag darin, daß fortan das Kind einer ausländischen Mutter, das von einem Schweizer anerkannt wird, nicht mehr die Staatsangehörigkeit des Vaters erwirbt. Die letzte, besonders erhebliche Novellierung des BüG erfolgte durch Bundesgesetz vom 14. Dezember 1984 (31). Seit dem Inkrafttreten dieser Gesetzesänderung am 1. Juli 1985 wird auch in der Schweiz die Staatsangehörigkeit a patre et a matre erworben. Diese Neuregelung wurde durch die Anderung der Bundesverfassung namentlich des Art. 44 ermöglicht. Diese Novellierung der Bundesverfassung wurde oben bereits beschrieben (32).

Die Gleichberechtigung von Mann und Frau ist im schweizerischen Staatsangehörigkeitsrecht jedoch noch immer nicht voll realisiert.

Durch die eben erwähnte Ändenung des BüG am 14. Dezember 1984 können nun Mann und Frau ihr Schweizer Bürgerrecht im Prinzip auf gleiche Weise ihren Kindern weitergeben. In der Schweiz wird aber beabsichtigt, den Grundsatz der Gleichstellung von Mann und Frau auch in den übrigen Bereichen des 
Bürgerrechtsgesetzes zu verwirklichen. Dazu wurde am 21. April 1986 ein Vorentwurf mit Erläuterungen veröffentlicht (33). Die wesentlichsten Neuerungen in diesem Vorentwurf sind die Aufhebung des automatischen Bürgerrechtserwerbs durch Heirat für die ausländische Ehefrau eines Schweizers (Streichung des Art. $3 \mathrm{BüG}$ ), die erleichterte Einbürgerung für ausländische Ehegatten von Schweizerinnen und Schweizern (Art. 27 (neu) in Verbindung mit Art. 26 (neu)) und die Möglichkeit für Ehegatten, individuell eingebürgert und individuell aus dem Schweizer Bürgerrecht entlassen zu werden (Streichung von Art. 32 und 43). Bemerkenswert ist weiter, daß vorgeschlagen wird, das nichteheliche Kind eines ausländischen Vaters solle automatisch die schweizerische Staatsangehörigkeit von Rechts wegen erwerben, wenn die familienrechtliche Beziehung zum Vater durch Anerkennung oder Vaterschaftsurteil feststeht. Die Novellierungsbestrebungen des Vorentwurfes sollen auch einige andere Mängel des Bürgerrechtsgesetzes beseitigen. Die Erläuterungen betonen, daß das schweizerische Staatsangehörigkeitsrecht nach dieser Revision mit verschiedenen internationalen Regelungen übereinstimmen wird. Es entspricht dann dem Übereinkommen der Vereinten Nationen vom 18. Dezember 1979 zur Beseitigung jeder Form von Diskriminierung der Frau, dem Übereinkommen vom 29. Januar 1957 über die Staatsangehörigkeit verheirateter Frauen, den Fakultativ-Protokollen vom 18. April 1961 beziehungsweise 24. April 1963 über Staatsangehörigkeitserwerb zu den Wiener Übereinkommen über diplomatische beziehungsweise konsularische Beziehungen und den Resolutionen des Ministerkomitees des Europarates (77)12 und (85)2 über die Staatsangehörigkeit von Ehegatten verschiedener Staatsangehörigkeit beziehungsweise über Rechtsschutz gegen Benachteiligungen aufgrund des Geschlechts. Der Entwurf entspricht nicht in jeder Hinsicht der Konvention vom 30. August 1961 über die Verminderung der Staatenlosigkeit. Die allgemeinen Grundsätze dieses Abkommens werden zwar beachtet, Staatenlose erlangen aber in der Schweiz keinen Rechtsanspruch auf eine erleichterte Einbürgerung (34). Die von dem Vorentwurf vorgeschlagenen Novellierungen dürften voraussichtlich nicht vor 1990 realisiert werden. Über das Änderungsgesetz kann zudem eine Volksabstimmung verlangt werden (35). Bei der folgenden Beschreibung des geltenden schweizerischen Rechts wird an den einschlägigen Stellen jeweils auf die im Vorentwurf vorgeschlagenen Änderungen hingewiesen. Dabei wird dieser Vorentwurf als "Entwurf 1986" zitiert.

\subsubsection{Erwerb durch Geburt}

\subsubsection{Rüickblick}

Bereits im alten schweizerischen Recht galt der Grundsatz, daß das in einer rechtmäßigen Ehe gezeugte Kind das Bürgerrecht des Vaters, das nichteheliche Kind dagegen das Bürgerrecht der Mutter erhielt (36). Dieser Grundsatz war jedocth nicht im Gesetz formuliert. Auch in den Verfassungen von 1848 bzw. 1874 und im Bundesgesetz betreffend die Erwerbung des Schweizer Bürgerrechts und den Verzicht auf dasselbe vom 25. Juni 1903 findet man keine Bestimmung über den Erwerb des Schweizer Bürgerrechts durch Abstammung. Erst im BüG vom 29. September 1952 wurde dieser Abstammungsgrundsatz in Art. 1 kodifiziert (37). Nichteheliche Kinder erwarben bei Legitimation durch nachfolgende Heirat die Staatsangehörigkeit des schweizerischen Vaters (so bereits kraft Art. 54 Abs. 5 Bundesverfassung 1874) (38). Gemäß Art. 325 ZGB 
erwattb das nichteheliche Kind einer Ausländerin die schweizerische Staatsangehörigkeit, wenn es von einem Schweizer anerkannt (39) oder ihm mit Standesfolge zugesprochen wurde (40). Entsprechendes galt kraft Art. 1 Buchstaben b und c BüG i.d.F. 1952. Erst seit 1978 wird das Schweizer Bürgerrecht nicht mehr durch Anerkennung erworben. Seit 1973 kann dagegen die schweizerische Staatsangehörigkeit durch Adoption erworben werden. Vorher war dies nicht der Fall (41).

1928 wurde in der Bundesverfassung die Möglichkeit eröffnet "den in der Schweiz geborenen Kinder einer schweizerischen Mutter das Schweizer Bürgerrecht zu verleihen. Diese Möglichkeit wurde 1978 bei Änderung des BüG durch Einfügung des Art. 5 genutzt. Dort hieB es:

"Das Kind einer schweizerischen Mutter und ihres ausländischen Ehemannes erwirbt von Geburt an das Kantons- und Gemeindebürgerrecht der Mutter und damit das Schweizer Bürgerrecht:

a) wenn die Mutter von Abstammung Schweizer Bürgerin ist (42) und die Eltern zur Zeit der Geburt in der Schweiz ihren Wohnsitz haben;

b) wenn das Kind in den übrigen Fällen nicht von Geburt an eine andere Staatsangehörigkeit erwerben kann".(43)

Bei der Revision von 1984 wurde Art. 5 BüG wieder aufgehoben; seitdem gilt die heutige Regelung.

Seit 1952 erwirbt ein aufgefundenes Kind das Kantonsbürgerrecht des Kantons, in dem es ausgesetzt wurde, und damit gleichzeitig das Schweizer Bürgerrecht (Art. 6 BüG). Vorher erwarb ein solches Kind nicht automatisch die Staatsbirrgerschaft. Es mußte deshalb eingebürgert werden (44).

\subsubsection{Heutige Regelung}

Seit dem 1 Juli 1985 erwerben grundsätzlich alle ehelichen Kinder von Geburt an die schweizerische Staatsangehörigkeit, wenn ihr Vater oder ihre Mutter Schweizer Bürger sind (Art. 1 Abs. 1 Buchstabe a BüG) (45). Von diesem Prinzip gibt es eine interessante Ausnahme in Art. 2 BüG. Ein Kind, dessen Vater Ausländer ist, dessen Mutter ihr Schweizer Bürgerrecht aber nur durch eine frühere Heirat mit einem Schweizer erworben hat, kann die schweizerische Staatsangehörigkeit nicht durch Geburt erwerben. Dieser Ausschluß gilt nuir dann nicht, wenn das Kind durch Geburt keine andere Staatsangehörigkeit erwirbt, oder wenn es vor Erlangung der Volljährigkeit staatenlos wird. Gemäß Art. 3 BüG erwirbt eine ausländische Frau durch Eheschließung mit einem Schweizer Bürger noch immer automatisch die Staatsangehörigkeit der Schweiz. Art. 2 BüG bewirkt nun, daB die so erworbene Staatsangehörigkeit weniger schnell weitergegeben wird, als dies sonst der Fall ist. Diese Regelung des Art. 2 BüG wird aber wieder von Art. 28 BüG gemildert, kraft dessen ein solches Kind unter bestimmten Bedingungen leichter eingebürgert werden kann. Innerhalb von drei Jahren nach der Geburt kann die erleichterte Einbürgerung beantragt werden, wenn die Mutter eng mit der Schweiz verbunden ist, namentlich wenn sie in der Schweiz wohnt und dort schon wenigstens sechs Jahre gewohnt hat, oder wenn ein oder mehrere Kinder aus einer fruiheren Ehe der 
Mutter von Geburt an Schweizer Bürger sind. Die erleichterte Einbürgerung ist auch für ein Kind einer durch Ehe zur Schweizerin gewordenen Frau möglich, falls das betreffende Kind in der Schweiz wohnt und wenigstens sechs Jahre dort gelebt hat. In letzterem Fall, muß der Einbürgerungsantrag vor Vollendung des 22. Lebensjahres gestellt werden.

Das nichteheliche Kind erwirbt immer die schweizerische Staatsangehörigkeit, wenn die Mutter Schweizerin ist (Art. 1 Abs. 1 Buchstabe BüG). Dies gilt auch, wenn die Mutter selbst nur durch eine frühere Ehe Schweizerin geworden ist (46). Ein nichteheliches Kind kann die schweizerische Staatsangehörigkeit in zwei Fällen vom Vater herleiten. Es erwirbt die schweizerische Staatsangehörigkeit des Vaters, wenn die ausländische Mutter den schweizerischen Vater heiratet und das Kind deshalb legitimiert wird (Art. 1 Abs. 2 Buchstabe a BüG). Daneben erwirbt das nichteheliche Kind das Schweizer Bürgerrecht des Vaters, wenn es unter seiner elterlichen Gewalt aufwächst und durch Namensänderung seinen Familiennamen erhält (Art. 1 Abs. 2 Buchstabe b BüG). Dies wird aber nicht häufig der Fall sein (47). Ursprünglich wurde vom Bundesrat beabsichtigt, dem ausländischen nichtehelichen Kind bereits dann das Schweizer Bürgerrecht zuzubilligen, wenn es unter der bloßen Obhut seines schweizerischen Vaters stehen würde. Die zuständige Kommission fand dies jedoch nur gerechtfertigt, wenn das Rechtsverhältnis zwischen Vater und Kind eine gewisse Stabilität aufweise (48). Durch Anerkennung oder Feststellung der Vaterschaft wird die schweizerische Staatsangehörigkeit nicht erworben. Aus beiden Akten erwächst dem Kind auch kein Optionsrecht oder das Recht auf eine erleichterte Einbürgerung. Ein ausländisches minderjähriges Kind erwirbt die schweizerische Staatsangehörigkeit, wenn es von einem Schweizer oder einer Schweizerin adoptiert wird (Art. 7 Abs. 1 BüG) (49). Dies gilt nicht wenn es von einer Schweizerin adoptiert wird, die ihre Staatsangehörigkeit selbst nur durch Ehe erworben hat. In letzterem Falle ist wieder Art. 2 BüG anzuwenden.

Ein in der Schweiz aufgefundes Kind unbekannter Eltern ist Schweizer. Es verliert aber diese Staatsangehörigkeit, wenn während seiner Minderjährigkeit eine ausländische Abstammung festgestellt wird (Art. 6 Abs. 3 BüG). Stellt sich heraus, daß es durch Abstammung staatenlos ist, so erlischt das Schweizer Bügerrecht nicht. Diese Bestimmung ist die einzige Manifestierung des ius soli im Schweizer Staatsangehörigkeitsrecht. Allein die Tatsache, daß jemand in der Schweiz geboren wurde, gibt ihm weder ein Optionsrecht auf die schweizerische Staatsangehörigkeit noch wird auf diese Weise seine Einbïrgerung erleichtert. Falls ein Kind seine Jugend teilweise in der Schweiz verbracht hat, werden jedoch bei der Berechnung des für die Einbürgerung geforderten Aufenthaltszeitraums bestimmte Jahre doppelt gezählt (Art. 5 Abs. 2 und 3 BüG).

Da das Schweizer Bürgerrecht grundsätzlich nicht vom Kantons- und Gemeindebürgerrecht getrennt werden kann, regelt Art. $4 \mathrm{BüG}$, welches konkrete Kantons- und Gemeindebürgerrecht ein eheliches oder nichteheliches Kind durch Geburt erwirbt, wenn es von der Geburt an Schweizer Bürger ist. Auf diese Regelung soll im Rahmen dieser Abhandlung nicht näher eingegangen werden. Bemerkenswert ist aber, daß das Kind grundsätzlich das Gemeinde- und Kantonsbürgerrecht des Vaters erwirbt, auch wenn beide Eltern die schweizerische Staatsangehörigkeit besitzen. Die Gleichberechtigung von Mann und Frau ist in diesem Punkt also nicht realisiert. 
Im Entwuirf 1986 wird der Erwerb der schweizerischen Staatsbïrgerschaft in einigen interessanten Hinsichten geändert. Für Art. 1 BüG wird folgender Wortlaut vorgeschlagen:

"1. Das Kind eines Schweizer Bürgers erwirbt das Schweizer Bürgerrecht von Geburt an oder bei der Begründung eines Kindsverhältnisses, sofern es unmündig ist.

2. Hat das unmündige Kind bei der Begründung des Kindsverhältnisses eigene Kinder, erwerben diese ebenfalls das Schweizer Bürgerrecht".

Die nach geltendem Recht bestehende Einschränkung von Art. 1 BüG durch Art. 2 BüG bezüglich der Kinder von Schweizerinnen durch frühere Heirat soll wegfallen. Dies ist eine logische Konsequenz der ebenfalls vorgeschlagenen Aufhebung von Art. $3 \mathrm{BüG}$. Danach soll eine ausländische Frau, die einen Schweizer heiratet, die schweizerische Staatsangehörigkeit fortan nicht mehr automatisch erwerben. Auch die mit Art. 2 korrespondierende Vorschrift des Art. 7 Abs. $2 \mathrm{BüG}$ wird gestrichen. Wichtiger ist aber noch, daß im vorgeschllagenen Text des Art. 1 BüG die Begründung eines Kindschaftsverhältnisses zwischen dem schweizerischen Vater und dessen ausländischem nichtehelichen Kind (durch Anerkennung oder gerichtliches Urteil) dem Kind das Schweizer Bürgerrecht vermitteln soll. Die Erläuterungen sagen darüber:

"Die Einschränkungen des geltenden Rechts bedeuten eine Schlechterstellung des Kindes unverheirateter Eltern, für deren Aufrechterhaltung keine zwingenden Gründe vorliegen. Zwar ging man bei der Revision des Kindsrechts davon aus, daß das Kind vor allem daran interessiert sei, den gleichen Namen und das gleiche Bürgerrecht zu haben wie der Elternteil, bei dem es aufwachse. Das sei in der Regel die Mutter. Ihre soziale Verbindung mit dem Kind werde beeinträchtigt, wenn das Kind dem Vater im Namen und Bürgerrecht folge (vgl. Botschaft vom 5. Juni 1974 über die Änderung des ZGB, Ziff, 321-12). Diese Überlegungen zu Art. 271 Abs. 3 ZGB, die zu den Einschränkungen gemäß Art. 1 Abs. 2 Bst. b BüG führten, werden aber im internationalen Verhältnis (ausländische Mutter) der tatsächlichen Interessenlage nicht gerecht. Der Erwerb des Schweizer Bürgerrechts (zusätzlich zur ausländischen Staatsangehörigkeit der Mutter) liegt in der Regel im Interesse des Kindes.(Zitat unterbrochen) ....Zwar sind Gefälligkeitsanerkennungen vor allem aufgrund des schweizerischen internationalen Privatrechts, das ausländische Rechtsakte in großzïgiger Weise in der Schweiz wirksam werden läßt (vgl. IPR-Entwurf Art. 68 und 71, BB1. 1983, I, S. 488) nicht auszuschließen. Die Zahl der Mißbrauchsfälle dürfte aber gering sein".

\subsubsection{Enwerb mach der Geburt}

\subsubsection{Rückblick}

Seit 1876 waren es stets die Kantone, die die Einbürgerungspolitik bestimmten. Sie durften Ausländer jedoch nur nach vorheriger Bewilligung des Bundes einbuirgern. Im Bürgerrechtsgesetz von 1876 waren die Mindestvoraussetzungen für diese Einbürgerungsbewilligung in Art. 2 formuliert. Einbürgerungsbewerber mußten seit zwei Jahren ihren ordentlichen Wohnsitz in der Schweiz haben (50) 
und im Falle der Einbürgerung durften der Schweiz aus ihrer Stellung und ihren Verhälltnissen gegenüber dem bisherigen Heimatstaat keine Nachteile erwachsen. Aufgrund dieser Vorschrift mußten die Angehörigen einiger Staaten nachweisen, daß sie ihre Militärdienstpflicht erfüllt hatten, oder sie mußten eine Entlassungsbewilligung vorweisen (51). Wenn der Bund seine Einwilligung erteilt hatte, bestand dennoch gegenüber den Gemeinden und Kantonen kein Einbürgerungsanspruch. Einen Rechtsanspruch auf Einbürgerung hatten lediglich die Witwe, geschiedene Ehefrau oder Kinder eines entlassenen Schweizer Bürgers (A.r. 9). Diese Voraussetzungen für eine Einbürgerungsbewilligung wurden bei Einfuihrung des BüG 1903 inhaltlich nicht geändert (vgl. Art. 2 BüG i.d.F. von 1903). Im Jahre 1920 wurden jedoch wesentliche Änderungen vorgenommen. Seitdem konnte eine Einbürgerungsbewilligung nur an solche Bewerber erteilt werden, die während der letzten zwölf der Antragstellung auf Einbürgerung vorausgehenden Jahre mindestens sechs Jahre tatsächlich in der Schweiz gewohnt hatten. Für diesen Aufenthalt mußte von der zuständigen Behörde eine Aufenthalts- oder Niederlassungsbewilligung erteilt worden sein. Die letzten beiden der Antragstellung vorausgehenden Jahre mußte der Antragsteller auf jeden Fall in der Schweiz verbracht haben. Für Ausländer, die bis zur Vollendung des 20. Lebensjahres mindestens $10 \mathrm{Jahre}$ in der Schweiz verbracht hatten, galt eine herabgesetzte Mindestaufenthaltszeit: Sie konnten die Einwilligung erhalten, wenn sie während der letzten fünf Jahre vor Einreichung des Gesuches mindestens drei Jahre tatsächlich in der Schweiz gelebt hatten. Wie im bisherigen Recht wurde vorgeschrieben, daß die Beziehungen des Einbürgerungsbewerbers zu dem bisherigen Heimatstaat überprüft werden sollten. Nunmehr wurde aber weiter bestimmt, daß auch sonstige persönliche und Familienverhälttnisse des Einbürgerungsbewerbers zu berücksichtigen seien.

Der Bundesratsbeschluß vom 11. November 1941 machte die Einbürgerung vom Vorliegen einer weiteren Bedingung abhängig, die neben die uibrigen gesetzlichen Voraussetzungen trat. Danach konnte die Bewilligung der Einbürgerung nur erteilt werden, wenn die Behörde die volle Überzeugung gewonnen hatte, daß der Bewerber den schweizerischen Anschauungen und Verhältnissen entsprach, und wenn nach Charakter und Gesinnung von ihm erwartet werden konnte, daß er ein zuverlässiger Schweizer werden würde. Im Jahre 1952 wurde der geforderte Aufenthaltszeitraum grundsătzlich auf zwölf Jahre heraufgesetzt. Auch die übrigen Voraussetzungen wurden neu formuliert und bekamen ihre heutige Fassung.

Eine ausländische Frau, die einen Schweizer heiratete, erwarb die schweilzerische Staatsangehörigkeit. Um einem Mißbrauch dieser Regelung vorzubeugen, sah Art. 2 Abs. 2 des Bundesratbeschlusses vom 1.1. November 1941 die Möglichkeit vor, innerhalb von fünf Jahren nach Eheschließung den durch diese bewirkten Erwerb des Bürgerrechts für nichtig zu erklären, wenn der Eheschluß offenkundig die Umgehung der Einbürgerungsvorschriften bezweckte. Noch weiter ging aber seit 1952 Art. 120 Ziffer 4 ZGB, kraft dessen eine Ehe für nichtig erklärt wird, wenn sie lediglich wegen der staatsangehörigkeitsrechtlichen Folgen geschlossen worden ist (52). 


\section{2:8.3.2 Heutige Regelung}

Das schweizerische Staatsangehörigkeitsrecht kennt keine allgemeinen Optionsrechte auf die schweizerische Staatsangehörigkeit (53). Außer durch Legitimation, Namensänderung (Art. 1 Abs. 2 BüG), Adoption (Art. 7 BüG) oder für ausländische Frauen durch Ehe mit einem Schweizer (54), kann das Schweizer Bürgerrecht also nur durch Einbürgerung erworben werden. Die Einbürgerungen werden im $\mathrm{BüG}$ in ordentliche Einbürgerungen, erleichterte Einbürgerungen und Wiedereinbürgerungen unterschieden. Die Wiedereinbürgerung kann allerdings als besondere Form der erleichterten Einbürgerung betrachtet werden. Die Einbürgerung erfolgt durch die kantonale Behörde. Sie ist allerdings nur gültig, wenn eine Einbürgerungsbewilligung der Bundesbehörde vorliegt (Art. $12 \mathrm{Abs}$. 2 BüG). Art. 16 BüG betont weiter - eigentlich überflüssig neben Art. 12 -, daß die Verleihung eines Ehrenbürgerrechts an einen Ausländer durch einen Kanton oder eine Gemeinde ohne Bewilligung der Bundesbehörden nicht die Wirkungen einer Einbürgerung hat. Durch Erwerb des Kantons- und Gemeindebürgerrechts wird das Schweizer Bürgerrecht erworben. Diese grundsätzliche Zuständigkeit der Kantone bewirkt, daß im Prinzip die Kantone die Einbürgerungspolitik bestimmen. Die benötigte Bewilligung der Bundesbehörden bewirkt jedoch, daß zumindest die Grundlinien der Einbürgerungspolitik national einheitlich festgelegt werden. Einige Voraussetzungen für die Einbürgerung werden deshalb im BüG formuliert. Ein Einbiirgerungsantrag kann im Prinzip nur dann mit Aussicht auf Erfolg gestellt werden, wenn der betreffende Ausländer bereits insgesamt zwölf Jahre in der Schweiz gelebt hat, drei davon in den letzten fünf Jahren vor Einreichung des Gesuches. Während dieser Jahre muß er im Einklang mit den fremdenpolizeilichen Vorschriften der Schweiz gelebt haben (Art. 36 Abs. 1 BüG). Art. 36 Abs. 2 BüG stellt fest, daß ein nur kurzfristiger Aufenthalt im Ausland mit der Absicht auf Rückkehr den erforderlichen Wohnsitzzeitraum in der Schweiz nicht unterbricht. Eine Unterbrechung ist aber anzunehmen, wenn sich der Ausländer bei der Ausreise aus der Schweiz polizeilich abgemeldet oder sich mehr als sechs Monate unabgemeldet außerhalb der Schweiz aufgehalten hat (Art. 36 Abs. 3 BüG). Art. 15 Abs. 2 und 3 BüG bestimmen, daß unter bestimmten Voraussetzungen auch einzelne Jahre im Anrechnungszeitraum doppelt gezählt werden. Dies gilt für die Zeit, in der die Betreffenden zwischen ihrem vollendeten 10. und dem 20. Lebensjahr in der Schweiz gelebt haben; das gleiche gilt für die Zeit, in der ein Einbürgerungsbewerber in ehelicher Gemeinschaft mit einer gebürtigen Schweizerin in der Schweiz gelebt hat (Art. 15 Abs. 2 BüG). Art. 15 Abs. 3 BüG bestimmt schließlich, daß für (volljährige, vgl. Art. 7 BüG) Kinder, die durch Schweizer Bürger adoptiert werden, und für Kinder, die mit ihrer Mutter ausländischer Herkunft und deren schweizerischen Ehemann zusammenleben, bereits die in der Schweiz vor dem 10. Geburtstag verbrachte Zeit doppelt gezählt wird. Bemerkenswert ist die staatenangehörigkeitsrechtlliche Stellung des ausländischen Ehepartners einer Schweizerin. Er kann nach sechsjähriger Ehe einen Einbürgerungsantrag stellen (Art. 15 Abs. 2 BüG), falls das Ehepaar während dieser Zeit in der Schweiz zusammengelebt hat. Diese Position ist völlig verschieden von der Stellung der ausländischen Ehefrau eines schweizerischen Mannes. Letztere erwirbt die schweizerische Staatsangehörigkeit kraft Art. 3 BüG stets automatisch. Sie hat sogar keine Möglichkeit, den automatischen Erwerb auszuschlagen. Der ausländische Ehemann dagegen hat auch nach sechs 
Jahren keinen Einbürgerungsanspruch. Er hat nicht einmal ein Recht auf eine "erleichterte Einbürgerung"! (55).

Im BuG werden für die ordentliche Einbürgerung noch zwei weitere Voraussetzungen formuliert. VerhältnismäBig konkret ist die Forderung des Art. $17 \mathrm{BüG}$, $\mathrm{daB}$ der Einbürgerungbewerber alles zu unterlassen hat, was die Beibehaltung der bisherigen Staatsangehörigkeit bezweckt. Es wird sogar gefordert, daß "soweit es nach den Umständen zumutbar ist", auf die bisherige Staatsangehörigkeit verzichtet werden soll. Diese Bestimmung des Art. 17 BüG bezweckt eindeutig die Bekämpfung von Doppelstaatlichkeit. Dies ist insbesondere deshalb bemerkenswert, da die schweizerische Gesetzgebung ihrerseits bei freiwilligen Erwerb einer fremden Staatsbürgerschaft durch einen Schweizer dessen Schweizer Bürgerschaft nicht erlöschen läßt. In einem solchen Fall kann der Verlust der schweizerischen Staatsangehörigkeit nur durch Entlassung (Art. 42 BüG) oder - unter extremen Voraussetzungen - durch Entzug (Art. 48 BüG) erfollgen.

Eine weitere, jedoch außerordentlich vage Voraussetzung für die Einbürgerungsbewilligung, wird von Art. 14 BüG formuliert. Abs. 1 dieses Artikels stellt ganz pauschal fest, daß vor Erteilung der Bewilligung "die Eignung zur Einbürgerung" zu überprüfen ist. Abs. 2 lautet:

"Diese Untersuchung soll ein möglichst umfassendes Bild von der Persönlichkeit des Bewerbers und seiner Angehörigen geben".

Wie aber bereits betont wurde, sind diese Bestimmungen des BüG nur Rahmenvorschriften. Sie allein sind die Voraussetzungen, die erfüllt werden müssen, damit der Bund seine Einbürgerungseinwilligung erteilt. Die Kantone und Gemeinde dagegen können strengere Voraussetzungen fordern und sie tun dies auch tatsächlich. Die durch die Verbindung von Gemeinde-, Kantons- und Schweizer Bürgerrecht entstandene Dreistufigkeit des schweizerischen Staatsangehörigkeitsrechts bewirkt, daß auch das schweizerische Einbürgerungssystem dreistufig ist. Die Zuerkennung des Schweizer Bürgerrechts hängt letztlich vom Entscheid der Bürgergemeinde $a b$, in der der betreffende Ausländer lebt. Jeder Kanton und im Kanton jede Gemeinde ist im Prinzip autonom und berechtigt, unter Beachtung der Rahmenvorschriften des $\mathrm{BüG}$ die Einbürgerungsvoraussetzungen festzustellen.

Aus einer im Jahre 1981 durchgeführten Umfrage (56) ist hervorgegangen, daß die im Moment geltenden Normen über die kantonalen und kommunalen Wohnsitzerfordernisse und Taxen, sowie die weiteren geforderten Voraussetzungen und üblichen Beurteilungskriterien ganz erheblich voneinander abweichen. Alle 26 schweizerischen Kantone haben abweichende Voraussetzungen für die Einbürgerung formuliert und im Rahmen dieser in kantonalen Gesetzen genannten Voraussetzungen werden dann noch weiter voneinander abweichende Beurteilungskriterien benutzt. Dazu kommt daß die einzelnen Gemeinden jeweils Sonderkriterien benutzen können; dabei ist nicht auszuschließen, daß sie bei der Abwägung des öfteren hauptsächlich ihre eigene Kommunalpolitik im Auge behalten und die nationale Tragweite ihrer Entscheide überhaupt nicht ausreichend in Rechnung ziehen. Schon auf den ersten Blick fällt auf, daß die jeweiligen Wohnsitzerfordemisse ganz erheblich von 
einander abweichen. Das BüG fordert grundsätzlich nur einen zwölfjährigen Wohnsitz in der Schweiz, die Kantone und Gemeinde fordern jedoch auch noch jeweils, daß der einzubürgernde Ausländer während einiger Jahren im betreffenden Kanton und in der betreffenden Gemeinde gelebt hat (57). Ein innerhalb der Schweiz oder sogar innerhalb eines Kantons sehr mobiler Ausländer wird also nicht eingebürgert werden können. Einige Kantone fordern einen mindestens zweijährigen Wohnsitz in der Einbürgerungsgemeinde (Zürich (58), Bern (59)). Innerhalb dieser Kantone fordem einige Gemeinde dann jedoch wiederum einen längeren Wohnsitz. Es gibt aber auch Kantone, die eine sehr viel längere Aufenthaltszeit im Kanton fordern. So fordert die Stadt Luzern im Prinzip einen achtjährigen Wohnsitz (60), der Kanton Uri einen zehnjährigen Wohnsitz (61), und der Kanton Unterwalden nid dem Wald sogar einen zwölfjährigen Wolansitz im Kanton und einen dreijährigen Wohnsitz in der Einbürgerungsgemeinde (62). Erwähnt sei schließlich der Kanton St. Gallen, der zehn Jahre Wohnsitz im Kanton fordert (63), während in diesem Kanton wenigstens eine Gemeinde sogar zwanzigjährigen Wohnsitz fordert (64).

Die Einbürgerungsgebühren sind ebenfalls sehr unterschiedlich. Sowohl die Kantone als auch die Gemeinden fordern Einbürgerungstaxen. Im Kanton Luzern beträgt der billigste Gesamttarif 200 Schweizer Franken (65), im Kanton Genf der teuerste etwas über 75.000 Schweizer Franken (66).

Auch die übrigen Voraussetzungen und das Einbürgerungsverfahren weichen von einander $a b$. Das Verfahren soll hier nicht näher erörtert werden (67); erwähnenswert ist aber, daß einige Kantone Kurse für Bürgerrechtsbewerber organisieren (Zürich, Zug, Solothurn (68)). Sehr interessant ist jedoch, welche weiteren Einbürgerungsvoraussetzungen, die unterschiedlichen Kantone in ihren Gesetzen formuliert haben (69). Fast alle Kantone fordern ausdrücklich einen guten Leumund. Auch diese Voraussetzung ist in den verschiedenen Kantonen unterschiedlich formuliert. So heißt es abwechselnd: einwandfreie Lebensführung, tadelloser Leumund; einwandfreier Charakter, bürgerliche Ehrenfähigkeit, unbescholtenen Ruf. Zürich betont, daß der unbescholtene Ruf im wesentlichen aufgrund des Straf- und Betreibungsregisters beurteilt wird (70). Die Kantone Vaud (71) und Genf (72) bestimmen aber neben der Forderung der Unbescholtenheit noch ausdrücklich, daß der Bürgerrechtsbewerber nicht wegen emster Delikte verurteilt sein darf.

Acht Kantone (73) fordern die Fähigkeit des Bürgerrechtsbewerbers, den Lebensunterhalt seiner Familie zu gewährleisten. Vier Kantone (74) setzen geordnete persönliche Verhältnisse voraus, womit wohl (75) ebenfalls die Gewährleistung der Unterhaltssicherung gemeint ist. Drei Kantone (76) fordern die Erfüllung der privaten und öffentlichen Verpflichtungen. In diesem Zusammenhang soll auch die Forderung von Vaud (77) und Genf (78) erwähnt werden, daB der Antragsteller kein Sozialhilfeempfänger sein darf.

Dreizehn (79) Kantone verlangen eine ausreichende Möglichkeit bzw. Fähigkeit zur Eingliedenung und Assimilation. Zürich beabsichtigt wohl dasselbe, wo es eine enge Bindung an die Schweiz fordert (80). Auffallend ist, daß Appenzell I.Rh (81) neben der Wohnsitzerfordernis als einzige weitere Voraussetzung für die Einbürgerung die "Assimilation" aufführt, aber im Rahmen der Überprüufung dieser Assimilation wohl wieder Familienverhältnisse, Gesundheitszustand, Schulbesuch und Ausbildung in der Schweiz und Mitgliedschaft in schweizerischen Vereinen berïcksichtigt (82). 
Sieben Kantone (83) fordern Vertrautheit mit den staatlichen Einrichtungen, drei Kantone (84) Vertrautheit mit den örtlichen und schweizerischen Gegebenheiten, drei weitere die Bejahung der verfassungmäßigen Ordnung (85).

Drei Kantone (86) setzen ausdrücklich die Handlungsfähigkeit des Einbürgerungsbewerbers voraus, ein Kanton (87) einen guten Gesundheitszustand und drei Kantone (88) wiederum sprachliche Anpassung an die schweizerische Umgebung.

Die Vielfalt der ausdrücklich formulierten Einbürgerungsvoraussetzungen ist beeindruckend. Göpfert und Heinzmann stellen deshalb die Frage, ob es nicht wïnschenswert oder gar erforderlich sei, eine gewisse Vereinfachung und schrittweise Harmonisierung der kantonalen und kommunalen Einbürgerungsvorschriften und -praktiken möglichst bald zu erreichen, dies insbesondere angesichts von rund 270.000 ausländischen Jugendlichen die heute in der Schweiz leben (89). Die Autoren fordern, daß die vielerorts geltenden Normen über die kantonalen und kommunalen Wohnsitzerfordernisse und Taxen sowie die Befragung und Beurteilungskriterien kritisch überprüft werden. Sie weisen darauf hin, daß die heutigen zum Teil sehr strengen Wohnsitzerfordernisse schwer mit der wirtschaftlich notwendigen Mobilität der Menschen zu vereinbaren sind. Auch die Erhebung unverhältnismäßig hoher finanzieller Leistungen von Einbürgerungskandidaten müsse kritisch überprüft werden, sowie die Doppel- und Mehrfachbefragungen durch verschiedene Instanzen.

Die ausdrücklich geforderten Voraussetzungen sind bereits sehr vielfältig. Daneben ist aber noch $\mathrm{zu}$ berücksichtigen, daß viele der vage formulierten Voraussetzungen in der Praxis näher konkretisiert werden. Die von den Behörden der unterschiedlichen Kantone in der Praxis als bedeutsam empfundenen Beurteilungskriterien sind von Göpfert/Heinzmann ebenfalls inventarisiert (90). Aus dieser Inventarisierung geht auch deutlich hervor, daß manche Kantone zwar bestimmte Erfordernisse nicht im Gesetz oder in einer Verordnung ausführen, sie aber in der Praxis durch tatsächliches Vorgehen anhand nur wenig konkreter Ausführungen dennoch zugrundelegen. Oben wurde davon schon ein Beispiel gegeben, als darauf hingewiesen wurde, daß Appenzell i. Rh. "nur" die Assimilation fordert, diese Forderung aber in der Praxis näher konkretisiert.

So fordern nur drei Kantone (91) ausdrücklich eine "sprachliche Anpassung", aber zwanzig Kantone erwähnen Kenntnis der Amtsprache als bedeutsames Beurteilungskriterium (92). Nur Basel (Land) betont, daß die Sprachkenntnisse als nebensächlich zu beurteilen seien (93). Und obwohl nur ein Kanton den Gesundheitszustand des Bewerbers ausdrücklich als Erfordernis aufstellt, erachten zehn Kantone diesen für ein wichtiges Kriterium (94). Weitere Beurteilungskriterien sind (95): Familienverhältnisse (18 Kantone), staatsbürgerliche Kenntnisse (15 Kantone), Beziehungen zum Herkunftsland (13 Kantone), politische Betätigung (13 Kantone) (Bejahung der verfassungsmässigen Ordnung; der Kanton Schwyz erläutert dieses Kriterium mit dem Hinweis, daß vom Ausländer ganz allgemein Zurückhaltung in Bezug auf die politische Betätigung erwartet werden darf), Mitgliedschaft in schweizerischen Vereinen (10 Kantone), Schulbesuch (und Ausbildung) in der Schweiz (9 Kantone) und Alter (3 Kantone). Ein Kanton erwähnt die Einstellung zum Militärdienst in der Schweiz und das Militärverhältnis zum Heimatstaat als Kriterium. Genf nennt noch guten 
Leumund und gute Assimilation als Beurteilungsmaßstäbe, während wenigens einige Gemeinden in Graubünden und St. Gallen sogar die Konfession im Rahmen des Einbürgerungsverfahrens beachtlich finden.

Oben sahen wir bereits, daß gemäß dem BüG Ehemänner von Schweizerinnen schneller als andere Ausländer eingebürgert werden können. Obwohl die Rahmenvorschriften des BüG diese Möglichkeit eröffnen, wird diese nur von relativ wenigen Kantonen benutzt. Dazu muß betont werden, daß einige Kantone ausschließlich Vergünstigungen für ausländische Ehemänner von denjenigen Frauen kennen, die das Kantonsbürgerrecht des betreffenden Kantons haben (z.B. Appenzell i.Rh, St. Gallen) (96).

Besonders aus der vagen Vorschrift des Art. 14 BüG geht deutlich hervor, daß die Erteilung einer Einbürgenungseinwilligung im freien Ermessen der Behörde liegt. Dieses freie Ermessen erscheint noch größer zu sein als zunächst erwartet, da Art. 37 Abs. 1 BüG grundsätzlich den Änspruch auf Akteneinsicht verneint (97). In Art. 14 Abs. $3 \mathrm{BüG}$ wird aber vorgeschrieben, daB die Verweigenung einer Einbürgerungseinwilligung begründet sein muß. Gegen die Verweigerung einer Einwilligung gemäß Art. 51 BüG kann eine Verwaltungsbeschwerde erhoben werden.

Oben wurde darauf hingewiesen, daß die ordentliche Einbürgerung durch die kantonalen Behörde nach Einholung einer Einbüirgerungsbewilligung der Bundesbehörde erfolgt. Die erleichterte Einbürgerung (98) und die Wiedereinbürgerung erfolgen jedoch durch die Bundesbehörde nach Zustimmung der kantonalen Behörde (Art. 18, 26 BüG).

In drei Fällen ist eine erleichterte Einbürgerung vorgesehen. Grundsätzlich können Mann und Frau ihr Schweizer Bürgerrecht, wie oben ausgeführt, gleichermaßen an ihre Kinder weitergeben (Art. 1 BüG). Eine Ausnahme gilt jedoch für die Frau, die erst durch eine frühere Ehe kraft Art. 3 BüG Schweizerin geworden ist. Ihr ist es nur in beschränktem Umfang möglich, ihre schweizerische Staatsangehörigkeit an ihre Kinder weiterzugeben (Art. 2 und Art. 1 Buchstabe b BüG). Die ausländischen Kinder einer solchen Schweizerin können aber unter bestimmten Voraussetzungen erleichtert eingebürgert werden (Art. $28 \mathrm{BüG}$ ). Darauf und auf die Voraussetzungen für eine solche erleichterte Einbürgerung wurde bereits oben hingewiesen.

Ein außerordentlich interessanter Fall einer erleichterten Einbürgerung findet sich in Art. 29 Abs. 1 BüG. Wenn ein Ausländer während wenigstens fünf Jahren im guten Glauben gelebt hat, er sei Schweizer Bürger und während dieser Zeit von kantonalen oder Gemeindebehörden tatsächlich als solcher behandelt worden ist, dann kann er erleichtert eingebürgert werden. Nach Art. 29 Abs. 3 BüG wird die Mindestwohndauer von fünf Jahren nicht von denjenigen gefordert, die bereits den schweizerischen Militärdienst geleistet haben.

Die Vorschrift von Art. $30 \mathrm{BüG}$ ist dagegen weniger bedeutend; sie kommt wohl selten vor: Derjenige, der aufgrund eines Staatsvertrages die schweizerische Staatsangehörigkeit durch Option hätte erwerben kömnen, dies jedoch aus entschuldbaren Gründen nicht frist- oder formgerecht getan that, kann erleichtert eingebürgert werden, wenn er in der Schweiz lebt. 
Die erleichterte Einbürgerung ist im Unterschied zur ordentlichen Einbürgerung (Art. 38 BüG) unentgeltlich (Art. 26 Abs. 1 BüG); dies gilt auch für die Wiedereinbürgerung (Art. $18 \mathrm{BüG}$ ). Die erleichterte Einbürgerung ist keine bedingte Optionsmöglichkeit, denn die Bestimmungen der Art. 28,29, 30 BüG sind ausdrüicklich "Kann"-Vorschriften. Die Behörden haben ein freies Ermessen, nur der Ermessensfreiraum ist eingeschränkt.

Eine besondere Form der erleichterten Einbürgerung ist die Wiedereinbürgerung (Art. 18 ff. BüG). Nicht jeder ehemalige Schweizer Bürger kann jedoch erleichtert eingebürgert werden (99). Art. $19 \mathrm{BüG}$ erlaubt dies unter bestimmten Voraussetzungen fuir eine Frau, die durch Heirat oder Einbezug in die Entlassung ihres Ehemannes die schweizerische Staatsangehörigkeit verloren hat. Unter Umstănden (Art. 20 BüG) können auch die minderjährigen Kinder einer solchen Frau in die Wiedereinbürgerung mit einbezogen werden.

Art. 21 BüG sieht eine Wiedereinbürgerung für diejenigen vor, die die schweizerische Staatsangehörigkeit verloren haben, weil sie anläßlich eines Auslandaufenthalts aus entschuldbaren Grïnden die nach Art. 10 BüG erforderliche Meldung oder Erklärung unterlassen haben. Das Gesuch um Wiedereinbürgerung muß innerhalb von zehn Jahren nach Verlust der Staatsangehörigkeit gestellt werden. Ein Wohnsitz in der Schweiz ist dabei nicht erforderlich.

Kinder, die mit dem Inhaber der elterlichen Gewalt aus der schweizerischen Staatsangehörigkeit entlassen worden sind, können ebenfalls wiedereingebürgert werden. Sie müssen zur Zeit dles Wiedereinbürgerungsgesuches aber wieder in der Schweiz leben und dürfen höchstens 29 Jahre alt sein. Der Antrag muß innerhalb von zehn Jahren nach Zurüickkehr in die Schweiz gestellt werden (Art. 22 BüG).

Auch Erwachsene können unter Umständen wiedereingebürgert werden, nachdem sie aus dem Schweizer Bürgerrecht entlassen worden sind. Voraussetzung ist, daß sie durch besondere Verhältnisse genötigt waren, dlie Entlassung zu beantragen. Der Wiedereinbürgerungsantrag muß innerhalb von zehn Jahren nach Zurïckkehr in die Schweiz gestellt werden.

Im Entwurf 1986 werden eingehende Änderungen bezïglich der im BüG formulierten Voraussetzungen für eine Einbürgerungsbewilligung vorgeschllagen. Nach heute geltendem Recht schreibt Art. 14 BüG lediglich vor, daß die Eignung des Bewerbers zu prïfen ist. Im Entwurf wird dies ausgearbeitet und vorgeschrieben, daß dies namentlich voraussetzt, daß der Bewerber

"a) in die schweizerischen Verhältnisse eingegliedert ist;

b) mit den schweizerischen Lebensgewohnheiten, Sitten und Gebräuchen sowie Wertvorstellungen vertraut ist;

c) die öffentlichen und privaten Pflichten erfüllt;

d) die demokratische Rechtsordnung bejaht und die innere und äußere Sicherheit der Schweiz nicht gefährdet".

Für die Wiedereinbürgerung (Art. $18 \mathrm{BüG}$ ) wird dies anders formuliert. Vorausgesetzt wird, daß der Bewerber 

"a) die besonderen Voraussetzungen eines nachstehenden Artikels erfüllt;
b) mit der Schweiz verbunden ist;
c) nicht der Wiedereinbürgerung offensichtlich unwürdig ist;
d) die innere und äußere Sicherheit der Schweiz nicht gefährdet".

Der Entwurf 1986 will die Art. 19, 20 und 22 aufheben. Die Art. 21 und 23, die sich auf Wiedereinbürgerung nach Verlust wegen Verwirkung bei Geburt im Ausland beziehungsweise nach Verlust wegen Entlassung beziehen, werden neuformuliert. Die vorgeschlagene Neuformulierung sei hier zitiert, damit die oben zitierte Klausulierung von Art. 18 Buchstabe a konkretisiert wird. Art. 21 soll folgenden Text bekommen:

"1. Wer aus entschuldbaren Gründen die nach Artikel 10 erforderliche Meldung oder Erklärung unterlassen und dadurch das Schweizer Bürgerrecht verwirkt hat, kann innert zehn Jahren seit der Verwirkung ein Gesuch um Wiedereinbürgerung stellen.

2. Wohnt der Bewerber seit drei Jahren in der Schweiz, kann er das Gesuch auch nach Ablauf der Frist stellen".

Für Art. 23 wird folgende Fassung vorgeschlagen:

"Wer die Entlassung aus dem Schweizer Bürgerrecht beantragt hat oder als Kind in die Entlassung einbezogen wurde, kann ein Gesuch um Wiedereinbürgerung stellen, wenn er seit einem Jahr in der Schweiz wohnt".

Die Erfordernisse für eine erleichterte Einbürgerung sollen wieder etwas anders formuliert werden (Art. 26). Vorausgesetzt wird, daß der Bewerber

" a) in die schweizerischen Verhältmisse eingegliedert ist;

b) die öffentlichen und privaten Pflichten erfuillt;

c) die demokratische Rechtsordnung bejaht und die innere und äußere Sicherheit der Schweiz nicht gefährdet".

Besondere Bedeutung hat die erleichterte Einbürgerung für die ausländischen Ehegatten von Schweizer Bürgern. Im Entwurf 1986 wird eine Regelung vorgeschlagen, die - anders als das heutige Recht - ausländische Frauen von schweizerischen Männern und ausländische Männer von schweizerischen Frauen gleich behandelt. Vorgeschlagen wird deshalb die Aufhebung von Art. 3, die Anderung von Art. 15 Abs. 2 und 3, aber vor allem die neuen Artikel 27, 28 und 28a:

"Art. 27 (neu) Ehegatte eines Schweizer Bürgers

1) Ein Ausländer kann nach der Eheschließung mit einem Schweizer Bürger ein Gesuch um erleichterte Einbürgerung stellen, wenn er seit einem Jahr in der Schweiz wohnt und insgesamt wenigstens finf Jahre hier gewohnt hat, sowie seit drei Jahren in ehelicher Gremeinschaft mit dem Schweizer Bürger lebt. 
2) Die Wohnsitzfrist von insgesamt fünf Jahren ermäBigt sich bei einer Ehedauer von mindestens sechs Jahren auf vier Jahre und bei einer Ehedaver von mindestens neun Jahren auf drei Jahre.

3) Der Bewerber erhält das Kantons- und Gemeindebürgerrecht seines schweizerischen Ehegatten.

Art. 28 (neu) Ehegatte eines Auslandschweizers

1) Der ausländische Ehegatte eines Auslandschweizers kann das Gesuch um erleichterte Einbürgerung stellen, wenn er seit zwölf Jahren in ehelicher Gemeinschaft mit dem Schweizer Bürger lebt und wenn er mit der Schweiz eng verbunden ist, namentlich wenn er wenigstens füf Jahre in der Schweiz gelebt hat und eine Landessprache spricht.

2) Der Bewerber erhält das Kantons- und Gemeindebürgerrecht seines schweizerischen Ehegatten.

Art. 28a (neu) Ehegatte eines schweizerischen Auslandbeamten

1) Der ausländische Ehegatte eines Beamten des Bundes, der im dipplomatischen und konsularischen Dienst eingesetzt ist, kann das Gesuch um erleichterte Einbürgerung stellen, wenn er seit fünf Jahren in ehellicher Gemeinschaft mit dem Beamten lebt.

2) Der Bewerber erhält das Kantons- und Gemeindebürgerrecht seines schweizerischen Ehegatten."

\subsubsection{Verlust der Staatsangehörigkeit}

\subsubsection{Rückblick}

Neben familienrechtlichen Tatbeständen, wie Anerkennung, Legitimation und Eheschließung, konnte 1876 lediglich eine Verzichtserklärung den Verlust der schweizerischen Staatsbürgerschaft hervorrufen (100). Der freiwillige Erwerb einer fremden Staatsangehörigkeit, die Anstellung im ausländischen Staatsdienst oder Auswanderung aus der Schweiz bewirkten keinen Verlust des Schweizer Bürgerrechts. Eine Verzichtserklärung konnte abgegeben werden, wenn der Betreffende kein Domizil in der Schweiz mehr hatte, im Sinne der Gesetze des Staates in dem er lebte geschäftsfähig war und bereits eine andere Staatsangehörigkeit besaß oder wenn ihm eine solche zugesichert wurde (Art. 6 BRG 1876; Art. 7 BRG 1903). Die schweizerische Staatsangehörigkeit konnte nicht entzogen werdlen. Bis 1928 garantierte dies Art. 44 Abs. 2 BVerf. In jenem Jahr wurde die Verfassung aber geändert, damit die Schaffung einer Entzugsregelung ermöglicht wurde (101). Von dieser Möglichkeit wurde aber erst 1941 Gebrauch gemacht. Art. 2 Abs. 1 des Bundesratsbeschlusses vom 11. November 1941 ermöglichte die Nichtigerklärung von Einbürgerungen oder Wiedereinbiurgerungen für die Dauer won zehn Jahren nach Erwerb der Staatsangehörigkeit (102). Dies galt aber nur, wenn der Bewerber das Bürgerrecht durch bewuBt falsche Angaben oder durch Verhehlen von erheblichen Tatsachen erschlichen hatte oder wenn er sich als von offenkundig unschweizerischer Gesinnung erwies. Der Erwerb des Schweizer Bürgerrechts durch Eheschließung konnte innerhalb von fünf Jahren nach Eheschließung rïckgängig gemacht werden, wenn der Eheschluß offenkandig die Umgehung der Einbürgerungsvorschriften bezweckte (Art. 2 Abs. 2). Art. 3 des gleichen Beschlusses ermöglichte die 
Entziehung der Staatsangehörigkeit eines Doppelstaatlers wegen eines Verhaltens, das den Interessen oder dem Ansehen der Schweiz erheblich nachteilig war. Von in der Schweiz lebenden Doppelstaatlern konnte die Aufgabe der fremden Staatsangehörigkeit gefordert werden; bei deren Verweigerung war als Sanktion dann die Entziehung des Schweizer Bürgerrechts möglich. Seit dem BundesratsbeschluB vom 18. Mai 1943 konnten auch solchen Personen die Staatsangehörigkeit entzogen werden, die keine andere Staatsangebörigkeit besaßen; dies war möglich wenn sie im Ausland gegen die Schweiz gerichteten politischen Tätigkeiten nachgegangen waren (103). Nur in einem Fall wurde ein Verlustgrund durch BundesratsbeschluB vom 11. November 1941 nicht verschärft, sondem im Gegenteil gemäßigt. Art. 5 Abs. 2 bestimmte nämlich, daß eine Schweizerin fortan ihre bisherige Staatsangehörigkeit nicht durch Eheschließung mit einem Ausländer verlor, wenn ihr durch diese Ehe nicht die Staatsangehörigkeit ihres Ehepartners vermittelt wurde, und ihr auch weiter keine Möglichkeit geboten wurde diese zu erwerben (104). Art. 5 Abs. 3 bestimmte weiter, daB das eheliche Kind einer solchen Frau die schweizerische Staatsangehörigkeit erwarb (falls es sonst unvermeidlich staatenlos sein wiirde). Vor dem Jahre 1941 behielt eine Schweizerin lediglich gewolnheitsrechtlich ihre Staatsangehörigkeit, wenn sie durch Eheschlie/3ung mit einem Ausländer nicht dessen Staatsangehörigkeit erwarb.

Im BüG 1952 wurden die Verlustgründe zum Teile stark revidiert. Bei der nachfolgenden Besprechung des geltenden Rechts werden manche Details näher untersucht. Hier sei aber bereits auf folgende Änderungen hingewiesen: Nach Art. 9 Abs. 1 BüG hatte die Schweizerin, die einen Ausländer heiratete, fortan die Möglichkeit eine Beibehaltserklärung abzugeben. Die Möglichkeit, die schweizerische Staatsangehörigkeit durch freiwillige Erklärung aufzugeben, wurde nun als Entlassungsmöglichkeit gestaltet und nicht mehr wie bisher als Verzichtsmöglichkeit (Art. 42-47 BüG). Die Möglichkeit des Entzugs der Staatsangehörigkeit wurde beibehalten, aber im Vergleich zu den Bundesratsbeschlüsssen der Jahre 1941 und 1943 erheblich eingeschränkt. Die wichtigste Änderung erfolgte jedoch in Art. 10 BüG i.d.F. von 1952. Danach verlor das im Ausland geborene Kind eines ebenfalls im Ausland geborenen Schweizer Bürgers die schweizerische Staatsangehörigkeit mit der Vollendung des 22 . Lebensjahres, wenn es noch eine andere Staatsangehörigkeit besaß und wenn es nicht bis dahin einer schweizerischen Behörde gemeldet hatte, Schweizer Bürger bleiben zu wollen (105). Im Jahre 1984 wurde dieser Verlustgrund noch verschärft und erhielt die heutige Fassung.

\subsubsection{Heutige Regelung}

Die Verlustgrüinde der Staatsangehörigkeit werden im BïG unterschieden in Verlust von Rechts wegen und Verlust durch behördlichen BeschluB. Nach Art. 8a verliert ein minderjähriger Schweizer Bürger die schweizerische Staatsangehörigkeit, wenn er von einem Ausländer adoptiert wird und dadurch die Staatsangehörigkeit des Adoptierenden erwirbt oder diese bereits besitzt. Dies gilt allerdings nicht, wenn noch wenigstens ein (Adoptiv-)Elternteil die schweizerische Staatsbürgerschaft innehat (Art. 8a BüG) (106).

Noch ummer wird in Art. 9 BüG bestimmt, daß die Schweizerin, die einen Ausländer heiratet, ihre Staatsangehörigkeit verliert, wenn sie durch Heirat mit 
einem Ausländer dessen Staatsangehörigkeit erwirbt oder diese bereits besitzt, es sei denn, sie hat vor der EheschlieBung erklärt, das Schweizer Bürgertecht beibehalten zu wollen (107).

Dern im Ausland geborenen Schweizer Bürger droht noch ein weiterer Verlustgrund von Gesetzes wegen. Falls das im Ausland geborene schweizerische Kind noch eine andere Staatsangehörigkeit besitzt, verliert es die schweizerische Staatsangehörigkeit mit der Vollendung des 22 . Lebensjahres, wenn es bis zu diesem Zeitpunkt nicht einer schweizerischen Behörde gemeldet worden ist oder sich selber gemeldet hat oder schriftlich erklärt, das Schweizer Bürgerrecht beibehalten zu wollen. Der Verlust erstreckt sich auch auf dessen Kinder.

Weitere Verlustgrüinde sind die Entlassung, der Entzug der Staatsangehörigkeit und die Nichtigerklärung der Einbürgerung. Die grundsätzlichen Voraussetzungen für die Entlassung aus der schweizerischen Staatsangehörigkeit werden in Art. 42 BüG formuliert: der betreffende Schweizer Bürger darf keinen Wohnsitz in der Schweiz haben, er muß mindestens 20 Jahre alt sein und muß eine andere Staatsangehörigkeit besitzen oder ihm muß eine andere Staatsangehörigkeit zugesichert sein. Eine Frau kann in Prinzip nur mit ihrem Ehemann entlassen werden, muß aber dann auch die Voraussetzungen von Art. 42 erfüllen. Falls letzteres nicht der Fall ist, kann auch die Entlassung des Ehemannes verweigert werden. Die mit einem Ausländer verheiratete Schweizerin braucht die Voraussetzungen des Art. 42 BüG nicht zu erfüllen. Sie kann immer aus der schweizerischen Staatsangehörigkeit entlassen werden, wenn sie eine ausländische Staatsangehörigkeit besitzt, oder ihr eine solche zugesichert ist. Sie kann also auch trotz Wohnsitzes in der Schweiz aus ihrer schweizerischen Staatsangehörigkeit entlassen werden. Die Entlassung erstreckt sich grundsätzlich auch auf die minderjährigen Kinder eines Entlassenen. Falls diese bereits 16 Jahre alt sind, müssen sie ihrer Entllassung allerdings selbst zustimmen (Art. $44 \mathrm{BüG})$.

Art. 48 BüG bestimmt, daß einem Doppelstaatler die schweizerische Staatsangehörigkeit entzogen werden kann, wenn sein Verhalten den Interessen oder dem Ansehen der Schweiz erheblich nachteilig ist. Weiter regelt Art. 41 BüG die Nichtigerklärung der Einbürgerung. Dies ist innerhalb von fünf Jahren nach Einbürgerung möglich, wenn die Einbürgerung durch falsche Angaben oder Verheimlichung erheblicher Tatsachen erschlichen worden ist. Soweit nicht ausdrïcklich anders verfügt wird, erstreckt sich eine solche Nichtigerklärung auf alle Famillienmitglieder, deren Schweizer Bürgerrecht auf der nichtigerklärten Einbürgerung beruht.

Bemerkenswert ist, daß die schweizerische Staatsangehörigkeit nicht durch freiwilligen Erwerb (durch Optionserklärung, oder Einbürgerung) einer fremden Staatsangehörigkeit verloren wird. Bei Erwerb einer ausländischen Staatsangehörigkeit wird das Schweizer Bürgerrecht grundsätzlich beibehalten. Es gibt allerdings viele Fälle, in denen die ausländischen Behörden die Aufgabe der bisherigen Staatsangehörigkeit fordern. In diesen Fällen bietet Art. 42 BüG die Möglichkeit der Entlassung. In einigen Fällen werden die schweizerischen Behörden den Erwerb der ausländischen Staatsangehörigkeit als nachteilig für die Interessen oder das Ansehen der Schweiz beurteilen. Art. 48 BüG bietet dann die Möglichkeit des Entzugs. Aber grundsätzlich verhütet lediglich Art. 10 $B \ddot{G}$, daß die schweizerische Staatsangehörigkeit in perpetuum weitergegeben 
wird. Der im Ausland eingebürgerte Schweizer wird in der Regel (falls er bei Einbïrgerung schon 22 Jahre war), die schweizerische Staatsangehörigkeit nicht kraft Art. 10 BüG verlieren können. Seine Kinder verlieren diese aber grundsätzlich, wenn sie das 22 . Lebensjahr vollenden, es sei denn, sie erklären Schweizer Behörden gegenüber, die schweizerische Staatsangehörigkeit weiterhin beibehalten zu wollen.

Wiederkehr (108) weist auf die amtliche Begruindung zum BüG hin, aus der zu entnehmen ist, daß der schweizerische Widerstand gegen den Verlust der schweizerischen Staatsangehörigkeit bei freiwilligem Erwerb einer anderen Staatsangehörigkeit vor allem bei den überseeischen Schweizerkolonien zu suchen ist. In vielen typischen Einwanderungsstaaten werden Immigranten relativ schnell eingebürgert, ohne daß deswegen die Verbundenheit mit der Schweiz als Heimat aufhören muß.

"Jene Schweizerkolonien sind politisch, kulturell und wirtschaftlich zu bedeutsam, als daß ohne zwingende Gründe eine tiefgreifende Änderung eingeführt werden darf."

Die enge Verknüpfung des Schweizer Bürgerrechts mit dem Kantons- und Gemeindebürgerrecht bewirkt, daß mehrere Vorschriften die Konsequenzen des Verlusts des Schweizer Bürgerrechts für die Kantons- und Gemeindebürgerrechte und die Verteilung der Zuständigkeit zwischen Bundes-, Kantonalen- und Gemeindebehörde regeln. Diese Bestimmungen wollen wir hier außer Betracht lassen, da diese für den internationalen Vergleich weniger interessant sind.

Im Entwurf 1986 werden einige Änderungen der Verlustgründe vorgeschlagen. Erstens soll Art. 9 ersatzlos gestrichen werden. Durch Aufhebung von Art. 43 soll fortan die getrennte Entlassung der verheirateten Frau ermöglicht werden. Art. 42 soll neugefaßt werden, wobei fortan auch Minderjährige Entlassung verlangen können. 


\subsection{SPANIEN}

\subsubsection{Allgemeine Bemerkungen}

Seit 1889 ist das spanische Staatsangehörigkeitsrecht nach französischer Tradition im Zivilgesetzbuch (Art. 17-28 Código civil, hier jeweils abgekirzt als C.c.esp.) geregelt (I). Die diesbezüglichen Bestimmungen sind allerdings haüfig tiefgreifend abgeändert worden (2). Die Artikel wurden durch Gesetze vom 15. Juli 1954 (3), 2. Mai 1975 (4) und 13. Juli 1982 (5) neu gefasst. Im Rahmen dieses Abschnitts wird nur eine Skizze der Entwicklung des spanischen Staatsangehörigkeitsrechts seit 1889 gegeben. Die vorherigen Entwicklungen sollen nur in einigen Ansätzen gezeigt werden.

Im Mittelalter konnte der Status eines spanischen Untertans durch Geburt sowohl iure soli als iure sanguinis erworben werden (6). Zu Anfang des 17. Jahrhunderts herrschte das ius soli vor (7). Neben dem Erwerb kraft Geburt stand der Erwerb kraft "Einbürgerung". Dieser wurde bereits in den "Siete Partidas" von Alfonso X (13. Jahrhundert) erwähnt: der Status eines spanischen Untertans wurde durch Heirat, Bekehrung zum Christentum, zehnjährigen Aufenthalt im Territorium des Königs erworben (8). Gerade der Erwerbsgrund des zehnjährigen Aufenthalts hat die Geschichte des spanischen Staatsangehörigkeitsrechts stark beeinflußt. In späteren Jahrhunderten wurden durch Gesetze Bedingungen entwickelt, unter denen Personen, die bereits zehn Jahre in Spanien lebten das Bürgerrecht (vecindad) erwerben konnten (9).

Im vorigen Jahrhundert wurde die spanische Staatsangehörigkeit zunächst von Verfassungsbestimmungen geprägt (10). Dabei fällt auf, daß die Constitución de Cadiz von 1812 noch vom ius soli ausgeht (11). Neben der Geburt in Spanien waren weitere Möglichkeiten zum Erwerb der Staatsangehörigkeit die "carta de naturaleza" (Einbürgerungsbrief), "diez años de vecindad" (ein zehnjähriger Aufenthalt) und für Sklaven die Freilassung. Von der spanischen Staatsangehörigkeit muß nach der Constitución vom 1812 noch die Position des "ciudano" unterschieden werden (Art. 18-26). Nur letzterer konnte öffentliche Ämter bekleiden.

Auch die Constitución de la Monarquía Española vom 18. Juni 1837 (12) ging zwar vom ius soli aus, kannte aber zugleich den Erwerb der Staatsangehörigkeit iure sanguinis (13). Als weitere Erwerbsgründe wurden wieder die Eỉnbürgerung und vecindad erwähnt. Die Freilassung wurde nicht mehr genannt. Als Verlustgründe wurden Einbürgerung im Ausland und der Eintritt in fremden Staatsdienst ohne Erlaubnis genannt.

Att. 1 der Constitución vom 23. Mai 1845 enthielt identische Regeln (14). Die Erwerbsgruinde der Constitución vom 1. Juni 1869 (15) sind ebenfalls wieder identisch (Art. 1). Verlustgründe werden in der Constitución von 1869 nicht erwähnt. In der Constitución vom 30. Juni 1876 (16) werden wieder dieselben Erwerbsgründe erwähnt (Art. 1), nun aber auch wieder die Verlustgrüinde Einbürgerung und fremder Staatsdienst (17).

Einige weitere Regeln über Erwerb und Verlust der spanischen Staatsangehörigkeit enthielten die Königliche Verordung vom 17. November 1852 über "Die 
Ausländer in Spanien und ihre Einteilung" (18) und das Gesetz über das Personenstandsregister vom 17 . Juni 1870 (19).

Wie oben bereits erwähnt wurde, waren in den Código civil von 1889 (20) mehrere Bestimmungen über die Staatsangehörigkeit aufgenommen worden, die die betreffenden Regelungen der Verfassung von 1876 ausarbeiteten. Art. 17 ermöglichte den Erwerb der Staatsangehörigkeit iure soli und iure sanguinis, sowie durch Einbürgerung und vecindad. Der Erwerb iure soli wurde von Art. 19 relativiert, kraft dessen die in Spanien geborenen Ausländerkinder die spanische Staatsangehörigkeit ausdrücklich beantragen mußten (21). Der Erwerb der spanischen Staatsangehörigkeit durch Einbürgerung oder aufgrund einer zehnjährigen "vecindlad" wurde in Art. 25 erwähnt. Interessant ist, daß Art. 25 C.c.esp. für den Erwerb der spanischen den Verzicht auf die bisherige Staatsangehörigkeit forderte (22). Die spanische Staatsangehörigkeit wurde auch nach dem Código civil von 1889 durch Einbürgerung im Ausland oder den Dienst bei einem fremden Staat (Art. 20) verloren, weiter für eine Spanierin durch die Eheschließung mit einem Ausländer (Art. 22). Aus Art. 26 kann weiter gefolgert werden, daß Spanier ihre Staatsangehörigkeit dann verloren, wenn sie sich in einem Staat niederließen, in dem durch die Begründung eines Wohnsitzes schon die Staatsangehörigkeit erworben wurde, es sei denn, sie hatten den zuständigen spanischen Behörden gegenüber eine Erklärung abgegeben, weiterhin die spanische Staatsangehörigkeit beibehalten zu wollen (23). Der Código civil von 1889 sah in mehreren Bestimmungen (Art. 21, 22, 23, 24) vor, daß diejenigen, die die spanische Staatsangehörigkeit verloren hatten, sie unter relativ leichten Voraussetzungen zurückerwerben konnten (24). An dieser Stelle ist noch kurz auf die "vecindad" einzugehen. Es wurde nie festgestellt, unter welchen Bedingungen durch einen Aufenthalt die "vecindad" und dadurch die spanische Staatsangehörigkeit erworben wurde (25). Die Praxis der Behörden war, daß einige Jahre Aufenthalt, ein selbständiger Gewerbebetrieb oder die Ehe mit einer Spanierin zum Erwerb der "vecindad" genügten. Durch Verordnung vom 6. November 1916 wollte man diese Situation beenden, u.a. um zu verhindern, daß auf diese Art die vielen wegen des Ersten Weltkrieges nach Spanien geflohenen Deserteure die spanische Staatsangehörigkeit erwerben würden (26). Die Regelung von 1916 erforderte einen formellen Antrag zur Feststellung der "vecindad" und schaltete Zentralbehörden zur Überprüfung der Voraussetzungen ein. Die Regelung von 1916 wurde durch eine Verordnung vom 29. April 1931 wieder einigermaßen gelockert (27).

Nach der Revolution von 1931 wollte man das Staatsangehörigkeitsrecht eingehend ändern, um die Gleichberechtigung von Mann und Frau zu verwirklichen. Dies zeigte sich in der Constitución vom 1931 (28). Eine Ausländerin, die einen Spanier heiratete, erwarb nicht mehr - wie bisher - automatisch die spanische Staatsangehörigkeit. Sie hatte lediglich ein Optionsrecht auf die Staatsangehörigkeit ihres Mannes. Die Verfassung sagte nicht ausdrücklich, daß eine Spanierin, die einen Ausländer heiratete, ihre Staatsangehörigkeit beibehalten konnte. Dies wurde aber in der Regel wohl angenommen (29). Bemerkenswert ist, daß die Constitución von 1931 zwar wieder den Erwerb der Staatsangehörigkeit iure soli und iure sanguinis vorsah, aber - anders als in dem C.c.esp. in der Fassung von 1889 - zuerst den Erwerb iure sanguinis und dann erst den Erwerb iure soli erwähnte (bzw. Art. 23 Ziffer 1 und 2). 
Ein neuer Gedanke manifestierte sich in Art. 24 Abs. 2 der Constitución. Im Falle des freiwilligen Erwerbs einer fremden Staatsangehörigkeit ging zwar die spanische Staatsangehörigkeit verloren, es wurde aber eine Ausnahme von diesem Grundsatz formuliert:
"Im Falle einer tatsächlichen internationalen Gegenseitigkeit und in Über- einstimmung mit den gesetzlichen Erfordernissen und Förmlichkeiten wird Personen, die aus Portugal und den hispano-amerikanischen $\mathbb{L} a ̈ n-$ dern, einschließlich Brasilien stammen, nach Niederlassung auf spani- schen Hoheitsgebiet auf Antrag die spanische Staatsangehörigkeit ver- liehen, ohne daß sie ihre ursprüngliche Staatsangehörigkeit hierdurch verlieren. Spanier können sich in den vorbezeichneten Ländern, falls deren Gesetze nicht entgegenstehen, einbürgern lassen, auch wenn diese Länder Gegenseitigkeit nicht gewähren. Die bisherige Staatsangehörigkeit geht nicht verloren" (30) (31).

General Franco hat die von der Constitución 1931 geschaffene selbständige staatsangehörigkeitsrechtliche Position der verheirateten Frau durch Verordnung vom 24. Mai 1938 widerrufen und bestimmt, daß - rückwirkend - Art. 22 Código civil anzuwenden sei (32). In der Franco-Epoche wurde erst 1954 das Staatsangehörigkeitsrecht wesentlich revidiert (33). Durch eine Verordnung vom 9. März 1939 (34) wurde lediglich angeordnet, welche Unterlagen bei einem "vecindad"-Antrag überreicht werden mußten. Weiter wurde im Códligo Penal von 1944 die Möglichkeit geschaffen durch richterliches Urteil die Staatsangehörigkeit abzuerkennen (35). Schließlich wurden die Verlustgrunde nochmal in der "Fuero de los Españoles" erwähnt (36).

Eine entscheidende (37) Änderung erfolgte durch das Gesetz vom 15. Juli 1954 (38). Die neuen staatsangehörigkeitsrechtlichen Bestimmungen wurden wieder als Art. 17-27 in den Código civil eingeführt. Die Artikel werden hiemach als C.c.esp. (i.d.F.1954) zitiert. In den Código civil-Bestimmungen von 1954 wurde wieder ius soli und ius sanguinis gemischt. Der Erwerb iure sanguinis wurde wie in der Constitución von 1931 - an erster Stelle erwähnt (39). Die spanische Staatsangehörigkeit wurde gemäß Art. 17 C.c.esp. (i.d.F. 1954) von Kindern eines spanischen Vaters erworben. Das Kind einer spanischen Mutter erwarb deren Staatsangehörigkeit, wenn es nicht die Staatsangehörigkeit des Vaters erwarb (40). In Spanien aufgefundene Kinder erwarben ebenfalls die Staatsangehörigkeit Spaniens. Der Erwerb der spanischen Staatsangehörigkeit iure soli wurde wesentlich geändert: Nunmehr erwarben die in Spanien geborenen Kinder von Ausländern, die selber auch in Spanien geboren waren, die spanische Staatsangehörigkeit (Art. 17 Ziffer 3 C.c.esp. (i.d.F. 1954)) (41). Die übrigen auf spanischem Boden geborenen ausländischen Kinder hatten nach Art. 18 Ziffer 1 C.c.esp. (i.d.F. 1954) ein Optionsrecht auf die Staatsangehörigkeit (42).

Dasselbe galt für die im Ausland geborenen Kinder eines ursprünglich spanischen Vaters oder einer ursprünglich spanischen Mutter (Art. 18 Ziffer 2 C.c.esp. (i.d.F. (1954)). Diese Optionsrechte muBten innerhalb eines Jahres nach Volljährigkeit ausgeübt werden. In der Regelung von 1954 bestanden Einbürgerung und Erwerb der Staatsangehörigkeit aufgrund von "vecindad" nicht mehr nebeneinander. Vielmehr ist der Erwerb kraft "vecindad" in die Einbürgerung eingegliedert (43). Nach Art. 19 C.c.esp. (i.d.F. 1954) geschah die Einbürgerung 
nach freiem Ermessen des Staatschefs, falls besondere Umstände vorllagen oder der Antragsteller während des im Art. 20 bestimmten Zeitraums seinen Wohnsitz in Spanien hatte. Art. 20 C.c.esp. (1954) forderte grundsätzlich einen ununterbrochenen Aufenthalt von zehn Jahren. Diese Frist wurde aber unter bestimmten Voraussetzungen auf fünf oder sogar zwei Jahre heruntergesetzt. Im Prinzip ging die spanische Staatsangehörigkeit verloren durch Einbürgerung im Ausland (Art. 22 C.c.esp. (i.d.F. 1954), wieder mit der Ausnahme der iberoamerikanische Staaten und nun auch mit Ausnahme der Philippinen (44). Außerdem trat Verlust der Staatsangehörigkeit durch Einbürgerung nur für Volljährige ein, die schon mindestens drei Jahre außerhalb Spaniens lebten und nicht der aktiven Wehrpflicht unterlagen (45) (es sei denn, sie waren davon von der Regierung freigestellt). Ein Verlust der Staatsangehörigkeit durch fremde Einbürgerung sollte weiter nicht eintreten, wenn Spanien sich im Krieg befindet (46) und schließlich auch nicht wenn eine Ehefrau sich im Ausland selbständig einbürgern läßt (47).

Nach Art. 23 C.c.esp. (i.d.F. 1954) wurde die Staatsangehörigkeit weiter verloren durch vom Staatschef ausdrücklich (48) verbotenen fremden Wehr- oder Staatsdienst (49), durch Aberkennung aufgrund des Strafgesetzbuches (50) und durch Ehe einer Spanierin mit einem Ausländer, dessen Staatsangehörigkeit sie erwirbt (51). Ein weiterer Verlustgrund ergab sich schließlich aus Art. 26 C.c.esp. (i.d.F. 1954). Dieser Artikel bestimmte, daß diejenigen die im Ausland lebten und dort als Abkömmling eines ebenfalls im Ausland geborenen spanischen Bürgers geboren waren, die spanische Staatsangehörigkeit nicht verlören, wenn sie erklärten die spanische Staatsangehörigkeit beibehalten zu wollen (52). Ferner sahen die neuen C.c.-Bestimmungen von 1954 vor, daß diejenigen, die die spanische Staatsangehörigkeit verloren haben, in der Regel unter relativ leichten Bedingungen diese wiedererwerben konnten (53). $\mathrm{Zu}$ den neuen $\mathrm{Be}$ stimmungen des Código civil 1954 wurden Durchführungsbestimmungen durch eine Verordnung vom 24. April 1955 erlassen (54).

Die Código civil-Bestimmungen von 1954 gingen von einem "système unitaire" im Staatsangehörigkeitsrecht aus. Die Position der verheirateten Frau war völlig abhängig von der ihres Mannes. Dies empfand man Anfang der siebziger Jahre als unzeitgemäß (55). Durch das Gesetz von 2. Mai 1975 (56), wurden deshalb die staatsangehörigkeitsrechtliche Bestimmungen bezüglich der verheirateten Frau geändert (57). Das Änderungsgesetz trat am 5. Mai 1975 in Kraft. Das "système unitaire" wurde verlassen. Geändert wurden die Art. 19-25 C.c.esp.; die übrigen Artikel, insbesonders die über den Erwerb der spanischen Staatsangehörigkeit durch Geburt oder durch Option blieben unverändert. Fortan hatte eine Eheschließung keine Folgen mehr für die staatsangehörigkeitsrechtliche Position der Frau (Art. 21 C.c.esp. (i.d.F. 1975). Der ausländische Ehegatte (Mann oder Frau) eines spanischen Bürgers erhielt nunmehr ein Optionsrecht auf die spanische Staatsangehörigkeit (Art. 21 Abs. 3 C.c.esp. i.d. F. 1975). Erwerb oder Verlust der spanischen Staatsangehörigkeit von einem verheirateten Mann hatte keine Konsequenzen mehr für dessen Ehegattin. Weiter wurden die Einbürgerungsvoraussetzungen leicht geändert. Die Gesetzesänderung von 1975 bewirkte aber noch nicht, daß spanische Männer und Frauen die gleichen Möglichkeiten hatten, ihre Staatsangehörigkeit an ihre Kinder weiter zu leiten. Die Revidierung von 1975 bewirkte nur Teiländerungen der Staatsangehörigkcitsregelung. 
Durch das Gesetz vom 13. Juli 1982 (58), in Kraft getreten am 20. August 1982, wurden jedoch die staatsangehörigkeitsrechtlichen Bestimmungen aus dem Código civil völlig geändert und neugefaßt (59). Ziel dieser Änderung war vor allem, das Staatsangehörigkeitsrecht mit den Vorschriften der Spanischen Verfassung von 1978 (60) in Übereinstimmung zu bringen (61). In dieser Verfassung ist namentlich Art. 11 Abs. 2 von großer Bedeutung, kraft dessen keinem gebürtigen Spanier (español de origen) die Staatsangehörigkeit entzogen werden darf. Der dritte Absatz des Art. 11 öffnet die Möglichkeit, mit Ländern iberischer Kultur oder solchen, die durch besondere Beziehungen mit Spanien verbunden waren oder sind, Verträge über Doppelstaatlichkeit abzuschließen. Das Staatsangehörigkeitsrecht blieb aber Teil des Código civil, geregelt in den Artikeln 17 bis einschließlich 26. Diese Neuregelung soll im folgenden als C.c.esp. i.d. F. 1982 zitiert werden.

Die wichtigste Änderung von 1982 ist zweifelsohne die Regelung der Staatsangehörigkeit in der Weise, daß Vater und Mutter ihre Staatsangehörigkeit unter gleichen Bedingungen ihren Kindern weitergeben können. Die Art. 17-26 C.c.esp. i.d.F. 1982 sind aber nicht nur in dieser Hinsicht neuformuliert worden. In vielen Punkten hat das spanische Staatsangehörigkeitsrecht ein neues Gesicht bekommen.

\subsubsection{Erwerb der Staatsangehörigkeit durch Geburt}

\subsubsection{Rückblick}

Im spanischen Staatsangehörigkeitsrecht war ursprünglich der Erwerb iure soli vorherrschend. So wurde in der Verfassung von 1812 lediglich bestimmt, daB die spanische Staatsangehörigkeit bei Geburt in Spanien erworben wurde (Art. 5 Ziffer 1). Bei Geburt außerhalb Spaniens konnte die Staatsangehörigkeit deshalb nicht iure sanguinis erworben werden. Ab 1837 wurde der Erwerb iure soli eingeschränkt: Die spanische Staatsangehörigkeit wurde erst erworben, wenn diese von dem auf spanischem Boden geborenen Kind oder dessen Vater beansprucht wurde (62). In diesem Zusammenhang sei weiter auf die Königliche Verordnung vom 17. November 1852 über "Die Ausländer in Spanien und ihre Einteilung" hingewiesen. Art. 1 Ziffer 4 dieser Verordnung bestimmte, daß alle Personen, die als Kinder ausländischer Eltern oder als Kind eines ausländischen Vaters und einer spanischen Mutter in Spanien geboren sind, als Ausländer anzusehen sind, wenn sie nicht um die spanische Staatsangehörigkeit ersuchen. Bei Geburt im Ausland war seit 1837 Erwerb iure sanguinis möglich. Art. 1 Constitución 1837 bestimmte, daß außer die auf spanischem Territorium geborenen Kindern, auch die im Ausland geborenen Kinder eines spanischen Vaters oder einer spanischen Mutter Spanier wurden. Dieser Erwerb wurde aber für die im Ausland geborenen Kinder eines ausländischen Vaters und einer spanischen Mutter (63) dermaßen eingeschränkt, daß diese als Ausländer zu behandeln waren, falls sie die spanische Staatsangehörigkeit nicht ausdrücklich beansprucht hatten (Art. 1 Ziffer 2 der Königlichen Verordnung vom 17. November 1852). In dem Código civil von 1889 wurde in Art. 17 der Erwerb iure soli (Ziffer 1) neben dem Erwerb iure sanguinis (Ziffer 2) erwähnt. Von einem reinen Erwerb iure soli war keine Rede mehr, eher konnte von einem Optionsrecht auf die spanische Staatsangehörigkeit infolge der Geburt in Spanien gesprochen werden (siehe Art. 18 Abs. 2 und 19 C.c.esp. i.d.F. 1889). Entsprechendes galt nach der 
Verfassung von 1931. In jener Verfassung wurde auch ausdrücklich erwähnt, daB das in Spanien geborene Kind unbekannter Eltern Spanier ist.

Im Gesetz von 1954 stand das ius sanguinis an erster Stelle, nunmehr ausdrücklich als ius sanguinis a patre formuliert (Art. 17 Ziffer 1 C.c.esp. i.d.F. 1954) Von der Mutter konnte ein Kind die spanische Staatsangehörigkeit herleiten, wenn es nicht die Staatsangehörigkeit seines Vaters erwarb (Art. 17 Ziffer 2 C.c.esp. i.d.F. 1954). Das in Spanien geborene Kind unbekannter Eltern wurde Spanier. Die in Spanien geborenen Auslländer hatten grundsätzlich wieder ein Optionsrecht auf die spanische Staatsangehörigkeit (Art. 18 Ziffer 1 C.c.esp. i.d.F. 1954). Wichtiger war die Regelung des Art. 17 Ziffer C.c.esp. i.d.F. 1954, kraft deren diejenigen, die in Spanien geboren waren als Kind won Eltern, die auch selber in Spanien geboren waren und dort zur Zeit der Geburt des Kindes ihren Wohnsitz hatten, von Rechts wegen Spanier wurden. Eine Ausnahme galt lediglich fuir Diplomatenkinder. Die zweite in Spanien geborene Generation wurde also automatisch spanisch.

Im Jahre 1975 wurde die Regelung des Erwerbs iure sanguinis und iure soli nicht geändert. 1982 wurden die betreffenden Artikel des Código civil aber eingehend revidiert. Seitdem gilt die heutige Regelung.

\subsubsection{Heutige Regelung}

Gemäß Art. 17 Abs. 1 Ziffer 1 C.c.esp. erwerben die Kinder eines spanischen Vaters oder einer spanischen Mutter die spanische Staatsangehörigkeit durch Geburt unabhängig davon, ob diese Geburt in Spanien oder im Ausland stattgefunden hat. Diese Regelung gilt nicht nur für eheliche Kinder, sondern auch für nichteheliche Kinder, unter der Voraussetzung, daß die Abstammung vom spanischen Vater oder der spanischen Mutter juristisch feststeht (64) (Art. 17 Abs. 2 C.c.esp.).

Iuri soli erwerben diejenigen Kinder die spanische Staatsangehörigkeit, die in Spanien von ausländischen Eltern geboren werden, sofern wenigstens ein Elternteil in Spanien (65) geboren ist. Die zweite in Spanien geborene Generation erwirbt also automatisch die spanische Staatsangehörigkeit (66). Eine Ausnahme gilt füir die Kinder ausländischer Eltern, die im ausländischen diplomatischen oder konsularischen Dienst stehen. In Spanien geborene potentiell staatenlose Kinder erwerben ebenfalls iuri soli die spanische Staatsangehörigkeit (Art. 17 Abs. 1 Ziffer 3 C.c.esp.). Das gleiche gült für in Spanien geborene Kinder unbekannter Abstammung oder in Spanien aufgefundene Kinder, deren Geburtsort unbekannt ist (67).

Die Regelung des Erwerbs der Statatsangehörigkeit durch Adoption (Art. 18 C.c.esp.) entspricht soweit wie möglich der Regelung des Erwerbs der Staatsangehörigkeit iure sanguinis. Durch Adoption erwirbt der Ausländer unter achtzehn Jahren die spanische Staatsangehörigkeit, wenn ein Adoptivelternteil die spanische Staatsangehörigkeit besitzt (68). Bemerkenswert ist noch folgendes: Diejenigen, die auf Grund des Art. 17 C.c.esp. die spanische Staatsangehörigkeit erwerben sind "españoles de origen" (von Ursprung Spanier). Diese Bezeichnung ist wichtig, da für Spanier, die nicht "españoles de origen" sind, zusätzliche Verlustgruinde der spanischen Staatsangehörigkeit gelten (Art. 24 C.c.esp.). 
Diejenigen nun, die durch Adoption die spanische Staatsangehörigkeit erwerben, gelten ebenfalls als "españoles de origen", wenn einer der Adoptiveltern zur Zeit der Geburt des Kindes die spanische Staatsangehörigkeit innehatte.

\subsubsection{Erwerb der Staatsangehörigkeit nach der Geburt}

\subsubsection{Rückblick}

$\mathrm{Zu}$ Anfang des vorigen Jahrhunderts galten außer Erwerb iure soli folgende Erwerbsgründe: Einbürgerung, Erwerb kraft "vecindad" und Freilassung (Constitución 1812). In der Verfassung won 1837 wird die Freilassung nicht mehr erwähnt. Das ius soli entwickelte sich seit $1837 \mathrm{zu}$ einem Optionsrecht kraft Geburt auf spanischem Grundgebiet. Daneben standen die Einbuirgerung und die "vecindad". Auch in dem Código civil von 1889 standen Einbürgerung und Erwerb kraft vecindad nebeneinander. Für die Einbürgerung wurden die Erfordenisse nicht im einzelnen spezifiziert. Gemäß Art. 25 C.c.esp. i.d.F. 1889 war aber der Verzicht auf die bisherige Staatsangehörigkeit und ein Treueid auf die Verfassung notwendig. Durch Option konnten in Spanien geborene Ausländer und ehemalige Spanier die spanische Staatsangehörigkeit erwerben (Art. 19, 21 und 24 C.c.esp. i.d.F. 1889); diejenigen ehemaligen Spanier, die ihre Staatsangehörigkeit wegen fremden Staats- oder Wehrdienstes verloren hatten, konnten aber nur nach vorheriger Genehmigung optieren (Art. 23 C.c.esp. i.d.F. 1889). Die ausländische Frau erwarb durch EheschlieBung mit einem Spanier dessen Staatsangehörigkeit (Art. 22 C.c.esp. i.d.F. 1889). Die Bestimmungen der Verfassung von 1931 entsprachen denen des Código civil, außer der Regelung der selbständigen staatsangehörigkeitsrechtlichen Position der verheirateten Frau. Letztere Regelung wurde aber 1938 mit Ruickwirkung wieder aufgehoben.

Im Código civil von 1954 waren wieder mehrere Optionsrechte vorgesehen. Ein Optionsrecht hatten die auf spanischem Boden geborenen Personen (soweit sie nicht bereits von Rechts wegen spanisch waren) (69), die außerhalb Spaniens geborene Kinder von ursprünglich spanischen Eltern (Art. 18 C.c.esp. i.d. F. 1954) und die meisten ehemaligen Spanier (Art. 24, 25 C.c.esp. i.d.F. 1954; beachtlich aber die Ausnahme des Art. 25 Abs. 3). Von den Optanten wurde gefordert, daß sie auf ihre frühere Staatsangehörigkeit verzichteten und "prestar juramento de fidelidad al Jefe del Estado y de obediencia a las leyes", also ein Treueeid leisteten. Der Verzicht auf die frühere Staatsangehörigkeit wurde nicht von den Staatsangehörigen anderer ibero-amerikanischen Staaten und der Philippinen gefordert. Das geht aus Art. 22 C.c.esp. (i.d.F. 1954) hervor. Die Einbürgerung und Erwerb kraft "vecindad" wurden nun nicht mehr nebeneinander erwähnt, sondern letztere wurde als besonderer Fall der Einbürgerung beschrieben. In Art. 19 C.c.esp. i.d.F. 1954 wurde erwähnt, daß eine Einbürgerung möglich war, wenn beim Antragsteller außergewöhnliche Umstände vorlagen. Ein Einbürgerungsantrag konnte von Personen, die mindestens 21 Jahre oder 18 Jahre alt und emanzipiert (70) waren gestellt werden. Die Einbürgerung erfolgte durch Eintragung als spanischer Staatsbiirger in das Personenstandregister, nachdem der Betreffende auf seine bisherige Staatsangehörigkeit verzichtet und einen Treueid geleistet hatte. Zum erstenmal wurden nun Aufenthaltsfristen in der Einbürgerungsregelung genannt. Grundsätzlich wurde ein zehnjähriger Aufenthalt gefordert. Unter bestimmten Voraussetzungen (Einfuihrung eines wichtigen Gewerbezweigs oder einer wichtigen Erfindung auf spanischem Staatsge- 
biet; die Eigenschaft als Eigentümer oder Leiter eines wichtigen landwirtschaftlichen, gewerblichen Betriebes oder Handelsunternehmens; die Leistung hervorragender Dienste für die nationale Kunst, Bildung oder Wissenschaft oder die hervorragende Förderung der spanischen Interessen) genügte eine Frist von fünf Jahren. Eine Frist von zwei Jahren reichte fuir. Personen aus, die nicht rechtzeitig ein ihnen zustehendes Optionsrecht benutzt hatten, die als Minderjährige von Spaniern adoptiert worden waren, die mit einer spanischen Frau verheiratet waren oder die Bürger eines lateinamerikanischen Landes oder Portugals waren. In dieser letzten Ausnahme manifestiert sich der Gedanke der "Hispanidad" (71), der einen wichtigen Einfluß auf das spanische, aber auch das latein-amerikanische Staatsangehörigkeitsrecht hat. Von den Staatsangehörigen dieser ibero-amerikanischen Staaten wurde auch nicht gefordert, daß die bisherige Staatsangehörigkeit aufgegeben wird (72). Auch gemäß dem C.c.esp. i.d.F. 1954 erwarb die ausländische Ehegattin eines Spaniers von Rechts wegen dessen Staatsangehörigkeit (Art. 21 C.c.esp. i.d.F. 1954) (73). Dies wurde 1975 geändert. Nach Art. 21 Abs. 3 C.c.esp. i.d.F. 1975 konnte der ausländische Ehegatte (Mann oder Frau) eines Spaniers für die spanische Staatsangehörigkeit optieren. Es handelte sich hierbei jedoch nicht um ein reines Optionsrecht, da die Verleihung der Staatsangehörigkeit aus Grïnden der öffentlichen Ordnung verweigert werden konnte (74). Der ausländische Ehegatte mußte auf die bisherige Staatsangehörigkeit verzichten und einen Treueeid leisten. Die Einbürgerungsvoraussetzungen wurden 1975 leicht revidiert. Das Mindesalter für eine Einbuirgerung wurde grundsätzlich auf achtzehn Jahren heruntergesetzt, Art. 20 C.c.esp. forderte noch immer prinzipiell zehnjährigen Aufenthalt in Spanien. Die Umstände, die eine Einbürgerung bereits nach fünfjährigem Aufenthalt möglich machen, wurden nun etwas abstrakter formuliert ("wenn der Antragsteller durch irgendeine Tätigkeit oder Arbeit bedeutsame Dienste geleistet hat, die die spanischen Interessen in bemerkenswerter Weise gefördert haben"). 1982 wurde die Regelung der Staatsangehörigkeit grundlegend geändert und bekam die nun geltende Version.

\subsubsection{Heutige Regelung}

Das heutige spanische Staatsangehörigkeitsrecht kennt in zwei Fällen (75) die Möglichkeit, die spanische Staatsangehörigkeit durch Option (76) zu erwerben. Art. 19 C.c.esp. gibt Personen, die unter der elterlichen Gewalt oder unter Vormundschaft eines spanischen Bürgers stehen, die Gelegenheit, für die spanische Staatsangehörigkeit zu optieren (77). Diese Option muß innerhalb von zwei Jahren nach Vollendung des 18. Lebensjahres, nach der Emanzipation (78) oder nach Wiedererlangung der vollen Geschäftsfähigkeit erklärt werden. Ab Vollendung des 14. Lebensjahres kann auch mit Beistand des gesetzlichen Vertreters optiert werden (79). Eine Optionsmöglichkeit haben auch ehemalige Spanier (Art. 26 C.c.esp.) (80). Die Option kann ausgeübt werden, wenn der Betreffende während eines Jahres unmittelbar vor Antragstellung einen gesetzmäßigen und ununterbrochenen Aufenthalt (81) in Spanien hatte. Wenn für die spanische Staatsangehörigkeit optiert wird, muß auf die bisherige Staatsangehörigkeit verzichtet werden. Die spanische Staatsangehörigkeit wird nicht durch die Wiedererwerbserklärung, sondern durch die Eintragung dieser Erklärung in das Zivilregister zurückerworben. Diejenigen, die die spanische Staatsangehörigkeit im Alter von mehr als vierzehn Jahren verloren haben, ohne in Spanien Militäroder Ersatzdienst geleistet zu haben, und diejenigen die die spanische Staatsan- 
gehörigkeit durch Aberkennung verloren haben, können nur für die spanische Staatsangehörigkeit nach vorheriger von der Regierung nach Ermessen erteilter Ermächtigung optieren. Es handelt sich in diesen Fällen also nicht um ein reines Optionsrecht. Ehemalige Spanier, die im Ausland leben, können zurückoptieren, nachdem sie vom Justizminister einen Dispens vom Erfordernis des Aufenthalts in Spanien bekommen haben. Auch hier handelt es sich deshalb um ein kontrolliertes Optionsrecht. Die früher vorgesehenen Optionsrechte für in Spanien geborene Ausländer und für im Ausland geborene Kinder von Personen, die ursprünglich Spanier waren, sind weggefallen (82).

Die Einbürgerungsvoraussetzungen sind in den Art. 21 und 22 C.c.esp. geregelt. Wenn besondere Umstände ("circumstancias excepcionales") vorliegen, kann die spanische Staatsangehörigkeit nach Ermessen vom König verliehen werden (Art. 21 C.c.esp.) (83). Eine solche Einbürgerung kann auch bei Auslandswohnsitz stattfinden. Der Antragsteller muß mindestens achtzehn Jahre alt sein, oder nach Vollendung des 14. Lebensjahrs mit Zustimmung seines gesetzlichen Vertreters handeln (84). Auf die bisherige Staatsangehörigkeit muß verzichtet werden (85), weiter muß dem König Treue und der Verfassung Gehorsam geschworen werden (86). Außer dem Fall von Art. 21 C.c.esp. wird für den Erwerb der spanischen Staatsangehörigkeit grundsätzlich ein zehnjähriger legaler (87) Aufenthalt (88) in Spanien gefordert. Die Einbürgerung kann aus Gründen der öffentlichen Ordnung oder des nationalen Interesses verweigert werden (89). Der Antragsteller muß achtzehn Jahre alt sein. Die Möglichkeit eines Antrages mit Zustimmung des gesetzlichen Vertreters wird in Art. 22 C.c.esp. nicht erwähnt. Der Verzicht auf die bisherige Staatsangehörigkeit, sowie Treue- und Gehorsamseid sind wieder notwendig. Wenn der Antragsteller jedoch Bürger eines lateinamerikanischen Landes, Andorras, der Phillippinen, Äquatorial-Guineas oder Portugals ist (90), oder es sich um einen sephardischen Juden (91) handelt, genügt ein Aufenthalt von zwei Jahren in Spanien. Diese Ausländer brauchen nicht auf ihre bisherige Staatsangehörigkeit zu verzichten (92). Die Liste der Staaten, deren Bürger bei der Einbürgerung in Spanien begünstigt werden, ist also im Vergleich zum vorherigen Recht ausgedehnt worden. Obwohl der Código civil nicht ausdrücklich fordert, daß ein Einbürgerungsbewerber die spanische Sprache beherrscht, sind solche Sprachkenntnisse im Rahmen des Einbürgerungsverfahrens doch erheblich. Dies geht aus Art. 220 des Reglemento para aplicación de la Ley de Registro civil hervor (93). Unter Ziffer 5 dieses Artikels wird vorgeschrieben, daß im Einbürgerungsantrag erwähnt werden muß
"si habla castellano o otra lengua española, cualquier circumstancia de aclaptación a la cultura y estilo de vida españoles, como estudios, activi- dades beñeficas o sociales, y las démas que estime conveniente"

(ob er die kastilische oder eine andere spanische Sprache (94) spricht; alle Umstände, die die Anpassung an die spanische Kultur und den spanischen Lebensstil zeigen, wie Studien, wohltätige oder soziale Aktivitäten und alles übrige, das als relevant beurteilt wird) (95). Eine Einbürgerung ist in Spanien kostenlos; dasgleiche gilt für die Registrierung von Optionserklärungen (96).

Wir sahen bereits, daß einige Gruppen, die vor 1982 ein Optionsrecht hatten, nunmehr eingebürgert werden müssen. Nach Art. 22 Abs. 3 C.c.esp. i.d.F. 1982 können diese Gruppen aber bereits nach einjährigem Aufenthalt in Spanien 
eingebürgert werden. Dies gilt für diejenigen, die in Spanien geboren wurden (Art. 22 Abs. 3 Ziffer 1 C.c.esp. i.d.F. 1982), für diejenigen, die im Ausland als Kinder ehemaliger Spanier geboren sind (Art. 22 Abs. 3 Ziffer 2 C.c.esp. i.d.F. 1982), für Personen, die ein bestehendes Optionsrecht nicht benutzt haben (Art. 22 Abs. 3 Ziffer 3 C.c.esp. i.d.F. 1982) und für die Ehegatten spanischer Bürger, auch wenn die Ehe inzwischen aufgelöst ist (Art. 22 Abs. 3 Ziffer 4 C.c.esp. i.d.F. 1982). Fortan haben die ausländische Ehegatten spanischer Bürger also kein Optionsrecht mehr, sondern lediglich die Möglichkeit, unter erleichterten Voraussetzungen eingebürgert zu werden. Eine Einbürgerung erstreckt sich nach spanischem Recht nicht auf minderjährige Kinder. Diese können unter den Voraussetzungen der Art. 19 und 20 C.c.esp. aber für die spanische Staatsangehörigkeit optieren (97).

\subsubsection{Verlustgründe}

\subsubsection{Rüickblick}

Bereits in der Verfassung von 1837 wurden die Einbürgerung und die Annahme eines Amts von einer fremden Regierung ohne Erllaubnis des Königs als Verlustgründe der Staatsangehörigkeit erwähnt. Die Verfassungen von 1845, 1869 und 1876 bestimmten Entsprechendes. Eine Spanierin verlor ihre Staatsangehörigkeit durch Eheschließung mit einem Ausländer (Art. 1 Ziffer 5 der Königlichen Verordnung vom 17 . November 1852). Durch Verlegung des Wohnsitzes ins Ausland konnte die spanische Staatsbürgerschaft verloren werden, wenn man sich nicht in das Konsularregister eintragen ließ und man im betreffenden Auslland aufgrund der Gesetzgebung automatisch als Bürger betrachtet wurde (Art. 4 Ziffer 4 und 112 des Gesetzes vom 17. Juni 1870).

Einbürgerung im Ausland und fremder Staats- oder Wehrdienst ohne Einwilligung des Königs wurden auch im Código civil i.d.F. 1889 als Verlustgründe erwähnt (Art. 20), ebenso für eine Spanierin die Eheschließung mit einem Ausländer (Art. 22) (98). Aus Art. 26 C.c.esp. i.d.F. 1889 ging hervor, daß die spanische Staatsangehörigkeit durch Verlegung des Wohnsitzes in das Ausland verloren wurde, wenn schon durch die Begriündung des Wohnsitzes die betreffende fremde Statsangehörigkeit erworben wurde. Der Verlust trat nicht ein, wenn eine entsprechende Erklärung vor einem diplomatischen oder konsularischen Vertreter Spaniens abgelegt wurde. In einigen Fällen konnte die spanische Staatsangehörigkeit durch Verzicht verloren werden (Art. 18 Abs. 2 C.c.esp. i.d.F. 1889).

In der Verfassung von 1931 war vorgesehen, daß eine Spanierin ihre bisherige Staatsangehörigkeit durch Eheschließung mit einem Ausländer nicht mehr verlor. 1938 wurde dies aber mit Rückwirkung revidiert. Art. 24 dieser Verfassung erwähnte als Verlustgründe den fremden Staats- oder Wehrdienst ohne Erlaubnis des spanischen Staates und den freiwilligen Erwerb einer fremden Staatsangehörigkeit. Zum ersten Mal wurde aber für diejenigen, die die Staatsangehörigkeit eines lateinamerikanischen Staates oder Portugals erwarben, die Möglichkeit einer Ausnahme erwähnt.

Seit 1945 konnte der Verlust der spanischen Staatsangehörigkeit wegen Landesverrats ausgesprochen werden. Im Código civil von 1954 wurde in Art. 22 der 
Verlust der Staatsangehörigkeit wegen des Erwerbs einer fremden Staatsbürgerschaft geregelt (99). Der Verlust trat aber nur für diejenigen ein, die bereits 21 Jahre alt (oder 18 Jahre alt und emanzipiert) (100) waren. Außerdem trat kein Verlust ein, wenn der Betreffende nicht bereits mindestens drei Jahre im Ausland lebte. Für Männer galt weiter, daß sie nicht dem aktiven Wehrpflicht unterliegen durften (101). Diejenigen, die die Staatsbürgerschaft eines lateinamerikanischen Staates oder der Philippinen erwarben, verloren u.U. die spanische Staatsangehörigkeit nicht. Auch gemäß dem Código civil in der Fassung von 1954 wurde die spanische Staatsangehörigkeit wegen fremden Staats- oder Wehrdiensts verloren, allerdings nur wenn dies gegen das ausdrückliche Verbot des spanischen Staatschefs geschah (Art. 23 Ziffer 1 C.c.esp. i.d.F. 1954) (102). Art. 23 erwähnte weiter den Verlust nach den Bestimmungen des Strafgesetzbuches (103) und für spanische Frauen den Verlust wegen der EheschlieBung mit einem Ausländer, dies allerdings nur, wenn sie dessen Staatsangehörigkeit erwarb. Der Staatsangehörigkeitsverlust erstreckte sich grundsätzlich auf Ehefrau und Kinder, falls diesen ebenfalls die neue Staatsangehörigkeit des Mannes, bzw. Vaters zustand (104).

Im Jahre 1975 wurden die Verlustgründe der Staatsangehörigkeit der nunmehr selbständigen staatsangehörigkeitsrechtliche Position der Ehefrau angepaßt. Durch Eheschließung verlor die Spanierin nicht mehr ihre Staatsangehörigkeit (Art. 21 Abs. 1 C.c.esp. i.d.F. 1975). Staatsangehörigkeitsänderungen des Ehemannes konnten sich fortan nicht mehr auf die Ehefrau ausstrecken. Im übrigen änderten sich die Verlustgriunde der Staatsangehörigkeit nicht wesentlich (105). Bei der 1982 vorgenommen Änderung der staatsangehörigkeitsrechtlichen Bestimmungen des Código civil wurden auch die Verlustgründe eingehend revidiert. Seitdem haben sie die heutige Fassung.

\subsubsection{Heutige Regelung}

Die spanische Staatsangehörigkeit wird grundsätzlich von Spaniern verloren, die freiwillig eine andere Staatsangehörigkeit erwerben (Aurt. 23 Abs. 1 C.c.esp.) (106). Voraussetzung für einen solchen Verlust ist allerdings, daß sie volljährig sind und bereits drei Jahre außerhalb Spaniens leben (107). Kein Verlust tritt ein, wenn die Betreffenden den zuständigen spanischen Behörden gegenüber erklären, daß der Erwerb der fremden Staatsangehörigkeit "por razón de emigración" geschieht. Diese Regelung bezieht sich auf alle Spanier, die aus Arbeitsoder Berufsgruinden ihren normalen Aufenthalt ins Ausland verlegt haben und auf deren Familienangehörige. Es wird nicht beabsichtigt, die Regelung so zu interpretieren, daß ein spanischer Konsul eine Untersuchung durchführen muß beziiglich der Motive, die einen Emigranten dazu gebracht haben, die Staatsangehörigkeit seines Aufenthaltstaats zu beantragen. Eine einfache Erklärung des Betreffenden, daß dies "por razón de emigración" geschah, genügt deshalb, um den Verlust der spanischen Staatsangehörigkeit zu verhindern (108). Die betreffende Beibehaltungserklärning muB innerhalb eines Jahres nach Erwerb der fremden Staatsangehörigkeit abgegeben werden (109). Eine solche Beibehaltungserklärrung kann nicht abgegeben werden von außerhalb Spaniens geborenen, bereits volljährigen Kindern spanischer Auswanderer (110). Wegen des freiwilligen Erwerbs einer fremden Staatsangehörigkeit wird die spanische Staatsangehörigkeit nicht verloren, wenn Spanien sich im Kriegszustand befindet (art. 23 Abs. 3 C.c.esp.). 
Minderjährige verlieren nicht die spanische Staatsangehörigkeit wegen freiwilligen Erwerbs einer ausländischen Staatsangehörigkeit. Nach Erreichung der Volljährigkeit können diese jedoch auf die spanische Staatsangehörigkeit verzichten (Art. 23 Abs. 2 C.c.esp.).Bemerkenswert ist schließlich die Regelung des Art. 23 Abs. 4 C.c.esp., kraft deren für diejenigen, die kraft Abstammung Spanier sind (español de origen) kein automatischer Verlust eintritt, wenn die Staatsangehörigkeit bestimmter anderer Staaten erworben wird. Es handelt sich um die Staatsangehörigkeiten der lateinamerikanischen Länder, Andorras, der Philippinen, Äquatorial-Guineas, Portugals und anderer Staaten, mit denen Spanien ein Abkommen über die doppelte Staatsangehörigkeit geschlossen hat (111). Im Falle des Erwerbs der Staatsangehörigkeit eines dieser Staaten kann ein volljähriger Spanier jedoch auf die spanische Staatsangehörigkeit verzichten.

Eine allgemeine Verzichtsregelung für Doppelstaatler fehlt in der spanischen Staatsangehörigkeitsregelung (112). Auch wird die spanische Staatsangehörigkeit nie durch Auslandsaufenthalt oder im allgemeinen nicht durch fremden Staatsoder Kriegsdienst verloren (113). Im spanischen Recht erstreckt sich der Verlust der Staatsangehörigkeit nicht auf minderjährige Kinder (Art. 25 C.c.esp.).

Für diejenigen, die nicht von Ursprung Spanier (españoles de origen) sind (Art. 17, 18 Abs. 2 C.c.esp.), gelten noch zusätzliche Verlustgründe, die in Art. 24 C.c.esp. formuliert sind. Sie können die Staatsangehörigkeit verlieren, wenn sie durch rechtskräftiges Urteil gemäß den Bestimmungen des Strafgesetżbuchs zu diesem Verlust verurteilt worden sind (114). Weiter kann die spanische Staatsangehörigkeit verloren werden, wenn sich herausstellt, daß beim Erwerb der Staatsangehörigkeit Fälschung, ein Verschweigen erforderlicher Angaben oder Betrug vorlag.

Schließlich wird die Staatsangehörigkeit von diesen Spaniern verloren, wenn sie gegen das ausdrückliche Verbot der Regierung freiwillig fremden Staats- oder Wehrdienst leisten (115). 


\section{FOLGERUNGEN}

\subsection{Allgemeine Bemerkungen}

In den Paragraphen 3.2.1 bis 3.4.12 sollen die positivrechtlichen Regelungen über die Erwerbs- und Verlustgrïnde der Staatsangehörigkeit der besprochenen Länder miteinander verglichen werden. Ausgangspunkt bildet dabei grundsätzlich die Regelung des niederländischen Rechts. Zweck des Vergleichs ist die Unterbreitung von Vorschlägen zar Verbesserung der niederländischen Staatsangehörigkeitsregelung. Diese Vorschläge werden in Paragraph 4 zusammengefaßt. Selbstverständlich halte ich aber entsprechende Änderungen der anderen beschriebenen Staatsangehörigkeitsregelungen für wünschenswert. Da jeder Staat jedoch grundsätzlich selber bestimmen darf, welche Personen seine Staatangehörigkeit besitzen, möchte ich meine Vorschläge nicht für den Erwerb und Verlust anderer Staatsangehörigkeiten explizieren.

Bei der Wertung der zu vergleichenden Lösungen spielt meine Auffassung ïber die Funktion der Staatsangehörigkeit eine wichtige Rolle. Es sei deshalb an dieser Stelle daran erinnert, daß ich die Staatsangehörigkeit als einen Koppelungsbegriff betrachte (siehe \& 1.3.2). Um die Funktion eines solchen Koppelungsbegriffes auf befriedigende Weise zu erfüllen, muß die Staatsangehörigkeit jedoch Manifestierung eines tatsächlichen Bandes zwischen einer Person und einem Staat sein. Für die Attribuierung der Staatsangehörigkeit im Moment der Geburt oder später aufgrund familienrechtlicher Beziehungen bringt dies mit sich, daß die Staatsangehörigkeit eines bestimmten Staates jenen Personen zugeteilt werden sollte, die aller Wahrscheinlichkeit nach ein tatsächliches Band mit dem betreffenden Staat entwickeln werden. Für Fälle späterer Zuteilung einer Staatsangehörigkeit (in der Regel: durch Optionserklärung oder Einbürgerung) muß m.E. lediglich maßgebend sein, daß eine Person dauerhafte Bande mit dem betreffenden Staat hat und diese sich vermutlich weiter intensivieren werden. Die Verlustbestimmungen der Staatsangehörigkeit sollten dergestalt sein, daß lediglich diejenigen Personen die Staatsangehörigkeit eines bestimmten Staates verlieren, die keine tatsächliche Beziehungen mit dem betreffenden Staat mehr haben oder deren noch existierende, schwache Verbindung zu diesem Staat, soweit vorhersehbar, weiter abnehmen wird.

\subsection{Erwerb der Staatsangehörigkeit durch Geburt}

\subsubsection{Ius sanguinis: eheliche Kinder}

Seit 1985 erwerben nach niederländischem Staatsangehörigkeitsrecht eheliche Kinder die niederländische Staatsangehörigkeit, wenn der Vater oder die Mutter zur Zeit der Geburt Niederländer sind, oder - falls ein Elternteil bereits verstorben ist - wenn dieser im Zeitpunkt seines Todes die niederländische Staatsangehörigkeit besaß (Art. 3 Abs. 1 RwNed). Unbeachtlich ist dabei, ob das Kind innerhalb oder außerhalb der Niederlande geboren ist. Die Staatsangehörigkeit wird also kraft Geburt iure sanguinis a patre et a matre erworben. Entsprechende Regelungen kennen auch die Bundesrepublik Deutschland ( $\$ 4$ Abs. 1, Ziffer 1 RuStAG; seit 1975), Frankreich (Art. 17 CNF; seit 1973), Italien (Art. 5 Abs. 
1 des Gesetzes vom 21 April 1983), Österreich (\$ 7 Abs. 1 StBG i.d.F. 1983) und Spanien (Art. 17 Abs. 1 Ziffer 1 C.c.esp.; seit 1982). In der Schweiz (Art. 1 Abs. 1 Bst. a BüG i.d.F. 1984) gilt grundsätzlich die gleiche Regelung; Art. 2 BüG bestimmt jedoch, daß eine schweizerische Frau, die die schweizerische Staatsangehörigkeit erst durch Ehe mit einem Schweizer erworben hat, diese Staatsangehörigkeit ihren Kindern nur dann weitergeben kann, wenn diese sonst staatenlos wären, oder während ihrer Minderjährigkeit staatenlos werden würden. Diese Ausnahme ist eine Folge von Art. $3 \mathrm{BüG}$, wonach eine ausländische Frau noch immer durch Ehe mit einem schweizerischen Mann automatisch dessen Staatsangehörigkeit erwirbt. Der schweizerische Novellierungsentwurf 1986 enthält den Vorschlag, diese Ausnahme zu streichen; dies steht in logischem Zusammenhang mit der ebenfalls vorgeschlagenen Aufhebung von Art. 3 BüG (automatischer Erwerb der Staatsangehörigkeit von der mit einem Schweizer verheirateten Frau) (siehe dariber auch \$ 3.3.2).

Der Erwerb der Staatsangehörigkeit iure sanguinis a patre et a matre verursacht viele Doppelstaatler. Im Wesen steht daher eine solche Erwerbsregelung in einem Spannungsverhältnis mit der in den meisten dieser Staaten immer noch vorherrschenden Tendenz, Doppelstaatlichkeit so weit möglich zu verhindern. Die erwähnten Gesetzgeber haben es aber vorgezogen, durch ihre Regelungen zu betonen, daß Kinder - wo auch immer geboren - aufgrund ihrer Abstammung von einem oder einer Staatsangehörigen des betreffenden Landes, relevante Beziehungen zu dem jeweiligen Stat haben. Bei den neuen Regelungen von Belgien und Großbritannien ist man einen anderen Weg gegangen. Bei Geburt im Inland gilt Erwerb iure sanguinis a patre et a matre, bei Geburt im Ausland wird die Staatsangehörigkeit nur unter bestimmten Voraussetzungen iure sanguinis erworben (Art. 8 CNB 1985; Sec. 1 und 2 BNA 1981). Bei Geburt im Inland werden also ius sanguinis- und ius soli-Elemente kumuliert. Von der Möglichkeit des Staatsangehörigkeitserwerbs kraft reinem ius soli wird noch in $\$ 3.2 .6$ die Rede sein.

Wir wollen nun die Voraussetzungen für den Erwerb der belgischen oder britischen Staatsangehörigkeit bei Geburt im Ausland näher erörtern. Die belgische Staatsangehörigkeit wird bei Geburt im Ausland erworben, wenn ein Kind als Kind eines belgischen Elternteils geboren ist, der selbst in Belgien oder in, unter belgischer Verwaltung stehenden, Staaten geboren wurde. Die belgische Staatsangehörigkeit wird ebenfalls won im Ausland geborenen Kindern belgischer Eltern erworben, die sonst staatenlos wären oder dies vor ihrem 18 . Geburtstag wüirden. Falls das Kind eines belgischen Elternteils nach den erwähnten Regeln nicht von Rechts wegen die belgische Staatsangehörigkeit erwirbt, kann der belgische Elternteil innerhalb von fünf Jahren nach der Geburt des Kindes durch eine Erklärung bewirken, daß dieses die belgische Staatsangehörigkeit erhält (Art. 8 Abs. 1 Ziffer 2 CNB 1985). Bei Geburt im Ausland wird das ius sanguinis-Prinzip also noch eine Generation lang uneingeschränkt durchgeführt, für weitere Auslandsgenerationen müssen zusätzliche Elemente hinzukommen: entweder eine ausdrückliche Erklärung des belgischen Elternteils oder potentielle Staatenlosigkeit.

Die Hauptzüge der britischen Regelung entsprechen der belgischen Lösung. Wer außerhallb des Vereinigten Königreiches als Kind eines britischen Staatsbürgers geboren wird, erwirbt die britische Staatsangehörigkeit, wenn der britische Elternteil aus einem anderen Grunde als durch Abstammung britisch ist, im 
Dienste der Britischen Krone oder der Europäischen Gemeinschaft steht oder ein anderes Dienstverhältnis hat, das in engem Zusammenhang mit außerhalb des Vereinigten Königreichs entfalteten Tätigkeiten der Regierung ihrer Britischen Majestät (Sec. 2 BNA 1981) steht. Wichtig ist es hier, den Begriff "britischer Staatsangehörige durch Abstammung" (British citizen by descent) näher zu erồrtern. Dieser Begriff bezieht sich nur auf den Erwerb der Staatsangehörigkeit iure sanguinis bei Geburt im Ausland. Wer die britische Staatsangehörigkeit durch Geburt im Inland als Kind eines Briten oder durch Einbürgerung oder durch Optionserklärung erworben hat, ist (im allgemeinen) kein britischer Stalsangehöriger durch Abstammung (British citizen by descent) in diesem Sinne. Vielmehr wird dieser als britischer Staatsangehöriger durch Geburt (British citizen by birth) bezeichnet. Wenn das Kind eines britischen Elternteils bei Geburt im Ausland nicht automatisch die britische Staatsangehörigkeit erwirbt, kann es aber doch innerhalb von 12 Monaten nach der Geburt als britischer Staatsbürger registriert werden (Sec. 3 (2), BNA 1981), falls bestimmte Voraussetzungen erfuillt sind. Das britische Staatsangehörigkeitsgesetz ist - wie im anglo-amerikanischen Rechtskreis üblich - sehr detailliert formuliert. Es würde deshalb zu weit führen, die Voraussetzungen an dieser Stelle präzise zu erläutern. In großen Zügen wird für die Registrierung aber gefordert, daß der Vater oder die Mutter des britischen Elternteils aus einem anderen Grund als durch Abstammung britischer Staatsbürger war und der britische Elternteil irgendwann drei Jahre im Vereinigten Königreich gelebt hat (Siehe \$ 2.4.2.2).

Wenn man die belgische und die britische Regelung vergleicht, fällt auf, daß die britische Staatsangehörigkeit etwas häufiger als die belgische beil Geburt im Ausland automatisch erworben wird. Beide Staaten fübren für eine Auslandsgeneration den Erwerb der Staatsangehörigkeit iure sanguinis durch. Für weitere Auslandsgenerationen gibt es nach belgischem Recht stets die Möglichkeit, durch Erklärung des belgischen Elternteils zu bewirken, daß das Kind die belgische Staatsangehörigkeit erhält. Im Vereinigten Königreich ist dies nur unter strengen Voraussetzungen möglich. Auf kurze Sicht ist das ius sanguinis hinsichtlich im Ausland geborener Kinder von Belgiem also etwas schwächer als hinsichtlich im Ausland geborener Kinder von Briten. Langfristig ist aber das belgische ius sanguinis dennoch stärker.

Erwälnnenswert ist in diesem Zusammenhang, daß die Möglichkeit, die belgische Staatsangehörigkeit iure sanguinis weiterzugeben, durch die, im Vergleich zu dem bisherigen belgischen Recht, neue Regelung des Art. $22 \S 1$, Ziffer 5 CNB 1985 negativ beeinflußt wird. Danach verlieren im Ausland geborene und dort dauerhaft wohnhafte Belgier unter bestimmten Voraussetzungen automatisch die belgische Staatsangehörigkeit; diesem Verlust kann aber bis zum 28. Geburtstag durch eine Beibehaltserklärung vorgebeugt werden. Diese Verlustregelung wird an späterer Stelle in $\$ 3.4 .4$ näher besprochen.

Auch bei der Beurteilung der schweizerischen und niederländischen Regelung des Erwerbs iure sanguinis bei Geburt im Ausland muß berïcksichtigt werden, daß diese Staaten einen der eben erwähnten belgischen Regelung entsprechenden Verlustgrund kennen. Dieser Verlustgrund bezweckt letztlich das gleiche wie die erwähnten Erwerbsvoraussetzungen bei Auslandsgeburt im belgischen und britischen Recht. Hierdurch soll verhindert werden, daß die Staatsangehörigkeit über Generationen im Ausland iure sanguinis weitergegeben werden 
kann, ohne daß noch irgendwelche Beziehungen zum Heimatland bestehen. Auch diese Verlustgründe werden in $\$ 3.4 .4$ näher erörtert. Das deutsche, italienische, französische, österreichische und spanische Recht kennen keine solchen Verlustgründe. Die Staatsangehörigkeit dieser Staaten kann auch bei Auslandsgeburt grundsätzlich zeitlich unbegrenzt weitergegeben werden, bis sie aus anderen Gründen (z.B. wegen freiwilligen Erwerbs einer fremden Staatsangehörigkeit) verloren wird. Hinsichtlich des französischen Rechts sei noch auf die seit 1945 existierende Möglichkeit hingewiesen, einem Franzosen die Staatsangehörigkeit wegen dauernden Auslandsaufenthalts oder Benehmens als ein fremder Staatsangehöriger zu entziehen (Art. 95, beziehungsweise 96 CNF). Der Zweck dieser Regelung ist wiederum, die Weitergabe der französischen Staatsangehörigkeit iure sanguinis dort zu begrenzen, wo konkrete Beziehungen zu Frankreich fehlen (siehe auch hierüber weiter \$ 3.4.4). Im deutschen Recht kannte das bis 1914 geltende RuStAG 1870 den Verlust der deutschen Staatsangehörigkeit bei zehnjährigem ununterbrochenen Auslandsaufenthalt (\$21). Diesem Verlust konnte aber durch Eintragung in die Matrikelliste eines Reichskonsulats vorgebeugt werden.

Die Verfolgung des verständlichen und allgemeinen Wunsches Doppelstaatlichkeit vorzubeugen, ist in den belgischen und britischen Regelungen eleganter gelungen als in den bundesdeutschen, französischen, italienischen, niederländischen, österreichischen, schweizerischen oder spanischen Lösungen. Alle Lösungen entsprechen Art. 9 Abs. 2 des Übereinkommens zur Beseitigung jeder Form von Diskriminierung der Frau vom 19. Dezember 1979 und Resolution 77 (13) des Ministerkomitees des Europarates vom 27. Mai 1977, wonach Frauen die gleichen Rechte wie Männer im Hinblick auf die Staatsangehörigkeit ihrer Kinder haben sollen (siehe § 1.4.2). Die letzte Lösung trägt jedoch eher der Tatsache Rechnung, daß auch im Ausland geborene Kinder häufig durchaus eine Beziehung zum Heimatsstaat ihrer Eltern haben. Soweit die so erworbene Staatsangehörigkeit wegen Auslandsaufenthalts verloren werden kann, wie dies z.B. im niederländischen und schweizerischen Recht der Fall ist, haben diese Kinder im Zeitraum von zehn Jahren nach Erreichung der Volljährigkeit die Möglichkeit, eine so enge Beziehung zum Heimatstaat der Eltern herzustellen, $\mathrm{daB}$ die iure sanguinis erworbene Staatsangehörigkeit erhalten bleibt. Die konkreten Voraussetzungen für den Verlust der Staatsangehörigkeit durch Auslandsaufenthalt werden in $\$ 3.4 .4$ näher verglichen und gewertet. An dieser Stelle soll aber festgehalten werden, daß diese Konstruktion m.E. wegen der größeren Selbstbestïmmungsmöglichkeit des Kindes einem beschränkten Erwerb iure sanguinis bei Auslandsgeburt vorzuziehen ist. Eine weitgehend entsprechende Selbstbestimmungsmöglichkeit könnte allerdings realisiert werden, wenn ein bei Auslandsgeburt beschränkter Erwerb iure sanguinis durch ein mindestens im Zeitraum von 10 Jahren nach Erreichung der Volljährigkeit auszuübendes Optionsrecht ausgeglichen würde.

Eine Selbstbestimmungsmöglichkeit besteht auch im italienischen Recht. Nach Art. 5 Abs. 2 des Gesetzes vom 21. April 1983 muß jeder Volljährige, der neben der italienischen Staatsangehörigkeit noch eine andere Staatsangehörigkeit besitzt, innerhalb eines Jahres nach Volljährigkeit zwischen seinen Staatsangehörigkeiten wählen. Entscheidet er sich nicht für die italienische, dann verliert er diese. Diese Wahlverpflichtung ist im italienischen Recht jedoch mangelhaft gestaltet (Siehe darüber \& 3.4 .7 ). Schon deshalb verdient sie nicht den Vorzag 
gegenüber der Konstruktion des Verlusts der Staatsangehörigkeit bei Auslandsaufenthalt. Ein weiterer Nachteil ist, daß schon in sehr jungem Aiter zwischen den durch Geburt erworbenen Staatsangehörigkeiten gewählt werden muß. Im allgemeinen wird jemand im neunzehnten Lebensjahr sozial, aber vor allem auch finanziell noch von seinen Eltern abhängig sein. Es wird deshalb in der Regel schwer vorauszusehen sein, ob es in der Zukunft möglich und wünschenswert ist, eine reelle Beziehung mit dem Staat herzustellen, dessen Staatsangehörigkeit zwar bei Geburt erworben wurde, in dem man aber nicht lebt. Die Tragweite einer solchen Wahl wird deshalb in diesem Alter nur begrenzt zu übersehen sein.

Aus dem vorherigen geht hervor, daß m.E. eine Regelung sicherlich wünschenswert ist, die Möglichkeit, die eigene Staatsangehörigkeit im Ausland iure sanguinis an nachfolgende Generationen weitergeben zu können, auf irgend eine Weise zu beschränken, damit die Staatsangehörigkeit eine reelle Beziehung zu einem bestimmten Staat manifestiert. Nur dann kann die Staatsangehörigkeit ihre Funktion als Anknüpfungsbegriff für Rechte und Pflichten erfüllen. Die im bundesdeutschen, österreichischen und spanischen Recht vorhandene Möglichkeit die Staatsangehörigkeit auch bei Auslandsgeburt uneingeschränkt weiterzugeben, muß unter diesem Aspekt abgelehnt werden. Sie ermöglicht, daß im Ausland Personen leben, die sich nicht bewuBt sind, noch immer die Staatsangehörigkeit ihrer Ahnen zu besitzen, während auch die betreffenden Staaten häufig nichts von der Existenz dieser Personen wissen. Wollen diese Staaten der Abstammung dieser Personen doch noch Rechnung tragen, dann könnte dies besser im Rahmen der Einbürgerungsvoraussetzungen geschehen (vgl. \& 3.3.3.2 Buchstabe b).

Am Ende dieses Paragraphen sei noch kurz auf ein gesetzestechnisches Detail hingewiesen. Art. 3 Abs. 1 RwNed bestimmt ausdruicklich, daß die Staatsangehörigkeit auch von einem vorhergestorbenen Elternteil hergeleitet werden kann. Entsprechende ausdrückliche Bestimmungen finden sich auch in mehreren Staatsangehörigkeitsgesetzen anderer Staaten (vgl. Art. 8 \& 2 CNB; Sec. 48 BNA; $\& 7 \mathrm{StBG}$ ). Bemerkenswert ist, daß diese Klausulierung nur beim Erwerb iure sanguinis aufgrund des Art. 3 Abs. 1 formuliert ist und nicht bei Art. 3 Abs. 3 (Erwerb der Staatsangehörigkeit durch das Kind eines zur Zeit seiner Geburt in den Niederlanden lebenden Vaters oder Mutter, der beziehungsweise die selbst eine ebenfalls in den Niederlanden lebende Mutter hatten), Art. 4 Abs. 2 (Erwerb durch Legitimation) oder Art. 5 Abs. 1 (Erwerb durch Adoption). Es liegt selbstverständlich nahe, diese Gesetzesvorschriften entsprechend zu interpretieren. Besser wäre es aber, die betreffenden Vorschriften zugunsten nachgeborener Kinder - wie z.B. in Großbritannien - in einem selbständigen Paragraphen zu regeln.

\subsubsection{Legitimation}

Legitimation bewirkt grundsätzlich in allen erwähnten Staaten, daß das legitimierte Kind die Staatsangehörigkeit des Vaters erwirbt. In den meisten Staaten ist dies allerdings nur unter der Voraussetzung der Fall, daB das legitimierte Kind noch minderjährig ist (Belgien: Art. 8 i.V.m. Art. 3 CNB; Frankreich: Art. 17 i.V.m. Art. 29 CNF; Großbritannien: Sec. 47 BNA; Italien: Art. 1 i.V.m. Art. 2 L.c. und Art. 5 Abs. 1 Gesetz vom 21. April 1983; Niederlande: Art. 4 
Abs. 2 RwNed; Schweiz: Art. 1 Abs. 2 Bst. a BüG). Lediglich in Deutschland und Spanien wird die väterliche Staatsangehörigkeit auch erworben, wenn das legitimierte Kind schon volljährig ist ( $\$ 5$ RuStAG; Art. 17 Ziffer 1 C.c.esp.).

Sehr bemerkenswert ist die österreichische Lösung. Bis 1986 erwarben minderjährige ausländische Kinder durch Legitimierung die Staatsangehörigkeit des österreichischen Vaters. Diese Regelung wurde aber am 12. Juni 1984 für verfassungswidrig erklärt (siehe $\$$ 2.7.1 und 2.7.2). Seit dem 1. Juni 1986 erwirbt nunmehr nur noch das noch nicht vierzehnjährige ausländische Kind durch Legitimierung die österreichische Staatsangehörigkeit des Vaters automatisch. Ist das legimimierte Kind noch minderjährig, aber bereits vierzehn Jahre alt, dann erwirbt es die österreichische Staatsangehörigkeit ausschließlich dann, wenn es selbst und sein gesetzlicher Vertreter zustimmen (\$ 7a Abs. 1 und 2 StBG i.d.F. 1985). Wird eine Zustimmung verweigert, dann kann diese durch das Vormundschafts- oder Pflegschaftsgericht ersetzt werden, "wenn der Erwerb der Staatsbürgerschaft aus erzieherischen, beruflichen oder anderen wichtigen Gründen dem Wohl des Legitimierten dient" ( $\$ 7$ a Abs. 5 StBG i.d.F. 1985). Im österreichischen Recht wird diese Regelung als Manifestierung des Prinzips der "Privatautonomie" im Staatsangehörigkeitsrecht verstanden. Der österreichische Gesetzgeber hat sich bemüht, die Erwerbs- und Verlustgründe der Staatsangehörigkeit so zu gestalten, $\mathrm{da}^{\mathrm{B}}$ die Staatsangehörigkeit grundsätzlich nur bei Einwilligung des Betroffenen erworben oder verloren wird.

Die in Österreich vertretene Ansicht hinsichtlich des Erwerbs der Staatsangehörigkeit durch Legitimation ist $\mathrm{m} . \mathrm{E}$. überzeugend. In zunehmendem Maße wird minderjährigen Kindern $a b$ einem gewissen Alter ein Mitbestimmungsrecht hinsichtlich der Entscheidungen eingeräumt, die sie persönlich betreffen. Auch bei dem Erwerbstatbestand der Legitimation ist ein solches Mitbestimmungsrecht geboten. Zwar sollen ehelich geborene und legitimierte Kinder prinzipiell hinsichtlich des Erwerbs der Staatsangehörigkeit gleich behandelt werden: Sie müssen nach neuerer Ansicht grundsätzlich die Staatsangehörigkeit sowohl vom Vater wie von der Mutter herleiten können. Der Erwerb der Staatsangehörigkeit des Vaters durch Legitimation kann jedoch häufig bewirken, daß die Staatsangehörigkeit der Mutter dadurch verloren wird; das ist der Fall, wenn das Staatsangehörigkeitsrecht des Staates, dem die Mutter angehört, noch nicht den Gleichberechtigungsgrundsatz im Staatsangehörigkeitsrecht verwirklicht hat. Gerade weill u.U. die bisherige Staatsangehörigkeit verloren wird, darf der Erwerb durch Legitimation $a b$ einem bestimmten Alter nicht ohne Einwilligung stattfinden. Allerdings wäre m.E. zusätzlich nicht nur Einwilligung des gesetzlichen Vertreters zu fordern, sondern auch die Einwilligung der Mutter, wenn durch den Staatsangehörigkeitserwerb das Kind ihre Staatsangehörigkeit verlieren würde. Der Mutter muß deshalb ausdriicklich ein eigenes Recht eingeräumt werden, weil sie zwar in der Regel, aber nicht immer gesetzlicher Vertreter ist. Das österreichische Recht eröffnet die Möglichkeit, daß eine nicht gegebene Einwilligung vom Vormundschaftsgericht ersetzt werden kann. Diese Möglichkeit muß grundsätzlich gutgeheißen werden, soweit es die erforderliche Einwilligung des gesetzlichen Vertreters (oder der Mutter) betrifft. Außer bei den im Gesetz erwähnten Gründen, die beachtet werden müssen, ist m.E. namentlich zu berücksichtigen, ob durch den Staatsangehörigkeitserwerb die bisherige Staatsangehörigkeit verloren wird. Die erforderliche Einwilligung des 
Minderjährigen soll m.E. nie vom Gericht ersetzt werden, wenn der Staatsangehörigkeitserwerb den Verlust der bisherigen Staatsangehörigkeit zur Folge hat.

Eine Übernahme der österreichischen Konstruktion in den anderen Staaten hätte zur Folge, daß nur bis zum vierzehnten Lebensjahr eines Kindes die Staatsangehörigkeit durch Legitimation automatisch erworben werden kann. Von der Vollendung des vierzehnten Lebensjahrs an gäbe es lediglich ein besonders ausgestaltetes Optionsrecht.

Erwägenswert wäre, den Erwerb kraft Legitimation auch vor dem vierzehnten Lebensjahr von der Einwilligung der Mutter abhängig zu machen. Dies wäre insbesondere in den Fällen angebracht, in denen der Erwerb den Verlust der bisherigen von der Mutter iure sanguinis hergeleiteten Staatsangehörigkeit verursachen würde. Zwar kann man darauf verweisen, daß ein Kind im Prinzip nicht ohne Mitwirkung der Mutter legitimiert werden kann, aber es ist m.E. wenig wuinschenswert, die Bereitschaft der Mutter zu einer Mitwirkung an der Legitimierung ihres eigenen Kindes, u.U. von staatsangehörigkeitsrechtlichen Erwägungen beeinflussen zu lassen. Das Ziel, einem nichtehelichen Kind durch Legitimation den Status eines ehelichen Kindes zu geben, ist zu bedeutsam, um die Legitimation eventuell an staatsangehörigkeitsrechtlichen Komplikationen scheitern zu lassen.

Aus dem vorherigen geht hervor, daß ich für das niederländische Staatsangehörigkeitsrecht eine dem österreichischen Recht entsprechende Regelung für den Erwerb der Staatsangehörigkeit durch Legitimation befürworten möchte. Im niederländischen Recht muß dieses Prinzip des Selbstbestimmungsrechtes des Kindes dlann auch beim Erwerb durch Anerkennung oder Adoption Berücksichtigung finden. Der Grundsatz der Privatautonomie eines Kindes etwa ab dem Alter von 14 Jahren hat weiter - wie das österreichische Recht bereits zeigt Folgen für die Regelung der Einbürgerung, die Bestimmungen bezüglich Erstreckung einer Einbürgerung beziehungsweise Erwerb kraft Optionserklärung auf Minderjährige und die Verlustgründe für Minderjährige. In den entsprechenden Paragraphen wird darauf hingewiesen ( $\$ 3.3 .6$ und 3.4.12).

Im österreichischen Recht hat ein Kind in den ihn betreffenden staatsangehörigkeitsrechtlichen Angelegenheiten ab seinem vierzehnten Geburtstag ein Mitbestimmungsrecht. Diese Altersgrenze ist selbstverständlich recht willkürlich gewăhlt. Eine etwas niedrige Altersgrenze ließe sich ebenfalls vertreten. In diesem Zusammenhang sei auf Art. 11 Abs. 2 RwNed hingewiesen, kraft dessen ein Kind $a b$ dem zwölften Geburtstag bezüglich der eventuell es selbst betreffenden Erstreckung einer Einbürgerung gehört werden muß (vgl. \$ 3.3.6). Für das niederländische Recht möchte ich deshalb ein Mitbestimmungsrecht ab Vollendung des zwölften Lebensjahres vertreten.

\subsubsection{Adoption}

Hecker hat in einem detaillierten, in der StAZ 1985 veröffentllichten Aufsatz, die Einflïsse der Adoption auf die Staatsangehörigkeit in sämtlichen Rechtsordnungen der Vergangenheit und Gegenwart beschrieben und typisiert. Er stellte dabei fest, daß die Regelungen außerordentlich vielfältig sind, und daß es kaum möglich ist, Schwerpunkte, Entwicklungstendenzen oder Vereinheitlichungsmög- 
lichkeiten aufzuzeigen. Auch die in dieser Studie beschriebenen Rechtsordnungen weisen eine beachtliche Variationsvielfalt auf. Dennoch läbt sich in soweit eine gemeinsame Tendenz feststellen: Alle beschriebenen Rechtsordnungen kennen einen Einfluß der Adoption auf die Erwerbsgründe der Staatsangehörigkeit.

Nach niederländischem Recht wird das in den Niederlanden durch eine richterliche Entscheidung adoptierte minderjährige Kind Niederländer, wenn der Adoptivvater oder die Adoptivmutter an dem Tage, an dem jene Entscheidung rechtskräftig wird, die niederländische Staatsangehörigkeit besitzt (Art. 5 Abs. 1 RwNed). Dies entspricht der Regelung des britischen Art. 1 (5) BNA 1981. Die Adoption muß also von einem niederländischen, beziehungsweise britischen Gericht ausgesprochen sein, ansonsten sind keine staatsangehörigkeitsrechtlichen Folgen an sie geknüpft. Nach niederländischem Recht muß das Kind im Zeitpunkt der erstinstanzlichen, richterlichen Entscheidung minderjährig sein.

Belgien hat in Art. $9 \mathrm{CNB}$ eine grundsätzlich andere Lösung gewählt. Von 1953-1985 hatte das von Belgiern adoptierte Kind lediglich einen Optionsanspruch. Seitdem wird das in Belgien geborene und von einem Belgier adoptierte minderjährige Kind immer Belgier. Dies entspricht der Kumulation von ius sanguinis und ius soli bei anderen Kindern mit Inlandsgeburt. Das im Ausland geborene und von einem Belgier adoptierte Kind wird Belgier, wenn ein (Adoptiv)Elternteil in Belgien oder in belgischen Kolonien geboren ist, das Kind sonst staatenlos sein würde, oder der belgische (Adoptiv)Elternteil innerhalb von fünf Jahren für das Kind eine Erwerbserklärung abgibt. Nach belgischem Recht können also auch ausländische Adoptionsurteile staatsangehörigkeitsrechtliche Folgen haben: Diese Regelung kann internationalprivatrechtliche Probleme verursachen, namentlich hinsichtlich der Frage, unter welchen Bedingungen diese Urteile in Belgien anerkannt werden können.

Solche kollisionsrechtlichen Fragen können ebenfalls in Deutschland, Frankreich, Italien, der Schweiz und Spanien auftreten, da auch nach den Gesetzen dieser Staaten heute minderjährige Adoptivkinder, ohne daß das Adoptionsurteil im Inland verkündet sein muß, die Staatsangehörigkeit erwerben. Bis 1977 erwarb das von Deutschen adoptierte ausländische Kind allein durch die Adoption noch nicht die deutsche Staatsangehörigkeit. Es hatte anch keinen Einbürgerungsanspruch. Seit dem 1. Januar 1977 erwirbt gemäB \&6 RuStAG das minderjährige durch einen Deutschen adoptierte Kind die deutsche Staatsangehörigkeit, sofern die Adoption nach deutschen Gesetzen wirksam ist. Seit 1945 wurde in Frankreich durch Adoptionslegitimation automatisch die Staatsangehörigkeit erworben. Seit 1966 gilt dies nunmehr für jede Volladoption. GemäB Art. 26 Abs. 2 i.V.m. Art. 29 CNF gilt dies allerdings nur für minderjährige Kinder. Die Staatsangehörigkeit kann sowohl vom Adoptivvater als von der Adoptivmutter hergeleitet werden.

Wie Frankreich führte auch Italien zuerst einen automatischen Staatsangehörigkeitserwerb im Falle einer Adoptionslegimation ein (Art. 5 des Gesetzes 431 vom 5. Juni 1967). Seit Inkrafttreten des Art. 39 des Adoptionsgesetzes vom 4. Mai 1983 wird aber durch jede Adoption die italienische Staatsangehörigkeit automatisch erworben. Dabei ist bemerkenswert, da 3 Art. 39 Adoptionsgesetz die italienische Staatsangehörigkeit nicht ausdrücklich bestimmt, daß die italie- 
nische Staatsangehörigkeit auch lediglich von einem italienischen Adoptivelternteil hergeleitet werden kann. Dies geht wohl ausdrücklich aus Art. 5 Abs. 1 des Gesetzes 123 vom 21. April 1983 hervor. Anzumerken bleibt, daB won den Staaten, die neben einer Vollacloption auch eine schwache Adoption kenmen (Frankreich und Italien), nur Italien auch auf eine schwache Adoption automatischen Staatsangehörigkeitserwerb folgen läßt. Im CNF wird ausdrücklich betont, daß eine schwache Adoption keinen Erwerb der französischen Staatsangehörigkeit bewirkt. Art. $55 \mathrm{CNF}$ sieht für schwach adoptierte minderjährige Kinder aber ein Optionsrecht mit Widerspruchsvorbehalt vor (siehe $\$ 3.3 .3 .2$ Buchstabe f).

In der Schweiz bestimmt Art. $7 \mathrm{BüG}$, daß ein minderjähriges ausländisches Kind, das von einem Schweizer oder einer Schweizerin adoptiert wird, die schweizerische Staatsangehörigkeit erwirbt. Wenn lediglich die Adoptivmutter die Staatsangehörigkeit besitzt und sie diese durch eine frühere Eheschließung mit einem Schweizer automatisch erworben hat, erwirbt das Adoptivkind diese Staatsangehörigkeit ausschlieBlich dann, wenn es sonst staatenlos sein würde. Im Entwurf 1986 wird vorgeschlagen diese Ausnahme zu streichen; das ist eine logische Folge der ebenfalls vorgeschlagenen Aufhebung des Art. 3 BüG.

In Spanien bestimmt seit 1982 Art. 18 Abs. 1 C.c.esp., daß das noch nicht achtzehnjährige Kind, das durch Adoption Kind eines spanischen Vaters oder einer spanischen Mutter wird, dadurch die spanische Staatsangehörigkeit erwirbt. Dies ist selbst dann der Fall, wenn die Adoption im Ausland stattgefunden hat. Bemerkenswert ist übrigens die Bestimmung des Art. 18 Abs. 2. Danach gilt das durch Adoption zum Spanier gewordene Kind als "español de origen", wenn ein Elternteil zur Zeit der Geburt des Kindes Spanier war. Diese Bestimmung ist wichtig, da das spanische Recht für diejenigen, die nicht "español de origen" sind zusätzliche Verlustgründe der Staatsangehörigkeit kennt (Art. 24 C.c.esp.). Von 1954 bis 1982 sah Art. 20 Abs. 3 C.c.esp. i.d.F. 1954 für ein von Spaniern adoptiertes Kind lediglich erleichterte Einbürgerungsvoraussetzungen vor.

Eine ganz andere Haltung gegenüber den Adoptivkindern zeigt z.B. Österreich. Ein Kind kann die österreichische Staatsangehörigkeit nicht durch Adoption erwerben. Ein von Österreichern adoptiertes minderjähriges Kind kann aber unter bestimmten Voraussetzungen einen Einbürgerungsanspruch geltend machen ( $\$ 12$ unter $\mathrm{d}$ in Kombination mit $\S 17 \mathrm{Abs}$. $4 \mathrm{StBG}$; siehe dazu $\$ 3.3 .3 .3$ Buchstabe $\mathrm{g}$ ).

Wir können aus derm vorherigen folgern, daB in den besprochenen Staaten die Regellung der Folgen einer Adoption in Bezug auf den Erwerb der Staatsangehörigkeit im allgemeinen den Minimalforderungen des Art. 11 Abs. 1 der Europaratskonvention über die Adoption vom 24. April 1967 entspricht (siehe $\S 1.4 .2$ ), wonach minimal eine erleichterte Einbürgerung verlangt wird. In allen studierten Staaten, außer Österreich, ist nunmehr ein automatischer Erwerb der Staatsangehörigkeit durch Adoption vorgesehen. Österreich kennt bis heute lediglich in bestimmten Fällen eine erleichterte Einbürgerung.

Die niederländische/britische Lösung kennt keine staatsangehörigkeitsrechtliche Folgen bei Adoptionen, die im Ausland erfolgen. Im Entwurf für das 1985 in Kraft getretene niederländische Staatsangehörigkeitsgesetz war ursprünglich eine 
andere Regelung vorgesehen. Die niederländlische Staatsangehörigkeit sollte auch von minderjährigen ausländischen Kindern erworben werden, die durch eine gemäß den Regeln des Internationalen Privatrechts in den Niederlanden anerkannte Adoption Kind eines niederländischen Elternteils wurden. Diese Regelung wurde aber geändert, da man befürchtete, auf diese Art und Weise könnten die - strengen - niederländischen Bestimmungen über die fremdenrechtliche Zulassung ausländischer Pflegekinder umgangen werden, die u.a. zum Ziel haben Kinderhandel vorzubeugen.

In den Niederlanden wird in den nächsten Jahren noch eine grundsätzliche Diskussion über die Adoption ausländischer Kinder stattfinden müssen. Diese Diskussion muß davon ausgehen, daß die von Niederländern adoptierten Kinder grundsätzlich genauso zu behandeln sind wie leibliche, (nicht-)eheliche Kinder von Niederländern. Adoptivkinder sollen deshalb grundsätzlich durch die Adoption die niederländische Staatsangehörigkeit erwerben. Andererseits sollen Adoptionen, die im Ausland stattgefunden baben, -gerade wegen der drohenden Gefahr eines potentiellen Kinderhandels- nicht stets bewirken, daß jedes Adoptionskind in die Niederlande einreisen darf, dessen Adoptiveltern oder zumindest ein Teil von ihnen die niederländische Staatsangehörigkeit besitzen. Nicht jede ausländische Adoption darf deshalb dem Kind die niederländische Staatsangehörigkeit vermitteln. Vielleicht wird das zukïnftige niederländische Recht die heutige Regelung handhaben und die niederländische Staatsangehörigkeit nur durch den Spruch eines niederländischen Gerichts vermitteln lassen. Wenn jedoch auch ausländische Adoptionsurteile die niederländische Staatsangehörigkeit vermitteln können, wird die Gestaltung der internationalprivatrechtlichen Anerkennungsregelung für den Erwerb der niederländischen Staatsangehörigkeit ausschlaggebend sein.

Hinsichtlich der staatsangehörigkeitsrechtlichen Folgen einer Adoption sei auf zwei weitere Fragen eingegangen. In $\$ 3.2 .2$ wurde im Zusammenhang mit der Besprechung der statsangehörigkeitsrechtlichen Folgen der Legitimation bereits auf die Tatsache hingewiesen, daß ein automatischer Staatsangehörigkeitserwerb wohl mit dem Selbstbestimmungsrecht eines älteren Minderjährigen kollidiert. Zumindest $a b$ Vollendung des zwölften Lebensjahres sollte deshalb der Erwerb einer Staatsangehörigkeit durch Adoption grundsätzlich nur mit der ausdrücklichen, schriftlichen Einwilligung des Kindes erfolgen.

In Belgien und Frankreich sind die Folgen der Adoption für das Staatsangehörigkeitsrecht so formuliert, daß die durch Adoption entstandenen familienrechtlichen Beziehungen auch in Verbindung mit bestimmten ius soli-Prinzipien die Staatsangehörigkeit vermitteln können. Dies gill für in Belgien beziehungsweise Frankreich geborene Kinder, wenn ein Adoptivelternteil selbst auch in Belgien beziehungsweise in Frankreich geboren wurde (Art. 9 CNB; Art. 23 i.V.m. 26 Abs. 2 CNF). Im niederländischen RwNed ist eine solche Verbindung zwischen Art. 5 und Art. 3 Abs. 3 RwNed nicht begründet. Art. 3 RwNed sollte m.E. aber entsprechend interpretiert werden.

\subsubsection{Ius sanguinis a matre: nicheheliche Kinder}

In Deutschland, Großbritannien, den Niederlanden, Österreich und der Schweiz gilt der Grundsatz "mater semper certa est". Dieses Prinzip führt im Staatsan- 
gehörigkeitsrecht dazu, daß nichteheliche Kinder nach den Bestimmungen dieser Staaten stets die Staatsangehörigkeit ihrer leiblichen Mutter erwerben (\$ 4 Ziffer 2 RuStAG; Sec. 1 (1) BNA 1981; Art. 3 Abs. 1 RwNed; \& 7 Abs. 3 StBG; Art. 1 Abs. 1 Bst. a BüG). Da alle diese Staaten seit einigen Jahren die Gleichberechtigung von Mann und Frau - jedenfalls bei der Regelung des Erwerbs der Staatsangehörigkeit iure sanguinis - realisiert haben, wird die so erworbene Staatsangehörigkeit nicht mehr im Falle von Anerkennung oder Legitimation des Kindes durch einen ausländischen Mann verloren. In den übrigen Staaten Belgien, Frankreich, Italien und Spanien - gilt der Grundsatz "mater semper certa est" nicht so absolut. Zwar erwirbt auch in diesen Staaten das nichteheliche Kind die Staatsangehörigkeit der Mutter, aber dazu muB die Mutterschaft zuerst juristisch festgestellt werden. In allen diesen Staaten mußte die Mutter ihr Kind zu diesem Zweck ursprünglich ausdrücklich anerkennen. Inzwischen ist dieser Grundsatz jedoch verlassen. Zwar kann die mütterliche Abstammung noch immer durch Anerkennung juristisch offenkundig gemacht werden, aber es gibt inzwischen auch andere Möglichkeiten. In Frankreich bestimmt seit 1982 Art. 334-8 Cc, daß die nichteheliche Abstammung durch freiwillige Anerkennung, Besitz des Personenstandes (possession d'état) oder durch die Wirkungen eines Urteils manifestiert werden können. In Spanien besagt seit 1981 Art. 120 C.c.esp., daß die nichteheliche Abstammung gesetzlich begründet wird:

a) durch das Anerkenntnis vor dem Standesbeamten, in einem Testament oder in einer anderen öffentlichen Urkunde;

b) durch einen Beschluß, der in einem Verfahren erging, das in Übereinstimmung mit dem Gesetz über das Zivilregister durchgeführt worden ist;

c) durch rechtskräftiges Urteil und

d) hinsichtlich der Mutter dann, wenn die Abstammung von ihr aus der fristgemäß erfolgten Geburtseintragung im Standesamt ersichtlich ist.

Auch in Italien können die verwandtschaftlichen Beziehungen zwischen Mutter und Kind durch Anerkennung und gerichtliche Feststellung entstehen. Seit 1975 bestimmt Art. 269 Abs. 3 C.c.it. hinsichtlich des Beweises der Mutterschaft, daB diese durch den Beweis der Identität desjenigen dargetan wird, der seine $\mathrm{Ab}$ stammung behauptet hat, sowie desjenigen, der von der Frau geboren wurde, um deren Mutterschaft es sich handelt. Art. 269 Abs. 1 C.c.it. betont allerdings, $\mathrm{da} ß$ die natürliche Mutterschaft oder Vaterschaft nur in Fällen, in denen eine Anerkennung möglich wäre, gerichtlich festgestellt werden kann. Eine Ausnahmestellung nahm bis 1987 Belgien ein. Gemäß Art. 8 CNB erwirbt das nichteheliche Kind einer belgischen Mutter grundsătzlich die belgische Staatsangehörigkeit. Gemäß Art. 334 C.c.belge mußte die Mutter aber zuvor ihr nichteheliches Kind anerkennen. Nur in einigen Ausnahmefällen konnte die Mutterschaft gerichtlich festgestellt werden (Art. 341 a C.c.belge). Nachdem der Europäische Menschenrechtsgerichtshof in der Marckxentscheidung das belgische Abstammungsrecht verurteilte, wurde dieses 1987 revidiert. Seitdem kann die familienrechtliche Beziehung zwischen Mutter und Kind auch in Belgien außer durch Anerkennung durch gerichtliche Feststellung der Abstammung entstehen.

Aus der Beschreibung dieser Regelungen geht hervor, daß die Rechtsordnungen Frankreichs, Italiens, Spaniens und Belgiens zwar traditionell nicht das Prinzip "mater semper certa est" kennen, heutzutage aber Regelungen haben, die diesem Prinzip in der Praxis außerordentlich nahekommen. In allen beschriebenen Rechtsordnungen erwirbt ein nichteheliches Kind daher grundsätzlich die Staatsangehörigkeit seiner Mutter. Dieser Grundsatz wird von mir bejaht. 


\subsubsection{Ius sanguinis a patre: nichteheliche Kinder}

Sehr unterschiedlich sind die Regelungen bezüglich der staatsangehörigkeitsrechtlichen Stellung eines Kindes gegenüber seinem nichtehelichen Vater. Kein Staat kennt hierbei einen automatischen Erwerb. Zunächst muB stets festgestellt werden, wer juristisch als Vater des nichtehelichen Kindes gilt. Aber auch wenn die väterliche Abstammung eines nichtehelichen Kindes festgestellt ist, erwirbt das Kind in allen Regelungen noch nicht automatisch die Staatsangehörigkeit seines biologischen Vaters. Das britische Staatsangehörigkeitsgesetz läBt die Staatsangehörigkeit grundsätzlich nur vom ehelichen Vater herleiten (Sec. 1 (1) in Verbindung mit Sec. 50 (9) BNA 1981). Das gleiche gilt in Deutschland und Österreich. Dort haben nichtebeliche Kinder aber die Möglichkeit, unter erleichterten Voraussetzungen eingebürgert zu werden. Häufig haben diese Kinder einen Einbürgerungsanspruch. Ein solcher Einbürgerungsanspruch ist in Deutschland seit 1975 in $\S 10$ RuStAG formuliert. Nach dreijährigem Aufenthalt in Deutschland, muß das ausländische Kind eines deutschen Mannes eingebürgert werden. Die Vaterschaft muß nach deutschem Recht wirksam feststehen, d.h., daß entweder eine Vaterschaftsanerkennung in öffentlich beurkundeter Form vorliegt ( $\$ 1600$ a BGB) oder die Vaterschaft in einem gerichtlichen Urteil festgestellt ist (siehe auch \$ 3.3.3.2 Buchstabe c). In Österreich kann ein Einbürgerungsanspruch aufgrund der Verbindung der $\$ 12$ Bst. d, $\$ 17$ Abs. 1 Ziffer 3 und $\$ 10$ Abs. 1 Ziffer 2 bis 8 und Abs. 2 StBG bestehen (siehe auch \$ 3.3.3.2 Buchstabe g). In Großbritannien haben die nichtehelichen Kinder eines Briten keinen Einbürgerungsanspruch. Hingewiesen sei aber auf Sec. 3 (1) BNA 1981, kraft dessen minderjährige Kinder immer nach Ermessen des Secretary of State als britische Staatsbürger registriert werden können.

In der Schweiz erwarb ein nichteheliches Kind seit Einführung des Zivilgesetzbuches im Jahre 1912 bis zum Jahre 1978 im Falle der Anerkennung durch einen schweizerischen Mann die schweizerische Staatsangehörigkeit; seit 1978 erwirbt es jedoch nur noch die Staatsangehörigkeit seines Vaters, wenn es unter dessen elterlicher Gewalt aufwächst und durch Namensänderung dessen Familiennamen erhält (Art. 1 Abs. 2 Bst. b BüG); eine erleichterte Einbürgerung wird für nichteheliche Kinder schweizerischer Männer nicht vorgesehen. Im Entwurf 1986 wird interessanterweise wieder vorgeschlagen, das BüG dahingehend zu ändern, daß ein nichteheliches Kind die schweizerische Staatsangehörigkeit vom Vater herleiten kann, wenn dieser das Kind anerkannt hat oder die Vaterschaft gerichtlich festgestellt ist.

Eine ganz andere Lösung findet man in den übrigen Staaten. So erwirbt in Belgien gemäB Art. 8 in Verbindung mit Art. 3 CNB das nichteheliche Kind eines belgischen Mannes grundsätzlich dessen Staatsangehörigkeit, wenn die Abstammung des Kindes während seiner Minderjährigkeit festgestellt wird. Dies entspricht auch der italienischen und französischen Regelung. Auch in Frankreich und Italien kann die väterliche Abstammung sowohl durch Anerkennung als auch durch ein Gericht festgestellt werden. Das im Zeitpunkt der Feststellung der Vaterschaft noch minderjährige Kind erhält die französische beziehungsweise italienische Staatsbürgerschaft seines Vaters. Dies ergibt sich in Frankreich aus der allgemeinen Bestimmung des Art. 29 CNF; in Italien aus Art. 5 Abs. 1 des Gesetzes vom 21. April 1983. In Spanien leitet ein nichteheliches Kind die spanische Staatsangehörigkeit vom Vater her, wenn die väter- 
liche Abstammung feststeht (Art. 17 Abs. 2 C.c.esp.); dies gilt auch, wenn die Feststellung der Vaterschaft erst nach Volljährigkeit des Kindes erfolgt.

Eine besondere Position nehmen die Niederlande ein. Ein ausländisches minderjähriges Kind erwirbt bei Anerkennung durch einen niederländlischen Mann die niederländische Staatsangehörigkeit (Art. 4 RwNed). Ein Erwerb durch gerichtliche Feststellung der Vaterschaft ist nicht vorgesehen, da nach niederländischem Zivilrecht ausschlieBlich durch Anerkennung familienrechtliche Beziehungen zwischen Vater und Kind entstehen. Eine Verurteilung des Erzeugers eines Kindes zu Unterhaltsleistungen hat keine familienrechtlichen Folgen. Im Moment wird in den Niederlanden anhand eines Referentenentwurfes uber die Revision des Abstammungsrechts diskutiert. Gemäß diesem Referentenentwurf wird auch die Möglichkeit einer Vaterschaftsfeststellung eingeführt werden. Eine solche Feststellung der Vaterschaft muß dann m.E. wie die Anerkennung: entsprechend den belgischen, französischen, italienischen und spanischen Regelungen und entsprechend dem in der Schweiz vorbereiteten Entwurf für minderjährige Kinder staatsangehörigkeitsrechtliche Folgen haben.

Das bei der Besprechung der staatsangehörigkeitsrechtlichen Folgen der Legitimation bei Betrachtung des österreichischen Rechts befürwortete Selbstbestimmungsrecht eines bereits zwölfjährigen Minderjährigen muß auch beim Staatsangehörigkeitserwerb kraft Anerkennung (oder gerichtlicher Feststellung der Vaterschaft) durchgeführt werden. Für eine inhaltliche Begründung und eine nähere Ausarbeitung der von mir befürworteten Regelung verweise ich nach den Erörtungen in \$ 3.2.2. Das niederländische Recht kennt für ausländische Personen, die als Volljährige durch Anerkennung Kind eines niederländischen Mannes werden, die Möglichkeit einer erleichterten Einbürgerung. Wenn in Zukunft auch nach niederländischem Recht die Feststellung der Vaterschaft familienrechtliche Beziehungen zwischen Vater und Kind hervorrufen, muß auch für volljährige Kinder, deren Abstammung von einem niederländischen Vater lediglich gerichtlich festgestellt wurde, die Möglichkeit bestehen, unter erleichterten Voraussetzungen eingebürgert $\mathrm{zu}$ werden (siehe auch $\$ 3.3 .8$.).

Eine abschließende Bemerkung soll jene minderjährigen, nichtehelichen Kinder betreffen, die von einem Niederiänder gezeugt worden sind, und die aufgrund einer gerichtlichen Entscheidung Unterhaltsansprüche gegen ihren Erzeuger haben. Wenngleich - wie im heutigen niederländischen Recht - durch eine solche Verurteilung keine familienrechtliche Folgen hervorgerufen werden, muß $\mathrm{m} . \mathrm{E}$. dennoch darüber nachgedacht werden, ob eine solche Verurteilung nicht die niederländische Staatsangehörigkeit vermitteln soll; wenigstens "sanguine" ist ein solches Kind in jedem Fall mit den Niederlanden verbunden. Wird der Ansicht gefolgt, daß ein automatischer Erwerb der Staatsangehörigkeit zu weit führen wiirde, wäre jedenfalls ein Optionsrecht angemessen. Obwohl das nichteheliche Kind eines Niederländers nach heutigem niederländischen Recht die niederländische Staatsangehörigkeit nicht durch Feststellung der Vaterschaft erwerben kann, ist bemerkenswert, daß sich gemäß Art. 11 RwNed die Einbürgerung eines Ausländers auf sämtliche minderjährige ausländische Kinder erstreckt, es sei denn, in dem BeschluB ist ein Vorbehalt enthalten. Aufgrund der Definitionen des Art. $1 \mathbb{R} w N e d$ erstreckt sich die Einbürgerung eines Mannes auf alle seine Kinder, die nach dem bisherigen Heimatrecht dieses Mannes mit ihm familienrechtliche Beziehungen haben; dies gilt auch, wenn diese Beziehun- 
gen z.B. durch Feststellung der Vaterschaft oder sogar lediglich durch ein Urteil betreffend Unterhaltsleistungen entstanden sind. Gerade unter dem Aspekt des iws sanguinis-Ausgangspunktes des niederländischen Staatsangehorigkeitsrechts. iberrascht es, daß sich deshalb manche nichtanerkannte, nichteheliche Kinder eines eingebürgerten Niederländers in einer besseren staatsangehörigkeitsrechtlichen Position befinden als die von einem Niederländer erzeugten, aber nicht anerkannten nichtehelichen Kinder. Auch aus diesem Grunde ist eine Erweiterung der Möglichkeiten des. Erwerbs der niederländischen Staatsangehörigkeit aufgrund nichtehelicher Abstammung von einem niederländischen Mann zi befürworten.

\subsubsection{Ins soli und ius domicilii}

Einige der hier erwähnten Staaten (Bundesrepublik Deutschland, Österreich und die Schweiz) haben in der Staatsangehörigkeitsgesetzgebung - abgesehen von den Regelungen für aufgefundene Kinder, die in \$ 3.2 .7 näher beschrieben werden sollen - keine ius soli-Elementen. Eine Geburt im Inland ist dort selbstverständlich im Rahmen eines Einbürgerungsverfahrens günstig, aber sogar daraus ergibt sich in der Regel noch kein Einbürgerungsanspruch: die Einbürgerung kann dennoch verweigert werden. In Deutschland und Österreich hat lediglich der in der Bundesrepublik beziehungsweise Österreich geborene Staatlose unter bestimmten Voraussetzungen einen Einbürgerungsanspruch (Art. 2 des Gesetzes zur Verminderung der Staatenlosigkeit vorm 29. Juni 1977, BGBI I, S. 1101; \& 14 StBG 1965) (siehe \& 3.3.3.3 Buchstabe b; vgl auch $\$ 3.3 .3 .3$ Buchstabe a).

Bis 1983 war die Lage im Vereinigten Königreich völlig abweichend. Die britische Staatsangehörigkeitsgesetzgebung ging grundsätzlich vom ius soli atrs. Die heutige Regelung kombiniert für Kinder die im Inland geboren werden, ius soli und ius sanguinis. Eine Geburt in Großbritannien bewirkt nur dann den Erwerb der britischen Staatsangehörigkeit, wenn ein Elternteil britisch oder wenigstens ein in GroBbritannien niedergelassener Ausländer ist (Sec. 1 (1) Buchstabe b i.V.m. Sec. 50 (2) BNA 1981).

Sehr bemerkenswert ist aun, daf durch die grundsătzliche Anderung des britischen Rechts die Staatsangehörigkeitsregelungen einiger kontinental-europäischer Staten plötzlich teilweise stärkere ius soli- Elemente beinhalten als Grofbritannier. Dies ist gerade deshalb interessant, da die kontinental-europäischen Staten seit Ende des vergangenen Jahrhunderts nach dem Prinzip des ius sanguinis verfuhren, seither aber almählich wieder iuss soli-Elemente aufnahmen.

An erster Stelle ist dabei selbstverständlich auf die neue Regelung von Art. 8 CNB hinzuweisen. Danach wird die belgische Staatsangehörigkeit bei Geburt in Belgien erworben, wenn zumindest ein Eltemteil die belgische Staatsangehörigkeit besitz; das gleiche gilt lediglich unter bestimmten Voraussetzungen bei Gebur im Ausland (siehe oben 33.21). Die Geburt im Inland hat in Belgien also, in Kombination mit der Abstammung, eine erneute Relevanz bekommen. Entsprechende Regelungen kennen die ubrigen kontinental-europäischen Staaten nich. Dennoch kömen ius soli-Elemente in den Staatsangehörigkeitsregelungen mehrerer Staaten erkannt werden. 
So kennen Belgien, Frankreich, Italien und Spanien ius soli-Bestimmungen zugunsten won im Inland geborenen potentiell staatenlosen Kindern. Gemäß dem seit 1985 geltenden Art. 10 Abs. 1 CNB erwerben in Belgien geborene, potentiell staatenlose Kinder die belgische Staatsangehörigkeit. Das in Belgien geborene Kind wird übrigens auch Belgier, wenn es zwar nicht bei der Geburt staatenlos war, dies vor Erreichung des achtzehnten Lebensjahres aber würde. Die so iure soli erworbene Staatsangehörigkeit wird wieder verloren, falls sich vor dem achtzehnten Geburtstag des Kindes herausstellt, daß es doch eine fremde Staatsangehörigkeit besitzt. In Frankreich geborene, potentiell staatenlose Kinder sind aufgrund Art. 21-1 CNF französisch. In Italien gilt bereits seit 1913 eine entsprechende Regelung aufgrund Art. 1 Abs. 1 Ziffer 3 L.c; man muß wohl annehmen, daß die so erworbene italienische Staatsangehörigkeit wieder entfällt, falls während der Minderjährigkeit solcher Kinder festgestellt wird, daß sie durch Abstammung eine fremde Staatsangehörigkeit besitzen. In Spanien wird die spanische Staatsangehörigkeit kraft Art. 17 Abs. 1 Ziffer 3 C.c.esp. von dort geborenen, potentiell staatenlosen Kindern erworben. In den Niederlanden erwerben im Inland geborene, potentiell staatenlose Kinder die niederländische Staatsangehörigkeit nicht. Sie haben lediglich ein nach mindestens dreijährigem Wohnsitz erstmals auszuübenes Optionsrecht (Art. 6 RwNed). Aus den Motiven zum RwNed geht u.a. hervor, daB die niederländische Regierung befürchtete, eine ius soli Regelung zugunsten solcher Kinder könne dazu führen, daß Frauen, die mit einem potentiell staatenlosen Kind schwanger wären, dessen Geburt bewußt in den Niederlanden planen könnten. Diese Befürchtung ist jedoch nicht sehr überzeugend, da bereits aus dem vorherigen hervorgeht, daß diese Frauen die Niederkunft auch in Belgien, Frankreich, Italien oder Spanien planen könnten. Insbesondere weil nun viele Staten - wie die in diesem Buch beschriebenen - ein ius sanguinis a patre et a matre kennen, dürfte die Anzahl von schwangeren Frauen mit potentiell staatenlosen Kindern außerdem auch statistisch bedeutungslos sein. Ein anderer Grund für die Entscheidung, potentiell staatenlose Kinder nicht iure soli die niederländische Staatsangehörigkeit erwerben zu lassen, war wohl die Tatsache, daß in den Niederlanden viele "Staatsangehörige" der untergegangenen Republik Maluku Selatan (Republik der Südmolukken) leben. Etwa $10 \%$ dieser Personen müssen aus völkerrechtlicher Sicht als staatenlos betrachtet werden, sie möchten jedoch aus politischen Gründen auch keine Staatsangehörigkeit erwerben. Die Einfiuhrung eines ius soli zugunsten potentiell Staatenloser würde bewirken, daß die Kinder dieser Personen die niederländische Staatsangehörigkeit kraft Geburt erwerben würden; das aber wollen ihre Eltern ebenfalls nicht. Diesem Wunsch zu entsprechen ist wohl auch Grund für die Entscheidung der niederländischen Regierung gewesen, für diese Personen kein ius soli einzuführen. Allerdings muß im Auge behalten werden, daß die jeweils zweite in den Niederlanden geborene Generation aufgrund der Bestimmung des Art. 3 Abs. 3 RwNed dennoch die niederländische Staatsangehörigkeit erwirbt. Die Entscheidung, wegen der Südmolukker auf eine ius soli-Bestimmung zugunsten der Staatenlosen zu verzichten, kann deshalb nur zeitlich begrenzt begrïndet sein, denn die jüngsten noch außerhalb der Niederlande geborene Südmolukker sind nunmehr fast 40 Jahre alt.

In diesem Zusammenhang darf die 1984 aufgehobene Bestimmung des Art. 44 Abs. 3 der schweizerischen Verfassung i.d.F, von 1982 nicht unerwähnt bleiben. Diese Vorschrift sah vor, daß dem in der Schweiz geborenen Kind einer schweizerischen Mutter die schweizerische Staatsangehörigkeit verliehen wurde. 
Die von Art. 44 Abs. 3 gebotene Möglichkeit wurde jedoch erst 1978 benutzt, als man die Kinder eines schweizerischen Vaters und einer schweizerischen Mutter grundsätzlich gleich behandeln wollte. Dazu fehlte aber eine ausreichende verfassungsrechtliche Grundlage. Durch Anwendung der von Art. 44 Abs. 3 gebotenen verfassungsrechtlïchen Möglichkeit wurden dann aber wenigstens jene Kinder schweizerischer Mütter, deren Eltern in der Schweiz lebten, Kindem schweizerischer Väter gleichgestellt. Die Bestimmung des Art. 44 Abs. 3 wurde also nicht aus ius soli-Motiven, sondern aus ius sanguinis a matre-Gründen benutzt. Nachdem 1984 die Verfassung geändert wurde, verschwand jedoch auch diese ius soli-ähnliche Regelung wieder aus dem BüG.

In Belgien und den Niederlanden haben alle Personen, die im Inland geboren sind, ein Optionsrecht auf die betreffende Staatsangehörigkeit. Hinzuweisen ist auf Art. 6 Abs. 1 Buchstabe a RwNed, kraft dessen der volljährige Ausländer, der in den Niederlanden geboren ist, und dort seit seiner Geburt Wohnsitz oder tatsä̀chlichen Aufenthalt hatte, für die niederländische Staatsangehörigkeit optieren kann. Dieses Optionsrecht muß vor Vollendung des 25. Lebensjahres ausgeibt werden. Die niederländlische Regierung hat keine Möglichkeit, dem Erwerb der niederländischen Staatsangehörigkeit durch die Ausübung dieses Optionsrechtes vorzubeugen. In den Niederlanden geborene Staatlose haben aufgrund von Art. 6 Abs. 1 Buchstabe b RwNed bereits nach dreijährigem Wohnsitz ein Optionsrecht auf die niederländische Staatsangehörigkeit. Auch dieses Optionsrecht muB vor Vollendung des 25 . Lebenjahres ausgeuibt werden (siehe § 3.3.3.1 Buchstabe a). Obwohl in Belgien die Art. 13-15 CNB ein Optionsrecht für in Belgien geborene Personen aussprechen, ist dort eher die Rede von einer erleichterten Einbürgerung, weil die Ausübung des Optionsrechtes aufgrund von in Art. 15 Abs. 2 CNB aufgeführten Gründen verweigert werden kann (siehe weiter § 3.3.3.2 Buchstabe a).

Die französische Staatsangehörigkeit kann zu einem bestimmten Zeitpunkt von in Frankreich geborenen Personen automatisch erworben werden. Ein in Frankreich von ausländischen Eltern geborenes Kind, das seit dem 16. Lebensjahr in Frankreich lebt, wird mit Erreichen der Volljährigkeit Franzose; dies gilt jedoch nur unter der Voraussetzung, daß es dann noch in Frankreich lebt (Art. 44 CNF): es gibt aber ein Ausschlagungsrecht des Betroffenen (Art. 45) und demgegenüber auch ein Widerspruchsrecht der Regierung. Die französische Regierung kann sich bis zum Zeitpunkt von einem Jahr vor Eintritt der Volljährigkeit des Betroffenen dem Erwerb der französischen Staatsangehörigkeit aus Griünden von Unwürdigkeit oder mangelnder Assimilierung widersetzen (Art. 46). Wenn aber ein in Frankreich geborener Ausländer in den französischen Militärdienst eintritt, so erwirbt er automatisch die französische Staatsangehörigkeit (Art. 48) (siehe weiter $\$ 3.3 .2$ ).

In Italien gilt eine entsprechende Regelung. Ein in Italien geborener Ausländer erwirbt die italienische Staatsangehörigkeit, wenn er in den italienischen Militäroder Verwaltungsdienst eintritt (Art. 3 Ziffer 1 L.c.). Der in Italien geborene Ausländer erwirbt zudem auch dann automatisch die italienische Staatsangehörigkeit, wenn er während der zehn, dem 21 . Lebensjahr vorabgehenden, Jahre in Italien wohnhaft war. Er kann jedoch vor Erreichen des 22. Lebensjahres die italienische Staatsangehörigkeit ausdrücklich ausschlagen. Bemerkenswert ist, $\mathrm{daB}$ diese automatischen Erwerbsgründen der italienischen Staatsangehörigkeit 
auch für (zufälligerweise) im Ausland geborene ausländische Kinder gelten, deren Eltern aber schon zur Zeit der Geburt mehr als zehn Jahren in Italien lebten (siehe auch \$ 3.3.2).

Das belgische bedingte Optionsrecht für in Belgien geborene Ausländerkinder wurde bereits erwähnt. Hinsichtlich des ius soli-Prinzips ist aber Art. $11 \mathrm{CNB}$ noch bemerkenswerter. In Belgien geborene Kinder von Eltern, die selbst auch in Belgien geboren wurden, können nach dieser Vorschrift durch einfache Erklärung die belgische Staatsangehörigkeit erwerben. Diese Erklärung muß jedoch vor dem 12 . Lebensjahr des Kindes von dem selbst auch in Belgien geborenen Elternteil abgegeben werden. Die belgische Regienung hat keine Möglichkeit, sich dieser Erklärung zu widersetzen. Hier handelt es sich also um ein reines Optionsrecht (siehe \$ 3.3.3.1 Buchstabe a).

Eine noch weitergehende Regelung beinhaltet Art. 3 Abs. 3 RwNed" dieser bestimmt, daß das Kind eines zur Zeit seiner Geburt in den Niederlanden lebenden Vaters oder einer Mutter, der beziehungsweise die selbst geboren ist zu einer Zeit, daß die Mutter des entsprechenden Elternteils in den Niederlanden lebte, automatisch Niederländer ist. Diese Regelung ist keine Manifestierung eines Erwerbs iure soli in reinem Sinne, aber sie ist dem ius soli sehr nah verwandt. Für die Anwendung von Art. 3 Abs. 3 RwNed ist nicht die Geburt auf niederländischem Boden ausschlaggebend, sondern der Wohnsitz eines Elternteils und der Mutter dieses Elternteils. Eine rein zufällige Geburt in den Niederlanden ist unerheblich. Man könnte Art. 3 Abs. 3 RwNed deshalb als Erwerb "iure domicilii" beschreiben oder gar als Erwerb iure sanguinis, wobei nun nicht Abstammung von einem Staatsangehörigen, sondern Abstammung von zwei in den Niederlanden lebenden Generationen relevant ist. Der Sinn dieser niederländischen Bestimmung besteht darin, Ausländer auch im staatsangehörigkeitsrechtlichen Sinne in die niederländische Gesellschaft zu integrieren. Nach zwei Generationen muß die Integration soweit fortgeschritten sein, daß die Zuteilung der niederländischen Staatsangehörigkeit keiner Überprüfung mehr bedarf. Die Betreffenden werden sich von (anderen) Niederländern nicht mehr unterscheiden und, falls dies doch der Fall ist, muß man dieses als Manifestierung dafür ansehen, daß die Niederlande allmählich eine pluriforme Gesellschaft bilden. Die Tatsache, daß die Niederlande nicht wie Belgien eine ausdrückliche Erklärung der Eltern fordern, hat zwei Vorteile. Erstens wird es dadurch unmöglich, daß bestimmte Familien bewußt über viele Generationen Ausländer in einer Gesellschaft bleiben und sich so den Rechten und Pflichten dieser Gesellschaft entziehen. Zweitens hat diese Konstruktion noch einen beweisrechtlichen Vorteil: Man kann seine eigene niederländische Staatsangehörigkeit einfach beweisen, wenn man nachweist, dalß zur Zeit der eigenen Geburt ein Elternteil in den Niederlanden lebte, und daß zur Zeit der Geburt dieses Elternteils dessen Mutter ebenfalls in den Niederlanden lebte. Damit ist die eigene niederländische Staatsangehörigkeit sicher bewiesen. Die belgische Regelung bedarf dieser beweisrechtlichen Funktion nicht. Art. $17 \mathrm{CNB}$ gesteht Personen, die 10 Jahre lang von belgischen Behörden als Belgier behandelt worden sind, ein Optionsrecht auf die belgische Staatsangehörigkeit zu (darüber auch \$ 3.3.3.1 Buchstabe e). Zwar kennt auch Frankreich in Art. 57.1 ein Optionsrecht im Falle einer zelanjährigen "possesion d'état", aber in Frankreich hat die Regierung auch in diesem Falle ein Widerspruchsrecht aus Grïnden der "indignité" oder "défaut d'assimilation" (siehe \$ 3.3.3.2 Buchstabe g). 
Eine der niederländischen Regelung weitgehend entsprechende Bestimmung findet man im französischen Staatsangehörigkeitsgesetz. Art. 23 bestimmt, daß das eheliche oder nichteheliche in Frankreich geborene Kind stets Franzose ist, wenn mindestens ein Elternteil selbst in Frankreich geboren ist. Art. 24 gibt solchen Kindern ein Ausschlagungsrecht für den Fall, daß nur ein Elternteil in Frankreich geboren ist. Dieses Ausschlagungsrecht muß innerhalb von sechs Monaten nach Volljährigkeit ausgeübt werden. Die Niederlande kennen ein solches ausdrückliches Ausschlagungsrecht nicht. Ein volljähriger Doppelstaatler kann aber durch die Kombination der Art. 15 und 14 RwNed immer auf die niederländische Staatsangehörigkeit verzichten. Ein ausdrüickliches Ausschlagungsrecht ist deshalb in den Niederlanden - anders als in Frankreich, wo die Verzichtsmöglichkeit beschränkter ist - überflüssig (siehe über Verzichtsmöglichkeiten $\$ 3.4 .3$ ).

Eine ius soli-Bestimmung zugunsten der zweiten im Inland geborenen Generation kennt auch Spanien (Art. 17 Abs. 1 Ziffer 2 C.c.esp.): Die spanische Staatsangehörigkeit wird von einem in Spanien geborenen Kind erworben, wenn es zumindest einen selbst auch in Spanien geborenen Elternteil hat. Eine Ausnahme gilt für die Kinder von diplomatischen und konsularischen Vertretern.

Die niederländische Domizil-orientierte Bestimmung des Art. 3 Abs. 3 RwNed ist m.E. gegenüber den auf den Geburtsort begründeten Regelungen des Art. 23 CNF und Art. 17 Abs. 1 Ziffer 2 C.c.esp. zu bevorzugen. Zwar ist die französisch/spanische Konstruktion juristisch-technisch leichter anzuwenden, weil bei Geburt eines Kindes im Inland relativ leicht und einwandfrei überprüft werden kann, ob ein Elternteil ebenfalls im Inland geboren ist. Die niederländische Konstruktion ist in der Anwendung wesentlich komplizierter, da die Wohnsitze der Eltern und Großmü̈tter geprüft werden mïssen, aber die niederländische Regelung hat einwandfrei den Vorteil, daß der Erwerb der niederländischen Staatsangehörigkeit durch nur zwei zufallige Geburten auf dem Gebiet der Niederlande auszuschließen ist. Außerdem bewirkt die niederländische Regelung des Art. 3 Abs. 3 RwNed, daß die niederländische Staatsangehörigkeit auch erworben werden kann, wenn eine Geburt zufällig im Ausland stattgefunden hat, der maßgebende Elternteil jedoch in den Niederlanden lebte. Bemerkenswert ist iibrigens, daß die niederländische Regelung nicht - wie z.B. die spanische ausführt, daß ein Erwerb der niederländischen Staatsangehörigkeit aufgrund der Bestimmung des Art. 3 Abs. 3 RwNed ausgeschlossen ist, wenn einer der Eltern des Kindes einen diplomatischen oder konsularischen Status hat. Da aber die Niederlande die Haager Staatsangehörigkeitskonvention von 1930 (siehe Art. 12) und die sich auf die Staatsangehörigkeit beziehenden Fakultativprotokolle zu den Wiener Diplomaten- und Konsularabkommen ratifiziert haben, gilt in den Niederlanden entsprechendes. Dabei muß m.E. die Regelung des Art. 3 Abs. 3 dahingehend interpretiert werden, daß diese nicht eingreift, wenn der Vater oder die Mutter eines Kindes zur Zeit von dessen Geburt einen diplomatischen oder konsularischen Status hat. Dagegen ist unbeachtlich, wenn der maBgebende Großelternteil im Zeitpunkt der Geburt des maßgebenden Elternteils diplomatischen oder konsularischen Status hatte. Wenn jedoch im Zeitpunkt der Geburt des Enkelkindes der maßigebende Großelternteil einen entsprechenden Status hatte, kann dies durchaus erheblich sein; wenigstens dann, wenn der maßgebende Elternteil zum Haushalt dieses Großelternteils gehörte. Der Grund dafür, daß 
Spanien die Ausnahme bezilglich Mitglieder einer diplomatischen oder konsularischen Mission ausdrücklich formuliert hat, lag wohl darin, daB Spanien die Fakultativprotokolle zu den eben erwähnten Abkommen nicht ratifiziert hat;" es war also notwendig, die entsprechende Ausnahme zu formulieren. In den Niederlanden dagegen ist eine solche Notwendigkeit nicht gegeben; die Regelung wäre aber verständlicher geworden, wenn die betreffende Ausnahme dennoch ausdrücklich genannt wäre.

Wie bereits erwähnt, fällt es auf, daß vor allem im Recht der Bundesrepublik Deutschland, Österreichs und der Schweiz ius soli-Elemente fehlen. Dies ist vor allem deshalb bemerkenswert, weil auch in diesen Staaten viele ausländische Familien leben und deren Integration durch Einführung bestimmter ius soli-Erwerbsgründe gefördert werden könnte. Dabei wäre namentlich daran zu denken, eine Regelung einzuführen, kraft deren die zweite im Inland geborene Generation die Staatsangehörigkeit erwerben würde. Eine andere Möglichkeit könnte die niederländische Domizil-orientierte Verfeinerung dieser Regelung biefen (vgl. Art. 3 Abs. 3 RwNed). In der Schweiz würde ein solcher Erwerbsgrund übrigens das logische Spiegelbild der Verlustbestimmung des Art. 10 Abs. 1 BüG bilden (siehe darüber \$3.4.4). Eine Einführung von ius soli-Bestimmungen dürfte allerdings in der Bundesrepublik Deutschland eine delikate Schwierigkeit verursachen. Da in der Bundesrepublik Deutschland die herrschende Lehre die vom RuStAG vermittelte Staatsangehörigkeit als die gesamtdeutsche Staatsangehörigkeit des Deutschen Reiches betrachtet, wäre auch eine kraft RuStAG iure soli erworbene Staatsangehörigkeit wohl als die gesamtdeutsche Staatsangehörigkeit anzusehen. Es ist aber sehr fraglich, ob eine Mehrheit im Bundestag bereit wäre das RuStAG lediglich dahingehend zu ändern, daß unter gewissen Voraussetzungen die deutsche Staatsangehörigkeit iure soli erworben wird, wenn ein Kind im Geltungsbereich des Grundgesetzes (inklusive Berlin-West) geboren wird. Andererseits wäre es aller Wahrscheinlichkeit nach völkerrechtswidrig, im RuStAG zu bestimmen, daß die deutsche Staatsangehörigkeit u.U. auch aufgrund einer Geburt in jenen Teilen des Deutschen Reiches erworben wird, die nach dem Stande vom 31. Dezember 1937 (Stichtag des Art. 116 Abs. 1 GG) zum damaligen Deutschen Reich gehörten, in denen aber heute das Grundgesetz der Bundesrepublik Deutschland nicht gilt. (Die Begrenzung des Auslandswahlrechts auf Deutsche mit ursprünglichem Wohmsitz in der Bundesrepublik Deutschland gemäß der letzten Novellierung des Wahlrechts, kann als ein Indiz in diese Richtung gewertet werden.) Wenn die hier signalisierten Schwierigkeiten tatsächllich bestehen, wird die Bundesrepublik Deutschland wohl solange von einer Einführung von ius soli-Regelungen in das RuStAG absehen, bis eine Wiedervereinigung erfolgt oder bis die herrschende Meinung verlassen ist, wonach die vom RuStAG vermittelte Staatsangehörigkeit die gesamtdeutsche darstellt (vgl. $\$ 1,4.1$ ).

Unter der Prämisse, daß es wünschenswert ist, ausländische Familien wenigstens auf Dauer auch staatsangehörigkeitsrechtlich zu integrieren, wïrde man erwarten, daß die Bundesrepublik Deutschland, Österreich und die Schweiz das Fehlen von ius soli-Bestimmungen durch Optionsrechte oder im Vergleich zu den anderen Staaten großzügigere Einbürgerungsregelungen ausgleichen würden. Gerade diese Rechtsordnungen kennen jedoch kaum Optionsrechte (oder Einbürgerungsansprïche). Die Einbürgerungsvoraussetzungen werden zudem im allgemeinen strenger als in den übrigen Staaten gehandhabt. Anscheinend wird der 
Wunsch, ausländische Familien möglichst staatsangehörigkeitsrechtlich zu integrieren, von den Regierungen dieser Staaten kaum geteilt. Dies widerspricht der Empfehlung 841 (1978) der Assemblée Parlementaire des Europarates betreffend Migranten der zweiten Generation und der Entschließung $\mathbb{R}$ (84) des Ministerkomitees des Europarates betreffend Gastarbeiter der zweiten Generation (siehe $\$ 1.4 .2$ ).

\subsubsection{Aufgefundene Kinder}

Nach niederländischem Recht wird das auf Staatsgebiet der Niederlande oder an Bord eines in den Niederlanden registrierten Seeschiffes oder Luftfahrzeuges aufgefundene Kind als Kind eines Niederländers betrachtet, es sei denn, daß sich innerhalb von fünf Jahren nach dem Tage des Auffindens herausstellt, daB das Kind durch Geburt eine ausländische Staatsangehörigkeit besitzt (Art. 3 Abs. 2 RwNed). Die anderen Staaten haben entsprechende Regelungen, wenngleich diese in Details wieder von einander abweichen.

So verliert ein in Belgien aufgefundenes Kind die iure soli erworbene belgische Staatsangehörigkeit, wenn sich vor dem 18 . Lebensjahr herausstellt, daß es Ausländer ist (Art. 10 Abs. 3 CNB). Eine entsprechende Regelung gilt in Frankreich (Art. $21 \mathrm{CNF}$ ) und in der Schweiz (Art. 6 Abs. 3 BüG).

In den britischen, deutschen, italienischen und österreichischen Staatsangehörigkeitsgesetzen wird dieser Erwerbsgrund sogar nur ganz allgemein dahingehend klausuliert, daB ein aufgefundenes Kind bis zum Beweis des Gegenteils als Bürger gilt (Sec. 1 (2) BNA; $\$ 4$ Abs. 2 RuStAG; Art. 1 Abs. 2 L.c.; $\$ 8$ Abs. 1 StBG; so auch noch Art. 2 Buchstabe b WNed; vgl. Art. 2 der New Yorker Konvention uiber die Verminderung der Staatenlosigkeit vom 30. August 1960).

In Spanien aufgefundene Kinder erwerben die spanische Staatsangehörigkeit aufgrund von Art. 17 Ziffer 4 C.c.esp.. Dieser Erwerb ist jedoch nicht klausuliert. Auch andere in Spanien geborene, potentiell staatenlose Kinder erwerben ebenfalls unklausuliert die spanische Staatsangehörigkeit (Art. 17 Ziffer 3 und 4 C.c.esp.).

Im niederländischen Staatsangehörigkeitsrecht ist der Erwerb der Staatsangehörigkeit dahingehend klausuliert, daß der Verlust der Staatsangehörigkeit nicht eintritt, wenn das Kind in diesem Fall staatenlos wäre (Art. 3 Abs. 2; vgl. auch Art. 14 Abs. 2 RwNed). Entsprechendes gilt auch ausdrücklich in Frankreich und in der Schweiz. Spanien kennt - wie bereits gesagt - uberhaupt keine Klausulierung. In den übrigen Staaten kann u.U. Staatenlosigkeit eintreten. In Belgien und Italien können Staatenlosigkeitsprobleme aber nur dann auftreten, wenn sich herausstellt, daß das Kind zwar dort ausgesetzt wurde, aber im Ausland geboren ist. In Deutschland und in Österreich tritt der Verlust der Staatsangehörigkeit immer ein, wenn nachgewiesen wird, daß das Kind keinen deutschen beziehungsweise österreichischen Elternteil hat. In Großbritannien ist die Präsumption zugunsten eines Findelkindes sogar doppelt klausuliert. Sie fällt weg, wenn entweder nachgewiesen wird, daß das Kind außerhalb Großbritanniens geboren wurde, oder daß3 es keinen Elternteil hat, der zur Zeit der Geburt des Kindes britischer Staatsangehöriger war oder seine ständige Niederlassung in Großbritannien hatte. 
Bemerkenswert ist auch, daß Deutschland, Italien, die Niederlande und die Schweiz bestimmen, daß dieser Erwerbsgrund für ein aufgefundenes Kind gilt; dies entspricht auch der Terminologie des Art. 2 der New Yorker Konvention über die Verminderung der Staatenlosigkeir vom 30. August 1960. Spanien spricht von einem aufgefundenen Minderjährigen. Belgien und Großbritannien bestimmen, $\mathrm{daB}$ es sich um ein aufgefundenes neugeborenes Kind handeln muB. Dabei wird in Großbritannien ein einjähriges Kind noch als "neugeboren" qualifiziert. Österreich bestimmt sogar ausdrücklich, daß das aufgefundene Kind jünger als sechs Monate sein muß. Für Frankreich geht aus Art. $58 \mathrm{Cc}$ hervor, das es sich um ein neugeborenes Kind handeln muB, ohne nähere Erläuterung des. Begriffes "neugeboren".

Aus verschiedenen Gründen ziehe ich von diesen Formulierungen die niederländische vor. Die schlichte Formulierung "Kind" bietet insbesondere die Möglichkeit, u.U. auch etwas ältere aufgefundene Kinder als Niederländer zu betrachten. Es bleibt somit eventuell der Rechtsprechung überlassen, darüber zu entscheiden, wo hier die Grenzen zu ziehen sind. Die belgische, britische, französische und österreichische Einschränkung auf sehr junge Kinder ist zu wenig umfassend. Die Erfahrungen des Zweiten Weltkrieges zeigen, daß manchmal auch die Identität von älteren Kindern nicht genau geklärt werden kann. Die niederländische Regelung stellt weiter ausdrücklich auf den Fundort ab und arbeitet nicht mit der Unterstellung, daß das Kind auch im Inland geboren ist. Diese Formulierung bewirkt, daB keine Schwierigkeiten auftreten, wenn sich herausstellt, daß das Kind als Staatenloser im Ausland geboren wurde.

In der Regelung ist nur eine kurze Frist von fünf Jahren vorgesehen, worin die aufgrund der Auffindung erworbene niederländische Staatsangehörigkeit wegen neu entdeckter Tatsachen wieder verloren werden kann. Wichtig ist somit vor allem, daß die Staatsangehörigkeit tatsächlich nur innerhalb einer bestimmten Frist wegen neuer Tatsachen entfallen kann. Bereits aus Gründen der Rechtssicherheit ist diese kurze Frist zu bejahen. Daneben ist eine relativ kurze Frist angemessen, da anzunehmen ist, daß ein aufgefundenes Kindes in einem niederländischen Kinderheim oder in einer niederländischen Familie erzogen wird. Es ist in solchem Fall nicht zweckmäßig, daß nach vielen Jahren gefolgert werden könnte, ein als Niederländer aufgewachsenes Kind besitze dennoch nicht die niederländische Staatsangehörigkeit. Die Frist von fünf Jahren ist auch deswegen glïcklich gewähllt, weil sie der in Art. 8 RwNed für eine Einbürgerung geforderten Aufenthaltsfrist entspricht.

In einer Hinsicht ist die Formulierung des Art. 3 Abs. 2 RwNed jedoch weniger deutlich. Eine buchstäbliche Interpretierung dieser Bestimmung würde bewirken, daß der Verlust der niederländischen Staatsangehörigkeit auch eintreten würde, wenn sich innerhalb von fünf Jahren nach Auffindung des Kindes herausstellt, daß das Kind kraft Geburt neben der niederländischen Staatsangehörigkeit auch noch eine andere erworben hat. Eine solche Interpretation widerspräche aber dem Zweck des Art. 3 RwNed. Es wäre daher besser, wenn der Text des Abs. 2 keinen Anlaß zu Zweifeln geben könnte. Dies ließe sich (sehr einfach) durch die Bestimmung realisieren, daß der Verlust der niederländischen Staatsangehörigkeit eintritt, wenn sich innerhalb von fünf Jahren herausstellt, daß ein Kind kraft Geburt lediglich eine ausländische Staatsangehörigkeit besitzt. 


\subsection{Erwerb der Staatsangehörigkeit nach der Geburt}

\subsubsection{Einführende Bemerkungen}

Im Abschnitt 3.2 wurden die Regelungen des Erwerbs der Staatsangehörigkeit durch Geburt oder durch spätere Feststellung familienrechtlicher Beziehungen zu einem Staatsangehörigen miteinander verglichen. Im Rahmen dieses Vergleichs wurden auch schon einige Tatbestände erwähnt, in denen die Staatsangehörigkeit nach der Geburt von Rechts wegen erworben werden kann. Daneben wurden bereits einige Optionsrechte und Fälle erleichterter Einbürgerung erörtert. In diesem Abschnitt sollen alle Fälle des späteren Staatsangehörigkeitserwerbs, die nicht auf Feststellung familienrechtlicher Beziehungen beruhen, näher untersucht und verglichen werden. Dabei sollen in $\$ 3.3 .2$ zunächst einige Fälle des automatischen Staatsangehörigkeitserwerbs nach der Geburt im belgischen, französischen, italienischen, österreichischen und schweizerischen Recht besprochen werden. In $\$ 3.3 .3$ folgt eine Übersicht der Optionsrechte nach dem allgemeinen Staatsangehörigkeitsrecht der untersuchten Staaten. Die in Staatsverträgen, besonderen Gesetzen und Übergangsbestimmungen formulierten Optionsrechte werden dabei grundsätzlich außer Betracht gelassen. Bei der Besprechung der Optionsrechte soll unterschieden werden zwischen reinen Optionsrechten, wobei die Behörden auf die Kontrollmöglichkeit beschränkt sind, ob der Optierende die Voraussetzungen für das Abgeben der Optionserklärung erfüllt, d.h. ohne Ermessenspielraum, und Optionsrechte, bei denen Behörden die Möglichkeit haben, sich der Optionserklärung aus anderen Gründen (z.B. öffentliche Ordnung, nationales Interesse, mangelnde Assimilierung des Optierenden) zu widersetzen.

Bei dieser letzten Kategorie wird von kontrollierten Optionsrechten oder von Optionsrechten mit Widerspruchsvorbehalt gesprochen. Bei diesen Optionsrechten handelt es sich - rechtsvergleichend betrachtet - um Fälle erleichterter Einbürgerung. Ein Unterschied zwischen kontrollierten Optionsrechten einerseits und erleichterten Einbürgerungen andererseits besteht in der Regel darin, daß die Staatsangehörigkeit bei einer kontrollierten Option im Moment der Optionserklärung erworben wird. Bei einer erleichterten Einbürgerung in den hier untersuchten Staaten ist der Staatsangehörigkeitserwerb dagegen immer konstitutiv. Es gibt aber Fälle, in denen der Erwerb der Staatsangehörigkeit durch kontrollierte Optionserklärung erst eintritt, wenn innerhalb einer bestimmten Frist kein Einspruch erhoben ist oder sogar erst, wenn die Optionserklärung von den Behörden genehmigt worden ist. Man vergleiche z.B. Art. 56 CNF (Erwerb im Moment der Optionserklärung, aber rückwirkender Verlust im Falle eines Widerspruchs der französischen Regierung) mit Art. 15 Abs. 3 CNB (Erwerb im Moment der Eintragung der von der Regierung bereits genehmigten Optionserklärung in die Register des Standesamtes). Namentlich in Belgien ist ein Optionsrecht mit Widerspruchsvorbehalt also faktisch eine erleichterte Einbürgerung.

Einen besonderen Platz nimmt der im britischen Recht bekannte Erwerb der Staatsangehörigkeit "by registration" ein (u.a. Sec. 1 (3), 3, 4, 5, 7 BNA 1981). Die "registration" kann unter bestimmte Voraussetzungen beantragt werden. Sind diese beï Überprïfung erfüllt, findet die "registration" statt. Erst im Moment der "registration" wird die britische Staatsangehörigkeit erworben (Sec. 42(4) BNA 1981). Im allgemeinen ist vor der "registration" ein "oath of alle- 
giance" zuleisten (Sec. 42 (1) und (2) BNA 1981). Die meisten Fälle des Erwerbs "by registration" stellen im Kern einen Erwerb durch Optionserklärung dar. Allerdings wird dabei die Staatsangehörigkeit in dem Augenblick erworben, wenn die Behörden durch Eintragung der betreffenden Person den Registrationsantrag akzeptieren. Die "registration" kann in diesen Fällen nur verweigert werden, wenn bestimmte Voraussetzungen nicht erfüllt sind. Es gibt im englischen Recht aber auch Fälle, in denen die Möglichkeit die britische Staatsangehörigkeit zu erwerben, eher einem kontrollierten Optionsrecht ähnelt. Dies ist z.B. bei "registrations" aufgrund Sec. 7 BNA 1981 der Fall, da Subsection 4 ausdrücklich bestimmt, daß eine "registration" in bestimmten in Sec. 7 erwähnten Fallen ausschlieBlich stattfindet, wenn "it seems to the Secretary of State fitting that he should be so registered by reason of his close connection with the United Kingdom". Das hier vorhandene freie Ermessen bewirkt, daB von einem reinen Optionsrecht keine Rede mehr ist. Dies gilt a fortiori für die Bestimnung des Sec. 3 (1) BNA 1981, wo vorgesehen ist "If while a person is a minor an application is made for his registration as a British citizen, the Secretary of State may, if he thinks fit, cause him to be registered as such a citizen". Diese Vorschrift muß als erleichterte Einbürgerung eingestuft werden.

In $\$ 3.3 .4$ werden die Einbürgerungsvoraussetzungen in den beschriebenen Staatsangehörigkeitsregelungen verglichen. Dieser Vergleich beschränkt sich hauptsächlich auf die in Gesetzen und Richtlinien formulierten Voraussetzungen. Hierbei muß man jedoch beachten, daß die in manchen Staaten explizit formulierte Voraussetzungen, in anderen Staaten im Rahmen anderer Voraussetzungen implizit eine Rolle spielen können. Soweit dies aus der staatsangehörigkeitsrechtlichen Literatur hervorgeht, wird hierauf hingewiesen. Beil der Besprechung der Einbürgerungsvoraussetzungen wird jeweils summarisch erwähnt, in welchen Fällen diese Bedingungen erleichtert werden.

Die sogenannte "Wiledereinbürgerung" wird als Fall der erleichterten Einbürgerung beschrieben. Dies entspricht der Regelung des niederländischen Staatsangehörigkeitsrechts und dem Inhalt der Regelungen des Wiedererwerbs der Staatsangehörigkeit in den übrigen Staaten. Als Fälle erleichterter Einbürgerung werden sämtliche Regelungen aufgefaßt, in denen die allgemeine Einbürgerungsworaussetzungen reduziert werden. Dies sei ausdrücklich betont, da im schweizerischen Recht die Einbürgerungen in drei Kategorien unterteilt werden, namentlich die ordentliche Einbürgerung, die Wiedereinbürgerung und die erleichterte Einbürgerung. Die Wiedereinbürgerung und die erleichterte Einbürgerung sind - anders als die ordentliche Einbürgerung - unentgeltlich. Aber auch im Rahmen der" schweizerischen Regelung der ordentlichen Einbürgerung gibt es Bestimmungen, die die Wohnsitzvoraussetzung, die für eine normale Einbürgerung gilt, reduzieren. Auch diese Fälle werden - abweichend von der schweizerischen Terminologie - als erleichterte Einbürgerungen beschrieben.

Danach wird in \$ 3.3.5 einen Überblick über besondere Fálle der Einbürgerung gegeben: Die meisten der beschriebenen Staten kennen die Möglichkeit, in Abweichung von allen im Gesetz formulierten Voraussetzungen, nach freiem Ermessen der Behörde Personen einzubürgern. \$ 3.3.6 ist der Problematik der Erstreckung einer Einbürgerung auf andere Personen gewidmet. Früher betraf dies grundsätzlich die Erstreckung der Einbürgerung eines Mannes auf dessen Ehefrau und dessen (minderjährige) Kinder; heutzutage bezieht sich die eventuelle Erstreckung der Einbürgerung eines Elternteils lediglich auf dessen minderjährige Kinder. Ein eigener Paragraph (3.3.7) wird einigen zusammenfassen- 
den Bemerkungen über die staatsangehörigkeitsrechtliche Position des ausländischen Ehepartners eines Staatsangehörigen gewidmet. Außer in der Schweiz haben diese in allen untersuchten Staaten die Möglichkeit unter erleichterten Voraussetzungen eingebürgert zu werden. In der Schweiz gilt dies auch für den ausländischen Ehemann einer schweizerischen Frau; die ausländische Ehefrau erwirbt jedoch durch ihre Eheschließung mit einem Schweizer noch immer von Rechts wegen dessen Schweizer Bürgerrecht.

\subsubsection{Fälle automatischen Staatsangehörigkeitserwerbs}

Alle Staaten kennen Regelungen, auf Grund deren bestimmte Personen im Augenblick ihrer Geburt automatisch die Staatsangehörigkeit dieses Staates erwerben. Diese Regelungen wurden in den $\$ 3.2 .1,3.2 .4,3.2 .6$ und 3.2 .7 besprochen. Daneben kennen diese Rechtsordnungen Fälle, in denen durch nachträgliche Feststellung der Abstammung eines ausländischen Minderjährigen von einem Staatsangehörigen oder durch Adoption die Staatsangehörigkeit von Rechts wegen erworben wird. Diese Fälle wurden in den $\$ 3.2 .2,3.2 .3$ und 3.2.5 besprochen. Auch wenn eine Staatsangehörigkeit von einem Minderjährigen durch Erstreckung der Einbürgerung eines Elternteils erworben wird, kann von einem automatischen Erwerb gesprochen werden (siehe \$ 3.3.6). Über diese automatische Erwerbsarten einer Staatsangehörigkeit wurde bereits vorher (in den $\$ 3.2 .2,3.2 .3$ und 3.2.5) bemerkt, daß sie lediglich für jüngere Minderjährige unter gewissen Voraussetzungen zu bejahen sind. Älteren Minderjährigen (ab etwa Vollendung des 12. Lebensjahres) muß ein Selbstbestimmungsrecht in staatsangehörigkeitsrechtlichen Angelegenheiten eingeräumt werden.

In diesem Paragraphen sollen Erwerb der Staatsangehörigkeit durch (nachträgliche) Feststellung der Abstammung, Adoption oder Erstreckung nicht mehr erörtert werden, es sollen jedoch einige besondere Erwerbsgründe der Staatsangehörigkeit von Rechts wegen nach der Geburt erwähnt und gewertet werden, die im belgischen, französischen, italienischen, österreichischen und schweizerischen Recht vorhanden sind. Das heutige britische, deutsche, niederländische und spanische Recht kennt solche zusätzliche Fälle automatischen Staatsangehörigkeitserwerbs nicht.

Die belgische Staatsangehörigkeit wird ipso iure von einem im Ausland geborenen Kind belgischer Eltern erworben, die selbst im Ausland geboren wurden, wenn es vor Vollendung des achtzehnten Lebensjahres oder vorheriger Volljährigkeit staatenlos wird (Art. $8 \& 1 \mathrm{CNB}$ ). Das gleiche gilt für jedes in Belgien geborene ausländische Kind, wenn es vor seinem 18 . Geburtstag staatenlos wird (Art. 10 Abs. 1 CNB).

In \$ 3.2.6 wurde bereits erwähnt, daß in Frankreich und Italien geborene Personen unter bestimmten Voraussetzungen bei Volljährigkeit oder kurz danach automatisch die französische, beziehungsweise italienische Staatsangehörigkeit erwerben. In Frankreich ist dies der Fall, wenn der Betreffende während der fünf dem 18. Geburtstag vorangehenden Jahre in Frankreich lebte und dies auch am 18. Geburtstag noch der Fall ist (Art. 44 CNF). In Italien muß der Betreffende die zehn dem 21. Geburtstag vorangehenden Jahren in Italien gelebt haben; innerhalb des 22. Lebensjahres kann er die italienische Staatsangehörigkeit aber ausschlagen (Art. 3 L.c.). Auch in Frankreich kann der Staatsangehö- 
rigkeitserwerb vom Betreffenden ausgeschlagen werden, doch kann ebenso die Regierung diesem Erwerb wegen Unwürdigkeit ader mangelnder Assimilierung widersprechen. In Italien gibt es ein derartiges Widerspruchsrecht der Behörden nicht. In Italien gilt eine entsprechende Regellung für außerhalb Italiens geborene Kinder, deren Eltern zur Zeit der Geburt dieser Kinder seit mehr als zehn Jahren in Italien lebten; die Regelung gilt auch für Personen, deren Mutter, Vater oder Großvater väterlicherseits italienische Staatsangehörige aufgrund der Geburt waren (Art. 3 Abs. 2 L.c.) sowie füir Personen, die als Minderjährige die italienische Staatsangehörigkeit verloren haben (Art. 12 Abs. 2 L.c.). Sowohl in Frankreich als auch in Italien gilt weiterhin die Regelung, daß ein dort geborener Ausländer durch Eintritt in den französischen beziehungsweise italienischen Militärdienst die betreffende Staatsangehörigkeit erwirbt (Art. 48 CNF; Art. 3 Ziffer 1 L.c.) In Italien gilt entsprechendes auch für den Eintritt in den italienischen Zivildienst. Auch diese italienische Regelung gilt wiederum für außerhalb Italiens geborene Kinder, deren Eltern schon zur Zeit der Geburt dieser Kinder mehr als zehn Jahren in Italien lebten. Personen, die die italienische Staatsangehörigkeit verloren haben, können sie ebenfalls unter bestimmten Voraussetzungen automatisch zurückerwerben (Art. 9 L.c.). Dies ist erstens der Fall, wern sie in Italien Wehrdienst leisten oder eine staatliche Anstellung annehmen. Unter dem Vorbehalt, daß die itallenische Regierung keinen Einspruch erhebt, wird die italienische Staatsangehörigkeit auch durch Verzicht auf die andere Staatsangehörigkeit oder durch Ausscheiden aus dem fremden Staats- oder Wehrdienst zurückerworben. Zusätzliche Bedingung ist dann in der Regel, daß der Betreffende sich innerhalb eines Jahres in Italien niederläBt (Art. 9 Abs. 1 Ziffer 2 i.V.m. Abs. 3 L.c.). Wenn der Verlust der Staatsangehörigkeit die Folge des Erwerbs einer fremden Staatsangehörigkeit war, wird die italienische Staatsangehörigkeit durch zweijährigen Aufenthalt in Italien wieder zurïckerworben; die italienische Behörden können Widerspruch erheben (Art. 9 Abs. 1 Ziffer 3 i.V.m. Abs. 2 L.c.).

In Österreich wird die Staatsangehörigkeit durch den Dienstantritt als ordentlicher Universitätsprofessor an einer österreichischen Universität, als ordentlicher Hochschulprofessor an der Akademie der bildenden Künste oder an einer österreichischen Kunsthochschule von Rechts wegen erworben ( $\$ 25$ StBG 1965; \&6 StBG 1945/1949; \& 3 Ziffer 2 Buchstabe b StBG 1925). Diese Regelung entspricht dem Bundesverfassungsgesetz, das in Art. 6 Abs. 4 entsprechendes bestimmt. Dieser Erwerbsgrund ist ein Rudiment der früheren österreichischen Regelung, die bestimmte, daß die Staatsangehörigkeit durch Eintritt in den öfentlichen Dienst erworben wurde ( $829 \mathrm{ABGB})$. Da die eben erwähnte Regelung nunmehr Verfassungsstatus hat, wird sie wohl noch lange ein Curiosum des österreichischen Rechts bleiben.

Wie bereits erwähnt erwirbt in der Schweiz die ausländische Frau, die einen schweizerischen Staatsangehörigen heiratet noch immer automatisch die schweizerische Staatsangehörigkeit. Die übrigen Staaten kannten friiher entsprechende Regelungen, haben aber diesen Erwerbsgrund inzwischen abgeschafft. In der Schweiz wird dies in nächster Zukunft ebenfalls geschehen. Im Entwurf 1986 ist in den Artikeln 27,28 und 28a eine erleichterte Einbürgerung des ausländischen Ehepartners eines Schweizer Bürgers unabhängig vom Geschlecht vorgesehen. 
Alle in diesem Paragraphen erwähnten Tatbestände des automatischen Staatsangehörigkeitserwerbs rechtfertigen im allgemeinen, daB die betroffenen Personen die betreffende Staatsangehörigkeit erwerben. Ein automatischer Staatsangehörigkeitserwerb muß jedoch prinzipiell abgelehnt werden. In den Paragraphen 3.2.2 wurde bereits die Ansicht vertreten, daß Personen ab einem bestimmten Alter ein Selbstbestimmungsrecht in Staatsangehörigkeitsangelegenheiten haben sollten. Fälle automatischen Staatsangehörigkeitserwerbs sind mit diesem Ausgangspunkt nicht zu vereinbaren. Sogar ein automatischer Erwerb mit einer befristeten Ausschlagungsmöglichkeit wie sie z.B. in Frankreich vorgesehen ist, muß unter diesem Gesichtspunkt abgelehnt werden; es ist nicht garantiert daB der Betroffene immer über den Erwerbstatbestand und die für ihn vorhandene Ausschlagungsmöglichkeit informiert ist. Auch aus beweisrechtlichen Grïnden muß die Konstruktion eines automatischen Staatsangehörigkeitserwerbs zurückgewiesen werden. Um den Besitz einer von Rechts wegen erworbenen Staatsangehörigkeit nachweisen zu können, muß der Betreffende immer schriftliche Nachweise aufbewahren, aus denen hervorgeht, daß zu einem bestimmten Zeitpunkt einer der erwähnten automatischen Erwerbstatbestände erfüllt war. Falls diese Nachweise verloren gehen, ist es manchmal schwierig, den Erwerb der Staatsangehörigkeit zu beweisen. Allein aus diesem Grund ist in den betreffenden Fällen bereits eine (erleichterte) Einbürgerung oder Erwerb durch Optionserklärung vorzuziehen, da diese Erwerbsarten behördlich registriert werden.

Bei der Ablehnung der beschriebenen Fälle automatischen Staatsangehörigkeitserwerbs, möchte ich jedoch eine Ausnahme machen. Die belgische Regelungen des Art. $8 \S 1$ und 10 Abs. $1 \mathrm{CNB}$ sind m.E. zu bejahen. Zwar haben auch diese Regelungen die eben erwähnten Nachteile, demgegenüber steht aber als einwandfreien Vorteil die Bekämpfung der Staatenlosigkeit. In diesen besonderen Fällen sollen die Einwände hinter der so zu realisierenden Vermeidung der Staatenlosigkeit zurücktreten.

\subsubsection{Optionsrechte}

Alle Staaten kennen die Möglichkeit, an Personen, die nicht etwa aufgrund ihrer familienrechtlichen Beziehungen oder aufgrund ihres Geburtortes die Staatsangehörigkeit des betreffenden Staates von Rechts wegen erworben haben, diese Staatsangehörigkeit nachträglich zuverleihen. Dazu muß festgestellt werden, daß die betroffenen Personen so enge Beziehungen zu diesem Staat entwickelt haben, daß es gerechtfertigt ist, sie als dem Staat und der Gemeinschaft seiner Bürger zugehörig anzusehen. Dieser Staatsangehörigkeitserwerb erfolgt normalerweise durch Einbürgerung. Im Rahmen eines Einbürgerungsverfahrens wird überprüft, ob die Beziehungen eines Einbürgerungsbewerbers zum Inland die Verleihung der Staatsangehörigkeit rechtfertigen können. Durch die Einbürgerung werden also die Gründe, kraft deren die Staatsangehörigkeit von Rechts wegen erworben wird, in Einzelfällen korrigiert. Ausländer, die enge Beziehungen zum Inland haben, werden in die Gemeinschaft der Staatsangehörigen integriert. Im Rahmen eines Einbürgerungsverfahrens werden die Beziehungen eines Ausländers zum Inland in der Regel ausführlich überprüft, bevor die Staatsangehörigkeit verliehen wird. Es gibt aber auch Fälle, in denen die Beziehungen eines Ausländers zum Inland offensichtlich sind: Einige Staaten haben deshalb bestimmt, daß bei Vorliegen bestimmter, eine enge Beziehung zum Inland garantierender Voraussetzungen die Staatsangehörigkeit von den betref- 
fenden Personen von Rechts wegen erworben wird. Der Staat indiziert auf diese Weise, daB der Staatsangehörigkeitserwerb angemessen ist. Diese Fälle automatischen Staatsangehörigkeitserwerbs wurden eben in $\$ 3.2 .2$ besprochen, aber wegen Mißachtung einer Selbstbestimmungsmöglichkeit der Betreffenden mit einer Ausnahme abgelehnt. Die nun zu besprechenden Optionsrechte bilden eine elegante Zwischenlösung. Sie stehen zwischen Einbürgerung und den Fällen des automatischen Erwerbs. Außer den betreffenden Voraussetzungen brauchen die weiteren Beziehungen zam Inland nicht überprüft zu werden. Da aber die Staatsangehörigkeit lediglich erworben wird, wenn der Betreffende eine Optionserklärung abgibt, ist dem Sellbstbestimmungsrecht des Betreffenden Rechnung getragen. Optionsrechte müssen daher unter diesem Gesichtspunkt bejaht werden. Sie fördern daneben die Integration von Ausländern, weil der Erwerb einer Staatsangehörigkeit durch Optionserklärung wesentlich weniger kompliziert ist als durch Einbürgerung. Wenn der Betreffende nachweist, daß er die Optionsvoraussetzungen erfüllt, kann er durch eíne einfache Optionserklärung die Staatsangehörigkeit erwerben. Dagegen muß er sich für eine Einbürgerung jedoch einer behördlichen Überprüfung seiner Beziehungen zum Inland unterwerfen. Andererseits ist die Bejahung von Optionsrechten aber nur unter gewissen Voraussetzungen angemessen. Die zu erfïllenden Voraussetzungen müssen klar formuliert und leicht zu überprüfen sein. Vage Voraussetzungen wie "ausreichende Assimilierung" oder "Würdigkeit" sind jedenfalls abzulehnen. Sind ferner die Optionsvoraussetzungen zu kompliziert oder lediglich nach eingehender Überprüfung festzustellen, empfiehlt sich auch ein Einbürgenungsverfahren. Infolge dessen sind $\mathrm{m} . \mathrm{E}$. deshalb lediglich reine Optionsrechte mit klaren, leicht zu überprüfenden Voraussetzungen zu bejahen. Die in $\$ 3.3 .3 .2 \mathrm{zu}$ besprechenden Optionsrechte mit Widerspruchsvorbehalt müssen deshalb abgelehnt werden.

\subsubsection{Reine Optionsrechte}

\section{a. Im Inland geborene Ausländer}

Wenn wir von den besonderen Vorschriften zugunsten im Inland geborener Staatenloser und von besonderen Regeln zugunsten der zweiten im Inland geborenen Generation (siehe darüber $\$ 3.2 .6$ ) absehen, kennen lediglich die Niederlande, Großbritannien und Italien reine Optionsrechte für im Inland geborene Ausländer. Belgien und Frankreich kennen für diese Kategorie von Personen ein Optionsrecht mit Widerspruchsvorbehalt (siehe $\$$ 3.3.3.2 Buchstabe a). Belgien sieht allerdings für die zweite dort geborene Generation ein reines Optionsrecht vor; diese Generation erwirbt in Frankreich, den Niederlanden und Spanien automatisch die Staatsangehörigkeit des Geburtsstaates (\$3.2.6). Deutschland, Österreich und die Schweiz kennen für diese Kategorie kein Optionsrecht. Die eben erwähnten Optionsrechte sollen nun näher beschrieben werden.

Der achtzehnjährige, in den Niederlanden geborene Ausländer, der dort seit der Geburt ununterbrochen wohnhaft ist, hat ein Optionsrecht auf die niederländische Staatsangehörigkeit; es muß vor Vollendung des 25 . Lebensjahres ausgeübt werden (Art. 6 Abs. 1 Ziffer a RwNed).

Nach britischem Recht erwerben im Vereinigten Königreich geborene Kinder von dort niedergelassenen ausländischen Eltern automatisch die britische Staats- 
angehörigkeit (Sec. 1 (1) Ziffer 6 BNA 1981). Ist der Erwerb auf diese Weise nicht möglich, weil eine der Voraussetzungen im Zeitpunkt der Geburt nicht erfüllt ist, so besteht zu späterer Zeit noch die Möglichkeit einer "registration". Diese tritt zum einen ein, wenn der Vater oder die Mutter nachträglich die britische Staatsangehörigkeit oder den Status eines Niedergelassenen erwirbt (Sec. 50 BNA 1981; Sec. 1 (3) BNA 1981; vgl. \$ 3.3.6 über das Fehlen einer Erstreckung der Einbürgerung eines Elternteils auf minderjährige Kinder im britischen Recht; siehe auch $\$ 3.3 .3 .1$ Buchstabe c). Ist auch diese Voraussetzung nicht erfüllt, ist eine "registration" allenfalls möglich, wenn das Kind die ersten zehn Jahre seines Lebens im Vereinigten Königreich verbracht hat. Grundsätzlich darf ein solches Kind in keinem dieser Jahre mehr als 90 Tage auBerhalb des Vereinigten Königreiches verbracht haben (Sec. 1 (4) und (7) BNA 1981).

In Italien geborene Ausländer erwerben unter bestimmten Voraussetzungen (Art. 3 Abs. 1 und 3) die italienische Staatsangehörigkeit automatisch mit Vollendung des 22. Lebensjahres. Diejenigen, die diese Voraussetzungen nicht erfüllen, können als Einundwanzigjährige für die italienische Staatsangehörigkeit optieren, wenn sie seit mindestens zehn Jahren in Italien leben.

Nach belgischem Recht hat die zweite in Belgien geborene Ausländergeneration ein reines Optionsrecht auf die belgische Staatsangehörigkeit. Die Optionserklärung muß vor Vollendung des zwölften Lebensjahres beim Standesamt des Hauptaufenthaltsortes des Kindes in Belgien abgegeben werden. Erklärungsberechtigt ist der in Belgien geborene Elternteil, der zur Zeit der Erklärung selbst in Belgien leben muß (Art. 11 CNB). Die erste in Belgien geborene Generation hat zwischen ihrem 18. und 22. Geburtstag ein kontrolliertes Optionsrecht auf die belgische Staatsangehörigkeit (art. 13, $14 \mathrm{CNB}$ ). Ein solches Optionsrecht mit Widerspruchsvorbehalt kennt auch das französische Recht für die erste im Inland geborene Generation: Dieses Optionsrecht kann im Namen des Kindes bereits ausgeuibt werden, nachdem es fünf Jahre in Frankreich gelebt hat (Art. 52-54 CNF) (siehe über diese Optionsrechte mit Widerspruchsworbehalt \$ 3.3.3.2 Buchstabe a). Die zweite in Frankreich geborene Generation erwirbt die Staatsangehörigkeit iure soli. Anders als in der Gesetzgebung bis 1982 gibt es in Spanien für dort geborene Ausländer in Spanien kein Optionsrecht. Nach einjährigem Aufenthalt in Spanien ist aber schon eine Einbürgerung möglich (Art. 22 C.c.esp.).

Ein Optionsrecht für im Inland geborene Ausländer ist $\mathrm{m} . \mathrm{E}$. auf jeden Fall gerechtfertigt, wenn sie ununterbrochen dort gelebt haben. Sie werden ohne Frage mit dem Land, in dem sie aufgewachsen sind, eng verbunden sein. Derartige intensive Beziehungen zum Gastland rechtfertigen eine Einbürgerung auch ohne die genaue behördliche Überprüfung dieser Beziehungen im Rahmen eines speziellen Einbürgerungsverfahrens. In diesem Zusammenhang muß jedoch konkret geregelt werden, wann von einem "ununterbrochenen Aufenthalt" im Inland gesprochen werden kann. Weiter ist zu bestimmen, in welchem Alter das Optionsrecht entstehen soll und ob dieses Optionsrecht befristet oder unbefristet sein soll. Hinsichtlich der Frage, wann ein Aufenthalt als "ununterbrochen" bezeichnet werden kann, ist namentlich das britische Recht interessant. In Großbritannien wird die Ununterbrochenheit dahingehend definiert, daß der Optant in keinem Jahr mehr als 90 Tage außerhalb des Vereinigten Königreiches ver- 
bracht haben dlarf. Diese Präzisierung resultiert daraus, daß in der britischen Gesetzgebung stets dem Prinzip der sehr genauen und detaillierten Formulierung gefolgt wird. Auch ist diese Voraussetzung aufgrund der Insellage GroBbritanniens leichter als in den kontinental-europäischen Staaten zu überprüfen. In den übrigen europäischen Staaten ist es nicht üblich, die Rechtsprechung so sehr zu binden. Die Übernahme einer solchen Definition in die kontinental-europäischen Rechtsordnungen empfiehlt sich deshalb nicht. Die britische Formulierung bietet aber als eine interessante Richtschnur die Möglichkeit, den vagen Begriff "ununterbrochener Aufenthalt" auch für andere Rechtsordnungen im Rahmen einer Auslegung zu konkretisieren. Letzten Endes ist es aber der richterlichen Entscheidung überlassen, ob die gestellte Voraussetzung des ununterbrochenen Aufenthalts im jeweiligen Land erfuillt ist.

Dariber hinaus ist der Zeitpunkt zu bestimmen, in dem ein Optionsrecht entsteht. Das Alter einer erstmals optionsberechtigten, im Inland geborenen, Person hängt untrennbar und eng mit dem Grund zusammen, aus dem man das $O p$ tionsrecht entstehen läßt.

Sieht man eine Art van "ius soli"' als Grund für dieses Optionsrecht an, dann liegt es auf der Hand, daß die geforderte Frist des Inlandsaufenthaltes nicht die für eine normale Einbürgerung geforderte Aufenthaltsfrist überschreitet. Rechtsvergleichend stellt sich das Optionsrecht in diversen Variationen dar. In Belgien entsteht das kontrollierte Optionsrecht im Zeitpunkt des achtzehnten Geburtstages; jedoch nur unter der Voraussetzung, daß der Betreffende zwischen seinem 14. und 18. Geburtstag im Inland lebte oder insgesamt neun Jahre. Im britischen Recht entsteht das Optionsrecht, wenn das dort geborene Kind die ersten zehn Jahre seines Lebens in Großbritannien verbracht hat. Während in Frankreich das Optionsrecht bereits nach fünfjährigem Aufenthalt entsteht, kann in Italien nur im 22. Lebensjahr optiert werden, wenn der Betreffende seit dem 21. Lebensjahr in Italien gelebt hat. Das niederländische Recht schließlich sieht ein Optionsrecht für den dort geborenen Ausländer vor, wenn dieser seit seiner Geburt ununterbrochen in den Niederlanden gelebt hat. Die Variationen der zeitlichen Wohnsitzvoraussetzungen sind also bemerkenswert.

Andererseits wird ein im Inland geborener Ausländer aber in der Regel hauptsächlich durch seine Schulerziehung integriert. Gründet man das Optionsrecht auf dieser Unterstellung, so sollte die geforderte Aufenthaltszeit so bemessen sein, daß sie einen Aufenthalt des im Inland geborenen Ausländers gerade für seine Schulzeit garantiert. Ein auf dieser Überlegung beruhendes Optionsrecht könnte man seinem Grund nach als "ius educationis" bezeichnen. Aus diesem Gedanken heraus kann die in Belgien geforderte Aufenthaltsfrist verstanden werden. Auch die strenge niederländische Forderung des seit der Geburt ununterbrochenen Aufenthalts beruht wohl auf diesem Hintergrund. Die britische Regelung garantiert dagegen lediglich, daß die Volksschulausbildung teilweise in Großbritannien absolviert wurde; Grund des britischen Optionsrechts ist daher wohl eine Mischung der Prinzipien des "ius soli" und des "ius educationis".

Wiegt man das "ius soli" und das "ius educationis" als Begründung für ein Optionsrecht von im Inland geborenen ausländischen Personen gegeneinander $a b$, so muß m.E. gefolgert werden, daß eine Geburt und ein daran anschließender relativ kurzer Aufenthalt im Inland noch keine engen und dauerhaften $\mathrm{Be}$ ziehungen zwischen dem Betreffenden und dem Geburtsland garantiert. Das "ius educationis", eine Schulerziehung im Inland, gibt diese Garantie eher. Schon 
deshalb sind die belgische und niederländische Lösung den anderen vorzuziehen.

Das Entstehen des Optionsrechts im belgischen und niederländischen Recht erst mit Vollendung des achtzehnten Lebensjahr soll möglichst einer Doppelstaatlichkeit vorbeugen. Entsprechend den Vorschriften vieler Staaten geht eine Staatsangehörigkeit jedenfalls dann verloren, wenn eine bereits achtzehnjährige Person freiwillig - durch Einbürgerung oder Optionserklärung - eine ausländische Staatsangehörigkeit erwirbt (siehe darüber \$ 3.4.2). Eine Ausübung des belgischen oder niederländischen Optionsrechts bewirkt also häufig den Verlust der bisherigen Staatsangehörigkeit. Unter dem Gesichtspunkt einer wünschenswerten Bekämpfung der mehrfachen Staatsangehörigkeit kann demnach gutgeheißen werden, daß das Optionsrecht erst im 19. Lebensjahr des Optanten erstarkt. Es würden sich sonst die Fälle mehrfacher Staatsangehörigkeit häufen. Für die prinzipielle Frage, ob Bekämpfung von Doppelstaatlichkeit in der Tat wünschenswert ist, sei aber auf § 3.3.4.8 verwiesen, wo der Wunsch nach Verhinderung mehrfacher Staatsangehörigkeit kritisiert wird. Wenn man deshalb von der Bekämpfung der mehrfachen Staatsangehörigkeit absieht, wäre im Sinne des "ius educationis" $\mathrm{zu}$ vertreten, daß das Optionsrecht für im Inland geborene Ausländer in dem Zeitpunkt entsteht, in dem die gesetzlich vorgeschriebene Schulausbildung abgeschlossen ist; nach niederländischem Recht also im 16. Lebensjahr. Als Voraussetzung für die Entstehung dieses Optionsrechts dürfte m.E. maximal gefordert werden, daß der betreffende Ausländer seine gesamte Schulzeit im Inlland verbracht hat; nach niederländischem Recht wäre dies die Zeit zwischen dem 5. und 16. Lebensjahr. Eine Entstehung des Optionsrechts mit dem 16. Lebensjahr wäre auch mit den in $\$ 2.3 .3$ befürworteten Prinzip der Selbstbestimmung in Staatsangehörigkeitsangelegenheiten zu vereinbaren. Das Optionsrecht wäre damn von dem gesetzlichen Vertreter des Minderjährigen mit dessen ausdrücklicher Einwilligung oder vom Minderjährigen mit grundsätzlicher Einwilligung seines gesetzlichen Vertreters auszuüben (siehe für weitere Einzelheiten \$ 3.2.2).

Sieht man aber ein "ius educationis" als Grund für das Optionsrecht eines im Inland geborenen Ausländerkindes an, so muß die niederländische Forderung des ununterbrochenen Aufenthaltes seit der Geburt abgelehnt werden. Für das Entstehen des Optionsrechtes muß dann unerheblich sein, ob ein in den Niederlanden geborenes Kind zwischen seiner Geburt und Einschulung im Ausland gelebt hat; maßgebend ist allein, ob es seine Schulausbildung in den Niederlanden erhalten hat. Im Rahmen dieser Erörterungen kann man sich sogar fragen, ob nicht auch füir im Ausland geborene Personen, die ihre ganze gesetzlich vorgeschriebene Schulzeit im Inland verbracht haben, ein Optionsrecht angemessen ist. Dies ist m.E. ebenfalls aus den oben dargelegten Gründen zu bejahen. Für die Integration ist nicht die vielleicht zufällige Geburt im Inland, sondern die Schulerziehung in Inland maßgebend (vgl. auch \$ 3.3.3.2 Buchstabe c). Dies entspricht auch der Empfehlung 841 (1978) betreffend Migranten der zweiten Generation der Assemblée Parlementaire des Europarates, die befüwortete, den Erwerb der Staatsangehörigkeit des Empfangstaates zu vereinfachen für junge Migranten, die in diesem Land geboren wurden oder dort den größten Teil ihrer Schulausbildung bekommen haben.

Gegenüber einem Optanten, der bereits 18 Jahre alt ist, von Geburt an im Inland gelebt und auch dort zur Schule gegangen ist - wie dies das niederländi- 
sche Recht fordert - ist m.E. ein Widerspruchsrecht der Behörden in jedem Fall abzullehen. Die Zurückweisung der Optionserklärung einer solchen Person kann nicht thehr überzeugend gerechtfertigt werden; dennoch wird sie z.B. im französischen Recht zugelassen. Die Ausweisung einer solchen Person, die ihr ganzes bisheriges Leben im Inland verbracht hat, kommt m.E. unter keinerlei Umständen in Betracht; dies gilt sogar im Falle einer Bedrohung für die öffentliche Ordnung. Es würde den Mißbrauch einer historisch-biographischen Zufälligkeit bedeuten, wollte man einen im Inland geborenen Achtzehnjährigen, der die öffentliche Ordnung bedroht, deshalb ins Ausland abschieben, weil er zufalligerweise als Kind ausländischer Eltern geboren wurde. Einem solchen MiBbrauch ist auch dann nicht abgeholfen, wenn man dem Betreffenden zwar weiterhin den Aufenthalt im Inland erlaubt, ihm jedoch die Staatsangehörigkeit verweigert. Die Verweigerung der Staatsangehörigkeit aus solchem Grund impliziert die Ansicht, daß nur solche Personen die Staatsangehörigkeit erwerben dürfen, die einem gewissen Idealbild eines Staatsbürgers entsprechen. Der Erwerb der Staatsangehörigkeit wird dann eine Art von Auszeichnung. Die Auffassung muB aber - wenigstens für Westeuropa - entschieden zurückgewiesen (siehe \$ 1.3; vgl. weiter \$ 3.3.4.7)

Darüber hinaus ist zu fragen, ob es erforderlich ist, die Geltendmachung des Optionsrechts eines im Inland geborenen Ausländers zu befristen. Die europäischen Staaten haben dazu sehr unterschiedliche Regelungen getroffen. In Frankreich und Großbritannien ist das Optionsrecht unbefristet. In Italien kann ausschließlich im 22. Lebensjahr optiert werden. In den Niederlanden muß die Optionserklärung vor dem 25. Geburtstag abgegeben werden. In Belgien muß eine Optionserklärung zugunsten der zweiten in Belgien geborenen Generation vor dem 12. Geburtstag des Betreffenden und die normale Option mit. Widerspruchsvorbehalt vor dem 22. Geburtstag abgegeben werden. Auch in dieser Hinsicht können wir also wieder eine beachtliche Anzahl von Variationen beobachten.

Eine Befristung des Optionsrechts von im Inland geborenen Ausländern die dort seit ihrer Geburt leben - wie das niederländische Recht dies vorsieht - läßt sich m.E. ebenfalls kaum vertreten. Grund für die Befristung ist wohl die Befuirchtung, daß optionsberechtigte Personen ihre Optionserklärung solange aufschieben, bis keine Gefahr mehr besteht, daß sie noch in die Armee eingezogen werden. Für Frauen jedoch ist diese Begründung untauglich. Wollte man aber das Optionsrecht für Männer, nicht jedoch für Frauen befristen, so würde dies eine bemerkenswerte Diskriminierung darstellen. Auch aus anderen Gründen ist die vorgesehene Befristung jedenfalls in den Niederlanden unhaltbar. Wenn ein bereits 25-jähriger Ausländer, der in den Niederlanden geboren und seitdem wohnhaft ist, seine Einbürgerung beantragt, so besteht keine überzeugende Begrïndung einen solchen Einbürgerungsantrag zurïckzuweisen. Insbesondere kann die Tatsache, daß wegen drohender Gefahr des Militärdienstes keine Optionserklärung abgegeben wurde, in keinem von Art. 8 oder 9 RwNed genannten Verweigerungsgrund resultieren.

Abschließend sei noch eine "technische" Bemerkung über die Gestaltung des Optionsrechts im niederländischen Recht erlaubt. Es ist bemerkenswert feststellen zu müssen, daß das Optionsrecht von Art. 6 Abs. 1 Buchstabe a RwNed auf eine Geburt in den Niederlanden abstellt, während Art. 3 Abs. 3 RwNed bei der 
Regelung zugunsten der zweiten Generation - aus übrigens überzeugenden Gründen (siehe \& 3.2.6) - auf den Wohnsitz der Eltern zur Zeit der Geburt abstellt. Art. 6 Abs. 1 Buchstabe a RwNed wäre m.E. dementsprechend zu erweitem oder anzupassen (vgl. \$ 3.3.3.2 Buchstabe a).

\section{b. Im Inland geborene Staatenlose}

In $\$ 3.2 .6$ wurde darauf hingewiesen, daß in Belgien (seit 1985), Frankreich, Italien (seit 1912) oder Spanien (seit 1982) geborene, potentiell staatenlose Kinder iure soli die Staatsangehörigkeit erwerben. Die Niederlande und Großbritannien sehen Optionsrechte vor, während Deutschland und Österreich für diese Kategorie unter gewissen Voraussetzungen Einbürgerungsansprüche kennen. Die Schweiz kennt für dort geborene Staatenlose weder ein Optionsrecht noch einen Einbüirgerungsanspruch. An dieser Stelle sollen die niederländische und britische Optionsrechte näher beschrieben werden.

Gemäß Art. 6 Abs. 1 Ziffer b RwNed hat ein in den Niederlanden geborener Staatenloser nach dreijährigem Aufenthalt in den Niederlanden ein Optionsrecht auf die niederländische Staatsangehörigkeit. Dieses im Vergleich zu der niederländischen Staatsangehörigkeitsgesetzgebung von vor 1985 neue Optionsrecht muß vor Erreichung des 25 . Lebensjahres ausgeibt werden. Die Geburt am Bord eines niederländischen Seeschiffes oder Flugzeuges wird in diesem Falle einer Geburt in den Niederlanden gleichgestellt (siehe darüber weiter $\$ 3.2 .6$ ).

Für in Großbritannien geborene Staatenlose gilt grundsätzlich das gleiche wie für andere dort geborene Kinder, vgl. aber auch die Sonderbestimmungen des Schedule 2, wonach Sec. 36 BNA 1981 verweist. Von den Vorschriften des Schedule 2 ist vor allem $\S 3$ wichtig. Ein im Vereinigten Königreich geborener Staatloser kann zwischen der Vollendung seines 10. und 21. Lebensjahres durch "registration" die britische Staatsangehörigkeit erwerben, wenn er für die Dauer von fünf Jahren im Vereinigten Königreich gelebt hat und dabei höchstens 450 Tage abwesend war.

In $\$ 3.2 .6$ wurde schon darauf hingewiesen, weshalb die Niederlande wohl den in den Niederlanden geborenen Staatenlosen lediglich ein Optionsrecht gegeben und sich nicht für Erwerb iure soli entschieden haben. Im Moment mag diese Wahl mit Rücksicht auf die in den Niederlanden lebenden Südmolukker noch zu vertreten sein, auf Dauer ist sie wenig überzeugend.

Art. 6 Abs. 1 Buchstabe b RwNed stellt auf die Geburt auf dem Staatsgebiet der Niederlande $a b$. Anders als beim Optionsrecht des Art. 6 Abs. 1 Buchstabe a RwNed gilt die Geburt an Bord eines niederländischen Schiffes oder Flugzeuges als Geburt im Inland; diese Erweiterung des Inlandbegriffes beruht auf einer völkerrechtlichen Verpflichtung aus der New Yorker Konvention über die Verminderung der Staatenlosigkeit aus 1961 (Art. 3). Bei diesem Optionsrecht kann deshalb nicht - wie in $\S 3.3 .3 .1$ Buchstabe a hinsichtlich des Optionsrechtes von Art. 6 Abs. 1 Buchstabe a RwNed vorgeschlagen wurde - ausschließlich auf den Wohnsitz der Eltern zur Zeit der Geburt des staatenlosen Kindes abgestellt werden. Eine Erweiterung in diese Richtung möchte ich aber befürworten. 
Ein weiterer wesentlicher Unterschied zwischen dem Optionsrecht gemäB Art. 6 Abs. 1 Buchstabe a und dem gemäß Buchstabe b RwNed liegt darin, daß für das letztgenannte Optionsrecht nicht gefordert wird, daß der optierende Staatenlose seit seiner Geburt ununterbrochen in den Niederlanden lebt. Es reicht aus, wenn der Optant drei Jahre Wohnsitz in den Niederlanden hatte. Anders als bei Ausübung des Optionsrechts gemäß Buchstabe a kann man deshalb nicht sagen, daß eine sehr spät ausgebrachte Option regelmäßig eine besonders enge Beziehung zu den Niederlanden garantiert. Eine Befristung dieses Optionsrechtes ist hier deshalb zu vertreten. Angesichts dieser Befristung ist jedoch wenig verständlich, warum ein entsprechender Optant bereits von Geburt an staatenlos sein soll. Die belgische Regelung des Art. $10 \mathrm{CNB}$ ist in dieser Hinsicht inspirierend: Die die Staatenlosigkeit bekämpfende Regelung soll auch angewendet werden, wenn jemand bis zu einem bestimmten Alter (in Belgien: vor Erreichung der Volljährigkeit) staatenlos wird. Eine entsprechende Regelung möchte ich für die Niederlande befürworten.

Eben wurde darauf hingewiesen, daß die Befristung des Optionsrechts für in den Niederlanden geborene Staatenlose zu vertreten ist. Es ist aber bemerkenswert, daß es im niederländischen Recht im Rahmen der Einbürgerungsvoraussetzungen überhaupt keine Erleichterung für volljährige Staatenlose gibt. Es ist fraglich, ob dies mit Art. 32 der Konvention über die Rechtstellung der Staatenlosen aus dem Jahre 1954 in Einklang steht, da dieser Artikel vorschreibt, daß die Vertragsstaaten die Eingliederung und Einbürgerung Staatenloser soweit möglich erleichtern (vgl. auch § 3.3.4.8).

c. Personen unter elterlicher Gewalt oder Vormundschaft eines Staatsangehörigen

Ein bemerkenswertes Optionsrecht kennt seit 1982 das spanische Recht. Ausländer, die unter elterlicher Gewalt oder Vormundschaft eines spanischen Staatsangehörigen stehen, können ab ihrem 14. Lebensjahr mit dem Beistand ihres gesetzlichen Vertreters für die spanische Staatsangehörigkeit optieren (Art. 19 Ziffer 1 C.c.esp.). Diese Optionserklärung kann auch noch im Zeitraum von zwei Jahren nach Erlangung der Volljährigkeit abgegeben werden (Art. 19 Ziffer 2 C.c.esp.). Für den Erwerb der spanischen Staatsangehörigkeit ist neben der eigentlichen Optionserklärung ein Verzicht auf die bisherige Staatsangehörigkeit und ein Treueid erforderlich (vgl. in dieser Zusammenhang auch \$ 3.3.3.2 Buchstabe f). Auch in Belgien, GroBbritannien und in der Schweiz gibt es unter bestimmten Voraussetzungen vergleichbare Regelungen.

Nach belgischem Recht erwirbt außer im Falle sonstiger Staatenlosigkeit lediglich die erste im Ausland geborene Generation noch automatisch die belgische Staatsangehörigkeit. Zugunsten der übrigen im Ausland geborenen Kinder eines belgischen Elternteils kann der belgische Elternteil innerhalb von fünf Jahren nach Geburt des Kindes eine Erklärung abgegeben, durch die das Kind Belgier wird (Art. $8 \$ 2$ Buchstabe b CNB). Eine entsprechende Regelung kennt das belgische Recht für Kinder, die im Ausland geboren sind und von Belgiern adoptiert worden sind, die auch selbst im Ausland geboren wurden (Art. $9 \$ 2$ Buchstabe b CNB). Vgl. auch das im belgischen Recht vorgesehene kontrollierte Optionsrecht von Kindern (ehemaliger) belgischer Staatsangehöriger (Art. 13 Ziffer 2 und $3 \mathrm{CNB}$; dazu $\$ 3.3 .3 .2$ Buchstabe b). 
Nach britischem Recht können im Inland geborene minderjährige Personen, von denen ein Elternteil die britische Staatsangehörigkeit oder den Status eines im Vereinigten Königreich Niedergelassenen erwirbt, durch "registration" die britische Staatsangehörigkeit erwerben (Sec. 1 (3) BNA 1981; vgl. auch oben \$ 3.3.3.1 Buchstabe a). Im Ausland geborene Kinder eines Briten kraft Abstammung haben unter bestimmten Voraussetzungen einen Anspruch auf Erwerb der britischen Staatsangehörigkeit durch "registration" (Sec. 3 (2) bis (6) BNA 1981). Gemäß Sec. 3 (1) BNA 1981 kann der Secretary of State nach freiem Ermessen alle minderjährige Personen, für die ein entsprechender Antrag gestellt wird, als Staatsangehörige registrieren lassen. In diesem Zusammenhang sei schlieBlich auf die schweizerische Regelung hingewiesen; danach können Kinder, die mit ihrer Mutter ausländischer Herkunft und deren schweizerischem Ehemann zusammenleben, schneller als andere Ausländer eingebürgert werden (Art. 15 Abs. $3 \mathrm{BüG}$ ). In den übrigen Staaten fehlen entsprechende Regelungen.

Die in diesem Paragraphen erwähnten Bestimmungen des belgischen, britischen und schweizerischen Rechts finden ihre Ursache in anderen Besonderheiten jener Staatsangehörigkeitsregelungen. Die Optionsrechte für im Ausland geborene Kinder eines belgischen Staatsangehörigen sind eine Konsequenz aus der Tatsache, daß diese Kinder die Staatsangehörigkeit ihrer Eltern nicht immer iure sanguinis erwerben. Die britische Regelung des Sec. 1 (3) BNA existiert wohl primär mangels einer Vorschrift, daß eine Einbürgerung sich auch auf minderjährige Kinder eines Eingebürgerten erstreckt; sie wurde dann unter dem Gesichtspunkt des Sec. 1 (2) Buchstabe b BNA (Erwerb der britischen Staatsangehörigkeit kraft Geburt in Großbritannien aus dort niedergelassenen Eltem) erweitert. Die schweizerische Bestimmung resultiert aus der Regelung, daß eine ausländische Frau durch ihre Ehe mit einem Schweizer ipso iure die Staatsangehörigkeit ihres Mannes erwirbt (Art. 3 BüG); dieser Erwerb erstreckt sich aber nicht auf ihre Kinder (vg1. \& 3.3.3.2 Buchstabe b).

Grundsätzlich wäre also nur die spanische Regelung für eine Weiterentwicklung des niederländischen Staatsangehörigkeitsrechts interessant. Eine Rezeption dieser Regelung sollte m.E. jedoch nicht bejaht werden. Die bloße Tatsache, daß ein ausländisches Kind unter der elterlichen Gewalt oder Vormundschaft eines Staatsangehörigen steht, rechtfertigt m.E. noch kein Optionsrecht. Wenn das betreffende Kind z.B. in einem ausländischen Internat aufwächst, ist es nicht unbedingt wahrscheinlich, daß eine enge Verbindung zu dem Staat entsteht, dem der betreffende Elternteil oder Vormund angehört. Ob dennoch solche enge Bande entstanden sind, die den Erwerb der Staatsangebörigkeit angemessen erscheinen lassen, kann besser im Rahmen eines Einbürgerungsverfahrens üiberprüft werden. In den Niederlanden kann zwar ein Minderjähriger normalerweise nicht eingebürgert werden (infolge der Volljährigkeitsvoraussetzung des Art. 8 RwNed; dazu \& 3.3.4.2), eine Einbürgerung über den Weg des Art. 10 RwNed ist aber grundsätzlich möglich (siehe $\$ 3.3 .5$, vgl. weiter die Bemerkungen in $\$ 3.3 .6$ ).

\section{d. Ehemalige Staatsangehörige}

Alle Rechtsordnungen sehen Regelungen vor, die den meisten ehemaligen Staatsangehörigen auf einfache Art oder unter vereinfachten Bedingungen den Wiedererwerb ihrer ehemaligen Staatsangehörigkeit gewähren. In einigen Staaten haben bestimmte Gruppen von ehemaligen Staatsangehörigen ein reines 
Optionsrecht (GroBbritannien, Spanien) oder ein Optionsrecht mit Widerspruchsvorbehalt (Belgien, Frankreich). In Italien wird die verlorene Staatsangehörigkeit unter bestimmten Voraussetzungen sogar automatisch zurückerworben (siehe \$ 3.3.2). In Deutschland und Österreich bestehen für einige Gruppen ehemaliger Staatsangehöriger Einbürgerungsansprüche (siehe dazu $\$$ 3.3.3.3 Buchstabe e). In den Niederlanden und in der Schweiz besteht jedoch lediglich die Möglichkeit einer erleichterten Einbürgerung ( $\$ 3.3 .4 .3$ und 3.3.4.7). Diese Regelungen sollen nun in der genannten Reihenfolge näher betrachtet werden.

Wenn ein britischer Staatsangehöriger auf seine britische Staatsangehörigkeit verzichtet hat, um eine andere Staatsangehörigkeit zu erwerben oder zu behalten, kann er unter der Voraussetzung, daß er voll geschäftsfähig ist, die britische Staatsangehörigkeit durch "registration" zurückerwerben (Sec. 13 (1) BNA) 1981). Ein solcher Rückerwerb durch "registration" ist nur einmalig möglich; wenn der Betreffende also noch einmal auf die britische Staatsangehörigkeit verzichtet, ist Rückerwerb durch "registration" unmöglich (Sec. 13 (2) BNA 1981). Wenn ein Brite aus anderen Grüinden auf seine Staatsangehörigkeit verzichtet hat, kann der Secretary of State lediglich nach freiem Ermessen eine "registration" veranlassen (Sec. 13 (3) BNA 1981).

In Spanien können die meisten ehemaligen Staatsangehörigen durch Optionserklärung die spanische Staatsangehörigkeit zurückerwerben (Art. 26 C.c.esp.). Grundsätzlich wird vorausgesetzt, daß sie wieder für die Dauer eines Jahres ihren ununterbrochenen und legalen Wohnsitz in Spanien haben. Von diesem Wohnsitzerfordernis kann aber dispensiert werden. Diese Dispens wird immer erteilt, wenn es sich um spanische Emigranten handelt oder um Spanier, die freiwillig die Staatsangehörigkeit ihres Ehepartners erworben haben. Kein reines Optionsrecht haben dagegen:

a) ehemalige Spanier, die die spanische Staatsangehörigkeï verloren haben, nachdem sie bereits mindestens vierzehn Jahre alt waren und in Spanien keinen Militär- oder Ersatzdienst geleistet haben und

b) Personen, die die spanische Staatsangehörigkeit durch strafrechtliches Urteil, wegen Betrugs bei der Einbürgerung oder wegen fremden Staats- oder Militärdienstes verloren haben.

Diese ehernaligen Spanier können nur nach vorher erteilter Genehmigung der spanischen Regierung optieren. Die heutige Regelung geht zuriick auf ältere Staatsangehörigkeitsregelungen Spaniens (vgl. Art. 19, 21 und 24 C.c.esp. i.d.F. 1889 und Art. 24 und 25 C.c.esp. i.d.F. 1954).

In Italien erwerben ehemalige Staatsangehörige, die ihre Staatsangehörigkeit als Minderjährige verloren haben, diese unter bestimmten Voraussetzungen automatisch zurück (art. 3 i.V.m. 12 Abs. 2 L.c.; vgl. oben \$ 3.3.2). Bemerkenswert ist weiter, daß Personen, deren Vater, Mutter oder GroBvater väterlicherseits italienische Staatsangehörige durch Geburt gewesen sind, unter den in Art. 3 L.c. genannten Voraussetzungen ebenfalls durch Optionserklärung die italienische Staatsangehörigkeit erwerben können.

Im belgischen Staatsangehörigkeitsrecht hatten ehemalige Staatsangehörige bis 1985 unter bestimmten Voraussetzungen ein reines Optionsrecht auf ihre frühere Staatsangehörigkeit (Art. 18 Cc; Art. 13 Ziffer 1 Gesetz 1909; Art. 19 Abs. 1 Gesetz 1932). Seitdem ist aber lediglich ein Optionsrecht mit Widerspruchsvorbehalt vorgesehen (dazu $\S$ 3.3.3.2 Buchstabe e). Auch ehemalige französische 
Staatsbürger haben u.U. ein solches kontrolliertes Optionsrecht auf ihre frühere Staatsangehörigkeit (Art. 97-2 bis 97-6 CNF).

Bis 1935 gab es in Deutschland einige Fälle, in denen ehemalige Deutsche zwar kein Optionsrecht, jedoch einen Einbürgerungsanspruch geltend machen konnten; dies galt z.B. unter bestimmten Voraussetzungen für solche Personen, die als Minderjährige ihre deutsche Staatsangehörigkeit durch Entlassung aus dem Staatsverband verloren hatten ( $\$ 10$ RuStAG, aufgehoben durch Gesetz vom 15. Mai 1935). Nach dem Zweiten Weltkrieg wurden in das RuStAG Einbürgerungsansprüche für ehemalige Staatsangehörige nicht wieder aufgenommen. Mehrere Gruppen ehemaliger Deutsche haben aber noch nachkriegsbedingte Einbürgerungsansprüche; dies sind z.B. diejenigen, denen zwischen dem 30 . Januar 1933 und dem 8. Mai 1945 die deutsche Staatsangehörigkeit aus politischen, rassischen oder religiösen Gründen entzogen wurde, sowie die Abkömmlinge dieser Personen (siehe $\S$ 3.3.3.3 Buchstabe e). Das österreichische Recht kennt in $\S 12$ Buchstabe b und c StBG 1965 unter bestimmten Voraussetzungen für ehemalige Österreicher einen Einbürgerungsanspruch (vgl. weiter die Übergangsbestimmung des $\S 13$ StBG i.d.F. 1983) (vgl. $\$ 3.3 .3 .3$ Buchstabe e).

In den Niederlanden ist die Möglichkeit einer erleichterten Einbürgerung in Art. 8 Abs. 2 RwNed, in der Schweiz in den Art. 18-25 BüG vorgesehen (siehe \$ 3.3.4.3 und 3.3.4.7).

Aus diesen Beschreibungen geht hervor, $\mathrm{da} B$ also nicht nur die Art und Weise des Rückerwerbs der Staatsangehörigkeit für ehemalligen Staatsangehörige, unterschiedlich ist, sondem auch die Voraussetzungen, die dafür erfüllt sein müssen. Grundsätzlich ist es gerechtfertigt, daß ehemalige Staatsangehörige schneller als andere Ausländer ihre frühere Staatsangehörigkeit erwerben können. Sie haben häufig noch intensive persönliche und kulturelle Beziehungen zum früheren Heimatstaat. Für einige Staaten wiegt auch wohl mit, daß die Betreffenden in der Regel "sanguine" mit dem Staat, dessen Staatsangehörigkeit sie wiedererwerben wollen, verbunden sind (vgl. in diesem Zusammenhang auch die belgischen, italienischen und spanischen Regelungen zugunsten der $\mathrm{Ab}$ kömmlinge ehemaliger Staatsangehöriger; dazu \$ 3.3.3.2 Buchstabe $b$ und \$ 3.3.2). Aber diese Verbundenheit ehemaliger Staatsangehöriger mit dem früheren Heimatstaat ist nicht immer gewährt; sie dauert in der Regel nicht unbeschränkt fort und schwächt in der Regel umso mehr ab, je mehr Zeit nach der Ausbürgenung verstreicht; auch Personen, die in ihrer Jugend die Staatsangehörigkeit verloren, haben kaum eine starke Binding zum Geburtsland. Weiter ist es auch von Bedeutung, ob der betreffende ehemalige Staatsangehörige im nahegelegenen Ausland oder etwa auf einem anderen Kontinent lebt. Diese Faktoren müssen im Auge behalten werden, wenn man für ehemalige Staatsangehörige Optionsrechte konstruieren möchte. Es liegt ferner auf der Hand, danach zu unterscheiden, aus welchem Grund die Staatsangehörigkeit verloren wurde. Ein Optionsrecht für z.B. einen ehemaligen Staatsangehörigen, dessen Staatsangehörigkeit wegen Betrugs beim Einbürgerungsverfahren entzogen wurde (siehe $\$ 3.4 .5$ ) wäre wenig logisch. Alle diese Variablen würden ein kompliziertes System von Optionsrechten erforderlich machen. Unter diesem Gesichtspunkt kann man das niederländische oder das schweizerische System gutheißen, wonach lediglich eine erleichterte Einbürgerung vorgesehen ist. Bedauerlich ist aber, daß beide Verfahren für den Staatsangehörigkeitserwerb einige sehr vage 
Forderungen aufstellen (siehe namentlich $\$ 3.3 .4 .5$ ). (Siehe weiter $\$ 3.3 .3 .2$ Buchstabe e, \$3.3.4.3 und 3.3.4.7).

\section{e. Personen, die als Staatsangehörige behandelt wurden}

Nach Art. 17 Abs. 1 CNB kann eine Person, die zehn Jahre lang ohne Unterbrechung den Stand eines Belgiers genossen hat, das heißt während dieser Zeit von den belgischen Autoritäten als Belgier behandelt wurde, durch eine Optionserklärung die belgische Staatsangehörigkeit erwerben. Diese Erklärung muB innerhalb eines Jahres, nachdem die Fakten bezüglich des Innehabens der belgischen Staatsangehörigkeit nicht mehr feststehen, abgegeben werden. Wenn es sich um einen Minderjährigen handelt, dessen Abstammung von einem belgischen Elternteil nicht mehr feststeht, wird die Optionsfrist bis zum Alter von neunzehn Jahren verlängert. Zwar gillt für diese Option, daß sie vom Gericht überprüft werden muß und erst den Erwerb bewirkt, nachdem die Genehmigung des Gerichts in die Standesamtsregister eingetragen worden ist (Art. 15 CNB). $\mathrm{Da}$ aber das Gericht die Genehmigung lediglich verweigem darf, wenn der vorgegebene "possession d'état" unzureichend ist, beinhaltet die Regelung des Art. $17 \mathrm{CNB}$ m.E. dennoch ein reines, uneingeschränktes Optionsrecht.

Frankreich kennt in Art. 57-1 CNF eine ähnliche Regelung: nach zehnjährigem "possession d'état" kann die Staatsangehörigkeit durch Optionserklärung erworben werden. Die französische Regierung hat aber in Fällen der Unwürdigkeit oder mangelnden Anpassung ein innerhalb einer Frist von sechs Monaten auszuübendes Widerspruchsrecht (siehe § 3.3.3.3 Buchstabe g).

In diesem Zusammenhang muß Art. 29 des schweizerischen BüG zum Vergleich herangezogen werden. Dem Ausländer, der für die Dauer von wenigstens fünf Jahren im guten Glauben gelebt hat, er sei Schweizer Bürger, und während dieser Zeit von kantonalen oder Gemeindebehörden tatsächlich als solcher behandelt worden ist, kann gemäß Abs. 1 erleichtert eingebürgert werden. Nach Abs. 3 desselben Artikels gilt keine Mindestfrist, wenn der Bewerber schon schweizerischen Militärdienst geleistet hat (siehe auch \$ 3.3.4.3).

Die uibrigen besprochenen Rechtsordnungen kennen keine Optionsrechte oder Anspüche auf erleichterte Einbürgerung aufgrund "possession d'état". Dennoch wird auch dort manchmal eine bisher unterstellte faktische Situation aufgrund des Vertrauensschutzes beibehalten. Hingewiesen sei z.B. auf diesbezügliche Erörterungen Bleckmanin's in ZaöRV 1974.

Grundsätzlich ist zu bejahen, daß Personen die längere Zeit gutgläubig der Meinung waren, Staatsangehörige zu sein und vom Staat auch als solche behandellt wurden, in einfachem Verfahren die Staatsangehörigkeit erwerben können, wenn sich plötzlich herausstellt, daß die Annahme, sie seien Staatsangehörige, falsch war. Fraglich ist nur über welche Regelung man dies erreichen soll. Wenn wir die beschriebenen Regelungen miteinander vergleichen, fallen folgende Punkte auf.

Die belgische Konstruktion ist zwar unter dem Aspekt der Rechtssicherheit elegant, hat aber einige Nachteile. Die Frist von zehn Jahren kann u.U. zu lang sein, vor allem in Fällen, in denen bereits Militärdienst geleistet wurde. Weiter 
wird nicht ausdrücklich gefordert, daß der Betreffende gutgläubig war. Auch wird wohl nicht immer einwandfrei festzustellen sein, in welchem Zeitpunkt die Optionfrist beginnt: häufig werden wahrscheinlich zuerst lediglich Zweifel über die Fakten aufkommen, aufgrund deren die Staatsangehörigkeit hätte erworben sein müssen; erst allmählich werden diese Zweifel zur Sicherheit. Letztlich ist die belgische Konstruktion eines Optionsrechtes mit Widerspruchsvorbehalt mit Ausnahme von Frankreich in den übrigen Staaten unïblich. Sie ist aber in jedem Fall der französischen vorzuziehen die eine Widerspruchsmöglichkeit der Regierung wegen Unwürdigkeit odler mangelnder Assimillierung vorsieht. Außer bei bosgläubigem Besitz der Staatsangehörigkeit ist ein solches Widerspruchsrecht in Fällen des Vertrauensschutzes nicht zu vertreten.

Eine mögliche Alternative für die belgische beziehungsweise französische Konstruktion eines Optionsrechts mit Widerspruchsvorbehalt wäre ein reines Optionsrecht. Eine solche Regelung ist jedoch wenig praktikabel, weil wohl fast auf jede Optionserklärung aufgrund einer gutgläubigen "possession d'état" ein gerichtliches Verfahren folgen wïrde, um zu klären, ob die Optionsvoraussetzungen auch wirklich erfüllt waren.

Die schweizerische Lösung einer erleichterten Einbürgerung ist deshalb eher praktikabel. Dabei sollte aber festgelegt werden, daß in einem solchen Fall ein Einbürgerungsantrag lediglich zurückgewiesen werden darf, wenn der "possession d'état" nicht (oder nicht ausreichend lange) feststeht. Ein solches Einbürgerungsverfahren ist auch besser als eine Optionskonstruktion geeignet, um zu klären, wann die "possession d'état" begonnen ist. Ich möchte deshalb befürworten, daß auch nach niederländischem Recht der Einbürgerungsantrag einer gutgläubigen Person, die längere Zeit von den niederländischen Behörden als Niederländer behandelt wurde, nicht zurückgewiesen werden kann. Zu entscheiden ist dann, wie lange die Behörden eine solche Person bereits als Staatsangehörigen behandelt haben müssen, damit ein solcher Einbürgerungsanspruch entsteht. In Belgien und Frankreich wird eine Frist von zehn Jahren gefordert, in der Schweiz sind es lediglich fünf Jahre. Auch für die Niederlande scheint mir eine Frist von fünf Jahren angemessen; sie würde der im Rahmen eines Einbürgerungsverfahrens geforderten Wohnsitzfrist entsprechen (siehe $\$ 3.3 .4 .3$ ). Art. 8 RwNed ist daher um eine Bestimmung zu erweitern, daß der Einbürgerungsantrag von einer Person, die mehr als fünf Jahre gutgläubig den Status eines Niederländers innegehabt hat, nicht zurückgewiesen werden kann. Es sei übrigens darauf hingewiesen, $\mathrm{da}$ aß bereits nach geltendem niederländischen Recht im Falle des berechtigten Vertrauensschutzes eine Einbürgerung gemäß Art. 10 RwNed (Ermessenseinbürgerung nach Anhörung des Staatsrates) angemessen erscheint. In besonderen Härtefällen (etwa wenn die betreffende Person bereits in den Niederlanden Militärdienst geleistet hat) wäre auch neben der vorgeschlagenen Erweiterung von Art. 8 noch eine Einbürgerung über Art. 10 denkbar. Vgl. auch $\$ 3.2 .7$.

\subsubsection{Kontrollierte Optionsrechte}

Das belgische und französische Staatsangehörigkeitsrecht kennen mehrere Fälle von Optionsrechten mit Widerspruchsvorbehalt. In den Artikeln 13, 16 und 24 CNB wird für einige Kategorien die Möglichkeit geboten, die belgische Staatsangehörigkeit "par option" zu erwerben. Diese "option" muß jedoch gemäß Art. 
$15 \& 2 \mathrm{CNB}$ gerichtlich genehmigt werden. Das Gericht hat dabei nicht nur die Erfüllung der Voraussetzungen đer "option" zu überpriffen, sondern muB die Genehmigung auch verweigern "si un empêchement résulte de faits personnels graves, ..." oder "s'il y a des raisons, .... d'estimer que la volonté d'intégration du déclarant est insuffisante". GemäB Art. $15 \& 3$ Abs. 2 CNB wird bei der "option"' der Erwerb der belgischen Staatsangehörigkeit erst in dem Zeitpunkt wirksam, wenn die Genehmigung des Gerichts in die Standesamtsregister eingetragen wird. Es handelt sich bei einer solchen "option" des bellgischen Rechts deshalb nicht um ein reines Optionsrecht. Sie wird hier als "kontrolliertes Optionsrecht" oder "Optionsrecht mit Widerspruchsvorbehalt" beschrieben (siehe \$ 3.3.1). Auch im französischen Recht gibt es viele Fälle, in denen eine Person für die französisch Staatsangehörigkeit optieren kann, die Regierung aber ein Widerspruchsrecht hat (Art. 52 bis 58 ; 97-2 bis 97-6). Die Optionserklärung kann im allgemeinen wegen "indignité" et défaut d'assimilation", bei der Wiedereinbürgerung lediglich wegen "indignité" zurückgewiesen werden.

Das italienische, niederländische und spanische Recht kennen solche kontrollierte Optionsrechte nicht. Bemerkenswert ist aber, daß ausländische Ehegatten von spanischen Bürgem von 1975 bis 1982 ein kontrolliertes Optionsrecht auf die spanische Staatsangehörigkeit hatten. Das britische Recht kennt einige Beispiele von "registrations" nach Ermessen, die einem kontrollierten Optionsrecht einigermaßen ähneln (siehe darüber \$ 3.3.1). Auch im deutschen, österreichischen und schweizerischen Recht sind Optionsrechte mit Widerspruchsvorbehalt unbekannt. Nach deutschem und österreichischem Recht gibt es aber mehrere Fälle, in denen sogenannte Einbürgerungsansprüche bestehen.

Kontrollierte Optionsrechte möchte ich aus mehreren Gründen generell ablehnen. Soweit die Staatsangehörigkeit nach Ausübung eines Optionsrechtes mit Widerspruchvorbehalt erst - wie in Belgien - im Augenblick der Eintragung der von der Regierung bereits genehmigten Optionserklärung in die Register des Standesamtes erworben wird, ist die Benutzung des Begriffes "Optionsrecht" irreführend; gerade wenn die Genehmigung der Option aus vagen Gründen z.B. wegen persönlicher Mängel oder wegen mangelnder Anpassung verweigert werden kann, handelt es sich bei solchen Optionsrechten um erleichterte Einbürgerungen. Von einer absoluten Irreführung ist bei der französischen Konstruktion, nach der die Staatsangehörigkeit grundsätzlich im Moment der Optionserklärung erworben, aber im Falle eines Widerspruchs der französischen Regierung wieder rückwirkend verloren wird, zwar keine Rede; die Bezeichnung "Optionsrecht" ist dort aber wenig treffend, berücksichtigt man, daß die Option aus vagen Gründen wie Unwürdigkeit oder mangelnde Anpassung zurückgewiesen werden kann. Diese vagen Zurückweisungsgründe lehne ich in den 3.3.4.5 und 3.3.4.7 - sogar im Rahmen eines Einbürgerungsverfahrens - ab.

Die französische Konstruktion beinhaltet zudem als erheblichen Nachteil, daB während eines halben Jahres nach Ausübung des Optionsrechtes die staatsangehörigkeitsrechtliche Position des Optierenden unsicher ist: Die neu erworbene französische Staatsangehörigkeit kann wieder verloren werden. Daneben ist undeutlich, ob der Betreffende, während der ersten sechs Monate nach der Optionserklärung noch als Bürger des bisherigen Heimatstaates betrachtet werden kann, falls der Erwerb der französischen Staatsangehörigkeit den Verlust der bisherigen Staatsangehörigkeit bewirkt. Bejaht man dies, so besteht für den 
Optanten, falls die Behörde seiner Optionserklärung widerspricht, das Risiko, am Ende der sechsmonatigen Periode ohne Staatsangehörigkeit und damit staatenlos zurückzubleiben.

\section{a. Im Inland geborene Ausländer}

GemäB Art. 13 Ziffer $1 \mathrm{CNB}$ haben in Belgien geborene Ausländer ein kontrollierfes Optionsrecht auf die belgische Staatsangehörigkeit. Dieses Recht muß zwischen dem 18. und 22. Geburtstag ausgeuibt werden (Art. 14 CNB). Grundsätzlich muß der Betroffene während der zwölf letzten seiner Erklärung vorausgehenden Monate seinen gewöhnlichen Aufenthalt in Belgien haben. Weiter muB er entweder von seinem vierzehnten bis achtzehnten Lebensjahr oder insgesamt neun Jahre in Belgien gelebt haben. Ein Aufenthalt im Ausland kann jedoch dem Aufenthalt in Belgien gleichgestellt werden, wenn der Betroffene nachweist, daß er eine tatsächliche enge Bindung an Belgien hatte. Die "option" kann aufgrund schwerwiegender persönlicher Fakten oder wegen unzureichenden Eingliederungswillens zurüickgewiesen werden (Art. $15 \& 2$ CNB). Die Voraussetzungen für dieses vom Gericht kontrollierte Optionsrecht, wie die Kontrolle selbst, entsprechen in weiten Zügen den bereits seit 1922 in Belgien geltenden Bestimmungen (vgl. Art. 6, 8, 10 und 12 Gesetz 1932) (reine Optionsrechte gab es vorher in Art. $9 \mathrm{Cc}$ und Art. 7 Gesetz 1909).

In Frankreich bestimmen die Art. 52-54 CNF, daß der in Frankreich geborene Ausländer nach fünfjährigem Aufenthalt in Frankreich ein Optionsrecht erwirbt. Wenn eine solche Person das Alter von 16 Jahren erreicht hat, kann er dieses Optionsrecht selbst ausüben. Bis zu seinem 18. Geburtstag benötigt er dafür allerdings die Einwilligung desjenigen oder derjenigen, die über ihn die elterliche Gewalt ausüben. Das Optionsrecht von Personen, die jünger als 16 Jahre alt sind, kann vom Sorgeberechtigten ausgeübt werden, sofern dieser selbst bereits mindestens fünf Jahre in Frankreich lebt. Die französische Regierung kann der Option aus Gründen von "indignité" oder "défaut d'assimilation" widersprechen (Art. 57 CNF). Das Optionsrecht kann zudem nicht von Personen ausgeübt werden, gegen die eine Ausweisung oder ein Zwangsaufenthalt angeordnet ist.

Über die staatsangehörigkeitsrechtliche Position von im Inland geborenen Ausländern wurde schon in \$3.3.3.1 Buchstabe a geschrieben: unter gewissen Voraussetzungen wurde ein reines Optionsrecht befürwortet; vgl. weiter die Erörterungen in \$ 3.2.6.

\section{b. Kinder eines (ehemaligen) Staatsangehörigen}

Das im Ausland geborene Kind, von dessen Eltern zumindest ein Teil die belgische Staatsangehörigkeit besitzt, hat zwischen seinem 18. und 22. Geburtstag ein kontrolliertes Optionsrecht auf die belgische Staatsangehörigkeit (Art. 13 Ziffer 2 CNB). Dasgleiche gilt für ein im Ausland geborenes Kind, von dessen Eltem zumindest ein Teil zur Zeit der Geburt Belgier von Geburt (Belge de naissance) war oder gewesen ist. Voraussetzung für die "option" ist ein gewöhnlicher Aufenthalt von mindestens zwölf Monaten in Belgien, dies unmittelbar der Optionserklärung vorausgehend. Weiter wird gefordert, daß der Betroffene entweder von seínem 14. bis 18. Geburtstag oder im ganzen neun Jahre lang in 
Belgien gelebt hat; diese letzte Voraussetzung gilt nicht, wenn ein Elternteil zur Zeit der Geburt des Betroffenen Belgier von Geburt war oder gewesen ist. Der Aufenthalt im Ausland wird dem Aufenhalt in Belgien gleichgestellt, wenn der Betroffene nachweist eine tatsächlliche Bindung an Belgien zu haben. Die "option" kann aufgnund schwerwiegender persönlicher Fakten oder wegen unzureichenden Eingliederungswillens zurückgewiesen werden (Art. $15 \& 2 \mathrm{CNB}$ ). Auch die Voraussetzungen dieses kontrollierten Optionsrechtes, ebenso wie die Kontrolle selbst, entsprechen den früheren Bestimmungen (Art. 6, 8, 10, 12 Gesetz 1932). Mit dem belgischen kontrollierten Optionsrecht des Kindes eines Staatsangehörigen sind die in $\$ 3.3 .3 .1$ Buchstabe $c$ beschriebenen Regelungen zu vergleichen. Dabei ist zu berücksichtigen, $\mathrm{daB}$ ausschließlich in Belgien und Großbritannien das eheliche Kind eines Staatsangehörigen nicht immer ipso iure durch Geburt die Staatsangehörigkeit erwirbt. In Deutschland, Großbritannien, Österreich und in der Schweiz erwerben nichteheliche Kinder nicht die Staatsangehörigkeit ihres Vaters, während dies in den übrigen Staaten durchaus der Fall ist. Die Einbürgerung eines Ausländers erstreckt sich in den meisten Staaten regelmäßig auf dessen minderjährige Kinder. Aufgrund dieser Tatsache erübrigt sich ein Optionsrecht für solche Kinder. Eine grundsätzlich andere Rechtslage besteht aber in Großbritannien und Spanien (siehe für weitere Einzelheiten \$ 3.3.6).

Für Kinder ehemaliger Staatsangehörigen kennt außer Belgien auch Italien ein Optionsrecht (Art. 3 L.c.). Dort haben solche Kinder aber unter gewissen Voraussetzungen ein reines Optionsrecht; dasgleiche gilt für Personen, deren Großvater väterlicherseits ehemaliger Italiener war. In Spanien kennt Art. 22 Abs. 3 Ziffer 2 C.c.esp. Einbürgerungserleichtungen für Personen, die außerhalb Spaniens als Kind eines Elternteils geboren sind, der kraft Herkunft Spanier (español de origen) war. In dieser Zusammenhang sei schließlich wieder auf die in Großbritannien für Minderjährige vorgesehene Ermessensregistration von Sec. 3 (1) BNA 1981 hingewiesen.

Die Frage, ob dieses Optionsrecht für Kinder eines Staatsangehörigen oder für Kinder eines ehemaligen Staatsangehörigen, in den Niederlanden übernommen werden sollte, muß m.E. verneint werden. Nach niederländischem Recht haben minderjährige Kinder eines Staatsangehörigen fast immer ebenfalls die niederländische Staatsangehörigkeit. Eine Ausnahme gilt nur, wenn die Einbürgerung eines Elternteils sich aufgrund einer ausdrücklichen Klausel in der Einbürgerungsurkunde micht auf ein bestimmtes Kind erstreckt (siehe § 3.3.6). Gerade dann ist aber ein Optionsrecht für ein solches Kind nicht angemessen, da eine entsprechende Klausel nur aufgenommen wird, weil das betreffende Kind offensichtlich keine Beziehungen zu den Niederlanden hat, etwa weil es im Ausland lebt (vgl. weiter die Erörterungen in \$ 3.3.3.1 Buchstabe c). Ein Optionsrecht für Abkömmlinge eines ehemaligen Staatsangehörigen muß a fortiori abgelehnt werden. Hingewiesen sei auch auf $\$ 3.3 .3 .1$ Buchstabe d, wo bereits ein Optionsrecht für ehemalige Staatsangehörige zurückgewiesen wurde.

\section{c. Personen, die als Kind im Inland gelebt haben}

Ein zwischen dem 18. und 22. Geburtstag auszuübendes kontrolliertes Optionsrecht auf die belgische Staatsangehörigkeit hat seit 1985 ein Kind, das in der Zeit vor seinem 6. Geburtstag mindestens für die Dauer eines Jahres zusammen 
mit seinem gesetzlichen Vertreter in Belgien gelebt hat. Weitere Voraussetzungen sind ein zwölfmonatiger gewöhnlicher Aufenthalt in Belgien, unmittelbar der Optionserklärung vorausgehend. AuBerdem muß es entweder zwischen seinem 14. bis 18. Geburtstag oder im ganzen neun Jahre in Belgien gelebt haben; falls ein Elternteil im Zeitpunkt der Geburt des. Kindes Belgier von Geburt (belge de naissance) war oder gewesen war, gilt letztere Voraussetzung nicht. Der Aufenthalt im Ausland wird dem Aufenthalt in Belgien gleichgestellt, falls der Betroffene nachweist, eine tatsăchliche Bindung an Belgien zu haben. Die "option" kann wieder aufgrund schwerwiegender persönlicher Mängel oder wegen eines unzureichenden Eingliederungswillens zurückgewiesen werden (Art. $15 \$ 2 \mathrm{CNB}$ ).

Dieses belgische Optionsrecht ist einzigartig. Die übrigen Rechtsordnungen kennen keine entsprechende Regelungen; man vergleiche aber für Großbritannien wieder die Ermessensregistration von Sec. 3 (1) BNA 1981. In diesem Zusammenhang muß weiter auf eine schweizerische Regelung hingewiesen werden; dort wird für die Berechnung der für die Einbürgerung geforderte Frist die Zeit doppelt gerechnet, während der der Bewerber zwischen seinem vollendeten 10. und 20. Lebensjahr in der Schweiz gelebt hat (Art. 15 Abs. 2 BüG).

Soweit das belgische Optionsrecht die Kinder eines Elternteils betrifft, der zur Zeit der Geburt des Kindes "belge de naissance" war, ist dies aus dem Gesichtspunkt des niederländischen Staatsangehörigkeitsrechts nicht aufsehenerregend: jene Kinder erwerben nach niederländischem Recht ipso iure die niederländische Staatsangehörigkeit (siehe $\$ 3.2 .1,3.2 .4$ und 3.2.5). Insoweit dieses Optionsrecht aber Kinder betrifft, die vor ihrem 7 . Lebensjahr mindestens ein Jahr mit ihrem gesetzlichen Vertreter in Belgien gelebt haben und weiterhin während eines Teils ihrer Schulzeit in Belgien lebten, ist die Regelung inspirierend. Grund für dieses Optionsrecht ist wohl die Tatsache, dab man unterstellen darf, solche Kinder seien durch ihre Schulerziehung völlig integriert. $\mathrm{Zu}$ dieser Grundlage des "ius educationis" wurden bereits in \& 3.3.3.1 Buchstabe a einige Bemerkungen gemacht. Dort wurde vertreten, daß jedenfalls für im Inland geborene Personen, die ihre gesetzlich vorgeschriebene Schulzeit im Inland absolviert haben, ein Optionsrecht auf die Staatsangehörigkeit angemessen ist. Die belgische Konstruktion des kontrollierten Optionsrechtes für gröBtenteils im Inland erzogene Kinder muß zwar abgelehnt werden (siehe die einführende Bemerkungen zu \$ 3.3.3.2), zu überlegen bleibt aber, ob nicht das in \$ 3.3.3.1 Buchstabe a befürwortete Optionsrecht auch für nicht im Inland geborene Personen angemessen ist, die dennoch ihre Schulerziehung im Inland genossen haben (siehe auch $\S 3.3 .3 .2$ Buchstabe f).

\section{d. Ausländische Ehegatten eines Staatsangehörigen}

Seit 1985 hat gemäß Art. $16 \& 2 \mathrm{CNB}$ der mit seinem belgischen Ehepartner in Belgien zusammenlebende Ausländer nach sechsmonatigem Aufenthalt in Belgien ein kontrolliertes Optionsrecht auf die belgische Staatsangehörigkeit. Die "option" muß wieder nach Art. 15 CNB vom Gericht genehmigt werden und kann aufgrund schwerwiegender persönlichen Mängel oder wegen unzureichenden Eingliederungswillens verweigert werden. Das Gericht kann seine Entscheidung maximal zwei Jahre hinausschieben, wenn es der Meinung ist, daß die Dauer des gemeinsamen Aufenthalts in Belgien nicht ausreichend ist, um eine 
Beurteilung des Eingliederungswillens des Betreffenden zu ermöglichen. Das Zusammenleben im Ausland wird einem Zusammenleben in Belgien gleichgestellt, wenn der Antragsteller nachweist, daß zwischen ithm und Belgien eine tatsächliche Bindung entstanden ist (Art. $16 \$ 2 \mathrm{Abs} .2 \mathrm{CNB}$ ). Die belgische Regelung ist eindeutig von der französischen Regelung inspiriert. Art. 37.1 CNF gibt dem ausländischen Ehegatten nach sechsmonatiger Ehe nämlich ebenfalls ein Optionsrecht, das aufgrund von "indignité" oder "defaut d'assimilation" zurückgewiesen werden kann. Die Regierung Chirac hatte aber im Jahre 1986 vorgeschlagen, dieses Optionsrecht durch eine erleichterte Einbürgerungsregelung zu ersetzen.

In Italien hat der ausländische Ehegatte eines italienischen Bürgers ein kontrolliertes Optionsrecht auf die italienische Staatsangehörigkeit. Dies geht aus den Art. 1-3 des Gesetzes Nr. 123 vom 21. April 1983 hervor. Dieses Optionsrecht entsteht beim Inlandsaufenthalt nach sechsmonatiger Ehe, sonst nach dreijähriger Ehe. Die Option kann aufgrund bestimmter strafrechtlicher Verurteilungen oder wegen des Bestehens erwiesener Gründe, die die Sicherheit der Republik betreffen, zurückgewiesen werden. Die italienische Staatsangehörigkeit wird erst durch Dekret des Präsidenten der Republik erworben. Von 1975 bis 1982 kannte auch das spanische Recht für den ausländischen Ehepartner ein Optionsrecht mit Widerspruchsvorbehalt; seit 1982 besteht für diesen ausländischen Ehepartner aber lediglich die Möglichkeit einer erleichterten Einbürgerung. Vgl. weiter bezüglich der staatsangehörigkeitsrechtlichen Stellung ausländische Ehepartner $\$ 3.3 .7$, siehe auch $\$ 3.3 .4 .3$.

\section{e. Ehemalige Staatsangehörige}

In Belgien können bestimmte Gruppen ehemaliger Staatsangehöriger die belgische Staatsangehörigkeit durch eine kontrollierte Optionserklärung zuriickerwerben (Art. $24 \mathrm{CNB}$ ). Voraussetzungen sind, daß sie früher Belgier von $\mathrm{Ge}$ burt (belge de naissance) waren. Sie dürfen also gemäB Art. 5 CNB die belgische Staatsangehörigkeit nicht durch Einbürgerung oder als ausländische Ehegatten eines Belgiers durch genehmigte Optionserklärung erworben haben. Sie müssen mindestens 18 Jahre alt sein und sie müssen während der zwölf Monate, die der Erklärung vorausgehen, grundsätzlich ihren gewöhnlichen Aufenthalt in Belgien gehabt haben. Die Genehmigung des Gerichts kann wegen schwerwiegender persönlicher Fakkten oder wegen unzureichenden Eingliederungswillens verweigert werden. Auch wenn der Betreffende seinen Hauptaufenthaltsort nicht in Belgien hat, ist eine Wiedereinbürgerung möglich; dann aber muß das Gericht im Rahmen des Genehmigungsverfahrens die Umstände, unter denen der Betreffende die belgische Staatsangehörigkeit verloren hat, und die Grïnde, weshalb er sie wiedererlangen möchte, beurteilen. Diese Ümstände, beziehungsweise Gründe, müssen auch überprüft werden, wenn der Antragsteller die belgische Staatsangehörigkeit durch Verzicht verloren hat. Falls jemandem die belgische Staatsangehörigkeit aberkannt worden ist, kann diese nicht durch Optionserklärung zurückerworben werden. Bis 1985 hatte der gebïrtige Belgier, der die belgische Staatsangehörigkeit durch Erwerb einer fremden Staatsangehörigkeit oder durch Verzicht verloren hatte, nach zweijährigem Aufenthalt in Belgien ein reines Optionsrecht auf die belgische Staatsangehörigkeit (Art. 19 Abs. 1 Gesetz 1932). Der Wiedererwerb war aber ausgeschlossen, wenn er anhand der staatsangehörigkeitsrechtlichen Regelungen seines neuen Heimatstaa- 
tes die Möglichkeit hatte, seine ausländische Staatsangehörigkeit beizubehalten (Art. 7 Gesetz 1932) (Vgl. auch Art. 18 C.c. und Art. 13 Ziffer 1 Gesetz 1909, in denen für ehemalige Belgier Optionsrechte vorgesehen waren).

Auch in Frankreich haben ehemalige Staatsangehörige unter bestimmten Voraussetzungen ein kontrolliertes Optionsrecht auf die französische Staatsangehörigkeit. Art. 97.4 CNF gibt ehemaligen Franzosen kraft Geburt ein Optionsrecht, wenn sie ihre Staatsangehörigkeit durch Eheschließung, Einbürgerung oder Option verloren haben. Voraussetzung dafür ist aber, daß diese Personen mit Frankreich erkennbare Bindungen, insbesondere kultureller, beruflicher, wirtschaftlicher oder familiärer Art bewahrt oder aufgenommen haben. Personen, deren Ausweisung oder Zwangsaufenthalt angeordnet wurde, können nicht optieren; gleiches gilt für ehemalige Franzosen, die wegen eines der in Art. 79 CNF aufgefuihrten Delikte verurteilt worden sind. Art. 97.5 CNF sieht vor, daß die Regierung dem Erwerb der französischen Staatsangehörigkeit innerhalb einer Frist von sechs Monaten wegen "indignite" widersprechen kann.

In $\S$ 3.3.3.1 Buchstabe $d$ wurde ein Optionsrecht für ehemalige Staatsangehörige bereits abgelehnt. Dies gilt selbstverständlich ebenfalls für die hier besprochemen Optionsrechte mit Widerspruchsvorbehalt (vgl. weiter die $\$ 3.3 .4 .3$ und 3.3.4.7).

\section{f. Adoptions- oder Pflegekinder eines Staatsangehörigen}

Nach französischem Recht haben ausländische Kinder, die durch sogenannte schwache Adoption Kind eines Franzosen geworden sind, und Pflegekinder französischer Staatsangehörigen ein kontrolliertes Optionsrecht auf die französische Staatsangehörigkeit (Art. 55 CNF). Dieses Optionsrecht muß vor Vollendung des 18. Lebensjahres ausgeübt werden; der Optierende muß sich im Zeitpunkt der Erklärung in Frankreich aufhalten. Die Regierung hat gemäß Art. 57 CNF ein Widerspruchsrecht hinsichtlich "indignité" oder "défaut d'assimilation". Personen, gegen die eine Ausweisung oder ein Zwangsaufenthalt angeordnet ist, sowie Personen, die wegen der in Art. 79 genannten Delikte verurteilt wurden, können nicht optieren. Für Pflegekinder gilt die zusätzliche Forderung, daß sie entweder von einem Franzosen aufgezogen oder einer französischen Fürsorgeanstalt anvertraut sein müssen oder jedenfalls für die Dauer von mindestens fünf Jahren eine französische Ausbildung erhalten haben. Entsprechende Regelungen kennen die übrigen Staaten nicht.

Im übrigen kennt neben dem französischen Recht lediglich das italienische Recht noch die schwache Adoption. In Italien erwirbt das von italienischen Staatsangehörigen schwach adoptierte Kind die italienische Staatsangehörigkeit von Rechts wegen (siehe $\$ 3.2 .3$ ).

Besondere Regelungen für Pflegekinder eines Staatsangehörigen sind in den uibrigen Staaten ebenfalls unbekannt. Soweit der Pflegeelternteil gleichzeitig Vormund des Pflegekindes ist, sei aber auf die spanische Regelung zugunsten von ausländischen Kindern hingewiesen, die unter der Vormundschaft eines spanischen Staatsangehörigen stehen (siehe darïber \$3.3.3.1 Buchstabe c). Soweit das Pflegekind im Inland erzogen wird, muß rechtsvergleichend die schweizerische Regelung hervorgehoben werden, aufgrund deren bei Berech- 
nung der Aufenthaltsdauer die zwischen dem 10. und 20. Geburtstag in der Schweiz verbrachte Zeit doppelt gezählt werden muß (Art. 15 Abs. 2 BüG). Für Großbritannien ist wieder auf die Möglichkeit einer Ermessensregistration himzuweisen (Sec. 3 (1) BNA 1981). Nach niederländischem Recht wäre lediglich die Möglichkeit einer Sondereinbürgerung gemäB Art. $10 \mathrm{RwNed}$ (nach Anhörung des Staatsrats des Königreiches) gegeben (siehe \$3.3.5). Ein generelles Optionsrecht für Kinder eines Staatsangehörigen wurde bereits in \& 3.3.3.1 Buchstabe $c$ abgelehnt; die dort gegebene Begründungen gelten ebenfalls hinsichtlich Pflegekinder. Soweit ein Kind seine gesamte gesetzliche Schulzeit im Inland verbracht hat, ist jedoch schon in den \$ 3.3.3.1 Buchstabe a und 3.3.3.2 Buchstabe $c$ ein eventuelles Optionsrecht bejaht.

\section{g. Personen, die als Staatsangehörige behandelt wurden}

Nach französischem Recht (Art. 57.1 CNF) können Personen nach zehnjähriger "possession d'état" die französische Staatsangehörigkeit durch Optionserklärung erwerben; die französische Regierung hat aber ein innerhalb von sechs Monaten auszuübendes Widerspruchsrecht im Falle von Unwürdigkeit oder mangelnder Anpassung. Siehe weiter die Erörterungen in $\$ 3.3 .3 .1$ Buchstabe e. In \$ 3.3.3.1 Buchstabe e wurde bereits ein Optionsrecht aufgrund "possession d'état" abgelehnt, ein Einbürgerungsanspruch jedoch befürwortet.

\subsubsection{Anhang: Einbürgerungsansprüche}

Im deutschen Recht gib es mehrere Fälle, in denen die Einbürgerungsbehörde kein freies Ermessen mehr hat, sondern, falls die gesetzlich formulierten Voraussetzungen erfüllt sind, einbuirgern muß. Diese sogenannten Einbürgerungsansprïche geben dem Betroffenen deshalb ein Recht, das in der Regel stärker ist als die im vorherigen Paragraphen besprochenen kontrollierten Optionsrechte des belgischen oder französischen Rechts. Im folgenden werden die allgemeinen Einbürgerungsansprï̈che des deutschen Staatsangehörigkeitsrechts im einzelnen erwähnt. Nicht mehr existierende oder spezielle nachkriegsbedingte Optionsansprüche werden dabei außer Betracht gelassen. Neben diesen Einbürgerungsanspriichen gibt es Fälle, in denen die Einbürgerung bestimmter Personen zwar nicht erfolgen muß, sondem nur erfolgen soll. Die Ehegatteneinbürgerung gemäß \& 9 RuStAG billet ein Beispiel für eine solche privilegierte Soll-Einbürgerung. In diesen Fällen ist das freie Ermessen der Einbürgerungsbehörde erheblich - unter Umständen "auf null" - reduziert.

Auch im österreichischen Recht gibt es mehrere Fälle von Einbürgerungsanspriichen. Nachdem in $\$ 10 \mathrm{StBG} 1965$ die Voraussetzungen für eine Einbürgerung festgelegt werden und in $\$ 11$ betont wird, daß "die Behörde ... sich bei der Ausübung des ihr im $\$ 10$ eingeräumten freien Ermessens von Rücksichten auf das gemeine Wohl, die öffentlichen Interessen und das Gesamtverhalten der Partei" hat leiten zu lassen, finden sich in den $\S 11 \mathrm{a}, 12,13$ und 14 einige Fälle, in denen die Staatsangehörigkeit nicht nur verliehen werden kann, sondern $\mathrm{zu}$ verleihen ist.

In den übrigen in diese Erörterung einbezogenen Rechtssystemen gibt es keine Einbürgerungsansprüche. In diesem Zusammenhang ist es aber angemessen, an die von der niederländischen Regierung bei Einfuihrung des RwNed vertretene 
These zu erinnern, die Einbürgerung sei im RwNed nunmehr dergestalt geregelt, daß die Möglichkeit der Einbürgerung von einer "Gunst" zu einem "Recht" geworden sei. Sollte diese These stimmen, so würde dies bedeuten, daß die Einbürgerungsvoraussetzungen im niederländischen Recht dermaßen formuliert sind, daß von einem Einbürgerungsanspruch gesprochen werden kann, wenn die Voraussetzungen enfüllt sind. Dies würde nur bei den reinen Ermessenseinbürgerungen in Sonderfallen gemäß Art. $10 \mathrm{RwNed}$ nicht gelten. Da aber auch in den Niederianden ein Einbürgerungsantrag aufgrund einiger sehr vagen Klauseln (z.B. wegen mangelnder gesellschaftlicher Eingliederung zurückgewiesen werden kann, kann zur Zeit von unmittelbaren Einbürgerungsansprüchen noch keine Rede sein, wenngleich im Staatsangehörigkeitsgesetz die Ermessensfreiheit der Einbürgerungsbehörde stark eingeschränkt ist. Falls in Zukunft die Rechtsprechung die noch vorhandenen unbestimmten Klauseln im Rahmen gerichtlicher Überprüfung zurüickgewiesener Einbürgerungsanträge näher präzisiert, könnte die Regelung der Einbürgerung in den Art. 8 und 9 RwNed jedoch einem Einbürgerungsanspruch nahe kommen.

\section{a. Staatenlose Soldaten}

Gemäß $\S 2$ Abs. 2 Satz 2 des deutschen Wehrpflichtgesetzes in der Fassung vom 5. November 1977 (BGB1.I, 2021) hat ein staatenloser Wehrpflichtiger, der in Deutschland seinen Grundwehrdienst abgeleistet hat, bei Inlandswohnsitz einen Einbürgerungsanspruch. Dieser Anspruch wurde durch Gesetz vom 28. November 1960 eingefiigt. Diese Bestimmung hängt eng mit der Vorschrift des § 2 Abs. 2 Satz 1 des Wehrpflichtgesetzes zusammen, kraft dessen durch Rechtsverordnung bestimmt werden kann, daß auch Staatenlose der Wehrpflicht unterliegen, wenn sie ihren ständigen Aufenthalt im Geltungsbereich des Wehrpflichtsgesetzes, d.h. in der Bundesrepublik Deutschland haben. Bis jetzt ist eine solche Rechtsverordnung jedoch nicht ergangen.

Dieser Einbürgerungsanspruch ist grundsätzlich zu bejahen; es ist nicht einzusehen, weshalb jemand bereit sein muß, für einen Staat zu sterben, aber denmoch keinen Anspruch auf die Staatsangehörigkeit dieses Staates haben soll. Unverständlich ist jedoch, weshalb einem solchen Staatenlosen nicht die Möglichkeit gegeben ist, die deutsche Staatsangehörigkeit durch Option zu erwerben (vgl. die Erörterungen in den $\S 3.2 .6$ und 3.3.3.1 Buchstabe b). Siehe für Betrachtungen über die staatsangehörigkeitsrechtliche Stellung von Ausländern, die zu Unrecht Wehrdienst haben leisten müssen, $\$ 3.3 .3 .1$ Buchstabe e.

\section{b. Im Inland geborene Staatenlose}

In der Bundesrepublik Deutschland geborene Staatenlose haben gemäß Art. 2 des Gesetzes zur Verminderung der Staatenlosigkeit vom 29. Juni 1977 nach fünfjährigem rechtmäßigem Inlandswohnsitz bis zur Vollendung des 21 . Lebensjahres einen Einbürgerungsanspruch, es sei denn, daß sie rechtskräftig zu einer Freiheits- oder Jugendstrafe von fünf Jahren oder mehr verurteilt worden sind. Der Geburt in der Bundesrepublik wird Geburt an Bord eines deutschen Schiffes oder Flugzeuges gleichgestellt.

GemäB \& 14 StBG 1965 haben in Österreich geborene Staatlose ebenfalls unter gewissen Voraussetzungen einen Einbürgerungsanspruch. Sie müssen insgesamt 
mindestens zehn Jahre in Österreich gelebt haben, wovon mindestens fünf Jahre dem Einbürgenungsantrag unmittelbar vorausgehen müssen; sie dürfen nicht aufgrund bestimmter in $\$ 14$ Abs. 1 Ziffer 3 aufgezählter Delikte rechtskräftig verurteilt sein; sie dürfen zudem weder von einem österreichischen noch von einem ausländischen Gericht zu einer Freiheitsstrafe mehr als fünf Jahren verurteilt sein. Die Verurteilung durch ein ausländisches Gericht verhindert die Einbürgerung nur, wenn der zugrundeliegende Tatbestand auch nach österreichischem Recht strafbar ist. Der Einbürgerungsantrag muß zwischen dem 18. und 21. Geburtstag gestellt werden. Siehe weiter die Erörterungen in \$3.2.6, vgl. \$ 3.3.3.1 Buchstabe a und \$ 3.3.3.2 Buchstabe a.

\section{c. Nichteheliche Kinder eines Staatsangehörigen}

Seit dern 1. Januar 1975 hat das nichteheliche Kind eines deutschen Mannes nach fünfjährigem (seit dem 6. Juni 1977: dreijährigem) rechtmäßigem dauerndem Aufenthalt in der Bundesrepublik einen Einbürgerungsanspruch, wenn eine nach den deutschen Gesetzen wirksame Feststellung der Vaterschaft erfolgt ist. Der Einbürgerungsantrag muß vor Vollendung des 23. Lebensjahres gestellt werden.

Durch die Kombination der $\S \S 12$ Buchstabe $d$ und 17 Abs. 1 Ziffer 3 StBG i.d.F. 1983 hat das nichteheliche Kind eines österreichischen Mannes, dessen Vaterschaft festgestellt oder anerkannt ist und dem die Pflege und Erziehung des Kindes zusteht, einen Einbürgerungsanspruch, falls es die Voraussetzungen des $\S 10$ Abs. 1 Ziffer 1 bis 8 und Abs. 2 erfuillt (siehe $\$ 3.3 .3 .3$ Buchstabe $\mathrm{g}$ ).

In $\$ 3.2 .5$ wurde bereits befürwortet, daß das nichteheliche Kind eines Mannes seine Staatsangehörigkeit durch Abstammung erwirbt, wenn zwischen ihm und dem Kind familienrechtliche Beziehungen bestehen.

\section{d. Ausländische Ehegatten eines Staatsangehörigen}

In Österreich hat gemäß $\S 11$ a StBG i.d.F. 1983 der ausländische Ehegatte eines österreichischen Bürgers unter gewissen Voraussetzungen einen Einbürgerungsanspruch. Siehe weiter $\$ 3.3 .7$, vgl. auch $\$ 3.3 .4 .3$.

\section{e. Ehemalige Staatsangehörige}

Nach österreichischem Recht haben bestimmte Gruppen ehemaliger Staatsangehöriger gemäß \& 12 Buchstabe b und c StBG 1965 einen Einbürgerungsanspruch, wenn sie die Voraussetzungen des $\$ 10$ Abs. 1 Ziffer 2 bis 8 und Abs. 2 erfüllen. (Siehe über die Rechtsstellung ehemaliger Staatsangehöriger $\$ 3.3 .3 .1$ Buchstabe d; vgl. weiter \$3.3.3.2 Buchstabe e).

\section{f. Langjährige Einwohner}

Personen, die bereits seit mindestens 30 Jahren ununterbrochen ihren Wohnsitz in Österreich haben, sind unter der Voraussetzungen des $\S 10$ Abs. 1 Ziffer 2 bis 8 und Abs. 2 StBG 1965 einzubürgern, falls sie die österreichische Staatsangehörigkeit nicht infolge von Entziehung oder Verzicht verloren haben. Siehe hierzu die Erörterungen in $\$ 3.3 .4 .3$. 


\section{g. Andere Personen}

Unter den Voraussetzungen von $\S 10$ Abs. 1 Ziffer 2 bis 8 und Abs. 2 StBG iid.F. 1983 haben sämtliche in $\S 17$ erwähnte Gruppen von Personen gemäß Art. 12 Buchstabe d einen Einbürgerungsanspruch. AuBer den in $\$ 3.2 .5$ bereits erwähnteu nichtehelichen Kindern eines österreichischen Mannes, dessen Vaterschaft festgestellt oder anerkannt ist und dem die Pflege und Erziehung dieser Kinder zusteht, ist diese Regelung vor allem für Adoptivkinder $(\$ 17 \mathrm{Abs} .1$ Ziffer 4; siehe dazu oben die Bemerkungen in \$ 3.2.3) und für behinderte Kinder wichtig, wenn die Behinderung erheblich ist und das betreffende Kind mit dem österreichischen Elternteil in gemeinsamem Haushalt lebt oder diesem die Sorgepflicht für das Kind obliegt und er seiner Unterhaltspflicht nachkommt ( $\$ 17$ Abs. 3) (vgl. dazu $\$$ 3.3.3.1 Buchstabe c.)

\subsubsection{Einbürgerung}

\subsubsection{Allgemeine Bemerkungen über die Einbürgerungsvoraussetzungen}

In diesem Abschnitt werden die Voraussetzungen für eine Einbürgerung in den besprochenen Staaten miteinander verglichen. Ein solcher Vergleich unterliegt gewissen Schwierigkeiten. In einigen Staaten sind die Voraussetzungen im Gesetz oder in Verwaltungsrichtlinien wesentlich stärker detailliert als in anderen. Zudem kennen alle Staaten einige "vage" formulierten Voraussetzungen, deren konkrete Ausfüllung nicht immer gleich deutlich ist. So ist es möglich, $\mathrm{daB}$ bestimmte Voraussetzungen der Einbürgerung von einem Staat nicht ausdrücklich formuliert werden, daß aber diese Voraussetzungen dennoch im Rahmen anderer - vager - Voraussetzungen eine wichtige Rolle spielen. Insoweit dies offenkundig ist oder wenigstens mit einiger Sicherheit vermutet werden kann, wird darauf hingewiesen.

\subsubsection{Volljährigkeit}

In einigen der besprochenen Staaten ist Volljährigket eine der für die Einbürgerung gestellten Voraussetzungen. Dies gilt - außer für die Niederlande - für Belgien, Frankreich, Großbritannien und Spanien.

In den Niederlanden wird grundsätzlich die Volljährigkeit der einzubürgernden Person in Art. 8 Abs. 1 unter a RwNed gefordert. Art. 1 RWNed bezeichnet denjenigen als volljährig, der das achtzehnte Lebensjahr vollendet oder vorher geheiratet hat. Dies entspricht der ab dem 1. Januar 1988 geltenden Fassung des Art. 133 BW. Eine diesbezügliche ausdrückliche Bestimmung im Staatsangehörigkeitsgesetz war u.a. notwendig, um eine einheitliche Anwendung im ganzen Königreich zu bewirken, da in den Niederländischen Antillen und Aruba die Volljährigkeit erst mit Vollendung des 21. Lebensjahres oder bei vorheriger EheschlieBung eintritt. Außerdem bewirkt die Definition des Art. 1 RwNed, daß die Volljährigkeit von Ausländern im Rahmen der Anwendung niederländischer staatsangehörigkeitsrechtlicher Vorschriften immer anhand der niederländischen Definition festgestellt werden muß. Im übrigen ist die Einbürgerung eines Minderjährigen nicht völlig unmöglich. Sie kann über die Sonderbestimmung des Art. $10 \mathrm{RwNed}$ (Einbürgerung nach Anhörung des Staatsrates) erfolgen (siehe \$ 3.3.5). 
Eine sehr ähnliche Regelung kennt Spanien. Art. 22 C.c.esp. fordert grundsätzlich Volljährigkeit, aber über die Sonderbestimmung des Art. 21 C.c.esp. können auch Minderjährige eingebürgert werden, wenn diese bereits vierzehn Jahre sind und mit Beistand ihres gesetzlichen Vertreters handeln.

Auch Belgien fordert für die gewöhnliche Einbürgerung, daß der Antragsteller mindestens 18 Jahre alt ist (Art. 19 Abs. 1 CNB). Für die sogenannte große Einbürgerung ist sogar ein Mindestalter von 25 Jahren vorgeschrieben (Art. 25 Ziffer $1 \mathrm{CNB}$ ). In Frankreich betont Art. $66 \mathrm{CNF}$, daß niemand eingebürgert werden kann, der nicht das 18. Lebensjahr vollendet hat. Belgien und Frankreich sehen von diesen Regelungen keine Ausnahmen vor.

Das britische Recht fordert ebenfalls Volljährigkeit als Voraussetzung für die Einbürgerung. Minderjährige können aber nach einem entsprechenden Antrag nach freiem Ermessen vom Secretary of State als britische Staatsbürger registriert werden (Sec. 3 (1) BNA 1981).

Anders ist die Lage in Deutschland, der Schweiz und Österreich. In Italien fehlen ausdrückliche Bestimmungen. Im deutschen Recht kann die Einbürgerung auch von Minderjährigen beantragt werden ( $\$ 7$ Abs. 2 RuStAG). Wenn der Minderjährige noch keine sechzehn Jahre alt ist, muß der Antrag vom gesetzlichen Vertreter gestellt werden. Sechzehn- und Siebzehnjährige können den Einbürgerungsantrag mit Zustimmung ihres gesetzlichen Vertreters selbst stellen. In der Schweiz können ebenfalls Minderjährige eingebürgert werden (Art. 34 BüG). Der Einbürgenungsantrag muß dann aber vom gesetzlichem Vertreter eingereicht werden. Selbst wenn der Minderjährige unter Vormundschaft steht, ist Zustimmung der vormundschaftlichen Behörden nicht erforderlich. Abs. 2 des Art. 34 BüG sieht vor, daß Minderjährige, die bereits 16 Jahre alt sind, ihren eigenen Willen zum Erwerb des Schweizer Bürgerrechts schriftlich erklären müssen. Es ist bemerkenswert, daß sowohl in Deutschland als auch in der Schweiz Sechzehn- und Siebzehnjährigen nicht mehr ohne ihre eigene Mitwirkung eingebürgert werden können. Österreich geht in dieser Hinsicht sogar noch weiter. Gemäß \& 19 Abs. 2 StBG muß für einen Minderjährigen der Einbürgerungsantrag vom gesetzlichen Vertreter oder mit schriftlicher Zustimmung des gesetzlichen Vertreters gestellt werden. Unter dem Aspekt des gewährten und in $\$ 3.2 .2$ bereits besprochenen staatsangehörigkeitsrechtlichen Selbstbestimmungsrechts von mindestens vierzehnjährigen Personen, muß ein minderjähriger Aus länder, der bereits das 14. Lebensjahr vollendet hat, einem ihn betreffenden Einbürgerungsantrag ausdrücklich schriftlich zustimmen. \& 19 Abs. 3 StBG sieht vor, daß die Zustimmung des gesetzlichen Vertreters oder des bereits 14-jährigen Minderjăhrigen durch das Gericht ersetzt werden kann, wenn die Verleihung der Staatsbürgerschaft aus erzieherischen, beruflichen oder anderen wichtigen Gründen dem Wohl des Fremden dient. Gleiches gilt, wenn der minderjăhrige Ausländer keinen gesetzlichen Vertreter hat oder dieser nicht erreichbar ist und die Bestellung eines gesetzlichen Vertreters auf unüberwindliche Hindernisse stößt. Entsprechendes gilt auch, wenn der Minderjährige unbekannten Aufenthaltes oder sonst nicht erreichbar ist.

Wenn wir diese Regelungen iiberblicken, stellen wir fest, daß es heutzutage grundsätzlich nicht unverständlich ist, wenn einige Staaten nur die Einbürgerung 
von Volljährigen zulassen. Gerade weil sowohl die Einbürgerung eines ausländischen Mannes als die einer ausländischen Frau sich meistens automatísch auf deren minderjährige Kinder erstrecken oder jedenfalls relativ mühelos erstreckt werden können (siehe \$ 3.3.6), besteht in der Regel kaum ein Bedürfnis zur selbständigen Einbürgerung von Minderjährigen. Nur in Ausnahmefăllen ist deshalb die Möglichkeit einer Einbürgerung von Minderjährigen wünschenswert. Dies ist z.B. der Fall, wenn bei der Einbürgerung eines Elternteils ursprünglich bewußt von einer Erstreckung auf bestimmte Kinder abgesehen wurde und später doch gewünscht wird, daß ein solches Kind, die von dem Elternteil bereits erworbene Staatsangehörigkeit, erhält. Auch wenn ein Kind ursprünglich zusammen mit einem Elternteil (durch Erstreckung) eingebürgert werden sollte und dieser Elternteil während des Einbürgerungsverfahrens stirbt, ist die Möglichkeit einer selbständigen Einbürgerung des betroffenen Minderjährigen zu begrüßen. Obwohl die Niederlande, Großbritannien und Spanien prinzipiell Volljährigkeit fordern, ist eine solche Möglichkeit dennoch gegeben. Dies muß positiv beurteilt werden. Dagegen ist das Fehlen einer solchen Möglichkeit in Belgien und Frankreich abzulehnen.

Die Einbürgerung eines Minderjährigen hat aber manchmal auch den Verlust seiner bisherige Staatsangehörigkeit zur Folge. Zum Schutz des Minderjährigen ist deshalb eine sorgfältige Regelung seiner Vertretung beim Einbürgenungsantrag erforderlich. Die österreichische Regelung ist in dieser Hinsicht vorbildlich. Verwiesen sei weiter auf die Ausführungen in \$ 3.2.2. Die österreichische Bestimmung könnte aber noch in einigen Punkten verbessert werden. Soweit nicht beide Eltern gesetzliche Vertreter des Minderjährigen sind, sollte auch die Einwilligung jenes Elternteils, der nicht gesetzlicher Vertreter ist, eingeholt werden müssen. Unter Umständen geht durch die Einbürgerung ja gerade die Staatsangehörigkeit dieses Elternteils verloren. Weiter darf eine mangelnde Zustimmung des betreffenden Minderjährigen m.E. nicht durch die Entscheidung eines Gerichts ersetzt werden, wenn der Minderjährige durch die Einbürgerung seine bisherige Staatsangehörigkeit verlieren wird.

Es ist m.E. nicht erforderlich, die Möglichkeit der Einbürgerung eines Minderjährigen ausdrücklich im RwNed zu regeln. Die Regelung der Sondereinbürgerung von Art. 10 RwNed ist ausreichend. Gemäß Art. 10 RwNed soll ein Minderjähriger aber ausschließlich dann eingebürgert werden, wenn er beim Einbürgerungsantrag ordnungsgemäß vertreten wurde und alle betroffenen Personen (also außer dem gesetzlichen Vertreter auch Eltern, die eventuell nicht gesetzliche Vertreter sind, und der betroffene Minderjährige selbst ) über die Einbürgerung gehört wurden.

\subsubsection{Wohnsitz}

Sămtliche Staaten fordern für eine Einbürgerung grundsätzlich einen Wohnsitz im Inland; die regelmäßig geforderte Aufenthaltsfrist variiert jedoch stark. In diesem Abschnitt werden zunächst die geforderten Aufenthaltsfristen miteinander verglichen. Dabei wird auch auf die von den meisten Rechtsordnungen gestellte Forderung eingegangen, daß die geforderte Aufenthaltsfrist dem Einbürgerungsantrag unmittelbar vorausgegangen beziehungsweise ohne Unterbrechung gewesen sein muß. Danach werden einige Ausnahmen behandelt, in denen die im Inland verbrachte Zeit bei der Berechnung der geforderten Aufent- 
haltsfrist nicht mitzählt; die Frage, ob illegal im Inland verbrachte Zeit bei Berechnung der geforderten Aufenthaltsfrist erheblich ist, wird nicht in diesem Abschnitt sondern erst im nächsten ( $\$ 3.3 .4 .4$, im Zusammenhang mit dem ausländerrechtlichen Status) erörtert. Alle Staaten kennen Regelungen, kraft deren unter bestimmten Voraussetzungen auch bei Auslandswohnsitz eine Einbürgerung möglich ist; die betreffenden Regelungen werden in diesem Paragraphen beschrieben. Weiter werden in allen Staaten für verschiedene Ausländergruppen die geforderte Aufenthaltsfrist gekürzt. Auch diese Regelungen werden kurz angesprochen; dabei sei im Auge behalten, daß diese Ausnahmen um so bedachtsamer sind, je länger sich die normalerweise geforderte Aufenthaltsdauer bemißt. Abschließend werden die erwähnten Regelungen inhaltlich gewertet.

Die Niederlande, Belgien, Frankreich, Großbritannien und Italien fordern grundsätzlich einen fïnfjährigen Aufenthalt im Inland (Art. 8 Abs. 1 Buchstabe c RwNed: Art. 19 Abs. 1 CNB; Art. 62 CNF; $\$ 1$ (2) Ziffer 1 und 2 Schedule 1 BNA; Art. 4 L.c.). Es ist bemerkenswert, daß Deutschland, Österreich und Spanien genau die doppelte Frist, nämlich zehn Jahre fordern (Nr. 3.2.1 der deutsche Einbürgerungsrichtlinien; $\S 10$ Abs. 1 Ziffer 1 StBG; Art. 22 C.c.esp.). Die Schweiz verlangt sogar einen zwölfjährigen Wohnsitz im Inland (Art. 15 Abs. 1 BüG). Für Spanien hat die lange Dauer der Aufenthaltsfrist historische Wurzeln: früher bildeten "diez años de vecindad" neben der Einbürgerung einen selbständigen Erwerbsgnund. Dagegen ist die lange Dauer der in Deutschland, Österreich und der Schweiz geforderten Aufenthaltsfristen offenbar eine Besonderheit des germanischen Rechtskreises, wobei allerdings in Österreich die Wohnsitzfrist bis 1965 lediglich vier Jahre betrug ( $\$ 5$ Abs. 1 Ziffer 3 BBG 1925 und \& 5 Abs. 1 Ziffer 3 StBG 1945/1949). An dieser Stelle sei zudem darauf hingewiesen, da 3 das belgische Recht neben einer normalen Einbürgerung, für die ein fünfjähriger Aufenthalt im Inland gefordert wird, noch die sogenannte "große Eünbürgerung" kennt. Für sie formuliert das belgische Recht keine ausdrückliche Wohnsitzforderung. Implizit geht eine solche Forderung aber doch aus Art. 20 Ziffer 3 CNB hervor; die "große Einbürgerung" ist nur möglich, wenn der Betreffende für Belgien große Dienste erbracht hat oder in der Zukunft erbringen kann oder, wenn er die belgische Staatsangehörigkeit schon mindestens 5 Jahre durch normale Einbürgerung oder durch genehmigte Optionserklärung als ausländischer Ehegatte eines Belgiers besitzt. Hieraus geht hervor, daß jemand zur Zeit der "großen Einbürgerung" im allgemeinen mindestens zehn Jahre in Belgien leben muß.

Die geforderte Aufenthaltsdauer muß im allgemeinen dem Einbürgerungsantrag "unmittelbar vorabgegangen" und "ununterbrochen" gewesen sein. In Deutschland und in der Schweiz müssen dabei von den geforderten zehn beziehungsweise zwölf Jahren des Aufenthaltes "nur" fünf Jahre unmittelbar vor dem Einbürgerungsantrag im Inland verbracht worden sein. Bemerkenswert ist die niederlẳndische Bestimmung des Art. 8 Abs. 3 RwNed gemäß der eine dem Antrag unmittelbar vorausgehende Aufenthaltsdauer von zwei Jahren für diejenigen genïgt, die insgesamt mehr als zehn Jahre in den Niederlanden gelebt haben. Nur in Großbritannien wird ganz präzise beschrieben, unter welchen Voraussetzungen ein Aufenthalt ununterbrochen ist: während der fünf dem Einbürgerungsantrag vorausgehenden Jahre, darf sich der Bewerber insgesamt höchstens 450 Tage außerhalb des Vereinigten Königreiches aufgehalten haben, 
wobei im letzten Jahr vor Antragstellung nur eine Abwesenheit von 90 Tage zulässig ist. In besonderen Fällen kann aber von diesen Regeln abgewichen werden. In Sec. 9 won Schedule 1 BNA wird noch bestimmt, daß die Zeit, die man in britischen Strafanstalten oder Anstalten für Geisteskranke verbringt, nicht als Aufenthalt in Großbritannien gilt; das gleiche gilt für die Zeit, die man in Großbritannien als Inhaber eines diplomatischen Status verbringt. In diesem Zusammenhang soll auch auf die Bestimmung des östereichischen \& 15 Abs. 1 StBG i.d.F. 1985 hingewiesen werden, kraft deren die geforderte Wohnsitzdauer durch ein rechtskräftiges Aufenthaltsgebot oder einen mehr als sechsmonatigen Aufenthalt in einer Anstalt zum Vollzug von Freiheitsstrafen oder in einer anderen Justizanstalt unterbrochen wird. In der Bundesrepublik Deutschland betonen die Richtlinien (Nr. 3.2.1), daß die im Inland ausschlieBlich unter Ausländer verbrachte Zeit nicht gilt.

Alle Staaten sehen vor, daß u.U. auch bei Auslandswohnsitz eingebürgert werden kann. Einige Staaten kennen eine Generalklausel aufgrund deren unter bestimmten Voraussetzungen Auslandsaufenthalt einem Inlandsaufenthalt gleichgestellt wird. Andere Staaten bestimmen lediglich, daß bestimmte Gruppen von Personen auch bei Auslandwohnsitz eingebürgert werden können.

In den Niederlanden können einige Personen eingebürgert werden auch wenn sie reinen Wohnsitz im Ausland haben; dazu gehören: ehemalige Niederländer, Personen, die schon mindestens drei Jahre mit einem Niederländer verheiratet sind, und diejenigen, die nach Vollendung des 18. Lebensjahres oder, nachdem sie geheiratet haben, durch Anerkennung, Legitimierung oder Adoption Kind eines niederländischen Elternteils geworden sind (Art. 8 Abs. 2 und 3 RwNed). In diesen Fällen darf der Betreffende aber nicht in einem Land leben, dessen Staatsangehörigkeit er ebenfalls bereits besitzt (Art. 9 RwNed); von dieser letzten Regel kann nur über die Sonderbestimmung des Art. 10 RwNed (Einbürgerung nach Anhörung des Staatsrates) eine Ausnahme gemacht werden. Auch in anderen nicht in Art. 8 RwNed vorgesehenen Fällen ist bei Auslandswohnsitz in Prinzip eine Einbürgerung gemäß Art. $10 \mathrm{RwNed}$ denkbar.

Das belgische Recht kennt die allgemeine Klausel, daß ein Aufenthalt im Ausland dem Aufenthalt in Belgien gleichgestellt wird, wenn der Antragsteller nachweist, daß er mit dem belgischen Staat während der geforderten Aufenthaltsperiode durch tatsächliche Bindungen verbunden war (Art. 19 Abs. 2 CNB).

Nach deutschem Recht können gemäB \& 13 RuStAG zumindest ehemalige Deutschen auch bei Auslandswohnsitz eingebürgert werden. Andere Ausländer können in besonderen Fällen ohne Begründung eines Wohnsitzes im Inland aufgrund des $\$ 1$ der Verordnung zur Regelung von Staatsangehörigkeitsfragen vom 20. Januar 1942 eingebürgert werden, sofern die übrigen gesetzlichen Voraussetzungen nach \& 8 RuStAG erfüllt sind (vgl. dariber 6.5.4 der deutschen Einbürgerungsrichtlinien).

Art. 78 Abs. 1 CNF stellt im bestimmten Fällen einen Aufenthalt im Ausland einem Aufenthalt in Frankreich gleich. Dies gilt erstens für den Aufenthalt eines Ausländers außerhalb Frankreichs, wenn der Auslandsaufenthalt der Ausübung einer öffentlichen oder privaten beruflichen Tätigkeit im Dienst Frankreichs 
oder einer Einrichtung dient, deren Tätigkeit ein besonderes Interesse für die französische Wirtschaft oder Kultur darstellt. Zweitens gilt dies für den Aufenthalt in Ländern, die mit Frankreich in Zollunion stehen, und die durch Dekret festgesetzt worden sind. Drittens ist dies der Fall in Friedens- sowie Kriegszeiten bei Diensten außerhalb Frankreichs in einer regulären Einheit der französischen Armee oder bei Ableistung des nationalen aktiven Wehrdienstes. Abs. 2 des Art. $78 \mathrm{CNF}$ bestimmt zusätzlich, daß die Gleichstellung des ausländischen Aufenthaltes mit einem Aufenthalt in Frankreich zugunsten eines Ehegatten auch für den mit ihm tatsächlich zusammenlebenden anderen Ehegatten gilt.

Schedule 1 des BNA regelt in Sect. 1 (3), daß die Zeit, die außerhalb Großbritanniens im Dienste der Krone verbracht wird, wie der Aufenthalt in GroBbritannien zählt.

Italien kennt die Möglichkeit einer Einbürgerung bei Auslandswohnsitz für diejenigen, die bereits mindestens drei Jahre im Dienste des italienischen Staates sind (Art. 4 ziffer 1 L.c.).

Auch nach österreichischem Recht ist in mehreren Fällen eine Einbürgerung bei Auslandswohnsitz möglich. Erstens gilt eine solche Ausnahme, wenn die Einbuirgerung im Interesse der Republik ist (Art. 10 Abs. 3 StBG). Weiter ist dies der Fall bei ausländischen Ehegatten, die mindestens fünf Jahre mit einer Person verheiratet sind, die ihrerseits bereits mindestens seit zehn Jahren die österreichische Staatsangehörigkeit besitzt ( $\$ 11 \mathrm{a}$ Ziffer 4 Buchstabe b StBG i.d.F. 1985). Ausländische Ehegatten von österreichischen Auslandsbeamten können gegebenenfalls noch schneller eingebürgert werden ( $\$ 11$ a Ziffer 4 Buchstabe a i.V.m. $\S 5$ Abs. 2 StBG). Eine Wohnsitzforderung wird ebenfalls nicht für diejenigen gestellt, die als Minderjăhrige die Staatsangehörigkeit auf andere Weise als durch Entziehung verloren haben, und die Wiedereinbürgerung innerhalb von zwei Jahren nach Erreichung der Volljährigkeit beantragen ( $\$ 12$ Buchstabe c StBG) und schließlich für die in $\S 17$ StBG ( $\$ 12$ Buchstabe d StBG) aufgezählten Personengruppen.

In der Schweiz ist Einbürgerung bei Auslandswohnsitz möglich, wenn eine Frau wegen ihrer Ehe mit einem Ausländer die schweizerische Staatsangehörigkeit verloren hat (Art. $19 \mathrm{BüG}$ ). Bei Auslandswohnsitz kann auch derjenige eingebürgert werden, der die schweizerische Staatsangehörigkeit nach Art. 10 BüG wegen seiner Geburt im Ausland verloren hat (Art. 21 BüG). In Spanien ist bei Auslandswohnsitz eine Ermessenseinbürgerung möglich, wenn beim Interessenten besondere Umstände vorliegen (Art. 21 C.c.esp.).

Sämtliche Staaten kennen zahlreiche Ausnahmen von der grundsätzlich geforderten Aufenthaltsfrist. Diese Ausnahmen sollen hier kurz beschrieben werden. Dabei ist zu berüicksichtigen, daß diese Einbürgerungserleichterungen nur in Zusammenhang mit den von den verschiedenen Staaten vorgesehenen Optionsrechten verglichen werden können. Wo manche Staaten Optionsrechte verleihen, sehen andere lediglich Einbürgerungserleichterungen vor. Im folgenden sollen lediglich noch die Fälle erwähnt werden, in denen eine kürzere als die normale Aufenthaltsfrist gefordert wird. Die oben bereits erwähnten Fälle, in denen sogar bei Auslandswohnsitz eingebürgert werden kann, werden im allgemeinen nicht wiederholt. 
In den Niederlanden wird die fünfjährige Wohnsitzfrist für ledige Personen auf drei Jahre verkürzt, wenn diese schon seit mindestens drei Jahren in den Niederlanden in einem eheähnlichen Verhältnis mit einem unverheirateten Niederländer zusammenleben. Es sei daran erinnert, daß der ausländische Ehepartner eines Niederländers nach dreijähriger Ehe auch bei Auslandswohnsitz eingebürgert werden kann (siehe weiter \$ 3.3.7).

Im belgischen Recht wird die fünfjährige Wohnsitzfrist lediglich für Flüchtlinge und bestimmte Gruppen von Staatenlosen auf drei Jahre herabgesetzt (Art. 19 Abs. 1 CNB). Man denke aber daran, daß das belgische Recht viele Fülle kontrollierter Optionsrechte kennt, die faktisch auch erleichterte Einbürgerungen darstellen.

In Deutschland wird die grundsätzlich zehnjährige Frist für mehrere Gruppen won Einbürgerungsbewerbern erheblich gekürzt. Die Einbürgerungsrichtlinien (Nr. 3.2.2 und 3.2.3) führen - ohne allerdings genau festzustellen um wieviele Jahre die Aufenthaltsforderung reduziert wird - auf: ehemalige Deutsche; deutsche Volkszugehörige ohne Einbürgerungsanspruch; Personen aus dem deutschsprachigen Raum oder solche, die sich längere Zeit im deutschsprachigen Raum aufgehalten haben; Personen, die sich erst seit fünf Jahren im Inland aufhalten, aber zusammen mit ihrem Ehegatten, der die Einbürgerungsvoraussetzungen erfüllt, eingebürgert werden sollen; miteinzubürgernde Kinder; Personen mit schweren Kriegsbeschädigungen in deutschen Diensten; nahe Angehörige von im Dienst der Deutschen Wehrmacht gefallenen oder vermißten Personen. Ehegatten von deutschen Bürgern können in der Regel schon eingebürgert werden, wenn sie sich fünf Jahre, oder drei Jahre nach ihrer EheschlieBung, in Deutschland aufgehalten haben. Für mit Deutschen verheiratete Einbuirgenungsbewerber aus dem deutschsprachigen Raum genügt sogar ein zweijähriger Aufenthalt und zweijährige Ehe (Richtlinie Nr. 6.1.3). Nr. 3.2.3.1 der deutschen Einbürgerungsrichtlinien erwähnt schließlich die Möglichkeit, daß wenn "ein herausragendes öffentliches Interesse besteht, den Einbürgerungsbewerber durch die Einbürgerung für eine "Tätigkeit im Bundesgebiet zu gewinnen oder zu erhalten" immer bereits "nach kurzer Aufenthaltsdauer" eingebürgert werden kann.

In Frankreich bestimmt Art. $63 \mathrm{CNF}$, daß die grundsätzlich fünfjährige Frist auf zweil Jahre herabgesetzt wird; diese Regelung gilt für Ausländer, die mit Erfolg zwei Jahre höhere Studien absolviert haben, um ein Diplom zu erwerben, das von einer französischen Universität oder einer höheren französischen Lehranstalt verliehen wird, und für diejenigen, die durch ihre Befähigungen oder Begabungen Frankreich wichtige Dienste erwiesen haben oder erweisen können. In den Art. 64 und 64.1 CNF werden mehrere Kategorien von Personen erwähnt, die ohne Bedingungen in Bezug auf die Aufenthaltsdauer eingebürgert werden können. Grundsätzlich müssen diese Personen im Moment der Einbürgerung aber in Frankreich leben (Art. 61 CNF). Es betrifft hier den Ehegatten und die volljährigen Kinder einer Person, die die französische Staatsangehörigkeit erwirbt; den Vater oder die Mutter von drei minderjährigen Kindern; den Ausländer, der in einer Einheit der französischen Armee gedient oder der sich in Kriegszeiten freiwillig in der französischen oder alliierten Armee verpflichtet hat; eine Person, die aus den Territorien oder Staaten, bezüglich denen Frankreich die Souveränität ausgeübt hat, oder aus einem Protektorat, Mandatsgebiet oder Tutelarstaat Frankreichs stammt; den Ausländer, der Frankreich außerge- 
wöhnliche Dienste erwiesen hat, oder denjenigen, dessen Einbürgerung für Frankreich ein außergewöhnliches Interesse darstellt; und schließlich die Person, die dem französischen kulturellen oder sprachlichen Bereich angehört, wenn sie Staatsbürger einer der Territorien oder Staaten ist, deren offizielle Sprache oder eine der offiziellen Sprachen französisch ist und wern ihre Muttersprache französisch ist.

Schedule 1 BNA sieht ganz allgemein vor, daß in besonderen Fällen von den geforderten Aufenthaltsfristen abgewichen werden kann. Für ausländische Ehegatten eines britischen Staatsangehörigen wird lediglich ein dreijähriger Wohnsitz gefordert.

Italien verlangt grundsätzlich einen fünfjährigen Aufenthalt im Inland. Die Frist wird jedoch in einigen Fällen erheblich herabgesetzt (Art. 4 Ziffer 2 L.c.). Sie dauert nur zwei Jahre für Personen, die beachtliche Dienste für Italien geleistet haben (Art. 4 Ziffer 2 L.c.). Dieselbe Frist galt ursprünglich für den ausländischen Mann einer Italienerin; seit 1983 hat dieser aber ein kontrolliertes Optionsrecht auf die italienische Staatsangehörigkeit. Personen, die ein Optionsrecht auf die italienische Staatsangehörigkeit hatten, dies aber nicht benutzt haben, können nach sechsmonatigem Aufenthalt eingebürgert werden (Art. 4 Ziffer 4 L.c.). Ausländer, die seit mindestens drei Jahren im Dienste Italiens stehen, können - auch bei Auslandswohnsitz - eingebürgert werden.

Das österreichische Recht sieht in $\S 10$ Abs. 3 StBG Abweichungen von der Wohnsitzforderung vor, wenn es sich um Minderjährige oder um Ausländer handelt, die bereits mindestens vier Jahre in Österreich leben; weitere Voraussetzung ist, daß ein besonders berücksichtigungswürdiger Grund für die Verleihung der Staatsbürgerschaft vorliegt oder, daß die Verleihung der Staatsbürgerschaft wegen der von dem Ausländer bereits erbrachten oder von ihm noch zu erwartenden außerordentlichen Leistungen im Interesse der Republik liegt. Für die Stellung des ausländischen Ehegatten eines Österreichers sei auf $§ 3.3 .7$. verwiesen.

Auch die im schweizerischen Recht grundsätzlich geforderte zwölfjährige Wohnsitzfrist ist für mehrere Personengruppen gemindert. So bestimmt Art. 15 Abs. 2 BüG, daß die Zeit, in der der Bewerber zwischen seinem vollendeten 10. und 20. Lebensjahr in der Schweiz gelebt hat, doppelt gerechnet wird. Das gleiche gilt für die Zeit, während der ein ausländischer Mann in ehelicher Gemeinschaft mit einer gebürtigen Schweizerin gelebt hat. Für von Schweizern adoptierte volljährige Kinder sowie für Kinder, die mit ihrer Mutter ausländischer Herkunft und deren schweizerischem Ehemann zusammenleben, wird auch die vor dem 10. Lebensjahr in der Schweiz verbrachte Zeit doppelt gerechnet (Abs. 3). In den Fällen, für die das schweizerische Recht eine Wiedereinbürgerung unter erleichterten Bedingungen (Art. 19, 20, 21, 22, 23 BüG) oder eine erleichterte Einbürgerung (Art. 28, 29, $30 \mathrm{BüG}$ ) vorsieht, wird in der Regel nur ein Wohnsitz in der Schweiz gefordert, jedoch keine bestimmte Wohnsitzfrist (z.B. Art. 22, 23 BüG). Manchmal gilt sogar, daB auch bei Auslandswohnsitz eingebürgert werden kann (Art. 19 und 21 BüG; vgl. weiter Art. 28 Abs.1 Buchstabe $\mathrm{c}$ BüG). Es sei aber darauf hingewiesen, daß die Wohnsitzfristen des BüG nur für die Einbürgerungsbewilligung des Bundes gelten; den Kantonen und Gemeinden steht es frei, strengere Forderungen zu stellen. 
In Spanien fordert Art. 22 C.c.esp. für eine Einbürgerung grundsätzlich zehnjährigen Aufenthalt in Spanien. Dies entspricht den bereits im Mittelalter geforderten "diez años de vecindad". Diese Frist wird aber für Bürger lateinamerkanischer Staaten, Andorras, der Philippinen, Aquatorial-Guineas oder Portugals und für sephardische Juden auf zwei Jahre herabgesetzt. Für auf spanischem Boden geborene Personen, für diejenigen, die außerhalb Spaniens als Kind eines ursprünglich von Geburt spanischen Elternteils ("español de origen") geboren wurden, für Personen, die ein Optionsrecht auf die spanische Staatsangehörigkeit nicht rechtzeitig ausgeübt haben, oder für diejenigen, die mit einem spanischen Bürger verheiratet sind (sogar falls die Ehe inzwischen aufgelöst ist) gilt lediglich eine einjährige Wohnsitzfrist.

Die grundsätzliche Forderung der Staaten, daß der Einbürgerungsbewerber eine gewisse Zeit im. Inland gelebt haben muß, um seinen Anspruch erstarken zu lassen, ist durchaus verniunftig und sachgemäß. In der Regel entsteht ja tatsächlich nur durch Inlandsaufenthalt eine solch enge Beziehung zwischen einer Person und einem Staat, daß die Verleihung der Staatsangehörigkeit berechtigt ist. Die Frage ist nunmehr, wie lang der regelmäßig geforderte Inlandsaufenthalt sein sollte. Rechtsvergleichend kann man feststellen, daß die Ansichten hierüber ganz erheblich von einander abweichen. Grundsätzlich ist die Bestimmung der prinzipiell geforderten Dauer des Inlandsaufenthaltes selbstverständlich eine politische Entscheidung. Rechtstechnisch könnte man aber vertreten, daß längere Aufenthaltsfristen berechtigt erscheinen, wenn neben der Wohnsitzforderung nur noch wenige zusätzliche Einbürgerungsvoraussetzungen gestellt werden. Wenn neben dem Wohnsitzkriterium aber noch mehrere andere Einzelvoraussetzungen geprüft werden und vorliegen sollen, müßte eigentlich eine relativ kurze Wohnsitzfrist ausreichen. Da im niederländischen Recht neben der Aufenthaltserfordernis noch mehrere weitere Voraussetzungen geprüft werden, sehe ich keinen Anlaß für eine Änderung der in den Niederlanden geforderten Aufenthaltsfrist.

In allen Staaten muß der Aufenthalt im Inland wenigstens teilweise unmittelbar dem Einbürgerungsantrag vorausgehen. Auch diese Forderung ist verständlich, da garantiert werden soll, daß im Zeitpunkt der Einbürgerung eine tatsächliche Beziehung des Antragstellers zum Inland gegeben ist und diese vermutlich in Zukunft auch weiterhin Bestand haben wird. Unter dem Gesichtspunkt der heutigen allgemeinen und internationalen Mobilität der Bevölkerung ist es aber weder zweck- noch verhältnismäßig zu fordem, die gesamte Zeit des Inlandaufenthaltes müsse unmittelbar dem Einbürgerungsantrag vorausgehen. Eine gewisse Eleganz hat deshalb die niederländische Regelung. Darin wird grundsätzlich ein dem Einbürgerungsantrag unmittelbar vorausgehender fünfjähriger Inlandsaufenthalt gefordert; wenn sich der Bewerber jedoch insgesamt mehr als zehn Jahre in den Niederlanden aufgebalten hat, reduziert sich die Aufenthaltsdauer auf nur zwei Jahre unmittelbar vor Antragstellung. In diesem Zusammenhang kann die britische Präsizierung der Ununterbrochenheit des geforderten Aufenthalts auch für die Rechtsprechung in anderen Staaten inspirierend sein. Dennoch empfiehlt es sich nicht, eine solche Konkretisierung auch für die Gesetzgebung anderer Staaten zu befürworten. Dies wïrde dem Charakter der kontinentaleuropäischen Gesetze widersprechen. Die britische Regelung sowie die österreichische Regelung, die besagt, daß die geforderte Aufenthaltszeit durch "Einsitzen" in einer österreichischen Strafanstalt unterbrochen wird, müssen m.E. abgelehnt 
werden. In allen Staaten kann Straffälligkeit eines Einbürgerungsbewerbers unter gewissen Voraussetzungen die Ablehnung des Einbürgerungsantrages bewirken (siehe \$ 3.3.4.7). Die werschiedenen Ablehnungsgründe eines Einbürgerungsantrages sollen jedoch m.E. möglichst klar voneinander unterschieden werden. Die britiscte und österreichische Lösung widersprechen dieser Forderung; die Aufenthaltserfordernis und die Straffälligkeit als Ablehnungsgrund werden miteinander vermischt. Eine ebenso abzulehnende Vermischung zweier Voraussetzungen können wir auch feststellen, wo die deutschen Einbürgerungsrichtlinien betonen, daB ein Inlandsaufenthalt, der sich überwiegend unter Ausländern, z. B. in Ausländerwohnstätten abgespielt hat, in der Regel nicht auf die Aufenthaltsdauer anzurechnen ist. Hier findet eine Vermischung der geforderten Aufenthaltsdauer namentlich mit den "kulturellen" Voraussetzungen statt (siehe \$ 3.3.4.5 und 3.3.4.6). Von einem Ausländer, der überwiegend unter Ausländern lebt, ist ja kaum zu erwarten, daß er ausreichende Kenntnisse z.B. der Landessprache erwirbt; werden diese jedoch erworben, dann darf die Tatsache, daß er hauptsächlich in Ausländerwohnstätten lebte, kein Grund zur Zurüickweisung seines Einbürgerungsantrages sein (siehe weiter $\$ 3.3 .4 .6$ ).

Die britische Bestimmung, wonach die Zeit, die man im Inland als Inhaber eines diplomatischen Status verbrachte, nicht als Aufenthalt im Inland gilt, verdient m.E. ebenfalls keine Nachahmung. Eine solche Regelung wird keineswegs von den Fakultativprotokollen zu den Wiener Diplomaten- und Konsularabkommen aus 1961 und 1963 gefordert. Diese schreiben lediglich vor, daß die Mitglieder einer diplomatischen oder konsularischen Mission oder die zu ihrem Haushalt gehörenden Familienmitglieder nicht automatisch kraft den Rechtsyorschriften des Empfangsstaates dessen Staatsangehörigkeit erwerben dürfen. Über Erwerb der Staatsangehörigkeit auf Antrag sagen diese Protokolle nichts aus. Zu betonen ist, daß auch -vielleicht sogar gerade- die Zeit, die eine Person als Diplomat im Inland verbracht hat. durchaus geeignet ist, um sich in die soziokulturellen Eigentümlichkeiten eines Staates einzuleben. Es ist deshalb nicht realistisch, diese Zeit im Rahmen eines Einbürgerungsverfahren nicht zu berücksichtigen.

Auch die britische Bestimmung, die die in einer Anstalt für Geisteskranke verbrachte Zeit für die Berechnung der geforderten Aufenthaltsfrist nicht mitzählt, ist abzulehnen. Zwar ist die in der Anstalt verbrachte Zeit nicht freiwillig im Inland verbracht. Aber jene Zeit ist dennoch im Inland - sei es in einer etwas atypischen Umgebung - verbracht. Gerade für geistig weniger stabile Personen ist es aber von Bedeutung, nicht ins Ausland abgeschoben zu werden. Ein Krankheitsriickfall ist sonst wahrscheinlich. Wenn es diesen Personen jedoch weiterhin erlaubt wird, im Inland zu bleiben, ist nicht einzusehen, was dann noch einer Einbürgerung entgegenstände. Die Einbürgerung lediglich aufgrund der geistigen Labilität zu verweigern, hieße die Staatsangehörigkeit als Auszeichnung aufzufassen. Die Ansicht, die Staatsangehörigkeit als Auszeichnung anzusehe $\mathbf{n}$ habe, ich bereits in $\$ 1.3 .2$ abgelehnt (vgl. auch nachher die $\$ \$ 3.4 .5$ und 3.4.8). Man könnte in diesem Falle von einer unzulässigen Diskriminierung sprechen, die mit dem heutigen Menschenbild nicht übereinstimmt und damit gegen die Menschenrechte verstößt.

Auch wenn ein Einbürgerungsbewerber im Ausland lebt, kann u.U. doch eine so enge Beziehung zum Inland vorhanden sein, daß eine Einbürgerung berechtigt 
ist. Dies ist sicher bei Personen der Fall, die im Dienste eines Staates im Ausland leben und bei deren Ehegatten. Weiter ist dies der Fall bei einigen Gruppen ehemaliger Staatsangehöriger. Es ist deshalb durchaus angemessen gesetzlich zu bestimmen, daß hinsichtlich bestimmter Gruppen von Ausländem die Forderung des Inlandsaufenthaltes nicht gestellt wird. Daneben soll für Ausnahmefalle die Möglichkeit einer Einbürgerung ohne Inlandsaufenthalt offengehalten werden. In Belgien geschieht dies indem bestimmt wird, daß ein Aufenthalt im Ausland einem Aufenthalt in Belgien gleichgestellt wird, wenn der Betreffende nachweist, daß auch ohne Inlandswohnsitz zwischen ihm und Belgien enge Beziehungen entstanden sind. In den anderen Staaten gibt es eine derartige Klausel nicht. Wo aber - wie im niederländischen Staatsangehörigkeitsrecht eine generelle Möglichkeit zu einer Ermessenseinbürgerung besteht (Art.10 RwNed), kann von dieser Möglichkeit gerade dann Gebrauch gemacht werden, wenn deutlich ist, daß ein im Ausland lebender Einbürgerungsbewerber, der nicht unter die in Art. 8 Abs. 2 und 3 RwNed erwälnten Ausnahmekategorien fällt, doch eine so enge Beziehung zu den Niederlanden hat, daß eine Einbürgerung gerechtfertigt ist. Selbsverständlich sollten von diesem Erwerber die im übrigen geforderten Einbürgerungsvoraussetzungen erfüllt sein.

Eine letzte Bemerkung sei zu der niederländischen Regelung erlaubt, daß keine im Ausland lebende Person eingebürgert werden kann, die die Staatsangehörigkeit des Staates besitzt, in dem sie lebt. Die niederländische Regierung hat beim Zustandekommen des neuen Staatsangehörigkeitsgesetzes behauptet, dies wäre ein völkerrechtliches Prinzip. Diese Behauptung ist aber absolut unhaltbar. Eine solche völkerrechtliche Regel läßt sich nicht nachweisen. In keinem der völkerrechtlichen Verträge mit Bezug zu Staatsangehörigkeitsfragen und in keinem der hier betrachteten Staaten haben wir eine solche Regel finden können. Daß diese Behauptung der niederländischen Regierung gegenüber dem Parlament lediglich Teil eines "Pokerspiels" war, läßt sich übrigens auch schon dlaraus folgern, daß Art. 10 RwNed ausdrücklich die Möglichkeit gibt Ausnahmen von dieser angeblich völkerrechtlichen Regel zu gewähren. Art. 9 Abs. 1 Buchstabe c RwNed ist deshalb ersatzlos zu streichen.

\subsubsection{Fremdenrechtlicher Status}

In allen Staaten bestehen gewisse Beziehungen zwischen dem Einbürgerungsvoraussetzungen und dem Ausländerrecht. Dies ist nicht erstaunlich. Eine Einbürgerung von Personen, gegen die rechtskräftig eine Ausweisung angeordnet ist, wäre nicht denkbar. Dennoch sind die Beziehungen zwischen Einbürgerungsvoraussetzungen und Ausländerrecht sehr vielfältig. Diese Beziehungen sollen nun näher betrachtet werclen.

In den Niederlanden wird nicht gefordert, daß die ganze im Rahmen des Einbürgerungsverfahrens geforderte Wohnsitzdauer in Übereinstimmung mit den fremdenrechtlichen Regelungen stand. Dies muß jedoch im Zeitpunkt des Einbürgerungsantrages der Fall sein. In diesem Zeitpunkt dürfen keine Bedenken gegen den Aufenthalt des Antragstellers in den Niederlanden für unbestimmte Zeit bestehen (Art. 8 Abs. 1 Buchstabe b RwNed). Das heißt erstens, daß er in den Niederlanden nicht unter Verletzung der Fremdengesetzgebung leben darf. Aber weiter bildet die Formulierung "keine Bedenken gegen einen Aufenthalt für unbestimmte Zeit" in den Niederlanden auch einen weiteren impliziten 
Hinweis auf die Fremdengesetzgebung. Im Prinzip erfüllen nur Personen, die eine Niederlassungs- oder eine Aufenthaltsgenehmigung innehaben, die nicht für bestimmte Zwecke (wie Studienaufenthalt oder medizinische Behandlung) abgegeben war, diese Voraussetzung. Aus der Gesetzesgeschichte geht jedoch hervor, daB nicht beabsichtigt wurde, eine zwingende Beziehung zwischen Staatsangehörigkeits- und Ausländerrecht zu schaffen. Die Feststellung, daB keine Bedenken gegen einen Aufenthalt für unbestimmte Zeit in den Niederlanden bestehen, kann deshalb auch autonom von den Einbürgerungsbehörden getroffen werden.

Das belgische Staatsangehörigkeitsrecht stellt keine ausdrückliche Forderung hinsichtlich des fremdenrechtlichen Status eines Antragsstellers. Da aber der Einbürgerungsantrag aufgrund schwerwiegender persönlicher Fakten zurückgewiesen werden kann (Art. $15 \& 2$ Abs. 1 CNB), liegt es auf der Hand, daß Gründe, die dazu führen können, eine Aufenthalts- oder Niederlassungsgenehmigung zu verweigem oder gar einzuziehen, auch die Verweigerung der Einbürgerung bewirken können. In Deutschland wird nur eingebürgert, wenn ein öffentliches Interesse an der Einbürgerung besteht. Das ausschließliche Vorliegen der Mindestvoraussetzungen der $\$ 8$ und 9 RuStAG rechtfertigt eine Einbürgerung noch nicht (Einbürgerungsrichtlinien Nr. 2.2). Nr. 3.2.4 der Richtlinien betont, $\mathrm{da} \beta$ ein öffentliches Interesse an der Einbürgerung nur bejaht werden kann, wenn sich der Einbürgerungsbewerber rechtmäßig im Inland aufhält. Dies gilt jedenfalls ab dem Zeitpunkt der Stellung des Einbürgerungsantrages. Dabei ist nicht deutlich, ob der Einbürgerungsbewerber immer die ganze geforderte Aufenthaltdauer, rechtmäßig in Inland zugebracht haben muß. Richtlinie Nr, 3.2.1 erwähnt die Rechtmäßigkeit nicht ausdrücklich, wo sie die grundsätzliche Aufenthaltsdauer von zehn Jahren formuliert. Andere Richtlinien (z.B. $5.2 .3,5.2 .5 .2,5.2 .5 .3)$ fordern aber wohl ausdrücklich die Rechtmäßigkeit des Aufenthaltes.

In Frankreich wird durch Art. 65 CNF bestimmt, daß ein Ausländer, demgegenüber eine Ausweisungsverfügung oder eine Verfügung erlassen worden ist, durch die ihm der Aufenhaltsort vorgeschrieben wird, nicht eingebürgert werden kann, bevor eine solche Verfïgung wieder aufgehoben ist. AuBerdem wird, für die Dawer solcher Verwaltungsmaßnahmen, der Aufenthalt in Frankreich nicht bei der Berechnung der geforderten Dauer eines Inlandsaufenthaltes mitgezählt. Das französische Recht fordert jedoch nicht positiv, daß die ganze Aufenthaltsdauer in Übereinstimmung mit dem Fremdenrecht stand.

In Großbritannien wird gefordert, daß der Bewerber während der Dauer von fünf Jahren ohne Verletzung der Einwanderungsgesetze im Inland gelebt hat. Während des letzten Jahres darf der Aufenthalt keiner Einschränkung der Einwanderungsgesetzgebung unterliegen (Schedule 1, \&1 (2) Buchstabe $c$ und d). Italien kennt keine entsprechenden ausdrücklichen Vorschriften. In Österreich aber wird in $\$ 10 \mathrm{Abs}$. 1 Ziffer 5 StBG 1965 ausdrücklich verlangt, daB gegen einen Einbürgerungsbewerber kein Aufenthaltsverbot bestehen darf.

In der Schweiz bestimmt Art. 36 BüG ausdrücklich, daß als Wohnsitz im Sinne jenes Gesetzes für Ausländer nur Anwesenheit in der Schweiz in Übereinstimmung mit den fremdenpolizeirechtlichen Vorschriften gilt.

Das spanische Recht schreibt ebenfalls vor ${ }^{\text {daß }}$ der für die Einbürgerung geforderte Aufenthalt legal sein muB (Art. 22 C.c.esp.). Man kann in den verschiede- 
nen Regelungen also unterschiedliche Beziehungen zwischen Staatsangehörigkeits- und Fremdenrecht beobachten. Gegen den Einzubürgernden darf kein Aufenthaltsverbot bestehen. Dies gilt in den Niederlanden, Deutschland, Großbritannien, Frankreich, Österreich, Schweiz und Spanien und wohl - wenn auch nicht ausdrücklich formuliert - für Belgien und Italien. Diese Wechselbeziehung ist $\mathrm{zu}$ bejahen, weil das Fremdenrecht nicht auf dem Wege über das Staatsangehörigkeitsrecht, umgangen werden darf.

In einigen Staaten wird zudem ausdrücklich gefordert, daß der Aufenthalt während der gesamten geforderten Dauer rechtmäßig gewesen sein muß. Dies wird ausdrücklich in Großbritannien, Schweiz und Spanien verlangt und gilt wohl auch in der Bundesrepublik Deutschland. Für die Niederlande gilt diese Forderung zwar nicht, jedoch muß der Aufenthalt wohl im Augenblick der Stellung des Einbürgerungsantrages rechtmäßig sein. M.E. ist die Bedingung, daß3 der Aufenthalt z.Zt. des Einbürgerungsantrages rechtmäßig sein muß, zu bejahen. Lediglich das nicht Vorliegen eines Ausweisungsgebotes zu verlangen, könnte dazu führen, daß u.U. ein solches lediglich aus diesem Grund ausgefertigt wird. Falls aber der Aufenthalt des Einbürgerungsbewerbers zur Zeit des Antrages rechtmäßig ist, der Staat also seine Anwesenheit im Inland gutheißt, dann braucht $\mathrm{m} . \mathrm{E}$. nicht unbedingt gefordert zu werden, daß die ganze Periode des Inlandsaufenthaltes in Übereinstimmung mit den Einwanderungsgesetzen erfolgte. Wohl muß der Einbürgerungsbewerber selbstverständlich seinen Inlandsaufenthalt und eventuell dessen Ununterbrochenheit überzeugend nachweisen können und dies wird in der Regel nur möglich sein, wenn Aufenthalt in der Tat rechtmäßig war.

Großbritannien fordert zusätzlich, daß der Aufenthalt des Einbürgerungsbewerbers während des letzten Jahres vor dem Einbürgenungsantrag keiner Einschränkung aufgrund der Einwanderungsgesetzgebung unterlag. Die niederländische Regelung geht ebenfalls in diese Richtung, indem sie verlangt, daß keine $\mathrm{Be}-$ denken gegen einen zeitlich unbegrenzten Aufenthalt in den Niederlanden bestehen dürfen. Wir sahen bereits, daß dies ein impliziter Hinweis auf die Fremdengesetzgebung ist, da im Prinzip nur solche Personen diese Bedingung erfuillen, die eine Niederlassungsgenehmigung oder eine unbeschränkte Aufenthaltserlaubnis (d.h. eine Aufenthaltsgenehmigung, die nicht für bestimmte Zwecke abgegeben wurde) haben. Im niederländischen Recht ist diese Forderung übrigens so formuliert, daß sie auch von denjenigen erfüllt werden muß, die bei Auslandswohnsitz eingebürgert werden wollen. In der Regel werden solche Personen jedoch nicht über eine Niederlassungs- oder Aufenthaltsgenehmigung für die Niederlande verfügen; sie werden eine solche aber auch nicht benötigen, wenn sie sich nicht in den Niederlanden niederlassen wollen. Da aus der Gesetzesgeschichte herworgeht, daß man nicht beabsichtigte, eine zwingende Beziehung zwischen dem Staatsangehörigkeitsrecht und dem Fremdenrecht herzustellen, müssen wir annehmen, daß zugunsten solcher im Ausland wohnhaften Einbürgerungsbewerber auch auf "alternative Weise" festgestellt werden kann, ob gegen ihren zeitlich unbegrenzten Aufenthalt in den Niederlanden Bedenken bestehen. Die Möglichkeit einer solchen "alternativen" Feststellung, daß keine Bedenken gegen einen zeitlich unbegrenzten Aufenthalt des Antragsstellers bestehen, kann auch von Nutzen sein, wenn eine Person, die schon seit langer Zeit in den Niederlanden lebt, jedoch lediglich über eine zweckbestimmte Aufenthaltsgenehmigung (z.B. für Studienzwecke) verfügt, die Einbürgerung bean- 
tragt. Indessen ist nicht klar formuliert, welche Behörde die erwähnte "alternative" Unbedenklichkeitsfeststellung treffen darf. Man muß wohl annehmen, daß die Einbürgerungsbehörde diese Erklärung selbst im Rahmen des Eỉnbürgerungsverfahrens abgeben kann. Falls man annehmen würde, diese Feststellung könnte lediglich von der Fremdenbehörde getroffen werden, wäre wieder eine zwingende Verbindung zwischen Staatsangehörigkeits- und Fremdenrecht hergestellt, wie sie in den Motiwen zum Staatsangehörigkeitsgesetz ausdrücklich verneint wird.

Die eben beschriebene Forderung des niederländischen Rechts, im Rahmen des Einbürgerungsverfahrens müsse festgestellt werden, daß der zeitlich unbegrenzte Aufenthalt des Antragstellers in den Niederlanden unbedenklich ist, muB m.E. bejaht werden. Bestimmte Einbürgerungsanträge von im Ausland lebenden Personen (siehe \$ 3.3.4.9) ader in den Niederlanden lebenden Personen, die sich hier lediglich zu Studienzwecken aufhalten dürfen (siehe \$3.3.4.10), können aus diesem Grunde zurückgewiesen werden. Bei der Überprïfung, ob ein unbeschränkter Aufenthalt unbedenklich ist, können die Einbürgerungsbehördlen sich an den Bestimmungen des Fremdenrechts orientieren, sie sind aber daran nicht gebunden. Die britische Forderung, wonach eine Einbürgerung erst möglich ist, nachdem der Aufenthalt des Antragsstellers schon während eines Jahres keiner Einschränkung der Einwanderungsgesetzgebung unterlag, muß jedoch abgelehnt werden. Erstens bewirkt diese Forderung eine absolute Abhängigkeit der Einbürgerungsbehörde von der Fremdenbehörde und ist schon deshalb wenig gelungen. Zweitens aber ist uiberhaupt nicht ersichtlich welche Gründe für eine solche Regelung sprechen. Was kann mit dieser einjährigen Wartefrist nach. Feststellung der Unbedenklichkeit des unbeschränkten Aufenthalts noch bezweckt werden?

\subsubsection{Gesellschaftliche Eingliederung}

In den Niederlanden wird für Einbürgerung auch eine gesellschaftliche Eingliederung ("inburgering") gefordert. Diese Eingliederung muß sich nach Art. 8 Abs. 1 Buchstabe d RwNed an erster Stelle durch Kenntnis der Landessprache manifestieren (dazu $\$ 3.3 .4 .6$ ), aber der Betreffende muß daneben auch "in die niederländische Gesellschaft aufgenommen sein". Äußerst unbestimmt ist, was darunter zu verstehen ist. Diese mangelnde Konkretisierung wurde selbst von der niederländischen Regierung zugegeben (Motiven, S. 11, 12). Die gesellschaftliche Eingliederung könnte nach Äußerungen der Regierung aus der Mitgliedschaft in niederländischen Klubs, Vereinen oder Verbänden, aus der Ehe mit einem Niederländer oder ähnlichem gefolgert werden.

Eine gesellschaftliche Eingliederung oder etwas Vergleichbares wird im italienischen, österreichischen und spanischen Recht nicht ausdrücklich gefordert. Österreich verlangt aber in $\$ 10$ Abs. 1 Ziffer 6 StBG 1965 durchaus eine bejahende Einstellung des Bewerbers zur Republik Österreich (vgl. \$ 3.3.4.7), diese Bedingung muß jedoch wohl eher "politisch" verstanden werden.

Das belgische, deutsche, französische und in gewisser Hinsicht auch das britische und schweizerische Recht stellen für die Einbürgerung Anfordenungen, die mit der niederländischen Voraussetzung der gesellschaftlichen Eingliederung vergleichbar sind, und die im folgenden näher beschrieben werden sollen. Das belgische Recht fordert seit 1985 in art. $21 \S 1$ Abs. 2 i.V.m. Art. $15 \$ 2$ CNB 
einen "Eingliederungswillen" (volonté d'intégration). Dies weicht von der früheren belgischen Regelung $a b$, die eine "Eignung" (idoneité) forderte. Im Rahmen der Überprüfung dieser Eignung wurde namentlich auf "adaption" und "assimilation" großen Wert gelegt. Die heutige Bedingung ist schwächer; sie geht wenigstens formell - weniger weit als die des niederländischen Rechts, da lediglich der Eingliederungswille und nicht die Eingliederung sellbst gefordert wird. In der Praxis werden aber die belgische und niederländische Forderung sehr ähnlich konkretisiert.

In der Bundesrepublik Deutschland verlangt das RuStAG zwar nicht die gesellschaftliche Integrierung des Einbürgerungsbewerbers, die Einbürgerungsrichtlinien formulieren jedoch durchaus in Nr. 3.2.1 eine solche Forderung: Die Einordnung in die deutschen Lebenswerhältnisse. Gerade wegen dieser Voraussetzung wird in der Regel ein langjähriger Inlandsaufenthalt gefordert. Bemerkenswert ist, daß die Richtlinien vorschreiben, daß ein Inlandsaufenthalt, der überwiegend unter Ausländem - z.B. in Ausländerwohnstätten - erfolgte, in der Regel nicht auf die Aufenthaltsdauer anzurechnen sei (siehe dazu $\$ 3.3 .4 .3$ ). In einigen Fällen wird nicht die bereits geschehene Einordnung in die deutschen Lebensverhältnisse gefordert, sondern als ausreichend angesehen, wenn diese Einordnung mit Sicherheit zu erwarten ist (so Richtlinie 6.1.3 für ausländische Ehegatten von deutschen Bürgern). Gleiches gilt, wenn der Antragsteller willens und fähig zu sein scheint, sich in die deutschen Lebensverhältnisse einzuordnen (so Richtlinie 6.5.4 für Sondereinbürgerungen aufgrund von \& 1 der Verordnung zur Regelung von Staatsangehörigkeitsfragen). Im letzteren Falle betont die Richtlinie, daß der Einbürgerungswille, beziehungsweise die Einbürgerungsfähigkeit z.B. aus deutscher Volkszugehörigkeit, früherem längerem Inlandsaufenthalt, Besuch deutscher Schulen oder anderen Ausbildungsstätten, Zugehörigkeit zu deutschen Vereinen, Tätigkeit im deutschen öffentlichen Dienst oder in deutschen Unternehmen, Ehe mit einem deutschen Staatsangehörigen, oder besonderen Verdiensten für Deutschland gefolgert werden kann. In diesem Zusammenhang sei noch darauf hingewiesen, da $\mathrm{B}$ die deutschen Einbürgerungsrichtlinien in Nr. 3.1 ausdrücklich eine freiwillige und dauernde Hinwendung zu Deutschland, Grundkenntnisse der deutschen staatlichen Ordnung und ein Bekenntnis zur freiheitlichen demokratischen Grundordnung voraussetzen (siehe dazu auch $\S 3.3 .4 .7$ ). Zwischen diesen Forderungen und der verlangten Einordnung in die deutschen Lebensverhältnisse besteht ein enger Zusammenhang.

In Frankreich kann gemäß Art. 69 CNF niemand eingebürgert werden, der nicht seine Assimilierung mit der französischen Gemeinschaft nachweist, insbesondere durch genügende, seinen Fähigkeiten entsprechende Kenntnisse der französischen Sprache (Art. 71 CNF). Art. 31 der Durchführungsverordnung schreibt vor, daß namentlich auch "le degré de leur assimilation aux moeurs et aux usages de la France" festgestellt werden muß.

Das britische Recht kennt zwar nicht die Forderung einer "gesellschaftlichen Integration", aber es stellt eine andere außerordentlich vage Bedingung: der Einbürgerungsbewerber muß einen "good charakter" haben (siehe dazu auch \$3.3.4.7).

In der Schweiz fordert Art. 14 BüG lediglich, daß die Eignung des Einbürgerungsbewerbers geprüft wird. Im Gesetz wird dies nicht näher konkretisiert. Im 
Entwurf 1986 wird Art 14 jedoch genauer bestimmt: Gefordert wird, daB der Bewerber in die schweizerischen Verhältnisse eingegliedert ist, mit den schweizerischen Lebensgewohnheiten, Sitten und Gebräuchen sowie Wertvorstellungen vertraut ist; die öffentlichen und privaten Pflichten erfillt; die demokratische Rechtsordnung bejaht und die innere und äußere Sicherheit der Schweiz nicht gefährdet (vgl. auch Art. 18 und 26 (neu)). Eindeutig soll also im Rahmen der Eignungspriffung die gesellschaftliche Eingliederung kontrolliert werden. Viele schweizerische Kantone fordern auch nun schon ausdrücklich eine ausreichende Eingliederung und Assimilation (Solothurn, Basel-Land, Schaffhausen, Appenzell, Appenzell i.Rh., Graubünden, Aargau, Thurgau, Ticino, Vaud, Vallis, Neuchâtel, Genève) Andere Kantone verlangen - vielleicht noch wenig konkret eine enge Beziehung zur Schweiz (Zürich, Zug). Manche Kantone bestimmen auch ausdrücklich "Vertrautheit mit den örtlichen und schweizerischen Gegebenheiten" (Sichwyz, Unterwalden ob dem Wald, Zug) oder auch "Vertrautheit mit den staatlichen Einrichtungen" (Unterwalden ob dem Wald, Unterwalden nid dem Wald, Glarus, Basel-Stadt, Aargan, Vaud, Vallis).

Wenn wir die in diesem Abschnitt erwähnten Einbürgerungsvoraussetzungen betrachten, können wir jedenfalls eine Gemeinsamkeit feststellen: Sie sind vage und unbestimmt. Dieser Mangel an Konkretisierung wird in den betreffenden Staaten auch zugegeben. In rechtsvergleichender Sicht nimmt die Unsicherheit über den genauen Inhalt dieser unpräzisen Begriffe nur zu. Die Niederlande fordern eine gesellschaftliche Eingliederung ("inburgering"), Belgien verlangte früher die Eignung ("idoneitté") und überprüfte dabei die Assimilierung des Einbürgerungsbewerbers, nummehr erwartet Belgien aber einen Eingliederungswillen ("volonté d'integration"); Frankreich setzt immer noch eine Assimilierung ("assimilation") voraus; die Bundesrepublik Deutschland eine "Einordnung in die deutschen Lebensverhältnisse"; während in der Schweiz wieder die "Eignung" im Mittelpunkt steht, und in diesem Rahmen die Eingliederung in die schweizerischen Verhältnisse, Bekanntheit mit den schweizerischen Lebensgewohnheiten, Sitten, Gebräuchen und Wertvorstellungen, Erfüllung der öffentlichen und privaten Verpflichtungen und eine Bejahung der demokratischen Rechtsordnung kontrolliert.

Wie unklar diese Begriffe sind, kann anhand folgender Tatsachen näher illustriert werden. Das niederländische Recht fordert in Art. $8 \mathrm{RwNed}$ die "inburgerung" (gesellschaftliche Eingliederung) als Voraussetzung für die Einbürgerung. Von dieser Voraussetzung kann sogar über die Ausnahmebestimmung von Art. 10 nicht abgesehen werden. In Art. 12 RwNed wird aber die Möglichkeit gegeben, in der Einbürgerungsurkunde den Namen des Einzubürgernden zu ändern. Eine Namensänderung gemäß Art. 12 Abs. 2 RwNed kann stattfinden, wenn dies für die "inburgering" (gesellschaftliche Eingliederung) von Bedeutung ist. Aus dieser Terminologie geht hervor, daß Art. 12 RwNed davon ausgeht, daß die gesellschaftliche Eingliederung im Augenblick der Einbürgerung noch nicht abgeschlossen zu sein braucht, während Art. 8 RwNed für die Einbürgerung gerade die bereits abgeschlossene gesellschaftliche Eingliederung voraussetzt. Es ist weiter bemerkenswert, $\mathrm{da}$ Belgien nicht die bereits abgeschlossene gesellschaftliche Eingliederung fordert, sondern lediglich einen Eingliederungswillen. Wenn man aber in den belgischen und niederländischen Gesetzesmotiven nachschlägt, welche prüfungsrelevanten Tatsachen aufgefiuhrt werden, anhand deren die gesellschaftliche Eingliederung, beziehungsweise der Eingliederungswille 
festzustellen ist, so zeigt sich, daß in Belgien und in den Niederlanden vergleichbare Tatsachen beachtet werden, namentlich Mitgliedschaft in Clubs, Vereinen, Verbänden u.s.w.

Betrachtet man die mit der Forderung der gesellschaftlichen Eingliederung zusammenhängenden Voraussetzungen näher, kann man grosso modo folgende Kategorien unterscheiden: Erstens werden allgemein gewisse Kenntnisse der Landessprache gefordert. Zweitens wird überprüft, ob zu den Bürgern des Staatses, dessen Staatsangehörigkeit begehrt wird, tatsächliche soziale Beziehungen bestehen. Drittens werden manchmal bestimmte Kenntnisse über die politischen und sozialen Verhältnisse des Staates gefordert, dessen Staatsangehörigkeit erworben werden soll. Und wiertens wird manchmal eine gewisse politische Einstellung diesem Staate gegenüber verlangt.

Zu diesen Voraussetzungen möchte ich folgendes bemerken. Es ist durchaus vernünftig, und angemessen für die Einbürgerung grundsätzlich Sprachkenntnisse zu fordern, um eine gewisse Kommunikationsfähigkeit des neuen Bürgers mit den übrigen Bürgern des Staates zu garantieren. Erworbene Kenntnisse der Landessprache sind selbstverständlich eine Manifestierung einer (teilweisen) gesellschaftlichen Eingliederung. M.E. sollte diese Forderung aber dennoch nicht im Rahmen der vagen Voraussetzung der gesellschaftlichen Eingliederung, sondern von dieser losgelöst gestellt werden. Es ist für einen Einbürgerungsbewerber wünschenswert, daß die Einbürgerungsvoraussetzungen klar und übersichtlich im Gesetz formuliert werden und sich möglichst nicht iiberschneiden (siehe weiter $\$ 3.3 .4 .6$ ).

Die Forderung, daß der Einbürgerungskandidat bestimmte soziale Beziehungen zu den Bürgern des Staates hat, dessen Staatsangehörigkeit er begehrt, ist zu wenig konkret. Es ist in der heutigen bürokratischen Gesellschaft kaum möglich, um als Eremit zu leben, und falls jemand dies dennoch schafft, wird er in der Regel nicht einmal grundlegende Sprachkenntnisse nachweisen können.

Weiterhin ist selbstverständlich wünschenswert, daß die Bürger eines Staates Grundkenntnisse über die politischen und sozialen Verhältnisse ihres Staates besitzen. Dennoch ist es m.E. fraglich, ob diese Kenntnisse im Rahmen der Einbürgerung zu fordern sind. Wir müssen leider feststellen, daß selbst viele Personen, die als Staatsangehörige geboren warden, diese Kenntnisse nicht besitzen. Deshalb ist nicht einzusehen, weshalb im Rahmen des Einbürgerungsverfahrens eine Bedingung gestellt werden soll, die nicht einmal manche als Staatsangehörige geborene Personen erfüllen. Wenn man in der Tat für die Einbürgerung bestimmte Kenntnisse fordern möchte, so läge es auf der Hand, in das Einbürgerungsverfahrens ein regelrechtes "Einbürgerungsexamen" einzubauen. Dies würde aber meiner Auffassung von der Staatsangehörigkeit als leerer Anknüpfungsbegriff (siehe oben \$1.3) keineswegs entsprechen. Aus westeuropäischer Sicht ist die Staatsangehörigkeit nicht mit der Staatsbürgerschaft identisch, wie z.B. in osteuropäischen Staaten vertreten wird. Es paBt deshalb nicht, als Voraussetzung für den Erwerb der Staatsangehörigkeit eine Forderung zu stellen, die theoretisch lediglich als Voraussetzung für Erwerb der Staatsbürgerschaft angemessen sein würde, aber nicht einmal dort gestellt wird. Schließlich sei darauf hingewiesen, daß die Forderung nach bestimmten staatsbürgerlichen Kenntnisse für die Einbürgerung auch deshalb seltsam erscheint, 
weil in einigen Staaten Ausländern nach einer gewissen Aufenthaltsdauer im Inland zumindest auf Kommunalebene bereits ein Wahlrecht zugestanden wird. Die Forderung nach staatsbürgerlichen Kenntnissen im Rahmen des Einbürgerungsverfahrens erfolgt in diesen Staaten deshalb verspätet. Auch das Verlangen nach Bejahung der Rechtsordnung des Staates, dessen Staatsangehörigkeit man erwerben möchte sollte nicht im Rahmen der Forderung der gesellschaftlichen Integrierung gestellt werden. Erstens ist fraglich, ob eine solche ausdrückliche Bejahung der Rechtsordnung überhaupt gefordert werden soll oder ob es nicht genügt zu bestimmen, daß der Betreffende nicht wegen einschlägiger Straftaten verurteilt sein darf (siehe dazu $\$ 3.3 .4 .7$ ). Gleich wie man diese Frage auch beantworten möchte, in jedem Fall erscheint es besser, diese mit der öffentlichen Ordnung und Staatssicherheit zusammenhängende Bedingung nicht im Rahmen einer Überprüfung der Eingliederung zu stellen. Das Verfahren bleibt dann übersichtlicher; Überschneidungen mit anderen Forderungen werden dadurch vorgebeugt. Ergebnis dieser Betrachtungen ist deshalb, daß die Einbürgerungsvoraussetzung der gesellschaftlichen Integrierung m.E. zu streichen ist. Gewisse Sprachkenntnisse jedoch sollten selbständlich gefordert werden.

\subsubsection{Kenntnis der Landessprache}

Eine tatsächliche Beziehung zu einem Staat kann im allgemeinen nur dann entstehen, wenn man im Stande ist, mit den Bürgern dieses Staates in der Landessprache zu verkehren. Regelmäßig sind deshalb gewisse Sprachkenntnisse eine nicht unerhebliche Voraussetzung für die Verleihung der Staatsangehörigkeit. Es fält dabei auf, daß diese Sprachkenntnisse fast immer, im Rahmen der im vorigen Abschnitt abgelehnten, allgemein formulierten Voraussetzung der gesellschaftlichen Eingliederung überprifft werden. Lediglich in Großbritannien werden gewisse Sprachkenntnisse als selbständiges Erfordernis formuliert; im vorigen Abschnitt habe ich bereits befürwortet, daß dies auch in den anderen Staaten geschehen sollte.

Art. 8 Abs. 1 Buchstabe d RwNed fordert, daß jemand, der seine Einbürgerung beantragt, ausreichende Kenntnisse der niederländischen Sprache für eine einfache Konversation besitzt. In einigen Ausnahmefällen reicht füir in den Niederländischen Antillen oder Aruba wohnhafte Bewerber auch die Kenntnisse in bestimmten anderen Sprachen (Papiamento beziehungsweise Englisch) aus. Diese Sprachkenntnisse werden in der Regel durch ein "Gespräch" mit einem Beamten geprüft.

Das belgische Staatsangehörigkeitsgesetz fordert nicht ausdrücklich die Kenntnis einer der Landessprachen. Im Rahmen der Überprüfung des von Art. 21 \& 1 Abs. 2 CNB geforderten Eingliederungswillens spielt diese dennoch eine wichtige Rolle.

Das deutsche RuStAG fordert ebenfalls nicht ausdrücklich die Kenntnis der deutschen Sprache; in den Einbürgerungsrichtlinien wird jedoch verlangt, daß ein Einbürgerungsbewerber die deutsche Sprache in Wort und Schrift in dem Umfang beherrscht, wie dies von Personen seines Lebenskreises erwartet werden kann (Richtlinie 3.1.1). Betont wird aber, daB bei älteren Einbürgerungsbewerbem deren Bildungsstand und gewisse altersbedingte Schwierigkeiten, die deutsche Sprache zu erlernen, berücksichtigt werden, insbesondere dann wenn 
die übrigen Familienangehörigen des Bewerbers die deutsche Sprache hinreichend beherrschen, und die Einbürgerung der gesamten Familie wünschenswert erscheint.

In Frankreich fordert Art. 69 CNF ausdrücklich Kenntnisse der französischen Sprache (vgl. Art. 71 CNF und Art. 31 der Durchführungsverordnung) und zwar als Manifestierung der Assimilierung.

Im allgemeinen wird in Großbritannien erwartet, daß ein Einbürgerungskandidat die englische, schottische oder walische Sprache beherrscht (Schedule 1, Sec. 1 (1) c). Die Sprachkenntnisse müssen für eine normale Unterhaltung mit anderen Bürgern ausreichen. Eine Beherrschung der Schriftsprache wird nicht verlangt. Wegen des Alters oder der körperlichen oder geistigen Verfassung des Betreffenden kann von der Forderung nach Beherrschung einer der Landessprachen abgesehen werden (Schedule 1, Sect. 2 (e)). Von dem ausländischen Ehepartner eines britischen Staatsangehörigen werden keine Sprachkenntnisse gefordert. In Großbritannien werden die Sprachkenntnisse im allgemeinen durch ein Gespräch mit einem gewöhnlichen Polizisten überprüft.

Auch in der Schweiz wird wohl kaum eine Eignung für die Einbürgerung (Art. 14 BüG) angenommen, wenn der Bewerber keine der schweizerischen Amtssprachen beherrscht. Dennoch wird auch in der im Entwurf 1986 vorgeschlagenen Neufassung die Beherrschung einer dieser Sprachen nicht ausdrücklich zur Bedingung gemacht. In den Vorschriften einiger Kantone (Zürich, Vallis und Neuchâtel) wird aber eine sprachliche Anpassung ausdrücklich vorausgesetzt. In insgesamt 20 Kantonen wird die Kenntnis der Amtssprache als ein wichtiges Beurteilungskriterium angesehen.

Obwohl der spanische Código civil nicht ausdrücklich fordert, daß ein Einbürgerungsbewerber die spanische Sprache beherrscht, sind solche Sprachkenntnisse im Rahmen des Einbuirgerungsverfahrens erheblich. Dies geht aus Art. 220 des Reglemento para aplicación de la Ley de Registro civil hervor (93). Unter Ziffer 5 dieses Artikels wird vorgeschrieben, daß im Einbürgetungsantrag erwähnt werden muß der Einbürgerungserwerber die kastilische oder eine andere spanische Sprache spricht.

In der österreichischen und italienischen Gesetzgebung werden die Sprachkenntnisse von Einbürgerungsbewerbern nicht ausdrïicklich erwähnt.

Die geforderten Kenntnisse sind am weitreichendsten in der Bundesrepublik Deutschland formuliert; dort wird in den Einbürgerungsrichtlinien ausdrücklich die mündliche und schriftliche Beherrschung der Sprache vom Einbürgerungsbewerber vorausgesetzt und zwar in einem Umfang, wie dies von Personen seines Lebenskreises erwartet wird. Dies Erfordernis geht wesentlich weiter als die z.B. in den Niederlanden und Großbritannien gestellte Forderung, daß die Sprachkenntnisse für eine normale Unterhaltung mit anderen Bürgern ausreichen müssen. Die deutsche Bedingung ist daher wohl zu streng formuliert. Sie könnte dahingehend interpretiert werden, daB z..B. von ausländischen Akademikern ein nahezu perfektes -in linguistischer Terminologie "elaboriertes"- Deutsch gefordert werden sollte. $\mathrm{Ob}$ diese Personen aber im Stande sind, in Deutschland ein so gutes Deutsch zu erlernen, hängt nicht allein von ihrer gesellschaftlichen Umgebung und Eingliederung ab, sondern auch - und vielmehr - von ihrer 
Sprachenbegabung. In diesem Zusammenhang ist übrigens zu bedenken, daß sicherlich auch viele Deutsche kein perfektes Deutsch beherrschen.

Bemerkenswert ist daneben, daß in den Niederlanden und Großbritannien nicht ausnahmslos die Beherrschung der offiziellen Landessprache, des niederländischen beziehungsweise des englischen, gefordert wird. Für die in den Niederländischen Antillen oder Aruba wohnhaften Einbürgerungsbewerber reichen mitunter auch Kenntnisse des Papiamento oder des Englischen aus, während in GroBbritannien die Beherrschung der schottischen oder walisischen Sprache ausreicht, wenn ein Ausländer in Schottland oder Wales lebt. Diese Nuanzierung der Forderung nach Sprachkenntnissen entspricht dem eigentlichen Zweck dieser Bedingung, nämlich die Kommunikationsfähigkeit des Bewerbers mit Bürgern des Staates, dessen Staatsangehörigkeit angestrebt wird, zu überprüfen. Unter dem Aspekt dieser Zielsetzung ist es m.E. gerechtfertigt, nicht stets die Beherrschung der Amtssprache zu fordern, sondern der Art und Weise wie diese Sprache in bestimmten Teilen eines Landes gesprochen wird, Rechnung zu tragen; denn für eine Kommunikationsfähigkeit reicht stets auch die Beherrschung des Dialektes aus, der in der als Wohnsitz angestrebten Region gesprochen wird.

Es fällt schließlich auf, daß jedenfalls in Großbritannien die Sprachkenntnisse des Einbürgenungsbewerbers durch ein Gespräch mit einem Polizeibeamten geprüft werden. Dabei ist es aber m.E. fraglich, ob ein beliebiger Polizist ein geeigneter Examinator für Sprachkenntnisse ist. Es wäre besser, mit dieser UTberprüfung eine andere Behörde zu beauftragen.

\subsubsection{Keine Gefährdung der öffentlichen Ordnung}

Sämtliche Staaten sehen vor, Einbürgerungsanträge aus Gründen einer Gefahr für die öffentliche Ordnung zurückweisen zu können. Die Art und Weise, wie dieser Verweigerungsgrund formuliert ist, variiert aber stark. Auffallend ist, daB manche Staaten lediglich einen Abweisungsgrund formulieren, während andere "positive" Forderungen aufstellen, wie z.B. einen guten Leumund oder eine Bejahung der demokratischen Rechtsordnung. Die entsprechenden Regelungen sollen hier nun verglichen werden.

Aufgrund des Art. 9 Abs. 1 Buchstabe a RwNed wird ein Einbürgerungsantrag zurückgewiesen, wenn aufgrund des Verhaltens des Antragstellers emsthafte Verdachtsgründe bestehen, daß er die öffentliche Ordnung, die guten Sitten, die Volksgesundheit oder die Sicherheit des Königreiches gefährden wird. In diesem Zusammenhang darf -gemäßs den Motiven- unter Gefährdung der Volksgesundheit nicht etwa das Übertragen gefährticher Bazillen usw. verstanden werden; es sind vielmehr Drogenhändler und ähnliche Personen gemeint. Denjenigen gegenüber, die die niederländische Staatsangehörigkeit als Minderjährige verloren haben, sind diese Verweigerungsgründe jedoch laut Art. 9 Abs. 2 RwNed nur begrenzt wirksam. Die (Wieder-)Einbürgerung dieser Personen darf ausschließlich dann verweigert werden, wenn der Betreffende in den zehn, dem Antrag vorausgehenden Jahren wegen einer Straftat gegen die Sicherheit des Königreiches oder wegen anderer Delikte zu einer Gefängnisstrafe von mindestens 5 Jahre verurteilt ist wegen einer anderen Straftat. 
Das belgische Recht sieht in Art. $21 \S \rrbracket$ Abs. 2 i.V.m. Art. $15 \S 2$ CNB vor, $\mathrm{da} B$ ein Einbürgerungsantrag aufgrund schwerwiegender persönlicher Gründe zurückgewiesen werden kann.

In Deutschland wird in den Einbürgerungsrichtlinien (Nr. 3.1.2) gefordert, daß der Einbürgerungsanwärter nach seinem Verhalten in Vergangenheit und Gegenwart Gewähr dafiir bietet, daß er sich zur freiheitlichen demokratischen Grundordnung bekennt und für ihre Erhaltung eintreten wird. Betont wird, daB Personen, die in innerer Abhängigkeit zu totalitären Ideologien stehen, die Einbürgerung zu versagen ist. $\$ 8$ Abs. 1 Ziffer 2 RuStAG fordert einen unbescholtenen Lebenswandel des Einzubürgernden. Diese Bedingung wird in den Richtlinien unter Nr. 3.3 näher erläutert. Dabei wird darauf hingewiesen, daß die Lebensführung nicht ausschließlich unter strafrechtlichen Gesichtpunkten zu beurteilen ist: "Die Feststellung, daß über den Einbürgerungsbewerber Nachteiliges nicht bekannt geworden ist, genügt für sich allein nicht. Bei der Prüfung müssen vielmehr Feststellungen getroffen werden, die Aufschlüße über den Lebensweg und das Persönlichkeitsbild des Einbürgerungsbewerbers geben". Strafrechtliche Verurteilungen bilden in der Regel ein Einbuirgerungshindernis; bei geringfïgigen oder längere Zeit zurückliegenden Strafen kann aber über diese hinweggesehen werden. Wiederholte Ordnungswidrigkeiten schließen eine Einbï̈gerung aus, "wenn aus der Art und der Häufigkeit der Rechtsverstöße zu schließen ist, daß der Einbuirgerungsbewerber nachhaltig die Rechtsordnung mißachtet hat. Ausdruicklich schreiben die Richtlinien vor, daß Fehlentwicklungen der Persönlichkeit, wie Alkohol- oder Rauschmittelsucht, fortdauernde Verletzung der Unterhaltspflicht und Arbeitsunwilligkeit die Einbürgerung ausschließen.

In Großbritannien wird gefordert, daß der Antragsteller einen "good character" hat (Schedule 1, Par, 1 (1) b). Im Rahmen der Überprüfung des Charakters wird primär auf strafrechtliche Verurteilungen geachtet. Auch ernsthafte Verdachtsgründe krimineller Aktivitäten genügen bereits, um eine Einbürgerung zu verweigern, ebenso wie "financial irresponsability", "commercial malpractices" und ähnliches. "Scandalous sexual misbehaviour" oder "heavy drinking, gambling or a disinclination to work" führen jedoch nur in Ausnahmefällen zu einer Abweisung eines Einbürgerungsantrages.

Der französische CNF betont in Art. 68, daß niemand eingebürgert werden kann, der nicht "de bonne vie et moeurs" ist oder wegen in Art. 79 CNF genannter Delikte verurteilt worden ist. Es handelt sich dabei um alle Verbrechen (crimes), um Vergehen (délits) gegen die Sicherheit des Staates, und um mehrere andere, spezifisch genannte, Vergehen wie Diebstahl, Betrug und ähnliche. Eine Verurteilung zu einer Strafe von mehr als sechs Monaten schließt stets eine Einbürgerung aus, auch wenn es sich um ein nicht in Art. 79 CNF spezifiziertes Vergehen handelt.

Art. 4 L.c. schreibt nicht ausdrücklich vor, daß ein Einbürgerungsantrag aus Gründen der Gefahr für die öffentliche Ordnung zurückgewiesen werden kann. Die Zulässigkeit einer Optionserklärung aufgrund des Gesetzes Nr. 123 vom 21. April 1983 ist jedoch wohl in diesem Sinne klausuliert. Man kann deshalb durchaus unterstellen, daß die in Art. 2 dieses Gesetzes formulierten Gründe im Sinne des Art. 4 L.c. ebenfalls eine Einbürgerung unmöglich machen. Es han- 
delt sich dabei um Verurteilungen aufgrund von Delikten gegen die Sicherheit des Staates beziehungsweise um Verurteilungen zu einer Freiheitsstrafe won mehr als zwei Jahren aus anderen Gründen.

Osterreich fordert in \$10 Abs. 1 Ziffer $6 \mathrm{StBG} 1965$, daß der Antragsteller nach seinem bisherigen Verhalten Gewähr dafür bietet, daß er zur Republik Österreich bejahend eingestellt ist und keine Gefahr für die öffentliche Ruhe, Ordnung oder Sicherheit darstellt. In $\$ 10$ Abs. 1 Ziffer 2 bis 4 StBG i.d.F. 1983 wird ausführlich aufgeschlüsselt, welche strafrechtliche Verurteilungen eine Einbürgerung ausschließen.

In der Schweiz wird im Rahmen der allgemeinen Eignungsüberprüfung u.a. auch kontrolliert, ob der Bewerber die demokratische Rechtsordnung bejaht und die innere und äuf̉ere Sicherheit der Schweiz nicht gefährdet (so ausdruicklich: Art. 14 Buchstabe d Entwurf 1986). Einige Kantone (Zürich, Uri, Basel-Stadt) fordern ausdrücklich Bejahung der verfassungsmäßigen Ordnung. Fast alle Kantone verlangen z.B. eine einwandfreie Lebensführung, tadellosen Leumund, bürgerliche Ehrenfähigkeit, einen einwandfreien Charakter oder einen unbescholtenen Ruf. Einige Kantone setzen voraus, daß der Bewerber ïberhaupt nicht wegen eines Delikts verurteilt sein darf (ausdrücklich: Vaud, Genève).

In Spanien kann die Einbürgerung aus Gründen der öffentlichen Ordnung oder des nationalen Interesses verweigert werden (Art. 22 Abs. 1 C.c.esp.).

Wie bereits in $\$ 3.3 .4 .5$ hinsichtlich der Forderung der gesellschaftlichen Eingliederung dargestellt, kann auch hinsichtlich der mit der offentlichen Ordnung zusammenhängenden Verweigerungsgründe eine nur sehr geringe Konkretisering der Formulierungen in den Staatsangehörigkeitgesetzen der verschiedenen Staaten konstatiert werden. M.E. entsprechen solche vagen Verweigerungsgründe, basierend auf den Begriff der öffentlichen Ordnung, nicht einem modernen Staatsangehörigkeitsrecht. Wir fassen in Westeuropa die Staatsangehörigkeit als einen leeren Koppelungsbegriff auf (siehe \$ 1.3) und nicht - wie es früher bei uns der Fall war und heute in Osteuropa noch der Fall ist - als Auszeichnung eines Bürgers. Dann aber ist nicht einzusehen, weshalb einem Ausländer die Staatsangehörigkeit verweigert werden soll, allein weil er nicht dem Idealbild eines Bürgers entspricht, also gemäß den herrschenden Auffassungen nicht in allen Hinsichten eine "bonne vie et moeurs" hat oder vielleicht der herrschenden Ordnung gegenúber kritischer eingestellt ist, als die Regierung eines Landes dies als angenehm empfindet. Es ist aus der Sicht einer modernen Staatsangehörigkeitsauffassung nicht mehr gerechtfertigt zu fordern, daß ein neuer Bürger besser und tugendhafter sein soll als viele Personen, die bereits kraft Geburt die betreffende Staatsangehörigkeit erworben haben. Nicht zu vertreten ist, daß jemand zwar weiterhin eine Aufenthaltserlaubnis oder gar eine Niederlassungsgenehmigung hat, um im Inland $z u$ verbleiben, ihm aber die Einbürgerung aus Gründen der öffentlichen Ordnung verweigert wird.

Diese These besagt jedoch nicht, daß eine Einbürgerung niemals aus Gründen, die mit der öffentlichen Ordnung verknüpft sind, verweigert werden darf. Es soll lediglich der Anwendungsbereich der Versagungsgründe reduziert werden. Die Einbürgerung soll ausschließlich dann abgelehnt werden, wenn der Antragsteller wegen bestimmter Straftaten verurteilt worden ist. Wenn im Zeitpunkt der Überprüfung eines Einbürgerungsantrages noch ein Strafverfahren anhängig 
ist, sollte die Möglichkeit bestehen, das Einbürgerungsverfahren zunächst auszusetzen. Die niederländische Regelung entspricht dieser Ansicht keineswegs. AuBer im Falle der Wiedereinbürgerung won Personen, die als Minderjährige die niederländische Staatsangehörigkeit verloren haben, kann die Einbürgerung schon verweigert werden, wenn ernsthafte Verdachtsgründe bestehen, da $B$ der Einbürgerungsbewerber die öffentliche Ordnung, die guten Sitten, die Volksgesundheit oder die Sicherheit des Königreiches gefährden könnte. In den Motiven zu dieser Gesetzesbestimmung wird darauf hingewiesen, die Einbürgerung sei schon dann zu versagen, wenn sich der Bewerber in der Zukunft möglicherweise so verhalten könnte, $\mathrm{da} B$ ihm als Ausländer eine Niederlassungsgenehmigung verweigert wird. Hat sich jedoch ein Einbiurgerungsbewerber in der geforderten Aufenhaltsfrist nicht in der Weise strafbar gemacht, daß er ausgewiesen hätte werden können, geht m.E. eine solche Zurückweisung des Einbürgerungsantrages aufgrund möglicher zukünftiger stafbarer Handlungen wesentlich $\mathrm{zu}$ weit. Eine solche Verweigerung manifestiert Rudimente der Auffassung, wonach eine Einbürgerung doch eine Art von Auszeichnung darstellt.

M.E. empfiehlt es sich in das Staatsangehörigkeitsgesetz eine Regelung aufzunehmen, die die Versagung der Einbürgerung ermöglicht, wenn der Antragsteller innerhalb einer dem Antrag vorangehenden Frist von etwa zehn Jahren wegen bestimmter Delikte verurteilt worden ist oder eine solche Verurteilung während des Einbürgerungsverfahrens folgt. Bei der Aufschlüsselung dieser Delikte können die Regelungen des Art. 79 CNF oder $\$ 10$ Abs. 1 Ziffer 2-4 StBG als Vorbild dienen. Zum Vergleich kann ebenfalls Art. 2 des italienischen Gesetzes vom 21. April 1983 herangezogen werden. Um nun die Einbürgerung von Ausländern, die in den Niederlanden zo langen Freiheitsstrafen verurteilt worden sind, zu verhindern, muB eine solche Vorschrift noch dahingehend ergänzt werden, daß auch solche Personen nicht eingebürgert werden können, die sich zur Zeit der Stellung ihres Einbürgerungsantrages aufgrund eines mehr als zehn Jahre zurückliegenden Urteils in einer niederländischen Strafanstalt aufhalten.

Für Personen, die als Minderjährige die Statsangehörigkeit verloren haben, muß die heutige Regelung des Art. 9 Abs. 2 RwNed grundsätzlich beibehalten werden, weil diese dem Art. 5 Abs. 2 des New Yorker Abkommens von 1961 entspricht. In einer Hinsicht bedarf diese Bestimmung m.E. aber einer Ergänzung. Dem Wortlaut dieses Absatzes nach könnte ein Einbürgerungsantrag nicht zurückgewiesen werden, wenn der Antragsteller während des Einbürgerungsverfahrens zu einer Gefängnisstrafe von mehr als fünf Jahren verurteilt wird. Art. 9 Abs. 2 sollte m.E. deshalb dahingehend ergänzt werden, daß auch in diesem Falle eine Zurückweisung des Antrages möglich ist. Das erwähnte New Yorker Abkommen steht einer solchen Änderung nicht entgegen.

Aus dem vorherigen geht schon hervor, daß ich auch die mit der öffentlichen Ordnung zusammenhä̈ngenden Formulierungen der übrigen Rechtssysteme ablehne. Die belgische Fassung, wonach ein Einbürgerungsantrag aus schwerwiegenden persönlichen Gründen zurückgewiesen werden kann, mangelt es ebenfalls an ausreichender Konkretisierung. Diese schwerwiegenden Gründe dürfen $\mathrm{m}$.E. ausschließlich strafrechtliche Verurteilungen betreffen. Das französische Recht lehne ich insoweit ab, als neben der Voraussetzung, daß der Einbürgerungsbewerber nicht wegen der in Art. $79 \mathrm{CNF}$ genannten strafrechtlichen Delikte verurteilt worden ist, noch zusätzlich eine "bonne vie et moeurs" gefordert 
wird. Die erste Voraussetzung bietet m.E. hinreichenden Schutz. Auch die Forderung des britischen Rechts nach einem "good character" des Bewerbers ist nicht in anwendungsfähiger Weise konkretisiert. Im deutschen Recht lehne ich die Bedingung $a b$, der Einbürgerungsanwärter müsse die freiheitlich demokratische Grundordnung bejahen. Die ausdrückliche Bejahung der freiheitlichen demokratischen Grundordnung, sowie der Wille, für ihre Erhaltung einzutreten, wird ansonsten nur von Beamten verlangt und selbst hierzu gibt es kritische Stimmen. Dieses Erfordernis bereits an die zukünftigen "Neubürger" zu stellen, erscheint mir den Bogen doch weit zu überspannen. Dies gilt unsomehr als die Erfahrungen mit dem sogenannten "Radikalenerlaß" gezeigt haben, wie schwierig sich doch eine solche Anforderung wie die "Bejahung der freiheitlichen demokratischen Grundordnung" in konkrete, juristisch verantwortete Kriterienfassen läßt.

Solange eine Person die Ablehnung nicht durch Straftaten manifestiert hat, sollte eine Einbürgerung nicht aus diesem Grunde verweigert werden. Wesentlich zu weit geht m.E. das deutsche Recht auch insofern wiederholte Ordnungswidrigkeiten ein Ablehnungsgrund sein können. Das gleiche gillt für die Regelung, daß Fehlentwicklungen der Persönlichkeit die Ablehnung einer Einbürgerung bewirken können. Im italienischen Recht sind m.E. zumindest in Art. 2 des Gesetzes vom 21. April 1983 die Ablehnungsgründe ausreichend konkretisiert. Das gleiche gilt auch für $\S 10$ Abs. 2 Ziffer 2 bis 4 des österreichischen StBG. Neben dieser Formulierung sehe ich aber keinen Sinn und Zweck in der Formulierung des $\$ 10$ Abs. 2 Ziffer 6 StBG. Schließlich wären im schweizerischen und spanischen Recht die Ablehnungsgründe erheblich genauer zu konkretisieren.

\subsubsection{Verlust der bisherigen Staatsangehörigkeit}

Nach niederländischem Recht wird für eine Einbürgerung in der Regel gefordert, da 3 der Antragsteller entweder durch den Erwerb der niederländischen Staatsangehörigkeit seine bisherige Staatsangehörigkeit automatisch verliert beziehungsweise seinerseits die erforderlichen Schritte für deren Verlust unternommen hat, oder nach Erwerb der niederländischen Staatsangehörigkeit zu unternehmen bereit ist. Von dieser Forderung wird nur dann abgesehen, wenn es billigerweise, wie z.B. bei politischen Flüchtlingen oder bei Gefahr einer erheblichen finanziellen Schädigung durch den Verlust der bisherigen Staatsangehörigkeit nicht verlangt werden kann. Vergleichbare Regelungen kennen Deutschland, Österreich, Schweiz, Spanien und wohl auch Italien. Diese Regelungen sollen nun näher beschrieben werden.

Im deutschen Recht wird vorgeschrieben, daß eine Einbürgerung nur vollzogen werden soll, wenn nachgewiesen wird, daß der Einbürgerungsbewerber spätestens mit der Einbürgerung seine bisherige Staatsangehörigkeit verliert. Ausnahmen kommen nur in Betracht, wenn die Versagung der Einbürgerung wegen drohender Mehrstaatlichkeit eine unzumutbare Härte darstellen würde. Betont wird dabei, daß dem Betreffenden u.U. durchaus mehrjährige Wartefristen bei Entlassungsanträgen zuzumuten sind. Zumutbar sind - so die Richtlinien - ferner wirtschaftliche Nachteile im Heimatstaat (z.B. Erbrechtsbeschränkungen oder die Auflage, Grundbesitz zu veräußem). In den Nr. 5.3.3.1 bis 5.3.7. der Richtlinien werden mehrere Ausnahmefälle aufgeführt. Von diesen Ausnahmen ist Nr. 
5.3.3.7 besonders erwähnenswert. Vom Einbiirgerungshindernis wegen eintretender Mehrstaatlichkeit kann abgesehen werden, wenn der Einbürgerungsbewerber zwar die Verweigerung der Entlassung zu vertreten hat, sich aber schon langer als zwanzig Jahre nicht mehr in seinem Heimatstaat aufgehalten, davon mindestens zehn Jahre im deutschen Bundesgebiet gelebt hat und über vierzig Jahre alt ist.

Im italienischen Recht fordert Art. 4 L.c. für Einbürgerung als Italliener nicht ausdrücklich den Verlust der bisherigen Staatsangehörigkeit. Da Italien - zumindest seit 1983 - ausdrücklich versucht, doppelte Staatsangehörigkeit auf Dauer zu bekämpfen (siehe Art. 5 Abs. 2 des Gesetzes 123 vom 21. April 1983), ist wahrscheinlich, daB danach gestrebt wird, auch bei Einbürgerung keine mehrfache Staatsangehörigkeit zu fördern.

Das österreichische Recht bestimmt in $\S 10$ Abs. 2 StBG 1965, daß die Staatsbürgerschaft nicht verliehen wird, wenn der Antragsteller die für das Ausscheiden aus seinem bisherigen Staatsverband erforderlichen Handlungen unterläßt, obwohl sie ihm möglich und zumutbar sind und er kein Flüchtling ist, oder wenn er aufgrund seines Antrages oder auf andere Weise absichtlich die Beibehaltung seiner bisherigen Staatsangehörigkeit erwirkt.

In der Schweiz schreibt Art. 17 BüG ausdrücklich vor, daß ein Einbürgerungsbewerber alles zu unterlassen hat, das die Beibehaltung der bisherigen Staatsangehörigkeit bezweckt. Er soll "soweit es nach den Umständen zumutbar ist" auf die bisherige Staatsangehörigkeit verzichten.

Auch in Spanien wird im Prinzip der Verzicht auf die bisherige Staatsangehörigkeit gefordert (Art. 22 i.V.m. Art. 20 C.c.esp.) (so bereits Art. 25 C.c.esp. i.d.F. 1889). Eine Ausnahme gilt aber für Angehörige lateinamerikanischer Staaten, die ohne ihre bisherige Staatsangehörigkeit aufgeben zu müssen, eingebürgert werden können.

In der Mehrheit der beschriebenen Staten ist also der Verlust der bisherigen Staatsangehörigkeit eine Voraussetzung für die Einbürgerung. In Belgien und Frankreich wird diese Forderung nicht ausdrüicklich gestellt. In GroBbritannien wird ebenfalls nicht verlangt, daß die bisherige Staatsangehörigkeit aufgegeben werden soll. Man hat dort ausdrücklich diskutiert, ob diese Bedingung nicht doch gestellt werden soll, hat dies aber letzten Endes abgelehnt, weil anerkannt wird, daß sich Personen durchaus mit mehreren Staaten innerlich verbunden fühlen können. Diese Begründung ist interessant und $\mathrm{m} . \mathrm{E}$. überzeugend. In $\S 1.3$ wurde bereits darauf hingewiesen, daß man die psychologische Dimension einer Staatsangehörigkeit aus der Perspektive eines Individuums nicht gänzlich verneinen darf. Die Menschen fühlen sich häufig innerlich mit dem Staate verbunden dessen Staatsangehörigkeit sie besitzen. Dies ist gerade besonders häufig der Fall, wenn sie im Ausland leben. Die Bereitschaft, die Staatsangehörigkeit des Staates zu erwerben in dem man lebt, wird aus diesem Grund in der Regel nur geringer, wenn damit stets der Verlust der bisherigen Staatsangehörigkeit, folglich eine Schwächung der Bindung an die Heimat, verbunden sein soll. Dies fördert nicht die staatsangehörigkeitsrechtsrechtliche Eingliederung von ausländischen Familien. Schon deshalb kann man an der Forderung zwei- 
feln, die bisherige Staatsangehörigkeit müsse aufgegeben werden, wenn sỉe durch die Einbuirgerung nicht bereits automatisch verloren wird.

Zwar entspricht die Forderung, die bisherige Staatsangehörigkeit aufzugeben, dem Ziel des Straßburger Abkommens von 1961, sie wird aber won diesem Abkomrnen nicht ausdruicklich vorgeschrieben. Es ist auch kaum wahrscheinlich, daß seitens des Europarates jemals die Initiative ergriffen wird, das StraBburger Abkommen durch Zusatzprotokolle in diesem Sinne zu erweitern. Eher sprechen Indizien dafür, daß der Inhalt des Straßburger Abkommens in Zukunft auf ganz andere Weise revidiert wird und die Mehrstaatlichkeit bekämpfenden Vorschriften dieses Abkommens eingeschränkt werden. Dies geht namentlich aus den Aktivitäten des Europarates hinsichtlich der staatsangehörigkeitsrechtlichen Stellung von Gastarbeiterkindern hervor (siehe \& 1.4.2). Es ist eine eindeutige Tendenz dahingehend zu erkennen, daß diese Kinder möglichst unter erleichterten Bedingungen eingebürgert werden sollten. Möchte man die Einbürgerung dieser Kinder fördern, dann wäre das Verlangen um Aufgabe der bisherigen Staatsangehörigkeit auß̉erordentlich unvernünftig.

Dieses ist auch in anderer Hinsicht fragwürdig. Durch die modemen, schnellen und relativ billigen Reisemöglichkeiten ist es heutzutage durchaus möglich, daß eine Person mit mehreren Staaten sehr enge Kontakte pflegt. Die Forderung, eine solche Person müsse sich für eine Staatsangehörigkeit entscheiden, ist daher u.U. nicht nur psychologisch unvernüftig, sie entspricht manchmal auch überhaupt nicht den tatsächlichen Beziehungen. Dies gilt insbesonders dann, wenn eine Person die Staatsangehörigkeit eines Staates der Europäischen Gemeinschaft innehat und nun die Staatsangehörigkeit eines anderen EG-Staates erwerben möchte. Beide Staatsangehörigkeiten vermitteln gleichermaßen die grundsätzliche Freizügigkeit innerhalb der EG (vgl. § 1.4.2).

Die in Art. 9 Abs. 1 Buchstabe b RwNed gestellte Voraussetzung für eine Einbürgerung erscheint im Hinblick auf diese Tatsachen fragwürdig. Die Streichung dieser Forderung wäre deshalb zu erwägen. Dabei ist eventuell durchaus auch eine Zwischenlösung denkbar. Es wäre möglich, das Verlangen nach Aufgabe der bisherigen Staatsangehörigkeit nicht generell zu streichen, sondern es lediglich hinsichtlich bestimmter Staaten aufzugeben, mit denen besonders intensive Kontakte unterhalten werden. Das läge z.B. auf der Hand, wenn es sich jeweils um Staatsangehörigkeiten won EG-Stalen oder Mitgliedstaaten des Europarates handelt. Aus Grüinden der Integrationsförderung von Gastarbeiterfamillien ist weiter zu empfehlen, diese Forderung ebenfalls dann nicht zu stellen, wenn der Einbürgerungsbewerber die Staatsangehörigkeit eines Staates besitzt, mit dem - namentlich während der sechziger Jahre - Gastarbeiterabkommen geschlossen worden sind. Vorläufig möchte ich diese Zwischenlösung vertreten. Nachdem mit dieser Lösung (positive) Erfahrungen gesammelt worden sind, könnte eventuell die Forderung nach Verzicht auf die bisherige Staatsangehörigkeit generell gestrichen werden.

Schließlich sei in diesem Zusammenhang noch auf folgendes hingewiesen. Es besteht ein eindeutiger Zusammenhang zwischen der Bedingung bei Einbürgerung die bisherige Staatsangehörigkeit aufzugeben, und der Verlustbestimmung, nach der die Staatsangehörigkeit im Falle des freiwilligen Erwerbs einer fremden Staatsangehörigkeit verloren wird. Beidle Regelungen bilden ein Spiegelbild. 
Grundsätzlich wäre zu erwarten, daß Staaten, die bei der Einbïrgerung den Verzicht auf die bisherige Staatsangehörigkeit fordern, auch im Falle des freiwilligen Erwerbs einer fremden Staatsangehörigkeit selbstverständlich den automatischen Verlust der eigenen Staatsangehörigkeit kennen. Insofern ist bemerkenswert, feststellen zu muissen, daß die Schweiz hierbei inkonsequent ist (siehe hierüber weiter $\$ 3.4 .2$ ) und auch die Bundesrepublik Deutschland mit $\$ 25$ Abs. 2 RuStAG keine generell wirkende Verlustregel getroffen hat.

\subsubsection{Wirtschaftliche Voraussetzungen}

$\$ 8$ Abs. 1 Ziffer 3 und 4 RuStAG fordern, daß der Einbürgerungsbewerber im Inland eine Wohnung oder Unterkommen hat, und daß er im Stande ist, sich und seine unterhaltsberechtigten Angehörigen zu ernähren (so auch wiederholt von Nr. 3.4.1 Einbürgerungsrichtlinien). Grundsätzlich muB dieser Unterhalt aus eigenen Mitteln aufgebracht werden. Nur in einigen Ausnahmefällen reicht ein Anspruch auf Sozialhilfe aus. Vergleichbare Forderungen findet man in Österreich, in der Schweiz und gewissermaßen auch in Großbritannien.

In Österreich wird von $\S 10 \mathrm{Abs}$. 1 Ziffer 7 StBG 1965 gefordert, daB der Lebensunterhalt des Einbürgerungsbewerbers hinreichend gesichert ist, oder daß er sich obne sein eigenes Verschulden in einer finanziellen Notlage befindet.

Auch die Schweiz stellt für die Einbürgerung gewisse wirtschaftliche Bedingungen. Dies geht schon aus der im Entwurf 1986 vorgeschlagenen Neuformulierung von Art. 14 BüG hervor, wo u.a. gefordert wird, daß der Bewerber seine öffentlichen und privaten Verpflichtungen erfüllt. Aber auch in den geltenden Regelungen verlangen einige Kantone bereits die Erfüllung der öffentlichen und privaten Verpflichtungen (Unterwalden nid dem Wald, Basel-Stadt und Schaffhausen). Andere Kantone stellen ähnliche Voraussetzungen wie "geordnete persönliche Verhältnisse" (Bern, Schaffhausen, St. Gallen, Thurgau) oder die "Fähigkeit, sich und die Familie zu unterhalten" (Luzern, Uri, Unterwalden ob dem Wald, Fribourg, Aargau, Thurgau, Genève, Jura). Insgesamt 12 Kantone stellten bei der Umfrage von Göppert/Heinzmann klar, daß die finanziellen Verhältnisse des Bewerbers für die Einbürgerung von Bedeutung sind. Vaud und Genève regeln sogar ausdrücklich, daß ein regelmäßiger Soziallilfeempfänger nicht eingebürgert werden kann.

Im Rahmen der Forderung eines "good character" (Schedule 1, \$1 (1) b) werden in Großbritannien grundsätzlich auch einige wirtschaftliche Bedingungen gestellt: "Financial irresponsibility, serious insolvency or bankruptcy" führen zur Zurückweisung eines Einbürgerungsantrages. Lediglich "financial incompetence" ist aber ebensowenig ein Hinderungsgrund wie die Tatsache, daß der Betreffende arbeitslos oder Sozialhilfeempfänger ist.

In den übrigen Staaten werden keine ausdrücklichen wirtschaftlichen Voraussetzungen formuliert. Man muß hierbei aber bedenken, daß solche Bedingungen in der Regel implizit doch bestehen, da für die meisten Einbürgerungen Wohnsitz im Inland gefordert wird. Die dafür benötigte Aufenthalts- oder Niederlassungsgenehmigung wird jedoch in der Regel nur erteilt, wenn die betreffenden Personen ihre Lebenshaltungskosten ohne staatliche Hilfe bestreiten können. Gerade deshalb, weil die wirtschaftlichen Voraussetzungen bereits im Rahmen des 
Fremdenrechts eine bedeutende Rolle spielen, sollten sie m.E. nicht nochmals als selbstăndige Bedingung für die Einbürgerung gestellt werden. Es ist nicht uberzeugend, daß jemand sich wohl weiterhin im Inland aufhalten darf, aber aufgrund seiner wirtschaftlichen Verhältnisse nicht einbürgert werden kann. Für die Fälle, die aufgrund des Europäischen Fürsorgeabkommens nicht ausgewiesen werden dürfen, jedoch Sozialhilfeempfänger sind, erscheint es ebenfalls nicht angernessen die Einbürgerung alleine aufgrund dieser Tatsache zu verweigern.

Wirtschaftliche Voraussetzungen könnten aber dennoch bei der Einbürgerung von im Ausland lebenden Personen angemessen sein. $\mathrm{Zu}$ denken wäre dabei namentlich an die Wiedereinbürgerung ehemaliger Staatsangehöriger. Es muB verhindert werden, daß Personen lediglich ihre Wiedereinbürgerung beantragen, um nach Einbiirgerung und Niederlassung im Inland die Sozialfürsorge in Anspruch nehmen zu können. Daher ist zu erwägen, ob Art. 8 des niederländischen Staatsangehörigkeitsgesetzes nicht um eine entsprechende Vorschrift erweitert werden sollte. Diese Frage ist aber m.E. zu verneinen. Im Ausland lebende Personen können in den Niederlanden lediglich eingebürgert werden, nachdem von der Einbürgerungsbehörde festgestellt worden ist, daß keine Bedenken gegen einen unbeschränkten Aufenthalt des Einbürgerungsbewerbers in den Niederlanden bestehen (sieh \$ 3.3.4.4.). Daher besteht m.E. kein Regelungsbedarf für eine entsprechende Anderung der Einbürgerungsvoraussetzungen bei Auslandsaufenthalt. $\mathrm{Ob}$ eine Einbürgerung lediglich aufgrund der niederländischen Sozialleistungen beantragt wird, kann deshalb bereits im Rahmen der bisherigen gewöhnlichen Prüfung geklärt werden.

\subsubsection{Abwesenheit von entwicklungspolitischen Hindernissen}

Eine bemerkenswerte Einbürgerungsvoraussetzung kennt die Bundesrepublik Deutschland. GemäB der deutschen Einbürgerungsrichtlinien (Nr. 5.2) werden Staatsangehörige aus Entwicklungsländern im Prinzip nicht eingebürgert, wenn sie ursprünglich zur Aus- oder Weiterbildung in die Bundesrepublik gekommen sind. Die Bereitstellung von Schul-, Studien- und Forschungsplätzen, sowie Lehr- und Praktikantenstellen wird als personelle Entwicklungshilfe betrachtet. Diese Hilfe erfüllt aber nur dann ihren Zweck, wenn die betreffenden Personen nach Beendigung der Aus- oder Weiterbildung in ihre Heimat zurïckkehren. In einigen Fällen werden entwicklungspolitische Bedenken gegen eine Einbürgerung aber zurückgestellt; dies ist namentlich bei Asylberechtigten der Fall und unter gewissen Voraussetzungen - bei mit deutschen Ehegatten verheirateten Einbürgerungsbewerbern, sowie bei von Deutschen als Erwachsene adoptierte Personen. Außerdlem können unter Berücksichtigung der Grundsätze des Vertrauensschutzes und der humanitären Rücksichtnahme im Einzelfall Ausnahmen gemacht werden (Nr. 5.2.5 der Richtlinien). Dabei ist erwähnenswert, daß die entwicklungspolitischen Bedenken zurïckgestellt werden, wenn der Einbürgerungsbewerber sich länger alls fünfzehn Jahre nicht mehr in seinem Heimatstaat und davon zwölf Jahre im Bundesgebiet rechtmäßig aufgehalten hat, über fünfunddreißig Jahre alt ist und sein Abschlußexamen oder eine andere Aus- oder Weiterbildung seit mindestens drei Jahren beendet hat. Von außerordentlicher Bedeutung ist in diesem Zusammenhang jedoch noch, daß wenn entwicklungspolitische Bedenken zurückgestellt werden, die Einbürgerung in der Regel auch nur dann erfolgt, wenn die Rückzahlung der von deutschen Stellen gewährten finanziellen Ausbildungshilfen sichergestellt ist. Die Forderung, einmal gewährte 
Stipendien zurückzuzahlen, ist lediglich dann unzulässig, wenn sich die Lebensverhältnisse des mit einem deutschen Staatsangehörigen verheirateten Ausländers im Bundesgebiet nach einem langen Aufenthalt so verfestigt haben, daß eine Rückkehr in seine Heimat oder in ein anderes Entwicklungsland gänzlich unwahrscheinlich geworden ist.

In den übrigen Staaten wird ein entsprechendes Einbürgerungshindernis nicht formuliert. Es sei aber darauf hingewiesen, daß auch in den Niederlanden und in Großbritannien Personen, die sich lediglich zu Studienzwecken im Lande aufhalten dürfen, in Prinzip nicht eingebürgert werden können, weil es ihnen nicht gestattet ist, sich für unbeschränkte Zeit im Inland aufzuhalten.

Die deutsche Regelung ist interessant und zum Teil überzeugend. Als Arbeitnehmer kann man heutzutage in der Regel nur unter sehr strengen Voraussetzungen einen Wohnsitz in den besprochenen Staaten begründen. Eine Ausnahme gilt in den Mitgliedstaaten der Europäischen Gemeinschaft lediglich für die Angehörigen anderer EG-Staaten. Wenn ein ausländischer Arbeitnehmer nun viele Jahre im Inland lebt und eine Einbürgerung beantragt, soll diesem Antrag grundsätzlich stattgegeben werden, wenn die allgemeinen Voraussetzungen erfiullt sind (Siehe $\$ 3.3 .4 .3$ vgl. ebenfalls $\$ 3.3 .4 .8$ ).

Relativ leicht ist es dagegen, in den besprochenen Staaten eine Aufenthaltsgenehmigung zu Studien- oder Ausbildungszwecken zu bekommen. Die deutschen Einbürgerungsrichtlinien weisen zurecht darauf hin, daß dies von großer entwicklungspolitischer Bedeutung ist. Eine große Anzahl dieser ausländischen Studenten lebt vielle Jahre im Inland. Gerade in den Staaten, in denen die Wohnsitzforderung für eine Einbürgerung lediglich fünf Jahre beträgt, wird diese Bedingung bei Abschluss des Studiums häufig erfülltt sein. Aber sogar in Staaten in denen ein zehnjähriger Aufenthalt gefordert wird, kommt es relativ häufig vor, daß diese Frist - z.B. nach einem Medizinstudium - erfïllt ist, besonders dann, wenn der Betroffene noch eine Facharztausbildung absolvierte. Nach einem solchen Studium wird wohl in allgemeinen festgestellt werden müssen, daß die betreffenden Personen grundsätzlich geeignet sind, als Staatsangehörige aufgenommen zu werden. Sie werden die Landessprache in der Regel fließend beherrschen und im allgemeinen auch relativ gut in die Gesellschaft integriert sein. Dennoch ist bei der Einbürgerung solcher Personen Zurückhaltung geboten. Der erste Grund dafür kann darin zu sehen sein, daß die entsprechenden Personen eventuell aus Entwicklungsländern stammen. Diese Staaten haben in der Regel ein großes Interesse daran, daß gut ausgebildete Kräfte in ihr Land zurückkehren. Das berechtigte Interesse eines Individuums an seiner Einbürgerung muß daher gegen das ebenfalls berechtigte Interesse des Heimatstaates an der Rückkehr der betreffenden Person abgewogen werden. Jedenfalls dann, wenn ein Ausländer auf Kosten des Wohnstaates studiert hat, muß eine Einbürgenung verweigert werden können bis empfangene Stipendien zuríckgezahlt sind. Solche Stipendien sollten der personellen Entwicklungshilfe dienen, und dieses Ziel wird nicht erreicht, wenn der geförderte Student als Eingebürgerter im Inland bleibt. Wenn der Staat die Stipendiengelder jedoch zurückempfängt, können diese emeut zur Entwicklungshilfe verwendet werden. Auch wenn ein Student auf Kosten seimes Heimatstaates studiert hat, muß eine Einbürgerung u.U. verweigert werden können, biss der Betreffende sein finanzielles Verhältmis zum Heimatstaat befriedigend geklärt hat. $\mathrm{Ob}$ im letzteren Falle eine 
Einbürgeruing tatsăchlich von der Rückzahlung der finanziellen Förderung des Heimatstaates abhängig gemacht werden soll, ist eine politische Entscheidung. Sie ist davon abhängig, ob das Verhältnis des Einbürgenungsstaates zum Heimatstaat des Betreffenden durch eine Einbürgerung ohne Zurückzahllung der früher empfangenen Unterstützung getrübt wird. In diesem Zusammenhang ist das allgemeine politische Verhältnis zwischen dem einbürgernden Staat und dem Heimatstaat des Betroffenen von großer Bedeutung.

Soll nun in Kenntnis der obenstehenden Erörterungen das Fehlen entwicklungspolitischer Hindernisse auch im niederländischen Recht als selbständige Einbürgerungsvoraussetzung formuliert werden? Diese Frage ist m.E. zu verneinen. Die entwicklungspolitische Abwägung kann auch im Rahmen der Überprüfung der Unbedenklichkeit eines unbeschränkten Aufenthalts des Antragstellers in den Niederlanden worgenommen werden.

\subsubsection{Abwesenheit von intensiven Beziehungen zu fremden Staaten}

Österreich fordert, daß der Einbürgerungsbewerber mit fremden Staaten nicht in solchen Beziehungen steht, daß bei Verleihung der Staatsangehörigkeit die Interessen oder das Ansehen der Republik Schaden nehmen würde. Eine ähnliche Regelung können wir in der Schweiz finden, wo einige Kantone den Beziehungen des Antragstellers zu seinem Herkunftsland im Rahmen des Einbürgerungsverfahrens beachtlichen Wert beimessen. In anderen Staaten finden wir keine entsprechenden Regelungen.

Diese Forderungen sollten jedoch $m . \mathbb{E}$. nicht als selbständige Einbürgerungsvoraussetzungen formuliert werden. Zunächst darf dem Antragsteller überhaupt nicht vorgeworfen werden, daß3 er noch eine gewisse moralische Verbundenheit zu seinem Herkunftland empfindet: eine Person kann sich sehr wohl mit mehreren Staaten, seinem Herkunftland und seinem Wohnsitzstaat, dessen Staatsangehörigkeit er nunmehr begehrt, verbunden fühlen (siehe dazu auch $\S 3.3 .4 .8$ ). Normale Beziehungen zum Herkunftland dürfen also kein Grund sein, einen Einbürgerungsantrag zurückzuweisen. Ganz anders wird die Lage aber, wenn der Einbürgerungsbewerber etwa verdächtigt wird, Spionageaktivitäten für sein Herkunftland ausgeübt zu haben. Erinnert sei jedoch an die Erörterungen in \$ 3.3.4.7: bloße Verdachtsgründe dürfen m.E. keine Zurückweisung des Einbuirgerungsantrages verursachen; lediglich eine gerichtliche Verurteilung kann eine Zurückweisung legitimieren (siehe für weitere Einzelheiten $\$ 3.3 .4 .7$ ). Eine besondere Position nehmen Einbürgerungsbewerber ein, die im Dienst des Herkunftlandes stehen oder Familienangehörige einer solchen Person sind: für solche Bewerber dürften in der Regel die Bestimmungen der Zusatzprotokolle zu den Wiener Diplomaten- und Konsularabkommen gelten. Diese Protokolle verbieten lediglich, daß Personen, die zu einer diplomatischen oder konsularischen Mission gehören, automatisch die Staatsangehörigkeit des Empfangstaates erwerben; eine Einbürgerung solcher Personen auf eigenen Antrag hin wird nicht untersagt. Dennoch dürfte eine solche Einbürgerung nicht immer zu bejahen sein. Auch diese Frage kann aber im Rahmen der Überprüfung der Unbedenklichkeit eines unbeschränkten Aufenthalts im Inland geklärt werden (siehe \$ 3.3.4.4). 
Eine besondere Schwierigkeit stellt noch die Einbürgerung von Personen dar, die in ihrem Heimatstaat sehr hohe politische Funktionen innehatten, aber nach einem Regierungssturz fliehen mußten. Die Einbürgerung solcher Personen könnte das politische Verhältnis zwischen dem Einbürgerungsstaat und dem frïheren Heimatstaat des Betroffenen -wenigstens vorübergehend- trüben. Diese Tatsache soll eine Einbürgerung solcher Personen jedoch nicht verhindern. Eine Einbürgerung ist keine besondere Ehrung, sondern lediglich die Feststellung, daß jemand -normalerweise nach langjährigem Aufenthalt im Inland- sehr enge Beziehungen zum Wohnsitzstaat entwickelt hat. Wenn dies konstatiert werden kann, ist eine EinbUrgerung gerechtfertigt.

Am SchluB dieses Abschnittes sei schließlich noch an die niederländische Bestimmung erinnert, daß keine Person eingebürgert werden kann, die in dem Staat lebt, dessen Staatsangehörigkeit sie besitzt. Diese Regelung, die mit Hinweis auf $\mathrm{zu}$ intensive Beziehungen mit dem Wohnsitzstaat begründet werden könnte, wurde jedoch bereits in $\$ 3.3 .4 .3$ abgelehnt.

\subsubsection{Gesundheitszeugnis}

Gemäß dem Wortlaut des Art. 9 Abs. 1 Buchstabe a RwNed darf das Verhalten eines Einbürgerungsbewerbers nicht die Volksgesundheit des Königreiches gefährden. Aus den Motiven zu dieser Vorschrift geht indessen hervor, daß sie nicht die Einbürgerung von kranken Personen verhindern soll, sondern von Personen, die als Drogenhändler bekannt sind. Allerdings dürfte $\mathrm{m} . \mathrm{E}$. auch die Einbürgerung solcher Personen ausschließlich dann verweigert werden, wenn die Betreffenden innerhalb einer bestimmten dem Einbürgerungsantrag vorangehenden Frist strafrechtllich verurteilt worden sind. Bloßer Verdacht auf Drogenhandel darf kein Verweigerungsgrund sein (siehe oben \$ 3.3.4.7).Im deutschen Recht forderten die Richtlinien aus 1971 noch ein amtsärztliches Zeugnis, aus dem hervorgehen mußte, daß der Gesundheitszustand des Einbürgerungsbewerbers gut sei. Seit 1977 wird ein solches Zeugnis nicht mehr verlangt.

In Frankreich wird im Rahmen des Einbürgerungsverfahren dagegen noch immer gefordert ein amtsärztliches Zeugnis vorzulegen. Dazu schreibt Art. 32 der Durchfuihrungsverordnung von 10 . Juli 1973 vor: "Ce document doit obligatoirement specifier si l'interessé est exempt de toute infirmité et de toute vice de constitution, s'il n'est atteint de tuberculose, de maladie vénérienne, ni d"aucune affection mentale et s'il n'est pas toxicomane."

In der Schweiz fordert nur ein Kanton ausdrücklich einen guten Gesundheitszustand als Einbürgerungsvoraussetzung. Mehrere Kantone halten den Gesundheitszustand eines Einbürgerungsbewerbers aber im Rahmen des Einbürgerungsverfahrens für beachtlich.

Die übrigen Staaten stellen keine Bedingungen hinsichtlich des Gesundheitszustandes. Erinnert sei aber an die britische Bestimmung, kraft deren die Zeit, die man in einer Anstalt für Geisteskranke verbringt, nicht bei der Berechnung der für eine Einbürgerung erforderlichen Aufenthaltsfrist im Inland mitzählt (\$ 3.3.4.3). Die Einbürgerung von Geisteskranken in Großbritannien ist daher schwierig. 
Die Forderung nach einem guten Gesundheitszustand als Voraussetzung für die Einbürgerung beurteile ich als bedenklïch. Diese Bedingung zeigt wieder Berührungspunkte mit dem Ausländerrecht, denn häufig wird ja auch im Rahmen der Verleihung einer Aufenthaltsgenehmigung ein Gesundheitszeugnis gefordert. Wenn also eine Person nach mehrjährigem Aufenthalt im Inland plötzlich eine Krankheit hat, ist es offensichtlich, daß die Person diese Krankheit im Inland aufgrund von Tatsachen und Umständen erworben hat, die durchaus auch bei Staatsangehörigen hätten auftreten können. Es wäre also bereits sehr bedenklich, einer solchen Person wegen dieser Krankheit eine Verlängerung des Aufenthaltserlaubnisses zu verweigern. "Wenn sich der betreffende Ausländer aber weiterhin im Inland aufhalten darf, wäre es um so bedenklicher, ihm die Einbürgerung wegen der festgestellten Krankheit zu verweigern. Eine solche Verweigerung könnte ja wohl nur mit der verwerflichen Auffassung begründet werden, die Gemeinschaft der Staatsangehörigen des Wohnsitzstaates bilde eine weitestgehend krankheitsfreie Rasse.

\subsubsection{Treneid}

Im britischen, italienischen, österreichischen und spanischen Recht wird bei der Einbürgerung ein Treueid gefordert $(\$ 21$ StBG 1965, Art, 5 L.c.., Schedule 5 BNA 1981, Art. 20 Abs. 2 C.c.esp.). Das belgische, deutsche, französische und niederländische Recht kennt indessen eine solche Bedingung nicht.

Das Fordern eines Treueids muß m.E. abgelehnt werden. Zwar gibt eine solche Vereidigung dem Erwerb der neuen Staatsangehörigkeit eine feierliche Dimension, aber wenn man diese Feierlichkeit unbedingt wïnscht, ist dies auch schon durch eine (kurze) Ansprache bei Überreichung der Einbürgerungsurkunde zu erreichen. Selbstverständlich ist der Neubürger seinem neuen Staat zur Treue verpflichtet, aber er ist dies nicht in stärkerer oder anderer Weise als Personen, die diese Staatsangehörigkeit bei Geburt oder später von Rechts wegen erworben haben. Von diesen anderen Personen wird indes auch kein Treueid verlangt. Die Treue eines Staatsangehörigen seinem Staate gegenüber wird regelmäßig auch dadurch abgesichert, daß einige strafrechtliche Delikte, namentlich der Landesverrat, ausschlließlich durch Staatsangehörige, nicht aber durch Ausländer begangen werden können. Diese Absicherung der Treue eines Bürgers müßte genügen; eine zusätzliche Vereidigung eines Neubürgers stellt von vomeherein eine wesentliche Mißtrauensbekundung dar.

\subsubsection{Zahlung eines Entgelts}

Aufgrund des Art. 13 RwNed wird in der Regel die Zahlung von Einbuirgerungsgebühren gefordert. Diese Summe beträgt gemäß der Durchführungsverordnung von 27. Januar 1986, Stb. 1986, 18 (geändert durch Verordnung vom 2. Mai 1988, Stb. 1988, 247) grundsätzlich 400 Gulden. Die Zahlung dieses Betrages kann ganz oder teilweise erlassen werden. Im Falle der Einbürgerung von Ehe- oder Konkubinatspartnem braucht die Gebühr nur einmal entrichtet werden. Die Gebühr ist im voraus zu bezahlen. Bis Inkrafttreten der Änderungsverordnung von 1988 wurde das Geld zurückerstattet, falls der Einbürgerungsantrag zurückgewiesen wurde. In der niederländischen juristischen Literatur wird die Tatsache, daß man u.U. für eine Einbürgerung zahlen muß, stark kritisiert. 
In Belgien sieht Art. $21 \S 2 \mathrm{CNB}$ vor, daB eine Registrationsgebühr gezahlt werden muß. Die Höhe der Gebühr wird anhand der Art. 238-240 bis des Code des droits d'enregistrement, d'hypothèque et de greffe vom 20. November 1939 bestimmt (geändert durch Art. $14 \$ 4$ des Gesetzes vom 28. Juni 1984). Die Gebühr für die normale Einbürgerung beträgt $16.000 \mathrm{BF}$. Falls der Einbürgerungsbewerber noch keine 22 Jahre ist, werden lediglich $2.000 \mathrm{BF}$ gefordert. Weiter sind ErmäBigungen oder sogar Freistellungen vorgesehen. Die Gebühr für die große Einbürgerung beträgt ebenfalls $16.000 \mathrm{BF}$; sie ist auf lediglich $2.000 \mathrm{BF}$ für diejenigen gemindert, die früher bereits die Gebuihren für die normale Einbürgerung gezahlt haben. Die Gebühren müssen im voraus entrichtet werden. Wenn der Einbürgerung nicht stattgegeben wird, kann die Hälfte der gezahlten Gebühr zurückgefordert werden. In der Bundesrepublik Deutschland variieren die Einbürgerungsgebühren zwischen 100 und $5000 \mathrm{DM}$, jeweils abhängig vom Monatseinkommen des Einzubürgernden. In einigen Fällen wird die Grundgebühr um die Hälfte oder um ein Viertel ermäßigt ( $\$ 2$ Abs. 3 Staatsangehörigkeitsgebührenverordnung). In anderen Fällen ( $\$ 1$ Abs. 2 Ziffer 1 derselben Verordnung) ist die Einbürgerung sogar gebührenfrei.

In Frankreich wird für eine Einbürgerung $3000 \mathrm{~F}$ und für eine Wiedereinbürgerung $1500 \mathrm{~F}$ verlangt, zusätzlich $131 \mathrm{~F}$ für ein Inserat in dem Journal Officiel.

Die an einer Einbürgerung verbundenen Kosten sind in Großbritannien 160,Pounds. Ehegatten eines britischen Bürgers brauchen lediglich $55,-$ Pounds zu zahlen. Die Kosten einer "registration" belaufen sich ebenfalls auf 55,- Pounds.

In Spanien ist eine Einbürgerung kostenlos.

In Österreich sind die Kosten einer Einbürgerung im Gebührengesetz 1957, \$ 14 TP 2 geregelt. Für eine Ermessenseinbürgerung muß 4000 Schilling, für eine Einbürgerung kraft Rechtsanspruch 3000 Schilling gezahlt werden. Die Erstreckung einer Einbürgerung auf die Ehefrau oder Erwerb der Staatsangehörigkeit kraft Optionserklärung kostet 1000 Schilling.

In Italien sind die Anträge und Erklärungen bezüglich des Erwerbs oder Wiedererwerbs der italienischen Staatsangehörigkeit gemäß Art. 13 Abs. 2 L.c. gebühren- und kostenfrei.

In der Schweiz können die Kosten der normalen Einbürgerung sehr erheblich von einander abweichen, je nachdem, in welcher Gemeinde und in welchem Kanton die Einbürgerung beantragt wird. Sie variieren zwischen 200 und 75.000 Schweizerische Franken.

Die Erhebung einer Gebühr für die Einbürgerung widerspricht grundsätzlich der Auffassung, workach die Staatsangehörigkeit als reiner Koppelungsbegriff und nicht mehr als die Auszeichnung eines Individuums zu sehen ist. Eine verhältnismäßig niedrige Gebühr könnte vielleicht mit dem Argument verteidigt werden, daß dadurch die Stellung von Einbürgerungsanträgen verhindert wird, die ohnehin keine Chance auf Bewilligung haben, so daß die Behörden unnötig bemüht werden. Diese Auffassung ist aber jedenfalls dann unglaubhaft, wenn wir - wie bis Juli 1988 in den Niederlanden - sehen, daß bei Nichteinwilligung des Antrages das bereits gezahlte Geld zuriickerstattet wird. Anscheinend betrachteten die Niederlande die Einbürgerungsgebühren durchaus als direkte 
Gegenleistung für die Einbürgerung. In den Niederlanden wird betont, daß die Gebühren in der Regel etwa kostendeckend sind. Es ist aber nicht einzusehen, $\mathrm{daB}$ - der Auffassung folgend, daß die Einbürgerung von Ausländern als Manifestierung der juristischen Integrierung ausländischer Bürger durchaus auch im Interesse des Staates ist - die eingebürgerte Personen selbst die Kosten der Einbürgcrungsbehörden zahlen müssen. Einbürgerungsgebühren wären deshalb abzuschaffen.

Aus den Argumenten gegen die relativ niedrige Gebühr im niederländischen Einbürgerungsrecht geht schon hervor, daß höhere Gebühren a fortiori zurückgewiesen werden müssen. Bei hohen Gebühren sei zudem im Auge behalten, daß die Verpflichtung, hohe Einbürgerungsgebühren zu zahlen den Einbürgerungswillen eines Ausländers nicht eben fördert und gerade dies widerspricht dem Interesse des Staates.

\subsubsection{Sondereinbürgerung}

Gemäß Art. 10 RwNed kann nach Anhörung des Staatsrates des Königreiches in Abweichung von den Bestimmungen des Art. 8 Abs. 1 Buchstabe a (Volljährigkeitsvoraussetzung), c (Wohnsitzvoraussetzung) und d (Voraussetzung der gesellschaftlichen Integrierung) oder in Abweichung des Art. 9 Abs. 1 Buchstabe c (keine Einbürgerung, wenn Wohnsitz im bisherigen Heimatstaat) eingebürgert werden. Eine Einbürgerung über Art. 10 RwNed in Abweichung der Voraussetzungen von Art. 8 Abs. 1 Buchstabe b oder Art. 9 Abs. 1 Buchstaben a und b RwNed ist nicht vorgesehen, aber die betreffenden Voraussetzungen sind selbst bereits so wenig konkret, beziehungsweise in sich bereits derart klausuliert, daß es wohl nicht erforderlich war, eine Ausnahmemöglichkeit über Art. $10 \mathrm{zu}$ schaffen.

Nach deutschem Recht ist eine Einbürgerung ohne Beachtung der in den $\S 8$ und 9 RuStAG formulierten Voraussetzungen nur unter Anwendung des $\$ 1$ der Verordnung zur Regelung von Staatsangehörigkeitsfragen möglich. Auf diese Weise kann z.B. jemand ohne Wohnsitz in Deutschland eingebürgert werden.

In Frankreich sieht Art. 64 Ziffer 6 CNF eine Sondereinbürgerung für Ausländer vor, die für Frankreich außerordentliche Dienste geleistet haben oder deren Einbürgerung für Frankreich von außerordentlichem Interesse ist. Eine solche Einbuirgerung kann nur nach Zustimmung des Staatsrates und nach einem begründeten Bericht des zuständigen Ministers erfolgen.

In Großbritannien läßt Sec. 2 von Schedule 1 Ausnahmen von fast allen in Sec. 1 formulierten Forderungen zu. Der Einbürgerungsbewerber muß jedoch mindestens einen "good character" haben und entweder in Großbritannien leben wollen oder im britischen Dienste verbleiben.

Art. 4 Abs. 2 L.c. sieht in Italien ganz generell vor, daß ausnahmsweise und aufgrund besonderer Umstände auch naturalisiert werden kann, wenn die normalen Einbüirgerungsvoraussetzungen nicht erfüllt sind.

Nach österreichischem Recht ist eine Sondereinbürgerung möglich, wenn die Bundesregierung bestätigt, daß die Verleihung der Staatsbürgerschaft wegen der vom Fremden bereits erbrachten oder von ihm noch zu erwartenden außeror- 
dentlichen Leistungen, insbesondere auf wissenschaftlichen, wirtschaftlichen, küinstlerischen oder sportlichen Gebieten, im Interesse der Republik liegt. Der Einbürgerungsbewerber braucht dann nicht in Österreich zu leben, sein Lebensunterhalt braucht nicht gesichert zu sein und auch eine eventuelle doppelte Staatsangehörigkeit wird hingenommen. Die übrigen Voraussetzungen gelten aber wohl (keine bestimmte Verurteilungen oder Strafverfahren, kein Aufenthaltsverbot, keine Gefährdung der öffentlichen Ordnung).

Das spanische Recht gibt im Art. 21 C.c.esp. ganz generell die Möglichkeit, daB eine Person eingebürgert wird, wenn besondere Umstände vorliegen. Die übrigen Staaten kennen solche allgemein formulierten Ausnahmen nicht.

Eine allgemeine Bestimmung, die eine Sondereinbürgerung ermöglicht ist $\mathrm{m.E}$. zu bejahen. Dabei sind gesetzestechnisch keine Ausführungen darüber erforderlich, welche Voraussetzungen dennoch erfüllt werden müssen. Es spricht wohl für sich, daß die Möglichkeit einer Sondereinbürgerung nicht zugunsten von Personen genutzt wird, die die öffentliche Ordnung gefährden. Die niederländische Formulierung, die Ausnahmen von einigen wenig konkreten oder in sich schon klausulierten Voraussetzungen ausschließt, ist deshalb unnötig kompliziert und kann vereinfacht werden. Bei der Sondereinbürgerung ist eine spezielle Kontrolle durch den Staatsrat zu begrüßen.

\subsubsection{Erstreckung der Einbürgerung}

Die Staatsangehörigkeitsregelungen einiger Staaten geben reiativ detaillierte Regelungen hinsichtlich der Frage, in wieweit sich eine Einbürgerung auf eventuelle Kinder des Eingebürgerten erstreckt. Ursprünglich erstreckte sich die Einbürgerung eines verheirateten Mannes grundsätzlich auch auf dessen Ehefrau. Diese Regelung gilt in den, in diesem Buch besprochenen, Staaten aber heutzutage nicht mehr. Ein gewisses Rudiment jener Regelung sieht man aber noch in Art. 32 Abs. 1 des schweizerischen BüG, der bestimmt, daß eine Ehefrau grundsätzlich nur zusammen mit ihrem Ehemann eingebürgert werden kann und mit ihrer schriftlichen Zustimmung in seine Einbürgerung einbezogen wird. Im folgenden sollen die Regelungen der Erstreckung einer Einbürgerung auf minderjährige Kinder des Eingebürgerten näher betrachtet werden.

Nach niederländischem Recht erstreckt sich eine Einbürgerung grundsätzlich auf die minderjährigen Kinder eines Eingebürgerten, es sei denn, in der Einbürgerungsurkunde wurde ein Vorbehalt gemacht (Art. 11 RwNed). Im Rahmen des Einbürgerungsverfahrens werden der gesetzliche Vertreter und die betreffenden Kinder, wenn sie bereits das Alter von zwölf Jahren erreicht haben, zu der eventuellen Erstreckung gehört. Grundsätzlich bezieht sich die Einbürgerung einer Person ebenfalls auf die Kinder, deren gesetzliche Vertretung der Eingebürgerte nicht hat. Die Erstreckung gilt nach niederländischem Recht auch für Adoptivkinder.

Gemäß Art. 12 CNB erstreckt sich in Belgien die Einbürgerung eines Elternteils automatisch auf alle Kinder und Adoptivkinder, die noch nicht das 18. Lebensjahr vollendet haben und nicht vorher "emanzipiert" (beschränkt volljährig erklärt) waren. 
GemäB Art. 16 Abs. 2 des deutschen RuStAG bezieht sich eine Einbürgerung, insofern die Einbürgerungsurkunde keinen Vorbehalt enthält, auf diejenigen Kinder, deren gesetzliche Vertretung dem Eingebürgerten kraft elterlicher Gewalt zusteht. Ausgenommen sind aber Töchter, die verheiratet (gewesen) sind.

Nach französischem Recht erstreckt sich eine Einbürgerung grundsätzlich auf alle unverheirateten Kinder (einschließlich Adoptivkinder) die noch nicht das Alter von achtzehn Jahren erreicht haben (Art. 84, 85 CNF). Eine Ausnahme gilt lediglich für Kinder, gegen die bereits ein Dekret über den Widerspruch gegen den Erwerb der französischen Staatsangehörigkeit wegen Unwürdigkeit oder mangellnder Anpassung (Art. $57 \mathrm{CNF}$ ) ergangen ist, oder die wegen den Art. 65 (Ausweisung oder Zwangsaufenthalt) oder Art. 79 CNF (Verurteilung wegen bestimmter Delikten) nicht eingebürgert werden können. Die französische Regelung sieht nicht vor, daß aus einem anderen Grund ein Vorbehalt gemacht werden kann. Ebensowenig wird vorgeschrieben, daß gesetzliche Vertreter oder das Kind selbst $a b$ einem gewissen Alter gehört werden müssen.

Gemäß Art. 12 Abs. 1 des italienischen L.c. erwerben die minderjährigen Kinder eines ausländischen Mannes, der in Italien eingebürgert wird, ebenfalls die italienische Staatsangehörigkeit, es sei denn, sie leben im Ausland und behalten nach dem Recht des Staates, dem sie angehören, die bisherige Staatsangehörigkeit. Nach Abs. 3 desselben Artikels gilt grundsätzlich das gleiche, wenn nach dem Tode des Vaters die Mutter, welche die elterliche Gewalt oder gesetzliche Vormundschaft ausübt und eine andere Staatsangehörigkeit als der verstorbene Vater besaß, anders als durch Eheschließung, Italienerin wird. Die Regelung des Art. 12 entspricht eindeutig nicht dem Gleichberechtigungsgrundsatz. Es ist deshalb vertretbar, daß Art. 12 Abs. 3 L.c. aufgrund von Art. 8 des Gesetzes 123 vom 21. April 1983 außer Kraft getreten ist und die Regelung des Abs. 1 auch für die Einbürgerung einer ausländischen Frau gilt.

Eine sehr interessante Regelung kennt das österreichische Recht. $§ 18$ StBG sieht die Möglichkeit der Erstreckung vor und bestimmt ausdrücklich, daß diese nur gleichzeitig mit der Einbürgerung verfügt werden kann. Die Erstreckung der Einbürgerung muB laut $\$ 19$ Abs. 1 StBG beantragt werden; eine Einbürgerung erstreckt sich also nicht automatisch auf die Kinder des Eingebürgerten. Der Antrag auf Erstreckung einer Einbürgerung auf einen Minderjährigen muß von seinem gesetzlichen Vertreter oder mit dessen schriftlicher Zustimmung von einer dritten Person oder von dem Minderjährigen selbst gestellt werden. Falls der Antrag von dem gesetzlichen Vertreter oder von einem Dritten gestellt wird, ist die schriftliche Zustimmung des betreffenden Minderjährigen erforderlich, sofem er schon das 14. Lebensjahr vollendet hat. Abs. 3 des \& 19 StBG sieht vor, daß die Zustimmung des gesetzlichen Vertreters oder des bereits vierzehnjährigen Minderjährigen durch ein Gericht ersetzt werden kann.

Im schweizerischem Recht wird lediglich bestimmt, daß minderjährige Kinder in der Regel in die Einbürgerung ihrer Eltem einbezogen werden (Art. 33 i.V.m. 32 BüG).

Im britischen und spanischen Recht erstreckt sich eine Einbürgerung nicht auf minderjährige Kinder. Seit dem BNA 1948 bezieht sich die Einbürgerung eines Elternteils nach britischem Recht nicht mehr auf minderjährige Kinder. Der 
Secretary of State hat aber die Möglichkeit, minderjährige Kinder nach freiem Ermessen als britische Staatsangehörige registrieren zu lassen (Sec. 7 BNA 1948; Sec. 3 (1) BNA 1981). (Siehe \& 3.3.3.2 Buchstabe b). Anders als in früheren Regelungen kennt das heutige spanische Recht ebenfalls keine Erstreckungsregelung. Das Kind eines spanischen Staatsangehörigen kann aber gemäB Art. 19 C.c.esp. ab seinem 14. Lebensjahr durch Optionserklärung die Staatsangehörigkeit des eingebürgerten Elternteils erwerben, allerdings unter der Voraussetzung, da $B$ dieser die elterliche Gewalt ausübt (siehe weiter \& 3.3.3.1 Buchstabe c).

Die beschriebenen Regelungen überblickend, ziehe ich die österreichische Lösung vor, möchte diese aber noch in einigen Punkten verfeinern. Verwiesen sei auf die Erörterungen in $\$ 3.2 .2$, wo vertreten wurde, daß die Zustimmung des bereits vierzehnjährigen Kindes nicht durch ein Gericht ersetzt werden darf, wenn es durch die Erstreckung seine bisherige Staatsangehörigkeit verlieren würde. Ebenfalls wurde vorgeschlagen, zu bestimmen, daß bei Einbürgerung eines Elternteils auch der andere Elternteil, wenn dieser nicht gesetzlicher Vertreter ist, seine Zustimmung für die Erstreckung erteilen soll, falls der Minderjährige durch die Erstreckung die Staatsangehörigkeit dieses anderen Elternteils verlieren würde. Diese Zustimmung muß jedoch durch ein Gericht ersetzt werden können. Letztlich wurde darauf hingewiesen, daß es selbstverständlich willkürlich ist, die Mitbestimmungsgrenze bei 14 Jahren festzulegen; auch ein Mitbestimmungsrecht $\mathrm{ab}$ dem 12 . Lebensjahr wäre vertretbar.

Die meisten besprochenen Staaten sehen grundsätzlich eine automatische Erstreckung vor, während Österreich nur die Erstreckung auf Antrag kennt. Gerade falls ab einem gewissen Alter die Zustimmung des betroffenen Kindes gefordert wird, ist eine Erstreckung auf Antrag einer automatischen Erstreckung vorzuziehen. Sonst könnte es passieren, daß eine Einbürgerung sich "versehentlich" doch auf Kinder erstreckt, deren Zustimmung nicht eingeholt wurde.

In soweit sich die Einbürgerung eines Elternteils nicht auf dessen minderjähriges Kind bezieht, ist die Frage relevant, ob noch eine spätere Erstreckung bewirkt werden kann. Eine solche spätere Einbeziehung ist in keinem Staat ausdrücklich vorgesehen, in Österreich wird eine solche Möglichkeit sogar expressis verbis verneint $(\$ 18 \mathrm{StBG})$. In den Niederlanden wird in der juristischen Literatur behauptet, daß ein Vorbehalt der Erstreckung aus einer Einbürgerungsurkunde widerrufen werden könne: die Rechtsgrundlage dieser Ansicht ist aber unklar. Selbstverständlich wäre die Frage nach einer nachträglichen Erstreckung weniger relevant, wenn minderjährige Personen eingebürgert werden können. In \$ 3.3.4.2 sahen wir aber bereits, daß dies in den Niederlanden unmöglich ist. $\mathrm{Zu}$ überlegen ist nun, ob die Möglichkeit der nachträglichen Erstreckung einer Einbürgerung ausdrücklich im niederländischen Gesetz aufgenommen werden sollte. Diese Frage ist m.E. zu verneinen. Für den Fall, daßß die Verleihung der niederländischen Staatsangehörigkeit angemessen ist, ist eine Einbürgerung über die Sonderbestimmung des Art. 10 RwNed möglich (siehe dazu § 3.3.5). Diese Möglichkeit reicht aus (so auch \& 3.3.4.2). 


\subsubsection{Die staatsangehörigkeitsrechtliche Position des ausländischen Ehegatten}

In allen erwähnten Staaten hat ursprünglich die ausländische verheiratete Frau automatisch die Staatsangehörigkeit ihres Ehemannes erworben. Später wurde dieser Automatismus in der Regel aufgegeben und der ausländischen Ehefrau ein Optionsrecht zugebilligt. Dies wurde aber auf Dauer als Widerspruch zur geforderien Gleichberechtigung beurteilt. Diese Gleichberechtigung hätte realisiert werden können, indem auch ausländischen Ehemännern ein Optionsrecht gegeben wurde. Vor dieser Konsequenz hat man aber zurückgeschreckt, weil das Optionsrecht der ausländischen Ehegattin häufig mißbraucht und dies nun auch bei den Ehemännern erwartet wurde. Die meisten Staaten haben deshalb nun das Optionsrecht abgeschafft und statt dessen den ausländischen Ehefrauen und ausländischen Ehemännern eigener Staatsbürger die Möglichkeit gegeben, unter erleichterten Bedingungen eingebürgert zu werden.

In den Niederlanden kann ein Ausländer normalerweise nach fünfjährigem Aufenthalt im Inland eingebürgert werden. Für Ehepartner niederländischer Staatsbürger gilt aber eine günstigere Regelung. Sie können sogar ohne in den Niederlanden zu leben eingebürgert werden. Sie müssen dann allerdings folgende Voraussetzungen erfüllen:

- sie müssen bereits seit drei Jahren mit einem niederländischen Staatsangehörigen verheiratet sein;

- sie müssen volljährig sein;

- gegen ihren Aufenthalt in den Niederlanden dürfen keine Bedenken bestehen;

- sie müssen aufgrund hinreichender Kenntnisse der niederländischen Sprache als in die niederländische Gesellschaft integriert betrachtet werden können und sich zudem in die niederländische Gesellschaft haben aufnehmen lassen;

- es dürfen keine auf das Verhalten des Betreffenden gegründete ernsthaften Verdachtgründe bestehen, daß sie die öffentliche Ordnung, die guten Sitten, die Volksgesundheit oder die Sicherheit der Niederlande gefährden;

- sie müssen, falls sie eine andere Staatsangehörigkeit besitzen, alles in ihren Kräften stehende getan haben, um jene Staatsangehörigkeit zu verlieren, oder bereit sein, dies nach der Einbürgerung zu tun, es sei denn, daß dies billigerweise nicht verlangt werden kann;

- sie dürfen nicht in einem Staat leben, dessen Staatsangehörigkeit sie ebenfalls besitzen.

Die Vergünstigungen für den ausländischen Ehepartner bestehen in den Niederlanden also im wesentlichen nur im Wegfall der Aufenthaltsforderung. Alle anderen Voraussetzungen der Einbürgerung behalten Gültigkeit.

In Belgien wird die staatsangehörigkeitsrechtliche Stellung des ausländischen Ehepartners in Art. 16 in Verbindung mit Art. $15 \mathrm{CNB}$ geregelt. Der ausländische Ehepartner kann, nachdem er zusammen mit seinem Partner sechs Monate in Belgien gelebt hat, durch Optionserklärung die belgische Staatsangehörigkeit erwerben. Auch wenn die Ehepartner nicht in Belgien leben, ist eine Option möglich, falls sie nachgeweisen, daß zwischen dem ausländischen Partner und Belgien eine tatsächliche Bindung entstanden ist. All dies scheint wesentlich großzügiger zu sein als die niederländische Regelung. Die Option auf die Staatsangehörigkeit darf aber von der belgischen Regierung aufgrund wich- 
tiger Tatsachen, die sich auf die Person des Optierenden beziehen, oder aufgrund mangelnden Integrationswillen, zurückgewiesen werden. Letztlich kann man folglich bezweifeln, ob die belgische Regelung günstiger als die niederländische ist.

In der Bundesrepublik Deutschland wird die staatsangehörigkeitsrechtliche Stellung der ausländischen Ehegatten von $\$ 9$ RuStAG bestimmt, kraft dessen sie "unter der Voraussetzungen des $\$ 8^{\prime \prime}$ eingebürgert werden sollen, wenn sie ihre bisherige Staatsangehörigkeit verlieren oder aufgeben, und gewährleistet ist, daß sie sich in die deutschen Lebensverhältnisse einordnen; das gilt nicht, wenn der Einbürgerung erhebliche Belange der Bundesrepublik Deutschland, insbesondere solche der äußeren und inneren Sicherheit, sowie der zwischenstaatlichen Beziehungen entgegenstehen. Interessant ist, daß das deutsche Recht dem ausländischen Gatten diese günstigere Stellung bis zum Ablauf eines Jahres nach dem Tode des deutschen Ehegatten oder nach Rechtskraft des die Ehe auflösenden Urteils gibt, falls dem Partner die Sorge für die Person eines Kindes aus der Ehe zusteht, das bereits die deutsche Staatsangehörigkeit besitzt. Gemäß den Erläuterungen in den Einbürgerungsrichtlinien zur Einbürgerung aufgrund von Art. 9 RuStAG wird hinsichtlich der Einordnung in die deutschen Lebensverhältnisse folgendes erwartet (Art. 6.1.3):

"Es genügt, daß die Einordnung in die deutschen Lebensverhältnisse nach dem Umständen des Falles mit Sicherheit zu erwarten ist. Diese Erwartung gründet sich auf den Inlandsaufenthalt und auf den Bestand der Ehe mit dem deutschen Ehegatten. Deshalb ist eine gewisse Dauer des Inlandsaufenthaltes und der Ehe erforderlich. In der Regel soll ein Inlandsaufenthalt als ausreichend angesehen werden, wenn er fünf Jahre oder drei Jahre nach der Eheschließung bestanden hat; für Einbürgerungsbewerber aus dem deutschsprachigen Raum genügt ein Inlandsaufenthalt von zwei Jahren. Die Ehe soll stets zwei Jahre bestanden haben. Wenn nach den tatsächlichen Feststellungen in einem Einzelfall die Einordnung nicht zu erwarten ist, kommt eine Einbürgerung nicht in Betracht".

Der ausländische Ehegatte muß aber grundsätzlich seine vorherige Staatsangehörigkeit aufgeben. Die Richtlinien betonen weiter, daß 3 die Einbürgerung nicht gegen erhebliche Belange der Bundesrepublik verstoßen darf. Interessant ist in diesem Zusammenhang die Richtlinie bezüglich der Einbürgerungsbewerber aus Entwicklungsländern. In der Richtlinie (Nr. 5.2.3) steht dies bezüglich:

"Bei mit deutschen Ehegatten verheirateten Einbürgerungsbewerbern, die Angehörige eines Entwicklungslandes sind und im Rahmen der personellen Entwicklungshilfe eine Aus- oder Weiterbildung erfahren haben, kommt Artikel 6 des Grundgesetzes, der Ehe und Familie unter den besonderen Schutz der staatlichen Rechtsordnung stellt, gegenüber Belangen der Entwicklungspolitik erhebliche Bedeutung zu. Entwicklungspolitische Bedenken gegen eine Einbürgerung können daher zurückgestellt werden, wenn sich der Einbürgerungsbewerber mindestens acht Jahre im Inland rechtmäßig aufhält und sein Abschlußexamen oder eine andere Aus- oder Weiterbildung mindestens seit zwei Jahren beendet hat." 
Aus den Richtlinien geht deshalb herwor, $d a B$ Ehegatten deutscher Bürger unter einfacheren Bedingungen eingebürgert werden als andere Ausländer. Ihre Rechtsstellung ist aber weit von einem Einbürgerungsanspruch entfernt. Im Vergleich zu den Niederlanden fallt die geforderte lange Aufenthaltsfrist (grundsätzlich fünf Jahre) auf und die "weite" Interpretation der erheblichen Belange der Republik. Ein im Ausland lebender Ehegatte kann nur über die Sonderregelung von \& 1 der Verordnung zur Regelung von Staatsangehörigkeitsfragen aus 1942 eingebürgert werden. Positiv fällt jedoch auf, daß ein ausländischer Ehegatte seine Sonderposition nicht unbedingt gleich nach Auflösung der Ehe zu verlieren braucht.

Bis vor kurzem konnte der ausländische Ehegatte eines Franzosen gleich nach Eheschließung durch Optionserklärung die französische Staatsangehörigkeit erwerben (Art. 37.1). Dies ist nun seit kurzem geändert: Der ausländische Ehepartner kann die Optionserklärung erst sechs Monate nach EheschlieBung abgeben; Voraussetzung dafür ist, daß das eheliche Zusammenleben fortdauert und der Ehepartner noch immer französisch ist. Durch die Erklärung wird automatisch die französische Staatsangehörigkeit erworben (Art. 38). Die französische Regierung kann sich aber innerhalb eines Jahres dem Erwerb der Staatsangehörigkeit aufgrund von "indignité ou défaut d'assimilation" (Unwürdigkeit oder mangelnde Assimilierung) widersetzen. Obwohl gerade der letzte Grund für die Regierung in vielen Fällen die Möglichkeit eröffnet, sich der Einbürgerung zu widersetzen, ist die Regelung insgesamt doch großzuigiger als die bisher erwähnten. Die Regierung Chirac hat jedoch Ende 1986 vorgeschlagen, das kontrollierte Optionsrecht des ausländischen Ehegatten zu streichen und durch die Möglichkeit einer erleichterten Einbürgerung zu ersetzen. Dieser Vorschlag gehörte auch zu den Wahltopoi der französischen Präsidentschaftswahlen des Jahres 1988. Aufgrund des Wahlergebnisses dürfte der Vorschlag der Regierung Chirac zumindest vorläufig seine Aktualität verloren haben.

Auch in Großbritannien gibt es eine Sonderregelung für ausländische Ehepartner. Sie werden unter folgenden Bedingungen eingebürgert (Sec. 6 (2) in Verbindung mit Anhang 1 (Schedule 1), Par. 3): Der Betreffende muß mindestens die, dem Einbürgerungsantrag unmittelbar vorausgehenden, drei Jahre mit gültiger Aufenthaltserlaubnis in Großbritannien gelebt haben. Grundsätzlich darf er in diesen drei Jahren Großbritannien nur 270 Tage verlassen haben, seine Aufenthaltserlaubnis muß unbefristet sein und er muß über einen "good-character" verfiggen. Ein Aufenthalt in Großbritannien wird nicht bei Ehegatten von Staatsbürgern gefordert, die im Dienste der Krone im Ausland leben.

Die Stellung der ausländischen Ehegatten eines italienischen Bürgers ist im Gesetz nr. 123 vom 21. April 1983 unübersichtlich formuliert. Art. 1 des Gesetzes bestimmt, daß der ausländische Ehegatte die italienische Staatsangehörigkeit erwirbt, wenn er mindestens sechs Monate in Italien lebt oder drei Jahre nach Eheschließung, unter der Voraussetzung, daß die Ehe dann noch fortdauert und keine Trennung von Tisch und Bett ausgesprochen ist. Der Erwerb der italienischen Staatsangehörigkeit erfolgt aber nicht automatisch. Erstens werden in Art. 2 des Gesetzes bestimmte Personen vom Erwerb der Staatsangehörigkeit ausgeschlossen. Betroffen sind Personen, die wegen bestimmter politischer Straftaten verurteilt sind oder gegen die eine Strafverfolgung wegen solcher Delikte anhängig ist; weiter sind diejenigen ausgeschlossen, die zu einer mehr 
als zweijährigen Gefängnisstrafe verurteilt sind oder aufgnund eines bereits anhängigen Strafverfahrens verurteilt werden können; schließlich diejenigen, die die Staatssicherheit gefährden. Aus Art. 3 des Gesetzes geht dann hervor, daß die Staatsangehörigkeit von dem ausländischen Ehepartner in Prinzip nur auf eigenen Antrag hin erworben werden kann. Bemerkenswert ist aber, daß auch der italienische Partner diese Erklärung zugunsten des einzubürgernden Ehegatten abgeben kann. Die Erklärung wird bei den zuständigen italienischen Behörden abgegeben. Innerhalb eines Jahres muB der ausländische Ehepartner dann durch ein Einbürgerungsdekret eingebürgert werden. Die Einbürgerung darf nur wegen der in Art. 2 ausgeführten Gründe verweigert werden.

In Österreich hat der ausländische Ehegatte unter bestimmten Voraussetzungen gemäß $\S 11 \mathrm{a}$ des österreichischen Staatsangehörigkeitsgesetzes einen bedingten Einbürgerungsanspruch. Wenn der ausländische Ehegatte keinen Wohnsitz in Österreich hat, entsteht der Anspruch nach fünfjähriger Ehe; zusätzlich wird gefordert, daß der österreichische Gatte im Zeitpunkt der Antragstellung schon mindestens zehn Jahre ununterbrochen Staatsbürger ist. Falls der ausländische Ehegatte in Österreich lebt, entsteht der Anspruch schneller. Nach vierjährigem ununterbrochenen Wohnsitz in Österreich entsteht der Anspruch bereits nach einjähriger Ehe, bei dreijährigem Wohnsitz nach zweijähriger Ehe ( $\$ 11$ a Abs. 4). Ein Einbürgerungsanspruch aufgrund des \& 11 a entsteht nicht, wenn der ausländische Gatte früher Österreicher gewesen ist, ihm die Staatsangehörigkeit aber wegen erheblicher Schädligung der österreichischen Interessen oder des Ansehens der Republik im Dienst eines fremden Staates entzogen ist. Obwohl der ausländische Ehegatte u.U. einen Einbürgerungsanspruch hat, müssen die Voraussetzungen des $\$ 10$ Abs. 1, Ziffer 2-8 und Abs. 2 erfüllt sein. Das heißt, daß er im Vergleich zu anderen Personen, die eingebürgert werden möchten, nur der Voraussetzung des $\$ 10$ Abs. 1 Ziffer 1 enthoben ist; es wird nicht gefordert, daß der ausländische Ehegatte bereits seit zehn Jahren in Österreich lebt.

Gemäß schweizerischem Recht erwirbt die Ausländerin, die einen Schweizer Bürger heiratet, noch immer automatisch die schweizerische Staatsangehörigkeit ohne die Möglichkeit, diese auszuschlagen (Art. 3 BüG). Es manifestiert sich also noch das alte "système unitaire". Absolut anders ist die Position des ausländischen Mannes, der eine schweizerische Frau heiratet. Er kann, nachdem er mit seiner schweizerischen Ehefrau mindestens sechs Jahre in der Schweiz zusammengelebt hat, eingebürgert werden, wenn er alle übrigen Voraussetzungen erfüllt.

In Spanien kann der ausländische Ehegatte eines Spaniers nach einjährigem Aufenthalt in Spanien eingebürgert werden, auch wenn die Ehe inzwischen aufgelöst ist. Der ausländische Ehegatte muß auf seine bisherige Staatsangehörigkeit verzichten und einen Treueeid leisten (Art. 20 C.c.esp.) Eine erleichterte Einbürgerung eines im Ausland lebenden Ehegatten eines Spaniers ist nicht vorgesehen.

Wenn man diese Regelungen vergleicht, kann man feststellen, daß ausländische Ehepartner von Staatsbürgern überall unter leichteren Voraussetzungen als andere Ausländer eingebürtert werden können. Dies ist auch berechtigt: durch das Zusammenleben mit einer Person anderer Staatsangehörigkeit werden in der 
Regel enge Beziehungen zu dessen Heimatstaat entstehen, die auf Dauer eine Einbürgerung legitimieren können. Selbstverständlich entstehen solche Beziehungen vor allem dann, wenn das Ehepaar im Inland lebt. Aber auch bei Wohnsitz im Ausland ist es wahrscheinlich, daB sich Beziehungen zum Heimatstaat des Ehegatten entwickeln. Dies ist namentlich der Fall, wenn der Ehegatte durch berufliche Beziehungen mit seinem Heimatstaat verbunden ist. Weiter soll aber auch noch berücksichtigt werden, daß heutzutage Kinder in der Regel iure sanguinis die Staatsangehörigkeit beider Elternteile erwerben, also auch die Kinder des im Ausland lebenden ausländischen Ehepartners die Staatsangehörigkeit dieses Staates besitzen. Diese Tatsache bewirkt haüfig eine zusätzliche psychologische Verbundenheit mit diesem Staat.

Es ist jedoch vor der Hand liegend, daß bei Inlandswohnsitz solch intensive Beziehungen zum Heimatstaat in der Regel schneller entstehen; daher ist eine Einbürgerung dann früher gerechtfertigt als bei Auslandswohnsitz. Dieser Tatsache wird am besten in der italienischen und österreichischen Regelung Rechnung getragen. In Italien entsteht bei Inlandswohnsitz bereits nach sechsmonatiger Ehe ein kontrolliertes Optionsrecht, bei Auslandswohnsitz jedoch erst nach dreijähriger Ehe; bei Auslandswohnsitz ist in Österreich erst nach fünfjähriger Ehe eine Einbürgerung unter erleichterten Bedingungen möglich, bei einem bereits vierjährigen Inlandswohnsitz reicht für eine erleichterte Einbürgerung jedoch bereits eine einjährige Ehe. Diese Differenzierung zwischen Auslandsehen und Inlandsehen ist realistisch und elegant. Der Ehegatte eines Staatsangehörigen, der im Dienste seines Heimatstaates im Ausland lebt, sollte jedoch so behandelt werden als lebe er im Inland. Dies entspricht der britischen und der österreichischen Regelung. Als weniger realistisch abzulehnen sind $\mathrm{m} . \mathrm{E}$. deshalb jene Regelungen, die Inlands- und Auslandsehen gleich behandeln oder bei Auslandswohnsitz überhaupt keine Einbiirgerungsvergünstigungen für den ausländischen Ehepartner kennen.

Auf welche Weise soll ein ausländischer Ehegatte nun die Staatsangehörigkeit seines Partners erwerben können? Die Niederlande, Deutschland, Großbritannien, die Schweiz, Österreich und Spanien sehen lediglich Einbürgerungserleichterungen hinsichtlich der geforderten Wohnsitzfrist vor, die sich in den meisten dieser Staaten auf Null reduzieren kann; Belgien, Frankreich und Italien kennen kontrollierte Optionsrechte. In der Einführung $\mathrm{zu} \& 3.3 .3 .2$ habe ich diese kontrollierten Optionsrechte bereits abgelehnt und möchte deshalb auch an dieser Stelle lediglich die Reduzierung der Wohnsitzforderung befürworten. Im übrigen sollen m.E. die weiteren Einbürgerungsvoraussetzungen, soweit sie in den vorherigen Abschnitten bejaht sind, wie gewöhnlich im Rahmen des Einbürgerungsverfahrens überprüft werden, namentlich also auch, ob der ausländische Ehegatte für ein normales Gespräch ausreichende Sprachkenntnisse hat.

Es muß entschieden werden, wie lang die Ehe mit einem Staatsangehörigen andauern muß, um die Einbürgerungserleichterung zugunsten des ausländischen Ehepartners herbeizuführen. Dabei soll berücksichtigt werden, daß die geforderte Dauer der Ehe so gewählt sein sollte, daß sie - eventuell kombiniert mit einem Wohnsitz im Inland - gewisse Beziehungen zum Inland hervorgerufen hat. Weiter ist darauf zu achten, daß die erforderliche Ehedauer nicht so kurz sein darf, daß Ausländer verführt werden, nur deshalb eine Ehe mit einem Staatsangehörigen zu schließen, um dann relativ schnell die Staatsangehörigkeit des 
Ehepartners erwerben zu können. Die geforderte Ehedauer sollte die Möglichkeit staatsangehörigkeitsrechtlicher Scheinehen minimalisieren. Wenn bereits nach sehr kurzer Ehedauer eingebürgert, beziehungsweise optiert werden kann, besteht auch die Wahrscheinlichkeit, daß Behörden - wenn sie eine Ehe zwecks Staatsangehörigkeitserwerbs vermuten - den Staatsangehörigkeitserwerb durch strengere Interpretation anderer Einbürgerungs- ,beziehungsweise Optionsvoraussetzungen vorzubeugen versuchen. Es empfiehlt sich deshalb, sich bei der Festlegung der für Einbürgerungserleichterungen zu fordernden Ehedauer an der gewöhnlichen Wohnsitzforderung zu orientieren. Für die Niederlande möchte ich deshalb folgende Lösung befürworten. Normalerweise kann ein Ausländer nach fünfjährigem Inlandswohnsitz eingebürgert werden (Art. 8 Abs. 1 Buchstabe $c$ RwNed). Falls nun ein Ausländer nicht im Inland lebt, aber mit einem Niederländer verheiratet ist, soll nach fünfjähriger Ehe eine Einbürgerung möglich sein, soweit die übrigen Einbürgerungsvoraussetzungen, - in dem Umfang sie in den vorherigen Abschnitten bejaht wurden, - erfüllt sind. Soweit ein mit einem Niederländer verheirateter Ausländer während dieser Ehe in den Niederlanden lebt, ist diese im Inland verbrachte Zeit der Ehe auf die geforderte Wohnsitzfrist anzurechnen. Ein Ausländer, der sich also am Tage seiner Ehe mit einem Niederländer in den Niederlanden niederläßt, muß deshalb nach zweieinhalb Jahren eingebürgert werden können. Lebte der betreffende Ausländer schon ein Jahr vor der Eheschließung in den Niederlanden, dann müBte eine zweijährige Ehe mit einem Staatsangehörigen ausreichen, lebte er schon zwei Jahre vor der Ehe im Inland, dann sollte sogar eine anderthalbjährige Ehe ausreichend sein.

Zwei weitere Probleme müssen in diesem Zusammenhang noch erörtert werden. Soll die Ehe mit einem Staatsangehörigen auch einbürgerungsrelevant sein, wenn die Ehegatten offensichtlich nicht mehr zusammenleben? Und soll die Tatsache, daß jemand mit einem Staatsangehörigen verheiratet war, auch noch beachtlich sein, nachdem die Ehe durch Tod dieses Staatsangehörigen oder durch Ehescheidung aufgelöst wurde?

Es ist bemerkenswert, daß nach heutigem niederländischen Recht die Vergünstigungen für den ausländischen Ehepartner eines Niederländers auch dann gelten, wenn die Ehe zwar noch, das eheliche Zusammenleben jedoch nicht mehr fortbesteht. Dagegen fordern z.B. Belgien und Frankreich, daB das eheliche Zusammenleben im Zeitpunkt der Optionserklärung noch fortdauern muB. Italien fordert zwar kein Fortdauern des ehelichen Zusammenlebens, verlangt aber, daß noch keine Trennung von Tisch und Bett ausgesprochen wurde. Eine gewisse Überprüfung des Fortbestehens der Ehe des Ausländers mit dem Staatsangehörigen halte ich für angebracht. Diese Überprïfung darf aber nicht soweit gehen, $\mathrm{daB}$ Behörden die privaten Beziehungen zwischen Ehegatten überprüfen und werten. Deshalb sollte m.E. lediglich überprüft werden, ob die Ehegatten nicht schon von Tisch und Bett getrennt sind oder eine solche Trennung oder gar eine Ehescheidung bei Gericht beantragt wurde. Art. 8 Abs. 2 RwNed ist entsprechend zu ändern.

Andererseits vermag ich nicht einzusehen, weshalb die mit einem Staatsangehörigen verbrachte Ehezeit plötzlich irrelevant wird, nachdem die Ehe durch Tod dieses Staatsangehörigen oder durch Ehescheidung erloschen ist. Wenn wir die heutigen Regelungen studieren, können wir jedoch nur in Deutschland und 
Spanien nach Auflösung der Ehe noch Einbürgerungsvergünstigungen für den ehemaligen Ehepartner eines Staatsangehörigen feststellen, wobei die Vergünstigung in Deutschland lediglich bedingt und auf ein Jahr befristet ist. Die Zeit, die der betreffende Ausländer mit einem Staatsangehörigen verheiratet war, bleibt auch nach Auflösung der Ehe ein Faktor, der bewirken kann, daß tatsächliche Beziehungen mit dem Heimatstaat des verstorbenen oder geschiedenen Ehegatten entstanden sind. Dies gilt selbstverständlich vor allem, wenn aus dieser Ehe Kinder geboren sind; aber auch, wenn dies nicht der Fall war, bildet die betreffende Ehezeit einen integrationsfördernden Faktor. Für die Niederlande möchte ich deshalb vorschlagen, auch nach Auflösung der Ehe die Ehedauer als relevant anzurechnen, wobei allerdings die Zeit, in der bereits Ehescheidung oder Trennung von Tisch und Bett beantragt war, oder die Ehegatten schon von Tisch und Bett getrennt lebten, außer Betracht zu lassen ist.

Die Erleichterung der Einbürgerungsvoraussetzungen für Ehegatten findet heutzutage ihren Ursprung nicht mehr in der Tatsache der Ehe, sondern in der Annahme, daß durch das Zusammenleben eines Ausländers mit einem Staatsangehörigen in der Regel gewisse Beziehungen zu dessen Heimatstaat entstehen. Lediglich die Niederlande haben daraus bis jetzt die Konsequenz gezogen, daß nicht nur eine eheliche, sondern auch eine außereheliche Lebensgemeinschaft, bestimmte Einbürgerungserleichterungen bewirken kann.

Art. 8 Abs. 4 des niederländiscben Staatsangehörigkeitsgesetzes setzt die für Einbürgerung geforderte Aufenthaltsfrist für Unverheiratete, die mindestens seit drei Jahren mit einem unverheirateten niederländischen Staatsangehörigen in einer außerehelichen dauerhaften Beziehung zusammenleben, auf drei Jahre fest. Die Frist von drei Jahren entspricht der Dauer, die in Abs. 2 für eine Ehe gefordert wird. Abs. 4 ist aber so formuliert, daß unverheiratete Partner nicht bei Wohnsitz im Ausland eingebürgert werden können. Die Betreffenden müssen drei Jahre in den Niederlanden zusammengelebt haben. Wichtig ist es, noch einmal ausdrücklich darauf hinzuweisen, daß beide Partner unverheiratet sein müssen. Die Vergünstigung gilt sowohl für hetero- als für homosexuelle Beziehungen.

Diese Regelung zugunsten unverheirateter Partner muß grundsätzlich bejaht werden, weil das Zusammenleben eines Staatsangehörigen und eines Ausländers in einer nichtehelichen Lebensgemeinschaft genauso wie das Zusammenleben in einer Ehe, das Entstehen enger Beziehungen des betreffenden Ausländers zum Heimatstaat seines Partners fördert. Der hetero- oder homosexuelle Charakter dieses Zusammenlebens ist in diesem Zusammenhang irrelevant. Dennoch könnte die niederländische Regelung noch verfeinert werden. Auch bei Auslandswohnsitz kann eine nichteheliche Lebensgemeinschaft zwischen einem Niederländer und einem Ausländer Beziehungen zu den Niederlanden entstehen lassen. In den Niederlanden wird diese Tatsache nicht verneint. Dennoch wurde wohl aus beweisrechtllichen Gründen entschieden, nur diejenigen ausländischen nichtehelichen Lebenspartner eines Niederländers zu priviligieren, die mit ihrem Partner in den Niederlanden leben. Man meinte wohl, daß bei Auslandswohnsitz haüfig das eheähnliche Zusammenleben nicht überzeugend bewiesen werden könnte. Diese an sich verständliche Angst vor Beweisschwierigkeiten läßt aber einige Ausnahmen zu. An erster Stelle müßten auch die ausländischen nichtehelichen Partner von Niederländern, die im niederländischen Staatsdienst im 
Ausland leben, so behandelt werden als lebten sie in den Niederlanden. Weiter wären $\mathrm{m} . \mathrm{E}$. jedenfalls auch diejenigen ausländischen nichtehelichen Partner eines Niederländers zu priviligieren, die in anderen Mitgliedstaaten der Europäischen Gemeinschaft oder in anderen Mitgliedstaaten des Europarates mit ihrem Partner zusammenleben. Außerdem sollte die Regelung zugunsten des ausländischen, nichtehelichen Lebenspartners eines Niederländers den oben unterbreiteten Vorschlägen zur Änderung der staatsangehörigkeitsrechtlichen Stellung des ausländischen Ehepartners eines Niederländers angepaßt werden. 


\subsection{Verlust der Staatsangehörigkeit}

\subsubsection{Einführende Bemerkungen}

Es ist in diesem Rahmen unmöglich, alle Verlustgründe im Staatsangehörigkeitsrecht der hier erwähnten Staaten genau zu analysieren. Es wird hier deshalb nur versucht, einen globalen Überblick über die Verlustgründe des allgemeinen Staatsangehörigkeitsrechts zu geben. Dabei wollen wir uns auf die für Volljährige geltenden Verlustgründe konzentrieren.

\subsubsection{Freiwilliger Erwerb einer fremden Staatsangehörigkeit}

Manche Staaten bestimmen grundsätzlich, daß Staatsangehörige ihre Staatsangehörigkeit verlieren, wenn sie freiwillig eine fremde Staatsangehörigkeit erwerben; andere Staaten kennen keine entsprechende Regelung. $\mathrm{Zu}$ der ersten Gruppe gehören - außer den Niederlanden - Belgien, Deutschland, Italien, Österreich und Spanien, zu der zweiten sind Frankreich, Großbritannien und die Schweiz zu rechnen. Wir wollen nun zuerst die Regelungen der ersten Gruppe näher betrachten und können dabei viele Ausnahmen in Hinblick auf das Grundprinzip beobachten.

Die niederländische Staatsangehörigkeit wird immer verloren, wenn eine ausländische Staatsangehörigkeit von einem wolljährigen Niederländer freiwillig (durch Einbürgerung oder Optionserklärung) erworben wird (Art. 15 unter a RwNed). Es ist dabei unbeachtlich, ob der Betreffende Wohnsitz im In- oder Ausland hat. Die niederländische Regierung kann keine Einwilligung zur Beibehaltung der niederländischen Staatsangehörigkeit geben. Diese Regelung entspricht der vor 1985 geltenden Bestimmung des Art. 7 Ziffer 1 und 3 WNed. Im BW 1838 (Art. 9 Ziffer 1) und im Gesetz 1850 (Art. 10 Ziffer 1) wurde die niederländische Staatsangehörigkeit lediglich durch Einbürgerung im Ausland verloren, also nicht im Falle des Erwerbs durch Optionserklärung. Allerdings muß berücksichtigt werden, daß gemäß BW 1838 und Gesetz 1850 , die niederländische Staatsangehörigkeit durch Niederlassung im Ausland ohne Absicht wieder in die Niederlande zurückzukehren (Art. 9 Ziffer 3 BW 1838; Art. 10 Ziffer 3 Gesetz 1850) verloren wurde.

Nach belgischem Recht gilt grundsätzlich das gleiche; nur diejenigen, die noch wehrpflichtig sind, verlieren die Staatsangehörigkeit im allgemeinen lediglich nach Einwilligung durch den König (Art. $22 \S 1$ Ziffer 1 und $\$ 2 \mathrm{CNB}$; vgl. die entsprechenden früheren Regelungen: Art. 17 Ziffer $1 \mathrm{Cc}$; Art. 11 Ziffer 1 Gesetz 1909; Art. 18 Ziffer 1 Gesetz 1932: die Beschränkung für Wehrpflichtige kennt das belgische Recht seit 1926).

Nach deutschem Recht wird die Staarsangehörigkeit durch freiwilligen Erwerb nur bei Wohnsitz im Ausland verloren ( $\$ 25$ Abs. 2 RuStAG). Nach $\S 25$ Abs. 2 RuStAG kann die Bundesregierung aber auch bei Auslandsaufenthalt schriftlich die Beibehaltung der deutschen Staatsangehörigkeit genehmigen. Von dieser Möglichkeit wird aber nur sehr zurückhaltend Gebrauch gemacht. Art. 1 des von der deutschen Bundesrepublik ratifizierten Straßburger Europaratsabkommens von 1963 bewirkt darüber hinaus auch bei Inlandswohnsitz Verlust der 
deutschen Staatsangehörigkeit, wenn freiwillig die Staatsangehörigkeit einer anderen Vertragspartei erworben wird.

Auch nach italienischem Recht wird die Staatsangehörigkeit grundsätzlich nur beil Wohnsitz im Ausland verloren oder, wenn der Betreffende vorhat sich im Ausland niederzulassen (Art. 8 Ziffer 1 L.c.). Die italienische Regierung kann jedoch bewirken, daß auch bei Wohnsitz im Inland die italienische Staatsangehörigkeit wegen Erwerbs einer fremden Staatsangehörigkeit verloren wird. Normalerweise tritt aber bei Inlandwohnsitz kein Verlust ein; die Staatsangehörigkeit wird dann lediglich verloren, wenn nachträglich der Wohnsitz ins Ausland verlegt wird. Italien ist ebenfalls Partei des eben erwähnten Abkommens von Straßburg. Die Bestimmung des Art. 1 dieses Abkommens haben dennoch für Italliener, die während sie im Inland leben eine ausländische Staatsangehörigkeit erwerben, keine Folgen, da Italien bei der Ratifizierung einen diesbezüglichen Vorbehalt gemacht hat (Vorbehait 1 der Anlage zum Abkommen).

Nach österreichischem Recht wird die österreichische Staatsangehörigkeit im Falle des Erwerbs einer fremden Staatsangehörigkeit grundsätzlich auch bei Wohnsitz im Inland verloren ( $\$ 27$ StBG 1965; vgl. \& 10 BBG 1925 und $\S 9$ StBG 1945/1949). Der Verlust tritt aber nicht ein, wenn dem Betreffenden vorher die Beibehaltung der Staatsbürgerschaft bewilligt worden ist. Die Voraussetzungen unter denen eine solche Bewilligung erteilt werden kann, werden in $\S 28$ aufgezählt, wobei die Bestimmung des $\S 28$ Abs. 1 Ziffer 1 besonders bemerkenswert ist. Die Beibehaltung muß im Interesse Österreichs liegen.

Gemäß spanischem Recht wird die spanische Staatsangehörigkeit grundsätzlich wegen Erwerbs einer fremden Staatsangehörigkeit unter der Voraussetzung verloren, daß der Betreffende im Augenblick des Erwerbs der fremden Staatsangehörigkeit bereits mindestens drei Jahre im Ausland gelebt hat. Bezügllich dieses Prinzips gelten aber viele Ausnahmen. Erstens wird die spanische Staatsangehörigkeit (de origen) nicht verloren, wenn die Staatsangehörigkeit eines lateinamerikanischen Staates, Andorras, der Philippinen, Äquatorial-Guineas, Portugals oder eines Staates, mit dem Spanien ein Abkommen betreffend Doppelstaatsangehörigkeit abgeschlossen hat. Zweitens wird die spanische Staatsangehörigkeit nicht verloren, wenn der Betreffende nachweist, daß der Erwerb der fremden Staatsangehörigkeit aus Gründen der Emigration (por razón de emigración) geschah. Schließlich gilt dieser Verlustgrund nicht, wenn Spanien sich im Kriege befindet.

Es sollen nun die Regelungen der Staaten, die keinen Verlust der Staatsangehörigkeit wegen freiwilligen Erwerbs einer fremden Staatsangehörigkeit vorsehen, beschrieben werden. Nach französischem Recht wird die Staatsangehörigkeit nicht automatisch durch Erwerb einer ausländischen Staatsangehörigkeit verloren. In Zusammenhang mit dem Erwerb einer ausländischen Staatsangehörigkeit kanm aber auf die französische verzichtet werden (A.r. 87 CNF) (siehe $\$$ 3.4.3). Männer unter 35 Jahren können diese Erklärung nur abgeben, wenn sie bereits ihren Militärdienst abgeleistet haben, davon befreit oder ausgenommen sind. Außerdem kann einem Franzosen, der sich als Staatsangehöriger eines fremden Staates verhält die französische Staatsangehörigkeit entzogen werden (Art. 96 Abs. 1) (siehe \$ 3.4.4). 
Auch nach britischem Recht wird die Staatsangehörigkeit nicht durch den Erwerb einer fremden Staatsangehörigkeit verloren, Verzicht ist aber möglich (siehe wieder \$3.4.3). In der Periode 1870-1949 kannte das britische Recht dagegen grandsåtzlich den Verlust der Staatsangehörigkeit wegen Erwerbs einer fremden Staatsangehörigkeit (Sec. 6 NA 1870; Sec. 13 BNA 1914). Von 1870 bis 1914 war aber eine Beibehaltserklärung möglich.

Das schweizerische Recht kennt ebenfalls keinen Verlust der schweizerischen Staatsangehörigkeit wegen Erwerbs einer fremden Staatsangehörigkeit und kannte diesen Grund auch in der Vergangenheit nicht. Dennoch kann man nicht behaupten, daß das schweizerische Recht, - wie z.B. früher Großbritannien - ein Prinzip der "perpetual allegiance" kannte. Aus familienrechtlichen Gründen war Verlust des Schweizer Bürgerrechts möglich (Anerkennung, Legitimation oder Eheschließung). Außerdem bestand die Möglichkeit auf die schweizerische Staatsangehörigkeit zu verzichten. Bei Auslandswohnsitz ist nach heutigem schweizerischen Recht im Prinzip eine Entlassung aus der schweizerischen Staatsangehörigkeit möglich (Art. 42, 43 BüG). Voraussetzung dafür ist, daß der Betreffende mindestens zwanzig Jahre alt ist und eine andere Staatsangehörigkeit besitzt oder diese ihm zugesichert wurde (siehe $\$ 3.4 .3$ ). Im Moment wird eine verheiratete Frau nur zusammen mit ihrem Ehemann entlassen. Diese Bestimmung entfällt jedoch im Entwurf 1986. Außerdem kann die schweizerische Staatsbiirgerschaft durch Auslandsaufenthalt verloren werden (siehe § 3.4.4).

Es ist bemerkenswert, daß von allen besprochenen Regelungen lediglich nach niederländischem Recht durch freiwilligen Erwerb einer fremden Staatsangehörigkeit immer die niederländische verloren wird. Das belgische Recht kennt u.U. einen Wehrpflicht-, das deutsche und italienische einen Wohnsitzvorbehalt und das deutsche und österreichische Recht die Möglichkeit der Beibehaltsgenehmigung. Allerdings sind diese erwähnte Ausnahmen des belgischen, deutschen und osterreichischen Rechts statistisch nicht sehr bedeutsam. Im früheren spanischen Recht wurde die spanische Staatsangehörigkeit ebenfalls grundsätzlich durch Erwerb einer fremden Staatsangehörigkeit verloren (Art. 20 C.c. i.d.F. 1889). Heutzutage ist dies aber in vielen Fällen nicht mehr so. Wir sahen, daß nach französischen, britischen und schweizerischen Recht Erwerb einer fremden Staatsangehörigkeit kein Verlustgrund ist.

Die niederländische Lösung entspricht der des Art. 1 Abs. 1 des Straßburger Abkommens von 1961. Dieses Abkommen sieht in einer Anlage unter Ziffer 1 die Möglichkeit eines Wohnsitzvorbehalts vor. Die Regelung des Art. 1 Abs. 1 des Straßburger Abkommens entspricht aber keiner allgemeinen Tendenz der besprochenen Regelungen. Dies geht schon aus dem vorherigen hervor. Es ist weiter auch nicht zu erwarten, daß diese Regelung in nächster Zukunft stärker akzeptiert wird. Im Rahmen des Europarates wird darüber nachgedacht, wie die Einbürrgerung von Gastarbeiterkindern gefördert werden könnte (siehe § 1.4.2). Eine Möglichkeit wäre, die Staatsangehörïgkeitsregelungen der Heimatstaaten dieser Gastarbeiter dermaßen zu revidieren, daß Erwerb einer fremden Staatsangehörigkeit nicht mehr ohne weiteres Verlust der bisherigen Staatsangehörigkeit bewirkt. Die spanische Bestimmung, wonach die Staatsangehörigkeit nicht verloren wird, wenn eine fremde Staatsangehörigkeit "por razón de emigración" erworben wurde, entspricht schon dieser Tendenz. 
Eine Regelung zugunsten des Personenkreises, der aus Emigrationsgründen eine andere Staatsangehörigkeit erwerben will, kann allerdings nur wirklich zur Geltung kommen, wenn die Staaten deren Staatsangehörigkeit begehrt wird, auf die Forderung verzichten, wonach das Mögliche getan werden muß, um die bisherige Staatsangehörigkeit zu verlieren (siehe dazu \$ 3.3.4.8). Die Staaten müssen akzeptieren, daß ihre Neubürger auch noch mit ihren bisherigen Heimatstaaten durch staatsangehörigkeitsrechtliche Bande verbunden bleiben.

Wenn Staaten aber bei Einbürgerungen auf die Forderung verzichten, daß die bisherige Staatsangehörigkeit möglichst verloren wird, ist nicht einzusehen, weshalb die eigenen Bürger immer ihre Staatsangehörigkeit verlieren sollen, wenn sie freiwillig eine andere erwerben. Folglich muß heute die Regelung des Art. I Abs. 1 des Straßburgers Abkommens in Frage gestellt werden. Ist es wirklich angemessen anzunehmen, daß die Bande zwischen einer Person, die freiwillig eine andere Staatsangehörigkeit erwirbt, und ihrem bisherigen Heimatstaat durch den Erwerb der fremden Staatsangehörigkeit dermaßen geschwächt werden, daß Verlust der bisherigen Staatsangehörigkeit wegen Fehlens eines "genuine link" geboten ist? Wird eine Bejahung dieser Frage - wie in Art. 1 Abs. 1 des Straßburger Abkommens - nicht von einem blinden Kampf gegen Doppelstaatlichkeit eingegeben, wobei das Wesen der Staatsangehörigkeit - die Manifestierung von engen Beziehungen zwischen einer Person und einem Staat - im Feuer des Gefechts aus den Augen verloren wird? Ist es nicht eher eigenartig und unsachgerecht im Falle eines Erwerbs einer fremden Staatsangehörigkeit von einem Moment auf den anderen das Fehlen eines "genuine link" zu folgern? GewiB gibt es viele Fälle, bei denen der Erwerb der fremden Staatsangehörigkeit die endgültige Besiegelung einer allmählichen Verfremdung von dem bisherigen Heimatstaat darstellt. Der Verlust der bisherigen Staatsangehörigkeit ist dann angemessen. Ebenso sind aber auch zahlreiche Fälle nachzuweisen, in denen die Beziehungen zum bisherigen Heimatstaat aufrecht erhalten bleiben und der Erwerb der neuen Staatsangehörigkeit lediglich ein Zeichen der allmählichen Integrierung in den anderen Staat darstellt.

Wenn man die Lösung des Art. 1 Abs. 1 des Straßburger Abkommens verlassen möchte, wäre die weitgehendste Konsequenz, daß die bisherige Staatsangehörigkeit, im Falle von Erwerb einer fremden Staatsangehörigkeit, immer beibehalten bliebe. Jene Lösung würde aber die eben schon erwähnte Tatsache mißachten, $\mathrm{daB}$ in vielen Fällen der Erwerb einer fremden Staatsangehörigkeit doch die Besiegelung einer langsamen Entfremdung vom bisherigen Heimatstaat darstellt. Sie ist deshalb abzulehnen. Eine andere Möglichkeit wäre, jedenfalls bei Inlandswobnsitz durch den Erwerb einer fremden Staatsangehörigkeit keinen Verlust der bisherigen Staatsangehörigkeit auftreten zu lassen, weil der Inlandsaufenthalt garantiert, daß zumindest vorläufig noch eine enge Beziehung zum bisherige Heimatstaat bestehen bleibt. Dies zeigt sich übrigens auch dadurch, daß im Falle einer doppelten Staatsangehörigkeit meistens die alte Staatsangehörigkeit gerade wegen des Wohnsitzes als die effektive beurteilt werden wird. Erwerb einer fremden Staatsangehörigkeit bei Auslandswohnsitz sollte dahingegen im Prinzip Verlust der bisherigen Staatsangehörigkeit verursachen, weil dieser Erwerb in der Regel wohl auf eine Entfremdung deutet. Auch von diesem Prinzip müßten aber einige Ausnahmen gemacht werden. Erstens wäre eine Ausnahme angemessen, wenn die Staatsangehörigkeit eines im nahen Ausland gelegenen Staates erworben wird. Die heutige Verkehrsmittel machen es in 
dem Falle möglich, weiterhin intensive Kontakte zu dem bisherigen Heimatstaat zu pflegen. Im Falle der Niederlande wäre jedenfalls zu überlegen, ob eine solche Ausnahme nicht für den Erwerb der Staatsangehörigkeit eines anderen EG-Staates eingeführt werden müßte. Dabei wăre allerdings nicht nur die geographische Nähe der anderen EG-Staaten ein Argument für diese Ausnahme, sondern auch die Tatsache, daß sämtliche EG-Staatsangehörigkeiten gleichermaßen die Freizügigkeit in den Territorien der anderen EG-Staaten vermitteln (siehe auch $\$ 1.4 .2$ und 3.3.4.8). Zu vertreten wäre auch, eine Ausnahme für den Erwerb der Staatsangehörigkeit eines anderen Mitgliedstaates des Europarates zu machen. Zweitens wäre eine Ausnahme zu machen, wenn vor Erwerb der fremden Staatsangehörigkeit eine Exklärung abgegeben wurde, die bisherige Staatsangehörigkeit beibehalten zu wollen. Eine solche Regelung ist $\mathrm{m} . \mathrm{E}$. der spanischen Bestimmung, wonach eine fremde Staatsangehörigkeit nicht verloren wird, wenn sie aus Gründen der Emigration erworben wurde, vorzuziehen. Es ist im Einzelfall häufig schwierig zu bestimmen, welche Gründe jeweils zur Beantragung einer anderen Staatsangehörigkeit geführt haben. Übrigens sei bemerkt, daß in der spanischen Praxis immer dann Erwerb aus Gründen der Emigration angenommen wird, wenn die betreffenden Personen dies behaupten. Die Konstruktion einer Beibehaltungserklärung wäre deshalb auch im spanischen Recht realistischer.

Eine Alternative zu der Konstruktion einer Beibehaltungserklärung wäre die einer Beibehaltungsgenehmigung. Wenn die letzte Konstruktion gewählt würde, wäre aber genau aufzuzählen, in welchen Fällen eine solche Beibehaltungsgenehmigung abzugeben ist. Hierbei müßten die Fälle Berücksichtigung finden, bei denen angenommen werden kann, daß die betreffenden Personen noch intensive Kontakte zu dem bisherigen Heimatstaat pflegen werden. Diese Konstruktion lehne ich jedoch $a b$ und möchte befürworten, es der einzelnen Person zu ïberlassen, durch eine Beibehaltungserklärung zu manifestieren, ob sie glaubt fortan noch Bande mit dem bisherigen Heimatstaat zu haben.

Wird nun die Möglichkeit einer Beibehaltungserklärung gewählt, ist zu überlegen, ob eine solche Erklärung die umbefristete oder befristete Beibehaltung der bisherigen Staatsangehörigkeit bewirken soll. Da im Laufe der Zeit die Beziehungen zu dem bisherigen Heimatstaat doch abschwächen können, ist m.E. eine befristete Wirkung der Beibehaltungserklärung zu befürworten. Dabei wäre an folgende Regelung zu denken: Eine Erklärung bewirkt, daß die bisherige Staatsangehörigkeit für eine Frist von zehn Jahren beibehalten wird. Vor Ablaufen dieser Frist kann die Beibehaltung durch eine neue Erklärung mit jeweils zehn Jahren verlängert werden. Unterlassung einer Erklärungsabgabe bewirkt dann Verlust der bisherigen Staatsangehörigkeit (vgl. die alte Konstruktion des Art. 7 Ziffer 5 RwNed, worüber auch $\$ 3.4 .4$ ).

Schließlich sei darauf hingewiesen, daß die Aufgabe von Art. 1 Abs. 1 des Straßburger Abkommens keineswegs das Verlassen der Grundsätze dieses Abkommens zu bedeuten hat. Die von Art. 2 dieses Abkommens vorgesehene grundsätzliche Möglichkeit eines Verzichts auf eine Staatsangehörigkeit im Falle einer doppelten Staatsangehörigkeit soll weiterhin gefördert werden, auch bei Inlandsaufenthalt (siehe \$ 3.4.3). Weiter wäre in einem Abkommen zu vereinbaren, unter welchen Umständen die Staatsangehörigkeit durch langjährigen Auslandsaufenthalt verloren wird (siehe darüber \$ 3.4.4). Die Abschwächung 
des Verlusttatbestands bei freiwilligem Erwerb einer fremden Staatsangehörigkeit könnte also durch eine Verschärfung des Verlusttatbestands bei langjährigem Auslandsaufenthalt kompensiert werden.

\subsubsection{Verzicht oder Entlassung}

Die meisten in diesem Buch besprochenen Staaten kennen für Doppelstaatler die grundsätzliche Möglichkeit, um auf die Staatsangehörigkeit der betreffenden Staaten zu verzichten. Ausnahmen bilden lediglich Frankreich und Spanien, die keine allgemeine Verzichtsbestimmung kennen. Nach französischem Recht ist aber in mehreren besonderen Fällen eine Verzichtsmöglichkeit gegeben (u.a. Art. 19 Abs. 1; Art. 24 Abs. 1; Art. 87; Art. 94 Abs. 1 CNF). Das spanische Staatsangehörigkeitsrecht kennt in Art. 23 C.c.esp einige besonderen Fälle, in denen auf die spanische Staatsangehörigkeit verzichtet werden kann. Wir wollen nun die Verzichtsregelungen der übrigen Staaten näher betrachten. Dabei fallen namentlich mehrere Ausnahmen auf die allgemeine Verzichtsmöglichkeit auf.

Wenn eine volljährige Person neben der niederländischen Staatsangehörigkeit noch eine weitere Staatsangehörigkeit besitzt, ist immer Verzicht auf die niederländische Staatsangehörigkeit möglich, dies gilt auch bei Inlandswohnsitz. Als allgemeine Regelung ist dieser Grundsatz im niederländischen Staatsangehörigkeitsrecht zum ersten Mal 1985 formulient. Seit 1893 gab es jedoch mehrere Fälle, in denen Verzicht auf die niederländische Staatsangehörigkeit möglich war (Art. 6 Abs. 1, Art. 9 WNed i.d.F. 1892). Seit 1936 konnte jeder volljährige niederländischer Mann oder jede unverheiratete volljährige Niederländerin, die eine andere Staatsangehörigkeit besaßen und beide Staatsangehörigkeiten ohne eigene Willenserklärung erworben hatten, bei Auslandswohnsitz auf die niederländische verzichten (Art. 7 Ziffer 2 WNed i.d.F. 1936).

Nach belgischem Recht gilt grundsätzlich das gleiche wie im heutigen niederländischen Recht; nur Wehrpflichtige brauchen eine Genehmigung des Königs (Art. $22 \S 1$ Ziffer 2 und $\$ 2 \mathrm{CNB}$ ). Ferner ist nach belgischem Recht auch ein Verzicht möglich, wenn der Betreffende neben der belgischen Staatsangehörigkeit zwar noch keine andere Staatsangehörigkeit besitzt, aber eine fremde Staatsangehörigkeit als Folge des Verzichts erwerben wird. In früheren Regelungen waren lediglich einige Sonderyorschriften (siehe Art. 6, 12, 14 Gesetz 1909 und Art. 4, 5, 18 quater und 21 Gesetz 1932) verankert.

Nach deutschem Recht gelten ähnliche Beschränkungsmöglichkeiten bezüglich des Verzichts. Nach \$26 RuStAG kann ein Deutscher, der Doppelstaatler ist, auf die deutsche Staatsangehörigkeit verzichten. Dazu bedarf es aber einer behördlichen Genehmigung. Die behördliche Genehmigung darf nur verweigert werden, wenn der Betreffende im deutschen öffentlichen Dienst steht oder noch wehrpflichtig ist. Diese Verweigerungsgründe gelten aber nicht, wenn der Betreffende bereits seit mindestens zehn Jahren im Ausland lebt oder bereits seinen Militärdienst geleistet hat. Das deutsche Recht kennt neben der Möglichkeit des Verzichts noch die der Entlassung. Nach $\S 18$ RuStAG wird ein Deutscher auf Antrag aus der Staatsangehörigkeit entlassen "wenn er den Erwerb einer ausländischen Staatsangehörigkeit beantragt und ihm die zuständige Stelle die Verleihung zugesichert hat". Die Entlassung wird nicht erteilt, wenn es sich um Personen im deutschen öffentlichen Dienst handelt oder um Wehrpflichtige, 
solange nicht der Verteidigungsminister erklärt hat, daß gegen die Entlassung keine Bedenken bestehen ( $\$ 22$ Ziffer 2 RuStAG).

Nach britischem Recht (Sec. 12 BNA 1981) können Doppelstaatler auf die britische Staatsangehörigkeit verzichten. Ein Vorbehalt besteht nur für Kriegszeiten.

Ein Doppelstaatler kann nach Art. 8 des italienischen Staatsangehörigkeitsgesetzes auf die italienische Staatsangehörigkeit verzichten, falls er im Ausland lebt oder sich dort niederlassen wird. Bei Wohnsitz im Inland kann die italienische Regierung den Verzicht gestatten. An dieser Stelle sei weiter auf die "Wahlpflicht" eines Doppelstaatlers hingewiesen. Ein Doppelstaatler muß innerhalb eines Jahres nach seiner Volljährigkeit zwischen seinen Staatsangehörigkeiten wählen (Art. 5 Abs. 2 Gesetz Nr. 123 vom 21 April 1983). Personen, die aufgrund von Art. 3 Ziffer 3 L.c. automatisch die italienische Staatsangehörigkeit erwerben, können diese ausschlagen.

Auch österreichische Doppelstaatler können im Prinzip auf die österreichische Staatsangehörigkeit verzichten (\& 37 StBG 1985). Unter einigen Umständen kann derjenige, der noch keine fünf (in StBG 1965 noch: zehn) Jahre ununterbrochen Wohnsitz auBerhalb Österreich hat, nicht auf die österreichische Staatsangehörigkeit verzichten. Dies ist der Fall, wenn gegen den Betreffenden wegen einer strafbaren Handlung, die mit mehr als sechs Monate Freiheitsstrafe bedroht ist, ein Strafverfahren oder eine Strafverfolgung läuft. Männer dürfen weiter nicht auf die Staatsangehörigkeit verzichten, falls sie im Bundesheer beschäftigt sind oder - wenn sie zwischen 16 und 36 Jahre alt sind - noch Millitärdienst leisten müssen.

Auch die Schweiz kennt grundsätzlich nur eine Entlassungsmöglichkeit für diejenigen, die Wohnsitz im Ausland haben. Die Betreffenden müssen mindestens 20 Jahre alt sein und entweder neben der schweizerischen noch eine andere Staatsangehörigkeit besitzen oder eine andere Staatsangehörigkeit muß bereits zugesichert sein.

Wenn wir die beschriebenen Regelungen überblicken, ist festzustellen, daß nur in den Niederlanden von Doppelstaatlern immer auf die Staatsangehörigkeit verzichtet werden kann. Belgien, Deutschland und Österreich kennen u.U. Wehrpflichtvorbehalte, Großbritannien einen Vorbehallt für Kriegszeiten, während Italien und die Schweiz grundsätzlich nur bei Auslandswohnsitz Verzicht gestatten; Österreich kennt schließlich noch einen Vorbehalt bezüglich Personen, die strafbare Handlungen begangen haben. Frankreich und Spanien kennen keine allgemeine Regelung des Verzichts. Die niederländische Regelung entspricht der des Straßburger Abkommens 1963.

Bemerkenswert ist, daß Belgien und Deutschland auch die Möglichkeit des Verzichts, beziehungsweise der Entlassung für Personen kennen, die zwar keine Doppelstaatler sind, aber eine andere Staatsangehörigkeit erwerben wollen.

Der in einigen Staaten gemachte Wehrpflichtsvorbehalt ist nicht unverständlich, m.E. aber heutzutage überholt. Dies gilt jedenfalls dann, wenn derjenige, der auf eine Staatsangehörigkeit verzichten möchte, neben dieser Staatsangehörigkeit noch die eines Staates besitzt, mit dem ein Abkommen zur Vermeidung doppel- 
ter Wehrpflicht besteht. Auch im Verhältnis zu anderen Staaten sollte der Abschluß solcher Abkommen angestrebt werden. Die Lösung von Problemen der Wehrpflicht über staatsangehörigkeitsrechtliche Konstruktionen ist unsachgemäB. Auch der britische Vorbehalt für Kriegszeiten ist unter diesem Gesichtspunkt abzulehnen.

Etwas seltsam ist der österreichische Vorbehalt für Personen, die strafbare Handlungen begangen haben. Auch wenn solche Personen die österreichische Staatsangehörigkeit verlieren, bleibt ein österreichisches Strafverfahren grundsätzlich möglich. Allerdings muß eingeräumt werden, daß sich u.U. das Auslieferungsverfahren bezüglich des Betroffenen erschwert.

Die Einschränkung der Verzichtsmöglichkeit auf diejenigen, die im Ausland leben, kann Individuen in bestimmten Fällen in Schwierigkeiten bringen. Dies ist namentlich der Fall, wenn die betreffenden Personen neben der Staatsangehörigkeit ihres Wohnsitzstaates noch die Staatsangehörigkeit eines anderen Staates besitzen, dessen Staatsangehörigkeitsrecht für Mehrstaatler eine Wahlverpflichtung zwischen ihren Staatsangehörigkeiten kennt. So verpflichtet z.B. Japan Personen, die neben der japanischen noch eine andere Staatsangehörigkeit besitzen, im 21. Lebensjahr zwischen ihren Staatsangehörigkeiten zu wählen. Bei der Wahl für die japanische Staatsangehörigkeit, muB der Verzicht auf die andere(n) Staatsangehörigkeit(en) nachgewiesen werden. Wenn aber nun eine Person gerade wohnhaft in dem Staat ist, auf dessen Staatsangehörigkeit er zugunsten der japanischen verzichten möchte, treten erhebliche Schwierigkeiten auf, wenn dieser Staat seinen Bürgern nicht zugesteht, bei Inlandswohnsitz auf die Staatsangehörigkeit zu verzichten. Die Regelung, wonach bei Inlandswohnsitz ein Verzicht unmöglich ist, muß deshalb abgelehnt werden.

Für die Inlandseinschränkung der Verzichtsmöglichkeit spricht allerdings, daß im Moment des Verzicht aufgrund des Wohnsitzes eindeutig eine enge Beziehung zwischen der betreffenden Person und dem Staat, auf dessen Staatsangehörigkeit sie verzichten möchte, vorhanden ist. Objektiv betrachtet, würde man daher sagen, daß diese intensive Beziehung auch vermutlich weiterhin bestehen bleibt und damit der Besitz der Staatsangehörigkeit des Wohnsitzstaates in der Zukunft angemessen ist. Indessen ist aber der subjektive Standpunkt vorzuziehen. Wenn ein Doppelstaatler auf die Staatsangehörigkeit seines Wohnsitzstaates verzichtet, gibt er damit zu erkennen, daß seines Erachtens der Schwerpunkt seines Lebens in Zukunft nicht im seinem jetzigen Wohnsitzstaat liegen wird. Der Wohnsitzstaat hat m.E. diese subjektive Ansicht seines Bürgers $\mathrm{zu}$ respektieren.

Das Fehlen einer allgemeinen Verzichtsregelung im französischen und spanischen Recht ist zu bedauem. Auch ist zu konstatieren, daß der CNF an Ubersichtlichkeit gewinnen würde, wenn die vielen, verschiedenen Verzichtsmöglichkeiten von heute durch eine einheitliche Regelung ersetzt würden.

So eben wurden sämtliche Einschränkungen bezïglich der Verzichtsmöglichkeit für Doppelstaatler abgelehnt. Dieser Standpunkt geht erheblich weiter, als die Vorschrift des Art. 2 des Straßburger Abkommens von 1963. Abs. 1 dieses Artikels sieht vor, daß ein Mehrstaatler auf eine oder mehrere seiner Staatsangehörigkeiten verzichten kann, sofern die Vertragspartei, auf deren Staatsangehörig- 
keit er verzichten will, dies genehmigt. Hinsichtlich dieser Genehmigung betont Abs. 2, daB diese nicht verweigert werden darf, falls der Betroffene schon seit mindestens zehn Jahren seinen gewöhnlichen Aufenthalt im Ausland und zwar im Hoheitsgebiet derjenigen Vertragspartei hat, deren Staatsangehörigkeit er beibehalten will. Aus den vorherigen Erörterungen geht hervor, daB ich eine erhebliche Verschärfung dieser Bestimmung begrüßen würde.

Es wurde bereits darauf hingewiesen $d a \beta$ das belgische und deutsche Recht eine Verzichts-, beziehungsweise Entlassungsmöglichkeit kennen, wenn eine Person zwar kein Doppelstaatler ist, aber der Verlust der bisherigen Staatsangehörigkeit notwendig ist, um eine andere Staatsangehörigkeit zu erwerben. Eine solche Verzichts- oder Entlassungsmöglichkeit ist namentlich dann von Bedeutung, wenn der Staat, dessen Staatsangehörigkeit erworben werden soll, für den Erwerb dieser Staatsangehörigkeit den Nachweis fordert, daß die bisherige Staatsangehörigkeit bereits verloren ist oder durch den Erwerb der neuen Staatsangehörigkeit automatisch verloren wird. Das niederländische Staatsangehörigkeitsrecht kennt eine solche Möglichkeit nicht. Im Moment besteht für eine derartige Regelung auch kein Bedraf, da gemäß Art. 15 Buchstabe a RwNed die Staatsangehörigkeit immer verloren wird. Falls aber jene Bestimmung - wie in $\$ 3.4 .2$ befürwortet - abgeschwächt würde, wäre es wesentlich, eine Verzicht- oder Entlassungsmöglichkeit wie sie im belgischen und deutschen Recht vorgesehen ist, auch im niederländischen Recht zu schaffen. Nicht notwendig ist dahingegen m.E., die Verzichtsregelung des Art. 15 Buchstabe b RwNed zu ändern. Zwar geht diese Regelung wohl grundsätzlich davon aus, daß eine Verzichtserklärung bedingungslos mit unmittelbarer Wirkung abgegeben wird, es wäre sicher jedoch nicht rechtswidrig, die Verzichtserklärung unter der auflösenden Bedingung, innerhalb einer bestimmten Frist keine andere Staatsangehörigkeit zu erwerben, abzugeben. Eine Sonderregelung wie im belgischen und deutschen Recht erübrigt sich damit.

\subsubsection{Langjähriger Auslandsaufenthalt}

Nach niederländischem, belgischem und schweizerischem Recht wird die Staatsangehörigkeit wegen langjährigen Auslandsaufenthalts verloren. In Frankreich gilt eine vergleichbare Regelung. Diese Regelungen verdienen eine nähere Betrachtung.

Wenn ein Niederländer nach seiner Volljährigkeit, während eines ununterbrochenen Zeitabschnittes von zehn Jahren außerhalb der Niederlande in dem Land lebt, wo er geboren ist und dessen Staatsangehörigkeit er ebenfalls besitzt, verliert er die niederländische Staatsangehörigkeit. Eine Ausnahme gilt nur für diejenigen, die im Dienst der Niederlande stehen. Diese seit 1985 geltende Verlustbestimmung ist einerseits enger, andererseits weiter als die bisherige. Bis 1985 galt eine entsprechende Verlustregelung fuir alle im Ausland geborenen Niederländer, auch wenn sie neben der niederländischen keine fremde Staatsangehörigkeit besaßen; dieser Verlustgrund konnte folglich Staatenlosigkeit verursachen (Art. 7 Ziffer 3 RwNed. i.d.F. 1910). Andererseits konnten die betreffenden Niederländer durch eine Erklärung, weiterhin Niederländer bleiben zu wollen, dem Verlust vorbeugen. Diese letzte Möglichkeit ist nun nicht mehr gegeben. Von 1893 bis 1910 galt diese Verlustregelung sogar für alle im Ausland lebende Niederländer, auch wenn sie im Inland geboren waren (Art. 7 Ziffer 3 
WNed i.d.F. 1892). Das BW 1838 (Ant. 9 Ziffer 3) und das Gesetz 1850 (Ant. 10 Ziffer 3) kannten Verlust der niederländischen Staatsangehörigkeit durch Niederlassung in Ausland mit der eindeutigen Absicht nicht wieder in die Niederlande zurückzukehren.

Das belgische Recht (Art. $22 \S 1$, Ziffer 6) kennt seit 1985 eine entsprechende Regelung, die aber in Einzelheiten auf interessante Weise von der niederländischen Regel abweicht. Der im Ausland geborene Belgier verliert diese Staatsangehörigkeit, wenn er auch eine andere Staatsangehörigkeit besitzt und nach seinem 18. Lebensjahr zehn ununterbrochenene Jahre im Ausland lebt. Anders als gemäß der niederländischen Regelung ist dabei für den Verlust nicht der Auslandsaufenthalt auf das Land der anderen Staatsangehörigkeit beschrănkt. Eine Ausnahme gilt für denjenigen, der im Dienste der belgischen Regierung, einer belgischen Gesellschaft, eines belgischen Vereins oder durch Vermittlung der belgischen Regierung in Ausland arbeitet. Bevor er die Staatsangehörigkeit verliert, kann er eine Beibehaltungserklärung abgeben. In diesem Falle beginnt eine neue Frist von zehn Jahren. Vor 1985 kannte das belgische Recht keinen entsprechenden Verlustgrund, sieht man von der Bestimmung des Art. 17 Ziffer 3 C.c. (Verlust wegen Niederlassung im Ausland ohne Rückkehrwillen) ab, die bis 1909 in Belgien galt.

In der Schweiz gilt ein ähnlicher Verlustgrund seit 1953. Bis dahin konnte die schweizerische Staatsangehörigkeit nicht wegen längerem Auslandsaufenthalt verloren werden. Seitdem verlor das im Ausland geborene Kind eines ebenfalls im Ausland geborenen Schweizer Bürgers, das noch eine andere Staatsangehörigkeit besaß, die schweizerische Staatsangehörigkeit mit Vollendung des 22. Lebensjahres, wenn es bis dahin nicht bei schweizerischen Behörden gemeldet war (Art. 10 Abs. 1 BüG i.d.F. 1952). Jede Mitteilung von Eltern, Verwandten oder Bekannten im Hinblick auf die Eintragung in das heimatliche Register, die Immatrikulation oder die Ausstellung von Ausweisen genügten (Abs. 3). In Jahre 1984 wurde dieser Verlustgrund erheblich verschärft. Ohne Meldung wird fortan die schweizerische Staatsangehörigkeit am 22. Geburtstag von jeder im Ausland geborenen Person verloren, die noch eine andere Staatsangehörigkeit besitzt. In einem neuen zweiten Absatz wird verdeutlicht, daß ein solcher Verlust sich auch auf die Kinder des Betreffenden erstreckt.

Eine gewisse Ähnlichkeit mit den eben erwähnten Regelungen hat die französische Bestimmung des Art. 95 CNF. Hiernach kann durch Gerichtsurteil festgestellt werden, daß jemand die französische Staatsangehörigkeit verloren hat, wenn der Betreffende, zwrar iure sanguinis die französische Staatsangehörigkeit erworben hat, aber nicht den Status eines französischen Staatsangehörigen besitzt und niemals einen gewöhnlichen Wohnsitz in Frankreich hatte. Ein solches. Urteil kann nur ausgesprochen werden, wenn auch seine Vorfahren, von denen er die französische Staatsangehörigkeit abgeleitet hat, seit mindestens einem halben Jahrhundert selbst weder den Status von Franzosen besaßen, noch ihren Wohnsitz in Frankreich hatten.

Die übrigen Staaten kennen heutzutage keinen Verlust der Staatsangehörigkeit wegen Auslandsaufenthalts. In früheren Regelungen war ein solcher Verlustgrund dagegen häufig vorgesehen. Diese Regelungen hatten ihr Vorbild in der bis 1889 geltenden Bestimmung des Art. 17 Ziffer 3 C.c. 1804, die vorsah, daß 
die französische Staatsangehörigkeit durch Niederlassung im Ausland ohne Rückkehrabsicht verloren wurde (vgl. auch die bereits erwähnte Regelung des Art. 9 Ziffer 3 des niederländischen BW 1838 und des Art. 10 Ziffer 3 des niederländischen Gesetzes 1850). Eine entsprechende Bestimmung fand sich bis 1925 im österreichischen Art. 32 ABGB. In Spanien bewirkte es bis 1954 Verlust der spanischen Staatsangehörigkeit, wenn ein Spanier sich in einem Staat niederließ, wo er kraft Niederlassung die Staatsangehörigkeit erwarb, ohne sich in die Register des zuständigen spanischen diplomatischen Behörden einzutragen (Art. 4 Ziffer 4 und 112 des Gesetzes vom 17. Juni 1870 und Art. 26 C.c.esp. i.d.F. 1889). In Deutschland war ein entsprechender Verlustgrund vor 1914 ebenfalls bekannt. Gemäß \& 21 RuStAG 1870 verloren Deutsche, die das Reichsgebiet verlassen hatten und sich zehn Jahre lang ununterbrochen im Ausland aufhielten dadurch ihre Staatsangehörigkeit, falls sie sich nicht in die Matrikelliste eines Reichskonsulat eintrugen (vgl. weiter die Entziehung der deutschen Staatsangehörigkeit von im Ausland lebenden Juden kraft $\& 2$ der Verordnung vom 25. November 1941). Hingewiesen sei schließlich noch auf Art. 11 Ziffer 1 C.c.it. i.d.F. 1865, kraft dessen ein Italiener auf seine Staatsangehörigkeit unter der Bedingung verzichten konnte, daß er anschließend seinen Aufenthalt ins Ausland verlegte. Großbritannien hingegen kannte zu keinem Zeitpunkt eine allgemeine Regelung des Verlusts der britischen Staatsangehörigkeit durch Auslandsaufenthalt.

Heutzutage bewirkt also lediglich in den Niederlanden, Belgien und der Schweiz u.U. Auslandsaufenthalt Verlust der Staatsangehörigkeit. In Frankreich kann die Staatsangehörigkeit im Falle eines sehr langen Auslandsaufenthalts entzogen werden. Diese letzte Konstruktion ist $\mathrm{m}$.E. abzulehnen, da es vom zufälligen Informationsstand französischer Behörden abhängt, ob von dieser Entzugsmöglichkeit Gebrauch gemacht wird. Die Anwendung dieser Entzugsregelung kann dem Geruch der Willkur daher nicht entgehen. Die systematischen Regelungen der drei anderen Staaten verdienen somit den Vorzug.

Es ist m.E. grundsätzlich zu befürworten, daß eine Staatsangehörigkeit bei Auslandswohnsitz nicht uneingeschränkt iure sanguinis in perpetuum weitergegeben werden kann. Zu einem bestimmten Zeitpunkt muß festgestellt werden, daß die Beziehungen einer Person zum ursprünglichen Heimatstaat außerordentlich schwach geworden sind, wodurch es nicht mehr angemessen erscheint, daß die betreffende Person die Staatsangehörigkeit dieses Staates weiterhin innehat. Die Staatsangehörigkeit kann dann nicht mehr als die Manifestation einer reellen Beziehung aufgefaßt werden. Es ist daher geboten, dann die ius sanguinis-Kette aufzubrechen.

Eine Unterbrechung der ius sanguinis-Kette kann in verschiedenen Formen bewirkt werden. Eine Möglichkeit ist, daß bei Auslandsgeburt nicht immer die Staatsangehörigkeit der Eltern iure sanguinis vermittelt wird. Belgien und Großbritannien haben dieser Konstruktion den Vorzug gegeben, die in $\$ 3.2 .1$ besprochen wurde. Ein anderer Weg ist, im Ausland geborene Doppelstaatler vor einem gewissen Alter zu verpflichten, zwischen den von ihnen erworbenen Staatsangehörigkeiten zu wählen. Verwiesen sei auf die Erörterungen in den $\$ 3.2 .1$ und 3.4.7. In $\$ 3.2 .1$ habe ich bereits angeführt, daß ich diese Konstruktion anderen Lösungen. zumal auch wegen des Gesichtspunktes der staatsangehörigkeitsrechtlichen Selbstbestimmung, vorziehe. 
Eine andere Möglichkeit der Aufbrechung der ius sanguinis-Kette ist es, dem längeren Auslandsaufenthalt in Kombination mit einer Auslandsgeburt Bedeutung beizumessen. Bei einem Vergleich der niederländischen, belgischen und schweizerischen Regelungen en détail, fallen mun folgende Unterschiede auf. Die belgische und schweizerische Staatsangehörigkeit kann wegen Auslandsaufenthalt nur verloren werden, wenn der Betroffene noch eine andere Staatsangehörigkeit besitzt. Dieser Verlustgrund darf also keine Staatenlosigkeit bewirken. Insoweit ist die Regel in den Niederlanden identisch. Daneben wird hier aber gefordert, daß der Betreffende zusätzlich zur niederländischen Staatsangehörigkeit noch die Staatsangehörigkeit des Staates besitzt, wo er lebt und auch geboren ist. Diese zusåtzlichen Bedingungen, die erst 1985 in das niederländische Staatsangehörigkeitsrecht eingefügt wurden, sind m.E. grundsätzlich zu bejahen. Mittels dieser Klausel wird vorgebeugt, daß etwa ein in Deutschland wohnhafter Niederländer, der neben der niederländischen Staatsangehörigkeit zufälligerweise auch noch die brasilianische innehat, die niederländische wegen Auslandsaufenthalts verliert. Ein solcher Verlust wäre deshalb sehr bedenklich, weil die Beziehungen dieser Person zu den Niederlanden alleine schon der geographischen Nähe wegen vermutlich viel enger als zu Brasilien sind. Weiter muß aber berüicksichtigt werden, da $B$ die aufenthaltsrechtliche Position eines Niederländers in der Bundesrepublik Deutschland in der Regel vorteilhafter ist als die eines brasilianischen Bürgers. Häufig wird er als Niederländer unter die sonderaufenthaltsrechtlichen Regeln bezüglich EG-Angehöriger fallen, während er diesen Sonderstatus als Brasilianer verlieren würde.

Belgien und die Schweiz sehen für den im Ausland lebenden Bürger eine "Verlängerungsmöglichkeit" durch diesbezïgliche Erklärungen vor. In den Niederlanden ist diese Möglichkeit 1985 mit der Konsequenz gestrichen worden, daß, falls der objektive Verlusttatbestand erfüllt ist, dem Verlust auch nicht mehr durch den subjektiven Wunsch Niederländer bleiben $\mathrm{zu}$ wollen, vorgebeugt werden kann. In soweiten ist die niederländische Regelung strenger als die belgische beziehungsweise schweizerische. Bei einem Vergleich zwischen Belgien und der Schweiz muß im diesem Punkt die belgische Regelung als die restriktivere angesehen werden. Der Auslandsbelgier muß nähmlich nach Volljährigkeit alle zehn Jahre eine Beibehaltungserklärung abgeben, wohingegen die Eidgenossenschaft sich mit einer einmaligen Erklärung bis zum Ende des Lebens begnügt.

Die strengere niederländische Regelung muß unter Berücksichtigung der im vorigen Absatz besprcchenen Tatsache gesehen werden, daß der Verlust nur eintritt, wenn der Niederländer im seinem Geburtsland lebt und auch dessen Staatsangehörigkeit besitzt.

M.E. erfüllt die niederländische Regelung zwar prinzipiell am weitestgehenden die Forderung Doppelstaatler zu vermeiden, die aufgrund von Auslandsgeburt und Auslandsaufenthalt nur noch äußerst schwache oder gar keine Beziehungen zu einem der Staaten unterhalten, dessen Staatsangehörigkeit sie ebenfalls besitzen. Dennoch sind an diese Lösung einige Haken und Osen gebunden. Dies gilt vor allem für die Doppelstaatler, die neben der niederländischen noch die Staatsangehörigkeit eines weitern EG-Mitgliedstaates innehaben. Soweit sie in dem betreffenden anderen EG-Staat geboren sind, werden sie durch diese Regelung nicht unerheblich in ihrem Recht auf Freizügigkeit tangiert. Sie werden 
konstant mit der Gefahr konfrontiert die niederländische Staatsangehörigkeit zu verlieren, fails sie sich für eine längere Periode im ihrem Geburtstaat niederlassen wollen. Gerade für diese Personengruppe trifft es jedoch häufig nicht zu, daß sie nur noch schwache oder gar keine Beziehungen mehr zu den Niederlanden hat, wodurch der Verlust der Staatsangehörigkeit gerechtfertigt wäre. Nehmen wir z.B. eine in Lüttich geborene Person mit belgischer Mutter und niederländischem Vater. Würde sich diese Person nun nach einer in den Niederlanden verbrachten Jugend zum Zwecke des Studiums oder der Arbeitsaufnahme in Belgien niederlassen, so drohte ihr nach zehnjährigem Aufenthalt der Verlust der niederländischen Staatsangehörigkeit, selbst wenn sie noch täglich die Eltern in Maastricht besucht. Von einem Mangel an reeller Bindung zu den Niederlanden kann in einem solchen Fall sicher nicht die Rede sein. Auch scheint mir nicht gerechtfertigt, von dieser Person zu verlangen, Arbeitsplatz und Wohnsitz zurúck in die Niederlande zu verlegen, nur um den drohenden Verlust vorzubeugen. Dies wäre silcher nicht im Sinne der europäischen Integration. Es erscheint mir daher angemessen, entweder in die niederländische Regelung von Art. 15 Buchstabe $\mathrm{c}$ RwNed eine Ausnahmeklausel zumindest bezüglich der anderen EG-Mitgliederstaaten - zu denken wäre aber auch an die Staaten des Europarates - aufzunehmen, oder aber zurückzukommen auf die vor 1985 bestehende Möglichkeit durch Beibehaltungserklärung den Verlust abzuwenden. Ein Paßverlängerungsantrag könnte dabei als Beibehaltungserklärung aufgefaßt werden.

Ein auffallender Unterschied zwischen der niederländischen Regelung einerseits und den belgischen und schweizerischen Bestimmungen andererseits ist desweiteren, daß nach niederländischem Recht Verlust der Staatsangehörigkeit auch im hohen Alter noch gegen den Willen des Betreffenden eintreten kann. Nach schweizerischem Recht tritt Verlust der Staatsangehörigkeit spätestens mit Vollendung des 22 . Lebensjahres ein, nach belgischem Recht ist dies grundsätzlich der Fall mit Vollendung des 28 . Lebensjahres, wobei die belgische Staatsangehörigkeit jeweils mit einer Frist von zehn Jahren verlängert werden kann. Nach belgischem Recht droht ein Verlust aufgrund des Art. $22 \& 1$ Ziffer 5 CNB aber lediglich dann, wenn der Betreffende von seinem 18. bis 28 . Lebensjahr ununterbrochen im Ausland gelebt hat. Nach niederländischem Recht wird aber die Staatsangehörigkeit auch verloren, wenn ein Doppelstaatler später zehn ununterbrochenen Jahre in seinem Geburtsstaat lebt. Dies sei anhand des folgenden Beispiels erläutert: Eine in Deutschland geborene deutsche Frau erwarb in Zusammenhang mit ihrer Ehe mit einem Niederländer die niederländische Staatsangehörigkeit, behielt aber daneben ihre deutsche Staatsangehörigkeit bei. Fast vierzig Jahre lebte das Ehepaar in den Niederlanden. Nach dem Erreichen des Ruhestandsalters möchtet das Ehepaar sich nun in Deutschland niederlassen, um dort seinen Lebensabend in einer von der Frau geerbten Wohnung zu verbringen. Nach niederländischem Recht wird die Frau, nachdem sie emeut zehn Jahre in Deutschland gelebt hat, die niederländische Staatsangehörigkeit verlieren. Ein solcher Verlust, der u.U. Rentenansprüche gefährden könnte, ist m.E. ebensowenig wiinschenswert, wie die oben bereits erläuterte Beschränkung des Freiziigigkeit. Dies gilt um so mehr, wenn die Kinder eines solchen Ehepaares in den Niederlanden leben, und damit die faktischen Beziehungen zu den Niederlanden genügend intensiv sind, um die niederländische Staatsangehörigkeit einer solchen Frau zu rechtfertigen. 
Die niederländische und belgische Regelungen sehen vor, daß die Staatsangehörigkeit nicht wegen Auslandsaufenthalt verloren wird, wenn die betreffende Person in einem bestimmten Dienstverhältmis zum Heimatstaat steht. Dabei fallt auf, daß die belgische Klausel viel großzügiger als die niederländische gefaßt ist. Nicht nur ein Dienstverhältnis mit dem belgischen Staat, sondem auch ein Dienstverhältnis in einer belgischen Gesellschaft oder einem Verein oder ein durch Vermittlung der belgischen Regierung zustandegekommenes Dienstverhältnis genügt, um den Verlust vorzubeugen. Die belgische Regel ist m.E. besser ausgearbeitet als die niederländische; nicht nur bei einem formellen Dienstverhältnis mit dem Heimatstaat ist eine so enge Beziehung mit dem betreffenden Staat anwesend, daß Beibehaltung der Staatsangehörigkeit legitimiert ist. Die niederländische Regelung wäre deshalb entsprechend abzuändern.

\subsubsection{Widerruf der Einbürgerung}

Sämtliche hier besprochenen Staaten sehen die Möglichkeit vor, Eingebürgerten unter bestimmten Voraussetzungen die neu erworbene Staatsangehörigkeit wieder zu entziehen. Eine Einbürgerung kann nach niederländischem Recht nur in einem Falle widerrufen werden, nämllich dann, wenn jemand nach erfolgter Einbürgerung unterlassen hat, sein Möglichstes zu tun, um seine ursprüngliche Staatsangehörigkeit zu verlieren (Art. 15 Buchstabe d RwNed). Dieser 1985 in das niederländische Staatsangehörigkeitsrecht eingeführte Verlustgrund ist im Vergleich zu den bisherigen Regelungen neu.

Auch in Belgien können Einbürgerungen widerrufen werden. Die belgische Regel ist jedoch weitgehender formuliert. Die Staatsangehörigkeit eines Belgiers, der seine Staatsangehörigkeit nicht von einem Elternteil ableitet, der am Tage seiner Geburt belgischer Staatsangehöriger war, kann widerrufen werden, falls er seine Pflichten als Belgier grob vernachlässigt (Art. $23 \mathrm{CNB}$ ). Auf Antrag der Staatsanwaltschaft wird der Verlust der Staatsangehörigkeit durch Urteil des Gerichtshofes ausgesprochen. Dieser Verlustgrund gemäß Art. 23 CNB ist weitgehend buchstäblich dem durch Gesetz vom 30. Juli 1934 eingeführten Art. 18bis, des vor 1985 geltenden belgischen Staatsangehörigkeitsrechts entnommen. Diese Regel hatte ihre Wurzel in der durch Gesetz vom 25. Oktober 1919 anläßlich der Erfahrungen des Ersten Weltkrieges eingeführten Aberkennungsregelung (vgl. weiter das Abkennungsverfahren im Geset 2 vom 15. Mai 1922 und im Gesetz vom 4. August 1926). Die durch Erlaß vom 6. Mai 1944 als Art. 18ter und 18quater in das Gesetz eingefügte Möglichkeit, um auch den Geburtsbelgiem die Staatsangehörigkeit abzuerkennen und zwar aufgrund einer Strafverurteilung im Abwesenheitsverfahren bei bestimmten im Krieg begangenen Handlungen, gibt es im CNB 1985 nicht mehr.

In Deutschland gibt es keine besondere Regelung des Widerrufs in Staatsangehörigkeitsangelegenheiten. Es finden aber die allgemeinen Verwaltungsverfahrensregeln bezüglich des Widerrufs von Verwaltungsakten ihre Anwendung. Allerdings verbietet Art. 16 Abs. 1 des deutschen Grundgesetzes ausdriucklich Entzug der Staatsangehörigkeit gegen den Willen des Betroffenen, falls Staatenlosigkeit hieraus folgt. Das frühere deutsche Recht kannte mehrere Verlustgründe, die in weiten Sinne zu dieser Kategorie zu rechnen sind; z.B. Entziehung der Staatsangehörigkeit von Auslandsdeutschen, die bei Krieg oder Kriegsgefahr eine Rückkehraufforderung nicht befolgten $(\S 2$ RuStAG 1870; $\$ 27$ RuStAG 
1913, aufgehoben durch Art. 16 GG) und Verlusterklärung der Staatsangehörigkeit bei Verurteilung wegen Steuerflucht (\$ 23 des Gesetzes vom 26. Juli 1918 außer Kraft seit dem 31. Dezember 1924).

Nach britischem Recht kann eine Einbürgerung oder der Erwerb der britischen Staatsangehörigkeit durch "registration" widerrufen werden, wenn sich herausstellt, daß die Staatsangehörigkeit "by means of fraud, false representation of the concealment of any material fact" erworben wurde (Sec. 40 (1) BNA 1981). Sec. 40 (3) BNA 1981 läßt weiter Entzug der britischen Staatsangehörigkeit bei illoyalem Verhalten, Unterstützung des Feindes während eines Krieges und Verurteilung $z \mathrm{zu}$ einer Gefängnisstrafe von mindestens 12 Monate innerhalb von fünf Jahren nach Erwerb der britischen Staatsangehörigkeit zu. Entzug der Staatsangehörigkeitwegen einer Verurteilung geschieht nicht, wenn Staatenlosigkeit hiervon die Folge wäre.

Nach französischem Recht kann eine Einbürgerung wegen Verbrechen gegen die Sicherheit des Staates, Delikte gegen die Verfassung, Nichterfüllung des Militårdienstes, Handlungen zugunsten eines fremden Staates, die Frankreich schaden, oder Verurteilung zu einer mindestens fünfjährigen Gefängnisstrafe widerrufen werden. Der Widerruf der Einbürgerung kann nur innerhalb von zehn Jahren nach der Einbürgerung ausgesprochen werden (Art. 98, 99). Zu beachten ist weiter Art. 112 CNF, aufgrund dessen eine Einbürgerung nach vorheriger Zustimmung des Conseill d'Etat innerhalb einer Frist von einem Jahr seit ihrer Veröffentlichung im Joumal Officiel zurückgenommen werden kann, wenn der Betreffende nicht die gesetzlichen Bedingungen erfüllt. Bei Betrug oder Täuschung kann eine Einbürgerung innerhalb einer Frist von zwei Jahren seit der Aufdeckung dieser Täuschung zurückgenommen werden.

Das österreichische Recht kennt eine der niederländischen Bestimmung des Art. 15 Buchstabe d RwNed entsprechende Regelung. Die Staatsangehörigkeit kann eingezogen werden, wenn jemand zwei Jahren nach seiner Einbürgerung noch immer die frühere Staatsangehörigkeit beibehalten hat (\$ 34-36 StBG i.d.F. 1983; vgl. die entsprechende Paragraphen in StBG i.d.F. 1965). Gemäß \& 34 Abs. 2 StGB ist der betreffende Bürger mindestens sechs Monate vor der beabsichtigten Entziehung der Staatsbïrgerschaft hieriber zu belehren. Die Entziehung ist nach Ablauf von sechs Jahren nach der Einbürgerung nicht mehr zulässig ( \$ 34 Abs. 3).

In der Schweiz kann eine Einbiirgerung nur nichtig erklärt werden, wenn sich innerhalb von fünf Jahren nach der Einbuirgerung herausstellt, daß die Einbürgerung durch falsche Angaben oder Verheimlichung erheblicher Tatsachen erschlichen worden ist (Art. 41 BüG i.d.F. 1952). Diese Möglichkeit wurde in das schweizerische Recht durch Art. 2 Bundesratsbeschlusses vom 11. November 1941 eingeführt. Damals war die Widernuffrist allerdings zehn Jahre; außerdem konnte die Einbürgerung auch wegen "offenkundig unschweizerischer Gesinnung" widerrufen werden.

Spanien kennt einige Verlustbestimmungen, die ausschließlich für Personen gelten, die die spanische Staatsangehörigkeit nicht kraft Abstammung besitzen. Sie können die spanische Staatsangehörigkeit durch Strafurteil verlieren, wenn sie wegen bestimmter Delikte gegen die Sicherheit des Staates verurteilt wer- 
den. Weiter kann die spanische Staatsangehörigkeit entzogen werden, wenn festgestellt wird, daß bei der Einbürgerung Fälschung, Verschweigen oder Betrug vorlag. Schließlich bewirkt Verlust der spanischen Staatsangehörigkeit, der freiwillige Eintritt in den ausländischen Wehr- oder Staatsdienst gegen das ausdrüickliche Verbot der Regierung (Art. 24 C.c.esp.).

Bezüglich Italien sei darauf hingewiesen, daß dieses die Möglichkeit des Entzugs der italienischen Staatsangehörigkeit kennt, wenn ein Staatsangehöriger im Ausland eine Tat begangen hat, die darauf abzielt die öffentliche Ordnung in Italien zu stören, italienischen Interessen Schaden zuzufügen oder den guten Namen und das Ansehen Italiens beeinträchtigen kann (Gesetz vom 31. Januar 1926). Zwar ist dieser Verlustgrund nicht auf Eingebürgerte beschränkt, aber der Hintergrund dieser Verlustbestimmung ist ähnlich (siehe auch $\$ 3.4 .8$ ). Seit Inkrafttreten der italienischen Verfassung von 1947 ist eine solche Aberkennung der Staatsangehörigkeit, wenn sie wenigstens aus politischen Gründen geschieht, jedoch verfassungswidrig (Art. 22). In diesem Zusammenhang sei übrigens auch auf den Entzugsgrund des Art. 48 des schweizerischen BüG hingewiesen. Einem Doppelstaatler kann die schweizerische Staatsangehörigkeit entzogen werden, wenn sein Verhalten den Interessen oder dem Ansehen der Schweiz erheblich abträglich ist.

Lediglich die Niederlande und Österreich kennen die Möglichkeit einem Eingebürgerten die Staatsangehörigkeit deshalb zu entziehen, weil dieser sich nicht ausreichend bemüht hat, seine bisherige Staatsangehörigkeit zu verlieren. Diese Forderung muß selbstverständlich in engem Zusammenhang mit der im Rahmen des Einbürgerungsverfahrens gestellten und in $\$ 3.3 .4 .8$ besprochenen Verpflichtung betrachtet werden, bei einer Einbürgerung grundsätzlich auf die bisherige Staatsangehörigkeit zu verzichten. Dieses Erfordernis wurde dort schon kritisiert und teilweise abgelehnt. Auf jene Bemerkungen sei verwiesen. Wenn man aber jene Verpflichtung stellen möchte, ist die hier besprochene Verlustregelung des niederländischen und österreichischen Rechts eine logische Konsequenz. Dabei ist die österreichische Regelung rechtstechnisch besser als die niederländische. Zwar würde ein Widerruf der Einbürgerung ohne vorheriger Belehrung oder erst nach sehr vielen Jahren auch in den Niederlanden allgemeinen Prinzipien des Verwaltungsrechts widersprechen, aber aus Rechtssicherheitsgründen ist die österreichische Formulierung vorzuziehen. Die niederländische Bestimmung des Art. 15 Buchstabe d RwNed sollte deshalb entsprechend geändert werden. Anders als im österreichischen Recht, jedoch gemäß der schweizerischen Regelung des Art. 41 BüG und entsprechend der in den Niedlerlanden geforderten Wohnsitzfrist bei einer normalen Einbürgerung, würde ich vorschlagen die Widerrufungsmöglichkeit auf fünf Jahre nach der Einbürgerung zu befristen.

Seltsamerweise kennen nur Frankreich, Großbritannien, die Schweiz und Spanien die ausdrückliche Möglichkeit, um die Staatsangehörigkeit zu entziehen, falls bei der Einbürgerung gefälscht, verheimlicht oder betrogen wurde. Dieser Verlustgrund ist durchaus vertretbar. Eine entsprechende Regelung möchte ich auch für das niederländische Recht befürworten. Aus Rechtssicherheitsgründen ist dann aber ebenfalls eine Befristung der Widerrufsmöglichkeit entsprechend dem schweizerischen Recht zu empfehlen. Belgien, Frankreich, Großbritannien und Spanien kennen die Möglichkeit, die Staatsangehörigkeit eingebürgerter Personen aufgrund "schllechten Benehmens" des betreffenden Bürgers zu entzie- 
hen. In Belgien ist dieser Verlustgrund äußerst vage formuliert (grobe Vernachlässigung der Pflichten eines Belgiers), in den überigen Staaten wird dieser Grund näher detailliert. In Frankreich und Großbritannien ist nur befristeter Entzug aus diesem Grunde möglich (in Frankreich bis zu zehn Jahren; in Großbritannien lediglich bis zu fünf Jahre nach Einbürgerung). Hingewiesen sei noch auf die Verlustgründe des Art. 48 des schweizerischen BüG und des italienischen Gesetzes vom 31. Januar 1926, die sich zwar nicht ausschlieBlich auf Eingebürgerte beziehen, aber doch eine Entziehung der Staatsangehörigkeit wegen illoyalem Benehmen vorsehen. Vergleiche weiter auch § 3.4.8. Ein solcher Widerruf einer Einbürgerung aufgrund des Benehmens des Betroffenen muß m.E. jedoch absolut abgelehnt werden. Er entspricht nicht einer modernen Auffassung des Staatsangehörigkeitsrechts, in der die Staatsangehörigkeit als leerer Koppelungsbegriff aufgefaßt werden soll (siehe darüber $\S 1.3$ ). In diesem Zusammenhang ist bemerkenswert, $\mathrm{daB}$ die Wurzeln dieser Regelungen in einer Epoche liegen, deren Erfahrungen sich hoffentlich nie wiederholen werden. In Deutschland wurde die Möglichkeit Einbürgerungen zu widerrufen 1933 von den Nationalsozialisten eingeführt; in Österreich wurde Entzug der Staatsangehörigkeit wegen österreichfeindlicher Handlungen ebenfalls 1933 als Reaktion auf die nationalsozialistischen Entwicklungen in Deutschland ermöglicht. Nach Beendigung des Zweiten Weltkriegs wurden diese Verlustgründe in beiden Staaten aber gestrichen. In Belgien wurde die Möglichkeit des Entzugs der Staatsangehörigkeit wegen grober Verletzung der Pflichten eines Bürgers 1934 introduziert; Frankreich ermöglichte die Wiederausbürgerung 1915, Großbritannien und Italien 1918. Die betreffenden Ausbürgerungsregelungen der Schweiz und Spanien schließlich haben ihre Wurzeln in den Jahren 1941 und 1944. Teilweise waren diese Regelungen vor allem darauf gerichtet die Wiederausbürgerung von ehemaligen Angehörigen von Feindesstaaten zu ermöglichen, die der Spionage - oder anderen staatsfeindlichen Aktivitäten - verdächtigt wurden. Zum Teil hatten die Regelungen aber auch faschistische Hintergründe. M.E. sollten diese Verlustgründe ersatzlos gestrichen werden. Falls eingebürgerte Personen staatsgefährliche Handlungen begehen, soll strafrechtlich und nicht staatsangehörigkeitsrechtlich gegen sie vorgegangen werden.

\subsubsection{Eintritt in fremden Staats- oder Wehrdienst}

Ursprünglich kannten fast alle Staatsangehörigkeitsgesetzgebungen Eintritt in einen ausländischen Staats- oder Wehrdienst als Verlustgrund der eigenen Staatsangehörigkeit. Eintritt in fremden Staats- oder Wehrdienst wurde als Untreue dem eigenen Land gegenüber angesehen, Verlust der Staatsangehörigkeit war davon deshalb die Folge. Von den in diesem Buch besprochenen Staaten kennen im Moment lediglich noch Frankreich, Italien, Österreich und Spanien diesen Verlustgrund.

Allerdings tritt in Frankreich kein automatischer Verlust ein. Der Verlust erfolgt durch Dekret zwei bis acht Wochen nach einer Aufforderung den fremden Dienst zu verlassen (Art. $97 \mathrm{CNF}$ ). Italien kennt eine entsprechende Regelung. Gemäß Art. 8 Ziffer 3 L.c. wird die italienische Staatsangehörigkeit von demjenigen verloren, der bei einer ausländischen Regienung eine Anstellung angenommen hat oder in den Wehrdienst einer fremden Macht eingetreten ist und darin verbleibt, obwohl er von der italienischen Regierung aufgefordert wurde, innerhalb einer bestimmten Frist die Anstellung oder den Wehrdienst aufzuge- 
ben (vgl. aber auch die Bestimmungen des Gesetzes vom 16. Juni 1927, Nr. $1170)$.

Das österreichische Recht unterscheidet fremden Staatsdienst und fremden Militärdienst. Wer freiwillig in den Militärdienst eines fremden Staates tritt, verliert die österreichische Staatsangehörigkeit automatisch (\$32 StBG 1965; vgl. \& 10 BBG 1925 und $\& 9 \mathrm{StBG}$ 1945/1949). Im Falle von fremden Staatsdienst tritt kein automatischer Verlust ein, kann aber die österreichische Staatsangehörigkeit entzogen werden, falls der Betreffende durch sein Verhalten die Interessen oder das Ansehen Österreichs erheblich schädigt ( $\$ 33$ StBG 1965; vgl. $\$ 10$ BBG 1925 und \& 9 StBG 1945/1949).

In Spanien kannte man bis 1982 freiwilligen fremden Staats- oder Militärdienst gegen das ausdrückliche Verbot der spanischen Regierung als für alle Spanier geltender Verlustgrund. Seit 1982 gilt dieser Verlustgrund aber lediglich noch füir Personen, die die spanische Staatsangehörigkeit durch Einbürgerung oder Option erworben haben (Art. 24 Ziffer 2 C.c. esp.).

Von den übrigen hier studierten Staaten galten früher in den Niederlanden, Belgien und Deutschland entsprechende Regelungen. Die Niederlande kannten freiwilligen fremden Staats- oder Militärdienst ohne Einwilligung der niederländischen Regierung bis 1985 als Verlustgrund (Art. 9 Abs. 2 BW 1838; Art. 10 Abs. 2 Gesetz 1850; Art. 7 Ziffer 4 WNed 1892), Belgien bis 1909 (Art. 17 Ziffer 2 und Art. 21 C.c.). In Deutschland war friiher ebenfalls ein entsprechender Verlustgrund bekannt. Einem Deutschen konnte die Staatsangehörigkeit entzogen werden, wenn er ohne Erlaubnis seiner Regierung in den ausländischen Staatsdienst trat und einer Aufforderung zum Austritt aus diesem Staatsdienst nicht Folge leistete ( $\$ 28$ RuStAG 1913; $\$ 22$ RuStAG 1870). In Folge der Wirkung von Art. 16 GG trat $\S 28$ RuStAG am 23. Mai 1949 außer kraft. In Großbritannien und in der Schweiz war und ist dieser Verlustgrund unbekannt.

Grundsätzlich ist es nicht unberechtigt aus der Tatsache, daß ein Bürger in den Dienst eines fremden Staates tritt, zu folgem, daß dadurch die Beziehungen zu dem bisherigen Heimatstaat so geschwächt wurden, den Verlust der Staatsangehörigkeit zu rechtfertigen. Dies gilt im Prinzip a fortiori, wenn durch den Eintritt in den fremden Dienst auch die Staatsangehörigkeit des fremden Staates erworben wird (siehe \$3.3.2). Dennoch hat dieser Verlustgrund mehrere Nachteile.

An erster Stelle ist nicht immer feststellbar, ob jemand in den ausländischen öffentlichen oder Militärdienst getreten ist. Der Betreffende wird diese Tatsache in der Regel nicht selbst seinen Heimatbehörden mitteilen. Dies bewirkt insbesondere Schwierigkeiten, wenn fremder Dienst als automatischen Verlustgrund konstruiert ist. Manchmal muß dann von den Behörden festgestellt werden, daß die Staatsangehörigkeit schon vor vielen Jahren verloren wurde.

Weiter sind die Grenzen zwischen öffentlichen Dienst oder Militärdienst einerseits und anderen Dienstverhältnissen andererseits nicht immer deutlich. Sehwierigkeiten verursachen namentlich mit einem Staat eng verbundene paramilitärische Organisationen (z.B. einer politischen Partei, die ebenfalls in der Regie- 
rung vertreten ist). Fraglich ist weiter, ob lediglich im Falle eines Beamtenverbältnisses die Verlustbestimmung effektuiert wird oder auch, wenn man lediglich eine befristete zivilrechtliche Anstellung im öffentlichen Dienst hat.

Auch erscheint es im Hinblick auf die Freizügigkeitsbestimmungen des Art. 48 E.W.G.-Vertrages nicht mehr gerechtfertigt, fremden Staatsdienst in einem anderen Mitgliedstaat der Europäischen Gemeinschaft als Verlustgrund für die Staatsangehörigkeit, die gerade diese Freizügigkeit gewährleistet, anzunehmen. Zwar findet gemäß Art. 48 E.W.G.-Vertrag die Freizuigigkeitsgarantie keine Anwendung auf die Beschäftigung in der öffentlichen Verwaltung, und damit könnte man sagen auf den öffentlichen Dienst. Der Begriff der "öffentlichen Verwaltung" ist jedoch gemäß der Rechtsprechung des Europäischen Gerichtshofes äußerst restriktiv auszulegen. Zumindest für den Eintritt in den öffentlichen Dienst in anderen Mitgliedstataten der Europäischen Gemeinschaft müBten daher zumindest Ausnahmeregeln gelten.

Namentlich nach dem Zweiten Weltkrieg hat sich in den Niederlanden noch ein weiterer Nachteil gezeigt. In mehreren Strafprozessen stellte sich heraus, daß ein als Niederländer geborener Angeklagter für bestimmte von ihm im Ausland begangene Delikte strafrechtlich nicht in den Niederlanden verfolgt werden konnte, weil er während des Krieges und zwar bevor er die betreffenden Delikte begangen hatte, wegen ausländischen Kriegs- oder Zivildienstes die niederländische Staatsangehörigkeit verloren hatte. Dadurch waren die betreffenden $\mathrm{De}-$ likte von einem Ausländer im Ausland begangen und fehlte damit gemäß dem niederländischen Strafgesetzbuch mit Ausnahme der Verbrechen gegen die Menschlichkeit die internationale strafprozeBrechtliche Zuständigkeit. Aus diesen Grïnden muß der Eintritt in fremden Staats- oder Wehrdienst als Verlustgrund der Staatsangehörigkeit abgelehnt werden.

\subsubsection{Unterlassung einer Wahlverpflichtung}

Italien ist das einzige in diesem Buch studierte Land, das für Doppelstaatler eine Wahlpflicht eingeführt hat. Innerhalb eines Jahres nach Volljährigkeit muß ein Doppelstaatler wählen, ob er ausschließlich die italienische oder seine fremde Staatsangehörigkeit besitzen möchte (Art. 5 Abs. 2 des Gesetzes 123 vom 21. April 1983). Wenn die fremde Staatsangehörigkeit gewählt wird, wird hierdurch die italienische verloren. Wird allerdings die Wahl zugunsten der italienischen Staatsangehörigkeit ausgesprochen, so bewirkt dies nicht unbedingt, daß dadurch die fremde Staatsangehörigkeit verloren wird. Die italienische Wahlverpflichtung ist deshalb im Moment nur mangelhaft gestaltet. In $\$ 3.2 .1$ wurden bereits Anmerkungen bezüglich dieses Verlustgrundes gemacht. Dort und in \$ 3.4.4 wurde betont, daB der Verlustgrund des Auslandsaufenthaltes der italienischen Konstruktion einer Wahlverpflichtung vorzuziehen ist. Soweit man doch eines Wahlverpflichtung den Vorzug einräumt, sollte das Alter in dem gewählt werden muß m.E. nicht auf achtzehn, sondern etwa auf achtundzwanzig Jahre festsetzen, da es gerade für Doppelstaatler im Alter von 18 Jahren häufig noch nicht möglich ist, zu sagen in welchem seiner Heimatstaaten er in Zukunft vermutlich leben wird. 


\subsubsection{Verurteilung wegen bestimmter Straftaten}

In \$3.4.5 wurde schon hinsichtlich der belgischen, französischen, britischen und spanischen Regelungen angemerkt, daß eine Einbürgerung u.a. widerrufen werden kann, wenn der neue Bürger wegen bestimmter Straftaten verurteilt worden ist. In diesem Zusammenhang wurde bereits auf die mehr allgemeine Entzugsmöglichkeiten, die nur noch das italienische und schweizerische Recht kennen, hingewiesen. Auch wurden einige ältere bereits außer Kraft getretene Regelungen erwähnt.

Die betreffenden Regelungen habe ich bereits alle abgelehnt. Verwiesen sei auf die Erörtungen und Begriindungen in $\$ 3.4 .5$.

\subsubsection{Wegfall familienrechtlicher Beziehungen}

Wenn eine Person eine Staatsangehörigkeit aufgrund familienrechtlicher Beziehungen (in der Regel iure sanguinis) erworben hat, kann sich das Problem stellen, wie sich die staatsangehörigkeitsrechtliche Lage dieser Person entwickelt, bei Wegfall dieser famillienrechtlichen Beziehungen aus irgendwelchem Grund. Dabei ist vorallem an solche Fälle, in denen nachgewiesen wird, daß die Annahme gewisser familienrechtlicher Beziehungen auf falsche standesamtliche Eintragungen beruht, in denen die eheliche Vaterschaft oder eine Anerkennung erfolgreich angefochten werden, in denen alte familienrechtliche Beziehungen wegfallen, weil durch Adoption neue geschaffen werden, oder in denen eine Adoption wieder aufgehoben wird, zu denken. In den Niederlanden und Beigien wird diese Problematik ausdrücklich im Staatsangehörigkeitsgesetz geregelt. In den anderen Staaten fehlen spezielle Regelungen.

Aus Art. 14 Abs. 1 RwNed geht hervor, daß die niederländische Staatsangehörigkeit wegen des Wegfalls der familienrechtlichen Beziehungen, die als Grundlage für den Erwerb der Staatsangehörigkeit dienten, verloren wird, es sei denn, Staatenlosigkeit wäre die Folge.

Aus Art. $8 \& 4$ CNB geht hervor, daß die belgische Staatsangehörigkeit in diesem Fall lediglich verloren wird, wenn die betreffende Abstammung nicht mehr feststeht, bevor der Betreffende das 18. Lebensjahr vollendet hat oder vor diesem Alter volljährig erklärt wurde.

Nach niederländischem Recht kann die Staatsangehörigkeit aus diesem Grunde also auch noch wegfallen, nachdem der Betroffene bereits volljährig ist. Dies ist aus Rechtssicherheitsgründen wenig wünschenswert. Desweiteren muß berïcksichtigt werden, daß die betreffende Person, falls die famillienrechtlichen Beziehungen erst nach Volljährigkeit wegfallen, bis dahin als Niederländer aufgewachsen und behandelt worden ist. Im Falle des Verlustes der Staatsangehörigkeit wäre deshallb eine unmittelbare Einbürgerung angemessen (vgl. die \& 3.3.3.1 Buchstabe e und 3.3.3.2 Buchstabe g). Die belgische Regelung ist deshalb m.E. zu bevorzugen. Eine entsprechende Änderung der niederländischen Regelung wäre wuinschenswert. Darauf hingewiesen sei ferner, daß eine Staatsangehörigkeit lediglich wegen Wegfalls der familienrechtlichen Beziehungen verloren werden kann, wenn keine ande-ren Erwerbsgründe vorliegen, die den Besitz der betreffenden Staatsangehörigkeit legitimieren. Wurde die niederländi- 
sche Staatsangehörigkeit iure sanguinis a patre erworben und nun die Vaterschaft erfolgreich angefochten, verliert der Betreffende die niederländische Staatsangehörigkeit dennoch nicht, falls zur Zeit seiner Geburt die Voraussetzungen von Art. 3 Abs. 3 RwNed ebenfalls erfüllt waren; er besitzt fortan die Staatsangehörigkeit nicht mehr iure sanguinis sondem iure domicilii (siehe $\$$ $3.2 .6)$.

Sowohl das niederländische als das belgische Recht bestimmen, daß die Staatsangehörigkeit verloren wird, wenn ein Minderjähriger durch einen Ausländer adoptiert wird und durch diese Adoption dessen Staatsangehörigkeit erwirbt (Art. 16 Abs. 1 Buchstabe a RwNed; Art. 22 \& 1 Ziffer 4 CNB). Soweit durch eine solche Adoption die bisherigen familienrechtlichen Beziehungen wegfallen, ist dies ein besonderer Fall eines Verlusts der Staatsangehörigkeit aufgrund Wegfalls der familienrechtlichen Beziehungen, dessen Regelung überflüissig wäre. Bemerkenswert ist aber, daß sowohl nach niederländischem als nach belgischem Recht auch eine sogenannte schwache Adoption, wodurch nicht alle bisherigen familienrechtlichen Beziehungen abgebrochen werden, Verlust der bisherigen Staatsangehörigkeit verursachen kann, unter der Voraussetzung, daB diese schwache Adoption die Staatsangehörigkeit eines Adoptivelternteils vermittelt. Diese Lösung ist namentlich im niederländischen Recht wenig elegant, weil umgekehrt eine schwache Adoption nie den Erwerb der niederländischen Staatsangehörigkeit bewirken kann (siehe \& 3.2.3). Schon deshalb sollte dieser Verlustgrund gestrichen werden. Außerdem ist die Regelung des Art. 16 RwNed in Bezug auf die Adoption noch in soweit unklar, als Abs. 2 erklärt, die niederländische Staatsangehörigkeit werde nicht werloren, falls und solange der andere Elternteil noch Niederländer ist (Art. 16 Abs. 2 RwNed). Das Verhältnis zwischen dieser Bestimmung und der Regelung des Verlust durch (schwache) Adoption ist undeutlich. Wenn die biologischen Eltern des adoptierten niederländischen Kindes leben und noch die niederländische Staatsangehörigkeit besitzen, wäre die Anwendung von Abs. 2 zu vertreten, weil eine schwache Adoption die familienrechtlichen Beziehungen nicht abgebrochen haben und somit die biologischen Eltern noch als Elternteil im Sinne des zweiten Absatzes gelten.

Gemäß den Staatsangehörigkeitsgesetzen der meisten Staaten wurde die Staatsangehörigkeit früher auch von Minderjährigen verloren, wenn sie von einem Ausländer anerkannt oder legitimiert wurden. Unter dem Gesichtspunkt der Gleichberechtigung wurde dieser Verlustgrund aber in der Regel gestrichen. Art. 16 Abs. 1 Buchstabe a RwNed ist deshalb bemerkenswert, wonach die niederländische Staatsangehörigkeit durch Anerkennung oder Legitimierung verloren wird, falls der Betreffende dadurch die Staatsangehörigkeit des Anerkennnenden, beziehungsweise Legitimierenden erwirbt oder diese bereits besitzt. Allerdings tritt dieser Verlust, falls die Mutter noch die niederländische Staatsangehörigkeit besitzt, nicht ein. Deshalb wirkt dieser Verlustgrund nur, wenn die Mutter Ausländerin oder schon vor der Anerkennung, beziehungsweise Legitimierung gestorben ist. Es ist m.E. deshalb fraglich, ob dieser Verlustgrund gerechtfertigt ist. Die Folge der Regelung ist nämlich, daßs nichteheliche Kinder einer niederländischen Mutter und eines ausländischen Vaters, wie eheliche Kinder einer niederländischen Mutter und eines ausländischen Vaters, jedenfalls die niederländische Staatsangehörigkeit ihrer Mut-ter haben und zusätzlich die ausländische Staatsangehörigkeit ihres Vaters, wenn sie diese durch Anerkennung 
erwerben. Dies gill aber nicht, wenn die Mutter vor der Anerkennung gestorben ist. Entsprechendes gilt im Falle der Legitimierung. M.E. kann diese unterschiedliche Behandlung von nichtehelichen Kindern einer bereits gestorbenen und noch lebenden niederländischen Mutter durch nichts gerechtfertigt werden. Die Regelung ist um so bedenklicher, da der in Art. 16 Abs. 1 Buchstabe a RwNed formulierte Verlustgrund. formell sogar wirkt, wenn der Anerkennende oder Legitimierende Bedingungen erfüllt, die in Bezug auf das anerkannte oder legitimierte Kind die Erfilllung der Voraussetzungen des Art. 3 Abs. 3 RwNed bewirken würden, und dieses Kind also iure domicilii Niederländer wäre. Aufgrund dieser Kritikpunkte möchte ich deshalb befürworten, die Regelung des Art. 16 Abs. 1 Buchstabe a RwNed ersatzlos zu streichen.

\subsubsection{Wegfall einer bedingt erworbenen Staatsangehörigkeit}

Manchmal wird die Staatsangehörigkeit unter der Bedingung erworben, daß sich nicht, beziehungsweise nicht innerhalb einer bestimmten Frist, der Besitz einer anderen Staatsangehörigkeit herausstellt, oder, daß der Betreffende nicht, beziehungsweise nicht innerhalb einer bestimmten Frist, eine andere Staatsangehörigkeit erwirbt. Bei Eintritt der Bedingung wird dadurch die dergestalt verliehene Staatsangehörigkeit verloren. In diesem Paragraphen sollen die entsprechenden Regelungen näher betrachtet werden.

In den Niederlanden wird die Staatsangehörigkeit ausschließlich im Falle des Art. 3 Abs. 2 RwNed bedingt erworben. Ein in den Niederlanden aufgefundenes Kind wird Niederländer, verliert diese Staatsangehörigkeit aber, wenn sich innerhalb von fünf Jahren herausstellt, daß es ausschließlich eine andere Staatsangehörigkeit besitzt. Die niederländische Staatsangehörigkeit wird dann "ex nunc" verloren (Art. 2 RwNed).

Das belgische Recht kennt mehrere Fälle bedingten Erwerbs der Staatsangehörigkeit (Art. $8 \S 1$ Ziffer 2 Buchstabe c; Art. 9 Ziffer 2 Buchstabe c; Art. 10 Abs. 1). In diesen Fällen wird die so erworbene Staatsangehörigkeit wieder verloren, wenn sich vor Erreichung des achtzehnten Lebensjahres oder vorheriger Volljährigkeit herausstellt, daß das Kind eine fremde Staatsangehörigkeit besitzt (Ärt. 8 \& 4; Art. 9 Abs. 3; Art. 10 Abs. 3 CNB).

In Deutschland, Großbritannien, Italien und Österreich ist die Staatsangehörigkeit eines aufgefundenen Kindes wieder der einzige bedingte Erwerbsgrund (bis zum Beweise des Gegenteils) ( $\$ 4$ Abs. 2 RuStAG; Sec. 1 (2) BNA; Art. 1 Abs. 2 L.c.; $\$ 8$ Abs. 1 StBG 1965). Wird dieser Beweis geliefert, dann wird die so erworbene deutsche beziehungsweise britische, italienische oder österreichische Staatsangehörigkeit wieder verloren, auch wenn die Beweisführung erst nach vielen Jahren geschieht. In der Schweiz verliert ein aufgefundenes Kind lediglich die schweizerische Staatsangehörigkeit, wenn die Abstammung noch während seiner Minderjährigkeit festgestellt wird und sich herausstellt, daß es nicht staatenlos ist (Art. 6 Abs. 3 BüG). Eine entsprechende Regelung kennt Frankreich (Art. 21 CNF).

Die eben in diesem Paragraphen erwähnten Erwerbsgruinde haben alle als Ziel Staatenlosigkeit vorzubeugen; sie existieren nur weil die Betreffenden sonst staatenlos wären. Es ist deshalb nicht unlogisch, wenn nach den meisten 
Rechtsordnungen die so erworbene Staatsangehörigkeit wieder verloren wird, falls sich der Besitz einer anderen Staatsangehörigkeit herausstellt. Eine solche Entdeckung sollte aber nur innerhalb einer relativ kurzen Frist zum Verlust der Staatsangehörigkeit führen können. Siehe darüber die Ausführungen in \$ 3.2.7. Vgl. weiter \& 3.3.3.1 Buchstabe e und $\S$ 3.3.3.2 Buchstabe g. Die anderen Regelungen sind daher abzullehnen.

\subsubsection{Eheschließung}

In der Schweiz wird die Staatsangehörigkeit einer Schweizerin noch immer bei Eheschließung mit einem Ausländer verloren, es sei denn, die Frau würde dadurch staatenlos werden. Die Frau kann aber eine Beibehaltungserklärung abgeben (Art. $9 \mathrm{BüG}$ ). In den übrigen Staaten ist dieser Verlustgrund gestrichen (siehe \$ 3.1.1). Auch in der Schweiz sind die Tage dieses Verlustgrundes gezählt. Im 1986 veröffentlichten Vorentwurf eines Anderungsgesetzes des BüG ist er nicht mehr vorgesehen.

\subsubsection{Erstreckung auf Kinder}

In einigen hier besprochenen Staaten erstreckt sich der Verlust der Staatsangehörigkeit durch die Eltern auf ihre minderjährige Kinder, in anderen Staaten aber gerade nicht. Die entsprechende Regelungen sollen hier beleuchtet werden. Ursprünglich erstreckte der Verlust der Staatsangehörigkeit eines Mannes sich immer auch auf dessen Ehefrau. Keiner der untersuchten Regelungen sieht dies aber nun noch vor. Im niederländischen Staatsangehörigkeitsrecht verloren bis 1985 minderjährige Kinder lediglich dann die niederländische Staatsangehörigkeit, wenn sie zusammen mit ihren Eltern im Ausland eingebürgert wurden, also nicht, wenn sie z.B. iure soli bereits die Staatsangehörigkeit besaßen, die ihre Eltern durch Einbürgerung erwarben (Art. 7 Ziffer 1 RwNed). Für eheliche und vom Vater anerkannte, nichteheliche Kinder war dabei ursprünglich ausschlieBlich die Einbürgerung des Vaters maßgebend, seit 1962 nach dem Tode des Vaters auch die der Mutter; für vom Vater nicht-anerkannte, nichteheliche Kinder war nur die Einbürgerung der Mutter relevant. Im Jahre 1985 hat dieser Verlustgrund aber erhebliche Anderungen untergangen. Erstens wird die Staatsangehörigkeit nie verloren, wenn Staatenlosigkeit die Folge wäre (Art. 14 Abs. 2 RwNed). Als Folge der Realisierung der Gleichberechtigung von Mann und Frau im Staatsangehörigkeitsrecht wird die Staatsangehörigkeit auch dann nicht verloren, falls und solange ein Elternteil die niederländische Staatsangehörigkeit beibehält (Art. 16 Abs. 2 RwNed). Unter Beachtung dieser beiden Ausgangspunkte verliert ein Minderjähriger die niederländische Staatsangehörigkeit, wenn sein Vater und seine Mutter freiwillig eine fremde Staatsangehörigkeit erwerben und dieser Erwerb sich auf ihn erstreckt oder er diese Staatsangehörigkeit (z.B iure soli) bereits besitzt (Art. 16 Abs. 1 Buchstabe b RwNed). Er verliert ebenfalls die niederländische Staatsangehörigkeit, wenn er selbständig durch Einbürgerung oder Option dieselbe Staatsangehörigkeit wie sein Vater und seine Mutter erwirbt (Art. 16 Abs. 1 Buchstabe d RwNed). Ebenfalls wird die niederländische Staatsangehörigkeit durch Erstreckung verloren, wenn Vater und Mutter die niederländische Staatsangehörigkeit durch Verzicht, Auslandsaufenthalt oder Widerrufung der Einbürgerung verlieren (Art. 16 Abs. 1 Buchstabe c RwNed). 
Die belgische Regelung der Erstreckung des Staatsangehörigkeitverlusts auf minderjährige Kinder entspricht in großen Zügen der niederländischen (Art. 22 $\$ 1$ Ziffer 3,4 und $6 \mathrm{CNB}$ ). Bis 1985 wurde diebelgische Staatsangehörigkeit von einem minderjährigen Kind verloren, wenn es zusammen mit dem Elternteil, der über ihn das Sorgerecht ausiibte (bis 1974 bei ehelichen Kindern im Regelfall der Vater), im Ausland eingebürgert wurde. Seit 1985 wird die Staatsangehörigkeit nicht mehr verloren, solange noch ein Elternteil Belgier bleibt.

Im italienischen Recht wird die Erstreckung des Verlusts der italienischen Staatsangehörigkeit eines Elternteils auf minderjährige Kinder in Art. 12 L.c. geregeit. Sie verlieren die Staatsangehörigkeit ebenfalls, wenn sie den Aufenthalt des betreffenden Elternteils, der die elterliche Gewalt oder gesetzliche Vormundschaft hat, teillen und selbst dje fremde Staatsangehörigkeit erwerben. Ausdrücklich ist bestimmt, daß dies auch gilt, wenn die Mutter eine andere Staatsangehörigkeit besitzt als der vorher verstorbene Vater. Die Regel findet somit keine Anwendung, wenn die Mutter durch eine neue Ehe eine andere Staatsangehörigkeit erwirbt. Da seit 1983 Kinder ihre italienische Staatsangehörigkeit sowohl vom Vater als von der Mutter herleiten können, ist undeutlich, ob die Regelung des Art. 12 L.c. in unveränderter Form weiter gilt.

In Österreich erstreckt sich der Verlust der Staatsangehörigkeit wegen Erwerbs einer fremden Staatsangehörigkeit ( $\$ 27 \mathrm{StBG}$ ) auf die ledigen, minderjährigen, ehelichen (Adoptiv-)Kinder eines (ehemaligen) Staatsangehörigen, wenn diese von Rechts wegen in die fremde Staatsangehörigkeit folgen oder folgen würden, falls sie diese nicht bereits besaßen ( $\$ 29$ StBG). Dasgleiche gilt grundsätzlich auch für nichteheliche Kinder, wenn der gesetzliche Vertreter dem Erwerb der fremden Staatsangehörigkeit ausdrïicklich zugestimmt hat. Das nichteheliche Kind eines österreichischen Mannes kann jedoch nur zusammen mit seinem Vater die österreichische Staatsangehörigkeit verlieren, wenn die Vaterschaft festgestellt oder anerkannt ist und dem Vater die Pflege und Erziehung des Kindes zusteht. Ein eheliches Kind verliert die Staatsangehörigkeit nicht, solange ein Eltemteil weiterhin Staatsbürger ist. Seit 1985 kann ein Kind, das bereits das 14. Lebensjahr vollendet hat, die Staatsbürgerschaft ausschließlich verlieren, wenn es der, auf den Erwerb der fremden Staatsangehörigkeit gerichteten, Willenserklärung ausdrücklich zugestimmt hat. Die übrigen Verlustgründe der österreichischen Staatsangehörigkeit (Eintritt in fremden Militărdienst, Entziehung und Verzicht) erstrecken sich nie auf Minderjährige.

Im schweizerischen Recht erstreckt sich der Verlust der Staatsangehörigkeit der Eltern im allgemeinen auch auf die Kinder. Art. 44 BüG bestimmt, daß die unmündigen, unter der elterlichen Gewalt des Entlassenen stehenden Kinder in die Entlassung einbezogen werden. Dies gilt jedoch für Kinder über 16 Jahre ausschlieBlich, wern sie schriftlich zustimmen. Verlust durch Adoption oder EheschlieBung und Verlust durch Entzug erstrecken sich nicht auf Kinder. Verlust wegen Auslandsgeburt löst diese Wirkung seit 1984 dahingegen aus.

Die deutsche Staatsangehörigkeit wird weder im Falle von Entlassung oder Verzicht noch wegen Erwerbs einer fremden Staatsangehörigkeit durch Erstreckung verloren. Für minderjährige Deutsche kann aber gemäß \& 19 RuStAG selbständig Entlassung oder Genehmigung einer Verzichtserklärung beantragt werden. In dem Falle ist die Genehmigung des Vormundschaftsgerichts notwendig. Wenn 
ein Minderjähriger auf Antrag seines gesetzlichen Vertreters eine fremde Staatsangehörigkeit erwirbt und die Genehmigung des deutschen Vormundschaftsgerichts vorliegt, wird die deutsche Staatsangehörigkeit ebenfalls verloren.

In Frankreich erstreckt sich der Verlust der Staatsangehörigkeit eines Elternteils nicht auf minderjährige Kinder. Dies gilt seit der Aufhebung von Art. 94 Abs. 2 CNF im Jahre 1984. Auch in GroBbritannien und Spanien ist Erstreckung des Verlustes der Staatsangehörigkeit auf Minderjährige unbekannt. Art. 25 C.c.esp. bestimmt für minderjährige Personen sogar ausdrü̈cklich, daß die Staatsangehörigkeit nicht deswegen verloren wird, weil sie unter der elterlichen Gewalt eines Ausländers stehen oder, weil diejenigen, die über sie die elterliche Gewalt ausüben, die spanische Staatsangehörigkeit verlieren.

Eine Erstreckung des Verlusts der Staatsangehörigkeit durch einen Elternteil auf dessen minderjährige Kinder ist $\mathrm{m}$.E. grundsätzlich gerechtfertigt. Wenn die Beziehungen der Eltern zu ihrem Heimatland dermaßen geschwächt sind, daß sie die Staatsangehörigkeit dieses Landes verlieren, bestehen im allgemeinen auch keine reellen Beziehungen zwischen ihren minderjährigen Kindern und dem früheren Heimatstaat, die den Besitz der Staatsangehörigkeit für diese Kinder weiterhin rechtfertigen. Bei Fehlen yon Regeln bezüglich der Erstreckung des Verlusts der Staatsangehörigkeit können Folgen eintreten, die zumindest als merkwürdig zu bezeichnen sind. Manchmal besitzen dadurch Personen eine Staatsangehörigkeit die vorige Generationen ihrer Familie schon längst verloren haben. Dies soll anhand eines Beispiels illustriert werden. Das 1985 außer Kraft getretene niederländische Staatsangehörigkeitsgesetz von 1892 sah u.a. Verlust der niederländischen Staatsangehörigkeit wegen Erwerbs einer fremden Staatsangehörigkeit vor. Ein solcher Verlust der niederländischen Staatsangehörigkeit wegen Erwerbs einer fremden Staatsangehörigkeit erstreckte sich auf minderjährige Kinder, wenn diese zusammen mit ihrem Vater oder unter gewissen Voraussetzungen zusammen mit ihrer Mutter die fremde Staatsangehörigkeit erwarben. Sie verloren deshalb die niederländische Staatsangehörigkeit nicht, wenn sie nicht zusammen mit ihren Eltern eingebürgert wurden, weil sie die Staatsangehörigkeit des Landes, bereits iure soli besaßen. Solche im Ausland geborenen Kinder verloren aber die niederländische Staatsangehörigkeit, wenn sie nicht innerhalb von zehn Jahren nach Erreichung der Volljährigkeit, also spätestens im 31. Lebensjahr eine Erklärung abgaben, weiterhin Niederländer bleiben zu wollen. Dieser Verlust erstreckte sich wiederum nicht auf ihre minderjährige Kinder. Diese blieben weiterhin Niederländer bis der Verlust bei ihnen ebenfalls wegen Auslandsaufenthalts nach Vollendung des 31. Lebensjahr eintrat. Auch jener Verlust erstreckte sich dann aber wieder nicht auf inzwischen geborene Kinder. So kann es also geschehen, daß Nachkommen von Personen, die bereits rund 1900 die niederländische Staatsangehörigkeit verloren hatten, mangels einer guten Erstreckungsregelung formell noch die niederländische Staatsangehörigkeit besitzen. Dieses Phänomen wird man aber ab dem 1 . Januar 1995 alls ausgestorben ansehen können (vgl. hierzu die Übergangsregelung des Art. 26 RwNed). Wie aus dem oben beschriebenen Regelung des RwNed 1985 hervorgeht, kennt das niederländische Staatsangehörigkeitsrecht seit 1985 wohl eine gute Erstreckungsregelung.

Eine Erstreckung des Verlusts der Staatsangehörigkeit auf minderjährige Kinder ist selbstverständlich nur insoweiten zu bejahen, als der Verlust der Staatsan- 
gehörigkeit bei den Eltem eine Manifestierung mangelnder Beziehungen zum bisherigen Heimatstaat darstellt. Wenn der Verlustgrund dahingegen im Wesentlichen eine Strafmaßnahme ist ( $\mathrm{vgl}$. die Verlustgründe der $\$ 3.4 .5,3.4 .6$ oder 3.4.8) ist selbstverständlich nur zu begrüßen, daß eine Erstreckung eines solchen Verlusts unterbleibt. Bei den Verlustgründen, die oben grundsätzlich bejaht wurden, ist eine Erstreckung auf minderjährige Kinder aber im Prinzip zu empfehlen.

Allerdings ist unter dem Gesichtspunkt eines Mitbestimmungsrecht die Erstreckung des Verlusts der Staatsangehörigkeit auf ein minderjăhriges Kind nicht gerechtfertigt, wenn dieses bereits das zwölfte Lebensjahr vollendet hat. Bei Erstreckung des Verlusts wegen Erwerbs einer fremden Staatsangehörigkeit schreibt daher das österreichische Recht zurecht vor, daß der Verlust sich nur dann erstreckt, wenn der Minderjährige, der auf den Erwerb der fremden Staatsangehörigkeit gerichteten Willenserklärung, ausdrücklich zugestimmt hat. Auch bei Verlust durch Verzicht muß m.E. eine ausdrückliche Einwilligung des älteren Minderjährigen gefordert werden. Anders ist die Lage $\mathrm{m} . \mathrm{E}$. beim Verlust der Staatsangehörigkeit wegen Auslandsaufenthalts, weil in diesem Falle des Verlusts der Staatsangehörigkeit unabhängig vom Willen der Betreffenden eintritt. Wo der Wille der Eltern bereits unerheblich ist, wäre es unlogisch und nicht sachgemäß für die Erstreckung eine zustimmende Willenserklärung des älteren Minderjährigen zu fordern. Dies gilt allerdings in dieser Schärfe nur für die niederländische Konstruktion des Verlustgrundes bei Auslandsaufenthalt, bei der eine Verlängenungsmöglichkeit fehlt. Soweit eine Verlängerungsmöglichkeit besteht, wäre es angemessen, diesen Verlust nur dann auf ältere Minderjährige $\mathrm{zu}$ erstrecken, falls sie über den bevorstehenden Verlust informiert waren und von einer Verlängerungserklärung abgesehen haben. Unter Berücksichtigung der Verwirklichung der Gleichberechtigung im Staatsangehörigkeitsrecht, namentlich in Beżug auf den Erwerb der Staatsangehörigkeit iure sanguinis, ist eine Regelung, wonach die Staatsangehörigkeit nicht durch Erstreckung verloren wird, solange noch ein Elternteil die alte Staatsangehörigkeit besitzt, ausdrücklich zu bejahen. In diesem Zusammenhang sei noch darauf hingewiesen, daß die niederländische Formulierung des Art. 16 Abs. 2 RwNed "falls und solange noch ein Elternteil die niederländische Staatsangehörigkeit besitzt" nicht sehr deutlich ist. M.E. soll die Staatsangehörigkeit nicht durch Erstreckung verloren werden, falls ein Elternteil die Staatsangehörigkeit verliert, der andere Elternteil dieselbe jedoch noch besitzt. Wenn dann auch dieser die Staatsangehörigkeit verliert, sollte der Verlust sich auf dann noch minderjährige Kinder erstrecken. Nach dieser Auffassung sind die Wörter "und solange" in Art. 16 Abs. 2 RwNed jedoch überflüssig. 


\section{5 Änderungen im Staatsangehörigkeitsrecht: einige Tendenzen}

\subsubsection{Einführende Bemerkungen}

Nach dem Vergleich der positivrechtlichen Erwerbs- und Verlustgründe soll in den folgenden Abschnitten versucht werden, aufgrund der Länderberichte kurz einige Entwicklungstendenzen im Staatsangehörigkeitsrecht unter Berücksichtigung der historischen Dimension zusammenzufassen.

Wenn man die Staatsangehörigkeitsregelungen der westeuropäischen Staaten seit Anfang des vorigen Jahrhunderts überschaut, kann man feststellen, daß diese Bestimmungen sich bis zum heutigen Tage ganz erheblich geändert haben (1). Es ist aber nicht einfach, die einzelnen Tendenzen aufzuzeichnen, die diese Änderungen verursacht haben. Die Entwicklungen haben sich häufig beeinflußt. Deshalb unterscheiden sie sich zwar voneinander, können aber kaum voneinander getrennt betrachtet werden. Wenn in den folgenden Erörterungen Tendenzen unterschieden werden, muß daher deren relative Abhängigkeit stets im Auge behalten werden.

Im nachfolgenden werden sechs Strömungen beschrieben. Sie alle haben mit einer Ausnahme, sowohl die Erwerbs- als auch die Verlustgriunde beeinflußt. Lediglich die in $\$ 3.1 .3$ besprochene Tendenz bezieht sich primär auf den $\mathrm{Er}$ werb der Staatsangehörigkeit durch Geburt. Daneben könnte man noch weitere Änderungen aufzeigen, etwa die sukzessive Einbeziehung des Instituts der Adoption in das Staatsangehörigkeitsrecht, eine allmähliche Konkretiserung der Einbürgerungsvoraussetzungen oder etwa ein zunehmendes staatsangehörigkeitsrechtliches Selbstbestimmungsrecht des älteren Minderjährigen. Diese Veränderungen sind aber relativ jungen Datums und können auch noch nicht in allen beschriebenen Rechtssystemen beobachtet werden. Sie sind aber schon teilweise aus der Beschreibung der positivrechtlichen Regelungen zu folgern.

\subsubsection{Vom "Système unitaire" zum "Système dualiste" (2).}

Im vorigen Jahrhundert herrschte in allen beschriebenen Staaten das Prinzip der Familieneinheit ("système unitaire") im Staatsangehörigkeitsrecht. Aus diesem System ergaben sich die folgenden Regelungen: Ehemann und Ehefrau besaßen immer dieselbe Staatsangehörigkeit. Wenn ein Mann eine ausländische Frau heiratete, erwarb diese durch die Eheschließung von Rechts wegen seine Staatsangehörigkeit und verlor ihre eigene (3). Der Staat, dessen Staatsangehörigkeit der Ehemann besaB, konnte dem Erwerb der Staatsangehörigkeit durch die ausländische Gattin nicht vorbeugen. Auch sie selbst hatte keine solche Möglichkeit. Ebensowenig konnte sie den Verlust ihrer bisherigen Staatsangehörigkeit verhindern. Die verheiratete Frau hatte staatsangehörigkeitsrechtlich also eine von ihrem Ehemann völlig abhängige Stellung. Diese Abhängigkeit ging sogar soweit, daß eine Frau, die einen Staatenlosen heiratete, dadurch in der Regel ihre bisherige Staatsangehörigkeit verlor und ebenfalls staatenlos wurde (4). Auch während der Ehe teilte die Ehefrau das staats-angehörigkeitsrechtliche Schicksal ihres Gatten. Eine Einbürgerung oder ein Staatsangehörigkeiterwerb durch Optionserklärung erstreckte sich regelmäßig auch auf sie (5). Verlor der Ehemann eine Staatsangehörigkeit, dann ging seine Frau dieser ebenfalls verlustig (6). Wurde der Ehemann staatenlos, dann war dies auch das Schicksal seiner 
Frau. Eheliche Kinder erwarben grundsätzlich die Staatsangehörigkeit des Vaters und teilten während ihrer Minderjährigkeit wie ihre Mutter das staatsangehörigkeitsrechtliche Schicksal des Vaters (7). Erst wenn der Vater verstorben war, war für sie die staatsangehörigkeitrechtliche Stellung der Mutter bestimmend (8). Auch minderjährige eheliche Kinder erwarben folglich die fremde Staatsangehörigkeit, die ihre Eltern durch Einbürgerung oder Option erwarben. Sie verloren ihre Staatsangehörigkeit, wenn die Eltern diese Staatsangehörigkeit verloren, häufig selbst dann, wenn dies Staatenlosigkeit zur Folge hatte. Eine verheiratete Frau oder minderjährige Kinder konnten grundsätzlich nicht unabhängig von Ehemann und Vater eine andere Staatsangehörigkeit durch Einbürgerung oder Option erwerben (9).

Innerhalb einer Familie hatten deshalb der Ehemann und die Ehefrau, sowie deren minderjährige Kinder, grundsätzlich die gleiche Staatsangehörigkeit. Von diesem Prinzip der staatsangehörigkeitsrechtlichen Familieneinheit (système unitaire), wurden im Laufe der Zeit einige Ausnahmen entwickelt. Ziel dieser Ausnahmeregelungen war es, die Staatenlosigkeit zu bekämpfen. Die Tatsache, daß die Staatenlosigkeit eines Mannes immer auch die Staatenlosigkeit seiner Ehefrau und Kinder nach sich zog, wurde als unerwünscht empfunden, da sich auf diese Weise die Zahl der Staatenlosen sehr rasch vermehrte. So wurde bestimmt, daß eine Frau ihre Staatsangehörigkeit nicht verlor, wenn sie einen staatenlosen Mann heiratete; gleiches galt, wenn sie durch die EheschlieBung mit einem Ausländer dessen Staatsangehörigkeit weder erwarb noch erwerben konnte (10). Diese Regelung wurde auch Bestandteil des Haager Staatsangehörigkeitsabkommens von 1930 (11). Das Zweite Protokoll zu diesem Abkommen bestimmte weiter, daß in Fällen, in denen der Ehemann staatenlos war, die Ehefrau aber dennoch eine Staatsangehörigkeit besaß, ihre ehelichen Kinder die Staatsangehörigkeit der Mutter erwerben soliten. Voraussetzung dafür war aber, daß sie im Hoheitsgebiet des Staates, dessen Staatsangehörigkeit die Mutter besaß, geboren wurden (12).

Die eben erwähnten Regelungen brachen mit dem Prinzip der absoluten Abhängigkeit der verheirateten Frau in ihrer staatsangehörigkeitsrechtlichen Stellung und bildeten den Ausgangspunkt einer prinzipiellen Diskussion über die Stellung der Frau im Staatsangehörigkeitsrecht. Allmählich änderten mehrere Staaten ihre Gesetzgebung dahingehend, daß die verheiratete Frau auch in Fallen, in denen der Ehemann nicht staatenlos war, eine andere Staatsangehörigkeit als ihr Ehemann besitzen konnte (13). Von entscheidender Bedeutung für diese Entwicklung war das New Yorker Abkommen von 1957 bezïglich der Staatsangehörigkeit der verheirateten Frau (14). Durch dieses Abkommen wurde das Prinzip der Familieneinheit im Staatsangehörigkeitsrecht grundsätzlich verlassen; es wurde anerkannt, daß die verheiratete Frau prinzipiell eine von ihrem Ehemann unabhängige Staatsangehörigkeit besitzt. Das "système unitaire" wurde als Ausgangspunkt des Staatsangehörigkeitsrechts aufgegeben und durch ein "système dualiste" ersetzt (15). Das Abkommen von New York untersagte den automatischen Staatsangehörigkeitsverlust der Frau durch Heirat mit einem Ausländer. Auch die automatische Erstreckung des Staatsangehörigkeitsverlustes des Ehemannes auf seine Ehefrau wurde verboten. Ebenfalls wurde der automatische Erwerb der Staatsangehörigkeit des Mannes durch die ausländische Ehefrau im Falle der Eheschließung verurteilt. Nach und nach haben die meisten westeuropäischen Staaten ihre Staatsangehörigkeitsregelungen diesen Grundprin- 
zipien des New Yorker Abkommens angepaßt (16). Dennoch ist, seit der Anpassung der Staatsangehörigkeitsregelungen an die Ausgangsideen des New Yorker Abkommens, das Prinzip der Familieneinheit im Staatsangehörigkeitsrecht nicht völlig verlassen worden. Denn, obwohl das New Yorker Abkommen grundsätzlich die unabhängige staatsangehörigkeitsrechtliche Stellung der verheirateten Frau betont, schreibt das Abkommen doch vor, daß der ausländischen Frau die Möglichkeit geboten werden muß, durch erleichterte Einbürgerung die Staatsangehörigkeit ihres Mannes zu erwerben (17). Weitere Möglichkeiten, die für die Frau den Erwerb der Staatsangehörigkeit ihres Mannes vereinfachen wie z.B. der Erwerb mittels Optionserklärung - wurden ausdrücklich als zulässig erklärt. Nach dem New Yorker Abkommen wurde zwar das "système unitaire" nicht mehr ausschließlich zugrundegelegt. Grundsätzlicher Ausgangspunkt wurde nunmehr das "système dualiste", jedoch blieb die Familieneinheit auf dem Gebiete des Staatsangehörigkeitsrecht ausdrücklich förderungswürdig. Die Familieneinheit manifestiert sich auch weiterhin durch die in den meisten Staaten abhängige Stellung der minderjährigen Kinder. Diese erwarben und verloren häufig auch weiterhin ihre Staatsangehörigkeit mit dem Vater (18). In jüngster Zeit wurden mehrere Staatsangehörigkeitsregelungen dahingehend geändert, daß ein minderjähriges Kind seine Staatsangehörigkeit nicht verliert, falls zwar dessen Vater der Staatsangehörigkeit verlustig geht, die Mutter diese aber beibehält (19).

Das Prinzip der Familieneinheit im Staatsangehörigkeitsrecht gekoppelt an die Staatsangehörigkeit des Mannes, manifestierte die frïher eindeutig herrschende Ansicht, daß der Mann als Oberhaupt der Familie im Prinzip autonom das Schicksal seiner Familie bestimmen kann. Diese Ansicht gehört in Westeuropa nunmehr der Vergangenheit an. Obwohl im Staatsangehörigkeitsrecht die Hegemonie des Mannes zwar die Grundlage eines auferlegten "système unitaire" gewesen ist, so war diese Hegenomie jedoch sicherlich nicht der einzige Grund für eine Förderung des "système unitaire". Die Tatsache, daß in einer Ehe einer der Ehegatten eine bestimmte Staatsangehörigkeit besitzt, ist an sich schon ein gewisser Rechtfertigungsgrund für die Möglichkeit, daß der andere Ehegatte diese Staatsangehörigkeit auf relativ einfache Art erwerben kann. Die Staatsangehörigkeit soll eine tatsächliche Beziehung zwischen einer Person und dem Staat symbolisieren, dessen Staatsangehörigkeit diese Person besitzt (20). Wenn nun ein Staatsangehöriger mit einem Ausländer verheiratet ist, kann man erwarten, daß sich allmählich eine solche Beziehung zwischen diesem Ausländer und dem Heimatstaat seines Ehegatten entwickelt. Jessurun d'Oliveira hat diese Folge des Zusammenlebens als "translative Wirkung" bezeichnet (21). Und gerade diese Wirkung bildet auch einen Grund für eine gewisse Erleichterung der Erwerbsvoraussetzungen dieser Staatsangehörigkeit.

Traditionell erwarb die ausländische Frau die Staatsangehörigkeit ihres Ehemannes automatisch im Zeitpunkt der Eheschließung. Die staatsangehörigkeitsrechtliche Beziehung wurde also in der Regel schon hergestellt, bevor tatsächliche Beziehungen zwischen ihr und dem Heimatstaat ihres Mannes entstanden waren. Später hatte die ausländische Gattin die Möglichkeit, durch Option (22) oder erleichterte Einbürgerung (23) die Staatsangehörigkeit ihres Mannes zu erwerben. Auf diese Weise wurde die staatsangehörigkeitsrechtliche Beziehung von der tatsächlichen Verbundenheit gelöst. Dennoch wird sich diese Verbundenheit häufig im Laufe der Ehe wohl doch entwickelt haben, insbesonders wenn die 
Ehegatten im Heimatstaat des Mannes lebten. Bemerkenswert war aber, daß für den ausländischen Ehemann in der Regel keine wesentlichen Erleichterungen galten, falls er die Staatsangehörigkeit seiner Frau erwerben wollte (24). Diese Regelung war unter dem aufkommenden Aspekt der Gleichberechtigung nicht länger $\mathrm{zu}$ vertreten. Rein praktisch wurde hier der Mann diskriminiert. Aber auch die Ehefrau wurde durch diese Regelung auf ideologische Weise diskriminiert, weil sie faktisch gezwungen wurde, die Staatsangehörigkeit ihres Ehemannes zu erwerben, falls beide Ehegatten dieselbe Staatsangehörigkeit besitzen wollten (25). Die Einseitigkeit der Erwerbserleichterungen im Staatsangehörigkeitsrecht kann somit als ein eindeutiges Rudiment der Hegenomie des Mannes angesehen werden.

Allmählich haben die meisten der besprochenen Staaten ihre Regelungen so formuliert, daß Mann und Frau gleich behandelt werden. Fast alle Staaten haben dabei das Prinzip der Gleichberechtigung dergestalt realisiert, daß die Erwerbsvoraussetzungen für die ausländische Ehefrau erheblich erschwert, während die für den ausländischen Ehemann etwas erleichtert worden sind (26). Die Erleichterung der Erwerbsvoraussetzungen für die Staatsangehörigkeit des Ehepartners findet heutzutage nicht mehr ihren Grund in dem Factum der Ehe, sondern in der Tatsache, daß, durch das Zusammenleben mit einer Person anderer Staatsangehörigkeit gewisse Beziehungen zu deren Heimatstaat entstehen. Die Niederlande haben hieraus die Konsequenz gezogen, daß nicht nur eine eheliche, sondern auch eine nichteheliche Lebensgemeinschaft bestimmte Erleichterungen bewirken kann. Der Ausländer, der mit einem Niederländer zusammenlebt, kann allerdings nur dann unter erleichterten Bedingungen Niederländer werden, wenn die Partner in den Niederlanden zusammenleben (Art. 8 Abs. 4 RwNed). Diese Einschränkung hat beweisrechtliche Grïnde. Es wird interessant sein, rechtsvergleichend zu beobachten, ob andere Staaten diese auf der Hand liegende Konsequenz ebenfalls ziehen. Eine "translative Wirkung" der Staatsangehörigkeit kann man auch erkennen, wo Staatsangehörigkeitsregelungen die Einbürgerung ausländischer (minderjähriger) Kinder von eigenen Staatsbürgern erleichtern (27). Die Bedeutung dieser Bestimmungen wird allerdings abnehmen, da nun regelmäßig die Staatsangehörigkeit a patre et a matre abgeleitet wird und ansonsten minderjährige Kinder nunmehr in der Regel den Staatsangehörigkeitserwerb beider Elternteile teilen (28).

\subsubsection{Allmähliche Gleichberechtigung der Geschlechter}

Wie bereits festgestellt, hatte die verheiratete Frau im vorigen Jahrhundert immer die gleiche Staatsangehörigkeit wie ihr Ehemann. Soweit die Staatsangehörigkeitsregelungen den Erwerb der Staatsangehörigkeit iure sanguinis normierten, war dies für eheliche Kinder grundsätzlich als ius sanguinis a patre formuliert (29). Durch die vom Ehemann abhängige Staatsangehörigkeit der Mutter bedeutete dies faktisch aber gleichfalls ein ius sanguinis a matre. Nachdem die abhängige staatsangehörigkeitsrechtliche Stellung der verheirateten Frau etwas gelockert wurde - anfänglich wegen der Bekämpfung der Staatenlosigkeit, später wegen des grundsätzlichen Wunsches nach Gleichberechtigung von Mann und Frau - stellte sich eine weitere Frage. Es war zu entscheiden, ob bei unterschiedlichen Staatsangehörigkeiten der Ehepartner beide Ehegatten ihre Staatsangehörigkeit an ihre Kindern weitergeben und den Kindern auf diese Weise eine doppelte Staatsangehörigkeit vermitteln sollten. Ursprünglich wurde 
diese Frage verneint (30). Später konnte eine Frau ihren ehelichen Kindern allenfalls dann ihre Staatsangehörigkeit weitergeben, wenn das Kind anderenfalls staatenlos geworden wäre (31). Manchmal wurde in einem solchen Falle allerdings zusätzlich die Geburt im Inland gefordert (32).

Nachdem die verheiratete Frau in den meisten Staaten eine selbståndige Stellung im Staatsangehörigkeitsrecht erworben hatte, vergingen mehrere Jahre, ehe auf internationaler Ebene die Forderung formuliert wurde, daß Kinder grundsätzlich ihre Staatsangehörigkeit iure sanguinis gleichermaßen vom Vater wie von der Mutter herleiten müßten (33). Relativ schnell wurden daraufhin die Staatsangehörigkeitsregelungen der besprochenen Staaten entsprechend abgeändert (34). Es fällt dabei auf, daß die meisten Staaten alle ehelichen Kinder eines Bürgers oder einer Bürgerin iure sanguinis die Staatsangehörigkeit erwerben lassen (35). Nur Belgien und Großbritannien schränken den Erwerb iure sanguinis bei Ausiandsgeburt ein (36). Es ist bemerkenswert, daß dadurch dem Prinzip der Gleichberechtigung bei dem Erwerb iure sanguinis Vorrang von dem Wunsch gegeben wurde, möglichst einer Doppelstaatlichkeit vorzubeugen. Die Tatsache, daß die Staatsangehörigkeit nun in sovielen Fällen a patre et a matre erworben werden kann, wird auf Dauer die Gestaltung der Verlustgründe der Staatsangehörigkeit erheblich beeinflussen (37)(38).

In Paragraph 3.1.1. wurde bereits beschrieben, daß der Wunsch nach Realisierung der Gleichberechtigung im Staatsangehörigkeitsrecht Grund für die heutigen Staatsangehörigkeitsregelungen der besprochenen Staaten war, die nun vorsehen, daß der ausländische Ehemann oder die ausländische Ehefrau unter gleichen Voraussetzungen die Staatsangehörigkeit der Ehepartners beziehungsweise der Ehepartnerin erwerben können. Die meisten Staaten sehen dazu eine erleichterte Einbürgerung vor (39)(40); nur Belgien, Frankreich und Italien geben den ausländischen Gatten ein (kontrolliertes) Optionsrecht (41). In allen behandelten Staaten ist anerkannt, daß die Gleichberechtigung auch im Staatsangehörigkeitsrecht verwirklicht werden muß. Deren Realisierung ist aber noch kein völlig abgeschlossenes Kapitel. Erstens erwirbt in der Schweiz eine Ausländerin, die einen Schweizer heiratet, noch immer automatisch die schweizerische Staatsangehörigkeit. Dies wäre selbstverständlich zu änderen. Aber auch in anderem Staaten sind noch Änderungen der Staatsangehörigkeit als Folge der Realisierung der Gleichberechtigung zu erwarten. Dies gilt namentlich für die Regelung der Erstreckung des Verlustes der Staatsangehörigkeit auf minderjährige Kinder (42)

\subsubsection{Von ius soli zu ius sanguinis?}

Die moderne Staatsangehörigkeit hat sich am Anfang des vergangenen Jahrhunderts aus der Untertanschaft entwickelt. "Staatsangehörigkeit" war ursprünglich grundsätzlich an den jeweiligen Wohnsitz gekoppelt. Schätzel (43) schreibt dariber: "Bisher waren Erwerb und Verlust der Angehörigkeit in einem Lande die automatische Folge der Begründung oder Aufgabe des Wohnsitzes. Nunmelur werden für das verselbständigte Rechtsverhältnis eigene Erwerbs- und Verlustgründe geschaffen". Diese Trennung von Staatsangehörigkeit und Wohnsitz wird namentlich illustriert durch $\S 13$ des preußischen Gesetzes vom 31 . Dezember 1842 (44). "Der Wohnsitz innerhalb Unserer Staaten soll in Zukunft für sich allein die Eigenschaft als Preuße nicht begründen". Als relevante Anknüpfungspunkte für die Verleihung der Staatsangehörigkeit entwickelten sich 
allmählich zwei Systeme: das ius soli und das ius sanguinis. Das ersterwähnte System betrachtet die Geburt im Hoheitsgebiet eines Staates als wesentlichen Anknüpfungspunkt, während das zweite jenen Kindern eine Staatsangehörigkeit verleiht, deren Eltern zur Zeit der Geburt der Kinder die betreffende Staatsangehörigkeit besaßen.

Da die Staatsangehörigkeit historisch mit dem Wohnsitz verknüpft war, ist es nicht erstaunlich in den Staatsangehörigkeitsregelungen des vergangenen Jahrhunderts häufig noch starke ius soli-Elemente zu entdecken. Beispiele dafüir bilden Art. 5 Ziffer 1 des niederländischen BW 1838 und Art. 1 Ziffer 1 des niederländischen Staatsangehörigkeitsgesetzes 1850 , kraft deren alle Kinder von in den Niederlanden zur Zeit ihrer Geburt niedergelassenen Eltern, die niederländische Staatsangehörigkeit erwarben. Die spanischen Grundgesetze des vergangenen Jahrhunderts und auch noch Art. 17 Ziffer 1 C.c. esp. i.d.F. 1889 sahen vor, $\mathrm{da}$ im spanischen Hoheitsgebiet geborene Kinder Spanier waren. Aus diesem auf den ersten Blick als ius soli-Erwerb erscheinenden Grundsatzes wurde aber seit Mitte des 19. Jahrhunderts lediglich ein Optionsrecht für diese Personen hergeleitet. Erwähnenswert ist weiter Art.8 Abs.1 des italienischen Codice civile aus 1865, kraft dessen das in Italien geborene Kind eines Ausländers mit der Geburt die italienische Staatsangehörigkeit erwarb, falls der Vater schon mindestens zehn Jahre ununterbrochenen Wohnsitz in Italien hatte. Das österreichische ABGB aus 1811 ging zwar in $\$ 28$ Satz 2 von einem strikten ius sanguinis aus, aber diese ius sanguinis-Regelung hatte eine verborgene ius soli-Dimension durch die Vorschrift des § 29 ABGB; danach erwarben Ausländer die österreichische Staatsangehörigkeit durch einen zehnjährigen ununterbrochenen Wohnsitz in Österreich (45).

Dagegen ging das französische Staatsangehörigkeitsrecht, das bis 1838 ebenfalls in den Niederlanden galt und auch in Belgien rezipiert wurde, von einem strengen ius sanguinis aus; dies wurde allerdings dadurch gellockert, daß ein in Frankreich beziehungsweise Belgien geborenes Kind bei Volljährigkeit ein Optionsrecht auf die französische beziehungsweise belgische Staatsangehörigkeit hatte (Art.9 C.c). Das französische System des ius sanguinis hat sich am Ende des neunzehnten Jahrhunderts in den besprochenen Staaten Kontinental-Europas durchgesetzt. Um 1900 gingen diese Staaten alle grundsätzlich vom ius sanguinis aus (46). Von diesem Prinzip des ius sanguinis gab es in einigen Regelungen Ausnahmen zugunsten des ius soli. Wie oben bereits erwähnt wurde das ius sanguinis-Prinzip in Frankreich und Belgien durch Optionsrechte für im Inland geborene Kinder gelockert (47). Entsprechende Optionsrechte kannten auch Italien und Spanien (48). Einige dieser Optionsrechte waren als reine, positive Optionen gestaltet: durch die Optionserklärung wurde die fremde Staatsangehörigkeit erworben. Frankreich und Italien kannten (und kennen) unter bestimmten Voraussetzungen jedoch einen automatischen Erwerb der italienischen beziehungsweise französischen Staatsangehörigkeit, die aber ausgeschlagen werden kann (negative Optionserklärung; art. 3 L.c.) (49). Belgien kannte von 1909 bis 1922 eine entsprechende Regelung (Art.7 Gesetz 1909).

Eine weitere Ausnahme bildete die Regelung des Art. 8 Abs. 3 des französischen Code Civil in der Fassung von 1889, kraft deren alle in Frankreich geborenen Kinder die französische Staatsangehörigkeit iure soli erwarben, von denen ein Elternteil auch selbst in Frankreich geboren war (50). In den Niederlanden 
galt seit 1892 ebenfalls eine solche ius soli-Bestimmung zugunsten der zweiten im Inland geborenen Generation; dies galt aber nur, wenn die Kinder aus dieser Generation sonst staatenlos gewesen wären (51).

Eine weitere Ausnahme vom Prinzip des ius sanguinis betraf aufgefundene Kinder. Diese Kinder erwarben iure soli die Staatsangehörigkeit des Staates, in dem sie aufgefunden wurden (52). Ein reines ius soli war dies aber nicht. Eher war die Rede von einer Präsumption iuris sanguinis. Dies ging deutlich aus der allgemein üblichen Klausulierung hervor, daß diese so erworbene Staatsangehörigkeit wieder verloren ging, wenn sich herausstellte, daß das Kind durch Abstammung eine andere Staatsangehörigkeit besaß (53).

Eine entsprechende Regelung gab es in vielen Staaten für Kinder juristisch unbekannter Eltern (54). Diese Regelung betraf nichteheliche Kinder, deren Eltern faktisch zwar bekannt waren, die aber juristisch keine familienrechtlichen Beziehungen zu ihren Eltern hatten. Juristisch befanden sich diese Kinder in der gleichen Lage wie aufgefundene Kinder. Die Staaten des germanischen Rechtskreises (55) brauchten eine solche Regelung nicht, da in diesen Staaten der Grundsatz "mater semper certa est" galt (56) und deshalb immer familienrechtliche Beziehungen zwischen der Mutter und ihrem nichtehelichen Kind entstanden. In den Staaten des romanischen Rechtskreises (57) galt der Grundsatz "mater semper certa est" jedoch nicht: erst durch Anerkennung entstanden familienrechtliche Beziehungen zwischen Mutter und Kind, und erst dann konnte das Kind seine Staatsangehörigkeit von der Mutter herleiten. Sollange also weder Mutter noch Vater das Kind anerkannt hatte, befand dieses sich - wie ein aufgefundenes Kind - in einem familienrechtlichen Vakuum.

Es ist bemerkenswert, daß die ius soli-Ausnahmen in den Staatsangehörigkeitsregelungen einiger der besprochenen Staaten im Laufe des zwanzigsten Jahrhunderts zunahmen. Einerseits wurde dies durch den Wunsch nach Bekämpfung der Staatenlosigkeit verursacht. So forderte das Zusatzprotokoll zum Haager Staatsangehörigkeitsabkommen von 1930, daß eheliche Kinder eines staatenlosen Vaters und einer nicht-staatenlosen Mutter, wenigstens dann bei der Geburt die Staatsangehörigkeit von der Mutter herleiten könnten, wenn sie im Heimatland der Mutter geboren wurden (58). Dementsprechend wurde das niederländische Staatsangehờrigkeitsgesetz 1936 geändert (59). Im Jahre 1963 wurde die niederländische Staatsangehörigkeitsregelung dahingehend ergänzt, daß das eheliche Kind eines nicht-niederländischen Vaters und einer niederländlischen Mutter nicht nur die Staatsangehörigkeit erwarb, wenn der Vater staatenlos war, sondern auch, wenn das Kind aus irgendwelchem anderen Grund keine Staatsangehörigkeit vom Vater herleiten konnte, Voraussetzung blieb aber, daß das Kind im Inland geboren war (60). Selbstverständlich war diese Ausnalhme keine reine Manifestierung des ius soli: es war eine eindeutige Mischung von ius soli und ius sanguinis a matre. Seit das ius sanguinis a matre grundsätzlich anerkannt wurde, besteht für diese Ausnahme kein Bedarf mehr.

Ein weiterer Grund für Ausnahmen vom strengen ius sanguinis bildete der Wunsch, ausländische Familien, die bereits seit sehr langer Zeit auf dem Grundgebiet eines Staates lebten, auch in Bezug auf ihre Staatsangehörigkeit zu integrieren. Die oben bereits erwähnte französische Regelung von 1889, kraft deren in Frankreich geborene Kinder won auch in Frankreich geborene Eltern durch Geburt französisch waren, stand hierfür Modell. In den Niederlanden wurde die 
Regelung zugunsten der zweiten Generation dahingehend geändert, daß das Kind ausländischer Eltern stets Niederländer wurde, falls es zu einer Zeit geboren wurde, da sein Vater (oder für nicht-anerkannte nichteheliche Kinder die Mutter) seinen Wohnsitz in den Niederlanden hatte, und dieser selber auch geboren wurde, als seine Mutter in den Niederlanden lebte (61). Diese Regelung zugunsten der zweiten Generation hat seit Realisierung der Gleichberechtigung im Staatsangehörigkeitsrecht (in den Niederlanden 1985) noch an Bedeutung gewonnen, da nunmehr bei Anwendung dieser Bestimmung der jeweilige Wohnsitze beider Eltern und der betreffenden Großmutter von Bedeutung sind. Neben Frankreich und den Niederlanden kennen auch Belgien (seit 1985), und Spanien (seit 1954) eine Regelung zugunsten der zweiten im Inland geborenen Generation (62). Ein bemerkenswerter Unterschied zwischen der niederländischen einerseits und den anderen Regelungen anderseits besteht darin, daß in den Niederlanden nicht der Geburtsort des Kindes, sondern der Wohnsitz der Eltern entscheidend ist. In den Niederlanden ist also stricto sensu nicht die Rede vom Erwerb iure soli, sondern vom Erwerb iure domicilii oder anders formuliert iure sanguinis; dabei ist nicht die Abstammung von einem Staatsangehörigen erforderlich, sondern die Abstammung von einer Person mit Wohnsitz in den Niederlanden, die selbst geboren wurde, als ihre Mutter Wohnsitz in den Niederlanden hatte (63).

Bezüglich der Ausnahmen zugunsten des ius soli können wir einen Gegensatz zwischen den traditionellen Staaten des germanischen Rechtskreises (Deutschland, Österreich, Schweiz) und den Staaten des romanischen Rechtskreises (Belgien, Frankreich, Italien, Niederlande, Spanien) konstatieren. In den germanischen Staaten wird das ius sanguinis streng durchgeführt. Seit Realisierung des ius sanguinis a patre et matre gilt die einzige (Pseudo-) Ausnahme zugunsten aufgefundener Kinder. In den romanischen Staaten sind die Ausnahmen vielfach, auch wenn es sich nicht immer um ein echtes ius soli handelt, sondern manchmal (in den Niederlanden) um ein dem ius soli sehr ähnliches ius domicilii.

Das ius sanguinis war ursprünglich ein ius sanguinis a patre. Nur nichteheliche Kinder konnten die Staatsangehörigkeit (manchmal noch unter bestimmten Voraussetzungen) iure sanguinis a matre erwerben. In $\$ 3.5 .3$ wurde beschrieben wie sich nach und nach das ius sanguinis a patre in Richtung eines ius sanguinis a patre et a matre entwickelt hat. Diese Entwicklung hat dazu gefihrt, daß in zunehmendem Maße Kinder bei der Geburt iure sanguinis mehrere Staatsangehörigkeiten erwerben. Diese Tatsache hat namentlich Belgien dazu bestimmt, dem ius soli in völlig neuer Perspektive Relevanz zu verleihen. Das belgische Staatsangehörigkeitsgesetz von 1985 hat den Erwerb iure sanguinis dahingehend eingeschränkt, daß bei Geburt in Belgien die belgische Staatsangehörigkeit erworben wird, wenn ein Elternteil diese Staatsangehörigkeit hat. Bei Geburt im Ausland wird diese Staatsangehörigkeit jedoch - außer bei sonstiger Staatenlosigkeit - nur erworben, wenn wenigstens ein belgischer Elternteil selbst in Belgien geboren wurde (Art.8 CNB). Der Kern des ius soli, das heiBt die Verleihung der Staatsangehörigkeit aufgrund einer Verbundenheit mit dem Grundgebiet eines Staates, hat im belgischem Recht dadurch eine neue Bedeutung bekommen. 
Eine gewisse Relevanz hat diese Verbundenheit mit dem Territorium des Heimatstaates auch im niederländischen Recht: bei Auslandsgeburt tritt der Verlust der niederländischen Staatsangehörigkeit unter bestimmten Voraussetzungen frühestens 10 Jahre nach Volljährigkeit, automatisch ein (64). Auch Belgien (seit 1985) und die Schweiz (seit 1952) kennen entsprechende Verlustgründe; in beiden Staaten kann derjenige, dessen Staatsangehörigkeit verloren zu gehen droht, aber eine Beibehaltserklärung abgeben (65)(66).

In diesem Abschnitt wurde Großbritannien nicht erwähnt. Das Verhältnis zwischen ius soli und ius sanguinis war dort ursprünglich grundsätzlich anders als auf dem Kontinent. Ausgangspunkt war ein strenges ius soli: Geburt in Großbritannien hatte den Erwerb der britischen Staatsangehörigkeit zufolge. Bei Auslandsgeburt galt nur ein eingeschränktes ius sanguinis a patre (und für nichteheliche Kinder ein ius sanguinis a matre). Die britische Staatsangehörigkeit wurde in dem Falle nur iure sanguinis erworben, wenn der Vater (beziehungsweise die Mutter) eine bestimmte Verbundenheit mit Großbritannien hatte, z.B. wegen seiner (ihrer) Geburt in Großbritannien oder, weil er (sie) mehrere Jahre dort gelebt hat. Seit 1983 hat nun die Bedeutung des ius sanguinis bei Ausllandsgeburt zugenommen. Nicht nur die Verbundenheit des Vaters mit Großbritannien, sondern auch die der Mutter, kann iure sanguinis den Erwerb der britischen Staatsangehörigkeit begründen. Anderseits ist die Bedeutung des ius soli seitdem eingeschränkt. Neben den in Großbritannien geborenen Kindern von britischen Staatsbürgern erwerben ausschließlich die in Großbritannien geborenen Kinder von dort dauerhaft niedergelassenen Ausländern iure soli die britischen Staatsangehörigkeit. Wir können also feststellen, daß mehrere Staaten in ihren Staatsangehörigkeitsgesetzen eine deutliche Mischung von ius sanguinisund ius soli-Ausgangspunkten kennen. Es ist zu erwarten, daß auf Dauer alle Staaten zu einer solchen Mischung übergehen werden (67).

\subsubsection{Gleichberechtigung der ehelichen und nichtehelichen Kinder}

Eine Ungleichbehandlung von ehelichen und nichtehelichen Kindern ist im Staatsangehörigkeitsrecht nur möglich, wenn eine Staatsangehörigkeitsregelung die staatsangehörigkeitsrechtliche Stellung eines Kindes an seine Abstammung anknüpft. Bei einer strikten Anwendung des ius soli kommt diesem Punkt keine Bedeutung zu. Aber sobald ein ius soli System bei Auslandsgeburt Fälle des Erwerbs iure sanguinis kennt, ist die Möglichkeit einer ungleichen Behandlung wieder gegeben.

In den vorigen Paragraphen wurde wiederholt betont, daß im vergangenen Jahrhundert die Staatsangehörigkeit in ius sanguinis Systemen im Prinzip iure sanguinis a patre erworben wurde. Für eheliche Kinder war dies ein eindeutiges Kriterium. Bei nichtehelichen Kindern war diese Regelung selbstverständlich nur dann von Bedeutung, wenn juristische Beziehungen zwischen Vater und Kind vorhanden waren. Sonst war die Beziehung zu der Mutter auch staatsangehörigkeitsrechtlich ausschlaggebend.

Im deutschen, österreichischen und schweizerischen Recht konnte ein nichteheliches Kind seine Staatsangehörigkeit immer von der Mutter herleiten (68). Dies war eine Folge des Prinzips "mater semper certa est". Meistens wurde die so erworbene Staatsangehörigkeit aber wieder verloren, wenn das Kind durch einen 
Ausländer legitimiert wurde, häufig sogar, wenn es dadurch keine fremde Staatsangehörigkeit erwarb (69). Später trat dieser Verlust nur ein, wenn es durch die Legitimation die Staatsangehörigkeit des Vaters erwarb (70). Vollkommen anders war die Situation in den Staaten mit einer romanischrechtlichen Tradition. Ein nichteheliches Kind konnte die Staatsangehörigkeit der Mutter nur erwerben, wenn diese ihr Kind anerkannte (71). Wurde es nach Anerkennung durch die Mutter noch durch einen ausländischen Mann anerkannt, dann verlor es in den Niederlanden wieder die Staatsangehörigkeit der Mutter; ursprünglich sogar dann, wenn es auf dieser Weise staatenlos wurde (72). Seit 1936 galt diese Regelung nicht mehr, wenn das in den Niederlanden geborene Kind von einem staatenlosen Vater anerkannt wurde (73). In 1962 wurde dieser Verlustgrund in zweifacher Hinsicht weiter eingeschränkt: erstens hatte die Anerkennung keine staatsangehörigkeitsrechtlichten Folgen mehr, wenn das Kind inzwischen volljährig war und zweitens wirkten diese fortan nicht mehr für in den Niederlanden geborene Minderjährige, die durch die Anerkennung keine fremde Staatsangehörigkeit erwarben (74).

In Belgien galt eine ähnliche, leicht abweichende Regelung (75). Falls eine belgische Frau ein Kind anerkannt hatte, erwarb es dadurch die belgische Staatsangehörigkeit; eine spätere Anerkennung durch einen Ausländer war staatsangehörigkeitsrechtlich unerheblich. Wurde ein Kind zuerst von einem belgischen Mann anerkannt, dann wurde es dadurch belgisch, und blieb dies auch, wenn es nachher von einer Ausländerin anerkannt wurde. Hatte eine ausländische Frau ein Kind anerkannt, dann hatte die spätere Anerkennung durch einen belgischen Mann keinen Erwerb der belgischen Staatsbürgerschaft zur Folge.

In den romanischrechtlichen Staaten konnte ein nichteheliches Kind grundsătzlich die Staatsangehörigkeit von seinem Vater herleiten, wenn dieser das Kind anerkannt hatte. In Belgien und Frankreich war dies allerdings anders, wenn die Mutter des Kindes bereits vorher anerkannt hatte (76). In Italien wurde die Staatsangehörigkeit sogar schon bei Feststellung der Vaterschaft erworben (77). Von 1912 bis 1952 wurde auch in der Schweiz durch Anerkennung durch einen Schweizer die schweizerische Staatsangehörigkeit erworben. Seitdem hat die Schweiz die gleiche Lösung als Deutschland und Österreich: das nichteheliche Kind leitet keine Staatsangehörigkeit von seinem Vater her (78). Im britischen Recht hat die Feststellung der Vaterschaft eines nichteheliches Kindes ebenfalls keine staatsangehörigkeitsrechtlichen Folgen (79).

Die staatsangehörigkeitsrechtliche Position der nichtehelichen Kinder hat sich im Laufe der Zeit entwickelt. Die Staaten, die die iure sanguinis a matre erworbene Staatsangehörigkeit eines Kindes als Folge einer Anerkennung oder Legitimation durch einen Ausländer wegfallen ließen, auch wenn das Kind durch die Anerkennung nicht die Staatsangehörigkeit des Vaters erwarb, haben dies früher oder später dergestalt korrigiert, daß diese Folge nur eintreten konnte, wenn das Kind nicht staatenlos wurde. Die niederländische Entwicklung wurde bereits beschrieben. Die romanischrechtlichen Staaten haben allmählich weitgehend das Prinzip mater semper certa est eingeführt (80). In den Niederlanden war dies seit 1947 der Fall (81). Dadurch erwarben nichteheliche Kinder auch ohne Anerkennung die Staatsangehörigkeit der Mutter. Wurde das Kind aber später von einem Ausländer anerkannt und erwarb er deshalb dessen Staatsangehörig- 
keit, dann verlor es die Staatsangehörigkeit der Mutter wieder. Die Realisienung der Gleichberechtigung von Mainn und Frau hatte in mehreren Staaten auch Folgen für die staatsangehörigkeitsrechtliche Position der nichtehelichen Kinder, dies gilt namentlich in den Staaten des romanischen Rechtskreises. Es wurde angesichts der Gleichberechtigung als widersinnig empfunden, daß ein Kind die iure sanguinis von der nichtehelichen Mutter abgeleitete Staatsangehörigkeit verlor, wenn es durch Anerkennung seitens eines Ausländers eine fremde Staatsangehörigkeit erwarb. Sowie eheliche Kinder die Staatsangehörigkeit iure sanguinis sowohl von der Mutter wie vom Vater ableiten konnten, sollten auch nichteheliche Kinder ihre Staatsangehörigkeit von beiden Eltern ableiten können. In einigen Staaten ist dies der Fall, wenn der Vater das betreffende Kind anerkannt hat (Niederlande) (82), in anderen Staaten wird diese Forderung nicht gestellt, aber eine juristische Beziehung muß zwischen Vater und Kind festgestellt werden, um den Staatsangehörigkeitserwerb begründen zu können (83). Es ist bemerkenswert festzustellen, daß die romanischrechtlichen Staaten fruiher ein nichteheliches Kind so stark diskriminierten, das es im allgemeinen sogar von der Mutter keine Staatsangehörigkeit herleiten konnte. Dies hat sich inzwischen geändert. In Prinzip erwerben solche Kinder die Staatsangehörigkeit ihrer Mutter. Nun sind es aber die germanischrechtlichen Staaten die nichtehelichen Kinder diskriminieren. In den romanischrechtlichen Staaten erwerben diese die Staatsangehörigkeit ihrer Väter, wenn die familienrechtlichen Beziehungen zwischen Vater und Kind feststehen. In den germanischrechtlichen Staaten ist dies nicht der Fall. Es wird rechtswergleichend interessant sein zu beobachten, wann dies sich ändern wird.

\subsubsection{Bekämpfung der Staatenlosigkeit}

Alle Staaten bestimmen in Prinzip ganz autonom, wann eine Person ihre Staatsangehörigkeit besitzt (84). Es ist dadurch möglich, daß eine Person keine Staatsangehörigkeit besitzt, weil keine Staatsangehörigkeitsregelung irgendeines Staates ihr eine Staatsangehörigkeit zuteilt. Am Endle des vorigen Jahrhunderts und am Anfang des zwanzigsten Jahrhunderts häuften sich diese Fälle der Staatenlosigkeit. Dies wurde durch mehrere Umstände gefördert.

Erstens sahen die Staatsangehörigkeitsbestimmungen der meisten Staaten vor, daß die Staatsangehörigkeit wegen ausländischen Staats- oder Wehrdienstes ohne Rücksicht auf potenzielle Staatenlosigkeit verloren ging (85). Der Eintritt in den Staats- oder Wehrdienst eines fremden Staates wurde als Untreue dem eigenen Staat gegenüber empfunden, deshalb sollte Entzug oder sogar automatischer Verlust der Staatsangehörigkeit die - strafende - Folge sein. Die Gesetze einiger Staaten sahen demgegenüber im Falle des Eintritts eines Ausländers in den eigenen Staats- oder Wehrdienst deshalb gerade den - belohnenden - Erwerb der eigenen Staatsangehörigkeit vor (86). Sie neutralisierten auf diese Weise den von anderen Staaten vorgesehenen Verlust. Aber ein solcher Erwerbsgrund war eher die Ausnahme. Meistens verursachte fremder Staats- oder Wehrdienst Staatenlosigkeit. Einige Staaten sahen auch noch andere Entzugsgründe vor, die mit - empfundener - Untreue dem Heimatstaat gegenüber zusammenhingen (87).

Ein weiterer Grund der Staatenlosigkeit war mangelnde Abstimmung der jeweiligen Staatsangehörigkeitsregelungen miteinander. So bestimmten mehrere 
Staatsangehörigkeitsbestimmungen, daß eine Frau durch ihre Eheschließung mit einem Ausländer ihre eigene Staatsangehörigkeit verlor (88). Die Grundidee dieser Regelungen war, daß die verheiratete Frau - wie dies in den Staatsangebörigkeitsgesetzen der betreffenden Staaten vorgesehen war - durch die Eheschließung die Staatsangehörigkeit ihres Mannes erwarb. In einigen Fällen war dies aber nicht der Fall. Die Frau wurde dann staatenlos. Die gleiche Folge trat übrigens häufig ein, wenn der neue Ehemann staatenlos war, oder wenn ein verheirateter Mann z.B wegen fremden Staats- oder Wehrdienstes staatenlos wrurde. In beiden Fällen teilten seine Ehefrau und seine minderjährigen Kinder in der Regel wegen des streng durchgeführten "système unitaire" diese Rechtsfolge (89).

Allmählich wurden in die Staatsangehörigkeitsregelungen mehrerer Staaten Bestimmungen aufgenommen, die das eindeutige Ziel hatten, der Staatenlosigkeit vorzubeugen oder diese zu bekämpfen. In diesem Sinne wurde z.B. in der belgischen, niederländischen und spanischen Gesetzgebung bestimmt, daß eine Frau, die einen Ausländer heiratete, nur dann ihre bisherige Staatsangehörigkeit verlor, wenn sie durch die Eheschließung die Staatsbürgerschaft ihres Mannes erwarb (90). Die meisten Staaten, die davon ausgingen, das nichteheliche Kinder bei Anerkennung durch den ausländischen Vater automatisch dessen Staatsangehörigkeit erwarben, bestimmten auch, daß die bisherige von der nichtehelichen Mutter hergeleitete Staatsangehörigkeit nur dann verloren ging, falls das Kind durch die Anerkennung des ausländischen Vaters tatsächlich dessen Staatsangehörigkeit erwarb.

Auch in internationalen Abkommen wurden einige dieser MalBnahmen zur Bekämpfung der Staatenlosigkeit geregelt. Dies war erstmals der Fall im Haager Staatsangehörigkeitsabkommen inklusiv Zusatzprotokollen aus dem Jahre 1930 (91). Darin wurde erstens vorgeschrieben, daß eine Frau durch ihre EheschlieBung mit einem Ausländer ausschließlich ihre Staatsangehörigkeit verlieren sollte, wenn sie die Staatsangehörigkeit ihres Mannes erwarb. Weiter wurde vorgeschrieben, $\mathrm{da} ß$ das Kind eines staatenlosen Vaters und einer nicht staatenlosen Mutter wenigstens dann die Staatsangehörigkeit der Mutter erwerben sollte, wenn es im Heimatland der Mutter geboren wurde. Mehrere Staaten änderten ihre Staatsangehörigkeitsregelungen entsprechend dieser Zusatzprotokolle zum Haager Staatsangehörigkeitsabkommen. Manche Staaten gingen sogar noch etwas weiter und bestimmten, daß ein Kind die Staatsangehörigkeit der Mutter erwarb, wenn es keine Staatsangehörigkeit vom Vater herleiten konnte (92). Anfang der fünfziger Jahre wurde ein Abkommen über den Status von Staatenlosen verabschiedet. Dieses Abkommen sah vor, daB Staatenlose unter erleichterten Bedingungen eingebürgert werden sollten (93),

Durch die Bestimmungen des Haager Staatsangehörigkeitsabkommens und durch das Abkommen über den Status von Staatenlosen wurden spezifizische Fälle der Staatenlosigkeit bekämpft. Ein solcher spezifischer Fall wurde weiter durch das im Rahmen der CIEC im Jahre 1973 zustandegekommene Abkommen von Bern bekämpft (94). Die systematische Bekämpfung der Staatenlosigkeit war auch das Ziel des New Yorker Abkommens zur Bekämpfung der Staatenlosigkeit aus dem Jahe 1961 (95). Dieses Abkommen schreibt vor, daß die Gründe für den Verlust einer Staatsangehörigkeit grundsätzlich so klausuliert werden sollen, daß Staatenlosigkeit nicht eintreten kann. Nur in ganz wenigen Fällen ist, der Entzug 
einer Staatsangehörigkeit mit Staatenlosigkeir als Folge zoläBig. Die Staatenlosigkeit wird weiter durch die Vorschrift bekämpft, daß einem auf dem Territorium eines der Mitgliedstaaten geborenen staatenlosen Kind entweder automatisch die Staatsangehörigkeit verliehen wird oder, daß das Kind ein Optionsrecht auf diese Staatsangehörigkeit haben soll. Die Ausübung dieses Optionsrechss darf nur von den in diesem Abkommen abschließend aufgezählten Voraussetzungen abhängig gemacht werden. Von den besprochenen Staaten lassen Italien und Spanien Staatenlose die Staatsangehörigkeit iure soli erwerben (96); die andere Staaten sehen Optionsrechte beziehungsweise Einbürgerungsanspriche vor (97).

Die Verlustgründe der Staatsangehörigkeit sind in allen besprochenen Staaten nun so formuliert, daß nur in sehr wenigen Fällen Staatenlosigkeit eintreten kann. Die Niederlande bestimmt sogar ausdrücklich, daß die Staatsangehörigkeit nie verloren werden kann, wenn Statenlosigkeit die Folge wäre (Art. 14 Abs: 2 RwNed). In Spanien können geborene Spanier nie durch Verlust der spanischen Staatsangehörigkeit staatenlos werden. Dies wird durch Art. 11 Abs. 2 der spanischen Verfassung garantiert. Wer die spanische Staatsangehörigkeit durch Einbürgerung oder Option erworben hat, könnte u.U. staatenlos werden, indem er die spanische Staatsangehörigkeit durch Strafurteil, Widernuf der Einbürgerung wegen Betruges oder aufgrund freiwilligen fremden Staats- oder Militärdienstes verliert.

Die Bekämpfung der Staatenlosigkeit wird in den beschriebenen Staaten deshalb allgemein als Ziel der Gesetzgebung anerkannt. Kein Staat kennt Regelungen, die dem Abkommen von New York aus 1961 widersprechen. Zu erwarten ist, daß die in den Art. 7 und 8 dieser Konvention gegebenen Möglichkeiten zur Entziehung der Staatsangehörigkeit immer weniger benutzt werden.

\subsubsection{Bekämpfung der mehrfachen Staatsangehörigkeit}

Mehrfache Staatsangehörigkeit wurde seit jeher als eine Ausnahmeerscheinung betrachtet. Erinnert sei an die Worte von P. Weis: "On ne peut pas avoir deux patries, comme on ne peut pas avoir deux mères" (98). Dennoch wurde die mehrfache Staatsangehörigkeit nicht systematisch bekämpft.

Soweit eine Person durch die Inkongruenz der Staatsangehörigkeitsgesetzungen doch mehrere Staatsangehörigkeiten besaß, wurde sie von jedem der betreffenden Staaten als eigener Staatsangehöriger betrachtet. Die daraus resultierenden Schwierigkeiten, die zwischen Großbritannien und der Vereinigten Staaten bestanden, und die zu den Bancroftverträge geführt haben, illustrieren diese Tatsache (99).

Im vergangenen Jahrhundert wurde die mehtfache Staatsangehörigkeit nicht systematisch bekẩmpft. Dennoch gab er viele Verlustbestimmungen, die eindeutig zum Ziel hatten, Mehrfachstaatsangehörigkeit zu verhindern. Das deutlichste Beispiel bildet die weit verbreitete Regelung, daß eine Staatsangehörigkeit durch freiwilligen Erwerb einer fremden Staatsangehörigkeit verloren wird (100). Seit Ende des vorigen Jahrhunderts ist wiederholt vertreten worden, daB es wünschenswert wäre, neben Staatenlosigkeit auch die Mehrfachstaatsangehörigkeit durch völkenrechtliche Verträge zu bekämpfen (101). Durch in Krafttre- 
ten des Straßburger Abkommens von 1963 erzielten diese Bestrebungen in Westeuropa einen deutlichen Erfolg (102). Die Zielsetzung des Straßburger Abkommens kollidiert jedoch mit dem in den meisten westeuropäischen Staaten bestehenden Wunsch, bereits lange im Inland lebende Ausländer und namentlich die im Inland aufgewachsenen Ausländer auch staatsangehörigkeitsrechtlich zu integrieren. Die Einbürgerungsbereitschaft bei diesen Ausländer ist aber häufig gering, wenn sie in Folge der Einbürgerung die Staatsangehörigkeit ihres Heimatstaates, mit dem sie sich emotional noch verbunden fühlen, aufgeben müssen. Eine grundlegende Änderung des Straßburger Abkommens ist deshalb wïnschenswert (103). Eine Einbürgerung unter Beibehaltung der bisheriger Staatsangehörigkeit muß ermöglicht werden (104).

Eine solche Einbürgerungsmöglichkeit ohne Verlust der bisherigen Staatsangehörigkeit empfiehlt sich namentlich auch in Verhältnis zu anderen EG-Staaten, vielleicht aber auch im Verhältnis zu anderen Mitgliedstaaten des Europarates. Innerhalb der EG dürfte eine solche Mehrfachstaatsangehörigkeit dann als Vorstufe der Staatsangehörigkeit einer Europäischen Union betrachtet werden (105). 


\section{VORSCHLÄGE ZUR ÄNDERUNG DES NIEDERLÄNDISCHEN STAATSANGEHÖRIGKEITSGESETZES}

In den $\$ 3.2 .1$ bis 3.4 .12 werden mehrere Vorschläge zur Änderung des niederländischen Staatsangehörigkeitsgesetzes unterbreitet. Diese Vorschläge sollen in diesem Kapitel dergestalt zusammengefaBt werden, daß pro Artikel die gemachten Änderungsvorschläge resumiert werden. Zuerst wird jeweils eine deutsche Übersetzung der betreffenden Artikel des niederländischen Staatsangehörigkeitsgesetzes vorangestellt. Auch Artikel, bezüglich denen aufgrund der rechtsvergleichenden Erörterungen dieser Arbeit keine Änderungsvorschläge formuliert werden, sind in einer deutschen Übersetzung wiedergegeben.

\section{Allgemeine Bestimmungen}

\section{Artikel 1}

Bei der Anwendung dieses Reichsgesetzes wird verstanden unter

a. Unser Minister: Unser Minister der Justiz des Königreichs;

b. Volljährige(r): wer das 18. Lebensjahr vollendet oder vorher die Ehe geschlossen hat;

c. Mutter: die Frau, die das Kind geboren hat;

d. Vater: der Mann, zu dem das Kind, anders als durch Adoption, im ersten Grad aufsteigender Linie in familienrechtlichen Beziehungen steht;

e. Ausländer: wer die niederländische Staatsangehörigkeit nicht besitzt; und

f. Staatenloser: wer keine Staatsangehörigkeit hat oder wessen Staatsangehörigkeit nicht festgestellt werden kann.

Artikel 2

Der Erwerb und der Verlust der niederländischen Staatsangehörigkeit haben keine ruickwirkende Kraft.

Erwerb der niederländischen Staatsangehörigkeit von Rechts wegen

Artikel 3

1. Niederländer ist dlas Kind, dessen Vater oder Mutter zur Zeit seiner Geburt Niederländer ist, sowie das Kind eines niederländischen Staatsangehörigen, der vorher verstorben ist.

2. Das im Hoheitsgebiet der Niederlande, beziehungsweise der Niederländischen Antillen oder Aruba, oder an Bord eines in den Niederlanden, den Niederländischen Antillen oder Aruba registrierten Seeschiffes oder Luftfahrzeuges, aufgefundene Kind, gilt als Kind eines Niederländers, es sei denn, es stellt sich innerhalb von fuinf Jahren, gerechnet ab dem Tage, an dem es aufgefunden wurde, heraus, daß das Kind durch Geburt eine ausländische Staatsangehörigkeit besitzt.

3. Niederländer ist das Kind eines Vaters oder einer Mutter, der bzw. die zur Zeit der Geburt in den Niederlanden, in den Niederländischen Antillen oder Aruba lebte und selbst aus einer in einem dieser Länder lebenden Mutter geboren ist. 
In Absatz 2 sollte klar gestellt werden, daß ein aufgefundenes Kind nut die niederländische Staatsangehörigkeit verliert, wenn innerbalb von fünf Jahren, nachdem es aufgefunden wurde, nachgewiesen wird, dal3 es ausschließlich eine fremde Staatsangehörigkeit besitzt. Die niederländische Staatsangehörigkeit darf nicht verloren werden, wenn sich herausstellt, daß es neben der niederländischen auch noch eine fremde Staatsangehörigkeit besitzt (siehe $\$ 2.6 .2$, vgl. weiter die Betrachtungen in $\$ 3.2 .7$ ).

In der Perspektive der Gleichberechtigung wäre Abs. 3 dahingehend zu ändern, daß auch das Kind eines Vaters oder einer Mutter, der bzw. die zur Zeit der Geburt im Königreich der Niederlande lebt, aber selbst geboren ist als Kind eines im Königreich lebenden Vaters, die niederländische Staatsangehörigkeit iure domicilii erwirbt. (siehe $\$ \S 2.6 .2$ und 3.2.6). Bezüglich der Bestimmung des Abs. 3 sollte - wie beim Abs. 1- klargestellt werden, daß die niederländische Staatsangehörigkeit aufgrund dieser Bestimmung auch erworben werden kann, wenn der maßgebende Elternteil bereits vor Geburt des Kindes gestorben ist, jedoch zur Zeit seines Todes in den Niederlanden lebte (siehe \$ 3.2.1). Weiter sollte explizient werden, daß die Regelung des Art. 3 Abs. 3 nicht für Kinder von Mitgliedern einer ausländischen diplomatischen oder konsullarischen Mission gilt (\$ 3.2.6).

\section{Artikel 4}

1. Niederländer wird der minderjährige Ausländer, der von einem Niederländer anerkannt wird.

2. Niederländer wird der minderjährige Ausländer, der ohne Anerkennung durch Legitimation Kind eines Niederländers wird.

3. Das Kind desjenigen, der durch Anerkennung oder Legitimation die niederländische Staatsangehörigkeit erwirbt, nimmt an diesem Erwerb teil.

Die Anerkennung oder Legitimation eines bereits zwölfjährigen Minderjährigen sollte im Prinzip nicht ohne dessen Einwilligung Erwerb der niederländischen Staatsangehörigkeit bewirken (siehe \$ 3.2.2). Erwägenswert wäre darüberhinaus, den Erwerb kraft Anerkennung oder Legitimation von der Einwilligung der Mutter abhängig zu machen, wenn der Erwerb der niederländischen Staatsangehörigkeit bewirkt, daß das Kind dadurch die Staatsangehörigkeit der Mutter verliert; eine von der Mutter verweigerte Einwilligung mußte jedoch durch eine gerichtliche Entscheidung ersetzt werden können (siehe ebenfalls \& 3.2.2).

Klargestellt werden sollte, daß die niederländische Staatsangehörigkeit durch Legitimation auch erworben werden kann, wenn der Vater zur Zeit der Legitimation schon gestorben ist (siehe $\$ 3.2 .1$ ). Ebenfalls sollte verdeutlicht werden, daß ein Kind die niederländische Staatsangehörigkeit erwirbt, wenn es durch Anerkennung oder Legitimation Kind eines Ausländers wird, jedoch die Voraussetzungen des Art. 3 Abs. 3 erfüllt sind.

Falls in der Zukunft auch nach niederländischem Recht durch Feststellung der Vaterschaft familienrechtliche Beziehungen zwischen einem nichtehelichen Kind und dessen Erzeuger hergestellt werden können, muB eine solche Feststellung der Vaterschaft unter den gleichen Voraussetzungen wie im Falle einer Anerkennung Erwerb der niederländischen Staatsangehörigkeit bewirken. Bereits jetzt ist es gerechtfertigt einem nichtehelichen minderjährigen Kind eines niederländischen Erzeugers, der zu Unterhaltsleistungen für dieses Kind verurteilt worden 
ist, ein Optionsrecht auf die niederländische Staatsangehörigkeit zul geben (8.2.5).

\section{Artikel 5}

1. Niederländer wird das Kind, das in den Niederlanden, den Niederländischen Antillen oder Aruba aufgrund einer richterlichen Entscheidung adoptient wird, wenn der Adoptivvater oder die Adoptivmutter an dem Tag, an dem das Urteil rechtskräftig wird, die niederländische Staatsangehörigkeit besitzt und das Kind am Tag der erstinstanzlichen Entscheidung minderjährig war.

2. Das Kind desjenigen, der durch Adoption die niederländische Staatsangehörigkeit erwirbt, nimmt an diesem Erwerb teil.

Adoption eines bereits zwölfjährigen Minderjährigen darf nicht ohne dessen Einwilligung Erwerb der niederländischen Staatsangehörigkeit bewirken (siehe \$ 3.2.2). Klargestellt werden sollte ferner, daß die niederländische Staatsangehörigkeit auch durch Adoption erworben werden kann, wenn der maBgebende Adoptivelternteil an dem Tage, an dem das Adoptivurteil rechtskräftig wird, bereits verstorben ist (siehe $\$ 3.2 .1$ ). Auch sollte deutlich werden, daß die niederländische Staatsangehörigkeit erworben werden kann, wenn ein Kind in den Niederlanden von Ausländern adoptiert wird, und die Voraussetzungen des Art. 3 Abs. 3 erfüllt sind (siehe $\$ 3.2 .3$ ).

\section{Erwerb der niederländischen Staatsangehörigkeit durch Option}

Artikel 6

1. Durch Abgabe einer dahingehenden Erklärung erwirbt die niederländische Staatsangehörigkeit:

a. der volljährige Ausländer, der in den Niederlanden beziehungsweise in den Niederländischen Antillen oder Aruba geboren ist, dort seit seiner Geburt seinen Wohnsitz oder tatsächlichen Aufenthalt und das Alter von 25 Jahren noch nicht vollendet hat;

b. wer in den Niederlanden, beziehungweise in den Niederländischen Antillen oder Aruba geboren ist, dort mindestens drei Jahre seinen Wohnsitz oder tatsăchlichen Aufenthalt hat und seit seiner Geburt staatenlos ist, sofern er das Alter von 25 Jahren noch nicht vollendet hat. Für einen Minderjährigen muß die Erklärung von seinem gesetzlichen Vertreter abgegeben werden.

2. Für die Anwendung der Bestimmung im ersten Halbsatz und unter b wird eine Geburt an Bord eines in den Niederlanden, den Niederländischen Antillen oder Aruba eingetragenen Seeschiffes oder Luftfahrzeuges einer Geburt in den Niederlanden, beziehungsweise den Niederländischen Antillen oder Aruba gleichgestellt.

Es ist gerechtfertigt einem nichtehelichen, nichtanerkannten, minderjährigen Kind eines niederländischen Erzeugers ein Optionsrecht auf die niederländische Staatsangehörigkeit zu geben, wenn dieser Erzeuger zu Unterhaltsleistungen für dieses Kind verurteilt worden ist (siehe $\$ 3.2 .5$ ).

Das Optionsrecht des Art. 6 Abs. 1 Buchstabe a sollte nicht auf den Geburtsort des Betreffenden abstellen, sondern in der Perspektive der Regelung des Art. 3 
Abs. 3 auf den Wohnsitz der Eltern zur Zeit der Geburt der betreffenden Person. Es sollte für die Entstehung dieses Optionsrechts irrelevant sein, ob der Betreffende in der Zeit zwischen seiner Geburt und Einschulung im Ausland gelebt hat; maßgebend müßte sein, ob er seine ganze Schulzeit in den Niederlanden verbracht hat. Der Zeitpunkt, an dem das Optionsrecht entsteht (18 Jahre) ist unter dem Gesichtspunkt der Bekämpfung der mehrfachen Staatsangehörigkeit zu bejahen; von diesem Streben abgesehen wäre auch zu vertreten, dieses Optionsrecht in dem Alter entstehen zu lassen, ab dem eine Person nicht mehr der gesetzlichen Schulpflicht unterliegt. $\mathrm{Zu}$ erwägen wäre sogar, ob nicht jeder - auch einer im Ausland geborenen - Person, die ihre Schulerziehung in den Niederlanden genossen hat, ein Optionsrecht auf die niederländische Staatsangehörigkeit eingeräumt werden sollte (siehe $\$$ 3.3.3.1 Buchstabe a und $\$$ 3.3.3.2 Buchstabe c). Die vorgesehene Befristung des Optionsrechts einer in den Niederlanden geborenen Person ist jedenfalls nicht zu vertreten (siehe \$ 3.3.3.1 Buchstabe a).

Aufgrund des Art. 3 der New Yorker Konvention aus 1961 kann bei dem Optionsrecht des Art. 6 Abs. 1 Buchstabe b nicht lediglich auf den Wohnsitz der Eltern zur Zeit der Geburt des staatenlosen Kindes abgestellt werden. Dieses Optionsrecht sollte dermaßen erweitert werden, daß es auch entsteht, wenn das staatenlose Kind im Ausland geboren wird, während ein Elternteil seinen Wohnsitz in den Niederlanden hat. Außerdem sollte die Regelung dergestalt geändert werden, daß ein in den Niederlanden geborenes Kind (bzw. ein im Ausland geborenes Kind, das zur Zeit seiner Geburt einen in den Niederlanden wohnhaften Elternteil hat) auch für die niederländische Staatsangehörigkeit optieren kann, wenn es vor Vollendung des 18 . Lebensjahr staatenlos wird (§ 3.3.3.1 Buchstabe b).

Verleihung der niederländischen Staatsangehörigkeit

Artikel 7

1. Unter Beriicksichtigung der Bestimmungen dieses Kapitels verleihen Wir auf Vorschlag Unseres Ministers Ausländern auf deren Antrag die niederländische Staatsangehörigkeit.

2. Bezüglich derjenigen, die in den Niederländischen Antillen, beziehungsweise Aruba wohnhaft sind, gibt Unser Minister der Justiz der Niederländischen Antillen, beziehungsweise Unser Minister der Justiz von Aruba, beziiglich des Antrags seine Stellungnahme ab.

Artikel 8

1. Für Verleihung der niederländischen Staatsangehörigkeit gemäß Artikel 7 kommen nur Antragsteller in Betracht:

a. die volljährig sind;

b. gegen deren unbefristeten Aufenthalt in den Niederlanden, beziehungsweise den Niederländischen Antillen oder Aruba, keine Bedenken bestehen;

c. die mindestens fünf dem Antrag unmittelbar vorangehende Jahre Wohnsitz oder tatsächlichen Aufenthalt in den Niederlanden, beziehungsweise den Niederländischen Antillen oder Aruba gehabt haben; und 
d. die als in die niederländische, beziehungsweise niederländisch-antillianische oder arubaische Gesellschaft integriert betrachtet werden können aufgrund hinreichender Kenntnisse der niederländischen Sprache oder falls sie in den Niederländischen Antillen oder Aruba leben - der Sprache, die neben niederländisch auf der betreffenden Insel ferner gebraüchlich ist, und die sich auch im übrigen in die niederländische, beziehungsweise niederländisch-antillianische oder arubaische Gesellschaft haben aufnehmen lassen.

2. Die Voraussetzung des Absatzes 1 unter c) gilt nicht für einen Antragsteller, der entweder einmal die niederländische Staatsangehörigkeit oder den Status eines niederländischen Untertans-Nicht-Niederländers besessen hat, oder seit mindestens drei Jahren der Ehepartner eines niederländischen Staatsangehörigen ist oder während seiner Volljährigkeit durch Anerkennung oder Legitimation Kind eines Niederländers geworden ist, oder in den Niederlanden, den Niederländischen Antillen oder Aruba von Eltern adoptiert worden ist, von denen jedenfalls einer die niederländische Staatsangehörigkeit besitzt.

3. Die im ersten Absatz unter c) genannte Frist wird für diejenigen, die insgesamt mindestens zehn Jahre in den Niederlanden, beziehungsweise den Niederländischen Antillen oder Aruba gelebt haben auf zwei Jahre verkürzt.

4. Die im ersten Absatz unter c) genannte Frist wird für Unverheiratete, die seit mindestens drei Jahren mit einem unverheirateten niederländischen Staatsangehörigen in einer dauerhaften nichtehelichen Lebensgemeinschaft zusammenleben, auf drei Jahre verkürrzt.

Eine gesellschaftliche Eingliederung sollte im Rahmen des Einbürgerungsverfahrens nicht als ausdrückliche Voraussetzung für eine Einbürgerung gestellt werden $(\$ 3.3 .4 .5)$. Beherrschung der niederländischen Sprache, bzw. einer anderen am Wohnort (in den Niederlanden, beziehungsweise den Niederländischen Antillen oder Aruba) üblichen Sprache sollte als selbständige Einbürgerungsvoraussetzung formuliert werden; dabei wäre im Auge zu behalten, daß nicht eine perfekte mündliche oder schriftliche Beherrschung einer dieser Sprachen überprüft werden soll, sondern die Kommunikationsfähigkeit in einer dieser Sprachen $(\$ 3.3 .4 .6)$. Art. 8 Abs. 1 Buchstabe $d$ sollte entsprechend abgeăndert werden.

Art. 8 sollte um eine Bestimmung erweitert werden, wonach ein Einbürgerungsantrag einer Person, die mehr als zehn Jahre gutgläubig den Status eines Niederländers gehabt hat, nicht zurückgewiesen werden kann $(\$ 3.3 .3 .1$ Buchstabe e). Verdeutlicht werden sollte, welche Behörde befugt ist festzustellen, ob gegen den unbefristeten Aufenthalt des Antragstellers im Königreich der Niederlande (keine) Bedenken bestehen und welchen Maßstab diese Behörde dabei anzulegen hat (siehe \$ 3.3.4.4).

Die Bestimmungen des Abs. 2 und 4 zugunsten des Ehepartners, bzw. des nichtehelichen Partners eines Niederländers sollten geändert werden. Der ausländische Ehepartner eines Niederländers sollte bei Auslandswohnsitz grundsätzlich erst nach fünfjähriger Ehe eingebürgert werden. Ist der niederländische Ehepartner jedoch im Dienste des niederländischen Staates, dann ist der ausländische Ehepartner so zu behandeln, als lebe er in den Niederlanden. Bei Wohnsitz in den Niederlanden während der Ehe muß die geforderte Wohnsitzfrist um die in den Niederlanden verbrachte Ehezeit verkürzt werden. Bei Berechnung der Ehedauer wird die Zeit, während der ein Ehescheidungsantrag 
oder Antrag auf Trennung von Tisch und Bett anhängig waren und die Zeit, die die Ehegatten von Tisch und Bett getrennt lebten, nicht angerechtnet. Die Regelung zugunsten von nichtehelichen Partnem unverheirateter Niederländer sollte entsprechend gestaltet werden. Für die im Ausland lebenden nichtehelichen Partner niederländischer Staatsangehöriger sollten jedoch nur dann Einbürgerungserleichterungen gelten, falls der niederländische Partner im niederländischem Staatsdienst steht oder die Partner in einem Mitgliedstaat des Europarates zusammenleben.

\section{Artikel 9}

1. Ein Antrag, der den Bestimmungen der beiden vorherigen Artikel entspricht, wird gleichwohl zurückgewiesen, wenn

a. aufgrund des Verhaltens des Antragstellers ernsthafte Verdachtsgründe bestehen, daß er die öffentliche Ordnung, die guten Sitten, die Volksgesundheit oder die Sicherheit des Königreichs gefährdet; oder

b. der Antragsteller, der eine andere Staatsangehörigkeit besitzt, nicht sein Möglichstes zur Aufhebung jener Staatsangehörigkeit getan hat, oder nicht dazu bereit ist nach Zustandekommen der Einbürgerung, sein Möglichstes zur Aufhebung jener Staatsangehörigkeit zu tun, es sei denn, daß dies billigerweise nicht verlangt werden kann.

c. der Antragsteller, auf den eine der Ausnahmen des Artikels 8, Abs. 2 zutrifft, in dem Staat lebt, dessen Staatsangehörigkeit er besitzt.

2. Wenn der Antragsteller die niederiändische Staatsangehörigkeit infolge Artikel 16, Absatz 1 verloren hat, kann der Antrag aufgrund des im vorigen Absatz unter a) bezeichneten Grundes nur zurückgewiesen werden, wenn er während der letzten zehn Jahre vor der Antragstellung wegen einer Straftat gegen die Sicherheit des Königreichs oder wegen einer anderen Straftat zu einer Gefängenisstrafe von mindestens fünf Jahren verurteilt worden ist.

3. Über den Antrag wird innerhalb eines Jahres nach Antragstellung entschieden. Die Entscheidung kann höchstens zweimal für sechs Monate ausgesetzt werden.

4. Entscheidungen über Abweisung oder Aussetzen von Anträgen auf Erwerb der niederländischen Staatsangehörigkeit können von Unserem Minister getroffen werden.

Art. 9 Abs. 1 Buchstabe a) sollte dergestalt geändert werden, daß ein Einbürgerungsantrag lediglich zuruickgewiesen werden kann, wenn der Antragsteller innerhalb einer dem Antrag vorangehenden Frist von zehn Jahren wegen genau präzizierter Delikte verurteilt worden ist, oder eine solche Verurteilung während des Einbürgerungsverfahrens stattfindet. Ein Einbürgerungsantrag müßte ferner abgewiesen werden können, wenn der Antragsteller sich zur Zeit seines Antrages aufgrund eines mehr als 10 Jahre zurickliegenden Urteils in einer Strafanstalt aufhält. Wenn ein Strafverfahren gegen den Antragsteller läuft, müßte das Einbürgerungsverfahren bis zu dessen Abschluß ausgesetzt werden $(\S 3.3 .4 .7)$.

Die unter Buchstabe b) gestellte Forderung, daß ein Einbürgerungsbewerber alles Mögliche tun muß, um seine bisherige Staatsangehörigkeit zu verlieren, sollte nicht gestellt werden, wenn es sich bei der bisherigen Staatsangehörigkeit, um die eines anderen EG-Staates (oder eines Mitgliedstaates des Europarates) handelt oder die eines Staates, mit dem die Niederlande ein Gastarbeiterabkommen geschlossen hat ( $\$ 3.3 .4 .8)$. Art. 9 Abs. 1 Buchstabe c) ist ersatzlos zu 
streichen (\$ 3.3.4.3). Art. 9 Abs. 2 sollte dermaßen ergänzt werden, daß eine Einbïrgerung auch verweigert werden kann, wenn eine solche Verurteilung während des Einbürgerungsverfahrens stattfindet $(\$ 3.3 .4 .7)$.

Artikel 10

Wir können, nach Anhörung des Staatsrats des Königreichs, in besonderen Fällen die niederländische Staatsangehörigkeit in Abweichung von den Bestimmungen der Artikel 8, Absatz 1, erster Halbsatz und unter a), c) und d) und Artikel 9, Absatz 1, erster Halbsatz und unter c) verleihen.

Art. 10 ist unnötig kompliziert formuliert. Es reicht aus, daß nach Anhörung des Staatsrates eine Einbürgerung ohne Beachtung der Voraussetzungen des Art. 8 und 9 ermöglicht wird (\$ 3.3.5).

\section{Artikel 11}

1. Das minderjährige nichtniederländische Kind eines Vaters oder einer Mutter, denen die niederländische Staatsangehörigkeit verliehen wird, nimmt an diesem Erwerb teil,sofern der Beschluß keinen diesbezüglichen Vorbehalt enthält. Dem gesetzlichen Vertreter und sofern es das Alter von 12 Jahren erreicht hat, dem Kind, wird die Gelegenheit gegeben, seine Meinung über die Miteinbürgerung zu äußern.

2. Bei der Anwendung des ersten Absatzes wird unter Vater auch der Adoptivvater, unter Mutter auch die Adoptivmutter verstanden, wenn die Adoption in Übereinstimmung mit den Regeln des niederländischen internationalen Privatrechts zustande gekommen ist und das. Kind durch diese Adoption den Status eines ehelichen Kindes der Adoptiveltern erworben hat.

Art. 11 sollte in der Form geändert werden, da $B$ eine Einbürgerung eines Elternteils sich nur nach ordnungsgemäßen Antrag auf dessen minderjährige Kinder erstreckt. Eine Erstreckung auf ein bereits zwölfjähriges Kind sollte grundsätzlich nur erfolgen, wenn dieses Kind in die Erstreckung einwilligt. Weiter sollte die Einwilligung des gesetzlichen Vertreters eingeholt werden und ebenfalls die Einwilligung des Elternteils, der kein gesetzlicher Vertreter des Kindes ist, falls der Minderjährige durch die Erstreckung die Staatsangehörigkeit dieses Elternteils verlieren würde. Die mangelnde Einwilligung des gesetzlichen Vertreters oder eines Elternteils sollte im Interesse des Kindes durch Gerichtsentscheid ersetzt werden können. Eine mangelnde Einwilligung des Kindes sollte nur dann vom Gericht ersetzt werden können, wenn das Kind seine bisherige Staatsangehörigkeit durch die Erstreckung nicht verliert (siehe § 3.3.6).

Artikel 12

1. Hat der Antragsteller keinen Familiennamen oder Vornamen oder steht deren richtige Schreibweise nicht fest, werden diese mit seinem Einverständnis in dem Beschluß festgestellt, durch den die niederländische Staatsangehörigkeit veriliehen wird.

2. Der Name des Antragstellers wird erforderlichenfalls, in die im Königreich gebräuchlichen Schriftzeichen übertragen und kann, falls dies für die Integra- 
tion in die niederlăndische Gesellschaft von Bedeutung ist, mit Einwilligung des Antragstellers in dem BeschluB mit dem die niederländische Staatsangehörigkeit verliehen wird, geändert werden.

\section{Artikel 13}

Durch Rechtsverordnung des Reiches werden Vorschriften über die Gebühren für die Einbürgerung, über die völlige oder teilweise Befreiung von diesen Gebïhren und über deren Entrichtung erlassen.

Dieser Artikel ist ersatzlos zu streichen. Einbürgerungen sollten kostenlos sein (\$ 3.3.4.14).

Verlust der niederländischen Staatsangehörigkeit

Artikel 14

1. Außer durch den Wegfall der familienrechtlichen Beziehung, von der die niederländische Staatsangehörigkeit aufgrund einer der Bestimmungen der Artikel 3,4 und 5 abgeleitet wird, geht die niederländische Staatsangehörigkeit nur kraft einer der Bestimmungen der Artikel 15 und 16 verloren.

2. Kein Verlust der niederländischen Staatsangehörigkeit, aus welchem Grund auch immer, tritt ein, falls Staatenlosigkeit die Folge davon wäre.

\section{Artikel 15}

Ein Volljähriger verliert die niederländische Staatsangehörigkeit:

a. durch den freiwilligen Erwerb einer anderen Staatsangehörigkeit;

b. durch Verzichtserklärung;

c. wenn der Betreffende nach seiner Volljährigkeit, während eines ununterbrochenen Zeitraums von 10 Jahren außerhalb der Niederlande, der Niederländischen Antillen und Aruba, Wohnsitz in dem Lande hat, in dem er geboren ist und dessen Staatsangehörigkeit er ebenfalls besitzt, sofern er nicht in einem Dienstverhältnis mit den Niederlanden, beziehungsweise den Niederländischen Antillen oder Aruba oder einer internationalen Organisation steht, in der das Königreich vertreten ist, oder Ehegatte einer Person mit einem solchen Dienstverhältnis ist;

d. durch Widerruf des Beschlusses, durch den die niederländische Staatsangehörigkeit verliehen wurde, welcher erfolgen kann, falls der Betreffende nach erfolgter Einbürgerung es unterlassen hat das Möglichste zu tun, um seine ursprüngliche Staatsangehörigkeit zu verlieren.

Art. 15 Abs. 1 Buchstabe a) entspricht der Regelung des Art. 1 Abs. 1 des Straßburger Europaratsabkommens von 1963. Dennoch ist eine Änderung der Verlustregellung der Staatsangebörigkeit wegen freiwilligen Erwerbs einer fremden Staatsangehörigkeit wünschenswert. Bei Inlandswohnsitz sollte die miederländische Staatsangehörigkeit nicht wegen des Erwerbs einer fremden Staatsangehörigkeit verloren werden. Bei Auslandswohnsitz sollte die niederländische Staatsangehörigkeit wegen Erwerbs einer fremden Staatsangehörigkeit verloren werden, es sei denn, die Staatsangehörigkeit eines anderen Mitgliedstaates der Europäischen Gemeinschaften (oder eines anderen Mitgliedstaates 
des Europarates) wird erworben oder der betreffende Niederländer erklärt vor Erwerb der fremden Staatsangehörigkeit, seine bisherige Staatsangehörigkeit beibehalten zu wollen. Diese Beibehaltungserklärung sollte bewirken, daB die niederländische Staatsangehörigkeit zehn Jahre beibehalten bleibr; vor Ablauf dieser Zehnjahresfrist sollte die Abgabe einer erneuten Beibehaltungserklärung bewirken, daß die niederländische Staatsangehörigkeit wiederum zehn Jahre beibehalten wird (\$3.4.2).

In Art. 15 Abs 1 Buchstabe c) sollte entweder eine Ausnahmeklausel zumindest bezuiglich der anderen EG-Mitgliedstaaten (oder der anderen Mitgliedstaaten des Europarates), oder die Möglichkeit den Verlust der Staatsangehörigkeit durch Beibehaltungserklärung abzuwenden, aufgenommen werden. Ferner sollte auch ein Dienstverhältnis in einer niederländischen Gesellschaft oder Verein oder ein durch Vermittlung der niederländischen Regierung zustandegekommenes Dienstverhältnis genügen, um den Verlust der niederländischen Staatsangehörigkeit $\mathrm{zu}$ verhindern $(\$ 3.4 .4)$.

Art. 15 Buchstabe d ist dermaßen zu ändem, daß die niederländische Staatsangehörigkeit einem Eingebürgerten wieder entzogen werden kann, falls dieser entgegen einer für ihn bestehenden Verpflichtung es unterlassen hat, sein Möglichstes zu tun, um seine ursprüngliche Staatsangehörigkeit zu verlieren. Der betreffende Bürger ist mindestens sechs Monate vor der beabsichtigten Entziehung der Staatsangehörigkeit hierüber zu belehren. Eine Entziehung ist nach Ablauf von fünf Jahren nach der Einbürgerung nicht mehr zulässig (\$ 3.4.5).

Weiter sollte die Möglichkeit eröffnet werden, die Einbürgerung wegen Fälschung, Verheimlichung oder Betrugs während des Einbürgerungsverfahrens zu widerrufen; auch diese Möglichkeit müßte auf fünf Jahre nach der Einbürgerung befristet werden.

\section{Artikel 16}

1. Ein Minderjähriger verliert die niederländische Staatsangehörigkeit:

a. durch Anerkennung, Legitimation oder Adoption durch einen Ausländer, falls er dessen Staatsangehörigkeit dadurch erwirbt oder diese bereits besitzt;

b. falls sein Vater oder seine Mutter freiwillig eine andere Staatsangehörigkeit erwirbt und sich dieser Erwerb auch auf ihn erstreckt oder er diese Staatsangehörigkeit bereits besitzt;

c. falls sein Vater oder seine Mutter die niederländische Staatsangehörigkeit infolge Artikel 15, unter b., c. oder d. verliert;

d. falls er selbständig die Staatsangehörigkeit seines Vaters oder seiner Mutter erwirbt.

Bei der Anwendung der Bestimmungen unter b., c. und $d$. werden unter Vater, beziehungweise Mutter auch der Adoptivvater und die Adoptivmutter von denen der Minderjährige die niederländische Staatsangehörigkeit ableitet, verstanden.

2. Der Verlust der niederländischen Staatsangehörigkeit tritt nicht ein, falls und solange der andere Elternteil die niederländische Staatsangehörigkeit besitzt.

Art. 16 Abs. 1 Buchstabe a) ist ersatzlos zu streichen ( $\$ 3.4 .9)$. 
Feststellung der niederländischen Staatsangehörigkeit

\section{Artikel 17}

1. Jeder, der außerhalb eines bei einer richterlichen Instanz oder verwaltungsrechtlichen Berufungsinstanz in einem der Teile des Königreichs anhängigen Verfahrens, ein unmittelbares Interesse daran hat, kann bei der Arrondissementsrechtbank 's Gravenhage (Landgericht Den Haag) oder, falls er in den Niederländischen Antillen oder Aruba wohnhaft ist, beim Gemeenschappelijk Hof van Justitie (Gemeinschaftlichen Gerichtshof) der Niederländischen Antillen oder Aruba, einen Antrag auf Feststellung seiner niederländischen Staatsangehörigkeit oder auf Feststellung der Tatsache, daß er die niederländische Staatsangehörigkeit nicht besitzt, stellen. Der Antrag kann auch beinhalten festzustellen, daß der Betreffende die niederländische Staatsangehörigkeit zu einem bestimmten Zeitpunkt besessen oder nicht besessen hat.

2. Ein Antrag im Sinne des vorigen Absatzes kann auch bezüglich eines Verstorbenen gestellt werden.

Artikel 18

1. Zu Anträgen im Sinne des vorigen Artikels hört die Arrondissementsrechtbank (Landgericht), beziehungsweise der Gemeenschappelijk Hof van Justitie (Gemeinschaftliche Gerichtshof) die Meinung der Staatsanwaltschaft. Für die Niederlande sind die Artikel 429d, 429f - 429l und 429s-429t der Zivilprozeßordnung anwendbar.

2. Der Antragsteller und jeder andere Beteiligte kann gegen die Entscheidung ausschließlich Kassationsbeschwerde einlegen.

Artikel 19

An einen rechtskräftigen Beschluß, der gemäß Artikel 17 ergangen ist, ist jedes mit der Ausführung einer gesetzlichen Regelung beauftragte Organ gebunden.

Artikel 20

1. Besteht in einem bei einer richterlichen Instanz in den Niederlanden beziehungsweise den Niederländischen Antillen oder Aruba anhängigen Verfahren keine Gewißheit darüber, daß der vom Verfahren Betroffene im Besitz der niederländischen Staatsangehörigkeit ist oder zu einem früheren Zeitpunkt war, kann das Gericht Unseren Minister beziehungsweise Unseren Minister der Justiz der Niederländischen Antillen beziehungsweise Unseren Minister der Justiz von Aruba um Stellungsnahme ersuchen.

2. Besteht in einem bei einer verwaltungsgerichtlichen Berufungsinstanz in den Niederlanden beziehungsweise den Niederländischen Antillen oder Aruba anhängigen Verfahren eine Ungewißheit im Sinne des vorigen Absatzes, so setzt diese Instanz das Verfahren aus und ersucht Unseren Minister beziehungsweise Unseren Minister der Justiz der Niederländischen Antillen beziehungsweise Unseren Minister der Justiz von Aruba hierzu um Stellungnahme. 
3. Das Verfahren wird sofort wieder aufgenommen, nachdem die in den vorigen Absätzen bezeichnete Stellungnahme eingegangen ist.

\section{Erklärungen und Register}

\section{Artikel 21}

Für die Entgegennahme von Erklärungen über den Erwerb der und den Verzicht auf die niederländische Staatsangehörigkeit sind zuständig:

a. in den Niederlanden: die Bürgermeister;

b. in den Niederländischen Antillen: die von Unserem Minister der Justiz der Niederländischen Antillen beauftragten Beamten;

c. in Aruba: die von Unserem Minister der Justiz von Aruba beauftragten Beamten;

d. im Ausland: die Beamte der niederländischen diplomatischen und konsularischen Vertretungen.

Artikel 22

1. Unser Minister führt ein öffentliches Register über:

a. die Erklärungen über den Erwerb der und den Verzicht auf die niederländische Staatsangehörigkeit;

b. die Verleihung der niederländischen Staatsangehörigkeit;

c. die Widerrufe, im Sinne des Artikel 15, unter d.;

2. Unsere Minister der Justiz der Niederländischen Antillen und von Aruba führen ein öffentliches Register über die in Absatz 1 bezeichneten Urkunden, die sich auf Personen beziehen, die in ihrem Land wohnhaft sind.

\section{Schlußbestimmungen}

\section{Artikel 23}

Wir können durch Rechtsverordnung des Reiches nähere Vorschriften zur Ausfuihrung dieses Gesetzes erlassen.

Artikel 24

1. Dieses Gesetz kann zitiert werden als "Rijkswet op het Nederlanderschap" (Reichsgesetz über die niederländische Staatsangehörigkeit). Es tritt an einem von Uns zu bestimmenden Zeitpunkt in Kraft. Wir können einen anderen Zeitpunkt feststellen, an dem Kapitel 6 in Kraft tritt.

2. Das Gesetz vom 12. Dezember 1892, Staatsblad (Staatsanzeiger) 268 über die niederländische Staatsangehörigkeit und die Eingesessenschaft wird außer Kraft gesetzt.

\section{Übergangsbestimmungen}

Artikel 25

Niederländer im Sinne dieses Reichsgesetzes sind auch diejenigen, die bei seinem Inkrafttreten die niederländische Staatsangehörigkeit besitzen. 
Artikel 26

Die Frist in Artikel 15, unter $c$ beginnt für Niederländer, die im Zeitpunkt des Inkraftretens dieses Reichsgesetzes Wohnsitz außerhalb des Königreichs haben, zu diesem Zeitpunkt an.

\section{Artikel 27}

1. Artikel 3 dieses Reichsgesetzes ist nur auf Kinder anwendbar, die nach dem Inkrafttreten dieses Reichsgesetzes geboren sind.

2. Das nichtniederländische Kind - darunter fallt auch das in den Niederlanden, den Niederländischen Antillen oder Aruba adoptierte Kind - einer Frau, die Niederländerin ist, - oder falls sie verstorben ist - zur Zeit ihres Todes Niederländerin war, erwirbt, falls es zur Zeit des Inkrafttretens dieses Reichsgesetzes das Alter von 21 Jahren noch nicht vollendet hat und nicht verheiratet oder verheiratet gewesen ist, die niederländische Staatsangehörigkeit durch Abgabe einer darauf gerichteten Erklärung. Für diejenigen, die das Alter von 18 Jahren noch nicht vollendet haben, muß die Erklärung von der Mutter oder - falls diese gestorben ist - vom gesetzlichen Vertreter abgegeben werden. Diese Erklärung muß innerhalb von drei Jahren nach Inkrafttreten dieses Reichsgesetzes abgegeben werden.

\section{Artikel 28}

Die Frau, die die niederländische Staatsangehörigkeit durch oder in Zusammenhang mit einer vor Inkrafttreten dieses Reichsgesetzes geschlossenen Ehe verloren hat, erwirbt die niederländische Staatsangehörigkeit durch Abgabe einer darauf gerichteten Erklärung; sie muß innerhalb eines Jahres nach Auflösung der Ehe oder innerhallb eines Jahres, nachdem sie von der Auflösung der Ehe Kenntnis hat erlangen können, abgegeben werden. Dieser Erwerb wirkt bis zum Datum der Auflösung der Ehe zurück. 
5. FREMDSPRACHIGE ZUSAMMENFASSUNGEN

\section{$5.1 \quad$ Nederlandse samenvatting}

Nationaliteitsrecht in beweging

Een rechtsvergelijkende studie over verwervings- en verliesgronden van de nationaliteit.

In de afgelopen twee decennia heeft het nationaliteitsrecht van de meeste Westeuropese staten aanmerkelijke wijzigingen ondergaan. Langzamerhand is getracht om het beginsel van gelijkheid van mannen en vrouwen ook op dit gebied van het recht gestalte te geven. Voorts werd het tegengaan van staatloosheid een belangrijk uitgangspunt van de nieuwe regelingen Tevens is in meerdere staten ook geprobeerd meervoudige nationaliteit zo veel mogelijk te voorkomen. Geconstateerd kan worden dat met name de verwezenlijking van de gelijke behandeling van mannen en vrouwen in het nationaliteitsrecht en de bestrijding van de meervoudige nationaliteit gedeeltelijk met elkaar botsen. Immers juist de gelijke behandeling van beide geslachten bewerkstelligt dat -vooral indien ze met betrekking tot de verkrijging van de nationaliteit iure sanguinis aldus wordt gerealiseerd, dat de nationaliteit door afstamming in beginsel zowel van de vader als van de moeder kan worden afgeleid- aanmerkelijk meer personen met meervoudige nationaliteit zijn dan voorheen.

Elke wetgever moet derhalve de vraag beantwoorden waar de grens tussen deze beide beginselen moet worden getrokken. Reeds oppervlakkige bestudering van verschillende nationaliteitsregelingen leert dat deze grens op uiteenlopende wijze wordt getrokken. Daar alle nationaliteitsregelingen verder ook nog talrijke historisch bepaalde eigenaardigheden kennen, valt een uitermate grote variatie op. In het onderhavige boek worden de verwervings- en verliesgronden van de nationaliteit van negen Westeuropese staten met elkaar vergeleken. Het doel van deze vergelijking is het doen van voorstellen ter verbetering van het Nederlandse nationaliteitsrecht. Deze voorstellen worden in paragraaf 4 gedaan.

Het spreekt echter vanzelf, dat ik soortgelijke veranderingen van de nationaliteitswetgeving van andere staten wenselijk vind. Als Nederlands jurist wil ik echter geen uitdrukkelijke voorstellen tot wijziging van de nationaliteitsregelingen van andere staten doen. Uit het feit dat dit boek niet in het Nederlands is geschreven, kan evenwel de hoop worden afgeleid dat de hier gemaakte vergelijkingen ook bij toekomstige wijzigingen van buitenlandse nationaliteitsregelingen een zekere rol mogen spelen.

In de paragrafen 2.1 tot en met 2.9 worden achtereenvolgens beschreven de verwervings- en verliesgronden van de nationaliteit in België, de Bondsrepubliek Duitsland, Frankrijk, Groot-Britannië, Italië, Nederland, Oostenrijk, Zwitserland en Spanje. Per land wordt allereerst een schets van de algemene historische ontwikkeling van het nationaliteitsrecht gegeven. Daarna worden in drie paragrafen de diverse verwervings- en verliesgronden besproken. In de eerste plaats wordt steeds de verwerving van de nationaliteit door geboorte besproken. In dat kader wordt ook de verwerving van de nationaliteit door onwettige kinderen door (gerechtelijke) vaststelling van de afstamming, erkenning en legitimatie aan de orde gesteld, ook al gaat het daarbij stricto sensu niet om verkrijging op het ogenblik van de geboorte. Hetzelfde geldt voor verwerving op grond van adoptie. De beschrijving van de positiefrechtelijke regeling van de 
nationaliteit door geboorte wordt telkens ingeleid door een overzicht van deze verwervingsgronden in vroegere nationaliteitsregelingen van de desbetreffende staat. Daardoor kan soms een zekere herhaling van gegevens uit de algemene historische inleiding niet geheel worden vermeden, maar wordt het gemakkelijker de thans geldende verwervingsgronden in historisch perspectief te begrijpen.

Een volgende paragraaf is gewijd aan de verkrijging van de nationaliteit van rechtswege na de geboorte en door optieverklaringen of door naturalisatie. Ook deze paragraaf wordt door een historisch overzicht van de desbetreffende verwervingsgronden in vroegere regelingen ingeleid. Tenslotte worden - weer na een historisch exposé - de positiefrechtelijke bepalingen betreffende het verlies van de nationaliteit besproken.

Voor de beschrijving van het nationaliteitsrecht van de bestudeerde staten wordt in de paragrafen 1.3 en 1.4 eerst nog ingegaan op het begrip "nationaliteit" en de functie van dit rechtsinstituut, alsmede op de volkenrechtelijke beperkingen die gellen voor de nationaalrechtelijke regeling van de nationaliteit.

In paragraaf 1.3.1 wordt gesteld dat de nationaliteit moet worden beschouwd als status, die echter tegelijkertijd een juridische relatie tussen staat en persoon aangeeft. In paragraaf 1.3.2 wordt onderstreept, dat de nationaliteit juridisch-technisch beschouwd slechts het karakter van een koppelbegrip heeft dat op zichzelf geen inhoud heeft. Het begrip nationaliteit krijgt slechts waarde door de rechtsgevolgen die nationale of internationale rechtssystemen eraan koppelen. In dit perspectief wordt uitdrukkelijk de opvatting bestreden dat er twee verschillende nationaliteitsbegrippen zouden bestaan: een nationaalrechtelijk en een internationaalrechtelijk.

Ondanks het feit dat de nationaliteit eigenlijk een leeg koppelbegrip is, dient echter wel in het oog te worden gehouden dat ze een psychologische dimensie heeft. Deze dimensie heeft twee uiteenlopende aspecten: een psychologische dimensie uit het perspectief van de staat en een uit het perspectief van de burger. Enerzijds is het onwenselijk dat staten in het kader van de regeling van verwervings- en verliesgronden beklemtonen, dat het een eer is de desbetreffende nationaliteit te mogen bezitten. Anderzijds is het zeer wenselijk dat bij de regeling van die verwervings- en verliesgronden niet uit het oog verloren wordt, dat individuen - soms op irrationele gronden - aan "hun" nationaliteit hechten.

De beschrijving van de volkenrechtelijke beperkingen van de nationale autonomie op het gebied van de nationaliteit valt in twee delen uiteen. In paragraaf 1.4.1 worden opmerkingen over de algemene, uit het volkenrecht af te leiden beperkingen gemaakt. In dat kader wordt aan de hand van een voorbeeld aangetoond dat het niet steeds onrechtmatig is, indien een staat alle burgers van een andere staat zijn nationaliteit verleent. Tussen beide staten moeten dan echter wel zeer bijzondere historische relaties bestaan. In een volgende paragraaf (par. 1.4.2) wordt ingegaan op de invloed die de samenwerking van meerdere Europese landen in EG-verband zou kunnen hebben op het nationaliteitsrecht van deze landen. Daarbij worden twee feiten geconstateerd. Allereerst kan reeds nu worden vastgesteld dat zowel het rechtssysteem van de EG zelf; als de rechtssystemen van de lidstaten reeds diverse rechtsgevolgen koppelen aan de hoedanigheid van burger van een lidstaat der EG. Het is dan een relatief kleine 
stap om deze hoedanigheid van burger van een lidstaat der EG als koppelbegrip te vervangen door de hoedanigheid van burger der EG, zonder dat een dergelijke "nationaliteit" der EG het voortbestaan van de nationaliteiten der lidstaten hoeft uit te sluiten. In de tweede plaats moeten we aannemen dat de lidstaten van de EG reeds tegenwoordig niet meer volstrekt autonoom zijn bij het toekennen van hun nationaliteit, juist vanwege het feit dat de EG vele rechtsgevolgen koppelt aan de hoedanigheid van burger van de EG.

$\mathrm{Na}$ de beschrijving van de nationaliteitsrechtelijke regelingen van de bestudeerde landen worden in de paragrafen 3.2.1 tot en met 3.4.12 de diverse positiefrechtelijke verwervings- en verliesgronden van de nationaliteit en détail geanalyseerd en vergeleken. Bij de bespreking van elk van de verwervings- of verliesgronden wordt nagegaan, of na de vergelijking voorstellen tot verandering of verbetering van het Nederlandse nationaliteitsrecht kunnen worden gedaan.

Vervolgens wordt in de paragrafen 3.1.1 tot 3.1.7 gepoogd in de ontwikkeling van de nationaliteitswetgeving in de afgelopen anderhalve eeuw een aantal grote tendensen te onderkennen. Achtereenvolgens wordt de betekenis van het volgende nagegaan:

1) de ontwikkeling van een 'système unitaire' naar een 'système dualiste';

2) de geleidelijke verwerkelijking van de gelijke behandeling van man en vrouw;

3) een ontwikkeling van ius soli naar ius sanguinis;

4) de geleidelijke ontwikkeling van de gelijke behandeling wettige en onwettige kinderen;

5) de toenemende bestrijding van de staatloosheid;

6) de ontwikkeling in de houding ten opzichte van meervoudige nationaliteit.

De in de paragrafen 3.2.1 tot en met 3.4.12 gedane voorstellen tot verandering en verbetering van het Nederlandse recht worden in paragraaf 4 per artikel van de Rijkswet op het Nederlanderschap als volgt samengevat:

a) In art. 3 lid 2 moet duidelijk tot uitdrukking worden gebracht dat een vondeling de Nederlandse nationaliteit slechts verliest, indien binnen vijf jaren nadat hij gevonden werd, bewezen wordt dat hij op het moment van zijn geboorte uitsluitend een vreemde nationaliteit heeft verworven. Zo"n vondeling mag de Nederlandse nationaliteit niet verliezen, indien blijkt dat hij naast de Nederlandse voorts nog een andere nationaliteit bezit (zie par. 2.6.2; vgl. verder de beschouwingen in par. 3.2.7),

b) In het perspectief van de gelijke behandeling van mannen en vrouwen moet art. 3 lid 3 dusdanig worden gewijzigd, dat ook het kind van een vader of van een moeder, die ten tijde van de geboorte van dat kind in het koninkrijk der Nederlanden woont, maar zelf geboren is als kind van een in het $\mathrm{Ko}$ ninkrijk wonende vader, de Nederlandse nationaliteit iure domicilii verkrijgt (zie par. 2.6.2 en 3.2.6). Ten aanzien van de bepaling van art. 3 lid 3 zou verder - zoals bij lid 1 - duidelijk tot uitdrukking moeten worden gebracht dat de Nederlandse nationaliteit op grond van deze bepaling ook kan worden verworven wanneer de matgevende ouder reeds voor de geboorte van het kind is gestorven, maar ten tijde van zijn dood in Nederland woonde (par. 3.2.1). Verder is het wenselijk te expliciteren dat de regeling van art. 3 lid 3 
niet voor kinderen van leden van een buitenlandse diplomatieke of consulaire missie geldt (par. 3.2.6).

c) In beginsel zou de erkenning of legitimatie van een reeds twaalfjarige minderjarige niet zonder diens instemming verkrijging van de Nederlandse nationaliteit moeten kunnen bewerkstelligen (zie par. 3.2.2). Voorts ware het te overwegen om de verkrijging van het Nederlanderschap krachtens erkenning of wettiging van de instemming van de moeder afhankelijk te maken, indien de verkrijging van het Nederlanderschap bewerkstelligt dat het kind daardoor de nationaliteit van de moeder verliest; een door de moeder geweigerde instemming zou echter door de rechter moeten kunnen worden vervangen (zie eveneens par. 3.2.2).

d) In art. 4 zou duidelijk tot uitdrukking moeten worden gebracht dat de Nederlandse nationaliteit ook door legitimatie kan worden verworven, indien de vader reeds ten tijde van de legitimatie gestorven is (zie par. 3.2.1). Eveneens zou moeten worden geẻxpliciteerd dat een kind de Nederlandse nationaliteit verwerft, indien het door erkenning of legitimatie kind van een buitenlander wordt, maar de voorwaarden van art. 3 lid 3 vervuld zijn.

e) Indien in de toekomst ook naar Nederlands recht door (gerechtelijke) vaststelling van het vaderschap familierechtelijke betrekkingen tussen een onwettig kind en zijn verwekker tot stand gebracht kunnen worden, moet een dergelijke vaststelling van het vaderschap onder dezelfde voorwaarden alls in geval van een erkenning verwerving van de Nederlandse nationaliteit bewerkstelligen. Reeds nu is het echter op zijn plaats om een onwettig, minderjarig kind van een Nederlandse verwekker die tot het betalen van alimentatie voor dit kind is veroordeeld, een optierecht op de Nederlandse nationaliteit te geven (zie par. 3.2.5).

f) Adoptie van een reeds twaalfjarige minderjarige mag in beginsel niet zonder diens instemming verkrijging van de Nederlandse nationaliteit bewerkstelligen (zie par. 3.2.2). Voorts zou in art. 5 duidelijk tot uitdrukking moeten worden gebracht dat de Nederlandse nationaliteit ook door adoptie kan worden verworven, indien de maatgevende ouder op de dag waarop het adoptievonnis in kracht van gewijsde gaat, reeds gestorven is (zie par. 3.2.1). Ook zou moeten worden verduidelijkt dat de Nederlandse nationaliteit ook kan worden verworven, indien een kind in Nederland door buitenlanders wordt geadopteerd, doch de voorwaarden van art. 3 lid 3 zijn vervuld (zie par. 3.2.3).

g) Het optierecht van art. 6 lid 1 sub a zou niet moeten uitgaan wan de geboorteplaats van de betreffende persoon, maar -in het perspectief van de regeling van art. 3 lid 3-van de woonplaats van de ouders ten tijde van de geboorte van de betreffende persoon. Voorts zou het voor het ontstaan van dit optierecht in elk geval irrelevant moeten zijn, of de betreffende persoon in de tijd tussen zijn geboorte en het ontstaan van de leerplicht in het buitenland heeft gewoond; maatgevend dient te zijn, of hij zijn gehele schooltijd in Nederland heeft doorgebracht. De leeftijd waarop het optierecht ontstaat (18 jaar), kan in het perspectief van de bestrijding van de meervoudige nationaliteit worden begroet; los van dit streven zou echter te verdedigen zijn om het 
optierecht te laten ontstaan op de leeftijd waarop de leerplicht eindigt. Het ware zelfs te overwegen om elke - ook in het buitenland geboren - persoon die zijn gehele schoolopleiding in Nederland heeft genoten, een optierecht op de Necerlandse nationaliteit te geven (zie par. 3.3.3.1 sub a en par. 3.3.3.2 sub c).De temporele limitering van het optierecht van een in Nederland geboren persoon is onhoudbaar en dient derhalve te worden geschrapt (zie par. 3.3.3.1 sub a).

h) Vanwege art. 3 van de New Yorkse conventie van 1961 kan bij het optierecht van art. 6 lid 1 sub b niet van de woonplaats van de ouders ten tijde van de geboorte van het statenloze kind worden uitgegaan. Dit optierecht moet derhalve dusdanig worden uitgebreid, dat het ook ontstaat indien bet staatloze kind in het buitenland wordt geboren, terwijl een ouder zijn woonplaats in Nederland heeft. Bovendien moet de regeling zo worden veranderd, dat een in Nederland geboren kind (resp. een in het buitenland geboren kind, dat ten tijde van zijn geboorte een in Nederland wonende ouder heeft) ook voor de Nederlandse nationaliteit kan opteren, indien het voor vervalling van zijn achttiende levensjaar staatloos wordt (par. 3.3.3.1 sub b).

i) Inburgering moet in het kader van een naturalisatieprocedure niet als voorwaarde voor een naturalisatie worden gesteld (par. 3.3.4.5). Beheersing van de Nederlandse taal, resp. van een andere in de Nederlandse woonplaats gangbare taal moet als zelfstandige naturalisatievoorwaarde worden geformuleerd; daarbij moet in het oog worden gehouden dat niet de schriftelijke of mondellinge beheersing van een van deze talen moet worden getest, doch de communicatievaardigheid in een van deze talen (par. 3.3.4.6). Art. 8 lid 1 sub d moet dienovereenkomstig worden gewijzigd.

j) Aan art. 8 moet een bepaling worden toegevoegd, inhoudende dat niet kan worden afgewezen, een naturalisatieverzoek van een persoon, die reeds meer dan vijf jaar als Nederlander is behandeld zonder dat deze behandeling gevolg is geweest van enig verwijtbaar gedrag van verzoeker (par. 3.3.1 sub e). Voorts moet worden verduidelijkt, welke autoriteiten mogen vaststellen, of tegen het verblijf yan onbepaalde duur in Nederland (geen) bezwaar bestaat en welke criteria deze autoriteiten daarbij dienen aan te leggen (zie par. 3.3.4.4).

k) De bepalingen van art. 8 lid 2 en 4 ten gunste van de echtgenoot, resp. de niet-huwelijkse levenspartner van een Nederlander, dienen te worden veranderd. De in het buitenland woonachtige buitenlandse echtgenoot van een nederlander moet in principe pas na vijfjarig huwelijk kunnen worden genaturaliseerd. Is de Nederlandse echtgenoot in dienst van de Nederlandse staat, dan moet de buitenlandse echtgenoot worden behandeld als wone hij in Nederland. Bij woonplaats in Nederland gedurende het huwelijk wordt de vereiste termijn met de in Nederland doorgebrachte huwelijkstijd verkort. Bij de berekening van de huwelijksduur wordt de tijd gedurende welke een echtscheidingsverzoek of verzoek tot scheiding van tafel en bed aanhangig was en de tijd die de echtgenoten gescheiden van tafel en bed leefden, niet meegeteld. De regeling ten gunste van niet-huwelijkse levenspartners van ongehuwde Nederlanders moet overeenkomstig worden geconstrueerd. Voor in het buitenland wonende niet-huwelijkse levenspartners moet echter uitslui- 
tend naturalisatie onder verlichte voorwaarden mogelijk zijn, indien de Nederlandse partner in Nederlandse staatsdienst is of de partners in een lidstaat van de Raad van Europa samenleven.

1) Art. 9 lid 1 sub a moet dusdanig worden gewijzigd, dat een naturalisatieverzoek slechts kan worden afgewezen, indien de verzoeker binnen een aan het verzoek voorafgaande termijn van 10 jaren wegens limitatief opgesomde delikten veroordeeld is of een dergelijke veroordeling tijdens de naturalisatieprocedure plaatsvindt. Een naturalisatieverzoek moet verder afgewezen kunnen worden, indien de verzoeker ten tijde van het indienen van zijn verzoekschrift op grond van een meer dan tien jaar oud vonnis in een gevangenis verblijft. Indien een strafrechtelijke procedure tegen de verzoeker aanhangig is, moet de naturalisatieprocedure kunnen worden opgeschort (par. 3.3.4.7),

m) De in art. 9 lid 1 sub b gestelde eis, dat een verzoeker al het mogelijke moet doen om zijn oude nationaliteit te verliezen, zou niet moeten worden gesteld, indien deze de nationaliteit van een andere lidstaat van de Europese Gemeenschappen of de Raad van Europa is of de nationaliteit van een staat waarmee Nederland een gastarbeidersovereenkomst heeft gesloten (par. 3.3.4.8).

n) Art. 9 lid 1 sub c moet geschrapt worden. Art. 9 lid 2 moet dusdanig worden aangevuld, dat een naturalisatie ook kan worden geweigerd, indien een daar bedoelde veroordeling tijdens de naturalisatieprocedure plaatsvindt (par. 3.3.4.7).

o) Art. 10 is onnodig ingewikkeld geformuleerd. Het is voldoende dat, de Raad van State gehoord hebbende, een naturalisatie zonder inachtneming van de voorwaarden van art. 8 en 9 mogelijk wordt gemaakt.

p) Art. 11 moet dusdanig worden gewijzigd, dat een naturalisatie van een ouder zich slechts na daartoe gesteld verzoek uitstrekt over diens minderjarige kinderen. Een mede-naturalisatie van een reeds twaalfjarig kind dient in beginsel slechts plaats te vinden, indien dit kind met de mede-naturalisatie instemt. Voorts dient de instemming van diens wettelijk vertegenwoordiger te worden geëist en eveneens de instemming van een ouder, die niet wettelijk vertegenwoordiger is, indien de minderjarige door de mede-naturalisatie de nationaliteit van die ouder zou verliezen. De ontbrekende instemming van de wettelijke vertegenwoordiger moet in het belang van het kind door de rechter kunnen worden vervangen. De ontbrekende instemming van het kind moet uitsluitend dan door de rechter kunnen worden vervangen, indien het zijn oude nationaliteit door de mede-naturalisatie niet verliest (zie par. 3.3.6).

q) Art. 13 moet worden geschrapt: naturalisaties dienen gratis te zijn.

r) Art. 15 lid 1 sub a is in overeensteming met art. 1 lid 1 van het verdrag van Straatsburg uit 1963. Niettemin is een wijziging van de regeling van het verlies van een Nederlandse nationaliteit wegens het vrijwillig verwerven wan een vreemde nationaliteit wenselijk. In geval van woonplaats in het 
binnenland zou de Nederlandse nationaliteit niet wegens verkrijging van een vreemde nationaliteit moeten worden verloren. In geval van woonplaats in het buitenland zou de Nederlandse nationaliteit wegens de verkrijging van een vreemde nationaliteit moeten worden verloren, tenzij de nationaliteit van een andere lidstaat van de Europese Gemeenschappen of de Raad van Europa wordt verworven, of de desbetreffende Nederlander voor het verwerven van de vreemde nationaliteit verklaart zijn oude nationaliteit te willen behouden. Een dergelijke verklaring bewerkstelligt dat de Nederlandse nationaliteit gedurende tien jaren behouden blijft; voordat deze tien jaren zijn verstreken kan een nieuwe verklaring bewerkstelligen dat het Nederlanderschap nog eens tien jaren behouden wordt (par. 3.4.2).

s) In art. 15 sub c zou hetzij tenminste een uitzondering voor andere lidstaten van de EG en wellicht zelfs voor die van de Raad van Europa moeten worden opgenomen, of de mogelijkheid worden geschapen om door daartoe strekkende verklaring het verlies van de Nederlandse nationaliteit te voorkomen. Verder zou een dienstverband met een Nederlandse onderneming of vereniging of een door bemiddeling van de Nederlandse regering tot stand gekomen dienstverband voldoende moeten zijn om het verlies der Nederlandse nationaliteit te voorkomen (par, 3.4.4).

t) Art. 15 sub d moet dusdanig worden gewijzigd, dat de Nederlandse nationaliteit na een naturalisatie slechts onder bepaalde voorwaarden weer kan worden ontmomen, indien de genaturaliseerde persoon ondanks een voor hem bestaande verplichting heeft nagelaten al het mogelijke te doen om zijn oorspronkelijke nationaliteit te verliezen. De desbetreffende burger moet tenminste zes maanden tevoren over de voorgenomen ontneming worden geïnformeerd. Een ontneming kan niet meer plaatsvinden na verloop van vijf jaren na de naturalisatie (par. 3.4.5). Voorts moet de mogelijkheid worden geschapen om de naturalisatie wegens vervalsingen, verheimelijkingen of bedrog tijdens de naturalisatieprocedure te herroepen; ook deze herroeping moet slechts binnen vijf jaren na de naturalisatie mogelijk zijn.

u) Art. 16 lid 1 sub a moet worden geschrapt (par. 3.4.9). 


\subsection{English summary}

Nationality law in motion

A comparative law study of the grounds for acquisition and loss of nationality.

Translated by Marco Braeken, swom translator.

Revised by Caroline Forder, University of Lancaster and Rob Bakker, University of Limburg.

During the last two decades nationality law in most European countries has undergone considerable changes. Gradually, in this field of law efforts have been made to develop the principle of equality of men and women. The prevention of statelessness has become an important purpose of the new regulations. Furthermore, in various countries efforts have been made to prevent plural nationality as much as possible.

It is clear that the realization of equal treatment of men and women in the field of nationality law on the one hand, and the prevention of plural nationality on the other, partly conflict with each other. This is because the equal treatment of both sexes with respect to nationality law - especially if this is applied with respect to the acquisition of nationality iure sanguinis in such a way that, in principle, nationality by descent can be derived from the father as well as from the mother- will result in many more people having dual nationality than before. Each legislator is therefore presented with the question of where to draw the line between these two principles. A superficial study of the several nationality regulations suffices to show that this line is drawn in various ways. This variety is emphasized because of the different historical backgrounds which we find in the nationality regulations which are being studied here.

In this book a comparison will be made of the legal grounds for acquisition and loss of nationality in nine West Furopean countries. The purpose of this comparison is to make some proposals for the improvement of Dutch nationality law. These proposals are presented in para. 4.

It is evident that $I$ find such changes as are proposed equally necessary for other states. Being a Dutch lawyer, however, I do not intend to make any explicit proposals for changes in the nationality regulations of the other countries. From the fact that this book is not written in Dutch the conclusion, however, can be drawn that the comparisons made in this study might also be rellevant for changes in foreign nationality regulations.

In para 2.1 to 2.9 a description will be given of the grounds for acquisition and loss of nationality in Belgium, the Federal Republic of Germany, France, GreatBritain, Italy, The Netherlands, Austria, Switzerland and Spain. For each country, first, a sketch will be given of the historical development of the law of nationality, followed by an elaboration of the grounds of acquisition and loss. With respect to each country, first, attention will be given to the acquisition of nationality by birth; whereby - inspite of the fact that in the case of illegitimate children, strictly speaking, the acquisition does not take place at the moment of birth- the acquisition of nationality by illegitimate children (by determination of descent, recognition and legitimation) will also be discussed. The same can be said for the acquisition on the ground of adoption.

The description of the existing nationality regulations with respect to birth will, for each country, be introduced by a survey of these grounds of acquisition in 
former nationality regulations of the country concerned. By following this method a slight repetition of what has already been described in the general historical introduction cannot be avoided. The purpose of this method, however, is to make current grounds of acquisition more accessible in the light of their historical development.

For each country, the next paragraph treats the acquisition of nationality de iure, declaration of option and naturalisation, every time preceded by a historical survey of these grounds of acquisition in former regulations. In the third paragraph- again after a historic introduction- the existing regulations with respect to loss of nationality are discussed.

Before the actual description of the nationality regulations of the nine selected countries, the concept of "nationality", its function and its restrictions following from international law, insofar as this is relevant to the national regulations of nationality law, are considered in para. 1.3 and 1.4. In para. 1.3.1 it is argued that mationality represents status; status which, however, also refers to a legal relationship between the state and a person.

In para. 1.3.2 it is emphasized that nationality, strictly speaking, is only a formal concept and does not carry any substantial meaning in itself. The concept of nationality only acquires substantial meaning as a result of the legal consequences which national and international legal systems connect with it. For this reason, in this study the presumption of the existence of two separate concepts of nationality - a national next to an international one- is rejected.

In spite of the fact that nationality is a mere formal concept, attention should be given to its psychological dimension. This psychological dimension has two different aspects: one from the point of view of the state, and another from the point of view of the citizen. On the one hand, it is undesirable that a state should regulate the grounds of acquisition and loss in a way that would make it an honour for the citizen concerned to possess its nationality; on the other hand, it is very desirable that the state does not lose sight of the fact that individuals - sometimes on irrational grounds- are attached to "their" nationality.

The description of the way that international law restricts national autonomy in the field of nationality law is divided into two parts. In para. 1.4.1 attention will be paid to the general restrictions which follow from international law. An example given in this paragraph will show that it would not be unlawful under all circumstances for a state to confer its nationality on all the citizens of another state. In such a case it is a necessary condition that these two states have had a very strong historical relationship. In this paragraph the influence which the cooperation of various $\mathrm{EC}$ countries could have on their nationality regulations will also be discussed. It is clear that the legal systems of the EC and the legal systems of the member states themselves connect several legal consequences to the status of citizenship of a member state of the EC. It is thus only a small step to replace the status of citizenship of a member state of the EC by the concept of "nationality" of the EC as such. A definition of the concept of nationality of the EC would not preclude the further existence of the nationality of the member states. Furthermore, it should be noted that even at this moment the member states of the EC no longer have a full discretion in granting their nationality. This flows from the very fact that the EC connect many legal consequences to the status of citizenship of the EC. 
After the description of the nationality regulations of the countries concemed in para. 3.2.1 to 3.4.12, the grounds for acquisition and loss of nationality in the selected countries are analyzed and compared. Each time that the several grounds for acquisition and loss are discussed the question is raised whether the comparison gives rise to any proposals for change or improvement of Dutch nationality law.

After this, in para. 3.1.1 to 3.1.7 the reader"s attention is drawn to a number of major trends in the development of the law of nationality of the passed one hundred and fifty years. Subsequently the following points are considered:

1) the development from a "système unitaire" to a "système dualiste";

2) the gradual realization of equal treatment of men and women;

3) the development from a ius soli to a ius sanguinis;

4) the gradual development of an equal treatment of legitimate and illegitimate children;

5) the increase in the prevention of statelessness;

6) the changes in attitude towards plural nationality.

The proposals for change and improvement made in para. 3.2.1 to 3.412 will be summarized in par. 4 , in such a way that the proposed changes will be represented by changes of the articles concerned of the "Rijkswet op het Nederlanderschap" (Dutch Nationality Act). This approach results in the following proposals for change of the Dutch Nationality Act:

a) S. 3(2) should state expressly that a foundling will only lose Dutch nationality if ,within five years after being found, it is proved that, at the moment of birth, he/she possessed solely a foreign mationality. Dutch nationality may not be withdrawn if it appears that the foundling has an additional nationality apart from Dutch (see para.2.6.2 and 3.2.7).

b) In the light of the realization of equal treatment of men and women, s. 3(3) should be amended to read that a child, born to a father or mother living in the Kingdom of The Netherlands at the time of birth, but himself/herself born as the child of a father living in the Kingdom, acquires Dutch nationality iure domicilii (see para. 2.6 .2 and 3.2.6). Furthermore, it should be made express that, on the basis of this provision, Dutch nationality can also be acquired if the determinative parent has deceased before the child is born, but was living in The Netherlands at the time of death (para. 3.2.1). It would be desirable to state explicitly that the provision of $s .3(3)$ will not apply to children to foreign diplomatic or consular personnel (para. 3.2.6).

c) In principle, recognition or legitimation of children who have reached the age of twelve should not result in the granting of Dutch nationality without the consent of the child (see para. 3.2.2). Furthermore, the question whether the acquisition of Dutch nationality by recognition or legitimation should be made dependent on the consent of the mother, in cases in which the acquisition of Dutch nationality would mean that the child would lose the nationality of the mother. However, in case of the mother's refusal a court decision on this point should be possible (see para. 3.2.2). 
d) S. 4 should express clearly that Dutch nationality can also be acquired through legitimation, even if the father has deceased before legitimation (see para. 3.2.1). Also, it should be made clear that a child acquires Dutch nationality if it becomes, through recognition or legitimation, the child of an alien and the conditions of $\$ .3$ (3) are fulfilled.

e) If future Dutch law would make it possible for a family relationship between an illegitimate child and its procreator to be established by a court decision on fatherhood, that decision should also establish the right to Dutch nationality, just as is the case with recognition. But even at the present stage it would be appropriate to grant a right of option to Dutch nationality to an illegitimate child of a Dutch procreator who has been ordered to pay maintenance for this child ( see para. 3.2.5).

f) The adoption of a child who has reached the age of twelve should not result in the acquisition of Dutch nationality without the consent of the child (see para. 3.2.2). In s. 5 it should be made clear that Dutch nationality can also be acquired by adoption, if the determinative parent has deceased before the day that the court decision establishing adoption has become final (see para. 3.2.1). Furthermore, it should be clarified that Dutch nationality can also be acquired if the child living in the Netherlands is adopted by aliens and the conditions of s. 3(3) are fulfilled (see para. 3.2.3).

g) The right of option mentioned in s. 6(1)(a) should not be dependent on the place of birth of the person concerned, but on the place where the parents were living at the time of birth; this would be in conformity with $s .3(3)$. Furthermore, the fact that the person concerned would have lived abroad between the time of birth and the date of compulsory education, should in any case be irrellevant for the granting of this right of option. The circumstance of having spent the whole time of compulsory education in The $\mathrm{Ne}$ therlands should, however, be decisive in this respect. The age of eighteen at which this right of option becomes valid represents a welcome change in the law because it contributes to the prevention of plural nationality. It could, however, also be argued that the beginning of this right of option should be granted at the age at which compulsory education ends, and even to grant the right of option to Dutch nationality to each person who is born abroad but has spent the whole period of compulsory education in The Netherlands (see para. 3.3.3.1 under a and para. 3.3.3.2 under c). Setting an age limit with respect to the granting of the right of option for persons born in The Netherlands is indefensible and the provisions concerned should therefore be repealed.

h) Relying upon s. 3 of the New York Convention of 1961, the right of option of s. $6(1)$ (b) cannot be made dependent on the parents' residence at the time of birth of a stateless child. This right of option should therefore also be granted if the stateless child is born abroad whilst one of the parents lives in The Netherlands. Furthermore, the law should be changed in such a way that a child born in The Netherlands (or a child born abroad, having a parent living in The Netherlands at the time of birth) can also opt for Dutch nationality if the child would become stateless before reaching the age of eighteen (para. 3.3.3.1 under b). 
i) Domestication should not be required as a necessary condition for naturalisation (para. 3.3.4.5). Mastery of the Dutch language, or any other language typical for the place of residence in the Netherlands, should be made a separate condition for nationalisation. Decisive in this respect should not be the ability to master the language in written or oral form, but the ability to communicate in one of these languages (para. 3.3.4.6). S. 8(1)(d) should be amended accordingly.

j) S. 8 should be extended with the rule that the application for naturalisation of a person who has been treated as a Dutchman over a period of more than five years, whilst this treatment has not been due to any unlawful behaviour of the applicant, should not be rejected (para. 3.3.1 under e). Furthermore, it should be made clear which authorities have the power to decide whether there is any objection to an indefinite stay in The Netherlands and on which criteria the public authorities' decision should depend (para. 3.3.4.4).

k) 8(2) and (4), which makes provision for the spouse or the non-married partner of a Dutch citizen, will have to be amended. The spouse of a Dutch citizen living abroad can, in principle, only be naturalised after a period of five years of marriage. If the Dutch spouse is working for the Dutch state, the foreign spouse should be treated as if he/she has been living in The Netherlands. If the spouse has been living in The Netherlands during the marriage, the time spent in The Netherlands is deducted from the required period. On establishing the period of marriage, the time during which a request for divorce was pending, or the time during which the spouses were judicially separated is not included. The provision for non-married partners should be amended accordingly. For non-married partners living abroad, naturalisation under less strict conditions should only be made possible if the Dutch partner is working for the Dutch state or if the partners live together in a member state of the Council of Europe.

1) S. 9(1)(a) should be amended in such a way that an application for naturalisation can only be rejected if the applicant has been convicted within ten years prior to the application for one of the prescribed crimes, or if such a conviction takes place during the procedure of naturalisation. An application for naturalisation should also be rejected, if, at the time of application, the applicant is in prison serving a sentence ordered more than ten years ago. If criminal proceedings have been started against the applicant, a suspension of the procedure of naturalisation should be possible (para. 3.3.4.7).

m) In s. 9(1)(b), it should not be required that the applicant should do everything possible to lose his old nationality, if this is the nationality of another member state of the EC, of the Council of Europe or of one of the states with which The Netherlands has concluded a 'gastarbeidersovereenkomst' (a treaty concerning 'guest-workers') (para. 3.3.4.8).

n) S. 9(1)(c) should be repealed. S. 9(2) should be extended in such a way that an application for naturalisation can be rejected if such a conviction as is referred to in that article occurs during the procedure of naturalisation (para. 3.3.4.7). 
o) The wording of s. 10 is unnecessarily complicated. It would suffice if naturalisation would be made possible, regardless of the conditions of $\mathrm{s} .8$ and 9 , but after consultation with the Council of State.

p) S. 11 should be amended in such a way that naturalisation of a parent will only apply to the minor children of this parent, if a special application has been made for this purpose. In such cases naturalisation of children who have reached the age of twelve should, in principle, only take place if the child consents. Also the consent of the person exercising parental authority (i.e. custodian or guardian) and the parent who is not exercising his parental authority should be required, if the child would lose the nationality of the parent who is not exercising his parental authority. If the consent of the person exercising parental authority is not given, a court decision to grant consent should be possible. If the child does not consent to naturalisation with the parent, a court decision to naturalise should only be possible if the child would not lose its old nationality (see para. 3.3.6).

q) S. 13 should be repealed: naturalisations should be free of charge.

r) S. 15(1)(a) is in conformity with s. 1(1) of the Treaty of Strasbourg of 1963 . Nevertheless, an amendment to the provisions on the loss of Dutch nationality in the case of voluntary acquisition of a foreign nationality would be desirable. Persons living in The Netherlands should not lose Dutch nationality after acquisition of a foreign nationality. Persons living abroad should, however, lose Dutch nationality after the acquisition of a foreign nationality, unless this is the nationality of another member state of the EC or of the Councill of Europe, or if, before acquiring the foreign nationality, the Dutch citizen concerned has made a declaration that he/she wishes to keep Dutch nationality. Such a declaration establishes continuity of Dutch nationality for a period of ten years. A repetition of this declaration within this period establishes an extension of another ten years (para. 3.4.2).

s) S. 15(c) should include at least one exception for other member states of the $\mathrm{EC}$ or of the Council of Europe, or there should be a possibility of preventing the loss of Dutch nationality by means of a declaration. Furthermore, for the prevention of the loss of Dutch nationality it should suffice to be working for a Dutch company or to have a job as a result of mediation by the Dutch government (para. 3.4.4).

t) S. 15(d) should be amended in such a way that, in a case in which the person who has been naturalised has refrained from doing everything possible to lose his old nationality, in spite of having the obligation to do so, Dutch nationality acquired through naturalisation can only be repealed under specific conditions. In this case the citizen concerned should be informed about this intention at least six months beforehand. This deprivation of nationality may, however, not take place after a period of five years or more since the date of naturalisation (para. 3.4.5). Furthermore, a possibility should be created to repeal a naturalisation obtained by forgery or deceit. This deprivation should only be allowed within a period of five years after the date of naturalisation.

u) S. 16(1)(a) should be repealed (para. 3.4.) 


\subsection{Résumé français}

Le droit de la nationalité en mouvement

Une étude de droit comparé sur les modes d'acquisition et de perte de la nationalité.

Traduit par Marco Braeken, traducteur juré

Revise par Luc Wintgens, UFSAL Brussel et Cathërine Cisse, Paris

Lors des deux décennies précédentes le droit de la nationalité de la plupart des Etats de l'Europe occidentale a subi des modifications très importantes. Peu à peu, des efforts ont été faits afin de donner corps au principe de l'égalité des hommes et des femmes. De même, la réduction des cas d'apatridie est devenue un principe fondamental dans les nouvelles réglementations. En outre, des efforts ont été réalisés, pour réduire les cas de pluralité de nationalités. Notamment, on peut constater que la réalisation de l'égalité des droits entre les femmes et les hommes dans le droit de la nationalité et la réduction des cas de plurinationalité s'opposent partiellement. En effet, l'égalité des droits entre les hommes et les femmes a conduit à un accroissement considérable des cas de pluripatridie par rapport à la situation antérieure, et cela, surtout, dans l'hypothèse où la plurinationalité résulte de l'attribution de la nationalitế à raison de la filliation à l'égard de parents de nationalité différente.

Par conséquent, chaque législateur doit répondre à la question de savoir où la limite entre les deux principes mentionnés doit être marquée. L'étude superficielle des différentes réglementations relatives à la nationalité montre déjà les divergences d'appréciation de cette frontière. En raison des nombreuses particularités d'origine historique propres à chaque réglementation du droit de la nationalité, on constate une très grande variété. Dans cet ouvrage, une comparaison des modes d'acquisition et de perte de la nationalité est dressée entre neuf pays de l'Europe occidentale Le but de cette comparaison est de formuler des propositions en vue de l'amélioration du droit de la nationalité. Ces propositions sont faites au paragraphe 4 . Je crois, souhaitable, d'apporter également des modifications analogues dans les autres pays. Cependant, en tant que juriste néerlandais, je ne peut pas faire des propositions explicites concernant les modifications dans d'autres pays. Néanmoins ce livre, écrit dans une autre langue que le néerlandais devrait, je l'espère, contribuer aux modifications futures des droits étrangères de la nationalité.

Les modes d'acquisition et de perte de la nationalité en Belgique, en Allemagne fédérale, en France, en Grandle-Bretagne, en Italie, aux Pays-Bas, en Autriche, en Suisse et en Espagne sont déscrits aux aux paragraphes 2.1 jusqu"à 2.9. En commançant par donner pour chaque pays, un aperçu du développement historique général du droit de la nationalité. Ensuite, les différents modes d'acquisition et de perte de la nationalité sont analysés aux trois paragraphes suivants. L'attribution de la nationalité à raison de la naissance est analysée. Dans ce cadre l'attribution de la nationalité par un enfant illégitime par établissement judiciaire de la filiation, soit par la reconnaissance, ou par la légitimation sera traitée, bien que dans ces cas il ne s'agisse pas stricto sensu d'attribution au moment de la naissance. Pour chaque cas, la description des dispositions du droit positif relatives à la nationalité à raison de la naissance est introduite par un rappel de la législation antérieure de chaque pays. Ainsi la répétition des données de 
l'introduction historique générale est souvent inévitable, mais la compréhension des modes d'acquisition actuellement en vigueur s'en trouvera facilitée.

Il en est de même pour l'acquisition de la nationalité par adoption. Le paragraphe suivant traite de l'acquisition de plein droit de la nationalité après la naissance, par déclarations d'option, et de l'acquisition par naturalisation. Ce paragraphe est également introduit par un aperçu historique relatif aux modes d'acquisition prévus dans les anciennes réglementations. Les dispositions du droit positif relatives à la perte de la nationalité sont commentées après un exposé historique.

Précédant la description du droit de la nationalité des pays étudiés, les paragraphes 1.3 et 1.4 traitent d"abord du concept de "nationalité" et de la fonction de cette institution juridique ainsi que des limitations du droit international s'appliquant à la réglementation nationale de la nationalité. Au paragraphe 1.3.1, il est posé le principe selon lequel la nationalité doit être considérée comme un statut; lequel cependant désigne en même temps une relation juridique entre l'Etat et une personne.

Au paragraphe 1.3.2, nous soulignons le fait que la nationalité, considérée de manière juridico-technique, n'a que le caractère d'un concept purement formel dépourvu de son contenu. Le concept nationalité n'acquiert une signification qu'a travers les conséquences juridiques que les systèmes nationaux ou internationaux y attachent. Dans une telle perspective, l'opinion selon laquelle il existerait deux notions différentes de la nationalité, l'une en droit national et l'autre en droit international est explicitement contestée. Bien que la nationalité soit en effet un concept purement formel, il ne faut pas oublier qu'il a une dimension psychologique. Cette dimension a deux aspects divergents: une dimension psychologique du point de vue de l'Etat et une autre du point de vue du ressortissant. D"une part, il n'est pas souhaitable que des Etats, dans le cadre de la réglementation relative aux modes d'acquisition et de perte de la nationalité, déclarent que la possession de leur nationalité constitue un honneur; d'autre part, il ne faut pas perdre de vue que dans cette réglementation que les individus- parfois pour des motifs irrationels- s'attachent à "leur' nationalité.

La description des limitations du droit international à l'autonomie nationale relative a la nationalité se est divisée en deux parties. Au paragraphe 1.4.1, des remarques sont faites sur les limitations générales pouvant dériver du droit international. Dans ce cadre, il est montré à l'aide d'un exemple qu'il n'est pas toujours illégitime qu'un pays attribue sa nationalité a l'ensemble des ressortissants d'un autre pays. Cependant, il doit exister dans ce cas des relations historiques particulieres entre les deux pays. Aussi, traite-t-on dans ce paragraphe de l'influence que pourrait avoir la coopération entre plusieurs pays Européens liés à la $\mathrm{CE}$ sur le droit de la nationalité dans ces pays. Dans ce contexte on constate deux faits. Premièrement, on constate que le système juridique de la $\mathrm{CE}$, lui-même, ainsi que les systèmes juridiques des Etats membres tirent des conséquences juridiques divergentes de la qualité de ressortissant d'un Etat membre de la CE. C'est alors un pas relativement petit que de remplacer cette qualité de ressortissant d'un Etat membre de la $\mathrm{CE}$ comme concept purement formel par la qualité de ressortissant de la CE, sans qu'une telle "nationalité" de la CE exclut la persistance des nationalités des Etats membres.Deuxièmement, il faut accepter que les Etats membres de la CE ne soient plus complètement autonome dlans l'attribution de leur nationalité, notamment par le fait que la CE tire de multiples conséquences juridiques de la qualité de ressortissant de la CE. 
Après la description des réglementations du droit de la nationalité des pays étudiés suivant des paragraphes 3.2.1 à 3.4.12, une analyse et une comparaison détaillées des divers droits positifs relatifs à l'acquisition et la perte de la nationalité. Dans l'analyse de chacun de ces modes d'acquisition et de perte on recherche si après la comparaison pour faire des propositions de modification ou d'amélioration du droit néerlandais de la nationalité.

Ensuite, des paragraphes 3.1.1 à 3.1.7 nous tentons d'indiquer certaines des tendances les plus importantes dans le développement de la législation de la nationalité depuis un siècle et demi. Successivement, nous dégagerons la signification les notions suivantes:

1) le développement d'un système unitaire à un système dualiste;

2) la réalisation progressive de l'égalisation des droits entre femmes et hommes;

3) le développement du ius soli au ius sanguinis;

4) le développement progressif de l'égalisation des droits entre enfants légitimes et enfants illégitimes;

5) l'intensification du combat contre l'apatridie;

6) le développement de l'attitude à l'égard de la pluralité des nationalités.

Les propositions de modification et d'amélioration du droit néerlandais faites des paragraphes 3.2 .1 a 3.4.12 sont résumées au paragraphe 4 par article de la "Rijkswet op het Nederlanderschap" (loi du Royaume relative à la nationalité néerlandaise), comme suit:

a) L'article 3 paragraphe 2 doit prévoir qu'un enfant trouvé ne perd sa nationalité que si dans la période de cinq ans à compter du jour où il a êté trouvé, il apparait que l'enfant a acquis, au moment de la naissance, une nationalité étrangère. Dans un tel cas, l'enfant trouvé ne doit pas perdre la nationalité néerlandaise s'il apparait qu'il possède également une autre nationalité outre la nationalitế néerlandaise (v. par. 2.6.2; cf. aussi par. 3.2.7).

b) Dans la perspective de l'égalité des droits entre les femmes et les hommes, l'article 3 paragraphe 3 devrait être modifié de manière que l'enfant dont, au moment de la naissance, le père ou la mère habite le Royaume des Pays-Bas et qui est né d'un père habitant au Royaume, acquiert aussi la nationalité néerlandaise iure domicilii (v. par. 2.6.2 et 3.2.6). Par rapport à la même disposition, il faut disposer en outre -comme dans le premier paragrapheque la nationalité néerlandaise, en vertu de cette disposition, peut aussi être acquise si le père ou la mère décède avant la naissance, mais habitait aux Pays-Bas au moment du décès (par. 3.2.1). Aussi est-il souhaitable de prévoir que la disposition de l'article 3 paragraphe 3 ne s'appliquent pas aux enfants des agents diplomatiques et consulaires étrangers.

c) En principe, la reconnaissance ou la légitimation d'un mineur de douze ans ou plus ne doit pas entraîner l'acquisition de la nationalité néerlandaise, sans que le mineur soit mis en mesure de faire connaître son opinion (v. par. 3.2.2). Aussi, peut-on envisager de rendre subordonner à l'accord de la mère, l'acquisition de la nationalité néerlandaise par reconnaissance ou par légitimation. Le refus de la mère pourrait devoir être remplacé par une décision judiciaire (v. aussi par. 3.2.2). 
d) L'article 4 doit disposer que la nationalité néerlandaise peut être aussi attribuée par légitimation si le père est décédế au moment de la légitimation (v. par. 3.2.1). De plus, il doit être prévu qu'un enfant acquiert la nationalité néerlandaise s'il devient l'enfant d'un êtranger par reconnaissance ou légitimation, sous reserve que les conditions de 1"article 3 paragraphe 3 soient remplies.

e) Si, dans l'avenir, le droit néerlandais permet la création de rapports de droit familial entre un enfant illégitime et son géniteur par établissement (judiciaire) de paternité, un tel établissement de paternité doit permettre l'acquisition de la nationalité néerlandaise dans les mêmes conditions qu'en cas de reconnaissance. Déjà, il devrait être légitime de donner à un mineur naturel né d'un géniteur néerlandais, et qui est condamné à payer une pension alimentaire à celui-ci, le droit d'option pour la nationalité néerlandaise (v. par. 3.2.5).

f) En principe, l'adoption d'un mineur de douze ans ou plus ne doit pas avoir pour conséquence l'acquisition de la nationalité néerlandaise sans avoir obtenu le consentement du mineur (v. par. 3.2.2). De plus, l'article 5 devrait pré-voir que la nationalité néerlandaise peut aussi être obtenue par adoption si le père ou la mère décède le jour où cette décision est passée en force de chose jugée (v. par. 3.2.1). En outre, il devrait être prévu que la nationalité néerlandaise peut être acquise si l'enfant est adopté par des étrangers aux Pays-Bas, mais les conditions de l'article 3 paragraphe 3 étant remplies ( $v$. par. 3.2.3).

g) Le droit d'option dans l'article 6 paragraphe 1 alinéa a ne devrait pas partir du lieu de naissance de l'interessé, mais -dans l'optique des dispositions de 1'article 3 paragraphe 3 - du domicile des parents, au moment de sa naissance. Il devrait être sans conséquence pour la création de ce droit d'option que la personne en question a résidé à l'étranger depuis sa naissance jusqu'à l'âge scolaire. Le principe décisif est l'obligation pour le mineur d'avoir passé toute la scolarité aux Pays-Bas. Dans la perspective de la pluralité des nationalités, l'âge (18 ans) ì partir duquel est créé le droit d'option doit être accueilli. Cependant, on peut soutenir de créer le droit d'option à l'âge auquel la scolarité obligatoire se termine. On peut même envisager de donner à toute personne -y compris les personnes nées à l'étranger- qui a reçue une formation scolaire aux Pays-Bas, un droit d'option pour la nationalité néerlandaise (v. par. 3.3.3.1 alinéa a et par. 3.3.3.2 alinéa c).

La limitation temporelle du droit d'option d'une personne née aux Pays-Bas est insoutenable et devrait être, par conséquence, supprimée.

h) En raison de l'article 3 de la Convention (O.N.U.) de New York du 30 aout 1961 sur la réduction des cas d'apatridie, on ne peut partir du domicile des parents au moment de la naissance de l'enfant apatride qu'en cas de droit d'option prévu à l'article 6 paragraphe 1 alinéa $b$. Par conséquent, ce droit d'option doit être é-largi de façon à ce qu'il existe aussi pour l'enfant apatride, né à l'étranger, dont l'un des parents a son domicile aux Pays-Bas. En outre, la disposition devrait être modifiée d'une manière telle qu'un enfant né aux Pays-Bas (respectivement un enfant né à l'étranger, dont l'un des parents habitait aux Pays-Bas au moment de la naissance) puisse aussi opter 
pour la nationalité néerlandaise s'il devient apatride avant l'âge de dix-huit ans (par. 3.3.3.1 alinéa b).

i) Dans le cadre d'une procédure de naturalisation, l'intégration à la société ne doit pas constituer une condition de la naturalisation (par, 3.3.4.5). La maitrise de la langue néerlandaise, ou bien d'une langue qui, en plus du néerlandais, est parlée au domicile néerlandais, devrait etre formulée comme condition autonome de la naturalisation. Dans ce contexte, il ne faut pas oublier que ce n'est pas l'expression écrite ou orale d'une de ces langues qui doit ètre examinée, mais la facilité communicative dans l'une de ces langues (par. 3.3.4.6). Article 8 paragraphe 1 alinéa d devrait être modifié dans ce sens.

j) Il faudrait ajouter à l'article 8 une disposition selon laquelle ne peut être refusée, la demande d'acquisition de la nationalité néerlandaise par une personne traitée comme néerlandais pendant une période de plus de cinq ans, pour un motif autre que l'attitude répréhensible du requérant. Aussi, il est nécessaire de determiner les autorités compétentes pour décider si le séjour d'une durée indéterminée aux Pays-Bas donne lieu a des objections ou non et les critères applicables par ces autorités (v. par. 3.3.4.4).

k) Les dispositions de l'article 8 paragraphes 2 et 4 en faveur respectivement du conjoint, et du célibataire qui cohabite avec un Néerlandais célibataire, devraient être modifiées. En principe, la naturalisation du conjoint étranger d'un Néerlandais qui habite à l'étranger ne devrait être accordée qu'après cinq ans de mariage.

Si le conjoint néerlandais est fonctionnaire d'Etat aux Pays-Bas, le conjoint étranger devrait être traité comme résidant aux Pays-Bas. Le délai requis devrait être réduit en fonction de la période de mariage passé aux Pays-Bas, en cas de domicile aux Pays-Bas durant le mariage. En déterminant la période de mariage, la période durant une demande de divorce ou de séparation de corps est faite pendant ne devrait pas être prise en considération. Les dispositions en faveur des célibataires qui cohabitent avec des NEerlandais célibataires devraient être prévues dans ce sens. Cependant, dans le cas de célibataires vivant à l'étranger, la naturalisation à des conditions plus souples ne devrait être possible que si le concubin nérlandais est fonctionnaire d'Etat aux Pays-Bas ou si le couple non-marié cohabite dans l'un des Etats membre du Conseill de l'Europe.

1) L'article 9 paragraphe 1 alinéa 1 devrait être modifié de façon à ce qu'une demande de naturalisation ne puisse être refusée que si le requérant, dans la période de dix ans précédant la demande, a été condamné pour des délits énumérés limitativement ou si une condamnation pour ces délits a lieu pendant la procédure de naturalisation.

En outre, une demande de naturalisation devrait être refusée si le requérant, au moment de la demande, est détenu en suite d'une décision judiciaire de plus de dix ans. La procédure de naturalisation devrait être suspendue si une procédure pénale est pendant à l'encontre du requérant (par. 3.3.4.7).

m) Les dispositions de l'article 9 paragraphe 1 alinéa $b$, selon lesquelles le requérant doit faire tout ce qui est possible pour perdre son autre nationalité, devraitrester sans application si cette nationalité est celle d'un Etat membre 
de la CE ou du Con-seil de l'Europe ou d'un Etat avec lequel les Pays-Bas ont conchu un traité relatif aux travailleurs immigrés (par. 3.3.4.8).

n) L'article 9 paragraphe 1 alinéa c devrait être abrogé. Il faudrait ajouter à l'article 9 paragraphe 2 qu'une naturalisation peut être refusée si une condamnation mentionnée est prononcée pendant la procédure de naturalisation (paragraphe 3.3.4.7).

o) L'article 10 est formulé de façon trop compliquée. 11 suffirait que, après l'avis du Conseil d'Etat, lat naturalisation soit rendue possible sans application des conditions prévues aux articles 8 et 9 .

p) L'article 11 devrait être modifié de façon à ce que la naturalisation d'un parent n'étende ses effets à ses enfants qu'après la souscription d'une demande à cet effet. La co-naturalisation d'un enfant de douze ans ou plus ne devrait avoir lieu que si l'enfant donne son consentement à la co-naturalisation. Si le mineur perd la nationalité du parent par la co-naturalisation, il serait aussi demandé le consentement de son représentant légal ainsi que l'accord du parent qui n'est pas le représentant légal. L'absence de consentement du représentant légal devrait, dans l'intérêt de l'enfant, être remplacé par celui du tribunal. Le défaut de consentement de l'enfant ne devrait pouvoir être remplacé par celui du tribunal qu'au cas ou l'enfant ne perd pas son ancienne nationalité par la co-naturalisation (v. par 3.3.6)

q) L'article 13 devrait être abrogé: les naturalisations devraient être gratuites.

r) L'article 15 paragraphe 1 alinéa a est conforme à l'article 1 paragraphe 1 alinéa 1 de la Convention de Strasbourg du 6 mai 1963 relative à la réduction des cas de pluralité de nationalités. Néanmoins, une modification de la réglementation de la perte de la nationalité néerlandaise par l'acquisition volontaire d'une autre nationalité est souhaitable. En cas de domicile aux Pays-Bas, l'acquisition d'une autre nationalité ne devrait pas impliquer la perte de la nationalité néerlandaise. En cas de domicile à l'étranger, l'acquisition d'une autre nationalité devrait impliquer la perte de la nationalité néerlandaise, à moins que la nationalité d'un autre Etat membre de la $\mathrm{CE}$ ou du Conseil de l'Europe soit acquise ou que le requérant néerlandais exprime, par une déclaration, la volonté de garder sa nationalité avant l'acquisition de l'autre nationalité. Une telle déclaration devrait avoir pour effet de garder la nationalité néerlandlaise pour une période de dix ans. En souscrivant une nouvelle déclaration avant l"expiration de cette période, la nationalité néerlandaise devrait pouvoir être gardée pour une nouvelle période de dix ans (par. 3.4.2).

s) Il faudrait incorporer dans l'article 15 alinéa c, soit une exception pour les autres Etats membres de la $\mathrm{CE}$ ou du Conseil de l'Europe, soit la possibilité d'empêcher la perte de la nationalité néerlandaise par une déclaration. En outre, un contrat de travail conclu avec une entreprise ou une association néerlandaise, ou bien un contrat de travail passé par l'intermédiaire du gouvernement néerlandais, devrait pouvoir suffire pour empêcher la perte de la nationalité néerlandaise $(3.4 .4)$. 
t) L'art. 15 alinéa d devrait être modifié de telle façon que la nationalité néerlandaise, après naturalisation, ne puisse être retirée que sous certaines conditions, si la personne naturalisée n"a pas fait tout ce qui était possible pour perdre sa nationalité, bien qu'il existe une obligation à cet effet. Le ressortissant en question devrait pouvoir être informé du retrait prévu au moins six mois à l'avance. Un retrait ne pourrait plus être effectué après la période de cing ans suivant la naturalisation (par. 3.4.5). En outre, il devrait être créee la possibilité d'annuler la naturalisation en cas de falsification, dissimulation ou fraude pendant la procédure de naturalisation. Cette annulation ne devrait être effectuée que dans la période de cinq ans suivant la naturalisation.

u) L'article 16 paragraphe 1 alinéa a devrait être supprimé (par. 3.4.9). 


\subsection{Resumen español}

Tendencias actuales del derecho de la nacionalidad.

Estudio comparativo sobre las causas de adquisición y pérdida de la nacionalidad.

Traducido por J.M. Blanco Fernández, licenciado en Derecho Español y en Derecho Holandés; ayudante de Cátedra, departamento de Derecho Mercantill, Facultad de Derecho, Universidad Nacional de Limburg (Holanda).

El derecho de nacionalidad de la mayor parte de los países de la Europa occidental ha sufrido durante los últimos veinte años cambios considerables. Paulatinamente se ha tratado de introducir, también en este campo del derecho, el principio de igualdad entre hombre y mujer. Asimismo, las nuevas normativas han comenzado a considerar la lucha contra la apatridia como una prioridad. Por último, algunos estados han tratado de reducir en lo posible lla doble nacionalidad. Podemos constatar que entre la puesta en práctica del principio de igual tratamiento de hombre y mujer en el derecho de la nacionalidad y la lucha contra la múltiple nacionalidad existe una cierta contradicción. En efecto, debido a la igualdad de trato de ambos sexos -sobre todo cuando dicha igualdad, por lo que se refiere a la adquisición de la nacionalidad iure sanguinis, supone que la nacionalidad por filiación se puede derivar en principio tanto del padre como de la madre- existen más personas con múltiple nacionalidad de to que hasta hoy en día venía siendo el caso. A cada legislador corresponde pues, la tarea de trazar los límites de ambos principios.

Una somera lectura de la regulación del derecho de la nacionalidad en diversas legislaciones nos demuestra que dichos límites varían considerablemente. A ello contribuyen también las influencias ejercidas en las legislaciones por todo tipo de curiosidades históricas. En el presente estudio se comparan las causas de adquisición y pérdida de la nacionalidad tal y como se regulan en nueve estados de la Europa Occidental. El estudio se propone hacer algunas sugerencias para el amejoramiento del derecho de la nacionalidad holandés. Dichas sugerencias se encuentran en el parágrafo 4.

Evidentemente, considero que también el derecho de la nacionalidad de otros estados es susceptible de mejora. No obstante en mi condición de jurista holandés, no pretendo hacer ninguna propuesta para mejorar el ordenamiento de estos estados. Aún así, del hecho de que el libro no se escriba en holandés puede deducirse que las comparaciones hechas en el presente estudio puden tomarse en consideración en futuras modificaciones del derecho de la nacionalidad fuera de Holanda.

En los parágrafos 2.1 a 2.9 se describen las causas de adquisición y pérdida de la nacionalidad en Bélgica, la República Federal de Alemania, Francia, Gran Bretaña, Italia, Holanda, Austria, Suiza y España.

El tratamiento de cada país comienza con una descripción del desarrollo histórico del derecho de la nacionalidad. A continuación se comentan en tres parágrafos las diversas causas de adquisición y pérdida de la nacionalidad. La adquisición por nacimiento se trata siempre en primer lugar. También se analizan aquí -si bien stricto sensu no se trata de adquisición desde el momento del nacimiento- la adquisición de la nacionalidad por hijos no matrimoniales mediante la determinación (judicial) de la filiación, reconocimiento y legitimación. 
Lo mismo cabe decir de la adquisición por adopción. El estudio de la regulación de la nacionalidad por causa de nacimiento va precedido en cada caso de un resumen de estas causas de adquisición en las antiguas regulaciones del pals en cuestión. En este sentido, es posible que se repitan algunos datos ya mencionados en la exposición histórica general. Pero, de otra parte, ello ayuda a situar el régimen actual en una perspectiva histórica.

En el parágrafo siguiente se estudian la adquisición ex iure de la nacionalidad después del nacimiento así como la adquisición por opción y la nacionalización. También a esta exposición precede una introducción histórica sobre estas causas de adquisición.

Por último -y, nuevamente, tras una exposición histórica- se comentan las disposiciones reguladoras de las causas de perdida de la nacionalidad.

Antes de describir el derecho de la nacionalidad de cada uno de los países, se analizan en los parágrafos 1.3 y 1.4 el concepto de "nacionalidad" y la función que desarrolla esta figura jurídica, así como las limitaciones que el Derecho Internacional Público impone a las regulaciones particulares del derecho de la nacionalidad. En el parágrafo 1.3 .1 se defiende la tesis de que la nacionalidad debe ser considerada como un status, que, al mismo tiempo, indica una relacion juridica entre Estado y persona.

En el parágrafo 1.3.2 se subraya el hecho de que la nacionalidad, considerada desde el punto de vista técnico-jurídico, es simplemente un concepto con una función de unión, vacío de contenido. El concepto "nacionalidad" tiene un valor específico en cuanto que los ordenamientos nacionales o internacionales anudan a dicho concepto ciertas consecuencias jurídicas. En este sentido se rechaza con firmeza la tesis según la cual pueden distinguirse dos conceptos de nacionalidad: uno nacional y otro internacional.

Si bien el concepto de nacionalidad, de hecho, no es más que un concepto vacío, con una mera función de vínculo, no hay que olvidar la dimensión psicológica de dicho concepto. Dentro de esta dimensión pueden distinguirse dos matices diferentes: una dimensión psicológica desde la perspectiva del Estado y otra desde la perspectiva del ciudadano. De una parte no es de desear que los estados respectivos recalquen, en el contexto de la regulación de las causas de adquisición y perrdida de la nacionalidad, que es un honor poder tener la nacionalidad en cuestión. De otra parte, al regular dichas causas de adquisición y pérdida conviene tener en cuenta que la gente -a veces por motivos no del todo racionales- está apegada a "su" nacionalidad.

Dentro de las limitaciones que el ius gentium impone a la autonomfa dell legislador nacional en materia de derecho de la nacionalidad pueden distinguirse dos variantes. En el parágrafo 1.4.1 se analizan las limitaciones generales derivadas del derecho internacional público. Con un ejemplo se demuestra que no siempre puede considerarse ilícito el que un estado conceda su nacionalidad a todos los ciudadanos de otro, si bien para ello deben existir entre ambos estados unas relaciones históricas muy especiales. En el parágrafo 1.4.2 se presta atención a la influencia que la cooperación entre diversos estados europeos en el marco de la C.E.E. podría tener en el derecho de la nacionalidad de estos estados. En este sentido pueden destacarse dos hechos importantes. En primer lugar, tanto el ordenamiento de la C.E.E. como los ordenamientos de los estados miembros anudan ya ciertas consecuencias jurídicas a la condición de ciudadano de uno 
de dichos estados. Nos parece que, sin excesivas perturbaciones, podría sustituirse esta condición de ciudadano de un estado miembro como 'concepto wíncullo' por la de ciudadano de la C.E.E., sin que tal concepto de "nacionalidad" de la C.E.E. excluya la continuidad de las nacionalidades de los estados miembros.

En segundo lugar hemos de aceptar que, hoy en día, los estados miembros de la C.E.E. ya no gozan de absoluta libertad por lo que respecta a la concesión de sus respectivas nacionalidades, y ello porque la "ciudadania" de la C.E.E. conlleva importantes consecuencias juridicas.

Tras la descripción de las regulaciones del derecho de la nacionalidad en los diferentes países, en los parágrafos 3.2 .1 a 3.4 .12 se comparan y analizan detalladamente las diferentes causas de adquisición y pérdida de la nacionalidad. En el comentario que sigue a de cada una de estas causas se estudian las posibilidades de mejora del derecho holandés de la nacionalidad.

A continuación, en los parágrafos 3.1.1 a 3.1.7 se intentan trazar lás líneas generales de evolución de las legislaciones en materia de nacionalidad durante los últimos 150 años. Sucesivamente se estudia:

1) la evolución de un "système unitaire" a un "système dualiste";

2) la progresiva puesta en práctica del principio de igualdad de hombre y mujer;

3) una evolución del "ius soli" al "ius sanguinis";

4) el desarrollo paulatino del igual trato a hijos legitimos y naturales;

5) la lucha contra la apatriclia;

6) la evolución de la actitud con respecto a la múltiple nacionalidad.

Las propuestas de mejora del derecho holandés, hechas en los parágrafos 3.2.1 a 3.4.12, pueden resumirse, de acuerdo con el

articulado de la Ley Holandesa de la Nacionalidad, como sigue.

a) En el art. 3, párrafo 2 debe aclararse que el recien nacido cuya ascendencia se ignore y que se encuentre en territorio holandés, sólo perderá la nacionalidad holandesa si antes de cinco años desde que ha sido encontrado se demuestra que en el momento de su nacimiento adquirió únicamente una nacionalidad extranjera. Dicho recien nacido no debe perder la nacionalidad holandesa si resulta tener otra nacionalidad además de la holandesa (vid. par. 2.6.2 y las consideraciones en el par. 3.2.7).

b) A consecuencia del principio de igualdad de hombre y mujer debe modificarse el art. 3, párrafo 3 en el sentido que a continuación se expone. También el hijo de un padre o madre que en el momento del nacimiento del menor viven en Holanda, pero que son nacidos de un padre residente en territorio holandés, debe poder adquirir la nacionalidad holandesa iure domicillii (vid. par. 2.6.2 y 3.2.6). En el mismo párrafo de este artículo habría que aclarar - como sucede en el párrafo 1 - que la nacionalidad holandesa también puede adquirirse en base a esta disposición cuando el progenitor en cuestión ya ha fallecido y en el momento de la muerte residía en Holanda (par. 3.2.1). Por lo demás, conviene aclarar que el citado artículo no se aplica a los hijos de los miembros de representaciones diplomáticas o consulares (vid. par. 3.2.6). 
c) Habria de disponerse que, en principio, el reconocimiento o la legitimación de un menor que ha llegado ya a la edad de doce años no debe llevar consigo la adquisición de la nacionalidad holandesa si no media su consentimiento (vid. par. 3.2.2). Además conviene tomar en consideración la posibilidad de hacer depender la adquisición de la nacionalidad holandesa del consentimiento de la madre cuando el reconocimiento o la legitimación conlleven la pérdida de la nacionalidad de la madre. La negación de la madre para prestar su consentimiento podría suplirse no obstante por una declaración judicial (vid. asimismo 3.2.2).

d) En el art. 4 habría de disponerse con mayor claridad que la nacionalidad holandesa también puede adquirirse por legitimación si el padre en el momento de la legitimación ya ha fallecido (vid. par. 3.2.1). Tambien convendria prever la posibilidad de que un menor adquiera la nacionalidad holandesa si por reconocimiento o legitimación pasa a ser hijo de un extranjero cuando concurran las circunstancias del art. 3 párrafo 3 .

e) Si en el futuro el derecho holandés reconociese la posibilidad de que surjan relaciones familiares entre un hijo extramatrimonial y su progenitor por medio de la determinación (judicial) de la paternidad, dicha determinación habría de conllevar la adquisición de la nacionalidad holandesa en las mismas condiciones que en el caso de reconocimiento. Ya ahora, sin embargo, es aconsejable otorgar al hijo extramatrimonial, menor de edad, la posibilidad de optar por la nacionalidad holandesa si su progenitor posee dicha nacionalidlad y está obligado a costear el mantenimiento del menor (vid. par. $3.2 .5)$.

f) La adopción de un menor que ha alcanzado la edad de doce años no debe conllevar, en principio, la adquísición de la nacionalidad holandesa si no media su consentimiento (vid. par. 3.2.2). Asímismo habría de establecerse claramente en el art. 5 que la nacionalidad holandesa también puede adquirirse por adopción, si el progenitor en cuestión ya ha fallecido el día en que la sentencia de adopción adquiere la naturaleza de cosa juzgada (vid. par. 3.2.1). En fín, convendría aclarar que también el menor adoptado en Holanda por extranjeros tiene derecho a la nacionalidad holandesa si se cumplen las condiciones del art. 3 párrafo 3 (vid. par. 3.2.3).

g) La opción a que da derecho el art. 6, párrafo 1 sub a, no debería tomar como punto de partida el lugar de nacimiento de la persona en cuestión, sino -en vista de lo dispuesto por el art. 3, parrafo 3- el lugar de residencia de los padres cuando nació dicha persona. Por lo demás debería considerarse irrelevante que el menor haya residido en el extranjero durante el tiempo transcurrido entre el nacimiento y el comienzo de la edad escolar. Como criterio habría de tomarse el hecho de que el menor haya pasado todo su perfodo escolar en Holanda. La edad a partir de la cual existe la posibilidad de optar por la nacionalidad (18 años) es un factor que contribuye a la erradicación de la múltiple nacionalidad, aunque, al margen de esta ventaja, es de por sí aconsejable que el derecho de opción surja al término de la edad escolar. Incluso podría considerarse la posibilidad de otorgar dicho derecho de opción a toda persona -también a los nacidos en el extranjeroque haya seguido toda su educación escolar en Holanda (vid. par. 3.3.3.1 sub a en par. 3.3.3.2 sub c). 
La limitación temporal del derecho de opción que corresponde a una persona nacida en Holanda carece de fundamento $y$, por tanto, debe ser derogada (vid. par. 3.3.3.1 sub a).

h) En virtud de lo dispuesto por el art. 3 de la Convención de Nueva York de 1961, en el derecho de opción que otorga el art. 6, párrafo 1, sub b no es posible tomar como punto de partida el domicilio de los padres en ell momento del nacimiento del menor apatrida. Dicho derecho de opción habrá de extenderse por tanto a aquellos casos en los que el menor apatrida nazca en el extranjero y uno de los padres tenga su domicilio en Holanda. Además, la regulación vigente ha de ser modificada de forma que el nacido en Holanda (o el nacido en el extranjero que al tiempo del nacimiento tiene un padre residente en Holanda) pueda optar por la nacionalidad Holandesa si, antes de cumplir, los 18 años habría de quedar apatrida (vid. par. 3.3.3.1 sub b).

i) Durante el procedimiento de nacionalización no debe exigirse al candidato adaptación completa al país (vid. par. 3.3.4.5). El dominio de la lengua holandesa o de otra lengua que se hable en el lugar en el que el candidato ha de residir, ha de mencionarse como una condición explícita para la nacionalización. Ciertamente, no se trata de examinar la capacidad expresiva oral o escrita, sino de averiguar hasta qué punto el candlidato está en condiciones de comunicarse en una de las lenguas mencionadas (vid. par. 3.3.4.6). El art. 8 párrafo 1 habría de modificarse en ell mismo sentido.

j) Al art. 8 debe añadirse la siguiente disposición. No podrá rechazarse la solicitud de nacionalización de quien durante 5 años ha sido tratado como holandés, sin que dicho trato se deba a una actuación imputable al solicitante (vid. par. 3.3.1 sub e). Además debe aclararse a qué autoridades compete decidir si existen reparos contra la permanencia ilimitada de un extranjero en Holanda, y conforme a qué criterios se toma dicha decisión (vid. par. 3.3.4.4).

k) Las disposiciones contenidas en el art. 8, párrafos 2 y 4 con respecto al cónyuge o al compañero (no conyugal) de un ciudadano holandés deben ser modificadas. Cuando el cónyuge de un ciudadano holandés reside en el extranjero, el derecho a la nacionalización debe surgir tras 5 años de matrimonio. En caso de que el cónyuge holandés trabaje para el Estado, si el otro cónyuge es extranjero éste debe ser tratado como si residiese en Holanda. Si durante el matrimonio se fija el domicilio conyugal en Holanda, se acortará el tiempo exigido para la nacionalización con el tiempo que se haya pasado en Holanda durante el matrimonio. A efectos de cómputo de la duración dell matrimonio, no se contará el tiempo transcurrido desde la interposición de una demanda de divorcio o separación o el tiempo durante el cuall los cónyuges vivieron separados. La regulación de las uniones no matrimoniales debe partir de análogos principios. Sin embargo para el compañero no matrimonial residente en el extranjero la nacionalización podrá tener lugar en condiciones menos extringentes (en caso de que el compañero holandés trabaje para el Estado holandés o ambos residan en un estado miembro del Consejo de Europa).

1) El art. 9, párrafo 1 sub a debe ser modificado, en el sentido de modo que una solicitud de nacionalización sólo pueda ser rechazada si el solicitante en 
el transcurso de los 10 años precedentes a la solicitud o durante el proceso de nacionalización ha sildo condenado por uno de los delitos enumerados al efecto.

La solicitud de nacionalización debe poder rechazarse si el solicitante al tiempo de la presentación se encuentra en prisión a consecuencia de una sentencia dictada hace más de 10 años. Si el procedimiento judicial ya ha dado comienzo ha de preverse la posibilidad de interrumpir el procedimiento de nacionalización (vid. par. 3.3.4.7).

m) El requisito establecido en el art. 9 , párrafo 1 sub $b$, según el cual el solicitante debe hacer todo lo que esté de su parte para perder su antigua nacionalidad, no debería exigirse cuando la otra nacionalidad corresponde a un estado miembro de la C.E.E. (o del Consejo de Europa) o a un estado con ell que Holanda ha fimado un acuerdo de emigración (vid. par. 3.3.4.8).

n) El punto c, del primer párrafo del art. 9 debe ser derogado. El segundo párrafo debe prever la posibilidad de rechazar la nacionalización cuando se imponga una de las condenas expresadas en dicho artículo (vid. par. 3.3,4.7).

o) La formulación del art. 10 es en exceso complicada. Debe ser suficiente con posibilitar la nacionalización cuando, tras haber emitido dictamen el Consejo de Estado, no concurran las circunstancias de los arts. 8 y 9.

p) El art. 11 también debe ser objeto de reforma. Debe disponerse que la nacionalización de uno de los padres sólo se ha de hacer extensiva a los hijos menores cuando medie una petición al efecto. La nacionalización simultánea de un menor que ha alcanzado la edad de 12 años sólo será efectiva si el menor se muestra conforme con la misma. Además, será necesario el consentimiento de su representante legal y del padre, que no es al mismo tiempo representante legal, si el menor a consecuencia de la nacionalización perdiese la nacionalidad de dicho padre. Cuando ell interés del menor lo exija, la ausencia de permiso del representante legal o del padre podrá ser subsanada por una declaración judicial. Tal declaración podrá sustituir la declaración del menor únicamente en el caso de que el menor conserve su antigua nacionalidad (vid. par. 3.3 .6 ).

q) El art. 13 debe ser derogado: los procedimientos de nacionalición han de ser gratuitos.

r) El art. 15, párrafo $\mathbb{1}$ sub a concuerda con el art. 1, párrafo 1 del acuerdo de Estrasburgo de 1963. Sin embargo, es aconsejable modificar la regulación de las causas de pérdida de la nacionalidad cuando voluntariamente se adquiere otra nacionalidad. En caso de que se continúe la residencia en Holanda no habría de ser necesario que se perdiese la nacionalidad holandesa. Sí habría de perderse, al adquirir la nueva nacionalidad, cuando el domicilio se trasladase al extranjero, salvo que la nacionalidad adquirida corresponda a uno de los estados miembros de la C.E.E. (o del Consejo de Europa) o cuando el ciudadano holandés, antes de adquirir su nueva nacionalidad, declare expresamente que desea conservar la antigua. Tal declaración conlleva la conservación de la nacionalidad holandesa durante 10 años. Antes de que trans- 
curra este período puede emitirse una nueva declaración para prolongar la continuación de la nacionalidad holandesa por otros 10 años (vid. par. 3.4.2).

s) El art. 15 sub c debería, o bien contemplar una excepción para otros estados miembros de la C.E.E., o bien posibilitar la conservación de la nacionalidad holandesa mediante una declaración all efecto. Además, la existencia de una relación laboral con una empresa o asociación holandesa o cuando el gobierno holandés haya mediado en dicha relación, habría de ser causa suficiente para evitar la pérdida de la nacionalidad holandesa (vid. par. 3.4.4.).

t) El art. 15 sub d debe ser modificado, en el sentido de que, aunque la persona nacionalizada no haya hecho todo lo posible por perder su antigua nacionalidad, la nacionalidad holandesa sólo podrá retirársele bajo determinadas circunstancias. El ciudadano en cuestión debe ser informado del propósito de retirarle la macionalidad con 6 meses de antellación. Transcurridos 5 años desde la nacionalización, no se le podrá privar de la nacionalidad holandesa (vid. par. 3.4.5). Por lo demás debe constar la posibilidad de retirar la nacionalidad otorgada en caso de falsificación u otra forma de fraude durante el procedimiento de nacionalización. Ello también dentro del plazo de 5 años.

u) El art. 16, párrafo 1 sub a ha ser derogado (vid. par. 3.4.9). 


\subsection{Sommario italiano}

Il diritto di cittadinanza in evoluzione

Uno studio di diritto comparato sui modi di acquisto e di perdita della cittadinanza

Tradotto da Herman Zaaiman, Legale d'azienda

Rivisto dal Prof. Ass. Gianni Cimbalo, Università di Firenze

Negli ultimi vent"anni il diritto di cittadinanza ha subito cambiamenti notevoli nella gran parte degli Stati dell'Europa Occidentale. Lentamente si è provato ad introdurre il principio di uguaglianza tra uomo e donna anche in questo campo del diritto. Inoltre anche la riduzione dei casi di apatridia è divenuta un principio importante nelle nuove regolamentazioni. Infine numerosi Stati si sono sforzati di prevenire casi di doppia cittadinanza.

Possiamo constatare che tra la realizzazione dell'uguaglianza del diritto di cittadinanza tra uomo e donna e la lotta contro la doppia cittadinanza esiste una certa contraddizione. $\mathrm{E}^{\prime}$ proprio l'uguale trattamento dei due sessi che, sopratutto se posto in relazione all'acquisto della cittadinanza iure sanguinis, si ritiene che la cittadinanza da filiazione derivante in principio sia dal padre che dalla madre- provoca un incremento di casi di doppia cittadinanza. Ogni legislatore deve dunque fissare i limiti di questi due principi. Già uno studio sommario di varie regolamentazioni del diritto di cittadinanza ci dimostra che questo limite è fissato in modi diversi. Poichè tutte le regolamentazioni del diritto di cittadinanza hanno anche delle carateristiche che discendono da ragioni storiche, possiamo individuarne una grande varietà. In questo studio si comparano le cause di acquisto e di perdita della cittarlinanza di nove Stati dell'Europa Occidentale. Lo scopo è di dare dei suggerimenti per migliorare il diritto di cittadinanza Olandese. Questi suggerimenti sono sviluppati nel paragrafo 4.

Evidentemente considero utile delle modificazioni analoge nella legislazione di altri Stati. Come giurista olandese però, non voglio formulare suggerimenti espliciti per la modifica delle regolamentazioni del diritto di cittadinanza di altri Stati. Dal fatto però, che questo libro non è stato scritto in olandese si può evincere la speranza dell'autore che le comparazioni fatte potranno dare un contributo alle modifiche future delle regolamentazioni del diritto di cittadinanza di Stati stranieri.

Nei paragrafi 2.1 fino a 2.9 si descrivono i modi di acquisto e di perdita della cittadinanza in Belgio, Repubblica Federale Tedesca, Gran Bretagna, Italia, Olanda, Austria, Svizzera e Spagna.

In primo luogo si da, per ogni Stato, una descrizione dello sviluppo storico dell diritto di cittadinanza. In tre paragrafi si analizzano poi le diverse cause di acquisto e di perdita della cittadinanza. L'acquisto della cittadinanza per nascita viene analizzato sempre per primo. In questo contesto si tratta anche l'acquisto della cittadinanza per i figli illegitimi tramite la determinazione (giudiziaria) della filiazione, il riconoscimento e la legittimazione, anche se stricto sensu qui non si tratta di acquisto al momento della nascita. Lo stesso vale per l'acquisto 
tramite adozione. Lo studio della regolamentazione dell diritto di cittadinanza per causa di nascita è sempre preceduto da un resoconto di questi modi di acquisto nelle regolamentazioni precendenti dello Stato in questione. E inevitabile un certo ripetersi di dati dell'introduzione storica generale, ma ciò è però di aiuto per capire la regolamentazione in vigore nel quadro storico.

Nel paragrafo seguente si studia l'acquisto ex iure della cittadinanza dopo la nascita e l'acquisto tramite dichiarazioni di opzione e tramite naturalizzazione. Anche questo paragrafo e preceduto da un resoconto storico in relazione a questi modi di acquisto. Da ultimo, e nuovamente dopo una esposizione storica, vengono commentate le norme in vigore riguardanti la perdita della cittadinanza.

Prima di descrivere il diritto di cittadinanza di ognuno degli Stati, si analizza nei paragrafi 1.3 e 1.4 il concetto di "cittadinanza" e la funzione di questa figura giuridica, e le limitazioni che il Diritto Pubblico Internazionale pone alla regolamentazione nazionale del diritto di cittadinanza.

Nel paragrafo 1.3.1 si sostiene che la cittadinanza deve essere vista como uno status, che, allo stesso tempo, indica una relazione tra Stato e persona. Nel paragrafo 1.3.2 viene sottolineato che la cittadinanza, dal punto di vista tecnicogiuridico, tha semplicemente il carattere di concetto di unione, senza un contenuto proprio. Il concetto di cittadinanza acquista un valore solo a causa delle conseguenze giuridiche che gli ordinamenti nazionali 0 internazionali accordano ad essi. Da questo punto di vista contestiamo esplicitamente l'opinione secondo la quale esisterebbero due concetti di cittadinanza: uno nazionale ed uno internazionale.

Sebbene il concetto di cittadinanza è un concetto di unione senza contenuto, non bisogna dimenticare che ha una dimensione psicologica. Possiamo distinguere due aspetti diversi: un aspetto psicologico dal punto di vista statale ed uno dal punto di vista del cittadino. Da un lato non è auspicabile che gli Stati sottolineino che, nel quadro della regolamentazione dell'aquisto e della perdita, è un onore poter possedere la cittadinanza in questione. Dall'altra parte è necessario che, regolamentando i modi di acquisto e di perdita, non si dimentichi che gli individui, qualche volta per motivi irrazionali, si attaccano alla "loro" nazionalità.

La descrizione dei limiti imposti dal Diritto Pubblico Internazionale all'autonomia nazionale per ciò che riguarda la cittadinanza è divisa in due parti. Nel paragrafo 1.4.1 si analizzano i limiti generali derivanti dal Diritto Pubblico Internazionale. Con un esempio si dimostra che non sempre è illecito il fatto che uno Stato conceda la sua cittadinanza a tutti i cittadini di un altro Stato. Tra questi Stati però devono esistere delle relazioni storiche molto speciali. In questo paragrafo si tratta anche dell'influenza che la cooperazione tra diversi Stati Europei nella Communita Europea potrebbe avere sul loro stesso diritto di cittadinanza. In relazione a tutto ciò rileviamo due fatti.

In primo luogo possiamo constatare già da ora che sia il sistema giuridico stesso della C.E., che i sistemi giuridici degli Stati membri, traggono delle conseguenze giuridiche divergenti dalla condizione di cittadino di uno degli Stati membri della C.E. Ciò premesso costituisce un passo relativamente piccolo 
sostituire la condizione di cittadino di uno Stato membro della C.E. come concetto di unione con la condizione di cittadino della C.E., senza che una tale "cittadinanza" della C.E. escluda la persistenza della cittadinanza degli Stati membri. In secondo luogo dobbiamo accettare che gli Stati membri C.E. già ora non sono più completamente autonomi nella concessione della loro cittadinanza, poichè la C.E. fa discendere molte conseguenze giuridiche dalla condizione di cittadino della C.E.

Dopo la descrizione della regolamentazione del diritto di cittadinanza nei diversi paesi, nei paragrafi 3.2.1 fino a 3.4.12 si comparano e si analizzano dettagliamente le differenti cause di acquisto e di perdita della cittadinanza. Nel commentare ogni causa di acquisto e di perdita è oggeto di studio individuare se, dopo la comparazione, è possibile formulare dei suggerimenti per cambiare o migliorare il diritto di cittadinanza olandese.

In seguito, nei paragrafi 3.1 .1 a 3.1 .7 , si prova a individuare le tendenze generali nello sviluppo del diritto di cittadinanza negli ultimi 150 anni. Successivamente si effrontano i seguenti temi:

1) L'evoluzione da un "système unitaire" ad un "système dualiste";

2) la realizzazione progressiva dell'uguaglianza del diritto di cittadinanza tra uomo e donna;

3) lo passaggio dallo "ius soli" allo "ius sanguinis",

4) lo sviluppo progressivo di un trattamento uguale dei figli legittimi e illegittimi;

5) la lotta contro l'apatridia;

6) Ia tendenza verso il mantenimento della doppia cittadinanza.

I suggerimenti formulati nei paragrafi 3.2.1 fino 3.4.12 per cambiare e migliorare il diritto olandese saranno riassunti nel paragrafo 4 per ogni articolo della "Legge sulla cittadinanza dei Paesi Bassi" (Rijkswet op het Nederlanderschap) come segue.

a) Nel art. 3 paragrafo 2 bisogna provvedere a che un bambino di cui si ignora la discendenza (un trovatello) perda la cittadinanza olandese sollo se, entro cinque anni dal momento in cui è stato trovato, si può provare che al momento della nascita ha acquisito unicamente una cittadinanza straniera. In un tale caso, il bambino non può perdere la cittadinanza se risulta che ha, oltre la cittadinanza olandese, anche una cittadinanza diversa (ved. par. 2.6 .2 ; cf. anche par. 3.2.7).

b) Nella prospettiva di rendere effettiva l'uguaglianza di diritto tra uomo e donna è necessario cambiare l'art. 3 par. 2 in modo tale che possa ottenere la cittadinanza olandese iure domicilii (ved. par. 2.6 .2 e 3.2.6) anche il figlio il cui padre o la cui madre -a sua volta nato da un padre che vive nel Regno- erano viventi al momento della nascita del figlio nel Regno dei Paessi Bassi. Per quello che riguarda lo stesso paragrafo di questo articolo, bisognerebbe chiarire, come succede nel paragrafo 1, che è possibile acquistare la cittadinanza olandese anche se il genitore è già deceduto prima della nascita del figlio, ma che al momento della sua morte abitava in Olanda (par. 3.2.1). In seguito è raccomandabile esplicitare che la regola dell'articolo 3 paragrafo 3 , non si applica a figli di membri di rappresentanze diplomatiche o consolari (par. 3.2.6). 
c) In via di principio il riconoscimento o la legittimazione di un figlio minorenne che ha l'età di dodici anni non dovrebbe comportare l'aquisto della cittadinanza ollandese senza il suo consenso (ved. par. 3.2.2). Sarebbe anche da considerare la opportunità di far dipendere la possibilità di acquisto della cittadinanza olandese dal riconoscimento o dalla legittimazione dell'approvazione della madre, quando l'acquisto della cittadinanza olandese comporterà la perdita per il figlio della cittadinanza della madre; la negata approvazione della madre dovrebbe poter essere sostituita da una dichiarazione giuriziaria (ved. anche par. 3.2.2).

d) Nell'art. 4 bisognerebbe chiarire che la cittadinanza olandese può essere anche acquistata tramite legittimazione, anche se il padre nel momento della legittimazione è già deceduto (ved. par. 3.2.1). Inoltre deve essere previsto che un figlio acquista la cittadinanza olandese se, tramite riconoscimento o legittimazione, diventa figlio di uno staniero, ma a patto che le condizioni di cui art. 3 paragrafo 3 , siano state adempiute.

e) Se, nell futuro, il diritto olandese riconoscerà che tramite un accertamento (giudiziario) della paternita, potranno essere creati dei rapporti di diritto di famiglia tra il figlio illegittimo ed il suo progenitore, una tale determinazione della paternità deve permettere l'acquisto della cittadinanza alle stesse condizioni che in un caso di riconoscimento. Già da ora però sarebbe il caso di dare il diritto di opzione per la cittadinanza olandese al figlio illegittimo e minorenne d'un progenitore olandese se quest'ultimo è stato condannato a pagare una somma per mantenere questo figlio (ved. par. 3.2.5).

f) L'adozione di un minorenne che ha già l'età di dodici anni, non dovrebbe, per principio, avere la conseguenza di un acquisto della cittadinanza olandese senza il suo consenso (ved. par. 3.2.2). Inoltre l'articolo 5 dovrebbe prevedere chiaramente che la cittadinanza olandese puo essere acquistata anche tramite l'adozione, se il progenitore è già deceduto il giomo in cui la decisione giudiziaria d'adozione $\mathrm{e}$ passata in giudicato (ved. par. 3.2.1). Infine dovrebbe prevedere che la cittadinanza olandese puo essere acquistata, se un figlio è adottato in Olanda da stanieri e le condizioni del art. 3 par. 3 sono state adempiute (ved. par. 3.2.3).

g) Il diritto di opzione dell'art. 6 par. 1 sub a non dovrebbe avere come punto di partenza il luogo di nascita del soggetto, ma, nella prospettiva del art. 3 par. 3, il luogo di residenza dei genitori al momento della nascita della persona in questione. Inoltre dovrebbe essere in ogni caso irrelevante per l'esercizio di questo diritto di opzione se la persona in causa tra la sua nascita e l'inizio dell'età scolastica abbia abitato all'estero.

Il criterio dovrà essere riferito al fatto che il minore ha trascorso tutto il periodo scolastico in Olanda. Il fatto che all'età di $18 \mathrm{anni}$, nasca il diritto di opzione, contribuisce positivamente alla lotta contro la doppia cittadinanza. Però sil può anche sostenere di far maturare il diritto di opzione alla fine dell'età scolastica.

$\mathrm{Si}$ potrebbe anche considerare l'opportunità di concedere ad ognuno che ha trascorso tutto il periodo scolastico in Olanda, anche se è nato all'estero, il diritto di optare per la cittadinanza olandese (ved. par. 3.3.3.1 sub a e par. 3.3.3.2 sub c). Il limite nel tempo del diritto di opzione di una persona nata 
in Olanda è insostenibile e dovrà dunque essere cancellato (ved. par. 3.3.3.1 sub a).

h) In virtu dell'art. 3 della Convenzione di New York del 1961, nel diritto di opzione dell' art. 6 par.1 sub b non è possibile prendere come punto di partenza la residenza dei genitori al momento della nascita del figlio apatridico.

Questo diritto di opzione dovrà dunque estendersi fino a che esista anche nel caso in cui il figlio apatridico è nato all'estero, mentre uno dei genitori ha la residenza in Olanda. Inoltre la regola dovrà essere modificata in modo che un figlio nato in Olanda (o il figlio nato all'estero che al momento della nascita ha un genitore residente in Olanda) possa anche optare per la cittadinanza olandese, se, prima di compiere i 18 anni, diventi apatridico (par. 3.3.3.1 sub b).

i) In una procedura per la naturalizzazione l'integrazione nella società non dev'essere una condizione (par. 3.3.4.5). La dismestichezza della lingua olandese o di un'altra lingua che si parla correntemente nel luogo di residenza olandese dovrà essere formulata come condizione autonoma per la naturalizzazione; bisogna ricordare che mon bisogna esaminare la conoscenza orale - scritta, ma la capacità di poter comunicare in una di queste lingue (par. 3.3.4.6). L'art. 8 par. 1 sub d dovrà essere modificato in questo senso.

j) All'art. 8 si deve aggiungere la disposizione, che non è possibile rifiutare una domanda di naturalizzazione di una persona, che è stata trattata già da oltre 5 anni come un olandese, senza che questo trattamento sia il risultato di un comportamento imputabile al richiedente (par. 3.3.1 sub e). Poi à da chiarire a quale autorità compete decidere se esistono delle obiezioni o meno, avverso il soggiorno a tempo indeterminato in Olanda e quali saranno i criteri applicabili dalla autorità (par. 3.3.4.4).

k) Le disposizioni dell'art. 8 par. 2 e 4 in favore rispettivamente del coniuge e del convivente di un olandese, devono essere modificate. Un coniuge straniero di un cittadino olandese che abita all"estero, deve ottenere il diritto alla naturalizzazione solo dopo 5 anni di matrimonio. Se il coniuge olandese è al servizio dello Stato, il coniuge straniero dev'essere trattato come se abitasse in Olanda. Se durante il matrimonio la residenza è in Olanda, si accorcerà il tempo necessario per la naturalizzazione per un periodo pari al tempo trascorso in Olanda durante il matrimonio. Ai fini del calcolo del periodo di matrimonio, non si computerà il periodo trascorso mentre è pendente una richiesta di divorzio o una richiesta di separazione ed il periodo in cui i coniugi vivevano separati.

La regolamentazione a favore di conviventi di un olandese celibe dovrà essere concepita nello stesso modo. Per conviventi che vivono all'estero si può prendere in considerazione solamente la naturalizzazione a condizioni meno severe, se l'olandese celibe è al servizio dello Stato o se gli interessati convivono in uno Stato membro del Consiglio d'Europa.

1) Art. 9 par. 1 sub a deve subire una modifica tale che una richiesta di naturalizzazione può essere negata solamente se il richiedente, in un periodo di 10 anni precedente alla richiesta è stato condannato per delitti enumerati tassativamente o se una condanna per uno di quei delitti ha luogo durante la 
procedura di naturalizzazione. Una richiesta di naturalizzazione si dovrà poter rifiutare anche se il richiedente al momento della presentazione della richiesta si trova ancora in prigione a causa di una condanna a piu di 10 anni. Se una procedura penale è pendente contro il richiedente, la procedura di naturalizzazione dovrà essere sospesa (par. 3.3.4.7).

m) La condizione che il richiedente debba fare del suo meglio per perdere la sua vecchia cittadinanza formulata nell'art. 9 par. 1 sub b, non dovrà essere imposta se si tratta di una cittadinanza di un altro Stato menbro del Consiglio d'Europa o della C.E., o se si tratta della una cittadinanza di uno Stato con cui l'Olanda ha concluso un trattato per lavatori immigrati ("gastarbeidersovereenkomst") (par. 3.3.4.8).

n) L'art. 9 par. 1 sub c deve essere abolito. Art. 9 par. 2 dovrà essere modificato nel senso che si possa rifiutare una naturalizzazione quando una condanna, del tipo di quelle menzionate nell'articolo, è pronunciata durante la procedura di naturalizzazione (par. 3.3.4.7).

o) La redazione dell'art. 10 è inutilmente complicata. E' sufficiente prevedere che, sentito il parere del Consiglio di Stato, sarà possibile procedere ad una naturalizzazione senza applicare le regole degli articoli 8 e 9 .

p) L'articolo 11 dovrà essere modificato in modo che la naturalizzazione di un genitore si estende soltanto sui suoi figli minori dopo una richiesta in tal senso. Una naturalizzazione simultanea di un figlio che ha già l'età di 12 anni dovrà essere possibile soltanto se questo figlio da il suo consenso. In più dovrà essere richiesto il consenso del suo rappresentante legale ed anche il consenso di un genitore, che non è rappresentante legale, se il minorenne perde la cittadinanza di quel genitore a causa della naturalizzazione simultanea. Quando cio è nell'interesse del minore il giudice dovrà poter decidere in caso di assenza di consenso da parte del rappresentante legale. II mancato consenso da parte del figlio può solamente essere dato dal giudice, se il soggetto in questione con la naturalizzazione simultanea non perde la sua vecchia cittadinanza (ved. par. 3.3.6).

q) L'art. 13 dovrà essere abolito: le naturalizzazioni dovranno essere gratuite.

r) L'articolo 15 par. 1 sub a è in conformità con l'art. 1 par. 1 della Convenzione di Strasburgo del 1963. Nondimeno è opportuno cambiare la regolamentazione della perdita della cittadinanza olandese a causa di acquisto volontario di una cittadinanza straniera. Nel caso in cui la residenza si trova nei Paesi Bassi, non si dovrebbe perdere la cittadinanza olandese acquirendo la cittadinanza straniera. Nell caso in cui la residenza è all'estero, si dovrebbe perdere la cittadinanza olandese acquistando la cittadinanza straniera, a meno che non si acquisti una cittadinanza di uno Stato membro della C.E. o del Consiglio d'Europa, o che il richiedente olandese dichiari, prima dell' acquisto della cittadinanza straniera, di voler mantenere la sua vecchia cittadinanza. Una tale dichiarazione ha come effetto il mantenimento della cittadinanza olandese per 10 anni e, prima che 10 anni siano trascorsi, una nuova dichiarazione può avere come effetto che la cittadinanza olandese venga mantenuta per un secondo periodo di 10 anni (par. 3.4.2). 
s) Si dovrebbe includere nell'art. 15 sub $c$, sia una eccezione per altri Stati membri della C.E. o del Consiglio d'Europa, sia la possibilità di prevenire la perdita della cittadinanza olandese mediante una dichiarazione a questo fine. Inoltre, l'esistenza di un rapporto di lavoro con un industria o un'associazione olandese o quando il Governo olandese abbia agito da intermediario in questo rapporto di lavoro, dovrà essere sufficiente per evitare la perdita della cittadinanza olandese (par. 3.4.4).

t) L'art. 15 sub d dev'essere modificato in modo che la cittadinanza olandese, dopo la naturalizzazione, possa essere ritirata solo a certe condizioni, se la persona naturalizzata non ha fatto tutto il possibile per perdere la sua cittadinanza orginaria, benchè vi fosse obligato.

Il cittadino in questione dovrà essere informato del previsto ritiro della cittadinanza almeno 6 mesi prima. Tale revoca non può avere luogo trascorsi cinque anni dalla naturalizzazione (par. 3.4.5). Inoltre bisogna creare la possibilità di revocare la naturalizzazione per fallsificazioni, dissimulazione o frode durante il processo di naturalizzazione; anche questa revoca dovrà essere effettuata entro cinque anni dopo la naturazzazione.

u) Art. 16 par. 1 sub a dovrà essere abrogato (par. 3.4.9). 


\section{NOTEN ALLGEMENER TEIL}

1. Eine Ujbersetzung dieses Gesetzes findet man in 4 dieser Arbeit.

2. Gesetz vom 18. Dezember 1984, Stb1. 627.

3. Eine niederländische Übersetzung dieses Abkommens ist veröffentlicht im Trb. 1967, 124, eine deutsche Ubersetzung findet man im BGB1. 1977, II 597; siehe weiter UNTS, Bd. 989, 175; Vertragssammlung AA, Bd. 54 A 721.

4. Eine niederlándische Übersetzung dieses Abkommens ist veröffentlicht im Trb. $19644_{\text {, }}$ 4, eine deutsche Ubersetzung findet man im BGBl. 1969, II 1953; siehe weiter UNTS, Bd. 634, 221; Vertragssammlung AA, Bd. 36 A 483 .

5. Eine niederländische Ubbersetzung dieses Abkommens ist veröffentlicht im Trb. 1974, 32, eine deutsche Ubersetzung findet man im BGBL. 1977, II 597, 613; siehe weiter Vertragssammlung AA, Bd. 54 A 717.

6. Siehe die Motiven des Entwurfes (Memorie van Toelichting), S. 8 (Gesetzesentwurf 16947, R 1181).

7. Vgl. dariber Verwilghen, 144-151.

8. Dies ist auch in Übereinstimmung mit dem New Yorker Abkommen vom 30. August 1961, das mehrere Methoden zur Vermeidung der Staatenlosigkeit vorsieht.

9. Bemerkenswert ist in diesem Zusammenhang die Auffassung Schätzels aus dem Jahre 1954 (Grundrechre, Bd. II, 579): "Nichts spricht daftir, daB man bei der Fassung des Art. $3 \mathrm{GG}$ anch nur entfernt daran gedacht hat, aus dieser Gesetzesbestimmung Folgerungen für die Staatsangehờrigkeit zu ziehen". Vergleiche aber Schätzel, Festgabe, 176. Siehe dazu auch Makarov/von Mangoldt, GG Art. 3, Rdnr. 1.

10. In Deutschland bereits Hildegard Kritger, Ehe und Familie 1957, 435; Maraun, 153159; Scheffler, Grundrechte, Bd. IV, 301; Schwarz, 98, 99, 116-118.

11. So die Entscheidung des Bundesverfassungsgerichts vom 21. Mai 1974, BVerfGE 37, 217-264; BGBI. 1974 1, 1933; NJW 1974, 1609; FamRZ 1974, 579; StAZ 1974, 236 und die Urteile des (italienischen) Corte costituzionale vom 16. April 1975, Foro italiano 1975, 1321 und des Corte costituzionale vom 28. Januar 1983, Foro italiano 1983, 265; Gazetta ufficiale vom 16. Februar 1983, Nr.46. Siehe weiter auch die Entschließung (77) 13 des Ministerkomitees des Europarats betreffend die Staatsangehörigkeit von ehelichen Kindern vom 27 . Mai 1977.

12. Siehe daritber $\mathrm{z} . \mathrm{B}$. Verwilghen, 155-157.

13. Dariber de Groot, Preadvies, 69-76; siehe weiter Verwilghen, 211.

14. In diesem Zusammenhang sei auf die Erklärung der belgischen Regierung anläBlich des Gesetzesentwurfes thingewiesen, dem Vorlâufer des neuen belgischen Staatsangehörigkeitsgesetz: "il est radicalement impossible de mettre la legislation a jour du point de vue de l'égalité de l'homme et de la femme sans se prononcer en même temps sur d'autres options que celles qui ont trait a cette egalite" (Documents. parlementaires (Chambre des réprésentantes) 756-1 (17. Oktober 1983), 13). Vgl. bereits Schätzel, Festgabe, 167.

15. Dies entspricht auch dem Ausgangspunkt der nationalen Autonomie im Staatsangehörigkeitsrecht. Vgl. Art. 1 des Haager Abkommens vom 12. April 1930, Trb. 1967, 73; LNTS 179, 89.

16. C̈ber das bis zum 1. Januar 1985 geltende niederländische Staatsangehðrigkeitsrecht gibt es nur wenige fremdsprachige Veróffentlichungen. An dieser Stelle sei auf die deutsche Ubbersetzung des niederländischen Staatsangehörigkeitsgesetzes in Bergmann/Ferid, unter "Niederlande" (68. Lieferung; Stand 30. Juni 1980) und auf das im Jahre 1953 in der Serie "Sammlung geltender Staatsangehörigkeitsgesetze" des Hamburger Institutes für Internationale Angelegenheiten erschienene Buch von Fred S. Baumann (dleutsch) hingewiesen. Siehe auch Bachmann, StAZ 1952, 92 (deutsch); Czapski, RabelsZ 1951/52, 483-485 (deutsch); Chalenton (franzósisch); Czapski, StAZ 1968, 56-58 (deutsch); van Gelderen, 507-521 (deutsch); Ko Swan Sik, International Law, 1-79 (englisch); Ko Swan Sik/van Rijn van Alkemade, Jurisclasseur (französisch); Kojanec, Bd. 2, 343-350 (italienisch); Laws Concerning Nationallity (UN-Legislative Series 1954), 321 ff; Liutkenhaus, StAZ 1965, 112 (deutsch); Penna Marinho, Bd. 2, 291-296 (portugiesisch); van Sasse van Ysselt, NJW 1958, 1668 (deutsch); van Sasse van Ysselt/ van Praag, CIEC-Fiche II (1952) (französisch); für weitere fremdlsprachige Literaturhinweise Hecker, Eunopa, 230-245 und Penna Marinho, 291. 
17. Erwähnt seien aber Boele-Woelki, StAZ 1985, 228-231 (deutsch); de Groot, IPRax $1985,175-178$ (deutsch); van Loon, RCDIP 1986, 182-192 (französisch) und Wolfgang Weber, in Bergmann/Ferid, unter "Niederlande" (88. Lieferung; Stand 30. November 1986) (deutsch).

18. Wegen der Mehrsprachigkeit Belgiens ist das belgische Recht jedoch im allgemeinen zugänglicher als das niederländische. Eine sehr ausführliche Bibliographie zum belgischen Staatsangehörigkeitsrecht findet sich bei Verwilghen, 617-625. Siehe zusătzlich Pintens, StAZ 1985, 224-227.

19. Siehe zu dieser Frage Constantinesco, Rechtsvergleichung, Band II, 49-5I und Sauveplanne, 11-15.

20. Ich möchte an dieser Stelle nucht unterlassen darauf hinzuweisen, daß Rheinstein, 215 einige Sprachen nennt, die jeder Rechtsvergleicher wenigstens einigermaßen beherrschen sollte und dabei auch niederländisch erwähnt.

21. Vergleiche zur Frage der "Vergleichbarkeit" u.a. Constantinesco, Revise de droit compare 1973, 5-16 und ebenfalls Constantinesco, Rechtsvergleichung, Band II, 106-136, insbesondere 129-136.

22. Münch, 1117: "I'essence de la nationalité est la même dans tout le monde" .... (S. 1118) "On peut considérer la nationalité comme une institution générale et comparable". Vgl. auch Grawert, Der Staat 1984, 192: "Der normative Rechtsvergleich zeigt jedoch eine weitgehende Gleichformigkeit im Rahmen tradierter und standardisierter Typen".

23. Hingewiesen sei z.B. auf das oben bereits erwähnte New Yorker Abkommen vom 30 . August 1961 zur Verminderung der Staatenlosigkeit und die New Yorker Konvention berreffend die Staatsangehörigkeit der Ehefrau vom 29. Januar 1957. Siehe weiter Paragraph 1.4.2.

24. Vgl. Art. 18 des Staatsbürgerschaftsgesetzes der UdSSR vom 1. Dezember 1978, der die Möglichkeit der Aberkennung der Staatsangehörigkeit vorsieht, wenn eine Person Handlungen begangen hat, die den Ehrentitel eines Bürgers der UdSSR in Verruf bringen und dem Ansehen oder der staatlichen Sicherheit der UdSSR schaden. Dartuber Ginsburgs, 238-245; Kowal-Wolk, 123-143; Krawtschuk, 93; Riege, 33; Shevtsov, 168. Vgl. weiter Luchterhandt, Osteuroparecht 1984, 130-134; Schüller, Staat und Recht $1984,248-250$.

25. Riege, 17; um diesen Unterschied zu betonen wird in der DDR-Literatur deshalb der Begriff der Staatsbürgerschaft benitzt statt das Wort Staatsangehörigkeit.

26. Riege, 62. Hinweise auf weitere sozialistische juristische Literatur bei Riege, 55-64.

27. Riege, 74 .

28. $\quad$ Riege, 50 .

29. Es darf allerdings nicht unterlassen werden darauf hinzuweisen, daB dieser Verlustgrund gnundsätzlich dem gleichen Gedanken entspricht wie Regelungen, wonach die Staatsangehörigkeit wegen fremden Staats- oder Militårdienst verloren wird. Dieser Verlustgrund galt bis zum 1. Januar 1985 noch in den Niederlanden und gilt z.B. noch immer in Frankreich, Österreich und Spanien (siehe \$3.4.6).

30. Riege, 329.

31. Obwohl Riege auf sehr propagandistische Art Rechtsvergleichung betreibt. Vgl. beziglich dieser propagandistischen Art auch Bartels, 37-40, mit interessanten Hinweisen auf und Zitaten aus der Sowjet- und DDR-Literatur.

32. Obwohl betont werden muB, daß auch in auBereuropailischen Staaten interessante Entwicklungen festzustellen sind. Vgl. Dutoit, La nationalité de la femme mariée, Bd. II Afrique (Genf 1976) und Bd. III, Amérique-Asie-Océañe (Genf 1980). Zusáttzlich sei weiter noch hingewiesen auf die am 1. Januar 1985 in Kraft getretenen Anderungen der Staatsangehörigkeitsregelungen Japans, Asahi-Shinbun vom 19. Mai 1984, Kampo (Japanisches Staatsgesetzblatt) vom 25. Mai 1984. Siehe dariber Hosakawa, Japanese Annual of international law 1985, 11-28; Tanaka, 115-128; Yamauchi, (Japanese) Comparative Law Review 1983, 31-47; Yamauchi, IPRax 1985, 59, 60; vgl. weiter de Groot, Japanische Zeitschrift für Standesamtswesen 1985, Nr. 328, 2-8; Nr. 329, 2-11; Nr. 330, 2-10; Nr. 331, 36-48 und Ritsumeikan Law Review 1985, Nr. 5/6, 123-167, wo die neueren westeuropäischen Entwicklungen im Staatsangehörigkeitrecht mit der neuen japanischen Regeiung verglichen werden (veroffentlicht in japaruischer Sprache); siehe auch Bergmann/Ferid, unter Japan (83. Lieferung: Stand 30. April 1985).

33. Vgl. Paragraph 1.4.3; von größter Bedeutung ist im Rahmen des Europarates selbstverstẩndlich das Zustandekommen des Straßburger Abkommens zur Verminderung von 
Fâllen mehrfacher Stalsangehörigkeit vom 6. Mai 1963. Weiter sei auf die verschiedenen Resolutionen des Europarats hingewiesen, die sich auf Staatsangehörigkeitsrecht beziehen.

34. Siehe insbesonders de Groot, Loseblattkommentar und de Groot/Tratnik.

35.

Gesetz vom 28. Juni 1984; siehe darüber Paragraph 2.1.

36.

37.

38.

39.

40.

41.

42.

43.

Gesetz vom 30. Oktober 1981; siehe daríber Paragraph 2.4.

Gesetz vom 20. Dezember 1984; siehe dariber Paragraph 2.2.

Siehe oben Fußnote 11.

Vgl. z.B. fur die Niederlande de Groot, NJB 1975, 782-787.

Gesetz vom 14. Dezember 1984; siehe dariiber Paragraph 2.8.

Gesetz vom 3. Màrz 1983; siehe darüber Paragraph 2.7.

Siehe dariber ausfilihrlich u.a. Hecker, Code Napoléon.

Gemäß dem Gesetz vom 10. August 1927 erwarben die Kinder einer französischen Mutter und eines ausländischen Vaters die französische Staatsangehörigkeit, falls sie in Frankreich geboren wurden. Seit dem 19. Oktober 1945 erwarben diese Kinder auch die französische Staatsangehörigkeit bei Geburt im Ausland. Siehe darïber Paragraph 2.3 .

44. Gesetz vom 9. Januar 1973, siehe dariber Paragraph 2.3.

45. Gesetz vom 21. Juli 1983; siehe dariber Paragraph 2.5.

46. Gesetz vom 13. Juli 1982; siehe dariber Paragraph 2.9.

47. Art. 5 Abs. 2 des Gesetzes vom 21. April 1983; siehe dariber Paragraph 2.5.

48.

49.

50. Das türkische Staatsangehörigkeitsgesetz datiert vom 11. Februar 1964 und wurde letztlich abgeändert durch Gesetz Nr. 2383 vom 13. Februar 1981. Siehe über das tiirkische Staatsangehörigkeitsrecht u.a. Akguner, Annales de la Faculté de Droir d'Istanbul 1979, 443-458; Aksoy, IA 1982, 183-186; Ansay, IA 1981, 84, 85; Sevig, 195-213; Sevig, Jurisclasseur; Uluocak, Annales de la Faculté de Droit d'Istanbul 1980, 203-207; weitere Literaturhinweise bei Hecker, Europa. Siehe auch Bergmann/Ferid, unter Türkei 91. Lieferung; Stand 31. August 1987.

51. Staatsangehörigkeitsgesetz vom 27. Mai 1950, letztlich abgeändert durch das Gesetz wom 29. März 1978, Nr. 117. Siehe Bergmann/Ferid, unter Dänemark (66. Lieferung; Stand 30. November 1979) und NWG unter Dänemark (Lieferung 153); Vgl. Karnows Lovsamling 1982, 68-80* Sorensen, 430-433; Steffensen, 18-225 und Steffensen, Jurisclasseur.

52. Staatsangehörigkeitsgesetz vorn 8. Dezember 1950 , letztlich abgeändert durch Gesetz Nr. 7 vom 8. April 1981; siehe Bergmann/Ferid, unter Norwegen (84. Lieferung; Stand 1. Oktober 1985). Siehe weiter Brinkman, PS 1980, 28.

53. Staatsangehörigkeitsgesetz vom 22 . Juni 1950 , letztlich abgeändert durch Gesetz Nr. 139 vom 5. April 1979; siehe Bergmann/Ferid, unter Schweden (72. Lieferung; Stand 30.. September 1981). Vgl, auch das Gutachten "Medborgarskap", Stockholm 1976.

54. Staatsangehörigkeitsgesetz vom 28 . Juni 1968 , letzlich abgeändert durch Gesetz $\mathrm{Nr}$. 584 vom 10. August 1984; siehe Bergmann/Ferid, unter Finnland (83. Lieferung; Stand 30. April 1985).

55. Staatsangehórigkeitsgesetz vorn 23. Dezember 1952; siehe Bergmann/Ferid, unter Island (Originallieferung der 3. Auflage).

56. Gesetz Nr. 37/81 vom 3. Oktober 1981, Diário da Republica, Serie I, Nr. 228, 2648-2652; siehe Bergmann/Ferid, unter Portugal, (74. Lieferung; Stand 31. August 1982) und StAZ 1981, 331; dazu u.a. Jalles, in: Verwilghen, Nationalité et statut personnel, 169-193; Ravet-Gobbe; Pereira; Ramos; Vieira de Andrade, IA 1982, 186-189.

57. Irish Nationality and Citizenship Act vom 17. Juli 1956; siehe NWG, unter Irland (Lieferung 184); vgl. noch Bergmann/Ferid, unter Irland (74. Lieferung; Stand 31. August 1982); weiter Patoul/ $\mathrm{O}^{\prime}$ Connor/Fish, Jurisclasseur.

58. Gesetz über den Erwerb und den Verlust des Landesbïgerrechts vom 4. Januar 1934, letztlich geändert durch Gesetz vom 14. Oktober 1986, Liechtensteinisches Landesgesetzblatt 1986, Nr. 104; vgl. auch Bergmann/Ferid, unter Liechtenstein (88. 
Lieferung; Stand 30. November 1986). Siehe Wille, ZZW 1975, 37, 38 und weiter ZZW 1985, 6.

59. NWG unter Monaco (Lieferung 151).

60. Bergmann/Ferid, unter San Marino. (Originallieferung der 3. Auflage).

61. Gesetz Nr. 32 vom 27. Màrz 1984, Bollettino Ufficiale Nr. 3 vom 31. März 1984, S. 59 und Gesetz Nr. 33 vom 27. März 1984, Bollertino Ufficiale Nr. 3 vom 31. März 1984, S. 60. Darïber Bergmann/Ferid, unter San Marino (85. Lieferung; abgeschlossen am 31. März 1986), 2-4.

62. Codi de la Nationalitat Andorrana vom 11. März 1977, Decret n.77.6, Recall oficial dels Decrets it Actes de les MM. Ш. Delegacions Permanents, 1977/ 1978; der Text dieses Gesetzes ist auch abgedruckt bei Viñas i Farre, 103-111. Das Gesetz trat rïickwirkend in Kraft ab 1. Juli 1976; es wurde abgeändert durch Gesetz vom 7. September 1985 (dazı Rau, StAZ 1986, 228-232); siehe weiter Viñas i Farré, RJC 1980, 725-756; RDIPP 1983, 87-83; ebenfalls Viñas i Farré, Jurisclasseur.

63. Gesetz vom 22. Februar 1968 ibber die luxemburgische Staatsangehörigkeit, in der Fassung vom 1. Juli 1975, veröffentlicht in Memorial (Amtsblatt des Großherzogtums Luxemburg) 1975, A 42; letztlich geändert durch Gesetz vom 11. Dezember 1986. Siehe über das Staatsangehörigkeitsrecht Luxemburgs Franck, StAZ 1975, 285-295; Churchill, ICLQ 1976, 245, 246; F. Schockweiler, Nationalite 143-167; Schockweiler, Jurisclasseur; Bergmann/Ferid, unter Luxemburg (95. Lieferung; Stand 1988) und NWG, unter Luxemburg (Lieferung 180).

64. Siehe darüber vor allem auch die unterschiedlichen Bände der Reihe "Sammlung geltender Staatsangehörigkeitsgesetze" (SGS), herausgegeben vom Institut für internationale Angelegenheiten der Universität Hamburg.

65. Bevan, 49; vgl. auch Gonzalez Campos, Comentario, 22: "Por ello los estudios históricos del Derecho de la nacionalidad poseen una importancia innegable al poner relieve estos factores y objectivos, permitiendo conocer las líneas de evolución que conducen a la normativa hoy vigente

66. Vgl. - in anderem Zusammenhang - Grawert ${ }_{w}$ Der Staat 1984, 192; "Es liegt nahe anzunehmen, dalB das konkrete Verständnis der Staatsangehörigkeit vor allem die angehörigkeitsrechtlichen Regeln uber Erwerb und Verlust steuern, die für die Begrüindung und den Bestand des Staatsangehörigkeitsverhälmisses maßgebend sind".

67. Makarov, Allgemeine Lehren, 12-19; von Mangoldt, Anerkenmung, 44,45; vgl. auch die terminologische Bemerkungen von Verzijl, $11-18$.

68. Makarov, Allgemeine Lehren, $13 \mathrm{ff}$. mit mehreren Beispielen. Einer der von Makarov (S.16) gegebenen Beispiele betrifft das deutsch-niederländische Abkommen vom 29* März 1951 (BGB1. 1951, II, 222) über Sozialversicherung, dessen Art. 20 Abs. 1 bestimmte: "Deutsche oder Niederländische Staatsangehörige im Sinne dieses Abkommens sind auch Personen, die nach der Gesetzgebung eines der beiden Vertragsstaaten als Deutsche oder Niederiänder gelten". Siehe für weitere Beispiele funktioneller Staatsangehörigkeiten Van Panhuys, 140, 141. Vgl. auch die Ausführungen von Ko Swan Sik, Preadvies, 16 und NILR 1982, 100 und Hannappel, 24. Letzterer spricht ubbrigens won der "funktionellen" oder "fiktiven" Staatsangehörigkeit.

69. So auch Makarov, Allgemeine Lehren, 12; Van Panhuys, $166 \mathrm{f}$.

70. Makarov, Allgemeine Lehren, 12 schreibt: "Wenn wir vom allgemeinen Begriff der Staatsangehörigkeit sprechen, so meimen wir den Status der Zugehörigkeit zu einem Staat, an den dieser Staat durch seine innerstaatlichen Rechtsvorschriften und die Staatengemeinschaft durch wölkerrechtliche Normen gewisse Rechtsfolgen ankniupft, gewisse Rechte und Pflichten, die allen Angehörigen des betreffenden Staates gemeinsam sind, auch wenn einige Gruppen von ihnen einem speziellen Status unterworfen sind. Vgl. von Mangoldt, Anerkennung, 45; Van Panhuys, 38.

71. Makarow, Allgemeine Lehren, 50 mit weiteren Beispielen. Auf S. 51 gibt Makarov moch ein Beispiel einer örtlich-beschränkten Staatsangehörigkeit.

72. Siehe hieriber weiter de Groot/Tratnik, 45, 46 .

73. Der Begriff der "beschrä́nkten" Staatsangehörigkeit wird von Makarov in einem Kapitel "Arten der rechtlichen Gestaltung der Staatsangehörigkeit" erwathnt. In diesem Kapitel (Allgemeine Lehren, $40 \mathrm{ff}$.) widmet Makarov auch einigen anderen staatsangehörigkeitsrechtlichen Sonderkonstruktionen ausfuhrliche Erörterungen: die Staatsangehörigkeiten einiger Kolonialstaaten, die die Staatsangehörigkeit im weiteren and im engeren Sinne unterschieden; die Staatsangehörigkeiten in Staaten mit staatsangehörig- 
keitsrechtlichen Teilrechtsordnungen und Staatsangehörigkeiten auf Widerruf Vgl. auch Ko Swan Sik, Preadvies, 3.

74. Ko Swan Sik, Preadvies, 4 (Staatsangehörigkeit in sozio-politischer Bedeutung): Vgl. Fernández Rozas, 19 (nacionalidad de carácter sociológico); Van Panhuys, 37,38 (Staatsangehörigkeil im ethnologisch-soziologischen Sinne); Verzijl, 7 (Staatsamgehörigkeit im historiscli-biologischen oder ethnologischen Sinne).

75. Vgl. Ko Swan Sik, Diss., 1, 2; Mannoury, 7, 8. Manchmal wird der Begriff "soziologische Staatsangehörigkeit" aber verwandt in einer Bedeutung, die hiernach alls "Nationalität im ethnischen Sinne" beschrieben wird. Siehe Mannoury, 3 und FuBnote 19.

76. In Zusammenhang mit der Entscheidung der Arrondissementsrechtbank (Landgericht) Roemond yom 14. Dezember 1976, NJ 77, 299.

77. De Groot, Preadvies, 5. Vgl. Mannoury, 3, der jedoch mit soziologischer Staatsangehớrigkeit diejenige Eigenschaft meint, die hiernach als "ethnische Nationalitati" beschrieben wird.

78. So auch Ko Swan Sik, Diss., 2.

79. Hierauf wird auch von Van Panhuys, 37, 38 hingewiesen.

80. So auch Mannoury, 8. Vgl. z.B. Art. 8 des niederlänđiischen Staatsangehörigkeitgesetzes 1985 und $\$ 3.3 .4 .5$ dieses Buches.

81. Art. $15 \& 2 \mathrm{CNB}$.

82. Makarov, Allgemeine Lehren, 311 ff.; vgl. Boele-Woelki, Effektivitätsprüfung, 35-80; Somenberger, 9-22.

83. Triepel, Virtuelle Staatsangehörigkeit, 1921. Auch erwähnt von Meessen, in der EPIL, Bd. 8, 427. Der Begriff "virtuelle Staatsangehörigkeit" wurde neulich von Hecker," Recht in Ost und West 1987, 299 auch in Bezug auf DDR-Bírger benutzt.

84. Allgemein wird darauf hingewiesen, daß der Begriff "nationallite" in der Ausgabe des Dictionnaire de l'Académie française von 1835 zum ersten Mal in einem Wörterbuch erwahnt wird (so Makarov, 8 mit Hinweis auf Cogordan, 4, Fußnote 1). Dies mag stimmen für den Begriff "Nationalität" im Sinne von Staatsangehörigkeit. Das Wort "Nationalität" als solches wird aber schon eher in Wörterbuichern genannt: siehe Allgemeines deutsches Sach-Wörterbuch aller menschlichen Kenntnisse und Fertigkeiten, fortgesetzt von Albert Schiffner, Sechster Band, Meissen 1827: "Nationalität (Kiüchenlateinisch) $=$ Volkssinn, Gemeinsinn einer Nation, purist. Volksthümlichkeit, welches aber auch in anderm Sinne gebraucht wird; denn wenn man z.B. von preussischer Volksthümlichkeit spricht, so meint man etwas der (deutschen) Nationalitảt fast entgegengesetztes." und "Neuestes Conversations-Lexicon, oder allgemeine deutsche Real-Encycllopädie für gebildete Stände", von einer Gesellschaft von Gelehrten ganz neu bearbeitet, Band 13, Wien 1831, unter dem Stichwort "Nation": "Uberhaupt wird in dem Begriffe Nation aber mehr auf die natïlich verbindende Einheit gesehen, und bezeichnet dann dieses verbindende Eine als Nationalităt, ....."." Der Begriff "Nationalität" im Sinne von Staatsangehörigkeit soll zum ersten Mal won Napoleon benutzt worden sein (vgl. aber Plender, 3, 4, Fußnote 11 mit einem Hinweis auf Vattell, Droit de gens, Préliminaires, Par. 1 aus dem Jahre 1758). In der Bedeutung von ethnischer Zngehörigkeit wird die erste Benutzung des Begriffes "Nationalität" Kaiser Joseph II in seinen 'Disputes Autrichiennes" zugeschrieben. So Bendeddouche, 40 und Ruby, 21. Lexis (Dictionnaire de la langue française) nennt als Jahr der ältesten Erwähnung des Wortes "mationalite" 1808; ebenso Robert mit einem Hinweis auf Wartburg (1808) (Dictionnaire alphabétique et analogique de la langue française); Grand Larousse de la langue française nennt als Jalar der ältesten Erwăhnung $1778 \mathrm{mit}$ einem Hinweis auf J.J. Rousseau.

In der englischen Sprache ist der Begriff "nationality" noch älter. Oxford English Dictionary, Bd, 7, 32, gibt als ailteste Erwähnung Thomas Hale, An account of several new inventions; also a treatise of naval philosophy written by Sir W. Petty (1691), 37 ("The Ingredients employed ... are of Foreign growth; which we make use of not so much for the sake of the Nationality of its Arguments... ". Die allteste Erwähnung des Wortes "nationaliteit" in der niederländischen Sprache fand ich bis jetzt in Weekblad van het Regt vom 17. Dezember 1841: "... hopen en wenschen wij spoedig het auto-da-fe van geessel-palen en roeden en brandijzers te hooren verkondigen, opdat wij ons niet meer schamen, opdat wij niet meer blozen over onze nationaliteit" (vgl. Kluyver e.a., Woordenboek der Nederlandse taal, Bd. 9, 1594). 
85. Louis-Lucas, 1, 2 weist darauf hin, daß der Begriff "nationalite" in dieser Bedeutung besser durch "étatialité" hätte ersetzt werden können, aber so betont er "le mot (nationalité) est consacré et il ne saurait être question de lui en préférer un autre d'un néologisme aussi barbare".

86. So z.B. Van der Poel, 74-117; vgl. weiter Fernández Rozas, 20 (Fubnote 5); Van Panhuys, 37, 38 (Staatsangehörigkeit im ethnologisch-soziologischen Sinne)* Verzijl, 7 (Staatsangehörigkeit im historisch-biologischen oder ethnologischen Simne).

87. Vgl. Nemarokov/Proskoerin, De oplossing wan het nationalitieitenvraagstuk in de USSR, Moskau 1983.

88. Vgl Riege/Kulke, Nationalität: deutsch; Staatsbürgerschaft: DDR.

89. Vgl Schätzel, in: Neumann/Nipperdey/Scheuner, II, 542: "Volksdeutsch" ist an sich ein ethnographischer Begriff..... Diesen ethnographischen Begriff setzt das Grundgesetz voraus".

90. BGBI. $\mathrm{I}_{*} 1217$.

91. "Deutscher Volkszugehöriger im Sinne dieses Gesetzes ist, wer sich in seiner Heimat zum deutschen Volkstum bekannt hat, sofern dieses Bekenntnis durch bestimmte Merkmale wie Abstammung, Sprache, Erziehung, Kultur bestätigt wird".

92. Dazu Makarov/von Mangoldt, GG, Art. 116, Rdnr. 23-35; Weidelener/Hemberger, 17. 18. Über die Rechtsprechung des BVerwG anlaBlich Art. $116 \mathrm{GG}$ auch Meyer, NVwZ $1987,17$.

93. Daruber Makarov, Allgemeine Lehren, 22, 23, mit vielen Literaturhinweisen auf die ältere französische Literatur (Fußnote 20), u.a. auf Cogordan, 4 ("Le lien qui unit l'individu à l'Etat, c'est-ä-dire au groupe social suprême et indépendant, est ce que l'on appelle la nationalité") und Andre Weiss, II ("La nationalité peut .... être définie le lien qui rattache une personne ou une chose à une nation déterminés" $e^{\text {s" }}$. Makarov gibt jedoch auch Fundstellen aus der spanischen, belgischen und deutschen Literatur, wo die Staatsangehörigkeit als Rechtsverhältnis beschrieben wird. Biezüglich der deutschen Literatur nennt er Ernst lisay als Vertreter dieser Rechtsverhältnistheorie. Siehe hieriber u.a. auch Brownlie, BYIL 1963, 344 ff;; Fernández Rozas, 19, 20, 30-33; Ko Swan Silk, Diss., 3-6;, Riege, 63.

94. Die Rechtsverhältnistheorie geht in der französischen Literatur wohl zurück auf Auffassungen, die anlehnten an Rousseaus Lehre vom contrat social. Vgl. André Weiss, 8: "C'est dans un contrat synallagmatique, intervenu entre 1 'Etat et chacun des individus qui le composent, que se trouve, selon nous, le fondement juridique de la nationalite st. $^{\text {th }}$

95. Darüber Makarov, Allgemeine Lehren, 24-27; siehe vor allem die Literaturhinweisen in den Fußnoten $67-75$. Aus der deutschen Literatur erwahnt er vor allem Laband, 140 und Georg Jellinek, System, 114-135 als Vertreter dieser Theorie. Jellinek (118) beschreibt die Staatsangehörigkeit als Status als "ein dauerndes, kraft juristischer Anschauungsweise hypostasiertes Verhällmis, ein Sein im juristischen Sinne". Von den neueren deutschsprachigen Autoren geht Benz, 4 von der Rechtsverhältnistheorie aus, ebenso wohl noch Kammann, 7-9. Vgl. hieriber weiter Ko Swan Sik, Disss, 6; von Mangoldt, Anerkennung, 41-44, Riege, 64.

96. Makarov, Allgemeine Lehren, 27,28. So auch Ehrlich, 7; Grendelmaier, 15; Immer, 17. Vgl. weiter Makarov im Wörterbuch des Völkerrechts, 323: "Wenn im Schrifttum die Staatsangehórigkeit öfter als ein Rechtsverhältnis zwischen dem Staat und der zu ihm gehörenden Einzelperson bezeichnet wird, so ist es ein Rechtsverhälitmis, innerhalb dessen die Eigenschaft der Einzelperson als Subjekt dieses Rechtsverhältnisses: einen rechtlichen Status dieser Person bildet"; so auch buchstäblich Makarov/von Mangoldt, Einileitung I, Rdnr. 3; siehe weiter won Mangoldt, Anerkennung, 42, 43.

97. Makarow, Ailgemeine Lehren, 28.

98. Makarow, Allgemeine Lehren, 27,28. In dem Zitat sind die Fußnotenlainweisen weggelassen. Wo Makarov Isay erwähnt, meint er dessen 1907 veróffentlichtes Werk "Die Staatsangehörigkeit der juristischen Personen", namentlich S. 44.

99. So auch z.B.: Randelzhofer in EPIL Bd. 8, 417: "The opinions of writers differ as to whether this tie (i.e. the nationality) should be qualified as a legal relationship or as a legal status. In the opinion of the present writer nationality comprises elements of both" $^{\text {" }}$ vgl. Randelshofer, in: Berichte der Deutschen Gesellschaft für Volkerrecht, Heft $29,116,117$. Siehe weiter u.a. Ehrlich, 7, 12; Grendelmaier, 15; Immer, 17; Ko Swan Sik, Diss. 6-8; Verzijl 5 ff. Ebenfalls wohl auch Dubois, 4, der aber betont, daß die Staatsangehörigkeit vor allem ein Status sei; er stellt sich die Frage, ob es nơtig ist, in 
Zusammenhang mit der Staatsangehörigkeit den Begriff "Rechtswerhailtnis" itberhaupt zu verwenden $\mathrm{n}_{\mathrm{q}}$ da die Staatsangehörigkeit $s . \mathbb{E}_{\text {, }}$ soziologisch gesehen, worrechtlich, d.h. eine dem Recht vorgegebene, der menschlichen Gesellschaft angehörende Bieziehung sei. Dagegen sieht Z,B. Grawert, Der Staat 1984, 193 die innerstaatliche Staatsangehörigkeit wohl als Status: ("ausformungsbediürtige Rechtsstellung"), die völkerrechtliche Staatsangehôrigkeit aber wohl eher als Rechtswerhältunis. Riege, 64 lehnt die vermittelnde Theorie Makarovs als buirgerlich ab.

100. De Groot, PS 1978, 78-80; v gl. Terre, RCDIP 1975, 201.

1.01. So z.B. Burckhardt 337, 338 (auch zitiert bei Dubois): "Die Umschreibung der Staatsangehörigkeit erhält erst rechtliche Bedeutung unter der Annahme, daß der Staat, der eine Gruppe von Menschen derart als seine Angehörigen, als sein Volk, von den anderen Menschen unterscheidet, neben sich noch andere Staaten hat, die ebenfalls ihre Angehörigen haben und diese Menschen zu einer anderen Rechtsgemeinschaft zusammenfassen. Die Bedeutung der Staatsangehörigkeit besteht also darin, dab sie die, jedem Staat zugehörige, Gruppe von Menschen kennzeichnet".

102. Georg Jellinek. 179, 180. Zwar werden in den modernen allgemeinen Staatslehren manchmal von Jellinek abweichende Existenzkriterien eines Staates vertreten, sämtliche Theorien betrachten aber wenigstens ein Staatswolk als notwendiges Element eines Staates. Vgl. auch Dubois, 1; Grawert, Handbuch; Kammann, 4; Ko Swan Sik, Preadvies, 3, 4: Makarov, Allgemeine Lehren, 5; von Mangoldt, Anerkennung, 63, 64; Wiederkehr, 2.

103. Siehe über die Entwicklung des modernen Begriffes: "Staatsangehörigkeit" vor allem Grawert, Staat und Staatsangehörigkeit. Siehe weiter Kammann, 4-7; Schätzel, Geschichte, 15-26.

104. Vgl. auch Ko Swan Sik, Preadvies, 6 und Ko Swan Sik, NILR 1982, 100. Sielie weiter Böckenförde, Festgabe Carl Schmitt, 2. Teilband, 430, 431.

105. Wengler, 550: Die Staatangehörigkeit bildet "ein zunächst "leerlaufender", d.h. nicht von vomherein mit Rechtsfolgen ausgestatteter Bereitsschaftsstatus".

106. Makarov, Allgemeine Lehren, 30,31; so auch Makarov/won Mangoldt, Einleitung I, Rdnr. 4.

107. Ko Swan Sik, Preadwies,13, mit Verweisung nach PS 1951, 4-7 (Zitat in Übersetzung des Verfassers). Vgl. auch bereits Ko Swan Sik, Diss., 8.

108. Georg Jellinek, System, 118 ("Die zum Sein verdichtete Relation zwischen Individuum und Staat bleibt nämlich als solche ganz unverändert, welchen konkreten Inhalt man ihr auch immer setzen möge"); Koessler, Yale Law Journal 56 (1946-47), 70 ("The concept of nationality is no more than a formal frame, surrounding a picture of changeable character"); Seckler-Hudson, 6, 7; White, Journal of the Law Society of Scotland 1983, 267 ("Nationality is then a hook. What is hung on it ?"). Siehe fuir weitere Literaturhinweise Ko Swan Sik, Diss., 10, namentlich Fußnote 4 und von Mangoldt, Anerkennung, 42, namentlich Fußnote 10. Osteuropäische Autoren lehnen diese Ansicht allerdings entschieden $a b$; siehe Riege, 54-62 mit weiteren Literaturhinweisen.

109. Wiederkehr, 6 .

110. Van Panhuys, 20, 24-30; Wengler, 544-558; vgl. auch Koessler, Yalle Law Journal 56 $(1946 / 47), 62,63$; Hans-Jörg Jellinek, $37 \mathrm{ff}$. und Verdross, Jus Gentium, (Bd. 1) 1949, 137, worilber Dubois, 5 -7. Siehe weiter Grawert, Der Staat 1984, 183 und won Mangoldt, Anerkennung, 67-72.

111. Daruber Makarow, Allgemeine Lehren, 28, 29 mit weiteren Literaturlhinweisen (Fußnoten 80-86).

112. Riege, 54-62 mit weiteren Hinweisen.

113. Vgl. Art. 1 des Haager Abkommen vom 12. April 1930.

114. $P$. Weis, 239: "Nationality is .... a concept not only of municipal law but also of international law. As a concept of municipal law it is defined by municipal law; as a concept of international law it is defined by international law. From the aspect of municipal law there is, therefore, no one concept of nationality but as many concepts as there are municipal laws ....". Dagegen Makarov, Allgemeine Lehren, 11, 12 und im Wörterbuch des Völkerrechts, 324. Makarov weist u.a. darauf hin, daß schon die Tatsache, daß viele Staatsangehörigkeitsregelungen bestimmen, daß die eigene Staatsangehörigkeit von einer Person verloren wird, die freiwillig eine fremde Staatsangehörigkeit erwirbt schon ein Indiz eines einheitlichen Staatsangehörigkeitsbegriffes ist. Vgl. von Mangoldt, Anerkennung, 42, 43 . 
115. Dahm, 449; Hatschek, 214; Van Panhuys, 24 ff. (vor allem 30 f); Verdross, 305-313; P. Weis, 239; Wengler, 545 ff. (vor allem 547, 557).

116. So z.B. Wengler, 549. Dazu von Mangoldt, Anerkennung, 55.

117. So Berber, 383; Dubois, 9; Makarov, Allgemeine Lehren, 11; Makarov, im Wörterbuch des Völkerrechts, 324; Makarov/von Mangoldt, Einleitung I, Rdnr. 11; so wohl auch Terre, RCDPP 1975, 208. Gegen die Unterscheidung eines innerstaatlichen und internationalen Staatsangehörigkeitsbegriffes ebenfalls Riege, 65-71. Vgl. von Mangoldit, Anerkennung, 554-63.

118. Vgl. die Nottebohmentscheidung des IGH (ICJ Reports 1955, 4); dazu ausfuihrlicher \& 1.4.1.

119. Siehe \& 1.4.1.

120. So meint z.B. Randelzhofer in der EPIL, Bd. 8, 417, daß im internationalen Recht begriffsmäßig Rechtsfolgen mit der Staatsangehörigkeit werknüpft sind. Zuerst betont er "In fact nationality is a precondition of relevant rights and duties but not its immediate source. Municipal laws concerning nationality confine themselves to regulate acquisition and loss of nationality, but say nothing about rights and duties as a corollary of nationality". Aber anschließend schreibt er: "As far as nationality as a concept of international law is concerned, rights and duties of the State (not of the individual) are immediately derived from nationality: the right of diplomatic protection and the duty of admission". Siehe weiter P. Weis, $35 \mathrm{ff}$.; Wengler, 546.

121. So auch Koessler, Yale Law Journal 1946/47, 75, 76; Makarov, Allgemeine Lehren, 29,30; von Mangoldt, Anerkennung, 72.

122. So Koessler, Yale Law Journal 1946/47, 76; vgl. für das Recht des diplomatischen Schutzes: Ko Swan Sik, Preadvies, 17 (auch bereits Ko Swan Sik, Diss., 8, 9).

123. Über die Staatsangehörigkeit als Menschenrecht auch: de Groot/Tratnik, 1-5. Ganz anderer Ansicht wäre aller Wahrscheinlichkeit nach Zeballos, Bd. I, 160: "La Nationalité est quelque chose de suprême et de grand, inhérent à la nature de l'homme. C'est l'attribut le plus important de la liberté civile qui nous conduit, par une série d'évolutions, à nous grouper, abstraction faite de l'influence du territoire, des langues, des religions et des situations politiques anterieurs, pour réaliser un ideal commun de Justice, de Liberté, de Paix et de Travail"'. Vgl. Zeballos, Bd. 1, 233, 234. Vgl. auch N.A. Maryan Green, International Law, 3, ed. London 1987: "The Universal Declaration of Human Rights states that "everyone has the right to a nationality" (Art. 15 (1)). If this nationality is to be a benefit rather than a burden to the individual, it should follow that he has the right to renounce one nationality on acquiring a new one (the so-called "right of expatriation"). This is unfortunately not the case. Apart from persons born with double nationality, few states permit their nationals the option of remouncing their nationality on acquiring a new one."

124. Fernández Rozas, 37 weist in diesem Zusammenhang u.a. auf die Tatsache hin, daß im Rahmen des Zustandekommens der spanischen Konstitution ein Vorschlag zur Änderung der Redaktion won Art. 11 zurïckgewiesen wurde, worin die Rede war von. die "nacionalidad en cuanto derecho fundamental de la persona humana"..

125. Dieser "Terminus ist Mannoury, 10 entliehen.

126. Ko Swan Sik, Diss., 2 mit Hinweis auf Acts of the Conference, Bd. II: Minutes of the first committee, League of Nations doc. C 351 (a) M-145(a), 1930, V, S 48 ; vgl auch Herbert Kriger, 7.

127. Traité, 25 mit vielen Literaturhinweisen.

128. Vgl. Art. 18 des Staatsbiirgerschaftsgesetzes der UdSSR vom 1. Dezember 1978.

129. Vgl. die Erörterungen Rieges, 327-331 iber den Widerruf der Verleihung und uiber die Aberkenmung der Staatsangehơrigkeit.

130. Vgl. Schneider, der in Mededelingen van de Nederlandse Vereniging voor Internationaal Recht 1981, 20 auf die politissche Bedeutung der Staatsangehörigkeit in außereuropäischen Staaten hinweilst; siehe auch NILR 1982, 123; vgl. (kritisch) Zatzepine, Recueil Pénant 1986, 482-496; vgl. weiter Hingorani, 119: "Nationality may be defined as a symbol of belonging to a particular State".

131. Vgl, z.B. die bei Bevan, 114 zitierte Bemerkung aus den Sitzungsprotokollen des "House of Commons" (28 Januar 1981, col. 935): "Citizenship is inevitably a sensitive matter about which people feel very strongly".

132. Vgl. in diesem Zusammenhang Frowein, EuGRZ 1980, 1.51: "Wahrscheinilich ist das Band der Staatsangehörigkeit zum Heimatstaat der Elrern fir viele Gastarbeitnehmerkinder die wiclitigste noch vorhandene Briucke, die nicht leichthin aufgegeben 
werden wird. Es ist bekannt, daB aufgrund der Wirkung der Staatsangehörigkeitsgesetze vieler Länder und der außerordentlichen Mobilitär eines erheblichen Teils der Bevolkerung heute die Mehrstaatler ohnehin zunehmen. Es bedürfte genauere Uberlegung, ob man nicht bei Gastarbeitnehmern, die sich im Aufnahmeland mindestens fuir einen erheblichen Zeitraum ihres Lebens niederlassen, die Doppelstallereigenschaft duxchaus erleichtern sollte". Vgl. dazu auch Thränhardt, Aus Pollitik und Zeitgeschichte, Beilage 24 zur Wochenzeitung Das Parlament, Juni 1988, 13: "Auff dieser Grundlage sollte den erwachsenen Aus.ländern nach einer gewissen legallen Aufenthaltszeit (in Schweden zur Zeit fünf Jahre) das Regellangebot der Einbürgenung gemacht werden, ohne dies durch weitere Erfordernisse zu erschweren (außer beil Schwerkriminalităt und Mord oder Drogenhandel). Doppelstaatsangehörigkeiten müssen dabei in Kauf genommen werden, vor allem in cen Füllen, in denen die Herkunftsländer ihre Staatsangehörigen nicht entlassen wollen, wie dies fuir die meisten deutschen Ausländer gilt. Nach französisch-amerikanischem Vorbild sollte ferner den hier (d,h. Bundesrepublik Deutschland; d.G.) geboremen und aufgewachsenen Ausländern die deutsche Staatsangehörigkeit angeboten werden, damit sie sich von vormeherein an dieser Aussicht orientieren können."

$132 \mathrm{a}$ Die Gefahren einer Überbetonung der psychologischen Dimension der Staatsangehörigkeit waren gerade in jüngster Vergangenheit bei den französischen Präsidentschaftswahlen zu erkennen, wo teilweise die Staatsangehörigkeitdiskussion alls Mittel benutzt wurde, einen bereits virulenten AusländerhaB zu schüren. Vgl. zu den unterschiedlichen Nationalitäts- und Identitâtskonzepten in Frankreich und der Bundesrepublik Deutschland Thränhardt, 17-25.

133. Akehurst, 99, 100; Bar-Yaacov, 3; Bendeddouche, 66-80; Berber, 374; van Bogaert, 314; Brownlie, BYIL 1963, 284; Dutoit, Jurisclasseur, 7; Kammann, 9; Kimminich, Vbilkerrecht, 141; Lauterpacht, 300; Makarov, Allgemeine Lehren, 57, 58 (mit Literaturhinweisen in den Fußnoten 2 und 3); Menzel/Ipsen, 165; Oppenheim, Bd. 1, 186; Seckler-Hudson, 406; Strupp, 131; Völkerrecht DDR, 215; Weis, 65; André Weiss, 11; Wiederkehr, 10. Als spezieller Berichterstatter der International Law Commission unterstrich M.O. Hudson diese Ansicht, indem er ausfiuhrte: "In principle, questions of nationality fall within the domestic jurisdiction of each state. (YBILC 1952 II, 7).

134. Dazu Bluntschli, 213: "Jedem Staat steht das Recht zu, selbständig festzustellen, unter welchen Bedingungen seine Staatsgenossenschaft erworben wird und verloren werde." Siehe auch Zitelmann, 170.

135. Entscheidung vom 7. Februar 1923, PCIJ, Serie B. Nr. 4 (1923), 24. Siehe dariber Ko Swan Sik, Preadvies, 5. Vgl. auch die Entscheidung vom 15. September 1923, PCI, Serie B, Nr. 7; wozu Winkler, 238, 239; Weis, 71-75.

136. Dariber Fernández Rozas, 41; Lapradelle, RCDIP 1922/23, 1; Verzijl, 20; Winkler, 198-210; Weis, 71-75.

137. LNTS, Bd. 179, 89 ff; hierzu Brownlie, BYIL 1963, 299,

138. Siehe auch die Vorarbeiten in AJIL 1929. Supplement 11 ff; vgl. weiter Weis, 82-84

139.

140.

141.

142. Bei dieser Einteilung werden einige bilaterale Abkommen, die sich auf Sonderfragen der Staatsangehörigkeit beziehen außer Betracht gelassen. Makarov, Allgemeine Lehren, 132-140, erwähnt davon neben den hier erwähnten Kategorien: die Bancroftverträge, Verträge, die eine materiellrechtliche Regelung einiger Staatsangehörigkeitsfragen zum Gegenstand haben und Abkommen betreffend behördlicher Genehmigung zur Einbürgerung der Angehörigen des Vertragspartners. Siehe ïber völkerrechtliche Vertrage auf dem Gebiete der Staatsangehörigkeit \$1.4.3. Vgl. auch Rezek, RdC 1986 III, $370-384$.

143. Makarow, Allgemeine Lehren, 140, 141, 148, 149.

144. Beispiele bei Makarov, Allgemeine Lehren, 148, 149.

145. Moniteur Belge Nr. 122 vorm 2.5.1925, S. 2477, 2478.

146. Overeenkomst betreffende toescheiding van staatsburgers, aufgenommen im Gesetz vom 21. Dezember 1949, Stbl. I570. Vgl. de Groot, Loseblattkommentar, Einfuihrung, Nr. 40, 41. Vgl. weiter auch Bleckmann, 364-371, 494-501 und de Burlet, 117-200. 
147. Toescheidingovereenkomst inzake nationaliteiten, Trb. 1975, 132. Vgl. de Groot, Loseblattkommentar, Einführung, Nr. 45, 46; Vierdag, 428 .

148. RGBI. 1938 I, 790 mit Anderung in RGBl. $1939 \mathrm{I}$, 1072.

149. Siehe dazu auch die Entscheidung der amerikanisch-mexikanischen Claims Commission vom 3. Oktober 1928; vgl, in diesem Zusammenhang auch Ko Swan Sik, Preadvies, 7. Weiter; Cordova, YBILC $1953 \mathrm{II}, 169$ (Nr. 14-18); Cordova, YBILC $1954 \mathrm{II}, 63$ (Nr. 43); Jones, 12 ("..there are certain very limited though perhaps illdefined principles of international law which limit a state"s right to frame nationality law at will." ); Mc Nair, Bd. II, 3; Rundstein, Zeitschrift für Volkerrecht 1932, $14 \mathrm{ff}$; Harvard Law School Advisory Committee, Art. 2 Draft Convention on the Law of Nationality, AJIL 1929, special suppl., 27 ("Except as otherwise provided in this conwention each State may determine by its law who are its nationals, subject to the provisions of any special treaty to which the State nay be a party but under international law the power of a State to confer nationality is not unlimited.") und sehr betont für Schranken auf dem Gebiet des Staatsangehörigkeitsrechts Triepel, ZaöRV 1929, 195; vgl. aber dagegen die von Wiederkehr, 14, Fußnoten 17-19, angeführten Autoren, die die Existenz einer Volkerrechtsordnung generell in Zweifel ziehen.

150. Besonders weit ist darin Hatschek, 215-217 gegangen, der eine lange Reilhe von Grundsätzen aufzählt, die Schranken bilden, welche jedem Staat bei der Verleihung der Staatsangehörigkeit völkerrechtlich gesetzt sind. Dessen Theorie ist von Makarow (Allgemeine Lehren, 94, 95) und Dubois, $(27,28) \mathrm{m}$.A. nach iberzeugend bestritten. Genaue inhaltliche Normen, die Schranken der nationalen Autonomie im Staatsangehörigkeitsrecht darstellen, mïBten zur Bedingung haben, daß bestimmte Normen in den Staatsangehörigkeitsregelungen der unterschiedlichen Staaten so einheitlich sind, daß eine Staat völkerrechtswidrig handeln wïrde, wenn er won diesen Normen abweicht. Die Staatsangehörigkeitsregelungen der verschiedenen Staaten sind aber en détaill doch zu unterschiedlich um solche Normen aufzeichnen zu können. Hatschek (S. 215) hat z.B. die Ansicht vertreten, daB ein Staat nur befugt ist anzuordnen, ob er die Verleihung der Staatsangehörigkeit auf die Abstammung oder auf den Geburtsort abstellen wird (vgl. ibbrigens auch Seidl-Hohenveldern, 268-272). Hiergegen hat Dubois, 27 zurecht darauf hingewiesen, daB dies keine allgemeine Norm sein kann, da auch Staatsangehörigkeitsverleihung an ein Ausländerkind bei Auslandsgeburt wohl als legitim geurteilt werden muß, wenn ein Elternteil Wohnsitz im Inland hat (vgl. Art. 44 Abs. 3 der schweizerischen Bundeswerfassung und Art. 3 Abs. 3 RwNed). Vgl. dazu auch Berber, 375.

151. Dazu u.a. Mosler, 109; Wiederkehr, 14, 15; Weis 85, 86.

152. So Dahm, 449; Berber, 377 (lehnt Rechtsmißbrauch aber als zu vagen Begriff für eine Schranke ab); Hall, 275; Leibholz, ZaöR 1929, 95, 100 ff.; Triepel, ZaöRV 1929, 195. Als Beispiel des Willkiirverbotes auf dem Gebiet des Staatsangehörigkeitsrechts wird vor allem der willkürliche Entzug der Staatsangehörigkeit genannt; so Scelle, Revue critique de droit international 1934, 68; vgl. hierzu Brownlie BYI 1963, 339 und Hudson, YBLC 1952 II, 10, wobei von beiden Autoren jedoch eine nuanzierte Stellung beziiglich der Zulässigkeit des Staatsangelhörigkeitsentzugs im allgemeinen eingenommen wird.

153. Zum regionalen Völkergewohnheitsrecht vergleiche: Bernhardt, EPIL, Bd. 7, 65; Bleckmann, EPIL, Bd. 6, 176-182; Jessup, Columbia Joumal of Transnational Law, 1973, 415-429; Schindler, EPIL, Bd. 7, 404-409. Auch der Internationale Gerichtshof hat die Existenz von regionalem Völkergewohnheitsrecht in der Entscheidung "Right of Passage over Indian Territory" anerkannt. Hierin hat er festgestellt: "The Court sees no reason why long continued practice between two States accepted by them as regullating their relations should not form the basis of mutual rights and obligations between States". ICJ Reports (1960), 39.

154. Dennoch gibt es Beispiele, worin Gesetzgeber durch eine schlechte Formulierung die staatsangehörigkeitsrechtlichen Bestimmungen einer fremden Staatsangehörigkeit mit zu regeln scheinen. Vgl. z.B. Art. 5 Abs. 1. WNed. in der Fassung von 1892: "De vrouw volgt staande huwelijk den staat van haren man", der inhaltlich iibereinstimmte mit Art. $19 \mathrm{Abs} .1 \mathrm{Cc}$ : "Une femme francaise qui epousera un etranger suivra la condition de son marie". Siehe Berber, 377; Dahm, 446; Dubois, 20-23; Dutoit, Jurisclasseur, Nr. 396; Fernández Rozas, 41; Kammann, 11; Ko Swan Sik, Preadvies, 6 und Fußnote 13; derselbe, Diss., 22; Makarov, 61-64; Menzel/1psen, 166; Verdross, Abgrenzung, 139, Wiederkehr, 11-13. Vgl. weiter auch die von Makarov, Allgemeine 
Lehren, 60, 61, in Fußnote 8 gegebenen seltenen Beispiele von Fallen, worin Staten die Regelung ihrer eigenen Staatsangehörigkeit durch einen fremden Staat als rechtlich relevant anerkannt haben.

155. Makarow, Allgemeine Lehren, 60 und Makarow, in Wörterbuch des Völkerrechts, 325; Makarov/von Mangoldt. Einleitung I, Rdnr. 7. Vgl. aber die Ausfiuhrungen von Ko Swan Sik, Preadvies, 16. Siehe weiter von Mangoldt, Anerkennung, 48-52.

156. Literaturhinweise bei Ko Swan Sik, Diss., 2, 3, 24. Siehe weiter Akehurst, 83; Berber, 377; Brownlie, 389-392; Brownlie, BYL 1963, 297; Völkerrecht DDR, 217. Bemerkenswert ist, daß3 die deutsclie Regierung auf Fragen des Vorbereitungsausschusses der Haager Kodifikationskonferenz folgendes geantwortet hat:

"The general principle that all questions relating to the acquisition or loss af a specific nationality shall be governed by the laws of the State whose nationality is claimed or contested should be admitted. The application of this principle, however, should not go beyond the limits at which the legislation of one State encroaches on the sovereignty of another. For example, a State has no power, by means of law or administrative act, to confer its nationality on all the inhabitants of another State or on all foreigners entering its territory. Further, if the State confers its nationality on the subjects of other States without their request, when the persons concerned are not attached to it by any particular bond, as, for instance, origin, domicile or birth, the States concerned will not be bound to recognize such naturalization".

Dies geschah allerdings im Jalure 1929. (League of Nations, Conference for the Codification of International Law, Basis of Diskussion I, Nationality (1929), V.1.13). Eine derartige Stellungsnahme der Regierung der Bundesirepublik Deutschland zum heutigen Zeitpunkt ist aus wohl verständlichen Grinden kaum zu erwarten.

157. Siehe zu dieser Problematijk Makarov/von Mangoldt, Einleitung unter V. Literaturhinweise findet man bei Hecker, Bibliographie, 75, 76 und Hecker, Materialien, 76-79. Auch gab Hecker in Recht in Ost und West 1987, 294-300 einen Uberblick der in der Literatur vertretenen Ansichten mit vielen Hinweisen auf neue Veröffentlichungen. Hecker (S. 294) weist darauf hin, daß sich bis 198572 Aufsätze und Bücher mit der Problematik der deutsch-deutschen Staatsangehörigkeit beschäftigt haben. Inzwischen dirfte die Zahl 100 iiberschritten sein. Siehe u.a. Bernhardt, EPIL, Bd. 8, 258-260; Blumenwitz, 27-39; Böckenförde, 423-463; Czaplinski, RCDIP 1984, 439-448; Fritsche 1981; Geiger, in Zieger/Meissner/Blumenwitz, 125-132; Hoffmann, Archiv fir Völkerrecht 1981, 257-286; Klein, NJW 1983, 2289-2292; Mampel, Recht in Ost und West 1983, 233-244; von Margoldt, Königsteiner Kreis 1985, 4-11; von Mangoldt, Revue de la recherche juridique 1987, 875-889; von Mangoldt, in: Das geteilte Deutschland, 234-253; von Mangoldt, Politik und Kultur 1981, 27-46; von Mangoldt, RCDIP 1986, 33-57; Rasch, Blätter für deutsche und internationale Politik 1985, 262-264; Röper, Der Staat 1987, 31-56; Stern, DVB1. 1982, 165-173; Wyduckel, in: Recht und Staat im sozialen Wandel, 663-686; Zieger 1971; Zieger, Auslegung der Ostvertäge, 85-145; Zieger, NJW 1984, 699-704.

158. Siehe dazu Makarow/vorin Mangoldt, Einfilhrung V.

159. JZ 1988, 144-150; StAZ $1988,78-82$ mit abweichender Meinung des Richters Niebler; der Entscheidung ist eine Ablelhnung des Urteils ohne Begriindung durch den früheren Prăsidenten des BVerfG Zeidler beigefügt. Vgl, zu den staatsangehörigkeitsrechtlichen Problemen beziglich dieser Entscheidung zustimmend Silagi, StAZ 1988, 64-71 und ablehnend Wyduckell, DVB1. 1988, 284-287. Siehe weiter die Urteilsbesprechung von Blumenwitz, JuS 1988, 607-613; Gusseck, NJW 1988, 1302-1306; Röper, DóV 1988, 488-500; Silagi, Recht in Ost und West 1988, 151-157 und Wengler, Recht in Ost und West 1988, 145-151.

160. Das BVerfG hat nicht ausgearbeitet, in welchen. Fällen der Erwerb der DDR-Staatsbiirgerschaft aus Grüinden des ordre public nicht den Erwerb der deutschen Staatsangehörigkeit bewirkt. Das Gericht betonte lediglich: "Im Zusammenhang des Staatsangehörigkeitsrechts bestimmen sich Inhalt und Wirkungsweise des ordre public in erster Linie aus den rechtlichen Grundwertungen eben dieses Rechtsbereichs und insbesondere aus dem Wiedervereinigungsgebot des Grundgesetzes. Der vorliegende Fall bietet keinen Anlaß, die Grenzen näher zu bestimmen, die der ordre public dem Erwerb der dentschen Staatsangehörigkeit zufolge des Erwerbs der Staatsbürgerschaft der Deutschen Demokratischen Republik zu ziehen vermag; im Falle des Beschwerdefithrers begegnet dieser Erwerb unter den Gesichtspunkten des ordre public der Bundesrepublik Deutschland keine Bedenken". 
161. Das Reichs- und Staatsangehörigkeitsgesetz 1913 (RuStAG).

162. So auch Grawert, Der Staat 1984, 193: "Der Umstand, daf auf diese Weise Menschen in Anspruch genommen werden, die auch die DDR als ihre Angehorige bezeichnet, ist völkerrechtlich gewiß unbedenklich, da zum fortbestehenden Deutschen Reiches -nochhinreichend anerkennenswerte Anknüptungsbindungen bestehen".

163. Dieser Terminus ist zwar in der deutschen Literatur uniiblich. Er wird jedoch u.a. benutzt von Böckenförde in seinem Beitrag in der Festgabe für Carl Schmitt, 2. Teilband, 423-463 (450 ff). Anders z.B. Geiger, 274.

164. Vgl. BVerfG wom 21. Oktober 1987, JZ 1988, 146" "Es tiberschreitet diese Grenzen nicht, wenn die Bundesrepublik Deutschland die Staatsbürger der Deutschen Demokratischen Republik als zun Kreis der deutschen Staatsangehörigen im Sinne des Grundgesetzes gehörend betrachtet, den damit gegebenen Status aber immer erst darnn aktualisiert, wenn diese in den Hoheitsbereich der Bundesrepublik Deutschland gelangen und die Aktualisierung hinnehmen oder begehren". Vgl. Kewenig, EA 1987, $517 \mathrm{ff}$.

165. Auch das BVerfG ist wohl dieser Ansicht. Vgl. den BeschluB vom 21. Oktober 1987, JZ 1988, 148: "Ausschlaggebend dafiir, daß es nicht dem allgemeinen Volkerrecht widerspricht, wenn für die Rechtsordnung der Bundesrepublik Deutschland die deutsche Staatsangehörigkeit im Sinne des Grundgesetzes auch die Staatsbüinger der Deutschen Demokratischen Republik auf die oben bezeichnete Weise umfasst ${ }_{\text {" ist indes }}$ der Umstand, daß die Spaltung Deutschlands nicht vom Selbstbestimmungsrecht des deutschen Volkes gedeckt ist. Vielmehr hält das deutsche Volk in seiner überwattigenden Mehrheit sowohl in der Bundesrepublik Deutschland als auch in der Deutschem Demokratischen Republik an dem Willen fest, die Spaltung Deutschlands auf friedliche Weise zu tiberwinden und die volle staatliche Einheit wiederherzustellen". Vgl. weiter Böckenförde, Festgabe für Carl Schmitt, 2. Teil band, 462, 463; Grawert, Der Staat $1984,193$.

166. Londoner Abkommen vom 19. April 1839, Stbl. 1839, 26.

167. Gesetz vom 4. Juni 1839, Bulletin Officiel $\mathrm{XIX}, \mathrm{Nr}$. 256; siehe weiter die Gesetze vom 20. Mai 1845 (Moniteur Belge vom 31. Mai 1845), 5. Juni 1850 (Moniteur Belge vom 7. Juni 1850), 30. Dezember 1853 (Moniteur Belge vom 1. Januar 1854), 1. Juni 1878 (Moniteur Belge vom 2. Juni 1878) und 1. Juni 1911 (Moniteur Belge vom 4. Juni 1919).

168. In Art. 15 Absatz 2 der Allgemeinen Erklarung der Menschenrechte sind zwei Schranken genannt, nämlich das Verbot der Zwangsausbürgerung und das Recht auf Ausbürgerung auf Wunsch. Donner, 178, 179; vgl. uber das Willkiirverbot Brownlie, BYIL 1963, 339-344; Geiger, 270; Hudson, YBILC 1952 11, 10; Kammann, 11; Kimminich, Völkerrecht, 141; Ko Swan Sik, Preadvies, 8; Lapradelle, Revue de droit international privé 1929, 311; Lessing, 73-94 (mit vielen weiteren Nachweisen); van Panhuys, 163; Scelle, Revue critique de droit international 1934, 68; Weis, 117-131; Wiederkehr, 15.

169. Nur jene Ausgebïrgerte, die nach dem 8. Mai 1945 wieder ihren Wohnsitz in Deutschland genommen hatten und nicht einen entgegengesetzten Willen zum Ausdruck gebracht haben, erwarben von rechtswegen die deutsche Staatsangehörigkeit zurtick (Art. 116 Abs. 2, Satz 2 GG). Vgl, in diesem Zusammenhang auch das spanische Gesetz vom 29. Dezember 1948 betreffend Einbirgerung von sephardischen Juden in Agypten und Griechenland, Boletin Oficiall del Estado yom 9. Januar 1949, 118 und Art: 22 Abs. 2 C.c.esp. Vgl. Geiger, 271, der die Verleihung der Staatsangehörigkeit des Mannes an die Ehefrau als notwendige Folge der Eheschließung ohne Rücksicht auf den Willen der Frau als unvereinbar mit der Menschenwirde betrachtet.

170. ICJ Reports 1955, 4 (23); Fontes iuris gentium, Series $\mathrm{A}$, sectio 1, tomus 5,81 .

171. Geiger, 270. Vgl. Elias, 128; Kammann, 11, 12.

172. Siehe: Randelzhofer, in EPIL, Bd. 8, 421: "The decision of the ICJ in the Nottebohm Case does not deal with the conferment of nationality in general, nor with the conferment of nationality by naturalization, but only with diplomatic protection as a consequence of conferment of nationality by naturalization. Many textbooks give the impression the Court had declared itself in favour of a general rule concerning the conferment of nationality, citing only the statement of the Court that nationality is a legal bound having as its basis a social fact of attachment, a genuine connection of existence, interests and sentiments." Vgl. dazu auch Maury, Zeitschrift für ausländisches und internationales Privatrecht 1958, 530. 
173. Vgl. Donner, 141, 442; Kammann, 12; Ko Swan Sik, Preadvies, 11, 12 und NILR 1982, 102; Ko Swan Sik, Diss., 55-57; Ko Swan Sik, International Law, 14; Kollewijn, 26, 51, 52; van Panhuys, 168-169. Anderer Ansicht: Merrils, ICLQ 1974, 152, 153. $\mathrm{Zu}$ der Problematik, ob der völkerrechtswidrige Staatsiangehörigkeitsentzug gegenuiber deutschen Juden anzuerkennen war: Lauterpacht, Jewish Yearbook of International Law 1948, $164 \mathrm{ff}$; van Panhuys, 116, 117; Parry, ZaóRV 1958, 366.

174. Vgl Weis; 123,241 .

175. Dies könnte insbesondere dann der Fall sein, wenn der negierende Stalat das New Yorker Staatenlosigkeitsabkonmen aus 1963 ratifiziert hat.

176. So auch Ko Swan Sik, Preadwies, 12.

177. Vergleiche allgemein zum Grundrechtschutz in Europa Mosler/Bemhardt/ Hilf; 1977; Bleckmann, EPIL, Bd. 6, 180; Schindler, EPIL, Bd. 7, 406; EuGHE 1969, 419 (12. November 1969, RS 29/69, Stauder) EuGHE 1970, 1125 (17. Dezember 1970, RS 11/70, Internationale Handelsgesellschaft); EuGHE 1974, 491 (14. Mai 1974, RS 4/73, Nold); EuGHE 1975, 1219 (28. Oktober 1975, RS 36/75, Rutili); EuGHE 1976, 497 (8. April 1976, RS 48/75, Royer); EuGHE 1978, 1365 (RS 149/77, Defrenne II); Bulletin der EG, Suppl. 5/76, "The Protection of fundamental rights in the European Community".

178. Siehen \& 1.4.3. Vergleiche aber auch die EntschlließBung des Europäischen Parlaments vom 20. Januar 1984 bezilglich Diskriminierung hinsichtlich der Ubertragung der Staatsangehörigkeit; EuGRZ 1984, 167, sowie die Resolution des Europäischen Parlaments vom 18. September 1981, ABI. EG 1981 C260/100.

179. Siehe $\$ 3.2 .1$ bis 3.4 .12 .

180. Vgl. auch Pescatore, 64-72. Dagegen spricht jedenfalls nicht, daß z.B. Großbritanniem und Frankreich bei der Unterzeichnung der Konvention zur Beseitigung jeder Form der Diskriminierung der Frau, New York 1979, UN Doc. A/Res./34/180, Annex, Vorbehalte bezüglich Art. 9 (Staatsangehörigkeit) gernacht haben. Soweit es Grobbritannien betrifft, handelt es sich lediglich um einen Vorbehalt bezüglïch Übergangstegelungen, Frankreich hat selbst den Vorbehalt bei der Ratifizierung der Konvention nicht mehr wiederholt, vielmehr inzwischen seine Gesetzgebung entsprechend angepasst (UN Doc. St./Leg./SER.F 1986, 30.12.1986) (vgll. auch den am 19. Dezember 1986 eingezogen Vorbehalt won Irlland). Die deutsche Übersetzang dieser Konvention: BGBI. $1985 \mathrm{II}, 647$.

181. Vgl. darüber auch Grabitz, 103-116; van den Berghe/Huber, 755-774; Evans, AJCL 1984, 679-715; Plender, European citizenship, 39-53. Allerdings sollte man beachten, daß3 unter dem Begriff "Europäissche Bürgerschaft" von den unterschiedlichen Autoren nicht immer dasgleiche verstanden wird: vgl. hierüber Van den Berghe/Huber, 755: "European citizenship is a concept which in the last few years has penetrated into the wocabulary of the European Communities. As a catchword it has since formed an increasing usage. However, what this label really covers is not always immediately clear and moreover its content still largely depends on the personal appreciation of the individual user". Vgl. zum Begriff des "Europas der Bǜrger" auch Magiera, Dơv 1987, 221 ff. und Magiera, Politische Rechte, $123 \mathrm{ff}$, sowie "Europa der Bürger" (Bericht des Ad-hoc-Ausschusses), EG-Bulletin, Beilage 7/1985. Siehe weiter der Bericht "Towards European Citizenship", Bulletin of the European Communities, Supplement 7/75 und das Kapitel "A citizen"s Europe" im Tindemans Bericht über eine "Europäische Union", Bulletin of the European Communities, Supplement 1/76; vgll. auch Böhning, 18,19 (der über eine "embryonic" European citizenship spricht); Fernández Rozas, 29; Garth, 105, 108-111; Lasok, 112 ("Indeed equality, it seems, can be achieved only through a common Community citizenship and the harmonization of the relevant legislation"); Ress, 329-331. Siehe Commission Report on the Implementation of Point 11 of the Final Communique Issued at the European Summit Held in Paris on 9 and 10 December 1974 (COM (75) 231 final) and Parliamentary Resolution of November 1977, C299/25, sowie EG-Gesamtbericht 18/1984, 27. Siehe auch Verwilghen, 71, 72 und Rigaux, Band 2, 33.

182. Siehe oben 1.3 .2 .

183. RaB1. $1870,355$.

184. RGBI. 1871, 87.

185. RGBi. 1913, 583 .

186. RGB1. 1934 I, 85 . 
187. Evans, AJCL 1984, 714: "... inaportant elements of European citizenship are to be found in existing Community law"

188. Van den Berghe/Huber, 756; Evans, AJCL 1984, 680, Vgl. über die (Un-)Möglichkeit einer Staatsangehörigkeit eines Staatenbundes: Makarow, Allgemeine Lehren, 31, 36, 37.

189. Siehe z.B. die Artikel 48-66 E.W.G.-Vertrag. Siehe weiter Regulation 1612/68, Richtllinie 68/360, Richtlinie 64/220 und Richtlinie 73/148. Vgl. Durand, European Law Review 1979, 3-14; Evans, Modern Law Review 1982, 497; Gillian White, Current legal problems $1977,141-158$.

190. Vgl. Plender, European citizenship, 40: "Only twelve years after the conclusion of the Treaty of Rome, the Vice-President of the Commission discerned in the articles governing free movement of labour not merely an economic purpose but "an incipient form ... of European citizenship". (Bulletin of the European Communities, Bd. 1, Nr. 11 (1968), 5-6). Vgl. Evans, Modern Law Review 1982, 499-501.

191. Wie übrigens auch die Einfilhnung eines Europå̉ischen Passes; vgl. Plender, European citizenship, 60 mit Hinweis auf Implementation of Point 10 of the Final Communiqué Issued at the European Summit Held in Paris on 9 and 10 December 1974 Concerning a Passport Union, COM (75) 322 final, 7, 23. Siehe auch Cansacchi di Amelia, 731: "L'espressione "cittadinanza europea" viene cosi ad indicare uno status giuridico particolare dei cittadini degli Stati-membri ...".

192. Siehe füir weitere Folgen Evans, AJCL 1984, 689-714.

193. Vgl. Van den Berghe/Huber, 756, 757: "Although the competence of giving a definition of the purpose of this concept (i.e. "national of a Member State"; d.G.) in Community law rests with the institutions of the Community, it may be assumed that this concept rellates at any rate to persons, who, according to the law of different Member States have the nationality of one of these Member States". Siehe Plender, European citizenship,, 41.

194. Bleckmann, CMLR "1978, 435-446; Perez Vera, Revista de instituciones Europeas 1981, 685-703; Evans, Yearbook of European law 1982, 174-189; Fernández Rozas, 28030 .

195. Erklärung der Bundesregierung bei der Unterzeichnung des EWG-Abkommens am 25. März 1957. Siehe Treaties establishing the European Communities, Office for Official Publications of the European Communities 1978, 573. Dazu Bleckmann, CMLR 1978, 435; Oliver, 60 .

196. Erklärung der Regierung won GroBbritannien und Nord-Irland bei der "Final Act concerning the accession of the new Member States to the Treaties signed on 22. Januar 1972"; siehe ABI. (EG) 1972 L 73/196; BGBI. 1972 II, 1410. Dazu Oliver, 60 mit weiteren Literaturhinweisen in Fußnote 14: Plender, European citizenship, 42-45. Wegen des Inkrafttretens des British Nationality Act 1981 wurde eine neue Erklärung abgegeben, Cmnd. 9062. Dazu Simmonds CMLR 1984, 675-686.

197. Evans, AJCL 1984, 679-715, siehe auch Evans, Modern Law Review 1982, 512-515.

198. Dariber \& 2.4.1.

199. Evans, AJCL 1984, 688, Fußnote 56 schreibt hieriber "This seems to be recognized by the UK government in that the redefinition of UK Nationality for Community purposes felt to be necessitated by passage of the British Nationality Act 1981 was said to be matter "subject to discussions with the Community" ". Vgl. uber die europarechtliche Komplikationen anläBlich des BNA 1981: Hartley, RCDIP 1983, 580; Macdonald/Blake, 75, 77; von Mangoldt, StAZ 1983, 221; Simmonds, CMLR 1984, 675-686; White/Hampson, ICLQ 1982, 850.

200. Evans, AJCL 1984, 688: "Moreover, it is not clear whether inclusion in such a definition of persons lacking the necessary connection would constitute a violation of Community law or whether other member states would simply be absolved from the obligation to recognize such persons as nationals of the member state concerned for Community purposes ...".

201. In Spanien können Bürger lateinamerikanischer Staaten wesentlich schneller als andere Personen eingebiirgert werden. Siehe $\$ 2.9 .3 .2$.

202. Evans, Yearbook of European Law 1982, 189, schreibt, daß die Probleme in Zusammenhang mit dem neuen British Nationality Act 1981 konsequenterweise dazu fuhren, daß iber die Frage nachgedacht werden sollte, ob eine Harmonisierung der Staatsangehörigkeitsregelungen der Mitgliedstaaten nicht wünschenswert ist. In diesem Zusammenhang verweist er ubrigens auch auf die Resolution des Europalischen Parla- 
ments: won 18. September 1981, ABI. EG 1981 C 260/100, wo eine solche Harmonisierung schon befirwortet wird, um zu vermeiden, daß Personen innerhalb der Gemeinschaft staatenlos geboren werden. Vgl, auch Ewans, Scots Law Times 1981, 133-137.

203. Oliver, 59

204. Vgl. Bleckmann, CMLR 1980, 467, 477; Evans, Yearbook of European Law 1982, 173, Oliver, Yearbook of European Law 1985, 59.

205. EuGRZ 1984, 167.

206. Siehe Schwarze/Bieber, 582; vgl. bereits Mansholt am 19. April 1972 (P.E. Deb., Mir. 149, 107), dazu Evans, Modern Law Review 1982, 506, 507.

207. Vgl. namentlich Hecker, Melurseitige Verträge und Hannappel.

208. Resolution 217A (III) der Generalversammlung der Vereinten Nationen, United Nations General Assembly Official Records 3rd Session, Resolutions part 1, 71; deutsche Übersetzunig bei Sartorius II, Nr. 19; dariiber Marescaux, 18-24.

209. Resolution 1386 (XTV) der Generalwersammiung der Vereinten Nationen von 20. November 1959; dariber Marescaux, 30-33; Verwillghen, 3, 4.

210. UNTS Bd. 999, 171; BGB1. II, 1533; Trb. 1975, 60 Vertragssig. AA Bd. 50 A 683; dartiber Marescaux, 24-30; Verwilghen, 4.

211. UNTS Bd. 660, 195; BGB1. 1969 II, 961; Trb. 1966, 237; Vertragssig. AA Bd. 35 A 469.

212. Vgl. in dieser Zusammenhang auch Art. II, Buchstabe c des Internationalen Abkommen uber die Bekämpfung und Alnndung des Verbrechens der Apartheid wom 30. November 1973, UNTS Bd. 1015, 243.

213. In dieser Zusammenhang soll auch hingewiesen werden auf Art. 20 der Amerikanischen Menschenrechtskonvention (Pact of San José) vom 22. November 1969 (Organisation of American States, Official Records OEA/Ser. K/XVI/L.I, Document 65, Rev. 1 , Corr. $2 *$ deutsche Ubersetzung in Europäische Grundrechte-Zeitschrift 1980, 435). Abs. 1 von Art. 20 betont, wie Art. 15 Abs. 1 Allgemeine Erklärung der Menschenrechte, daß jede Person Anspruch auf eine Staatsangehörigkeit hat. Abs. 3 bestimmt, wie Art. 15 Abs. 2 Allgemeine Erklärung, daß3 niemandem seine Staatsangehörigkeit oder das Recht, diese zu wechseln, willkitrlich entzogen werden darf. Interessant ist aber vor allem Abs. 2, worin bestimmt wird, daß jede Person Anspruch hat auf die Stmatsangehörigkeit des Staates, auf dessen Territorium sie geboren wurde, falls sie keinen Anspruch auf irgendeine andere Staatsangehörigkeit hat.

214. United Nations General Assembly Official Records, 34th Session, Resolutions, 194; deutsche Ubersetzung in BGB1. $1985 \mathrm{II}$, 647. Uber die staatsangehörigkeitsrechtliche Bestimmung aus dieser Konvention Marescaux, 64-66.

215. UNTS Bd. 189, 137; BGB1. 1953 II, 559; Trb. 1966, 197; Vertragsslg. AA Bd. 3 A 28; dariber Marescaux, 35-46. Siehe fuir die Reichweite dieses Abkommens auch das Protokoll über die Rechtsstellung der Flüchtlinge vom 31. Januar 1967, BGB1. 1969 II, 1293; Trb. 1967, 76.

216. UNTS Bd. 360, 117; BGBL 1976 II, 473; Trb. 1955, 42 (1967, 22); Vertragssig. AA Bd. 53 A 701; dariber Marescaux, 46-51.

217. LNTS Bd. 179, 89; deutsche Übersetzung bei Hecker, Mehrseitige Verträge, 15-20 (nach Crusen, 1033-1035); niederländische Ubbersetzung Stbl. 1937, 17, 4-54 und Trb. 1967, 73; dazu u.a. Dutoit, Europa, 315-319; Scott, 6-91. Vgl. das lateinamerikanische Staatsangehörigkeitsabkommen von Montevideo vom 26. Dezember 1933, woríber u.a. Dutoit, Jurisclasseur, 9, 10. Siehe Guerrero (Paris 1930) und Lichter, StAZ 1956, 281-286.

218. LNTS, Bd. 178, 227; Trb. 1967, 75.

219. LNTS, Bd. 179, 115; Trb 1967, 74.

220. Text abgedruckt bei Hecker, Mehrseitige völkerrechtliche Verträge, 27.

221. Text abgedruckt bei Hecker, Mehrseitige völkerrechtliche Verträge, 28, 29.

222. UNTS, Bd. 309, 65; BGBl. 1973 II, 1249; Trb. 1965, 218; Vertragssig. AA Bd. 45 A 616; dariber Marescaux, 57-62. Über die Konvention von 1957: Nationality of Married Women, Report submitted by the Secretary-General, United Nations, Commission on the Status of Women, New York 1950; siehe auch: Convention on the nationality of married women, historical backgrounds, United Nations, Department of Economic and Social Affairs, New York 1962. Vgl. auch die lateinamerikanische Konvention von Montevideo vom 26. Dezember 1933, woriber u.a. Dutoit, Europa, 319-323* Dutoit, Jurisclasseur, 11; Fernández Rozas, 51, 52. 
223. UNTS, Bd. 989, 175; Trb. 1967, 124; BGBL. 1977 II, 597; Vertragsslg. AA Bd. 54 A 721; uber die New Yorker Konwention von 1961 Marescaux, 52-47; vgl. weiter

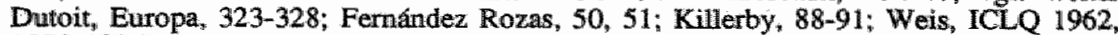
1073-1096.

224. UNTS, Bd. 500, 241; BGB1. 1964 II, 1006; Trb. 1984, 108; Vertragsslg; AA Bd. 22 A 260; dariiber Marescaux, 66-69.

225. UNTS, Bd. 596, 469; BGB1. 1969 II, 1674; Vertragsslg. AA Bd. 40 A 543; dariber Marescaux, 69, 70.

226. Trb. 1974, 32; BGB1. 1977 II, 597, 613; Vertragsslg. AA Bd. 54 A 717.

227. UNTS Bd. 932,81 ; Trb. 1965,91 .

228. Vgl. Makarov, ZaöRV 1973, 110-118.

229. UNTS Bd. 634, 221; Trb, 1964, 4; ETS, No, 43; BGB1. 1969 II, 1953; Vertragsslg. AA Bd. 36 A 483. Uber die Bekämpfung der mehrfachen Staatsangehörigkeit handelte auch Empfehlung 164/1958 der Beratenden Versammlung des Europarates. Siehe Killerby, 79-83.

230. Im Jahre 1954 hat im Rahmen der Vereinten Nationen auch die International Law Commission sich mit der Problematik der mehrfachen Staatsangehörigkeit beschảftigt, aber ohne Ergebnis (vgl. Report of the International Law Commission, 3 June - 28 July 1954, S. 8,39 ).

231. In Spanien wurde bereits seit einigen Jahren darüber diskutiert, ob Spanien diesem Abkommen zutreten soll; dazu sehr kritisch Fernández Rozas, 59-61 und 215.

232. Trb. 1981,45 .

233. Trb. $1981,46$.

234. UNTS Bd, 634, 255; Trb. 1964, 4; BGB1. 1980 II, 1093; Vertragssilg. AA Bd. 59 A 770; dariiber Killerby, 78 .

235. Dariiber Makarov, ZaöRV 1973, 108-124; Hannappel, 68-111; Killerby, 73-92.

236. Hannappel, 68, 69; vgl. auch Empfehlung 564 (1969) abgedruckt bei Hannappel, 76-78 und Empfehlung 696 (1973), abgedruckt bei Hannappel, 79-81. Siehe hieriber Makarov, ZaöRV 1973, 118-121.

237. Hannappel, 76-78; vgl. auch wieder Empfehlung 696 (1973), abgedruckt bei Hamnappel, 79-81. Siehe weiter Empfehlung 984 (1984) der Parlamentarischen Versammlung (Hannappel, 86, 87) und Entschließung (84) 21 des Ministerkommittees (Hianappel, 97), die im wesentlichen die Forderungen der Empfehlung 564 (1969) wiederholen. Siehe schließlich auch Entschließung (83) 1, betreffend staatlose Nomaden und Nomaden mit unt-lärter Staatsangehörigkeit.

238. Hannappel, 70-71, siehe hieriiber Makarov, ZaöRV 1973, 121-124.

239. Der Text dieser Resolution ist auch abgedruckt bei Hannappel, 89 und Killerby, 76. Vgl. Empfehlung 696 (1973) der Parlamentarischen Versammlung, abgedruckt bei Hannappel, 79-81.

240. Der Text dieser Resolution ist auch abgedruckt beil Hannappel, 90 und Killerby, 77 , 78. Vgl. weiter Killerby, 84; siehe auch bereits Empfehlung 696 (1973) de Parlamentarischen Versammlung, abgednuckt bei Hannappel, 79-81.

241.

242.

243.

244.

Siehe Killerby, 86, 87. Die ganze Empfehlung ist abgedruckt bei Hannappel, 82-85.

Killerby, 87.

Hannappel 1 93-96.

So auch die Mehrheit einer "European Council Committee of experts on the naturalization of migrant workers and members of their families and questions of dual nationality" in einer "draft of a final activity report" aus April 1985: "According to the majority, many permanently settled immigrants have a dual national identity, and it would not seem inappropriate that they should, if they wish, be allowed to acquire a dual nationality also. .... The majority of the Committee of experts invites member states to re-examine the traditional objections to dual nationality and to consider a possible modification of their legislation and practice in this mattex" (zitiert bei Hammar, 14, 15). Siehe nun auch: Rapport final d'activité adopté par la réunion d'echanges de vues sur la double nationalite (15-18 mars 1988) à l'attention du Comite européen de Coopération juridique pour sa $49 e ̀ m e$ réunion du 2 au 6 mai 1988:

"20. A l'issue de cet échange de vues, le Président a procédé à un vote sur la question ci-après: êtes-yous en faveur d'un examen plus approfonidi au sein d'un Comite d'experts du Conseil de l'Europe de la question de savoir si on peut permettre la double nationalité des conjoints de nationalités différentes et de leurs enfants? Tous les 
experts participants à la révnion se sont déclarés favorables à un tel examen, a l'exception de l"expert de la République Fédérale d'Allemagne qui s"est abstenu

26.A l'issue de cet echange de vues, le Président a procéde à un vote sur la question ci-après: êtes-wous en faveur d'un examen plus approfondi au sein d'un Comité d'experts du Conseill de l'Europe de la question de sawoir si l'on peut permettre aux migrants de la deuxième génération d'acquérir la nationalité du pays d'accueil sans avoir a renoncer a leur nationalité antérieure? Tous les experts participant à la réunion se sont prononcés en faveur d'un tel examen.

27. En ce qui concerne le mandat spécifique du Comite d'experts a créer pour examiner les deux questions qui ont fait l'objet de l'échange de vues, le Président a propose que ce mandat soit elargi afin de permettre audit Comite d'experts d'examiner également les problèmes de double nationalité relatifs a d'autres groupes que ceux des mariages mixtes et des migrants de la deuxième génération.

28. Cette proposition a fait l'objet d'un vote: 8 experts se sont prononcés en faveur de la proposition et 8 experts se sont prononcés contre. En raison de cette diwergence d"opinions et compte tenu du fait que le mandat spécifique devra être approuvé par le CDCJ et pourrait même, le cas échéant, être élargi par la suite, les experts sont convenus de limiter le mandat proposé aux deux cas qui ont fait l'objet des discussions pendant la réunion."

245. Erwähnenswert ist aber die Resolution des Europäischen Parlaments von 18. September 1981, ABI.1981 C260/100, wo anläßlich der Diskussion uber die BNA 1981 eine Harmonisierung befuirwortet wurde um zu vermeiden, daß Personen in der Gemeinschaft staaterlos geboren werden. Siehe weiter 1.4.2.

\section{NOTEN BELGIEN}

1. Veröffentlicht im Belgisch Staatsblad (Moniteur Belge) vom 12. Juli 1984, Nr. 134, 10.095-10.114. Das. "Wetboek van de Belgische nationaliteit" (Code de la nationalité belge) ist Teil eines Gesetzes uber einige Aspekte der Position von Ausländern (Loi relative a certains aspects de la condition des etrangers et instituant le Code de la Nationalité belge). Das neue Staatsangehörigkeitsrecht ist enthalten in Art. 13 dieses Sammelgesetzes. Durch den Art. 14-20 (Anderungsbestimmungen) wurden mehrere Gesetze an das neue Gesetzbuch angepasst. Von Art. 21 wurden verschiedene, vor allem staatsangehörigkeitsrechtliche Gesetze und Verordnungen aufgehoben. Vgl. aber Art. 26-30 des Gesetzbuches für Übergangsbestimmungen (woriber Verwilghen, 467-476). Uber das neue Staatsangehörigkeitsrecht Belgiens weiter: Beauthier, 190-233; Brinkman, PS 1985, 35-37; Closset, in: Jurisclasseur "Nationalité" (Kapitel Belgien); Heyvaert; Hobin, TVR 1984, 146-153; Lienard-Ligny, Ann. Fac. Dr. Liege 1985, 195-236; Lienard-Ligny, Belgisch tijdschrift voor international recht 1984/85, 649-671; Marescaux/Taverne, Journal des Tribunaux 1984, 625-636; Phillippary/Stroobants; De Valkeneer, Revue du notariat belge, 1984, 389-419.

2. In diesem Buch wird dieses Gesetzbuch jeweils abgekirzt als CNB.

3. Art. 22 des Gesetzes vom 28. Juni 1984 bestimmte, daß der CNB an einem năher za bestimmenden Tag in Kraft treten wirde. Dies geschah durch Königlichen Beschluß (arrêté royal) vom 18. Juli 1984, veröffentlicht in Moniteur Belge (Belgisch Staatsblad) wom 4. August 1984, 11.034-11.035. Ministerielle Rundschreiben betreffend das netre Gesetzbuch wurden verơffentlicht im Moniteur Belge (Belgisch Staatsblad) vom 14. August 1984, 11.477-11.482 (Rundschreiben vom 6. August 1984) und im Moniteur Belge (Belgisch Staatsblad) vom 5. Dezember 1984, 15.440 (Rundschreiben vom 27. November 1984), Vgl. dariber Verwilghen, 131-136. Im Anhang seines Buches gibt Verwilghen die "Texte des Gesetzbuches und der Rundschreiben wieder. Verwilghen, 134 weist darauf hin, dab die Rundschreiben zwar keine Gesetzeskraft haben, aber wegen der Tatsache, daß sie für die Behörden verbindliche Richtlinien enthalten, bedeutsam sind. Für die Gerichte sind sie aber nicht verbindlich.

4. Art. 65 der Wiener Kongreßakte von 1815; vgl. Art. VI des 1. Pariser Friedens von 1814.

5. Dischler, 9; Krombach, 42; Verwilghen, 20; vgl. auch Closset, Traite, 29.

6. Closset, Traite, 28, 29, Hecker, Code Napoléon, 97; Dischler, 10-13. 
7. Die staatsangehörigkeitsrechtlichen Bestimmungen des Code civil (Buch 1, Titel 1) traten am 18. Màrz 1803 in Kraft. Die friheren belgischen Bestimmungen bezüglich der Staatsangehörigkeit wurden mit Rulckwirkung ab 8. Mär 1803 aufgehoben. Vgl. Verwilghen, 18. Fußnote 6.

8. Siehe Gerbenzon/Algra, 203.

9. Das nie eingefihihte Ziwilgesetzbuch von 1830 enthielt staatsangehörigkeitsrechtliche Bestimmungen in den Art. 5-13. Das Gesetz war zweisprachig (niederlaindisch-französisch). Bemerkenswert ist, $\mathrm{daB}$ dort wo der niederländische Text von Niedierländern spricht, der französische Text von "Belges" spricht. Nach der Unabhängigkeit Belgiens wurde das Zivilgesetzbuch von 1830 in abgeänderter Form - und nur in niederlàndischer Fassung - im Jahre 1838 als Ziwilgesetzbuch der Niederlande (Burgerlijk Wetboek) eingefiihrt.

10. In deutscher Übersetzung bei Dischler, 100. Art. 9 Code civil wurde von dieser Verfassung aufgehoben.

11. Closset, Traite, 28, 29; Dischler, 13; Verwilghen, 20.

12. Die Art. 4 und 5 gelten noch immer in ungeänderter Form; Art. 133 - eine Uber-

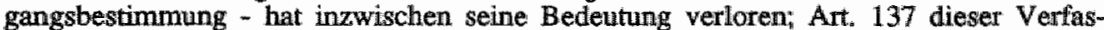
sung hob die niederländische Verfassung für Belgien am 22. Februar 1831 auf und führte Art. 9 Code civil wieder ein; am 10. Oktober 1830 war durch Beschlu $B$ der vorläufigen Regierung das "indigenat" am Wohnsitz in Belgien geknuipft werden. Closset, Traite, 30, 31, 34; Dischler, 13; Verwilghen, 5, 6, 20,21; de Visscher, 19.

13. Closset, Traité, 30; Dischler, 14; Verwilghen, 21 .

14. Über die "Erstabgrenzung" der belgischen Staatsangehörigkeir Closset, Traité, 29-31; Dischler. 14 ff; Ko Swan Sik, International Law, 29-31; Krombach, 42-45, Verwilghen, 22-24.

15. Closset, Traite, 30; Dischler, 14-16; Verwilghen, 22, 23, vor allem Fubnoten 17 und 20.

16. Verwilghen, 19 weist darauf hin, daß dieses grundsätzliche ius sanguinis ein starker Bruch mit der belgischen Tradition war. Er betont weiter, daß das Ablehnen des ius soli unter dem Einfluß $\beta$ des Tribunats gegen die Vorschläge des Ersten Konsuls geschah.

17. Gesetz vom 16. Juli 1889, Moniteur vom 16/17. August 1889, Pasinomie 1889, Nr. $240,313$.

18. Obwohl dies nicht ansdrücklich aus dem Gesetzestext hervorging. Dischler, 10, 77; Duranton, 31.

19. Moniteur vom 18. August 1881; Pasinomie 1881, Nr. 298, 382; dariuber Closset, Traité, 30; Dischler, 10; Verwilghen, 22.

20. Bulletin officiel, Nr. LII; Pasinomie 1835, Nr. 647, 285-290" siehe weiter Laurent $I_{\text {, }}$ 456-458; Duranton, 30, 31, wo auch der Text des Gesetzes abgedruckt ist.

21. $\quad$ Art. 2 des Gesetzes vom 22. September 1835.

22. Art. 5 des Gesetzes vom 22. September 1835.

23.

24.

25.

26.

27.

Moniteur vom 24. Juni 1865; Pasinomie 1865, Nr. 157, 171.

Moniteur vom 9. August 1881; Pasinomie 1881, Nr, 280, 362

Art. 3 des Gesetzes vom 6. August 1881 .

Art. 2 des Gesetzes vom 6 . August 1881 .

Moniteur vom 17. Juni 1909, Pasinomie 1909, Nr. 137, 112-157. Siehe dazu Otto, Brussell 1911 .

28. Siehe Closset, Traite, 31; Dischller, 19; Verwilghen, 25, schreibt dazu: "Mais le legislateur, Dieu sait pourquoi, ne profite pas de l'occasion pour revoir l'ensemble de la matière".

29. Neutral-Moresnet, PreuBisch-Moresnet, sowie Eupen und Malmedy.

30. Worüber Closset, Traité, 104-106; Dischler, 46-51; Krombach, 46-49; siehe auch Verwilghen, 27, vor allem Fußnote 35. Siehe für Fundstellen der einschlagigen Gesetze vor allem: Hecker, Europa, 14, 23, 24, 27, 28.

31. Moniteur vom 25. Mai 1922; Pasinomie 1922, Nr. 157, 97-131.

32. Closset, Traite, 32; Dischler, 25 ff; Verwilghen, 27, 28; siehe auch Closset, in: Verwilghen, Nationalite, 331,332 .

33. Die Gesetze vom 4. August 1926, (Moniteur vom 9/10 August 1926; Pasinomie 1926, Nr. 381, 837), 30. Mai 1927 (Moniteur vom 7. Juni 1927. Pasinomie 1927, Nr. 230, 223) und 15. Oktober 1932 (Moniteur vom 4. Dezember 1932; Pasinonie 1932, Nr. $467,518-526)$. 
34. Moniteur vom 17. Dezember 1932, Pasinomie 1932, Nr. 538, 559-562; siehe dazal Standaert; die Änderungen, die seitdem stattgefunden haben, sind erwahnt bei Eraww/de Foer, 71, siehe auch 76, 77.

35. Wo hier uber das Gesetz von 1932 gesprochen wird, mul bericksichtigt werden, dab die meisten Bestimmungen - wie bereits erörtert - schon seit 1922 galten; iber dieses Gesetz Closset, Traité, 57-134; Dischler, $25-44$.

36. Verwilghen, 49 , betont, daß es sich hier nicht um ein reines ius soli handelt, sondern eher um ein prâsumiertes ius sanguinis. So auch Closset. Traité, 60 ("filliation présumee") und Dischler, 28 (mit Hinweis auf die in der Pasinomie 1922, 124 veröffentlichten Motiven).

37. Diese Möglichkeit war vor allem relevant fitir die Kinder einer belgischen Frau, die durch Ehe mit einem Auslănder ihre Staatsangehörigkeit verloren hatte.

38. Oder Witwer oder geschiedenen Ehemann einer gebïrtigen Belgierin, von der er Nachkommen hat.

39. Closset, Traite, 93; Dischler, 29-32.

40. Closset, Traite, 110-129; Dischler, $37-43$.

41. Im Falle der Dienstpflichtigkeit war fir die Verzichtserklärung allerdings die Zustimmung des Konigs notwendig.

42. Moniteur vom 5. August 1934; Pasinomie 1934, 248.

43. Boshowers, 47-51; Closset, Traite, 122-129; Dischler, 39-43; De Man, 9-18.

44. Erlaß vom 6. Mai 1944, Moniteur vom 2. September 1944; Pasinomie 1944, 30.

45. Erlaß vom 1. Juni 1944 (Moniteur vom 5. August 1944; Pasinomie 1944, 54); Erlaß über die Anerkennung der belgischen Staatsangehörigkeit vom 20. Juni 1945 (Moniteur vom 24. Juni 1945; Pasinomie 1945, 507); Gesetz wom 5. Februar 1947 betreffend die Stellung der Ausländer, die politische Gefangene waren (Moniteur vom 15. Februar und 9/10. Juni 1947; Pasinomie 1947, 80).

46. Siehe Verwilghen, 35, 36 mit genauen Hinweisen; vgl. weiter Hecker, Europa, 18, 19

47. Moniteur vom 16/17. Februar 1953; Pasinomie 1953, 81. Bemerkenswert ist die Tatsache, daß in diesem Falle sowohi die belgische Staatsangehörigkeit des: Adoptivvaters alls auch die der Adoptivmutter erheblich war. Siehe Verwilghen, 58.

48.

49.

50. 51. Moniteur vom 12. April und 4. Juli 1969; Pasinomie 1969, 194; Closset, Traite, 57; Moniteur vom 24. Mărz und 24. April 1964; Pasinomie 1964, 329, 330.

Moniteur vom 15. Aprill und 19. Mai 1965; Pasinomie 1965, 479. Beil dieser Gesetzesändlerung wurde die Gleïchberechtigung der Geschlechter im Hinblick auf die

52. Documents parlementaires (Chambre des représentantes) $915(1970-71)-1$ bis $4 ; 222$ (1971-72) - 1 bis 6. Zu diesem Entwurf sind mehrere Änderungsworschläge gemacht. Der JustizausschuB berichtete über den Entwurf und machte einen alternativen Entwurf. Genaue Angaben finden sich bei Verwilghen, 102, 103, insbesondere Fußnote 2; Ygl. Saens, Jura Falconis 1982/83, 542.

53. Tellweise abgedrickt bei Erauw/de Foer, 77, 78.

54. Verwilghen, $98,103,104$.

55. Siehe z.B. Documents parlementaires (Sénat) 1982/1983, Nr. 430-1 (Entwurf Petry); Documents parlementaires (Chambre des représentantes) 1982/1983, Nr. 478-1 (Entwurf Dhovre/Lienard). Dartber ausfuhrlich mit weiteren Nachweisen, Saens, Jura Falconis 1982/83, 542-555 und Verwilghten, 105-118* vgl. auch Vanderveeren, Jura Fallconis $1982 / 83,557-592$.

56. Documents parlementaires (Chambre des représentantes) 756 (1983-84) 1 bis; ausführliche Daten uber das Zustandekommen des neuen Gesetzes bei Verwilghen, 118-1130; siehe auch Verwilghen, Nationalite, 351-423.

57. Verwilghen, 137; Documents parlementaires 756-1 (Chambre des représentantes) (17. Oktober 1983), 13-18. Verwilghen, 143 bedauert, das im neuen Gesetz nicht auch u.a. das Beweisrecht beziglich der Staatsangehörigkeit und die Materie der Staatsangehö-
rigkeitsnachweise geregelt wurden.

58. Motiven, Documents parlementaires (Chambre des représentantes) 1983-1984, Nr. $756-1,14$ und $20 ;$ Nr. 756-21, 13; Beauthier, 195; Heywaert, 11-15; Lienard-Ligny,
Belgisch tijdschrijt voor internationaal recht, 1984/85, 656-670; Lienard-Ligny, Ann.
Fac. Dr. Liege 1985, 196-201. Vgl, aber oben FuBnote 16 . 
60. Art. 9 Code civil unterschied nicht zwischen ehelichen und nichtehelichen Kindern. Diese Unterscheidung wurde aber in der juristischen Literatur entwickelt und durch spätere gesetzliche Bestimmungen expliziert, siehe Verwilghen 60 und in der alleren Literatur Marcade, Band 1, 95; vgl. weiter FuBnote 63.

61. Literaturhinweise in Fußnote 10.

62. Oben \& 2.1 .1

63. So auch bereits Cour de cassation 24. Mai 1904, Pasicrisie I, 244, zitiert bei Closset, Traité, 31; auch in der franzósischen Literatur des 19. Jahrhunderts wurde diese These vertreten: siehe z.B. Zachariae von Lingenthal/Dreyer, 206, Fußnote 1 mit weiteren. Literaturhinweisen.

64. Oben \& 2.1 .1

65. Auch in der niederländischen Periode (1815-1830) galt ius soli alls subsidiăres Kriterium. Siehe Verwilghen, 50.

66. Dischler, 10.

67. Sie dazu auch Colette Baumann, 158-159.

68. Im übrigen wurde das ius soli als "vestige de la féodalite" abgewiesen. Vgl. Colette Baumann, 159-162 und Verwilghen, 50 mit weiteren Hinweisen.

69. Hobin, TVR 1987, 166; Verwilghen; 260, 261.

70. Entscheidung vom 13. Juni 1979 (die sogenannte Marckxentscheidung), deutsche Übersetzung in NJW $1979,2449$.

71. Moniteur vom 27. Mai 1987, 8250-8270. Siehe auch "Loi modifiant diverses dispositions légales relatives à l'adoption" vom 27. April 1987, Moniteur vom 27. Mai 1987. 8270-8273 und "Loi relative à l'abandon d'enfants mineurs" vom 20. Mai 1987, Moniteur vom 27. Mai 1987, 8274-8276.

72. Siehe zu der Rechtslage unmittelbar vor Inkrafttreten der nenen Regelung VoB, IPRax 1986, 120-124. Dazu Senaeve, Tijdschrift voor familie- en jeugdrecht 1987, 179-188.

73. Dazu Pintens, StAZ 1988, 20-25.

74. Falls vor dem achtzehnten Lebensjahr erwiesen wird, dab das Kind eine - dauerhafte andere Staatsangehörigkeit besitzt, fällt die belgische Staatsangehörigkeit wieder weg. Man berücksichtige aber Art. 17 .

75. Im Parlament wurde die Frage gestellt, ob die Tatsache, daßs bei Auslandsgeburt regelmäßig eine Erklärung des belgischen Elternteils notwendig ist, nicht faktisch eine ungleiche Behandlung der (belgischen) Frau darstellt. Diese Frage wurde jedoch verneint. Siehe Verwilghen, 145, 146 mit weiteren Hinweisen.

76. Diese Regelung des Art. $8 \mathrm{CNB}$ soll Falle von Doppelstaatlichkeit beschränken. Die belgische Staatsangehörigkeitsgesetzgebung möchte der Bipatridie möglichst voubeugen. Dieses Ziel wurde nun von einem Mitglied des Parlaments angezweiffelt. Siehe Verwilghen, 156, namentlich Fußnote 71.

77. Heywaert, 22, 23; Hobin, 147; Verwillghen, 283. Bemerkenswert ist, daß der Widerruf der Adoption keinen Verlust der belgischen Staatsangehörigkeit bewirkt, auch nicht, wenn das Adoptivkind noch jïnger als achtzehn Jahre ist. Vgll. Documents Parlementaires 1983/1984, Nr. 756-21, 104; worliber Smet, 19, 20.

78. Beauthier, 198; Hobin, 147.

79. Man bericksichtige aber Art: $17 \mathrm{CNB}$.

80. - Daríber Beauthier, 199, 204; Heyvaent, 26; Verwilghen, 293-297.

81. Oben 2.1.1; Verwilghen, 358 .

82. Oben 2.1 .1 .

83. Dischler, $34,35$.

84. Closset, Traité, 85-88; Dischler, 35, 36; Verwilghen, 359-362.

85. Diese Voraussetzung wurde vom Gesetz des 15. Mai 1922 introduziert; wohl als Reaktion auf die sogenannte Lex Delbriick ( $\$ 25$ des deutschen RuStAG). Siehe Closset, Traite, 77-79 und 85; Dischler, 36 und Verwilghen, 62-65; vgl. kritisch Lienard-Ligny, Belgisch Tijdschrift voor internationaall recht 1984/85, 661, 662.

86. Dariber z.B. Closset, Traité, 81: "L'idonéité doit comprendre le loyalisme, la sincérité et la moralité de l'intéresse.... . Mais les tribunaux ne pourraient empiéter sur le terrain des convictions politiques et philosophiques qui sont garanties par la liberté d"opinion; mais peuvent être retenus des faits certains qui, quoi que se rattachant aux convictions politiques de l'intéressé, đémontrent que l'attachement a la patrie belge n'est ni réel, ni sincère"; vgl. Smet, 25.

87. Verwillghen, 162.

88. Verwillghen, 163-166. 
89. Verwilghen, 337.

90. Closset "Traite, 93 ff: Verwilghen, 59 .

91. Closset, Traite, 71, 72 .

92. Daruber sehr kritisch Beauthier, 218 und Verwilghen, 53-55. Beide beurteilen die Unterscheidung als iberholt,

93. Beauthier, 217 weist darauf hin, daB sogar diejenigen, die die grobe Einbïrgenng erlangt haben, noch richt in jeder Hinsicht gebuirtigen Belgiem gleichgestellt sind. Auch ihnen kann nämlich die belgische Staatsangehörigkeit aberkannt werden (Art. 23 CNB): Eine solche Aberkennung ist bei gebìitigen Belgiern unmöglich.

94. Dartiber Beauthier, 209; Verwilghen, 328, 329. Siehe weiter die Motiven, Documents Parlementaires (Chambre des representantes) 1983/1984, NI. 756-1, 22; und Nr. $757-21,114$. Heyvaert, 34, 35 weist darauf hin, daB man durch diese Formulierung hat erreichen wollen, daß nur "persönliche" Tatsachen einen Zurückweisungsgrund bilden können und keine allgemeinen, politischen Grïnden. Die allgemeine Lebensauffassung des Optierenden oder dessen pollitische Auffassungen können also keine gewichtigen Tatsachen sein, die eine Zurïckweisung legitimieren können. Strafbare Handlungen des Optierenden können aber wohl solche gewichtige Tatsachen darstellen; dabei seil im Auge behalten daß nicht särntliche Verbrechen solche gewichtige Tatsachen bilden, aber andererseits auch Vergehen manchmal solche gewichtige Tatsachen sind. Siehe auch Hobin, 149.

95. Art. 15, $\$ 2$, Abs. 1.: "Das erstinstanzliche Gericht entscheidet über die Bewilligung der Option, nachdem das Gutachten des Prokurators des Königs eingeholt worden ist. der Betreffende gehört oder vorgeladen wurde. Es verweigert sie, wenn ein Hindernis besteht wegen schwerwiegender persönlicher Fakten, die es in der Begriundung seiner Entscheidung genau angeben muß, oder wenn es aus verschiedenen Grinden, die es: ebenfalls genau angeben muß, der Meinung ist, daß der Wille des Betreffenden zur Eingliederung unzureichend ist. Durch diese Verweigerung wird eine spätere Erklärung nicht unzulầssig". (Übersetzung Bergmann/Ferid, unter Belgien (83. Lieferung)).

96. Heyvaent, 28, Verwilghen, 329-332.

97. Heyvaert, 28 ; Verwilghen, 332.

98. Der Betreffende muB also einen wesentlichen Teil seiner Schulzeit in Belgien verbracht haben. Die Grundlage dieses Optionsrechtes bezeichnet Lienard-Ligny, Belgisch tijdschrift voor internationaal recht 1984/85, 665 deshalb mit Recht alls "ius educationis". Sie erinnert in diesem Zusammenhang an den Worten von Albert de Lapradelle (Annuaire de I'Institut de droit international, Bd XXXIV, 700): "...c'est l'education, et non le sang qui, dans la moderne explication du jus sanguinis est la vivante source de la nationalité d'origine basée sur la filiation, comme elle est, dans la moderne explication du jus soli, la vivante source de la nationalité basée sur le territoire". Vgl. Heyvaert, $28,29$.

99. Heyvaert, 29* Verwilghen, 332, 333.

100. Art. 14 Abs. 3 * "...lorsque le déclarant prouve qu'il a conservê des attaches véritables avec la Belgique". Vgl. Erklärung des Justizministers in Documents parlementaires: 1983/1984, Ni.756-21, 112, 113: "il faut éviter un système rigide. Dans chaque cas le juge appréciera ... la Belgique peut avoir un intérêt à ce que l'intéressé demeure à l'étranger par exemple dans le cadre d'un service public ou d'une activité privee, pour faire des études etc.". Auch zitiert won Beauthier, 207; Heyvaert, 29; Verwilghen, 181, 182.

101. Heyvaert, 31 meint, daS der ausländische Ehegatte die Optionserklärung auch abgeben darf; wenn das sechsmonatige Zusammenleben in Belgien ganz oder teillweise vor der Eheschließung stattgefunden hat.

102. Das Gesetz sagt nicht, wie der Begriff "Zusammenleben" aufgefasst werden muB. Das Gericht kann deshalb frei beurteilen, ob von Zusammenleben die Rede ist (Parlamentarische Frage (Senat) vom 10. Juni 1986, 1985/6, 1274). Es ist tibrigens unkler, ob die Optionsvoraussetzungen lediglich im Moment der Optionserklärung oder auch noch im Moment der Genehmigung und Eintragung dieser Erklkirung erfillt sein muissen. In unterschiedlichem Sinne Landgericht Luittich 13. Juni 1986, Rev. Liege 1987, 1229 und Landgericht Antwerpen 9. Juni 1987, TVR 1987, 21. Siehe weiter Landgericht Briissel 12. Mai 1987, RW 1987/1988, 715. Vgl. Heyveart, 30.

103. Die staatsangehörigkeitsrechtliche Position des ausländichen Ehepartners entspricht somit der Gleichberechtigung der Geschlechter. Verwilghen, 147 weist darauf hin, daß von einer Egalisierung nach unten gesprochen werden kann. Die Tatsache, daf nicht 
der auslä̀ndischen Ehefrau eines Belgiers und dem ausländischen Fhemann einer Belgierin ein Optionsrecht auf die belgische Statsangehörigkeit gegeben wurde, gelnt zurilick auf eine Angst vor Scheinehen zwecks Staatsangehörigkeitserwerbs. Verwilghen, 148 meint, daß solche Scheinehen in der Vergangenheit jedoch nur sehr selten vorgekommen sind. Vgl. Beauthier, 214. Art. 16 Abs. 1 CNB entspricht übrigens buchstäblich Art. 37 des französischen Code de la nationalite.

104. Es reicht nicht aus, wenn jemand mal versehentlich für den Militärdienst oder als Wahler Unterlagen zugeschickt bekommen hat. Die Verwaltung muls den Betreffenden in mehreren Fällen konsequent als Belgier behandelt haben: Documents parlementaires (Chambre des représentantes) 1983/1984, Nr. 756-21, 99. Darüber Smet, 14.

105. Diese Bestimmung ist inspiriert von Art. 57-1 des französischen Code de la nationalite; siehe Verwilghen, 206; vgl. weiter Bleckmann, ZaöRV 1974, 320-329.

106. Beauthier, 209-212; Saens, Jura Falconis 1982/83, 534-538; Verwilghen, $358 \mathrm{ff}$.

107. Verwilghen, 375,376 .

108. Heyvaert, 13; Lienard-Ligny, Belgisch tijdschrift voor intermationaal recht, 1984/85, 661,662 .

109. Aus dieser letzten Bedingung kann gefolgert werden, daß der Ehegatte eines Belgiers, der durch Option Belgier wird, nur die Rechte erwirbt, die normalerweise mit der ordentlichen Einbürgerung verbunden sind. Siehe Smet, 31, 32; siehe hieriber auch kritisch Beauthier, 215; vgl. Documents parlementaires (Chambre des représentantes) 1983-1984, Nr. 756-21, 121.

110. Ein Antragsteller braucht seinen Integrationswillen nicht selber zu beweisen. Man gelnder Integrationswillen ist aber ein Grund fïr die Zurückweisung eines Optionsrechtes oder Einbiirgerungsantrages. Siehe Documents parlementaires (Sénat) $1983-84$, $\mathbf{N r}$. $660 / 2,82$; "En outre, l'immigre n'a pas la charge de la preuve de son intention d"intégration". Dazu de Moffarts, Tijdschrift voor vreemdelingenrecht 1987, 27, 30 (Fußnote 17).

11. Beauthier, 210; Verwilghen, 163, 164; vgl. Documents parlementaires (Chambre des representantes) 1983-1984, Nr. 756-1, 22 und 756-21, 114; weiter Documents parlementaires (Sénat) Nr. 660-2, 82-83 und Annales parlementaires (Sénat) vom 19. Juni 1984, S. 888.

112. Verwilghen, 169.

113. Annales parlementaires (Sénat) vom 20. Juni 1984, 894; dennoch versucht Verwilghen, 170-172 einige Kriterien für die Feststellung des Integrationswillen zu entwickeln; vgl. Beauthier, 210; Heyvaert, 35, 36; Lienard-Ligny, Belgisch tijdschrift voor internationaal recht $1984 / 85,669$.

114. Documents parlementaires 1983-1984, Nr. 756/21, 115; Documents parlementaires (Sénat) 1983-1984, Nr. 660/2, 82; Annales parlementailres (Sénat) vom 19. Juni 1984 2643; dazu de Moffarts, Tijdschrift voor vreemdelingenrecht 1987, 29, 30. Siehe weiter Landgericht Brussel 7. Januar 1987, Tijdschrift voor Vreemdelingenrecht 1987, 35, 36; "Attendu que si la connaissance insuffisante d"une des langues nationales et le souhail de sauvegarder certaines valeurs culturelles propres ne constituent, en soi, raisons suffisantes pour refus d'agrément, l'ensemble des elé- ments réunies par l'enquête menée par l'office du procureur du roi ajoutées aux constatations faites par le tribunal constituent un faisceau de présomptions suffisantes pour mettre en doute la rélle volonté d'intégration de la requérante dans la communauté nationale" que le situation constaté par le tribunal après deux années de séjour en Belgique implique: necessairement que la requétante se confine dans son milieu d'origine sans ouverture sur la communauté belge:"

115. Art. 238-240bis Code des diroits d'enregistrement, d'hypothèque et de greffe; dazu Heyvaert, 43, 44; Hobin, 151; Philippart/Stroobants, 69, 70 .

116. Heyvaert, 33, 34; Verwilghen, 424-436.

117. Heyvaert, 23 ; Hobin, 148 .

118. Siehe Closset, Traite, 92 ff; Verwilghen, $59 ; 337$.

119. Closset, Traité, 110-113; Dischler, 39.

120. Closset, Traite, 121-129; Dischler, 39-43.

121. Dischler, 12 .

122. Closset, Traite, 114-120; Dischler, 37-38.

123. Verwilghen, 52,53 .

124. Der Begriff des freiwilligen Erwerbs wird im belgischem Recht eng interpretiert. Verwilghen, 399 zitiert Standaert, 78: "L'acte de volonté doit émaner de l'intéressé 
lui-même. Ainsi, la déclaration acquisitive de nationalité etrangère, souscrite au nom du mineur par son représentant légal, ne lui fait pas perdre la nationalite bellge. So auch Closset, Traite, 112; siehe weiter Heyvaert, 52,53 .

125. In Parlament wurde die Frage gestellt, ob die Verbindung zwischen Verzichtsmöglichkeit und Militärdienstpflicht nicht eine indirekte Diskriminierung von Männern sei. Dies wurde jedoch werneint. Siehe Verwilghen, 146 mit weiteren Hinweisen und Heyvaert, 51,52 .

126. Dieser Verlustgrund ist inspiriert von Art. 7 Ziffer 5 des niederländischen Staatsangehörigkeitsgesetzes 1892 und Art. 8 Abs. 1 des dänischen Staatsangehörigkeitsgesetzest vorm 27 Mail 1950. Siehe Verwilghen, 207, 208; vgl. weiter Beauthier, 229; Heyvaert, 53,54 .

127. Verwilghien, 391. Beauthier, 228 spricht von "perte consentie" (gegeniber "perte volontaire" und "perte non volontaire").

128. In diesem Gesetze nicht volljăhrig erkläte Personen, die noch nicht das Alter von achtzehn Jahren erreicht haben; vgl. Heyvaert, 49,50 .

129. Beauthier, 228; Heyvaert, 50 .

130. Sehr kritisch hieruber Beauthier, 231; siehe weiter Heyvaert, 55-61.

131. Heyvaert 131.

\section{NOTEN BUNDESREPUBLIK DEUTSCHLAND}

1. RGBI 1913, 583; BGBI III, 102-1, in Kraft getreten am 1. Januar 1914, zuletzt geăndert durch Gesetz vom 25. Juli 1986, BGBL. 1986 I, 1142 ff. (IPR-Neuregelungsgestetz).

2. Siehe Hecker, Deutschland, $395 \mathrm{ff}_{n}$ Hecker, Materialien 1,2; auch Fundstellennachweis A 1983, Bundesministerium der Justiz, unter Nr. 102-1.

3. Vgl. Prälambel und \& 1 der Verfassung des Deutschen Reiches vom 16. April 1871, BGBI. $1871,64 \mathrm{ff}$.

4. Nach revolutionären Unruhen in mehreren deutschen Staaten rief der sozialdemokratische Staatssekretär Philipp Scheidemann am 9. November 1918 in Berlin die deutsche Republik aus. Am 11. August 1919 wurde die Verfassung des Deutschen Reichs (Weimarer Verfassung) verabschiedet (RGB1. 1919, 1383 ff.).

5. Gesetz uiber den Neuaufbau des Reichs vom 30. Januar 1934, RGB1 I 1934, 75.

6. Das RuStAG galt ungeändert, also mitt den von den National-sozialisten vorgenommenen Änderungen weiter. Bestimmte andere national-sozialistische staatsangehörigkeitsrechtliche Regelungen wurden jedoch aufgehoben: siehe Art. $\mathbb{1}$, Abs. 1 Buchstabe j des Amerikanischen Militärregierungsgesetzes Nr. 1; Art. 1 Abs. 1 Buchstabe 1 des Kontrollratsgesetzes Nr. 1 vom 20. September 1945 (ABI.KR, 3); Gesetz Nr. 12 der Allitierten Hohen Kommission vom 17. November 1949 (ABl.AHK, 361, auch abgedruckt bei Massffelder, 413).

7. Vom 20. Februar 1967, GBI. DDR I, 3, in Kraft getreten am 23. Februar 1967. Siehe dariber u.a. Bergmann/Korth, 129-132; Brunner, 92-94; Verfassung der DDR, Dokumente, Koinmentar Band 2, 26, 27; Mampel, 527-424; Makarov/von Mangoldr; Riege, Die Staatsbürgerschaft der DDR; Zieger, Das Staatsbuirgerschaftsgesetz der DDR.

8. BGB1. (des Norddeutschen Bundes) 1870, 335; in Kraft getreten am 1. Januar 1871, ausgenommen Bayern, wo es am 13. Mai 1871, Elsaß-Lothringen, wo es am 31. März 1873 und Helgoland, wo es am 1. April 1891 in Kraft gesetzt wurde. Die \$s 17 und 20 traten ubrigens bereits am 22. Joli 1870 in Kraft. Siehe für Literaturhinweise zum Gesetz diber die Erwerbung und den Verlust der Bundes- und Staatsangehörigkeit aus dem Jahr 1870: Hecker, Bibliographie, 13-21.

9. Siehe Hecker, Deutschland, 1-390; vgl. ebenfalls Hecker, Code Napoleon, 21-75; Makarov/von Mangoldt, Einleitung IV, Nr. I-10; Weidelener/Hemberger, 1, 2. Die Texte der Staatsangehörigkeitsregelungen in den deutschen Einzelstalten finden sich u.a. in der Sammlung "Die in den Europäischen Staaten geltenden Gesetze itber die Erwerbung und den Verlust der Staatsangehörigkeit unter Ausschlub des Deutschen Reichsgesetzes vom 1. Juni 1870. Nebst einem Anhang, enthaltend die vor dem 1. Januar 1871 in den Deutschen Bundesstaaten in Kraft gewesenen Staatsangehörigkeitsgesetze. Im Auftrage der Polizeibehörde der Freien und Hanse-Stadt Hamburg herausgegeben und erläutert, 1898 ". 
10. Siehe füir den Ubergang des Nord-Deutschen Bundes zum Kaiserreich; Forsthoff, 146-150; Hartang, 268-275; Huber, 742-749; Menger, 145-147; Kimminich, 406-428.

11. Makarov/von Mangoldt, Einleitung IV, Nr. 12, 13; Weidelener/Hemberger, 2; beil der Ubernahme als Reichsgesetz wurden einige kleinere Anderungen vorgenommen von 9 des Gesetzes vom 22. April 1871, RGB1, 87 (Aufhebung der \$1 Abs. 1, 8 Abs. 3 und 16).

12. Siehe die Angaben oben in Fußnote 3; vgl. darïber Hartung, 274; Huber, Band III, 785-808; Weil, Revue de droit international prive 1915/16, 142, 143.

13. Vgl, oben Fußnote 11; siehe weiter Gesetz von 20. Dezember 1875 betreffend Einbürgerung von Ausländern, die im Reichsdienst angestellt sind (Änderung von 9 Abs. 3 RuStAG 1870) und (Art. 41 des EGBGB vom 18. August 1896 (in Kraft am 1. Januar 1900) (Änderung der $\$ 11,19,21$ Abs. 2 und Einfulhrung von $\$ 14 a$ RuStAG 1870).

14. Cahn, Vorwort, III; Bahrfeldt, 3-29; 59-64; Makarov/ von Mangoldt, RuStAG, Einleitung, Nr. 1; vgl. auch die weitere Literatur zum RuS $₫ A G 1913$ bei Hecker, Bibliow graphie, 22-26.

15. Art 2, 12 Verfassung des deutschen Reiches vom 4. August 1919, RGB1 1383; daríber Hartung, 320-325; Menger, 169; Kimminich, 488-491.

16. Die einzige Änderung betraf $\$ 38$ (über die Kosten der Einbürgerungs- und Entlassungsurkunden): Gesetz vom 5. November 1923, RGBI I, 1077* Makarov/von Mangoldt, Einleitung IV, Rdnr. 15; siehe für Literaturhinweise uiber das RuStAG in der Periode 1918-1932; Hecker, Bibliographie, 27-35.

17. Gesetz vom 26. Juli 1918, außer Kraft am 31. Dezember 1924.

18. Hartung, 342-346; Menger, 179-181; Kimminich, 553-567; Forst hoff, 191, 192.

19. Gesetz vom 30. Januar 1934, RGBl. II, 75; Vgl. Hartung, 347; Chiaverini, 45-46.

20. RGBl. 1934 I, 85; BGBI. III, 102, 2.

21. Die Verordnung hob weiter $₹ 9$ des RuStAG auf. Schon 1927 hatte übrigens der Reichstag die Regierung ersucht, einen Gesetzentwurf vorzulegen, der für alle Deutschen an Stelle der Staatsangehörigkeit eine deutsche Reichsangehörigkeit setzt. Siehe darliber Makarov/von Mangoldt, Einleitung IV, Nr. 16, 17; Weidelener/Hemberger, 3.

22. Die $\$ \$ 10,11,12,26$, Abs. 3 Satz 2, 31 und 32 Abs. 3 und teilweise die $\$ \$ 15$ Abs. 2 und 34 .

23. RGB1. 1935 I, 593; BGBl. III 102, 1/1; Makarov/von Mangoldt, Einleitung IV, Rdnr. 17.

24. Siehe Makarov/von Mangoldt, Einleitung IV, Nr. 17; Fundstellen bei Hecker, Deutschland, 399-405, 409-421; siehe weiter Hecker, Bibliographie, 36-42.

25. RGBl. 1933 I, 480, abgeändert durch Gesetz des 10. Juli 1935, RGB1. 1935 I, 1015; auch abgedruckt bei Massfelder, 103-106.

26. RGBI. 1941 I, 772, in Kraft getreten am 27. November 1941. Das Reichsbilrgergesetz vom 15. September 1935, RGB1. I, 1146 (in Kraft getreten am 30. September 1935) unterschied den Staatsangehörigen und den Reichsbuirger. Reichsbiirger warten nur diejenigen Staatsangehörigen, die deutschen oder artverwandten Blutes waren, und die durch ihr Verhalten bewiesen, daß sie gewillt und geeignet waren, in Treue dem Deutschen Volk und Reich zu dienen. Nur der Reichsangehörige war Trager der vollen politischen Rechte nach Maßgabe der Gesetze. Die Haupdinien des Reichsbulrgergesetzes waren ubrigens schon in Kapitel 3 ("Staatsangehöriger und Staatsbüriger") des zweiten Bandes von Hitlers "Mein Kampf" zu erkennen. Bumerkenswert ist ubrigens, dab Hitler von der irrigen. Unterstellung ausging, daß die deutsche Staatsangehörigkieit iure soli erworben wurde. Siehe uber die nationalsozialistische Auffassung uber das Verhàltmis Staatsangehöriger/Staatsbürger u.a. auch Zenthöfer, Diss. Königsberg 1937. Vgl. Adam, Das Parlament, B 48/1985, 14-27.

27. Selbstwerständlich wurden diese "Interessen" großzuigig interpretiert. Siehe uber diese Ausbïrgerungen u.a. Lehmann, besonders 47-77. Siehe Lange (Diss. Hamburg 1936); vgl. auch Emmerich/Rothsschildt, Die Rechtslage deutscher Staatsangehöriger im Ausland; Lessing, 277-278, 288, 289.

28. Über die Rechtslage deutscher Juden: PS 1951, 25-30 und 68-71.

29. Siehe oben Fussnate 6.

30. Voin 23. Mai 1949, BGBI. 1949 I, 1; BGBl. III, 100-1.

31: Makarov/won Mangoldt zu Art. 16 GG: Lichter/Hoffmann, 17-21; Hamann/Lenz, 304-306.

32. Makarov/von Mangoldt zu den Art. 73 und $74 \mathrm{GG}$; Lichter/Hoffmann, 22-24; Von Münch, $539-544$. 
33. Bergmanu/Korth, 31-32; Makarov/won Mangoldt Art, 116 GG, Rdnr. 1-4; Schleser, 96-100: Lichter/Hoffmann, 25-34; Hamann/Lenz, 694-696.

34. Makarov/von Mangoldt Art. 116 GG, Rdnr. 67-140; Schleser, 58-60; Lichter/Hoffmann, 34-38; Hamann/ Lenz, 696-697.

35. Lichter/Hoffmann, 13-17.

36. Hamann/Lenz, 697-698; Makarow/won Mangoldt, GG Art. 3, Rdnr. 4.

37. So z.B. Schätzel, Grundrechte, Bd. 2, 579: "Nichts spricht dafür, dab man beil der Fassung des Art. $3 \mathrm{GG}$ auch nur entfemt daran gedacht hat, aus dieser Gesetzesbestimmung Folgerungen für die Sitaatsangehörigkeit zu ziehen". Später hat Schätzel seine Meinung allerdings geändert. Es stimmt allerdings; daß man sich während der Beratumgen über Art. 3 GG keine Rechenschaft über Konsequenzen fuir das Staatsangehörigkeitsrecht gegeben hat. Makarov/won Mangoldt, GG Art. 3, Nr. 1, 5.

38. Vgl. z.B. Scheffler, Juristentag, 7-12, 18; Maraun, passim und Schwarz, passim. Siehe weiter Makarov/von Mangoldt, GG Art. 3, Rdnr. 5.

39. 1953 wurden nur die $\$ \$ 14,15$ Abs. 1 und 16 Abs. 1 (teilweise) durch 194 des Bundesbeamtengesetzes vom 14. Juli 1953, BGBI 1953 I, 551 aufgehoben. Seitdem konnte die deutsche Staatsangehörigkeit nicht mehr aufgrund einer Ernennung zum Beamten erworben werden. Faktisch war diese Regelung jedoch bereits seit $1937 \mathrm{im}$ wesentlichen gegenstandslos, nachdem, seit dem Inkrafttreten des Deutschen Beamtengesetzes wom 26. Januar 1937 (RGB1. 1937 I, 39) die deutsche Staatsangehörigkeit grundsätzlich Voraussetzung für die Ernennung zum Beamten war.

40. BVerfGE $3,225-248$.

41. So stellte sich $2 . B_{\text {. das }}$ OVG Münster auf den Standpunkt, daß auch $\$ 6$ RuStAG auBer Kraft getreten war. Siehe VG Münster 26. Februar 1957, Entscheidungen der OVG Münster und Lüneburg. Amtliche Sammlung Band 12, 147-152. Vgl. auch Runderlaß des Auswärtigen Amts vom 26. Mai 1953, 522-09-V-51774/53; Schleser, 108; Makarov/von Mangoldt, GG Art. 3, nr. 8-15.

42. BGBI. 1957 1, 1251; BGBI. III, 102-7. Das erste und zweite Staatsangehörigkeítsregelungsgesetz vom 22. Februar 1955 (BGB1, 1955 1, 65), bzw. vom 17. Mai 1946 (BGBI. 1956 I, 431) betrafen typische nachkriegsbedingte Fragen. Vom Gesetz des 19. August 1957 wurden die $\$ 3$ und 6 RuStAG geändert.

43. Gab die Frau bei der Eheschließung keine Optionserklärung $a b$, dann hatte sie während der Ehe einen Einbiurgerungsanspruch. Hierüber Schleser, 110; Van der Weg, PS 1957, 129-133; siehe auch wan der Weg, PS 1956, 21-27 und PS 1957, 95-100.

44. BT-Drucksache III/1178; Stenographische Berichte, 3. Wahlperiode, 106. Sitzung vom 11. März 1969, 5752 B; Makarov/von Mangoldt, GG Art. 3, Nr. 16-18.

45. Vgl. auch die Empfehlung 194 (1959) des Europarates.

46. BVerwG 21-12-1962, BVerwGE 15, 221-231; DöV 1963, 468. Vg1. dazu Makarov/von Mangoldt, \& 4 RuStAG, Rdnr. 4.

47. Gesetz von 19-12-1963, BGB1. 1963 1, 982, in Kraft am 1. Januar 1964. BT-Drucksachen IV/1275, IV/1420, IV/1560; Stenographische Berichte, 94. Sitzung, 4316D4317B; siehe Makatrow/von Mangoldt, \& 4 RuStAG, Rdnr. 3; Schleser, 113 Van der Weg. PS 1964, 18, 19. Durch Gesetz des 30. August 1960 (BGBl. 1960 I, 721) wurde 22 RuStAG geändert; dazu Makarov/von Mangoldt, 22 RuStAG, Rdnr., 1-3.

48. Gesetz vom 8 9 1969, BGB1. 1969 I, 1581 (Änderung der \& \$ 3, 6, 9 RuStAG); siehe BT-Drucksache V/2676, V/3971 (neu); Stenographische Berichte, 5. Wahlperiode, 164. Sitzung, $8562 \mathrm{C}$ und 241 . Sitzung, $13454 \mathrm{C}-13456$. Siehe tiber das Zustandekommen dieses Gesetzes u.a. Arndt, StAZ 1969, 348, 349; Makarov/von Mangoldt, \& 6, Anm. B; vgl, bereits Schröder-Hilgendorff, 60-78; Schleser, 110-112. Eine kleine Anderung des 38 RuStAG wurde durch Gesetz des 23. Juni 1970 (BGBl. 1970 I, 805) vorgenommen.

49. Diese Abschaffung wurde u.a. damit begriundet, daß Ehen häufig ausschließlich geschlossen wurden, darnit die ausländische Frau die deutsche Staatsangehörigkeit olhne Einbirgerung erwerben konnte.

50. Siehe gegen die damalige Fassung des \& 4 RuStAG: Biesenbach, 211-213; Henrich FamRZ 1974, 105-111; Samtleben, FamRZ 1973, 1-4; Schickedans, StAZ 1970, 330-334 und StAZ 1972, 174-175; Sturm, JZ 1972, 734, 735 und StAZ 1974, 292294. Makarov " JZ 1972, 159, 160 und Wuppermann, FamRZ, 550, 551 meinten aber, dali es niicht notwendig sei $\$ 6$ RuStAG zu ändern, wăhrend Jayme und Neuhaus, NrW $1971,832,833$ zögerten. Vgl. Makarov/von Mangoldt, GG Art. 3, Nr. 19-21. 
51. BVerfG 21-5-1974, BVerfGE 37, 217-264, BGBl. 1974 I, 1933, NJW 1974, 1609; FamRZ 1974, 579; StAZ 1974, 236. Von großer Bedeutung sind weiter folgende Entscheidungen: BVerwG 26-6-1971, BVerwGE 38, 224-230, NJW 1971, 1720; FamRZ 1971, 577; StAZ 1972, 172; JZ 1972, 158 und BGH 20-12-1972, BGHZ 60, 68; NJW 1973, 417, 417, 440; FamRZ 1973, 138; StAZ 1973, 213. Siehe uber diese Entscheidungen u.a. Schleser, 114, 115 Sturm, StAZ 1973, 293, 294; Sturm, FamRZ $1974,617-631$; und de Groot, NJB 1975, 782-783.

52. Reichs- und Staatsangehörigkeitsänderungsgesetz vom 20-12-1974, BGB1. 1974 I, 3714 (in Kraft getreten am 1. Januar 1975)); BT- Drucksachen VII/1880, VII/2175; BRDrucksachen 249/74; Stenographische Berichte, 134. Sitzung, 9053D-9058D. Amdt, NJW 1975, 140-143; Brinkman, PS 1975, 41, 42; de Groot, NJB 1974, 782-784; Henrich, FamRZ 1974, 105-111; Makarov/von Mangoldt, \$ 3 RuStAG, Rdnr. 2; Münch, in Festschrift Pallieri, 449-460; Pestalozza, NJW 1976, 507-509; Schleser, 115-116; Sturm, FamRZ 1975, 198-202.

53. Die $\$ \$ 4,17$ und 39 wurden geầndert, waihrend neue $\$ \$ 10$ und 26 in das RuStAG eingefuigt wurden.

54. BGB1. 1975 1, 685 (in Kraft an 1. April 1975); Einfügung der Sătze 2 und 3 bei \$ 16 Abs. 11, der Sätze 3 und 4 bei $\$ 23$ Abs. 1 und Streichung des $\$ 39$ Abs. 2.

55. Gesetz vom 2. Juli 1976, BGBI. 1976 I, 1749 (in Kraft am 1. Januar 1977); Einfügung der Nr. 3 bei $\$ 3$ und Einfüigung der $\$ \$ 6,17$, Nr. 4 und 27 und Anderung des $\$ 13$.

56. Gesetz rom 29. Juni 1977, BGBI 1977 I, 1101; VgI. BT-Drucksache VII/13; VIII/321; BR-Drucksache 675/76; Neufassung der $\$ 810$ und 24, Einfigung eines neuen \$ 18, Aufhebung des $\$ 22$ Abs. 2 und Anderung des $\$ 25$ Abs. 1.

57. BGBI. 1979 I, 1061.

58. Gesetz vom 25. Juli 1986, BGB1. 1986 I $1142 \mathrm{ff}$. (Änderung des $\& 6$ RuStAG), dazu Pirrung, 88-90; siehe BT-Drs. 10/504, 96, BT-Drs. 10/504, 102, 103, 108, BT-Drs. $10 / 5632,48$.

59. Entwurf vom 16. April 1982, BR-Drucksache 9/1574. Dazu von Mangoldt, IZ 1982, 174-178; Jellinek, ZAR 1982, 91, 92; vgl. auch Frowein, EuGRZ 1980, 151, 154; Münch, Festschrift Kloss, 319-336; Uhlitz, Recht und Politik 1986, 143-152; Zulleeg, ZRP 1987, 188-191.

60. Vgl. Art. 1 Abs. 4 Verfassung DDR (1949): "Es gibt nur eine deutsche Staatsangehörigkeit".

61. Vgl. Zieger, Die Staatsangehörigkeit im geteilten Deutschland, passim (mit weiteren Hinweisen); Makarov/von Mangoldt, Einleiturng V (mit sehr ausfilhrlichen Hinweisen).

62. Makarov/von Mangoldt, Einleitung, V 1b, Nr. 11.

63. Siehe oben Fußnote 7.

64. Vgl. Riege, 19, 47-54.

65. BVerfG vom 21. Oktober 1987, JZ 1988, 144; wozu Wyduckel, DVBil. 1988, 284-287 und Silagi, StAZ 1988, 64-71. Vgl. BVerwG vom 30. November 1982, BVerwGE 66, 277 wozu u.a. Meyer, NVwZ 1987, 16. Uber die Problematik aus DDR-Sicht: Riege, 182-273; vgl, aus Sicht der Bundesrepublik Deutschland Hecker, Recht in Ost und West 1987, 294-300; Klein, JuS 1987, 279-283; Seiffert, Politik und Kultur 1982, 6068 und Makarov/von Mangoldt, Einleitung $V_{;}$, siehe für weitere Literaturhinweise auch Hecker, Bibliographie, 75, 76 .

66. Dies äußert sich z.B. im Kollisionsiecht. Die deutschen IPR-Handbücher unterscheiden sorgfaltig zwischen dem Internationalen Privatrecht und dem sogenannten "Interlokalen Rech"". Letzteres ist das "IPR" im Verhältmis Bundesrepublik Deutschland-DDR (manchmal sieht man auch die Begriffe "Innerdeutsches" oder "Interzonales" Recht). Siehe hieriber Firsching, 86; Kegel, 21,22 und Sonnenberger, 26-30.

67. Makarov/von Mangoldt, 4 RuStAG, Rdnr. 1-6.

68. BGB1. 1963 I, 982 (BGB1. III, $102-112$ ), in Kraft am 1. Januar 1964: Makarov/von Mangoldt, \& 4 RuStAG, Rdnr. 3, 4.

69. Makarov/yon Mangoldt, 4 RuStAG, Rdnr. 6.

70. RuStAG-Anderungsgesetz vom 20. Dezember 1974 (BGBl. 1974 I, 3714), in Kraft am 1. Januar 1974.

71. Art. 10 wurde nochmal geändert durch Gesetz von 29. Juni 1977 (BGB1. 1977 I, 1101, in Kraft am 6. Juli 1977). Siehe dazu Makarov/von Mangoldt, RuStAG \& 10 , Rdnr. 2

72. Makarov/von Mangoldt, 10 RuStAG, Rdnr. 1, erwähnen, daß $\$ 10$ ursprünglich nicht im Regierungsentwurf vorgesehen war. Er ist durch den BT-Innenausschuss auf An- 
regung des BT-Rechtsausschusses eingefügt worden. Siehe auch Schleser, 132. Das Zitat tentstammt BT-Drucksache $7 / 2814,4$.

73. Siehe Meyer, NVwZ 1987, 18; Makarov/von Mangoldt, 3 RuStAG, Rdrr. 3.

74. Eingefugt durch RuStAG-Anderungsgesetz vom 20. Dezember 1974 (BGBI. 1974 I. 3714), in Kraft am 1. Januar 1975. Vgl. über die staatsangehörigkeitsrechtliche Position des ausländischen nichtehelichen Kindes eines deutschen Mannes u.a. Makarow/von Mangoldt, 10 RuStAG, Rdnr. 5-40; Meyer, NVwZ 1987, 22.

75. Gedindert durch das Gesetz zur Verminderung der Staatenlosigkeit vom 29. Juni 1977 BGB1. 1977 1, 1101), in Kraft am 6. Juli 1977.

76. Makarov/von Mangoldt, \& 5 RuStAG, Rdnr. 14; Meyer, NVwZ 1987, 18, 19.

77. Eingefuhrt durch Adoptionsgesetz wom 2. Juli 1976 (BGB1. 1975 I, 685), in Kraft am 1. Juli 1977. \& 6 RuStAG wurde durch das IPR-Neuregelungsgesetz rom 25. Jull 1986, BGB1. 1986 I, 1142 abgeăndert. Dazu Pirrung, 88-90.

78. Siehe auch Stenographische Beriche des BT vom 10. November 1978 (Bd, 107, $9022 \mathrm{~A}-\mathrm{C}$, worin betont wird, daß die Bundesregienung nicht beabsichtigt, in Deutschland geborenen Gastarbeiterkindern iure soli die deutsche Staatsangelkörigkeit zu verleihen.

79. Makarov/won Mangoldt, \& 4 RuStAG, Rdnr. 42-44.

80. Siehe unter \& 2.2.3.2.

81. Cahn, 59.

82. \& 10, 11, 12, 15 Abs. 2, 26 Abs. 3, 31 und 34 RuStAG.

83. \& 2 des Gesetzes vom 15. Mal 1935, RGBl. 1935 I, 593 (BGBl. III 102-1/1), auch abgedruckt bei Massfelder, 78 .

84. $\quad \$ 1$ des in Fußnote 83 erwähnten Gesetzes.

85. Massfelder, 78.

86. Art. 116 Abs. $2 \mathrm{GG}$ und $\$ 10 \mathrm{RuStAG}$; siehe weiter $\$ \$ 6,8,9$ Abs. 2, 11 und 12 des 1. StARegG, 3 und 4 des 2. StARegG, 3 RuStAAndG 1974; Art. 2 des Gesetzes zur Verminderung von Staatenlosigkeit vom 29. Juni 1977; dazu Jellinek, Entwicklungstendenzen, 30-37; vgl. auch 38, 39 .

87. Die ersten Einbüirgerungsrichtlinien wurden 1956 aufgestellt, aber wurden nicht veröffentlicht (vgl. Hecker, Deutschland, 448); die zweiten Einbürgerungsrichtlinien wurden 1971 bei der Bundesdruckerei herausgegeben; sie sind in leicht gekürzter Fassung abgedruckt bei Herbert Krïger, $59 \mathrm{ff}$. Die nun geltenden Richtlinien datieren vom 1 . Juli 1977 und wurden 1981 und 1983 leicht abgeändert (siehe für Fundstellen: Hecker, Materialien, 4, wobei hinzugefüit werden muß Bergmann/Korth, 57-70; Groth, 88-105; Weidelener/Hemberger, 220-247). Über die Rechtsnatur der Einbirgerungsrichtlinien u.a. Meyer, NVwZ 1987, 21.

88. \$6 i.d.F. des 3. Staatsangehörigkeitsregelungsgesetzes wom 19. August 1957 (BGBl. I 1957,1231 ).

89. Makarow/von Mangoldt, \& 6 RuStAG, Anm. B.

90. \$194 des Gesetzes wom 14. Julli 1953 (BGBl. I. 55》). Siehe Makarow/von Mangoldt, 14 RuStAG, Ranr. $1-10$.

91. Siehe Makarov/von Mangoldt, \& 16, Rdnr. 1, wo auf kleine Unterschiede zwischen \$ 11. RuStAG 1870 und $\$ 16$ RuStAG 1913 hingewiesen wird.

92. Einbirrgerungstrichtlinien 1971, unter A. (Allgemeine Grundsäitze). Siehe weiter Groth, 16: Meyer, NVwZ 1987, 19 mit Hinweis auf BVwGE 67, 177. Makarov/von Mangoldt, \& 8 RuStAG, Renr. 7-10.

93. Richtlinien wom 1. Juli 1977 (siehe für Fundstellen unten FuBnote 87).

94. Vgl. BVerfGE 4, 298; 168; 7, 237; 49, 44. In einer Entscheidung vom 5. August 1980 (IA 1980, 311; BayVB1. 1980, 727) bestä̀igte das BVerwG, daß keine Abwägung stalatlicher gegenibber persönlichen Interessen stattzufinden braucht. Dagegen Rittstieg, IA 1980, 312. Siehe auch Meyer, NVwZ 1987, 19; Makarov/von Mangoldt, \& 8 RuStAG ${ }_{m}$ Rdnr. 7.

95. Aufgrund dieses Kriteriums wurde die Einbürgerung einer Frau abgelehnt, well sie DKP-Mitglied war. Diese Ablehmung, war nach Ansicht des BVerwG (Entscheidung vom 27. Juni 1983, DVB1, 1983, I013; IA 1983, 277; StAZ 1984, 77; NJW, 1984, 73) rechmäßig. Vgl dagegen VGH Baden-Wuirttemberg vom 10." September 1984 (StAZ 1985, 76: mit kritischer Anmerkung von Mangoldt, 169). Daritber auch Groth,
37-47; Meyer, NVwZ 1987, 22. 
97. In BT-Drucksache 1129 (vom 16. September 1970; Bd 142 zu Frage 95) wird behaupter, daB auch in den meisten anderen Staaten mindestens ein zehnjahriger Aufenthalt gefordert wird.

98. Vgl. Stenographische Berichte des BT vom 9. Dezember 1970 (Bd. 74, 4700 D).

99. Staatenlose haben u.U. sogar einen Einbïrgerungsanspruch; siehe \& 2 Abs. 2 des Wehrpflichtgesetzes und weiter das Ausfiuhrungsgesetz $z u$ dem Übereinkommen zur Vermeidung der Statenlosigkeit vom 21. Juli 1956 (BGBl. I, 651) i.d.F, vom 7. November 1977 (BGBI. I, 2021) geändert am 16. August 1980 (BGB1. I, 1429). Siehe die Erörterungen von Makarow/von Mangoldt za $\$ 2$ Abs. 2 Wehrpflichtgesetz, wo darauf hingewiesen wird, daß dieser Einbürgerungsanspruch auf Vorschlag des BTAusschusses füir Verteidigung durch Anderungsgesetz vom 28. November 1960 (BGB1. $\mathbb{I}, 853$ ) ins Wehrpflichtgesetz eingefiigt wurde.

100. Vgl. dariber Stenographische Berichte des BT vom 16. Januar 1970 (Bd. 71, 985 B). Siehe auch Entscheidung des BVerwG vom 1. Juli 1975, BVerwGE 49, 44; NJW 1975,$2156 ;$;Z 1975, 632; DôV 1975, 750; MDR 1976, 76; BayVBI 1976, 405, kraft deren das Wohlwollensgebot des Art. 34 der Flüchtlingskonvention bei Einbürgenung von Asylanten zu beachten ist, wenn die Eingliedenung in die deutschen Verhailtnisse gesichert erscheint; siehe auch VGH Stuttgart vom 3. Dezember 1979, ZaöRV 1981, 154.

101. OVG Berlin (Entscheidung vom 30. September 1971, DVB1. 1972, 283) urteilte, daß auch unbefugte Niederlassung genügt; so auch BVerwG vom 9. Dezember 1975 , Buchholz, 130. Über das Einbiurgerungsermessen bei unerlaubtem Aufenthalt; BVerwG wom 4. Februar 1982; IBAR 1982, 189; BayVB1 1982, 664; NVwZ 1982, 683; Buchholz, 130, \&8 RuStAG Nr. 15. Vgl. auch Groth, 16, 17, 51, 52; Meyer, NVwZ 1987, 19 und von Mangoldt, StAZ 1981, 331; Makarov/von Mangoldt, \& 8 RuStAG, Rdrr. 21 .

102. Vgl BVerwG vom 1. Februar 1977, Buchholz, 130 und BayVGH vom 20. August 1981, NVwZ 1982, 324; VGHE 34 1, 101. Siehe Groth, 19; Meyer, NVwZ 1987, 19; Makarov/von Mangoldt, \& 8 RuStAG, Rdnr. 27.

103. So bei einmaligem Fellverthalten von Ausländern der 2. und 3. Generation: Stenographische Berichte des BT wom 19. Juni 1970 (Bd. 73, 3429 A).

104. Vgl. BVerwG vom 2. November 1983, IA 1984, 108; Groth, 20; Makarov/von Mangoldt, \& 8 RuStAG, Rdnr. 32.

105. In den Eimbürgerungsrichtlinien von 1971 wurde (wohl in diesem Zusammenhang) auch noch eine Gesundheitsibescheinigung gefordert. In der heutigen Fassung der Richtlinien ist dies jedoch nicht mehr der Fall.

106. Vgl. BVerwG vom 5. August 1980; siehe für Fundstellen oben Fußnote 71. Siehe weiter Groth, 17, 22-25; Meyer, NVwZ 1987, 19; Makarov/von Mangoldt, \& 8 RuStAG, Rdnr. 33-34.

107. Groth, 31-33.

108. Uber das Verhältnis zwischen Einbürgerungspolitik und Entwicklungspolltik im allgemeinen: Stenographische Berichte des BT vom 21. Januar 1970 (Bdi. 71, 1006 C), vom 19. Juni 1970 (Bd. 73, 3410 C und 3413 D); BVerwG vom 18. September 1981 (IBAR 1981, 308; DöV 1982, 913; StAZ 1982, 108; NVWZ 1982, 119; BayVBI 1982, 121: Buchholz, 130, \& 8 RuStAG, Nr. 14); BVerwG vom 27. Juni 1984 (IBAR 1984, 319; StAZ 1985, 73). Siehe auch Groth, 35-37; Makarov/von Mangoldt, \& 9 RuStAG, Rdnir. 24; Meyer, NVwZ 1987, 21.

109. Andererseits hat das BVerwG am 16. Mai 1983 (Buchholz, 130, 9 RuStAG, Nr. 3) entschieden, daB DAAD- oder Universitätsstipendien nicht immer als Entwicklungshilfe zu werten sind.

110. Nach den Stenographischen Berichten des BT wom 13. Mai 1980 (Bd. 115, 17336 B-17337 A) bestelat auch ein Einbürgerungshindernis für Angehörige von Entwicklungsländern, die innerhalb von 5 Jahren nach der Einreise in die Bundesrepublik. Deutschland im Rahmen der Entwicklungshilfe eine Berufsausbildung begannen. Es gibt aber Ausnahmen.

111. Uber die Einbürgerung von mit Deutschen verheirateten Personen aus Entwicklungsländem im allgemeinem: Stenographische Berichte des BT wom 13. Juni 1973 (Bd. 83, 2304 B). Siehe Groth, 62, 63; Meyer, NVwZ 1987, 21.

112. Uber die Zulässigkeit der Rückkahlungspflicht: OWG Berlin vom 12 . Dezember 1975 (NJW 1976, 1226); VGH Stuttgart vom 13. Juni 1978 (ESVGH Bd. 29, 18); OVG Münster vom 4. Oktober 1979 (JZ 1979, 805; FamRZ 1980, 242; StAZ 1980, 98); 
BVerwG vom 16. Mai 1983 (IBAR 1983, 280, DVB1 1983, 1002; StAZ 1984, 74; BayVB1 1984, 218; NJW 1984, 70; Buchholz 130, \& 9 RuStAG Nr. 4); BVerwG vom 17. Mai 1983 (BVerwGE 67, 177; DVB1 1983, 1005; IBAR 1983, 277; NJW 1984, 69* StAZ 1984, 78; Buchholz 130, \& RuStAG Nr. 18).

113. In den Stenographischen Berichten des BT wom 15. Dezember 1977 (Bd. 104, 4908 B) wird betont, daß das Asylirecht der Entwicklungspolitik worgeht. Aber sogar wenn auts asylrechtlichen Grinden entgegen entwicklungspolitischen Bedenken eingebürgert wird, kann die Einbürgerung von der Räckzahlung von Ausbildungsbeihilfen abhängig gemacht werden.

114. Kritisch zur Forderung der Aufgabe der bisherigen Staatsangehörigkeit: OVG Münster vom 28. Oktober 1980 (IBAR 1981, 82; NJW 1981, 1920) und BVerwG vom 18. August 1981 (IBAR 1981, 308; StAZ 1982, 73; NJW 1982, 538; FamRZ 1982, 61; JA 1983, 466 (mit Anm. Meisner), BVerwGE 64, 7; Buchholz 130, \& 8 RuStAG Nr. 12). Vgl Groth, 33-35, 57, 58; Meyer. NVwZ 1987, 21.

115. Stenographische Berichte des BT vom 19. Juni 1970 (Bd. 73, 3430 B), vom 4. Dezember 1974 (Bd. 90, 9042 D), wom 27. Januar 1977 (Bd. 104, 5566 C).

116. In der Fassung von 8. September 1969 (BGBI. I, 1581).

117. Richtlinien 6.1.

118. OVG Münster vom 28. Oktober 1980; BVerwG vom 18. August 1981. Siehe für Fundstellen oben Fussnote 114. Zustimmend Zuleeg, NJW 1981, 1878, 1879.

119. Daruber Stenographische Berichte des BT vom 16. Oktober 1974 (Bd. 74, 4120 A) und vom 20. Juni 1974 (Bd. 88, 7582 A); vgl. Richtlinien 6.5.4; siehe weiter BVerwG vom 17. September 1981 (Buchholz, 130, 8 RuStAG, nr. 13). Siehe auch Meyer, NVwZ 1987, 19; Makarow/won Mangoldt, \& 8 RuStAG, Rdrr. 18-20.

120. Siehe 1 und 4 der Allgemeinen Verwaltungsvorschrift viber Urkunden in Staatsangehörigkeitssachen vom 18. Juni 1975 (GMB1. 1975, 462), geändert am 15. Juli 1977 (GMBI. 1977, 314), namentlich Anlage 1 (GMB1. 1975, 463). Text bei Weidelener/Hemberger, 248-251.

121. So - aber sehr kritisch - Makarov/von Mangoldt, \& 16 RuStAG, Rdnr. 36" vgl. auch Bergmann/Korth, 72, 73 .

122. Staatsangehörigkeitsgebiihrenordnung vom 28. März 1974 (BGB1. I, 809) geändert am 18. Juni 1975 (BGB1. I, 1436). Text bei Weidelener/Hemberger, 319-323. Vgl. Bergmann/Korth, 126, 127; Groth, 75,76.

123. Makarov/von Mangoldt, \& 3 RuStAG, Rdnr. 11, mit Hinweis auf Bleckmann, ZaóRV $1974,320-329$.

124. Siehe die Schrift "Weiterentwicklung der Ausländerpolitik - Beschlüsse der Bundesregierung vom 19-3-1980" und "sozial-politische Informationen" des BMA vom 27-3-1980. Die für das Staatsangehörigkeitsrecht relevanten Abschnitte werden von Schleser, 203-206 zitiert; siehe auch IA 1980, 216.

125. Beschluß Nr. 17. Vgl. auch bereits Küihn, 43, 44; "..... das Einbiirgerungsrecht (muß) so ausgestaltet werden, daß die Betroffenen einen vorbehaltlosen Rechsanspruch auf Einbiirgerung erwerben, über den sie im entscheidungsreifen Alter (Volljährigkeit) befinden können. Auch die Frage einer generellen Erleichterung des Einbürgerungsverfahrens für länger im Bundesgebiet lebende Zuwanderer mit der Absicht eines Daueraufenthaltes sollte in die weiteren Entscheidungen einbezogen werden." (VgI. StAZ $1980,342)$.

126. BR-Drucksache 52/80 vom 29.1.80. Dazu zustimmend Frowein, EuGRZ 1981, 151.

127. Entwuirf eines Vierten Gesetzes zur Regelung von Fragen der Staatsangehörigkeit. BR-Druckssache 3/82 vom 4-1-1982; BR-Sitzung (508. Sitzung) an 12-2-1982; BT-Drucksache 9/1574 vom 16-4-1982; 1. Beratung am 13.5.1982 (100. Sitzung) (vg\$. ZAR 1981, 158, 159; ZAR 1982,62,63). Dazu ablehnend von Mangoldt, JZ 1982, 174-178; zustimmend jedoch Jellinek, ZAR 1982, $91,92$.

128. Anlage 2 bei BT-Drucksache 9/1574.

129. Anlage 3 bei BT-Drucksache $9 / 1574$.

130. BT-Drucksache 10/1356. Vgl. Auch die Mitteilung des Senats der Freien und Hansestadt Hamburg an die Bürgerschaft (Drucksache Bürgerschaft Hamburg 11/2904):

"Daneben hailt der Senat .... folgende Massnahmen für geboten:

- Einräumung eines gesetzlichen Anspruchs auf eine gebihrenfreie Einbïrgenung fir die hier aufgewachsene zweite Ausländergeneration. .... 
- Prüfung der Frage, ob auch für die Angehörigen der ersten Ausländergeneration durch Schaffung eines Einbirgerungsanspruchs eine wesentliche Vereinfachung des Einbiirgerungsverfahrens erreicht werden kann. ....

- Zur Lösung der mit der Forderung nach der Entlassung aus der bisherigen Staatsangehörigkeit verbundenen Schwierigkeiten sollten mit den Hauptherkunftslindern der ausländischen Arbeitnehmer staatsvertragliche Regelungen angestrebt werden, durch die sichergestellt wird, daß mit der Einbiirgenung in der Bundesrepublik die bisherige Heimatstaatsangehörigkeit kraft Gesetzes erlischt.

- Zu endgültigen langfristigen staatsangehörigkeitsrechtlichen Eingliederung der Einwanderer könnte schließlich erwogen werden, den im RuStAG vorgesehenen Erwerb der deutschen. Staatsangehörigkeit durch Geburt - ähnlich wie in Frankreich - zu er weiteren."

131. Bergmann/Korth, 89; Makarov/von Mangoldt, $\$ 17$ RuStAG.

132. Bergmann/Korth, 89.

133. Die Frist wurde durch die Eintragung in die Matrikel eines Reichskonsulats unterbrochen (\$ 21 Abs. 1 Satz 3). Bahrfeldt, 7-29; Weil, Revue de droit international prive $1915 / 16,143-147$.

134. Bergmann/Korth, 76,77 .

135. Bergmann/Korth, 77,78 .

136. Bergmann/Korth, 88; Makarow/von Mangoldt, \& 25 RuStAG, Rdnr. 1; Weil, Revue de droit international prive $1915 / 16,148-153$.

137. Abs. 3 Satz 2 des 826 trat außer Kraft aufgrind des Gesetzes vom 15. Mai 1935 (RGBl. 1935 I, 593); die übrigen Vorschriften wahrscheinlich aufgrund der Verordmung vom 20. Januar 1942 (RGBl. 1942 I, 40). Die Regelung ist aber jedenfalls gegenstandislos, da aufgrund des Wehrpflichtgesetzes. Deutsche mit ständigem Aufenthalt im Ausland nicht wehrplichtig sind. Siehe Makarow/von Mangoldt, \$26 RuStAG, Rdnr. 1 und 2.

138. 23-25 des Gesetzes gegen die Steuerflucht vom 26. Juli 1918 (RGB1. 1918, 951 ). Diese Bestimmungen galten bis 31. Dezember 1924.

139. Gesetz yom 14. Juli 1933 (RGB1. 1933 I, 480).

140. Die erste Ausbiirgerungsliste, datiert am 23. August 1933, erschien in dem Reichsanzeïger Nr. 198 vom 25. August 1933. Diese erste Liste bïrgerte 33 Personen aus und deren Vermögen wurde beschlagnahmt; unter dliesen allerersten Ausgebürgerten waren Lion Feuchtwanger, Heinrich Mann und Kurt Tucholsky. Insgesamt sind bis zum 7. April 1945395 Ausbürgerungclisten im Reichsanzeiger veröffentlicht worden. Aufgrund dieser Regelung wurde 39.006 Personen die deutsche Staatsangehörigkeit entzogen. Siehe Michael Hepp (ed.), Die Ausbitrgerung deutscher Staatsangehöriger 19331945 nach den im Reichsanzeiger veröffentlichten Listen, 3 Bände, 1985; Vgl. weiter Lehmann, In Acht und Bann (Politische Emigration, NS-Ausbürgerung und Wiedergutmachung am Beispiel Willy Brandts), München 1976.

141. 11. Verordnung zum Reichsbiirgergesetz vom 25. November 1941 (RGB1. 1941 I, $772)$.

142. Bergmann/Korth, 89; Makarow/von Mangoldt, \& $17 \mathrm{RuStAG}, \mathrm{Rdinr} 6$.

143. Bergmann/Korth, 76, 77; Makarow/von Mangoldt, \& 27 RuStAG, Rdnr. 11,$2 ; 28$ RuStAG, Rdnr. 1 .

144. Bergmann/Korth, 77, 78; Malkarow/won Mangoldt, \$17, Rdnr. 14.

145. Dies ist tibrigens bemerkenswert spät, da bereits am 4. Mărz 1927 auf Antrag der demokratischen Reichstagsabgeordneten Frau Dr. Luiders vom Haughaltsausschuß des Reichstages einstimmig eine EntschlieBung angenommen wurde, worin die Reichsregienung aufgefordert wurde, unverzivglich einen das RuStAG 1913 abaindernden Gesetzentwurf zur Einschränkung des Staatsangehörigkeitsverlusts deutscher Frauen durch Eheschließung mit einem Ausländer vorzulegen. Dazu Zepf, Diss. 1929, 98, 99 und Müller-Sprenger, Diss. 1930.

146. Makarow/von Mangoldt \&26 RuStAG, Nr. 4.

147. Allerdings muB man bericksichtigen, daß aufgrund der Übereinkoinmen uber die Verringerung der Mehrstaatigkeit vom 6. Mai 1963 auch bei Inlandswohnsitz die Staatsangehörigkeit bei freiwilligem Erwerb einer ausländische Staatsangehörigkeit verloren wird; siehe Makarov/von Mangoldt \& 25 Ru.StAG, Nr. 21 mit genaueren Angaben.

148. Makarow/von Mangoldt, \& 25 RuStAG, Nr. 49.

149. Bergmann/Korth, 80, 81; Makarov/von Mangoldt, \& 19 RuStAG, Rdnr. 1-18. 
150. Bergmann/Korth, 86; Makarow/von Mangoldt, \& 25 RuStAG, Rdin. 37-44; vgl. weiter BVerwG 27. Juni 1956, N.JW 1956, 1411.

151. Diese Verlustbestimmung ist durch das Adoptionsggesetz vom 2, Jull 1976 (BGBI. I, 1749) eingefügt worden. Vgl. Art. 2 des Europäischen Übereinkommens vom 24. April 1967 (BGBL. 1980 II, 1093). Siehe Bergmann/Korth, 74-76; Makarow/von Mangoldt, 27 RuStAG, Rdnr. 1.

152. Groth, 74, 75; Jellinek, Entwicklungstendenzen, 43; Makaroy/von Mangoldt, \& 16 RuStAG, Rdnr. 31-34.

\section{NOTEN FRANKREICH}

1. Codle de la mationalite française vom 19. Oktober 1945 (Ordonnance Nr. 2441), in der Fassung des Loil Nr. 73/42 wom 9. Januar 1973, geändert von Loi Nr. 74/631 vom 5. Juli 1974, Loil Nr. 76/1179 wom 22. Dezember 1976 und Loi $\mathrm{Nr}$. 78/731 vom 12. Juli 1978, Loi Nrr. 78/753 vom 17 . Juli 1978, Loi Nr. 83/1046 vom 8. Dezember 1983 und Loi $\mathrm{Nr}_{\mathrm{r}}$ 84/341 vom 7 . Mai 1984.

2. Vgl. Marguerite Vanel, Diss. 1945; dieselbe, RCDIP 1946, 224 und dieselbe, RCDIP 1951, 23-26; siehe auch Colette Baumann, Diss. 1931, 27-34; Rapport CN II, 18-20.

3. Siehe für die Texte düeser Verfassungen: Jacques: Godechot, 37, 38, 83, 104, 151; siehe auch Textes NF, 53-55. Darifiber Loussouam/Bourel, 656, 657; vgl. auch Bendeddouche, 23-30.

4. Hecker, Code NapolEon, 7 weist darauf hin, daß das im Inland geborene Kind eines Ausländers in Frankreich nie - wie z.B. in Großbritannien - durch bloßes ius soli die franzỏsische Staatsangehörigkeit erwarb. Sämtliche Verfassungen forderten zusätzlich noch den Wohnsitz (résidence). Siehe auch Jean Merlin, 6; Rapport CN I, 20.

5. Mayer, 528 meint, daß die früheren französischen Verfassungen vielleicht wegen der vielen "émigrés" den Erwerb iure soli gewählt haben.

6. Die staatsangehörigkeitsrechtlichen Bestimmungen des Code civil waren übrigens bereits am 8 . Marz 1803 als Einzelgesetz (3 BL 354, Nr. 3677) erlassen und am 18. März 1803 in Kraft getreten; Verwilghen, 18, 19.

7. Siehe oben \& 2.1.1.

8. Mayer, 528 weist darauf hin, daß vor allem Bonaparte den Erwerb iure soli neben dem Erwerb iure sanguinis wïnschte. Das Tribunal war damit nicht einverstanden und sah das ius soli als Rudimert der Feudalitàt. Schließlich hat man sich auf die Regelung von Art. 9 Ce geeinigt. Siehe Locré, 182-186; vgl, weiter auch Rapport CN I, 20.

9. Loussouarn/Bourel, 657; vlg. auch Colette Baumann, 35, 36; Picot, 13, 14; Rapport CN I, $20,21$.

10. Åhnlich: Mayer, 528 der als Ursache dieser abrupten Änderung die Entwicklung des Nationalgefithles sieht, das wohl eher: durch die Verkniipfung tnit Blutsverwandschaft als mit zufälliger Geburt auf dem Territorium entsteht. Vgl. übrigens Fourré, Revue Jur. Pol. Indép. Coop. 1984; 567-570.

11. Loussouarn/Bourel, 657 weisen darauf hin, daß3 Frankreich damals 27 Millionen Einwohner zählte, Deutschland 20 Millionen und England lediglich 16 Millionen; vgl. Mayen, 529.

12. Uber die ursprïnglichen Code civil-Bestimmungen: Hecker, Code Napoléon, 7-20.

13. Vgl. auch Aitt. 4 der Constitution von 22 Frimaire Jahr VIII: "La qualite du citoyen se perd: - par la naturalisation en pays étranger; par l'acceptance de fonctions ou de pensions offertes par un gouvermement étranger: par l'affilliation a toute corporation étrangère quil supposerait des distinctions de naissance; par la condamnation a peines afflictives ou infamantes". Der ursprüngliche Text des $\mathrm{Cc}$ kannte auch noch Verlust der Staatsangehörigkeit wegen Eintritt in eine Korporation mit Geburtsunterschieden. Durch Gesetz vom 3. September 1807 wnurde dieser Verlustgrund aber gestrichen. Siehe Roman, 17, 21.

14. Vgl. Locre, 274-292; Merlin, Bd. 5, 317.

15. Bulletin des Lois de la République (BL), III. série, No. 224, SC No. 2044; siehe auch Textes NF, 55. Dieser Senatskonsult gailt anfänglich nur für die Dauer won fünf Jahren, wurde aber durch Senatskonsult vom 19. Februar 1808 durch eine unbeschränkte Regelung ersetzt (BL, IV. série, No. 181, SC No. 3064; siehe auch Textes NF, 56; Im 
Senatskonsult von 1808 wurde selbstverstündlich nicht melir von "Rẹpubilque" sondern von "i "Etat" gesprochen.

16. BL IV. série, Nr. 229. Dekret 4195; siehe auch Textes NF, 56; "Lorsqu'un etranger, en se conformant aux dispositions de l'acte des constitutions de l'Empire du 22 frimaire an VIII, aura rempli les conditions exigees pour devenir citoyen français, sa naturalisation sera prononcée par Nous. La demande en naturalisation et les pieces a l'appui seront transmises par le maire du domicile du pétitionnaire au préfet, qui les adressera, avec son avis, notre grand-juge ministre de la Justice......".

17. BL serie 4, Nr. 387, Dekret 7186; siehe auch Textes NF, 57, 58. Das Dekret wurde aufgehoben von Art. 6 vom Gesetz vom 26. Juni 1889 .

18. Dekret vom 28. März 1848, J.O. vom 31. März 1848; 10 BL 20, Nr. 178; Textes NF, 59.

19. Gessetz des 13, 21. November, 3. Dezember 1849, 10 BL 218, Nr. 1814; J.O. vom 3. Dezember 1849; Textes NF, 59, 60; geändert durch Gesetz des 29. Juni 1867 (I.O. vom 5. Juli 1867) and Dekret vom 26. Oktober 1870 (J.0. vom 31. Oktober 1870).

20. Gesetz vom 22. März 1849, $10 \mathrm{BL} 139, \mathrm{Nr}$. 1214; Textes NF, 59. Siehe dariber Colette Baumann, 48-52, 100-102; Rapport CN II, 21.

21. $10 \mathrm{BL} 352, \mathrm{Nr}$. 2730; J.O. vom 12. Februar 1851; Textes NF, 60. Siehe dariber Colette Baumann, 53-56, 103-110; Batiffol, Interpretation, 135; Jean Merlin, 7; Rapport CN II, 22, 23. Hauptgrund dieser Anderung war "I'odieux privilege des fils d'étrangers nés en France qui, pour se soustraire, aux charges du recrutement militaire, $s^{7}$ abstiennent de faire déclaration requise par le Code civil, allors pourtant qu'ils prennent leur part dans les affouages et pâtis communaux".

22. Gesetz vom 16. Dezember 1874 (J.0. vorn 29. Dezember 1874, Textes NF, 61, 62.) und Gesetz vom 14. Februar 1882 (J.O. vom 16. Februar 1882). Dariber Audinet, Journal du droit international privé 1889, 200; Hecker, Code Napoleon, 8, 9; Rapport $\mathrm{CN} \mathrm{II,} 22,23$.

23. $11 \mathrm{BL} 1503, \mathrm{Nr}, 15.256 ;$ J.O. vom 5. Juli 1867; Textes NF, 60.

24. J.O. vom 28. Juni 1889; Textes NF, 62-64. Siehe u.a. Andinet, Journal du droit international privé 1889, 197-206; Colette Baumann, 57-68, 111-120; Beauchet, Archiv für öffentliches Recht 1891, 443-465; Louis-Lucas, 4; Rapport CN II, 23-26.

25. Audinet, Journal du droit internationaal prive $1889,198-201$; Beauchet, Archiv fur offentliches Recht 1891, 449-458* Jean Merlin, 7; Picot, 15, 16.

26. Picot, 18.

27. Rapport CN II, 24.

28. Rapport CN II, 24, 25.

29. J.O. vom 23. Juli 1893; siehe auch Textes $\mathrm{LN}, 64,65$. Art. 8 Ziffer 3 Cc 1889 wurde durch Gesetz wom 18. Oktober 1915 (J.O. vom 26. Oktober 1915; siehe auch Textes NF, 67) für Kinder beligischer Eltern eingeschränkt. Siehe hieriber Colette Baumann, 69-73, 121-125; Jean Merlin, 7.

30. Art. 8 Ziffer 5 unter c Cc 1889 erwàhnt in großen Zügen die gleichen Verdienste, die bereits im Senatskonsult von 1802 erwähnt wurden und nennt zusätzlich den Militärdienst. Vgl, Audinet, Journal du droit international prive 1889, 201-205.

31. Loussouarn/Bourel, 660, Roman, 22-37. Roman, 31 weist darauf hin, daß die Stantsan" gehörigkeit aufgrund eines Dekrets vom 27. April 1848 weiter wegen Sklavenhandell oder Besitz won Sklawen verloren werden konnte; dazu auch Louis-Lucas, 11; vgl. Audinet, Journal du droit international privé 1899, 205, 206; Beauchet, Archiv für offentliches Recht $1891,460-462$.

32. Loussouam/Bourel, 658-661; Rapport CN I, 23-28; siehe bereits Audinet, Joumal du droit international prive $1889,197$.

33. Hecker/Tomison, 17; Loussouarn/Bourel, 658, 659.

34. Hecker/Tomson, 18; Loussouarn/Bourel, 659 .

35. Hecker/Tomson, 17; Loussowarn/Bourel, 659; Mayer, 530.

36. Hecker/Tomsion, 18 (mit Hinweis auf Lerebours, 72); fast identisch; Loussouarn/Bourel, 659 (ohne Literaturhinweis, weil Loussouarn/Bourel die Bearbeiter von Lerebours sind).

37. Vgl. Roman, 74

38. Siehe oben Fußnote 16: Änderung von Art. 8 Ziffer 3 und Art. 9 Cc.

39. J.O. vom 8. April 1909; Textes NF, 65; Einfügung won Art. 20 Abs. 4 Cc. 
40. Entwurf vom Justizminister Ratier, siehe daruber Louis-Lucas, 5-10 (mit weiteren Literanurhinweisen); Picot, 22-24. Picot, 25-76 beschreibt weiter den Inhalt der Entwirfe aus den Jahren $1916,1922,1925$ und 1927.

41. Gesetz vom 7. April 1915 (J.O. wom 8. April 1915; Textes NF, 66, 67) betreffend die Aberkennung der Einbitigerung beil ehemaligen Angehörigen der Feindmächte; Gesetz vom 18. Oktober 1915 (J.O. vom 26. Oktober 1915; Textes NF, 67) betreffend Einschränkung von Art. 8 Abs. 3 für Belgier: Gesetz vom 18. März 1917 (J.O. vom 21. März 1917; Textes NF, 67) betreffend den Staatsangehörigkeitserwerb einer Auslärnderin, die einen Franzosen heiratet und Änderung von Art. $12 \mathrm{Cc}$ für dile Kriegszeil; Gesetz vom 18. Juni 1917 (J.O. vom 20. Juni 1917; Textes NF, 67-69) betreffend die Aberkennung der Staatsangehörigkkeit eingebürgerter ehemaliger Feindangehöriger; Geserz vom 3. Juli 1917 iber den Staatsangehörigkeitserwerb der von Ausländern während des Krieges geborenen Kinder; J $\mathrm{JO}_{\text {. }}$ vom 5. Juli 1917; Textes NF, 69, 70. Dazu Roman, 51-71; Louis-Lucas, 5.

42. J.O. vom 14. August 1927; Textes NF, 73-76. Vgl. auch Durchfilhrungsdekret vom 10. August 1927, J.O. vom 18. August 1927; Textes NF, 76-78. Siehe u.a. Colette Baumann, 74-97, 126-140; Lowis-Lucas, 23-292; Picot, 77-153; Rapport CN II, 26-28; Valery, $9-81$.

43. Von 1927-1938 erwarb sie jedoch automatisch die französische Staatsangehörigkeit, wenn sie ihre bisherige durch die EheschlieBung automatisch verlor; Louis-Lucas; 184-192; Picot, 118-121; Valéry, 63-65; vgl, daruber kritisch Alice Weber, Diss. Zürich 1930.

44. Picot, 135-144; Roman, 74-93, wlg. weiter 94-117; Valéry, 66-79.

45. Vgl. bereits Picot, 155-173.

46. J.O. van 20. Julli 1934; Textes NF, 80.

47.

48.

49.

50. Gesetz vom 28. August 1936, J.O. wom 30. August 1936; Textes NF, 80.

Gesetz vom 20. Mai 1937, J.O. vom 21. Mai 1937; Textes NF, 80.

Eine kleine Anderung von Art. 6 Abs. 3 Ziffer 3 wurde noch vorgenommen durch ein Gesetz vom 25. Juni 1937, J.O. vom 27. Juni 1937; Textes NF, 80, 81.

Dekret vom 12. November 1938 über die Rechtsstellung der Ausländer, J.O. wom 13. November 1938; Textes NF, 81-84; Jean Merlin, 7.

51. Zu erwăhnen sind: Dekret vom 9. September 1939 betreffend die Staatsangehörigkeït der Frau feindlicher Ausländer (J.O vom 14. September 1939; Textes NF, 85, 86); Dekret vom 9. September 1939 betreffend die Aberkennung der Staatsangehörigkeiit (J.O. vom 14. September 1929; Textes NF, 85); Dekret vom 19. Oktober 1939 betreffend den Wiedererwerb der Staatsangehörigkeit für Ehefrauen (J.O. vom 27. Oktober 1939; Textes NF, 86); Dekret vom 19. Oktober 1939 betreffend das Optionsrecht von in Frankreich geborenen Ausländerkindern (J.O. vom 27. Oktober 1939; Textes NF, 86); Dekret vom 9. März 1940 betreffend den Verlust der Staatsangehörigkeit bei Einbürgerung im Ausland (J.O. vom 21. März 1940; Textes NF, 87); Gesetz vom 16. Juli 1940 befreffend das Verfahren der Aberkennung der Staatsangehörigkeit (J.O. vom 17. Juli 1940; Textes NF, 87, 88; bestǘtigt won der Ordonnance vom 24. Mai 1944); Gesetz vom 28. Oktoher 1940 betreffend Fristhemmungen (J.O. vom 15. November 1940 Textes NF 88; bestätigt durch Ordonnance vom 30. Dezember 1944). Dazu Roman, 120-143; vgl. Rapport CN II, 28.

52. Lagarde, 28,29; vgl weiter die arntliche Begrindung, in deutscher Übersetzung bei Hecker/Tomson, 140-145; Físslein, 5, 6.

53. J.O. vom 20. Oktober 1946; Textes NF, 91-111; siehe auch Ausfithrungsdlekret vom 2. November 1945 (Nr. 45-2698; J.O. vom 4. November 1945; Textes NF, 112-114). Dazu Füsslein, 6-14; Jean Merlin, 7; Rapport CN II, 28, 29.

54. Lagarde, 28

55. Lagarde, 29

56. Z.B.: Gesetz vom 24. Mail 1951, I.O. vom 31. Mai 1951 (betreffend den Staatsangehörigkeitserwerb durch die ausländische Ehefrau eines Franzosen); Ordonnance vom 7. Januar 1959, J.O. vom 8. Januar 1959 (aindert einige Bestimmungen bezüglich der Einbürgerung und des Erwerbs der franzósischen Staatsangehörigkeit aufgrund der Geburt und des Aufenthalts in Frankreich); Gesetz vorn 28. Juli 1960, J.O. vom 30. Juli 1960 (fiugt u.a. einen Titel uber die Anerkennung der französischen Staatsangehörigkeit in den CNF ein); Gesetz vom 22. Dezember 1961, J.O. vom 23. Dezember 1961 (aindert 11 Artikel und hebt 3 weitere auf); Gesetz vom 11. Juli 1966, J.O. vom 
11. Juli 1966 (aindert einige Vorschriften bezüghich der staatsangehorigkeitsrechtichen Folgen der Adoption); siehe u.a. Dischler, StAZ, 1957, 19-22.

57. J.O. vom 10. Januar 1973, Textes NF, 23-25. Dazu Brinkman, PS 1973, Floyd, New Law Journal 1977, 1006, 1007; Hertz, Tulane Law Review 1973, 33-36", 105-124: Lagarde, RCDIP 1973, 431-469; Merlin, 7-8; Rapport CN II, 29; Rieck, StiAZ 1973. 243-251; Viatte, Journal des Notaires $1973,553-560$.

58. Lagarde, 30; Jean Merlin, 10.

59. Verordungen vom 10. Juli und 28. Dezember 1973 und 23. September 1974. Siehe Lagarde, 302-315; Textes NF, 39-46.

60. Gesetz Nr. 74-631, J.O. 1974,7099.

61. Die Art. $30,44,45,53$ und 66 wurden geändert, während die Art. 64 und 67 aufgehoben urden.

62. Gesetz Nr. 76-1176, J.O. 1976, 7364.

63. Gesetz Nr. 78-731, J.O. 1978, 2784. Die Art. 115, 116 CNF. Siehe auch Dekret Nr. $80-306$ von 25 . April 1980, I.O. 1980, 1122.

64: Gesetz Nr. 78-753, J.O. $1978,2855$.

65. Gesetz Nr. 83-1046, J.O. 1983, 3550; siehe auch Gesetz Nr. 83-1096 vom 20. Dezember 1983, J.O. 1983, 3667 .

66. Vgl. Assemblé Nationale, septieme Législature, première session ordinaire 1983/1984, Nr. 1806 , S. 5: "Il est contraire au principe de l'égalite civile qui exige que tous les Français jouissent des mêmes droits, et à ce titre ne permet pas l"assimilation totale des Français naturalisés aux autres catégories des Français".

67. Gesetz Nr. 84-341, J.O. 1984, 1355; dazu u.a. Lagarde, RCDIP 1984, 541-546.

68. AuBer der Anderung von Art. 37-1 CNF wurde Art. 39 abgeảndert und Art. 96 Abs. 2 aufgehoben. Siehe Assemblée nationale, Septieme législature, seconde session ordinaire 1982/1983, Nr. 2049, S. 2: "Il a pour objectif, d"une part, d'unifier le régime d'acquisition de la nationalite française par mariage en supprimant les discriminations entre conjoints etrangers et apatrides et, d'autre part, de rendre plus rigoureuses les conditions d"acquisition de la nationalitê française par mariage pour lutter contre les mariages de complaisance"".

69. Assemblée Nationale, Huitième Législature, première session ordinaïre 1986/1987, Nr. 444. Der Expose des motifs dieses Gesetzesentwurfes ist darin abgedruckt auf den Seiten 3-6, der eigentliche Gesetzesentwur auf den Seiten 7-14.

70. Siehe daritiber kritisch Rapport CN II, 131-133, 218, 219 (Propositions 15-17).

71. Auch die Commission de la Nationalite ist für die Handhabung dieser Regelung des "double droit du sol": Rapport CN II, 115-117; 213 (Proposition Nr. 2).

72 .

73. Vgl. Le Monde vom 11. September 1987 (S. 10): "M. Jacques Chirac l'a clairement laissé entendre: le code de la nationalité ne sera pas réformé avant l'élection présidentielle du printemps $1988^{\prime \prime}$.

74. Dieser Bericht wurde alls Taschenbuch herausgegeben: Etre français aujourd'hui et demain, Rapport de la Commission de la nationalite présenté par M. Marceau Long, president, au Premier ministre; Tome I, Les auditions publiques; Tome II, Conclusions et propositions de la Commission de la Nationahité, Paris 1988.

75. Audinet; Journal du droit international prive 1889, 198, 199; Beaucher, Archiv fur offentliches Recht 1891, 444-446.

76.

77.

78.

Valéry, 22, 23; Rapport CN II, 27.

Locre, 87,88 .

Beauchet, Archiv fur offentliches Recht 1891, 446-448; Batiffol, Interpretation, 132; Valery, 23.

79. Audinet, Journal du droit international privé 1889, 198-201; Beauchet, Archiw fur öffentliches Recht 1891, 449-453; Rapport CN II, 23.

80. Ditoit, 124-126; Jean Merlin, 13; Rapport CN I, 31.

81. Übersetzung bei Tomson, 69; siche einige statistische Daten in Rapport CN $1.48,49$, 52.

82. Brinkman, PS 1973, 33-34; Lagarde, 51; Plender, ICLQ 1974, 719-721; Rapport CN 1, 31,32 .

83. Kritik hieran übt Tomson, 23 aus. Siehe Rapport CN I, 32, vgl. auch Proposition 41 der Commission de la Nationalite, Rapport CN II, 226.

84. Gemäß französischem Recht mit is Jahren. 
85. Hieniber Lagarde, RCDIP 1973, 437 (vor allem Fußnote 2); Jean Merlin, 13; Rapport CN 1, 32. Im Rapport CN II, Proposition 1 wird vorgeschlagen, die Möglichkeit einer solchen Verzichtserklärung auch noch im Jahr nach Erreichung der Volljährigkeit zu bieten.

86. Dies steht ganz in Übereinstimmung mit dem Ausgangspunkt der geltenden Fassung des Code Civil, um eheliche und wichteheliche Kinder soweit wie möglich gleich zu behandeln. Vgl. Loi 72-3 dex 3. Januar 1972, Recueil Dalloz Sirey 1972, 52-58. Siehe auch Nerson, 720-723; Rapport CN 1, 32.

87. Die gleiche Behandlung ehelicher und nichtehelicher Kinder ist im Staatsangehörigkeitsrecht seit 1973 verwirklicht durch Ergänzungen in đler "Assemblée nationale". Siehe darüber ausfuhrlich Hertz, 109-113

88. Vgl. NWG unter "Frankreich" 42

89. Guiho, Famille, 316-321.

$90 . \quad$ Guiho, Famille, 321-353.

91. Lagarde, 58-59; Rapport CN I, 32; Tomson, 18-19

92. Lagarde, 57-62; NWG unter "Frankreich", 44-45; Rapport CN 1, 32; siehe auch statistische Daten auf S. 52.

93. Vgl. Tribunal de grande instance d'Avesnes-sur-Helpe du 21 mars 1975, RCDIP 1975, 621-628 mit Anmerkung von Lagarde; Jean Merlin, 14" Rapport CN I, 32.

94. Dies gilt ebenfalls für in Frankreich geborene Kinder von in den fruheren "territoires: d"outre-mer" vor ihrer Unabhängigkeit geborenen Personen. Die Commission de la nationalité, Rapport $\mathrm{CN}$ II, 168-173, 224 (Proposition 37) schlägt vor, diese Regelung. einzuschränken auf vor dem 1. Januar 1995 geborene Kinder.

95. Dariber Tomson, 17; Lagarde, 62-64; Jean Merlin, 14; Rapport CN I, 34. Die Commission de la Nationalite, Rapport CN III, 115-117; 213 (Proposition 2) möchte diese Regelung handhaben.

96. Nach Ansicht der Commission de la Nationalité, Rapport CN II, 214 (Proposition 3) soll diese Verzichtsmöglichkeit auch noch im Jahr nach Erreichung der Volljăhrigkeit gegeben sein.

97. Lagarde, 99-104; Rapport CN I, 34; Tomson, 22, 24, 25. Siehe weiter einige statistische Daten in Rapport CN I, 52, 53. Die Regelung der Art. $44 \mathrm{ff}$. und $52 \mathrm{ff}$. CNF soll in nächster Zukunft eingehend geändert werden. Siehe Art. 44 des von der Regierung Chirac beim Parlament eingereichten Gesetzesentwurfes (oben Fußnote 69) und Rapport CN II, 119-134, 214-219. Die Commission de la Nationalité schlägt folgende Regelung vor. Die Regelung des Art. 44 CNF, kraft dessen jede in Frankreich von ausländischen Eltern geborene Person bei Volljährigkeit automatisch die französische Staatsangehörigkeit erwirbt, wenn sie zu diesem Zeitpunkt ihren Aufenthalt in Frankreich hat und wenn sie dort auch während der füf vorangehenden Jahre ihren gewöhnlichen Aufenthalt hatte, wird aufgehoben. In Frankreich geborene Personen sollen aber ab Vollendung ihres 16. Lebensjahres für die französische Staatsangehörigkeit optieren können, unter der Voraussetzung, daß sie die vorherigen fünf Jahre in Frankreich lebten. Die Optionserklärung muB vor Vollendung des 21 . Lebensjahres abgegeben werden. Für eine vor Vollendung des 18. Lebensjahres abgegebene Optionserklärung brauchen sie nicht die Einwilligung ihrer Eltern. Eine wor Vollendung des 18 . Lebensjahr abgegebene Optionserklärung kann von der Regierung nicht zurickgewiesen werden. Es handelt sich also um ein reines Optionsrecht. Eine nach Vollendung des 18. Lebensjahres abgegebene Optionserklairung kann won der Regierung zurückgewiesen werden aufgnund "'-condarnnation à une peine d'emprisonnement pour crimes et delits liés au terrorisme ou atteintes a la sûreté d'Etat;

- condamnation à une peine ferme de six mois d'emprisonnement pour proxénétisme ou pour trafic de stupéfiants:

- arrêté d'expulsion prononcé en raison de comportements constituant une menace pour l'ordre public". Die Möglichkeit einer Zurickweisung einer Optionserklarung auf grund "indignité" oder "deffaut d'assimilation" soll aufgehoben werden.

98. L'arrếté d'expulsion.

99. L'arrêté d'assignation à résidence. 100. Lagarde, 99-107; NWG, unter in Frankreich 45-46; Jean Merlin, 16; Rapport CN I,

101. Merlin, 16; Rapport CN I, 34 . 
102. Im CNF wird ausdricklich betont, daB eine schwache Adoption keinen Enwerb der französischen Staatsangehörigkeit bewirkt. Art. 55 CNF sieht fï schwach adoptierte minderjährige Kinder aber ein Optionsrecht mit Widerspruchsworbehalt vor.

103. Beauchet, Archiv für öffentliches Recht 1891, 457; Füsslein, 9, 10; Louis-Lucas, 184-192; Rapport CN II, 25.

104. Siehe über die Interpretation des Art. 37-1 CNF: Cour d'appel de Lyon 16. Januar 1980 (wozu Audit, Joumal du droit international 1981, 346-354); Cour de cassation 17. November 1981 (wozu Foyer, RCDIP 1982, 669-677); und Cour de cassation 19. Dezember 1983 (wozu Lagarde, RCDIP 1984, 617-623).

105. Dazu u.a. Annoussamy, Rev. Jur. Pol. Indép. Coop. 1984, 87-93.

106. Beauchet, Archiv für offentliches Recht 1891, 451-453; Füsslein, 8; Louis-Lucas, 88-91; Picot, 15, 16; Rapport CN II, 24, 25; Valéry, 24-33.

107. Füsslein, 8; Louis-Lucas, 75-87; Picot, 91-100; Valéry, 34-37.

108. Füsslein, 8, 9; Louis-Lucas, 142-146; Picot, 101-117.

109. Audinet, Journal du droit international privé 1889, 201; Beauchet, Archiv für öffentliches Recht $1891,454-456$.

110. Beauchet, Archiv für öffentliches Recht 1891, 463-465; Füsslein 9 ; Louis-Lucas, 283-288; Picat, $145-148$.

111. Merlin, 15; Rapport CN I, 35; II, 26; Frankreich mal für die einzubürgernde Person "le centre de ses intérêts" haben. Vgl. Conseil d'Etat 28. Februar 1986.

112. Batiffol/Lagarde, 119-121; Hallaux/Foyer/de Geouffie de La Pradelle, 50; Mayer, 542.

113. Batiffol/Lagarde, 120; Hollaux/Foyer/de Geouffre de La Pradelle, 50; Mayer, 542.

114. Batiffol/Lagarde, 121; Hollaux/Foyer/de Geouffre de La Pradelle, 50.

115. Art. 64-1 CNF ermöglicht ohne Wartezeit die Einbuirgerung von Personen, die Angehörige von Gebieten oder Staaten sind, deren Amtssprache Französisch ist, unter der Voraussetzung, daß Französisch die Muttersprache der betreffenden Personen ist. Die Commission de la Nationalité schlägt nun, vor die Muttersprachevoraussetzang zu ersetzen durch die Forderung "qu"ils auraient été scolarisés pendant cing ans au moins dans des établissements enseignant en langue française" (Rapport $\mathrm{CN}$ II, 225; Proposition 39).

116. Batiffol/Lagarde, 120; Hollaux/Foyer/de Geouffre de La Pradelle, 542; vgl. Colomb.

117. Batiffol/Lagarde, 121; Hollawx/Foyer/de Geouffe de La Pradelle, 542.

1118. Batiffol/Lagarde, 120.

119. Batiffol/Lagarde, 119.

120. Die Einbirgenung darf auch rerweigert werden, wenn die verhängte Strafe durch Amnestie aufgehoben wurde; Conseil d'Etat 23. November 1981 , wozu Julien-Laferrière, Journal du droit intemational 1984, $577-583$. Vgl. dariber auch die Vorschläge der Commission de la Nationalité, Rapport CN II, 157-163, 222, 223 (Propositions 31-33).

12L. Batiffol/Lagarde, 119.

122. Vgl. in dieser Zusammenhang auch Proposition 28 in Rapport CN II, 221: "Les candidats à la naturalisation devraient être peus systé- matiquement qu'aujourd hui reçus pour un entretien personnalisé, dans un lieu prévu a cet effet, par ưn personunel autant que possible volontaire pour cette tâche et formé en conséquence".

123. Hollaux/Foyer/de Geouffre de La Pradelle, 51.

124. Die Commission de la Nationalité, Rapport $\mathrm{CN}$ II, 222 (Proposition 29) schlägt vor, auch in diesen Fallen eine Begrindung vorzu schreiben.

125.

125. Batiffol/Lagarde, 111-116; Hollaux/Foyer/de Geouffre de La Pradelle, 48,49. Rapport CN II, 139-141,219,220 schlägt vor, das Optionsrecht des ausländischen Ehegatten in melireren Hinsichten zu ändern. Die Optionserklärung soll erst ein Jahr nach Eheschiließung abgegeben werden können. Ein Wohnsitz in Frankreich wird aber nicht gefordert. Schon vor Ende dieser Jahresfrist kann jedoch optiert werden, wenn aus der Ehe ein Kind geboren worden ist. Nach Abgabe der Optionserklärung kann diese während eines Jahres auf Veranlassung der Staatsanwaltschaft vom Gericht zurickgewiesen werden: "en cas de défaut ou de cessation de la communauté de vie ou $s^{\prime \prime} i l$ appairaissait que le conjoint $s^{\prime} e s t$ livré au profit d'un Etat étranger à des actes incompatibles avec la qualité de Français et préjudiciables aux intérêts de la France". Die Mögliclıkeit einer Zurüickweisung einer Optionserklärung aufgrund "indignité" oder "deffaut d"assimiliation" soll aufgehoben werden. 
127. Vgl. Proposition 35 der Commission de la Nationalite, Rapport CN II, 223: "La faculté d'opposition a posteriori des pouvoirs publics ne subsistant que dans le cas des acquisitions de la nationalite par déclaration souscrite à la suite d'un mariage, il y at lieu d'abroger toutes les dispositions se référant à la procédure d'opposition par décret ....". Vgl Rapport CN II, 137: Zwrischen 1984 und 1986 haben 38.103 Personen die französische Staatsangehörigkeit durch eine Erklärung aufgrund Art. 37-1 CNF erworben; lediglich $15 \mathrm{Mal}$ worde die Option von der Regierung zurlickgewiesen. Siehe weiter Rapport CN H, 255, 256.

128. Merlin, 16, wreist darauf hin, dafi in diesem Falle der Erwerb der französischen Statsangehơrigkeit nicht ausgeschlagen werden karn und die französische Regierung keine Widerspiruchsmöglichkeit hat.

129. Rapport CN I, 37. Die Commission de la Nationalite, Rapport CN II, 142-145, 220, 221 schlägt Anderungen der Regelung der Erstreckung wor. Fortan soll sich der Erwerb der französischen Staatsangehörigkeit durch eine Person nur auf deren ninderjathrige Kinder erstrecken, die ihren gewöhnlichen Aufenthalt bei dem betreffenden Eiternteil haben. Falls ein Minderjähriger deshalb die französische Staatsangehörigkeit nicht erwirbt, muß er eingebürgert werden können, sobald er den gleichen gewöhnlichen Aufenthalt wie sein in Frankreich eingebiirgerter Elternteil nimmt. Einbïrgerungsturkunden und Optionserklärungen sollen fortan die Namen sämtlicher Kinder, uber die sich der Staatsangehörigkeitserwerb erstreckt, beinhalten. Dies vereinfacht für diese Personen den Beweis des Erwerbs der französischen Staatsangehörigkeit. Die Erstreckung des Erwerbs der Staatsangehörigkeit soll sogar dann erfolgen, wenn Minderjathrige wegen in Art. 79 CNF erwahnten Delikten venurteilt worden sind.

130. Vgl. dazu Conseil d"Etat 11. Mai 1987, woriber Schrameck, Rev. fr. droit adm. 1987, 625-627, siehe einige statistische Daten über die Wiedereinbiirgerung in Rapport CN I, 53,54 .

131. Audinet, Journal du droit international privé 1889, 204; Beauchet, Archiv fir öffentliches Recht 1891, 461; Batiffol, Interprétation, 131, 132; Batiffol, Evollution 183, 184; Fusslein, 9, 10; Rapport CN II, 25.

132. Louis-Lucas, 238-245; Picot, 118-128

133. Bahrfeldt, 43-55; Beauchet, Archiv für offentliches Recht 1891, 460, 461; LouisLucas, 217-235; Picot, 133-137.

134. Batiffol, Evollution, 161 weist darauf hin, daß diese zusätzliche Voraussetzung zal gleicher Zeit mit der allgemeincn Wehrpflicht eingefuihrt wurde; siehe weiter Audinet; Journal du droit international privé 1889, 204: Beauchet, Archiv für öffertliches Recht 1889, 461; Füsslein, 11; Louis-Lucas, 228-230.

135. Audinet, Journal du droit international privé 1889, 204; Beauchet, Archiv für offentliches Recht 1891, 461, 462; Batiffol, Evolution, 167, 168; Louis-Lucas, 258-66; Roman, 28-34.

136. Louis-Lucas, 258-266; Picot, 138-139.

137. Fusslein, 11

138. Batiffol, Evolution, 160 betont: "La cause principale de l'abrogation en 1889 de $1^{*}$ article 17 (4) du Code civil parait avoir etté la difficulté de la preuve de la perte de l"esprit de retour".

139. Vgl. Batiffol/Lagarde, 136,137.

140. Batiffol, Evolution, 165,166; Beauchet, Archiv für öffentliches Recht 1891, 461; Fisslein, $11,12$.

141. Art. 8 vom Dekret vom 27. April 1848 und Gesetz vom 11. Februar 1851; Beauchet, Archiv für offentliches Recht 1891, 462; Louis-Lucas, 11, 257; dazu Roman, 21, 22, $34-37$

142. Louis-Lucas, 269-278; Roman, 130-143.

143. Batiffol/Lagarde, 137.

144. Da Frankcreich aber die Straßburger Europaratskonvention zur Verminderung von Fallen melirfacher Staatsangehörigkeit ratifiziert hat, gilt eine Ausnahme, wenn die Staatsangehơrigkeit einer anderen Partei dieser Konvention erworben wird; siehe Batiffol, Evolution, 162; Guiho, 151-167; Jean Merlin, 10; Rapport CN 1, 39.

145. Lagarde RCDIP 1984, 541-546.

146. So auch Conseil d'Etat 25. Juli 1986, wrozu Bonichot, Rev. fr. droit adm. 1987, 616-623 und Lagarde, RCDIP 1987, 549-552. Siehe statistische Daten in Rapport CN I, 54 . 
147. Statistische Daten in Rapport CN I, 54, 55. Doppelstaatlern, die in Frankreich ihren gewöhnlichen Aufenthalt haben, wird die Ausbürgenung in der Regel verweigert.

148. Fuisslein, 11, 12; Rapport $\mathrm{CN} \mathrm{I,} \mathrm{38,} 39$

149. Dazu u.a. Batiffol, Evolution, 160, 161; Lagarde, RCDIP 1973, 448. Die Commission de la Nationalite schlägt vor, den Erwerb der franzôsischen Staatsangehörigkeì bei Geburt im Ausland einzuschränken. Siehe Rapport CN II, 178-180, 226, namentlich Proposition 41: "Les Français par filiation apartenant a la deuxieme géneration né a $l^{\prime}$ étranger devraient pouvoir faire reconnâtre leur nationalité française par une declaration contirmative, .... . Cette déclaration devrait pouvoir être fatte par l"intéressé sa vie durant, .... A defaut, sa nationalite ne serait plus transmissible de plein droit par filiation à ses descendants".

150. Siehe Cour de cassation 17. Februar 1982, wozu Batiffol, RCDIP 1983, 249-257; vgl, auch Batiffol, Observations, 176-178; Batiffol, Evolution, 166, 167.

151. Batiffol/Lagarde, 145-147; Hollaw/Foyer/de Geouffre de La Pradelle, 56.

152. Batiffol/Lagarde, 148-150, vgl. auch 122, 123; Hollaux/Foyer/de Geouffre de La Pradelle, 57.

\section{NOTEN GROSSBRITANNIEN}

1. Dummett, British Journal of Law and Society 1981, 233; Stanbrook, XI; vgl. die Aussage von Parry, 5: "there is not and never has been any domestic concept of British nationality as such".

2. British Nationality Act 1981 (Commencement) Order 1982, SI 1982/933. Die Sections 49, 53 traten bereits am 30 . Oktober 1981 in Kraft. Siehe fur Anderungen des BNA 1981: British Nationality (Falkland Islands) Act 1983, British Nationality (Falklands Islands) Regulations 1983 (SI 1983, Nr. 479), British Nationality (Brunei) Order 1983 (SI 1983, Nr. 1699), Hong Kong. Act 1985 (Schedule) und Hong Kong (British Nationality) Order (SI 1986, Nr. 948). Der BNA 1981 ist u.a. abgedruckt bei Macdonald/Blake, 79-169 und Stanbrook, 133-205; Deutsche Ubersetzung bei Bergmann/Ferid, Internationales Ehe- und Kindschaftsrecht (Großbritannien) und in StAZ 1983, 222-231. Siehe auch die französischsprachigen Erörterungen von Killerby, Nationalité und Stanbrook, Jurisclasseur und den spanischen Aufsatz von Torres Ugena, Rewista Juridica de Catalunya 1983, 917-932.

3. Gesetz vom 30. Juli 1948, 11/12 Geo. 6, ch. 56. Der Nationality Act 1948 wurde 1958, 1964 (zweimal) und 1965 geändert; vgl hierzu J.M. Evans, 59.62; Turpin, 190195.

4. Gesetz vom 7. August 1914, 4/5 Geo. 5, ch. 17. Der Nationality Act 1914 wurde $1918,1922,1933$ und 1943 geändert.

5. Section 50 (1) BNA 1981; siehe auch J.M. Evars, 74-77; Macdonald/Blake, 25; von Mangoldt, StAZ 1983, 222; Turpin, 219-221.

6. Seit 1948 waren die Begriffe "British subject" und "Commonwealth citizen" Synonyme. Siehe nun aber Section 37 BNA 1981; vgl. die Aussage von Dummetr, British Journal of Law and Society 1981, 233: "Britishness has shrunk dramatically".

7. Section 15-25 BNA 1981; siehe weiter The British Nationality (Dependant Territories) Regulations 1982, SI 1982, Nr. 987), S. 2844 und "The British Dependant Territories Citizenship (Deprivation) Rules 1982, SI 1982, Nr. 989, S. 2861; vgl. Turpin, 222224.

8. Section 26-29 BNA 1981; dazu Turpin, 225, 226.

9. Section 30-32 BNA 1981

10. Section 38 und 50 (1) BNA 1981

11. "British citizen" (Section 1-14 BNA 1981)

12. Macdonald/Blake, 2; White, ICLQ 1974, 866-873; White/Hampson, ICLQ 1981, 250; vgl. auch Williams, Cambridge Law Journal 1948, 68-73; Blaser, Lausanne 1962 und Cuthbert Joseph, Gateshead 1968.

13. Henrich, in: Bergmann/Ferid (GroBbritannien); Halsbury's, suppl. 1985. Part 1, ad vol. 4. 27; White/Evans/Hampson, The Scots Law Times 1982, 17-21, 49-51.

14. Siehe kritisch: Blake, The Modern Law Review 1982, 192-195

15. Siehe darüber vor allem Giese, $11 \mathrm{ff}$.

16. Giese, 12, 13, der darauf hinweist daß im common law von "ligeance" gesprochen wird, und dals dieses Wort vom lateinischen "ligare" = binden stammt. In Calvin's case (7 Co.Rep. 1a" English Reports, vol. 77, 377) wurde "ligeance" definiert als: "The 
mutual bond and obligation between the King and his subjects whereby subjects are called his liege subjects because they are bound to obey and serve him..."; Bevan, 107. 108; Jones, 57-62; Cuthbert Joseph, 77; Plender, EPIL, Band 8, 53; Vanel, RCDIP 1951, 12-15.

17. Bevan, 107-109.

18. Vgl. bereits Elyas de Rabayn's case (1290; Bracton, De Legibus et Consuetudinibus Anglate (ed. Woodbire 1915), folio 427b); Giese; 12; Parry, 28; Plender, EPIL, Band 8. 53, Ross, Grotian Society Papers 1972, 5-8.

19. So für Thronfolger bereíts das Statut "De natis ultra mare" aus 1351 (25 Edw. $\mathbb{I}$, ch. 1; wg1. auch 42 Edw. II, ch, 10); Cockburn, 7-9; Giese, 13; Parry, 30-34 ff; Ross, Grotian Society Papers 1972, 8-10.

20. Auch bezeichnet als "Case of the Postnati" (7 Co. Rep. 1a; English Reports, vol. 77, 377). Giese, 13-17; Jones, 51-57; Cuthbert Joseph, 77, 78; Parry, 40-43; Plender, EPI, Band 8, 53.

21. 7 Anne, cli. 5, teilweise wieder aufgehoben won 10 Anne, ch. 5. Vgl dazu Parry, 60, 61 .

22. Giese, 17; Plender, EPI, Band 8, 53

23. Giese, 17; Parry, 60.

24. In Rex v. Eaton (1627, Lit. Rep. 23) z.B. wurde in einem "obiter dictum" davon ausgegangen, daB die Staatsangehörigkeit iure sanguinis auch in weiblicher Linie weitergegeben werden konnte. Anders aber British Nationality Act 1730 (13 Geo, III, c. 21). Vgl. auch British Nationality Act 1772; Cockburn, 10, 11; Odgers, 5; Plender, EPIL, Band 8,54 .

25. Giese, 17; Cuthbert Joseph, 78 .

26. Vgl. bereits die "denisation" of Elyas Daubeny in 1295 (Rot. Parl. I, 135a); Giese, 15, 16; Parry, 34, 35; Plender, EPIL, Band 8, 53.

27. Bevan, 109; Giese, 17, 18; Jones, 63-69; Parry, 34-40, 47-53.

28. Abgeleitet won "ex donatione regis" (Giese, 15, FuBnote 34). Bevan, 109; Giese, 16; Jones, 63" Parry, 34-40. Siehe uber denisations und naturalisations in der Periode 1509-1603: Page, passim.

29. Giese, 16; Jones, 66.

30. 7/8 Vict ch ch. 66. Cockburn, 34-36; Giese, 18, Parry, 69, 70; Plender, EPL, Band 8, 54. Aber auch nach 1844 konnte ein Ausländer nicht Reeder eines britischen Schiffes sein. So noch Merchant Shipping Act 1894, Section 1; siehe auch Section 14 Naturalization Act 1870.

31. 7/8 Vict., ch. 66, Section 16, woriber Cockburn, 12 und Parry, 71.

32. 33/34, Vict., ch. 14. Jones, 75-77; Cuthbert Joseph, 78-80; Parry, 78-80, 206-216.

33. Giese, 18, 19; Parry, 79.

34. Giese, 19.

Section 7; woriber Parry, 79.

Giese, 20; Jones, 78; Parry, 80, 81.

Jones, 72-74; Cuthbert Joseph, 80; Odgers, 28; Plender. EPIL, Band 8, 54.

Jones, 78, 79; Cuthbert Joseph, 81; Odgers, 1-9; Plender, EPIL, Band 8, 54.

Giese, 21; Jones, 80, 81; Cuthbert Joseph, 81-83; Plender, EPIL, Band 8, 55.

Plender, EPIL, Band 8, 55; Parry, 83.

4/5 Geo 5, ch. 17.

Dariber n.a. Plender, EPIL, Band 8, 55 .

45. Odgers, 26.

46. Section 7. Dariber Giese, 26.

47. 12/13 Geo 5, ch. 44. Dariber Giese, 24-27; Jones, 81, 82; Cuthbert Joseph, 86,87; vgl. auch die von Odgers, im Jahure 1916 gemachten Anderungsvorschlage.

48. British Nationality and Stans of Aliens Act 1922, 12/13 Geo 5, ch. 44, Giese, 24; Cuthbert Joseph, 86-89; Parry, 87; Jones, 82, weist darauf hin, daß diese Erweiterung des ius sanguinis eine Folge von Erfahrungen aus dem Ersten Weltkrieg war. Es hatte beeindrückt, da $\beta$ viele im Ausland geborene Personen britischer Abstammung, die nicht british subject waren, ins Mutterland zuriuckkehrten, un in der britischen Ammee zul dienen. 
49. British Nationality and Status of Aliens Act 1933, 24/25 Geo 5, ch. 49. Die Änderung geschah unter EunfluB des Haager Abkommens über Staatsangehörigkeïtsrecht aus 1930. Giese, 27, 28; Jones, 83; Cuthbert Joseph, 90, 91.

50. British Nationality and Status of Aliens Act 1943, 6/7 Geo 6, ch. 14, Vgl dariuber Jones, 84; Cuthbert Joseph, 89; Parry, 88, 194-199.

51. Dummett/Martin, 17; Hartley, RCDIP 1983, 574; Jones, 83; Cuthbert Joseph, 91-100; Parry, 92-94; White, Journal of the Law Society of Scotland 1983, 268 .

52. Canadian Citizenship Act vom 27. Juni 1946; Text bei Parry, 472-522. Siehe anch Fransman, 2; Cuthbert Joseph, 100-102; Turpin, 188, 189.

53. Bevan, 112; Fransman, 2; Jones, 88-95; Plender, EPIL, Band 8, 55.

54. Act vom 30. Juli 1948, 11/12 Geo 6, ch. 56; vgl. zu dieser Problematik Parry, BYIL $1953,247$.

55. Fransman, 4, 5; Giese, 32-34; White/Hampson, ICLQ 1981, 249, 250 .

56. Jones, 127-135.

57. Dummett/Martin, 17; Fransman, 5; Giese, 61; Jones, 123.

58. Giese, 52.

59. Jones, 190-195.

60. Siehe auch The British Protectorates "Protected States and Protected Persons Order in Council vom 29. Januar 1949 bei Jones, 264-268 und Parry, 356-363.

61. BNA 1948, Section 6.

62. Fransman, 4; Jones, 124, 173-185; Plender, EPIL, Band 8, 63.

63. Fransman, 4.

64. BNA 1948 Section 1 (1).

65. Giese, 53, 54; Jones, 185-189.

66. Dariber: Giese, 45, 46, Pany, 274, 275.

67. Giese, 36-38; Jones, 154-156; Parry, 229-238.

68. Giese, 38-40; Jones, 156-160; Parry, 239-253.

69. Giese, 38; Jones, 157; Parry, 242.

70. Giese, 38-40; Jones 158, 159; Parry, 244-253.

71. Fransman, 6, 7; Giese, 42, 43; Jones, 160-163.

$72 . \quad$ Jones, 85 .

73. British Nationality Act (Amendment) vom 20. Februar 1958, 6/7 Eliz. 2, C. 10; British Nationality Act (Amendment) vom 25. Mär 1964, 12/13 Eliz. 2, C. 22; British Nationality Act (Amendment) vom 16. Juli 1964, 12/13 Eliz. 2, C. 54; British Nationality Act vom 5. August 1965, 13/14 Eliz. 2, C. 34; Fransman, 9; Plender, EPIL, Band 8, 57. Weiter wurde der BNA 1948 mehrfach in Zusammenhang mit der Unabhängigkeit von bestimmten Territorien des Commonwealths abgeändert. Bevan, 148, Fußnote 60 erwahnt insgesamt 40 Ändenungen.

74. J.M. Evans, 15-23, 63-71; Macdonald/Blake, 5; Plender, EPIL, Band 8, 57; Turpin, 196-214; White/Hampson, ICLQ 1981, 251, 252.

75. Fransman, 9; Giese, 63, 64.

76. Act vom 18. April 1962, 10/1 1 Eliz. 2, C. 21 .

77. Bevan, 113, 114; Dummet//Martin, 17; Hartley, RCDIP 1983, 574; White, fournal of the Law Society of Scotland 1983, 268, 269.

78. Fransman, 7.

79. Bevan, 195-201; Giese, 64.

80. Act vom 1968, 16/17 Eliz. 2, ch. 9; siehe dazu u.a. Hepple, Modern Law Review $1968,424-428$.

81. Act vom 28. Oktober 1971, 19/20 Eliz. 2, ch. 77. Dariber Bewan, 192 ff.

82. Bevan, 114; Dummett/Martin, 12-14; Fransman, 10-17; Giese, 64, 65; Hartley, RCDIP 1983,575; White, Journal of the Law Society of Scotland 1983, 269, 270. Vgl. weiter Fransman, New Law Journal 1983, 691, 692, 727-731, 739-741, 787-789.

83. Vgl. Bevan, 201 ff; Fransman, 22, 23; White/Hampson, ICLQ 1982, 850. In diesem Zusammenhang ist tibrigens bemerkenswert, daß die Einwohner der Channel Islands und Isle of Man, wohl britische Staatsangehörige, aber keine "UK-Nationals" im Sinne des $\mathbb{E}$.W.G.-Abkommens sind.

84. Fransman, 23. Gemäß Sect. 5 BNA $1981 \mathrm{kann}$ ein Bürger Gibraltars durch Optionserklärung die britische Staatsangehörigkeit erwerben; dariber Bevan, 127: "a last-minute victory in the House of Lords".

85. Giese, 64,65 .

86. Fransman, 18-21. 
87. British Nationality Law: Discussion of Possible Changes, Command Paper 6795. Dazu u.A. Bates, Scots Law Times 1979, 33-36; 81-86; Rousseau, RCDIP 1977, 1166-1168; wgl. auch bereits Bindrnan, New Law Joumal 1976, 380-382.

88. British Nationality Law, Outline of Proposed Legislation, Command Paper 7987. Siehe Baker, Current Law Bulletin 1982,780-794; Samuels, New Law Journal 1980, 996-998; Trost, New Law Journal 1983, 3-5: White/Hampson, ICLQ 1981, 247-259; 1982, 849-855; White/Hampson, Public Law 1982, 6-20; White/Evans/Hampson, The Scots Law Times 1982, 17-21, 49-51. Vgl. auch Bewan, 114.

89. Krombach, 1-26; vgl. auch Dixon, Journal of Law and Society 1983, 161 der den BNA als "a vital but hitherto neglected feature of Thatcherist ideological politicis" beschreibt. Siehe ibber die Gesetzestechnik des BNA: Millet, Statute Law Review $1986,130-160$.

90. Dummett/Martin, 11; Fransman, 35; Wooldridge, Trent Law Journal 1981, 23, 24.

91. Dummett, British Joumal of Law and Society 1981, 234; Fransman, 38, 39; Halsbury's, Suppl. 1985, ad Vol. 4, 2; Khan, Solicitors Journal 1982, 403, 404; Macdonald/Blake, 14; Rousseaw, RCDIP 1983, 677; Torres Ugena, Revista Juridica de Catalunya $1983,921-927$.

92. Bevan, 129; Blake, Modern Law Review 1982, 189, 190; Dummett/Martin, 22-24; White/Hampson, ICLQ 1982, 850, 851; Halsbury"s, Supl. 1985, ad vol. 4, 35; Macdonald/Blake, 49-64; Torres Ugena, Revista Juridica de Catalunya 1983, 927-929. British Dependent Territories sind Anguilla, Bermuda, British Indian Ocean Territory, Cayman Islands, Falkland Islands and Dependencies, Gibraltar, Hong Kong, Montserrat, Pitcairn, Henderson, Ducie and Deno Islands, St. Helena and Dependencies, The Sovereign Base Areas of Akrotiri and Dhekelia, Turks and Caicos Islands und Virgin Islands. Die Einwohner der Falkland Inseln sind aber keine British Dependent Territories Citizen, sondern British Citizen (British Nationality (Falkland Islands) Act 1983) (dazu kritisch Dixon, Journal of Law and Society 1983, 163.

93. Dieser Status ist persönlich und kann nicht mehr weitergegeben werden. Bevan, 129, 130; Dummett/Martin, 24; Fransman, 39, Macdonald/Blake, 3, 65-68; White/Hampson. IICLQ 1982, 85; Halsbury"s, Suppl. 1985, ad col. 4, 36. Torres Ugena, Revista Juridica de Catalunya 1983,929,930 bezeichnet diese Kategorie etwas irrefuihrend als "Ciudadanos británicos en el extranjero".

94. Bevan, 132; Dummett/Martin, 10; Fransman, 3, 33; Macdonald/Blake, 6; von Mangoldt, StAZ 1983, 221; Plender, EPIL, Band 8, 58.

95. Diese leben hauptsächlich in Sri Lanka. Bewan, 132; Dummett/Martin, 25, 26; Macdonald/Blake, 68-70; Plender, EPL, Band 8, 58; Torres Ugena, Revista Juridica de Catalunya 1983, 930, 931; White/Hampson, Public Law 1982, 12, 13.

96. Siehe Bevan, 132; Dummett/Martin, 11, 24, 25; Halsbury's, Suppl. 1985, ad vol. 4, 38* Macdonald/Blake, 70; Plender, EPL, Band 8, 58.

97. Beachte weiter Section 2 (1) BNA 1964 (vom 16. Juli), worin bestimmt wurde, daßi das im Vereinigten Königreich oder Kolonien geborene Kind einer britischen Mutter immer die britische Staatsangehörigkeit erwarb, falls es sonst staatenlos sein wïrde Section 2 (2) desselben Gesetzes stellte klar, daß das im Vereinigten Königreich oder in den Kolonien aufgefundene Kind bis zum Beweis des Gegenteils als dort geboren gillt.

98. Odgers, 10-16.

99. Seit 1979 bestand unter gewissen Voraussetzungen aber die Möglichkeit ein solches Kind als britischer Staatsbürger registrieren za lassen. Dazu Brinkman, PS 1979, 54.

100. Gemais Section 23 (2) BNA 1948 erwarb das legitimierte Kind ausschließlich die britische Staatsangehơrigkeit des Vaters "if by the law of the place in which his father was domiciled at the time of the marriage the marriage operated immediately or subsequently to legitimate him, and not otherwise".

101. Adoption of Children Act 1949, Section 8; so auch Adoption Act 1976, Section 40 (1).

102. Uber diese Änderung: Bevan, 117, 118; Macdonald/Blake, 20, 25.

103. Blake, Modern Law Review 1982, 192, 193; Dummett/Martin, 27; von Mangoldt, StAZ 1983, 222; White/Hampson, Public Law 1982, 14.

104. Dummett/Martin, 27; Macdonald/Blake, 26; Stanbrook, 11, 12.

105. Bevan, 118-121; Dummett/Martin, 34; Macdonald/Blake, 27-30.

106. Stanbrook, 15, 16 .

107. Siehe SI 1982, 1004; dazu Dummett/Martin, 36. 
108. Bevan, 121, 122; Dummett/Martin, 36-41; Macdonald/Blake, 33 ff. Im BNA 1948 komnten in Ausland geborene Kinder won britischen Staatsbiirgern "by descent" immer durch registration die britische Staatsangehörigkeit erwerben; nun ist dies also nur noch unter bestimmten Voraussetzungen möglich. Bevan, 120.

109. In dieser Periode darf der betreffende Elternteil sich höchstens 270 Tage außerhalb des. Vereinigten Königreiches aufgehalten haben.

110. Gemäß Section 3 Abs. 4 BNA 1981 karm dieser Frist u.U. auf sechs Jahre verlängert werden. Für ein im Ausland geborenes staatenloses Kind britischer Eltern gillt nicht die Voraussetzung, daB ein Elternteil mindestens drei Jahre in Großbritannien gelebt haben muB.

111. Bevan, 120, 121 .

112. Das Kind $\mathrm{mu \beta}$ im Vereinigten Königreich geboren sein. Geburt an Bord eines britischen Flugzeuges oder Schiffes (oder Hovercraft. Section 50 (1) BNA 1981) reicht wahrscheinlich nicht aus (Section 50 (7) BNA 1981). Siehe daruber Macdonald/Blake, 25.

113. Siehe ijber diesen Begriff Bevan, 115; Blake, Madern Law Review 1982, 185-187* Dummett/Martin, 27-29; Macdonald/Blake, 21-23, 26; Stanbrook, 10, 11; White/Hampson, ICLQ 1982, 851, 852; White/Hampson, Public Law 1982, 14, 15; White/Evans/Hampson, New Law Journal 1981, 328, 329.

114. Section 8 (4) Buchstabe b und c Immigration Act 1971.

115. Section 8 (2) lautet: "The Secretary of State may by order exempt any person or class of persons, either unconditionally or subject to such conditions as may be inposed by or under the order, from all or any of the provisions of this Act relating to those who are not patrial. An order under this subsection, if made with respect to a class of persons, shall be made by statutory instrument, which shall be subject to annulment in pursuance of a resolution of either House of Parliament,"

116. Section 8(3) Immigration Act 1971.

117. Es muß im Moment der "registration" im Vereinigten Königreich leben, aber der Antrag der "registration" kann wăhrend des ganzen Lebens gestellt werden. So: Bevan, 116.

118. Bevan, 116; Dummett/Martin, 29.

119. Bevan, 115, 116 weist darauf hin, das der Terminus "newborn" nicht definiert ist. Während der parlamentarischen Debatten wurde darauf hingewiesen, daß dies aber noch ein einjähriges Kind mïtumfassen dïrfte. Ältere Kinder könnten allerdings u.U. iber Section 3 (1) als britische Staatsbürger registriert werden. Bevan betont weiter: "It is unfortunate that the benevolent use of executive discretion was so frequently relied upon during limitations, and here especially, of whatever age, are unlikely to be many. A broader concession would certainly not have been fatal to the Bill's overriding aims:. Vgl. auch Dummett/Martin, 32 und Macdonald/Blake, 27.

120. Stanbrook, 12 .

121. Siehe über die s.E. mangelhafte Bekämpfung der Staatenlosigkeit Blake, Modern Law Review 1982, 194, 195.

122. Vgl. das von Dummett/Martin, 31, 32 gegebene Beispiel.

123. Dummett/Martin, 33; Macdonald/Blake, 27; Stanbrook, 16.

124. Odgers, 26, 27, Parry, 83.

125. Giese, 44, 45; Parry, 267-272; Jones, 163-166. Siehe auch British Nationality Regulations Nr. 272 aus 1948, Section 7-10.

126. Odgers, 35.

127. Giese, 27; Jones 1947, 168-174.

128. Giese, 40; Jones $1947,186$.

129. Giese, 49 .

130. Giese, 20.

131. Naturalisation (Amendment) Act vom 6. Juli 1895, 58/9 Vic. 43, auch bei Polizei Hamburg, 94 und 98 .

132. Siehe aber die Einschränkungen duch BNA Act (Amendment) von 22. April 1943 (6/7 Geo. 6, c, 14), Section 7; Odgers, 17-19.

133. Giese, 27; Jones 1947, 165-167.

134. Parry, 268.

135. Section 13 BNA 1870; Section 25 BNA 1914; Odgers, 29, 30.

136. Siehe auch die British Nationality (Gieneral) Regulations 1982 , namentlich die Sections

3-7 (S.I. 1982, Nr. 986, S. 2830). Ufber die Einbïrgerungsvoraussetzungen u.a. Bevan, 
122 127; Blake, Modern Law Review 1982, 193, 194; Dummett/Martin, 50-54; Macdonald/Blake, 40-43. Gegen die Verweigerung einer Einbirgenung ist grundsätzlich keine Berufung möglich; vgl. dariber Bates; Public Law 1982, 179-187; vgl. Dummett/Martin, 52 .

137. Timothy Raison, Minister of State at the Home Office, in the House of Commons (Standing Committee F. Hansard, 19. März 1981, col. 692-3, 700), zitiert beil Bevan, 124 und bei Dummett/Martin, 52, 53.

138. Bewan, 124.

139. Gegeniber der Unbestimmtheit der Forderung "good character" ist Bewan namentlich auch deswegen kritisch, weil es keine Berufungsmöglichkeir gibt, wenn ein Einbürgerungsantrag zuruckgewiesen wird (Section 44 (2) BNA 1981). Siehe Bevan, 125, 126; vgl. dariber auch Bates, Public Law 1982, 179-187.

140. Dummett/Martin, 51; Macdonald/Blake, 41 .

141. Macdonald/Blake, 41.

142. Macdonald/Blake, 42; vgl. Stanbrook, 38.

143. Bevan, 140, mit Zitat von Mr. Raison M.P., Standing Committee Col. 188. Vgl. auch von Mangoldt, StAZ 1983, 222. Vgl. weiter Dummett/Martin, 61, 62.

144. Dummert/Martin, 51; Macdonald/Blake, 23.

145. Junior Home Office Minister, Standing Committee col. 692, zitiert bei Bevan, 124. und Macdonald/Blake, 40, 41. Vgl. Stanbrook, 38 .

146. Macdonald/Blake 43; White/Hampson, ICLQ 1982, 853.

147. Durnmett/Martin, 51-53.

148. Dummett/Martin, 41.

149. Dummert/Martin, 37, 38.

150. Dummett/Martin, 41-50.

151. Dummett/Martin, 48.

152. Dummett/Martin, 55, 56; vgl. British Nationality/(Fees) Regulations 1984, Nr. 230, S. 559.

153. Dummett/Martin, 53 .

154. Nemo potest, exuere patriam.

155. Williams, British Yearbook of Intemational Law 1927, 47, 48.

156. Giese, 48, 49; Parry, 324-328; Jones, 167-173.

157. Siehe dazu auch Section 8 und 9 British Nationality (General) Regulations 1982 (S.I. 1982, Nr. 986, S. 2830); Bevan, 132, 133; Dummett/Martin, 54, 55; Macdonald/Blake, 46: White/Hampson, ICLQ 1982, 854.

158. Dummett/Martin, 55, 56.

159. Siehe auch Section 10 British Nationality (General) Regulations 1982 (S.I. 1982, Nr. 986, S. 2830) (Notice of proposed deprivation of citizenship); weiter The British Citizenship (Deprivation) Rules 1982, S.I. 1982, Nr. 988, S. 2857; Bevan, 133-135; Blake, Modem Law Review 1982, 195-196; Dummett/Martin, 58, 59; Macdonald/Blaike, 46-48;

160. Bevan, 140; Macdonald/Blake, 45.

\section{NOTEN ITALIEN}

1. Siehe hierüber Hecker, Code Napoléon, 100, 101.

2. Durch Dekret vom 27. November 1870 wurde die Wirkung des Codice civile ausgedehnt auf Rom und durch Gesetz vom 26. März 1871 auf Venetien und Mantua.

3. Daríiber Doemer/Hecker, 17, 18, 314, 315; Hecker, Code Napoleon, 76-94, mit weiteren Hinweisen; Quadri, 316, 323; Gatteschi, 3, 4.

4. Für Kinder einer ehemaligen Italienerin und eines unbekannten Vaters galt aufgrund Art. 7 Abs. 2 C.c.it. entsprechendes.

5. Doerner/Hecker, 21, 22.

6. Gesetz Nr. 23; veröffentlicht in G.U. vom 4. Februar 1901, Nr. 29. Hieruiber Doerner/Hecker, 22, 23, 145, 146 .

7. Gesetz Nr. 217; veröffentlicht in G.U. vom 31. Mai 1906, Nr. 127. Hieriber Doemer/Hecker, $23,24,146,147$.

8. Doerner/Hecker, 27, 28.

9. Bemerkenswert ist, daß im Prinzip jeder auf seine ittalienische Staatsangehörigkeit verzichten konnte; Doemer/Hecker, 24, 25. 
10. Quadri, 323, siehe oben Fußnote 6 und 7.

11. Quadri, 323, FulBnote 4.

12. Gesetz Nr. 555, veröffentlicht in G.U. vom 30 . Juni $1912, \mathrm{NI} .153$, in Kraft getreten am 1. Juli 1912 (siehe Art. 20 L.c.). Siehe auch Koningliches Dekret vom 2. August 1912, Nr. 949, G.U. vom 9. September 1912, Nr. 213.

13. Doemer/Hecker, $29,30$.

14. Doerner/Hecker, 30, 31; vgl. auch Colette Baumann, 163-169.

15. Doerner/Hecker, $34,35,47,48$.

16. Doerner/Hecker, 36-38.

17. Doerner/Hecker, 38-41; insbesondere über das Einbürgerungsverfahren, 39.

18. Doerner/Hecker, 41-43.

19. Dekretgesetz Nr. 1997, G.U. vom 19. Dezember 1934, Nr. 297 (umgewandelt in Gesetz NI. 517 wom 4. April 1935, G.U. vom 7. Mai 1935, Nr. 107).

20. Es blieb jedoch die Möglichkeit, Ausläider unbeachtet der in Art. 4 Abs. 1 L.C. formulierten Voraussetzungen einzubiirgern iiber Art. 4 Abs. 2 L.c.. Art. 6 L.c. war eigentlich eine Art von Eihreneinbiirgerung.

21. Siehe Fußnote 54.

22. Jedenfalls traf dies die Art. 1 und 10 L.C.. Zobgern kann man aber z.B. iiber die Konsequenzen fuir die Bestimmungen des Art. 12 L.c.; siehe Arena, Stato civile 1986, 555; Barel, Leggi civili commentate 1984, 1010, Vercelli, Stato civile 1986, 494.

23. Dariber ausfithrlich Doerner/Hecker, 60-126.

24. Dekret Nr. 1144, G.U. vom 31. Juli 1915, NI. 190, Text bei Doerner/Hecker, 165. Siehe weiter die Einschränkung des Optionsrechts des Art. 3 L.c. von dem Deikret Nr. 1029 vom 14. Juli 1918, G.U. wom 31. Juli 1918, Nr. 180; Text bei Doerner/Hecker, 166.

25. Durch Dekretgesetz Ni. 1188 vom 21. August 1921, G.U. vom 10. September 1921, Nr. 215 (umgewandelt durch Gesetz N. 473 vom 17. April 1925, G.U. vom 5. Maí 1925, Nr. 104) wurde dlie Möglichkeit eröffnet, nachträglich Optionserklärnungen gemäß Art. 3 L.c. abzugeben; Text auch bei Doerner/Hecker, $173,174$.

26. Dekret Nr. 36, G.U. vom 24. Januar 1918, Nr. 20; Text auch bei Doerner/Hecker, 165.

27. Dekretgesetz $\mathrm{Nr}$. 1387, G.U. vom 6. November 1922, $\mathrm{Nr}$. 259 (umgewandelt durch Gesetz Nr. 473 vom 17. April 1925, G.U. vorn 5. Mai 1925, Nr. l04); abgealudert vom Dekretgesetz Nr. 1418 vom 14. Juni 1923, G.U. vom 9. Juli 1923, Nr. 160 (umgewandelt durch Gesetz Nr. 473 vom 17. April 1925, G.U. 5. Mai 1925, Nr. 104);

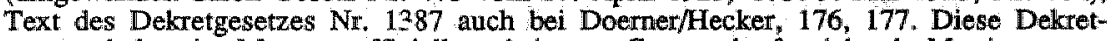
gesetze haben im Moment offiziell noch immer Gesetzeskraft siehe de Martino, unter Cittadinanza (89), Legge III, IV.

28. Dekretgesetz Nr. 16, G.U. 15. Januar 1926, Nr. 11 (umgewandelt durch Gesetz Nr. 898 vom 24. Mai 1926, G.U. 7. Juni 1926, Nr. 130); Text auch bei Doemer/Hecker, 182; siehe weiter de Martino, unter Cittadinanza (89), Legge $V$.

29. Gesetz Nr. 108, G.U. 4. Februar 1926, Nr. 28; Text auch bei Doerner/hlecker, 182, 183; siehe weiter de Martino, unter Cittadinanza (89), Legge VI. Die Aberkennungen aufgmund dieses Gesetzes sind durch das Dekret $\mathrm{Nr} .1510$ voun 17. November 1932 wieder aufgehoben worden.

30. Art. 3 der Dekretgesetzes Nr. 1381 vom 7. September 1938, G.U. vom 12. Septernber 1938, Nr. 208; erweitert vom Art. 23 i.V.m. Art. 8 des Dekretgesetzes $\mathbb{N r}$. 1728 betreffend MalBnahmen zum Schutze der italienischen Rasse vom 17. November 1938, G.U. vom 19. November 1938, Nr. 264 (umgewandelt durch Gesetz Nr. 274 vom 5 . Januar 1939, G.U. vom 27. Februar 1939, Nr. 48); beide Texte bei Doemer/Hecker, 197, 198. Uber die Rechtsstellung der Juden in Italien auch Doerner/Hecker, 127-129 mit weiteren Hinweisen.

31. Dekretgesetz Nr. 25 vom 20. Januar 1944, G.U., Serie speciale vom 9. Februar 1944, $\mathrm{Nr}$. 5. Siehe weiter auch Dekretgesetz Nr. 248 vom 5 . Oktober $1944, \mathrm{Nr}$. 70. Texte beil Doerner/Hecker, 206, 207.

32. Verfassung vom 27. Dezember 1947 (in Kraft am 1. Januar 1948), G.U. vom 27. Dezember 1947, Nr. 298. Formell gilt das betreffende Dekretgesetz aber noch immer: siehe de Martino, unter Cittadinanza (89), Legge V.

33. Falzone/Palermo/Cosentino, 87, 88.

34. Gesetzesentwurf Nr. 991 vom 24. Februar 1960. Text bei Doemer/Hecker, 228-233.

35. Zweiter Entwurf eines neuen Staatsangehorigkeitsgesetzes vom 27. April 1961 ; Fundstellen bei Doerner/Hecker, 343. 
36. Dritter Gesetzesentwurf (Nr. 3102) eines neuen Staatsangehörigkeitsgesetzes vom 13. Juni 1961; Text bei Doerner/Hecker, 233-238. Siehe auch Spinedi, RDI 1967, 126. Vgl. weiter den im RDI 1981, 231 veróffentlichten Entwurf, wozu Ziccardi, 642-648.

37. Dieser sogenannte Entwwurf Rocco wurde am 7. März 1930 dem Senat vorgelegt; Text bei Doemer/Hecker, 224-228.

38. Gesetz Nr. 431 vom 5. Juni 1967, G. U. vom 22. Juni 1967, Nr. 154.

39. Foro Italiano 1975, 1321; G.U. vom 23. April 1975, Nr. 108; weitere Fundstellen bei Hecker, StAZ 1987, 148 .

40. In Kraft getreten am 20. September 1975; siehe G.U. vom 23. Mai 1975, Nr. 135; vgl. dazi Bariatti, Nationalite, 130-135.

41. Art. 2 des Gesetzes Nr. 9 vom 8. Mărz 1975 (G.U. vom 10. März 1975, Nr. 67) ändert implizit auch die Altersgrenze des Art. 3 Abs. $2 \mathrm{Lc}$; formell geschah dies aber erst durch Gesetz Nr. 753 vom 3. Oktober 1977 (G.U. vom 21. Oktober 1977, Nr. 288)

42. In der italienischen Literatur werden diese Erwerbsgruinde immer als Erwerb "iuris communicationis" bezeichner.

43. Wichtig war in diesem Zusammenhang vor allem Art. 3 Abs. 1 der Verfassung: "Tutti i cittadini hanno pari dignita sociale e sono eguali davanti alla legge, senza distinzione di sesso, di razza, di lingua, di religione, di opinioni politiche, di condizioni personali e socialí" Bezüglich der Gleichberechtigung der Eltern ihren Kindern gegenüber war weiter Art. 29 Abs. 2 von Bedeuting: "II matrimonio erdlinato sull' eguaglianza morale e giuridica dei coniugi, con i limiti stabiliti dalla legge a garanzia dell'unità familiare".

44. Rivista di diritto intemazionale privato e processuale 1981,505 e.v.; G.U. vom 3. Dezember 1980, Nr. 332.

45. Rivista di diritto internazionale privato e processuale 1983, 114, 115; Foro Italiano 1983, 268; G.U. vom 12. Januar 1983, Nr, 11 .

46. Rivista di diritto internazionale privato e processuale 1977,884 ff., G.U. vom 25 . Mai 1977, Nr. 141; weitere Fundstellen bei Hecker, StAZ 1987, 148.

47. Rivista di diritto internationale privato e processuale 1983, 115-117, Foro Italiano 1983, 266, 267. Die Hauptrage wurde vom Corte Costituzionale nicht entschieden, da Art. 10 L.C. bevor es zu einer Entscheidung kommen konnte von Art. 8 in Kombination mit Art. 1 des Gesetzes vom 21. April 1983 aufgehoben wurde.

48. G.U. vom 5. Juni 1978, Nr. 154; weitere Fundstellen bei Hecker, StAZ 1987, 148.

49. G.U. yom 26. August 1981, Nr. 234; weitere Fundstellen bei Hecker, StAZ 1987, 149.

50. G.U. vom 16. Dezember 1981, Nr. 345; weitere Fundstellen bei Hecker, StAZ 1987, 149

51. Ginrisprudenza Costituzionale 1983, Parte seconda, 273-276.

52. G.U. vom 16. Februar 1983, Nr. 46; Giurisprudenza Costituzionale 1983, Parte prima, 91-102; Foro Italiano 1983, $265 \mathrm{ff}$; weitere Fundstellen bei Hecker, StAZ 1987, 149. GemäßB Art. 136 der italienischen Verfassung trat die Entscheidung des Corte Costituzionale am 17. Februar 1983 an Stelle der für verfassungswidrig erkannten Regelung. Daraufhin entstand ein Meinungsunterschied über die Frage, ob und wieweit die Entscheidung Rückwirkung hatte. Der Consiglio di Stato entschied an 15. April 1983, daß die Entscheidung des Corte Costituzionale rickwirkt bis zum Inkrafttreten der italienischen Verfassung an 1. Januar 1948: siehe Bariatti, Jurisclasseur, Suppl. 5, 1985, 2; van Es, 15; Pagano, 5; Panetta, 124-128; vgl. weiter Adami, Stato civile 1983, 262; Arena, Stato civile 1983, 195; Mancinelli, Stato civile 1983, 200; Vucusa Stato civile 1983,201 .

53. Siehe RDI 1981, 231; vgl. Foro Italiano 1983, 266 (Fußnote); dazu ausführlich Bariatti, 124-135.

54. Zitiertitel des Gesetzes: Disposizioni in materia di cittadinanza; G.U. vom 26. April 1983, Nr. 112; Leggi e decreti 1983, nr. 123; La legislazione italiana, Vol. XL. 1983, 931-933; dazu u.a. Jessurun d'Oliveira/Brunetti, PS 1987, 73-80; weiter Adami, Stato civile 1983, 262; Arena, Stato civile 1983, 259, 323, 387, 439, 623-625; Ballarino, Leggi civili commentate 1984, 969; Barel, L.c.c. 1984, 996" Carraro, 988; Chiese, Stato civile 1983, 326-328; Coscia, Amministrazione italiana 1983, 1282; Di Siena, Gazzetta valut. 1983, 1019; Fortunato/Giardina, Giur. it. 1983 IV, 324; Jayme, IPRax 1983, 253, 254; Leita, 973 und 1009: Mancinelli, Stato civile 1983, 499; Nascimbene, Foro italiano 1983 I, 1537; Palermo Fabris, 981; Salvo, Rassegna di diritto civille 1985, 105; Sinagra, Giurisprudenza costituzionale 1983, I, 578; Toneatti, Stato civile 
1983, 687; 1984, 13; Vucusa, Stato civile 1983, 562. Siehe fiir Literaturhinweise auch Hecker, StAZ 1987, 146-151.

55. Das Gesetz trat am Tage nach seiner Veröffentlichung in der Gazzetta Ufficiale in Kraft (Art. 9 des Gesetzes).

56. Van Es, 7; Panetta, $25 \mathrm{ff}$

57. Vgl. auch die Gesetzesinitiative des Abgeordneten Ricciuti vom 2. Juli 1987 (Integrazione alla legge 13 giugno 1912 , n. 555, concernante il riconoscimento della doppia cittadinanza), $\mathrm{X}$. Legislatura, Documenti Camera dei deputati. $\mathrm{Nr}$. 120 .

58. G.U. vom 17. Mai 1986, Nr. 1.13; RDI 1986, 668: "Art. 1. 1. Il termine per l'esencizio dell' opzione di cui all'art. 5, secondo comma, della legge 21 aprile n. 123 , e prorogato fino alla data di entrata in vigore della nuowa legge organica sulla cittadinanza. 2. Chi ha perduto la cittadinanza per non aver reso I'opzione prevista dall'art. 5 , secondio comma, della legge 21 aprile $1983, n$. 123 , la riacquista ove renda apposita dichiarazione all'art. 3, primo comma, della citate legge 21 aprile $1983, \mathrm{n}$. 123."

59. Arena, Stato civile 1986, 307; Clerici, RDI 1986, 347-349; Jayme, IPRax 1987, 191, 192; Zilwerentant, PS $1987,16$.

60. Die gerichtliche Feststellung der Vaterschaft war allerdings nur in den Fällen des Art. 189 C.c.it. 1865 zullässig.

61. Die gerichtliche Feststellung der Mutterschaft war geregelt in Art. 190 C.c.ilt. 1865" vgl. Art. 269 ff. C.c.it. 1942, eingehend abgeändert vom Gesetz vom 19. Mai 1975,

Nr. 151. Siehe Doierner/Hecker, 19, 31-34.

62. Doerner/Hecker, 31-34.

63. Doerner/Hecker, 56.

64. Ehebruchskinder und Inzestkinder durften nach Art. 180 und 193 C.c.it. 1865 nicht anerkannt werden und die Abstammung durfte auch nicht gerichtlich festgestellt werden; vgl. Art. 252 C.c.it. 1942, aufgehoben vom Gesetz vom 19. Mai 1975, Nr. 151. Siehe Doerner/Hecker, 19 und 34 (mit Hinweis auf eine Entscheidung des Gerichtshofes von Neapel vom 8. Juli 1936).

65. Dazu Colette Baumann, 160, 161.

66. Doemer/Hecker, 20.

67. GemäB Art. 323 C.c.it. mit Vollendung des 21. Lebensjahres.

68. Bariatti, Jurisclasseur, Suppl. 5, 1985, 1 .

69. Nach Art. 2 Codice civile ist dies mit Vollendung des 18. Lebensjahres der Fall. Eine Eheschließung macht nicht volljährig.

70. Der Consiglio dil Stato (15. April 1983, zitiert bei Panetta, 127) meint, daß Art. 5 Abs. 2 analog angewandit werden muB auf Volljährige, die aufgrund der Rückwirkung der Entscheidung des Corte Costituzionale vom 9. Februar 1983 Doppelstaatler geworden sind. Dariber Van Es, 181; Panetta, 72; vgl, weiter Arena, Stato civile 1983, 623; Barel, Leggi civile commentate 1984, 996; Filippi, Stato civille 1984, 520; Mancinelli, Stato civile 1983,$682 ; 1985,259 ;$ Vercelli, Stato ciwile 1984, 521. Siehe weiter Fußnote 58 .

71. Cian/Trabucchi, 267, 268; Grunsky, 145-147; Torrente/Schlesinger, 901-903.

72. Allgemein wird angenommen, daaß Art. 2 Abs. 1 L.c. auch nach in Krafttreten des Gesetzes 123 vom 21. April 1983 weiter gilt: Arena, Stat. civ. it. 1983, 323; Bariatti, Jurisclasseur. Suppl. 5, 1985, 1; Panetta, 87; Cian/Trabucchi, 268, 269; Torrente/Schlesinger, 904, 905; siehe auch Gesetzesentwurf Nr. 302, Senato, X. Legislatura (Norme regolatrici del tapporti fra genitori e figli).

73. Pagano, 5,6 ; Quadri, 325.

74. G.U. vom 17. Maî 1983, Nr. 133; dazu Bariatti, Jurisclasseur 5, 1985, 2; Jayme; IPRax 1983, 253; Nascimbene, Foro it. 1983, I, 1541; Pagano, Rassegna civile 1986, 344; Panetta, 70.

75. Pagano, 7; Quadri, 326.

76. Pagano, 7-11; Quadri, 326.

77. Die Möglichkeit solcher "kleinen" Einbürgerungen, die nicht den GentB aller politischen Rechte vermitteln, gibt es nach der Ansicht von Pagano, 14 formell noch immer. In der Praxis hat sie aber keine Bedeutung mehr. Quadri, 327 meint dagegen, daß die Regelung der "kleinen" Ënbiirgerung durch Inkrafttreten der Konstitution im Jahre 1947 aufgehoben ist, da die Verfassung die Gleichheit aller Bürger betont und dies deshalb die Existenz einer "kleinen" neben einer normalen Einbiirgerung ausschließe. 
78. Siehe Dekretgesetz vom 1. Dezember 1934, Nr. 1997, umgewandelt durch Gesetz Nr. 517 vom 4. April 1935.

79. Die Eidesformel ist in Art. 8 des Gesetzes vom 23. Dezember 1946, Nr. 478 vorgeschrieben; dazu auch Pagano, 13.

80. Titolo $\mathrm{I}_{\mathrm{s}} \mathrm{Nr}$. 1 Dekretgesetz vom 26. Oktober 1972, Nr. 641 (G.U. wom 11. November 1972, Nr. 292), schreibt eine Einheitsgebuihr vor für "Decreto del Capo dello Stato con quale viene concessa la cittadinanza a stranieri, permesso preventivo da parte del Governo di riacquistare la cittadinanza senza obbligo di stabilire la residenza in Itallia, dichilarazione dil rinunzia alla cittadinanza italiana e dispensa dalla condizione di transferimento della residenza all'estero per la perdita della cittadinanza di cui, rispettivamente, agli artt. $4,9,8 \mathrm{n}_{2} 2$ dello $\mathrm{L}, 13$ giugno $1912, \mathrm{n} .555$, e successive modificazione". Die Gebihr war 1972 10.000 Lire und wurde erhöht durch Dekretgesetz vom 23. Dezember 1976, Nr. 854, durch Gesetz vom 26 Mai 1978, Nr. 216, durch Dekretgesetz vom 8. Februar 1981, Nr. 38, durch Dekretgesetz vom 22. Dezember 1981, Nr. 787 and durch Dekretgeserz vom 30. Dezember 1982, Nr. 953.

81. Pagano, 13. Dennoch ist warscheinlich, daB mehrfache Staatsangehörigkeit möglichst wermieden wird; siehe Art. 5 Abs. 2 Gesetz Nr. 123 vom 21. April 1983.

82. Diese Altersgrenze gilt seir Inkrafttreten des Gesetzes vom 8. März 1975, Nr. 39; siehe Art. 1 des Gesetzes vom 3. Oktober 1977, Nr. 753 (G.U. wom 21. Oktober 1977, Nr. 288).

83. Wenn ein ehemaliger Italiener seit uber zwei Jahren nicht mehr in dem Staat lebt, dessen Staatsangehörigkeit er erworben hat, und nun in einem anderen ausländischen Staat dessen Staatsangehörigkeit er nicht erwirbt, lebt, kann ihm auch von der Regierung Wiedererwerb seiner italienische Staatsangehörigkeit gestattet werden. Vgl. auch Clerici, RDIPP $1986,575$.

84. "Scioglimento": Art. 1.49 Codice civile.

85. "Arinulamento": Art. 117-129bis Codice civile.

86. "Cessazione degli effetti civile": Art. 2 Ehescheidungsgesetz Nr. 898/70. So Van Es, 37. In meinem Aufsatz PS 1985, 53 (FuBnote 23) erwähnte ich zu Unrecht Art. 140 Abs. 2 Codice civile.

87. "Separazione legale": Art. 150 Codice civille.

88. Es handelt sich hier un die Art. 241 bis 294 Codice penale, wo die Verbrechen gegen die Staatssicherheit geregelt werden; "delitti contro la personalita intemazionale dello stato", "delitti contro la personalita interna dello stato" und "delitti contro i diritti politici del cittadino", mit Ausnahme der Verbrechen der Artikel 242, 243, 245, 246 und 269 Codice penale, da diese nur von Italienern begangen werden können. Vgl. Panetta, 44; Van Es, 39.

89. Art. 3 spricht von Mitteilung (communicazione) während ein Rundschreiben des Innenministeriums vom 2. Mai 1983 (bei Panetta, 120-123) ifber Zustellung (notificazione) spricht. Dariber Van Es, 40; siehe weiter Bariatti, Jurisclasseur, Suppl. 5, 1985, 2; Panetta, 56.

90. Arena, Stat. civ. it. 1983, 440; Bariatti, Jurisclasseur, Suppl. 5, 1985, 2; Van Es, 41 , 43; Panetta, 56.

91. Bariatti, Jurisclasseur, Suppl. 5, 1985, 2 mit Hinweis auf ein Rundschreiben des Innenministeriums yom 19. März 1984; Van Es, 39; anders: Arena, Stat. civ. it. 1983, 389; Fortunato/Giardina, Giur. it. 1983, IV, 328, Nascimbene, Foro it. 1983 I, 1541; Panetta, 40 .

92. Doerner/Hecker, 48 .

93. Vgl. Williams, British Yearbook of International Law 1927, 47.

94. Hecker, IA 1981, 195, Pagano, 17-20.

95. Beachtet werden muj3 in diesem Zusammenhang Art. 1 des Gesetzes vom 16. Juni

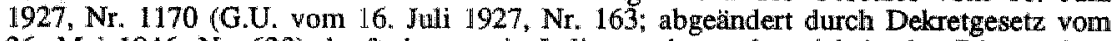
26. Mai 1946, Nr. 623), kraft dessen ein ltaliener, der vorthat sich in den Dienst eines ausländischen Staates oder einer intemationalen Organisation, in der Italien nicht teilnimmt, zu begeben, dies vorher den italienischen Behörden mitzuteilen hat.

96. Siche auch Bariatti, Jurisclasseur, Suppl. 5, 1985, 1.

97. Vgl. Ministero dell'interno, in einem Rundschreiben vom 19. März 1984, abgedruckt bei Panetta, 133 ff. Dagegen aber Panetta, 39, 40; Van Es, 38

98. Dies wird auch erwahnt von Panetta, 74.

99. Panetta, 135. Beachte übrigens die Verlängerung der von Art. 5 Abs. 2 vorgesehenen Frist, wozu Zilverentant, PS 1987, 16. 
100. Panetta, 80; vgl. Van Es, 17.

101. Bariatti, Jurisclasseur, Suppl. 5, 1985, 2.

\section{NOTEN NIEDERLANDE}

1. Vgl. dazu de Groot, Loseblattkommentar, wo die Artikel dieses Gesetzes systematisch kommentiert werden und weitere Literaturhinweise gegeben werden. Siehe weiter De Groot/Tratnik, 56-123. Siehe auf deutsch Boele-Woelki, StAZ 1985, 228-231 und de Groot, IPRax 1985, 175-178.

2. Bei de Groot, Laseblattkommentar, Einfihrung, Rdnr. 18, wird ein detaillierter Überblick der historischen Entwicklung der Artikel dieses Gesetzes mit weiteren Literaturhinweisen gegeben; siehe weiter namentlich Brinkman 1985, 77-120; de Groot/Tratnik, 49-53; Mannoury, 66-186.

3. Vgl. Hecker, Code Napolén, 54, 104; Krombach, 153, 154.

4. Gesetz vom 24. Februar 1809, in Kraft getreten am 1. Mail 1809; siehe de GrootTratnik, 40-42.

5. Der Code civil français in der Fassung won 1807 trat in Kraft am 1. Mărz 1811; siehe Gerbenzon/Algra, 203; Hecker, Code Napoleon, 54, erwähnt versehentlich den 1. Januar 1811.

6. Siehe zum Inhalt dieser Artikel \& 2.3.1

7. Allerdings mit Ausnahme von Art. 9 Code Civil, der schon von den Art. 8-10 des niederländischen Grundgesetzes anßer Kraft gesetzt wurde. Zwar wurde 1820 ein Entwurf veröffentlicht, in dem die Art. 90-105 eine ausfithrliche Regelung der Staatsangehörigkeit enthielten, aber dieser Entwurf wurde nie eingefuliht.

8. Voorduin, Bd. II, 367; Gerbenzon/Algra, 237; vgl. Van Hogendorp, Diss. 1827; Nahuijs., Diss. 1827; Sassen, 's Hertogenbosch 1827.

9. Voorduin, Bd. II, 368, siehe auch Ko Swan Sik, International Law, 5

10. Wichtig war deshalb die Frage, welche Regelung in welchen Angelegentheiten maßgebend war. Bemerkenswert ist in diesem Zusammenhang, daß3 in strafrechtlichen Angelegenheiten bis zum Inkrafttreten des (heutigen) Strafgesetzbuches vom 3. März 1881, Stbl. 35, am 1. September 1886 die staatsangehörigkeitsrechtlichen Bestimmungen des Zivilgesetzbuches maßgebend waren, seitdem jedoch das Gesetz von 1850 . Dariber detaillierter De Groot/Tratnik, 45, 46; Ko Swan Sik, Intemational Law, 5; siehe weiter Boissevain Diss. 1950; Raedt van Oldebarneveldt, Diss. 1851; Ras, Diss. 1885; Schreuder, Schiedam 1880; vgl. Diephuis 1856, 2-42; Diephuis 1886, 218-246; Opzoomer, 44,45.

11. Siehe zum Begriff der sachlich beschränkten Staatsangehörigkeit Makarov, Allgemeine Lehren 52.

12. Man vergleiche z.B. Art. 5 Ziffer 1 Zivilgesetzbuch 1838 ("Niederlärder sind alle, die im Konnigreich oder dessen Kolonien aus dort niedergelassenen Eltern geboren werden") und Art. 1 Ziffer 1 Staatsangehörigkeitsgesetz 1850 ("Niederländer ....... sind: 1. diejenigen, die aus innerhalb des Reiches in Europa niedergelassenen Eltern geboren sind"').

13. Diesen Begriff benutzt Dutoit, Europe, passim,

14. AusschlieBlich Art. 1 Buchstabe d ("Nederlanders door geboorte zijn: . d. het noch door den vader noch door de moeder erkend natururlijk kind, in het Rijk geboren".) und Art. 2 ("Nederlanders zijn ook: a) het kind van een ingezetene des Rijkss - hetzij vader, hetzij moeder, naar die in art. 1 gemaakte onderscheidingen - die zelf geboren is uit eene in het Rijk wonende moeder, tenzij blijkt dat het kind als vreemdeling tot een ander land behoort; b) het in het rijk te vondeling gelegd of verlaten kind, zoolang vam zijne afstamming, hetzij als wettig of gewettigd kind, hetzij door erkenning, niet blijkt" manifestierten ius soli. Siehe tiber das Staatsangehborigkeiltsgesetz von 1982: Land/Star Busman, 10-30; Loep Schuphoven, Zutphen 1893; Mulder, 's-Graverhage 1902; Sande Bakhuyzen, Leiden 1900; vgl. bereits Beyen, Diss. 1890; Mock, Diss. 1890.

15. Am stärksten durch Änderungsgesetz vom 15. Mai 1953, Stbl. 233; vlg. weiter aber auch das Änderungsgesetz wom 21. Dezember 1936, Stbl. 209.

16. Siehe dazu de Groot, Loseblattkommentar, Rdnr. 22.

17. Fili Fundstellen siehe Fußnote 217 in $\$ 1.4 .3$. 
18. Zu dieser Vorschrift Meijers, WPNR 4239 (1952), 185,186; de Winter, WPNR 4250 (1952), 312.

19. Fred. S. Baumann, 23-26; de Groot, Loseblattkomentar, Rdnr. 40; Ko Swan Sik, internationall Law, 31-34; vgl. weiter Barentsen, PS 1962, 51-52; Heinsius, PS 1950, 31-32; Kollewijn, NJE 1952, 378-379; Mannoury , Bestuurswetenschappen 1953, 125-141; Prins, PS 1952, 49-74; PS 1953, 34-38; PS 1962, 25-28; Stuttenheim, PS 1957, 31-33; Van der Weg, PS 1955, 63-66; siehe weiter Logemann, NJB 1958, $127-130$

20. In Niederlämdisch-Indien galt fur diejenigen, die keime Niederländer in Sinne des WNed waren, das Gesetz vom 10. Januar 1910, Stbl. 55, das die Regelung der niederländischen Untertanschaft won Nicht-Niederländern regelt ("houdende regeling van het Nederlands onderdaanschap van niet-Nederlanders"). Dieses Gesetz wurde durch Gesetz yom 10. Juni 1927, Stbl. 175 auch anwendbar erklärt für Surinam und Curaçao, wo dieses Gesetz bis zum 27. Dezember 1949 galt. Fïir Niederländisch Neuguinea galt es bis zum 1. Oktober 1.962. Siehe Groeneveld, PS 1963, 88-91; de Groot, Loseblattkommentar, Rdnr. 38; de Groot/Tratnik, 53, 54; Ko Swan Sik, International Law, 5, 6; Logemann, Indisch Tijdschrift wan het Recht 1932, 506.

21. Fîr ein nichteheliches vom Vater nicht anerkanntes Kind war hier die Murter maßgebend.

22. Eine bessere Bezeichnung wäre allerdings ius domicilii, da nicht der Geburtsort, sondern der Wohnsitz des Vaters, beziehungsweise der Mutter und der Wohnsitz der Großmutter wäterlicher-, beziehungsweise mütterlicherseits maßgebend war.

23. Das Abkommen wurde am 16. Juni 1966 von den Nivederlanden ratifiziert und trat für das niederländische Königreich am 6. November 1966 in Kraft (Trb. 1965, 218; 1966, 213). Siehe fur Fundstellen des Abkommens FuBnote 222 des $\$ 1.4 .3$.

24. Dutoit, Band I (Europa) bezeichnet dies als "systeme dualiste". Siehe zur Entwicklung der Position der mit einem Niederländer verheirateten ausländischen Frau: Achterberg, 89-96; Adriaansen/Van der Weg, F55 - F60d; Bakker PS 1956, 111 ff.; Bolten, Nemesis 1984/5, 101-104; Bolten, Nemesis 1984/5 155.156; Brinkman 1985, 107-109; Brouwer, Diss. 1955; Dubbink, NJB 1949, 158-160; de Groot, Preadvies, 50-54; de Groot (L.J.A.), PS 1952, 89-92; Kollewijn, NJB 1962, 954-961; Mannoury, 120-125, 167-169; Van Oven, NJB 1930, 129-134; Sölungen, Diss. 1930; Van der Weg, PS $1966,72-74,87-90$.

25. Toescheidingsovereenkomst inzake nationaliteiten; siehe de Groot, Loseblattkommentar, Rdnr. 40 und Anlage 30. Dazu Adhin, Surinaams Juristenblad 1982, 71.4-734: Alimad Ali 1979; de Boo, PS 1986, 67-73; Fernandez Mendes, AA 1981, 636-643; Ko Swan Sik, International Law, 34-35; Zilverentant, PS 1987, 13-14. Siehe auch Handleiding betreffende de toescheidingsovereenkomst inzake nationaliteiten 1975.

26. Siehe z.B. "voorlopig verslag" des Gesetzesentwurfes 12837 ( $R$ 944) (Sitzung 1973-74), 4; weiter Griffiths-Le Poole, NJB 1970, 1319-1324; de Groot, NJB 1975, 782-787.

27. Mitteillung in der Nederlandse Staatscourant 1976, Nr. 256; der Referentenentwurf und die Motive sind u.a. als Anlage des zweiten Heftes der Zeitschrift Personeel Statuut 1977 veröffentlicht; den Text des Referentenentwurfes findet man weiter bei de Groot, Preadvies, 100-108.

28. Advies Staatscommissie voor het internationaal privaatrecht over voorontwerp wet Nederlanderschap, PS 1977, 73-82; Advies Staatscommissie voor de burgerlijke wetgewing over voorontwerp wet Nederlanderschap, PS 1978, 23-28; Debat over het preadvies van Mr. G.R. de Groot; de Groot, Preadvies; de Groot, Burgerzaken 1982, 2-4; de Groot, Burgerzaken 1981, 67,68, 81-83, 95-97; Jessurun d'Oliveira, NJB 1977, 589-598; Koens, NJB 1980, 884-887; Zilverentant, Burgerzaken 1982, 1,2.

29. Siehe iber dliesen Entwurf: Boeles, 190-215; Brinkman, PS 1983, 93-94 und PS 1984, 34-40 und 51-57; Dekker, Burgerzaken 1984, 83-88 und 99-101; de Groot, NJB 1981, $1117-1126$ und PS 1984, 18-27; de Groot/Tramik, 56-58; Jessurun d'Oliveira, NJB $1982,245-256$, NJB $1983,1301-1310$ und NJB 1984, 417-421; Mackaay, NJB 1983,

30. Für Fundstellen siehe Fußnote 223 des 1.4 .3

31. Für Fundstellen siehe Fußnote 229 des $\$ 1.4 .3$.

32. Fir Fundstellen siehe Fußnote 226 des 1.4 .3 . 
33. Siehe za den Parlamentsdebatten: Hand. II 1983/84: UCV 38 (1-55), UCV 45 (1-13), $3856-3871,3874-3888,4019-4036,4039-4053,4074-4081,4143-4146,4318$; Hand. II $1984 / 85,2157$; Hand. I 1984/85, 72-77, 277-281, 362-368.

34. Gesetz vom 18. Dezember 1984, Stbl. 627 .

35. KB 20. Dezember 1984, Stbl. 1984, 655, jedoch mit Ausnahme der Artikell 17-20, die erst am 1. Oktober 1986 in Kraft traten (Beschluf3 vom 22. August 1986, Stb. 436).

36. Das Abkommen von New York trat fuir die Niedlerlande am 11. August 1985 in Kraft, das Abkommen von Straßburg am 10. Juni 1985 und das Abkommen von Bern am 19. Mai 1985. Siehe über die Konsequenzen dieser Abkommen fir die Niederlande Brinkman, PS 1986, 21-25.

37. Die Ratifizierung wurde vor allem von Jessurun d'Oliviera, NJB 1984, 417-421 kritisiert. Siehe auch Mackaay NJB 1982, 993 und NJB 1983, 1319-1322; de Groot, JZSt 1983 (308), 13-25. Darüber ebenfalls de Groot, Loseblattkommentar, Rdnr. 34; de Groot/Tratnik, 61, 62, 104, 105.

38. Siehe Gesetzesentwurf 19112 (R 1291) und zu den Parlamentsdebatten Hand. II 1984/85, 1548-1574, 1696-1697 und Hand. I 1985/86, Sitzung des 10. Dezember 1985.

39. $\quad \mathrm{KB}$ vom 13. Dezember 1985, Stbl. 661.

40. Ausnahmen gab es 1892 nur in Art. 1 Buchstabe d und in Art. 2 WNed. Siehe auch de Groot, Loseblattkommentar, Einfuthrung, Rdar. 18 und 19; de Groot/Tramik,46.

41. Siehe Art. 1 unter a WNed 1892; dariber Achterberg, 13-22; Schreuder 1893, 30-40, 48-52, 106-113, 121-128, 296-298; Thomas, 23, 24, 29-34, 39-48.

42. $\quad \mathrm{Zu}$ Art. 2 vor allem Mannoury, 73,86-88,91,93,96-100, 127,128; weiter Meijers, WPNR 4239 (1952), 185,186 und WPNR 4250 (1952), 312,313; de Winter, WPNR 4250 (1952), 312.

43. Bakker, PS 1962, 97-100.

44. Unter Niederlande wird in diesem Paragraph immer die Niederlande, die Niederlândischen Antillen und Aruba verstanden.

45. Siehe Art. 2ter WNed.

46. Vgl. für adoptierte Kinder Art. 1 bis WNed. Auch im Falle der Adoption war grundsätzlich die niederländische Staatsangehörigkeit des Vaters maßgebend, die der Mutter war nur beachtlich, falls der Vater am Tage des Inkraftrretens der Adoption bereits gestorben war.

47. Vgl. zu der Frage, was der Fall ist, wemn das Kind kraft Geburt eine ausländische Staatsangehörigkeit unter auflöscnder Bedingung erwirbt Griffiths-Le Poole, NJB 1970 , 1322.

48. Adriaansens/van der Weg, F20c-F20g.

49. Siehe zu der Frage, ob die niederländische Statatsangehörigkeit auch erworben werden kann, wenn ein ausländisches Kind von einem ausländischen Mann amerkannt wird, der selbst geboren wurde wabhrend sein Vater, beziehungsweise seine Mutter in den Niederlanden lebte, und die Großmutter väterlicher-, beziehungsweise mütterlicherseits auch bereits bei Geburt ihres Kindes in den Niederlanden wohnhaft war: Dokker, Burgerzaken 1984, 83-85, 99; Gewzinge. WPNR 5769 (1986), 62-67; de Groot, Loseblattkommentar Rdnr. 2 zu Art. 4; de Groot/Tratnik, 74, 75.

50. Brinkman 1985, 48-50 und PS 1984, 35,36; Dekker, BZ 1984, 84,85; Geuzinge, WPNR 5769 (1986), 63,64; de Groot, Loseblattkommentar, Rdnr. zu Art. 3; de Groot, Preadvies, 57-65; 84-90; De Groot, NJB 1984, 1119,1120 und Burgerzaken 1981, 95-97; Jessurum d'Oliveira, NJB 1977, 589-591; de Lange, Tijdschrift voor Bestuurswetenschappen en Publiekrecht 1985, 197; Pitlo/Koens/Rood-de Boer, 4-8; Tratnik, NJB 1985, 1402-1403.

51. Dazu kritisch de Groot, Loseblattkommentar, Rdnr.3 zu Art. 15, de Groot, NJB 1981 . 1125, PS 1984, 23,24, PS 1985,55; Jessurun d'Olliveira, NJB 1982, 247 und NJB 1984, 419, 420; Mackaay, NJB 1982, 993 und NJB 1983, 1319-1322.

52. Brinkman, 51,52 und PS 1984, 36, Dekker, Burgerzaken 1984, 83-85, 99; Geuzinge, WPNR 5769 (1986), 62-67; de Groot, Loseblattkommentar zu Art. 4; de Groot, NJB 1981, 1121,1122; de Groot, NJ 1988, 59, 60; de Groot/Tratnik 73-76; Pitlo/Koens/Rood-de Boer, 5 .

53. Die staatsangehörigkeitsrechtlichen Folgen einer Adoption werden in năchster Zukunft eingehend geändert im Ralımen einer grundsätzlichen Änderung des Rechtes der Adoption ausländischer Kinder. Siehe Brinkman 1985, 52,53; de Groot, Loseblattkommentar, zu Art. 5; de Groot/Tratnik. 76-78, Jessurun d'Oliveira, NJB 1982, 255, NJB 
1983, 1306; Jessurun d"Olveira, Bulletin Werkgroep Rechtsbijstand Vreemdelingenzaken 1984, 126-128; Jessurun d'Oliveira, Feestbundel Offerhaus, 105-121; de Lange, Tijdschrift voor Bestuurswetenschappen en Publiekrecht 1985, 197; Pitlo/Koens/Roodde Boer, 5,6 .

54. De Groot, Loseblattkommentar, Rdrur. 3 zu Art. 3, de Groot, NJB 1981, 1119-1120; de Groot/Tratnik 68-70, 72 .

55. Siehe dazu kritisch de Groot, NJB 1981, 1120 und Koens, NJB 1980, 881-887. Im Referentenentwurf (1976) war in Art 6 itbrigens noch vorgesehen, daB ein potenziell gtaatenloses Kind bei Geburt in den Niederlanden gleich die niederlandische Staatsangehörigkeit erwerben wilirde.

56. $\quad$ Brinkman, PS 1984, 35; de Groot, Loseblattkommenar, Rndr. 3 zu Art. 3.

57. Das Wort "ausschlieBlich" steht nicht im Gesetzestext. Es würde aber den Grundisätzen des RwNed widersprechen, wenn ein aufgefundenes Kind die niederländische Staatsangehörigkeit aufgrund der Klausulierung von Art. 3 Abs. 2 RwNed verlieren wilide, wenn sich herausstellt, daB das Kind durch seine Geburt neben der niederländischen Staatsangehơrigkeit noch eine fremde Staatsangehörigkeit erworben hat. De Groot, Loseblattkommentar, Rdnt. 2 bei Art. 3; de Groot/ Tratnik, 71, 72.

58. Brinkman 1985, 54,55 und PS 1984, 36,37; Dekker, Burgerzaken 1984, 85,86; de Groot, Loseblattkommentar, zu Art. 6; de Groot, NJB 1981, 1122; de Groot/Tratmik,79-81; Jessurun d'Oliveira, NJB 1983, 1303; Koens, NJB 1980, 881-887; Pitlo/Koens/Rood-de Boer, 6-9.

59. Sannes, 156-162, 190-202; Van Vollenhoven, 34-107.

60. De Groot/Tratnik, 43.

61. De Groot, Loseblattkommentar, zu Art. 3 und 4 WNed 1892; Schreuder 1893, 59-62, 135-155; Thomas, 52-64.

62. Art. 8a wurde 1963 neu formuliert und dann als Art. 9 ins Gesetz aufgenonmen. Nachdem er 1975 noch leicht geändert wurde, ist Art. 9 im Jahre 1976 aufgehoben worden. Die Regelung wurde jedoch geringfigig modifiziert in Art. 5 Buchstabe c wieder aufgenommen; dazu de Groot, Loseblattkommentar zu Art. 9 WNed 1892.

63. Gesetz vom 8. September 1976, Stbl. 465, in Kraft getreten am 15. Márz 1977. Vgl. de Groot, Loseblattkommentar, Anmerkungen zu den Art. 5, 5a und 5b WNed.

64. Richtlinien vom 10. März 1977, Stcrt 1977,81; diese wurden abgelöst von den Richtlinien des 23. März 1979, Stcrt. 1979, 65 und abgeändert durch einen BeschluB des Staatssekretärs der Jastiz vom 27. Januar 1981, Stcrt. 1981, 20.

65. Siehe Brouwer, Diss. 1955; de Groot, Loseblattkommentar, zu Art. 5 (alt) WNed 1892; de Groot, Preadvies, 50-54; Kollewijn, NJB 1962, 954-961; Sölingen, Diss. 1930.

66. Dazu ausfiuhrlich de Groot, Preadvies, 53, 54

67. Zu Art. 4 WNed 1892: Achterberg, 40,41; Adriaansen/Van der Weg, Fl9-F20a; Mannoury, 115; Schreuder 1893, 62, 153-155; Thomas, 64 .

68. Bei der Anwendung von Art. 5 Buchstaben f und $g$ und für Minderjährige wird jedoch gefordert, daß erwartet werden kann, daß der Betreffende in die niederländische Gesellschaft aufgenommen wird.

69. Dazu de Groot, Preadvies, 58 (FuBnote 49); Swart, Debat preadvies de Groot, 42 (wozu de Groot, Debat preadvies, 50).

70. Dazu die Motive zu Art. 18 des 1976 veróffentlichten Vorentwarfes; siehe de Groot, Loseblatkommentar, Rdur. 10 zu Art. 8; de Groot, Preadvies, 76-81,94; de Groot/Tratnik; 94, 95; Jessirun d'Oliveira, NJB 1977, 594-597.

71. Darilber Breukelaar, AAe 1985, 471; Brinkman 1985, 56-59 und PS 1984, 38,39; Dekker, Burgerzaken 1984, 87 und Burgerzaken 1985, 284-285, 295-298; de Groot, Loseblattkommentar, Anmerkungen zu den Art. 8 und 9; de Groot, Preadvies, 58-60, 76-84; de Groot, NJB 1981, 1124,1125 und PS 1984,26; Jessurun d'Oliveira, NJB 1977, 591-597. NJB 1982, 245-256; NJB 1983, 1302-1308, Koens, NJB 1980, 881-887; de Lange, Tijjschnift voor Bestuurswetenschappen en Publiekrecht 1985, 198-201; Pitlo/Koens/Rood-de Boer, 9-14.

72. Brinkman 1985, 57; de Groot. Loseblattkommentar, Rdnr. 3 zu Art. 8; de Groot, Preadvies, 82 (FuBnote 30); de Groot/Tratnik, 97-99; Jessurun d'OAiveira, NJB 1977, 592-594; Koens, NJB 1980, 885; Swart, Debat Preadvies de Groot, 42 .

73. Dariber de Groot, Loseblattkommentar, Rdnr. 4 zu Art. 8; de Groot/Tratnik, $86 \mathrm{ff}$. Diese Forderung wird nach ÄuBerungen der niederländischen Regierung nicht streng interpretiert (MvA II, 24; Nota n.a.v. Eindverslag; 13). Der Aufenthalt in den 
Niederlanden braucht auch nicht während der ganzen Frist legall gewesen zu sein. (MvA. I, 8,9). Siehe auch Nota n.a.v. Eindverslag über die Gesetzesentwïrfe 1788217914.

74. Kritisch zu dieser Forderung de Groot, Loseblattkommentar, Rulnr. 5 zu Art. 8; de Groot/Tramik, 97, 107; de Groot, PS 1984, 26; Jessurun d"Oliveira, NJB 1982, 248,249 und NJB 1983, 1302-1308; Advies Staatscommissie IPR, Anlage II zu Gesetzesentwur 16947 (R 1181) ad Art. 7 Vorentwurf

75. Für Personen ${ }_{n}$ die in Aruba, Bunaire oder Curaçao leben reichen auch Kenntnisse des Papiamento aus und für Personen aus Saba, St. Eustatius odler St. Maarten Kenntnisse der englischen Sprache. Siehe weiter de Groot, Loseblattkommentar, Rdnr. 6 zu Art. 8; de Groot/Tratnik, 98.

76. Siehe die Einbürgerungsrichtlinien vom 23. März 1979, geändert am 27. Januar 1981, Stcrt. 21.

77. Mit Motiven zitiert bei de Groot, Loseblattkommentar, Rdnr. 5 zu Art. 8.

78. Im Sinne des Gesetzes vom 10. Febnuar 1910, Stbl. 55. Daritber Adriaansen/Van der Weg, IA-10-13; Bakker, PS 1963, 9-11; Beets, Indisch Tijdschrift van het Recht 1933, 525-528; Groeneveld, PS 1963, 88-91; de Groot, Loseblattkommentar; Einfulhrung, Rdnr. 38 und 39 und Rdnr. 8 zu Art. 8; de Groot/Tratnik, 88, 89; Heinsius, Indisch Tijdschrift van het Recht 1933, 9-14; Logemann, Indisch Tijdschrift van het Recht 1932, 506 ff.; de Stoppelaer, Koloniaal Tijdschrift 1937, 268-272.

79. Dazu de Groot, Loseblattkommentar, Rdnr. 11 zu Art. 8; auch bereits de Groot, Preadvies, 70-72 und PS 1984, 27; siehe weiter de Groot/Tratnik, 96, 97.

80. De Groot, Loseblattkommentar, Rdnr, 1 zw Art. 9* de Groot, PS 1984, 25; de Groot/Tratmik, 99-101; Jessurun d'Oliveira, NJB 1977, 593,594; Koens, NJB 1980, 885.

81. Brinkman 1985, 61; de Groot, Loseblattkommentar, Rdnr, 2 zu Art. 9; de Groot/Tratnik, 102-104; Jessurun d'Oliveira, NJB 1982, 248, NJB 1983, 1306 und NRC Handelsblad vom 16. März 1984; Mackaay, NJB 1982, 993.

82. Art. 5 a WNed 1892 wurde 1976 eingefuigt. Vorther war in diesem Zusammenhang Art. 3 Abs. 6 von Bedeutung, worin stand, daB von einem Antragsteller, der zu einem anderen Lande gehörte, der Nachweis gefordert werden konnte, daß die Gesetzgebung seines Landes kein Hindernis gegen seine Einbuirgerung in den Niederlanden beinhaltet, vgl. Adriaansen/van der Weg. F 20i-F20k, Jessurun dOOliveira, NJB 1982, 839.

83. De Groot, Loseblattkommentar, Rdnr. $4 \mathrm{zu}$ Art. 15; de Groot/ Tratnik, 104, 105; Jessurun d'Oliveira, NJB 1982, 247.

84. De Groot, Loseblattkommentar, Rdnr. 3 zu Art. 9; de Groot/ Tratnik, 87, 88; Jessurun d'Oliveira, NJB 1983, 1307,1308 und NJB 1984, 418.

85. Jessurun d'Oliveira, NJB 1984, 418 hat deshalb die Ansicht vertreten, daß Art. 9 Abs.1 Buchstabe c unvereinbar ist mit dem New Yorker Abkommen vom 20. Februar 1957.

86. Vreemdelingenwet Art. 13; dariber de Groot. Preadvies, 82 und Swart, in Debat preadvies de Groot, Deventer 1978, 42.

87. Nach der nun geltenden Regelung kann der Ehepartner eines Niederländers wohl auch während eines Ehescheidungprozesses eine Einbürgerung auf Grund des Art. 8 Abs. 2 RwNed beantragen.

88. Siehe u.a. de Groot, Preadvies, 76-84; Hieriber auch de Groot, Loseblattkommentar, Rdrir. 9 zu Art. 8.

89. Namentlich wäre dies der Fall, falls z.B. aus politischen Grinden nicht von ihm verlangt werden kann, daß er mit diplomatischen Behörden seines Heirnatstaates Kontakt aufnimmit, weil er aus diesem Staat geflohen ist; siehe de Groot, Loseblattkommentar, Rdnr. 2 bei Art. 9.

90. So zum Beispiel de Groot, Preadvies, 80.

91. Jessurum d"Oliveira, NJB 1982, 245 ff. und Volkskrant vom 10. Februar 1982, 13.

92 .

93.

94.

95.

96.

97. Jessurun d"Oliveira, NJB 1982, 249, 250; Volkskrant vom 10. Februar 1982, 13. Jessurun d"Oliveira, NJB $1977,590$.

Zie de Groot/Tratnik, 103.

Gesetzesentwurf 16947 (R 1181), MvA II, 16.

MvA II, 5; Jessurun d'Oliveira, NJB 1983, 1302; vgl. de GrootTratnik, 104, 105.

Mehrere Amendemente versuchten vergeblich die betreffende Forderung zu lockern oder sogar abzuschaffen: Amendement Wessel-Tuinstra (Gesetzesentwurf 16947 ( $R$ 1181), Nr.18), Amendement Van Es (Gesetzesentwurf 16947 (R 1181), Nr. 27) und Amendement Hås-Berger (Gesetzesentwurf 16947 (R 1181), $\mathrm{Mr} .45$ ). 
98. De Groot, Loseblattkommentar, Rdrit. $1 \mathrm{zn}$ Art. 8; de Groot/Tratnik, 107.

99. Siehe hierzu die Folgerungen in \$ 3.4 .4 dieser Arbetit.

100. Sannes, 119-145.

101. Achrerberg, 56-84; Schreuder 1893, 20,21,37,39,41,68,79,114-116, 211-245; Thomas, 87-124; vgl. Bakker, NJB 1948, 474-476.

102. Gesetz wom 15. Julii 1910, Stbl. 216, in Kraft getreten an 16. August 1910 .

103. Gesetze wom 21. Dezember 1936, Stbl. 209 und Stbl. 913, in Kraft getreten am 1. Juli 1937.

104. Anderungen des Art. 7 Ziffer 2 und 3 in Zusammenhang mit der Ratifizienung des New Yorker Abkommens vom 20. Februar 1957, durch Gesetz vom 14. Nowember 1963, Stb1 467, in Kraft getreten am 1. März 1964.

105. Z.B. durch Verneinung der Vaterschaft oder durch Adoption im Ausland.

106. Das gleiche galt nach Art. 7 Ziffer 1 Satz 2, wenn die Mutter eines ehelichen, legitimierten oder adoptierten Kindes nach dem Tode des Vaters im Ausland eingebiurgert wurde und das Kind in die Einbiirgenung einbezogen wurde.

107. Nach Auflossung der Ehe hatte sie wieder ein Optionsrecht auf die niederländische Staarsangehörigkeit.

108. Dieser Werlustgrund war vor allem seit den DreiBiger Jahren sehr umstritten. Dariber: Bakker, NJB 1948, 474-476; Bockwinkel, NJB 1938, 193-198; Boelens, RM Themis 1950, 276-299; Dirkawager, NJB 1956, 547-552; Groeneveld, PS 1956, 114-118; Jessurun d'Oliveira, NJB 1977, 1081-1082 und NJB 1979, 655; Kisch, NJB 1937, 719-730; Menalda, NJB 1951, 594-598 und NJB 1952, 677-682; Wan Nijnatten, NJB 1947, 181-190; Siekmann, NJB 1979, 655-656 und NJB 1979, 490; Stoffels, NJB 1937, 921-926; van Tijen, NJB 1946, 237; Torley Duwel, WPNR 4196 (1951), 87-88; Valkhoff, RM Themis 1933, 1-27; Van der Weg, PS 1952, 93-96; de Winter, WPNR 4080 (1949), 166,167; de Zaaijer, NJB 1953, 355-358. Im Falle des Wehrdienstes war nur freiwilliger Wehrdienst beachtlich. Die niederländische Staatsangehörigkeit ging deshalb nicht verloren, wenn man im Ausland zur Wehrpflicht eingezogen wurde. Außerdem sei betont, daß die Einwilligung der niederländischen Regierung auch nachträglitch gegeben werden konnte. Diese nachträgliche Einwilligung kann sogar nach Inkrafttreten des neuen Staatsangehörigkeitsgesetzes noch erteilt werden (Art. 5 des Gesetzes vom 2. Julli 1986, Stbl. 373).

109. Tatsăchlich kann die Staarsangehörigkeit aber auch noch aufgrund von Art. 3 Abs.2 RwNed verloren gehen.

110. Brinkman 1985, 64,65; Dekker, Burgerzaken 1984, 99; de Groot, Loseblattkommentar, Rdnr. 1 2u Art. 14r de Groot/Tratnik, 111, 112.

11. Diejenigen Personen gelten als volljährig, die das Alter von achtzehn Jahren enreicht oder bereits vorher geheiratet haben.

112. Brinkman 1985, 66; de Groot, Loseblattkommentar, Rdnr. 1 zu Art. 15 und PS 1984, 23,24; Jessurum d'Oliveira, NJB 1984, 419,420; Mackaay, NJB 1982, 993 und NJB $1983,1319-1322$.

113. De Groot, Loseblattkommentar, Rdnr. 2 zu. Art. 15.

114. Brinkman, PS 1984, 53; de Groot, Loseblattkommentar, Rdnr. 3 zu Art. 15; de Groot/Tratmilk, 114, 115; de Groot, NJB 1981, 1125, PS 1984, 23,24 und PS 1985, 55; Jessurun d'Olivetra, NJB 1984, 420.

115. De Groot, Loseblattkommentar. Rdrur. 4 zu Art. 15; Jessurun d'Oliveira, NJB 1982, 47.

116. Brinkman 1985, 68,69; Dekker, Burgerzaken 1984, 100, 101; de Groot, Loseblattkommentar, Rdnr. zu Art. 16; de Groot, Preadwies, 91" Pitlo/Koens/Rood-de Boer, 16, 17.

\section{NOTEN ÖSTERREICH}

1. Gesetz vom 11. Julli 1973, BGB1. 1973, 394;

Gesetz vom 7. November 1974, BGB1. 1974, 703;

Gesetz vom 30. Juni 1977, BGBI. 1977, 403;

Gesetz vom 3. März 1983, BGBl. 1983, 170;

Gesetz vom 9. Mai 1985, BGBI. 1985, 202 und

Gesetz vom 3. Juli 1986, BGB1. 1986, 386.

2. Goldemund/Ringhofer/Theuer, 472 ff.: Seeler, 14; Von Zeiller, 133-136. 
3. JGS NI. 946; Entsprechende Bestimmungen enthielt bereits das Josephinische Gesetzbuch vom 1. November 1786, JGS Nr. 591. Dariber Heinl, 26; Pernthaler/Weber, 15. Das ABGB galt urspruinglich nur für die sogenannten deutschen Erbländer der österreichischen Monarchie, wurde jedoch 1849 auf alle Kronländer einschlieflich der Lainder der ungarischen Krone ausgedehnt.

4. Siehe Auswanderungspatent vom 10. August 1784. Von Zeiller, 139, 140 weist darauf hin, daB die Staatsangehörigkeit also micht durch Verurteilung wegen schweren Übertretungen und Verbrechen oder durch Landeswerweisung verloren werden konnte.

5. RGBl. 1867, 394; vgl. aber auch \& 23 der osterreichischen Reichsverfiassung vom 4. Màrz 1849 (RGBL. 1849, 151) Goldernund/ Ringhofer/Theuer 35, 36; Mayrhofer/Pace, 932-949; Seeler, 13,14.

6. Worïber Heinl, 26; Mayrhofer/Pace, 949-958; vgl. Pernthaler/ Weber, 15-17.

7. Siehe über das Heimatrecht, Heinl, 23-25; Hausenbichler, 17-29; Langhoff, 26-28; Seeler, 16, 17; Hugo Weiss, namentlich 2-44; Zeyringer/Mussger, 8, 9.

8. ThGS, Bd. 2, 365; auch beil Goldemund/Ringhofer/Theuer, 567.

9. PGS, Bd. 23, 4; auch bei Goldemund/Ringhofer/Theuer, 569 .

10. RGB1. 1849, 203; auch bei Goldemund/Ringhofer/Theuer, $584 \mathrm{ff}$.

11. Goldemund/Ringhofer/Theuer, $598 \mathrm{ff}$; man siehe weiter das Gemeindegesetz 1859 , RGB1. 1859, 95 .

12. RGB1. 1863, 368; Goldemund/Ringhofer/Theuer, $507 \mathrm{ff}$; Seeler, 17, $105 \mathrm{ff} . ;$ Weiss, 29-72.

13. Hofkanzleidekret vom 29. September 1818, PGS, Bd. 46, Nr. 102 (Dienst alls Offizier in der österreichischen Armee genügt nicht für Staatsangehörigkeitserwerb), Vgl. auch Hofkanzleidekret vom 29. Januar 1818. Darüber Seeler, 14.

14. Hofkanzleidekret vom 15. April 1828, PGS, Bd. 58, 5; auch bei Goldemund/Ringhofer/Theuer, 476 (Staatsangehörigkeitserwerb nur bei stabilem öffentlichen Dienst). Daribiber Seeler, 14.

15. RGB1. 1867, 394; auch beil Goldemund/Ringhofer/Theuer, 35; Polizei Hamburg, 152; Seeler, 104. Art. 3 machte der Eintritt in die öffentlichen Amter abhängig von der österreichischen Staatsangehörigkeit. Siehe über das Verhältnis zwischen dieser Bestimmung und \& 29 ABGB Polizei Hamburg, 143 mit Hinweisen auf Erlasse des österreichischen Ministeriums des Innern. Dariber auch Heinl, 34; Mayrhofer/Pace, 919-921; Seeler, 15. Vgl. übrigens auch Hofkanzleidekret vom 14. November 1823 (PGS Bd, 51, 285), das betont, daß nur ausnahmsweise Ausländer in Dienst genommen werden sollen.

16. Kaiserliche Verordnung vom 27. April 1860, RGBl: 1860, 222; auch bei Seeler, 104. Siehe über Staatsangehörigkeitserwerb durch Gewerbe auch Hofkanzleidekret vom 16. Januar 1817 (PGS, Bd. 45, 27; auch bei Goldemund/Ringhofer/Theuer, 478) and Hofkanzleidekret vom 20. Februar 1819 (bei Goldemund/Ringhofer/Theuer, 478). Siehe Mayrhofer/Pace, 922, 923.

17. Hofkanzleidekret vom 1. März 1833 (PGS Bd 61, Nr. 28; auch bei Goldemund/Ringhofer/Theuer, 480; Polizei Hamburg, 144; Seeler, 103).

18. Hofkanzleidekret vom 23. Februar 1833 (PGS, Bd. 61, Nir. 20, auch beil Goldemund/Ringhofer/Theuer, 475 und Seeler, 103), vgl auch Mayrhofer/Pace, 928.

19. Ministerialerlasse vom 30. August 1850 und 19. Dezember 1851, beide bei Goldemund/Ringhofer/Theuer, 482, 483. Dazu Mayrhofer/ Pace, 925-929.

20. Vgl. Hofkanzleidekret vom 28. August 1817 (PGS, Bd. 45, 416; auch bei Polizei Hamburg, 146) und Zirkular des Innenministeriums vom 13. Mai 1877 (bei Polizei Hamburg, 146). Dazu Mayrhofer/Pace, 927.

21. Vgl. Hofkanaleidekret vom 22. März 1832 (bei Polizei Hamburg, 146).

22. Heinl, $28 \mathrm{ff}$; Kramer, 7-188; Seeler, 19-33; Zeyringer/Mussger 1985, 9.

23. Das sogenannte Gebietsgesetz (StGBl. 1918, 51 ).

24. StGBL 1918, 129; dariber Goldemund/Ringhofer/Theuer, 413 ff; Kramer, 178, 179; Seeler, $20,21,119 \mathrm{ff}$.

25. StGB1. 1920, 995, in Kraft getreten am 16. Juli 1920; worüber Goldemund/Ringhofer/Thewer, 422 ff; Kramer, 71-87; Seeler, 23, $122 \mathrm{ff}$;

26. BGB1. 1921, 523, in Kraft getreten an 10. März 1921; woriber Goldemund/Ringhofer/Theuer, $453 \mathrm{ff}$ : Kramer, 144-151; Seeler. $130 \mathrm{ff}$.

27. Vgl. \& 1 Abs. 1 des Gesetzes vom 5. Dezember $1918, \& 2$ des Stalatsvertrages von Saint-Germain-en-Laye; 81 cles Brinner Vertrages; dazu u.a., Kramer, 7-18; Langhoff, 8-11. 
28. BGB1. 1920, Nr. I.

29. StGBil. 1920, Nr. 451; BGB1. 1920, Nr. 2. Dazu Goldernund/Ringhofer/Theuer, $29 \mathrm{ff} . ;$ Kramer, 182; Pernthaler/Weber, 17-19; Seeler, 141, 142.

30. BGBl., 64. Stück vom 14. August, $\mathrm{S}$. 1007, Nr. 285. Ebenfalls yom 30. Juli 1925 datieren ein Bundesverfassungsgesetz uiber Staatsangehörigkeitserwerb durch Hochschullehrant (BGB1. 1925, 62. Stilick wom 13. August, S. 940, Nr. 272), ein Bundesgesetz uber Anderung der Heimatgesetze von 1863 und 1896 sowie Durchruhrung von 14 des Gesetzes vom 1. Oktober 1920 (BGB1. 1925, 64. Stìck wom 14. August, Nir. 286) und ein Bundeswerfassungsgesetz über Änderung des Bundesverfassungsgesetzes vom 1. Oktober 1920 (BGB1. 1925, 61. Stiick vom 12. August, S. 927, Nr. 269), Goldemund/ Ringhofer/Theuer, 389 ff.; Seeler, 36 ff., 148 ff; Zeyringer/ Mussger, 9, 10.

31. Seit 1927 mit der bemerkenswerten Ausnahme, dab dies nicht galt fuir Österreicher, die im Ausland als Hochschullehrer ernannt wurden, ohne dadurch automatisch eine fremde Staatsangehörigkeit zu erwerben: Bundesgesetz vom 8. Juni 1927, BGBl., 61. Stück wom 8. August 1927, S. 1029, Nr. 236.

32. BGBI. 1933, 112. Strick wom 19. August 1933, S. 886, Nr. 369; abgeändert vom Bundesgesetz vom 24. September 1934, BGBl. 1934 II, 113. Stück vom 19. November 1934, S. 815, Nr, 352. In Deutschland hatten die Nationalsozialisten am 14. Juli 1933 ein änliches Gesetz exlassen; die österreichische Regelung ist ein eindeutiger Versuch, mit den gleichen Waffen zurickzuschlagen. Siehe Goldemund/Ringhofer/Theuer, 398 ff.: Seeler, $40,41$.

33. GBIÓ 1938, Nr. 75 .

34. RGBI. 1938 I, 790; GBI 1938, 74. Stuick vom 11. Juli 1938, S. 659, Nr. 236; vgl. Zeyringer/Mussger, 10.

35.

36.

37.

38.

39. StGB1. 1945, 16. Stück vom 14. Juli 1945 , S. 82 , Nr. 60.

40. Siehe tiber das StBG 1945, Alfred Heinl, insbesondere 80-83; wlg. auch L.J.A. de Groot, Hartmans Tijdschrift 1948, 41 .

41. Gesetz vom 9. Juni 1949, BGB1, 1949, 30. Stuick vom 18. Juli 1949, S. 729, Nr. 142* siehe auch die durch Gesetz vom 18. Januar 1946 (BGB1. 1946, 18. Stilick vom 30. Mărz 1946, S. 58, Nr. 53) vorgenommene Änderung des \& 9 Abs. 1 des Staatsbüirgerschaftsgesetzes 1945 und die Anderung durch das Gesetz tiber die Behandlung der Nationalsozialisten vom 6. Februar 1947 (BGBl. 1947, 8. Stück vom 17. Februar 1947.5 .277$, Nir. 25).

42. BGBL. 1949, 59. Stitek vom 31. Dezember 1949, S. 1169, Nr. 276. Kommentar in Buczkowski/Rockowanski, unter II; Seeler, 50-85.

43. Vgl. auch Hellbling, JB1. 1950, 3-7, 27-29, der eine Beschreibung des österreichischen Staatsangehörigkeitsrechtes nach dem Stande von 1949 gibt; siehe insbesondere S. 29, wo die Äusgangspunkte des Gesetzes gegeben werden.

44. Goldemund/Ringhofer/Theuer, $315 \mathrm{ff}$.

45. Siehe die Erläuternden Bemerkungen zur Regierungsvorlage betr. das Staatsbürgerschaftsgesetz 1965 (497 der Beilagen zu den stenographischen Protokollen des Nationalrates, X. GP); auch in Goldemund/Ringhofer/Theuer, 232, 233.

46. Dazu Seeler, $182-183$.

47. Gesetz vom 15. Juli 1965, BGBl. 1965, 68. Stitick vom 11. August 1965, S. 1171, Nir. 250.

48. Siehe die Erläutemden Bemerkungen zur Regierungsvorlage (Fundstelle in Fußnate 45) (auch in Goldemund/Ringhofer/Theuer, 234-237), wo 14 wichtige Anderungen erwithnt werden. Vgl. weiter Zedtwitz, der ebenfalls die Erläuternden Bemerkungen zur Regierungsvorlage gibt. Ausführliche Kommentare zum Gesetzestext findet man bei Buczkowski/Rockowanskd. Novak, ÖZÖR 1969, 145-186 beschreibt die Grundprinzipien, die s.E. die Ausgangspunkte des StBG 1965 sind; weiter Brinkman, PS 1967, 25, 26* Goldemund, OSTA 1965, 4-6, 16-19, 26, 27; Goldemund, StAZ 1966, 33-40; Kachler, ÖStA 1965, 89, 90; Seeler, 184-191; Van Sasse van Ysselt, PS 1966, 57. 
49. Gesetz vom 11. Juli 1973, BGB1. 1973, Nr. 394.

50. Änderung der $\$ 6,10,12,14,25,28,41,45,48,58,59$. Aufhebung des $\$ 40$ und Einfügung der $\$ 58 \mathrm{a}-58 \mathrm{c}$. Die Änderungen traten am 1. Januar 1974 in Kraft. Siehe die Erläuterungen zur Regienungsvorlage (729 der Beilagen zu den stenographischen Protokollen des Nationalrates, XIII.GP); auch in Goldemund/Ringhofer/Theuer Nachtrag 1975, 32 ff; eine Beschreibung der Staatsbürgerschaftsgesetz-Novelle 1973 gibt Novak, ÖJZ 1974, 589-593.

51. BGBI. 1974, Nr. 703.

52. Siehe die Erläuterungen zur Regierungsworlage (1134 der Beilagen zu den stenographischen Protokollen des Nationalrates, XIII.GP); auch in Goldemund/Ringhofer/Theuer, Nachtrag 1975, $40 \mathrm{ff}$.

53. BGBl. 1977, Nr. 403.

54. Siehe die $\mathrm{Nr}$. 60 und 587 der Beilagen au den stenographischen Protokollen des Nationalrates, XIV. GP.

55. BGB1. 1983, 170; Siehe die Nr. 1272 und 1475 der Beilagen zu den stenographischen Protokollen des Nationalrates, XV.GP. Siehe iber diese Anderung Ringhofer, Wien 1984 und de Groot, PS 1984, 18-27. Vgl. über den Vorentwurf Petz, OStA 1981, 90, 91; siehe auch Edtstadler, ÖStA 1983, 11-14 und ÖStA 1985, 81, 82.

56. Sichwimann, StAZ $1986,110$.

57. Kundmachung BGBI. Nr. 375/1984; auch veröffentlicht als Anlage bei der Regierungsvorlage zur Staatsbürgerschaftsgesetznovelle 1985,568 der Beilagen zu den stenographischen Protokollen des Nationalrates, XVI Gesetzgebungsperiode, 11-13. Dazu Edtstadler, ÖStA 1985, 92, 93.

58. Regierungsvorlage zur Staatsbiirgerschaftsgesetznovelle 1985, 568 der Beilagen zu den stenographischen Protokollen des Nationalrates, XVI. Gesetzgebungsperiode, 5.

59. Bundesgesetz vom 11. November 1983 über Änderungen des Personen- Ehe- und Kindschaftsrecht, BGB1. 1983, 566.

60. Bundesgesetz vom 9. Mai 1985, BGBll 1985, 202, woriber Pfersmann, ÖJZ 1985, 76, 77; Schwimann, StAZ 1986, 110-116.

61. Die Änderungen waren zusammen zo zahlreich, daß der Text des Staatsbürgerschaftsgesetzes im BGBI. 1985/3 11 wiederverlautbart wurde (Kundmachung des Bundeskanzlers und des Bundesministers für Inneres vom 19. Juli 1985).

62.

63. Bundesgesetz vom 3. Juli 1986, BGB1. 1986, 386.

Mayrhofer/Pace, 922; Seeler, 15.

Mayrhofer/Pace, 931; Seeler, 14.

65. Mayrhofer/Pace, 921; Seeler, 14.

66. PGS Bd. 61, Nr. 28; siehe oben Fußnote 17; vgl. Mayrhofer/Pace, 922.

67. Dazu Pichl, ÖStA 1972, 86-89.

68. Hingewiesen sei aber noch auf $\S 7 \mathrm{a}$ Abs. 5 StBG, kraft dessen eüne benötigte Zustimmung vom Gericht ersetzt werden kainn, wenn der Erwerb der Staatsbürgerschaft aus erzieherischen, beruflichen oder anderen wichtigen Grunden dem Wohl des Legitimierten dient. Vgl. Pfersmamn, OJZ 1985, 76, 77; Zeyringer/Mussger 1986, $11-14$.

69. VwGH 3. Februar 1976; siehe Ringhofer, 149.

70. Von Zeiller, 138.

71. Vgl. Novak, OZORR 1969, 152; Zeyringer/Mussger 1985, 35-38.

72. \$2 Heimatgesetz vom 3. Dezember 1963; vgl. Mayrhofer/Pace, 926.

73.

Kaiserliche Verordnung vom 27. April 1860; vgl. Mayrhofer/Pace, 922.

74. Mayrhofer/Pace, 925; Seeler, 15.

75. Siehe Heinl, 117-123.

76. Vgl. dazu VwGH 23. Oktober 1985.

77. Dazu de Groot, PS 1984, 23, 24. Vor 1985 galt dasselbe für den Dienstantritt eines auBerordentlichen Hochschulprofessors. Durch Novelle des Beantendienstrechts (BGBI. 1984/550) wurde die Kategorie des außerordentlichen Hochschulprofessors aber abgeschafft. Vgl. auch Kiemberger, 379-398; Pfersmann, ÖJZ 1985, 78, 79; Zeyringer/Mussger 1985, 84-87; Zeyringer/Mussger 1986, 29, 30 .

78. Abgesehen von der Übergangsbestimmung des Gesetzes vom 3. März 1983, in der minderjährigen, ehelichen oder legitimierten Kindern einer österreichischen Mutter ein befristetes und bedingtes Optionsrecht auf die österreichische Staatsangehörigkeit gegeben wurde. 
79. Dies gilt insbesondere für Personen, die als Flüchtlinge im Sinne der Konwention über die Rechisstellung von Flüchtlingen anerkannt worden sind. Auch sie miissen aber die tibrigen Voraussetzungen des $10 \mathrm{StBG}$ erfillen. In der Rechtsprechung fallt auf, da $\mathrm{B}$ in diesem Zusammenhang aber die Voraussetzung von \$10 Abs. 1 Ziffer 6 StBG (die betreffende Person darf keine Gefahr fuir die öffentliche Ruhe, Ordnung oder Sicherheit darstellen) strenger als normal beurteilt wird (siehe VwGH 25. Februar 1987, VwGH 21. Januar 1987).

80. Siehe darüber VwGH 18. April 1979, wozu Ringhofer, 149; Zeyringer/Mussger 1985, $41-43$.

81. Diese Klausulierung wird relativ extensiv interpretiert. Vgl. VwGH 24. Juni 1975: ".... wesentlich erscheint lediglich, dab es sich um einen Rechtsbruch handelt, der den SchluB gerechtfertigt erscheinen läBt, der Betreffende werde auch in Zukunft wesentliche, zur Abwehr und. Unterdrückung von Gefahren fit das Leben, die Gesundheit, Sicherheit, offentliche Ruhe und Ordnung erlassene Vorschriften mißachten. Demnach sind auch Personen, die sich Verstöße gegen Vorschriften, die der Sicherheit des Straßenverkehrs dienen, zuschulden kommen ließen, von der Verleilhung der Staatsbürgerschaft ausgeschlossen, sofern aus der Art, der Schwere oder der Häufigkeit dieser Ubertretungen die negatiwe Einstellung gegeniuber den zur Hintanhaltung von Gefahren fuir Leben, Gesundheit und Sicherheit der Allgemeinheit erlassenen Gesetzen in deutlicher Weise zum Ausdruck kommt". Dabei ist unbeachthich, daß der Einbürgerungsbewerber "die ïber ilm verhängten Strafen stets ohne weiteres akzeptiert habe und im ubrigen seit vielen Jahren unbeanstandet seinem Beruf als Kaufmann nachgehe" (VwGH 28. Januar 1981 und 12. November 1980; weiter VwGH 26. Jumi 1979 und 28. April 1982). Siehe Ringhofer, 149-151, mit weiteren Hinweisen. Vgl. VwGH 4. März 1987 (ZfVB 1987, 651), wo die Einbïrgenung eines Taxiunternehmens verweigert wird. Aus einer anderen Entscheidung des VwGH vom 4. März 1987 (ZFVB 1987, 651) geht sogar hervor, daß eine Einbiirgerungsbehörde meinte, daß die Nichteinhaltung der vorgeschriebenen Fahrtrichtung mit einem Fahrrad in Zusammenhang mit anderen verwaltungs-strafrechtlichen Beantstandungen eine Rilckweisung eines Einbürgerungsantrages begriinden konnte. Vgl. schließlich auch Pfersmann, OJZ 1985,79 , Zeyringer/Mussger 1985, 43, 44.

82. Finanzielle Zuwendungen einer Lebensgefährtin können nicht als hinreichende Sicherung des Lebensunterhaltes gewertet werden, da keine Gewähr dafür besteht, daf sie dem Einbürgerungsbewerber dauernd in ausreichendem MaBe zufließen werden (VwGH 29. Mărz 1977); das Vorliegen eines Unterhaitsanspruchs gemäß \& 89 ff. $A B G B$ bedeutet hingegen eine ausreichende Sicherung (VwGH 18. April 1979); dazu Ringhafer, 151, 152; Zeyringer/Mussger 1985, 45.

83. Vgl. für Möglichkeiten der Einbürgerung ohne Wohnsitz in Österreich Hintermulller, OStA $1975,73,74$.

84. Vgl. einige schöne Beispiele bei Edtstadler, ÖStA 1987, 105; Pfersmann, ÖJZ 1985, 72-74, 79; siehe auch Zeyringer/Mussger 1985, 48 .

85. Wenn die Voraussetzungen des $\$$ in StBG erfuill sind, besteht also noch kein Einbürgerungsanspruch. Vgl. WwGH 19. November 1986 (ZfVB 1987, 458), wo dieser Gerichtshof eine Entscheidung aufhebt, in der eine Einbiurgerung verweigert wurde, weil der Antragsteller infolge seiner Abstammung aus dem tïrkischen Kultur- und Sprachraum einen längeren Zeitraum zur erforderlichen Anpassung an die in Vorarlberg herrschenden Lebensgewohnheiten benötige, zumail er die sehr prägenden Kinderund Jugendjahre in Sprach- und Kulturraum seines Heimatlandes verbracht habe. Die Behörde hatte betont, daß dies durch die noch unzureichende Beherrschung der deutschen Sprache, insbesondere im Lesen und Schreiben zum Ausdruck komme (vgl. anch VwGH 7. Mai 1986, ZFVB 1987, 66, 67). Vgl. in diesem Zusammenhang auch Pfersmann, OrZ 1985, 79, der Kenntnis der deutschen Sprache als Voraussetzung für die Verleihuing der Stantsbürgerschaft ablehnt. Siehe weiter VwGH 23. April 1986, ZFVB 1987, 66, wo eine Entscheidung aufgehoben wurde, in der eine Behörde die Einbürgerung eines Kernmachers und Maskenformers verweigert hatte mit der Begrtindung, die angespannte Situation auf dem Arbeitsmarkt stiinde der Verleihung der österreichischen Staatsbitirgerschaft entgegen, weil dadurch im Widerspruch zum offentlichen Interesse österreichischen Staatsbuirgern potentielle Arbeitsplätze entzogen
witrden. 
86. Siehe zu diesen Vorschriften u. a. Hoyer, Zeitschrift für Rechtsvergleiclhung 1973, 83-88; Mänhardt, österreichische Richterzeitung 1973, 205-210; Mainhardt, StAZ 1976, 293-303; Pfersmann, ÖIZ 1972, 542, 543; Zeyringer/Mussger 1985, 72-76.

87. Zeyringer/Mussger $1985,67-70$.

88. Eine ausführliche Beschreibung der Verllusttatbestinde des österreichischen Staatsangehörigkeitsrechts und deren Geschichte gibt Schwimann, ÖIZ 1955, 381-391.

89. Heinl, 34; Mayrhofer/Pace, 941-947; Seeler, 15.

90. Mayrhofer/Pace, 932-940; Seeler, 16.

91. Goldemund, OStA 1956, 21, 22 erörtert den Begriff "triftige Gründe". Vgl, auch Itringer, ÖStA 1962, 54-56, 61-64 und Liehr, ÖStA 1949, 52-56, 75-76.

92. So auch bereits Goldemund, OStA 1956, 20; Zeyringer/Mussger 1985, 101, 102.

93. Siehe dann das Beispiel eines Spiones bei Pfersmann, ÓJZ $1985,73$.

94. Stichlberger, Österreichisches Verwaltungsarchiv 1979, 9-13.

95. Novak, OZZöR 1969, 164-166 betrachtet den Verzicht als Beispiel der Privatautonomie im Staatsangehörigkeitsrecht; siehe auch Zeyringer/Mussger 1985, 106, 107.

\section{NOTEN SCHWEIZ}

1. BB1. 1952 III, 137; seitdem mehrmals geändert.

2. Vgl. Bundesverfassung der Schweizerischen Eidgenossenschaft vom 29. Mai 1874 (unten weiter zu zitieren als BVerf), Art. 1, 3, 5, 6 und die unterschiedlichen Verfassungen der Kantone, z.B. Art. 1 Abs. 1 Verfassung des Kantons Bern vom 4. Juni 1893.

3. Die schweizerischen Gesetze werden auf Grund des Art. 116 Abs. 2 BVerf in der deutschen, französischen und italienischen Sprache veröffentlicht. In diesen $\mathbb{K a p i t e l}$ werden jeweils grundsätzlich die deutschsprachigen juristischen Begriffe benutzt.

4. Bridel, 293, 294 unterscheidet das "droit de cité suisse" in "le droit de cité communal" oder "bourgeousie", "le droit de cité cantonal" oder "indigénat" und "le droit de cité fédéral" oder "nationalite".

5. Aubert, 355; Bolleter, 10-14; Giacometti/Fleiner, 177; Immer, 38-40; Schröder, 1954, 9; Wiederkehr, 4. Nur in einigen Ausnahmefallen kann ein Kantonsbiirgerrecht oder Gemeindebürgerrecht - vorïbergehend - getrennt voneinander bestehen.

6. In diesem Buch werden die Begriffe "schweizerische Staatsangehörigkeit" und "Schweizer Bürgerrecht" als Synonymen benutzt. Wiederkehr, 7 schlägt dagegen vor, die Bezeichnung "schweizerisches Staatsangehörige" für das "äußere oder völkerrechtliche Verhältnis und die Bezeichnung "Schweizer Bürger" für das innere oder staatsrechtliche Verhälitmis zu verwenden.

7. Siehe darüber Giacometti/Fleiner, 178, 179 mit wielen weiteren Hinweisen; Schröder 1949, 7; Bridel, 289-293, Anbert, 356-357; Immer, 24-37; Hermann-Riütschi, 15-23; Wiedlerkehr, 2 ; Rieser, 10.

8. Immer, 26, 27; Schröder, 7

9. Siehe die Einheitsverfassung det Helwetik von 12. April 1798.

10. Art. 19 der helvetischen Verfassung bestimmte: "Tous ceux que sont actuellement bourgeouis effectifs, soit d'une ville municipale on dominante, soit d'un village sujet on non sujet, deviennent par la constitution citoyens suisses". Immer "28-33; Rieser, 38; Schröder. 7; Schröder, 7; Wiederkehr, 3.

11. Siehe Art. 43 und 56 Bundesverfassung vom 12. September 1848; worliber; Immer, 33, 34; Giacometti/Fleiner, 178; Wiederkehr, 4.

12. Schröder $8,12-14$.

13. Art. 22, 270, 324, 325 ZGB.

14. BBi. 1920 I, 515; IV 138; 1921 I 176; III 335; 1922 I 650, 654, 656, II 1, 871. Verworfen in der Volksabstimmung wom 11. Juni 1922.

15. AS 44.724; BBI. $1920 \mathrm{~V}$ 1; 1922 III $661 ; 1927$ II $269 ; 1928$ I 77, 79, 81, II 153. Angenommen in der Volksabstimmung vom 20 . Mai 1928 .

16. Siehe dariber Benz, 14, 15; Immer, 35; Luther 135-152; Wiederkeltr, 58-63; wgl. Frey, Diss. 1942; Hegi, $110,111$.

17. Aufinahme eines Art. 44 Abs. 2 bezïglich Beschränkung der Einbürgerungen $B B 1$. 1976 I $1373 *$ III $645 ; 1977$ I 21,$23 ;$ II 197,438 . Verworfen in der Volksabstimmung vom 13. März 1977. 
18. Art. 4 Abs. 2 BVerf; AS 1981. 1243; BB1. 1977 1 511; 1978 I 199; II 1219; 1980 I 69; III 701, 775; 1981 I 644, 645; II 1266 .

19. BBl. 1983 II 703 .

20. BBI. 1984 I 614. Dazu Gervasoni, ZZW 1983, 284, 285 und 1984, 9, 10; Rousseau, RCDIP 1984, 739 .

21. AS Bd. 2, 452; auch bell Polizei Hamburg; $193-196$.

22. BB1. 1903 IV, 216; AS Bd. 19, 690; auch abgedruckt bei Schröder, 58-62.

23. Vgl. aber auch den BundesratsbeschluB iuber die Anwendung von Art. 7 und 9 des Gesetzes aus 1903 in Kriege vom 23. Februar 1917, R.0. 1917, 91.

24. As Bd. 36, 639 .

25. AS Bd. 57, 1257; auch bei Schröder, 68-71. Kraft Art. 10 dieses Beschllusses wurde die Wirkung von den Art. 4 Abs. 3, \& Abs. 2, 11 und 12 des BüG 1903 suspendiert.

26. Dazu Frey, Diss. 1942, 27, 28; Jean Meyer, 62-85.

27. Vgl z.B. für den Kanton Zürich: Gesetz uber das Gemeindewesen vom 6. Juni 1926, 20-31 und die Verordnung liber das. Gemeindebijgenecht und das Landrecht vom 3 . Juli 1926; für den Kanton Bern: Dekret betreffend Erteilung des Gemeinde- und Kantonsbïrgerrechtes und die Entlassung aus demselben vom 10. Dezember 1918.

28. Bundesgesetz über die Einfügung von Art 58 bis ins Staatsangehörigkeitsgesetz vom 7. Dezember 1956, in Kraft getreter am 1. Mai 1957 (AS 1957, 306).

29. Bundesgesetz wom 30. Juni 1972 über die Anderungen des ZGB (Adoption) (AS 1972, 2819, 2829, BBI. 1971 I 1200). Vgl, bereits Gervasoni, ZZW 1969, 364-366.

30. Bundesgesetz vorm 25. Juni 1976 iuber die Anderung des Kinderrechts des Schweizerischen Zivilgesetzbuches; BundesratbeschluB wom 13. (Januar 1977, AS 1977, 237, 264; BBI. 1974 II 1); dazu u.a. Brinkman, PS 1978, 41; Nabholz, ZZW 1978, 184-188.

31. BB1. 1984 II 211, AS 1985, 420. Am 17. April 1985 wurde festgestellt, daB die Referendumfrist für dieses Gesetz am 27. März 1985 ungenuitzt abgelaufen war. Dazu Schärer, ZZW 1985, 203-207; siehe auch ZZW 1985, 201-203; Sturm/Sturm, StAZ 1986, 29-34; 57-64; Vgl. bereits Schärer, ZZW 1985, 53-59; Hegnauer, ZZW 1985. $112-114$.

32. Vgl. FulBnote 14.

33. Der Vorentwurf wurde mir vom Bundesamt für Polizeiwesen zur Verfügung gestellt. Siehe tiber die vorgenommene Ändenung auch den Bericht über die Richtlinien der Regierungspolitik 1983/1987 vom 18. Januar 1984, 53, 55 .

34. In der Volksabstimmung vom 4 Dezember 1983 wurden Einbürgerungserleichterungen für junge Ausländer, Flüchtlinge und Staatenlose abgelehnt.

35. Art. III des Entwurfes.

36. Wiederkehr, 50.

37. Wiederkehr, 51, weist darauf him, daß der Abstammungsgrundsatz des Art. 22 Abs. 2 ZGB nur im inter- und innerkantonalen Recht gilt.

38. Schroder, 26 ; Wiederkehr, 76,77. Siehe für Legitimation durch Ehelichkeilserklärung seit 1912 Ast. 263 Abs. $1 \mathrm{ZGB}$.

39. Wobei beachtet werden muß, daß nur der wirkliche Vater (oder Großvater) des Kindes anerkennen diuffe (Art. 303 ZGB). Die Anerkennung von Ehebruchs- ader Inzestkinder war ausgeschlossen (Arr. $304 \mathrm{ZGB}$ ).

40. Art. $323 \mathrm{ZGB}$; wenn der Vater der Mutter die Ehe versprochen hatte oder sich mit der Beiwohnung an ihr eines Verbrechens schuldig gemacht oder die ihm iber sie zustehendle Gewalt mißbraucht hat.

41. So ausdricklich: Art. 7 Bü i.d.F. 1952" wlg. für die Hintergründe der Änderung aus 1972: Wiederkehr, 90-93. Siehe weiter Gervasoni, ZZW 1969, 364-366; Hegnauer, ZZW $1980,39-41$.

42. Dazu Götz, ZZW 1979, 204: Stuber, ZZW 1984, 83, 84.

43. Siehe über diese Regelung Wiederkehr, 67-72, mit Hinweisen auf höchstrichterliche Entscheidungen uber die in diesem Artikel maBgebenden Begriffe "von Abstammung Schweizer Bitrgerin" und "Wolnsitz der Eltern". Siehe weiter Amacher, ZZW 1979, 47, 48; Baumgartner, ZZW 1977, 281-283; Halter, ZZW 1981, 374, 375; Inglin, ZZW 1979, 253-255; Trevisan, ZWW 1977, 359.

44. Art. 2 Abs. I Heimatlosengesetz vom 1850; siehe Schröder, 38, 39; Wiederkehr, 97-99.

45. Dazu Sturm/Sturm, StAZ 1986, 29-34; 57-64.

46. Wiederkehr, 55. 
47. Vgl. die skeptischen Ausfïhnngen won Wiederikehr, 52, 53.

48. Daza Hegnauer, ZZW 1985, 112 , 113; vgl. Hegnaver, ZZW 1980, 39-41.

49. Amt.Bull.St.R. 1975, 121; siehe auch Hengeler, $Z Z W W 1977,280$.

50. Durch Kreisschreiben vom 10. März 1884 (BBI. I, 430, 431; auch bei polizei Hamburg, 196, 197) wurde betont, daß es sich um einen tatsaichlichen und ununterbrochenen Aufenthalt handeln muB. AusschlieBlich schriftliche Beweisstücke reichten also nicht aus.

51. Diese Vorschrift wrurde konkretisient von $\$ 4$ der Anleitung vom 2. Juli 1876. Die Angehörigen einiger Staaten mußten nachweisen, nicht mehr wehrplichtig zu sein oder muBten eine Erklärung des bisherigen Heimatsstaates vorzeigen, daß einer Einbürgerung in der Schweiz nichts entgegenstand (siehe bei Polizei Hamburg, 197-200).

52. Siehe dazu kritisch Knapp, ZZW 1984, $277-285$.

53. Ein Optionsrecht war lediglich in der Übereinkunft zwischen der Schweiz und Frankreich betreffend die Nationalität der Kinder und den Militärdienst der Söhne von in der Schweiz naturalisierten Franzosen yom 23. Juli 1879 vorgesehen. Dazu Jezlex, Bern 1940; vgl. weiter Keller, ZZW 1980, 19, 20 und Perret, ZZW 1979, 148, 149.

54. Es sei denn, es handelt sich um eine Ehe zwecks Staatsangehörigkeitserwerbs. Eine solche Ehe ist aufgrund Art. 120 Abs. 4 ZGB nichtig.

55. In der Schweiz hat der Terminus "erleicherte Einbiirgenung" einen spezifischen Inhalt. Tatsächlich kann der ausländische Ehemann wohl schneller als andere eingebilrgert werden. Der Inhalt des Begriffes "erleichterte Einbürgerung" wird nachher erliutert. Vgl. dazu Grendelmeier, Zürich 1969; siehe auch Freund, Zeitschrift für schweizerisches Recht 1974, 61-92; Hirt, ZZW 1976, 108, 109.

56. Unter Verantwortung des Schweizerischen Verbandes der Bürgergemeinden und Korporationen des Schweizerischen Städteverbandes unơ der Eidgenössischen Kommission für Ausländerprobleme; die verantwortliche Redaktion wurde von Robert Göpfert und Hildebert Heinzmann gebildet.

57. Göpfert/Feinzmann, 2. Vgl. für Aargau Botteler, 32-48.

58. \$ 3 Verordinung uiber das Gemeinde- und das Kantonsbürgerrecht (Zürich) vom 25. Oktober 1978; siehe auch Benz, 42-49 und Göpfert/Heinzmann unter Zürich.

59. Art. 4 Dekret betreffend Ertellung des Gemeinde- und Kantonsbiirgerrechts und die Entlassung aus demselben (Biern) vom 10. Dezember 1918; siehe Göpfert/Heinzmann unter Bern.

60 Vgl. \& 3 Bürgerrechtsgesetz vom 29. Dezember 1922 (Kanton Luzern) mit Göpfert/Heinzmann unter Luzern über die Stadt Luzern.

61. Art. 3 Gesetz tiber den Erwerb des Landrechtes des Kantons Uri vom 5. Mai 1935; siehe Göpfert/Heinzmann unter Uri.

62. Bürgerrechtsgesetz vom 27. April 1969; zitiert bei Göpfert/ Heinzmann unter Unterwalden nid dem Wald.

63. Art. 8 Ziffer 1 Gesetz über Erwerb und Verlust des Kantons- und des Gemeindebirigerrechtes vom 5. Dezember 1955 (St. Gallen).

64. So Göpfert/Heinzmann unter 5 t. Gallen.

65. \$5 Büirgerrechtsgesetz vom 29. Dezember 1922 i.d.F. wom 9. Mârz 1954 setzt die dem Kanton zu zahlenden Summe grundsätzlich auf 100 SF fest, bestimint aber weiter daB diese Summe für Auslënder auf 10,000 SF erhöht werden kann. Neben der Kantonsgebuhr ist noch eine Giemejndegebuthr zu zahlen. Weiter ist zu bericksichtigen, $\mathrm{daB}$ auch für die Einbiirgerungsbewilligung Gebihhren gezahlt werden müssen.

66. Göpfert/Heinzmann, unter Genf. Vgl. für Aargau Botteler, 58-66 und fïr Zïrich Benz. 87-93.

67. Dazu Benz, 112-129; Botteler, 136-163.

68. Gopfert/Heinzmann unter Zürich, Zug und Solothurn; vgl. Benz, 79-82.

69. Göpfert/Heinzmann, passim; vgl. Benz, 40-94.

70. $\$ 6$ Verordnung über das Gemeinde- und Kantonsbürgerrecht (Zúrich): "Der Ruf des Bewerbers ist aufgrund des Strafregisters und des Betreibungsregisters zu beurteilen. Er gilt in der Regel als unbescholten, wenn die Registerauszüge für die letzten fünf Jahre keine Einträge von Bedeutung enthalten. Übertretungsstrafen sind nach ihrer Zahl und Schwere $z u$ wïrdigen. Laufendle Strafuntersuchungen werden wenn möglich aufgrumd eines Zwischenberichtes beurteilt". Vgl. Benz, 54-64. So in Prinzip auch in Aargau; siehe dazu Botteler, 53, 54, der allerdings weiter schreibt; "Aber auch schlechtes Benehmen, schwierige Charaktereigenschaften und unmoralischer Lebenswandel allein, ohne daß strafbare Handlungen die Folge davon gewesen sind, können 
für die Abweisung eines Einbürgerungsgesuches genügen". In Fussnote 188 weist er auf zwe Fâlle hin: a) Bewerber lebre im Konkubinat; b) Bewerber war die Ehefrau eines Landesverrâters.

71. Art. 5 Ziffer 3 Loi sur le froit de cite vaudois vom 29. November 1955: "n'avoir pas subi de condamnation pour délit grave et intentionnel, être d'une probité averéte et joulir d'une bonne réputation".

72. Daten iblber Genf bei Göpfert/Heinzmann, unter Genf.

73. Luzern, Uri, Unterwalden ob dem Wald, Fribourg, Aargau, Thurgau, Genève, Jura.

74. Bei Göpfert/Heinzmann wird dies erwăhnt für die Kantone: Bern, Schaffhausen, St. Gallen und Thurgau.

75. Vgl. Ant. 5 Ziffer 3 des Berner Dekrets betreffend Erteilung des Gemeinde- und Kantonsbitrgerrechtes und die Entlassung aus demselben vorn 10. Dezember 1918 ("Der Bewerber hat sich ferner auszuweisen .... über seine Fähigkeit, sich und seine Familie erhalten zu können, speziell iber das von ihm während der letzten zwei Jahren versteuerte Vermögen und Einkommen") mit der Aufzeichnung bei Göpfert/Heinzmann, Bern fordere "geordnete persönliche Verhältnisse". Vgl. weiter auch \& 9 Gesetz uber das Kantons- und Gemeindebuirgerrechil (Thurgau) vom 23. April 1976: "Die Erteilung von Kantons" und Gemeindebürgerrecht setzt die Eignung des Bewerbers sowie eine hinreichende Existenzgrundlage voraus".

76. Unterwalden nid dem Wald, Basel (Stadt) und Schaffhausen werden bei Göpfert/Heinzmann erwähnt. So ausdruicklich $\$ 14$ Abs. 1 Buchstabe 4 Bïgerrechtsgesetz Basel (Stadi) vom 19. Màrz 1964. Vgl. füir Aargau Botteler, 55-57.

77. Art. 5 Ziffer 4 Loi sur le droit de cité vaudois vom 29. November 1955: "ne pas être par sa faute a la charge de l'assistance publique d'une façon durable".

78. Daten uber Genf bei Gopfert/Heinzmann.

79. Göpfert/Heinzmann erwähnen: Solothurn, Basell (Land), Schaffhausen, Appenzell, Appenzell i.Rh., Graubünden, Aargau, Thurgat, Ticino, Vaud, Vallis, Neuchâtel, Genève. Siehe für Aargau Botteler, 19-22.

80. 821 Ziffer 1 Verordnung über das Gemeinde- und das Kantonsbürgerrecht (Zürich) vom 25. Oktober 1978: "Die Eignung ist gegeben, wenn er 1. zu keinem andern Land năhere Bindungen und Beziehungen alls zur Schweiz unterhält; ....". Siehe Benz, 70-77.

82. In Landsgemeindebeschluß ibber die Erteilung des Bürgerrechtes für den Kanton Appenzell i.Rh. wird sogar die "Assimilation" nicht ausdrüicklich erwähnt. In dem drei Artikel zâhlenden Beschlußs wird ausschließlich vom Wohnsitzerfordernis gesprochen.

83. Unterwalden ob dem Wald, Unterwalden nid dem Wald, Glarus, Basel-Stadt, Aargau, Vaud, Vallis.

84. Schwyz, Unterwalden ob dem Wald, Zug.

85. Zitich, Uri, Basell-Stadt; vgl. Benz, 79-81.

86. Göpfert/Heinzmann erwälhnen Bern, Fribourg, Solothurn. Vgl. für Aargau Botteler, 51, 52 und für Zürich Benz, 82-84.

87. Gopfert/Heinzmann erwälmen dies bei Solothurn. Im Gesetz über Erwerb und Verlust des Kantonsbürgerrechtes (Solothurn) vom 27. September 1959 wird dies allerdings. nicht ausdrücklich vorgeschieben. Vgl. Botteler, 55 , der betont, daß ein zweifelhafter Gesundheitszustand allein in Aargau noch in keimem Fall Abweisungsgrund war. Auf S. 54 sagt er uber die Forderung: "Derartige Bestimmungen stehen in erster Linie im Interesse eines erbgesunden Nachwuchses. Es werden aber bei ihrer Festlegung auch Ubberlegungen finanzieller Natur eine Rolle gespielt haben. Gesundheitliche Störungen müssen jedoch in allgetmeinen gegenüiber der Persönlichkeit und den menschlichen Werten zuriticktreten". Vgl. Benz, 69.

88. Zitrich, Vallis, Nenchâtel, dazu Benz, $76,77$.

89. Göpfert/Heinzmann, 2.

90. Göpfert/Fleinzmann, passim.

91. Oben FuBnote 84.

92. Für Aargau siehe Botteler, 25.

93. Göpfert/Heinzmann.

94. Fiir Aargau siehe Botteler, 55 und für Zuirich Benz, 69.

95. Vgl. die Merkmale der Assimilation bei Botteler, 23-27.

96. Art. 2 Abs. 2 Landsgemeindebeschluß über die Erteilung des Bürgerrechtes fïr den Kanton Appenzell i.Rh. vom 30. April 1972; Art. 3 Ziffer 3, Gesetz uber Erwerb und Verlust des Kantons- und des Gemeindebürgerrechtes vom 5. Dezember 1955. 
97. Vgl. aber Art. 26 ff. VwVG, SR 172.021. Benz, 112-129, Botteler, 79, 80.

98. Dazu Grendeimeier, Diss. 1969, der (S. 111) eine erleichterte Einbirgerung vorschliagt fir alle bereits 10 Jahre in der Schweiz lebende Personen, die vor Vollendung des 22. Lebensjahres Einbuirgenung beantragen. Siehe anch Burger, Diss. 1971; Freund, 99. Zeitschrift für schweizerisches. Recht

100. Stoll, Diss 1888 .

101. Etter, 93-129; Immer, 98-101.

102. Etter, 113-119.

103. Etter, 100-105; Inmer, 104-108.

104. Dazu u.a. Frey, Diss. 1942; Hegi, 110, 111; Luther, 135-152.

105. Immer, 141-200.

106. Dazu Hegnauer, ZZW 1985, 113.

107. Vg1. dazu auch Hartwig, ZZW 1982, 8, 9.

108. Wiederkehr, 37.

\section{NOTEN SPANIEN}

l.

2.

3.

4.

5.

6.

7.

8.

9.

10.

11 .

12.

13.

14.

15.

16.

17.

18.

19.

20.

21.

22.

23.

24 .

25.

26.

27.

28.

29. Hampe/von Waldheim, 15, 16 .

Codigo civil vom 26. März 1889, in Kraft getreten am 24. Juli 1889. Siehe Hecker, Staatsangehörigkeitsrecht im Code Napoléon.

Hecker, Europa, 509-515.

BOE vom 16. Juli 1954, Nr. 197.

In Kraft getreten am 5. Mai 1975; BOE vom 5. Mai 1975, Nr. 107.

In Kraft getreten am 20. August 1982; BOE vom 30. Juli 1982, $\mathrm{Nr}$. 181; siehe weiter Circular de la Dirección general de los registros y del notariado sobre nacionalidad espaffola vom 22. Mai 1975, BOE Nr. 124 vom 21. Mai 1975 und Instrucción de la Dirección de los registros y del notariado sobre nacionalidad espafíola vom 15. Maí $1983, \mathrm{BOE}$ Nr. 120 yom 20. Mai 1983.

Hampe/von Waldheim, 9.

Hampe/von Waldheim, 9.

4. Partida, 2. Gesetz, 24. Titel; siehe Hampe/von Waldheirn, 9,

Hampe/von Waldheim, 9, 10; vgl. Bercovitz Rodriguez-Cano, Anuario de derecho civil $1983,1149-1167$.

Hampe/von Waldheim, 10-12.

Uber die Constitución von Cadiz vom 19. März 18.12; de Esteban, 17-19 (Text auf S. 45-103); Hampe/von Waldheim, 10.

Ưber đie Constitución von 1837 de Esteban, 20, 21 (Text auf S. 105-114).

Hampe/von Waldheim, 11; so auch bereits Art. 1 des Proyecto de Constitución de la Monarquía Española del Ministerio Istrufz vom 20. Juli 1836.

Darüber de Esteban, 21, 22; Text beil de Esteban, 119-129. Ebenso Art. 1 der nie verkiundeten Constitución won 1856.

Darüber de Esteban, 22, 23; Text bei de Esteban, 137-154. Eine entsprechende Regelung ist auch zu finden im Art. 3 des Proyecto de Constitución federal de la Repüblica Espafiola yom 11. Februar 1873. Dariber de Esteban, 23, 24; Text bei de Esteban, 157-175.

Darilber de Esteban, 24, 25; Text bei de Esteban, 177-190.

Hampe/von Waldheim, 12,13 .

'Text u.a. bei Polizei Hamburg, 312; Scaevola, 388-395.

Text u.a bei Polizei Hamburg, 330, dazu Hampe/von Waldheim, 12.

Deutsche Übersetzung bei Polizei Hamburg, 323-325.

Manresa y Navarro, 240-243; Martínez Ruiz, 227; Scaevola, 359-376.

Manresa y Navarro, 255-256; Martinez Ruiz, 232; Scaevola, 363.

Manresa y Navarro, 248-254; Martinez Ruiz, 240/241; Scaevola, 384.

Marresa y Navarro, 256-257; Martínez Ruiz, 235-237; Scaevola, 384-387.

Hampe/von Waldheim, 13, 14.

Gazeta de Madrid vom 14. November 1916; dazu Hampe/von Waldheim, 14 .

Gazeta de Madrid vom 30. April 1931.

Verfassung vom 9. Dezember 1931; Text bei de Esteban, 191. Über diese Verfassung de Esteban, 25-27. 
30. Ubersetzung bei Hampe/von Waildheim, 44 .

31. Spanien hat mit den folgenden lateinamerikanischen Staten Abkommen über Doppelstatatsangehơrigkeiten geschlossen: Chile (Abkommen vom 24. Mai 1958 , ratifiziert an 28. Oktober 1958; BOE vom 14. November 1958, Nr. 273), Peru (Abkommen vom 16. Mai 1959, ratifiziert am 15. Dezember 1959; BOE vom 19. April 1960, Nr. 94), Paraquay (Ablcommen vom 25. Juni 1959, ratifizient am 15. Dezember 1959, BOE vom 19. April 1960, Nr. 94), Nicaragua (Abkommen vom 25. Juli 1961, ratifiziert am 25. Januar 1962; BOE vom 2. Mai 1962, Nr. 105), Guatamala (Abkommen vorm 28. Juli 1961, ratifiziert am 25. Januar 1962; BOE vom 10. Mărz 1962, Nr. 60), Bollivien (Abkommen vom 12. Oktober 1961, ratifiziert am 25. Januar 1962, BOE vom 14. April 1964, Nr. 90), Ecuador (Abkommen vom 4. März 1964, ratifiziert am 22. Dezember 1964, BOE vom 13. Januar 1965, Nr. 13), Costa Rica (Abkommen vom 8. Juni 1964, ratifiziert am 21. Januar 1965, BOE vom 25. Juli 1965, Nr. 151), Honduras (Abkommen vom 15. Juni 1966; BOE wom 18. Mai 1967), Dominikanische Republik (Abkommen vom 15. März 1968, ratifiziert am 16. Dezember 1968, BOE vom 8. Februar 1969, Nr. 34), Argentinien (Abkommen vom 19. April 1969, ratifiziert am 2. Februar 1970; BOE vom 2. Oktober 1971, Nr. 236) und Kolombien (Abkommen vom 27. Juni 1979, ratifiziert am 7. Mai 1980; BOE vom 29. November 1980, NI. 287); siehe wweiter Notenwechsel mit Venezuela vom 4. Juli 1974 (BOE vom 12. November 1975). Vgl. tiber diese Abkommen Abarca Junco/Pérez Vera, 194-197; Aznar Sánchez, 9-80; Barbera García, Boletin de Información 1971, 316: Marín López, Antario de derecho internacionall 1982, 219-232; Pérez. Vera, Emigración, 73-81; Miaja de la Muela, REDI 1966, 381-410; vgl. auch Diez del Corral Rivas, Revista de derecho privado $1983,799-802$.

32. BOE wom 31. Mai 1938, Nr. 586; siehe auch Dekret des Justizministers vom 9. Nowember 1939 (BOE wom 3. Dezember 1939, Nr. 337) über die Rückwirkung der Aufhebung der selbständigen staatsangehörigkeitsrechtlichen Position der Ehefirau in der Verfassung von 1931.

33. Neufassung der Art. 17-27 C.c.esp. durch Gesetz vom 15. Juli 1954, BOE vom 16. Juli 1954, Nr. 197.

34. Dekret des Justizministers vom 9. März 1939, BOE vom 16. März 1939, Nr. 75.

35. Art. 27, 34 und 141 des Código penal vom 23. Dezember 1944, BOE vom 14. Juli. 1945, Nr. 195.

36. Gesetz vom 17. Juli 1945 (Art. 20): "Ningún español podrá ser privado de su nacionalidad sino por delito de traición, definido en las Leyes penales, o por entrar al servicio de las armas o ejercer cargo puiblico en país extranjero contra la prohibicion expresa dell Jefe del Estado".

37. Obwohl die Motive betonten, daß die Reform "bajo el signo de una prudente moderación" stand.

38. Daruiber Herrero Rubio, 3-18.

39. Miaja de la Muela, 26.

40. Minja de la Muela, 29.

41. Hampe, 9, Fußnote 2, weist darauf hin, daß aus Art. 17 Abs. 3 C.c.esp. nicht vollkommen klar ist, ob nur der Vater (padre) oder beide Eltern (padres) in Spanien geboren sein müssen. Siehe dariber auch Diez del Corral Rivas, 7, mit Hinweis auf eine Resolución rom 19. Januar 1976. Vgl. úber Auswirkungen des ius soli im spanischen Recht Vendrell Ferrer, 188-192.

42. Espín Cánovas, 230-231; Miaja de la Muela, 33-34.

43. Vgl, Espín Cánovas, 231-232; Miaja de la Muela, 47 .

44. Miaja de la Muela, 70-71.

45. Miaja de la Muela, 70.

46. Miaja de la Muela, 71 .

47. Miaja de la Muela, 57-58.

48. Dariiber Hampe, 14.

49. Miaja de la Muela, 68-69.

50. Miaja de la Muela, 71-73.

51. Miaja de la Muela, 57.

52. Miaja de la Muela, $73-75$.

53. Miaja de la Muela, 75-77.

54. BOE vom 23, Mai 1955, Nr. 143: mit deutscher Übersetzung veröffentlicht bei Hampe, 23-31. 
55. Garcfa Petit, Revista Jurídica de Cataluña 1966, 100-103; Gonzallbez Giner, Anuario de Derecho intemacional 1974, 291-307.

56. $\quad$ Siehe oben Fußnote 4.

57. Dariiber u.a. Brinkman, PS 1975, 81-82: Diez del Corral Rivas, 15-18: Espin Cánovas, Festschrift, 145-252; Luces Gil, Revista General de Legislacion y Jurisprudencia 1975, 101-134; Marín López, 61-79; REDI 1976, 397-417 Mullerat Balmaña, Revista Junídica de Cataluna 1975, 787-801; Serrano García, Documentación Jurfidica, 665-690.

58. Siehe oben Fußnote 5.

59. Darüber Rau, StAZ 1982, 289, 290; vgl. auch Diez del Corral Rivas, Revista de derecho privado 1983, 791-819; Fernández Fernández, REDI 1983, 431-446.

60. Constitución española, von den Cortes angenommen am 31. Oktober 1978, genehmigt durch Referendum von 6. Dezember 1978, vom König unterschrieben am 27. Dezember 1978, BOE vom 29. Dezember 1978.

61. Amoras Guardiola/Bercovitz Rodríguez-Cano, 11; vgl. Abarca Junco, 349-364; Dilez del Corral Rivas, Revista de derecho privado 1983, 794-802; Fernández Rozas, 20, Gionzález Campos, Emigración, 91-102.

62. Hampe/von Waldheim, 11 (mit Hinweis auf einer Note der spanischen Regierung an den franzòsischen Botschafter in Madrid vom 28. März 1837).

63. Hampe/von Waldheim, 12 (FuBnote 10) meinen, daß hierbei in erster Linie an nichteheliche Kinder spanischer Mütter gedacht werden muB, da eine spanische Frau durch Eheschließung mit einem Ausländer ihre bisherige Staatsangehörigkeit verlor.

64. Díez del Corral Rivas, 6; Díez del Corral Rivas, Revista de derecho privado 1983, 812-813; González Campos, Comentario, 26-35; Marín López, 37; Paz Agüeras, 9-11; NWG (Lieferung 176), Spanje, 6; Auch eine gemäB ausländischem Recht erfolgte Anerkenmung kann u.U. Erwerb der spanischen Staatsangehörigkeit bewirken, siehe Abarca Junco/Pérez Vera, 174.

65. Über den Begriff "territorio español" Vila Costa in REDI 1986, 177, 178 anlaBlich Res. DGRN vom 18. Januar 1985, BIMJ, Nr. 1374, 1985, 63,64.

66. Vgl. Res. DGRN vom 19. Januar 1976, 349-350. Res. DGRN vom 4. Februar 1966; Anuario DGRN 1966, 2404; Res, DGRN vom 7. Mai 1980, Aranzadi, Jurisprudencia 1980 , Nr. 2964; Res. DGRN vom 15. November 1986, Repertorio de Jurisprudencia 1987, Nr. 2897; Abarca Junco/Pérez Vera, 174; Díez del Corral Rivas, Revista de derecho privado 1983, 811-812; González Campos, Comentario, 40-46; Marín López, 39-40; Paz Agiieras, 11-12.

67. González Campos, Comentaric , 46-49; Die spanische Staatsangehörigkeit wird in diesem Fällen "definitiv" erworben; sie wird also nicht verloren, wenn sich später herausstellt, daß die betreffenden Kindler doch noch eine andere Staatsangehörigkeit besitzen (so Abarca Junco/Pérez. Vera, 175); Paz Agiieras 11, 12.

68. Abarca Junco/Pérez Vera, 176, 177; Bercovitz Rodríguez-Cano, Comentario, 54-59; bis 1982 wurde die spanische Staatsangehb̈rigkeit nicht durch Adoption erworben: Drez del Corral Rivas, 6, 7: Diez del Corral Rivas, Rewista de derecho privado 1983, 802 803; Lasante, Revista de derecho privado 1975, 511-531: Marín López, 38; Paz Agüeras 14-16; Res. DGRN vom 13. Juli 1971. Anuario DGRN 1971, 349-351. Uber die Frage der Rîclkwirkung der neuen Regelung Rodrfguez Mateos, in REDI 1984, 579-581 anläßlich Res. DGRN wom 26 April 1984, BIMJ, Nr, 1350, 1984, 52, 53 und Rodriguez Mateos in REDI 1986, 172-177 anläßlich Res. DGRN wom 17. Juli 1985, BIMI, Nr. $1399 / 1400,1985,53-60$. Bis 1987 kannte das spanische Recht neben der sogenannten "adopción plena" eine "adopción simple; diese Unterscheidung ist aber seit in Kraft treten des Gesetzes 21/1987 vom 11. November 1987, BOE vom 17. November 1987 aufgehoben. Vgl. weiter Aguilo Piño, La Ley $\mathrm{Nr} .773$ (1983), 1-4.

69. Siehe zu einer Übergangsfrage Res. DGRN vom 15. September 1983, BIMJ, Nr. 1329 (1983), 67-70.

70. Die "emancipacion" ist eine Art Volljăhrigkeitserklẳnng; siehe Art. 314-324 C.c.esp.

71. Abarca Junco/Pétex Vera, 194-197; Aguilar Navarro, Revista de Estudios Americanos, 1955, 385; Castro y Bravo, RCADI 1961-1, 521-632; Díez del Corral Rivas, 12-14; González Campos, Lecciones, 106-109: Herrero Rubio, 17; Moreno Quintana, Actas, 572-575; Paz Agüeras, 29-31; Prieto-Castro Roumier, Cuadernos Hispano-Americanos 1972, 242-257; Prieto-Castro Roumier, Madrid 1962; Yiepes, Mundo Hispanico 1960, 4. Siehe auch: Medina Ortega, 743-757; Pérez Vera, Revista de instituciónes europeas 1981, 685-703. Vgl. bereits Fernández Marcana, Havana 1924; siehe weiter Medina Ortega, 743-757. 
72. Pérez Vera, Enigración, 79.

73. Es sei darauf hingewiesen, daß spanische Behörden aber diessen Staatsangehörigkeitserwerb manchmal nicht anerkennen, wenn die Betreffende weiterhin ganz als Ausländein lebte ("doctrina del asentimiento voluntario" $0^{\prime \prime}$ ). Vgl. dazu den in NWG, unter Spanien, S. 10 (Lieferung 180) abgedruckten Brief der niederländischen Botschaft in Madrid.

74. Durch Res. DGRN vom 13. Juni 1975, Anwario DGRN 1975, 367 wurde jedoch festgestellt, daß es sich dennoch in soweit um eine wirkliche Option handelte, dab die Staatsangehởrigkeit - wenn die spanische Regierung einwilligte - mit Rückwirkung vom Augenblick der Optionserklârung erworben wurde (dariber Gonzalez Campos, REDI 1980 ; 181).

75. Zusätzlich gibr es noch einige von der Rechtsprechung geschaffene übergangsrechtliche Optionsrechte; dazu Abarca Junco/Pérez Vera, 178; Paz Aglueras, 17-26.

76. Die Optionsrechte des heutigen spanischen Rechts sind grundsätzlich reine Optionsrechte ohne staatlicher Widerspruchsmöglichkeit. Siehe dazu die Ausfiuhrungen bei Abarca Juncio/Pérez Vera, 178; "La opcion constituye un mode especialmente favorablle de acquisición de la nacionalidad española que permite a los extranjeros que tienen una especial vinculación con nuestro pais adquirir dicha nacionalidad, a través de una mera declaración unilateral de voluntad. Es, pues, un derecho que habrá de ser reconocido, siempre que se cumplan determinados requisitos..... . Características de la opción es estar sujeta a plazos preclusivos y el necesitar de la homologación estatal". Ahnlich Gonzallez Campos, Comentario, 32, 48.

77. Diese Regelung ist wichtig für ausländische Kinder, deten Eltern eingebürgert worden sind. Bercovitz Rodriguez-Cano, 60-69; Abarco Junco/Perez Vera, 177. Bis in Kraft treten des Gesetzes 21/1987 vom 11. November 1987 war sie ebenfalls von Bedeutung für ausländische Kinder die durch "adopción simple" Kind eines Spaniers geworden waren.

78. Siehe Fußnote 71.

79. Der Gesetzgeber hat nicht die Möglichkeit schaffen wollen, daß ein gesetzlicher Vertreter für eine Person unter vierzehn Jahren in dessen Namen eine Optionserklärung abgeben kann. Siehe dazu Abarca Junco/Pérez Vera, 178, 179; Paz Aguieras, 18-21.

80. Abarca Junco/Perez Vera, 188-190; Marf́n López, ADI 1975, II, 338-345; Paz Aglieras, 63-7i.

81. Über die Wohnsitzforderung Rodriguez Mateos in REDI 1985, 174-179, anläßlich Res. DGRN vom 6. September 1984, BIMJ Nr. 1365, 1984, 44; vgl. auch Res. DGRN vom 17. Juni 1987, BIMJ 1987, 1739-1741 und Res. DGRN vom 28. September 1987, BIMJ 1987, 3087-3089. Über die Interpretation des Art. 26. C.c.esp. auch Alvarez Rodriguez in REDI 1984, 588- 593 und Res. DGRN vom 7. September 1983.

82. Vgl. iber einige ubergangsrechtliche Probleme hinsichtlich des Wegfallens dieser Optionsrechte die in REDI 1984, 583-586 von Moya Escudero besprochenen Resolu-

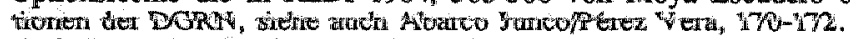

83. Auf dieser Art wurde durch Real Decreto Nr. 31 vom 5. Januar 1979, BOE vom 8. Januar 1979 (S. 346), Don Carlos Hugo de Bourbon-Parma eingebürgert wegen seiner "pertenencia a uma familia tan estrechamente vinculada a la historia de Espafia"; Abarca Junco/Pérez Vera, 181, 182; Fernando Pantaleón, 79-94; Gonzallez Campos, Comentario, 44; Marín López, $46,47$.

84. Siehe aber auch Res. DGRN vom 18. September 1986 , wozu Forner Dellaygua, REDI $1987,154-158$.

85. Dazu kritisch Abarca Junco/Pérez Vera, 180.

86. Erst im Augenblick des Treueeides wird die Staatsangehörigkeit erworben; vgl. Abarca Junco/Pérez Vera, 182.

87. Die Forderung daß der Aufenthalt legal sein muB, ist neu im Vergleich zum bisherigen Recht. Abarca Junco/Pérez Vera, 182; Diez del Corral Rivas, Revista de derecho privado 1983, 813-814; Fernando Pantaleón, 121; Paz. Aguieras 36-37.

88. Die Voraussetzung "Aufenthalt" (residencia) wird aber flexibel gehandhabt: siehe Res. DGRN vom S. Mai 1986, wo ein mit einer in Spanien lebenden Spanierin verheirateter Kapitän eines ausländischen Handelsschiffes eingebürgert wurde. Dazu Quiñones Escánez, REDI 1987, 148, 149. Vgl. weiter Aguilo Piño, Revista de derecho privado $1984,531-541$.

89. Fernando Pantaleón, 126, 127; Marín López, 55; Gonzallez Campos, Lecciones, weist: darauf hin, daß diese Grüinde der offentlichen Ordnung sich beziehen können auf die 
"condiciones personales o familiares del solicitante, o con los intereses de espantoles en las relaciones internacional". Er betont weiter, dafs diese Klausulierung auberordentlich vage ist:" "En realidad se trata de un auténtico cajón de sastre al que la Administración podra recurrir siempre en defensa de los principios socio-politicos que en cada momento imperen en nuestra sociedad. Vgl. Res. DGRN vom 8. Juni 1965, Anuario DGRN 1965, 289; wenn Behörden einen Einblirgerungsantrag auf Grund der offentlichen Ordnung zurïckweisen, kann yom Gericht überprüft werden, ob dies zu Recht geschah (Tribunal Supremo 7. Juni 1986, Repertorio de Jurisprudencia 1986, Nr. 6606; wozu Quifiones Escámex, REDI 1987, 149-152, siehe ebenfalls Abarca Junco/Pérez Vera, 184).

90. Abarca Junco/Pérez Vera, 198, 199; Marin López, 57-59. Paz Agijeras, 29-30 rechnet dazu auch Puerto Rico!

91. Siehe uber die staatsangehörigkeitsrechtliche Situation der sephardischen Juden vor 1982 Marfn Lopez in REDI 1981, 581-583 anläßlich Res. DGNR vom 21. Januar 1981, Anuario DGNR 1981, 745. Weiter: Abarca Junco/Pérez Vera, 182, 183; Bensabat Benarroch, Revista general de legislación y jurisprudencia 1979, 143-148; Diez Corral Rivas, Revista de derecho priwado 1983, 813; Fernando Pantaleón, 95-98, 99; González Campos, Comentario, 49; Marin López, 47.

92. Pérez Vera, Emigración, 79.

93. Decreto vom 14. November 1958, BOE nr. 296 vom 11. Dezember 1958, mit Rektifizierung im BOE nr. 18 vom 21. Januar 1959, geändert durch Real Decreto $1917 / 1986$ wom 19. August 1986, BOE vom 19. September 1986.

94. Mit den anderen spanischen Sprachen werden die galizische, baskische und katalanische Sprache gemeint. Aus Art. 221 Abs. 6 Reglamento geht hervor, daß diese Sprachkenntrisse von einem Beamten der Einbiirgerungsbehörde überprifft werden. Es gibt wohl keine veröffentlichte Fảlle, in denen eine Einbüirgerung aufgrund mangelnder Sprachkenntnisse verweigert wurde (Auskunft von Pedro-Pablo Miralles Sangro in einem Brief vom 8. März 1988).

95. Bemerkenswert ist, daß Art. 220 Ziffer 6 Reglamento vorschreibt, daß im Einbuirgerungsantrag auch die Finanzlage und die Religionszugehörigkeit erwähnt werden müssen.

96. Siehe Art. 1 des Ley 25/1986 vom 26. Dezember 1986: "Se suprimen las tasas judiciales y las que se devengan por las actuaciones del Registro Civil". Auch vor in Kraft treten dieser Bestimmung waren die Einbürgerungskosten bereits unbedeutend (Pedro-Pablo Miralles Sangro ir. Brief vom 8. März 1988).

97. Abarca Junco/Pérez Vera, 186.

98. Seit 1942 wurde aber angenommen, daß die spanische Staatsangehörigkeit beibehalten blieb, wenn sonst Staatenlosigkeit die Folge wäre: Res. DGRN vom 3. Juli 1942, woriber Hampe/von Waldheim, 25.

99. Vgl. Marin López, ADI 1975 II, 329, 333.

100. Siehe FuBnote 71 .

101. Diez del Corral Rivas, Revista de derecho privado 1983, 813:

102. Vgl. Marin López, ADI 1975 II, 333, 334.

103. Marfn Lopez, 87, 88; derselbe ADI 1975 II, 334.

104. Marín Löpez 88, 89; derselbe, ADI 1975 II, 335, 336.

105. Gonzílez Campos, Lecciones, 85.

106. Abarca Junco/Perez Vera, 185, 186; Dilez del Corral Rivas, Comentario, 133-146; siehe über den Begriff des freiwilligen Erwerbs auch Zabalo Escudero in REDI 1985, 179, 180 anläBlich Res. DGNR vom 17. Juni 1983, BIMJ, Nr. 1317, 183, 17.

107. Spanier die in dem Augenblick, in dem sie freiwillig eine fremde Staatsangehörigkeit erwerben, noch keine drei Jahre außerhalb Spaniens leben, verlieren die spanische Staatsangehörigkeit von dem Zeitpunkt, in dem sie drei Jahre im Ausland leben. So DGNR vom 17. Juni 1983, BIMJ Nr. 1317, 183, 47, worliber kritisch Morientes Rodríguez, REDI 1984, 586-588; vlg. weiter Res. DGRN vom 9. Oktober 1987, BIMJ, Nr. $1473,3381,3382$. Vgl. auch Hecker, IA 1981, 194.

108. Abarca Junco/Pérez Vera, 198; Drez del Corral Rivas, 140-142; Drez del Corral Rivas, Revista de derecho privado 1983, 807- 811; Gonzalez Campos, Comentario, 18, 19; Paz Agieras 42-51; Rau, StAZ 1982, 289, 290. Siehe weiter Alvarez Rodriguez, in REDI, 1986, 185, 186 anläßlich Res. DGNR vom 11. Juni 1985, BIMJ Mr. 1392-94, 1985, 104-107; vgl, auch Ortiz-Arce, REDI 1984, 527-546, namentlich 534-536 und Rau, IA $1985,295$. 
109. Rex. DGRN wom 11. Dezember 1986, Repertorio de Jurisprudencia 1987, Nr. 1063.

110. Res. DGRW vom 12. Januar 1987, Repertorio de Jurisprudencia, 1987, Nr. 2256; Res. DGRN wom 17 Juni 1987, BIMI, Nr. 1461, 1739-1741; Res. DGRN vom 28. September 1987, BIMJ, Nr. 1471, 3087-3089; Res. DGRN vom 29. September 1987, BIMJ, Nr. 1471, 3089-3090.

111. Diez del Corral Rivas, 142-144; Diez del Corral Riwas. Revista de derecho privadio 1983, 799-802; Pérez Vera, Emigración, 73-81; Marín López (Addendum 1983) 20 kritisiert, daß Brazil nicht erwähnt worden ist; Abarca Junco/Pérez Vera 183 meinen, daß außerdem nur politische Gründe erklären können, daßB die Sahel und Gibraltar ebenfalls nicht erwähnt worden sind; Paz Aguieras, 54-58.

112. Uber Verzichtsmöglichkeiten Morientes Rodriguez in REDI 1986, 178-181; siehe auch Res. DGFN vom 5. Februar 1985, Repertorio de Jurisprudencia $1986, \mathrm{Nr}_{\text {“ }} 6884$.

113. Díz, del Corral Rivas, 146-147.

114. Art. 27, 34 und 141 C6digo penal; diese Artikel werden aber voraussichtlich im Rahmen der beabsichtigten Reform des Código penal gestrichen; dazu Abarca Junco/Perez Vera, 187.

115. Abarca Junco/Pérez Vera, 186; Díz del Corral Rivas, 147-150; Paz Aguieras, 58-61.

\section{NOTEN TENDENZEN}

1.

2.

3.

mißbilligt". Darüber Hampe/von Waldheim, 25.

4. Wie beteits in Fußnote 3 erörtert, bildete Italien dabei schon friih eine beispielhafte Ausnahme.

5. B: Art. 12 C.c., Art. 5 Gesetz 1909

D; \$11 RuStAG $1870 ; \& 16$ RuStAG 1913 (insofern nicht in der Einbilrgenungsurkun-

de ein Vorbehalt gemacht war).

F: Art. 12 C.c.

G.B.: Sec. 10 (1) NA 1980; Sec. 10 (1) BNSA 1914 (bis 1933).

I: Art. 10 Abs. 4 C.c.it. (soweit sie sich auch in Italien niedergelassen hatte). Ähnlich Art. 11 L.c. mit einem Ausschlagungsrecht fiir die getrennt lebende Ehefrau.

N: Art. 5 WNed 1892.

Ö: 92 ABGB; vgl. weiter $\$ 2$ i.V.m. $\$ 6,7$ des Heimatsgesetzes vom 3. Dezember 1863.

Schw: Art. 3 BüG 1876; Art. 3 Bü 1953 (soweit sie unter Gewalt ihres Mannes stand und keine Ausnahme gemacht wuirde).

Sp. Art. 22 C.c.esp. 1.d.F. 1889; Art. 19 Abs. 3 C.c.esp.i.d.F. 1954, soweit sie nicht rechtmäBig von threm Ehemann getremt lebte.

6. B: Art. $19 \mathrm{C.C}$.

D: \& 19 RuStAG 1870 (eine Entlassung erstreckte sich auf die

Ehefrau, sofern nicht eine Ausnahme gemacht wurde); vgl. \& 18 RuStAG 1913.

F: Art. 19 C.c. 
GB:Sec. 10 (1) NA 1870; Sec. 10 (10) BNSA 1914.

I: Art. 11 Abs. 2 C.c.it. (es sei denn, sie behielt Wohnsitz in Italien); allnilich Art. 11 Abs. 1 L.c. (für die mit ithrem Marn zusammenlebende Ehefrau).

N: Art. 6 BW 1838; Art. 5 und 7 Ziffer 2 WNed 1892.

Ö: Vgl. \& 32 ABGB und $\S 19$ Gesetz über die Auswanderung vom 24. März 1832

Schw: Art. 8 Abs. 3 BüG 1876 (soweit sie mit ihrem Mann in gemeinsamer Haushaltung lebte und keine ausdrückliche Ausnahme gemacht wirde). Art. 9 Abs. 3 Bü 1903 (soweit sie unter der Gewalt ihres Mannes stand und keine Ausnahme gemacht wurde).

Sp: Art. 22 C.c.esp. i.d.F. 1889; Vgl. aber die in Fußnote 3 erwähnte Entscheidung der Generaldirektion für das Personenstandregister vom 3. Juli 1942.

7. B: Art. 10 Abs. 1 C.c.; der Verlust der Staatsangehörigkeit durch minderjăhrige Kinder war im C.c. nicht ausdrücklich geregelt.

D: $\$ 3$ und 19 RuStAG 1870; 84 Abs. 1 RuStAG 1913.

F: Art. 12 Abs. 3 und 18 C.c. 1889.

GB: Vgl. Sec. 1 BNSA 1914; Sec. 5 BNA 1948.

I. Art. 4, 10 Abs 4 und 11 Abs. 2 C.c.it.

N: Art. 6 und 7 Ziffer 1 Ned 1892

Ö: Siehe \& 146 ABGB.

Schw: Art. 3 BRG 1876; Art. 8 BRG 1876.

Sp: Art. 18 Abs. 1 C.c.esp. i.d.F. 1889; Art. 19 Abs. 3 C.c.esp. i.d.F. 1954; vlg. aber die in Fußnote 3 erwähnte Entscheidung der Generaldirektion für das Personenstandsregister.

8. Vgl. F: Art. 12 Abs. 3 C.c. 1889; GB: Für Einbürgenung: Sec. 10 (5) NA 1870 (falls Wohnsitz beim Vater): Sec 5 (1) BNSA 1914 (als Möglichkeit: vgl. Sec. 12 (6) und 7 BNA 1948; N: Für Einbuirgerung: Art. 6 Abs. 2 WNed 1892; Für Verlust: Art. 7 Ziffer 1 WNed i.d.F. 1962.

9. Vgl. z.B. I: Art. 10-12 L.c. ; vor allem Art. 10 Abs. 1.

N: Art. 5 Abs. 2 WNed 1892 (bis 1963).

Sch: Art. 32 Abs. 1 und Art. 43 Abs. 1 BüG 1952.

10. B: Art. 11 Ziffer 2 Gesetz 1909; vgl. auch Art. 18 Ziffer 2 Gesetz 1932.

D: 1949 durch den Einfluß von Ant. 16 Abs. 1. GG.

F: Art. 19 Abs. 1 C.c. 1889.

GB: Sec. 10 (2) BNSA 1.d.F. 1934.

I: So bereits Art. 14 C.c.it. 1865 und Art. 10 Abs. 3 L.c.

N: Art. 5 Abs. 1 WNed i.d.F. 1936.

Ö: \& 9 Abs. 1 StBG 1925; \& \& Abs. 1 StBG 1945/1949.

Sch: So gewohnheitsrechtlich mindestens seit 1926 (Schröder, 41); Ausdrüicklich Art. 5 Abs. 2 BeschluB 1941.

Sp: Entscheidung der Generaldirektion für das Personenstandsregister vom 3. Juli 1942; siehe weiter Art. 23 Ziffer 4 und 5 C.c.esp. i.d.F. 1954.

Bereits gegen die abhängige staatsangehörigkeitsrechtliche Position der Ehefrat außuerte sich Zeballos, Bd. I, 241-243; siehe weiter bereits Cauwes, 282 (Paris 1900); Kapralik (Paris 1925); Nacarry (Paris 1925); Pelletier (Paris 1925); Calbairac (Paris 1929); Zepf (Tübingen) 1929; Söhngen (Amsterdam 1930); Mutller-Sprenger (Halle-Wittenberg 1930). Vgl auch den Überblick beil Schröder-Hilgendorff, 52-59.

11. Art. 8-10; siehe dazu \& 1.4.3.

12. Art. 1 des zweiten Zusatzprotokolls" siehe dazu $\$ 1.4 .3$.

13. Seit 1927 verlor z.B. eine Französin, die einen Ausländer, heiratete, nicht mehr ihre Staatsangehörigkeit, es sei denn, sie verzichtete auf diese. Seit 1926 konnte eine gebïrtige Belgierin, die einen Ausländer heiratete innerhalb von sechs Monaten nach der Eheschließung erklären, weiterhin Belgierin bleiben zu wollen. In Österreich konnte einer Frau seit 19.49 "aus triftigen Gruinden" genehmigt werden, ihre Staatsangehörigkeit beizubehalten ( $\$ 8$ Abs.1 StBG 1949). Siehe zu diesen Entwicklungen u.a. Sauser-Hall (1933) und Kokkini-Latridou (1968), 4-17.

14. Siehe für Fundstellen $\$ 1.4 .3$.

15. Dutoit, Band 1, 7; 4 gl Dutoit, Nationalite, 445-465.

16. B: 1985 ; siehe Art. 16 \& 1 CNB.

D: 1953: Durch die Wirkung von Art. 3 Abs. 2 i.V.m. Art. 117 GG.

F: 1927: siehe Art. 8 CNF 1927; 1973: vgl. aber die Art. 37, 38 CNF i.d.F. 1945.

GB: Der BNA 1948 entsprach schon diesen Prinzipien (Section 6 (2) BNA 1948), 
1: 1975: durch Einfuhnung won Art. 143ter C.c.it. kein autonatischer Verlust mehr; 1983: Kein automatischer Erwerb mehr.

N: 1963: Art. 5 WNed wurde ersatzlos gestrichen; siehe weiter Art. 8 WNed id.F. 1963.

O: 1965: vg. 8 9 StBG 1965.

Sch: In der Schweiz erwirbt die Auslànderin, die einen Schweizer heiratet noch immer automatisch dessen StA (Art. 3 BüG 1952); die Schweizerin, die einen Ausländer heiratet, kann seit 1953 eine Beibehaltserklärung abgeben (Art. 9 Abs. 1 BïG 1952), Im Entwurf 1986 wird worgeschlagen Art. 3 und 9 aufzuheben.

Sp: 1975; vgl. Art. 21 Abs. 1 C.c.esp. i.d.F. 1975.

17. Art. 3 New Yorker Abkommen 1957.

18. Vgl. B: Nach Art. 5, beziehungsweise 18 Ziffer 4 Gesetz 1932 erstreckte sich die Einbưrgerung in Belgien beziehuingsweise Verlust der belgischen Staatsangehörigkeit durch Einbiirgerung im Ausland auf minderjährige Kinder einer Person, wenn er das Sorgerecht tiber die Kinder hatte. Dies war bei ehelichen Kindern regelmäBig der Vater.

I: Art. I und 12 L.c.

N: Art. 6 WNed; Art. 7 Ziffer 1 WNed; Staatsangehörigkeitserwerb oder -Verlust der Mutter erstreckte sich auf ihre ehelichen Kinder, wenn der Vater bereits gestorben war. O: \$ 7, 29 Abs. 1 StBG 1965: mur in dem Falle von \& 29 Abs. 2 folgten die Kinder die Staatsangehörigkeit der Mutter.

Sch: Vgl. Art. 33 i.V.m. 32 BüG und Art. 44 i.V.m. 42 und 43 BüG.

Sp: so Art. 23 Ziffer 5 C.c.esp. i.d.F. 1954; Art. 23 Ziffer 3 C.c.esp. i.d.F. 1975 bestimmte, daß dile Staatsangehörigkeit verloren wurde, wenn, derjenige der die elterliche Gewalt ausibbte, diese verlor, und das minderjăhrige Kind die fremde Staatsangehörigkeit dieses Elternteils erwarb. Bis 1981 stand aufgrund Art. 154 C.c.esp. die elterliche Gewalt im Prinzip dem ehelichen Vater zu. Erst seit 1981 uben Vater und Mutter den elterlichen Gewalt in Prinzip gemeinsam aus (Gesetz 11/1981 vom 13. Mai 1981).

19. So: B: Art. 22 \& $\mathbb{1}$ Ziffer 3 CNB 1985; N: Art. 16 Abs. 2 RwNed 1985; Oे: 29 Abs. 1 StBG i.d.F. 1983. In Deutschland, Frankreich, Grobbritannien und Spanien erstreckt sich der Verlust der Staatsangehörigkeit heutzutage nicht mehr auf minderjathrige Kinder. Siehe weiter \& 3.4.12.

20. Vgl. $\$ 1.3 .2$.

21. Jessurun d'Oliveira, NJB 1977, 596.

22. B. Art. 16 \& 2 CNB 1985.

D: 86 RuStAG i.d.F. 1957: Einbtirgerungsanspruch; bei EheschlieBung im Inland sogar Optionsmöglichkeit (bis 1969).

F" Art. 8 Abs. 1 CNF 1927; vgl. Art. 37-1 CNF i.d.F. 1984.

GB: Sec. 6 (2) BNA 1948.

I: Art. 1 Gesetz Nr. 123 vom 21. April 1983.

N: Art. 8 WNed id.F. 1963 (bis 1985).

Ö: $\$ 9$ StBG i.d.F. 1965 (bis 1983).

Sp: Art. 21 Abs. 3 C.c.esp. i.d.F. 1975 (bis 1982).

23. D: 6 RuStAG i.d.F. 1957: Einbirgeningsanspruch (bis 1969).

GB: Section 6 (2) i.V.m. Arihang I (Schedule 1) \& 3 .

N: Art. 8 Abs. 2 RwNed 1985 .

Ö: 11a StBG i,d.F. 1983 .

24. Sp: Art. 22 Abs. 3 Ziffer 4 C.c.esp. i.d.F. 1982. als die meisten anderen Ausländer eingebürgert werden (Art. 2 Gesetz 1889: große Einbiirgerung nach fünfjährigem Aufenthalt; Art. 12 und 14 Gesetz 1932* die normale

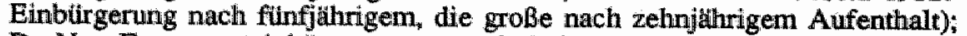

D: Nur Ermessenseinbiirgenung gemă \& \& RuStAG, wobei jedoch im Hinblick auf Art. 3 GG für die Zeit von 14-1953 bis 31-12-1969 wohlwollend verfahren wurde.

I: Einbüirgerung nach zweijtahrigem Aufenthalt in Italien, wobei Ehe mit Italienerin beachtlichen Diensten fuir Italien gleichgestellt wurde (Art. 4 Abs. 1 Ziffer 3 L.c.).

25. So Jessurun d'Oliveira, NJB 1985, 50-53; AAe 1985, 213. Jessurun d'Oliveira betont, daß wegen dieser Diskriminierung das Abkommen von New York daher auch gekiüdigt werden muß. So auch de Groot/Tratnik, 91, 92; Ko Swan Sik/Nan Rijn van Alkemade, Nr, 40 und 52. 
26. B: Art. 16 \& 2 CNB (kontrolliertes Optionsinecht); D: Art. 9 RuStAG; F: Art. 37-1 CNF; GB: Sec. 6 (1) BNA 1981. I: Gesetz Nr. 123 wom 21. April 1983: N: Art. 8 Abs. 2 RwNed; Ö: \& 8 StBG i.d.F. 1983" Schw: Im Entwurf 1986 wird eine erleichterte Einbiirgerung vorgesehen (Art. 27, 28, 28a) Sp: Art. 22 Abs. 3 Ziffer 4 C.c.esp. id.F. 1982. Siehe weiter $\$ 3.3 .7$.

27. Siehe $\$ 3.3 .3 .1$ Buchstabe c; 3.3 .3 .2 Buchstabe b.

28. Siehe $\$ 3.2 .1$.

29. B: Art. 10 Abs. 1 C.c.; vgl. Art. 1 Ziffer 1 Gesetz 1909 und Art. 1 Ziffer 1 Gesetz 1932.

D. \& 3 RuStAG 1870; \& 4 Absi. 1 RuStAG 1913.

F: Art. 10 Abs. 1 C.c. i.d.F. 1804; Art. 8 Ziffer 1 C.c. i.d.F. 1889.

GB: Sec. 1 BNSA 1914; Sec. 5 (1) BNA 1948.

I: Art. 4 L.c.it.

N: Art. 1 Buchstabe a WNEd 1892.

Ö: § 28 ABGB; vg1. \& 5 BBG 1925; \& 3 Abs. 1 StBG 1945/1949.

Sch: In der Schweiz galt dies bis 1952 nur gewohnheitsrechtlich; siehe aber ausdrücklich Art. 1 Buchstabe BüG 1952.

Sp: Eime gewisse Ausnahme bildete allerdings Art. 17 Ziffer 2 C.c.esp. i.d.F. 1889, kraft dessen die spanische Staatsangehörigkeit vona Vater oder von der Mutter hergeleitet werden konnte. Da spanische Frauen durch Ehe mit einem fremden. Staatsangehörigen aber ihre bisherige Staatsangehörigkeit verloren, thatte die muïtterliche Abstammung nur Relevanz, wenn der Vater staatenlos war.

30. So noch Schätzell, Grundrechte, Bd. II, 579.

31. B: So bereits Art. 1 Ziffer 1 Gesetz 1909; anders wieder Art. 1 Ziffer 1 Gesetz 1932 !

D: So in Deutschland wom 1-1-1964 bis 31-12-1974 (\$4 RuStAG i.d.F. 1964).

I: Bereits Art. 1 Ziffer 2 L.c. 1912.

Ö: \& 3 Abs. 1 Satz 2 StBG 1949 für den Fall eines staatenlosen Vaters; fuir alle Falle: drohender Staatenlosigkeit \& 7 Abs. 2 StBG 1965.

Sch: So Art. 5 Abs. 3 Beschlü 1941 und Art. 5 Abs. 1 BüG 1952.

Sp: Vgl. Art. 17 Ziffer 2 C.c.esp. i.d.F. 1889, woriber bereits FuBnote 29.

32. Art 2 Buchstabe c WNed i.d.F. 1936; vgl. Sec. 2 (1) BNA 1964 (Nr. 2). Dies entsprach der Regelung des Art. 1 des Haager Zusatzprotokolles aus 1930 . Vgl. aber auch Art. I Ziffer $\mathbb{1}$ CNF 1927, kraft dessen das eheliche Kind einer franzbsischen Mutter und eines ausländischen Vaters die französische Staatsangehörigkeit erwarb, falls es in Frankreich geboren wurde.

33. Siehe u.a. Europarat Resolution (77) 13, wozu $1,4.3$.

34. B: 1985; D: 1975; GB: 1981; I: 1985; N: 1985; Ö: 1983; Schw: 1984, (nachdem seit 1978 die Kinder einer nach Abstammung schweizerischen Mutter bereits die schweizerische Staatsangehörigkeit erwarben, wenn die Eltern zur Zeit deren Geburt Wohnsitz in der Schweiz hatten (Art. 5 BïG i.d.F. 1978)); Sp: 1982; in Frankreich wurde die Gleichberechtigung in dieser Hinsicht bereits in 1945 realisiert (Art. 19 Abs. 1 CNF), vgl. aber auch bereits die Ansattze der Gleichberechtigung in Art. I Ziffer 1 CNF 1927.

35. D: \& 4 RuStAG; F: Art. 17 CNF; I: Art. 5 des Gesetzes Nr. 123 wom 21. April 1985; N: Ant. 3 Abs. 1 RwNed; OO: 7 Abs. 1 StBG i.d.F. 1983; Schw: Art. 1 BuG i.d.F. 1984; Sp: Art. 17 Ziffer I C.c. i.d.F. 1982.

36. B: Art. 8 CNB; GB: Sec. 2 BNA 1981.

37. Dies gilt an erster Stelle für die Regelung der Erstreckung des Verlustes auf minderjahrige Kinder (dazu \$3.4.12).

38. Vgl. aber auch $\$ 3.4 .4$ und 3.4 .7 .

39. Deutschland, Großbritannien, Niederlande, Österreich, Spanien.

40. Siehe auch die Schweiz im Entwurf 1986 .

41. Bemerkenswert ist, daß die belgische Regelung (fast) buchstäblich der französsischem entspricht. In Frankreich wird allerdings dariber nachgedacht, um das Optionsrechr durch eine erleichterte Einbürgerung zu ersietzen (siehe den zuritckgezogenen Gesetzesentwurf 1986/87, $\mathrm{Nr}_{\text {r. 444). }}$.

42. Vor allem Italien, Art. $12 \mathrm{~L}$.c. ist wohl streitig mit dem Gesetz Nr. 123 vom 21. April 1983. Auch die schweizerische Regelung der Erstreckung des Verlust der Staatsangehörigkeit muß revidiert werden. Siehe $\$ 3.4 .12$.

43. Schätzel, Geschichte, $15,16$.

44. PrewBische Gesetzsammlung $1843, \$ 15$. 
45. Ab 1833 wurde die Staatsangehörigkeit nach zehnjährigem Aufenthalt allerdings nicht mehr automatisch erworben, sondern erst nach einem Untertaneneid und Ausreichung einer Beglaubigungsurkunde.

46. B: Art. 10 C.c.; Art. 1 Gesetz 1909; D: 3 RuStAG 1870; 8 RuStAG 1913: F: Art. 8 Ziffer 1 C.C. i.d.F. 1889; I: A.nt. 4 und 7 C.c.it.; beachte aber Art. 8 C.c.it; siehe weiter Art. 1 L.c.; N: Art. 1 WNed 1892; Ö: 28 ABGB; Schw: gewohnheitsrechtliche Regel, kodifiziert von Art. 1 BiiG $1952 ; \mathrm{Sp}$ : Art. 17 Ziffer 2 C.c.esp. i.d.F. 1889. Anders aber GB: Section 1 (1) BNA 1914 .

47. B: Art, 9 C.C.; F: Art. 9 C.c.

48. I: Art. 3 L.c.; bis 1913 erwarben die Kinder deren Eltern bereits mindestens zehn Jahre in Italien lebten iure soli die italienische Staatsangehörigkeit (Art. 8 C.c.it.); Sp: Art. 17 Ziffer 1 i.V.m. 19 C.c.esp. i.d.F. 1889 ; vgl. weiter 3.3 .3 .1 Buchstabe a; 3.3.3.2 Buchstabe a.

49. Siehe 3.3 .2 .

50. Ein Vorgänger dieser Regelung fand sich bereits in Aurt. 1 des Gesetzes von 29. Januar 1851 .

51. Art. 2 Buchstabe a WNed 1892.

52. B: Art. 4 Gesetz 1909; Art, 1 Zifer 2 Gesetz 1932; Art. 10 Abs. 2 CNB; D: $\$ 4$ RuStAG 1913; F: Art. 8 Ziffer 2 C.c. i.d.F. 1889; Art. 1 Ziffer 7 CNF 1927; Art. 21 CNF 1945; GB: Vgl. Sec 2 (2) BNA (Amendment) 1964 (Ni. 2) und Sec 1 (2) BNA 1981; I: Art. 7 Abs. 3 C.c.it ; Art. 1 Abs. 2 L.c.; N: Art. 2 Buchstabe b WNed 1892; O: \& 14 BBG 1925; \& 12 StBG 1945/1949; \& \& Abs. 1 StBG 1965; Sch: In der Schweiz erstmals geregelt in Art. 6 BüG; Sp: So ausdrücklich Art. 17 Ziffer 4 C.c.esp. i.d.F. 1954; vorher war wohl Art. 17 Ziffer I i.V.m. 19 esp. i.d.F. 1889 anzuwenden. Vgl. 3.2 .7 .

53. B: Art. 10 Abs. 2 CNB; D: $\$ 4$ RuStAG; F: Art. 21 CNF; GB: Für den Fall es auBerhallb GB geboren war (Sec. 1 (2) BNA); I: Art. 7 Abs. 3 C.c.it.; Art. 1 Abs. 2 L.c.; N: Art. 2 Buchstabe b WNed 1892; O: \& 14 BBG 1925; \& 12 StBG 1945/1949; 8 Abs. 1 StBG 1965; Schw: Art. 6 Abs. 3 Bü; Sp: Art. 17 Ziffer 4 C.c.esp. i.d.F. 1954. Vgl. \$ 3.4.10.

54. B: Gesetz vom 15. August 1881; Art. 4 Gesetz 1909; Art. 1 Ziffer 2 Gesetz 1932; im Moment bieter Art. 10 Abs. 1 CNB eine Lösung; F: Art. 8 Ziffer 2 C.c. i.d.F. 1889; Art. 1 Ziffer 7 CNF 1927; Art. 21 CNF 19.45; I: Art. 7 C.c.it; Art. 1 L.c.; N: Art. 1 Buchstabe d WNed 1892; Sp: So ausdricklich Art. 17 Ziffer 4 C.c.esp. i.d.F. 1954; vorher war Art. 17 Ziffer 1 i.V.m. 19 C.c. esp. i.d.F. 1889 relevant, siehe auch Art. 17 Ziffer 4 C.c.esp. i.d.F. 1982.

55. Deutschland, Österreich, Schweiz. Nach britischem Recht konnte das im Ausland geborene Kind nicht iure sanguinis die Staatsangehörigkeit von der nichtehelichen Mutter ableiten. Siehe Gonset, 76-92.

56. Siehe auch \& 3.2.4.

57. Belgien, Italien, Niederlande, Spanien. Siehe Gonser, 1-4, 12-49.

58. Dazu \& 1.4.3.

59.

60.

61.

Art. 2 Buchstabe c WNed i.d.F. 1936.

Art. 2 Buchstabe c WNed i.d.F. 1982.

61. Art. 2 Buchstabe a WNed i.d.F. 1953

62. B: Art. 11 CNB (Optionsrecht); vgl. auch Art. 7 Ziffer 2 Gesetz 1909; Sp: Art. 17 Ziffer 3 C.c.esp. i.d.F. 1954; so auch Art. 17 Ziffer 2 C.C.esp. i.d.F 1982.

63. Dazu weiter \& 3.2 .6 .

64. Airt. 15 Buchstabe c RwNed.

65.

66.

B: Art. $22 \$ 1$ Ziffer 5 CNB; Schw: Art. 10 BuG i.d.F. 1952; verschärt i.d.F. 1984. So auch Art. 7 Ziffer 5 WNed (in der von 1910-1985 geltenden Fassung). Von 1893-1910 galt dieser Verlustgrund auch für diejenigen, die im Inland geboren waren.

67. Vgl. $3.2 .1,3.2 .6$ und 3.4 .4 .

68. D: 3 RuStAG $1870 ;$ \& 4 RuStAG 1913; O: Aufgrund $\$ 28$ ABGB; $\$ 5$ Abs. 1 BBG 1925; \& 3 StBG 1945/1949; \& 7 Abs. 3 StBG 1965; Sch: Art. 324 Abs. 1 ZGB; Art. 1 Buchstabe b BüG i.d.F. 1952. Vgl. Gonset; siehe weiter Lagarde, Nationallite, 498-500.
69. Vgl. uber Legitimation: D: \$ 13 Ziffer 4 RuStAG 1870; \& 17 RuStAG 1913; Ö: \& 8 Ziffer 2 BBG 1925; Schw: Bis 1953 aufgrund des Gewohnheitsrechts (Schröder, 39 , 40); ab 1953 fur Legitimation Art. 8 Bü 1952.

70. Vgl. D: Seit 1949 wegen der Wirkung von Art. 16 GG kein Verlust bei drohender Staatenlosigkeit; Ö: 8 \& Abs. 4 StBG 1949 . 
71. Vgl. B: Art. 2 Gesetz 1909; Art. 2 Gesetz 1932; vorlaifig auch noch Art. 8 CNB; N: Bils 1947: Art. 1 Buchstabe c WNed; Sp: Bis 1981: Art. 129, 136 i.V.m. Art. 17 C.c.esp.; I: Art. 7 Abs. 1 C.c.it; Art. 1 L.c.

72. Art. $\mathbb{1}$ Buchstabe $\mathrm{c}$ WNed war dann nicht mehr anwendbar.

73. Art. 2 Buchstabe c WNed i.d.F. 1936.

74. Art. 2 Buchstabe c WNed i.d.F. 1962.

75. Art. 2 Gesetz 1909; Art. 2 Gesetz 1932.

76. B: Art. 2 Gesetz 1909; Art. 2 Gesetz 1932. Nach belgischem Recht vor 1985 erwarb das vom belgischen Water anerkannte Kind lediglich dessen Staatsangehorigkeit, wenn dieser das Kind vor der Mutter anerkannt hatte. Seit 1932 hatte die Anerkennung volljähriger Kinder keine staatsangehörigkeitsrechtlichen Folgen mehr. Ab 1985 ist Art. $8 \mathrm{CNB}$ maßgebend.

F: Siehe Locre, 87, 88; vgl. Art. 8 Ziffer 1 C.c. 1889; Art. 1 Ziffer 4 CNF 1927.

N: Art. 1 Buchstabe a WNed 1892; Art. 4 RwNed (allerdings nur für während ihrer Minderjährigkeit anerkannte Kinder; diese Einschränkung galt ab 1962 bereits aufgrund Art. 2ter WNed i.d.F. 1962.

Sch: Ab 1912 (Art. 325 ZGB) wurde die Staatsangehörigkeil durch Anerkennung erworben oder durch gerichtliche Zusprechung mit Standesfolge. So auch in BüG 1952 (Art. 2 Abs. 1 Buchstabe b und c). Seit 1978 ist dies aber nicht mehr der Fall, auBer im Falle von Art. 1 Abs. 2 Buchstabe b. Im Entwurf 1986 wird aber erneut vorgeschlagen die Staatsangehörigkeit durch Anerkennung oder gerichtliche Feststellung der Vaterschaft erwerben zu lassen.

77. $\quad$ L: Doerner/Hecker, 19 .

78. Siehe \$ 3.3.3.3 Buchstabe c.

79. Erst seit 1949 durch Legitimation Sec. 23 BNA 1948 und Sec. 47 BNA 1981.

80. Siehe \& 3.2.4.

81. Art. 1 Buchstabe c WNed i.d.F. 1947.

82. So z.B. Art. 4 RwNed (allerdings mit der Einschränkung, daß die Anerkennung während der Minderjährigkeit des Kindes geschieht.

83. Siehe \& 3.2 .4 .

84. Siehe Paragraph 1.4.1.

85. B: Art. 17 Ziffer 3 und Art. 20 C.c. Seit 1909 gab es diesen Verlustgrund nicht mehr; D: Vgl. \& 22 RuStAG 1870; \& 28 RuStAG 1913; F: Art. 17 Ziffer 3 und Art. 21 C.c. 1804; vgll. Art. 17 Ziffer 3 und 4 C.c. 1889; Art. 9 CNF 1927; Art. 97 CNF 1945; I: Art. 11 Abs. 1 Ziffer 3 C.c.it; Art. 8 Abs. 1 Ziffer 3 L.c.; N: Art. 7 Ziffer 4 WNed (bis 1985); so auch bereits Art. 9 Ziffer 2 BW 1838 und Art. 10 Ziffer 2 Gesetz 1850; Ó: Vgl. \$ 10 Abs. 1 Ziffer 2 BBG 1925; \& 9 Abs. 1 Ziffer 2 StBG 1945/1949; \& 32 und 33 StBG 1965; Sp: Art. 20 C.c.esp. i.d.F. 1889; Art. 23 Ziffer 1 C.c.esp. i.d.F. 1954; seit 1982 gilt dieser Verlustgrund allerdings für diejenigen Spanier, die diese Staatsangehörigkeit durch Einbuirgenung oder Option erworben haben. Die bisherige allgemeine Formulierung war seït 1978 verfassungswidrig (Art. 11 Abs. 2 Constitución 1978 ).

86. So Deutschland: \& 9 RuStAG 1870; 14, 15 RuStAG 1913 (geltend bis 1953); Öterreich: \& 29 BGB (1811) mit einigen Einschränkungen durch die HKD vom 29. September 1818 und 15. Aprill 1828 .

87. Siehe u.a. \$ 3.4.8; vgl. auch 3.4 .2 .

88. Siehe oben FuBnote 3.

89. Vgl. oben Fußnoten 5 und 6.

90. Belgien: Art. 11 Ziffer 2 Gesetz 1909; Großbritannien: Sec 10 (5) BNSA i.d.F. 1934; Schweiz: Art. 5 Abs. 2 BeschlluB 1941; Art. 9 Bü 1952; Deutschland: Ab 1949; Konsequenz von Art. $16 \mathrm{GG}$; Italien: Bereits von Art. 14 Abs. 1 C.c.it.; Niederlande: Art. 5 Abs. 1 WNed i.d.F. 1936; Österreich: \$9 Abs. 11 BRG 1925; In Spanien wurde dies klargestellt durch die Entscheidung der Generaldirektion fuir die Personenstandsregister vom 3. Juli 1942; im Gesetz wurde dies ausdricklich formuliert von Ant. 23 Ziffer 3 C.c.esp. i.d.F. 1954. Vgl. Art. 8 Abs. 3 CNF 1927. Vgl. Wiederkehr, 21-23; Mutharika, $21 \mathrm{ff}$.

91. Dazu $\$ 1.4 .3$. Siehe zur Problematik der Staatenlosigkeit u.a. folgende ältere Literatur: Lipovano (Paris 1935); vgl, auch Lessing (Leiden 1937). Siehe weiter. Weis (2. Auflage 1979) und Mutharika (New York 1980).

92. Vgl. oben Fußnote 31 . 
93. Art. 32 des Ubereinkommens über die Rechtsstellung vom Staatenlosen vom 28.

September 1954; dazu \& 1.4.3.

94. Abkommen von Bern zur Verringerung der Falle von Staatenlosigkeit vom 13. Abkommen voin Bern zur

95. Konvention uber die Vermindenung der Staatenlosigkeit vom 30. August 1961.

96. Italien: So bereits Art. 1 Abs. 1 Ziffer 3 L.c. 1912; Sp: Art. 17 Ziffer 3 C.c.esp. i.d.F. 1982; vgl. 3.26 .

97. Sitehe 83.3 .3 .1 Buchstabe $b ; 3.3 .3 .3$ Buchstaben a und $b$.

98. Weiss, 25.

99. Vgl. Wiederkehr, 39.

100. Siehe 3.4.2.

101. Dazu Kammann, 269-281 mit weiteren Literaturhinweisen.

102. Konvention zoir Verminderung von Fallen mehrfacher Staatsangehörigkeit und betreffend Wehrpflicht bei mehrfacher Staatsangehörigkeit. Dazu \& 1.4.3. Siehe zur Problematik der mehfachen Staatsangehörigkeit u.a. Müller (Köln 1927); Feer (Zïrich 1955); Ko Swan Sik (Leiden 1957); Bar-Yaacov (London/Jerusalem 1961); Kammann (Hamburg 1984).

103. Siehe 1.4.3, FuBnote 244 .

104. Dazu $\$ \$ 3.4 .2$ und 3.3.4.8.

105. Vgl. \& 1.4.2. 


\section{Curriculum vitae}

Gerard-René de Groot wurde am 25. August 1951 in Stadskanaal (Niederlande) geboren. Nachdem er im Jahre 1969 in seinem Geburtsort das altsprachige-mathematische Abitur (Gymnasium B) absolviert hatte, studierte er 1969-1973 Rechtswissenschaften an der staatlichen Universität Groningen (Niederlande), wo er die Titel Magister iuris und Doctorandus iuris erwarb. 1973/74 studierte er mit einem DAAD-Stipendium an der Westfälischen Wilhelmsuniversität in Münster i.W. (Bundesrepublik Deutschland), namentlich im Institut für internationales und ausländisches Privat- und Wirtschaftsrecht. Im Jahre 1974 wurde er an der staatlichen Universität Groningen ernannt, wo er in verschiedenen Rängen bis 1982 lehrte. Seit 1982 ist er als Universitätshauptdozent an der staatlichen Universität Limburg in Maastricht (Niederlande) tătig. Im Jahre 1983 wurde er im Nebenamt zum "rechter-plaatsvervanger" (stellvertretender Richter) der Arrondissementsrechtbank (Landgericht) Maastricht emannt.

Seit 1974 veröffentlicht er regelmäßig über zivilrechtliche und rechtsvergleichende Themen. Auf dem Gebiete des Staatsangehörigkeitsrechts veröffentlichte er u.a. "Gelijkheid van man en vrouw in het nationaliteitsrecht" (Gleichberechtigung von Mann und Frau im Staatsangehörigkeitsrecht) (Deventer 1977), "Nationaliteitswetgeving" (Staatsangehörigkeitsgesetzgebung) (in: Personen- en familierecht, Deventer, Loseblattkommentar) und (zusammen mit Matjaz Tratnik) "Nationaliteitsrecht" (Staatsangehörigkeitsrecht) (Zwolle 1986). Seit 1986 ist er Annotator der "Nederlandse Jurisprudentie" für staatsangehörigkeitsrechtliche Entscheidungen des "Hoge Raad der Nederlanden" (Oberster Gerichtshof der Niederlande).

Dem Autor wurde am 5. September 1988 der Edmond Hustinxpreis für die Wissenschaft verliehen. 